UCRL-ID-121566 Pt 2

\title{
Clementine Star Tracker Stellar Compass: Final Report Part 2
}

\author{
R. E. Priest, J. F. Kordas, I. T. Lewis, B. A. Wilson, \\ D. P. Nielsen, H.-S. Park, R. F. Hills, \\ M. J. Shannon, A. G. Ledebuhr, L. D. Pleasance
}

July 1995

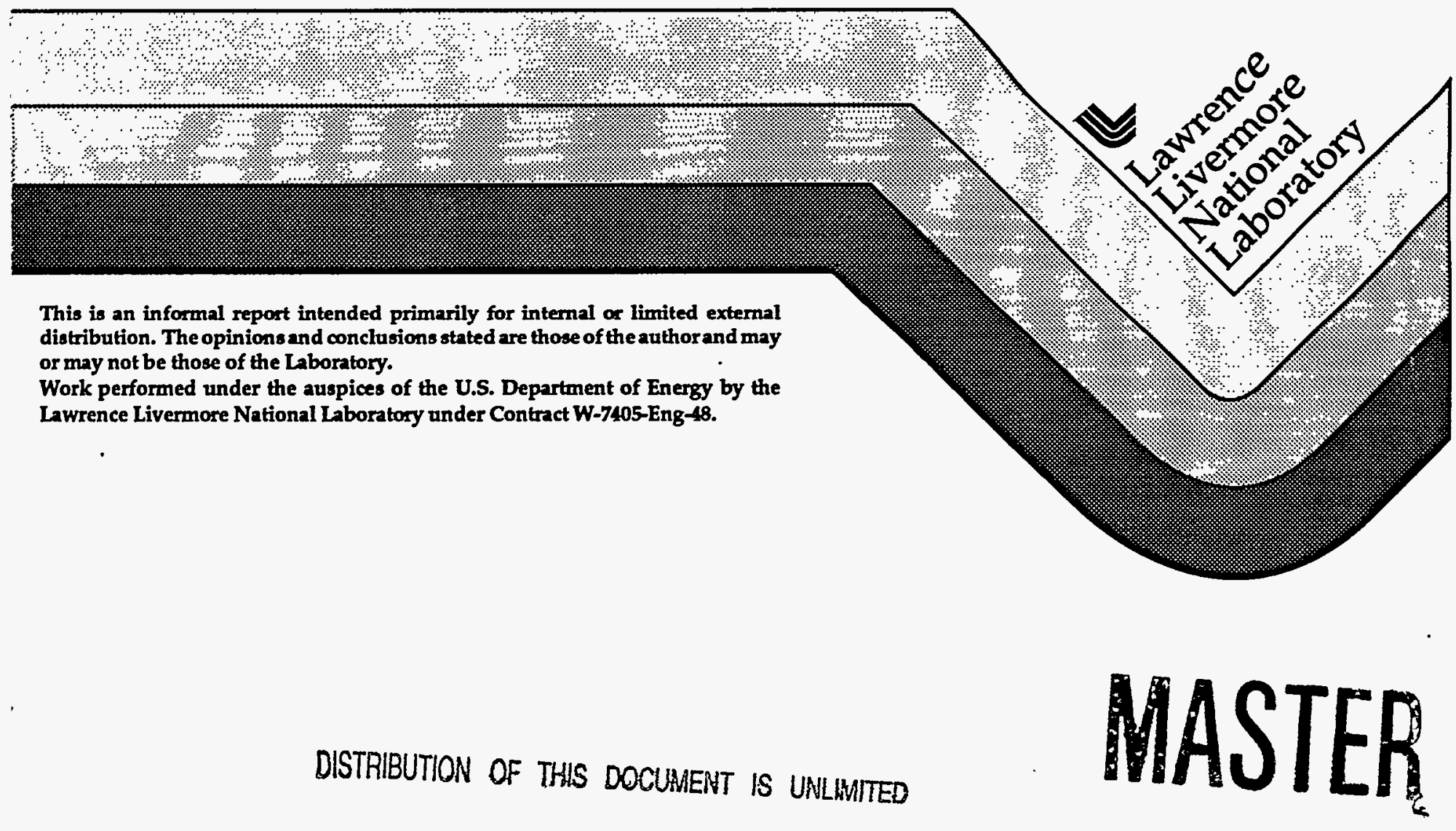




\section{DISCLAIMER}

This document was prepared as an account of work sponsored by an agency of the United States Government. Neither the United States Government nor the University of California nor any of their employees, makes any warranty, express or implied, or assumes any legal liability or responsibility for the accuracy, completeness, or usefulness of any information, apparatus, product, or process disclosed, or represents that its use would not infringe privately owned rights. Reference herein to any specific commercial product, process, or service by trade name, trademark, manufacturer, or otherwise, does not neoessarily constitute or imply its endorsement, recommendation, or favoring by the United States Government or the University of California. The views and opinions of authors expressed herein do not necessarily state or reflect those of the United States Government or the University of California, and shall not be used for advertising or product endorsement purposes.

This report has been reproduced directly from the best available copy.

Available to DOE and DOE contractors from the Office of Scientific and Technical Information P.O. Box 62, Dak Ridge, IN 37831

Prices available from (615) 576-8401, FIS 626-8401

Available to the public from the

National Technical Information Service

U.S. Department of Commerce 5285 Port Royal Rd., Springfield, VA 22161 


\section{DISCLAIMER}

Portions of this document may be illegible in electronic image products. Images are produced from the best available original document. 
Appendix G.3.4

Assembly Procedures 


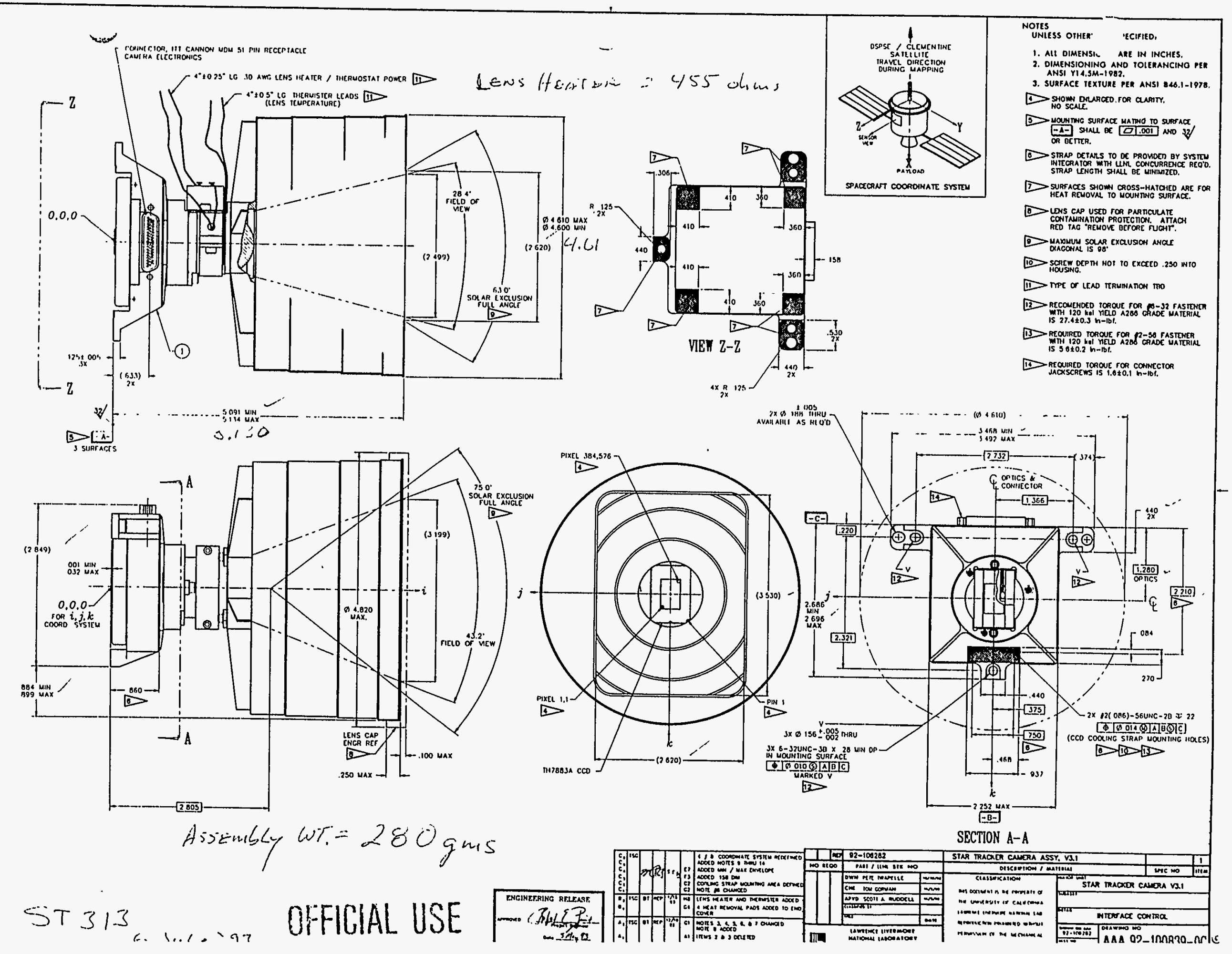


CLEMENTINE

Sensors Integration Project

TITLE: Star Tracker Camera Assembly Procedure

Abstract:

This document describes the assembly procedures for the Clementine Star

Tracker Camera

Revision: 0A

\begin{tabular}{|l|}
\hline ASSY: Star Tracker \\
\hline ORIG: Jim Dickie \\
\hline DATE: 7 Iune, 1993 \\
\hline APPR: 4 fenit \\
\hline
\end{tabular}

\section{CI-S1-012}

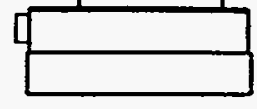

\section{Revision. OA}




\section{Engineering Note}

C1-S1-012

\section{CLEMENTINE}

Star Tracker Camera

Assembly Procedures

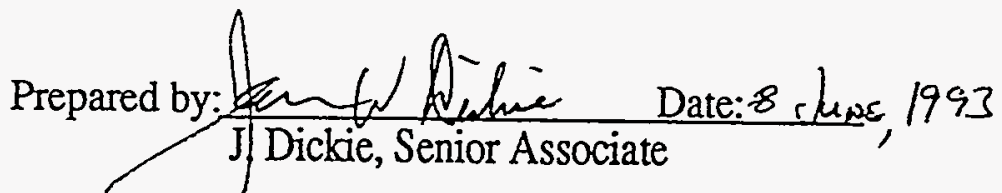

Reviewed by: ReA $\{$ Pixt Date: 9 gme 1993

Reviewed by: Newi

V. Lewis, Optical Engineer

Date: 9 Junce 1993

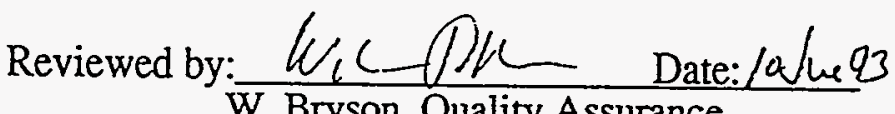

W. Bryson, Quality Assurance

Reviewed by: Neat $610-23$

W. Rice, Quality Assurance

Reviewed by:?./eld Date: $1^{0-\lambda u w}=93$

E. Schmitt, Production

Reviewed by: fon Kuter Date: 10 Jup 1993 Kordasp STC Sensor Engineer

Approved by $14 . \mathrm{cm}$ 


\subsection{General}

1.1 Scope

This document details steps required to assemble the Clementine Star Tracker Camera (STC).

\subsection{Description}

The STC consists of an Actel electronics PWA, a Thomson TH7883-FO2-01 $\mathrm{B} / \mathrm{T} \mathrm{CCD}$ (Flight cameras only, prototype cameras will utilize a non-B/T TH7883-F02-01 unit), mechanical hardware that encases the PWA and CCD, a mini-concentric Wide Field of View (WFOV) lens, and a light baffle. The camera is used for imaging stars to determine the position of a vehicle in space.

Assembly includes general mechanical assembly, testing to verify quality of optical couplant between the CCD and the lens fiber optic field flattener, measurement and possibly adjustment of the optical axis normal to the camera mounting surfaces, abbreviated electrical function testing prior to final staking, and final staking.

\subsection{Reference Documents and Drawings}

1.3.1 C1-ME-008, Clementine Sensors General Contamination Control Plan.

1.3.2 C1-S0-TBD, Clementine ESD Protection Plan.

1.3.3 C1-S1-TBD, STC Abbreviated Electronic Function Test Procedure.

1.3.4 MU-STD-1686, Handling of ESD Sensitive Equipment.

1.3.5 MUL-STD-1246B, Product Cleanliness Levels and Contamination Control Plan.

1.3.6 C1-S0-005, Adhesives, Compounds, and Optical Couplants.

1.3.7 C1-S0-TBD, Clementine Quality Assurance Program Plan

\subsection{Deviations}

Procedural deviations or changes from specified procedures which do not affect the physical assembly may be made at the discretion of the responsible engineer. Deviations or changes which require any mechanical or electronic change may be made only after review and approval by a suitable Material Discrepancy Review Board as defined in the Clementine QA Program Plan.

\subsection{Electro-Static Discharge Control Requirements}

The STC contains electrostatic-sensitive devices which are exposed on the PWA and CCD prior to assembly closure and at the electrical interfaces after assembly closure. Therefore, it shall be handled per MUL-STD-1686 Class 1 . All work shall be performed in an approved electrostatic discharge control area as defined by the Clementine Quality Assurance Group.

The STC, the test operator (using wrist straps), and related electrical test equipment shall be connected to a common ground before any electrical mating or de-mating operations, and during the use of any electrical test equipment probes. There shall be no "hot-plugging" of the test specimen with any test equipment. 
All electrostatic sensitive parts shall be stored in approved antistatic storage bags when not in use.

\subsection{Cleanliness and Contamination Control Requirements}

All assembly work shall be performed in a Class 100 laminar flow hood located within a Class 10,000 environment as defined in LLNL document 'Clementine Sensors General Contamination Control Plan'.

Handling of all parts shall be with clean lint-free gloves. Personnel shall wear face and hair protective smocks when handling exposed opiics.

\subsection{Photographs}

Photographs shall be taken of the unit at major subassembly steps and of the final assembled unit. A suitable ruler shall be used to provide scale.

\subsection{Disassembly Contingency}

Due to the optical bonding of the CCD to the lens fiberoptic, and the time required to dissolve this bond line, there is no disassembly of an STC allowed beyond step 4.3.5, with the special exception noted in step 4.3.9. If any camera is found to be defective at any point beyond step 4.3 .5 , a total restart of this assembly procedure is required.

\subsection{Parts List}

2.1 From the kitted assembly, where applicable, record all part serial numbers for this camera into the table below.

\begin{tabular}{|c|c|c|c|c|}
\hline$\underline{\text { Item }}$ & Description & Reference No. & Serial No. & Quantity \\
\hline 1 & Camera Housing & $92-106258$ & 07 & 1 \\
\hline 2 & Lens Standoff & $93-102550$ & $N / n$ & 1 \\
\hline 3 & End Cover & $92-106249$ & 02 & 1 \\
\hline 4 & Baffle Assembly & $92-108748$ & $r / A$ & 1 \\
\hline 5 & WFOV Lens Assembly & $92-109469$ & $\infty 4$ & 1 \\
\hline \multirow[t]{2}{*}{6} & $\begin{array}{l}\text { Actel PWA Assembly } \\
\text { Includes: }\end{array}$ & LEA92-3128-03 & $04-06$ & 1 \\
\hline & $\begin{array}{l}\text { Spacer, Tab-01 } \\
\text { Nut, 2-56 } \\
\text { Nut, PEM, 2-56 } \\
\text { Thermistor, Fenwal }\end{array}$ & $\begin{array}{l}\text { 92-104616 } \\
\text { NAS \#671-C02 } \\
\text { CRES } \\
\text { 137-562-ZXT-D02 }\end{array}$ & $\begin{array}{l}\mathrm{n} / \mathrm{a} \\
\mathrm{n} / \mathrm{a} \\
\mathrm{n} / \mathrm{a} \\
\mathrm{n} / \mathrm{a}\end{array}$ & $\begin{array}{l}2 \\
2 \\
2 \\
1\end{array}$ \\
\hline 7 & Jackpost, Tab-08 & $93-101167$ & $\mathrm{n} / \mathrm{a}$ & 2 \\
\hline 8 & $\mathrm{CCD}$, Thomson & $\begin{array}{l}\text { TH7883-FO2-01 } \\
\text { (Prototype Cameras) }\end{array}$ & & 1 \\
\hline
\end{tabular}




\begin{tabular}{|c|c|c|c|c|}
\hline 9 & CCD, Thomson & $\begin{array}{l}\text { TH7883-FO2-01 B/T } \\
\text { (Flight Camera Only) }\end{array}$ & $83 F 02 B / 5393-1$ & 1 \\
\hline 10 & Pad, Circuit Board & $92-104621$ & $\mathrm{n} / \mathrm{a}$ & 1 \\
\hline 11 & Pad, CCD Thermal & $93-102243$ & $\mathrm{n} / \mathrm{a}$ & 1 \\
\hline 12 & Connector Bracket & $92-106257$ & $\mathrm{n} / \mathrm{a}$ & 1 \\
\hline 13 & $\begin{array}{l}\text { Socket head cap } \\
\text { screw, } 2-56 \times .187 \mathrm{lg} \text {. }\end{array}$ & NAS \#1352-N02-3 & $\mathrm{n} / \mathrm{a}$ & 14 \\
\hline 14 & $\begin{array}{l}\text { Socket head cap } \\
\text { screw, } 2-56 \times .250 \mathrm{lg} \text {. }\end{array}$ & NAS \#1352-N02-4 & $\mathrm{n} / \mathrm{a}$ & 6 \\
\hline 15 & $\begin{array}{l}\text { Socket head cap } \\
\text { screw, } 2-56 \times .375 \text { lg. }\end{array}$ & NAS \#1352-N02-6 & $\mathrm{n} / \mathrm{a}$ & 3 \\
\hline 16 & $\begin{array}{l}\text { Socket head cap } \\
\text { screw, } 2-56 \times .50 \text { lg. }\end{array}$ & NAS \#1352-N02-8 & $\mathrm{n} / \mathrm{a}$ & 2 \\
\hline 17 & Washer, \#2, Ø0.25 & NAS \#620-N02 & $n / a$ & 8 \\
\hline 18 & Washer, Thermal & $93-102551$ & $\mathrm{n} / \mathrm{a}$ & 6 \\
\hline 19 & Thermistor, Fenwal & 534-31AG04-562 & $\mathrm{n} / \mathrm{a}$ & 1 \\
\hline 20 & Clamp, Lens Heater & $93-102221$ & $\mathrm{n} / \mathrm{a}$ & 1 \\
\hline 21 & Heater, Lens, Minco & HK17402-9311 & $\mathrm{n} / \mathrm{a}$ & 1 \\
\hline 22 & Switch, Sundstrand & $974-0014-774$ & $\mathrm{n} / \mathrm{a}$ & 1 \\
\hline 23 & Tape, Reflective & Sheldahl & $n / a$ & $a / r$ \\
\hline 24 & Shim, End, Upper & $93-102609$ & $n / a$ & 2 \\
\hline 25 & Shim, End, Lower & $93-102610$ & $\mathrm{n} / \mathrm{a}$ & 2 \\
\hline
\end{tabular}

\subsection{Required Tools}

2.2.1 As part of this procedure, the following tools, with current calibration certificates, are required for assembly.

1. Torque wrench, capable of reading 0 to 10 inch-pounds minimum, with 0.1 in-lb resolution.

2. 0-1 inch Micrometer with 0.0001 inch resolution.

3. 0-1 inch Depth micrometer with 0.0001 inch resolution. 


\subsection{Adhesives, Couplants, Staking Compounds}

3.1 For additional information on all compounds, refer to Clementine Engineering Note C1-S0-005, 'Adhesives, Compounds, and Optical Couplants'

\begin{tabular}{|c|c|c|c|c|c|}
\hline Item & Description & Pot Life & Cure & Lot No. & Exp. Date \\
\hline 1 & $\begin{array}{l}\text { Staking Compound } \\
\text { Hysol EA934NA }\end{array}$ & $30 \mathrm{~min}$. & 2 hrs. @ $50^{\circ} \mathrm{C}$ & 工 & $2 / 94$ \\
\hline 2 & $\begin{array}{l}\text { Optical Couplant } \\
\text { DC 93-500 }\end{array}$ & 2 hrs. & 24 hrs.@50 C & - & $5 / 94$ \\
\hline 3 & $\begin{array}{l}\text { Thermal Epoxy } \\
\text { BA-2151 }\end{array}$ & $30 \mathrm{~min}$. & 3 hrs.@50 $\mathrm{C}$ & - & \\
\hline 4 & $\begin{array}{l}\text { Silver Epoxy } \\
\text { BA-2902 }\end{array}$ & $30 \mathrm{~min}$. & 3 hrs.@50C & - & $12 / 93$ \\
\hline 5 & $\begin{array}{l}\text { Thermal Grease } \\
\text { DC- } 340\end{array}$ & $\mathrm{n} / \mathrm{a}$ & $\mathrm{n} / \mathrm{a}$ & - & - \\
\hline
\end{tabular}

\subsection{Assembly Procedure}

Initials / Date

4.1 PWA Installation Into Camera Housing

4.1.1 Remove the Actel Camera PWA, P/N LEA92-306703 , from the carrier per procedure C1-S0-TBD.

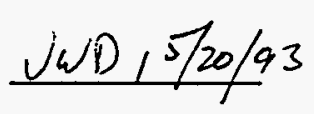

4.1.2 Using a certified micrometer accurate to 0.0001 inches, measure the PWA thickness at the four thermal pads as shown in figure 1 . Record these measurements to 4 significant figures (nominal is $.046 \pm 005$ ).

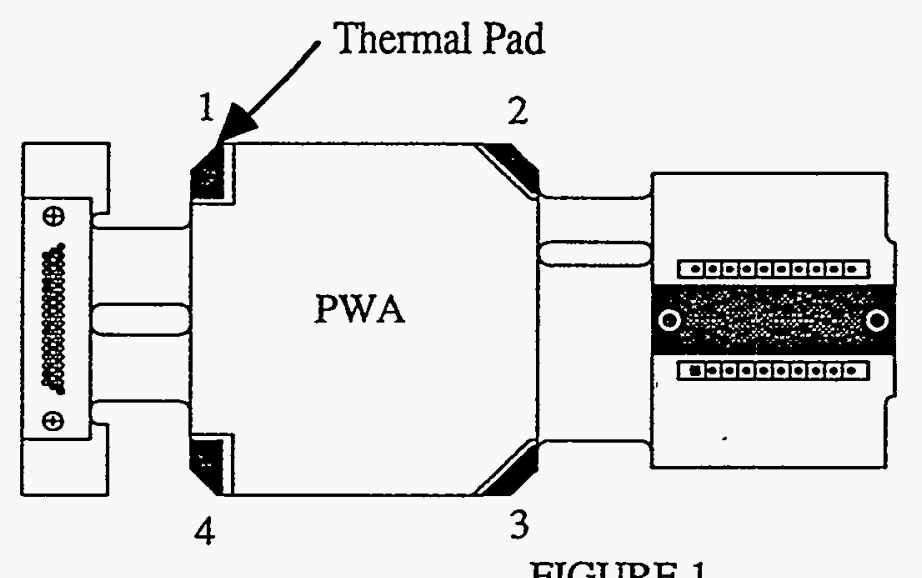

Pad Thickness

1.0410

2.0411

3.0413

4.0409

FIGURE 1

4.1.3 Place PWA in oven set to $50^{\circ} \mathrm{C}$ for 20 minutes. Remove PWA from oven and while still hot, bend to shape as shown in Circuit Board ICD drawing No. 92-104603 and figure 2.

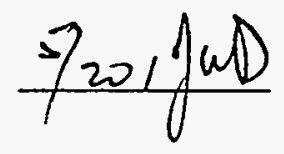


FLEX BOARD BENDING

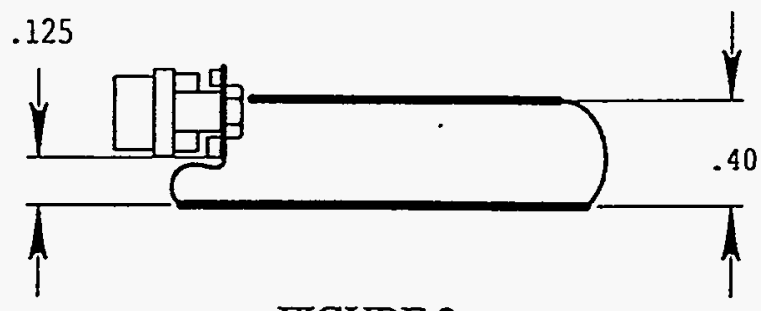

FIGURE 2

4.1.4 Using the optical comparator with the $100 \mathrm{X}$ objective for maximum sensitivity, measure the step height at the four corners for PWA mounting on the Camera Housing P/N 92-106258 as shown in Figures 3 and 5 (nominal is $.050+.000,-.005$ ). Record these measurements to 4 significant figures. This step should be $0.0005 \pm 0.0001$ less then the measured thickness of the PWA at the corresponding thermal pad areas as recorded in step 4.1.1. If correction is required, have the camera housing reprocessed, and the 2-56 threaded inserts installed before proceeding to step 4.1.5.
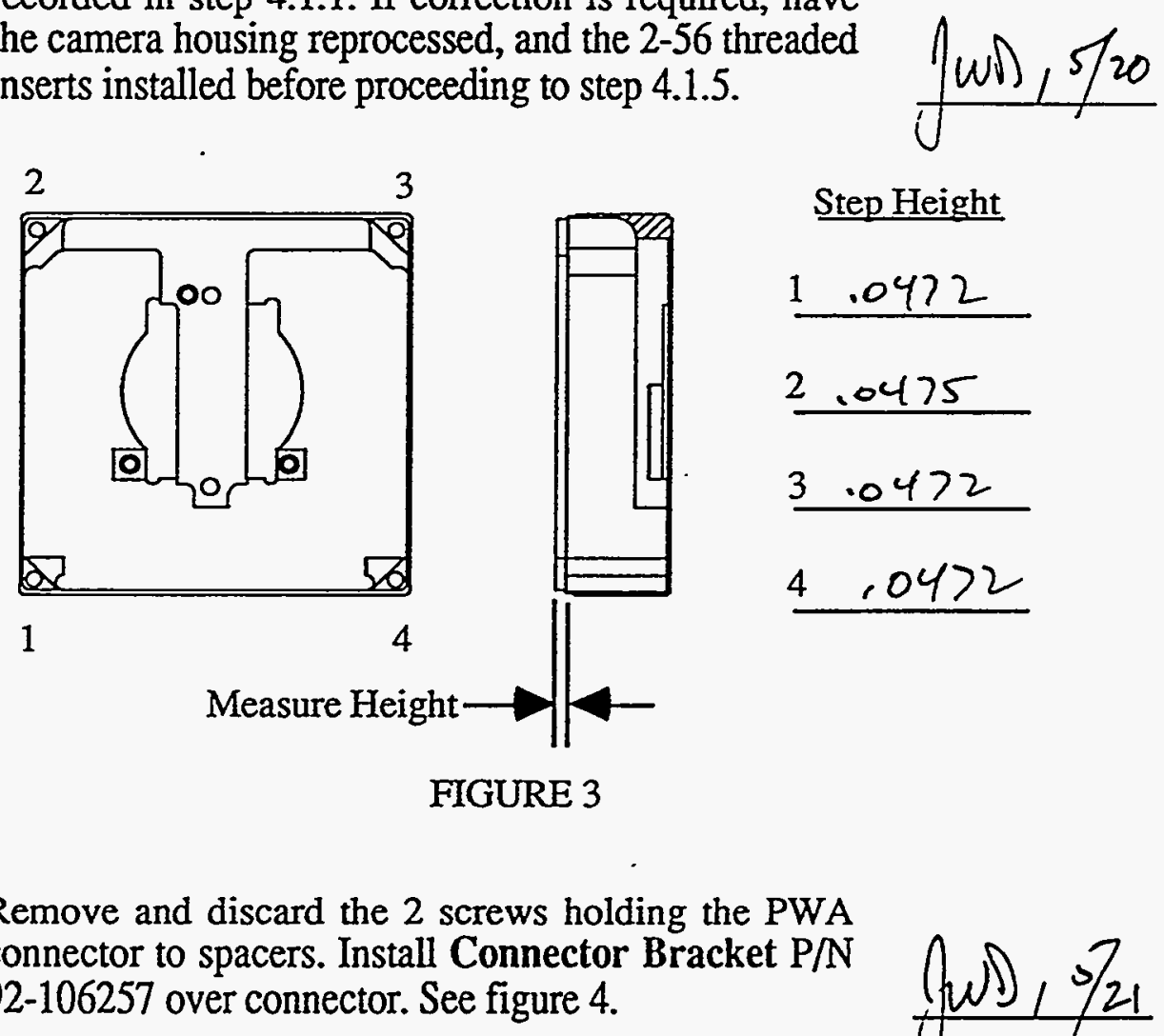

Step Height

1.0472

2.0475

3.0472

4.0472

FIGURE 3

\subsubsection{Remove and discard the 2 screws holding the PWA 92-106257 over connector. See figure 4.

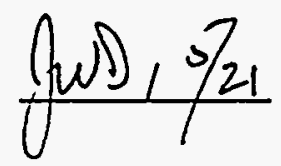


4.1.6 Install PWA board into Camera Housing with Circuit Board Pad P/N 92-104621 and 2-56 washers installed between PWA assembly and housing heat sink. Important, apply a thin layer (.001 in. thick, max.) of DC-340 thermal grease to both sides of the circuit board pad prior to installation.

Secure connector and connector bracket with 2 each, Jackposts P/N 92-104607-Tab 01. Torque to 3.5 \pm 0.1 in-lb.

The thermistor fits in the slot on the finger of the Camera Housing as shown in figure 4. Be careful not to pinch the thermistor leads.

Secure PWA with 2 each, $2-56 \times .25$ long socket head cap screws. Torque to $3.5 \pm 0.1$ in-lb.

Stake thermistor with BA-2151 thermal Compound.

Stake fasteners with EA934NA. Cure for 3 hrs at 50 ${ }^{\circ} \mathrm{C}$.
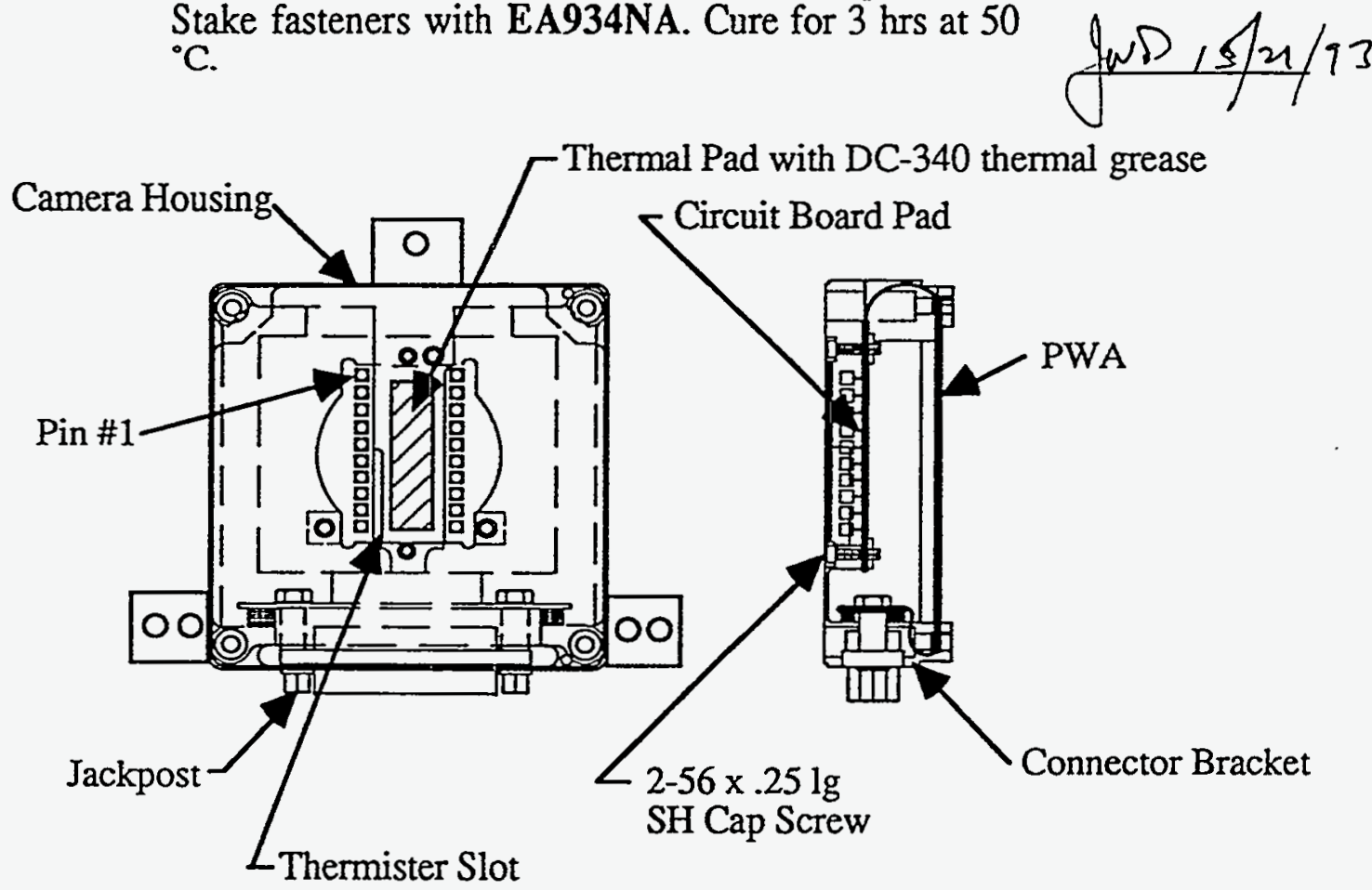

FIGURE 4

4.1.7 Apply a thin (.002 in. thick, max.) layer of BA-2902 Silver Epoxy to 4 thermal contact pads at internal corners of End Cover P/N 92-106249. Place End Cover Shims, P/N 93-102609 and 93-102610 in position on corresponding end cover pads. Cure for 3 hours at $50^{\circ} \mathrm{C}$.

4.1.8 Apply a thin (.001 in. thick, max.) layer of DC-340 thermal grease to both sides of the four PWA thermal contact areas at corners of camera body, and the mating corners of the end cover/shim assembly. Install end cover and secure with 4 each, 2-56 x .25 long socket head cap screws. Torque to $3.5 \pm 0.1$ in-lb. Do not stake fasteners at this time.
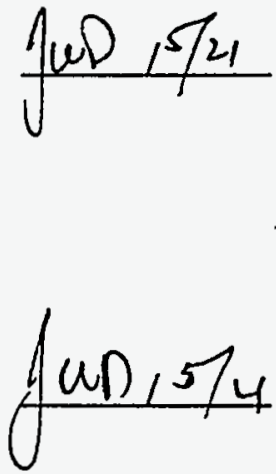
4.2 CCD Installation Into Camera Housing

4.2.1 Prior to installation of CCD into camera, with extreme caution so the fiberoptic is not scratched, measure the overall thickness of the CCD to 4 significant figures using the optical comparator with the $100 \mathrm{X}$ objective for maximum sensitivity. Record this measurement to 4 significant figures.

CCD Thickness .3397

4.2.2 Install Thomson TH7883-FO2-01 CCD (TH7883FO2-01 B/T for flight cameras only) into PWA connector, being careful to install CCD Thermal Pad $\mathrm{P} / \mathrm{N}$ 93-102243 between $\mathrm{CCD}$ and housing. IMPORTANT: be sure to apply a thin $(.001$ in. thick, max.) layer of DC-340 thermal grease to both surfaces of the thermal pad during installation. See figure 4.

IMPORTANT: Verify location of pin \#1 with socket \#1 prior to installation of CCD (see fig. 4).

Visually inspect assembly to verify $\mathrm{CCD}$ is completely and evenly seated onto thermal pad.

4.2.3 Perform abbreviated PWA board/CCD electronic functionality test per procedure $\mathrm{C} 1-\mathrm{S} 1-(\mathrm{TBD})$, and verify good thermal contact between $C C D$ and heat

sink.
Record results. Pass/No Pass_ PASS

4.2.4 If pass, proceed with assembly section 4.3.
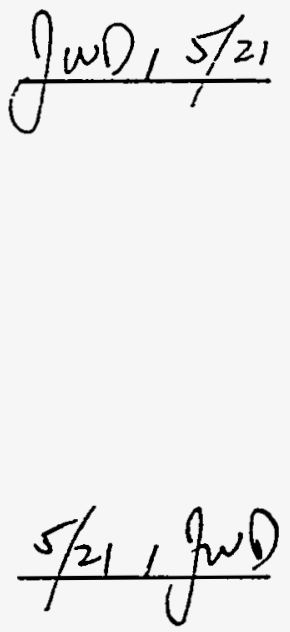

If no pass, stop assembly procedure until problem has been identified and corrected, and camera passes abbreviated electronics functionality test.

\subsection{Lens Standoff Installation}

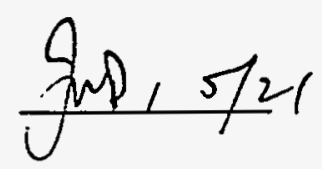

4.3.1 Using the optical comparator with the $100 \mathrm{X}$ objective for maximum sensitivity, measure the step height from the lens standoff mounting ring to the thermal finger surface in the camera body. Record this measurement to 4 significant figures. See Figure 5.

Housing Step Depth .0984

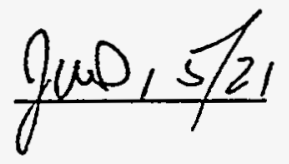




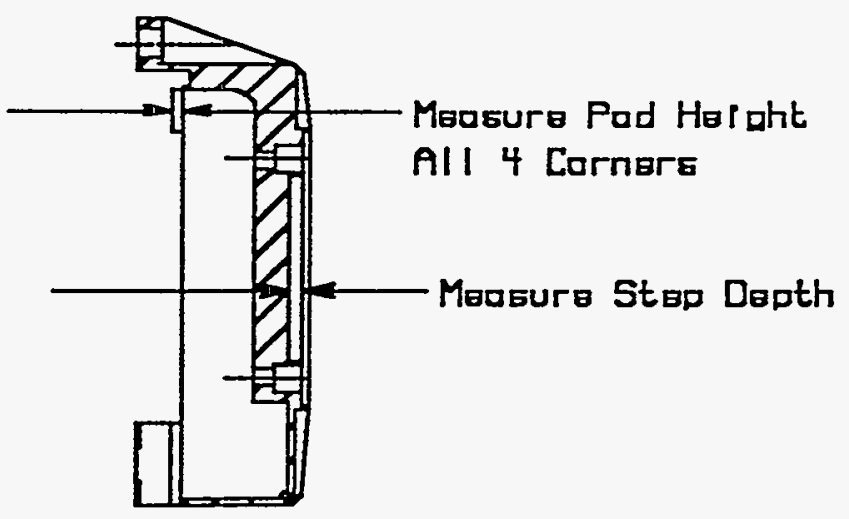

FIGURE 5

4.3.2 From the inspection data provided with WFOV Lens $\mathrm{P} / \mathrm{N}$ 92-109469, obtain the recorded depth from the face of the fiberoptic to the three mounting tabs (nominal is 0.125). Record these measurements to 4 significant figures.
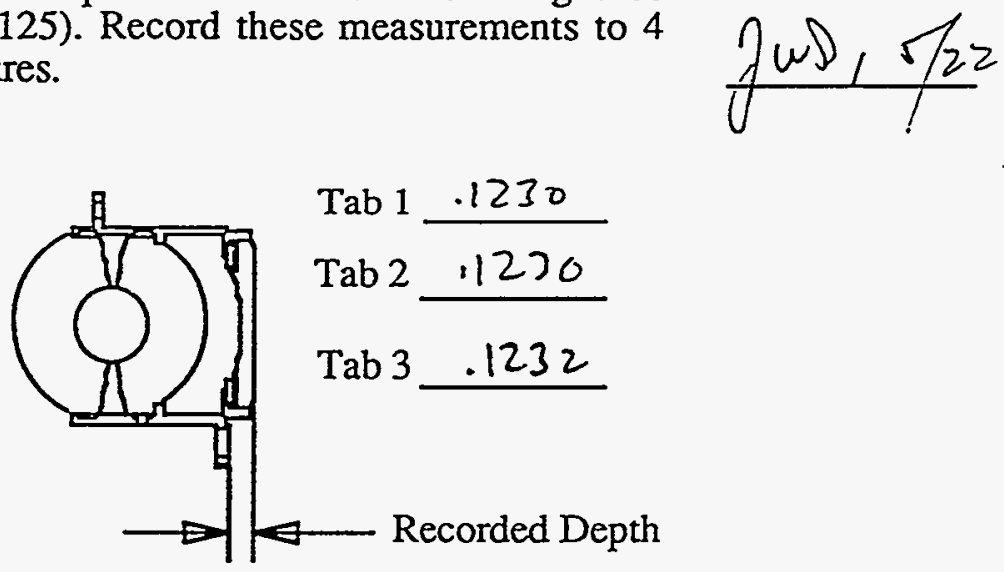

FIGURE 6

4.3.3 Calculate average depth to face of lens fiberoptic to 4 significant figures and record answer. Average Depth .1230

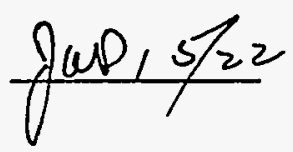




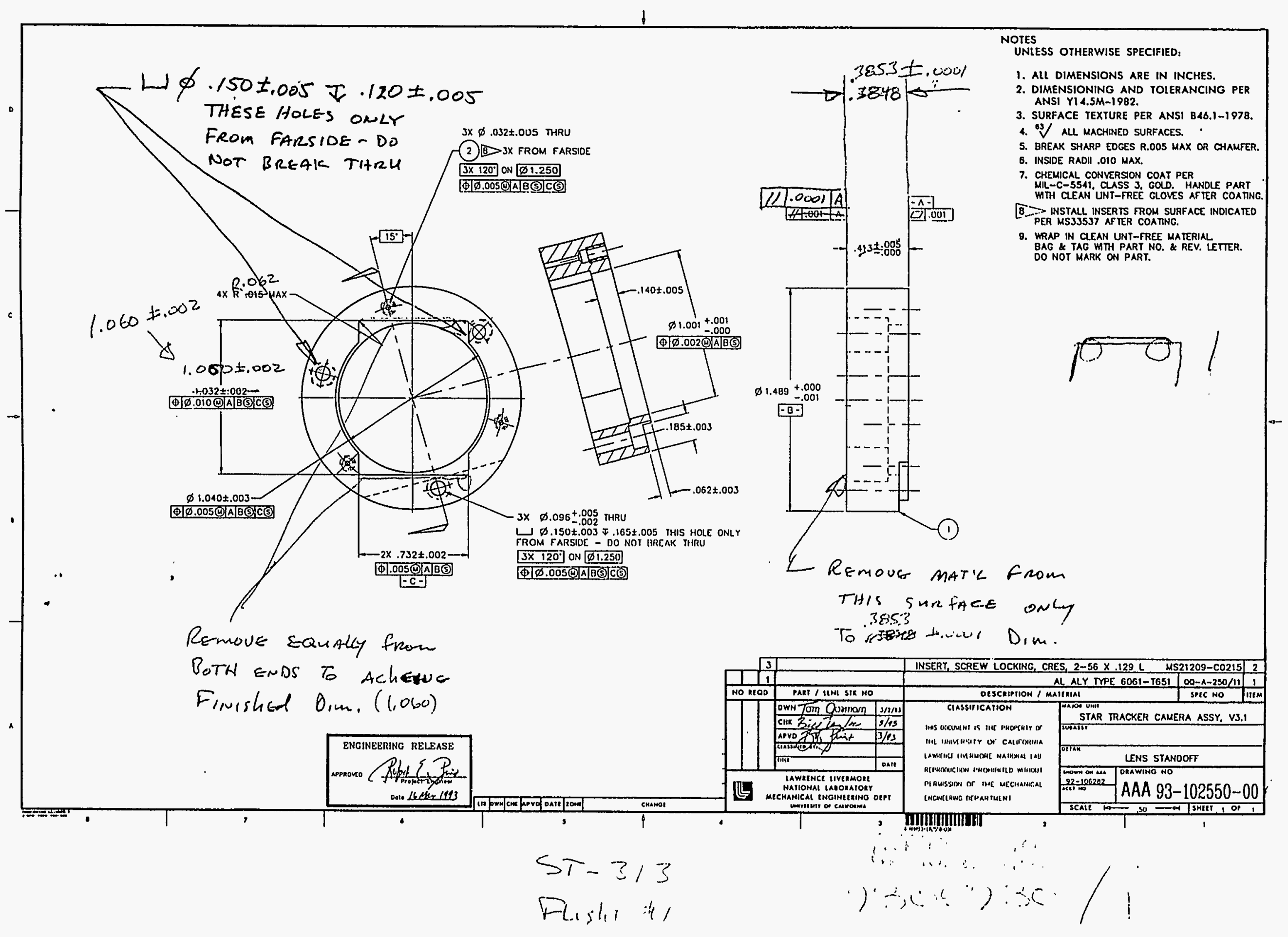




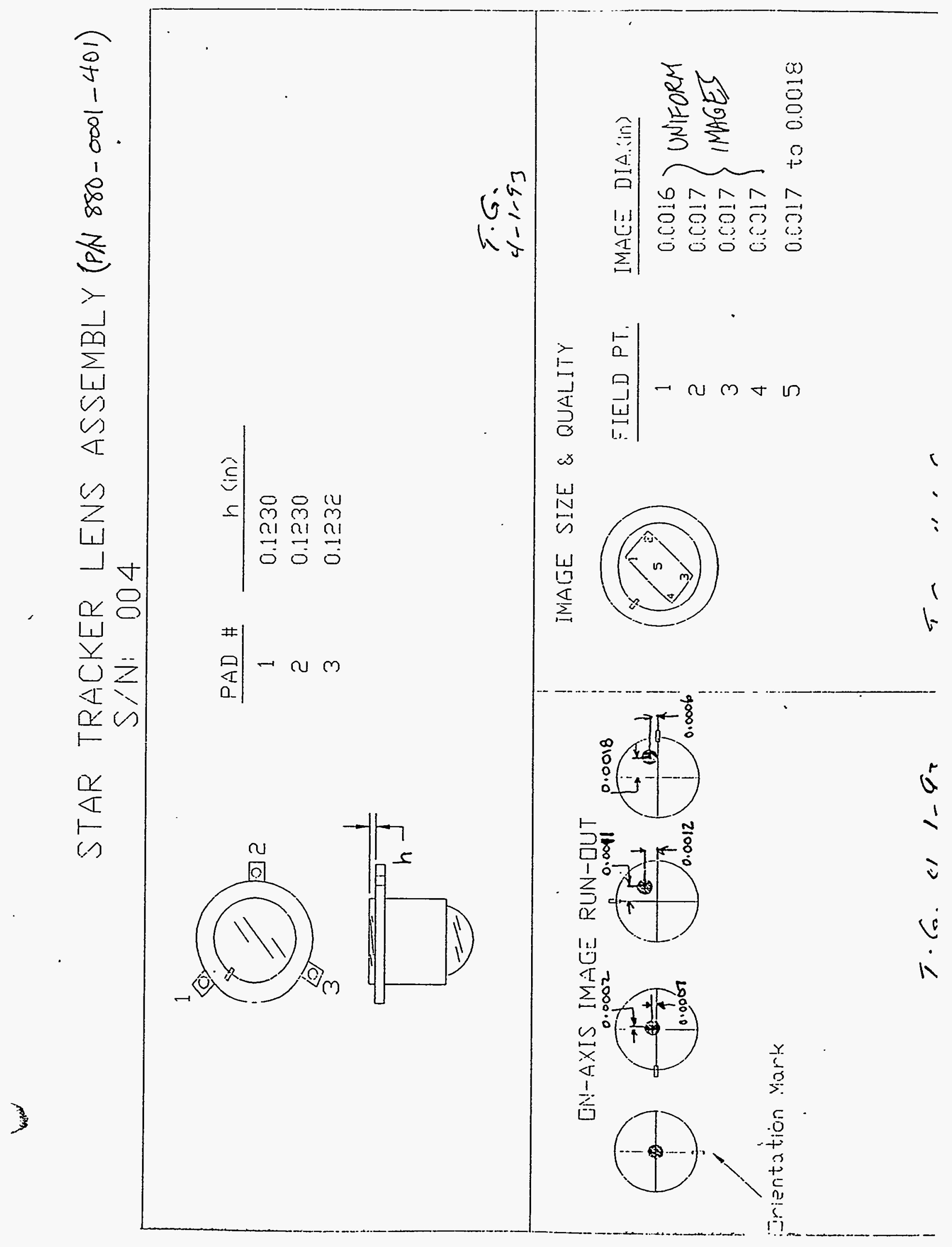




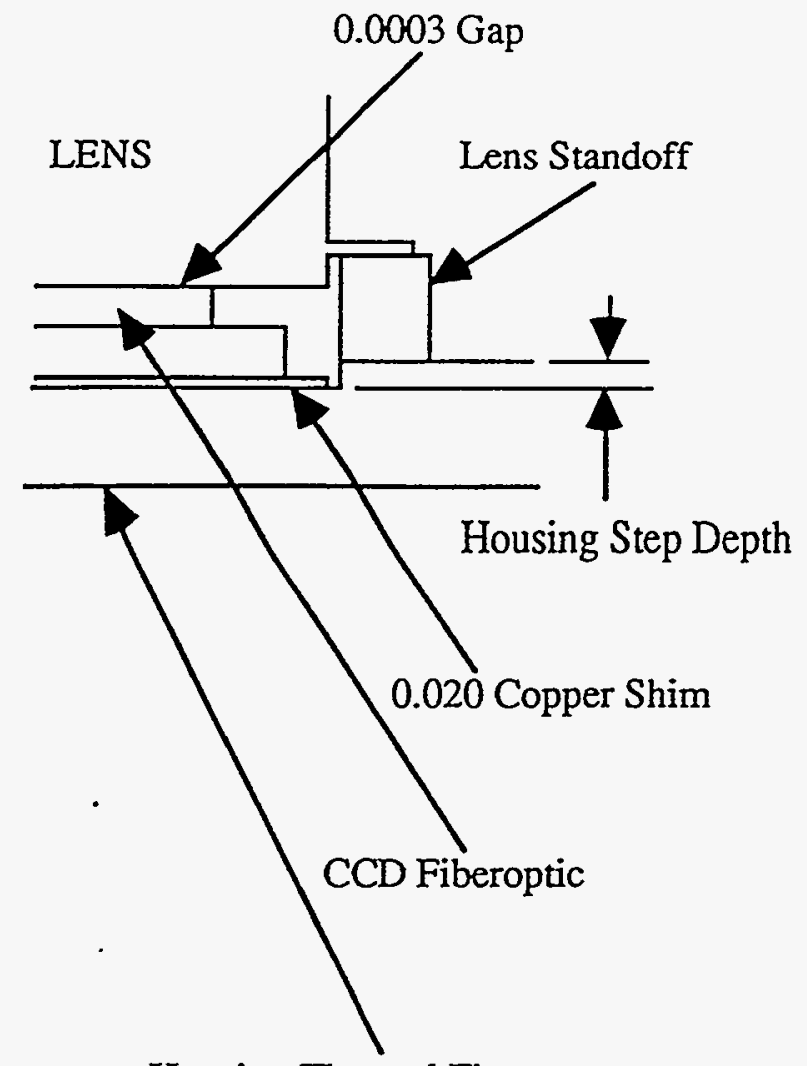

Add The Following:

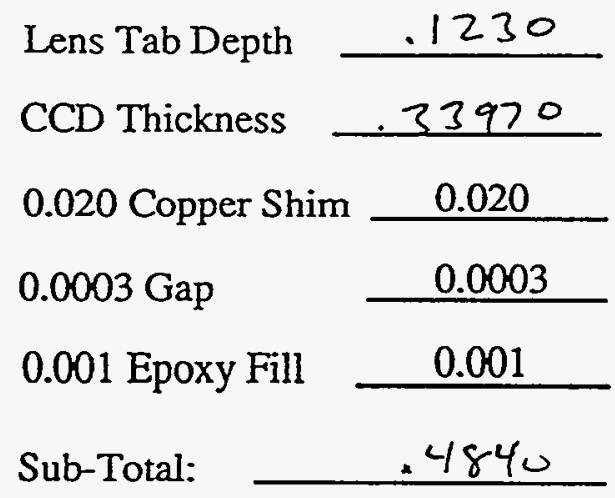

Subtract The Following:

Housing Step Depth .0984

Total is Lens

Standoff Thickness

Housing Thermal Finger

\section{FIGURE 7}

4.3.7 Perform the arithmetic as shown in Figure 7.

4.3.8 Remove the lens standoff and reprocess the bottom surface to achieve the thickness \pm 0.0001 , recorded from the arithmetic in Figure 7.

4.3.4 Apply a thin layer (.001 in. thick, max.) of DC-340 thermal grease to the standoff-to-camera body mechanical interface areas.

Install lens standoff to camera body with 1 each, 2-56 $x .375$ long and 2 each 2-56 x .50 long socket head cap screws. Torque to $3.5 \pm 0.1 \mathrm{in}-\mathrm{lb}$.

4.3.5 Using the optical comparator with the $100 \mathrm{X}$ objective for maximum sensitivity, measure distance from top of lens standoff to top of CCD fiberoptic at 4 positions $(1-4)$ to verify that the fiberoptic surface is parallel to the top of the lens standoff to within 0.0001 inches as shown in figures 8 and 9, and matches the lens-to-tab depth recorded in the inspection data from the vendor +0.0003 inches. If not, reposition the CCD to correct any error.
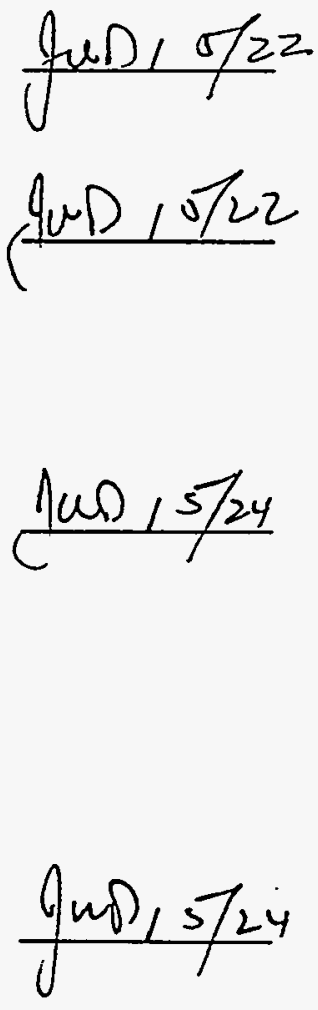


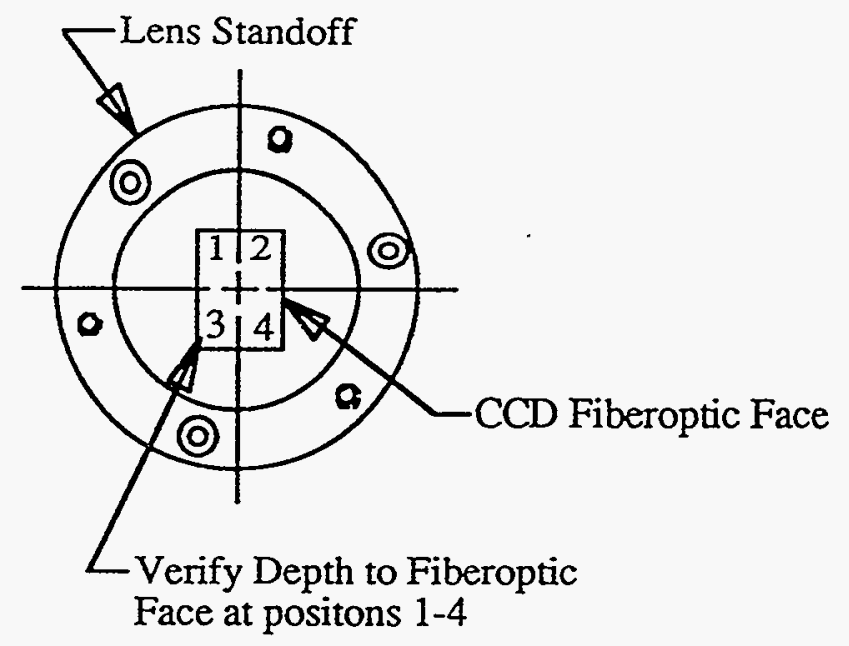

FIGURE 8

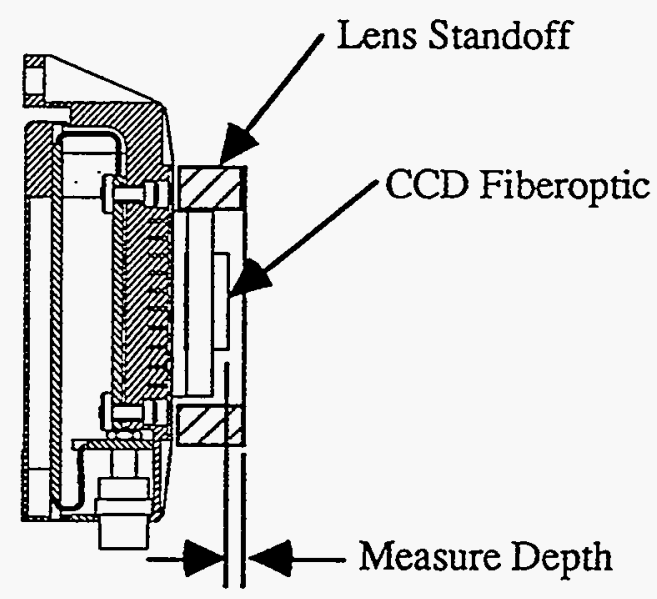

FIGURE 9

4.3.6 Stake fasteners with EA934NA Staking Compound. Cure at $60^{\circ} \mathrm{C}$ for $3 \mathrm{Hr}$.

4.3.7 Do not proceed to assembly section 4.4 unless there is a single time span of at least 8 hours available to complete all steps of section 4.4 .

\subsection{Lens Installation}
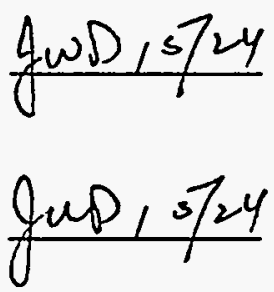

4.4.1 Mix a small quantity of DC 93-500 encapsulant and degas. Place one drop of the degassed encapsulant on top center of the CCD fiberoptic interface surface as indicated in figure 10 .

Apply a thin layer (.001 in. thick, max.) of DC-340 thermal grease to the mechanical interface between the lens standoff and the WFOV lens mount tabs.

Using extreme care to avoid any contact with the thermal grease, except at the mount points, place the WFOV lens into the lens standoff. 
At this point, verify the lens/CCD orientation. Visually inspect the optical interface through the lens to ensure that the encapsulant is evenly spread over the $\mathrm{CCD} / \mathrm{ens}$ interface with no bubbles evident.

Secure the lens to the lens standoff with 3 each, $2-56 x$ .187 long socket head cap screws with $\# 2 \times \varnothing 0.25$ CRES washers. Torque all 3 fasteners evenly $1 / 4$ turn at a time to $2.9 \pm 0.1 \mathrm{in}-\mathrm{lb}$.
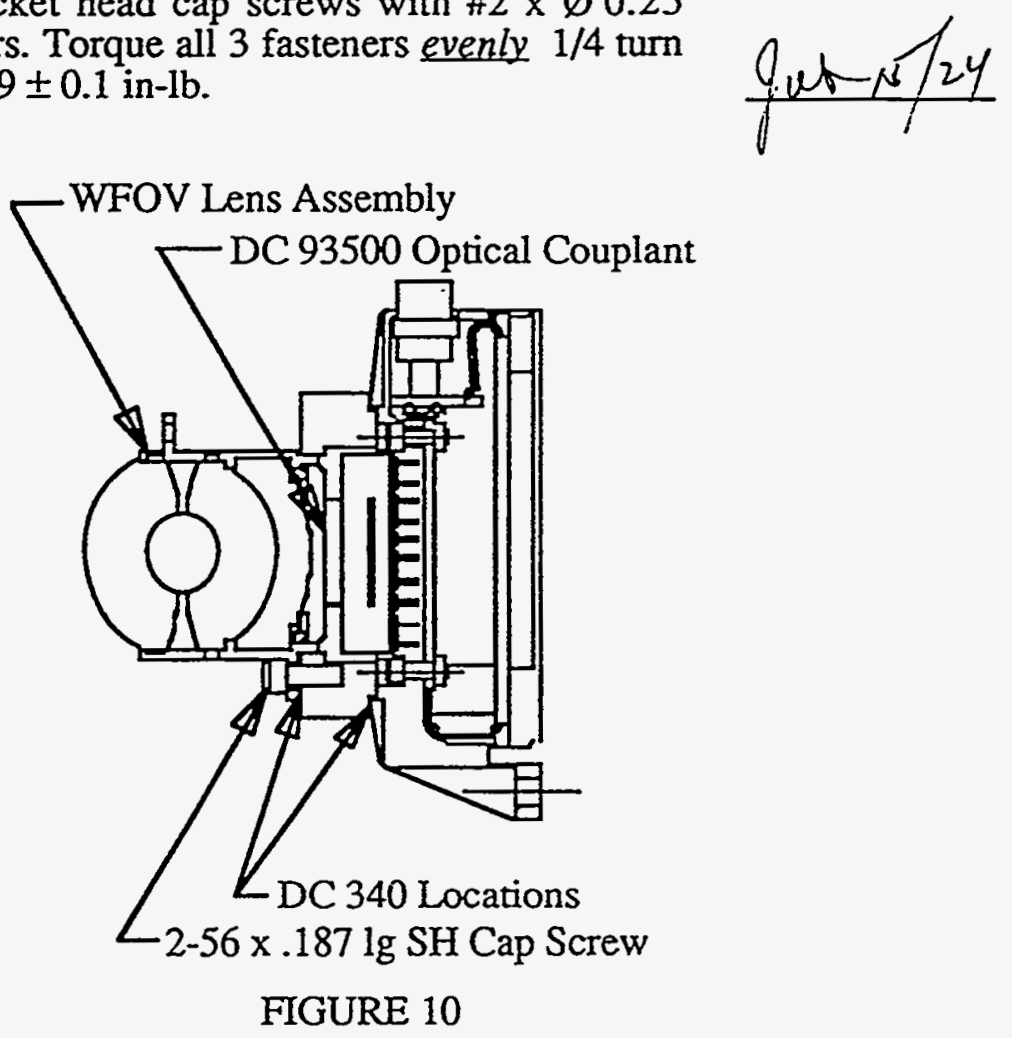

4.4.2 Within one hour of the procedures completed in step 4.4.1, perform an abbreviated camera electronic functionality test per procedure $\mathrm{Cl}-\mathrm{S} 1-(\mathrm{TBD})$.

Record results. Pass/No Pass Dass

If pass, proceed to step 4.4.3

If no pass, immediately proceed to step 4.4 .4

4.4.3 Within one hour of the test performed in step 4.4.2, perform a flat field optical test to look for bubbles and even distribution at the fiberoptic interface between the lens and CCD. Record results. Pass/No Pass PASS If pass, proceed to assembly section 4.5 If no pass, immediately proceed to step 4.4 .4
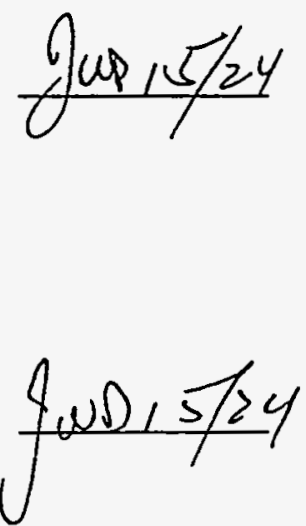
4.4.4 NOTE: This step is to be taken only as an emergency measure, and only if a $B / T C C D$ is being used. If the camera fails either of the tests required in steps 4.4 .2 or 4.4.3, immediately disassemble the lens from the camera housing, remove the $\mathrm{CCD}$, and carefully remove any.residual couplant from all optical surfaces to ensure that both the lens and the $\mathrm{B} / \mathrm{T} \mathrm{CCD}$ can be salvaged for reuse.

4.4.5 If step 4.4.4 is performed, the assembly procedure is aborted at this point and must be re-started.
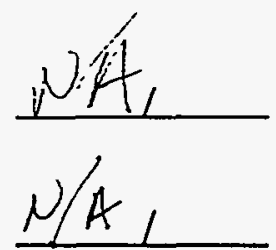

\subsection{Baffle Installation}

4.5.1 Install Baffle Assembly P/N 92-108748 onto the WFOV lens mounting tabs using 3 each, $2-56 \times .187$ long socket head cap screws and 6 each, Thermal Isolation Washers, P/N 93-102551. Do not torque fasteners beyond finger tight at this time. Ensure that the baffle assembly is evenly centered on the front of the WFOV lens by observing the gap between the lens and the baffle. For maximum thermal resistance, minimize metal-to-metal contact around this interface and between fasteners and mounting tabs.

See Figure 11.
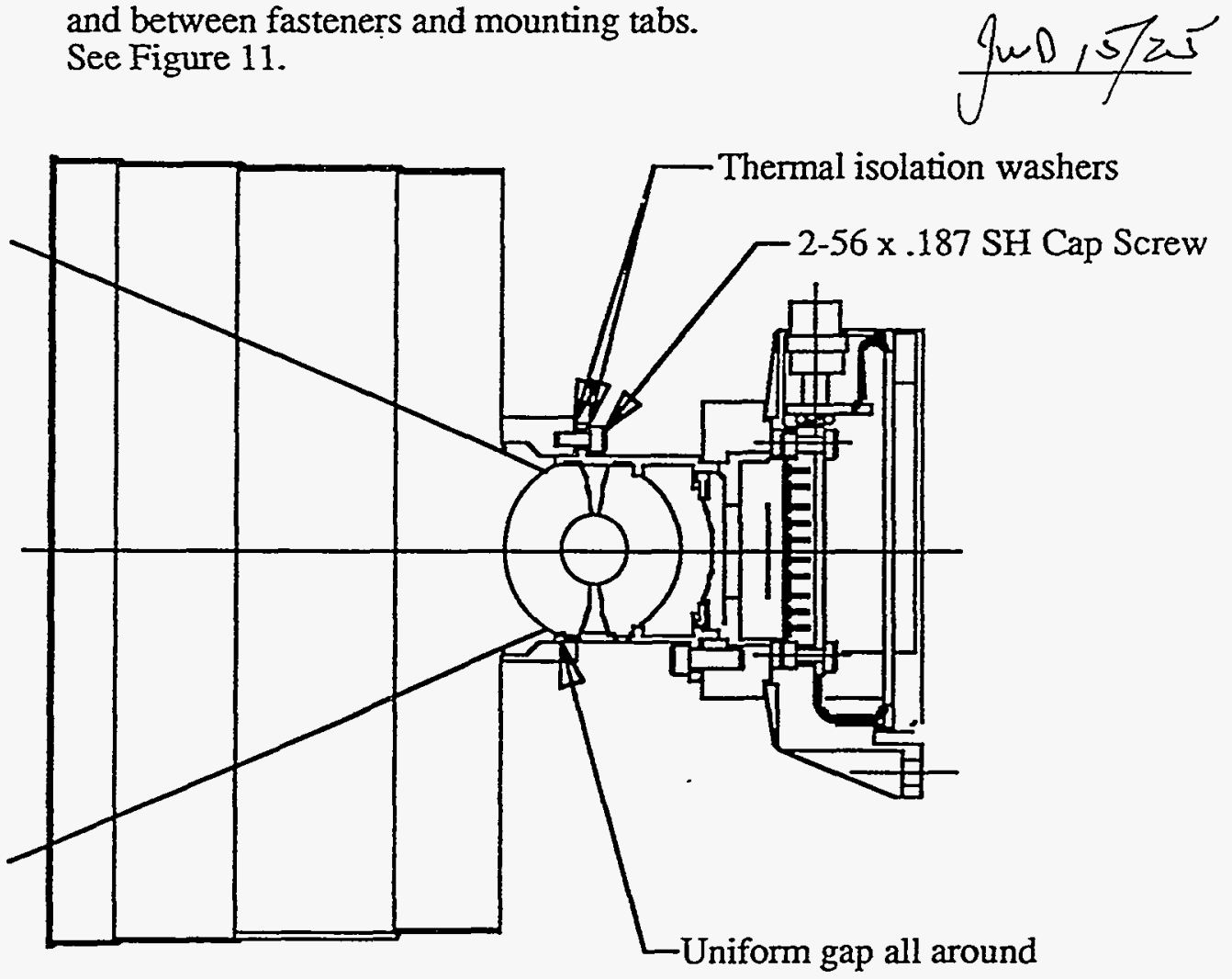

FIGURE 11

4.5.2 Perform abbreviated camera electronic functionality test per procedure C1-S1-(TBD). Record results. Pass/No Pass

Pass

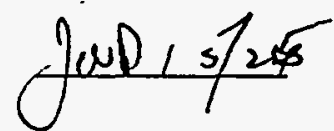


4.5.3 Angular orientation of the rectangular baffle cutout to the camera CCD is critical. Total angular tolerance is $0.3^{\circ}$ rotation. Visually verify orientation as shown in Figure 12, also verify by imaging with the camera and looking for any obscuration at the corners. If baffle is within tolerance, torque fasteners to $2.0 \pm 0.1 \mathrm{in}-\mathrm{lb}$.

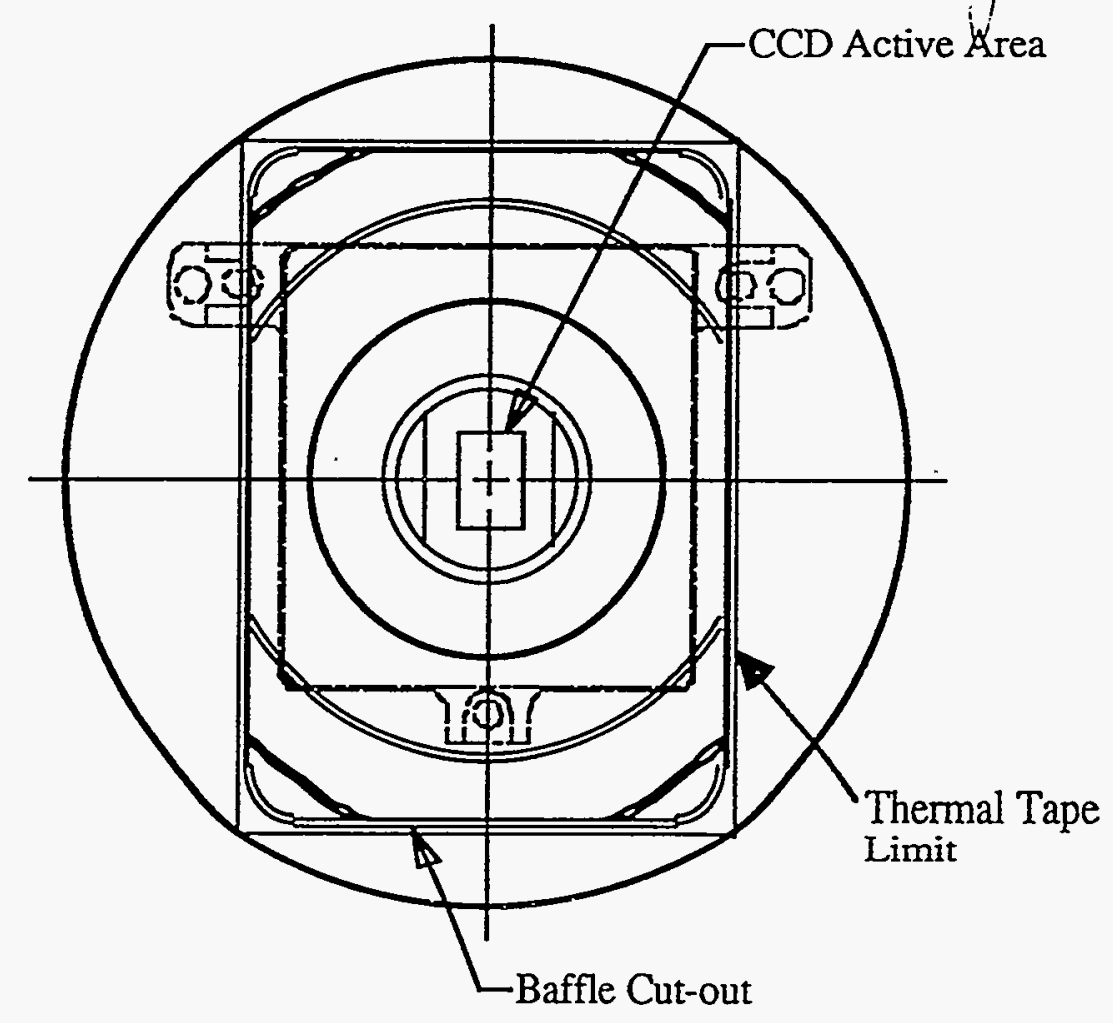

FIGURE 12

4.5.4 If camera/baffle assembly has passed all functionality tests, stake all lens, baffle, and camera end cover fasteners with EA934NA. Cure for $3 \mathrm{hrs}$. at $50^{\circ} \mathrm{C}$. Apply Sheldahl thermal tape to front of baffle vane. Trim to baffle outside diameter. IMPORTANT: Do not apply tape within 0.060 inches of the vane edge. See Figure 12.

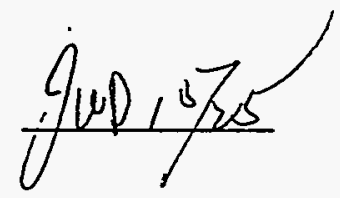




\subsection{Lens Heater Installation}

4.6.1 Install Lens Heater Clamp, P/N 93-102221, and Lens Heater Strip, Minco P/N HK17402-9311, onto the WFOV lens barrel using 2 each, 2-56 x .187 long socket head cap screws. Be careful when routing the heater wires out of clamp to avoid damage to wires. Install temperature control switch onto lens heater clamp using 2 each, $2-56 \times .187$ long socket head cap screws. Place a small drop of BA-2151 thermal epoxy under center of switch prior to installation to ensure good thermal contact. Torque all fasteners to $3.5 \pm 0.1$ in-lb.

Stake heater wires and fasteners with EA934NA. Cure for $3 \mathrm{hrs}$ at $50^{\circ} \mathrm{C}$.

4.6.2 Bond Thermistor, Fenwal P/N 534-31AG04-562, to side of lens heater clamp with BA-2151 epoxy. Cure for $3 \mathrm{hrs}$. at $50^{\circ} \mathrm{C}$.
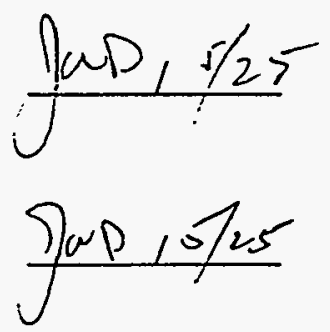


\section{Appendix G.3.5 \\ Test Procedures}




\section{Appendix G.3.5.1 \\ Calibration Data Files}


total 58

drwxrwxr-x 28 dwd

drwxrwxr-x 7 root

drwxrwxr-x 2 dwd

drwxrwxr-x 2 dwd

drwxrwxr-x 2 park

drwxrwxr-x 2 dwd

drwxrwxr-x 2 dwd

drwxrwxr-x 2 dwd

drwxrwxr-x 2 dwd

drwxrwxr-x 2 dwd

drwxrwxr-x 2 dwd

drwxrwxr-x 2 dwd

drwxrwxr-x 2 dwd

drwXrwxr-x 2 dwd

drwxrwxr-x 2 dwd

drwxrwxr-x 2 park

drwxrwxr-x 2 park

-rw-rw-r-- 1 dwd

-rw-rw-r-- 1 dwd

drwxrwxr-x 2 dwd

drwxrwxr-x 2 dwd

drwxrwxr-x 2 dwd

drwxrwxr-x 2 dwd

drwxrwxr-x 2 dwd

drwxrwxr-x 2 dwd

drwxrwxr-x 2 dwd

drwxrwxr-x 2 dwd

drwxrwxr-x 2 park

drwxrwxr-x 2 park

drwXrwXr-x 2 dwd
1024 Jul $\leqslant 11: 55 . ;$

512 Jun $21 \quad 12: 16 \ldots /$

512 Jun 28 19:23 OC_hi_center_post_vib/

512 Jun 30 12:49 0C-hi_dark_current/

512 Jul $317: 38$ oC-liñearīy/

512 Jun 30 12:53 0C_lon_dark_current/

1024 Jun $30 \quad 11: 21$ 0C-nominal_center/

1024 Jun 30 11:27 0C_nominal_center_post_vib/

512 Jun 29 13:45 0C_nominal_dark_current/

512 Jun 30 11:23 0C_nominal_spatial_post_vib/

2048 Jun 30 11:14 0c_lon_center_post_vib/

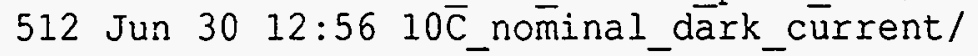

1024 Jun 30 12:06 20C_nominal_centēer_post_vib/

512 Jun 30 13:37 20C_nominal_dark_current/

3072 Jun 28 12:31 Optical_Distortion/

1536 Jul 3 17:58 Optical_Distortion_070293/

512 Jul \& 12:49 Optical_Distortion_070493/

5886 Jun 10 11:33 PDRatio_061093.1ist

5886 Jun 17 11:46 PDRatio-061793.list

512 Jun 30 13:17 SpectraI_Response/

512 Jun $29 \quad 13: 49$ focus/

$5632 \mathrm{Jul} 3$ 17:23 images/

1024 Jun $30 \quad 12: 14$ nl0C_nominal_center_post_vib/

512 Jun 30 13:40 nI0C_nominal_dark_cürrent/

2048 Jun 30 12:44 n20C_nominal_centēr_post_vib/

512 Jun 30 13:44 n20C_nominal_dark_current/

$7680 \mathrm{Jul} 111: 27$ noise//

2048 JuI 5 10:49 noise 1/

512 Jul $412: 25$ on of $\overline{\bar{y}}$ test/

512 Jul 3 14:56 warm_up/

1

Star Tracker ST 313

Calibration Reta files: name, locations 
Appendix G.3.5.2

Environmental Acceptance Test Procedures 


\section{Clementine \\ CCD Cameras}

Environmental Acceptance Test Procedures

$$
\begin{gathered}
\text { Camera Type: Star Tracker } \\
\text { S/N: ST } 313
\end{gathered}
$$

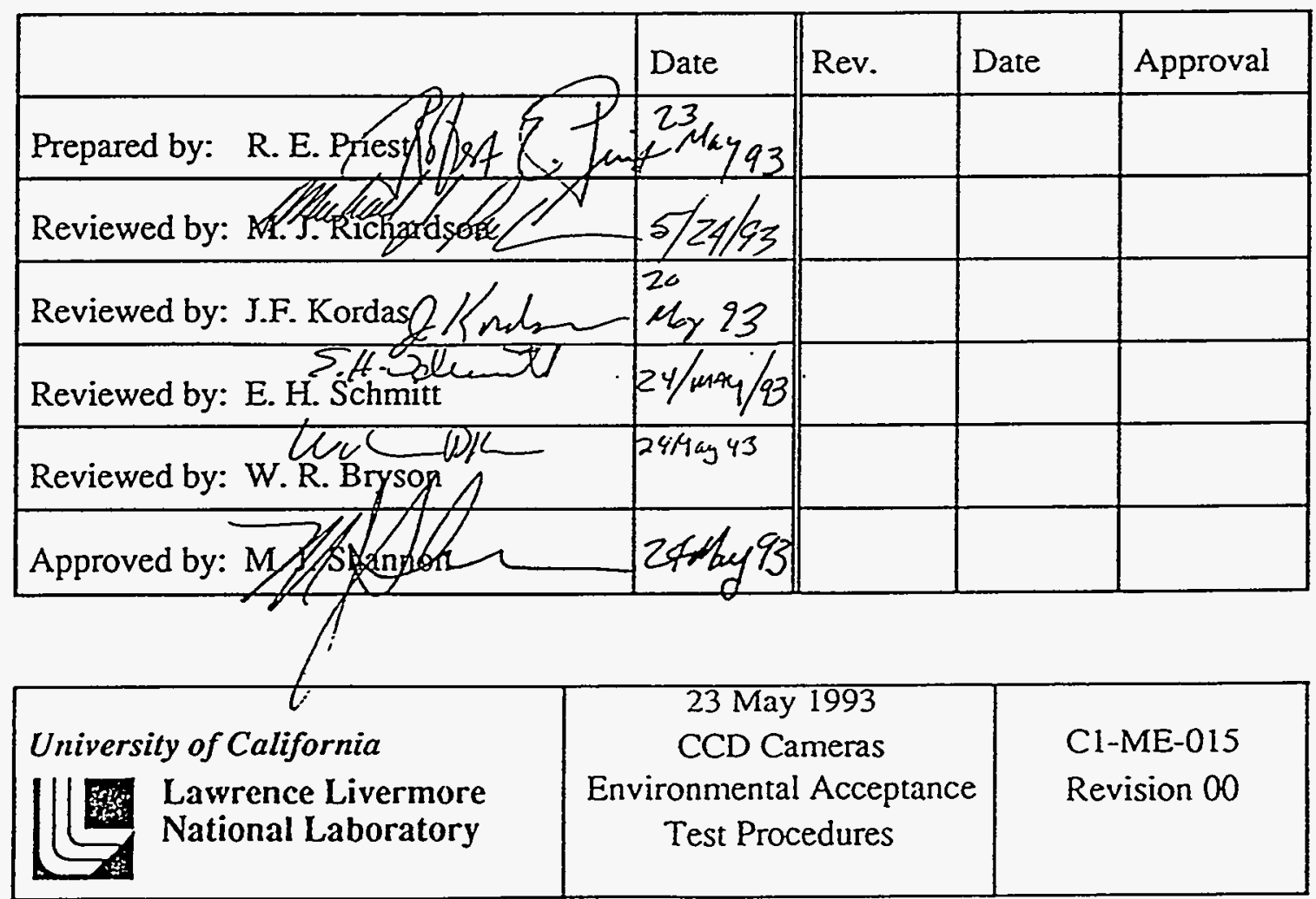

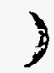




\section{Table of Contents}

1.0 General

1.1 Scope

1.2 Reference Documents

1.3 Deviations

1.4 Electro-Static Discharge Control Requirements

1.5 Cleanliness and Contamination Control Requirements

1.6 Measurement Calibration and Tolerances

1.7 Data Collection and Reduction

2.0 Equipment List

3.0 Testing Procedures

3.1 Pre-Random Vibration Abbreviated Function Test

3.2 Random Vibration

3.3 Post-Random Vibration Abbreviated Function Test

3.4 Thermal Cycle Testing

3.5 Thermal Vacuum Cycle

3.6 Burn-In Testing

4.0 Mechanical and Mass Properties

Appendix A - Camera Environmental Test Data Results 


\subsection{General}

1.1 Scope

This document details steps required to environmentally acceptance test the Clementine CCD cameras (Star Tracker, UV/Visible and HiRes/LIDAR Receiver). A copy of this document shall be maintained with each camera Certification Log. Data specific to that camera shall be recorded in Appendix A of this document.

\subsection{Reference Documents and Drawings}

Star Tracker

1.2.1 Drwg AAA92-100839, Star Tracker Camera Assy, V3.1

1.2.2 C1-S1-017, STC Abbreviated Function Test Procedures.

1.2.3 C1-S1-005, Star Tracker Camera Acceptance Level Characterization Procedures.

UVNisible

1.2.4 Drwg AAA92-103601, UV/Visible Camera Assy, V3.1

1.2.5 C1-S2-017, UVVC Abbreviated Function Test Procedures.

1.2.6 C1-S2-002, UV/Visible Camera Acceptance Level Characterization Procedures.

HiRes/LIDAR Receiver

1.2.7 Drwg AAA92-109116, HiRes/LIDAR Receiver Camera Assy, V3.1

1.2.8 C1-S4-024, HRC Abbreviated Function Test Procedures.

1.2.9 C1-S4-005, HiRes/LIDAR Receiver Acceptance Level

Common

Characterization Procedures.

1.2.10 C1-ME-008, Clementine Sensors Contamination Control Plan.

1.2.11 C1-EE-027, Clementine ESD Control Plan.

1.2.12 C1-S0-007, Clementine Quality Assurance Program Plan.

1.2.13 ML-STD-1686, Handling of ESD Sensitive Equipment.

1.2.14 MU-STD-1246B, Product Cleanliness Levels and Contamination Control Plan.

1.2.15 MIL-STD-1540B, Test Requirements for Space Vehicles

1.2.16 MU-HDBK-340, Application Guidelines for MLL-STD-1540B; Test Requirements for Space Vehicles

\subsection{Deviations}

Procedural deviations or changes from specified procedures which do not affect the physical assembly may be made at the discretion of the responsible engineer. Deviations or changes, which require any mechanical or electronic change may be made only after review and approval by a suitable Material Discrepancy Review Board as defined in the Clementine QA Program Plan.

1.4 Electro-Static Discharge Control Requirements

Each camera contains electrostatic-sensitive devices which are exposed on the electronics PWAs prior to assembly closure and at the electrical interfaces after assembly closure. Therefore, it shall be handled per MILSTD-1686 Class 1. All work shall be performed in an approved electrostatic 
discharge control area as defined by the Clementine Quality Assurance Group.

The Camera, the test operator (using wrist straps), and related electrical test equipment shall be connected to a common ground before any electrical mating or de-mating operations, and during the use of any electrical test equipment probes. There shall be no "hot-plugging" of the test specimen with any test equipment.

All electrostatic sensitive parts shall be stored in approved antistatic storage bags when not in use.

1.5 Cleanliness and Contamination Control Requirements

All assembly work shall be performed in a Class 100 laminar flow hood located within a Class 10,000 environment as defined in LLNL document "Clementine Sensors General Contamination Control Plan".

Handling of all parts shall be with clean lint-free gloves. Personnel shall wear face and hair protective smocks when handling exposed optics.

1.6 Measurement Calibration and Tolerances

1.6.1 Test chambers and test equipment shall be certified to be within their current calibration periods.

1.6.2 Vibration amplitude $14.0 \pm 1.4 \mathrm{~g} \mathrm{rms}, 19.8 \pm 2.0 \mathrm{~g}$ rms. Power spectral density spectrum $\pm 3 \mathrm{~dB}$.

1.6.3 Temperature $\pm 3^{\circ} \mathrm{C}$.

1.6.4 Humidity shall not be condensed on the camera at any time.

1.7 Data Collection and Reduction

Generally all data shall be recorded using an automated system (computer + software). Specific net results shall be recorded in the traveller copy of this procedure as required. Data reduction includes compiling all data into a summary table as outlined in Appendix A, and graphing mean and std dev image results vs test, and $C C D$ temperature value vs test.

\subsection{Equipment List}

2.1 Test Station

2.2 Clementine Cameras Power Supply

2.3 Clementine Filter Wheel Power Supply

2.4 Clementine DCDDC Converter Power Supply

2.5 Sensor 51-pin signal cable

2.6 Sensor 15-pin filter wheel power/signal cable

\subsection{Testing Procedures}

3.1 Pre-Random Vibration Abbreviated Function Test

Perform Camera Abbreviated Function Test (AFT) per the referenced procedures. Obtain data and record on data sheets. Keep the original data sheets with the camera Certification Log. 


\subsection{Random Vibration Testing}

Random vibration testing shall be performed with the camera powered off during dynamic loading. An abbreviated function test is required both before random vibration, and after all three axes of random vibration testing. Abbreviated function testing is not performed between axes tests.

The STC shall be tested to the $19.8 \mathrm{~g}$ rms level as specified in Fig. 3.1.

The UVVC and HRC shall be tested to the $14.0 \mathrm{~g}$ rms level as specified in Fig. 3.2.

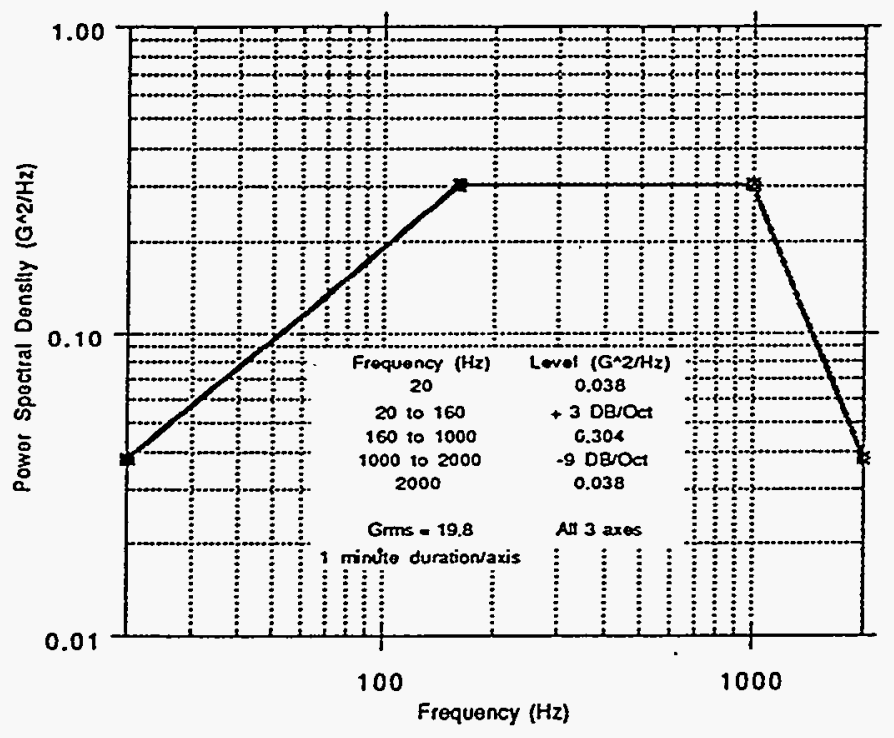

Fig. 3.1 Random Vibration Test Level for Star Tracker Camera 


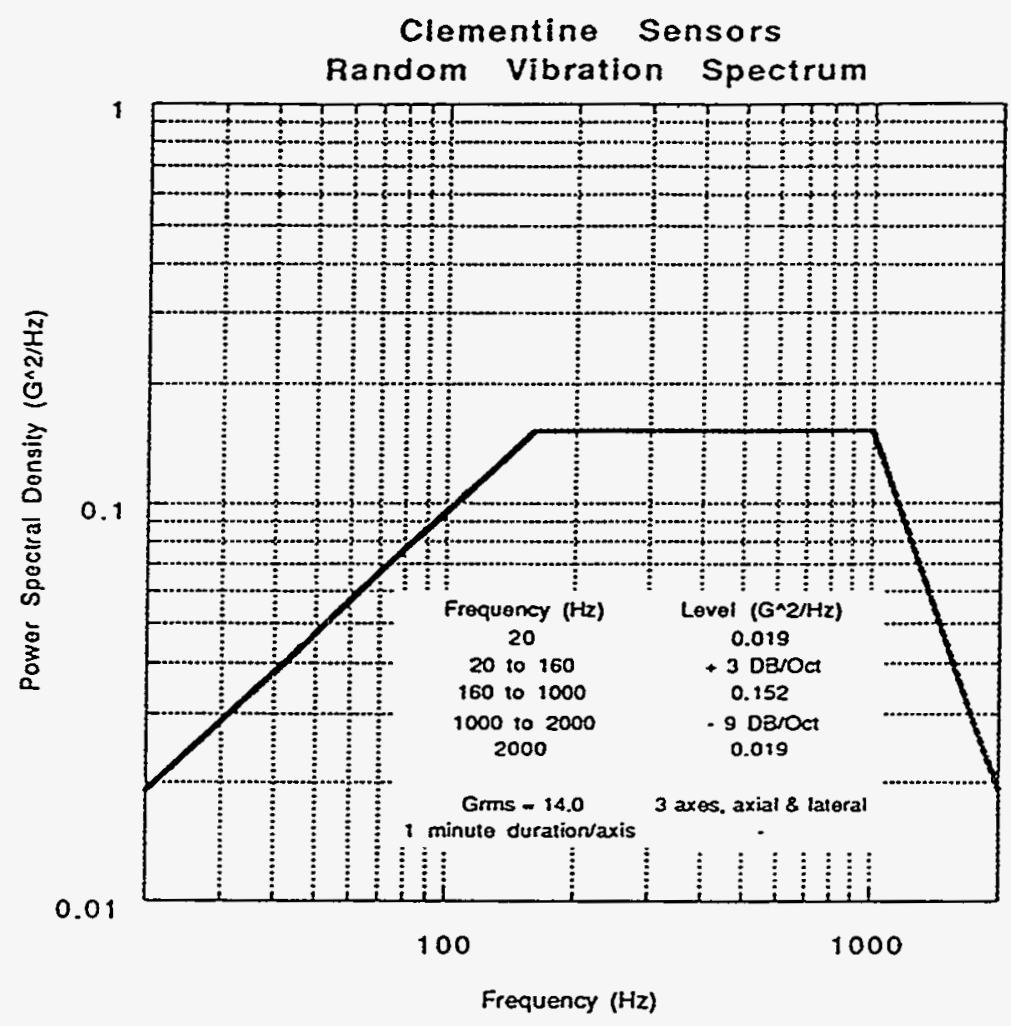

Fig. 3.2 Random Vibration Test Level for UV/Visible and HiRes/LIDAR Cameras

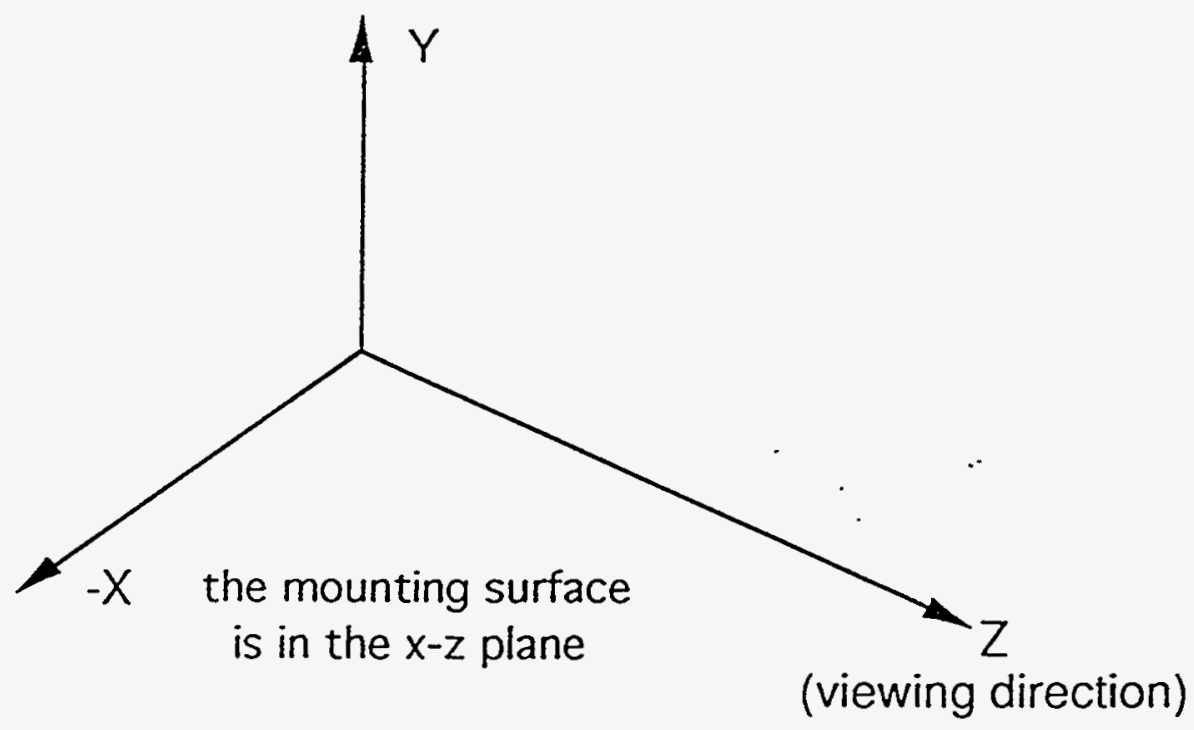

Fig. 3.3 Camera Coordinate System 
3.2.1 Mount the Test Cube with a tri-axial accelerometer on the shaker head. Perform a fixture survey to determine input excitation required to achieve the PSD level specified in Fig. 3.1 or Fig. 3.2 as appropriate. Repeat the test for all three principle axes defined in Fig. 3.3. Fixture survey is required once only for the fixture.

\subsubsection{X-Axis}

3.2.2.1 Configure the Test Cube for $x$-axis testing.

3.2.2.2 Install the Camera with lens cap in place onto the Test Cube using the appropriate NAS sockethead cap screws. Torque to values shown in Table 1.

Table 1

Camera Installation Torque Specifications

$\begin{array}{lll}\text { Size } & \text { NAS\# } & \text { Torque (in-lbf } \\ \# 4-40 & \text { NAS1352N04-x } & 14.7 \pm 0.3 \\ \# 6-32 & \text { NAS1352N06-x } & 27.4 \pm 0.5 \\ \# 8-32 & \text { NAS1352N08-x } & 50.7 \pm 0.5\end{array}$

" $x$ " designates the length of the fastener, and is selected to fit.

3.2.2.3 Remove lens cap. NOTE: the lens cap shall be off of the Camera for as short a period as practical to minimize particulate contamination.

3.2.2.4 Apply specified load for 60 second duration.

3.2.2.5 Replace the lens cap.

\subsubsection{Y-Axis}

3.2.3.1 Remove the Camera from the Test Cube and replace it on the Test Cube for $y$-axis testing.

3.2.3.2 Remove the lens cap.

3.2.3.3 Apply specified load for 60 second duration.

3.2.3.4 Replace the lens cap.

\subsubsection{Z-Axis}

3.2.4.1 Remove the Camera from the Test Cube and replace it on the Test Cube for $\mathrm{z}$-axis testing.

3.2.4.2 Remove the lens cap.

3.2.4.3 Apply specified load for 60 second duration.

3.2.4.4 Replace the lens cap.

3.2.4.5 Remove the Camera from the Test Cube and package. 


\subsection{Post-Random Vibration Abbreviated Function Test}

Perform Camera Abbreviated Function Test (AFT) per the referenced procedures. Obtain data and record on data sheets. Keep the original data sheets with the camera Certification Log.

\subsection{Thermal Cycle Testing}

The unit shall withstand thermal cycling testing that is $10^{\circ} \mathrm{C}$ below the min. operational limit, and $20^{\circ} \mathrm{C}$ above the max. operational limit. Testing shall be from $-30^{\circ} \mathrm{C}$ to $+20^{\circ} \mathrm{C}$ at $\leq 3^{\circ} \mathrm{C} / \mathrm{min}$ over six (6) cycles. Testing shall begin at room temperature, drop at the specified rate to $-30^{\circ} \mathrm{C}$, increase to + $20^{\circ} \mathrm{C}$, et cetera until all six cycles are completed.

The unit shall be mounted on small aluminum plate with a light layer of DC 340 thermal silicone between the mounting feet and the plate. Cooling straps are not required for this test, except for the stepper motors on the UV/Vis and HiRes cameras. Nylon standoffs are required between the plate and the floor of the thermal chamber.

The unit shall be powered "on" during the entire thermal cycle test duration. Camera electronics shall be in the disabled state except during AFT. The filter wheel electronics shall be in the Hold mode, except during AFT.

Function testing per Camera-specific AFT Procedures shall be performed at each temperature limit, for 5 minutes near the beginning of the dwell time and for 5 minutes near the end of the dwell time. Dwell time at maximum and minimum temperature shall be 1 hour.

Read the external Fenwall thermistor with an approved DVM to monitor the Camera temperature.

NOTE: Testing may be interrupted at a $20^{\circ} \mathrm{C}$ temperature setting, then resumed at a later time.

\subsubsection{Cycle $1,-30^{\circ} \mathrm{C}$}

Ramp the Camera down to $-30^{\circ} \mathrm{C}$ at a rate $<3^{\circ} \mathrm{C}$ minute. Allow temperature to stabilize within $\pm 3^{\circ} \mathrm{C}$. Perform AFT. Wait until near the end of the dwell period, then repeat AFT.

\subsubsection{Cycle $1,+20^{\circ} \mathrm{C}$}

Ramp the Camera up to $+20^{\circ} \mathrm{C}$ at a rate $<3^{\circ} \mathrm{C} /$ minute. Allow temperature to stabilize within $\pm 3^{\circ} \mathrm{C}$. Perform AFT. Wait until near the end of the dwell period, then repeat AFT. 


\subsubsection{Cycle $2,-30^{\circ} \mathrm{C}$}

Ramp the Camera down to $-30^{\circ} \mathrm{C}$ at a rate $<3^{\circ} \mathrm{C} /$ minute. Allow temperature to stabilize within $\pm 3^{\circ} \mathrm{C}$. Perform AFT. Wait until near the end of the dwell period, then repeat AFT.

3.4.4 Cycle $2,+20^{\circ} \mathrm{C}$

Ramp the Camera up to $+20^{\circ} \mathrm{C}$ at a rate $<3^{\circ} \mathrm{C} /$ minute. Allow temperature to stabilize within $\pm 3^{\circ} \mathrm{C}$. Perform AFT. Wait until near the end of the dwell period, then repeat AFT.

3.4.5 Cycle $3,-30^{\circ} \mathrm{C}$

Ramp the Camera down to $-30^{\circ} \mathrm{C}$ at a rate $<3^{\circ} \mathrm{C} /$ minute. Allow temperature to stabilize within $\pm 3^{\circ} \mathrm{C}$. Perform AFT. Wait until near the end of the dwell period, then repeat AFT.

3.4.6 Cycle $3,+20^{\circ} \mathrm{C}$

Ramp the Camera up to $+20^{\circ} \mathrm{C}$ at a rate $<3^{\circ} \mathrm{C} /$ minute. Allow temperature to stabilize within $\pm 3^{\circ} \mathrm{C}$. Perform AFT. Wait until near the end of the dwell period, then repeat AFT.

3.4.7 Cycle $4,-30^{\circ} \mathrm{C}$

Ramp the Camera down to $-30^{\circ} \mathrm{C}$ at a rate $<3^{\circ} \mathrm{C} /$ minute. Allow temperature to stabilize within $\pm 3^{\circ} \mathrm{C}$. Perform AFT. Wait until near the end of the dwell period, then repeat AFT.

3.4.8 Cycle $4,+20^{\circ} \mathrm{C}$

Ramp the Camera up to $+20^{\circ} \mathrm{C}$ at a rate $<3^{\circ} \mathrm{C} /$ minute. Allow temperature to stabilize within $\pm 3^{\circ} \mathrm{C}$. Perform AFT. Wait until near the end of the dwell period, then repeat AFT.

3.4.9 Cycle $5,-30^{\circ} \mathrm{C}$

Ramp the Camera down to $-30^{\circ} \mathrm{C}$ at a rate $<3^{\circ} \mathrm{C} /$ minute. Allow temperature to stabilize within $\pm 3^{\circ} \mathrm{C}$. Perform AFT. Wait until near the end of the dwell period, then repeat AFT.

3.4.10 Cycle $5,+20^{\circ} \mathrm{C}$

Ramp the Camera up to $+20^{\circ} \mathrm{C}$ at a rate $<3^{\circ} \mathrm{C} /$ minute. Allow temperature to stabilize within $\pm 3^{\circ} \mathrm{C}$. Perform AFT. Wait until near the end of the dwell period, then repeat AFT.

\subsubsection{Cycle $6,-30^{\circ} \mathrm{C}$}

Ramp the Camera down to $-30^{\circ} \mathrm{C}$ at a rate $<3^{\circ} \mathrm{C} /$ minute. Allow temperature to stabilize within $\pm 3^{\circ} \mathrm{C}$. Perform AFT. Wait until near the end of the dwell . period, then repeat AFT. 


\subsubsection{Cycle $6,+20^{\circ} \mathrm{C}$}

Ramp the Camera up to $+20^{\circ} \mathrm{C}$ at a rate $<3^{\circ} \mathrm{C} /$ minute. Allow temperature to stabilize within $\pm 3^{\circ} \mathrm{C}$. Perform AFT. Wait until near the end of the dwell period, then repeat AFT.

\subsection{Thermal Vacuum Cycling}

The unit shall withstand thermal vacuum cycle testing that is $5^{\circ} \mathrm{C}$ below and above the min. and max. operational limits. Additionally, radiometric response shall be verified at $-20^{\circ} \mathrm{C}$ and $0^{\circ} \mathrm{C}$ for correlation to calibration data acquired in a dry $\mathrm{N}_{2}$ forced convection thermal chamber.

Testing shall be from $-25^{\circ} \mathrm{C}$ to $+5^{\circ} \mathrm{C}$ at $\leq 3^{\circ} \mathrm{C} / \mathrm{min}$ over one cycle with ambient pressure of $\leq 1 \times 10^{-4}$ torr during the entire test. Temperature shall be provided by a controlled cold plate and cooling shroud. Testing shall begin at room temperature, drop at the specified rate to $-25^{\circ} \mathrm{C}$, then increase to $-20^{\circ} \mathrm{C}$, then increase to $0^{\circ} \mathrm{C}$, then increase to $+5^{\circ} \mathrm{C}$. The temperature of the cold plate and cooling shroud shall remain the same during testing. Abbreviated function tests shall be performed at $-25^{\circ}$ and $+5^{\circ} \mathrm{C}$ temperature limit. Abbreviated calibration measurements shall be performed per referenced calibration documents at $-20^{\circ} \mathrm{C}$ and $0^{\circ} \mathrm{C}$. Dwell time at test temperatures shall be $>2$ hours.

The camera need only be powered on during the 2 hour dwell time at temperatures. Camera may be Disabled and filter wheel in Hold, except during AFT and abbreviated calibration measurements. An AFT shall be performed near the beginning, and near the end of the dwell period.

3.5.1 Configure the Camera in the thermal vacuum chamber as shown in Fig. 3.4. Note that the light source may be inside or outside the chamber as long as the irradiance is measured with a calibrated radiometer at various locations of the optical aperture of the Camera. Conditioned power and SASI interface are required. Temperature stability shall be determined by the lens thermistor. 


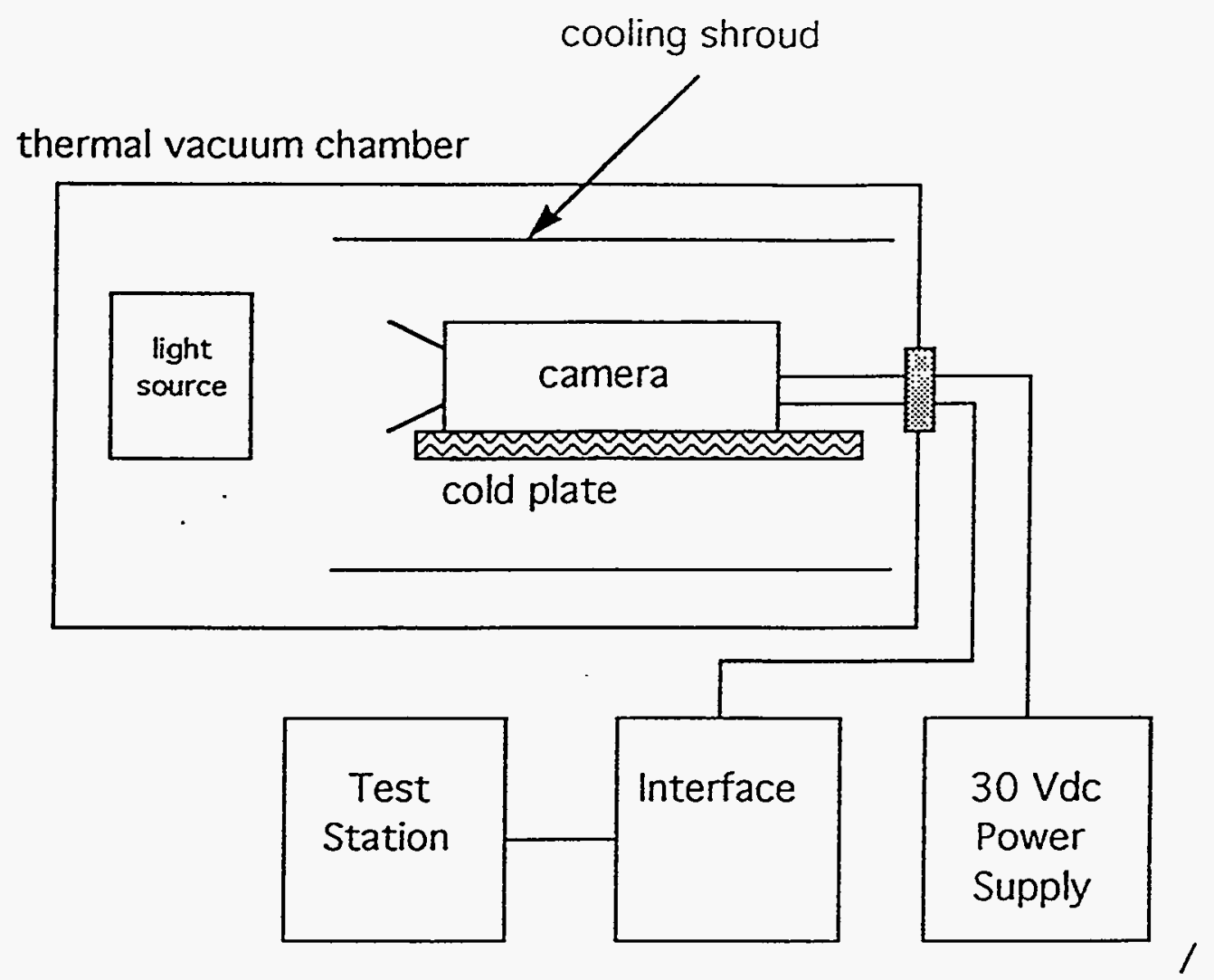

Fig. 3.4 Thermal Vacuum Test Schematic

\subsubsection{Pre-TVAC Check Out}

With the cold plate operating at $20^{\circ} \mathrm{C}$, Perform an AFT to verify camera operation.

\subsection{3 $-25^{\circ} \mathrm{CTVAC}$}

Evacuate the chamber to $<1 \times 10-4$ torr.

Ramp the cold plate and shroud down to $-30^{\circ} \mathrm{C}$ at a rate $<3^{\circ} \mathrm{C} /$ minute. Allow temperature to stabilize within $\pm 3^{\circ} \mathrm{C}$. Perform AFT. Wait until near the end of the dwell period, then repeat AFT.

\subsection{4 $-20^{\circ} \mathrm{CTVAC}$}

Ramp the cold plate and shroud up to $-20^{\circ} \mathrm{C}$. Perform abbreviated calibration measurements. Record all data per section 3.5, "Thermal Vacuum Cycle Testing" found in Appendix A.

Compare results with data obtained during full calibration in dry $\mathrm{N}_{2}$. Determine if there is any statistically substantiated change in performance. 


\subsection{5 +0 $+0^{\circ} \mathrm{CVAC}$}

Ramp the cold plate and shroud up to $0^{\circ} \mathrm{C}$. Perform abbreviated calibration measurements. Record all data per section 3.5, "Thermal Vacuum Cycle Testing" found in Appendix A.

Compare results with data obtained during full calibration in dry $\mathrm{N}_{2}$. Determine if there is any statistically substantiated change in performance.

3.5.6 $+5^{\circ} \mathrm{C}$ TVAC

Ramp the cold plate and shroud up to $+5^{\circ} \mathrm{C}$ at a rate $<3^{\circ} \mathrm{C} /$ minute. Allow temperature to stabilize within $\pm 3^{\circ} \mathrm{C}$. Perform AFT. Wait until near the end of the dwell period, then repeat AFT.

\subsubsection{Post-TVAC Testing}

Turn the cold plate and shroud off and return back to ambient temperature. Vent slowly with dry nitrogen to return the chamber to one atmosphere. Perform AFT. Remove the Camera from the chamber and return back to it's storage container.

\subsection{Burn-In}

The unit shall accumulate, as a goal, a total of 300 cummulative hours of Camera electronics powered-on operation. Powered-on time accumulated during other tests (e.g. - thermal cycling, etc.) count toward the 300 hours. If 300 hours is satisfied by the end of all testing (environmental ATP and calibration), then additional burn-in testing is not required.

The stepper motor electronics must accumulate, as a goal, a total of 300 hours of powered-on operation. Of these 300 hours, 5 hours of stepping shall be attained with the remaining 295 hours with the electronics in the hold mode. For reference, at one filter position change per $0.35 \mathrm{sec}$ stepping time, this equates to $>51,400$ filter position changes.

\subsection{Mechanical and Mass Properties}

4.1 Review all relevant mechanical features of the unit against LLNL interface control drawing, latest applicable revision, for conformance. Mark the actual measured dimension in green on the assembly drawing included in the Camera Certification Log. Note any descrepancies.

STC drawing AAA92-100839

$\mathrm{S} / \mathrm{N}: S T \geq 13$

UVVC drawing AAA92-103601

$\mathrm{S} / \mathrm{N}:$

HRC drawing AAA92-109116

S/N:

4.2 Weigh the Camera to the nearest gram.

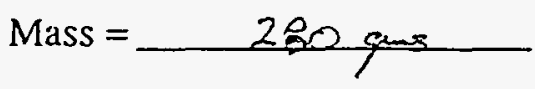


Appendix G.3.5.2.1

\section{Random Vibration Test Data}


Appendix A - Camera Environmental Test Data Results

3.1 Pre-Random Vibration Abbreviated Function Test Unit S/N:ST $3 / 3$

\begin{tabular}{|l|c|c|c|c|c|c|c|}
\hline Test & $\mathbf{T}_{\infty}\left({ }^{\circ} \mathrm{C}\right)$ & $\begin{array}{c}\text { Tau } \\
(\mathbf{m s e c})\end{array}$ & $\begin{array}{c}\text { Gain } \\
(\mathrm{e}-/ \mathrm{ct})\end{array}$ & $\begin{array}{c}\text { Offset } \\
(\text { level })\end{array}$ & $\begin{array}{c}\text { Filter } \\
(\mathrm{ctr} \text { wl) }\end{array}$ & $\begin{array}{c}\text { mean } \\
(\mathrm{cts})\end{array}$ & $\begin{array}{c}\text { sigma } \\
(\mathbf{c t s})\end{array}$ \\
\hline $\begin{array}{l}\text { Pre- } \\
\text { Rndm } \\
\text { Vibe }\end{array}$ & & & & & & & \\
\hline
\end{tabular}

3.2 Random Vibration Testing

Unit S/N: ST 313

Requirement:

$14.0 \pm 1.4 \mathrm{~g}$ rms and $\geq 60 \mathrm{sec}$ duration, each axis (UV/Vis, HiRes). $19.8 \pm 2.0 \mathrm{~g}$ rms and $60 \mathrm{sec}$ duration, each axis (Star Tracker).

\begin{tabular}{|l|c|l|}
\hline Axis & Measured level (g rms) & Measured duration (sec) \\
\hline $\mathrm{X}$ & $\mid 9.95$ & \\
\hline $\mathrm{Y}$ & $\mid 9.61$ & \\
\hline $\mathrm{Z}$ & $\mid 9.87$ & \\
\hline
\end{tabular}

Include data sheet for each axis in Certification Log.

3.3 Post-Random Vibration Abbreviated Function Test Unit S/N: ST $3 / 3$

\begin{tabular}{|l|l|l|l|l|l|l|l|}
\hline Test & $\mathrm{T}_{\infty}\left({ }^{\circ} \mathrm{C}\right)$ & $\begin{array}{c}\text { Tau } \\
(\mathrm{msec})\end{array}$ & $\begin{array}{c}\text { Gain } \\
(\mathrm{e}-/ \mathrm{ct})\end{array}$ & $\begin{array}{c}\text { Offset } \\
(\text { level })\end{array}$ & $\begin{array}{c}\text { Filter } \\
(\mathrm{ctr} \text { wl })\end{array}$ & $\begin{array}{c}\text { mean } \\
(\mathrm{cts})\end{array}$ & $\begin{array}{c}\text { sigma } \\
(\mathrm{cts})\end{array}$ \\
\hline $\begin{array}{l}\text { Post } \\
\text { Rndm } \\
\text { Vibe }\end{array}$ & & & & & & & \\
\hline
\end{tabular}


Appendix G.3.5.2.2

Thermal Cycle Test Data 
3.4 Thermal Cycle Testing

Unit $S / N$

\begin{tabular}{|c|c|c|c|c|c|c|c|}
\hline Test & $\mathrm{T}_{\infty}\left({ }^{\circ} \mathrm{C}\right)$ & $\begin{array}{c}\text { Tau } \\
\text { (msec) }\end{array}$ & $\begin{array}{l}\text { Gain } \\
(\mathrm{e}-/ \mathrm{ct})\end{array}$ & $\begin{array}{l}\text { Offset } \\
\text { (level) }\end{array}$ & $\begin{array}{c}\text { Filter } \\
(\mathrm{ctr} w \mathrm{w})\end{array}$ & $\begin{array}{c}\text { mean } \\
\text { (cts) }\end{array}$ & $\begin{array}{c}\text { sigma } \\
\text { (cts) }\end{array}$ \\
\hline $\begin{array}{l}\text { Cycle 1, } \\
-30^{\circ} \mathrm{C}\end{array}$ & & & & & & & \\
\hline $\begin{array}{l}\text { Cycle } 1 \text {, } \\
20^{\circ} \mathrm{C}\end{array}$ & & & & & & & \\
\hline $\begin{array}{l}\text { Cycle 2, } \\
-30^{\circ} \mathrm{C}\end{array}$ & & & & & & & \\
\hline $\begin{array}{l}\text { Cycle } 2, \\
20^{\circ} \mathrm{C}\end{array}$ & & & & & & & \\
\hline $\begin{array}{l}\text { Cycle 3, } \\
-30^{\circ} \mathrm{C}\end{array}$ & & & & & & & \\
\hline $\begin{array}{l}\text { Cycle } 3, \\
20^{\circ} \mathrm{C}\end{array}$ & & & & & & & \\
\hline $\begin{array}{l}\text { Cycle 4, } \\
-30^{\circ} \mathrm{C}\end{array}$ & & & & & & & \\
\hline $\begin{array}{l}\text { Cycle 4, } \\
20^{\circ} \mathrm{C}\end{array}$ & & & & & & & \\
\hline $\begin{array}{l}\text { Cycle 5, } \\
-30^{\circ} \mathrm{C}\end{array}$ & & & & & & & \\
\hline $\begin{array}{l}\text { Cycle 5, } \\
20^{\circ} \mathrm{C}\end{array}$ & & & & & & & \\
\hline $\begin{array}{l}\text { Cycle 6, } \\
-30^{\circ} \mathrm{C}\end{array}$ & & & & & & & \\
\hline $\begin{array}{l}\text { Cycle 6, } \\
20^{\circ} \mathrm{C}\end{array}$ & & & & & & & \\
\hline
\end{tabular}


3.5 Thermal Vacuum Cycle Testing Unit S/N:

TVAC Test Results

3.5.2 Pre-TVAC Abbreviated Function Test Results

\begin{tabular}{|l|l|l|l|l|l|l|l|}
\hline Test & $\mathrm{T}_{\infty}\left({ }^{\circ} \mathrm{C}\right)$ & $\begin{array}{c}\text { Tau } \\
(\mathrm{msec})\end{array}$ & $\begin{array}{c}\text { Gain } \\
(\mathrm{e}-/ \mathrm{ct})\end{array}$ & $\begin{array}{c}\text { Offset } \\
(\text { level })\end{array}$ & $\begin{array}{c}\text { Filter } \\
(\mathrm{ctr} \text { wl })\end{array}$ & $\begin{array}{c}\text { mean } \\
(\mathrm{cts})\end{array}$ & $\begin{array}{c}\text { sigma } \\
(\mathrm{cts})\end{array}$ \\
\hline$-25^{\circ} \mathrm{C}$ & & & & & & & \\
TVAC & & & & & & & \\
\hline
\end{tabular}

3.5.3 $-25^{\circ} \mathrm{C}$ TVAC Abbreviated Function Test Results

\begin{tabular}{|l|c|c|c|c|c|c|c|}
\hline Test & $\mathrm{T}_{\infty}\left({ }^{\circ} \mathrm{C}\right)$ & $\begin{array}{c}\text { Tau } \\
(\mathrm{msec})\end{array}$ & $\begin{array}{c}\text { Gain } \\
(\mathrm{e}-/ \mathrm{ct})\end{array}$ & $\begin{array}{c}\text { Offset } \\
(\text { level })\end{array}$ & $\begin{array}{c}\text { Filter } \\
(\mathrm{ctr} \text { wl) }\end{array}$ & $\begin{array}{c}\text { mean } \\
(\mathrm{cts})\end{array}$ & $\begin{array}{c}\text { sigma } \\
(\mathrm{cts})\end{array}$ \\
\hline$-25^{\circ} \mathrm{C}$ & & & & & & & \\
TVAC & & & & & & & \\
\hline
\end{tabular}

3.5.4 and 3.5.5 $-20^{\circ} \mathrm{C}$ and $0^{\circ} \mathrm{C}$ TVAC Abbreviated Calibration Test Results

Camera Settings

\begin{tabular}{|l|c|c|c|c|c|}
\hline Test & $\mathbf{T}_{\infty}\left({ }^{\circ} \mathrm{C}\right)$ & $\begin{array}{c}\text { Filter } \\
(\text { ctr wl) }\end{array}$ & $\begin{array}{c}\text { Tau } \\
\text { (msec) }\end{array}$ & $\begin{array}{c}\text { Gain } \\
(\mathrm{e}-/ \mathrm{ct})\end{array}$ & $\begin{array}{c}\text { Offset } \\
\text { (level) }\end{array}$ \\
\hline $\begin{array}{l}-20^{\circ} \mathrm{C} \\
\text { TVAC }\end{array}$ & & & & & \\
\hline $\begin{array}{l}0^{\circ} \mathrm{C} \\
\text { TVAC }\end{array}$ & & & & & \\
\hline
\end{tabular}

Notes: 
TVAC Calibration Results

\begin{tabular}{|l|l|l|l|l|}
\hline Parameter & $\begin{array}{c}-20^{\circ} \mathrm{C} \\
\mathrm{N}_{2}\end{array}$ & $\begin{array}{c}-20^{\circ} \mathrm{C} \\
\text { TVAC }\end{array}$ & $\begin{array}{c}0^{\circ} \mathrm{C} \\
\mathrm{N}_{2}\end{array}$ & $\begin{array}{c}0^{\circ} \mathrm{C} \\
\text { TVAC }\end{array}$ \\
\hline $\begin{array}{l}\text { Pixel sensitivity, C [gray } \\
\left.\left.\text { levels/(nJ/cm }{ }^{2} \text {-str- } \mu \mathrm{m}\right)\right]\end{array}$ & & & & \\
\hline $\begin{array}{l}\text { Dark level [cts] / FPA temperature } \\
\text { during measurement [K] }\end{array}$ & & & & \\
\hline $\begin{array}{l}\text { Dark current [cts] /CCD } \\
\text { temperature during measurement } \\
{\left[{ }^{\circ} \mathrm{C}\right]}\end{array}$ & & & & \\
\hline $\begin{array}{l}\text { Electronics warm-up effect [mean } \\
\text { gray level vs time graph] }\end{array}$ & & & & \\
\hline $\begin{array}{l}\text { CCD temperature vs time graph } \\
\text { Lens temperature vs time graph }\end{array}$ & & & & \\
\hline
\end{tabular}

3.5.6 $+5^{\circ} \mathrm{C}$ TVAC Abbreviated Function Test Results

\begin{tabular}{|l|l|l|l|l|l|l|l|}
\hline Test & $\mathrm{T}_{\infty}\left({ }^{\circ} \mathrm{C}\right)$ & $\begin{array}{c}\text { Tau } \\
(\mathrm{msec})\end{array}$ & $\begin{array}{c}\text { Gain } \\
(\mathrm{e}-/ \mathrm{ct})\end{array}$ & $\begin{array}{c}\text { Offset } \\
(\text { level })\end{array}$ & $\begin{array}{c}\text { Filter } \\
(\mathrm{ctr} \text { wl })\end{array}$ & $\begin{array}{c}\text { mean } \\
(\mathrm{cts})\end{array}$ & $\begin{array}{c}\text { sigma } \\
(\mathrm{cts})\end{array}$ \\
\hline $\begin{array}{l}+5^{\circ} \mathrm{C} \\
\text { TVAC }\end{array}$ & & & & & & & \\
\hline
\end{tabular}

3.5.7 Post-TVAC Abbreviated Function Test Results

\begin{tabular}{|l|c|c|c|c|c|c|c|}
\hline Test & $\mathrm{T}_{\infty}\left({ }^{\circ} \mathrm{C}\right)$ & $\begin{array}{c}\text { Tau } \\
(\mathrm{msec})\end{array}$ & $\begin{array}{c}\text { Gain } \\
(\mathrm{e}-/ \mathrm{ct})\end{array}$ & $\begin{array}{c}\text { Offset } \\
(\text { level })\end{array}$ & $\begin{array}{c}\text { Filter } \\
(\mathrm{ctr} \text { wl) }\end{array}$ & $\begin{array}{c}\text { mean } \\
(\mathrm{cts})\end{array}$ & $\begin{array}{c}\text { sigma } \\
(\mathrm{cts})\end{array}$ \\
\hline $\begin{array}{l}+5^{\circ} \mathrm{C} \\
\text { TVAC }\end{array}$ & & & & & & & \\
\hline
\end{tabular}


Cummulative Operation Time (Hrs)

i

\begin{tabular}{|c|c|c|c|}
\hline Log Date & $\begin{array}{l}\text { Camera } \\
\text { Electronics }\end{array}$ & $\begin{array}{l}\text { Filter Wheel } \\
\text { Electronics }\end{array}$ & $\begin{array}{l}\text { Stepping } \\
\text { Time }\end{array}$ \\
\hline BWA checkout & 16 thes & NA & $N A$ \\
\hline Ittenmal trests & 12 Hes & 1 & 1 \\
\hline Cotilongriow & $115 \mathrm{Has}$ & 1 & \\
\hline Functe Ths & 5 itres & 1 & l \\
\hline & & & \\
\hline & & & \\
\hline & & & \\
\hline & & & \\
\hline & & & \\
\hline & & & \\
\hline & & & \\
\hline & & & \\
\hline & & & \\
\hline & & & \\
\hline & & & \\
\hline & & & \\
\hline & & & \\
\hline & & & \\
\hline & & & \\
\hline & & & \\
\hline & & & \\
\hline & & & \\
\hline & & & \\
\hline & & & \\
\hline & & & \\
\hline
\end{tabular}


4.1 Mechanical and Mass Properties

STC drawing AAA92-100839

$\mathrm{S} / \mathrm{N}: \quad$ ST 313

UVVC drawing AAA92-103601

$\mathrm{S} / \mathrm{N}:$

HRC drawing AAA92-109116

$\mathrm{S} / \mathrm{N}:$

Applicable drawing revision:

Measure relevant dimensions indicated on a copy of the referenced drawing and mark the measured value on the drawing. Keep this marked drawing with the Certification Log.

\subsection{Mass}

Mass $=280$ grams 

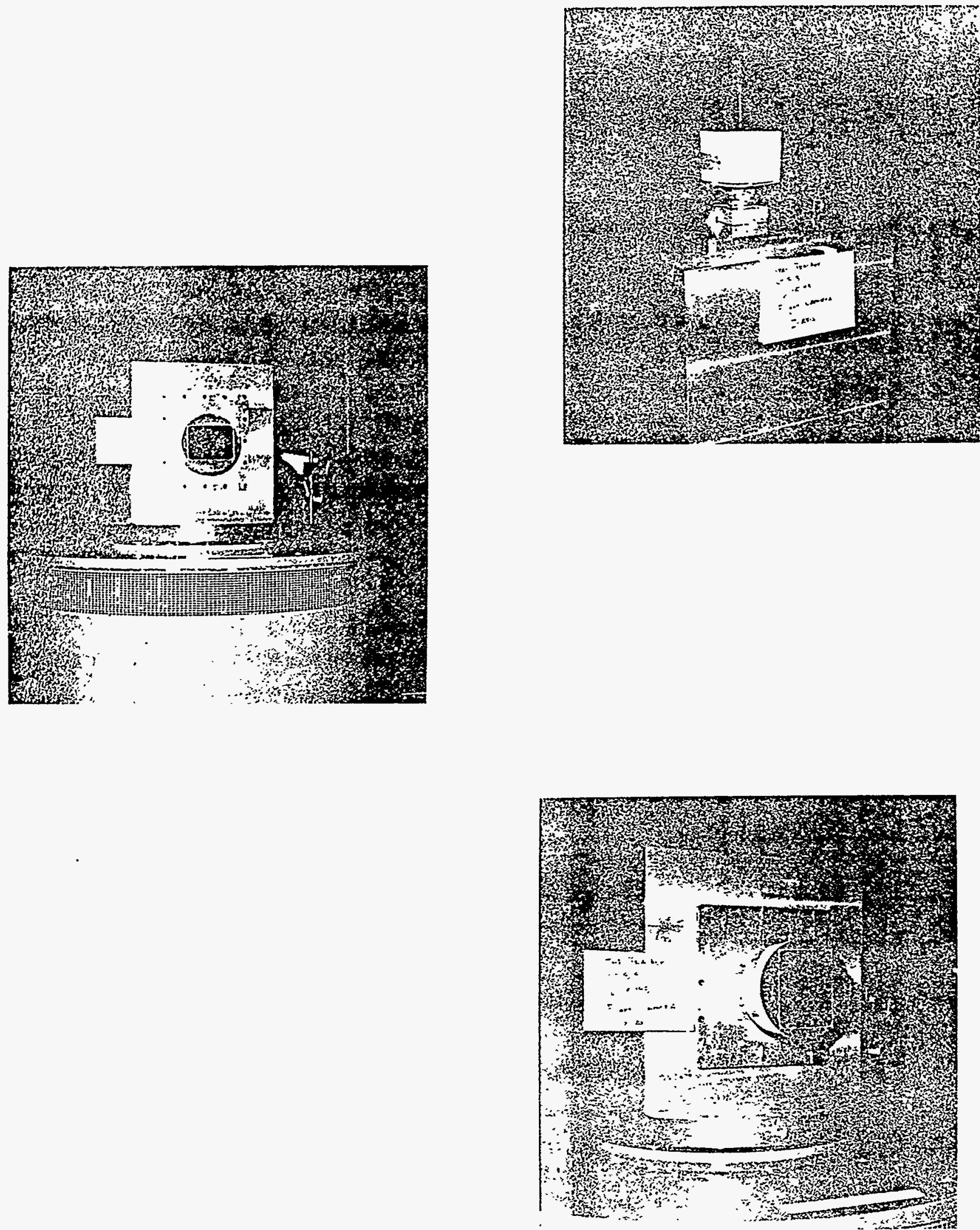


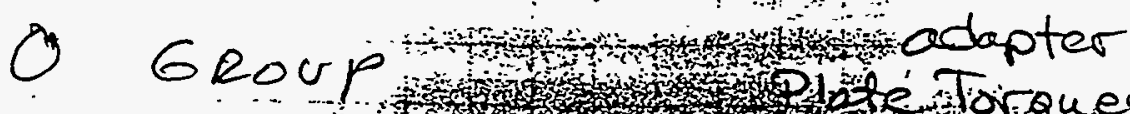

RUN HI STAR TRACK

S) 313
$6-15-93$

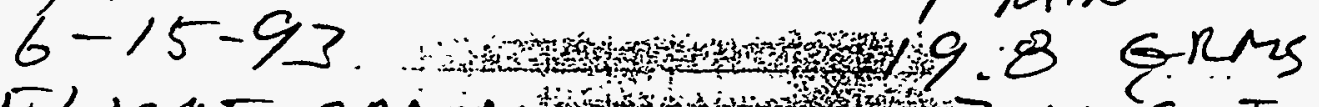

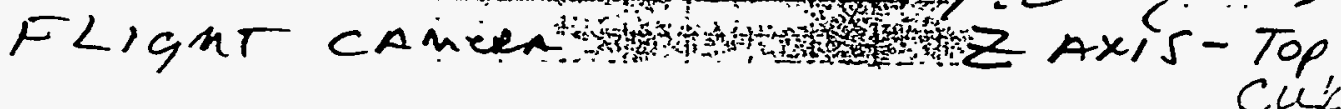

Run $\# 2$

$$
\begin{aligned}
& \text { STHR Tracker } \\
& S T=1 ? \\
& 6-1 \%
\end{aligned}
$$

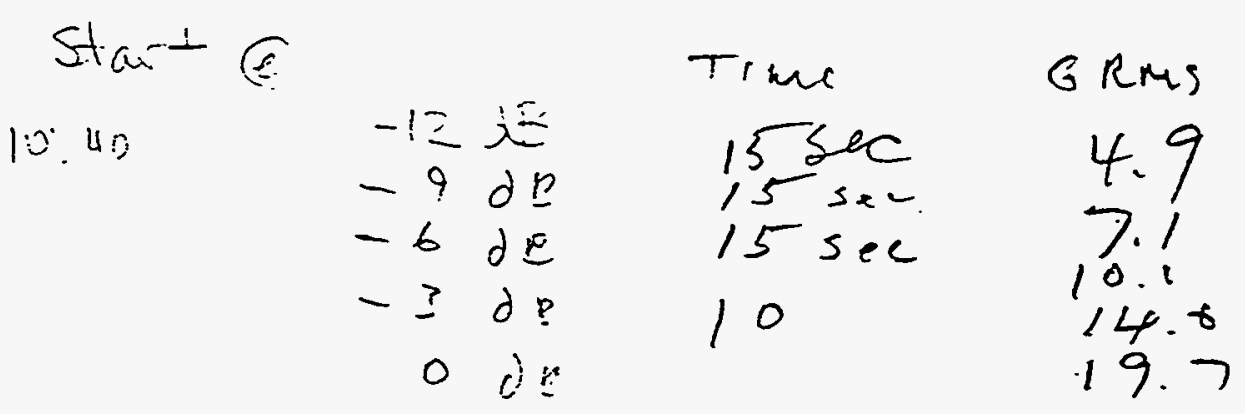

1 min test

19.8 g's.

$x-a \times 1 s$

sire of cube

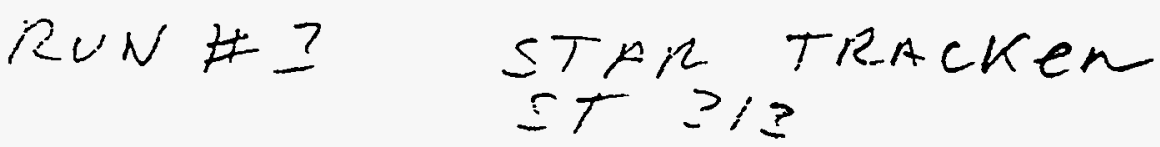

$$
\begin{aligned}
& 6-75-92 \\
& \text { Flight CAmeras }
\end{aligned}
$$

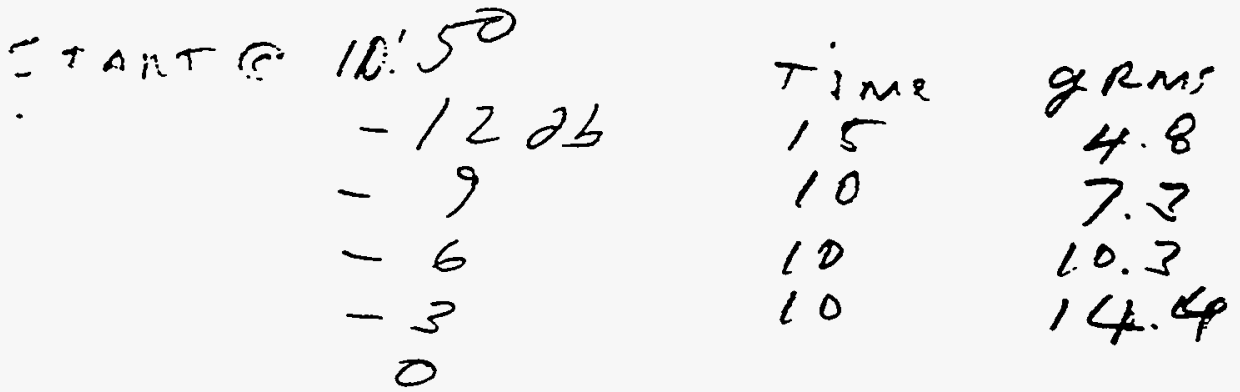

$$
\begin{aligned}
& 1 \text { min ers } \\
& \text {, } 9.5 \text { goes. } \\
& y-\beta \cdot x \operatorname{lig} \\
& \text { rise owe db }
\end{aligned}
$$




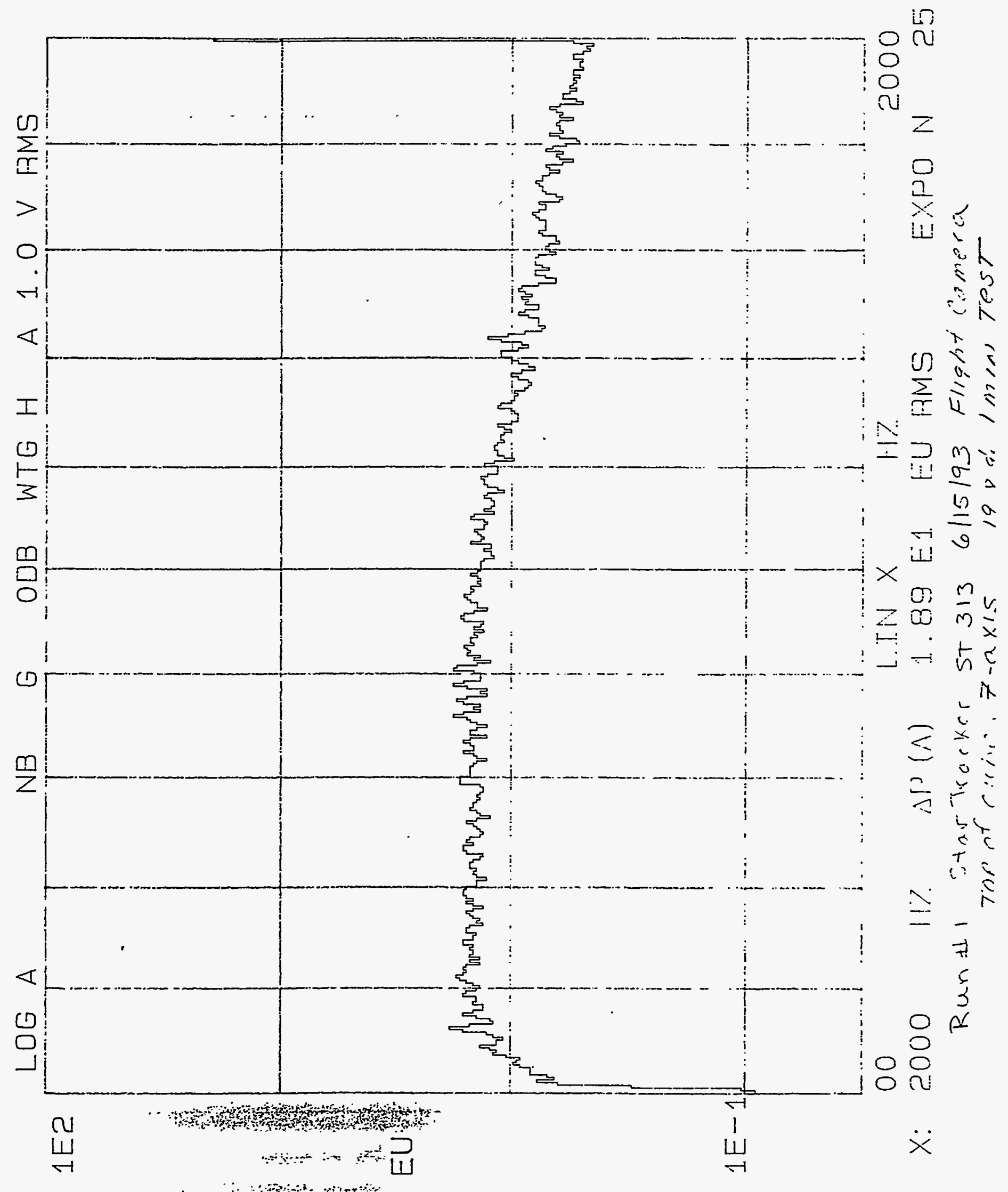

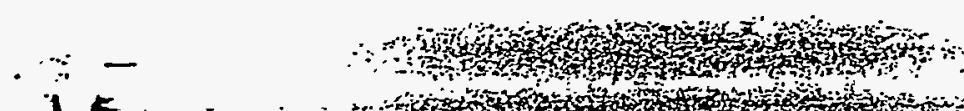

$\therefore<$

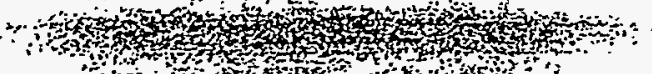

$\therefore$.

$\therefore \therefore$ a 


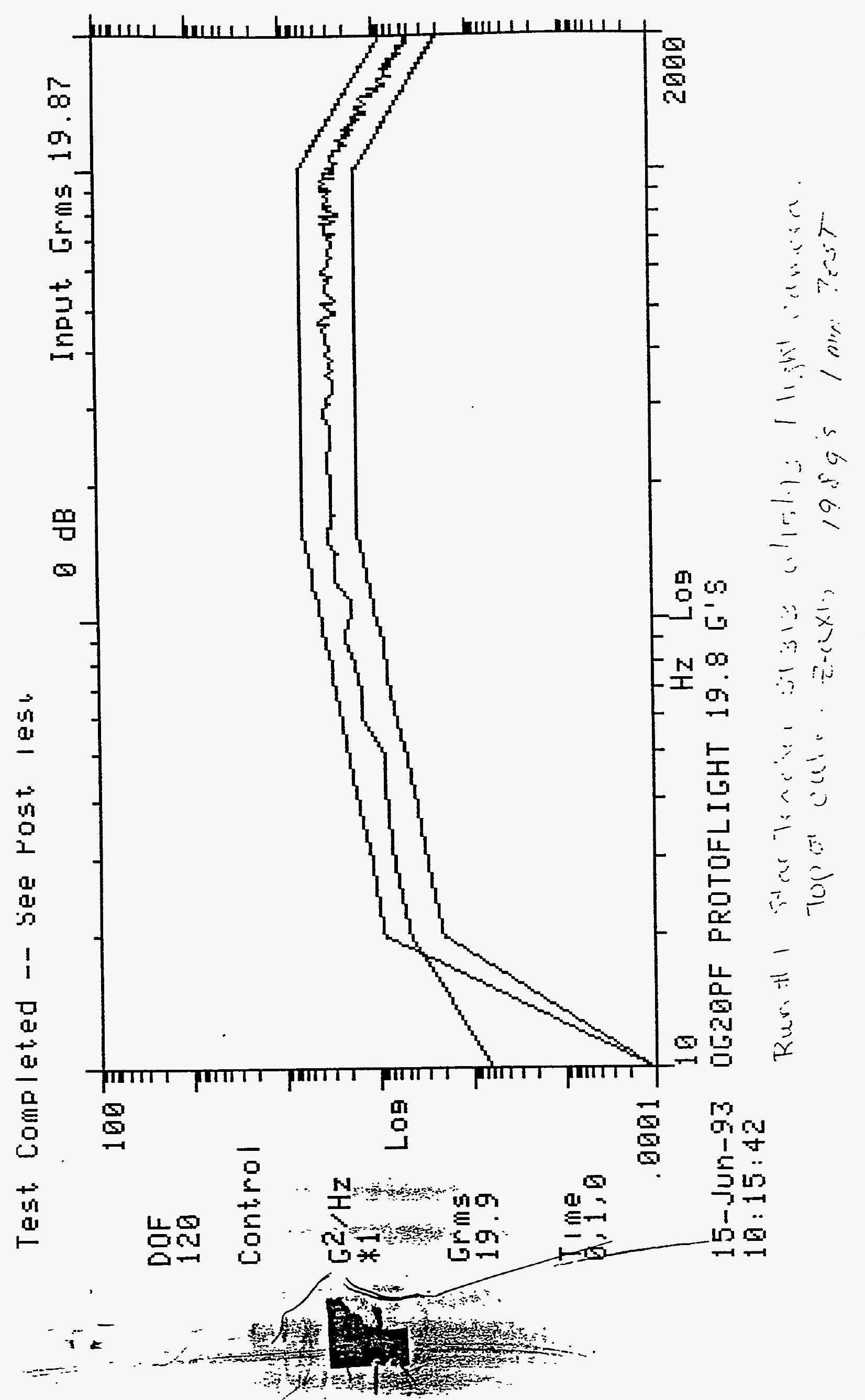




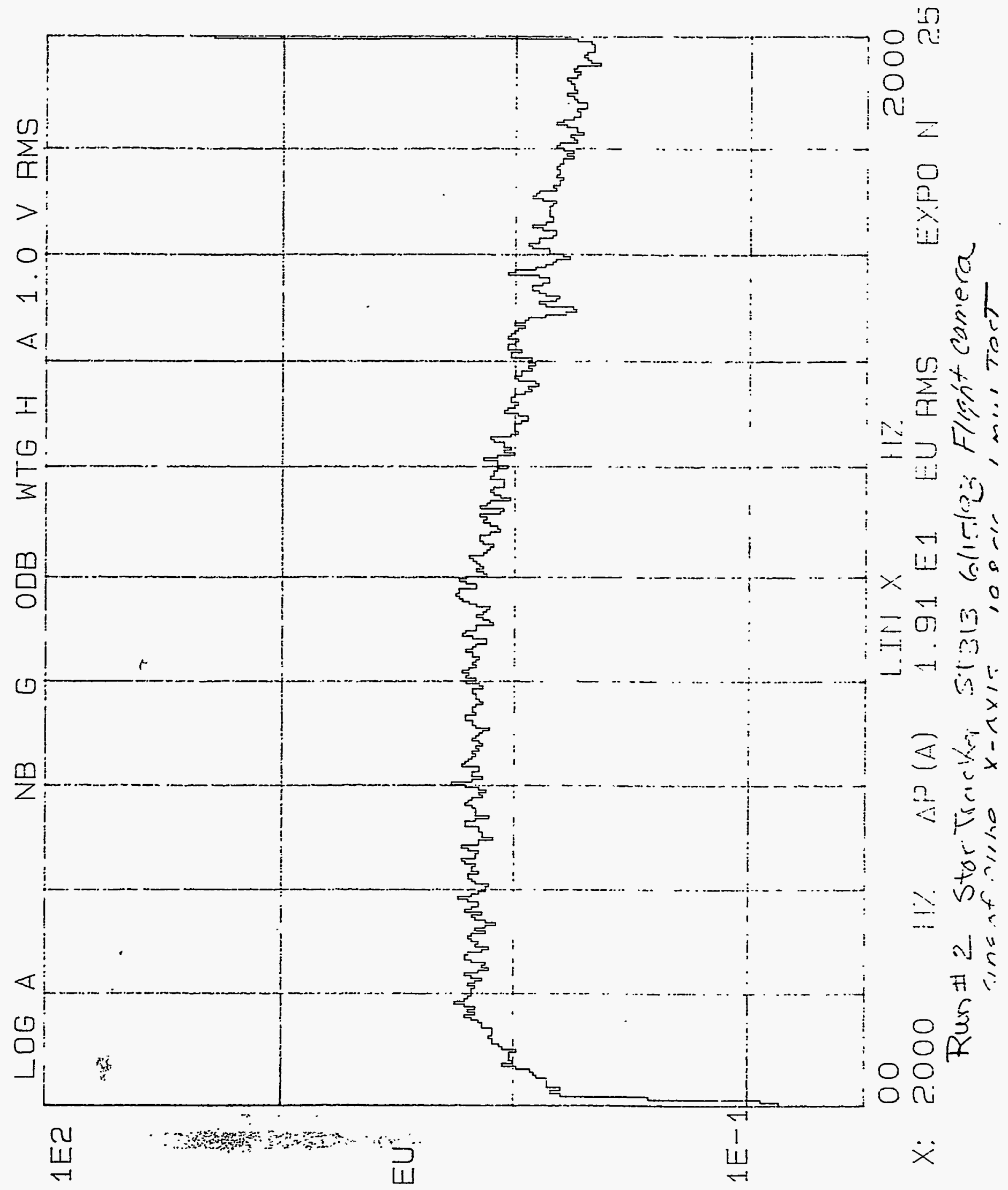

$\because \cdots$

$\therefore$ 7: 7 :

$\because<\quad, \quad \cdots$

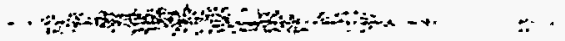




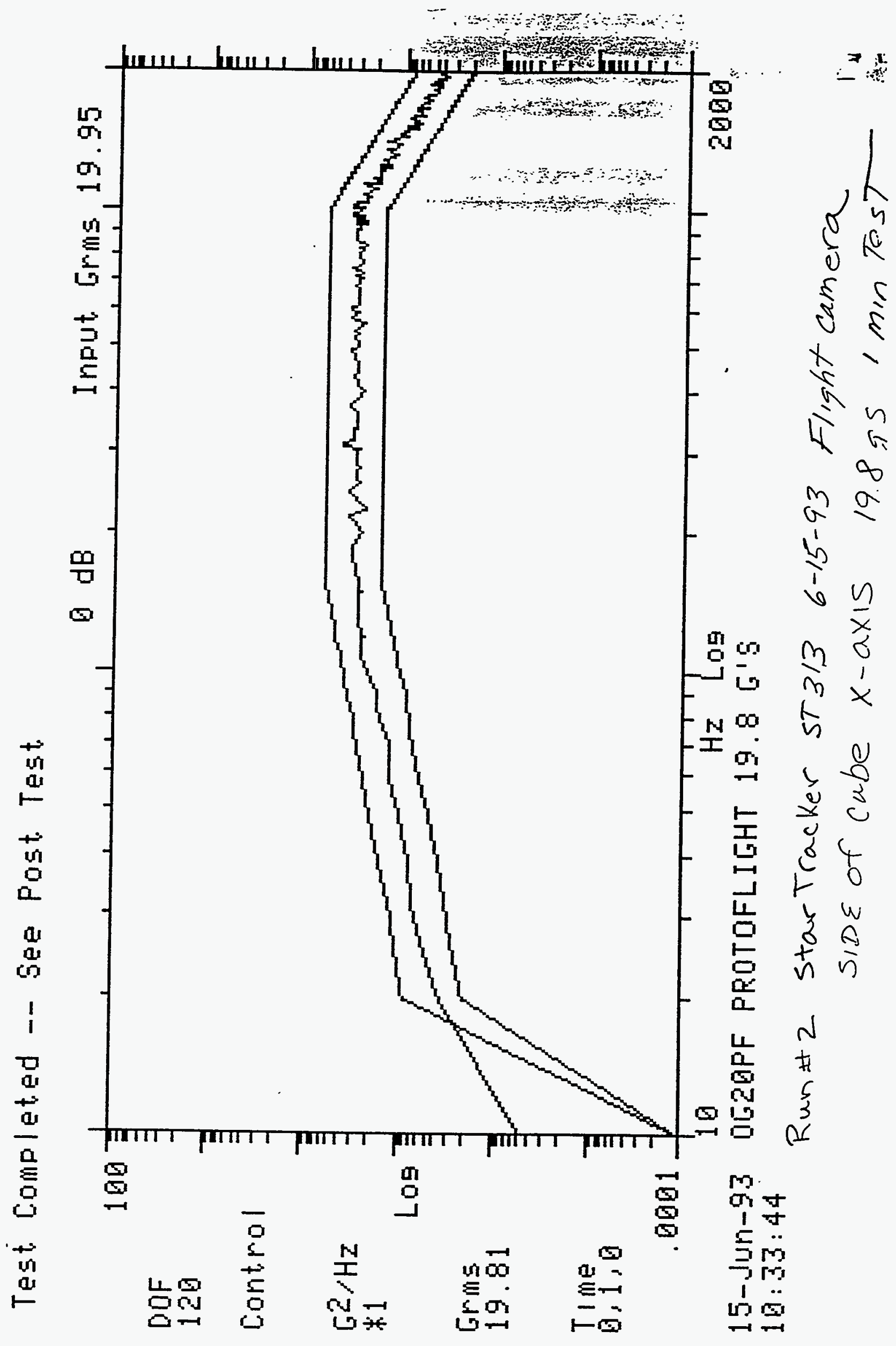




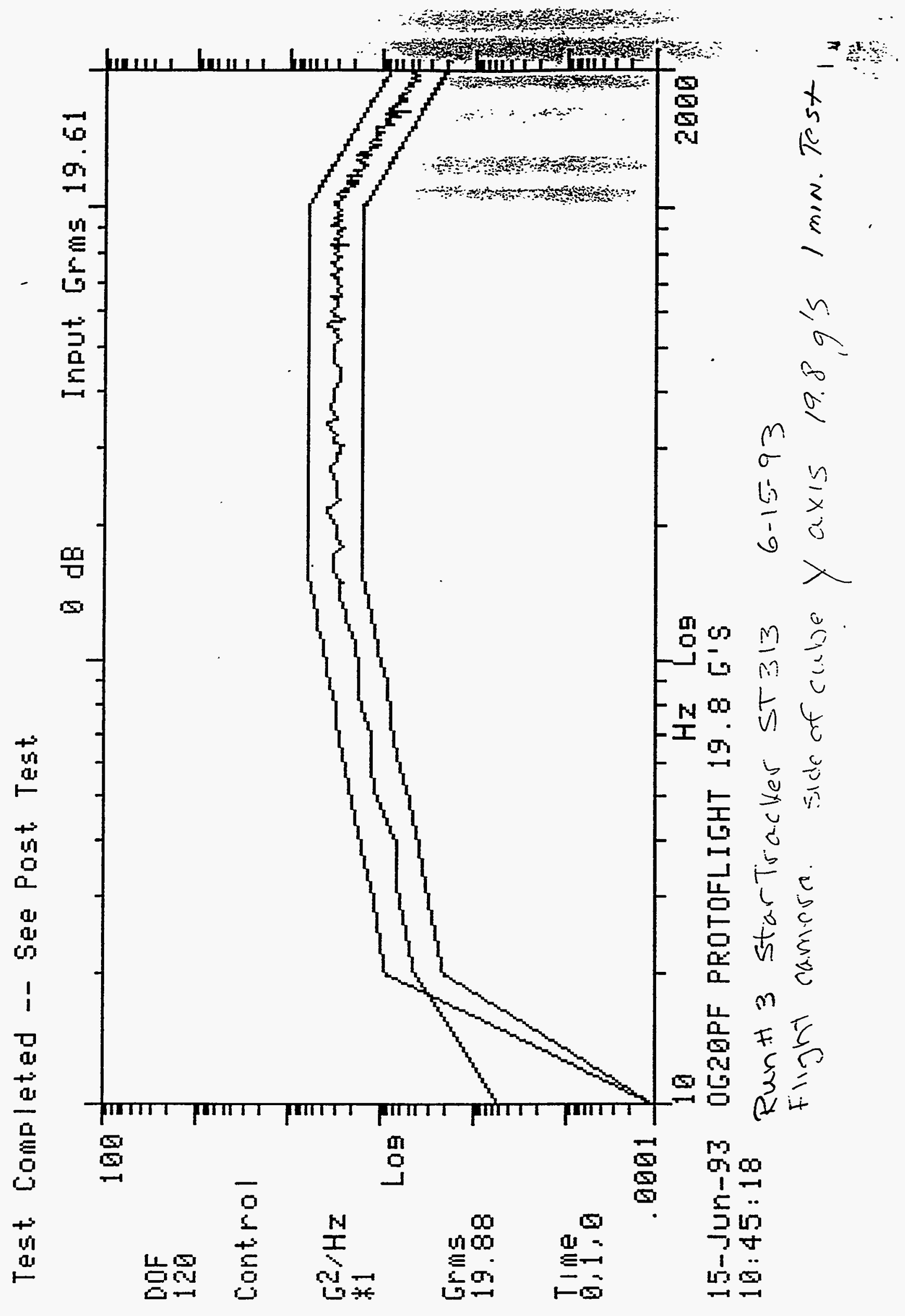




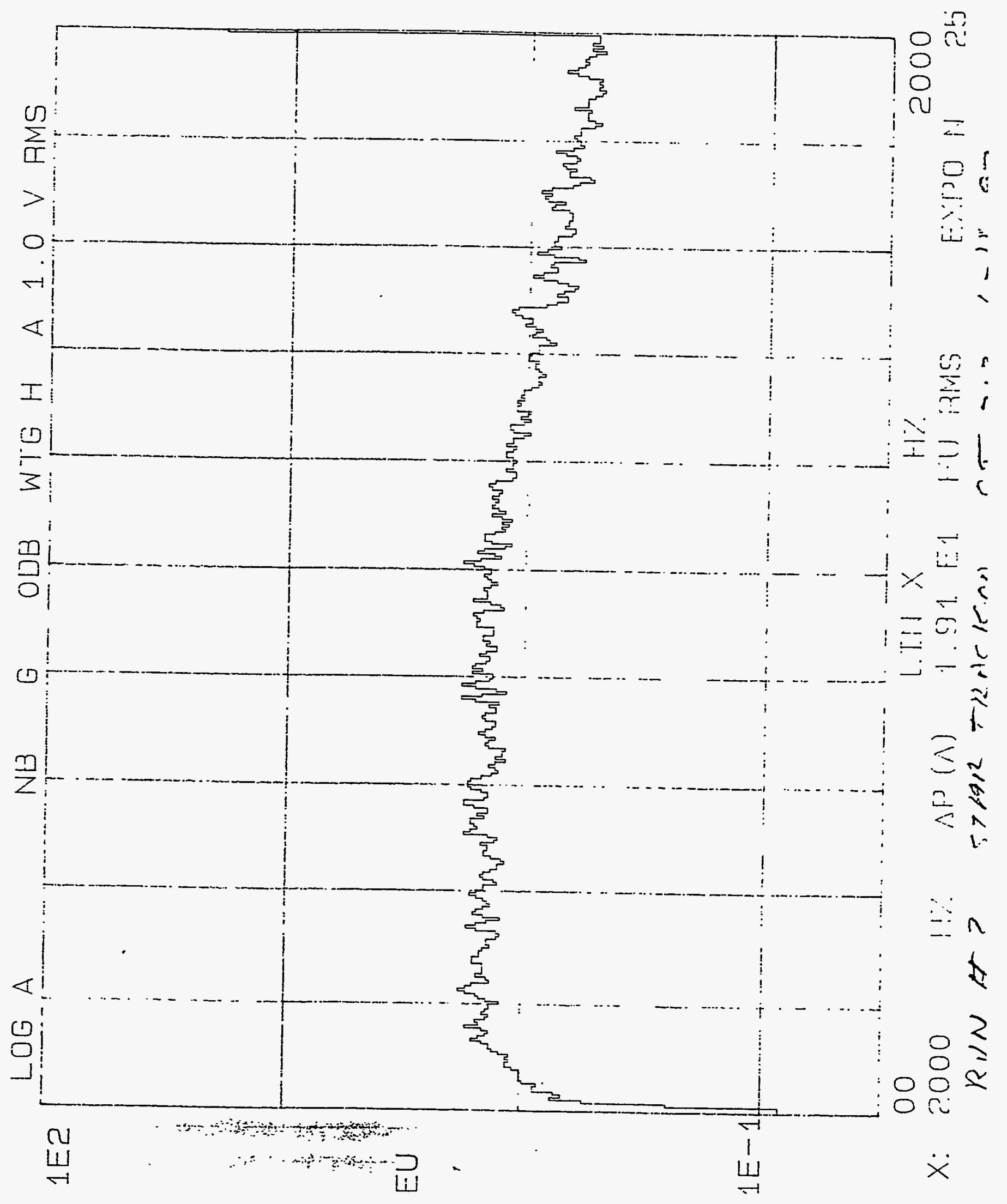

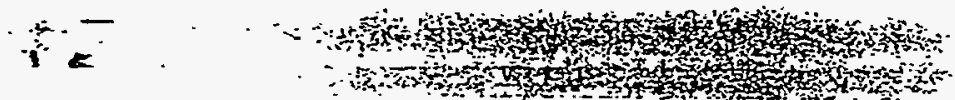




\section{TEST REQUEST}

\section{IEAPONS TEST GROUP IEAPONS ENGINEERING DIVISION}

TESTNO: $\quad 2953-1$

TEST PLANTO FOLLW: Yes__ No

ACOOUNTNO. 7069-29

DATE: $\quad$ May 18, 1993

21

ITLE: Clementine Sensors

\begin{tabular}{|c|c|c|c|c|c|}
\hline \multirow[b]{2}{*}{$\begin{array}{l}\text { Idg: } 131 \text { Facility: UD Shaker } \\
\text { EFERENCES: } \\
\text { O: } \\
\text { SSY PRINT\#: } \\
\text { SSY PRINT\#: } \\
\text { THER: Camera Design Documen } \\
\text { THER: }\end{array}$} & \multicolumn{3}{|c|}{ Start Date: $4 / 19 / 93$} & \multicolumn{2}{|c|}{ Duration: 3 months } \\
\hline & \multicolumn{2}{|c|}{$\begin{array}{l}\text { PARTCLASS: } \\
\text { UNC: } \mathrm{X} \\
\text { CRD: } \\
\text { SRD: } \\
\text { NELA: } \\
\text { VISUAL: }\end{array}$} & $\begin{array}{l}\text { HAZARD: } \\
\text { EXPLOSIES: } \\
\text { RADIOACTIVE: } \\
\text { TOXC: } \\
\text { FLAMMABLE: } \\
\text { NOHAZARD: }\end{array}$ & MATEBIAL & AMOUNT \\
\hline \multicolumn{4}{|c|}{ ATAACOUISITION } & \multirow{3}{*}{$\begin{array}{l}\text { REQUESTER: } \\
\text { PHONE: } \\
\text { TEST ENGINEER: } \\
\text { PHONE: } \\
\text { FACILITY OPR: } \\
\text { PHONE: } \\
\text { INSTRUMENTATION: } \\
\text { PHONE: }\end{array}$} & \multirow{3}{*}{$\begin{array}{l}\text { Jim Dickie } \\
3-2351 \\
\text { Bill Ford } \\
3-2849 \\
\text { Lori Stoneham } \\
2-8848 \\
\text { Dave Wanwas } \\
4-4541\end{array}$} \\
\hline $\begin{array}{ll}\text { ZANSDUCER } & N \\
\text { TYPE } & \mathrm{CH} \\
\end{array}$ & $\begin{array}{l}\text { O. OF } \\
\text { NNELSS }\end{array}$ & & $\begin{array}{l}\text { NG DEVICE } \\
\text { ROUI }\end{array}$ & & \\
\hline $\begin{array}{l}\text { Control Acc. } 7704-50 \\
\text { de response accels. }\end{array}$ & 1 & - SDa & & & \\
\hline
\end{tabular}

IRPQSE: To subject four different camera designs, listed below, to flight vibration (random PSD spectrum). The current spectron the response of the flight mounting plattorm and include $\$$ some design margin according to $O$ Program. See attached $F / 6.1 \% F / G .2$

ETAILS:

ameras: Star Tracker, UVIVIS. LIDAR and NIR -- See design document which will reside at control console. AT ROOM VIFM PSCAQUCE 1

Each camera will be vibratedAusing a one-minute ramp up to run level and a th-minute run time in each of three

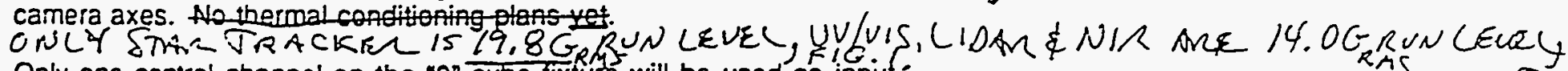

Only one control channel on the " 0 " Cube fixture will be used as input:

Verily bolt/screw torques, lock washer use, etc. on the camera system prior to vibration.

Use the same nominal-torques each test at the shaker/cube and cube/camera interface and enter the above values with each test record. Mark torques on cube.

TEST AXIS

Photograph each test unit including card ID with hardware title, and serial number, $\hat{j}$ and date of test. Also include camera purpose -- prototype, flight unit, or backup.

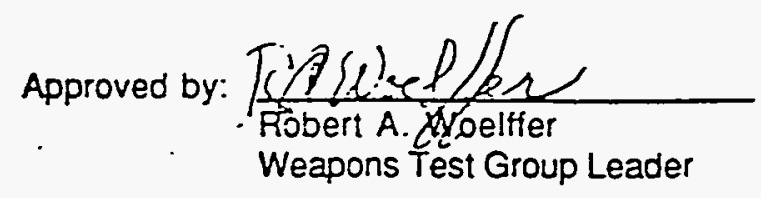

\section{3-017 WSF/Icd}

stribution:

skie, Jim

rd, Bill

Stoneham, Lori

WTG File

moian, Ron

Warwas, Dave

Woelffer, Bob 


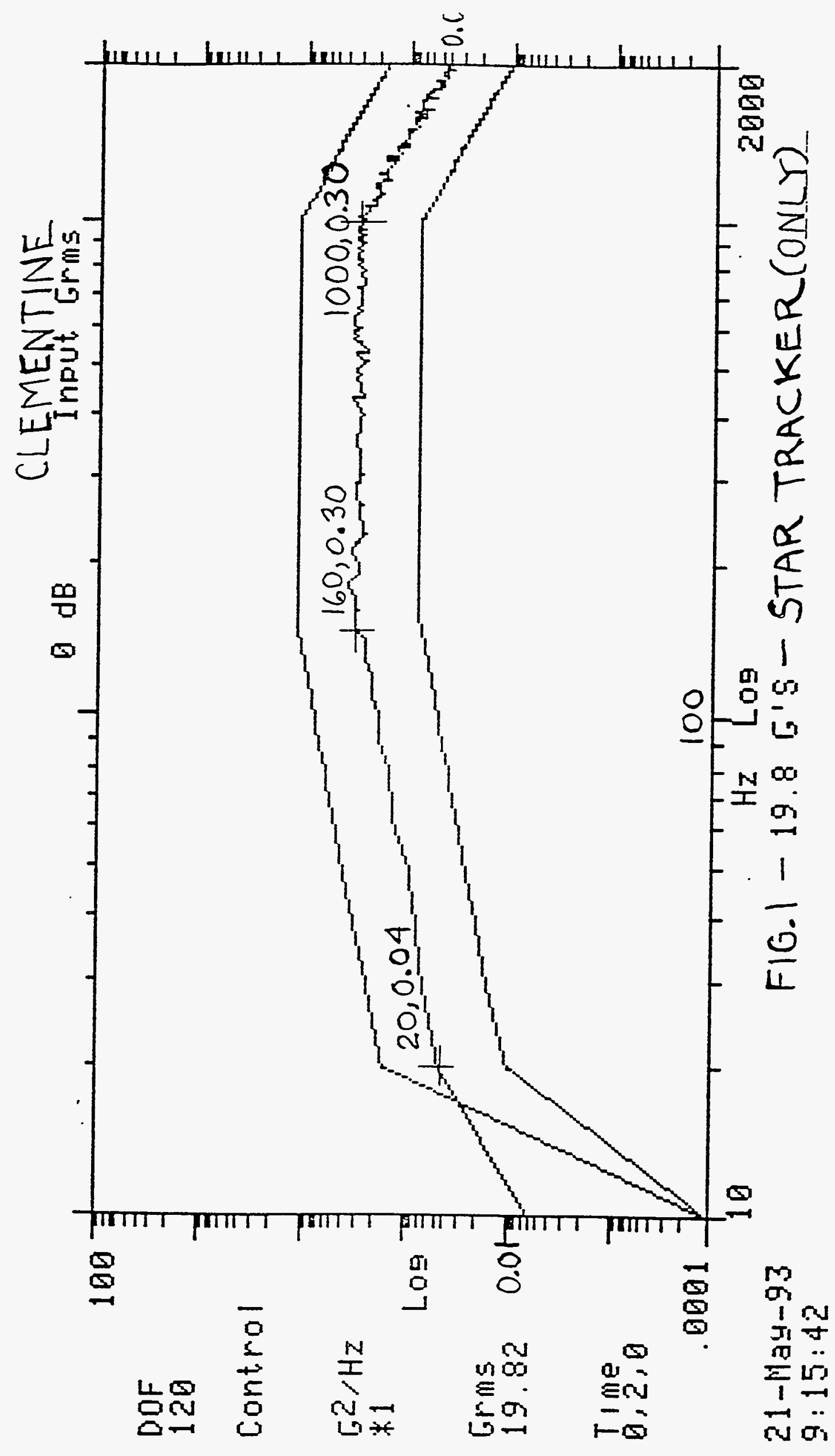




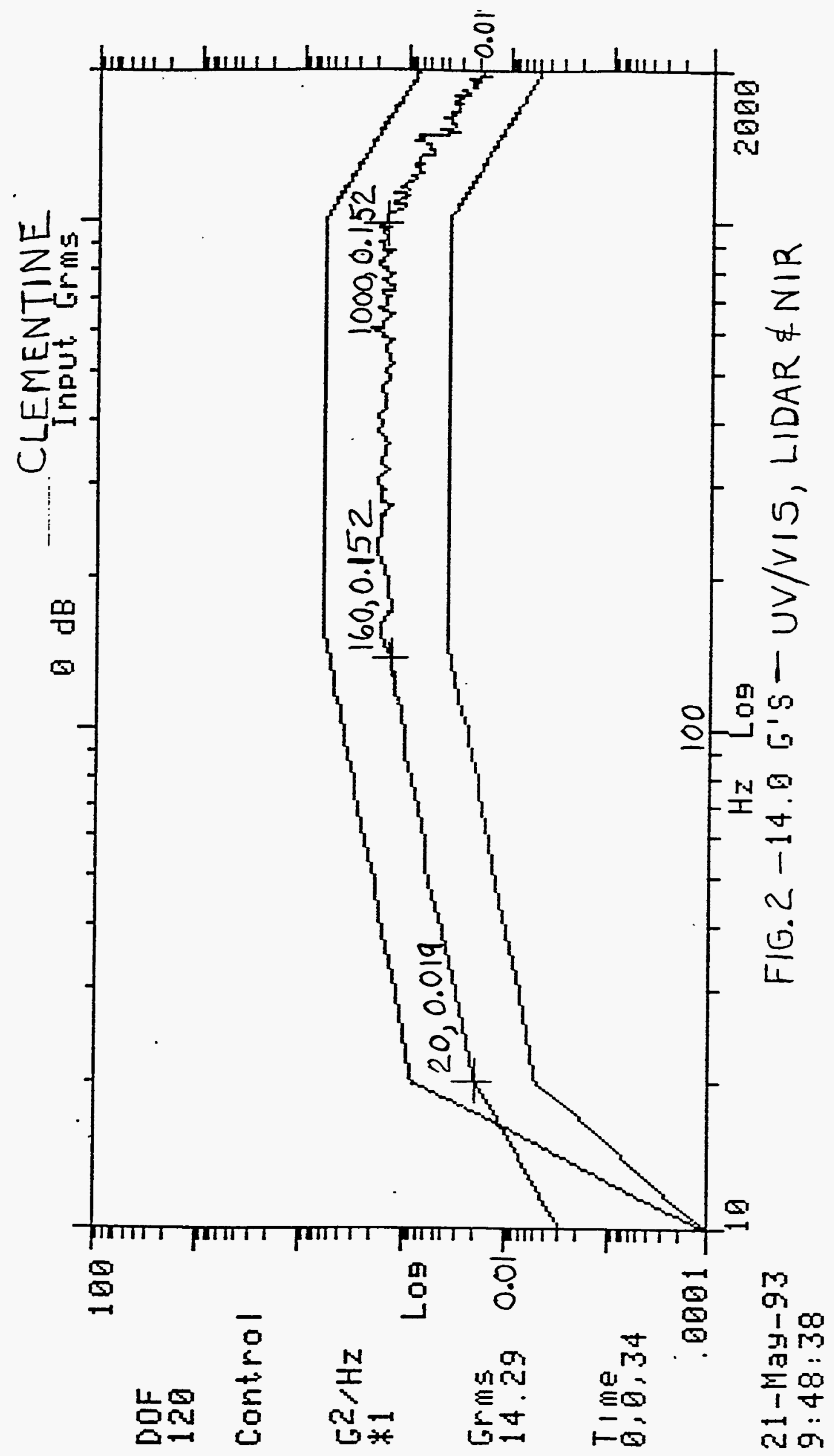




\section{TEST REQUEST}

WEAPONS TEST GROUP

WEAPONS ENGINEERING DIVISION
TEST NO: $\quad 2953$

TEST PLANTO FOUOW: Yes__ No $\underline{x}$

ACCOUNTNO: 7069-29

DATE: $\quad$ May 18, 1993

TITLE: Clementine Sensors

BIdg: 131 Facility: UD Shaker

Start Date: $4 / 19 / 93$

Duration: 3 months

\begin{tabular}{|c|c|c|c|c|c|}
\hline $\begin{array}{l}\text { REFERENCES: } \\
\text { J.O: } \\
\text { ASSY PRINT\#: } \\
\text { ASSY PRINT\#: } \\
\text { OTHER: Camera Design Document } \\
\text { OTHER: }\end{array}$ & \multicolumn{2}{|c|}{$\begin{array}{l}\text { PART CLASS: } \\
\text { UNC: } X \\
\text { CRD: } \\
\text { SRD: } \\
\text { NELA: } \\
\text { VISUAL: }\end{array}$} & $\begin{array}{l}\text { HAZARD: } \\
\text { EXPLOSNES: } \\
\text { RADIOACTVE: } \\
\text { TOXIC: } \\
\text { FLAMMABLE: } \\
\text { NOHAZARD: }\end{array}$ & MATERIAL & AMQUNT \\
\hline \multicolumn{4}{|l|}{ DATA ACQUISTIION } & \multirow{3}{*}{$\begin{array}{l}\text { REQUESTER: } \\
\text { PHONE: } \\
\text { TEST ENGINEER: } \\
\text { PHONE: } \\
\text { FACILITY OPR: } \\
\text { PHONE: } \\
\text { INSTRUMENTATION: } \\
\text { PHONE: }\end{array}$} & \multirow{3}{*}{$\begin{array}{l}\text { Jim Dickie } \\
3-2351 \\
\text { Bill Ford } \\
3-2849 \\
\text { Lori Stoneham } \\
2-8848 \\
\text { Dave Warwas } \\
4-4541 \\
\end{array}$} \\
\hline $\begin{array}{c}\text { TRANSDUCER } \\
\text { TYPE } \\
\end{array}$ & $\begin{array}{l}\text { OF } \\
\text { UNELS }\end{array}$ & \multicolumn{2}{|c|}{$\begin{array}{c}\text { RECORDING DEVICE } \\
\text { READQUT }\end{array}$} & & \\
\hline $\begin{array}{l}\text { - Control Acc. } 7704-50 \\
\text { - Ne response accels. }\end{array}$ & 1 & $\begin{array}{l}\text { - Mag. } \\
\text { - SD }\end{array}$ & & & \\
\hline
\end{tabular}

PURPOSE: To subject four different camera designs, listed below, to flight vibration (random PSD spectrum). The current spectrum of $19.8 \mathrm{G}$ rms envelopes the response of the flight mounting platform and includes some design margin according to $O$ Program. See attached.

\section{DETAILS:}

Cameras: Star Tracker. UVIVIS. LIDAR and NIR -- See design document which will reside at control console.

- Each camera will be vibrated using a one-minute ramp up to run level and a two-minute run time in each of three camera axes. No thermal conditioning plans yes.

- Only one control channel on the " 0 " cube fixture will be used as input.

- Verify boltyscrew torques, lock washer use, etc. on the camera system prior to vibration.

- Use the same nominal torques each test at the shaker/cube and cube/camera interface and enter the above values with each test record. Mark torques on cube.

- Photograph each test unit including card ID with hardware title and serial number and date of test. Also include camera purpose -- prototype, flight unit, or backup.

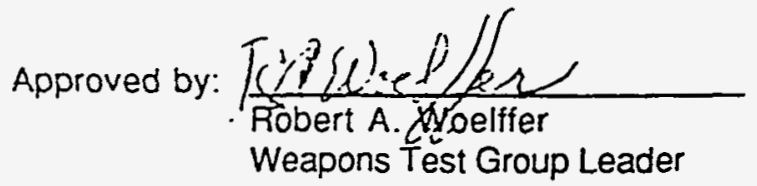

\{93-017 WSF/ICo

Distribution:

Dickie, Jim

Ford, Bill

Samoian, Ron
Stoneham, Lori

Warwas, Dave

Woelffer, Bob
WTG File 


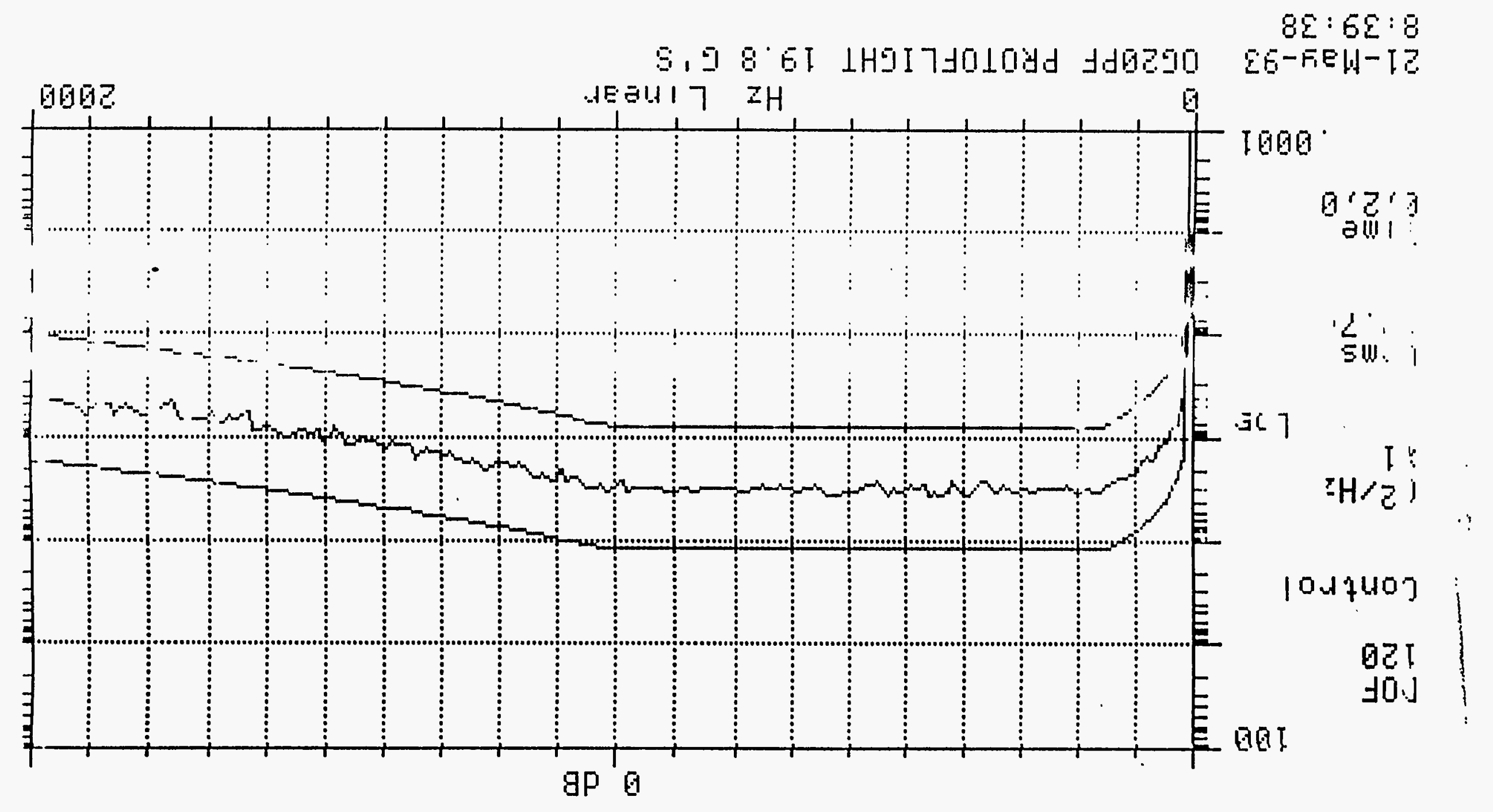




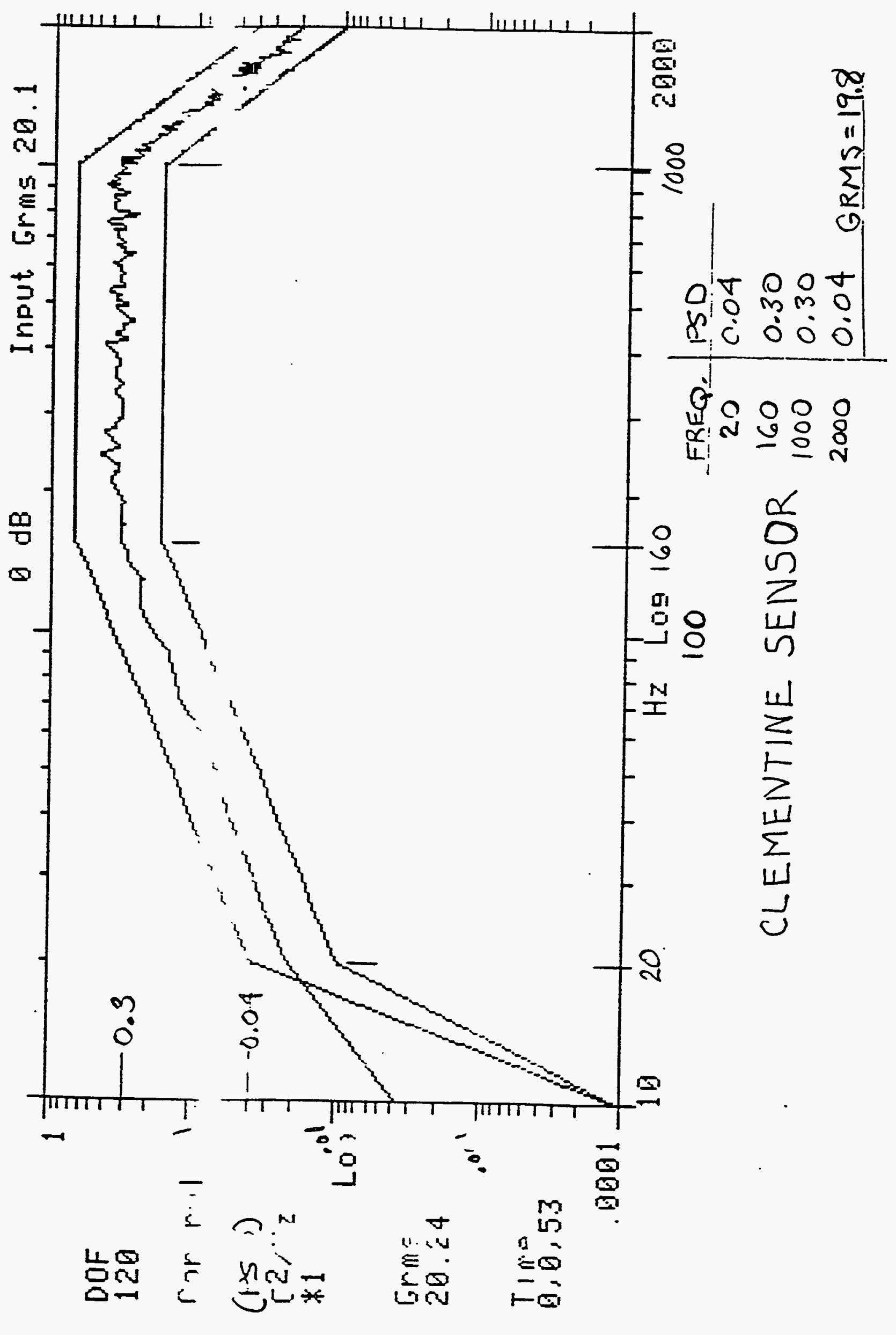


IEST REQUEST

PAIEADANS TEST GROUP "YEADNNS ENGINEERING DIVISION

$$
\begin{aligned}
& \text { TESTNO: } 2953 \\
& \text { TEST PLANTOFOLOW: Yes _ No X- }
\end{aligned}
$$$$
\text { ACCOUNTNO: } 7069-29
$$$$
\text { DATE: } 5 / 18 / 93
$$

- CLEMENTINE SENSORS

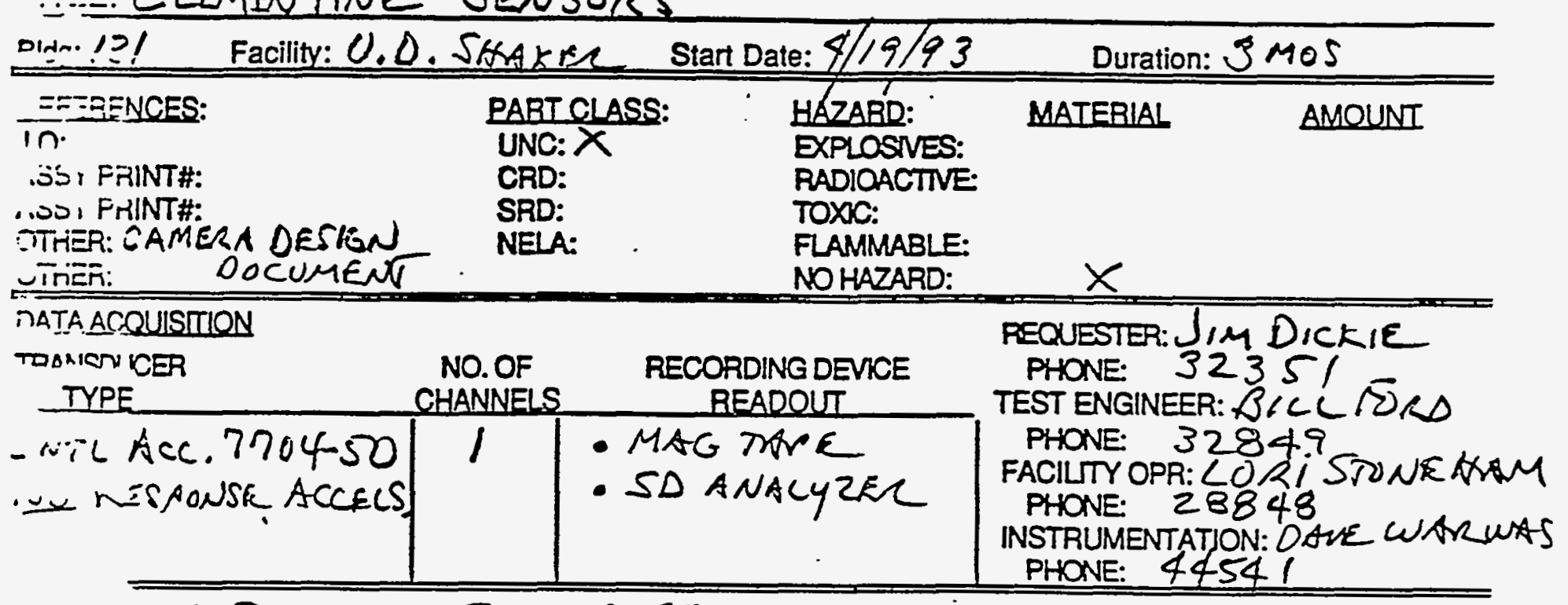

QIDONAE: TO SUBJECT FOUR DIFFERENT CAMFRA DESIGNS, LISTES NELOW, TO FLIGHF UIBNTFION (RANDOM PSD SPECMVM). THKE

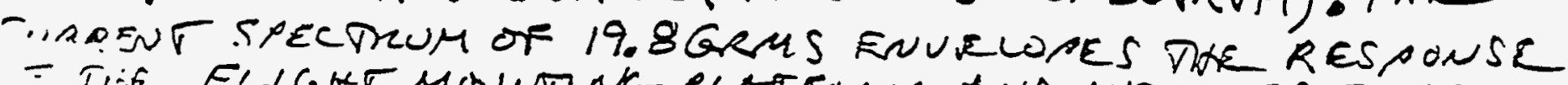

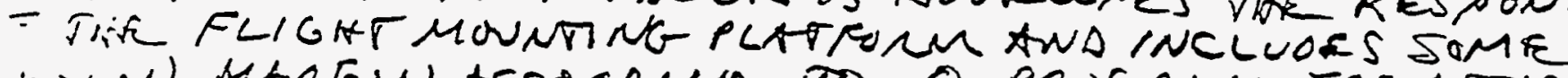

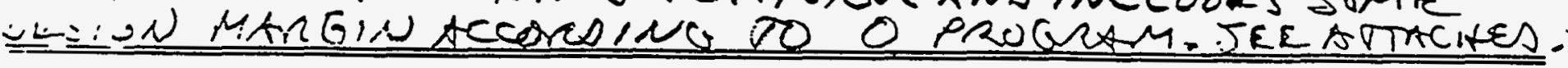
NaldLS:

WMERS: STAR MRACKER, UV/VIS, LIDAR \& NIR-SER - SIG N DOCUMEAT WATCH WILC RESIOR AT CONAROC CONSOLE.

- EACE CAMERA WIL BE VIBRATES USINE A IMINUTE RAMP $\because$ "TO RUN LEVEL \& A 2 MINUTE RUN TIMR IN FAC I

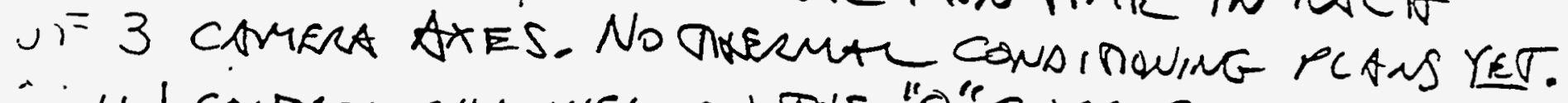

$\because$ Y I CONAROL CHANNEL ON TANR "O" CUBE FIXPURE N.-L BE USRA AS INAUT.

Robert A. Woelffer Weapons Test Group Leader

s

- VERIFy BOLT/SCREu TORQUUES, lOCKwAStior USE, ETC.

- 1 tar eamera system prion do visRttion.

- UJE TIRE SMME NOMINAL TORQ UE SEACH TEST AT THK SWAKER/CUBE \& CUBK/CAMERA INTENGACE E ENTER TWE

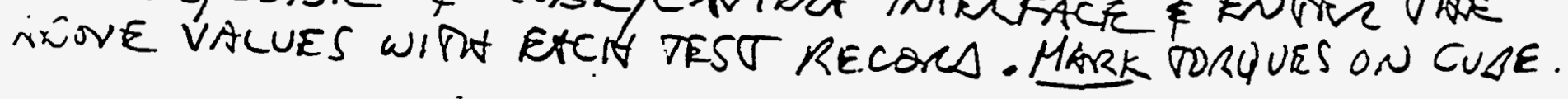




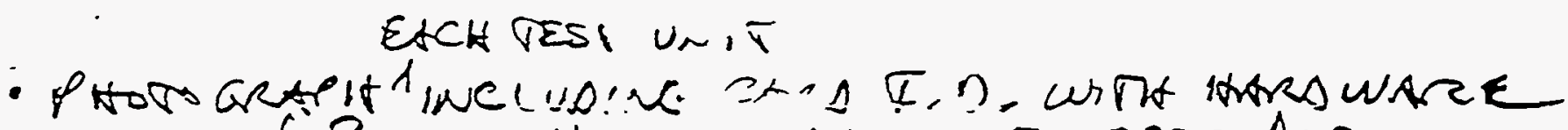
TRLR \& SERIT A. A JATR OF TEST. ASO INCLUDE CAMEA PU DUE - PAOTONR PE, FLIGAT
UNIT ON BACKU. 


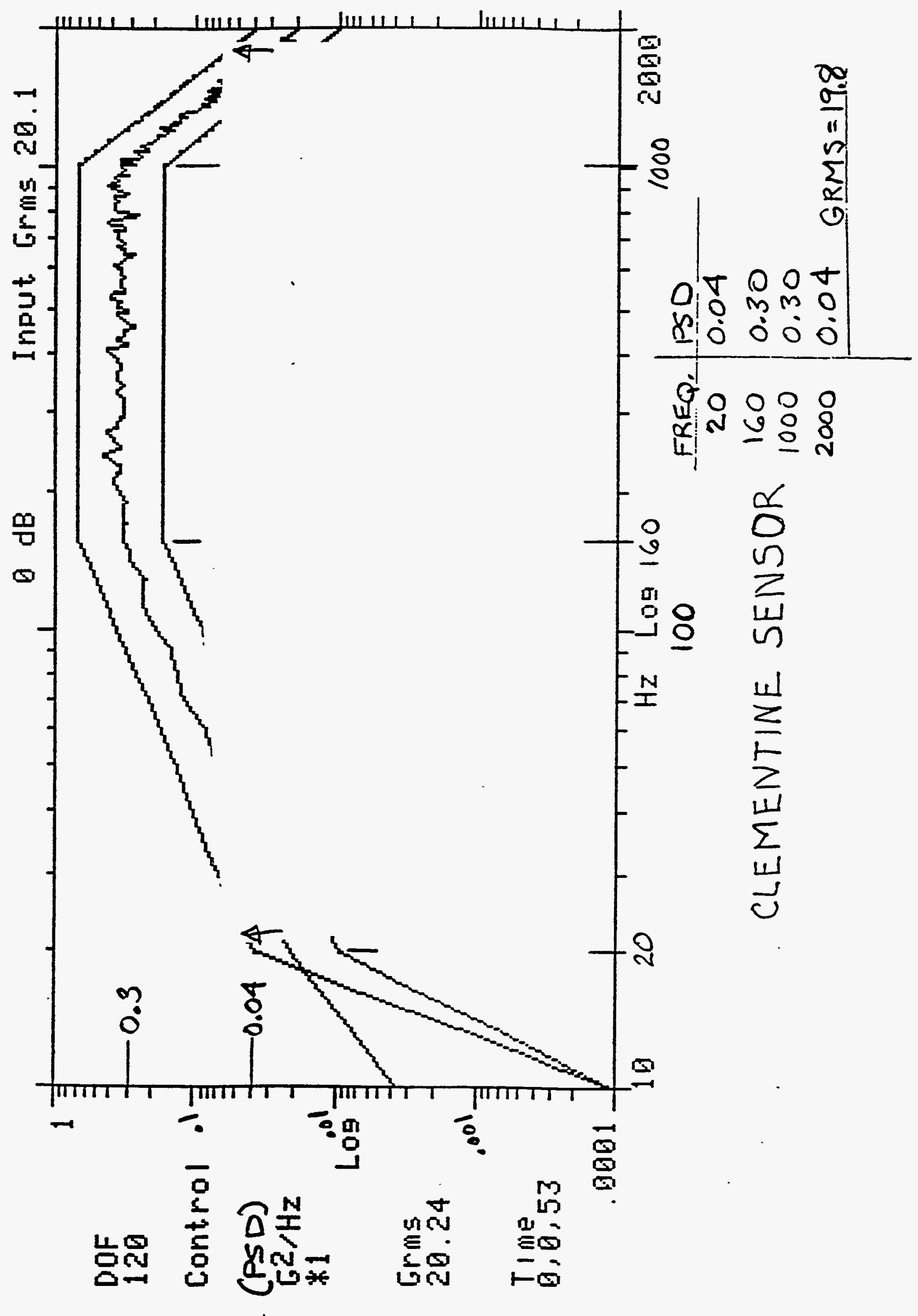




\section{Appendix $\mathrm{H}$ \\ Certification Log for StarTracker A (ST 314)}


StarTracker Camera

Document No. C1-AAA92-106282, Tab 02

Flight No. 2

Serial No. ST-314

May 3, 1993 


\section{Appendix H.1}

\section{Summary Technical Data}




\section{Summary Technical Data}

\section{ST 314}

\begin{tabular}{|l|l|l|}
\hline Parameter & Specification & Measured Value \\
\hline Mass & $<483 \mathrm{~g}$ & $285.6 \mathrm{~g}$ \\
\hline $\begin{array}{c}\text { Current at } 22^{\circ} \mathrm{C} \\
+5 \mathrm{Vdc} \text { analog } \\
+5 \mathrm{Vdc} \text { digital1 }\end{array}$ & $<155 \mathrm{~mA}$ & $107.4 \mathrm{~mA} / 105 \mathrm{~mA}$ \\
$-5 \mathrm{Vdc}$ & $<140 \mathrm{~mA} /<410 \mathrm{~mA}$ & $51 \mathrm{~mA} / 292 \mathrm{~mA}$ \\
$+15 \mathrm{Vdc}$ & $<60 \mathrm{~mA}$ & $41.2 \mathrm{~mA} / 41.2 \mathrm{~mA}$ \\
$-15 \mathrm{Vdc}$ & $<140 \mathrm{~mA}$ & $13.76 \mathrm{~mA} / 13.76 \mathrm{~mA}$ \\
& $<30 \mathrm{~mA}$ & \\
\hline $\begin{array}{l}\text { Lens Heater Resistance at } \\
22^{\circ} \mathrm{C} \text { (ST ONLY) }\end{array}$ & $450 \pm 45 \Omega$ & $454 \Omega$ \\
\hline
\end{tabular}

1 These values are with data bus disabled / data bus enabled with $150 \mathrm{ohm}$ termination. 


\section{INDEX}

\section{STAR TRACKER CAMERA \\ S T 314}

1. Summary Technical Data

2. Board Assembly Log

3. Electronic Test Data

4. Mechanical Assembly Log 


\section{Appendix $\mathbf{H} .2$ \\ Board Assembly Log}


Appendix H.2.1

Operations Sheet 


\section{Clementine Operations Sheet, Assembly Assembly Log \#}

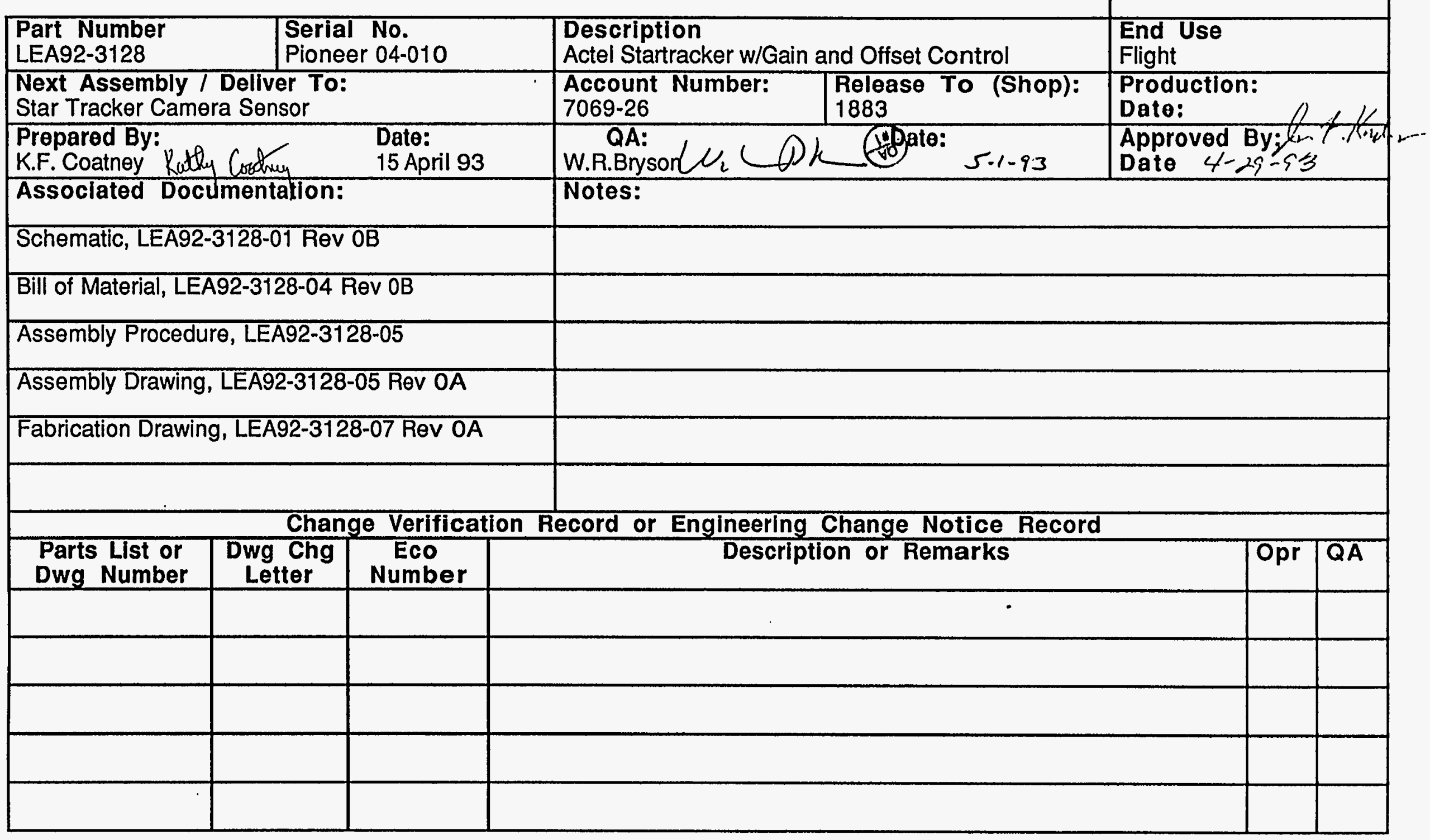


Appendix H.2.2

Work Sheets 


\begin{tabular}{|c|c|c|c|c|}
\hline & Work Sheet & & & \\
\hline $\begin{array}{l}\text { Part Nu } \\
\text { LEA92-3 }\end{array}$ & \begin{tabular}{l|l}
$\begin{array}{l}\text { Serial \#\# } \\
\text { P04-010 }\end{array}$ & $\begin{array}{l}\text { Title: } \\
\text { Pioneer Fabricated Actel Startracker }\end{array}$
\end{tabular} & Board & & $\begin{array}{c}\text { Sheet: } \\
\text { / }\end{array}$ \\
\hline \# & Operation & Dato: & Opor. & Insp \\
\hline 1 & Insperted Board Visualle - OKL"ol 6802 & $4 / 14 / 93$ & & \\
\hline 2 & Board Baked at $95 \mathrm{C}$ for 6 hrs in 0 men & $4 / 15 / 93$ & & \\
\hline & $S / N \# 12664-1 \quad 7: 00$ p.m. - 1:00 A.m & & & \\
\hline 3 & Turned board over to laura Aranda for & $4 / 6 / 9_{3}$ & & \\
\hline$\dot{-}$ & Assy/Solder. & $4 / 16 / 93$ & & \\
\hline 7. & received kit assigned to Helen Reisdarst yo & $4-16-93$ & & \\
\hline 8. & Werified ate resistirs and calacitors & & & \\
\hline & Fluke $3 / 19 / 93-3 / 19 / 95$ DYwasean $9 / 3 / 92-96 / 93$ & $4 \cdot 16 \cdot 93$ & & \\
\hline 9 & Took Resistiance measurements at J1 & $4 \cdot 16.93$ & & \\
\hline 10. & Assy $7.0-7.8$ Item 7 & $4-19.93$ & 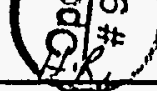 & \\
\hline 11 & Cleoved SoAkD Sent to QA & $4 \cdot 19.93$ & & \\
\hline & & & & \\
\hline & & & & \\
\hline
\end{tabular}




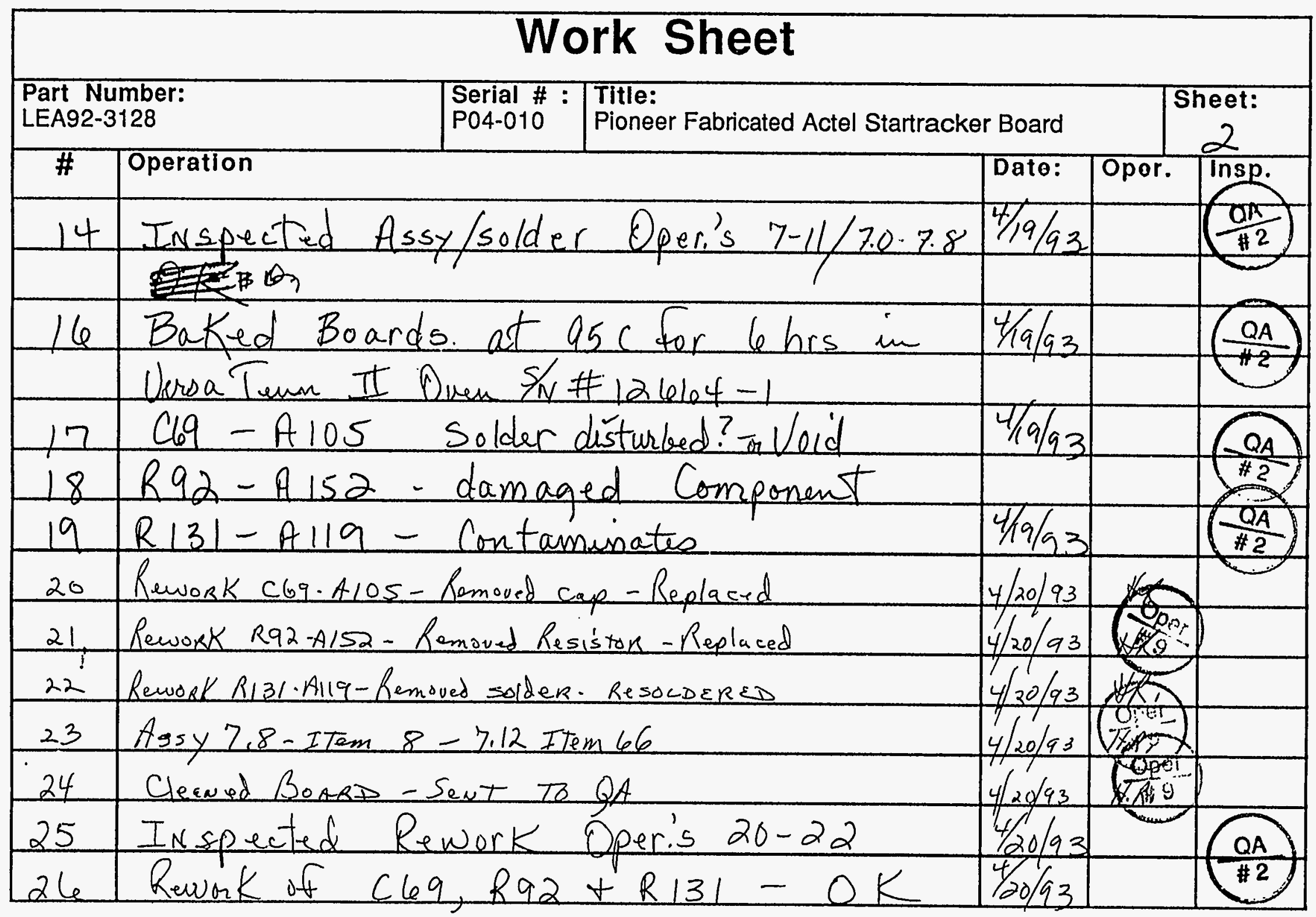




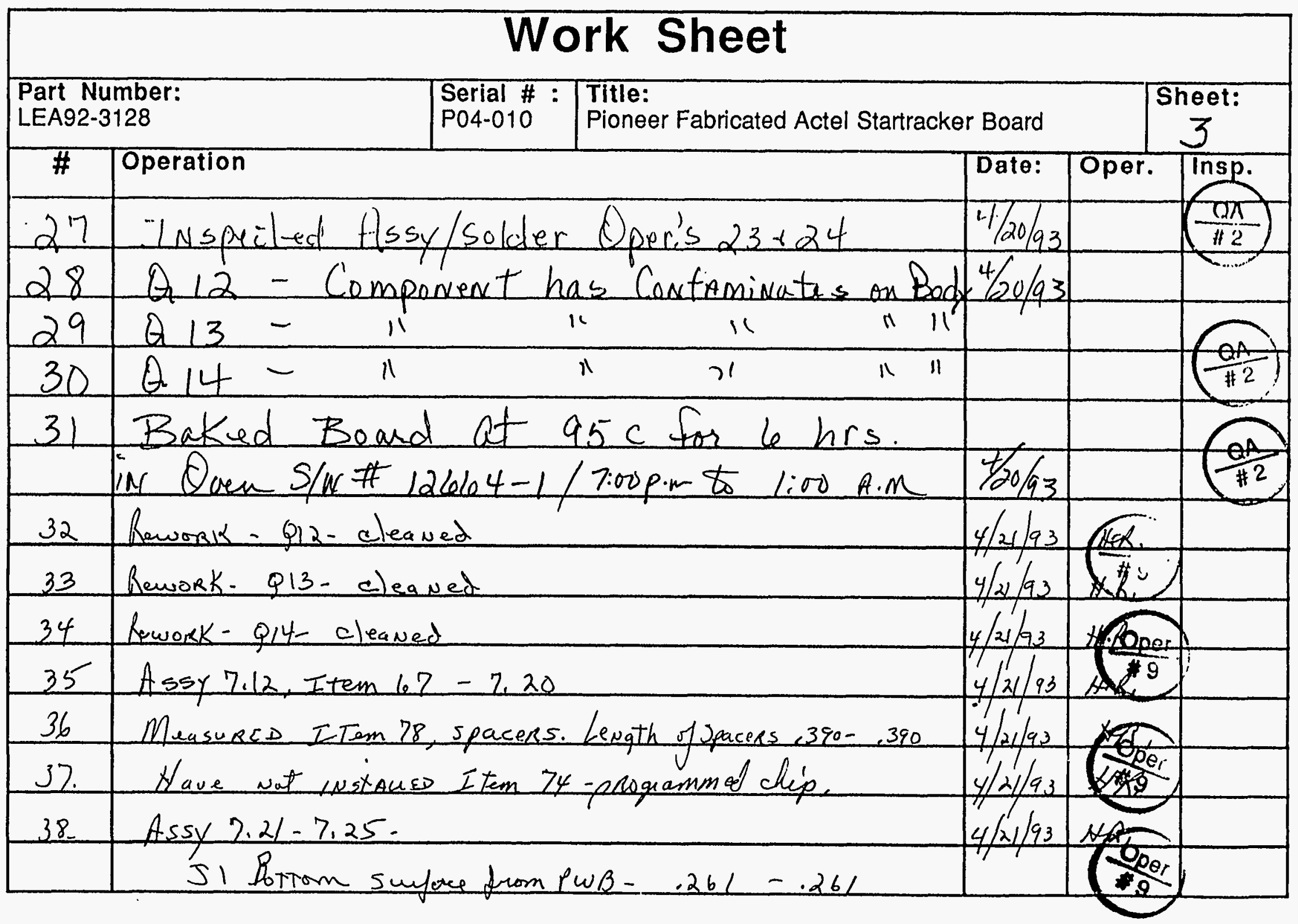




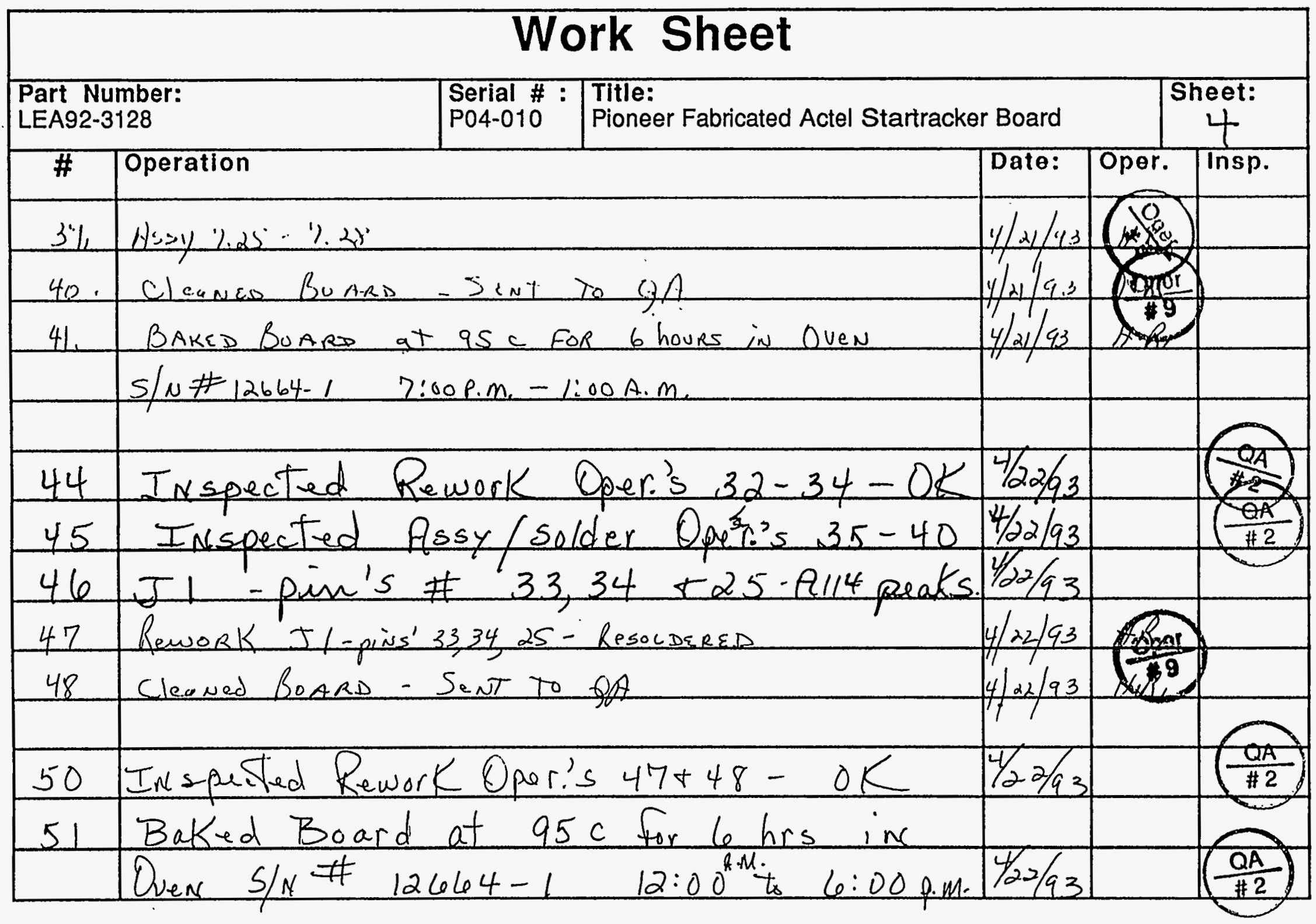




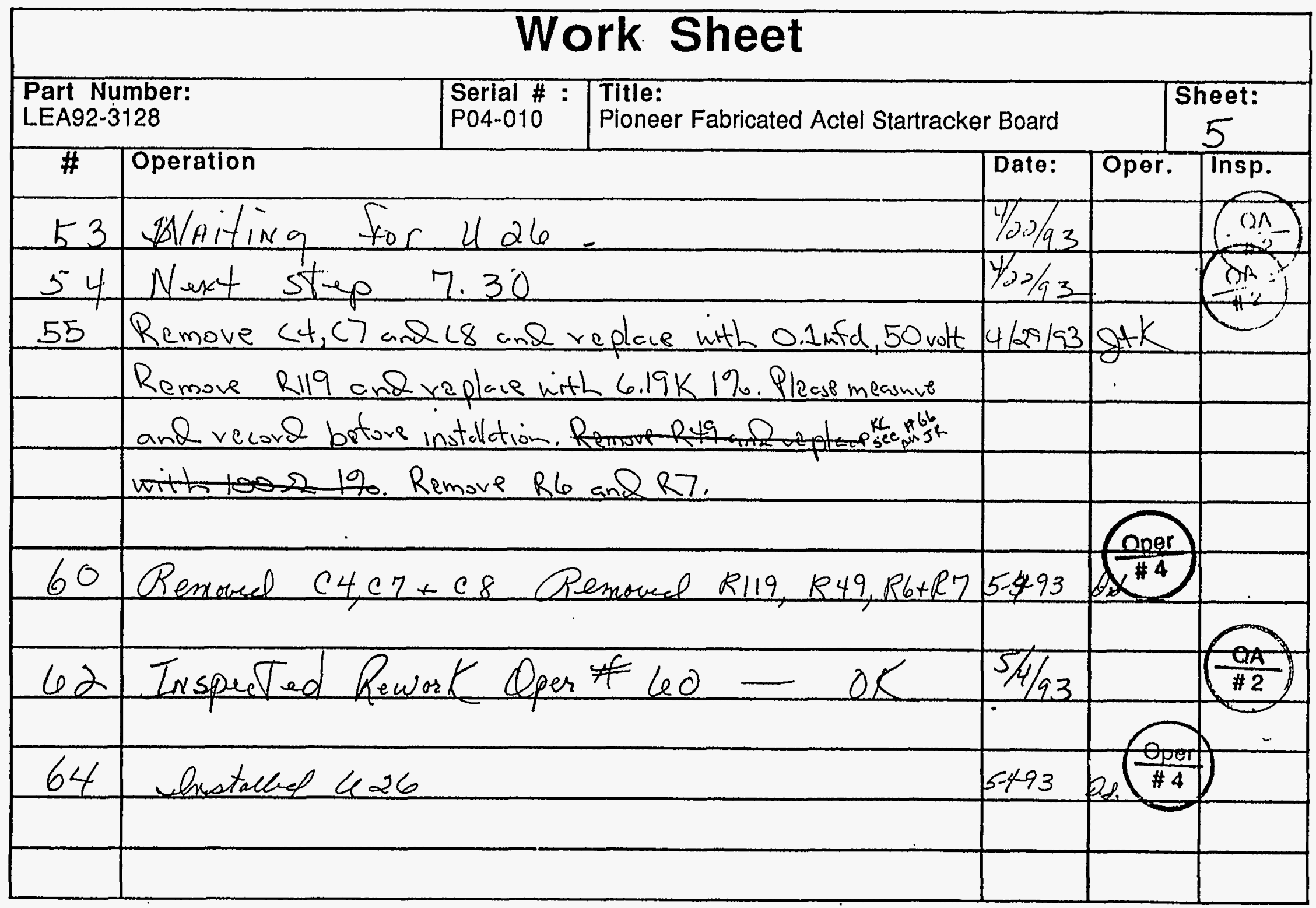




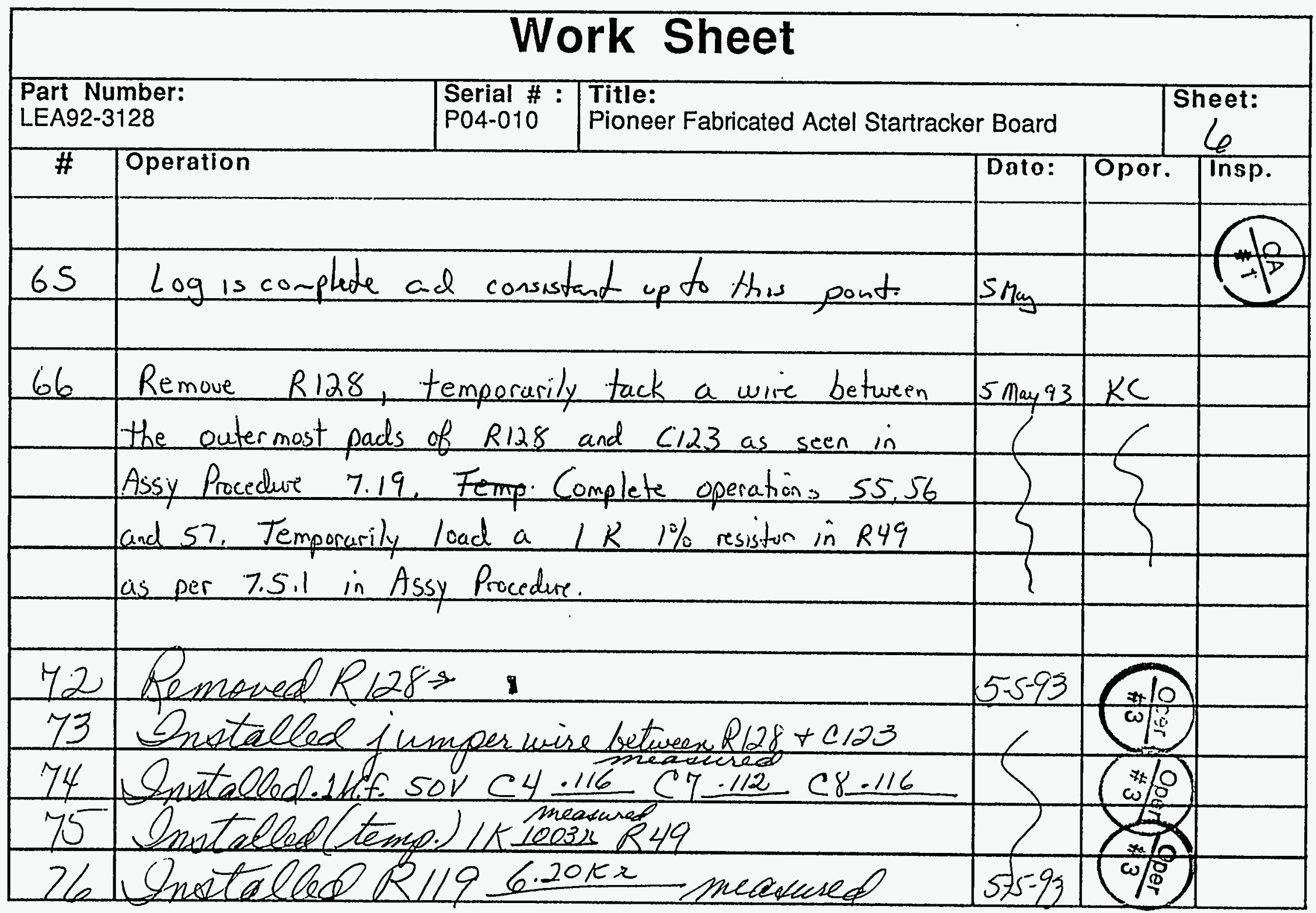




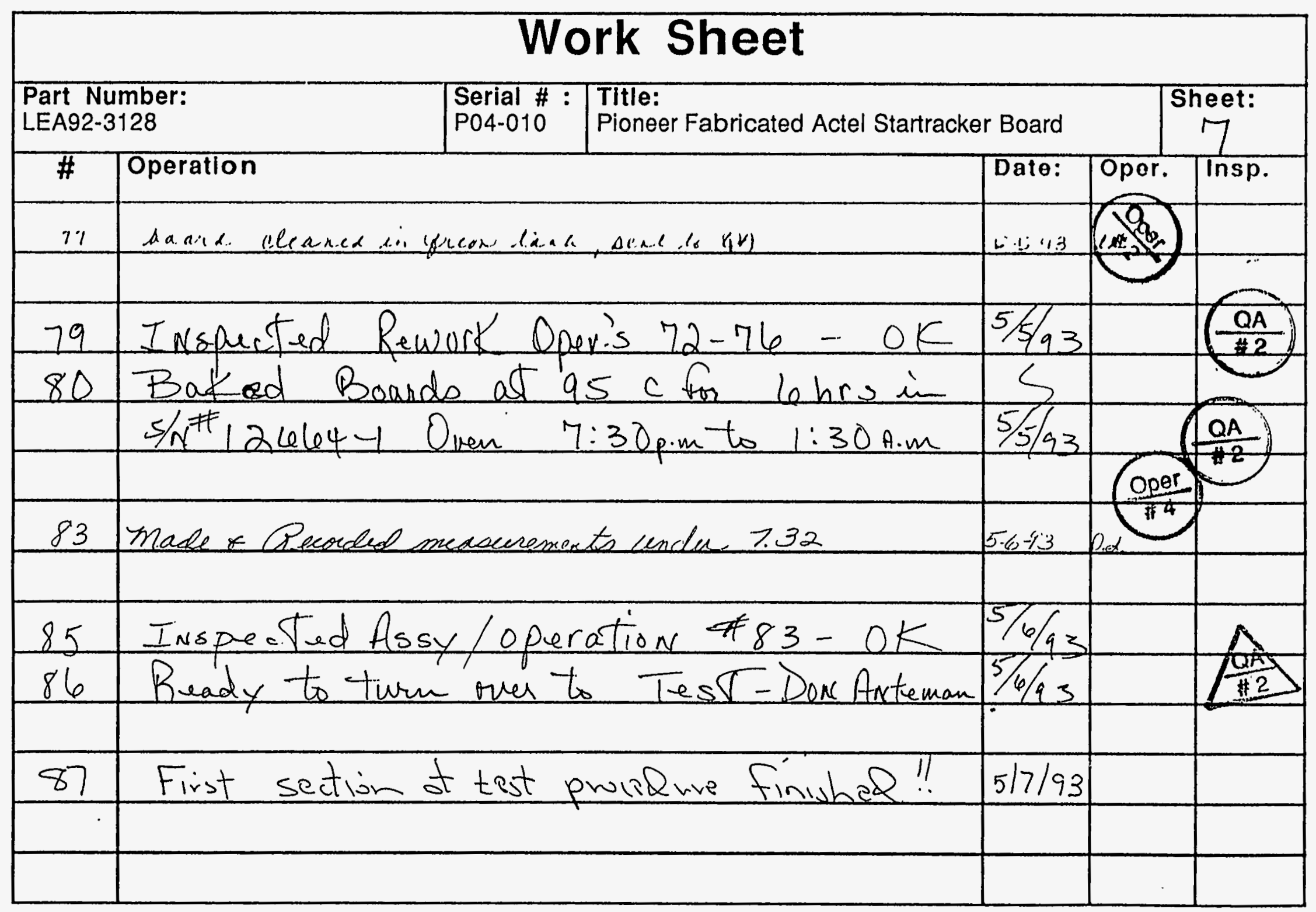




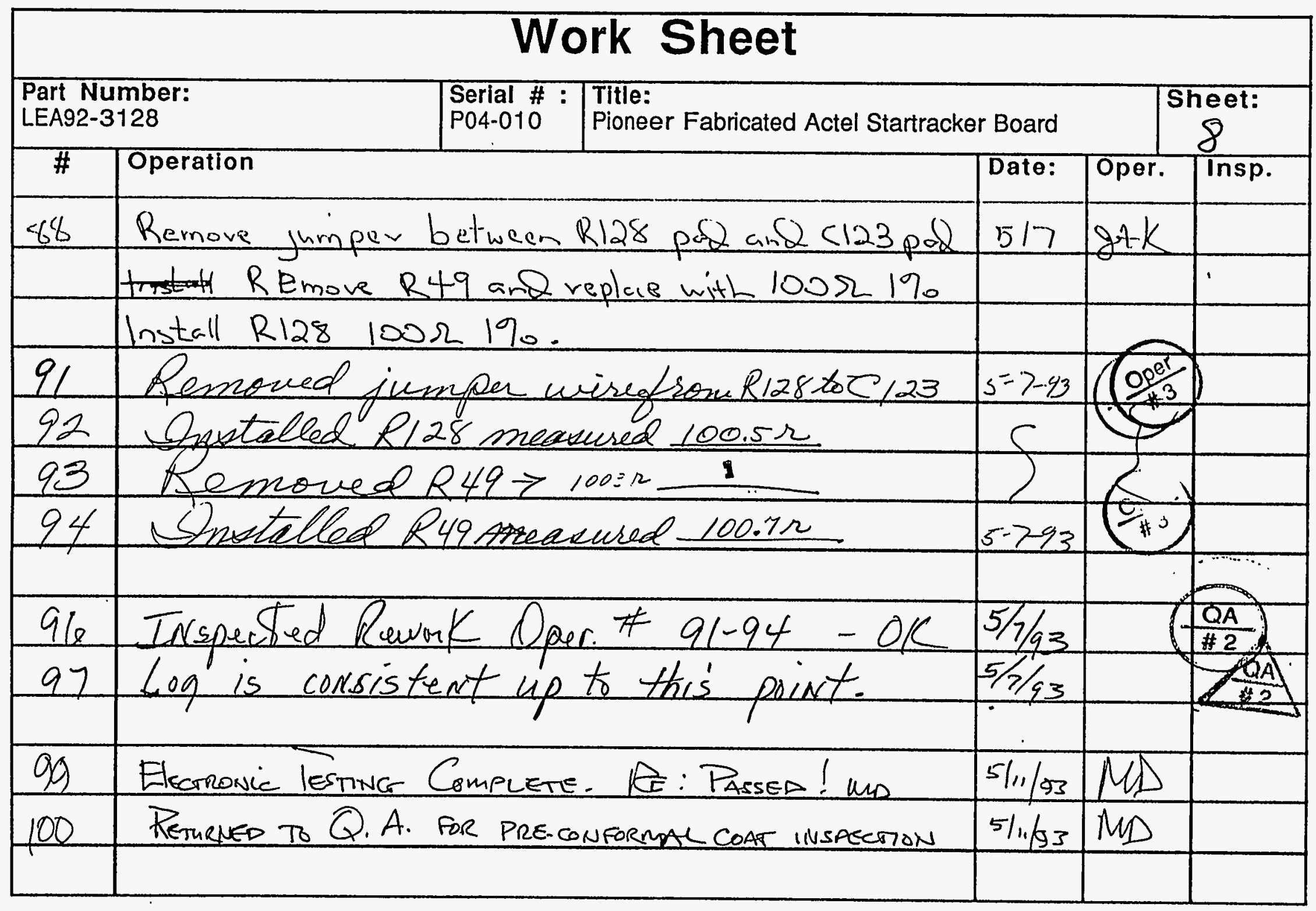




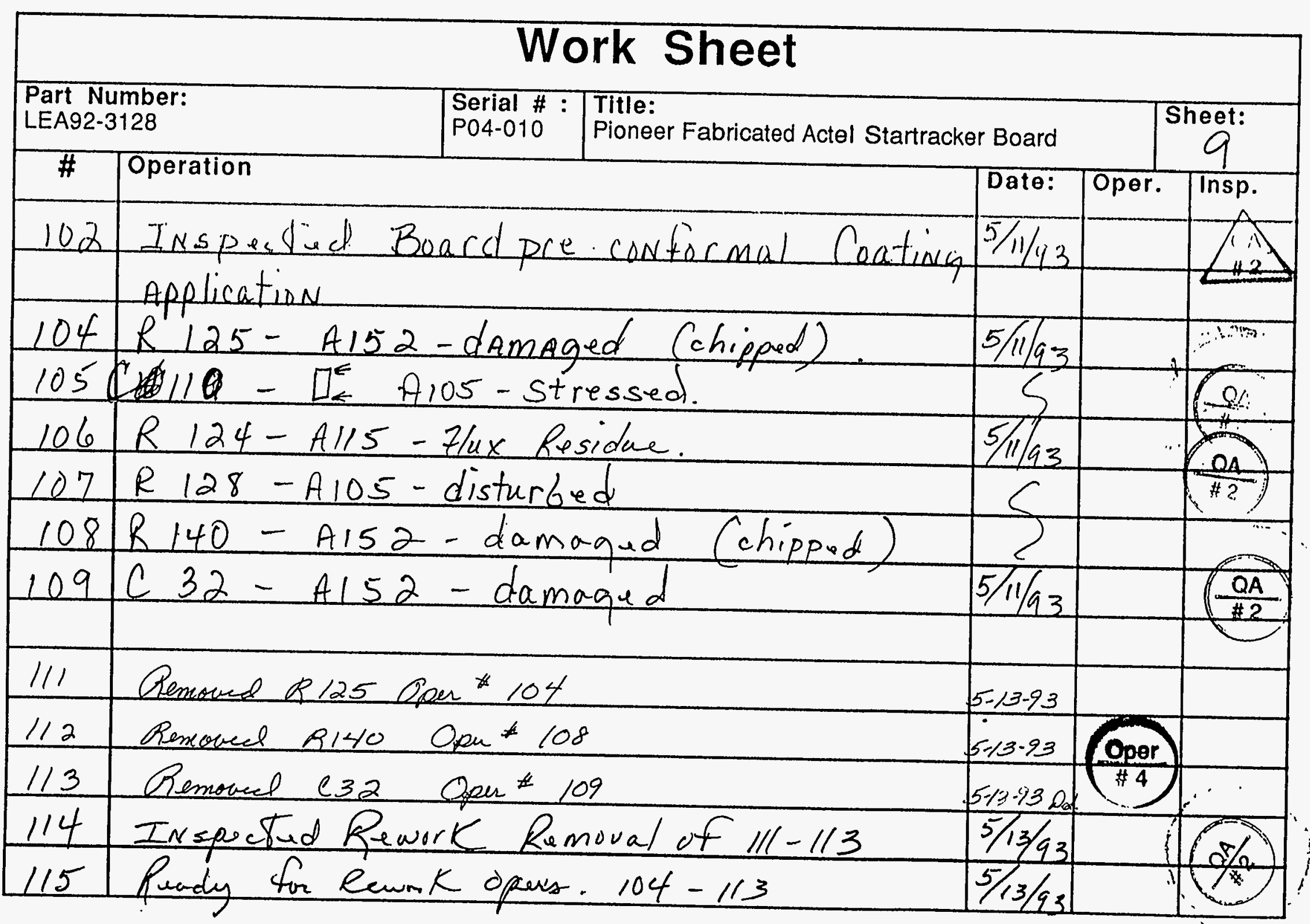




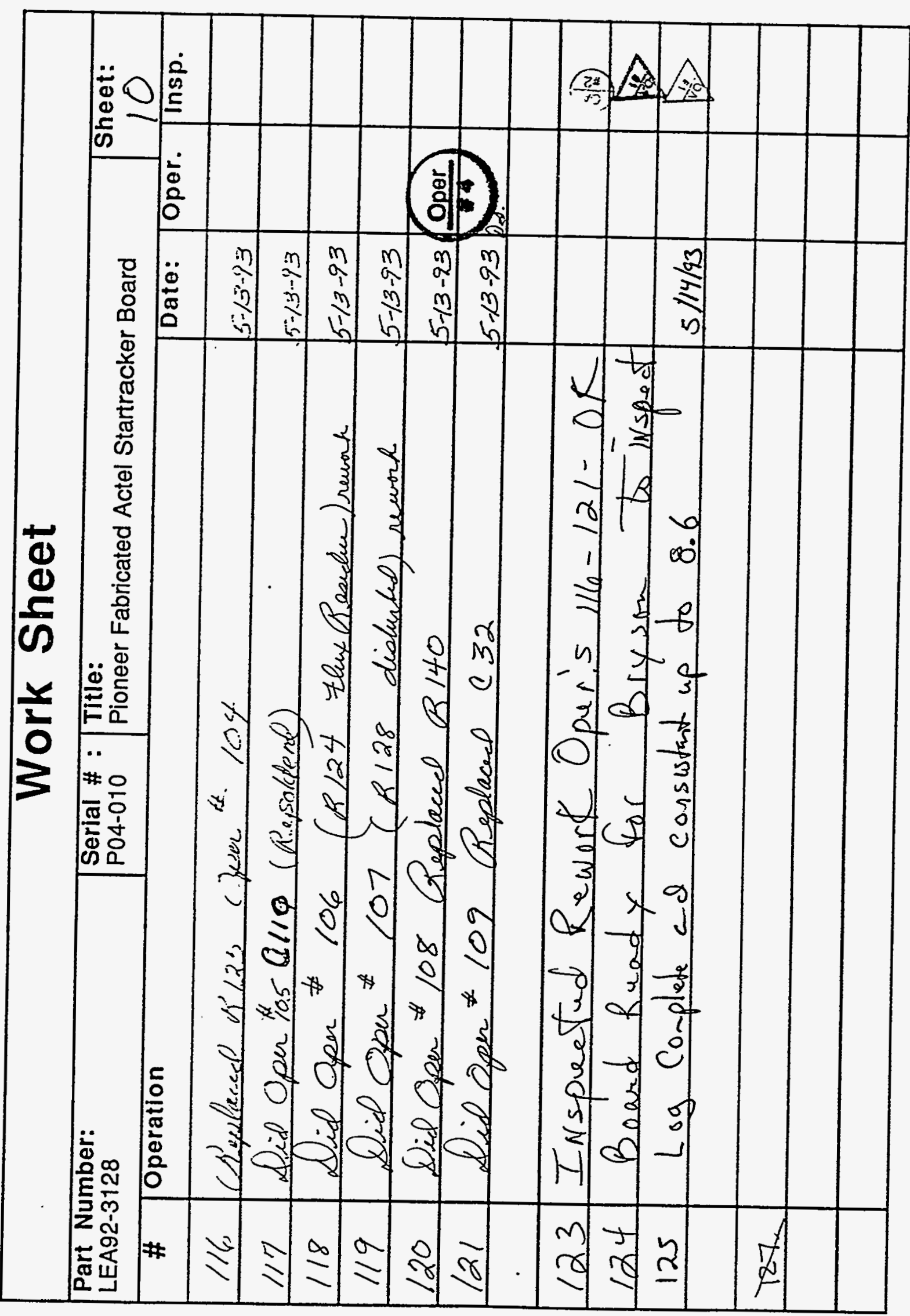




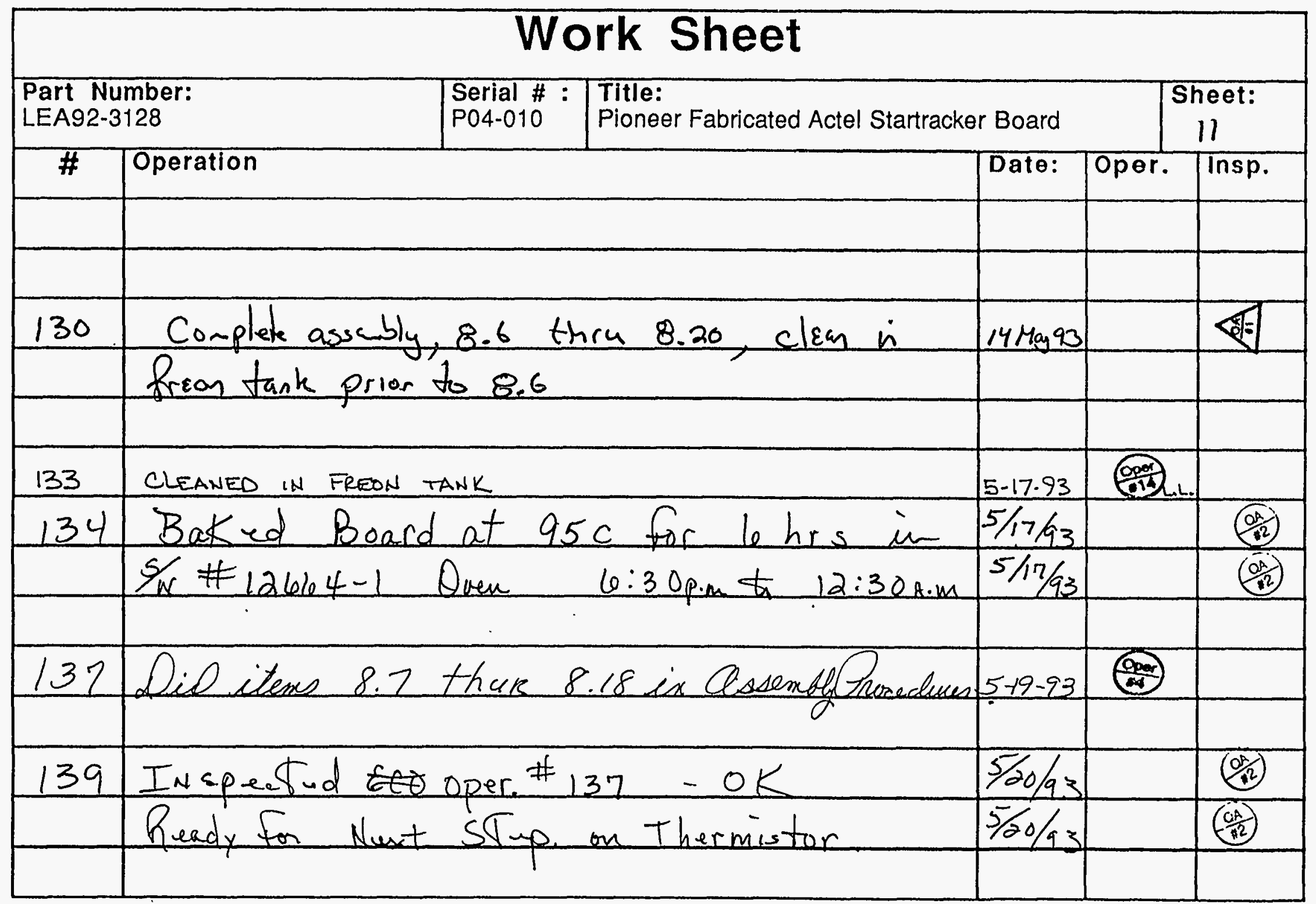




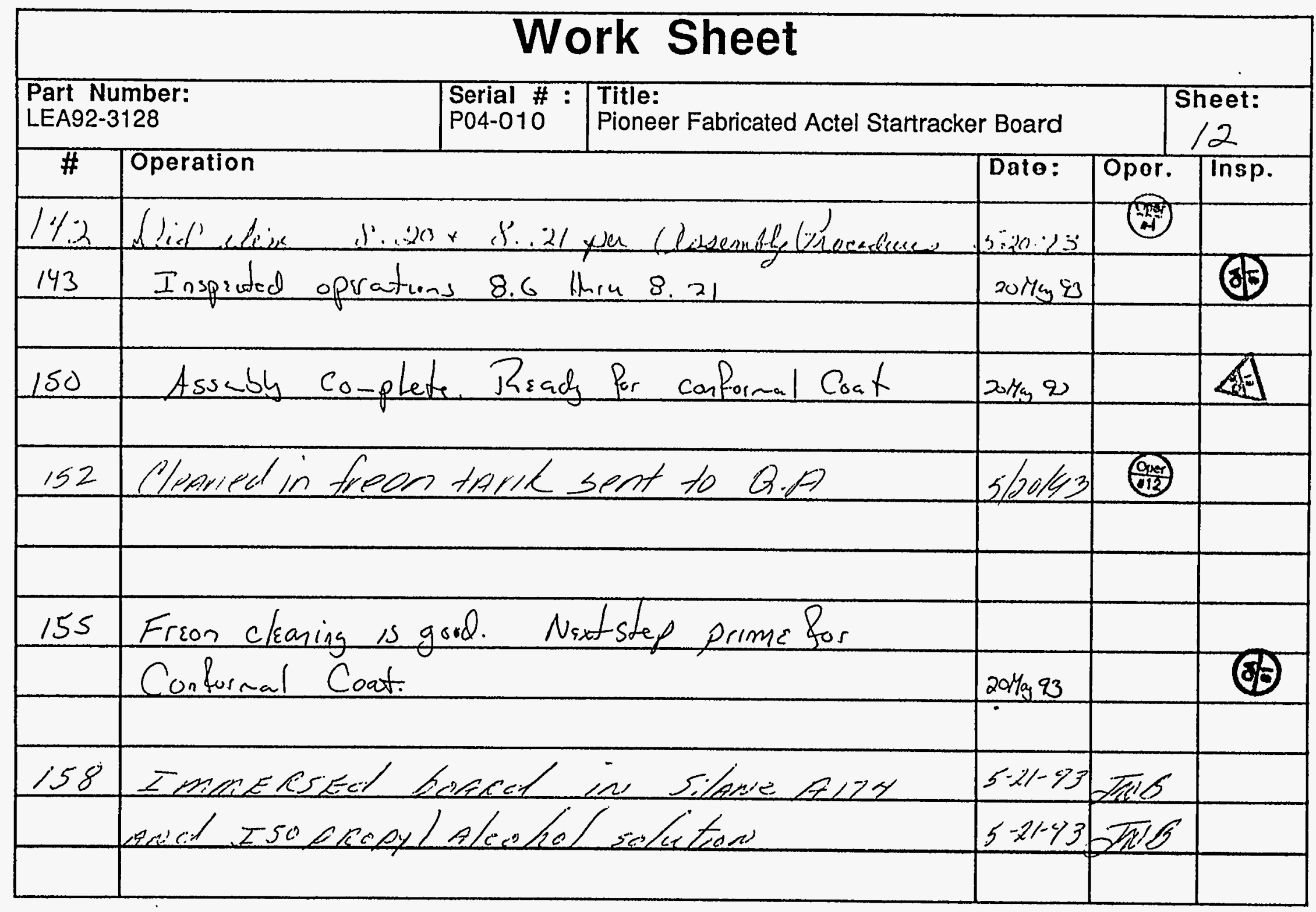




\begin{tabular}{|c|c|c|c|c|}
\hline & (20) & $\sqrt{55-6 e-5}$ & 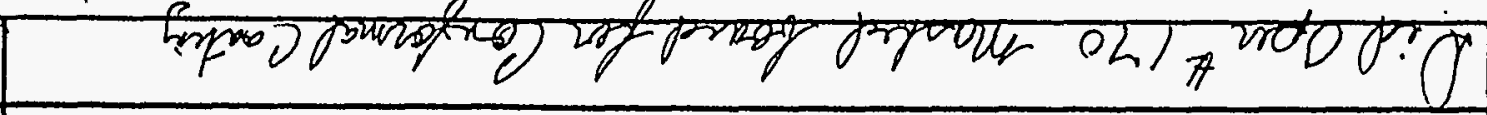 & Fill \\
\hline & Q & Cुक्जिय2 & 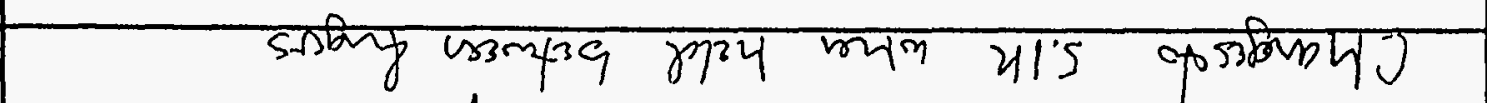 & \\
\hline & & & 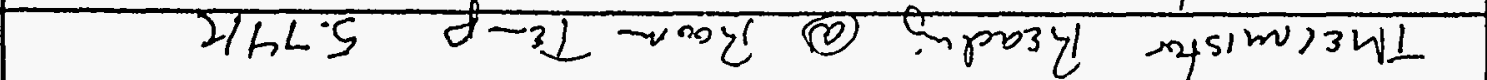 & い \\
\hline & & & & \\
\hline & & & 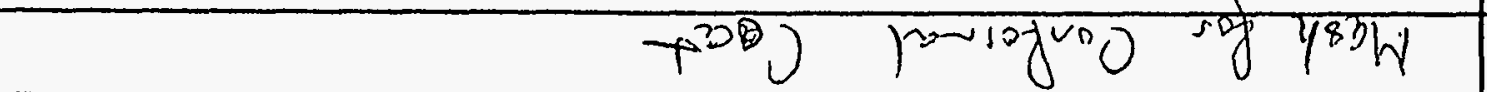 & \\
\hline & (क) & 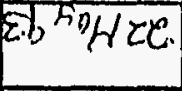 & 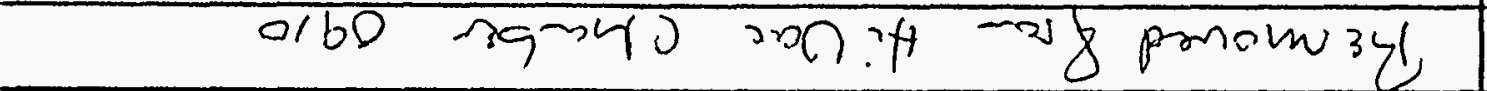 & $O C_{1}$ \\
\hline & & & & \\
\hline & & & & \\
\hline & & & & \\
\hline & Dape & $8 ! s \mid x-9$ & pingorf finde & TrOT \\
\hline & 1 & & |רत्रा & 70 \\
\hline & Sirke. & 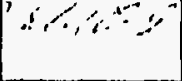 & ל ל & ๘"\% \\
\hline & 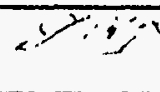 & 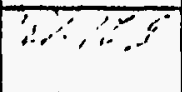 & pambl & $T .7 /$ \\
\hline$\cdot d$ dsul $_{1}$ & . Ledo & \multirow{2}{*}{\multicolumn{3}{|c|}{ 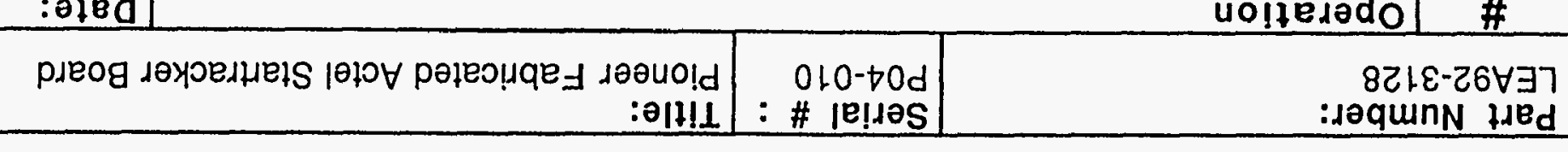 }} \\
\hline $\begin{aligned} \varepsilon \\
: 1021 \\
\end{aligned}$ & & & & \\
\hline \multicolumn{5}{|c|}{10045 Y10M } \\
\hline
\end{tabular}




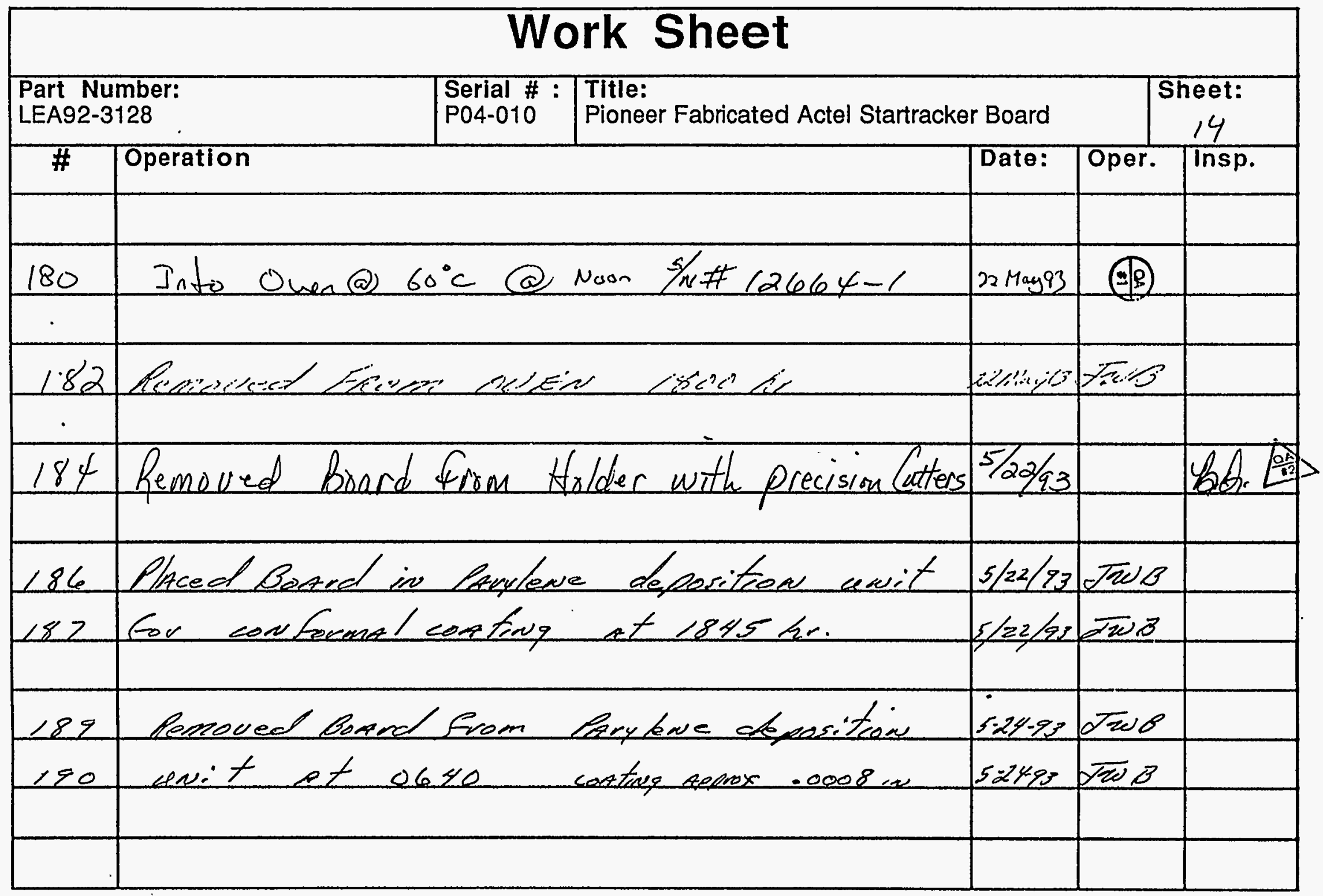




\begin{tabular}{|c|c|c|c|c|}
\hline \multicolumn{5}{|c|}{$\begin{array}{l}\text { Work Sheet } \\
\end{array}$} \\
\hline $\begin{array}{l}\text { Part Number: } \\
\text { LEA92-3128 }\end{array}$ & \begin{tabular}{|l|l|} 
Serial \# & Title: \\
P04-010 & Pioneer Fabricated Actel Startrac
\end{tabular} & Board & & $\begin{array}{l}\text { Sheet: } \\
15\end{array}$ \\
\hline \# & Operation & Date: & Oper. & \\
\hline & cuthere & & & \\
\hline 193 & Cut test ponits flush with plastic in & & & \\
\hline. & if not a lready cut. & $2414 \mathrm{y}^{93}$ & (6) & \\
\hline 196 & Removed Maskina & & 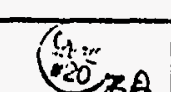 & \\
\hline 197 & Removed Test Points cut flush to & & (9) & \\
\hline 198 & Board as per Jim Dickye & & 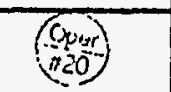 & \\
\hline 199 & Removed Conformal Coatine from flex & & 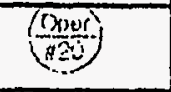 & \\
\hline & outer area's. & & 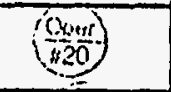 & \\
\hline 201 & Reture Boand to & $5 / 24 / 93$ & 《es & \\
\hline 2.02 & ATP Thermal Test Candete RE: DKII! & $6 / 30 / x 3$ & mo & \\
\hline & & & & \\
\hline
\end{tabular}


Appendix H.2.3

Bill of Materials 


\section{Actel Camera with Gain and Offset Control Startracker Configuration Rev. 00 Printed Wiring Board Bill of Materials, Rev. 00 . LEA92-3128-04}

\begin{tabular}{|c|c|c|c|c|}
\hline & Date & Rev. & Date & Approval \\
\hline Prepared by: K. F. Coatney & $30 \operatorname{mar} 43$ & $\angle A$ & 138,193 & $w_{L} \hookrightarrow_{-} x_{k}$ \\
\hline Reviewed by: W. R. Bryson & 30 14ar 93 & $O B$ & $16 A_{p r 1} 193$ & $\omega_{L} \subseteq \Delta / 1$ \\
\hline Reviewed by: Q. F. Kordas & $\mid 30-$ MOR-73 & OC & $22 A_{\rho v} 93$ & CKondes \\
\hline Reviewed by: M.L. Dickerson & 3131.93 & & & \\
\hline Reviewed by: E.H. S. S. Shmitunt & $4 / 2 / 93$ & & & \\
\hline Reviewed by: Alf st stannen & $4 / 2 / 23$ & & & \\
\hline $1 /$ & & & & \\
\hline $\begin{array}{l}\text { University of California } \\
\begin{array}{l}\text { Lawrence Livermore } \\
\text { National Laboratory }\end{array}\end{array}$ & \multicolumn{2}{|c|}{$\begin{array}{l}22 \text { March } 1993 \\
\text { Actel Startracker } \\
\text { Bill of Materials }\end{array}$} & \multicolumn{2}{|c|}{$\begin{array}{l}\text { LEA92-3128-04 } \\
\text { Revision } 00\end{array}$} \\
\hline
\end{tabular}




\subsection{Scope}

This document is the bill of materials for the Actel Camera with Gain and Offset Control for use in the Startracker, Rev 00 Printed Wiring Board, LEA92-3128-04, Rev 00.

\subsection{Parts}

Where a dual part number listing exists, the first number listed is a commercial part suitable for prototype work only. If the MIL-SPEC part is not available at the time flight boards are assembled, Quality assurance must OK the use of the commercial part on a part by part basis in writing.

Parts may not be substituted without the written permission of the Quality Assurance Group.

\begin{tabular}{|c|c|c|c|c|c|}
\hline Item & Qty. & Designator & Description & Case & $\begin{array}{c}\text { Mfg. I } \\
\text { Part Number }\end{array}$ \\
\hline 1 & 44 & $\begin{array}{c}\mathrm{C} 1, \mathrm{C} 3, \mathrm{C} 5, \mathrm{C} 6, \\
\mathrm{C} 15, \mathrm{C} 21, \\
\mathrm{C} 23, \mathrm{C} 25, \mathrm{C} 26, \\
\mathrm{C} 30, \mathrm{C} 31, \mathrm{C} 33, \\
\mathrm{C} 34, \mathrm{C} 38, \mathrm{C} 39, \\
\mathrm{C} 40, \mathrm{C} 42, \mathrm{C} 44, \\
\mathrm{C} 45, \mathrm{C} 47, \mathrm{C} 48, \\
\mathrm{C} 54, \mathrm{C} 56, \mathrm{C} 57, \\
\mathrm{C} 58, \mathrm{C} 59, \mathrm{C} 60, \\
\mathrm{C} 63, \mathrm{C} 64, \mathrm{C} 66, \\
\text { C67,C70,C91, } \\
\text { C92,C98,C102, } \\
\text { C103,C104,C106, } \\
\text { C109,C112,C114, } \\
\text { C121,C124 }\end{array}$ & $\begin{array}{c}0.039 \mu \mathrm{F} \\
50 \mathrm{~V}, 10 \% \\
\mathrm{FR}=0.01 \% / \\
1000 \mathrm{hr}\end{array}$ & RM1206 & CDR32BХ393AKUR \\
\hline 2 & 5 & $\begin{array}{c}\mathrm{C} 2, \mathrm{C} 51, \mathrm{C} 61, \mathrm{C} 62, \\
\mathrm{C} 122\end{array}$ & $\begin{array}{c}4.7 \mu \mathrm{fd}, \text { Tant, } \\
10 \mathrm{~V}, 10 \%, \\
\text { WFR }=0.01 \% / \\
1000 \mathrm{hr}\end{array}$ & H-CASE & CWR06FH475KC \\
\hline 3 & 1 & $\overline{C 9}$ & $\begin{array}{c}47 \mu \mathrm{fd}, \text { Tant, } \\
20 \mathrm{~V}, 10 \%\end{array}$ & R-CASE & $\begin{array}{c}\text { Sprague / } \\
\text { 1950476X9020R2T }\end{array}$ \\
\hline
\end{tabular}




\begin{tabular}{|c|c|c|c|c|c|}
\hline Item & Qty. & Designator & Description & Case & $\begin{array}{l}\text { Mfg. I } \\
\text { Part Number }\end{array}$ \\
\hline 4 & 2 & $C 10, C 11$ & $\begin{array}{l}22 \mu \mathrm{fd}, \text { Tant, } \\
15 \mathrm{~V}, 10 \%, \\
\text { WFR=0.01\% } \\
1000 \mathrm{hr} \\
19.8 \\
24.2\end{array}$ & G-CASE & CWR06HH226KC \\
\hline 5 & 4 & $\begin{array}{c}\mathrm{C} 12, \mathrm{C} 13, \mathrm{C} 17 \\
\mathrm{C} 105\end{array}$ & $\begin{array}{l}6.8 \mu \mathrm{fd}, \text { Tant, } \\
10 \mathrm{~V}, 10 \% \\
\mathrm{WFR}=0.1 \% \\
1000 \mathrm{hr} \\
6,42\end{array}$ & E-CASE & CWR06FH685KB \\
\hline 6 & 2 & $\mathrm{C} 20, \mathrm{C} 110$ & $\begin{array}{l}6.8 \mu \mathrm{fd}, \text { Tant, } \\
20 \mathrm{~V}, 10 \% \text {, } \\
\text { WFR }=0.01 \% \mathrm{~d} \\
1000 \mathrm{hr} \\
6.48 \\
0.48\end{array}$ & F-CASE & CWR06JH685KC \\
\hline 7 & 6 & $\begin{array}{l}\mathrm{C} 22, \mathrm{C} 24, \mathrm{C} 29, \\
\mathrm{C} 69, \mathrm{C} 90, \mathrm{C} 118\end{array}$ & $\begin{array}{l}2.40 \\
20 \mathrm{fd}, \text { Tant, } \\
20 \mathrm{~V}, 10 \%, \\
\text { WFR=0.01\%/ } \\
1000 \mathrm{hr} \\
19.8 \\
24.2\end{array}$ & H-Case & CWR06JH226KC. \\
\hline 8 & 4 & $\begin{array}{c}\text { C32,C52,C94, } \\
\text { C95 }\end{array}$ & $\begin{array}{c}10 \mu \mathrm{fd}, \text { Tant, } \\
25 \mathrm{~V}, 10 \% \\
\text { WFR=0.01\%/ } \\
1000 \mathrm{hr} \\
9.0 \\
11.0\end{array}$ & G-CASE & CWR06KH106KC \\
\hline 9 & 7 & $\mathrm{C} 35$ & $\begin{array}{r}0.22 \mu f d, \\
50 V, 10 \% \\
0.178,10 \% \\
0.242\end{array}$ & RC1206 & $\begin{array}{c}\text { Garrett / } \\
1206 Z 224 \mathrm{M} 500 \mathrm{~N}\end{array}$ \\
\hline 10 & 2 & $\mathrm{C} 46, \mathrm{C} 93$ & $\begin{array}{l}1.0 \mu \mathrm{fd}, \text { Tant } \\
35 \mathrm{~V}, 10 \%, \\
\text { WFR=0,01\% } \\
1000 \mathrm{hr} \\
1.9^{100}\end{array}$ & D-CASE & CWR06MH105KC \\
\hline 11 & 2 & $\mathrm{C} 49, \mathrm{C} 50$ & $\begin{array}{l}0.022 \mu \mathrm{fd}, \\
100 \mathrm{~V}, 10 \%, \\
\mathrm{FR}=0.01 \% \% \\
1000 \mathrm{hr} \\
0: 0198 \\
0.044^{2}\end{array}$ & RM1206 & $\begin{array}{c}\text { Garrett / } \\
\text { CE223K3NR }\end{array}$ \\
\hline 12 & 1 & $\overline{\mathrm{C53}}$ & $\begin{array}{l}15 \mathrm{pf}, \\
100 \mathrm{~V}, 5 \%, \\
\mathrm{FR}=0.01 \% / \\
1000 \mathrm{hr} \\
14.25 \\
15.75\end{array}$ & RM1206 & CDR32BP150BJUR \\
\hline
\end{tabular}




\begin{tabular}{|c|c|c|c|c|c|}
\hline Item & Qty. & Designator & Description & Case & $\begin{array}{l}\text { Mfg. I } \\
\text { Part Number } \\
\end{array}$ \\
\hline 13 & 5 & $\begin{array}{c}\mathrm{C} 73, \mathrm{C} 74, \mathrm{C} 75 \\
\mathrm{C} 76, \mathrm{C} 77\end{array}$ & $\begin{array}{c}3300 \mathrm{pf} \\
50 \mathrm{~V}, 10 \% \\
\mathrm{FR}=0.001 \% \mathrm{q} \\
1000 \mathrm{hr} \\
29700 \mathrm{hr} \\
3630\end{array}$ & $\begin{array}{l}\mathrm{RC} 0402 \\
\mathrm{RC} 0505\end{array}$ & $\begin{array}{c}\text { Novacap / } \\
\text { 0402B332K500N } \\
\text { CDR11BP332AKUS }\end{array}$ \\
\hline 14 & 1 & $\mathrm{C} 83$ & \begin{tabular}{|c|}
$0.01 \mu \mathrm{fd}$, \\
$100 \mathrm{~V}, 10 \%$ \\
$\mathrm{FR}=0.01 \%$ \\
$1000 \mathrm{hr}$ \\
$0.0 \% 99$ \\
0.011
\end{tabular} & RM1206 & CDR32BX103BKUR \\
\hline 15 & 1 & C111 & $\begin{array}{c}47 \mathrm{pf} \\
100 \mathrm{~V}, 5 \% \\
\mathrm{FR}=0.01 \% / \\
1000 \mathrm{hr}\end{array}$ & \begin{tabular}{|l|} 
RM1206 \\
44.65 \\
49,35
\end{tabular} & CDR32PB470BJUR \\
\hline 16 & 2 & $\mathrm{C} 115, \mathrm{C} 116$ & $\begin{array}{c}270 \mathrm{pf}, \\
100 \mathrm{~V}, 10 \%, \\
\text { FR }=0.01 \% / \\
1000 \mathrm{hr} \\
243 \\
297\end{array}$ & RM1206 & CDR32BP271BKUR \\
\hline 17 & 1 & D1 & $\begin{array}{l}\text { Diode, } \\
\text { Switching, } \\
50 \mathrm{~V}, 200 \mathrm{~mA} \\
\text { MBAV74 }\end{array}$ & SOT-23 & $\begin{array}{l}\text { Motorola I } \\
\text { MBAV74L } \\
\text { siv } \\
00202\end{array}$ \\
\hline 18 & 1 & D2 & $\begin{array}{c}\text { Diode, } \\
\text { Voltage } \\
\text { Reference } \\
\text { LM285-1.2 }\end{array}$ & SOIC-8 & $\begin{array}{l}\frac{\text { Linear I }}{\text { LM285MX-1.2 }} \\
\text { SN } \\
01502\end{array}$ \\
\hline 19 & 1 & D3 & $\begin{array}{l}\text { Reference, } \\
\text { Voltage, } \\
\text { Precision, } \\
\text { 10V, } \\
\text { REF-01 }\end{array}$ & SOIC-8 & $\begin{array}{l}\text { PMII } \\
\text { REF01CS } \\
\text { SiN) } \\
011919\end{array}$ \\
\hline 20 & 2 & $\mathrm{D} 4, \mathrm{D} 5$ & \begin{tabular}{|c|} 
Diode, \\
Schottky, $30 \mathrm{~V}$ \\
BAT54S
\end{tabular} & SOT-23 & $\begin{array}{l}\text { Phillips I } \\
\text { BAT54S } \\
5, N=57 \quad 3516 \\
0=516\end{array}$ \\
\hline 21 & 9 & $\begin{array}{l}\text { JP4,JP6,JP7,JP9, } \\
\text { JP11,JP13,JP14, } \\
\text { JP15,JP16 }\end{array}$ & $\begin{array}{l}\text { Jumper, } \\
0 \Omega, 1 \%, \\
1 / 4 \text { Watt }\end{array}$ & RM1206 & D55342K07B00DOS \\
\hline 22 & $\overline{3}$ & $\mathrm{L1}, \mathrm{L} 3, \mathrm{~L} 4$ & $\begin{array}{l}\text { Inductor, } \\
100 \mu \mathrm{H}\end{array}$ & $\mathrm{LQH4}_{4}$ & $\begin{array}{l}\text { MuRata Erie / } \\
\text { LQH4N101K-TA }\end{array}$ \\
\hline
\end{tabular}




\begin{tabular}{|c|c|c|c|c|c|}
\hline Item & Qty. & Designator & Description & Case & $\begin{array}{l}\text { Mfg. / } \\
\text { Part Number }\end{array}$ \\
\hline 23 & 1 & $\llcorner 5$ & $\begin{array}{l}\text { Inductor, } \\
10 \mu \mathrm{H}\end{array}$ & LQH4 & $\begin{array}{l}\text { MuRata Erie / } \\
\text { LQH4N100K-TA }\end{array}$ \\
\hline 24 & 1 & $\sqrt{1}$ & $\begin{array}{l}\text { Connector, } \\
51 \text { Contact, } \\
\text { Socket }\end{array}$ & MDM51 & M83513/04-G06N \\
\hline 25 & 5 & $\begin{array}{c}\text { Q1,Q4,Q9, } \\
\text { su's Q10,Q11 } \\
047010,04707,04788\end{array}$ & $\begin{array}{c}\text { Transistor, } \\
\text { FET, } \\
\text { SST215 } \\
04709,04710\end{array}$ & SOT-143 & $\begin{array}{c}\text { Calogic / } \\
\text { No Substitute } \\
\text { Calogic No. SST215E }\end{array}$ \\
\hline 26 & 3 & $\begin{array}{l}Q 2, Q 3, Q 8 \\
\sin ^{\text {is }} \\
00017,00016,00015\end{array}$ & $\begin{array}{l}\text { Transistor, } \\
2 \text { N3904 }\end{array}$ & SOT-23 & $\begin{array}{c}\text { Motorola / } \\
\text { MMBT3904 } \\
\text { No Substitute }\end{array}$ \\
\hline 27 & 3 & $\begin{array}{l}\text { Q12,Q13,Q14 } \\
5.15 \\
00917,916 \quad 0015\end{array}$ & $\begin{array}{l}\text { Transistor, } \\
\text { 2N7002 }\end{array}$ & SOT-23 & $\begin{array}{l}\text { Motorola / } \\
2 \text { N7002 } \\
\text { No Substitute }\end{array}$ \\
\hline 28 & 2 & $R 3, R 66$ & $\begin{array}{c}7.5 \mathrm{~K} \Omega, 1 \% \\
1 / 4 \mathrm{Watt} \\
100 \mathrm{ppm} \\
\mathrm{FR}=0.01 \% / \\
1000 \mathrm{hr}\end{array}$ & RM1206 & D55342K07B7E50R \\
\hline 29 & & $\begin{array}{c}\text { This space left } \\
\text { intentionally blank }\end{array}$ & & & \\
\hline 30 & 2 & $\mathrm{R} 14, \mathrm{R} 31$ & $\begin{array}{c}243 \Omega, 1 \% \\
1 / 4 \mathrm{Watt} \\
100 \mathrm{ppm}, \\
\text { FR=0.01\%/ } \\
\text { 1000hr }\end{array}$ & $\mathrm{RM} 1206$ & D55342K07B243DR \\
\hline 31 & 2 & R15,R32 & $\begin{array}{c}1.82 \mathrm{~K} \Omega, 1 \% \\
1 / 4 \mathrm{Watt} \\
100 \mathrm{ppm}, \\
\text { FR=0.01\%/ } \\
1000 \mathrm{hr}\end{array}$ & RM1206 & D55342K07B1E82R \\
\hline
\end{tabular}




\begin{tabular}{|c|c|c|c|c|c|}
\hline Item & Qty. & Designator & Description & Case & $\begin{array}{l}\text { Mfg. I } \\
\text { Part Number }\end{array}$ \\
\hline 32 & 5 & $\begin{array}{c}\text { R16,R116,R130 } \\
\text { R133,R136 }\end{array}$ & $\begin{array}{c}49.9 \Omega, 1 \% \\
1 / 4 \text { Watt, } \\
100 \mathrm{ppm}, \\
\text { FR=0.01\% } \\
1000 \mathrm{hr}\end{array}$ & RM1206 & D55342K07B49D9R \\
\hline 33 & 5 & $\begin{array}{c}\text { R17,R21,R49, } \\
\text { R74,R94,R95 } \\
\text { TEMPORARILY } \\
\text { LOAD R49 }\end{array}$ & $\begin{array}{c}1.0 \mathrm{~K} \Omega, 1 \%, \\
1 / 4 \mathrm{Watt}, \\
100 \mathrm{ppm}, \\
\mathrm{FR}=0.01 \% / \\
1000 \mathrm{hr}\end{array}$ & RM1206 & D55342K07B1E00R \\
\hline 34 & 7 & R18 & \begin{tabular}{|c|}
$2.49 \mathrm{~K} \Omega, 1 \%$, \\
$1 / 4 \mathrm{Watt}$, \\
$100 \mathrm{ppm}$, \\
$\mathrm{FR}=0.01 \% /$ \\
$100 \mathrm{hr}$
\end{tabular} & $\mathrm{RM} 1206$ & D55342K07B2E49R \\
\hline 35 & 1 & $\mathrm{R} 20$ & $\begin{array}{c}2.7 \mathrm{~K} \Omega, 2 \% \\
1 / 4 \mathrm{Watt}, \\
100 \mathrm{ppm} \\
\mathrm{FR}=0.01 \% / \\
1000 \mathrm{hr}\end{array}$ & $\mathrm{RM} 1206$ & $\mathrm{D} 55342 \mathrm{KO} 07 \mathrm{~B} 2 \mathrm{H} 70 \mathrm{R}$ \\
\hline 36 & 1 & R24 & $\begin{array}{c}1.62 \mathrm{~K} \Omega, 1 \% \\
1 / 4 \mathrm{Watt} \\
100 \mathrm{ppm} \\
\text { FR=0.01\%/ } \\
1000 \mathrm{hr}\end{array}$ & RM1206 & D55342K07B1E62R \\
\hline 37 & 1 & R25 & $\begin{array}{c}9.09 \mathrm{~K} \Omega, 1 \%, \\
1 / 4 \mathrm{Watt}, \\
100 \mathrm{ppm}, \\
\mathrm{FR}=0.01 \% / \\
1000 \mathrm{hr}\end{array}$ & RM1206 & D55342K07B9E09R \\
\hline 38 & 1 & $\overline{\mathrm{R} 26}$ & \begin{tabular}{|c|}
$24.3 \mathrm{~K} \Omega, 1 \%$ \\
$1 / 4 \mathrm{Watt}$, \\
$100 \mathrm{ppm}$, \\
$\mathrm{FR}=0.01 \% /$ \\
$1000 \mathrm{hr}$
\end{tabular} & RM1206 & D55342K07B24E3R \\
\hline
\end{tabular}




\begin{tabular}{|c|c|c|c|c|c|}
\hline Item & Qty. & Designator & Description & Case & $\begin{array}{c}\text { Mfg. / } \\
\text { Part Number }\end{array}$ \\
\hline 32 & 5 & $\begin{array}{c}\text { R16,R116,R130 } \\
\text { R133,R136 }\end{array}$ & $\begin{array}{l}49.9 \Omega, 1 \%, \\
1 / 4 \mathrm{Watt}, \\
100 \mathrm{ppm}, \\
\mathrm{FR}=0.01 \% \\
1000 \mathrm{hr} \\
49.40 \% \\
50.399\end{array}$ & RM1206 & D55342K07B49D9R \\
\hline 33 & 5 & $\begin{array}{c}\text { R17,R21, } \\
\text { R74,R94,R95 }\end{array}$ & $\begin{array}{l}1.0 \mathrm{~K} \Omega, 1 \% \text {, } \\
1 / 4 \mathrm{Watt} \\
100 \mathrm{ppm}, \\
\mathrm{FR}=0.01 \% \\
1000 \mathrm{hr} \\
990 \\
1.010\end{array}$ & RM1206 & D55342K07B1E00R \\
\hline 34 & $\overline{1}$ & $\overline{\mathrm{R} 18}$ & $\begin{array}{c}2.49 \mathrm{~K} \Omega, 1 \% \\
1 / 4 \mathrm{Watt} \\
100 \mathrm{ppm}, \\
\mathrm{FR}=0.01 \% \\
1000 \mathrm{hr} \\
2.465,9 \\
2.5149\end{array}$ & RM1206 & D55342K07B2E49R \\
\hline 35 & 1 & $\mathrm{R} 20$ & $\begin{array}{l}2.7 \mathrm{~K} \Omega, 2 \%, \\
1 / 4 \mathrm{Watt}, \\
100 \mathrm{ppm}, \\
\mathrm{FR}=0.01 \% / \\
1000 \mathrm{hr} \\
2.673 \\
3.237\end{array}$ & RM1206 & D55342K07B2H70R \\
\hline 36 & 1 & $\mathrm{R} 24$ & $\begin{array}{c}1.62 \mathrm{~K} \Omega, 1 \% \\
1 / 4 \mathrm{Watt} \\
100 \mathrm{ppm}, \\
\mathrm{FR}=0.01 \% \\
1000 \mathrm{hr} \\
1.6038 \\
1.6362\end{array}$ & RM1206 & D55342K07B1E62R \\
\hline 37 & 7 & $\overline{\mathrm{R} 25}$ & $\begin{array}{c}9.09 \mathrm{~K} \Omega, 1 \%, \\
1 / 4 \mathrm{Watt}, \\
100 \mathrm{ppm}, \\
\mathrm{FR}=0.01 \% / \\
1000 \mathrm{hr} \\
9.9991 \\
9809\end{array}$ & RM1206 & D55342K07B9E09R \\
\hline 38 & 1 & $\overline{R 26}$ & $\begin{array}{c}24.3 \mathrm{~K} \Omega, 1 \% \text {, } \\
1 / 4 \mathrm{Watt} \\
100 \mathrm{ppm}, \\
\text { FR=0.01\%/ } \\
1000 \mathrm{hr} \\
24.057 \\
24.543\end{array}$ & RM1206 & D55342K07B24E3R \\
\hline
\end{tabular}




\begin{tabular}{|c|c|c|c|c|c|}
\hline Item & Qty. & Designator & Description & Case & $\begin{array}{c}\text { Mfg. / } \\
\text { Part Number }\end{array}$ \\
\hline 39 & 1 & R27 & $\begin{array}{c}7.68 \mathrm{~K} \Omega, 1 \% \\
1 / 4 \mathrm{Watt} \\
100 \mathrm{ppm}, \\
\text { FR=0.01\% } \\
1000 \mathrm{hr}\end{array}$ & $R M 1206$ & D55342K07B7E68R \\
\hline 40 & 2 & R28,R91 & $\begin{array}{c}0 \Omega, 1 \%, \\
1 / 4 \mathrm{Watt}, \\
100 \mathrm{ppm} \\
\text { FR=0.01\%/ } \\
1000 \mathrm{hr}\end{array}$ & RM1206 & D55342K07BO0DOR \\
\hline 41 & 9 & $\begin{array}{c}\text { R29,R48,R101, } \\
\text { R102,R129,R132, } \\
\text { R135,R140,R141 }\end{array}$ & $\begin{array}{c}10 \mathrm{~K} \Omega, 1 \% \text {, } \\
1 / 4 \mathrm{Watt} \\
100 \mathrm{ppm} \\
\text { FR=0,01\%/ } \\
1000 \mathrm{hr}\end{array}$ & RM1206 & D55342K07B10EOR \\
\hline 42 & 1 & R30 & $\begin{array}{c}2.15 \mathrm{~K} \Omega, 1 \% \\
1 / 4 \mathrm{Watt} \\
100 \mathrm{ppm} \\
\mathrm{FR}=0.01 \% / \\
1000 \mathrm{hr}\end{array}$ & RM1206 & D55342K07B2E15R \\
\hline 43 & 4 & $\begin{array}{c}\text { R37,R115, } \\
\text { R49,R122,R128 } \\
\text { DO NOT LOAD } \\
\text { R49 OR R128 }\end{array}$ & $\begin{array}{c}100 \Omega, \text { T\%, } \\
1 / 4 \mathrm{Watt} \\
100 \mathrm{ppm}, \\
\mathrm{FR}=0,01 \% / \\
1000 \mathrm{hr}\end{array}$ & RM1206 & D55342K07B100DR \\
\hline 44 & 1 & R38 & $\begin{array}{c}3.01 \mathrm{~K} \Omega, 1 \% \text {, } \\
1 / 4 \mathrm{Watt}, \\
100 \mathrm{ppm}, \\
\mathrm{FR}=0.01 \% / \\
1000 \mathrm{hr}\end{array}$ & RM1206 & D55342K07B3E01R \\
\hline 45 & $\overline{2}$ & R42,R43 & $\begin{array}{c}30 \Omega, 2 \%, \\
1 / 4 \mathrm{Watt} \\
100 \mathrm{ppm}, \\
\mathrm{FR}=0.01 \% / \\
1000 \mathrm{hr}\end{array}$ & RM1206 & D55342K07B30G0R \\
\hline
\end{tabular}




\begin{tabular}{|c|c|c|c|c|c|}
\hline Item & Qty. & Designator & Description & Case & $\begin{array}{l}\text { Mfg. I } \\
\text { Part Number }\end{array}$ \\
\hline 39 & 1 & R27 & $\begin{array}{c}7.68 \mathrm{~K} \Omega, 1 \% \text {, } \\
1 / 4 \mathrm{Watt}, \\
100 \mathrm{ppm}, \\
F R=0.01 \% \\
1000 \mathrm{hr} \\
7.6032 \\
7.7568\end{array}$ & RM1206 & D55342K07B7E68R \\
\hline 40 & 2 & R28,R91 & $\begin{array}{c}0 \Omega, 1 \%, \\
1 / 4 \mathrm{Watt}, \\
100 \mathrm{ppm}, \\
\mathrm{FR}=0.01 \% \\
1000 \mathrm{hr}\end{array}$ & RM1206 & D55342K07B00D0R \\
\hline$\overline{41}$ & 9 & $\begin{array}{r}\text { R29,R48,R101, } \\
\text { R102,R129,R132, } \\
\text { R135,R140,R141 }\end{array}$ & $\begin{array}{c}10 \mathrm{~K} \Omega, 1 \% \\
1 / 4 \mathrm{Watt}, \\
100 \mathrm{ppm}, \\
\mathrm{FR}=0,01 \% \\
1000 \mathrm{hr} \\
9.90\end{array}$ & $\mathrm{RM} 1206$ & D55342K07B10EOR \\
\hline 42 & 1 & R30 & $\begin{array}{c}2.15 \mathrm{~K} \Omega, 1 \% \text {, } \\
1 / 4 \mathrm{Watt}, \\
100 \mathrm{ppm}, \\
\mathrm{FR}=0.01 \% / \\
1000 \mathrm{hr} \\
2,1285 \\
2,175\end{array}$ & RM1206 & D55342K07B2E15R \\
\hline 43 & 4 & $\begin{array}{l}\text { R37,R115, } \\
\text { R122,R128 }\end{array}$ & $\begin{array}{l}100 \Omega, 1 \%, \\
1 / 4 \mathrm{Watt} \\
100 \mathrm{ppm}, \\
\mathrm{FR}=0,01 \% / \\
1000 \mathrm{hr} \\
99 \\
10\end{array}$ & RM1206 & D55342K07B100DR \\
\hline 44 & 1 & R38 & $\begin{array}{l}3.01 \mathrm{~K} \Omega, 1 \%, \\
1 / 4 \mathrm{Watt}, \\
100 \mathrm{ppm}, \\
\mathrm{FR}=0.01 \% / \\
1000 \mathrm{hr} \\
2.9799 \\
3,0469 \\
\end{array}$ & RM1206 & D55342K07B3E01R \\
\hline 45 & 2 & R42,R43 & $\begin{array}{c}30 \Omega, 2 \%, \\
1 / 4 \mathrm{Watt}, \\
100 \mathrm{ppm}, \\
\mathrm{FR}=0.01 \% / \\
1000 \mathrm{hr} \\
29.40 \\
30.60\end{array}$ & RM1206 & D55342K07B30G0R \\
\hline
\end{tabular}




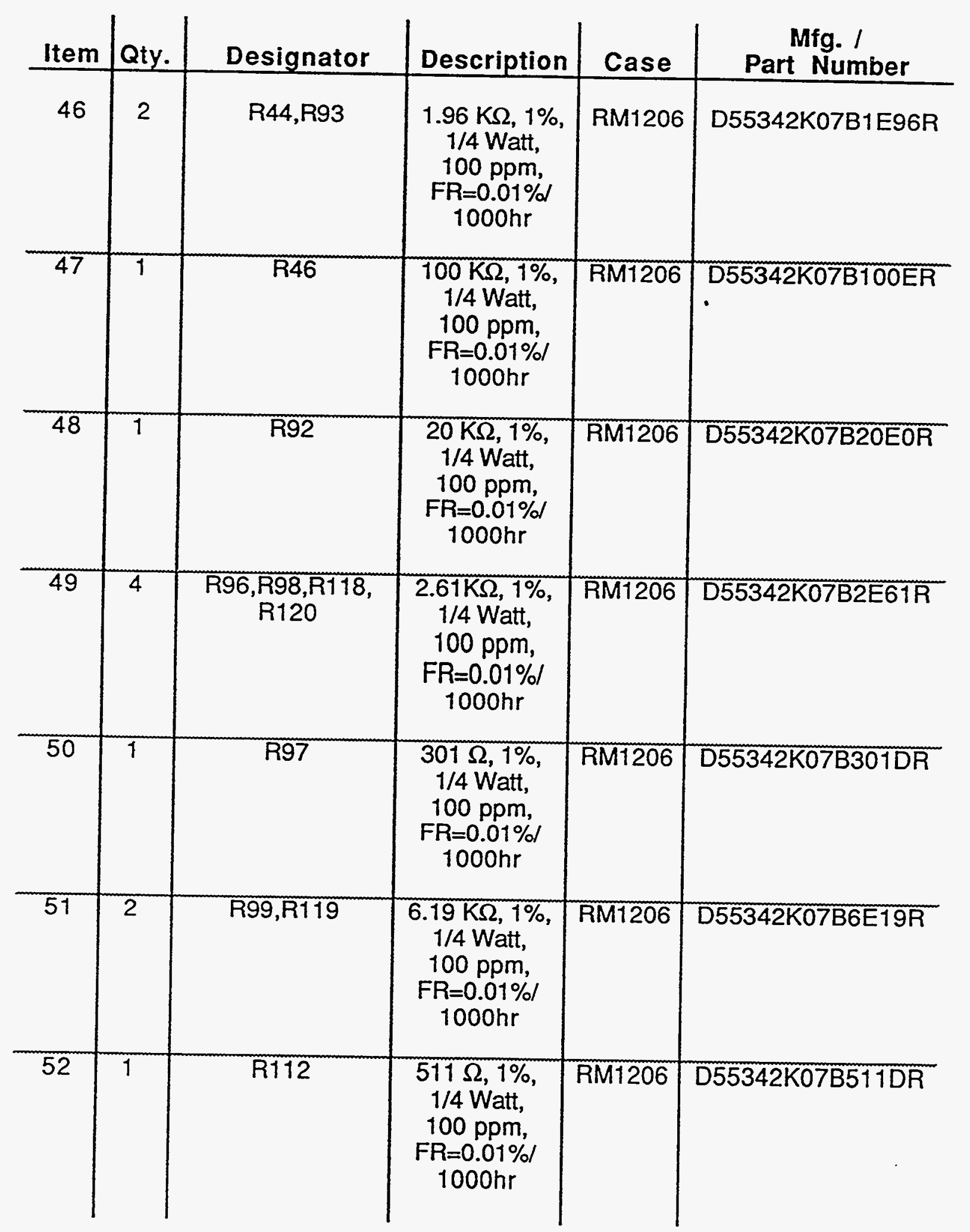




\begin{tabular}{|c|c|c|c|c|c|}
\hline Item & Qty. & Designator & Description & Case & $\begin{array}{c}\text { Mfg. / } \\
\text { Part Number }\end{array}$ \\
\hline 53 & 1 & $\mathrm{R} 117$ & $\begin{array}{c}40.2 \Omega, 1 \%, \\
1 / 4 \mathrm{Watt} \\
100 . \mathrm{ppm}, \\
\text { FR=0.01\%/ } \\
1000 \mathrm{hr}\end{array}$ & RM1206 & D55342K07B40D2R \\
\hline 54 & 1 & R121 & $\begin{array}{c}649 \Omega, 1 \% \text {, } \\
1 / 4 \mathrm{Watt}, \\
100 \mathrm{ppm}, \\
\mathrm{FR}=0.01 \% / \\
1000 \mathrm{hr}\end{array}$ & RM1206 & D55342K07B649DR \\
\hline 55 & 1 & R124 & $\begin{array}{l}5.1 \Omega 1 \%, \\
1 / 8 \text { Watt }\end{array}$ & RC1206 & $\begin{array}{c}\text { KOA / } \\
\text { RM73B2B5R1JT }\end{array}$ \\
\hline 56 & 1 & $R 125$ & $\begin{array}{c}499 \Omega, 1 \%, \\
1 / 4 \text { Watt, } \\
100 \text { ppm, } \\
\text { FR=0.01\%/ } \\
1000 \mathrm{hr}\end{array}$ & $\mathrm{RM} 1206$ & D55342K07B499DR \\
\hline 57 & 7 & $\overline{R 131}$ & $\begin{array}{c}931 \Omega, 1 \%, \\
1 / 4 \mathrm{Watt}, \\
100 \mathrm{ppm}, \\
\text { FR=0.01\%/ } \\
\text { 1000hr }\end{array}$ & RM1206 & $\begin{array}{c}\text { Dale / } \\
\text { CRCW12069310FT }\end{array}$ \\
\hline 58 & $\overline{1}$ & $R 134$ & $\begin{array}{c}383 \Omega, 1 \% \\
1 / 4 \mathrm{Watt} \\
100 \mathrm{ppm} \\
\mathrm{FR}=0.01 \% / \\
1000 \mathrm{hr}\end{array}$ & RM1206 & $\begin{array}{c}\text { Rohm / } \\
\text { MCR12064420FT }\end{array}$ \\
\hline 59 & 2 & R137,R49 & $\begin{array}{c}178 \Omega, 1 \% \text {, } \\
1 / 4 \text { Watt, } \\
100 p p m, \\
\text { FR=0.01\%/ } \\
1000 \mathrm{hr}\end{array}$ & RM1206 & D55342K07B178DR \\
\hline
\end{tabular}




\begin{tabular}{|c|c|c|c|c|c|}
\hline Item & Qty. & Designator & Description & Case & $\begin{array}{c}\text { Mfg. / } \\
\text { Part Number }\end{array}$ \\
\hline 60 & 1 & R139 & $\begin{array}{c}20.0 \Omega, 1 \% \text {, } \\
1 / 4 \mathrm{Watt}, \\
100 \mathrm{ppm}, \\
\text { FR=0.01\% } \\
1000 \mathrm{hr} \\
19 ., 7980 \\
20,200\end{array}$ & RM1206 & D55342K07B20D0R \\
\hline 61 & 1 & T1 & $\begin{array}{c}\text { Sensor, } \\
\text { Temperature } \\
\text { 534-31AG04- } \\
562\end{array}$ & TO-52/3 & $\begin{array}{c}\text { Fenwell } \\
\text { LTN11 Type } \\
\text { 534-31AG04-562 }\end{array}$ \\
\hline 62 & 1 & U1 & $\begin{array}{l}\text { Amplifier,. } \\
\text { Operational, } \\
\text { Clamping } \\
\text { CLC501AJE }\end{array}$ & SOIC-8 & $\begin{array}{l}\text { Comlineart } \\
\text { CLC501AJE } \\
5 N \\
0 \geq 2869\end{array}$ \\
\hline 63 & $\overline{1}$ & U2 & $\begin{array}{l}\text { Receiver, } \\
\text { Line } \\
\text { Quad } \\
\text { DS34C86 }\end{array}$ & SOIC-16 & $\begin{array}{l}\text { National / } \\
\text { DS34C86M } \\
5 S_{i} 5319\end{array}$ \\
\hline 64 & 2 & U3,U27 & $\begin{array}{l}\text { Amplifier, } \\
\text { Dual, Wide } \\
\text { Band } \\
\text { LF353 }\end{array}$ & SOIC-8 & $\begin{array}{l}\text { National/ } \\
\text { LF353M } \\
5^{N}{ }_{013}^{13} 01317\end{array}$ \\
\hline 65 & 1 & U5 & $\begin{array}{l}\text { Controller, } \\
\text { CCD } \\
\text { TH7990 }\end{array}$ & JLCC-44 & $\begin{array}{l}\text { Thomson-CSF I } \\
\text { TH7990C } \\
\text { s.u } i 4\end{array}$ \\
\hline 66 & 4 & $\begin{array}{l}\text { U6,U7, } \\
\text { U12,U25 }\end{array}$ & $\begin{array}{l}\text { Driver, Line, } \\
\text { Quad } \\
\text { DS34C87 }\end{array}$ & SOIC-16 & 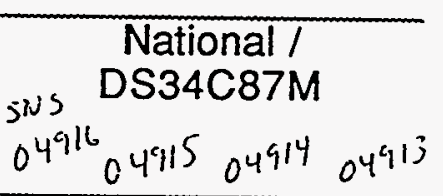 \\
\hline 67 & 1 & प8 & $\begin{array}{l}\text { Converter, } \\
\text { Analog to } \\
\text { Digital } 8 \text { bit } \\
\text { MP7684 }\end{array}$ & LCC-28 & $\begin{array}{c}\text { Micropower / } \\
\text { MP7684ATL/883 }\end{array}$ \\
\hline 68 & 4 & $\begin{array}{l}\text { U9,U10,U22 } \\
\text { U23 }\end{array}$ & $\begin{array}{l}\text { Driver, Dual } \\
\text { Inverting } \\
\text { TSC4426 }\end{array}$ & SOIC-8 & 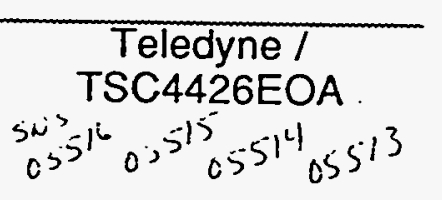 \\
\hline
\end{tabular}




\begin{tabular}{|c|c|c|c|c|c|}
\hline Item & Qty. & Designator & Description & Case & $\begin{array}{c}\text { Mfg. I } \\
\text { Part Number } \\
\end{array}$ \\
\hline 69 & 2 & U11,U30 & $\begin{array}{l}\text { Driver, } \\
\text { Differential, } \\
\text { Dual } \\
\text { TSC4428 }\end{array}$ & SOIC-8 & 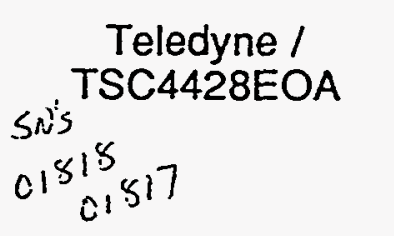 \\
\hline 70 & 1 & $\overline{\mathrm{U} 14}$ & $\begin{array}{l}\text { Amplifier, } \\
\text { Operational, } \\
\text { LF356 }\end{array}$ & SOIC-8 & $\begin{array}{l}\text { National I } \\
\text { LF356M } \\
\text { SN }{ }^{2} i 719\end{array}$ \\
\hline 71 & 2 & U17,U18 & $\begin{array}{l}\text { Regulator, } \\
\text { Voltage, } \\
\text { Adjustable } \\
\text { LM317 }\end{array}$ & SOIC-8 & $\begin{array}{l}\text { Nationall } \\
\text { LM317LM } \\
03704,03705\end{array}$ \\
\hline 72 & 1 & $\begin{array}{c}\text { U19 } \\
\text { DO NOT KIT }\end{array}$ & $\begin{array}{l}\text { Charged } \\
\text { Coupled } \\
\text { Device } \\
\text { CCD } \\
7860 \text { or } 7863\end{array}$ & DIP-20 & $\begin{array}{l}\text { Type Chosen on } \\
\text { Camera Selection }\end{array}$ \\
\hline 73 & 1 & U24 & $\begin{array}{l}\text { Amplifier, } \\
\text { Operational, } \\
\text { Clamping } \\
\text { CLC502 }\end{array}$ & SOIC-8 & $\begin{array}{l}\text { Comlinear, } \\
\text { CLC502AJE } \\
\text { sis: } \\
0.952\end{array}$ \\
\hline 74 & $\overline{1}$ & $\begin{array}{c}\text { U26 } \\
\text { DO NOT KIT }\end{array}$ & $\begin{array}{l}\text { Gate Array, } \\
\text { Field } \\
\text { Program, } \\
\text { ACT1020A }\end{array}$ & JLCC-44 & $\begin{array}{c}\text { Actel/ } \\
\text { ACT1020A-1JQ44B }\end{array}$ \\
\hline 75 & 1 & $\overline{\mathrm{U} 32}$ & $\begin{array}{l}\text { Converter, } \\
\text { Digital to } \\
\text { Analog } \\
\text { AD558TE/883 }\end{array}$ & LCC20 & $\begin{array}{c}\text { Analog Devices / } \\
\text { AD558TE/883 }\end{array}$ \\
\hline 76 & 1 & $\overline{X 1}$ & $\begin{array}{l}\text { Crystal, } \\
20 \mathrm{MHz} \\
\pm 50 p p m\end{array}$ & CXAT & $\begin{array}{l}\text { MicroCrystal/ } \\
20.000 \mathrm{MHz} \\
\text { CXAT-T2 }\end{array}$ \\
\hline 77 & 2 & U19 Socket & $\begin{array}{l}\text { Socket Strip } \\
10 \text { pin }\end{array}$ & SIP-10 & $\begin{array}{c}\text { LLNL I } \\
5975-64700\end{array}$ \\
\hline
\end{tabular}




\begin{tabular}{|c|c|c|c|c|c|}
\hline Item & Qty. & Designator & Description & Case & $\begin{array}{c}\text { Mfg. I } \\
\text { Part Number } \\
\end{array}$ \\
\hline 78 & 2 & N/A & Spacer & N/A & $\begin{array}{c}\text { AAA92-104616-OB } \\
\text { Tab-01 }\end{array}$ \\
\hline 79 & 2 & $\bar{N} / \mathrm{A}$ & $\begin{array}{l}\text { Brass CCD } \\
\text { Mounting } \\
\text { Nuts }\end{array}$ & N/A & $\begin{array}{c}\text { AAA92-109126 } \\
\text { REV } 00\end{array}$ \\
\hline 80 & 2 & N/A & $\begin{array}{c}\# 2-56 \\
\text { Stainless } \\
\text { Steel Nut }\end{array}$ & N/A & NAS671C2 \\
\hline 81 & 2 & N/A & $\begin{array}{l}\text { Washer, } \\
\text { Stainless } \\
\text { Steel, \#2 }\end{array}$ & N/A & NAS620C-2 \\
\hline 82 & 2 & TP1,TP2 & Test Points & N/A & $\begin{array}{c}\text { LLNL' } \\
5975-66833\end{array}$ \\
\hline 83 & 8 & $\begin{array}{c}4, C 7, C 8, C 82, \\
\text { C99,C100, } \\
\text { C101,C123 }\end{array}$ & $\begin{array}{c}0.1 \mu \mathrm{fd} \\
50 \text { Volt, } 10 \%\end{array}$ & $\mathrm{RC1206}$ & $\begin{array}{c}\text { Rohm / } \\
\text { CE104K3NR-T2 }\end{array}$ \\
\hline 84 & 1 & L2 & $\begin{array}{l}\text { Inductor, } \\
47 \mu \mathrm{H}\end{array}$ & LQH4 & $\begin{array}{l}\text { MuRata Erie I } \\
\text { LQH4N470K-TA }\end{array}$ \\
\hline
\end{tabular}




\section{Acte! Camera with Gain and Offset Control Startracker Configuration Rev. 00 Printed Wiring Board Bill of Materials, Rev. 00 LEA92-3128-04}

\begin{tabular}{|c|c|c|c|c|}
\hline & Date & Rev. & Date & Approval \\
\hline Prepared by: K. F. Coathey & $30 \operatorname{mar} 93$ & $O A$ & 13Apr. 193 & Wucok \\
\hline Reviewed by: W. R. Bryson & $30 \operatorname{Mar} 93$ & $O \beta$ & 16 Aor. $/ 93$ & $\omega_{\imath}<\infty$ \\
\hline Reviewed by: Q. F. Kordas & $30-A D A-73$ & & & \\
\hline Reviewed by: M.L. Dickerson & 313.193 & & & \\
\hline Reviewed by: E.H. S. Shimitt & $4 / 2 / 93$ & & & \\
\hline Reviewed by: An suldannen & $4 / 2 / 9=$ & & & \\
\hline $\begin{array}{c}\text { University of California } \\
\| \stackrel{\text { Lawrence Livermore }}{\text { National Laboratory }}\end{array}$ & $\begin{array}{l}22 \mathrm{March} \\
\text { Actel Star } \\
\text { Bill of Ma }\end{array}$ & $\begin{array}{l}1993 \\
\text { rtracker } \\
\text { aterials }\end{array}$ & $\begin{array}{r}\text { LEA92 } \\
\text { Revi }\end{array}$ & $\begin{array}{l}\text { 2-3128-04 } \\
\text { ision } 00\end{array}$ \\
\hline
\end{tabular}




\subsection{Scope}

This document is the bill of materials for the Actel Camera with Gain and Offset Control for use in the Startracker, Rev 00 Printed Wiring Board, LEA92-3128-04, Rev 00.

\subsection{Parts}

Where a dual part number listing exists, the first number listed is a commercial part suitable for prototype work only. If the MIL-SPEC part is not available at the time flight boards are assembled, Quality assurance must OK the use of the commercial part on a part by part basis in writing.

Parts may not be substituted without the written permission of the Quality Assurance Group.

\begin{tabular}{|c|c|c|c|c|c|}
\hline Item & Qty. & Designator & Description & Case & $\begin{array}{c}\text { Mfg. I } \\
\text { Part Number }\end{array}$ \\
\hline 1 & 47 & $\begin{array}{c}\text { C1,C3,C4,C5,C6, } \\
\text { C7,C8,C15,C21, } \\
\text { C23,C25,C26, } \\
\text { C30,C31,C33, } \\
\text { C34,C38,C39, } \\
\text { C40,C42,C44, } \\
\text { C45,C47,C48, } \\
\text { C54,C56,C57, } \\
\text { C58,C59,C60, } \\
\text { C63,C64,C66, } \\
\text { C67,C70,C91, } \\
\text { C92,C98,C102, } \\
\text { C103,C104,C106, } \\
\text { C109,C112,C114, } \\
\text { C121,C124 }\end{array}$ & $\begin{array}{c}0.039 \mu \mathrm{F} \\
50 \mathrm{~V}, 10 \% \\
\mathrm{FR}=0.01 \% \\
1000 \mathrm{hr}\end{array}$ & RM1206 & CDR32BХ393AKUR \\
\hline 2 & 5 & $\begin{array}{c}\mathrm{C} 2, \mathrm{C} 51, \mathrm{C} 61, \mathrm{C} 62 \\
\mathrm{C} 122\end{array}$ & $\begin{array}{c}4.7 \mu \mathrm{fd}, \text { Tant, } \\
\text { 10V, } 10 \% \text {, } \\
\text { WFR=0.01\%/ } \\
1000 \mathrm{hr} \\
\begin{array}{c}4.23 \\
5.17\end{array}\end{array}$ & H-CASE & CWR06FH475KC \\
\hline 3 & 1 & $\mathrm{Cg}$ & $\begin{array}{l}47 \mu \mathrm{fd}, \text { Tant, } \\
20 \mathrm{~V}, 10 \% \\
42.3 \\
5.7\end{array}$ & R-CASE & $\begin{array}{c}\text { Sprague / } \\
\text { 1950476X9020R2T }\end{array}$ \\
\hline
\end{tabular}




\begin{tabular}{|c|c|c|c|c|c|}
\hline Item & Qty. & Designator & Description & Case & $\begin{array}{l}\text { Mfg. / } \\
\text { Part Number }\end{array}$ \\
\hline 4 & 2 & $\mathrm{C} 10, \mathrm{C} 11$ & $\begin{array}{c}22 \mu \mathrm{fd}, \text { Tant, } \\
\text { 15V, } 10 \%, \\
\text { WFR=0.01\%/ } \\
1000 \mathrm{hr}\end{array}$ & G-CASE & CWRO6HH226KC \\
\hline 5 & 4 & $\begin{array}{c}\mathrm{C} 12, \mathrm{C} 13, \mathrm{C} 17 \\
\mathrm{C} 105\end{array}$ & $\begin{array}{c}6.8 \mu \mathrm{fd}, \text { Tant, } \\
\text { 10V, } 10 \%, \\
\text { WFR }=0.1 \% \\
1000 \mathrm{hr}\end{array}$ & E-CASE & CWR06FH685KB \\
\hline 6 & 2 & $\mathrm{C} 20, \mathrm{C} 110$ & $\begin{array}{c}6.8 \mu \mathrm{fd}, \text { Tant, } \\
20 \mathrm{~V}, 10 \% \\
\text { WFR }=0.01 \% / \\
1000 \mathrm{hr}\end{array}$ & F-CASE & CWR06JH685KC \\
\hline 7 & 6 & $\begin{array}{l}\text { C22,C24,C29, } \\
\mathrm{C} 69, \mathrm{C} 90, \mathrm{C} 118\end{array}$ & $\begin{array}{c}22 \mu \mathrm{fd}, \text { Tant, } \\
20 \mathrm{~V}, 10 \%, \\
\text { WFR=0.01\%/ } \\
1000 \mathrm{hr}\end{array}$ & H-Case & CWR06JH226KC \\
\hline 8 & 4 & $\begin{array}{c}\mathrm{C} 32, \mathrm{C} 52, \mathrm{C} 94, \\
\mathrm{C} 95\end{array}$ & $\begin{array}{c}10 \mu \mathrm{fd}, \text { Tant, } \\
25 \mathrm{~V}, 10 \%, \\
\text { WFR=0.01\%/ } \\
1000 \mathrm{hr}\end{array}$ & G-CASE & CWR06KH106KC \\
\hline 9 & 1 & C35 & $\begin{array}{l}0.22 \mu f d, \\
50 \mathrm{~V} ; 10 \%\end{array}$ & $\mathrm{RC} 1206$ & $\begin{array}{c}\text { Garrett / } \\
1206 Z 224 M 500 \mathrm{~N}\end{array}$ \\
\hline 10 & 2 & C46,C93 & $\begin{array}{c}1.0 \mu \mathrm{fd}, \text { Tant } \\
35 \mathrm{~V}, 10 \% \\
\text { WFR }=0,01 \% \\
1000 \mathrm{hr}\end{array}$ & D-CASE & CWR06MH105KC \\
\hline 11 & 2 & C49,C50 & $\begin{array}{c}0.022 \mu f d, \\
100 \mathrm{~V}, 10 \% \text {, } \\
\mathrm{FR}=0.01 \% \\
1000 \mathrm{hr}\end{array}$ & RM1206 & $\begin{array}{c}\text { Garrett / } \\
\text { CE223K3NR }\end{array}$ \\
\hline 12 & 1 & C53 & $\begin{array}{c}15 \mathrm{pf} \\
100 \mathrm{~V}, 5 \% \\
\mathrm{FR}=0.01 \% \text {, } \\
1000 \mathrm{hr}\end{array}$ & RM1206 & CDR32BP150BJUTR \\
\hline
\end{tabular}




\begin{tabular}{|c|c|c|c|c|c|}
\hline Item & Qty. & Designator & Description & Case & $\begin{array}{c}\text { Mfg. I } \\
\text { Part Number }\end{array}$ \\
\hline 13 & 5 & $\begin{array}{c}\mathrm{C} 73, \mathrm{C} 74, \mathrm{C} 75 \\
\mathrm{C} 76, \mathrm{C} 77\end{array}$ & $\begin{array}{c}3300 \mathrm{pf} \\
50 \mathrm{~V}, 10 \% \\
\text { FR=0.001\%/ } \\
1000 \mathrm{hr}\end{array}$ & $\begin{array}{l}R C 0402 \\
R C 0505\end{array}$ & $\begin{array}{c}\text { Novacap / } \\
\text { 0402B332K500N } \\
\text { CDR11BP332AKUS }\end{array}$ \\
\hline 74 & 7 & $\mathrm{C} 83$ & $\begin{array}{c}0.01 \mu \mathrm{fd}, \\
100 \mathrm{~V}, 10 \%, \\
\text { FR=0.01\% } \\
1000 \mathrm{hr}\end{array}$ & RM1206 & CDR32BX103BKUR \\
\hline 15 & 1 & C111 & $\begin{array}{c}47 \mathrm{pf} \\
100 \mathrm{~V}, 5 \% \\
\mathrm{FR}=0.01 \% / \\
1000 \mathrm{hr}\end{array}$ & RM1206 & CDR32PB470BJUR \\
\hline 16 & 2 & C115,C116 & $\begin{array}{c}270 \mathrm{pf} \\
100 \mathrm{~V}, 10 \%, \\
\text { FR=0.01\%/ } \\
1000 \mathrm{hr}\end{array}$ & RM1206 & CDR32BP271BKUR \\
\hline 17 & 1 & $\overline{\mathrm{D} 1}$ & $\begin{array}{c}\text { Diode, } \\
\text { Switching, } \\
50 \mathrm{~V}, 200 \mathrm{~mA} \\
\text { MBAV74 }\end{array}$ & SOT-23 & $\begin{array}{l}\text { Motorola / } \\
\text { MBAV74L }\end{array}$ \\
\hline 18 & 1 & D2 & $\begin{array}{c}\text { Diode, } \\
\text { Voltage } \\
\text { Reference } \\
\text { LM285-1.2 }\end{array}$ & SOIC-8 & $\begin{array}{c}\text { Linear } / \\
\text { LM285MX-1.2 }\end{array}$ \\
\hline 19 & 1 & D3 & $\begin{array}{l}\text { Reference, } \\
\text { Voltage, } \\
\text { Precision, } \\
10 \mathrm{~V}, \\
\text { REF-01 }\end{array}$ & SOIC-8 & $\begin{array}{c}\text { PMI/ } \\
\text { REF01CS }\end{array}$ \\
\hline 20 & 2 & $\mathrm{D4,D5}$ & $\begin{array}{c}\text { Diode, } \\
\text { Schottky, } 30 \mathrm{~V} \\
\text { BAT54S }\end{array}$ & SOT-23 & $\begin{array}{l}\text { Phillips I } \\
\text { BAT54S }\end{array}$ \\
\hline 21 & 9 & $\begin{array}{l}\text { JP4,JP6,JP7,JP9, } \\
\text { JP11,JP13,JP14, } \\
\text { JP15,JP16 }\end{array}$ & $\begin{array}{l}\text { Jumper, } \\
0 \Omega, 1 \%, \\
1 / 4 \text { Watt }\end{array}$ & $\mathrm{RM} 1206$ & D55342K07B00DOS \\
\hline 22 & 3 & $\overline{L 1, L 3, L 4}$ & $\begin{array}{l}\text { Inductor, } \\
100 \mu \mathrm{H}\end{array}$ & LQH4 & $\begin{array}{l}\text { MuRata Erie / } \\
\text { LQH4N101K-TA }\end{array}$ \\
\hline
\end{tabular}




\begin{tabular}{|c|c|c|c|c|c|}
\hline Item & Qty. & Designator & Description & Case & $\begin{array}{l}\text { Mig. / } \\
\text { Part Number }\end{array}$ \\
\hline 23 & 1 & $\llcorner 5$ & $\begin{array}{l}\text { Inductor, } \\
10 \mu \mathrm{H}\end{array}$ & LQH4 & $\begin{array}{l}\text { MuRata Erie / } \\
\text { LQH4N10OK-TA }\end{array}$ \\
\hline 24 & 1 & $\sqrt{1}$ & $\begin{array}{l}\text { Connector, } \\
51 \text { Contact, } \\
\text { Socket }\end{array}$ & MDM51 & M83513/04-G06N \\
\hline 25 & 5 & $\begin{array}{c}\text { Q1,Q4,Q9, } \\
\text { Q10,Q11 } \\
\text { sisi } \\
0+700,04701, .04\end{array}$ & $\begin{array}{c}\text { Transistor, } \\
\text { FET, } \\
\text { SST215 } \\
\text { S's, C4705, 04710 }\end{array}$ & SOT-143 & $\begin{array}{c}\text { Calogic / } \\
\text { No Substitute } \\
\text { Calogic No. SST215E }\end{array}$ \\
\hline 26 & 3 & 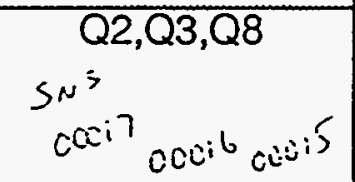 & $\begin{array}{l}\text { Transistor, } \\
\text { 2N3904 }\end{array}$ & SOT-23 & $\begin{array}{c}\text { Motorolal } \\
\text { MMBT3904 } \\
\text { No Substitute }\end{array}$ \\
\hline 27 & 3 & 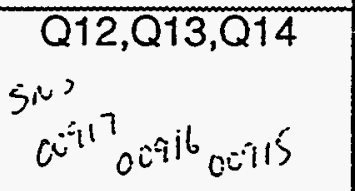 & $\begin{array}{c}\text { Transistor, } \\
\text { 2N7002 }\end{array}$ & SOT-23 & $\begin{array}{c}\text { Motorola / } \\
2 \text { N7002 } \\
\text { No Substitute }\end{array}$ \\
\hline 28 & 2 & $\overline{R 3, R 66}$ & $\begin{array}{l}7.5 \mathrm{~K} \Omega, 1 \% \\
1 / 4 \mathrm{Watt}, \\
100 \mathrm{ppm}, \\
\text { FR=0.01\%/ } \\
1000 \mathrm{hr} \\
7.425 \\
7.575 \\
\end{array}$ & $\mathrm{RM} 1206$ & D55342K07B7E50R \\
\hline 29 & 2 & R6,R7 & $\begin{array}{c}150 \Omega, 1 \%, \\
1 / 4 \mathrm{Watt}, \\
100 \mathrm{ppm}, \\
\text { FR=0.01\%/ } \\
1000 \mathrm{hr} \\
148.50 \\
151.50\end{array}$ & $\mathrm{RM} 1206$ & D55342K07B150DR \\
\hline 30 & 2 & R14,R31 & $\begin{array}{c}243 \Omega, 1 \%, \\
1 / 4 \mathrm{Watt}, \\
100 \mathrm{ppm}, \\
\mathrm{FR}=0.01 \% / \\
1000 \mathrm{hr} \\
240,57 \\
245,43 \\
\end{array}$ & RM1206 & D55342K07B243DR \\
\hline$\overline{31}$ & 2 & $R 15, R 32$ & $\begin{array}{c}1.82 \mathrm{~K} \Omega, 1 \%, \\
1 / 4 \mathrm{Watt} \\
100 \mathrm{ppm} \\
\mathrm{FR}=0.01 \% / \\
1000 \mathrm{hr} \\
1.8018 \\
1.8382\end{array}$ & RM1206 & D55342K07B1E82R \\
\hline
\end{tabular}




\begin{tabular}{|c|c|c|c|c|c|}
\hline Item & Qty. & Designator & Description & Case & $\begin{array}{l}\text { Mfg. I } \\
\text { Part Number }\end{array}$ \\
\hline 32 & 5 & $\begin{array}{l}\text { R16,R116,R130 } \\
\text { R133,R136 }\end{array}$ & $\begin{array}{c}49.9 \Omega, 1 \% \\
1 / 4 \mathrm{Watt}, \\
100 \mathrm{ppm} \\
\text { FR=0.01\% } \\
1000 \mathrm{hr}\end{array}$ & $\mathrm{RM} 1206$ & D55342K07B49D9R \\
\hline 33 & 5 & $\begin{array}{c}\text { R17,R21, } \\
\text { R74,R94,R95 }\end{array}$ & $\begin{array}{c}1.0 \mathrm{~K} \Omega, 1 \% \text {, } \\
1 / 4 \mathrm{Watt} \\
100 \mathrm{ppm}, \\
\mathrm{FR}=0.01 \% \\
1000 \mathrm{hr}\end{array}$ & RM1206 & D55342K07B1E00R \\
\hline$\overline{34}$ & 1 & $\overline{R 18}$ & $\begin{array}{c}2.49 \mathrm{~K} \Omega, 1 \% \\
1 / 4 \mathrm{Watt}, \\
100 \mathrm{ppm} \\
\mathrm{FR}=0.01 \% / \\
1000 \mathrm{hr}\end{array}$ & RM1206 & D55342K07B2E49R \\
\hline 35 & 1 & $\overline{R 20}$ & $\begin{array}{c}2.7 \mathrm{~K} \Omega, 2 \% \text {, } \\
1 / 4 \mathrm{Watt} \\
100 \mathrm{ppm}, \\
\mathrm{FR}=0.01 \% \\
1000 \mathrm{hr}\end{array}$ & RM1206 & D55342K07B2H70R \\
\hline 36 & 1 & R24 & $\begin{array}{c}1.62 \mathrm{~K} \Omega, 1 \%, \\
1 / 4 \mathrm{Watt}, \\
100 \mathrm{ppm}, \\
\mathrm{FR}=0.01 \% / \\
1000 \mathrm{hr}\end{array}$ & RM1206 & D55342K07B1E62R \\
\hline 37 & 1 & $\overline{\mathrm{R} 25}$ & $\begin{array}{c}9.09 \mathrm{~K} \Omega, 1 \% \\
1 / 4 \mathrm{Watt} \\
100 \mathrm{ppm} \\
\mathrm{FR}=0.01 \% / \\
1000 \mathrm{hr}\end{array}$ & RM1206 & D55342K07B9E09R \\
\hline 38 & 1 & $\bar{R} 26$ & $\begin{array}{c}24.3 \mathrm{~K} \Omega, 1 \% \\
1 / 4 \mathrm{Watt} \\
100 \mathrm{ppm} \\
\mathrm{FR}=0.01 \% / \\
1000 \mathrm{hr}\end{array}$ & RM1206 & D55342K07B24E3R \\
\hline
\end{tabular}




\begin{tabular}{c|c|c|c|c|c} 
Item & Qty. & Designator & Description & Case & Mfg. I \\
Dart Number
\end{tabular}




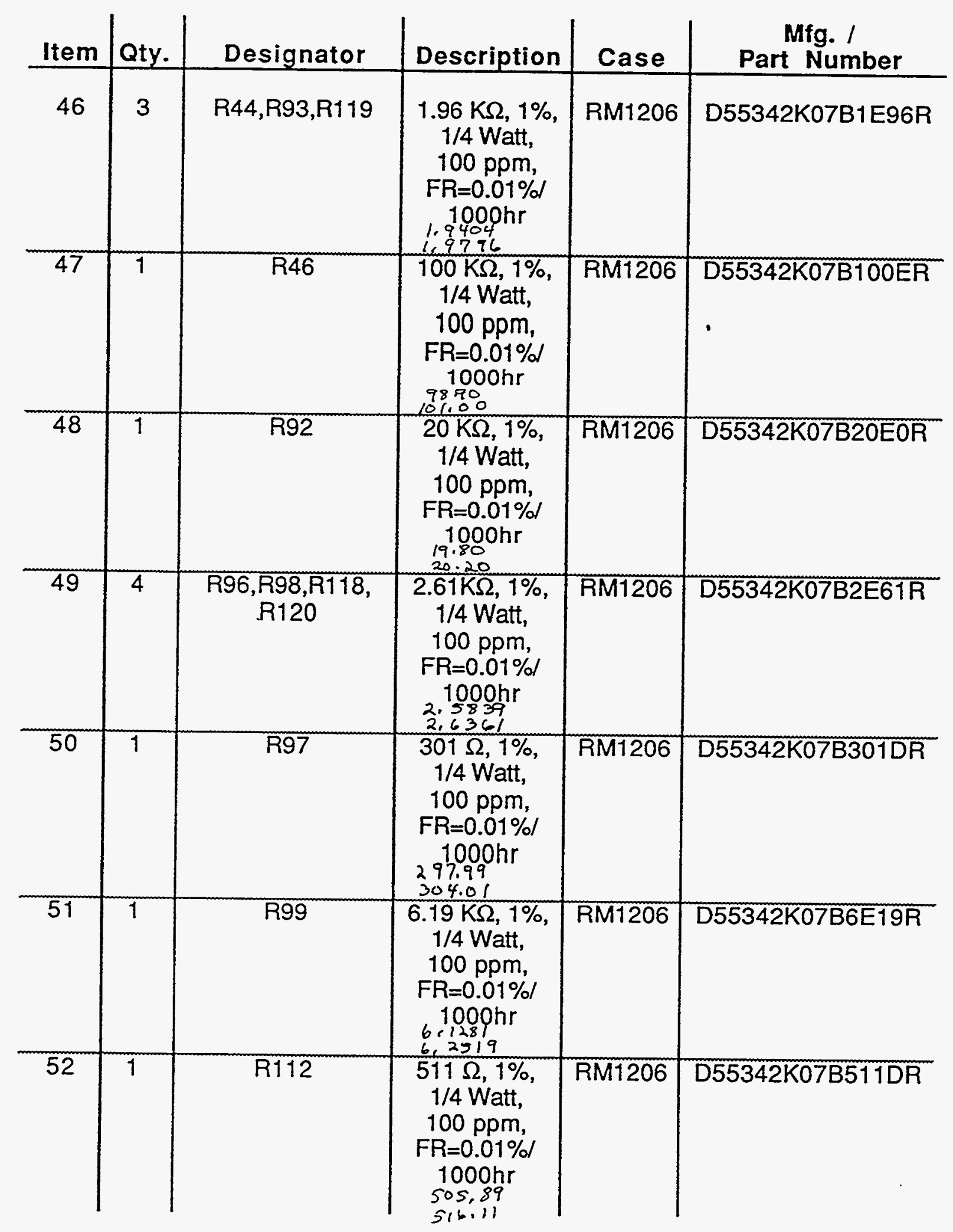




\begin{tabular}{|c|c|c|c|c|c|}
\hline Item & Qty. & Designator & Description & Case & $\begin{array}{l}\text { Mfg. I } \\
\text { Part Number }\end{array}$ \\
\hline 53 & 1 & R117 & $\begin{array}{c}40.2 \Omega, 1 \%, \\
1 / 4 \mathrm{Watt}, \\
100 \mathrm{ppm}, \\
\text { FR=0.01\% } \\
1000 \mathrm{hr} \\
39.798 \\
40.602\end{array}$ & RM1206 & D55342K07B40D2R \\
\hline 54 & 1 & R121 & $\begin{array}{l}649 \Omega, 1 \% \\
1 / 4 \mathrm{Watt}, \\
100 \mathrm{ppm}, \\
\text { FR=0.01\% } \\
1000 \mathrm{hr} \\
642,51 \\
655.49\end{array}$ & RM1206 & D55342K07B649DR \\
\hline 55 & $T$ & $\overline{\mathrm{R} 124}$ & $\begin{array}{l}5.1 \Omega 1 \%, \\
1 / 8 \mathrm{Watt} \\
5.049 \\
5.151\end{array}$ & RC1206 & $\begin{array}{c}\text { KOAI } \\
\text { RM73B2B5R1JT }\end{array}$ \\
\hline 56 & 1 & R125 & $\begin{array}{l}499 \Omega, 1 \%, \\
1 / 4 \mathrm{Watt}, \\
100 \mathrm{ppm}, \\
\mathrm{FR}=0.01 \% / \\
1000 \mathrm{hr} \\
494.06 \mathrm{~s} \\
503.99\end{array}$ & RM1206 & D55342K07B499DR \\
\hline 57 & 1 & R131 & $\begin{array}{c}931 \Omega, 1 \%, \\
1 / 4 \mathrm{Watt}, \\
100 \mathrm{ppm}, \\
\mathrm{FR}=0.01 \% / \\
1090 \mathrm{hr} \\
72,1069 \\
940,31 \\
\end{array}$ & RM1206 & $\begin{array}{c}\text { Dale / } \\
\text { CRCW12069310FT }\end{array}$ \\
\hline 58 & $\bar{T}$ & $\overline{R 134}$ & $\begin{array}{c}383 \Omega, 1 \%, \\
1 / 4 \mathrm{Watt}, \\
100 \mathrm{ppm}, \\
\mathrm{FR}=0.01 \% / \\
1000 \mathrm{hr} \\
379.17 \\
386.83\end{array}$ & RM1206 & $\begin{array}{c}\text { Rohm / } \\
\text { MCR12064420FT }\end{array}$ \\
\hline 59 & 1 & R137 & $\begin{array}{c}178 \Omega, 1 \%, \\
1 / 4 \mathrm{Watt}, \\
100 \mathrm{ppm}, \\
\mathrm{FR}=0.01 \% \\
1000 \mathrm{hr} \\
176.22 \\
179.78\end{array}$ & RM1206 & D55342K07B178DR \\
\hline
\end{tabular}




\begin{tabular}{|c|c|c|c|c|c|}
\hline Item & Qty. & Designator & Description & Case & $\begin{array}{c}\text { Mfg. I } \\
\text { Part Number }\end{array}$ \\
\hline 60 & 1 & R139 & $\begin{array}{c}20.0 \Omega, 1 \% \\
1 / 4 \mathrm{Watt}, \\
100 \mathrm{ppm}, \\
\text { FR=0.01\%/ } \\
1000 \mathrm{hr}\end{array}$ & $\mathrm{RM} 1206$ & D55342K07B20DOR \\
\hline 61 & 1 & $\mathrm{T1}$ & $\begin{array}{c}\text { Sensor, } \\
\text { Temperature } \\
\text { 534-31AG04- } \\
562\end{array}$ & TO-52/3 & $\begin{array}{c}\text { Fenwell } \\
\text { LTN11 Type } \\
\text { 534-31AG04-562 }\end{array}$ \\
\hline 62 & 1 & U1 & $\begin{array}{l}\text { Amplifier,. } \\
\text { Operational, } \\
\text { Clamping } \\
\text { CLC501AJE }\end{array}$ & SOIC-8 & $\begin{array}{l}\text { Comlinear/ } \\
\text { CLC501AJE }\end{array}$ \\
\hline 63 & 1 & U2 & $\begin{array}{c}\text { Receiver, } \\
\text { Line } \\
\text { Quad } \\
\text { DS34C86 }\end{array}$ & SOIC-16 & $\begin{array}{c}\text { National / } \\
\text { DS34C86M }\end{array}$ \\
\hline 64 & 2 & U3,U27 & $\begin{array}{c}\text { Amplifier, } \\
\text { Dual, Wide } \\
\text { Band } \\
\text { LF353 }\end{array}$ & SOIC-8 & $\begin{array}{l}\text { National I } \\
\text { LF353M }\end{array}$ \\
\hline 65 & 1 & U5 & $\begin{array}{c}\text { Controller, } \\
\text { CCD } \\
\text { TH7990 }\end{array}$ & JLCC-44 & $\begin{array}{c}\text { Thomson-CSF/ } \\
\text { TH7990C }\end{array}$ \\
\hline 66 & 4 & $\begin{array}{c}\text { U6,U7, } \\
\text { U12,U25 }\end{array}$ & $\begin{array}{c}\text { Driver, Line, } \\
\text { Quad } \\
\text { DS34C87 }\end{array}$ & SOIC-16 & $\begin{array}{c}\text { National/ } \\
\text { DS34C87M }\end{array}$ \\
\hline 67 & 1 & U8 & $\begin{array}{l}\text { Converter, } \\
\text { Analog to } \\
\text { Digital } 8 \text { bit } \\
\text { MP7684 }\end{array}$ & LCC-28 & $\begin{array}{c}\text { Micropower I } \\
\text { MP7684ATL/883 }\end{array}$ \\
\hline 68 & 4 & $\begin{array}{l}\text { U9,U10,U22 } \\
\text { U23 }\end{array}$ & $\begin{array}{l}\text { Driver, Dual } \\
\text { Inverting } \\
\text { TSC4426 }\end{array}$ & SOIC-8 & $\begin{array}{l}\text { Teledyne / } \\
\text { TSC4426EOA }\end{array}$ \\
\hline
\end{tabular}




\begin{tabular}{|c|c|c|c|c|c|}
\hline Item & Qty. & Designator & Description & Case & $\begin{array}{c}\text { Mfg. I } \\
\text { Part Number }\end{array}$ \\
\hline 69 & 2 & U11,U30 & $\begin{array}{c}\text { Driver, } \\
\text { Differential, } \\
\text { Dual } \\
\text { TSC4428 }\end{array}$ & SOIC-8 & $\begin{array}{l}\text { Teledyne / } \\
\text { TSC4428EOA }\end{array}$ \\
\hline 70 & 1 & U14 & $\begin{array}{c}\text { Amplifier, } \\
\text { Operational, } \\
\text { LF356 }\end{array}$ & SOIC-8 & $\begin{array}{l}\text { National' } \\
\text { LF356M }\end{array}$ \\
\hline 71 & 2 & U17,U18 & $\begin{array}{l}\text { Regulator, } \\
\text { Voltage, } \\
\text { Adjustable } \\
\text { LM317 }\end{array}$ & SOIC-8 & $\begin{array}{l}\text { National/ } \\
\text { LM317LM }\end{array}$ \\
\hline 72 & 1 & $\begin{array}{c}\text { U19 } \\
\text { DO NOT KIT }\end{array}$ & \begin{tabular}{|c|} 
Charged \\
Coupled \\
Device \\
CCD \\
7860 or7863
\end{tabular} & DIP-20 & $\begin{array}{l}\text { Type Chosen on } \\
\text { Camera Selection }\end{array}$ \\
\hline 73 & 1 & U24 & $\begin{array}{l}\text { Amplifier, } \\
\text { Operational, } \\
\text { Clamping } \\
\text { CLC502 }\end{array}$ & SOIC-8 & $\begin{array}{l}\text { Comlinear, } \\
\text { CLC502AJE }\end{array}$ \\
\hline 74 & 1 & $\begin{array}{c}\text { U26 } \\
\text { DO NOT KIT }\end{array}$ & $\begin{array}{l}\text { Gate Array, } \\
\text { Field } \\
\text { Program, } \\
\text { ACT1020A }\end{array}$ & JLCC-44 & $\begin{array}{c}\text { Actel/ } \\
\text { ACT1020A-1JQ44B }\end{array}$ \\
\hline 75 & 1 & $\mathrm{U} 32$ & \begin{tabular}{|c|} 
Converter, \\
Digital to \\
Analog \\
AD558TE/883
\end{tabular} & LCC20 & $\begin{array}{l}\text { Analog Devices / } \\
\text { AD558TE/883 }\end{array}$ \\
\hline 76 & 1 & $\overline{X 1}$ & $\begin{array}{l}\text { Crystal, } \\
20 \mathrm{MHz} \\
\pm 50 \mathrm{ppm}\end{array}$ & CXAT & $\begin{array}{l}\text { Microcrystal/ } \\
20.000 \mathrm{MHz} \\
\text { CXAT-T2 }\end{array}$ \\
\hline 77 & 2 & U19 Socket & $\begin{array}{l}\text { Socket Strip } \\
10 \text { pin }\end{array}$ & SIP-10 & $\begin{array}{c}\text { LLNLLI } \\
5975-64700\end{array}$ \\
\hline
\end{tabular}




\begin{tabular}{|c|c|c|c|c|c|}
\hline Item & Qty. & Designator & Description & Case & $\begin{array}{c}\text { Mfg. I } \\
\text { Part Number }\end{array}$ \\
\hline 78 & 2 & N/A & Spacer & N/A & $\begin{array}{c}\text { AAA92-104616-OB } \\
\text { Tab-01 }\end{array}$ \\
\hline 79 & 2 & $\mathrm{~N} / \mathrm{A}$ & $\begin{array}{l}\text { Brass CCD } \\
\text { Mounting } \\
\text { Nuts }\end{array}$ & $\overline{N / A}$ & $\begin{array}{l}\text { AAA92-109126 } \\
\text { REV } 00\end{array}$ \\
\hline 80 & 2 & N/A & $\begin{array}{c}\# 2-56 \\
\text { Stainless } \\
\text { Steel Nut }\end{array}$ & N/A & NAS671C2 \\
\hline 81 & 2 & N/A & $\begin{array}{l}\text { Washer, } \\
\text { Stainless } \\
\text { Steel, \#2 }\end{array}$ & N/A & NAS620C-2 \\
\hline 82 & 2 & TP1,TP2 & Test Points & N/A & $\begin{array}{c}\text { LLNL / } \\
5975-66833\end{array}$ \\
\hline 83 & 5 & $\begin{array}{c}\text { C82,C99,C100, } \\
\text { C101,C123 }\end{array}$ & $\begin{array}{c}0.1 \mu \mathrm{fd}, \\
50 \text { Volt, } 10 \%\end{array}$ & RC1206 & $\begin{array}{c}\text { Rohm / } \\
\text { CE104K3NR-T2 }\end{array}$ \\
\hline 84 & 1 & R49 & $\begin{array}{c}200 \Omega, 5 \%, \\
1 / 4 \text { Watt, } \\
100 \mathrm{ppm}, \\
\mathrm{FR}=0,01 \% / \\
1000 \mathrm{hr}\end{array}$ & RM1206 & D55342K07B200JR \\
\hline 85 & 1 & L2 & $\begin{array}{l}\text { Inductor, } \\
47 \mu \mathrm{H}\end{array}$ & LQH4 & $\begin{array}{c}\text { MuRata Erie / } \\
\text { LQH4N470K-TA }\end{array}$ \\
\hline
\end{tabular}


Appendix H.2.4

Assembly Procedures 


\section{Assembly Procedure for ACTEL Camera with Gain and Offset Control, StarTracker Configuration}

Address: 1

\begin{tabular}{|l|l||l|l|l|}
\hline & Date: & Rev.: & Date: & Approval: \\
\hline Prepared by: W. R. Bryson & & & & \\
\hline Reviewed by: M. L. Dickerson & & & & \\
\hline Reviewed by: J.F. Kordas & & & & \\
\hline Reviewed by: R. E. Priest & & & & \\
\hline Reviewed by: E.H. Schmitt & & & & \\
\hline Approved by: M.J. Shannon & & & & \\
\hline
\end{tabular}

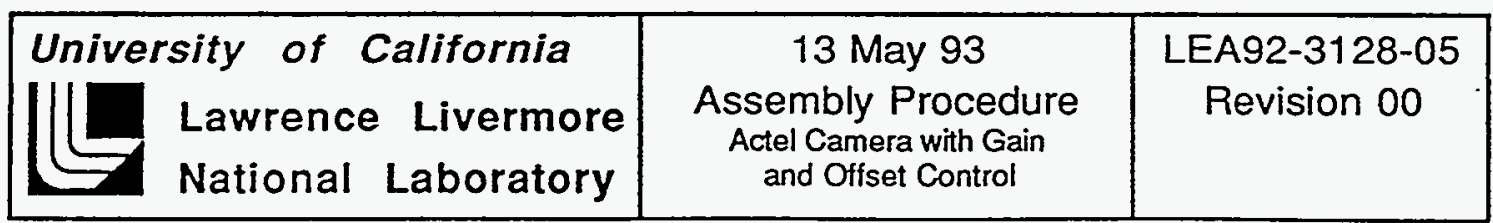




\subsection{Scope}

This document describes the assembly procedure for the Actel Camera with Gain and Offset Control, StarTracker Configuration, Rev 00 printed wiring board. This procedure has been written for hand assembly, workmanship standards shall be MIL-STD-2000.

\subsection{Required and Related Documents and General Notes}

2.1 Required documents:

Bill of Materials, LEA92-3128-04 Actel Camera with Gain and Offset Control, StarTracker Configuration, Rev 00 Printed Wiring Board

Assembly Drawing, LEA92-3128-03 Actel Camera with Gain and Offset Control, StarTracker Configuration, Rev 00 Printed Wiring Assembly

Adhesive Compounds and Optical Couplets, C1-S0-005

Preparation of Gold Plated Leads, C1-EE-023

Polyimide Based Printed Wiring Board Conditioning Methods, C1-EE-029

2.2 Related documents:

MIL-STD-1686A

Clementine Quality Assurance Program Plan, C1-S0-007

Clementine Sensor Suite Waiver Procedure, C1-S0-006

Clementine Failure Reporting, Analysis and Corrective Action System, C1-EE-0021

\subsection{General Notes}

1) All measuring devices used during the assembly of the Actel Camera board with Gain and Offset Control must be in current calibration. The calibration expiration date must be far enough in the future to allow completion of this assembly.

2) Printed wiring boards are to be stored in an airtight, antistatic bag with a desiccant at all times the board is not being loaded, cleaned, inspected or baked.

3) Clean and inspect, followed by printed wiring board bake are inserted at recommended locations. More or less components may be installed between clean and inspect points at the discretion of the QAG. It is mandatory that the printed wiring board is baked after solvent cleaning operations prior to continued solder assembly. 


\subsection{Visual Inspection}

3.1 The printed wiring board shall have been inspected by the Quality Assurance Group (QAG) prior to loading. Record inspectors name both below and in the certification log work sheets by paragraph number.
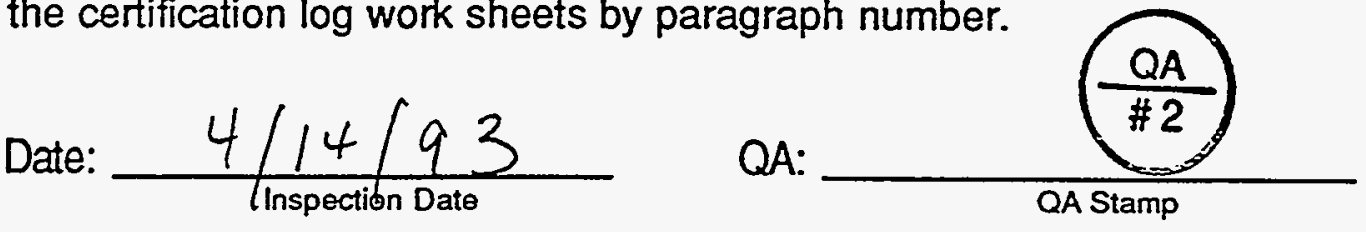

3.2 Record the manufacturer, serial number and manufactures lot code of the printed wiring board to be used in this assembly. Record both below and in the certification log work sheets by paragraph number.
Manufacturer Ploneer Circuits Inc.
Serial \#: $104-010$ Lot Code:
6862

3.3 Mount the printed wiring board in an Actel Camera printed wiring board carrier.

\subsection{Printed Wiring Board Bake Out}

4.1 The printed wiring board shall be baked at $130 \pm 5^{\circ} \mathrm{C}$ for a minimum of 6 hours prior to loading, per Polyimide Based Printed Wiring Board Conditioning Methods, C1-EE-029. Prior to baking the printed wiring board, verify that the oven to be used is in current calibration and has been verified by the QAG. The start and end times along with the start and end temperatures shall be recorded. The oven temperature profile shall be recorded, using a strip chart recorder, for the duration of the bake out. Record the date, assembly, serial number, assembly step and operator on the chart and insert in the certification section of the assembly log. The make, model and serial number of the oven used for bake out shall be recorded. Record both below and in the certification log work sheets by paragraph number.

Oven Calibration and Certification Current:

Start Time:

$7: 00$ p.m

Start Temp:

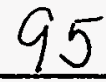

Oven Make: Versa Teka II

Oven Serial \#: $12664-1$

Date:

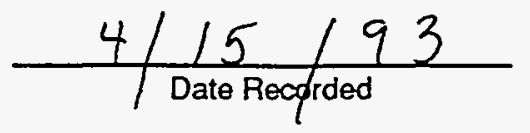

End Time: $1: 00$ p.m ${ }^{\circ} \mathrm{C} \quad$ End Temp: 95 ${ }^{\circ} \mathrm{C}$ Oven Model: $T H J R$

Operator:

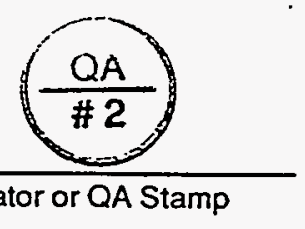


Note: Printed wiring boards are to be stored in an aitight, antistatic bag with a desiccant at all times the board is not being loaded, cleaned, inspected, tested or baked.

\subsection{Parts Verification}

5.1 Verify that all measuring devices to be used in $\mathbf{5 . 2}$ are in current calibration. Record both here and in the Assembly Log work sheets.

$$
\begin{aligned}
& \text { Equipment is in current calibration. Operator: }
\end{aligned}
$$

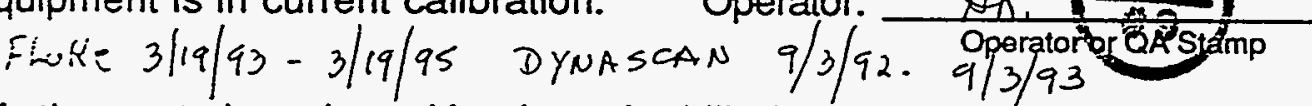

5.2 Verify that parts have been kitted per the bill of materials, LEA92-3128-04. This includes verification that all resistors and capacitors are within proper tolerance as specified in the bill of materials. Record both below and in the certification log work sheets by paragraph number.

Date:

$$
\frac{1}{\text { Date Verified } 16,1993}
$$

Operator:

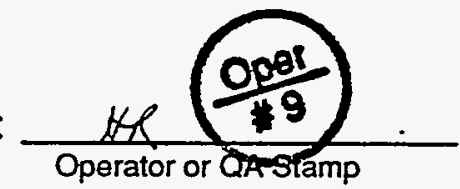

\subsection{Resistance Measurements}

6.1 Resistance measurements are to be made at $\mathrm{J} 1$ prior to assembly. Make and record the measurements as indicated in table 1 . All readings must be greater than $10 \mathrm{Meg}$ ohms, except where noted. See figure 1 below for the location of pins in $\mathrm{J1}$.

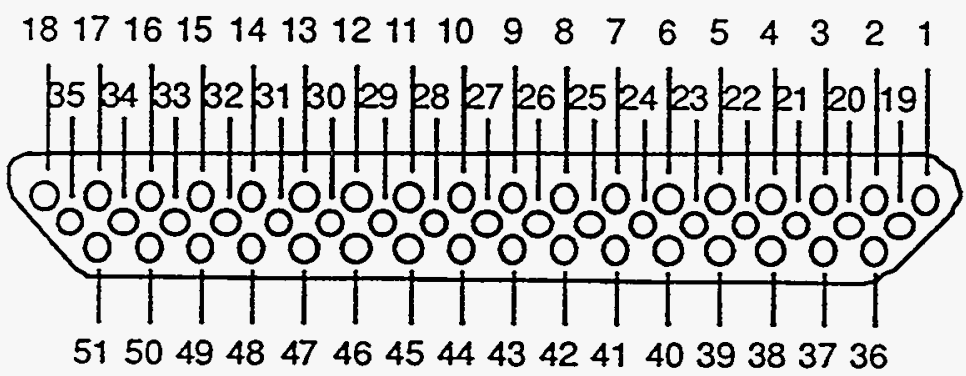

MDM 51 Contact Connector. Face View of Socket Insert.

Figure 1. 


\begin{tabular}{|l|l|l|l|l|}
\hline $\begin{array}{c}\text { Meter } \\
\text { Common }\end{array}$ & Signal & $\begin{array}{c}\text { Meter } \\
\text { Signal }\end{array}$ & Signal & Actual \\
\hline \hline$J 1-5$ & AGND & $J 1-39$ & $+15 V D C$ & 0.4 \\
\hline$J 1-5$ & AGND & $J 1-4$ & $-15 V D C$ & $0 . L$ \\
\hline$J 1-5$ & AGND & $J 1-37$ & $+5 V D C$ & $0 . L$ \\
\hline$J 1-5$ & AGND & $J 1-3$ & $-5 V D C$ & $0 . L$ \\
\hline$J 1-5$ & AGND & $J 1-40$ & $+5 V I N$ & $0 . L$ \\
\hline$J 1-5$ & AGND & $J 1-20$ & DGND & $0 . L$ \\
\hline$J 1-20$ & DGND & $J 1-39$ & $+15 V D C$ & $0 . L$ \\
\hline$J 1-20$ & DGND & $J 1-4$ & $-15 V D C$ & $0 . L$ \\
\hline$J 1-20$ & DGND & $J 1-37$ & $+5 V D C$ & $0 . L$ \\
\hline$J 1-20$ & DGND & $J 1-3$ & $-5 V D C$ & $0 . L$ \\
\hline$J 1-20$ & DGND & $J 1-40$ & $+5 V I N$ & $0 . L$ \\
\hline$J 1-39$ & $+15 V D C$ & $J 1-4$ & $-15 V D C$ & $0 . L$ \\
\hline$J 1-39$ & $+15 V D C$ & $J 1-37$ & $+5 V D C$ & $0 . L$ \\
\hline$J 1-39$ & $+15 V D C$ & $J 1-3$ & $-5 V D C$ & $0 . L$ \\
\hline$J 1-39$ & $+15 V D C$ & $J 1-40$ & $+5 V I N$ & $0 . L$ \\
\hline$J 1-4$ & $-15 V D C$ & $J 1-37$ & $+5 V D C$ & $0 . L$ \\
\hline$J 1-4$ & $-15 V D C$ & $J 1-3$ & $-5 V D C$ & $0 . L$ \\
\hline$J 1-4$ & $-15 V D C$ & $J 1-40$ & $+5 V I N$ & $0 . L$ \\
\hline$J 1-37$ & $+5 V D C$ & $J 1-3$ & $-5 V D C$ & $0 . L$ \\
\hline$J 1-37$ & $+5 V D C$ & $J 1-40$ & $+5 V I N$ & $0 . L$ \\
\hline$J 1-3$ & $-5 V D C$ & $J 1-40$ & $+5 V I N$ & $0 . L$ \\
\hline
\end{tabular}

Table 1. 


\subsection{Detailed assembly}

7.1 Installation of item 79, brass CCD mounting nuts, AAA92-109126-00.

7.1.1 Insert item 79 from the secondary side of the printed wiring board as shown in figure 2 below.

\section{Secondary Side View}

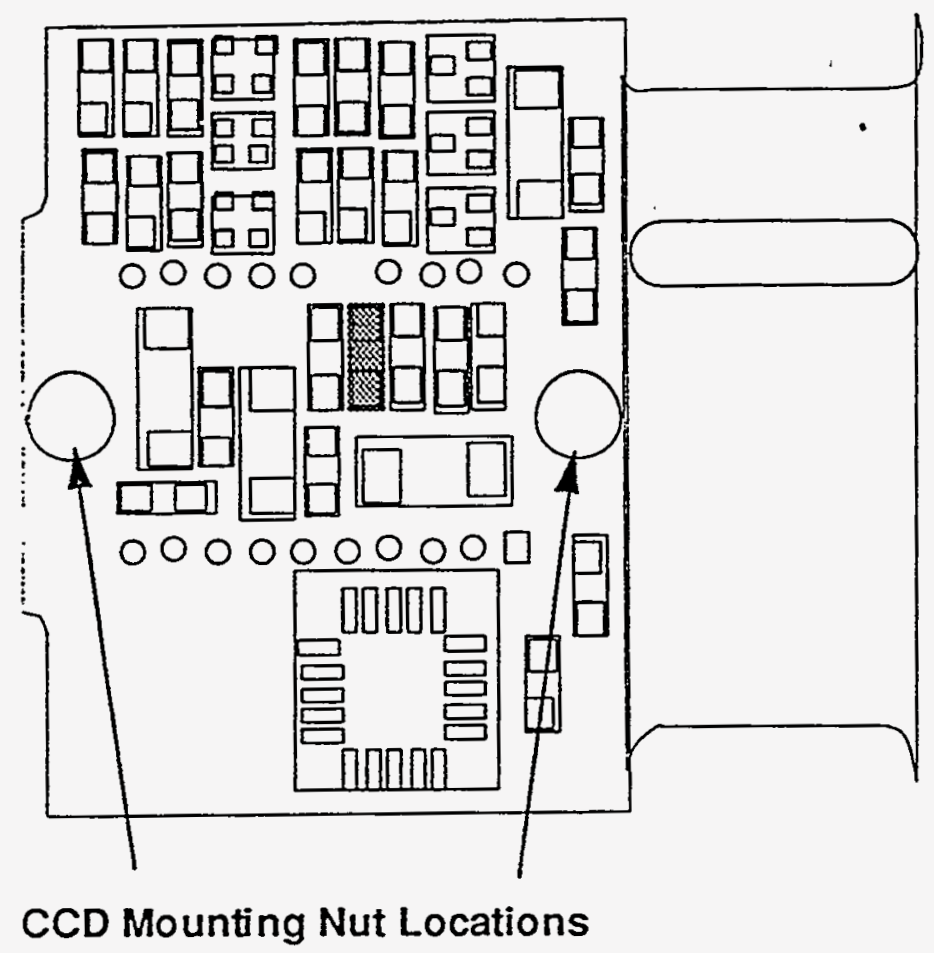

Figure 2.

7.1.2 Verify that the flange on the CCD nut is flush with the surface of the printed wiring board.

7.1.3 Solder the CCD mounting nuts in place.

Note: Use caution to prevent solder from entering the threaded area of the CCD nut. 


\subsection{Detailed assembly}

7.1 Installation of item 79, brass CCD mounting nuts, AAA92-109126-00.

7.1.1 Insert item 79 from the secondary side of the printed wiring board as shown in figure 2 below.

\section{Secondary Side View}

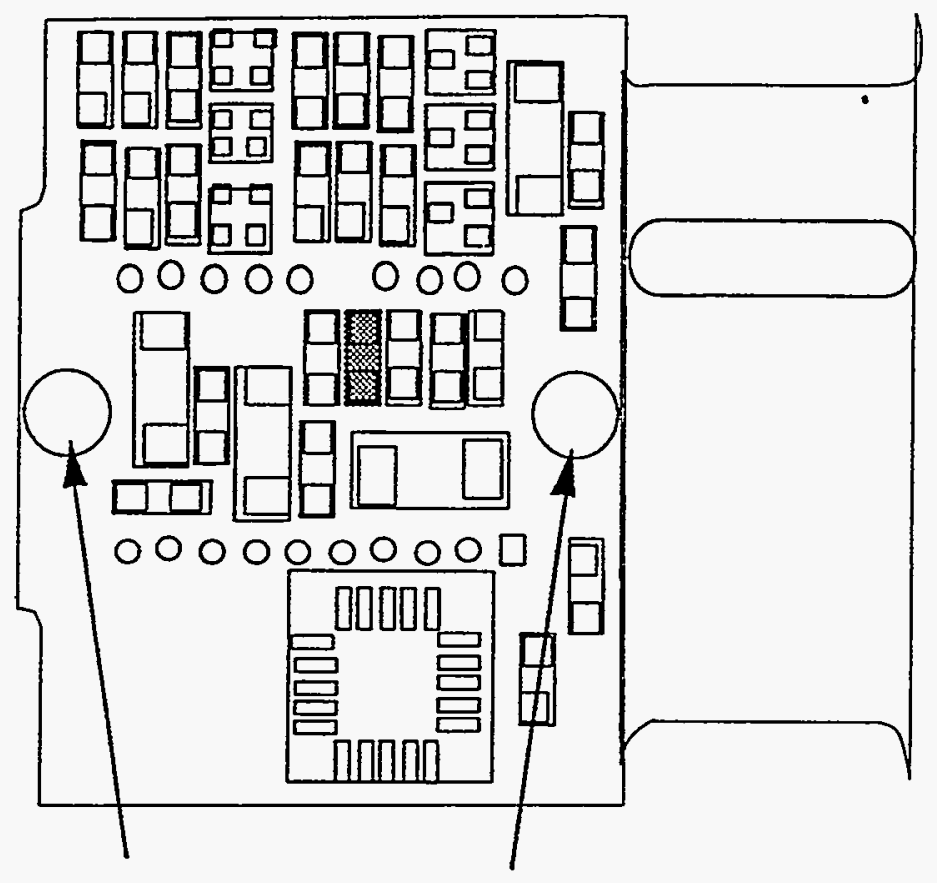

CCD Mounting Nut Locations

Figure 2.

7.1.2 Verify that the flange on the CCD nut is flush with the surface of the printed wiring board.

7.1.3 Solder the CCD mounting nuts in place.

Note: Use caution to prevent solder from entering the threaded area of the CCD nut.

7.2 Install the items listed in the table 2 below: 
7.2 Install the items listed in the table 2 below:

\begin{tabular}{|c|c|c|c|c|}
\hline Item & Qty & Designator & Description & Case \\
\hline 1 & 44 & $\begin{array}{c}\mathrm{C} 1, \mathrm{C} 3, \mathrm{C} 5, \mathrm{C} 6, \mathrm{C} 15, \mathrm{C} 21, \\
\mathrm{C} 23, \mathrm{C} 25, \mathrm{C} 26, \\
\mathrm{C} 30, \mathrm{C} 31, \mathrm{C} 33, \mathrm{C} 34, \mathrm{C} 38, \\
\mathrm{C} 39, \mathrm{C} 40, \mathrm{C} 42, \mathrm{C} 44, \mathrm{C} 45, \\
\mathrm{C} 47, \mathrm{C} 48, \mathrm{C} 54, \mathrm{C} 56, \mathrm{C} 57, \\
\mathrm{C} 58, \mathrm{C} 59, \mathrm{C} 60, \mathrm{C} 63, \mathrm{C} 64, \\
\mathrm{C} 66, \mathrm{C} 67, \mathrm{C} 70, \mathrm{C} 91, \mathrm{C} 92, \\
\mathrm{C} 98, \mathrm{C} 102, \mathrm{C} 103, \mathrm{C} 104, \\
\mathrm{C} 106, \mathrm{C} 109, \mathrm{C} 112, \mathrm{C} 114, \\
\mathrm{C} 121, \mathrm{C} 124\end{array}$ & $\begin{array}{l}0.039 \mu \mathrm{F} \\
100 \mathrm{~V}, 10 \%\end{array}$ & RM1206 \\
\hline 9 & 1 & C35 & $\begin{array}{l}0.22 \mu f d \\
50 \mathrm{~V}, 10 \%\end{array}$ & RM1206 \\
\hline 11 & 2 & $\mathrm{C} 49, \mathrm{C} 50$ & $\begin{array}{l}0.022 \mu \mathrm{fd} \\
100 \mathrm{~V}, 10 \%\end{array}$ & $\mathrm{RM} 1206$ \\
\hline 12 & 1 & $\mathrm{C53}$ & $\begin{array}{c}15 \mathrm{pf} \\
100 \mathrm{~V}, 5 \%\end{array}$ & RM1206 \\
\hline 13 & 5 & C73,C74,C75,C76,C77 & $\begin{array}{l}3300 \mathrm{pf}, \\
50 \mathrm{~V}, 10 \%\end{array}$ & $\begin{array}{l}\mathrm{RC} 0402 \\
\mathrm{RC} 0505\end{array}$ \\
\hline 14 & 1 & $\mathrm{C} 83$ & $\begin{array}{c}0.01 \mu \mathrm{fd} \\
100 \mathrm{~V}, 10 \%\end{array}$ & RM1206 \\
\hline 15 & 1 & $\mathrm{C} 111$ & $\begin{array}{c}47 \mathrm{pf} \\
100 \mathrm{~V}, 5 \%\end{array}$ & RM1206 \\
\hline 16 & 2 & $\mathrm{C} 115, \mathrm{C} 116$ & $\begin{array}{c}270 \mathrm{pf} \\
100 \mathrm{~V}, 10 \%\end{array}$ & RM1206 \\
\hline 83 & 8 & $\begin{array}{c}\text { C4,C7,C8,C82,C99, } \\
\text { C100, C101,C123 }\end{array}$ & $\begin{array}{c}0.1 \mu \mathrm{fd}, \\
50 \text { Volt, } 10 \%\end{array}$ & RC1206 \\
\hline 28 & 2 & R3,R66 & $7.5 \mathrm{~K} \Omega, 1 \%$ & RM1206 \\
\hline 30 & 2 & R14,R31 & $243 \Omega, 1 \%$ & RM1206 \\
\hline 31 & 2 & $\mathrm{R} 15, \mathrm{R} 32$ & $1.82 \mathrm{~K} \Omega, 1 \%$ & RM1206 \\
\hline
\end{tabular}

Table 2. 


\begin{tabular}{|c|c|c|c|c|}
\hline Item & Qty & Designator & Description & Case \\
\hline 1 & 47 & 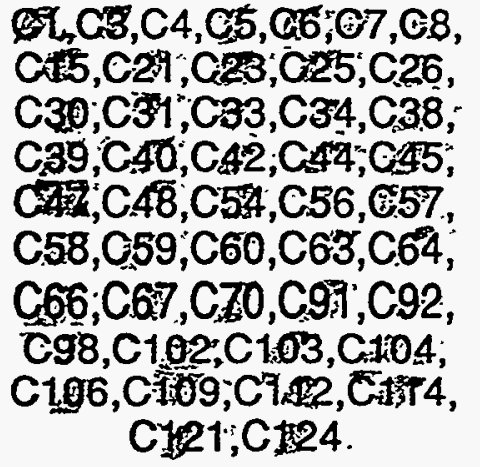 & $\begin{array}{l}0.039 \mu \mathrm{F}, \\
100 \mathrm{~V}, 10 \%\end{array}$ & RM1206 \\
\hline 9 & 1 & $\mathrm{C} 35^{-3}$ & $\begin{array}{c}0.22 \mu \mathrm{fd} \\
50 \mathrm{~V}, 10 \%\end{array}$ & RM1206 \\
\hline 11 & 2 & $\mathrm{C} 49, \mathrm{C} 50^{\circ}$ & $\begin{array}{l}0.022 \mu \mathrm{fd} \\
100 \mathrm{~V}, 10 \%\end{array}$ & $\overline{R M 1206}$ \\
\hline 12 & 1 & C53 & $\begin{array}{c}15 \mathrm{pf} \\
100 \mathrm{~V}, 5 \%\end{array}$ & RM1206 \\
\hline 13 & 5 & $\mathrm{C} 73, \mathrm{C} 74, \mathrm{C} 75, \mathrm{C76,C77}$ & $\begin{array}{l}3300 \mathrm{pf} \\
50 \mathrm{~V}, 10 \%\end{array}$ & $\begin{array}{l}\text { RC0402 } \\
\text { RC0505 }\end{array}$ \\
\hline 14 & 1 & $\mathrm{C} 83^{\circ}$ & $\begin{array}{c}0.01 \mu \mathrm{fd}, \\
100 \mathrm{~V}, 10 \%\end{array}$ & RM1206 \\
\hline 15 & 1 & C111: & $\begin{array}{c}47 \mathrm{pf} \\
100 \mathrm{~V}, 5 \%\end{array}$ & RM1206 \\
\hline 16 & 2 & C115,C116: & $\begin{array}{c}270 \mathrm{pf} \\
100 \mathrm{~V}, 10 \%\end{array}$ & RM1206 \\
\hline $\begin{array}{r}83 \\
\text { s }\end{array}$ & 5 & $\begin{array}{l}\mathrm{C} 82, \mathrm{C} 99, \mathrm{C} 100 \\
\text { C101,C123: }\end{array}$ & $\begin{array}{c}0.1 \mu \mathrm{fd} \\
50 \text { Volt, } 10 \%\end{array}$ & $\overline{\mathrm{RC} 1206}$ \\
\hline 28 & 2 & R3,R66 & $7.5 \mathrm{~K} \Omega, 1 \%$ & RM1206 \\
\hline 29 & 2 & R6,R7: & $150 \Omega, 1 \%$ & RM1206 \\
\hline 30 & 2 & R14,R31: & $243 \Omega, 1 \%$ & RM1206 \\
\hline $31^{\circ}$ & 2 & R15;R32: & $1.82 \mathrm{~K} \Omega, 1 \%$ & RM1206 \\
\hline
\end{tabular}

Table 2. 
7.3 Clean and inspect all solder joints per MIL-STD-2000. Rework any substandard solder joints. Record inspection both here and in the certification log worksheets.

Date:

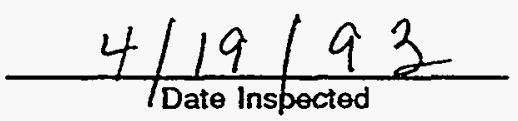

QA:$$
\text { ( } \frac{\mathrm{QA}}{\# 2}
$$

QA Stamp

7.4 The printed wiring board shall be baked at $130 \pm 5^{\circ} \mathrm{C}$ for a minimum of 6 hours prior to loading, per Polyimide Based Printed Wiring Board Conditioning Methods, C1-EE-029. Prior to baking the printed wiring board, verity that the oven to be used is in current calibration and has been verified by the QAG. The start and end times along with the start and end temperatures shall be recorded. The oven temperature profile shall be recorded, using a strip chart recorder, for the duration of the bake out. Record the date, assembly, serial number, assembly step and operator on the chart and insert in the certification section of the assembly log. The make, model and serial number of the oven used for bake out shall be recorded. Record both below and in the certification log work sheets by paragraph number.

Calibration and Certification Current, Initial:

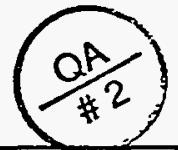

Operator or QA Stamp

Start Time:

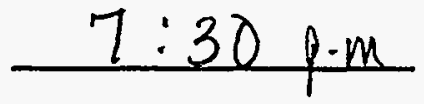

End Time:

$1: 30$ A.M

Start Temp:

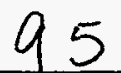
${ }^{\circ} \mathrm{C}$

End Temp:

95 ${ }^{\circ} \mathrm{C}$

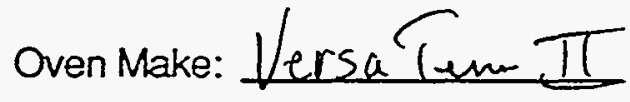

Oven Model:

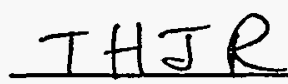

Oven Serial \#: $12664-1$

Date:
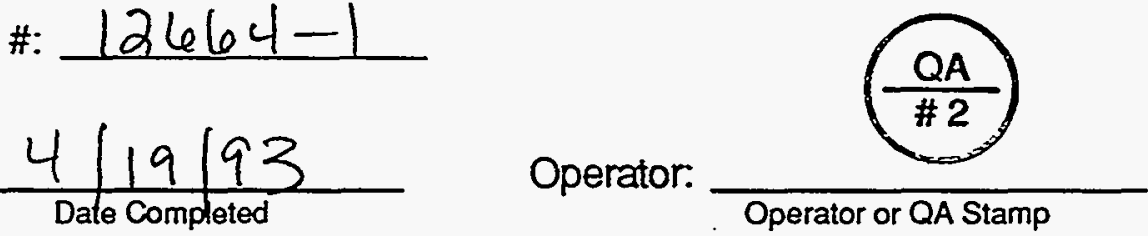

Note: Printed wiring boards are to be stored in an airtight, antistatic bag with a desiccant at all times the board is not being loaded, cleaned, inspected, tested or baked. 
7.5 Install the items listed in tables $3 a$ and $3 b$ below.

\begin{tabular}{|c|c|c|c|c|}
\hline Item & Qty & Designator & Description & Case \\
\hline 32 & 5 & $\begin{array}{l}\text { R16,R116,R130, } \\
\text { R133,R136 }\end{array}$ & $49.9 \Omega, 1 \%$ & RM1206 \\
\hline$\overline{33}$ & 5 & $\mathrm{R} 17, \mathrm{R} 21, \mathrm{R} 74, \mathrm{R} 94, \mathrm{R} 95$ & $1.0 \mathrm{~K} \Omega, 1 \%$ & RM1206 \\
\hline 34 & 1 & R18 & $2.49 \mathrm{~K} \Omega, 1 \%$ & RM1206 \\
\hline 35 & 1 & $\mathrm{R} 20$ & $2.7 \mathrm{~K} \Omega, 5 \%$ & RM1206 \\
\hline 36 & 1 & R24 & $1.62 \mathrm{~K} \Omega, 1 \%$ & RM1206 \\
\hline 37 & 1 & $\mathrm{R} 25$ & $9.09 \mathrm{~K} \Omega, 1 \%$ & RM1206 \\
\hline 38 & 1 & R26 & $24.3 \mathrm{~K} \Omega, 1 \%$ & RM1206 \\
\hline 39 & 1 & R27 & $7.68 \mathrm{~K} \Omega, 1 \%$ & RM1206 \\
\hline 40 & 2 & $\mathrm{R} 28, \mathrm{R} 91$ & $0 \Omega, 1 \%$ & RM1206 \\
\hline 41 & 9 & $\begin{array}{c}\text { R29,R48,R101,R102,R129, } \\
\text { R132,R135,R140,R141 }\end{array}$ & $10 \mathrm{~K} \Omega, 1 \%$ & RM1206 \\
\hline 42 & 1 & $\mathrm{R} 30$ & $2.15 \mathrm{~K} \Omega, 1 \%$ & RM1206 \\
\hline 43 & $\overline{3}$ & R37,R115, R122 & $100 \Omega, 1 \%$ & $\mathrm{RM} 1206$ \\
\hline 44 & 1 & R38 & $3.01 \mathrm{~K} \Omega, 1 \%$ & $\mathrm{RM} 1206$ \\
\hline 45 & 2 & R42,R43 & $30 \Omega, 2 \%$ & $\overline{R M 1206}$ \\
\hline 46 & 2 & R44,R93 & $1.96 \mathrm{~K} \Omega, 1 \%$ & RM1206 \\
\hline 47 & 1 & R46 & $100 \mathrm{~K} \Omega, 1 \%$ & RM1206 \\
\hline 48 & 1 & R92 & $20 \mathrm{~K} \Omega, 1 \%$ & RM1206 \\
\hline 49 & 4 & $\mathrm{R} 96, \mathrm{R} 98, \mathrm{R} 118, \mathrm{R} 120$ & $2.61 \mathrm{~K} \Omega, 1 \%$ & RM1206 \\
\hline 50 & 1 & R97 & $301 \Omega, 1 \%$ & RM1206 \\
\hline
\end{tabular}

Table 3a. 
7.5 Install the items listed in tables $3 a$ and $3 b$ below.

\begin{tabular}{|c|c|c|c|c|}
\hline Item & Qty & Designator & Description & Case \\
\hline 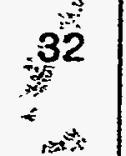 & 5 & $\begin{array}{l}\text { R16,R116;R130, } \\
\text { R133,R136 }\end{array}$ & $49.9 \Omega, 1 \%$ & RM1206 \\
\hline $\begin{array}{l}33 \\
33 \\
y_{x}\end{array}$ & 5 & R17;R21,R74,R94,R95 & $1.0 \mathrm{~K} \Omega, 1 \%$ & RM1206 \\
\hline $\begin{array}{l}3.4 \\
2 \\
\end{array}$ & 1 & R18 & $2.49 \mathrm{~K} \Omega, 1 \%$ & RM1206 \\
\hline $\begin{array}{c}35 \\
0 \\
\end{array}$ & 1 & R20. & $2.7 \mathrm{~K} \Omega, 5 \%$ & RM1206 \\
\hline $\begin{array}{r}36 \\
\because \% \\
\end{array}$ & 1 & $\mathrm{R} 24$. & $1.62 \mathrm{~K} \Omega, 1 \%$ & RM1206 \\
\hline $\begin{array}{l}37 \\
3 \\
3\end{array}$ & 1 & R25: & $9.09 \mathrm{~K} \Omega, 1 \%$ & RM1206 \\
\hline 38 & 1 & $\mathrm{R} 26$ & $24.3 \mathrm{~K} \Omega, 1 \%$ & RM1206 \\
\hline 39 & 1 & R27 & $7.68 \mathrm{~K} \Omega, 1 \%$ & RM1206 \\
\hline 40 & 2 & R28,R91 & $0 \Omega, 1 \%$ & RM1206 \\
\hline 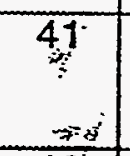 & 9 & $\begin{array}{l}\text { R29,R48,R101;R102,R129, } \\
\text { R132,R135,R140,R141: }\end{array}$ & $10 \mathrm{~K} \Omega, 1 \%$ & RM1206 \\
\hline 42 & 1 & R30. & $2.15 \mathrm{~K} \Omega, 1 \%$ & RM1206 \\
\hline 43 & 4 & R37,R115, R122;R128 & $100 \Omega, 1 \%$ & RM1206 \\
\hline 44 & 1 & R38 & $3.01 \mathrm{~K} \Omega, 1 \%$ & RM1206 \\
\hline $\begin{array}{r}45 \\
+\quad 3 \\
\end{array}$ & 2 & R42,R43 & $30 \Omega, 2 \%$ & RM1206 \\
\hline 46 & 3 & R44,R93,R119. & $1.96 \mathrm{~K} \Omega, 1 \%$ & RM1206 \\
\hline 47 & 1 & R46: & $100 \mathrm{~K} \Omega, 1 \%$ & RM1206 \\
\hline 48 & 1 & R92. & $20 \mathrm{~K} \Omega, 1 \%$ & RM1206 \\
\hline 49 & 4 & R96,R98,R118,R120. & $2.61 \mathrm{~K} \Omega, 1 \%$ & RM1206 \\
\hline 50 & 1 & R97 & $301 \Omega, 1 \%$ & RM1206 \\
\hline
\end{tabular}

Table 3a. 


\begin{tabular}{|c|c|c|c|c|}
\hline Item & Qty & Designator & Description & Case \\
\hline 51 & 2 & R99,R119 & $6.19 \mathrm{k} \Omega, 1 \%$ & RM1206 \\
\hline 52 & 1 & $\mathrm{R} 112$ & $511 \Omega, 1 \%$ & RM1206 \\
\hline 53 & 1 & R117 & $40.2 \Omega, 1 \%$ & RM1206 \\
\hline 54 & 1 & R121 & $649 \Omega, 1 \%$ & $\overline{R M 1206}$ \\
\hline 55 & 1 & R124 & $5.1 \Omega 1 \%$ & $\overline{R M 1206}$ \\
\hline 56 & 1 & $\overline{R 125}$ & $499 \Omega, 1 \%$ & RM1206 \\
\hline 57 & 1 & R131 & $931 \Omega, 1 \%$ & RM1206 \\
\hline 58 & $T$ & $\overline{R 134}$ & $383 \Omega, 1 \%$ & RM1206 \\
\hline 59 & $T$ & R137 & $178 \Omega, 1 \%$ & $\overline{\mathrm{RM1206}}$ \\
\hline 60 & 1 & R139 & $20.0 \Omega, 1 \%$ & RM1206 \\
\hline
\end{tabular}

Table 3b.

7.5.1 Temporarily install a $1 \mathrm{~K} 1 \%$ RM1206 resistor for R49. Tack this part only do not fully solder.

7.6 Clean and inspect all solder joints per MIL-STD-2000. Rework any substandard solder joints. Record inspection both here and in the certification log worksheets.

Date:

QA:

Date Inspected

QA Stamp

7.7 The printed wiring board shall be baked at $130 \pm 5^{\circ} \mathrm{C}$ for a minimum of 6 hours prior to loading, per Polyimide Based Printed Wiring Board Conditioning Methods, $C 1-E E-029$. Prior to baking the printed wiring board, verify that the oven to be used is in current calibration and has been verified by the QAG. The start and end times along with the start and end temperatures shall be recorded. The oven temperature profile shall be recorded, using a strip chart recorder, for the duration of the bake out. Record the date, assembly, serial number, assembly step and operator on the chart and insert in the certification section of the assembly log. The make, model and serial number of the oven used for bake out shall be recorded. Record both below and in the certification log work sheets by paragraph number. 


\begin{tabular}{c|c|c|c|c} 
Item & Qty & Designator & Description & Case \\
\hline 51 & 2 & R99,R119 & $6.19 \mathrm{~K} \Omega, 1 \%$ & RM1206 \\
\hline 52 & 1 & $\mathrm{R} 112$ & $511 \Omega, 1 \%$ & RM1206 \\
\hline 53 & 1 & $\mathrm{R} 117$ & $40.2 \Omega, 1 \%$ & RM1206 \\
\hline 54 & 1 & $\mathrm{R} 121$ & $649 \Omega, 1 \%$ & RM1206 \\
\hline 55 & 1 & $\mathrm{R} 124$ & $5.1 \Omega 1 \%$ & RM1206 \\
\hline 56 & 1 & $\mathrm{R} 125$ & $499 \Omega, 1 \%$ & RM1206 \\
\hline 57 & 1 & $\mathrm{R} 131$ & $931 \Omega, 1 \%$ & $\mathrm{RM1206}$ \\
\hline 58 & 1 & $\mathrm{R} 134$ & $383 \Omega, 1 \%$ & $\mathrm{RM1206}$ \\
\hline 59 & 1 & $\mathrm{R} 137, \mathrm{R} 49$ & $178 \Omega, 1 \%$ & RM1206 \\
\hline 60 & 1 & $\mathrm{R} 139$ & $20.0 \Omega, 1 \%$ & RM1206
\end{tabular}

Table $3 b$.

7.6 Clean and inspect all solder joints per MIL-STD-2000. Rework any substandard solder joints. Record inspection both here and in the certification log worksheets.
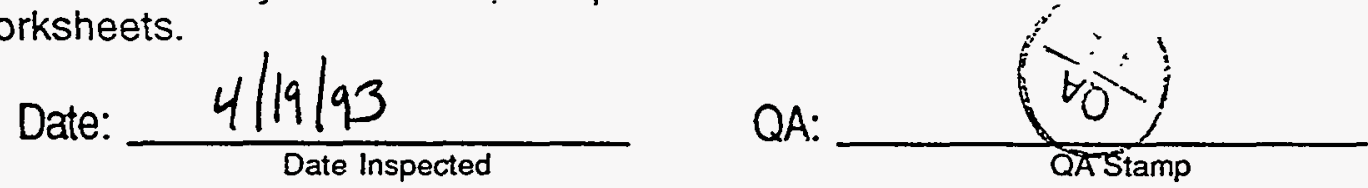

7.7 The printed wiring board shall be baked at $130 \pm 5^{\circ} \mathrm{C}$ for a minimum of 6 hours prior to loading, per Polyimide Based Printed Wiring Board Conditioning Methods, $\mathrm{C}_{1}-\mathrm{EE}-029$. Prior to baking the printed wiring board, verify that the oven to be used is in current calibration and has been verified by the QAG. The start and end times along with the start and end temperatures shall be recorded. The oven temperature profile shall be recorded, using a strip chart recorder, for the duration of the bake out. Record the date, assembly, serial number, assembly step and operator on the chart and insert in the certification section of the assembly log. The make, model and serial number of the oven used for bake out shall be recorded. Record both below and in the certification log work sheets by paragraph number.

Calibration and Certification Current, Initial:

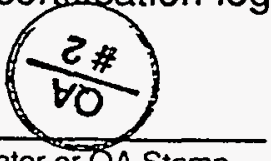




\begin{tabular}{|c|c|c|c|c|}
\hline Item & Qty & Designator & Description & Case \\
\hline $4^{51}$ & 1 & R99 & $6.19 \mathrm{~K} \Omega, 1 \%$ & RM1206 \\
\hline 52 & 1 & $\mathrm{R} 112$ & $511 \Omega, 1 \%$ & RM1206 \\
\hline 53 & 1 & R117.. & $40.2 \Omega, 1 \%$ & RM1206 \\
\hline 54 & 1 & $\overline{\text { R121: }}$ & $649 \Omega, 1 \%$ & RM1206 \\
\hline 55 & 1 & R124 & $5.1 \Omega 1 \%$ & RM1206 \\
\hline 56 & 1 & R125 & $499 \Omega, 1 \%$ & RM1206 \\
\hline 57 & 1 & R131: & $931 \Omega, 1 \%$ & RM1206 \\
\hline 58 & 1 & R134; & $383 \Omega, 1 \%$ & $\overline{\mathrm{RM} 1206}$ \\
\hline 59 & 1 & R137: & $178 \Omega, 1 \%$ & $\overline{R M 1206}$ \\
\hline $\begin{array}{l}60 \\
:\end{array}$ & 1 & R139. & $20.0 \Omega, 1 \%$ & RM1206 \\
\hline 84 & 1 & R49. & $200 \Omega, 5 \%$ & RM+206 \\
\hline
\end{tabular}

Table 3b.

7.6 Clean and inspect all solder joints per MIL-STD-2000. Rework any substandard solder joints. Record inspection both here and ip the certification log worksheets.

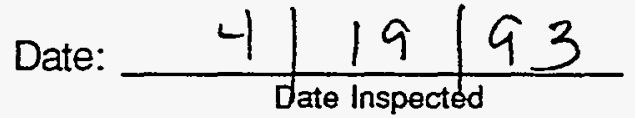

QA:

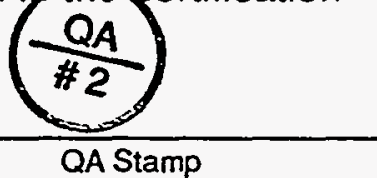

7.7 The printed wiring board shall be baked at $130 \pm 5^{\circ} \mathrm{C}$ for a minimum of 6 hours prior to loading, per Polyimide Based Printed Wiring Board Conditioning Methods, C1-EE-029. Prior to baking the printed wiring board, verify that the oven to be used is in current calibration and has been verified by the QAG. The start and end times along with the start and end temperatures shall be recorded. The oven temperature profile shall be recorded, using a strip chart recorder, for the duration of the bake out. Record the date, assembly, serial number, assembly step and operator on the chart and insert in the certification section of the assembly log. The make, model and serial number of the oven used for bake out shall be recorded. Record both below and in the certification log work sheets by paragraph number.

Calibration and Certification Current, Initial:

$\left(\frac{Q_{A}}{\# 2}\right)$

Operator or QA Stamp 
Start Time: $1: 30$ f.me End Time: 1:30 p.m Start Temp: $\quad 95 \quad 5^{\circ} \mathrm{C} \quad$ End Temp: $\quad 95$ Oven Make: Versa Tem II Oven Model: THJR Oven Serial \#: $12664-1$

Date: $\frac{4 / 19 / 93}{\text { Date Completed }}$ Operator: $\frac{\left(\frac{Q A}{\# 2}\right)}{\text { Operator or } Q A \text { Stamp }}$ Note: Printed wiring boards are to be stored in an airtight, antistatic bag with a desiccant at all times the board is not being loaded, cleaned, inspected, tested or baked.

7.8 Install the items listed in tables $4 a$ and $4 b$ below.

\begin{tabular}{|c|c|c|c|c|}
\hline Item & Qty & Designator & Description & Case \\
\hline 2 & 5 & $\mathrm{C} 2, \mathrm{C} 51, \mathrm{C} 61, \mathrm{C} 62, \mathrm{C} 122$ & $\begin{array}{l}4.7 \mu f d, \text { Tant } \\
10 \mathrm{~V}, 10 \%\end{array}$ & D-CASE \\
\hline 3 & 1 & C9: & $\begin{array}{l}47 \mu \mathrm{fd}, \text { Tant, } \\
20 \mathrm{~V}, 10 \%\end{array}$ & R-CASE \\
\hline 4 & 2 & C10,C11 & $\begin{array}{c}22 \mu \mathrm{fd}, \text { Tant, } \\
15 \mathrm{~V}, 10 \%\end{array}$ & G-CASE \\
\hline 5 & 4 & $\mathrm{C} 12, \mathrm{C} 13, \mathrm{C} 17, \mathrm{C} 105$ & $\begin{array}{l}6.8 \mu \mathrm{fd}, \text { Tant, } \\
10 \mathrm{~V}, 10 \%\end{array}$ & E-CASE \\
\hline 7 & 6 & $\begin{array}{c}\mathrm{C} 22, \mathrm{C} 24, \mathrm{C} 29, \mathrm{C} 69, \mathrm{C} 90 ; \\
\text { C118 }\end{array}$ & $\begin{array}{l}22 \mu \mathrm{fd}, \text { Tant, } \\
20 \mathrm{~V}, 10 \%\end{array}$ & H-CASE \\
\hline 8 & 4 & $\mathrm{C} 32, \mathrm{C} 52, \mathrm{C} 94, \mathrm{C} 95$ & $\begin{array}{c}10 \mu \mathrm{fd}, \text { Tant, } \\
25 \mathrm{~V}, 10 \%\end{array}$ & G-CASE \\
\hline 10 & 2 & C46,C93. & $\begin{array}{c}1.0 \mu \mathrm{fd}, \text { Tant } \\
35 \mathrm{~V}, 10 \%\end{array}$ & D-CASE \\
\hline
\end{tabular}

Table 4a. 


\begin{tabular}{|c|c|c|c|c|}
\hline Item & Qty & Designator & Description & Case \\
\hline 17 & 1 & aD13 & $\begin{array}{l}\text { Diode, } \\
\text { Switching, } \\
\text { MBAV74 }\end{array}$ & SOT-23 \\
\hline 20 & 2 & 列4,D5: & $\begin{array}{c}\text { Diode, } \\
\text { Schottky, 30V } \\
\text { BAT54S }\end{array}$ & SOT-23 \\
\hline 26 & 3 & Q2,Q3,Q8 & $\begin{array}{l}\text { Transistor, } \\
\text { 2N3904 }\end{array}$ & SOT-23 \\
\hline 27 & 3 & Q12,Q13,Q14 & $\begin{array}{l}\text { Transistor, } \\
\text { 2N7002 }\end{array}$ & SOT-23 \\
\hline 22 & 3 & $\mathrm{E} 1, \mathrm{~L} \mathrm{~L}, \mathrm{~L} 4$ & $\begin{array}{l}\text { Inductor, } \\
100 \mu \mathrm{H}\end{array}$ & LQH4 \\
\hline 23 & 1 & IES: & $\begin{array}{l}\text { Inductor, } \\
10 \mu \mathrm{H}\end{array}$ & LQH4 \\
\hline 86 & 1 & E2: & $\begin{array}{l}\text { Inductor, } \\
47 \mu \mathrm{H} \text { or } \\
39 \mu \mathrm{H}\end{array}$ & LQH4 \\
\hline 25 & 5 & $\begin{array}{c}\text { Q1,Q4;Q9, } \\
\text { Q10;Q11 }\end{array}$ & $\begin{array}{l}\text { Transistor, } \\
\text { FET, } \\
\text { SST215 }\end{array}$ & $\overline{\text { SOT }-143}$ \\
\hline 76 & $i$ & $\overline{x 1}$ & $\begin{array}{l}\text { Crystal, } \\
20 \mathrm{MHZ}\end{array}$ & CXAT \\
\hline
\end{tabular}

Table 4b.

7.8.1 The lancing pattern for item 6 was incorrectly designed on some boards. If so, item 6 must be installed on its side. Install item 6 as listed in table 5 below.

\begin{tabular}{c|c|c|c|c}
\cline { 2 - 5 } Item & Qty & Designator & Description & Case \\
\hline 6 & 2 & C20;C1.10 & $\begin{array}{c}6.8 \mu f d, T a n t, ~ \\
20 \mathrm{~V}, 10 \%\end{array}$ & F-CASE
\end{tabular}

Table 5. 
7.9 Install the jumpers indicated in table 6 below. These parts are located as shown in Figure 3 on the primary side of the printed wiring board and in Figure 4 on the secondary side of the printed wiring board.

\begin{tabular}{c|c|c|c|c} 
Item & Qty & Designator & Description & Case \\
\hline 21 & 9 & $\begin{array}{r}\text { JP4,JP6,JP7,JP9,JP11; } \\
\text { JP13,JP14,JP15,JP16. }\end{array}$ & $\begin{array}{c}\text { Jumper, } \\
0 \text { S, 1\% }\end{array}$ & RM1206 \\
& & RM &
\end{tabular}

Table 6.

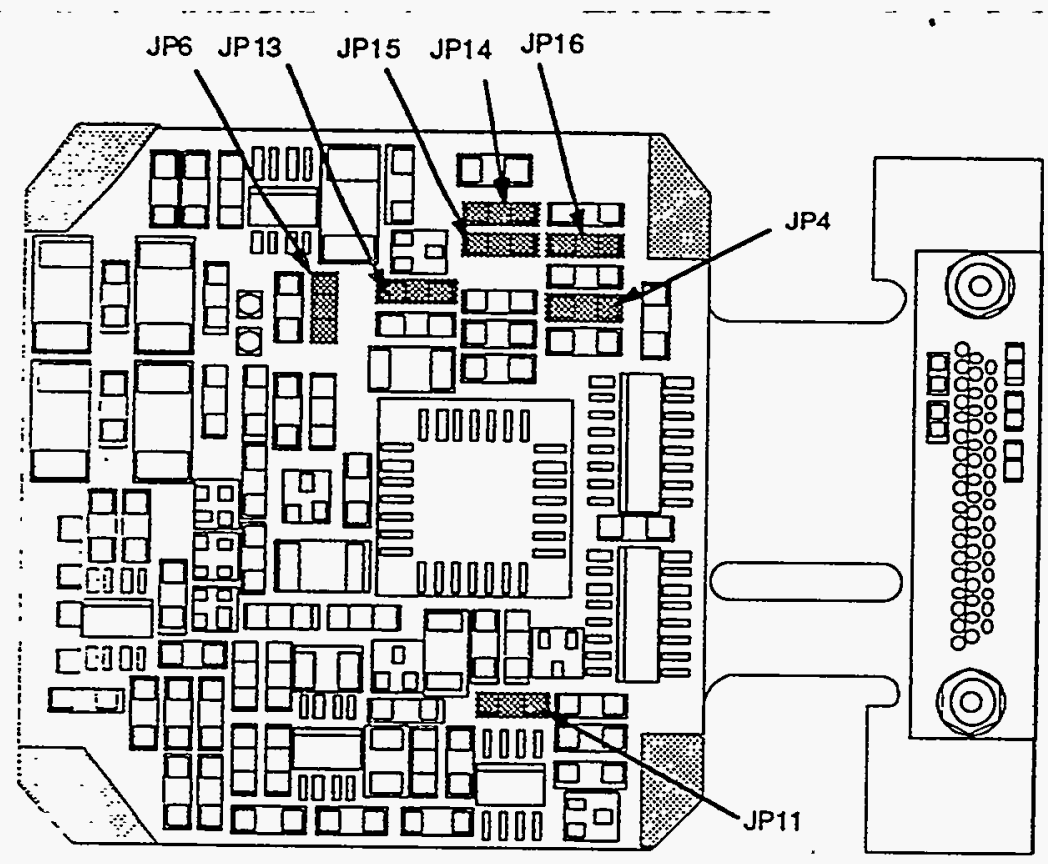

Figure 3, Primary Side View.

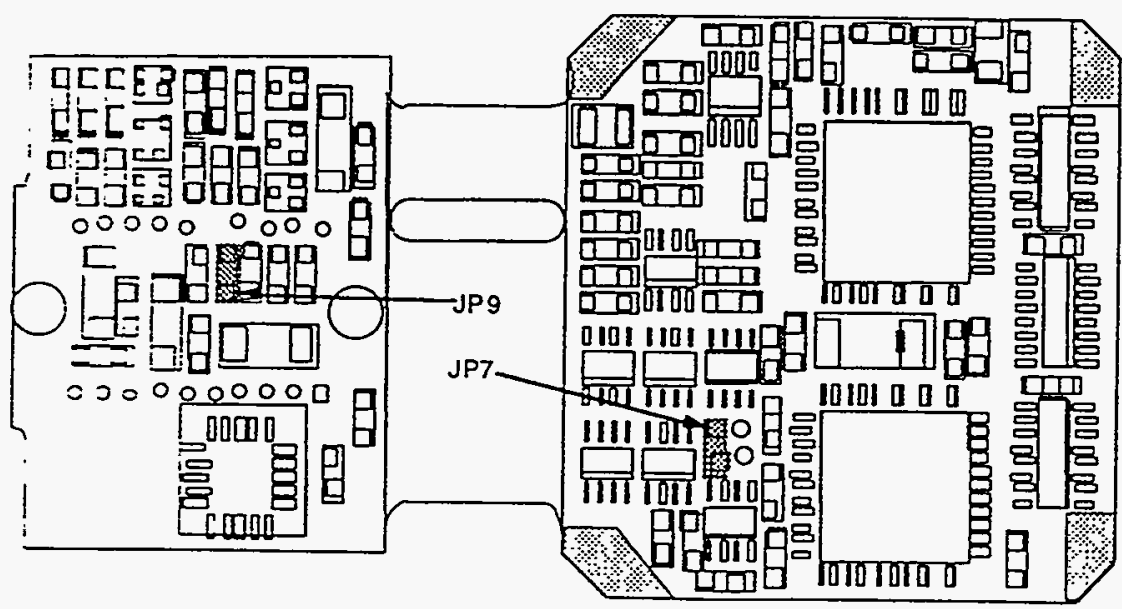

Figure 4, Secondary Side View. 
7.10 Clean and inspect all solder joints per MIL-STD-2000. Rework any substandard solder joints. Record inspection both here and in the certification log worksheets.

Date:

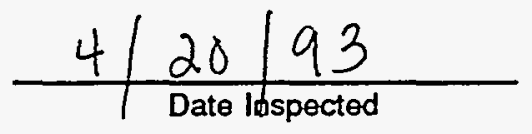

QA:

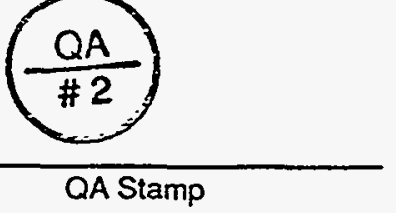

7.11 The printed wiring board shall be baked at $130 \pm 5^{\circ} \mathrm{C}$ for a minimum of 6 hours prior to loading, per Polyimide Based Printed Wiring Board Conditioning Methods, C1-EE-029. Prior to baking the printed wiring board, verify that the oven to be used is in current calibration and has been verified by the QAG. The start and end times along with the start and end temperatures shall be recorded. The oven temperature profile shall be recorded, using a strip chart recorder, for the duration of the bake out. Record the date, assembly, serial number, assembly step and operator on the chart and insert in the certification section of the assembly log. The make, model and serial number of the oven used for bake out shall be recorded. Record both below and in the certification log work sheets by paragraph number.

Calibration and Certification Current, Initial:

Start Time: 7:00 p.m End Time: $1: 00$ $A \cdot M$. Start Temp: 95 ${ }^{\circ} \mathrm{C} \quad$ End Temp: 95 ${ }^{\circ} \mathrm{C}$ Oven Make: Versa Temm II Oven Model: $T+1 J R$ Oven Serial \#: $12664-1$ Date:
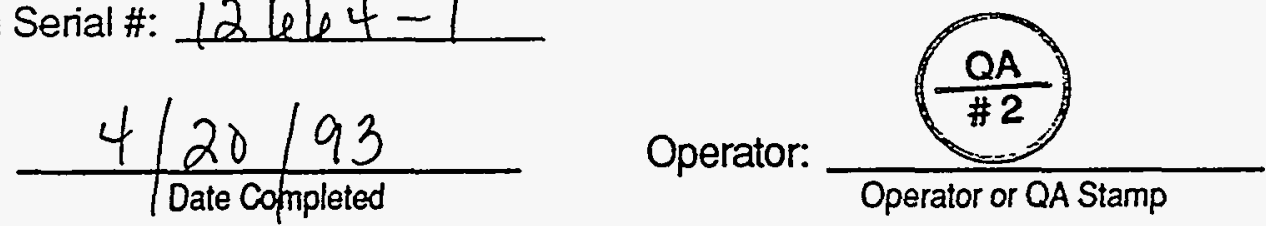

Note: Printed wiring boards are to be stored in an airtight, antistatic bag with a desiccant at all times the board is not being loaded, cleaned, inspected, tested or baked. 
7.12 Insiail the items listed in tables $7 \mathrm{a}$ and $7 \mathrm{~b}$ below.

\begin{tabular}{|c|c|c|c|c|}
\hline Item & Qty & Designator & Description & Case \\
\hline 18 & 1 & D2 & $\begin{array}{c}\text { Diode, } \\
\text { Voltage } \\
\text { Reference } \\
\text { LM285-1.2 }\end{array}$ & SOIC-8 \\
\hline 19 & 1 & $\mathrm{D} 3$ & $\begin{array}{l}\text { Reference, } \\
\text { Voltage, } \\
\text { Precision, } \\
\text { 10V, REF-01 }\end{array}$ & SOIC-8 \\
\hline 62 & 1 & $\mathrm{U1}$ & $\begin{array}{l}\text { Amplifier,. } \\
\text { Operational, } \\
\text { Clamping } \\
\text { CLC501AJE }\end{array}$ & SOIC-8 \\
\hline 64 & 2 & U3,U27 & $\begin{array}{c}\text { Amplifier, } \\
\text { Dual, Wide } \\
\text { Band } \\
\text { LF353 }\end{array}$ & SOIC-8 \\
\hline 68 & 4 & $\begin{array}{c}\text { U9,U10,U22 } \\
\text { U23 }\end{array}$ & $\begin{array}{c}\text { Driver, Dual } \\
\text { Inverting } \\
\text { TSC } 4426\end{array}$ & SOIC-8 \\
\hline 69 & 2 & U11,U30 & $\begin{array}{c}\text { Driver, } \\
\text { Differential, } \\
\text { Dual } \\
\text { TSC4428 }\end{array}$ & SOIC-8 \\
\hline 70 & 1 & U14 & $\begin{array}{c}\text { Amplifier, } \\
\text { Operational, } \\
\text { LF356 }\end{array}$ & SOIC-8 \\
\hline 71 & 2 & U17,U18 & $\begin{array}{l}\text { Regulator, } \\
\text { Voltage, } \\
\text { Adjustable } \\
\text { LM317 }\end{array}$ & SOIC-8 \\
\hline
\end{tabular}

Table 7a. 


\begin{tabular}{|c|c|c|c|c|}
\hline Item & Qty & Designator & Description & Case \\
\hline 73 & 1 & U24 & $\begin{array}{l}\text { Amplifier, } \\
\text { Operational, } \\
\text { CLC502 }\end{array}$ & SOIC-8 \\
\hline 63 & $\overline{1}$ & $\mathrm{U2}$ & $\begin{array}{l}\text { Receiver, } \\
\text { Line, Quad } \\
\text { DS34C86 }\end{array}$ & SOIC-16 \\
\hline 66 & 4 & $\begin{array}{l}\text { U6,U7, } \\
\text { U12,U25 }\end{array}$ & $\begin{array}{c}\text { Driver, Line,' } \\
\text { Quad } \\
\text { DS34C87 }\end{array}$ & SOIC-16 \\
\hline 67 & 7 & U8" & $\begin{array}{l}\text { Converter, } \\
\text { Analog to } \\
\text { Digital } 8 \text { bit } \\
\text { MP7684 }\end{array}$ & LCC-28 \\
\hline 75 & 1 & U32 & $\begin{array}{c}\text { Converter, } \\
\text { Digital to } \\
\text { Analog } \\
\text { AD558TE/883 }\end{array}$ & LCC20 \\
\hline 65 & 1 & U5 & $\begin{array}{c}\text { Controller, } \\
\text { CCD } \\
\text { TH7990 }\end{array}$ & JLCC-44 \\
\hline
\end{tabular}

Table $7 b$.

7.13 Item 74, U26, an Actel ACT1020A is a programmed device. Due to its critical function in the operation of the Acte! Camera it is not provided until requested. QA verification of the Actel array is required. Record below and in the Assembly Log work sheets the identifying information for the Actel gate array. Record the address on the front page of this document.

File Name: STI D

Check Sum:

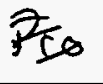
Link File date $4 / 20 / 93$

Programming Date: 3 May 93

StarTracker Address

1

\#1 or \#2

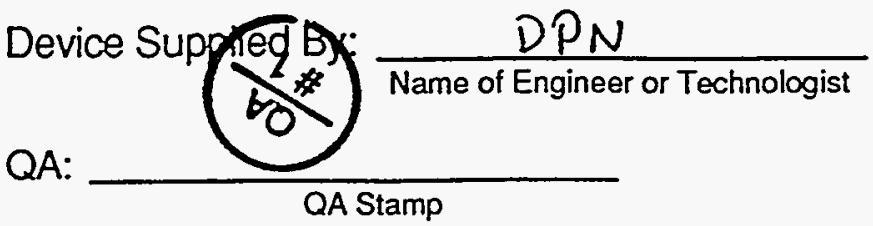


7.14 Install item 74, U26, ACTEL ACT1020A.

7.15 Cut pin number 16 of Item 77, socket strip for U19. Important! The cut must be flush with the base of the taper. See figure 5 below.

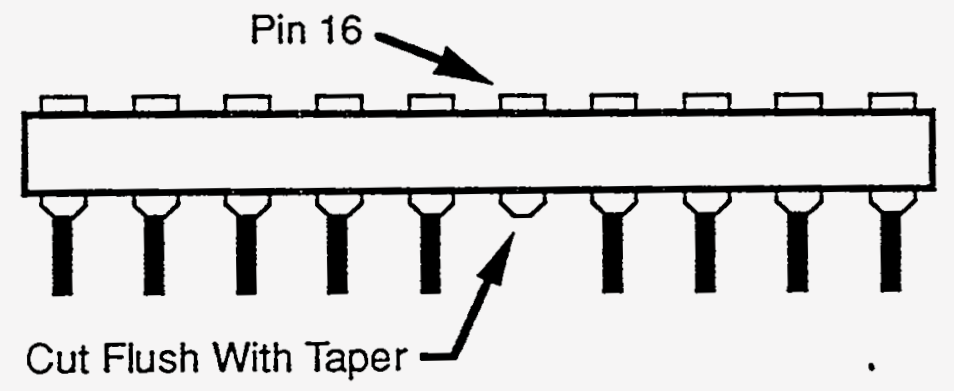

Figure 5.

7.16 Insert both strips of item 77,U19 socket, through the printed wiring board. Insert a dummy 20 pin DIP into the socket strips. Verify that the dummy DIP is completely seated in the socket strips and that the strips sit square and flat to the printed wiring board. Solder the socket strips to the printed wiring board. Remove the dummy DIP from the socket strips.

7.17 Pretin the leads of item 82 TP1 and TP2, two pin terminal strips per C1-EE-023, Preparation of Gold Plated Leads.

7.18 Install Item 82, two pin terminal strips

7.19 Temporarily tack a wire between the outermost pads of R128 and C123. See figure 6 below.

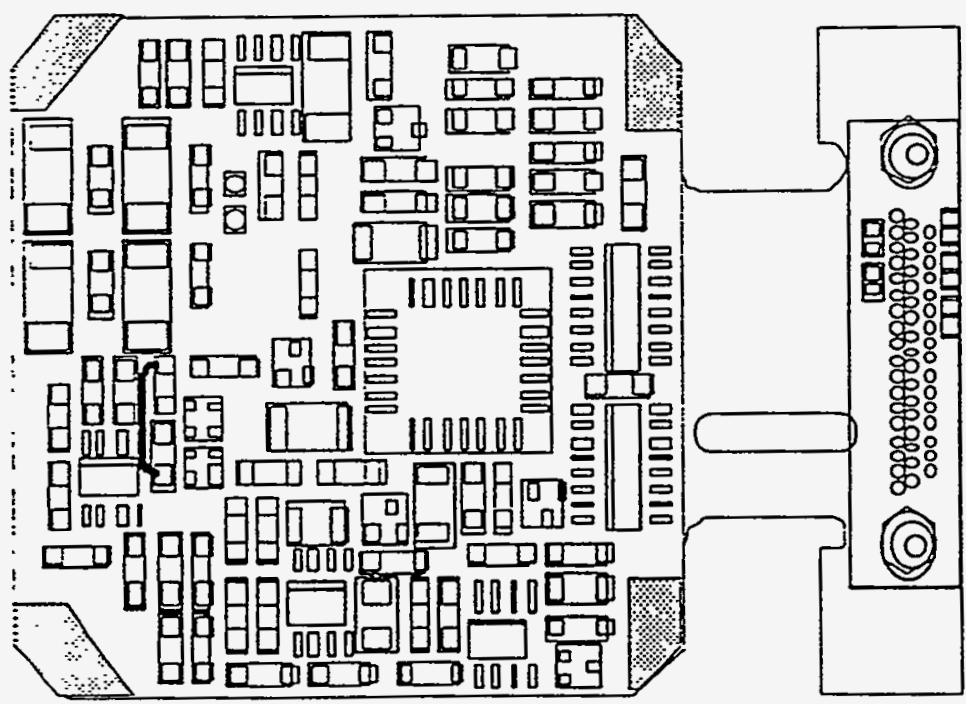

Figure 6. 
7.14 Install item 74, U26, ACTEL ACT1020A.

7.15 Cut pin number 16 of Item 77, socket strip for U19. Important! The cut must be flush with the base of the taper. See figure 5 below.

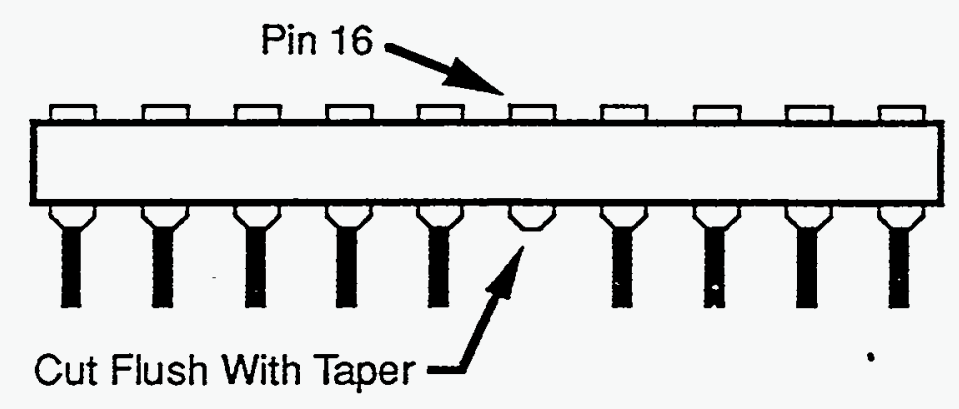

Figure 5.

7.16 Insert both strips of item 77,U19 socket, through the printed wiring board. Insert a dummy 20 pin DIP into the socket strips. Verify that the dummy DIP is completely seated in the socket strips and that the strips sit square and flat to the printed wiring board. Solder the socket strips to the printed wiring board. Remove the dummy DIP from the socket strips.

7.17 Pretin the leads of item 82 TP1 and TP2, two pin terminal strips per C1-EE-023, Preparation of Gold Plated Leads.

7.18 Install Item 82, two pin terminal strips

7.19 Pretin the leads of item 24, J1 per C1-EE-023, Preparation of Gold Plated Leads.

7.20 Measure the longest dimension of item 78, spacers, AAA92-104616-0B TAB 01. They should be $0.385+0.005,-0.000$ inch long. Record the measurement both here and in the assembly log work sheets.

Length of Spacers

.390

.390

7.21 Assemble 2 each spacers, 2 each \#2 stainless steel washers, item 81, and 2 each \#2-56 stainless steel nuts, item 80 , through the printed wiring board as shown in figure 6 . Spacers are mounted from the primary side with nuts and washers on the secondary side. Using a calibrated tool, torque nuts to $40.0 \pm 2$ oz-in.

$$
\begin{aligned}
& \text { Tingyed with UnCALIORATES Tooh, Torqued to } \\
& 4010 \text { or I vches }
\end{aligned}
$$


7.20 Pretin the leads of item 24, J1 per C1-EE-023, Preparation of Gold Plated Leads.

7.21 Measure the longest dimension of item 78, spacers, AAA92-104616-0B TAB 01. They should be $0.385+0.005,-0.000$ inch long. Record the measurement both here and in the assembly log work sheets.

Length of Spacers $\quad .390 \quad .390$

7.22 Assemble 2 each spacers, 2 each \#2 stainless steel washers, item 81 , and 2 each \#2-56 stainless steel nuts, item 80 , through the printed wiring board as shown in igure 7. Spacers are mounted from the primary side with nuts and washers on the secondary side. Using a calibrated tool, torque nuts to $40.0 \pm 2$ oz-in.

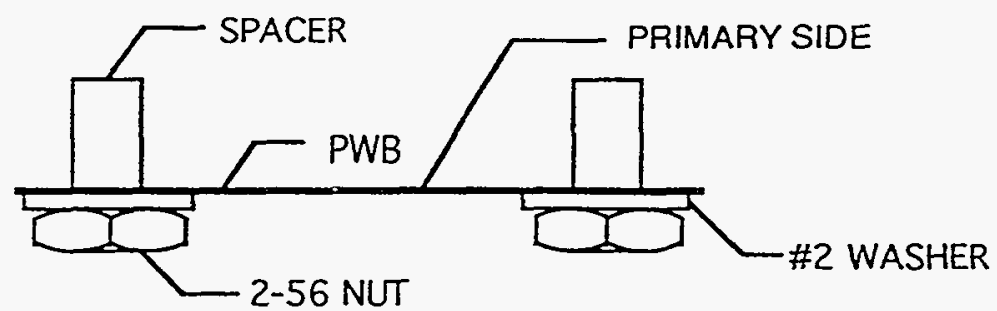

Figure 7.

7.23 insert the leads of $J 1$ through the printed wiring board. The connector $J 1$ sits on top of the standoffs.

7.24 Assemble $J 1$ to the spacers using 2 each \#2-56 $\times .25$ long. screws as shown in figure 8 . Finger tighten only, do not torque.
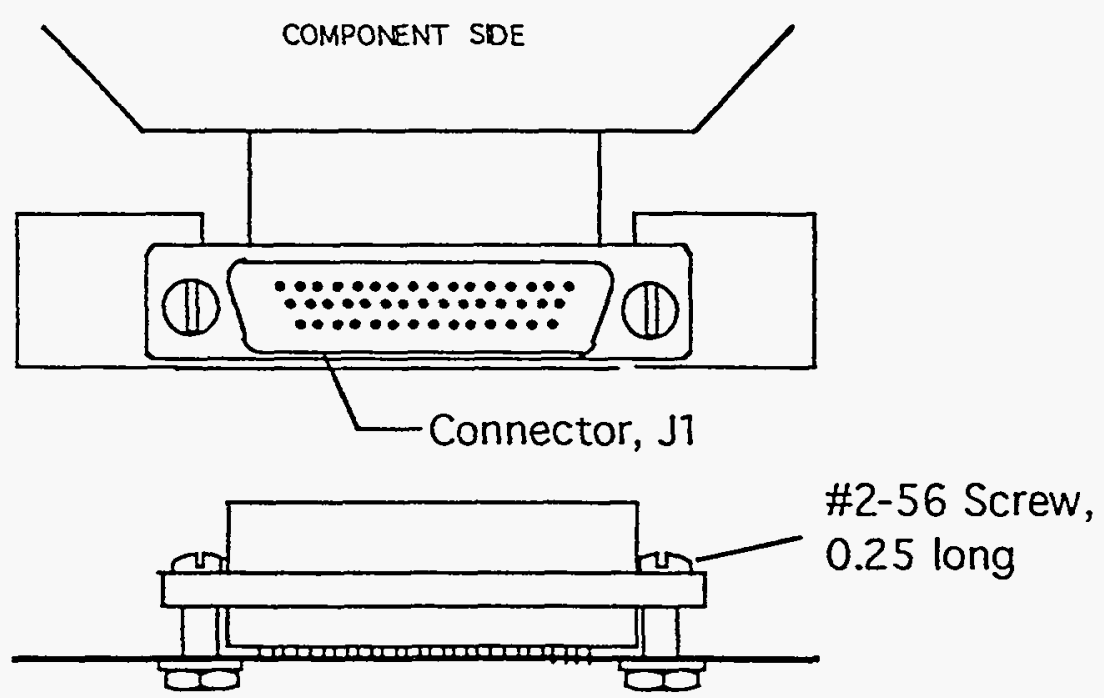

Figure 8. 


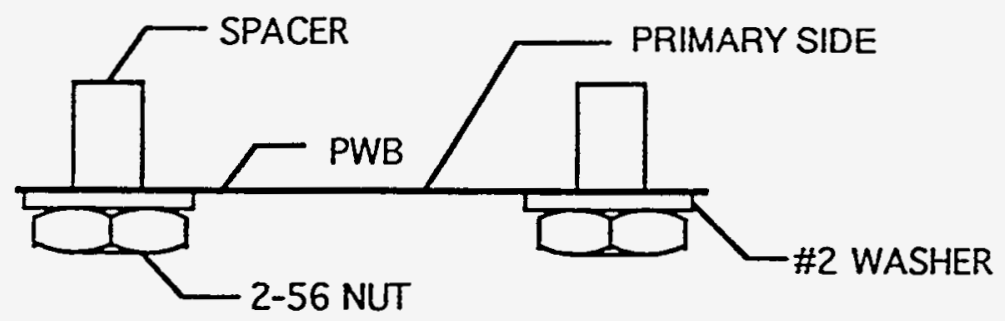

Figure 6.

7.22 Insert the leads of $\mathrm{J} 1$ through the printed wiring board. The connector $\mathrm{J} 1$ sits on top of the standoffs.

7.23 Assemble $\mathrm{J} 1$ to the spacers using 2 each \#2-56 $\times .25$ long. screws as shown in figure 7 . Finger tighten only, do not torque.

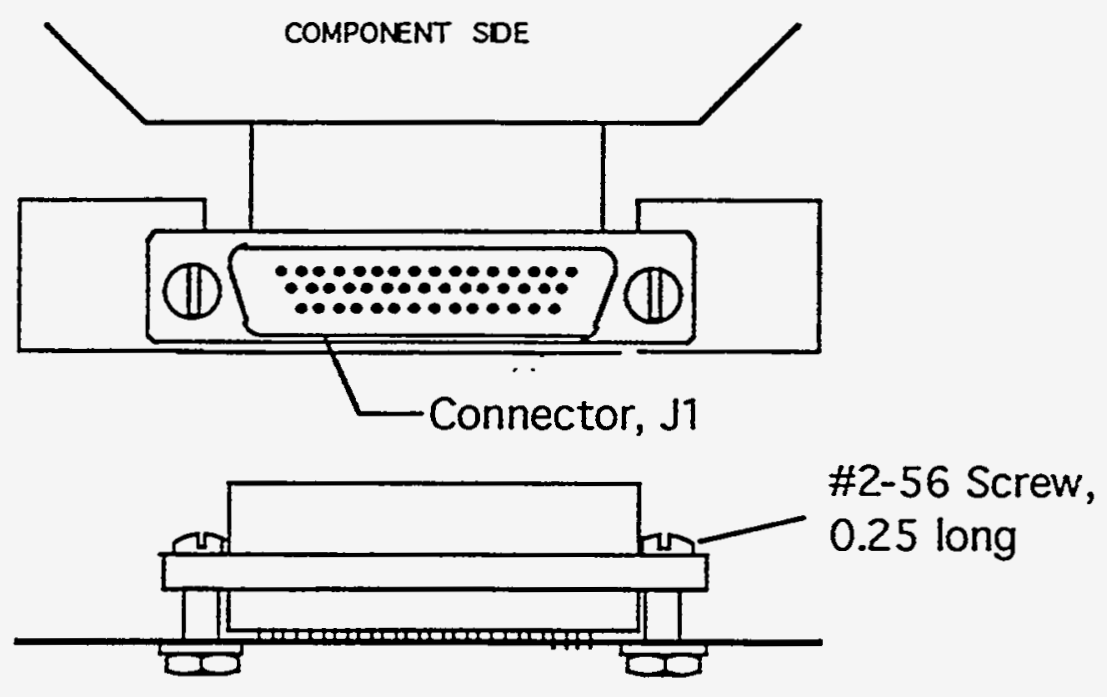

Figure 7.

7.24 Trim the leads of $\mathrm{J} 1$ such that they extend thru the printed wiring board by 0.020 to 0.040 inch.

7.25 Verify that the bottom surface of the flange of $\mathrm{J} 1$ is $0.257 \pm .005$ inch from the surface of the printed wiring board at both ends of the connector. Record the spacing both here and in the work sheet section of the assembly log.

J1 Bottom Surface distance from PWB: .261

J1 Bottom Surface distance from PWB: .261

Operator: $\frac{H \cdot i \cdot\left(\frac{008}{119}\right)}{\text { Operator or QA Stamp? }}$ 
7.25 Trim the leads of $\mathrm{J} 1$ such that they extend thru the printed wiring board by 0.020 to 0.040 inch.

7.26 Verify that the bottom surface of the flange of $\mathrm{J} 1$ is $0.257 \pm .005$ inch from the surface of the printed wiring board at both ends of the connector. Record the spacing both here and in the work sheet section of the assembly log.

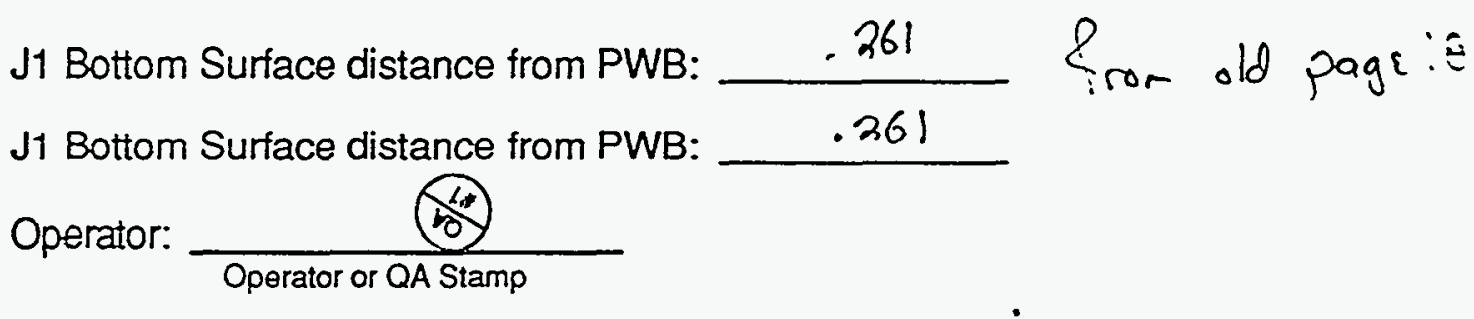

7.27 Solder the leads of $\mathrm{J} 1$ to the printed wiring board.

7.28 Installation of item $61, \mathrm{~T} 1$, thermistor will be done after completion of engineering evaluation.

7.29 Installation of items listed in table 8 below will be done after engineering evaluation.

\begin{tabular}{l|l|c|c|c} 
Item & Qty & Designator & Description & Case \\
\hline \multirow{2}{*}{43} & 2 & $\mathrm{R} 49, \mathrm{R} 128$ & $100 \Omega, 1 \%$, & $\mathrm{RM} 1206$ \\
& & & $\begin{array}{c}1 / 4 \mathrm{Watt}, \\
100 \mathrm{ppm},\end{array}$ & \\
& & & $\begin{array}{c}\text { FR=0.01\%/ } \\
1000 \mathrm{hr}\end{array}$ &
\end{tabular}

Table 8.

7.30 Clean and inspect all solder joints per MIL-STD-2000. Rework any substandard solder joints. Record inspection both here and in the certification log worksheets. from ald paye 19

Date: $\frac{1 / 22 / 93}{\text { Date Inspected }}$

QA:

(8)

QA Stamp

Note: Printed wiring boards are to be stored in an airtight, antistatic bag. with a desiccant at all times the board is not being loaded, cleaned, inspected; tested or baked.

7.31 Install a connector saver on $\mathrm{J1}$.

7.32 The printed wiring assembly now goes to engineering for evaluation. 
7.26 Solder the leads of $\mathrm{d} 1$ to the printed wiring board.

7.27 Installation of item $61, \mathrm{T1}$, thermistor will be done after completion of engineering evaluation.

7.28 Clean and inspect all solder joints per MIL-STD-2000. Rework any substandard solder joints. Record inspection both here and the certification log worksheets.

Date:
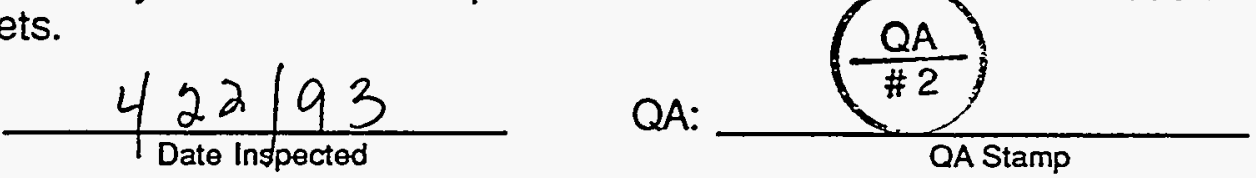

Note: Printed wiring boards are to be stored in an airtight, antistatic bag with a desiccant at all times the board is not being loaded, cleaned, inspected, tested or baked.

7.29 Install a connector saver on J1.

7.30 Resistance measurements are to be made at $\mathrm{d} 1$ at this time. Make and record the measurements as indicated in table 8 . All readings must be greater than $1 \mathrm{~K} \Omega$, except where noted. See figure 8 below for the location of pins in $\mathrm{J1}$.

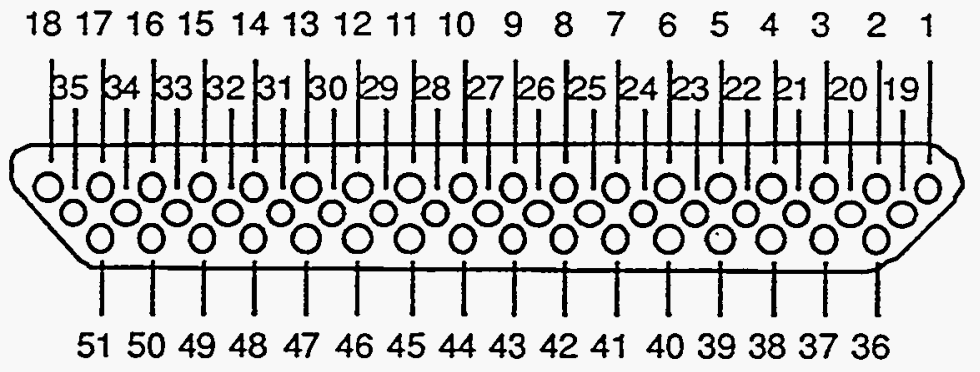

MDM 51 Contact Connector. Face View of Socket Insert.

Figure 8. 


\section{Post Evaluation Assembly}

8.1 The printed wiring board shall be baked at $130 \pm 5^{\circ} \mathrm{C}$ for a minimum of 6 hours prior to loading, per Polyimide Based Printed Wiring Board Conditioning Methods, C1-EE-029. Prior to baking the printed wiring board, verify that the oven to be used is in current calibration and has been verified by the QAG. The start and end times along with the start and end temperatures shall be recorded. The oven temperature profile shall be recorded, using a strip chart recorder, for the duration of the bake out. Record the date, assembly, serial nurinber, assembly step and operator on the chart and insert in the certification section of the assembly log. The make, model and serial number of the oven used for bake out shall be recorded. Record both below and in the certification log work sheets by paragraph number.

Calibration and Certification Current, Initial:

Start Time:

End Time:

Start Temp: ${ }^{\circ} \mathrm{C} \quad$ End Temp: ${ }^{\circ} \mathrm{C}$

Oven Make:

Oven Model:

Oven Serial \#:

Date:

Date Completed

Operator:

Operator or QA Stamp

Note: Printed wiring boards are to be stored in an airtight, antistatic bag with a desiccant at all times the board is not being loaded, cleaned, inspected, tested or baked.

8.2 Remove the jumper from outermost pads of $\mathrm{R} 128$ and $\mathrm{C} 123$ that was installed at step 7.19

8.3 Install the items listed in table 9 below.

\begin{tabular}{c|c|c|c|c} 
Item & Qty & Designator & Description & Case \\
\hline \multirow{2}{*}{43} & 2 & R49,R128 & $100 \Omega, 1 \%$, & RM1206 \\
& & & $\begin{array}{c}1 / 4 \text { Watt, } \\
100 \mathrm{ppm}, \\
\text { FR=0.01\%/ } \\
1000 \mathrm{hr}\end{array}$ &
\end{tabular}

Table 9. 


\section{Post Evaluation Assembly}

8.1 The printed wiring board shall be baked at $130 \pm 5^{\circ} \mathrm{C}$ for a minimum of 6 hours prior to loading, per Polyimide Based Printed Wiring Board Conditioning Methods, $C 1-E E-029$. Prior to baking the printed wiring board, verify that the oven to be used is in current calibration and has been verified by the QAG. The start and end times along with the start and end temperatures shall be recorded. The oven temperature profile shall be recorded, using a strip chart recorder, for the duration of the bake out. Record the date, assembly, serial number, assembly step and operator on the chart and insert in the certification section of the assembly log. The make, model and serial number of the oven used for bake out shall be recorded. Record both below and in the certification log work sheets by paragraph number.

Calibration and Certification Current, Initial:
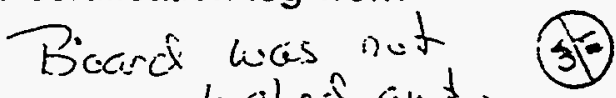
baiked ont.

End Time:

Start Time:

Start Temp: ${ }^{\circ} \mathrm{C}$ End Temp: ${ }^{\circ} \mathrm{C}$

Oven Make:

Oven Model:

Oven Serial \#:

Date:

Operator:

Date Completed

Operator or QA Stamp

Note: Printed wiring boards are to be stored in an airtight, antistatic bag with a desiccant at all times the board is not being loaded, cleaned, inspected, tested or baked.

8.2 Remove the jumper from outermost pads of R128 and C123 that was installed at step 7.19

8.3 Install the items listed in table 9 below.

\begin{tabular}{|c|c|c|c|c|}
\hline Item & Qty & Designator & Description & Case \\
\hline 43 & 2 & $R 49, R 128$ & $\begin{array}{c}100 \Omega, 1 \%, \\
1 / 4 \mathrm{Watt}, \\
100 \mathrm{ppm}, \\
\text { FR=0.01\%/ } \\
1000 \mathrm{hr}\end{array}$ & RM1206 \\
\hline
\end{tabular}

Table 9. 
8.4 Clean and inspect all solder joints per MIL-STD-2000. Rework any substandard solder joints. Record inspection both here and in the certification log worksheets.

$$
\text { see old page } 21
$$

Date:

$5-7-93$

QA:

Date Inspected

QA Stamp

8.5 The printed wiring assembly now goes to engineering for additional evaluation. 
8.4 Clean and inspect all solder joints per MIL-STD-2000. Rework any substandard solder joints. Record inspection both here and in the certification log worksheets. Prom

Date: $5 / 7 / 9.3$ Date Inspected workstivits iten 96

QA:<smiles>[191In]</smiles>

QA Stamp

8.5 The printed wiring assembly now goes to engineering for additional evaluation. 
8.6 The printed wiring board shall be baked at $130 \pm 5^{\circ} \mathrm{C}$ for a minimum of 6 hours prior to loading, per Polyimide Based Printed Wiring Board Conditioning Methods, C1-EE-029. Prior to baking the printed wiring board, verify that the oven to be used is in current calibration and has been verified by the QAG. The start and end times along with the start and end temperatures shall be recorded. The oven temperature profile shall be recorded, using a strip chart recorder, for the duration of the bake out. Record the date, assembly, serial number, assembly step and operator on the chart and insert in the certification section of the assembly log. The make, model and serial number of the oven used for bake out shall be recorded. Record both below and in the certification log work sheets by paragraph number.

Calibration and Certification Current, Initial:

$$
\text { see old page } 22 \text { (8) }
$$

Operator or QA Stamp

Start Time: $6: 30 \mathrm{p} \cdot \mathrm{m}$

Start Temp: 95 ${ }^{\circ} \mathrm{C}$

Oven Make:

:

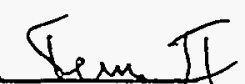

Oven Serial \#:

Date:

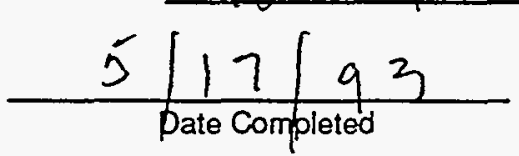

End Time:

$12: 30$ H.w.

End Temp:

95 ${ }^{\circ} \mathrm{C}$

Oven Model:

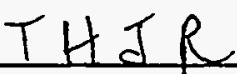

Operator:

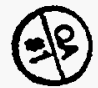

Operator or QA Stamp

Note: Printed wiring boards are to be stored in an airtight, antistatic bag with a desiccant at all times the board is not being loaded, cleaned, inspected, tested or baked.

8.7 Trim and form the leads of TR1 and TR2 as shown in figure 10 below.
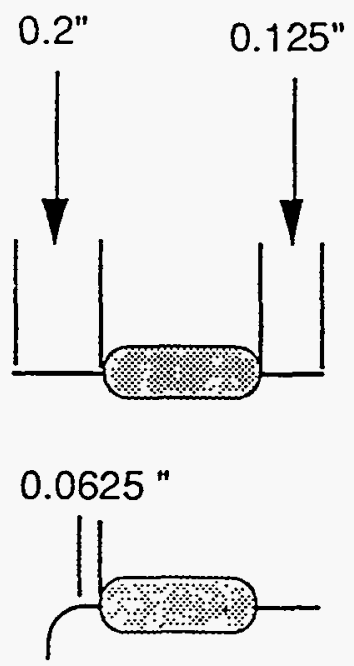

Figure 10. 
8.6 The printed wiring board shall be baked at $130 \pm 5^{\circ} \mathrm{C}$ for a minimum of 6 hours prior to loading, per Polyimide Based Printed Wiring Board Conditioning Methods, C1-EE-029. Prior to baking the printed wiring board, verify that the oven to be used is in current calibration and has been verified by the QAG. The start and end times along with the start and end temperatures shall be recorded. The oven temperature profile shall be recorded, using a strip chart recorder, for the duration of the bake out. Record the date, assembly, serial number, assembly step and operator on the chart and insert in the certification section of the assembly log. The make, model and serial number of the oven used for bake out shall be recorded. Record both below and in the certification log work sheets by paragraph number.

Calibration and Certification Current, Initial:

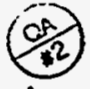

Operator or QA Stamp

Start Time:

$10.30 \mathrm{Am}$

End Time:

25 12:30 A.m

Start Temp:

95 ${ }^{\circ} \mathrm{C}$

End Temp:

95 ${ }^{\circ} \mathrm{C}$

Oven Make: Versa Tew II

Oven Model: $T H J R$

Oven Serial \#: $12664-1$

Date:

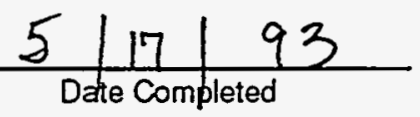

Operator:

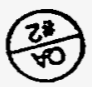

Operator or QA Stamp

Note: Printed wiring boards are to be stored in an airtight, antistatic bag with a desiccant at all times the board is not being loaded, cleaned, inspected, tested or baked.

8.7 Trim and iorm the leads of TR1 and TR2 as shown in figure 10 below.
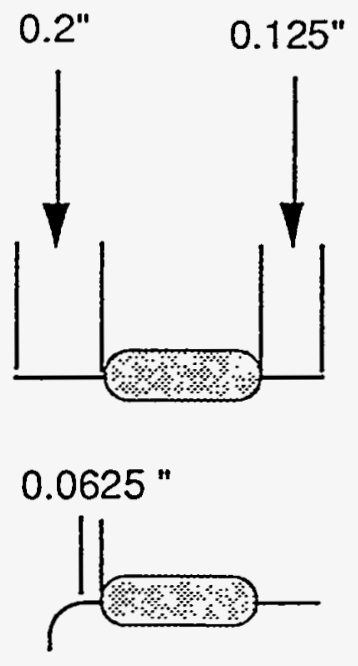

Figure 10. 
8.8 Place, do not solder at this point, TR1 and TR2 on the secondary side of the board as shown in figure 11 below.

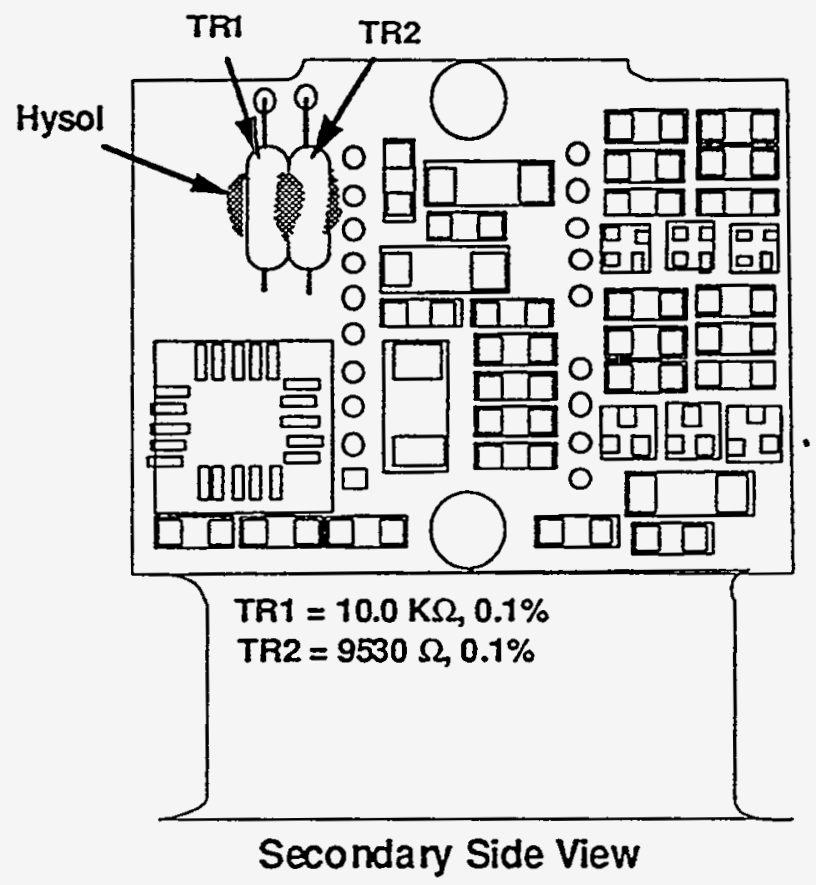

Figure 11.

8.9 Bond TR1 and TR2 to the printed wiring board as shown in figure 11 using EA 934 (reference, Eng. Note C1-S0-005). Bake for 30 minutes at $60^{\circ} \mathrm{C}$.

8.10 Identify the leads of item $61, T 1$, thermistor. Lead $L 1$ is the longest lead, $L 4$ is the shortest and $L 2 / L 3$ is in between. Verify the lead identity by making resistance measurements as shown in figure 12 .

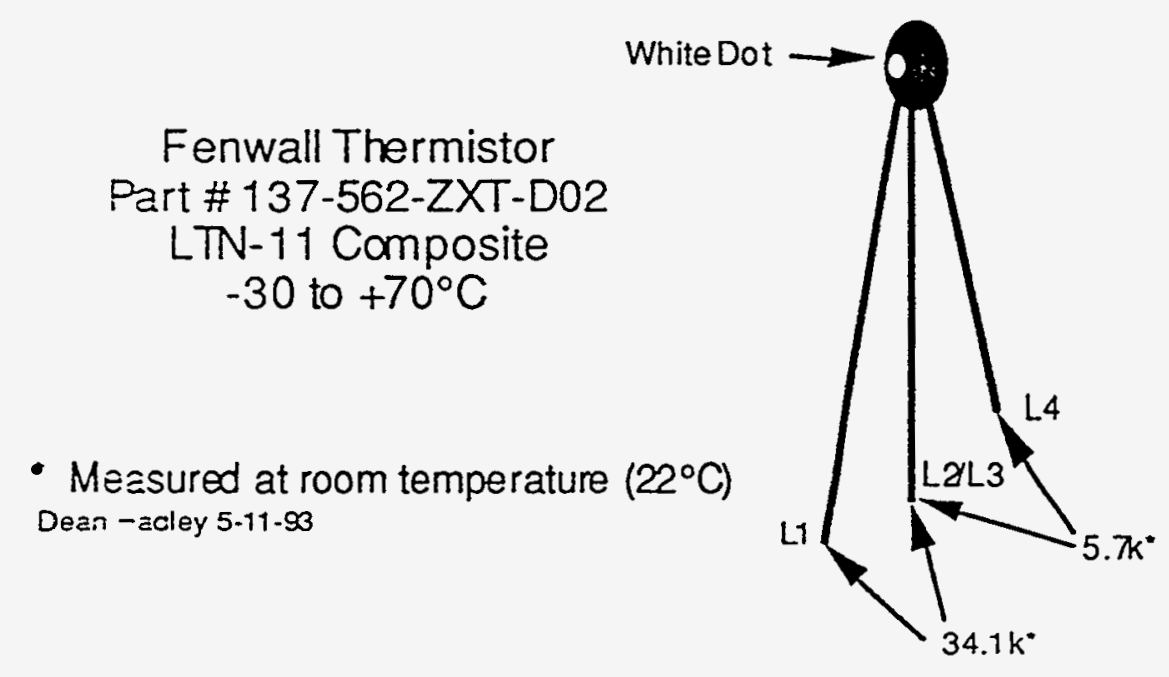

Figure 12. 
8.11 Using $\# 28$ wire wrap wire insulation, insulate lead $L 4$ and $L 1$ to a length of 0.75 inch. Insulate leads $L 2 / L 3$ to a length of 1.5 inch. Use a different color insulation for each lead.

8.12 Insert the lead for $L 4$, from the primary side, through the hole indicated in figure 13. The lead from TR2 is also in this hole. Allow 0.75 inch of lead length between the printed wiring board and the body of the thermistor. See figure 14 for detail.

8.13 Insert the lead for $L 1$, from the primary side, through the hole indicated in figure 13. The lead from TR1 is also in this hole. Allow 0.75 inch of lead length between the printed wiring board and the body of the thermistor. See figure 14 for detail.

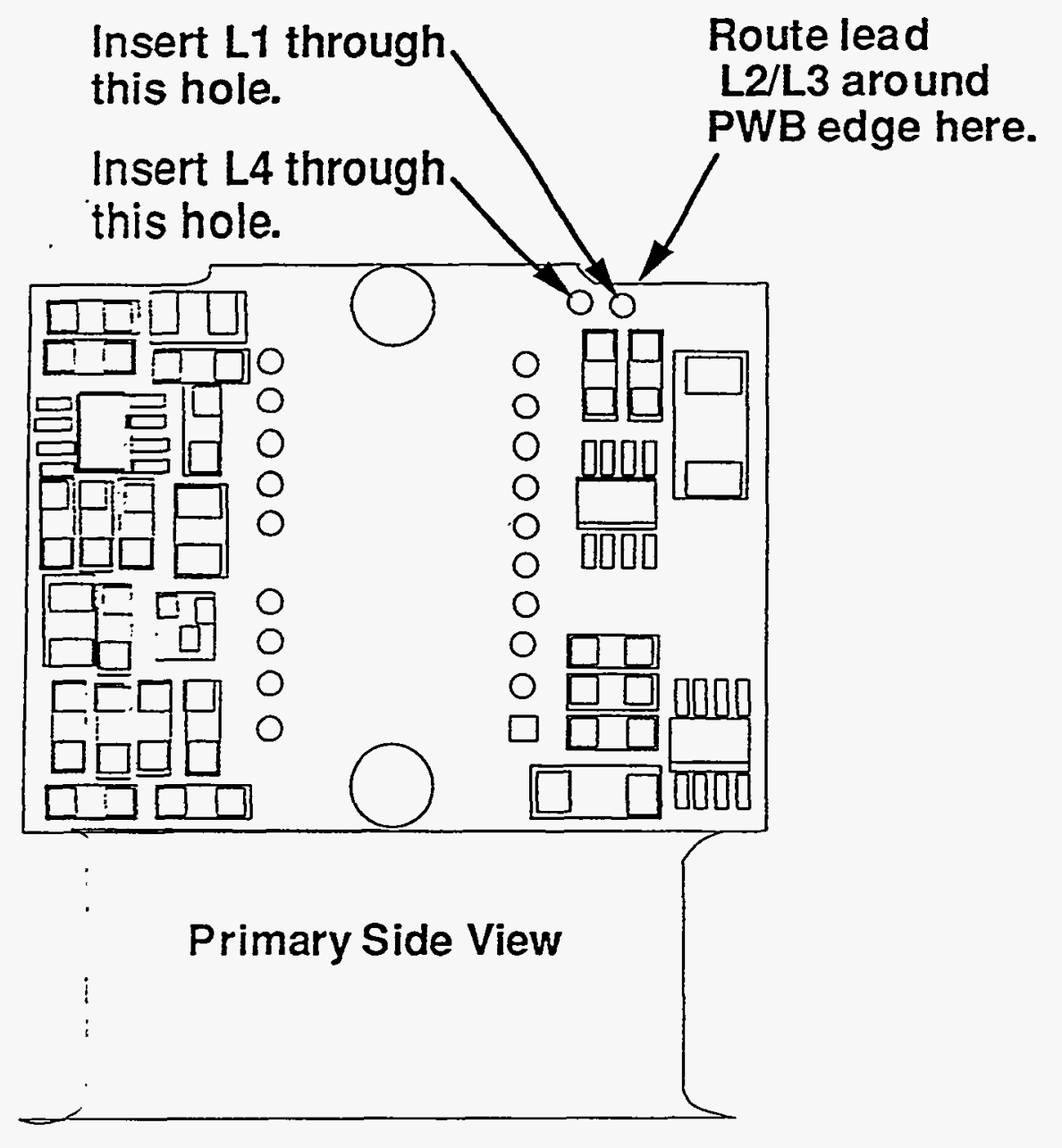

Figure 13. 


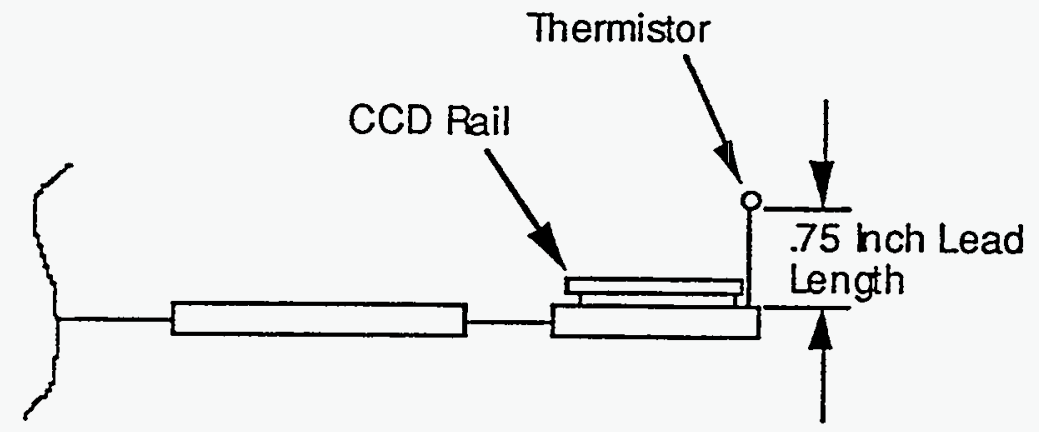

Figure 14.

8.14 Trim $L 4$ to the correct length and solder it along with TR2. Do not trim the lead $L 1$.

8.15 Without trimming the lead, solder L1 and TR1.

8.16 Route lead $L 2 / L 3$ of $T 1$ around the edge of the printed wiring board and to TR1 as shown in figures 13 and 15. Route lead L1 to TR2 as shown in figure 15.

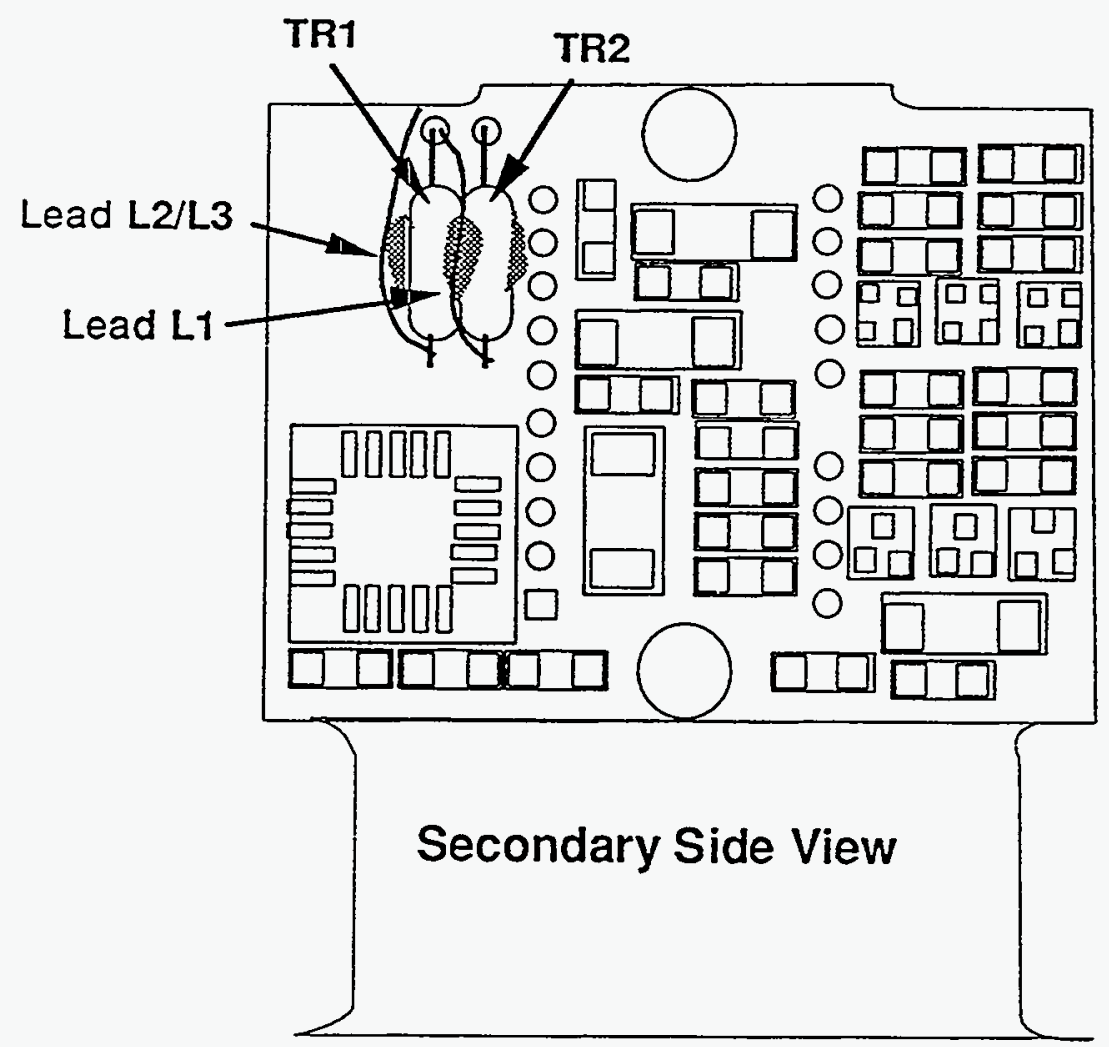

Figure 15. 
8.17 Dress the thermistor wires around the end of the CCD rail as shown in figure 16 below.

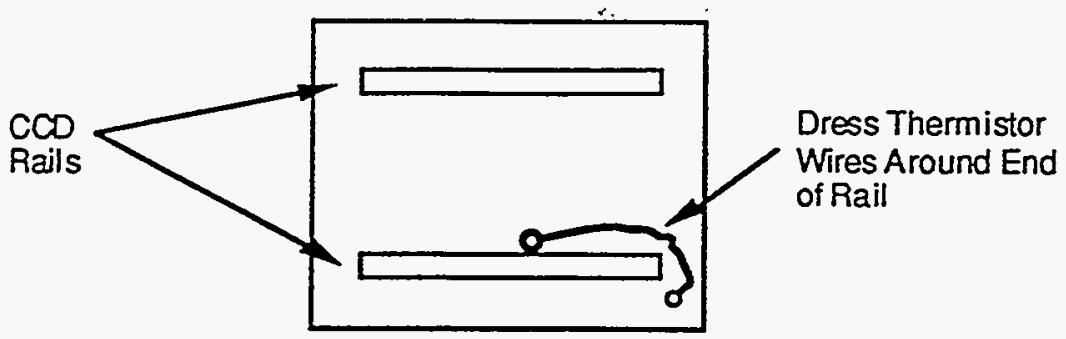

Primary Side View

Figure 16.

8.18 Solder the leads of the thermistor to the leads of TR1 and TR2 as shown in figure 15. The leads of T1 must be wrapped at least 3 times around the lead of TR1 or TR2. Wrap the leads in the middle of the resistor lead.

8.19 Clean and inspect all solder joints per MIL-STD-2000. Rework any substandard solder joints. Record inspection both here and in the certification log worksheets.

Date:

$$
\frac{20 \operatorname{May} 93}{\text { Date Inspected }}
$$

QA:

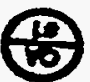

QA Stamp

8.20 Stake the thermistor wires, using EA 934 (reference, Eng. Note C1-SO005), on the secondary side of the printed wiring board as shown in figure 17. Keep the staking on the edge of the printed wiring board as thin a practical.

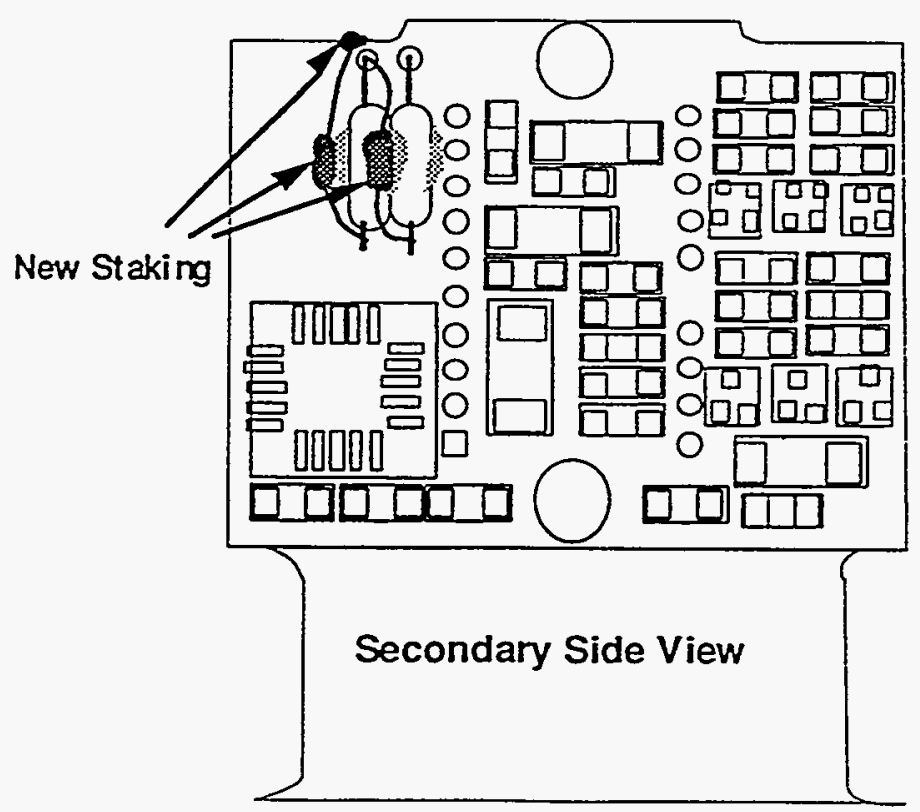

Figure 17. 
8.21 Stake the connector standoff nuts and any other items indicated by Quality Assurance. Bake for 30 minutes @ $60^{\circ} \mathrm{C}$.

8.22 Inspect all staking operations. Record inspection both here and in the certification log worksheets.

Date:

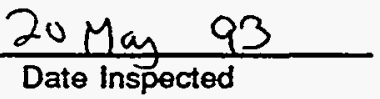

QA:

(중

Date inspected

QA Stamp

Note: Printed wiring boards are to be stored in an airtight, antistatic bag with a desiccant at all times the board is not being loaded, cleaned, inspected, tested or baked. 


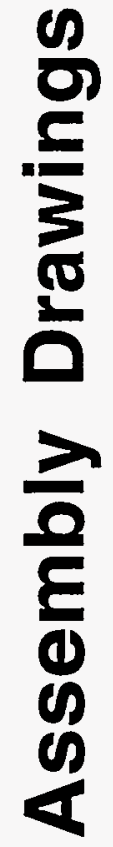



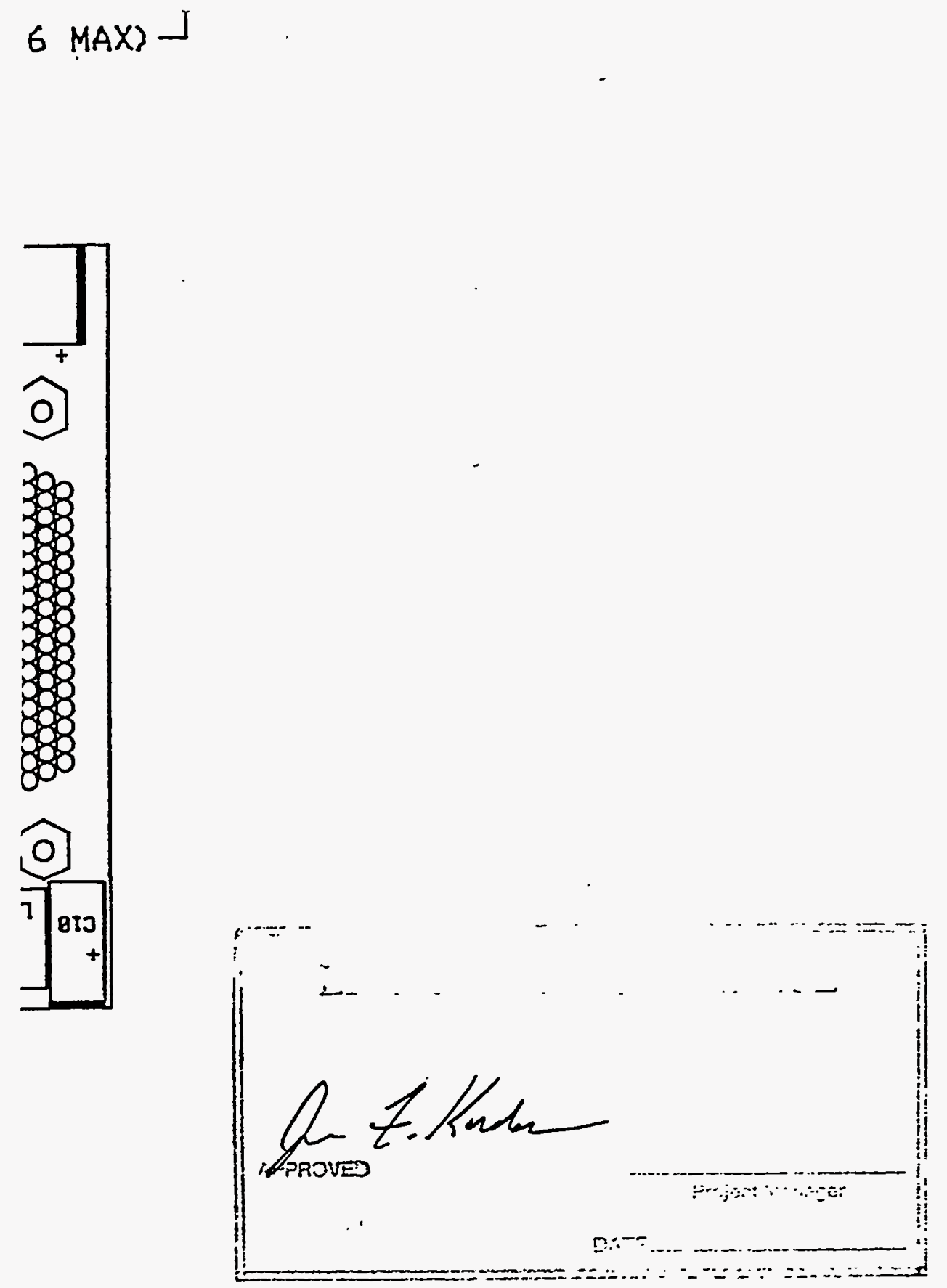

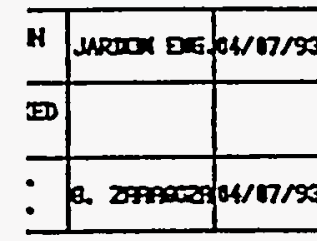
frrace of

$:$

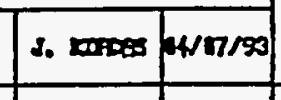
D. Mutesen 04/07/90 HEXT USTE BFALB 2

\section{LAWRENCE LIUERMORE NATIONAL LABORATORY}

PCB, ASSEMBLY-

CAMERA (ACTEL) W/GAIN AND GFFSET CDNTRLL

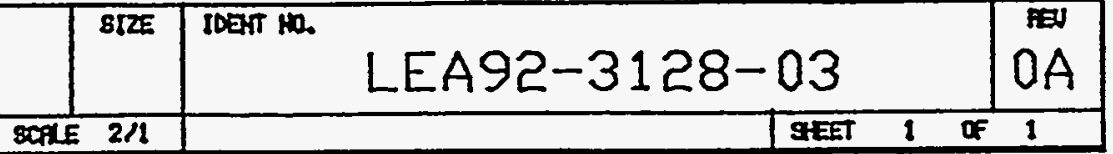


Appendix H.2.5

Certificates of Conformance 
7

3.6 Pre-Test Operations

CAUTION

ESD SENSITIVE HARDWARE.

HANDLE PER MIL-STD-1686 Class 1

X(1) Assure readiness to test, including the following items:

(a) Visual examination of the test item and its interfaces, including any special test instrumentation.

(b) Calibration is current for measuring instruments

(c) Proper edition of the procedure, and QA approval of any unincorporated redlines.

(c) Notification of QA of the time that testing will begin.

X(2) Record the "Occasion for Test" on all Data Sheets.

* (3) On the applicable data sheets, record the required information for measuring equipment to be used in the test. Verify that all such equipment bears current calibration stickers, and that calibration will not expire prior to the end of the test.

X (4) Have completed Actel Camera Array Test Board Certification C1-EE-033.

X(5) Solicit and obtain the QA inspector's "OK to Continue."

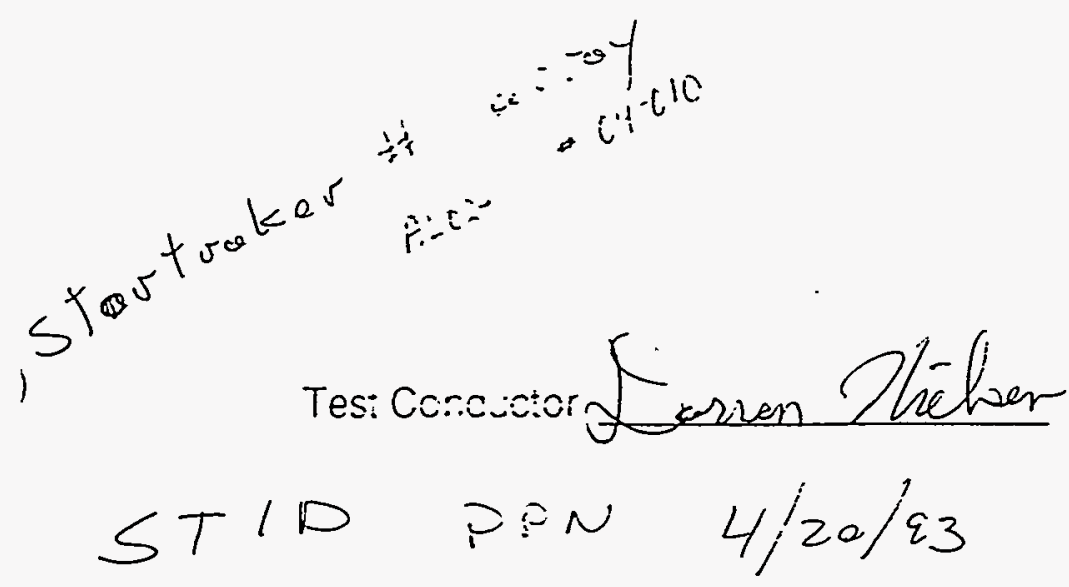




\section{Functions to Be tested}

1. Sasi Functions

- Check bits can be set and cleared and reag back.

Name:

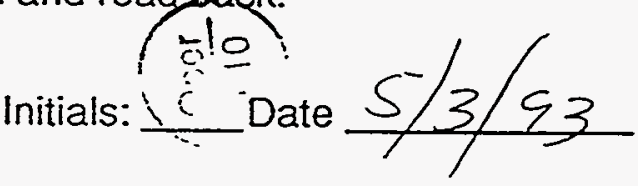

2. Double Correlated Sampling

TP14 is OL2

TP15 is ORfet

TP16 is OR

Name:
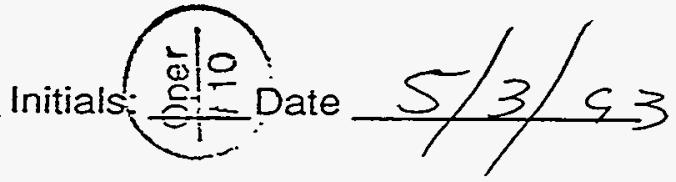

3. Precision Integration mode Check and Frame Enable \{frame xier of UV-vis arrays\}

TPG SM1

TP10 Sivio

TPII EOL

TP3 I'Syric \{frame enable $\}$

IFT3 VTC

TPIL

Name:

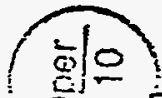
Initials:

.

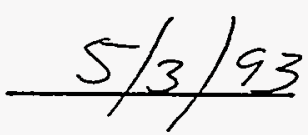

4. Tes: rritialization

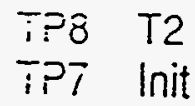

Nam̃:

DATA is to go in certification log of camera that array is going into. 


\section{$3.7 \quad$ TEST}

Test Stari Date: $5 / 3 / 43 \quad$ Test Completion Date: $5 / 3 / \varepsilon 3$

Equipmeni Used

TDS 542 $\frac{B 02376010 / 1 / 53}{M_{a C 2} D_{2 x} 5251672}$

Enter Name oi LabView programs to Use

Name

Date Created

Actel Test Piogram

$4 / 24 / 43$

Date Modified

$5 / 3 / 53$

\section{NOTES:}

Test Concues:

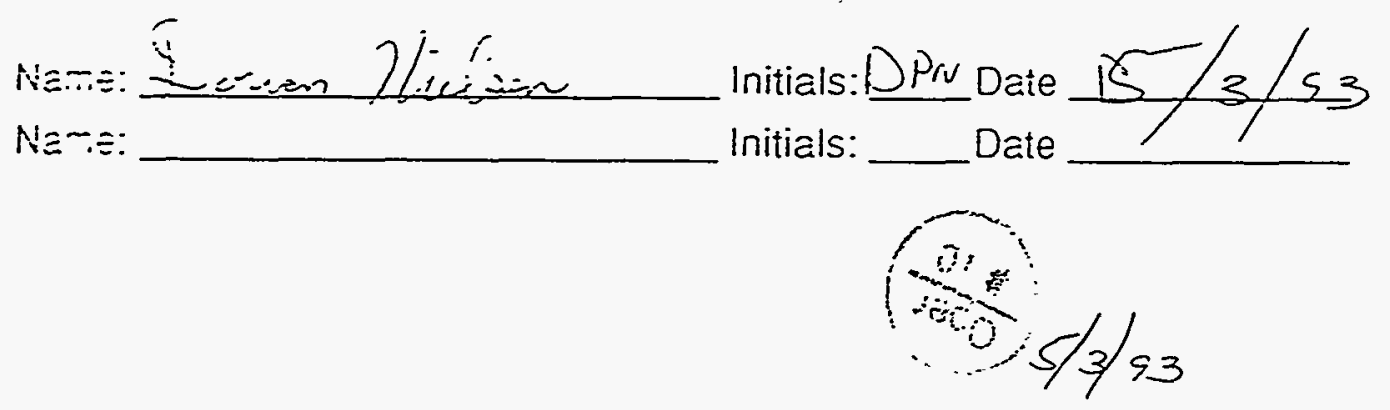




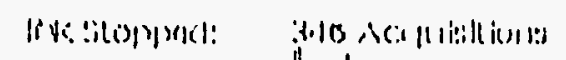

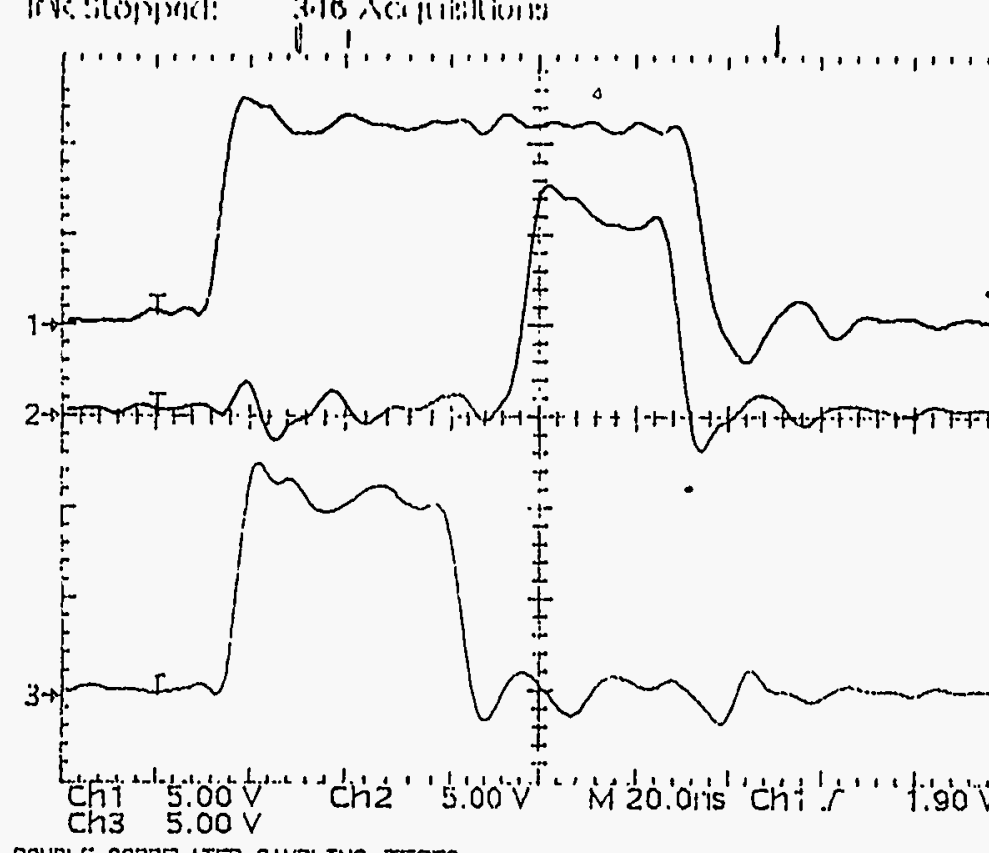

QOUBLE COARELATED SAMPLING TEST2

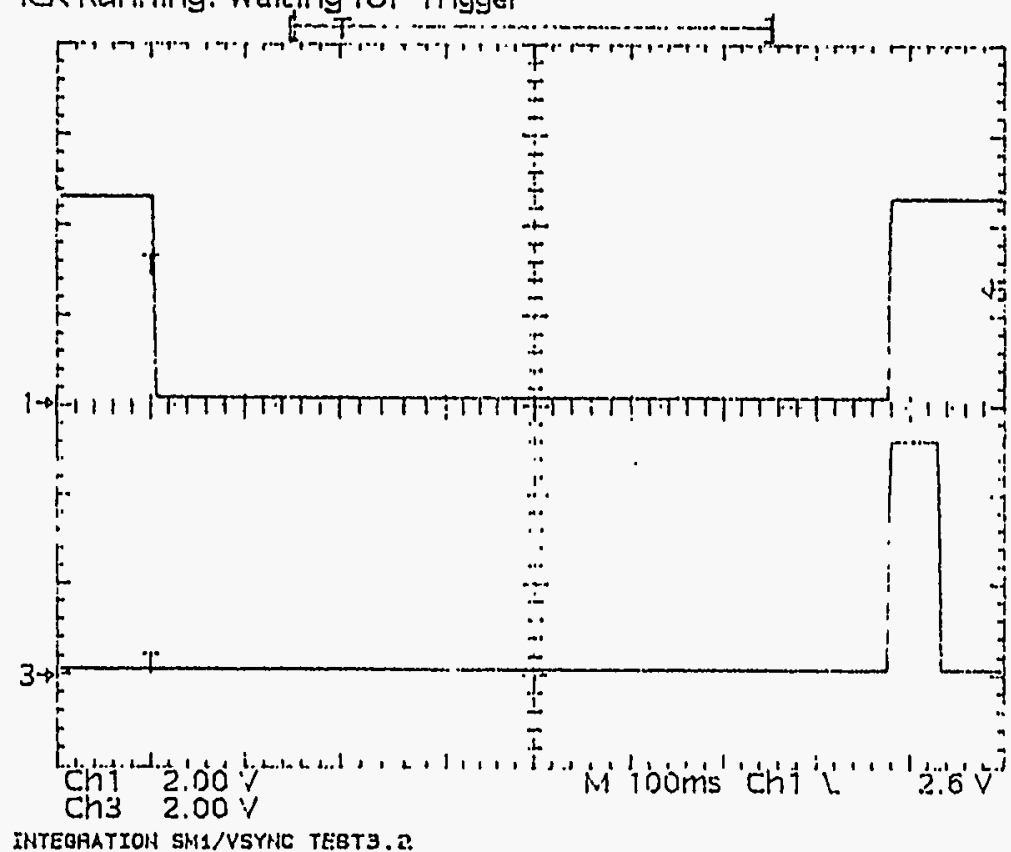

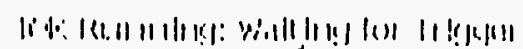

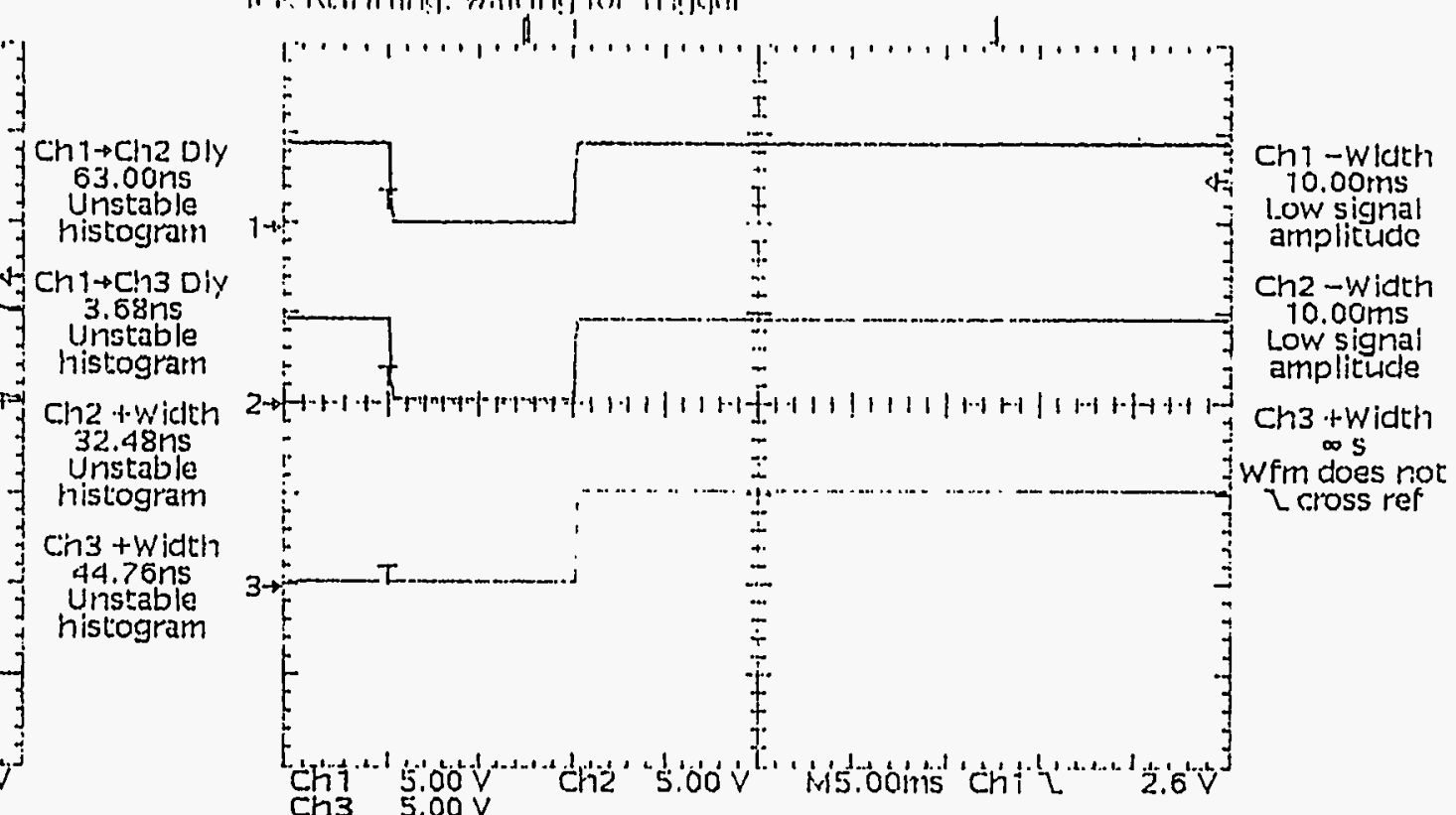

INTEGATIION SM1/GMO/YSYNC TEST3 'I

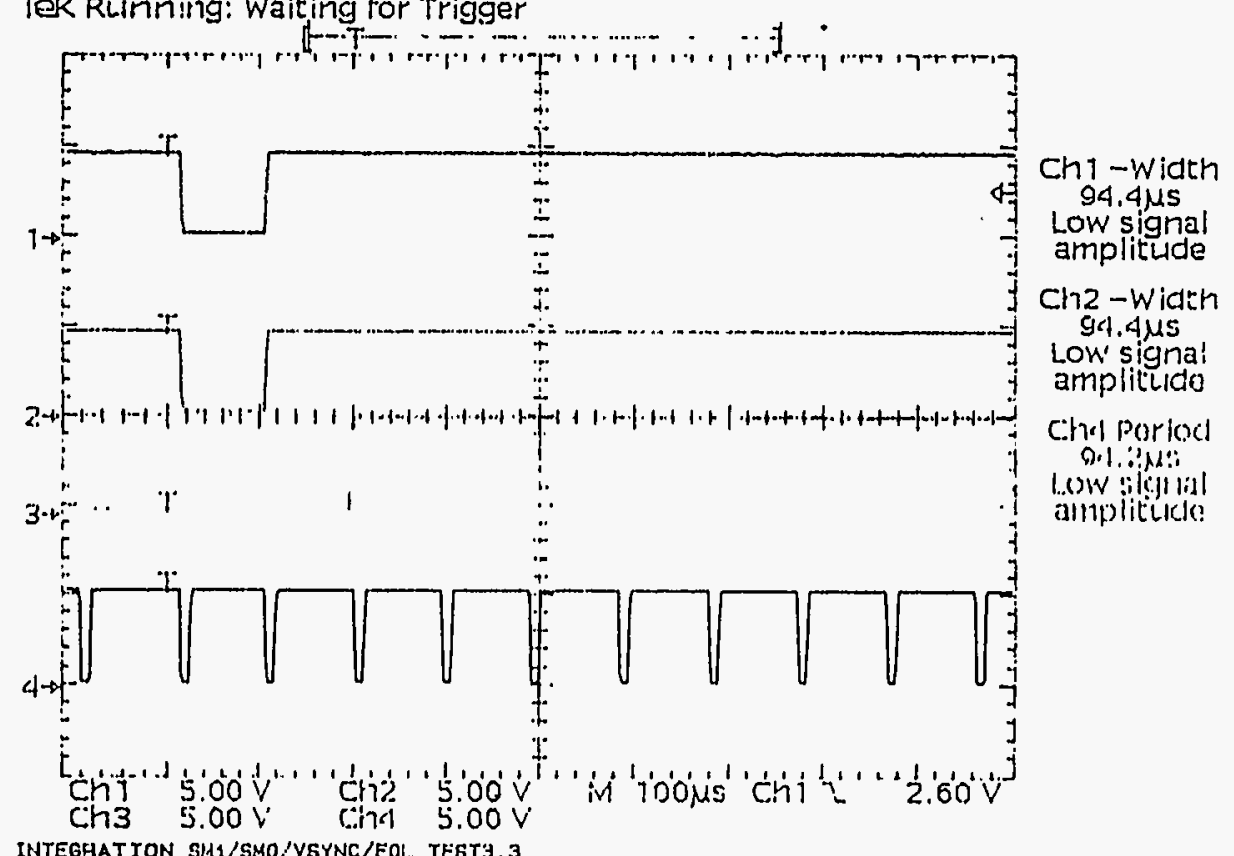
INTEGHATION SH1/SMO/VEYNC/EOL TEGT3.3 
F153.1 $27 / 7845$

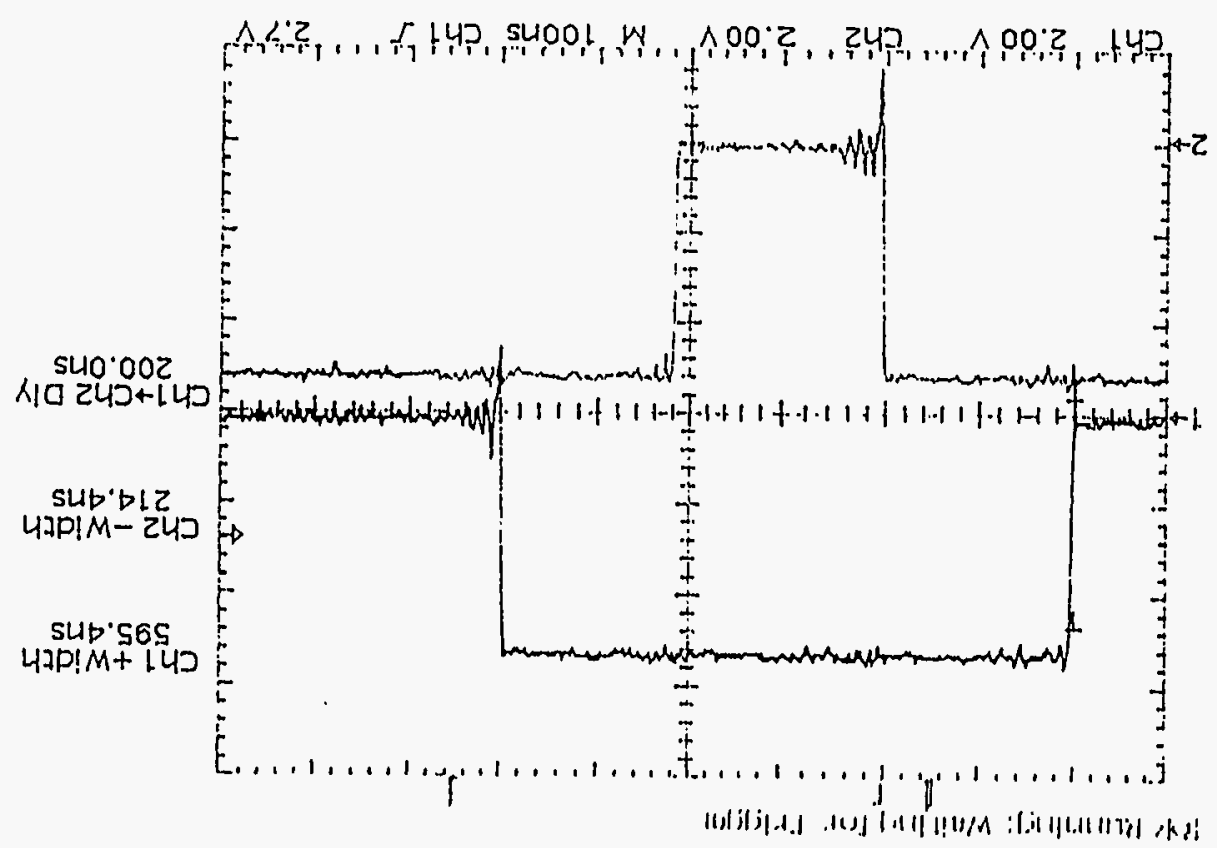

D.ELS:AL TUSNOKS/THE NOILVHOZUNI

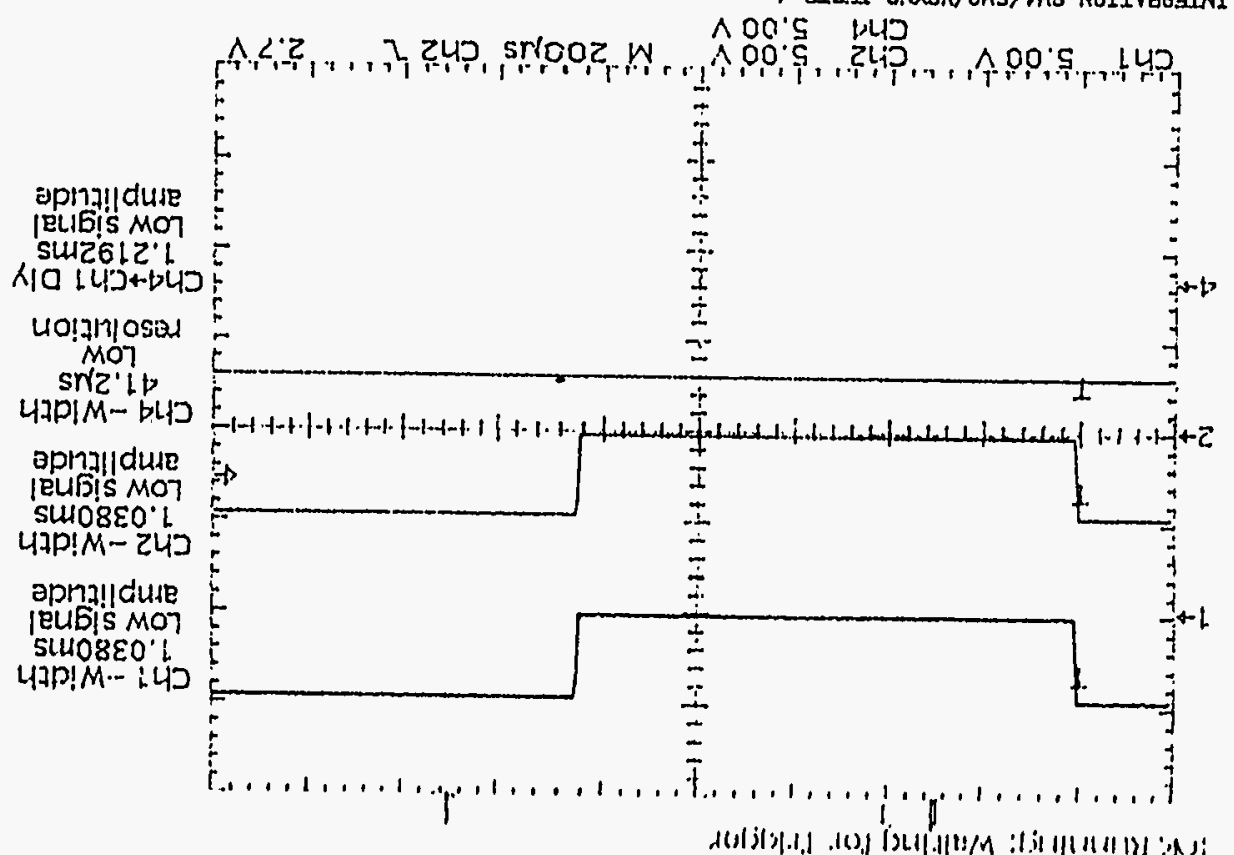


ACTEL CAMERA ARRAY TEST

PROGRAM OF ARRAY AND DATE CODE

$.1 \mathrm{~d}$

$4-20-93$

TESTER NAME DARRON NIELSEN

$5 / 3 / 93$

$20: 59$

SASI BIT TEST 1

SASI BIT TEST 1 PASSED

$5 / 3 / 93$

$20: 59$

DOUBLE CORRELATED SAMPLING TEST2

DOUBLE CORRELATED SAMPLING TEST 2 PASSED

$\mathrm{CH} 1 \rightarrow \mathrm{CH} 2$ DELAY

6.30E-8s

$\mathrm{CH} 1 \rightarrow \mathrm{CH} 3$ DELAY

$3.68 \mathrm{E}-9 \mathrm{~s}$

CH2 +WIDTH

$3.25 \mathrm{E}-8 \mathrm{~s}$

$\mathrm{CH} 3+$ WIDTH

4.48E-8s

$\mathrm{CH} 1+$ WIDTH

1.00E-7s

$5 / 3 / 93$

$21: 04$

INTEGRATION SM1/SMO VSYNC TEST3.1

PASSED

PARM ID 09

PARM ID 11

PARM ID $26 \mathrm{~A}$

PARM ID 30

PARM ID 510

CH1 -WIDTH

$1.00 \mathrm{E}-2 \mathrm{~s}$ 
$1.00 E-2 s$

$\mathrm{CH} 3+$ WIDTH

$9.90 \mathrm{E} 37 \mathrm{~s}$

$5 / 3 / 93$

$21: 07$

INTEGRATION SM :VSYNC TEST3.2

PASSED

PARM ID 09

PARM ID 11

PARM ID $2 \mathrm{FF}$

PARM ID $31 \mathrm{~F}$

PARM ID $51 D$

CH1 -WIDTH

7.73E-1s

$\mathrm{CH} 3+$ WIDTH

5.50E-2s

$5 / 3 / 93$

$21: 09$

' 'TEGRATION SM1:SMONSYNC/EOL TEST3.3

-ASSED

PARM ID 09

PARM ID 11

PARM ID 21

PARM ID 30

PARM ID 5 1D

$\mathrm{CH} 1-$ WIDTH

9.90E37s

$\mathrm{CH} 2+$ WIDTH

$9.90 \mathrm{E} 37 \mathrm{~s}$

$\mathrm{CH} 4$ PERIOD

$9.90 \mathrm{E} 37 \mathrm{~s}$

$5 / 3 / 93$

$21: 13$

INTEGRATION SM1/SMO/VSYNC TEST3.4

PASSED

PARM ID 09

IRM ID 11 
PARM ID 2 B

PARM ID 30

PARM ID $51 D$

.11-WIDTH

1.04E-3s

$\mathrm{CH} 2$-WIDTH

1.04E-3s

CH4 -WIDTH

4.12E-5s

$/ \mathrm{CH} 4 \rightarrow / \mathrm{CH} 1$ delay

1.22E-3s

$5 / 3 / 93$

$21: 17$

init/t2 TEST4

PASSED

$\mathrm{CH} 1$-WIDTH

5.95E-7s

$\mathrm{CH} 2$-WIDTH

2.14E-7s 
SPRAQUE

$P Q P * 97$

$7 / 16 / 82$

Customer NAME Capatone Clectrones DATE $1-8-93$ CUSTOMER ORCER \# CUOTOMER PART \# CURROGFH475KC LOTHIDATE CODE $93607 / 9302 T$ spraque M.O. A5397401 SUMMARY OF TEST DATA MIL-C- $55365 \mathrm{C}$

QRQUP A INSPECTION DATA (WeIBUII) C

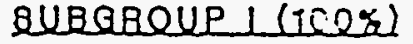

Welbull Life

SUBQBQUP

DC Loakage

Capaollenoe

Disalpallon Faotor

EBR (whon appllosble)

Heohanloal Exam

\&UBGRQUP Ш

VIAUAI Exam

SUBQReUP IV

otablilly at Low a

Hloh Tomporalure

SURGBQUP $Y$

solderabllily ..

SUBGRQUP

Vibrallon, High fiequenoy,

Thermal 8 hook

SUBGRQUP II

Roslelanco To 8olicer tical

Molslure Raslalance

\&URQRQUP U

Lile (2000 hrs. +1:2500)

SUBgBQUe $Y$

Roslalanoe lo Bolvento

(when applloablo)
BEE AMQUNT AMQUNT ALLEWER

PABA. IESTER EALLED EALLUREQ

4.7.17 $100 \% F / R=.005 / \because \mathrm{N} / \mathrm{A}$

4.7 .4

4.7 .6

4.7 .0

4.7 .10

4.7 .2

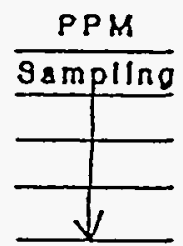

\begin{tabular}{c}
0 \\
\hline 0 \\
\hline 0 \\
\hline 0 \\
\hline 0 \\
\hline
\end{tabular}

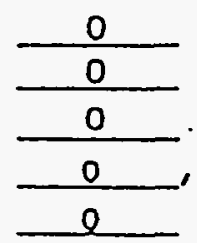

4.7 .2
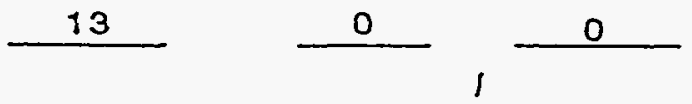

4.7 .12

13
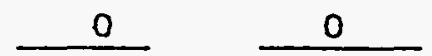

4.7 .15

13
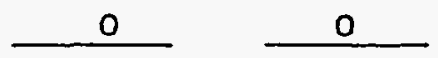

SRQUP E INSPECTION OATA

MOTE, Capaolsore lurnished agelnat the eppllozble epeolflostlon and a represented by thle taet data meet all regulrementa.

- N/A lo gold plaled iermination finishos.

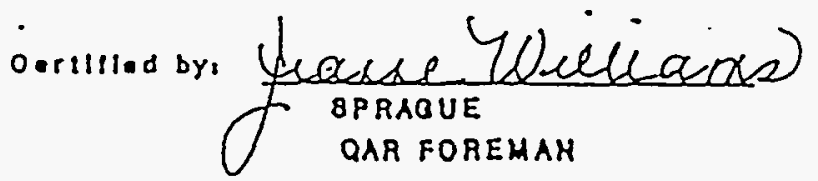


SPRAQUE

CONCORD, NEW HAMPBHIRE
customer name Capstone Electronex Onp Date $12 / 34 / 92$

PQP* 37

$7 / 15 / 82$ CUBTOMER ORDER $\#-6 \times 12344000$ CUSTOMER PART \# CUSRO6 HH226KC BPRAQUE M.O. A53974-03 SUMMARY OF TEST DATA MIL-C- $55305 \mathrm{C}$

RBOUP A INSPEGTION DATA (WOIbUUl)

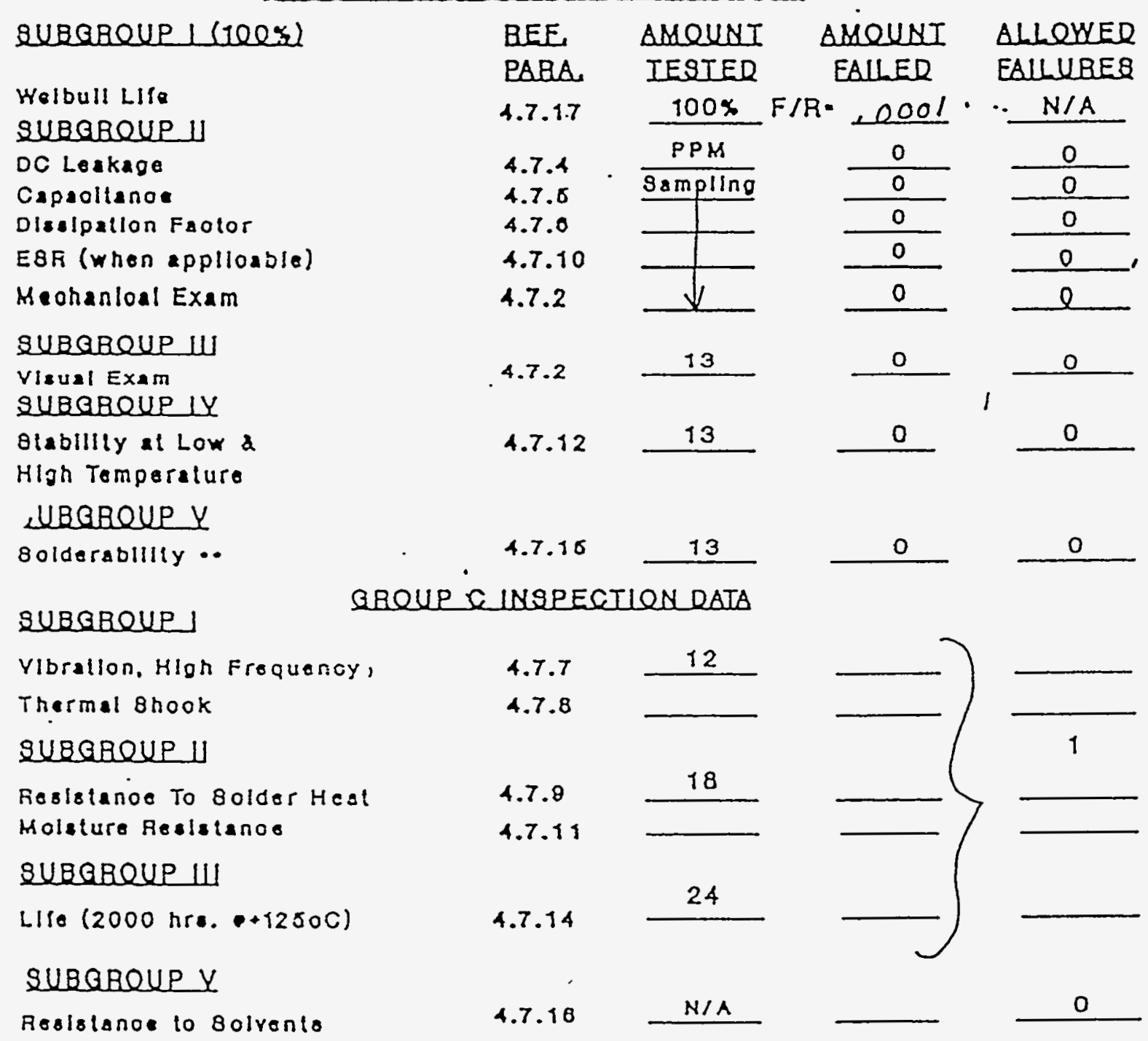

(whon appilosble)

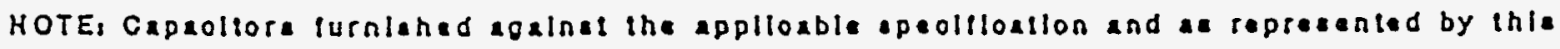
lact deta meet all requiremente.

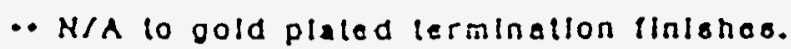

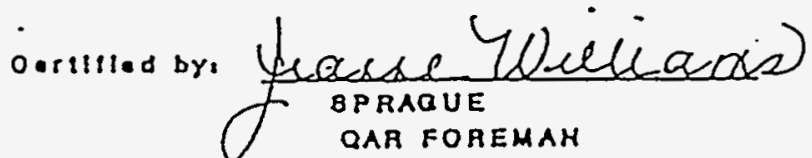


SPRAQUE

CUstomer name Capotone Clectróces CUBTOMER ORDER \# $6 \times 12344000$

DATE

GZQUP A INSPECTLON DATA (Wolbull) C

\begin{tabular}{|c|c|c|c|c|}
\hline ¿UBGBQUe 1 (ines) & $\begin{array}{l}\text { BEE. } \\
\text { PABA. }\end{array}$ & $\begin{array}{l}\text { AMQUNI } \\
\text { IESTED }\end{array}$ & $\frac{\text { ABOUNT }}{\text { EAILER }}$ & $\begin{array}{l}\text { ALLOWED } \\
\text { EAlWUBES }\end{array}$ \\
\hline Holbul! LIF & 4.7 .17 & $100 x$ & $F / R=.0005$ & - N/A \\
\hline $\begin{array}{l}\text { SUBaBauP II } \\
\text { DC Leakage }\end{array}$ & 4.7 .4 & PPM & 0 & 0 \\
\hline Capaollano: & 4.7 .6 & sampling & 0 & 0 \\
\hline Dlusipallon Facior & 4.7 .0 & & 0 & 0 \\
\hline E8R (whon eppllcste) : & 4.7 .10 & & 0 & 0 \\
\hline Moohanloal Exam & 4.7 .2 & $\sqrt{2}$ & 0 & e \\
\hline $\begin{array}{l}\text { SURGRQUP UU } \\
\text { VIsusi Exam }\end{array}$ & 4.7 .2 & 13 & o & 0 \\
\hline QUBRBQUE IY & & & & l \\
\hline $\begin{array}{l}\text { Olabllily at Low a } \\
\text { High Tomperature }\end{array}$ & 4.7 .12 & 13 & O & 0 \\
\hline $\begin{array}{l}\text { SUEGRQUP Y } \\
\text { soldorabllliy }\end{array}$ & 4.7 .15 & 13 & o & 0 \\
\hline SUBGRQUP & INSPES & QNDEIA & & \\
\hline Ylbratlon, Hloh Frequenoy, & 4.7 .7 & 12 & & \\
\hline Thermal 8 hook & 4.7 .8 & & $\longrightarrow$ & \\
\hline SUBGRQUP U & & & & 1 \\
\hline $\begin{array}{l}\text { Resletenoc To Boles Heat } \\
\text { Holsture Roslatence }\end{array}$ & $\begin{array}{l}4.7 .8 \\
4.7 .11\end{array}$ & 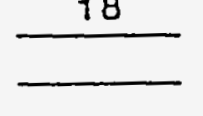 & & \\
\hline SUBQRQUP Ш & $A$ & 24 & & \\
\hline surargue $y$. & 1.7 .18 & N/A & & 0 \\
\hline
\end{tabular}

Rosistsnoe to ooiverits

(when appllosblo)

HOTE, Cepeollora iusnished agelnat the epplloable epoollloallon and es represenicd by thle leat dalx metet all regeiramente.

- N/a lo gold plated ierminalion finlohos. 


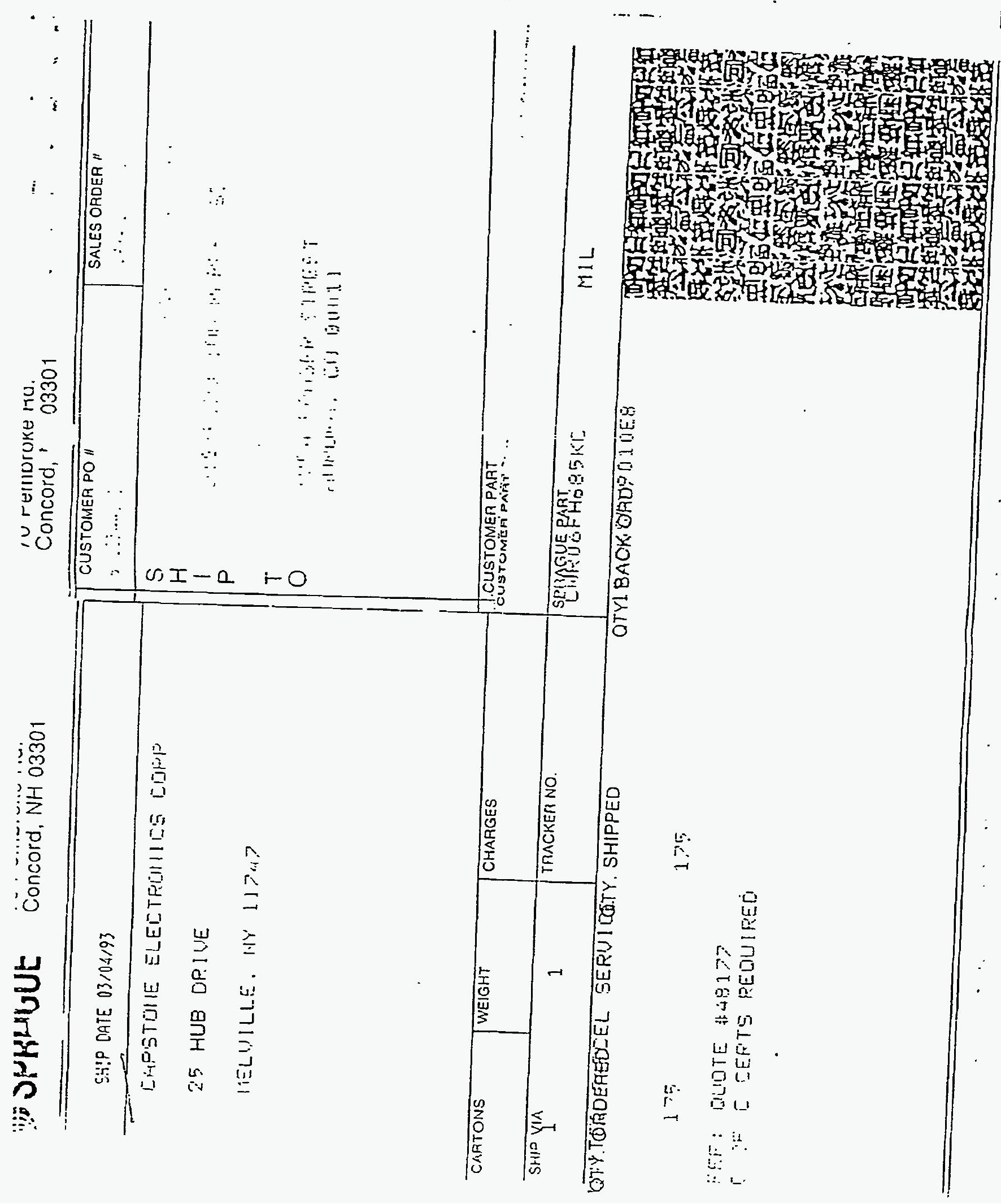




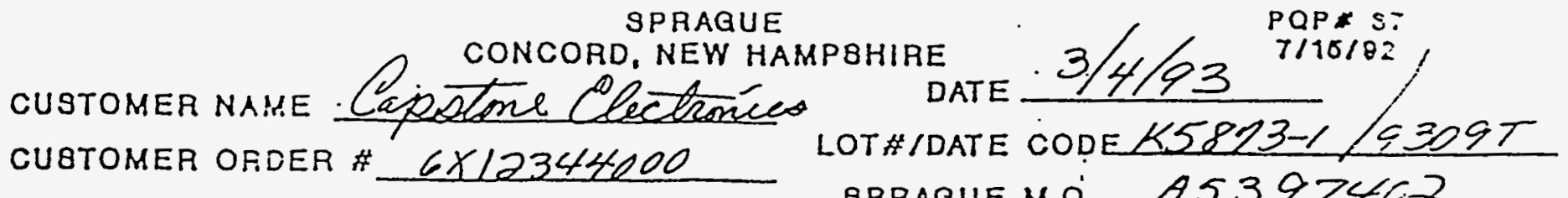
CURTOMER PAPT $\%$ CUPOGFHGQSKC BPRAQUE M.O. A5397462 SUMMARY OF TEBT DATA AMOUNT BHIPPED MIL-C- $55386 \mathrm{C}$

GEUP A UNBPECTION DATA (Molbuli) C

\section{QU日GBQUP 1 (1025)}

Welbull Life

SUBRBQUP

DC Leakage

Capeollanoe

Dlaclpallon Faolor

EQR (whon appllosble)

Heohanloal Exam

BUBRBQUP U

VIsual Exam

SUBRBQUP IY

Qlabllily at Low \&

High Temporalure

SUBGBQUP $Y$

soldarablilty...

sUвQReUP

Ylbrallon, HIoh fres:ancy,

Thermal 8 hook

BUBQRQUP

Reslstanco To Boider ticel

Molsluro Roslatance

SUBRRQUP iU

Lllo (2000 hrs. + +12500)

SUBRBour $Y$

Roslolance lo Bolvenis

(whon applloabla)
BEF

PARA TEQTED

AMQUNT

4.7 .17

4.7 .4

4.7 .8

4.7 .0

4.7 .10

1.7.2

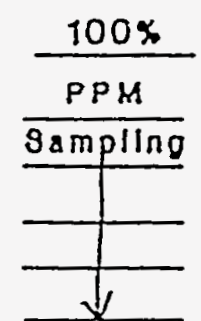

AMQUNT EALLEQ"i

QLLEWED

EAILURES

N/A

$\frac{0}{0}$

O

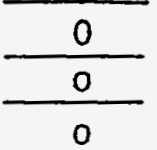

$\frac{0}{0}$

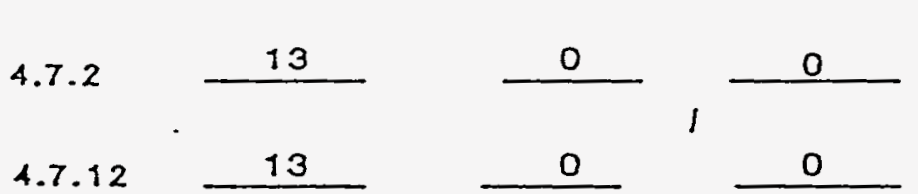

4.T.16

13

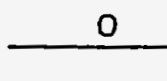

GRQUPC INSPECIIEN RATA

HOTE, Capaoltore surnished eqalnat the applloxble epeofflostlon end as reprecented by thle taet data $m \in$ all regutrentonta.

- Mia lo gola plalez iermination finishoo.
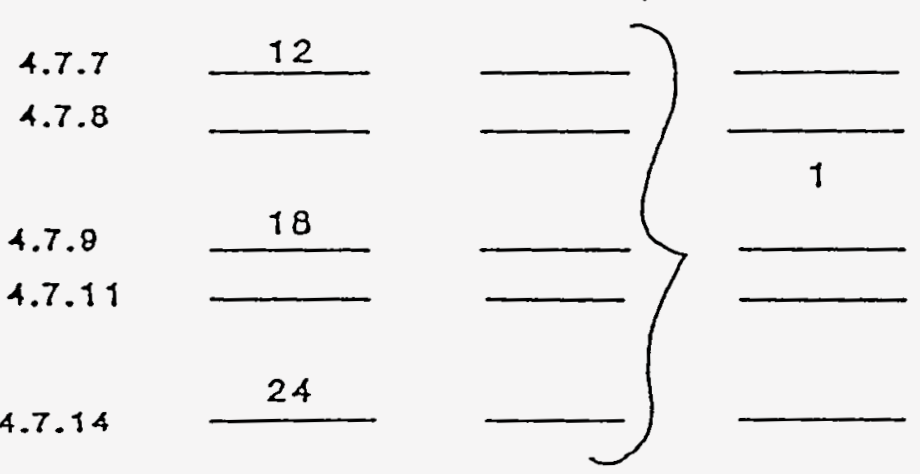

$4.7 .10 \quad N / A$

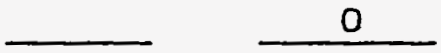

0

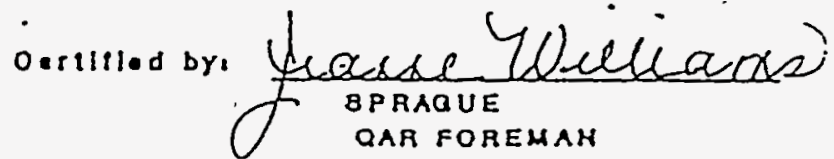




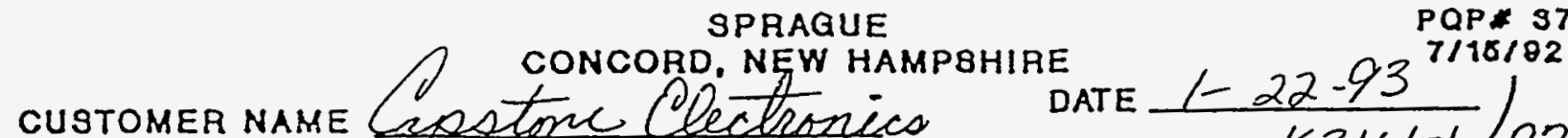

PQP * 97 customer nAME Lastonc (Dectronico CUBTOMER ORDER \# $6 \times 1234400 /$ CUSTOMER PART \# CUR O6JH LOT IDATE CODEK3/61-1/930\%sPRAGUE M.O. A5397702 SUMMARY OF TEST DATA AMOUNT BHIPPED 200 MIL-C-55365C QRQUP A INSPECTION DATA KWOLWULl C SUBRRQUP L (100\%) BEE AMQUNT AMQUNT PABA. IESTED EALLED

ALLEWEQ

Welbull LIfe

4.7 .17 $100 \% F / R$

$905 \%$

EALUUREQ

SUBGROUP U

$\because N / A$

DC Leakage

Capeoltano

Dlesipation Faotor

E8R (whon applloable)

4.7 .4

4.7 .6

4.7 .6

Meohanloal Exam

4.7 .10

4.7 .2

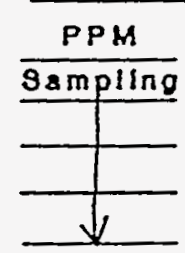

\&UBgreup III

VIsual Exam

4.7 .2

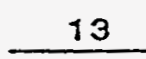

4.7 .12

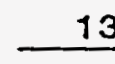

13

4.7 .15

13
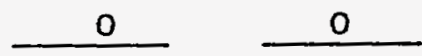

\section{SUBGROUP}

\section{SRQUP EINSPECTION DATA}

Vibrallon, HIgh Frequenoy,

$4.7 .7 \quad 12$

Thermel shook

4.7 .8

SURGRQUP

Resistance To Bolder Heat

Molsiure Reslstance

4.7 .9

18

QUBRRQUP HII

Llle (2000 hrs. +1250G)

4.7 .11

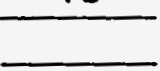

$4.7 .14 \quad 24$

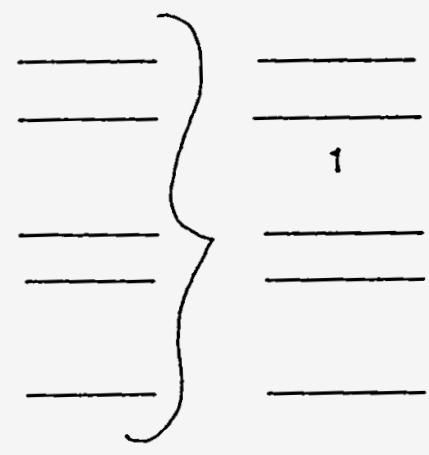

SUBQRQUP $Y$

Resistance lo Bolvonis

4.7.16 N/A
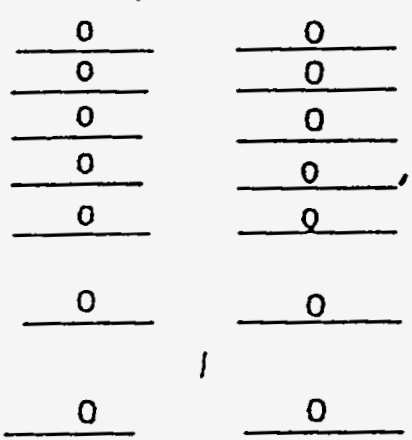

(when applloablo)

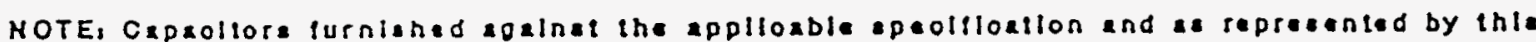
tert dala meet all tequlramente.

- N/A to gola platod termination ilinionos.

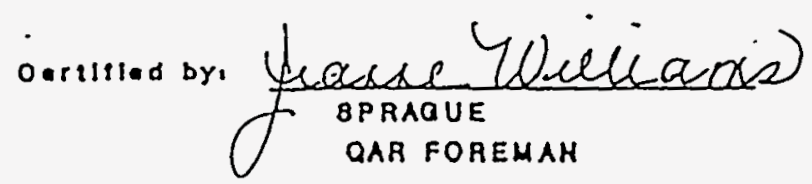



SPRAQUE

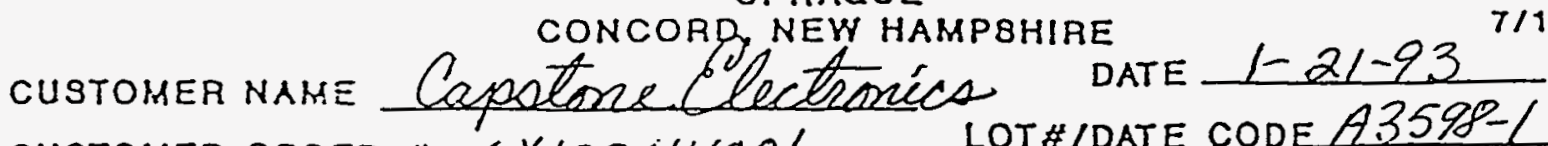

$P Q P * 97$

$7 / 16 / 82$
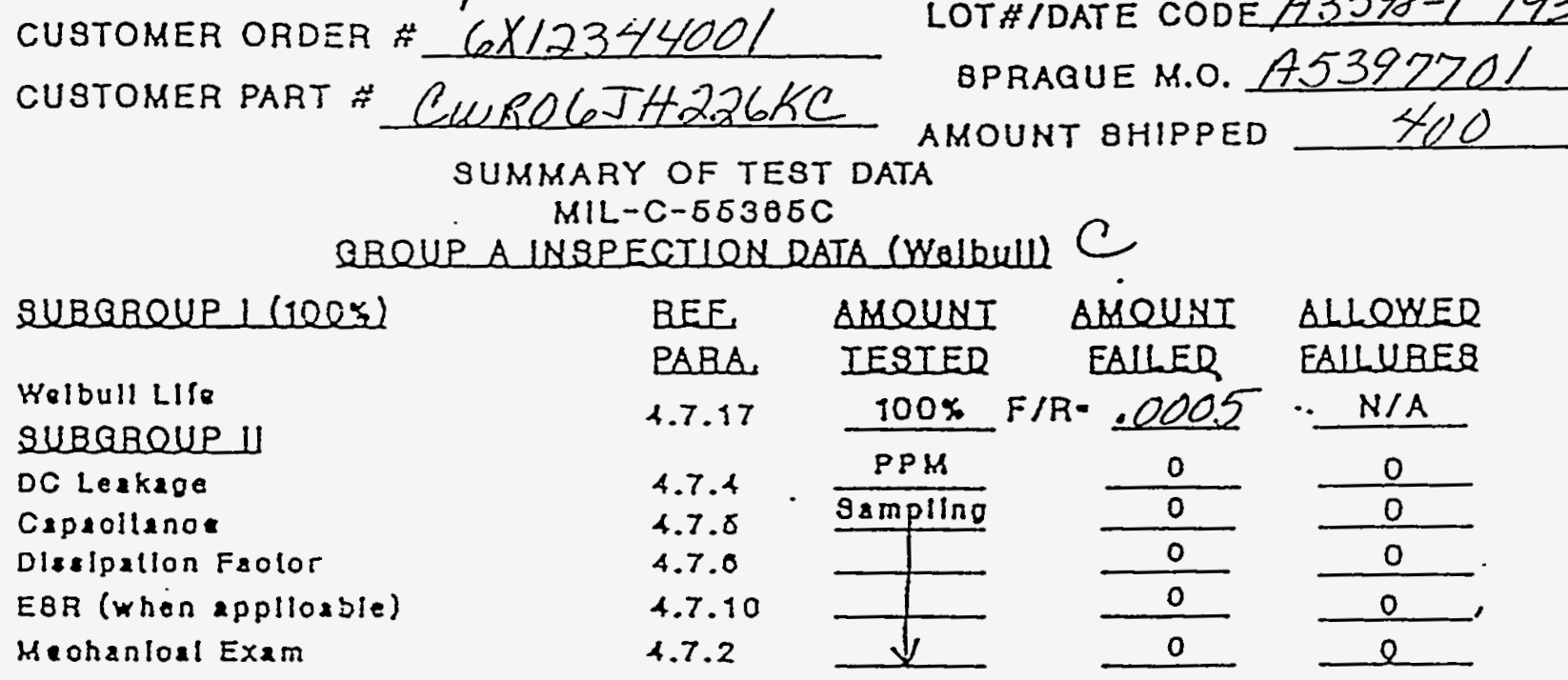

SUBQRQUP U

VIsual Exam

4.7 .2

13

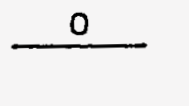

SUBQRQUP IY

Blabillly at Low \&

4.7 .12

13

4.7 .16

13
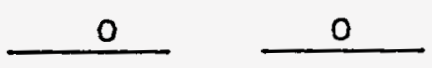

SUBageue $Y$

solderabllily ..

SURGROUP

GBQUP \& INSPECTIEN DATA

Ylbrallon, Migh frecuenoy,

4.7 .7

12

Thermal 8 hook

4.7 .8

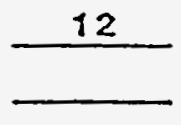

SURGRQUP U

Resisteño To Bolder Hesl

4.7 .8

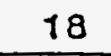

Molslure Reslstanoe

4.7 .11

SUBRBQUP III

Lifo (2000 hrs. $+1250 \mathrm{C})$

4.7 .14

24

SUBGROUPY

Resisisnoe to solvents

4.7 .98

$N / A$

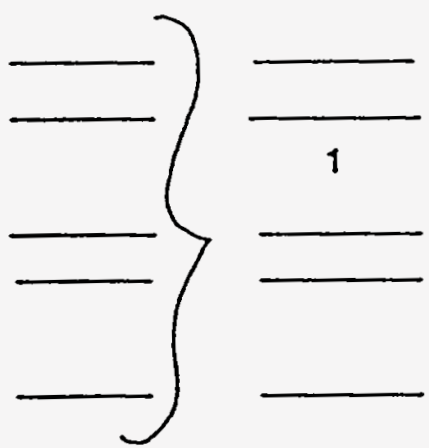

(when appllosbie)

HOTE, Cepeoltora lurnisted sosinal the applloxble epeolfloallon and ax represented by thla last dalx ment all requlramenle.

- N/a lo gold plaled lerminallon linizhos.

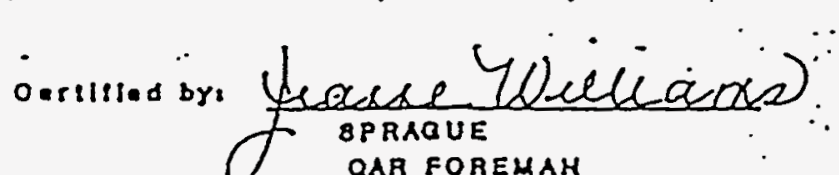


CUSTOMER NAME L CUSTOMER PAFT $\because$ BPRAQUE M.O. A5397201 BPRAQUE M.O. $\frac{15397}{12}$ SUMMARY OF TEST DATA MIL-C- $563 B 5 C$

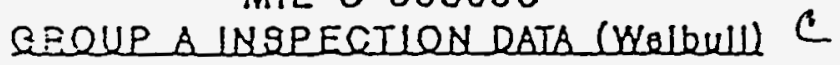

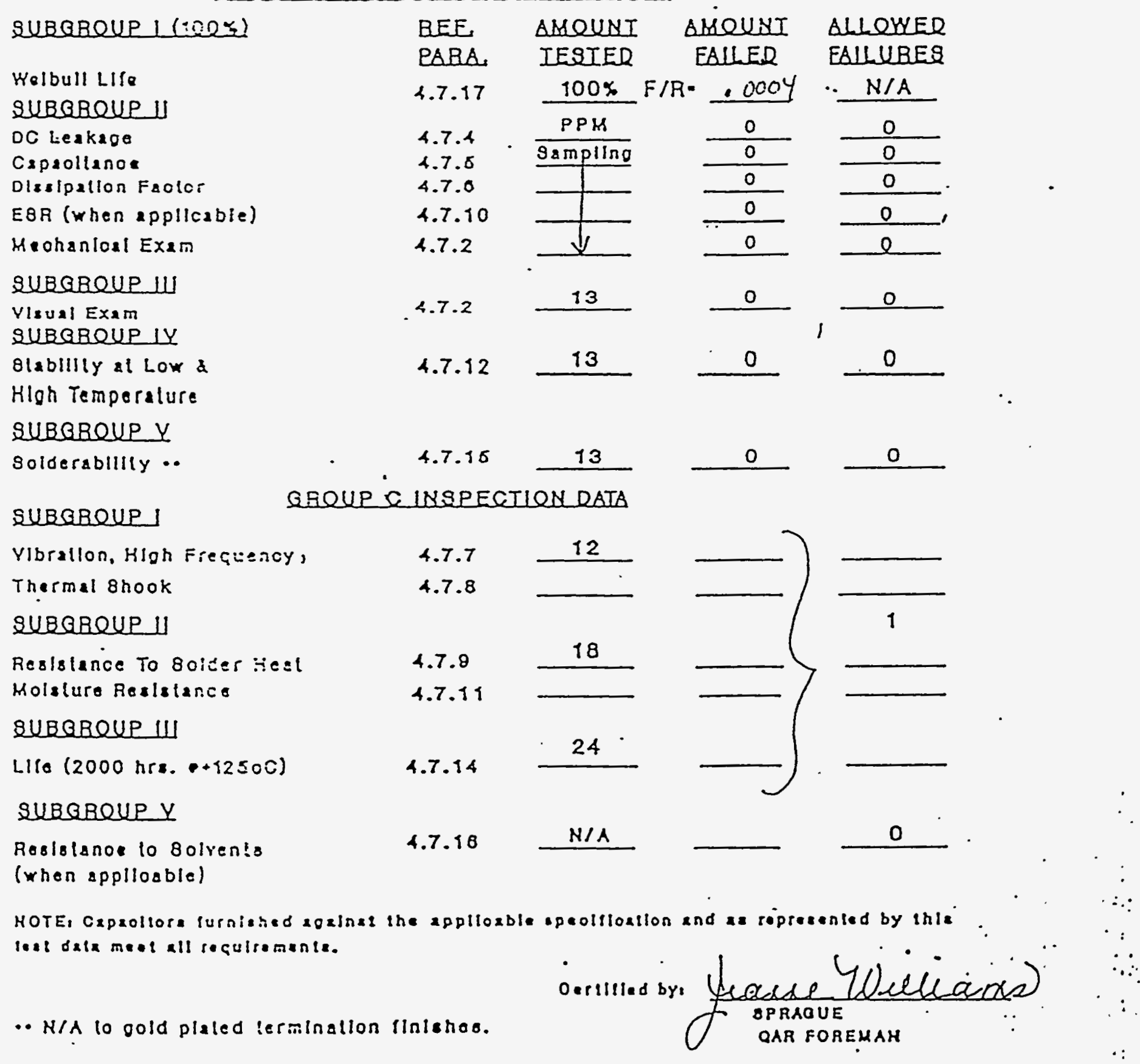




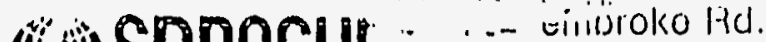

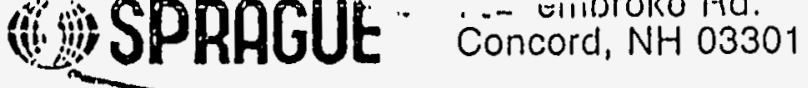

1

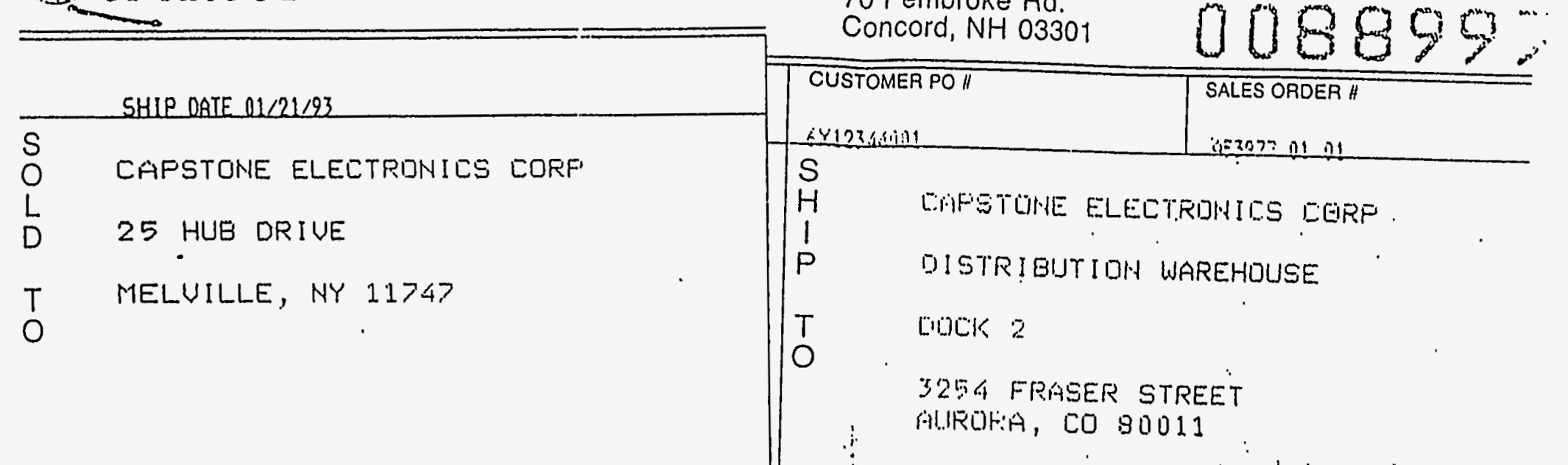

: OTYTORDEPRER A.

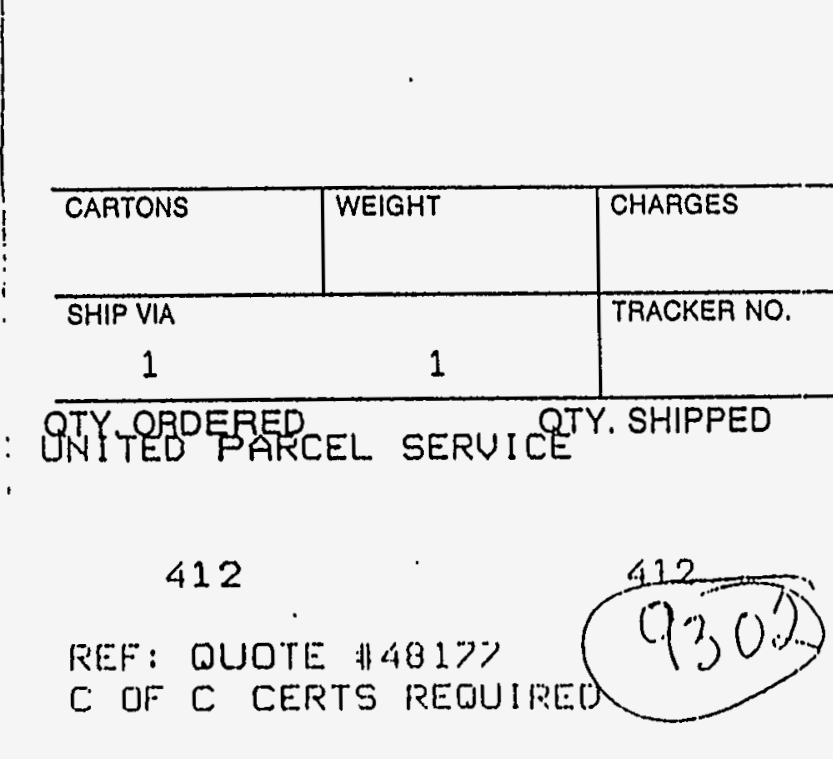

$-$

REF: QUDTE \#481\%\%
C OF C CERTS REDUIPEC
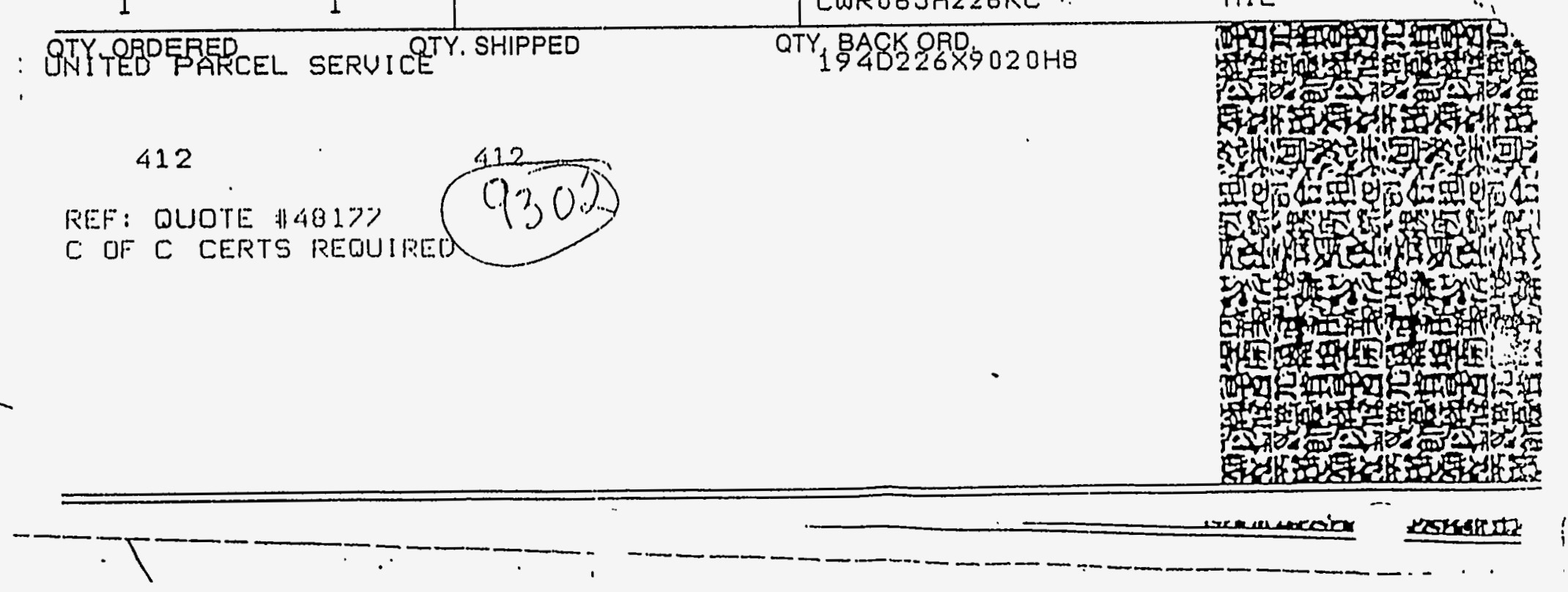
\begin{tabular}{ll} 
SPRAGUE & PQP* 37 \\
\hline CONCORD NEW HAMPSHIRE & $7116 / 82$
\end{tabular}

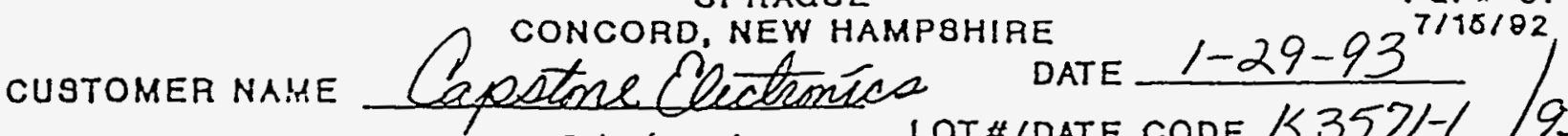
CUSTOMER OFDER \# $6 X 12344001$ CUSTOMER PAลT " QUUPOCKH $106 \mathrm{KC}$

\section{SUMMARY OF TEST DATA MIL-C- $56365 \mathrm{C}$}

GERUP A INSPECTION RATA (Welbull) e

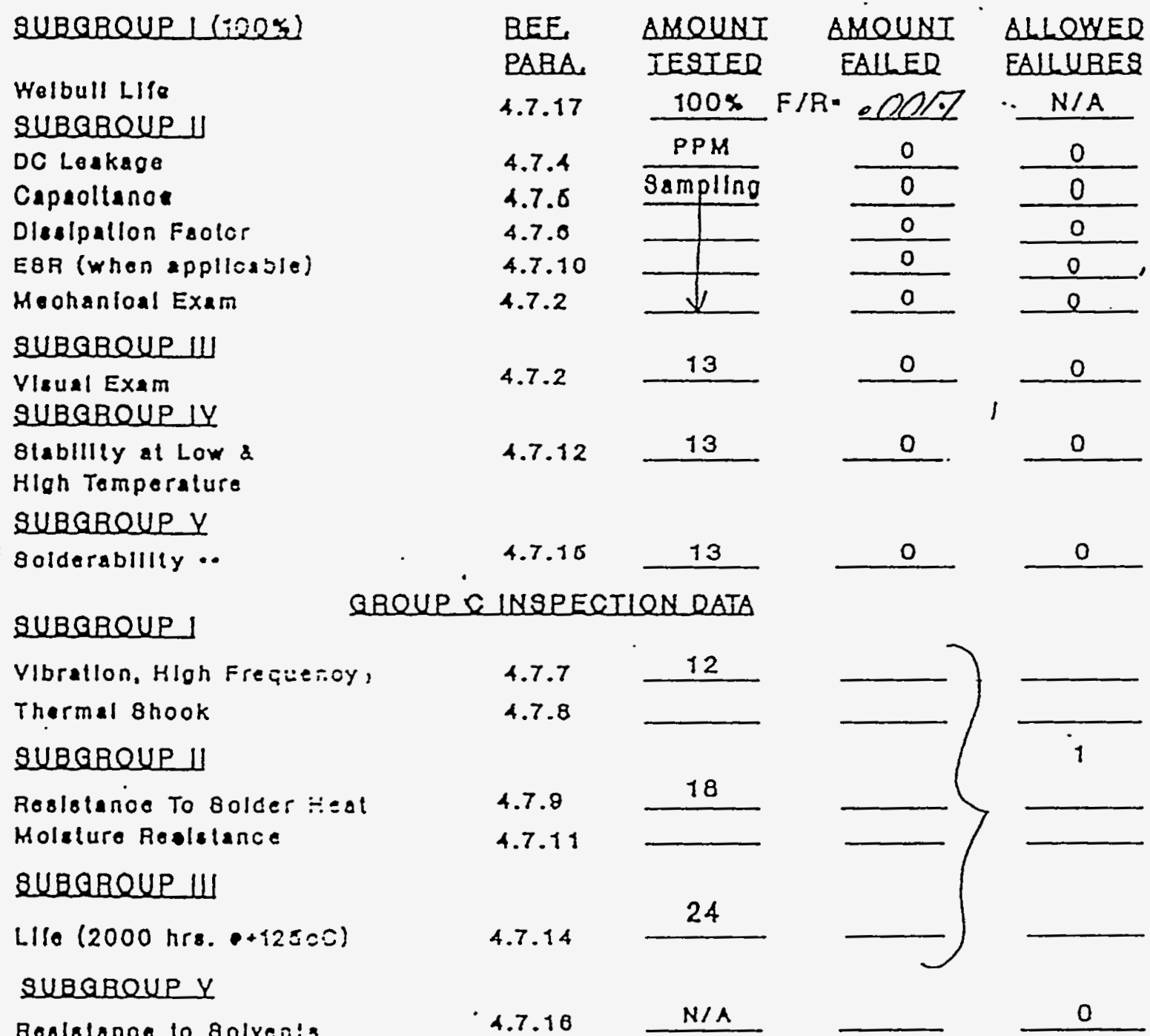

Reolstanoe to solvenis

(whon applloablo)

LOTHIDATE CODE $153521-1 / 93656^{\prime}$ SPRAQUE M.O. AS397703

AMOUNT BHIPPED

225

\section{(n)}



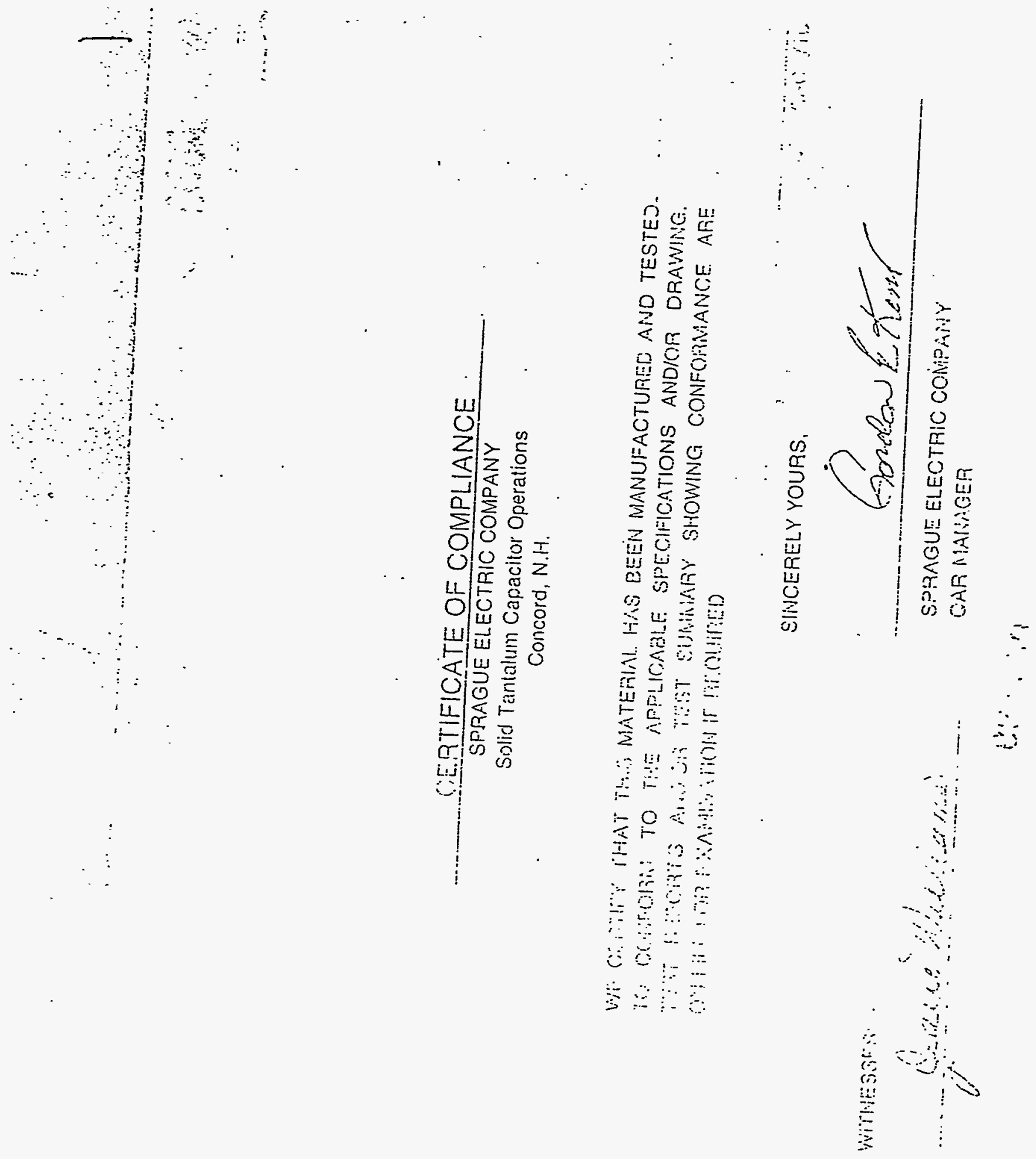
CUSTOMER NAME Copecone Concorg NEY HAMPBHIRE CUATOMER OFDER $6 \times 12344002$ CUBTOMER PART H CWROGMHLOSKC - SUMMARY OF TEBT DATA MIL-C-55385C

\section{\&UBGRQUP / (iees)}

Welbull Life

SUBGBQUP ل

DC Leakage

Capaoltanoe

Dlaslpallon Faolor

E8R (whon applloatie)

Heohanloal Exam

\&U日RBQUP W

VIsual Exam

SURGBQUP IY

Qlabllily at Low 2

HIgh Tomporalure

SUBGBQUP $Y$

solderablllly..

SUBGRQUP

'Vibration, High frequenoy,

Thermal shook

SURBRQUP

Feslsianoo To Eclese? Heal

Molaturo Roslatance

SURareup U1

Lile (2000 hrs. p+12Esc)

SURGBQUP $Y$

Roslalano lo solyento

(when appllosble)
SPRAQUE

LOTAIDATE CODE K5072-1/305U bPRaque M.o. A53978D BPRAQUE M.O.
AMOUNT BHIPPED

\section{BEE}

EABA.

4.7.17

4.7 .4

4.7 .6

4.7 .0

4.7 .10

4.7 .2 A

270

PQP * ST;

T/10/85i

DATE

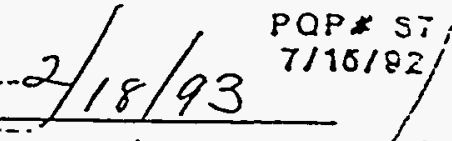
당 


\section{CERTIFICATE OF COMPIIANCE}

DATIE : $1 / 25 / 93$

PURCEASER: $\therefore$ IAWRENCE IIVERMORE IABS

ORDER : 3231974

ITES: 52 500pCE. CDR32BX333AkDS

Е4 500PCS, CDR32BX103BRUS

THIS IS $=0$ CERTIEY THAT THE MAIERIATS, RROCESEES AND EINISEDO PARTS OSED IN THE NANDEACTURE OF THESB ITEMS WERE COSTROLIED AND TIESTED IN ACCORDANCE WITH TEE APPLICSETE SPECIEICATIONS.

OBJECTIVE QUAIITY EVIDENCE AND SUBSTANTIATIVE TEST DATA IS ON FIUZ FOR EXAMINATION UPON REQURST.
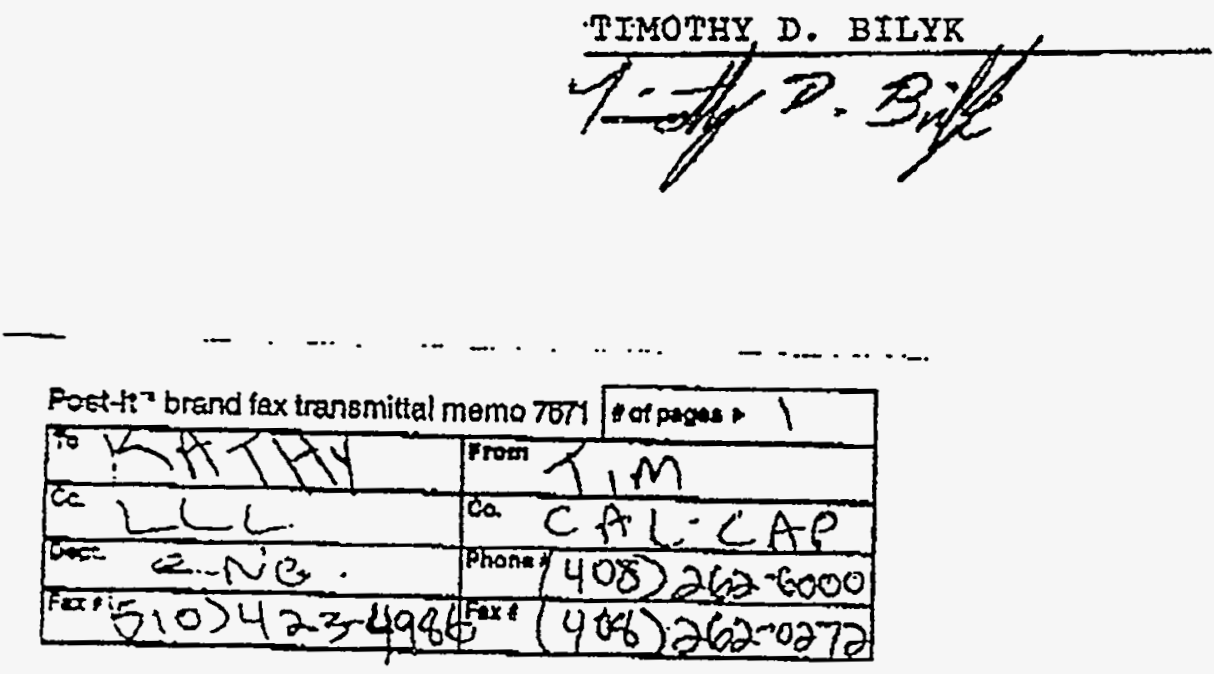


$$
\because \cdots \text {; }
$$

\begin{tabular}{|l|}
\hline CUSTOMER PIO NUMBER \\
S:ㄴํㄴ
\end{tabular}

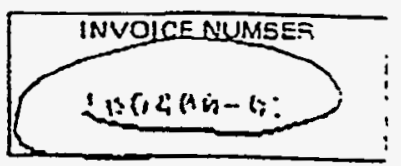

BILL TO

LAWRENCE LIUERTEAE LABS

PO' BEX 5UOI/ACCT. DEPT.

LIVERMORE, CA.

SHIP TO

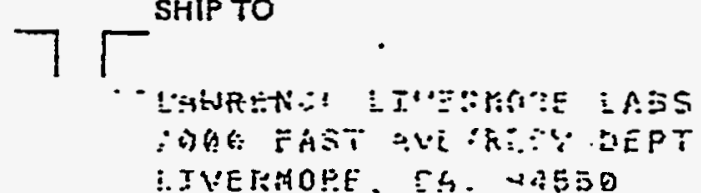

94550

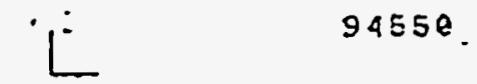

\begin{tabular}{|c|c|c|c|c|c|c|}
\hline :OMPLETE & PARTAL & $x$ & PIDNE: & 5104221200 & EXT.: & BUYER: KAY MZNKLEK \\
\hline
\end{tabular}

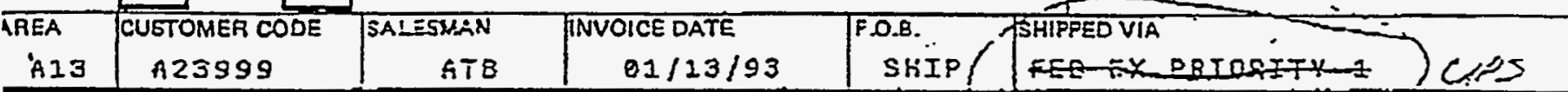

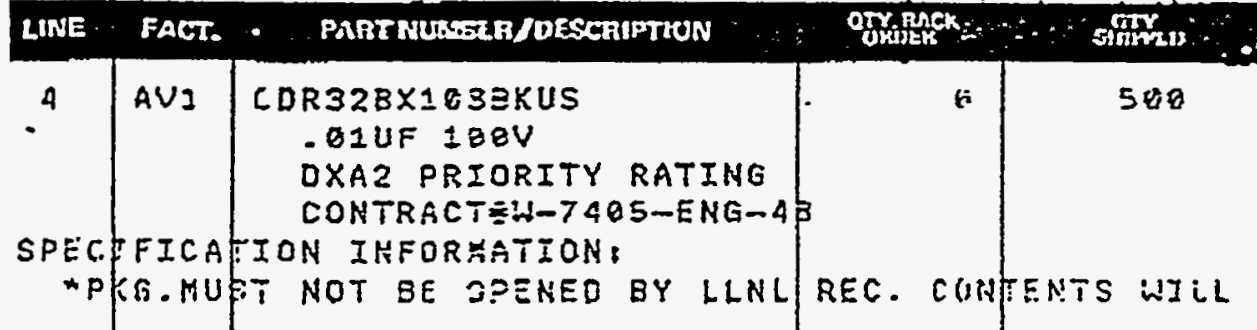

TOTAL UNITS SHIPPED:

1

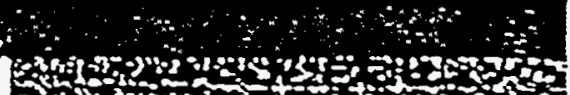
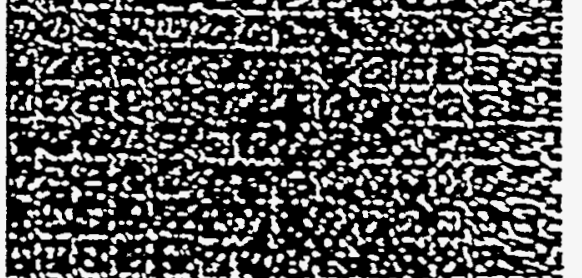

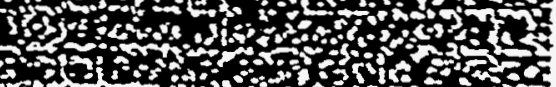

A 0 in

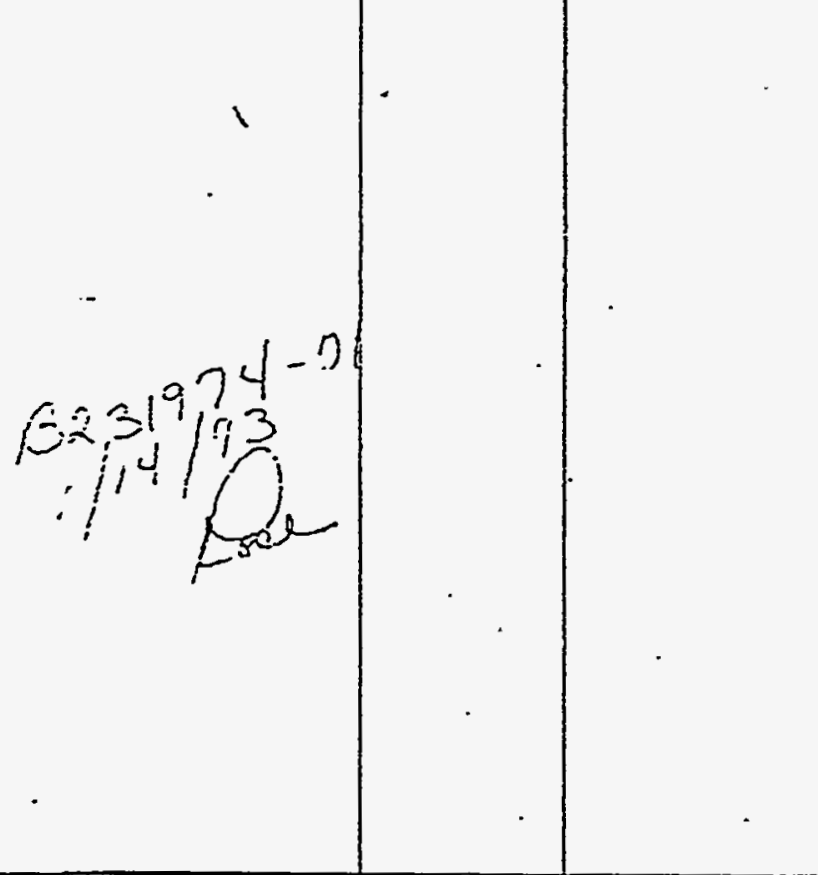

PACKING SLIP

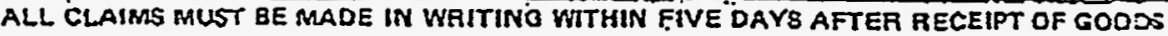

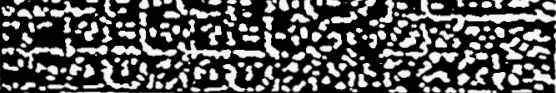
RETURN NO GOODS WITHOUT OUR PREVIOUS WRITTEN AUTHORIZATIOI: $\therefore \because \cdots$

EEN - SHP/ACAD, YELLOW - PACKING SLIP, YHITE - SALES

REC'D $\because \because \cdot$ $\because$ 


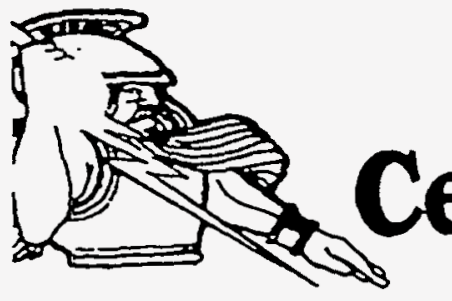

$\frac{\text { ITTENTION: QUALITY ASSURANCE DEPARTMENT }}{\text { CUSTOMER NAME AND AODRESS }}$

military distribution specialists

ficate of Conformance

and Procurement Traceability

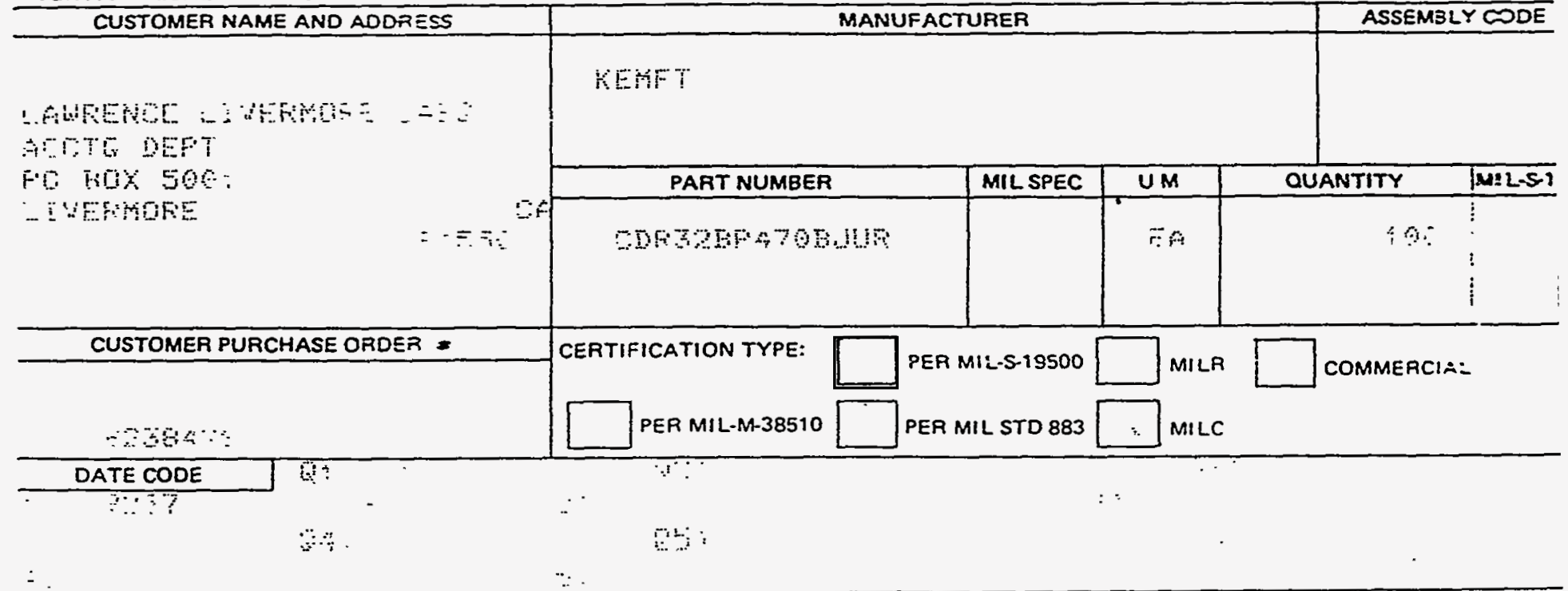

RETEST

$\div ;$

EXPIRATION

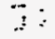

The undersigned certifies that all articles included in each shipment under the above purchase order are in accordance with said purchase order and with all requirements, specifications and drawings referenced therein; and that records of inspection and test providing objective evidence of the foregoing are on file at this facility, or at the manufacturer's plant, and are available upon request. Certification that this shipment is a part of the shipment covered by the manufacturer's documentation.

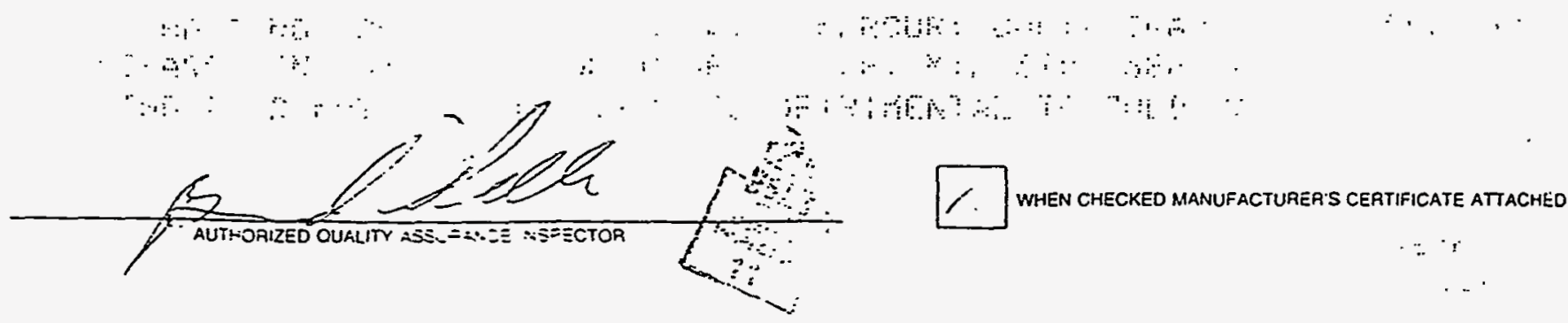

NOTICE REGARDING RETUF: $\because$ CCEPTANCE OF MATERIAL.

ZEUS cannot accept the re:- :-:- $:$ lot or any part of this lot which does not include the original or copies of this and a:-

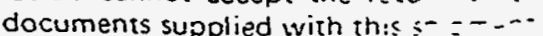


KEPIET ELECTRONECS CORFORATION H.T GHWAY 385 S. E. GREENUII.LE, SUUTH CAROLINA 29066 803/563-6300 - FAX: 803/963-6322 - TELEX: 570496- TWX: 8.10/287-2536

ADDRESS REPLY TO:

P. R. BOXX 5928

GREENUILLE, S. C. 29086

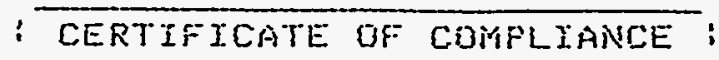

TO: ZEUS SEMICAP, ITSC.

REF: PUREHASE ORIER NUBYBEER: 749137

WE HEREBY CERT:YY THAT THE CAPACTTORS SUFPLIEU TO THE ABOVE MAMED COMPANY ABAIISST THE REFERENCES PURCHASE ORIBER WIERE MATULAETURED IN ACEORDANCE WITH THAT PURCHASE DRUER AND ALL GPPLICABLE NOCUAENTS.

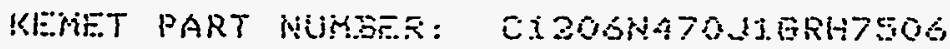

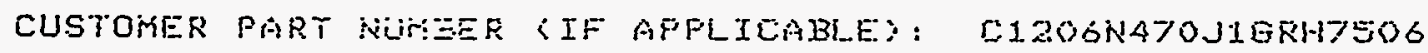

DATE/LOT COOHE(S):

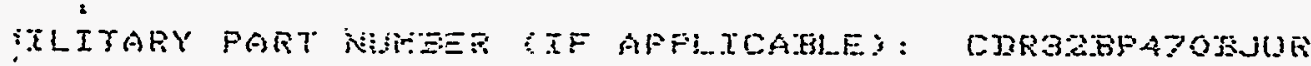

NILITARY INSPECTIOT LOT NUMBERSS: (IF APPLILABLE): 9237LH

TOTAL GUANTITY SHEFFET:

TNUOTCE NUMBER: SZMOSE: LINE: $104 \mathrm{~A}$

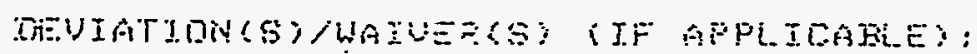

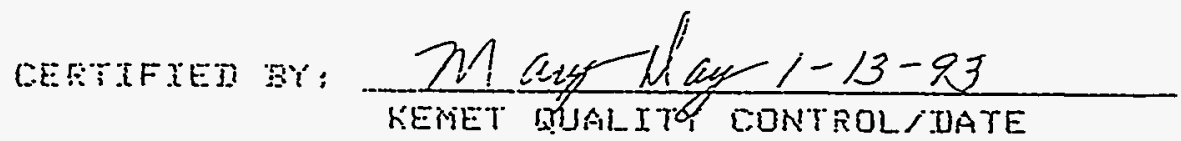




\section{Certificate of Campliance}

To: In iversity of california

I.atrence Iivermore Iab

3000 East zuve.

Iiverwore, CA 94550

Date $70-9-92$.

It is hereby certified that the products (Model numbers listed belowl supplied to Lawrence Iivermore Lab on Purchase Order No. B2275 55 are in confomance with aH your purchase order requirements, including applicable government, your or other specifications and. drawings, to the extent specified.

The required :sst and/or inspection reports resulting fmm compliance with applicable purchase order reouirements are on file and available for review by your representative or government insoectors at any reasonable time.

ANA.LOG DEVICES, INC.

$(97$ DO) REEClCs

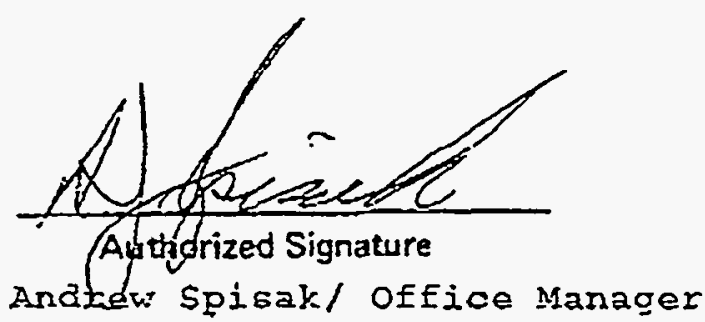




\section{Certificate of Campliance}

To: Hnir:=-c: - of California

Iavrence Iitrarmore Iab_

$7000 \equiv \equiv 5=$ L.v.

Iiver:..o=三, C: 94550

Date $70-0-92$

It is hereby ce-i:ied that the products (Model numbers listed below) supplied to Lawre:ce i̇vertore Lab on Purchase Order No. B227575. are in conio-nt:- $\infty$ with aH your purchase order requirements, including applicable government, :0; of other specifications and drawings, to the extent specified.

The required iss and/or inspection reports resilting from compliance with applicable purchase order recuirements are on file and available for review by your representative or governmeni insestcrs ai any reasonable time.

ANA.LOG DEVICES, INC.

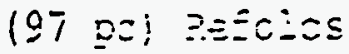

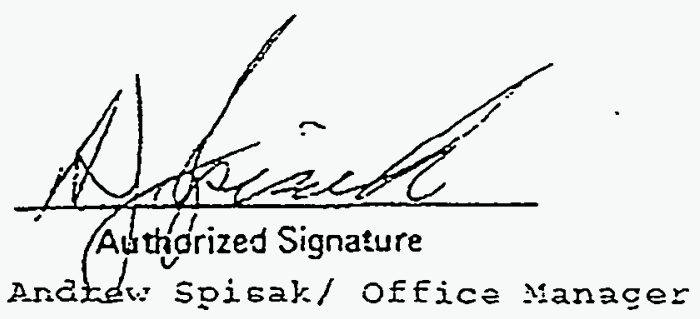




\section{Certificate of Campliance}

To:

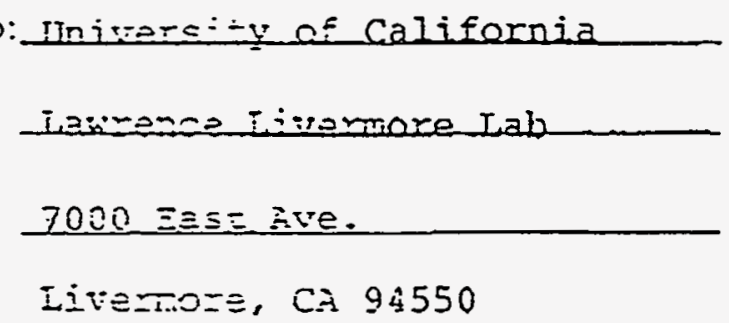

Date $70-0-92$.

It is hereby centied ihat the products (Model numbers listed below) supplied to ianresce Żvermore iab on Purchase Order No. B227575. are in conforrs.roc with all your purchase order requirements, including applicable government, yoi- o: other specifications and drawings, to the extent specified.

The requirad iss and/or inspection reports resulting from compliance with applicable purchase order ixuirements are on file and available for review by your representative or governmeni :-secicrs ai any reasonable time.

ANALOG DEVICES, INC.

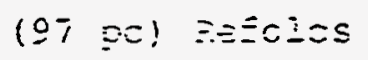

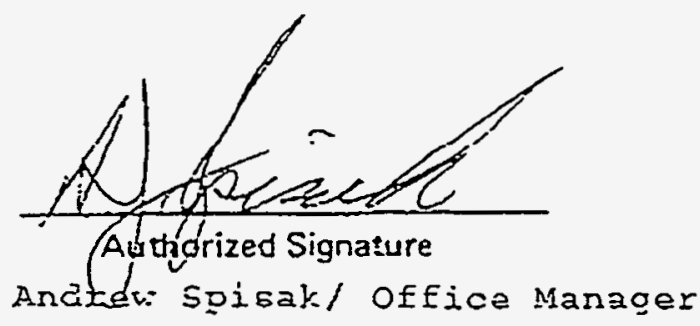


ACCEPTANCE DATA

CUSTOMER $=0 .: B 243053$
CUSTOMER M.E.C. JOB\# 301093
M.E.C. PART M M83513/04-GO6N

LOT SIZE 32PCS DATE CODE OR LOT $\$ 2308$

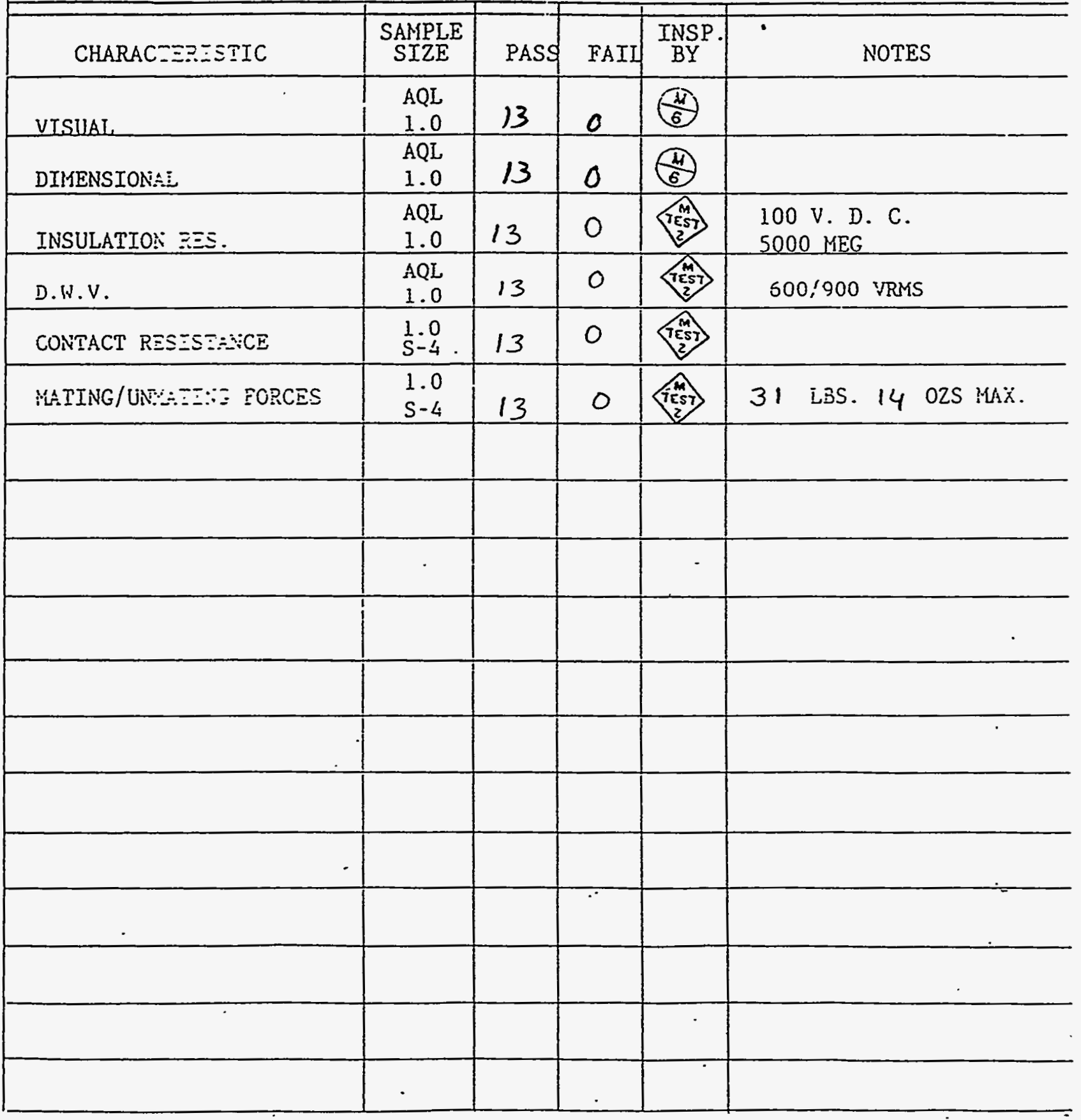

DATE. $\quad 2.25 .93$ 
ACCEPTANCE DATA

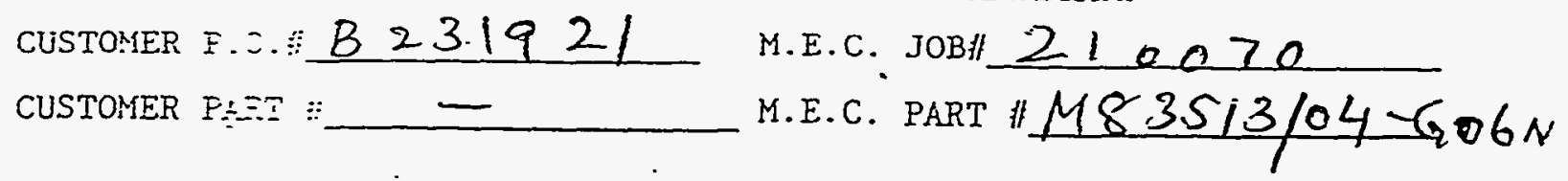
LOT S.IZE $30 \mathrm{PCS}^{\prime}$ DATE CODE OR LOT \# 9245

\begin{tabular}{|c|c|c|c|c|c|}
\hline 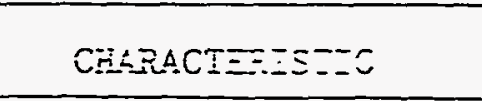 & $\begin{array}{l}\text { SAMPLE } \\
\text { SIZE }\end{array}$ & PASS & FAII & $\underset{B Y}{\operatorname{INSP}}$ & NOTES \\
\hline ITCIIST & $\begin{array}{l}\text { AQL } \\
1.0\end{array}$ & 13 & 0 & $\frac{\pi}{6}$ & \\
\hline DIRENSTONAI & $\begin{array}{l}\text { AQL } \\
1.0\end{array}$ & 13 & 0 & $\frac{\pi}{6}$ & \\
\hline XNSLETON $=\Xi S$. & $\begin{array}{l}A Q L \\
1.0 \\
\end{array}$ & 13 & 0 & 59 & $\begin{array}{l}100 \text { V. D. C. } \\
5000 \text { MEG }\end{array}$ \\
\hline D.R.i. & $\begin{array}{l}A Q L \\
1.0 \\
\end{array}$ & 13 & $c$ & ह5 & 600,900 VRMS \\
\hline 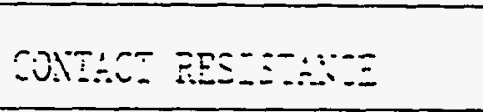 & $\begin{array}{r}1 \\
\vdots: 0 \\
5-4 \\
5\end{array}$ & 13 & $\hat{c}$ & {$\left[\begin{array}{l}2 \\
0 \\
0\end{array}\right]$} & \\
\hline 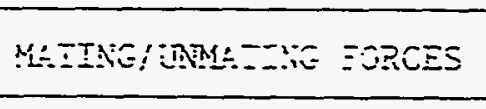 & $\begin{array}{l}1.0 \\
5-4\end{array}$ & 13 & 2 & Fy & 31 IBS. 14 OZS MAX. \\
\hline & & & & & \\
\hline & & & & & \\
\hline & & & & & - \\
\hline & & & & & \\
\hline - & & & & & \\
\hline & & & & & \\
\hline & & & & & \\
\hline & & & & & \\
\hline & & & & & \\
\hline & & & & & \\
\hline & & & & & \\
\hline
\end{tabular}




\section{Certificate of Compliance}

It is hereby certified that the parts furnished on this Certificate of Compliance have been manufactured in conformance with the requirements of all applicable drawings and specifications as defined by the purchase order.

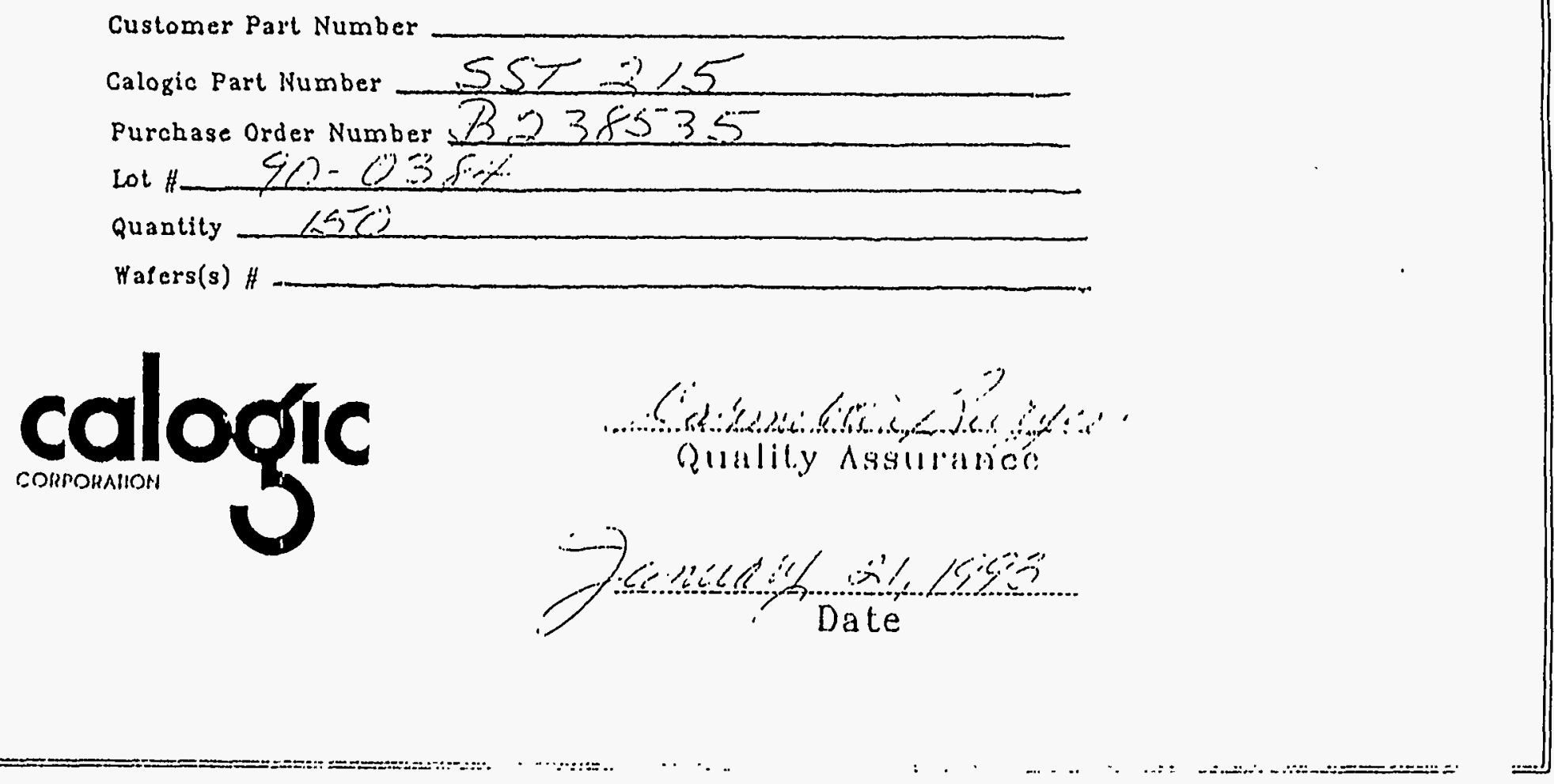




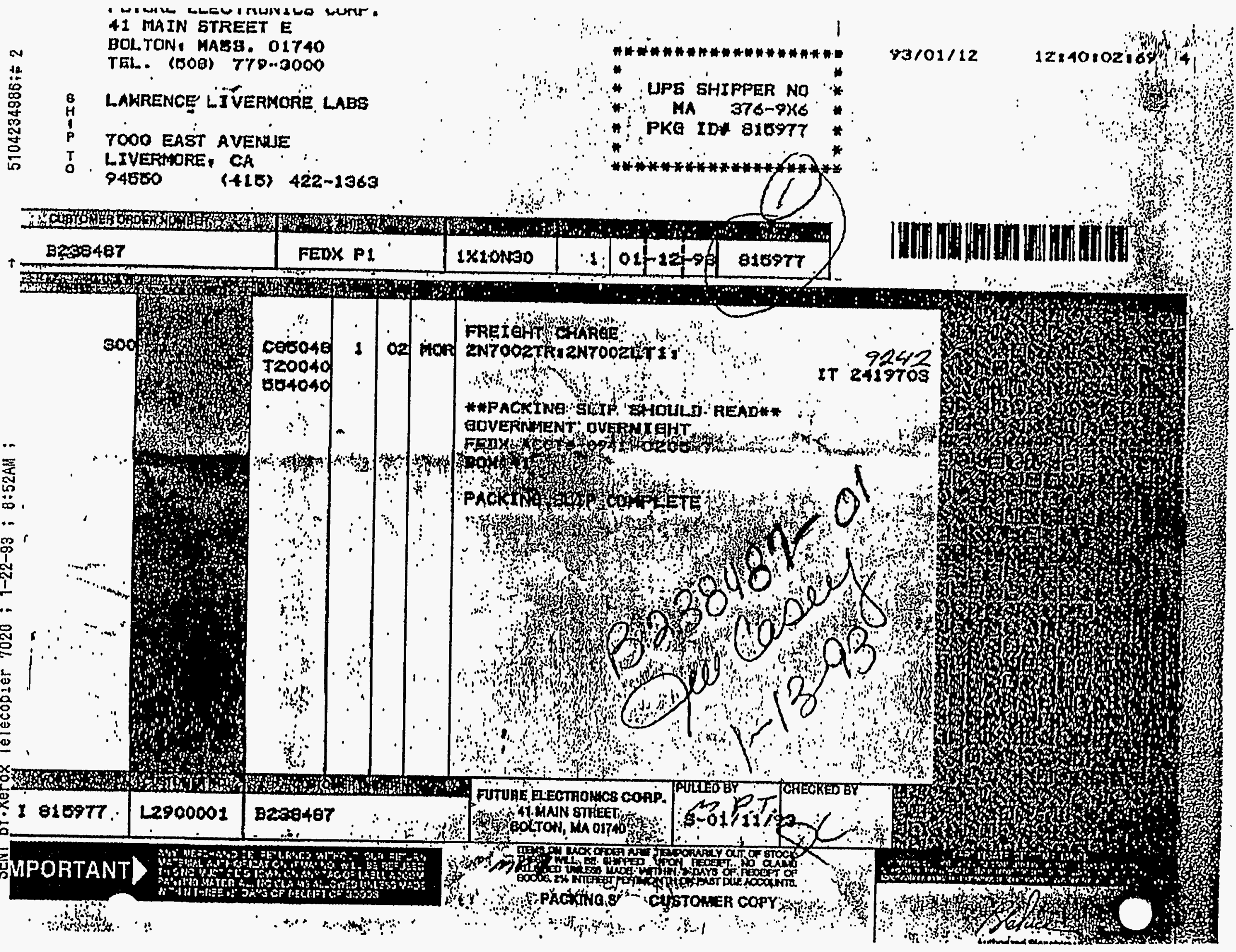




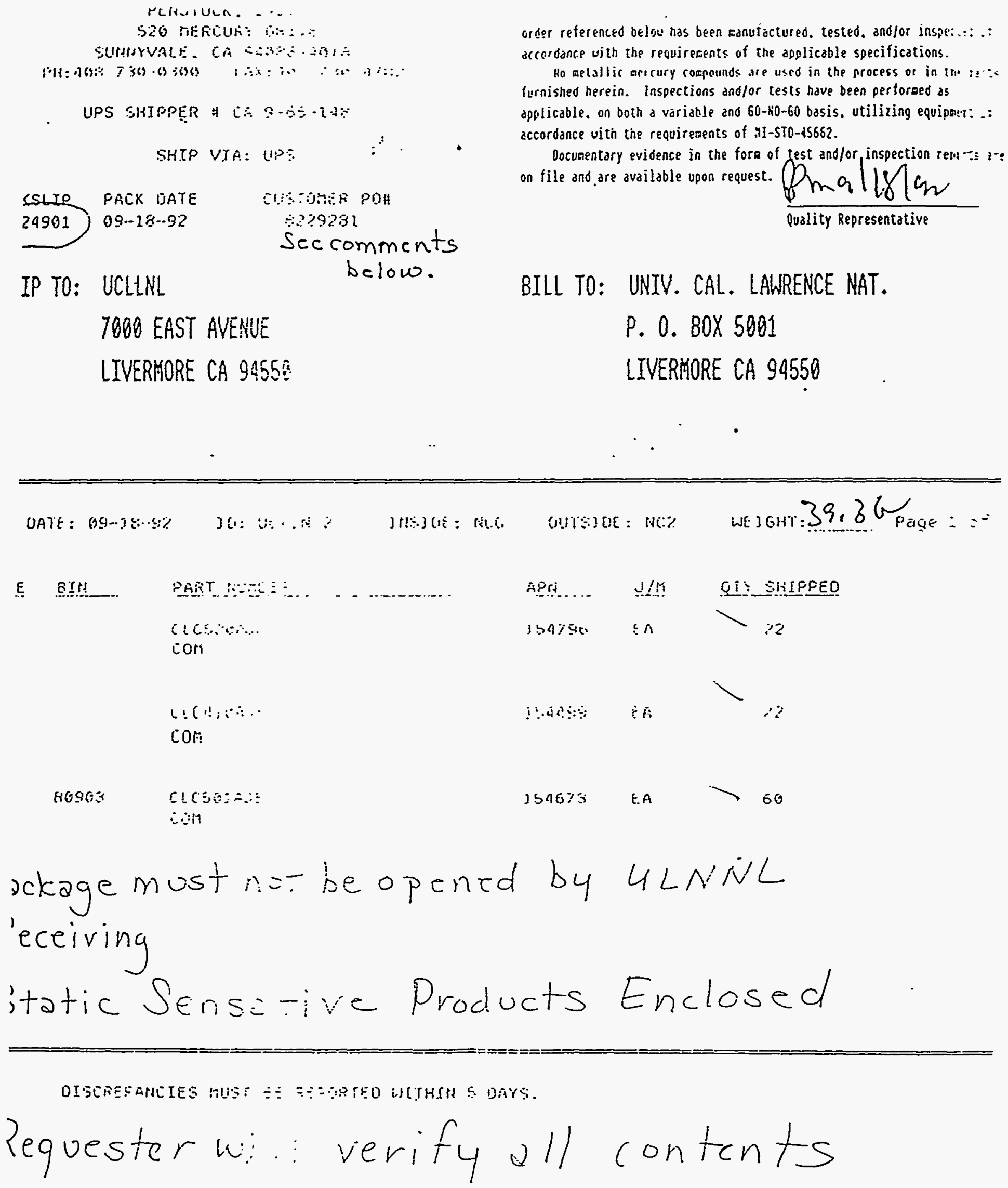




\section{THOMSON COMPONENTS AND TUBES CORPORATION THOMSON MILITARY AND SPACE COMPONENTS DIVISION}

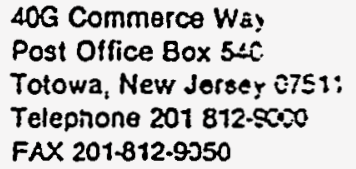

FAX 201-812-9350

\section{CERTIPICATE OF CONEQRHATCE} ISC2-

TO:_LLNI

DATE: $10-13-92$

7000 EAST AVE, IIVERMORE, CA 94550

CUSTOMER P/O: $\quad 3228341$

(CUSTOMER'S NAME AND ADDRESS)

TETD ORDER CONEIRMATION:

CCD1038

SHIPPING DOCUMENT:

210102247

DEVICE TYPE: TE7990C

IOI SIZE:

IOT: NUMBER:

DATE CODE: SHIPPED QUANTITY:

20

GENERIC SPECEE⿱E龰TTION: 1989 CCD DATABOOK

DETAIL SPECEFICZTIOA:

SCREENING C:ニSS: REV :

REMRRKS :

OLD PART IUYSES: TYY 33501

THE UNDERSIG:ZD CERIIFE THAT THE PARTS LISTED UNDER YOUR PURCIIASE CRDER SIOAN ABOVE ARE PART OF THE SHIPMENT COVERED BY TUE MANUEAC_-KER'S CERTIFICATION ATTACHED, THAT FIL FRODUCTS ARE IS DESCRIBED ON THE CERTIFICATE, AND THAT

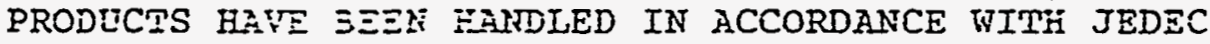

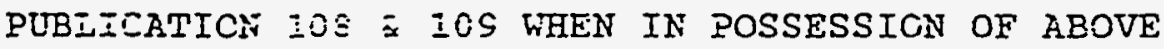
VENDOR.

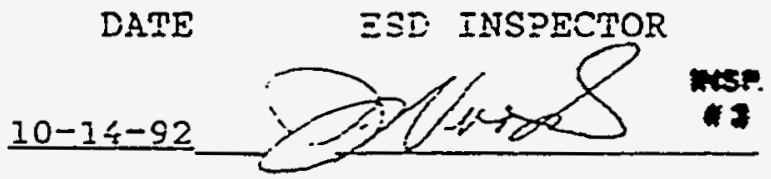
MIIITAPY APPROVAL \{WHEN REQUESTED\}

HOTE: WHEN REEEERINE TO THESE PARTICUTAR DEVICES, PLEASE MENTION THE IOZONTIYG INSPECTION NUMBER: 2D10034/2I.I0 22 $\div 7$ 


\title{
1 THOMSON COMPONENTS AND TUBES CORPORATION THOMSON MILTARY AND SPACE COMPONENTS DIVISION
}

\author{
4OG Commerce Way \\ Post Office $80 \times 540$ \\ Totowa, New Jersey 0751: \\ Telephone $201812-9000$ \\ FAX 201-812-9250
}
CERTIFICATE OF CONFORHAXCE - $\mathrm{SC2} 2-$

TO:_ILNL

DATE: $10-13-92$

7000 EAST AVE, IIVERMORE, CA 94550

CUSTOMER P/O: $\quad 3223341$

(CUSTOMEK'S NAME AND ADDRESS)

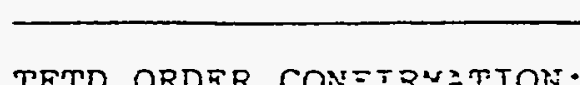

SHIPPINE DOCUNENT:

$\operatorname{CCD} 1038$

210102247

DEVICE TYPE: TETOSOC

IOT SIZE:

LOT NUMBER:

DATE CODE:

SHIPPED QUANTITY:

20

GENERIC SPECIFECAIION: - I983 CCD DATABOOK

DETAII SPECIFICAFION:

SCREENING CIASS:

REMARKS :

OLD PART NUMBEA: TRX33501

THE UNDERSIGNED CERTIEY THAT THE PARTS I.ISTED UNDER YOUR PURCTASSE ORDER SECART ASOVE ARE PART OF THE SHIPMENT COVERED

BY THE MANUFAC UTEER'S CERTIEICATION ETTACHED, THAT ZLL

PRODUCTS ARE AS DESCRIBED ON THE CERTIFICATE, AND THAT

PRODUCTS HAVE SEE: TAITIED IN ACCORDANCE WITH JEDEC

PUBIIEFTICN IOE $\bar{\square}$ IUS WHEN IN POSSESSION OF RBOVE

VENDOR.

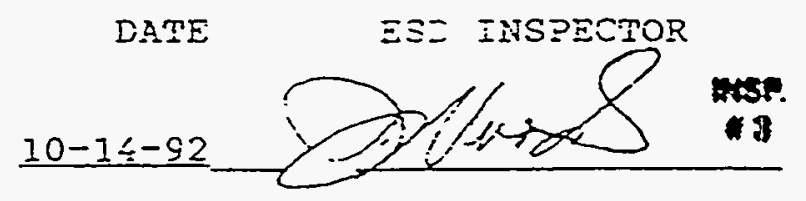

MILITARY PPPROVEL (WHEN REQUESTED)

HOTE: WHEN REEEREZSE TO THESE PARTICULAR DEVICES, PLEASE MENTION THE EOIIN 


\title{
目
}

\section{Micro Power Systems}

\section{CERTIFICATE OF CONFORMANCE}

TO: UC Lamerence Livermore Labs.

$\frac{7000 \text { EAST AVE. }}{\text { Livarmore CA.94550 }}$

\author{
DATE: Sept. 30,1992 \\ SALES ORDER NO: 38676 \\ PURCHASE ORDER NO: D 3390689 \\ CUSTOMER PART NO: MP 7684 ATL $/ 883$
}

CUSTOMER DWG NO:

MPS PART NO:

COUNTRY OF ORIGIN:
$7684 A$
$115 A$
LOT NO: $7688084 A^{A 1-3}$
QUANTITY: 50
DATE CODE: $2 B \quad 9226$
LAST ELECTRICAL TEST DATE: $\not 128 / 92$

\section{SELLER CERTIFIES T:-AT:}

1. The parts iurr:sined against this purchase order were produced in conformance with all corirea:jelly applicable specifications.

2. Data taken to characierize the final product under the above purchase order is available for exemination by duly authorized personnel.

SELLER: MICRO FOWER SYSTEMS, INC.

qualitr representative: M1. Havlav

TITLE: QA Specialist

P.O. Sox 54965, 3100 Afred Street, Santa Clara 950940965

Telephone: (408) 727-5350 Fax: (408) 562,3605

Exhibit 11

SPECIFICATION NUMBER: QA 303, Rev. F, Page 1 of 12 


\section{挆 \\ Nicro Ponez Systems}

\section{CEPTIFICATE OF CONFORMANCE}

To: UC Laurence Livermare Labs

$\frac{7000 \text { East Aneume }}{\text { Livermare CA.94550 }}$

\footnotetext{
DATE: Oct. 15,1992

SALES ORDER NO: 38676

PURCHASE OADER NO: $\frac{\text { D3390689 }}{\text { CUSTOMER PAAT NO: }}$

CUSTOMER D: $\because$ NO:

MPS PA-IT NO: $\overline{7684 A-\pi--883}$

COUNTRY OF ORIGIN:

LOTNO: $7688084 \mathrm{Al} \div-1$

QUANTITY:

10

DATE CODE: $2 B 9226$

LAST ELECTRICAL TEST DATE: $10 / q / 92$
}

SELLER CERTIFIES THAT:

1. The parts fur.tined egainst this purchase order were produced in coniormance with all contres:ielly applicable specifications.

2. Data taken: : statacterize the final product under the above purchase order is available icr exemination by duly authorized personnel.

SELLER: MICEO PONER SYSTEMS, INC.

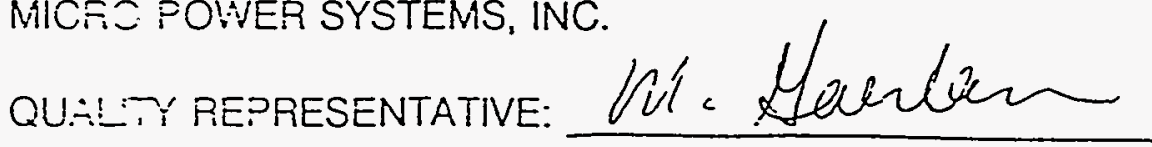

TITLE: QA Specialist

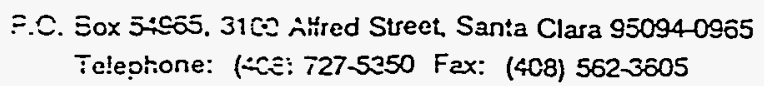




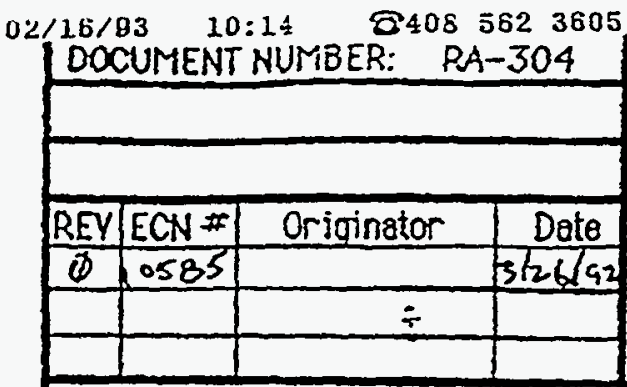

TEST PER 883 CAASS 8 M5005
HICRO POFER SYS.

QUALIFICATION

TEST DATA

FLOW TRAVELER

\section{FLASH CONVERTERS GROUP A TEST DATA}

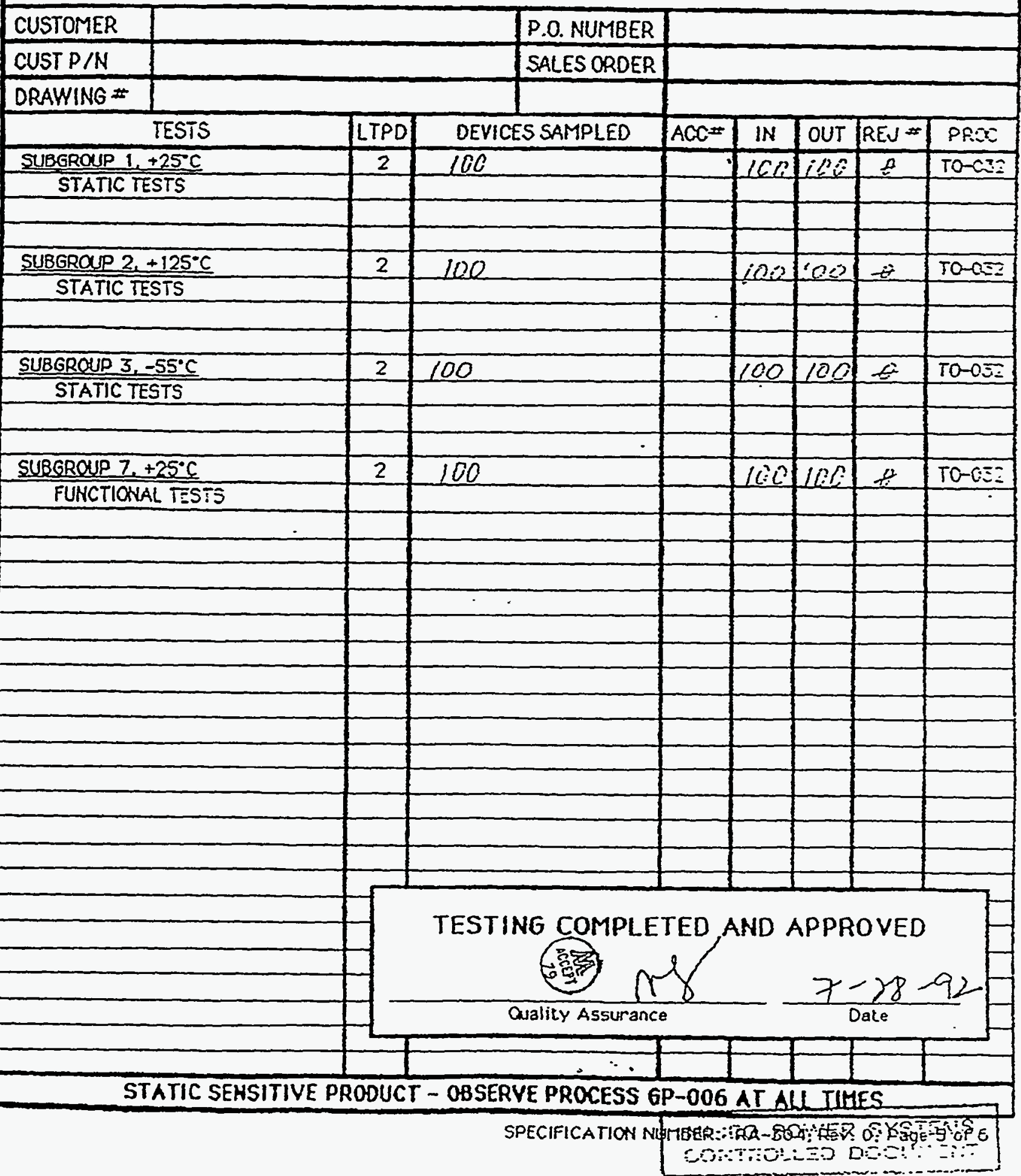




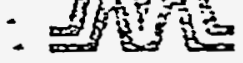

Mlicto Forye: Systems

\section{OEPTIFICATE OF CONFORMANCE}

TO: UC haurence Livermore Labs

7000 East Aneme

Livermare CA.94550

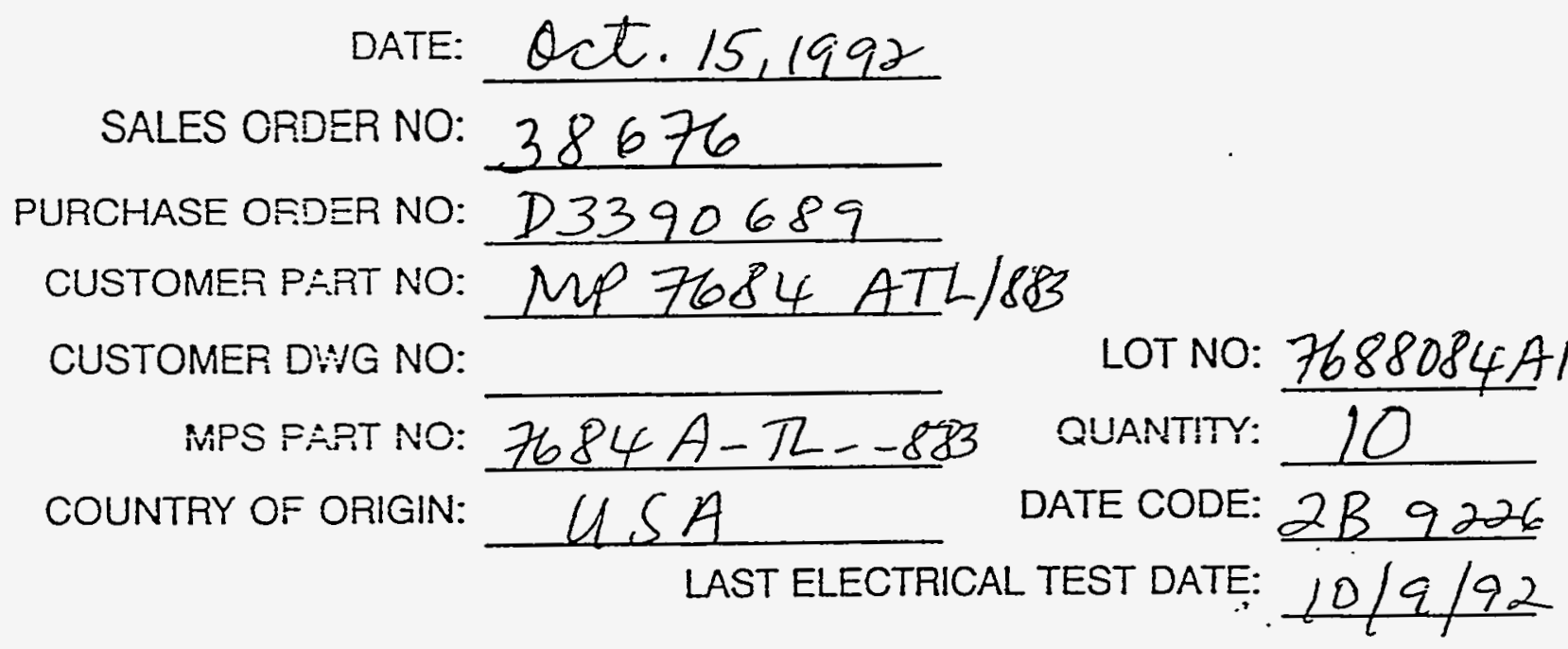

SELLER CERTIFIES THAT:

1. The parts - -rished against this purchase order were produced in conformance with all cor:- $\equiv$ ctually applicable specifications.

2. Data taken : c characterize the final product under the above purchase order is available ic: Exemination by duly authorized personnel.

SELLER: MUIC:O POWER SYSTEMS, INC.

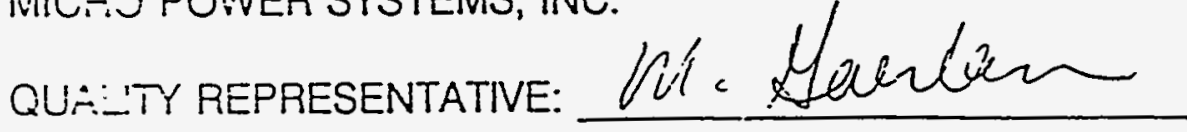

TITLE: QA Specialist

P.ว. Eox 54\$65, 3100 Affred Street, Santa Clara 950940905

Telephone: (408) 727-5350 Fax: (408) 562-3605 
$\sqrt[\mathbb{N}]{ }$

13229988

Micro Power Systems

CERTIFICATE OF CONFORMANCE

TO: UC Lamenence Livermore labs.

7000 EAST AVE.

Livermore CA.94550

DATE: Sept. 30,1992

SALES ORDER NO: 38676

PURCHASE ORDER NO: D 3390689

CUSTOMER PART NO: MP P 7684 ATV $/ 883$

CUSTOMER DWI NO:

LOT NO: $7688084:-3$

MES P:AT:O: $7684 A-\pi--883$

COUNTRY OF ORIGIN: ll SA

OIIANTITY. 50

DATE CODE: $2 B \quad 9226$

LAST ELECTRICAL TEST DATE: $7 / 28 / 92$

uced in conformance

$\begin{aligned} C & \therefore \\ & \therefore \therefore\end{aligned} \leftrightarrow$

le purchase order is

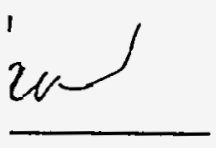

P.O. Box 54965, 3100 Alfred Street. Santa Clara 950940965

Telephone: (408) 727-5350 Fax: (408) 562-3605

Exhibit II

SPECIFICATION NUMBER: QA -303, Rev. F, Page 1 of 12 


\title{
ALLAMERICAN
}

a quality electronics distributor

16085 N.W. 52ND AVENUE, MIAMII, FLORIDA 33014-9317

\section{CERTIFICATE OF CONFORMANCE}

\author{
CUSTOMER NAME UNIV. CALIF LIVERMORE \\ ANDADDRESS LWERMORE NAT'L LABS \\ 7000 EAST AVENUE, RECEIVINC \\ LIVERORE, CA 94550
}

ALL AMERICAN CERTIFIES THAT THE MATERIAL SUPPLIED ON YOUR PURCHASE ORDE= BD227573

IS DESIGNED TO MEET SPECIFICATIONS PEF:

1) $\square$ MIL-S-19500:

2) $\square$ MIL-M-38510

3) $\square$ MIL-STD-8E:

4) $\square$ DESC DRAWING NO

5) $\triangle$ COMMERCI:-

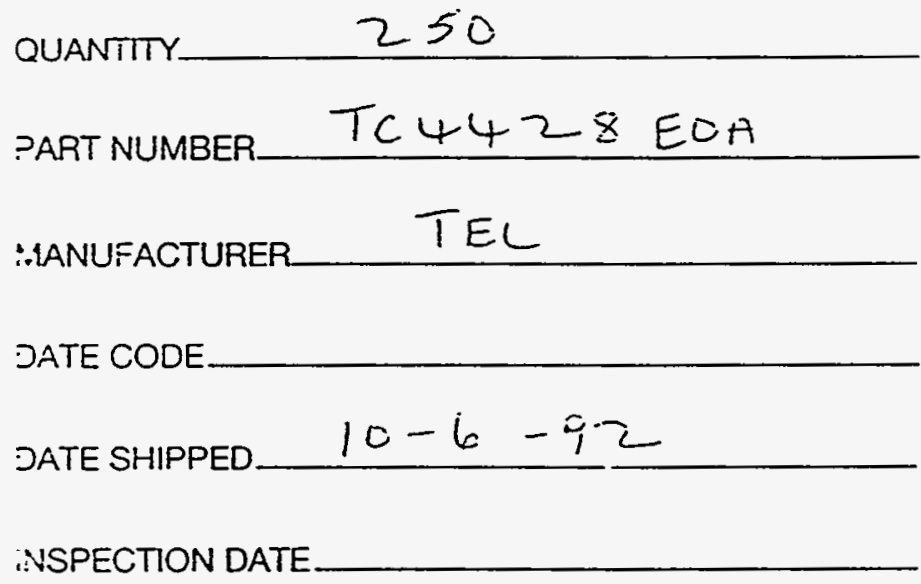

ALL AMERICAN SEMICONDUCTOR CERTIFIES THAT ALL ARTICLES INCLUDED IN EACH SHIPMENT UNDER THE ABOVE F'JRCHASE ORDER(S) ARE MANUFACTURED IN ACCORDANCE WITH ALL MANUFACTURER'S AND;OR APPLICABLE MILITARY SPECIFICATIONS SO DESIGNATED ON SUBJECT PURCHASE ORDER. AND FURTHER CERTIFIES THAT THIS SHIPMENT IS A PART OF THE SHIPMENं COVERED BY THE MANLLFACTURER'S DOCUMENTATION. TEST REPORTS FOR MATERIAL SUPPLIED ARE ON FILE, AND ARE AVAIL-BLEE FOR EXAMINATION AT THE POINT OF MANUFACTURE.

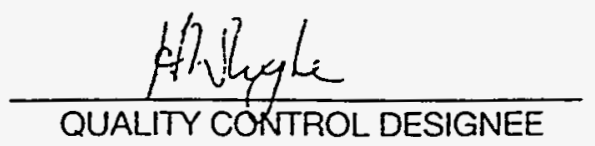




\title{
ALLAMERICAN
}

a quality electronics distributor

16085 N.W. 52ND AVENUE, MLAMI, FLORIDA 33014-9317

\section{CERTIFICATE OF CONFORMANCE}

\author{
CUSTOMER NAME UNIV. CAL IF LIVER MORE \\ ANDADDRESS LIVER MORE NAT'L LABS \\ 7000 EAST AVENUE, RECEIVING \\ LIVERMORE, CA 94550 .
}

ALL AMERICAN CERTIFIES THAT THE MATERIAL SUPPLIED ON YOUR PURCHASE ORDE= BB22 27573 IS DESIGNED TO MEET SPECIFICATIONS PEF:

1) $\square$ MIL-S-19500:

2) $\square$ MIL-M-38510 3) $\square$ MIL-STD-8E:

4) $\square$ DESC DRAWING $: 0$

5) BCOMMERCIA:

PUANTITY_ 250

PART NUMBER TC 4426 EOA

:AANufacturer TEL

SiRTE CODE.

IATE SHIPPED $10 \div 6-92$

INSPECTION DATE

ALL AMERICAN SE::ICONDUCTOR CERTIFIES THAT ALL ARTICLES INCLUDED IN EACH SHIPMENT UNDER THE ABOVE ?URCHASE ORDER(S) ARE MANUFACTURED IN ACCORDANCE WITH ALL MANUFACTURER'S A:D'OR APPLICABLE MILITARY SPECIFICATIONS SO DESIGNATED ON SUBJECT PURCHASE ORDER. $\because \because$ FURTHER CERTIFIES THAT THIS SHIPMENT IS A PART OF THE SHIPMENT COVERED BY THE MLN'L=ACTURER'S DOCUMENTATION. TEST REPORTS FOR MATERIAL SUPPLIED ARE ON FILE, AND ARE AVA:L-BLE FOR EXAMINATION AT THE POINT OF MANUFACTURE.

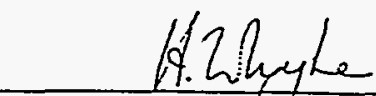

QUALITY CONTROL DESIGNEE 


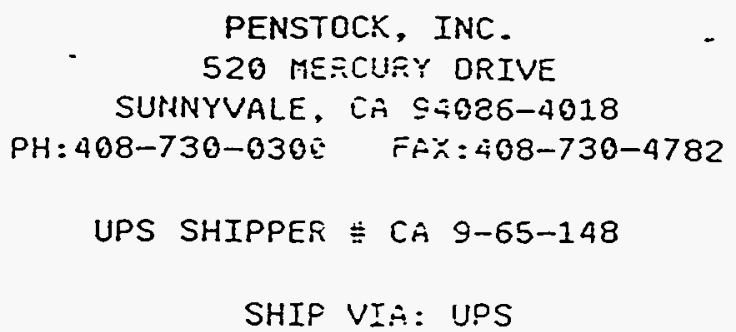

$\begin{array}{llc}\text { PACKSLIP } & \text { PACK DATE } & \text { CUSTOMER PO\# } \\ \text { P9324903 } & 10-06-92 & 8229281\end{array}$

SHIP TO: UCLLNL

7000 EAST AVENUE

LIVERMORE CA 94550
This is to certify that the naterial furnished pursuzat : $:$ ie pu:

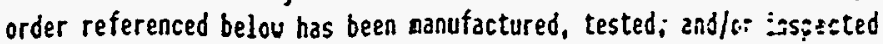
accordance vith the requirements of the applicable specificz:ias. :

no aetallic aercury coapounds are used in the process ti is te pi furnished herein. Inspections and/or tests have been perfores as applicable, on both a variable and 60-\$0-60 basis, utilizing esoigeent accordance vith the requirenents of MI-STQ-45662.

Documentary evidence in the fors of test and/or Inspec:in rsport! on file and are available upon request.

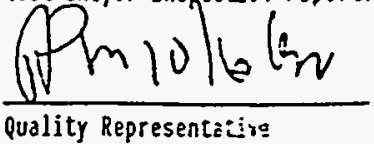

\section{BILL TO: UNIV. CAL. LAWRENCE NAT.}

P. O. BOK 5001

LIVERMORE CA 94550

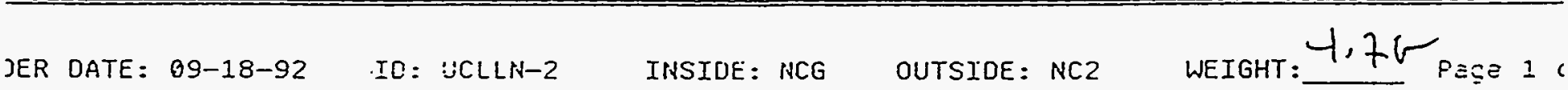 \\ IINE BIN PART $\because \because=\equiv \equiv \Omega$ \\ 303 \\ CLC502:-E \\ COM \\ APY $\quad \underline{U}$ /A OTY SHIPPED \\ $154710 \quad E A$

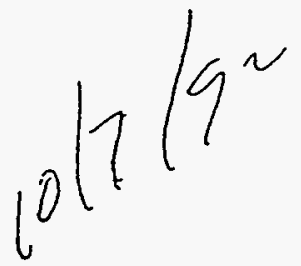


NYVALE CA $94086-4018$

PH: $408-730-0300 \quad F A X: 408-730-4782$

UPS SHIPPER \#CA $9-65 \rightarrow 148$

SHIP VIA: UPS's

PACKSLIP PACK DATE CUSTOMER POH

$P 9324902 \quad 10-01-92 \quad 8229281$

SHIP TO: UCLLNL

7000 EAST AVENUE

LIVERMORE CA 94550 viver cererealieu o 705 oeen aanuiactured, tested, and/or Inspected in accordance with the .. yulienents of the applicable specifications.

Ho aetallic mercury compounds are used in the process or in the parts furnishod herein. Inspections and/or tests have been perforaed as appllcable, on both a varlable and 60-H0-60 basis, utllialng equipment in accordance ulth the riquilenents of $11-570-15662$.

Documentary evidence In the forn of test and/or Inspection reports are on flle and are avallable upon request.

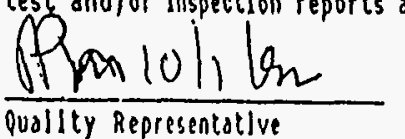

BILL TO: UNIV. CAL. LAWRENCE NAT.

P. D. BOX 5001

LIVERMORE CA 94550

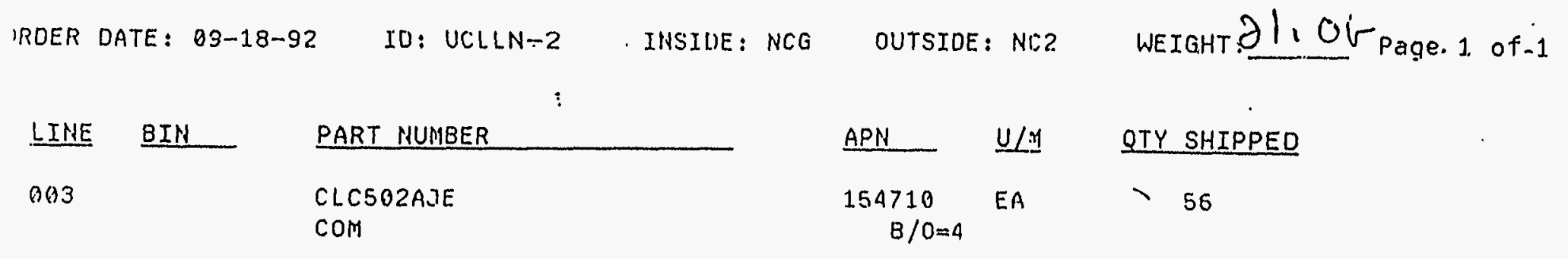

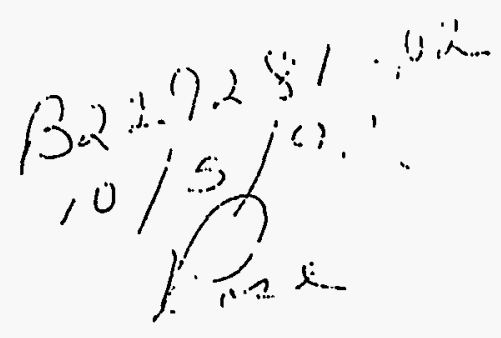




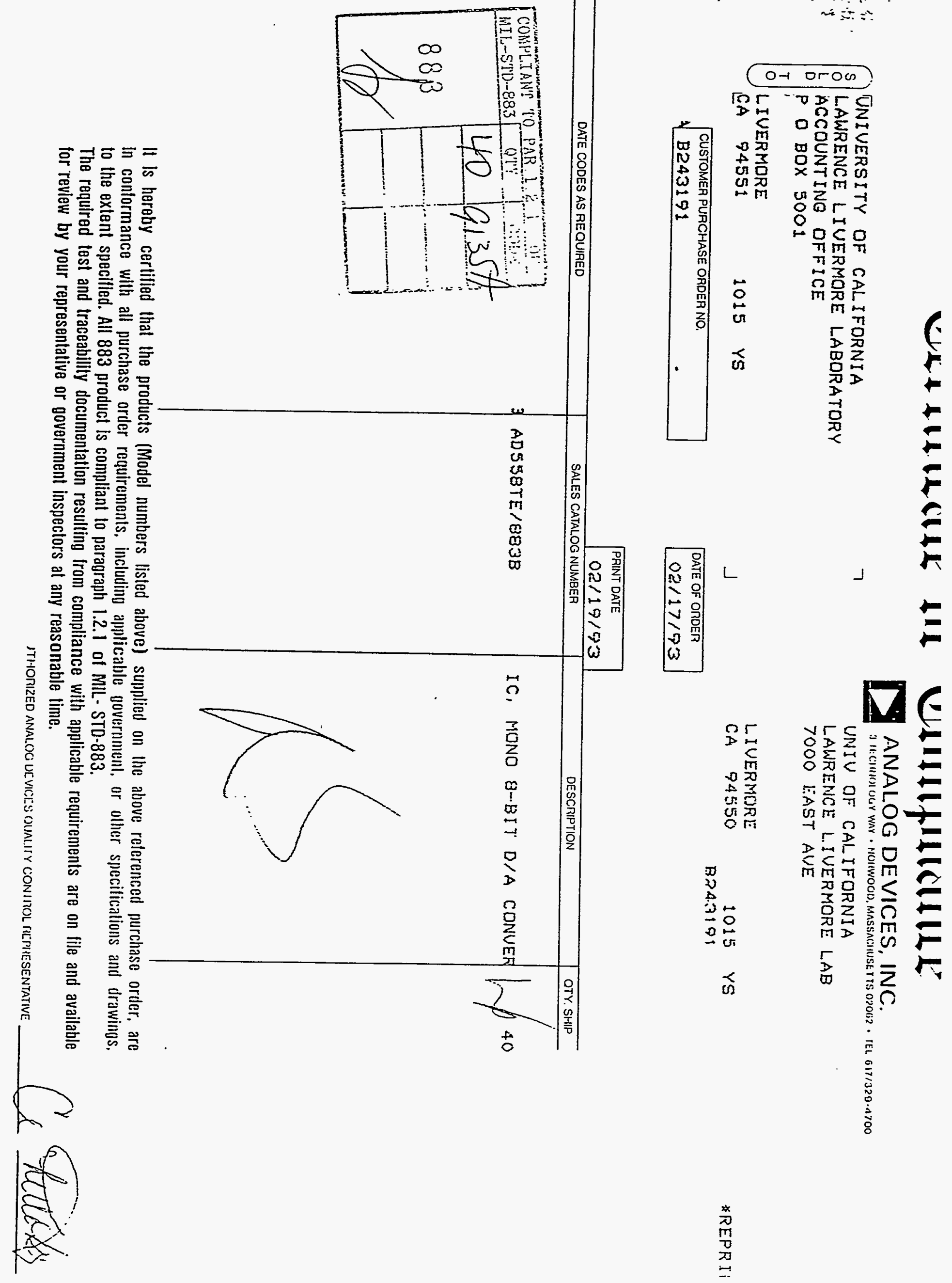




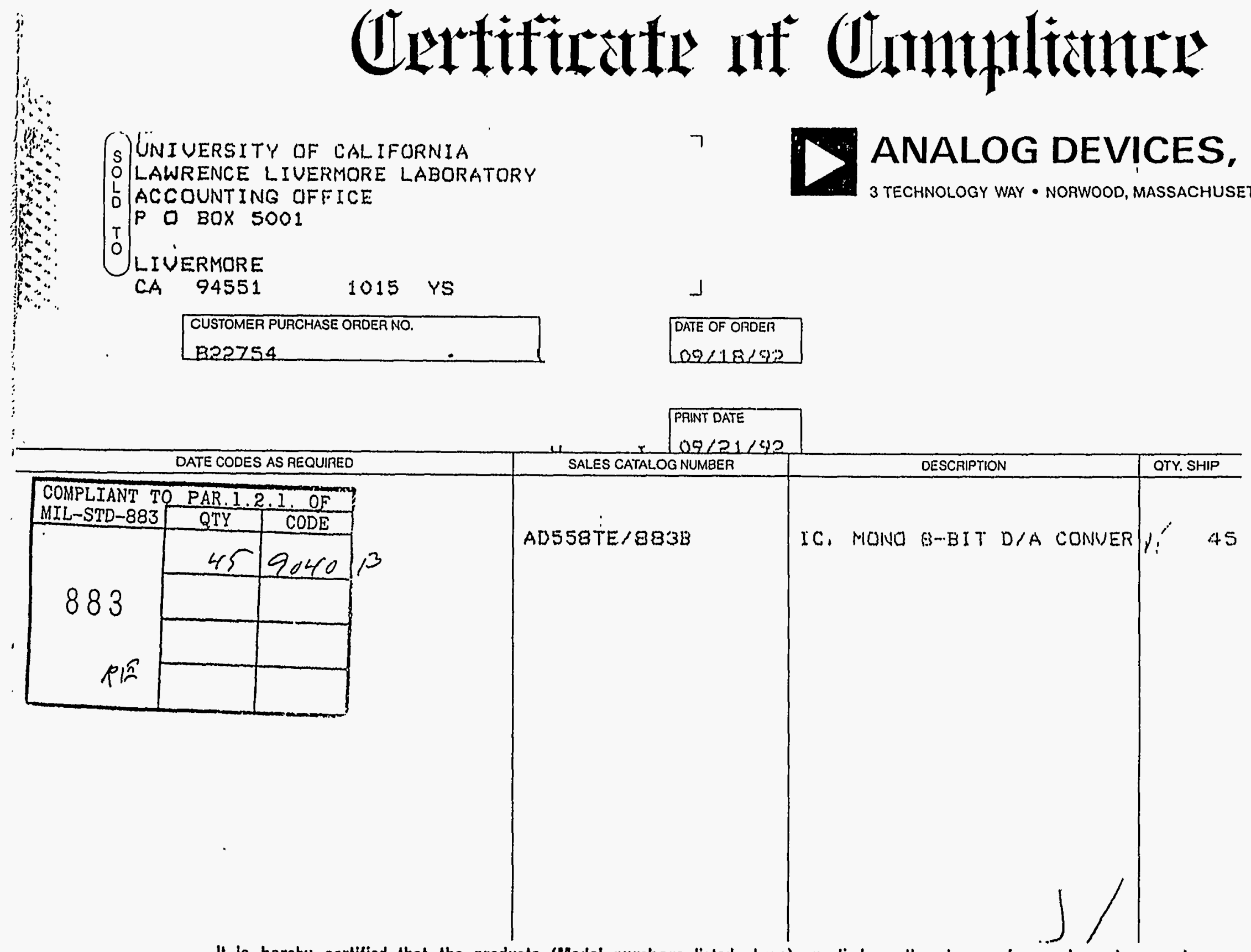

It is hereby certified that the products (Model numbers listed above) supplied on the above referenced purchase order, are in conformance with all purchase order requirements, including applicable government, or other specificalions and drawings, to the extent specilied. All 883 product is compliant to paragraph 1.2.1 of MIL- STD-883.

The required test and traceability documentation resulting from compliance with applicable requirements are on file and available for review by your representative or government inspectors al any reasonable time. 


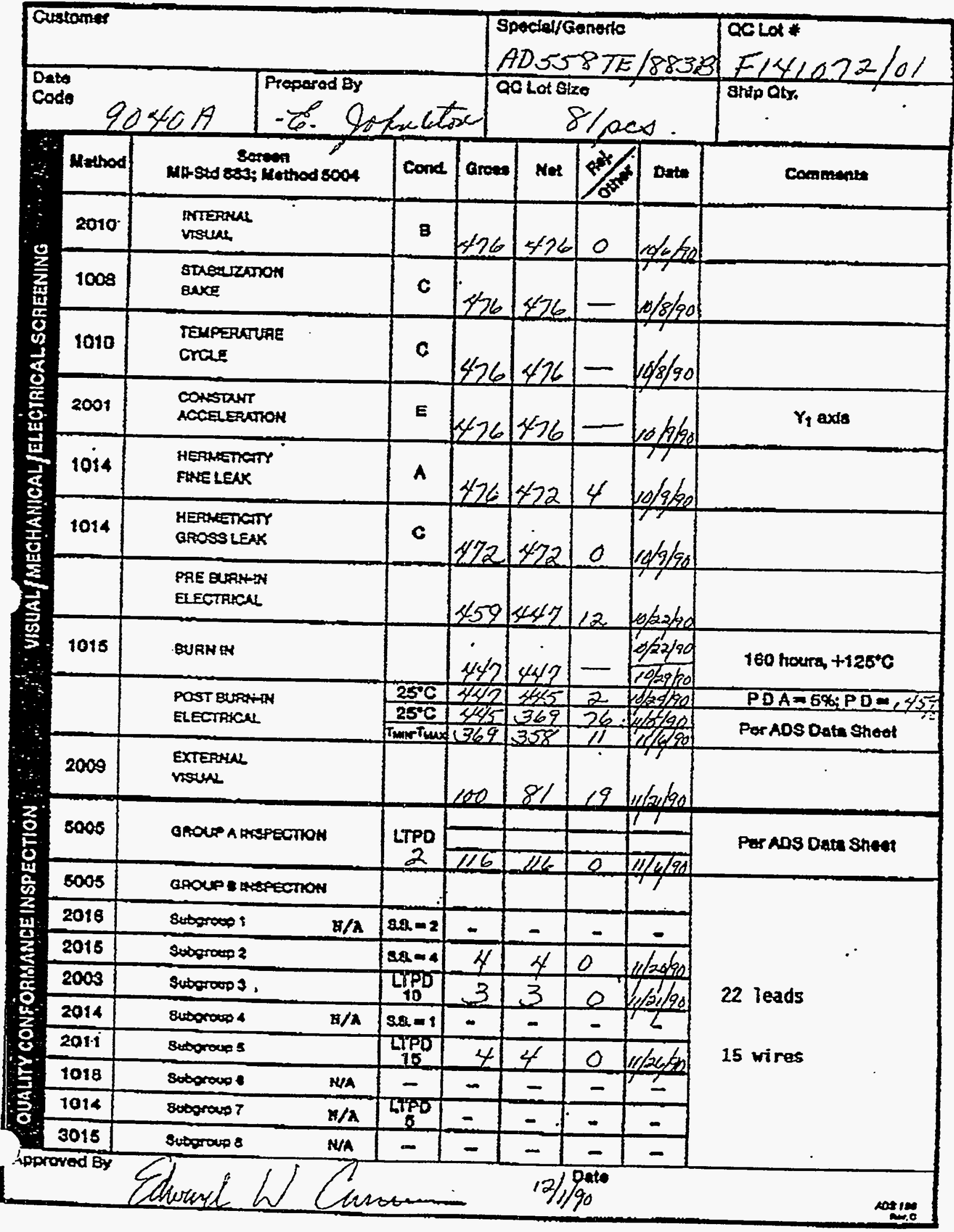




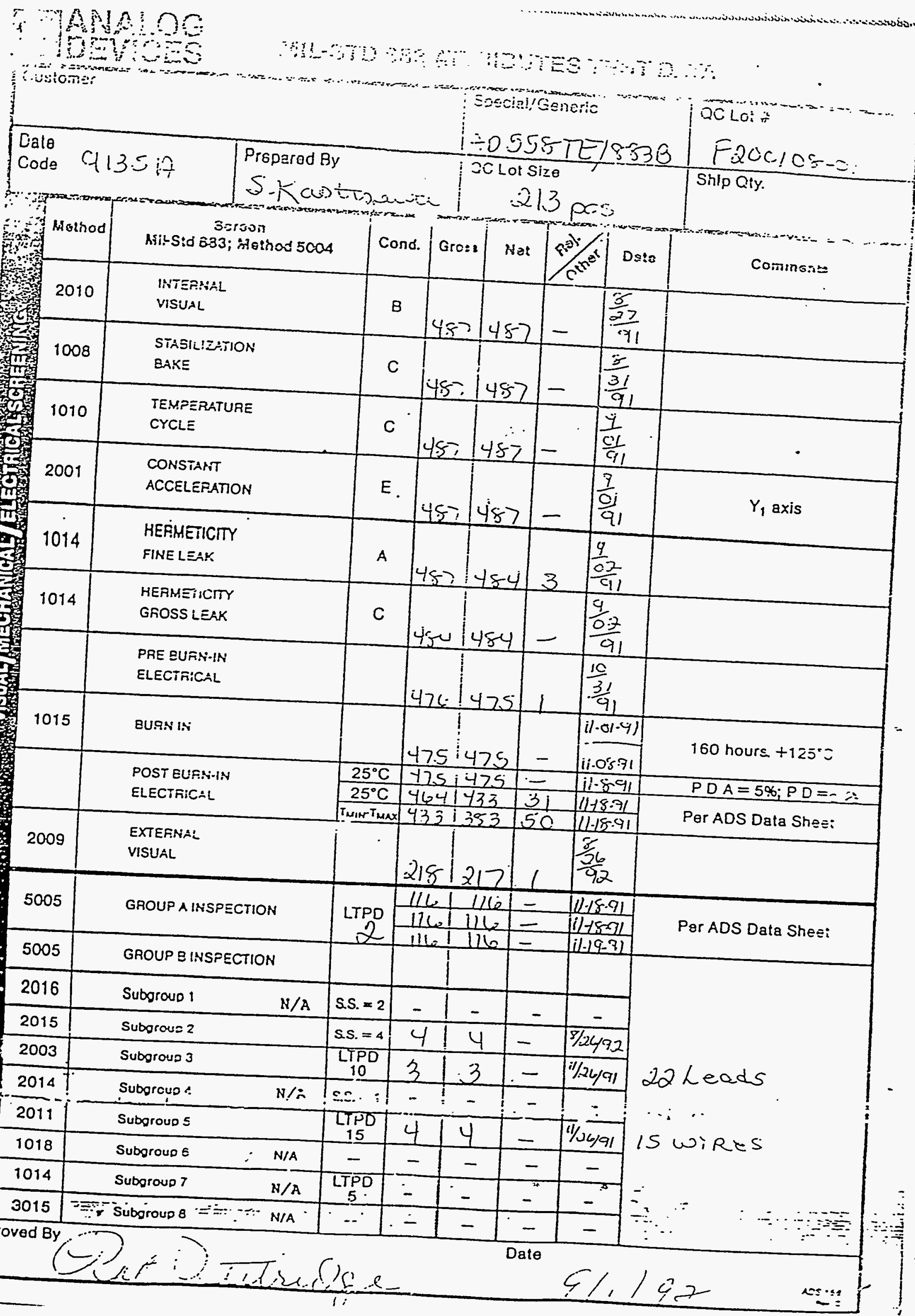




\section{QUALITY CONFORMANCE INSPECTION MIL-C-3098 G}

\begin{tabular}{|c|c|}
\hline customer uni of California & PO.No. B 243124 \\
\hline TYPE $\quad$ CXAT-T2 & PCS 25 \\
\hline \multicolumn{2}{|l|}{ LOT No: $\operatorname{CQOON} 76$} \\
\hline FREQUENCY $\quad 20.0 \mathrm{MHz}[\mathrm{kHz}]$ & FREQ.TOLERANCE \pm 50 \\
\hline LOAD CAPACTTANCE $\mathrm{Cl}_{L} \quad 20 \quad\left[\begin{array}{lll}\mathrm{pF} & 1\end{array}\right.$ & SHUNT CAPACITANCE Co $3.20[\mathrm{FF}]$ \\
\hline SERIES RESISTANCE R $10050[\mathrm{k} \Omega]$ & OPERAT.TEMP.RANGE $-55^{\circ} \div+125^{\circ} \mathrm{C}$ \\
\hline DRIVE LEVEL MAX & MARKING MC $20.000 \mathrm{MT}$ \\
\hline MEASURING EQUIPMENT No.QC-Tester II & OSCILlATOR No. 999 \\
\hline
\end{tabular}

\begin{tabular}{|c|c|c|c|c|c|}
\hline & \begin{tabular}{|r|} 
Insp.Level \\
\end{tabular} & $\begin{array}{c}\mathrm{n}-\mathrm{c} \\
\mathrm{min} \\
\text { STD 105D }\end{array}$ & $\begin{array}{c}n-c \text { eff } \\
\text { EFFECIVE }\end{array}$ & $\begin{array}{c}\bar{X} \\
\text { ARTHM. MENN }\end{array}$ & $\begin{array}{c}S \\
\text { STAND. DE*. }\end{array}$ \\
\hline SERIES RESISTANCE $\mathrm{R} 1 \mathrm{l}$ [ $\Omega$ ] & $2 / 0.65$ & 10 & $25-0$ & 0.015 & 0.004 \\
\hline SERIES CAPACITANCE C 1 [f F] & $2 / 0.65$ & & $25-0$ & 9.84 & 0.24 \\
\hline FREQUENCY DEITAI. $\quad \Delta_{\mathrm{f} / \mathrm{f}[\mathrm{ppm}]}$ & $2 / 0.65$ & $10 \%$ & $25-0$ & 8.4 & 7.3 \\
\hline VISUAL & $2 / 1.0$ & & $25-0$ & & \\
\hline TURNOVER POINT & $54 / 0.65$ & & 25 & 48.01 & 7.8 \\
\hline TEMP.COEFFICIENT $\quad \alpha \quad\left[{ }^{\circ} \mathrm{C}^{-1}\right]$ & $S 4 / 0.65$ & $\%$ & $25-0$ & $-.162-6$ & .1098 \\
\hline TEMP.COEFFICIENT $\quad \beta \quad\left[{ }^{\circ} \dot{C}^{-2}\right]$ & $54 / 0.65$ & & & & \\
\hline OPERATING TEMP.RANGE & $S 4 / 0.65$ & $\%$ & $25-0$ & & \\
\hline & & & & & \\
\hline & & & & & \\
\hline & & & & & ? \\
\hline & & & & & \\
\hline & & & & & \\
\hline QUALITY FACTOR 57704 & & \multicolumn{4}{|c|}{$\left.\mathrm{AGTNG} \backslash 7185^{\circ} \mathrm{C}\right] \Delta \mathrm{f} / \mathrm{f}[\mathrm{ppm}]$} \\
\hline DATE. if Fobruar as & & & & $\mathrm{Q} A \mathrm{~K}$ & \\
\hline
\end{tabular}


Appendix H.2.6

Artwork 


- …는


$E-E$

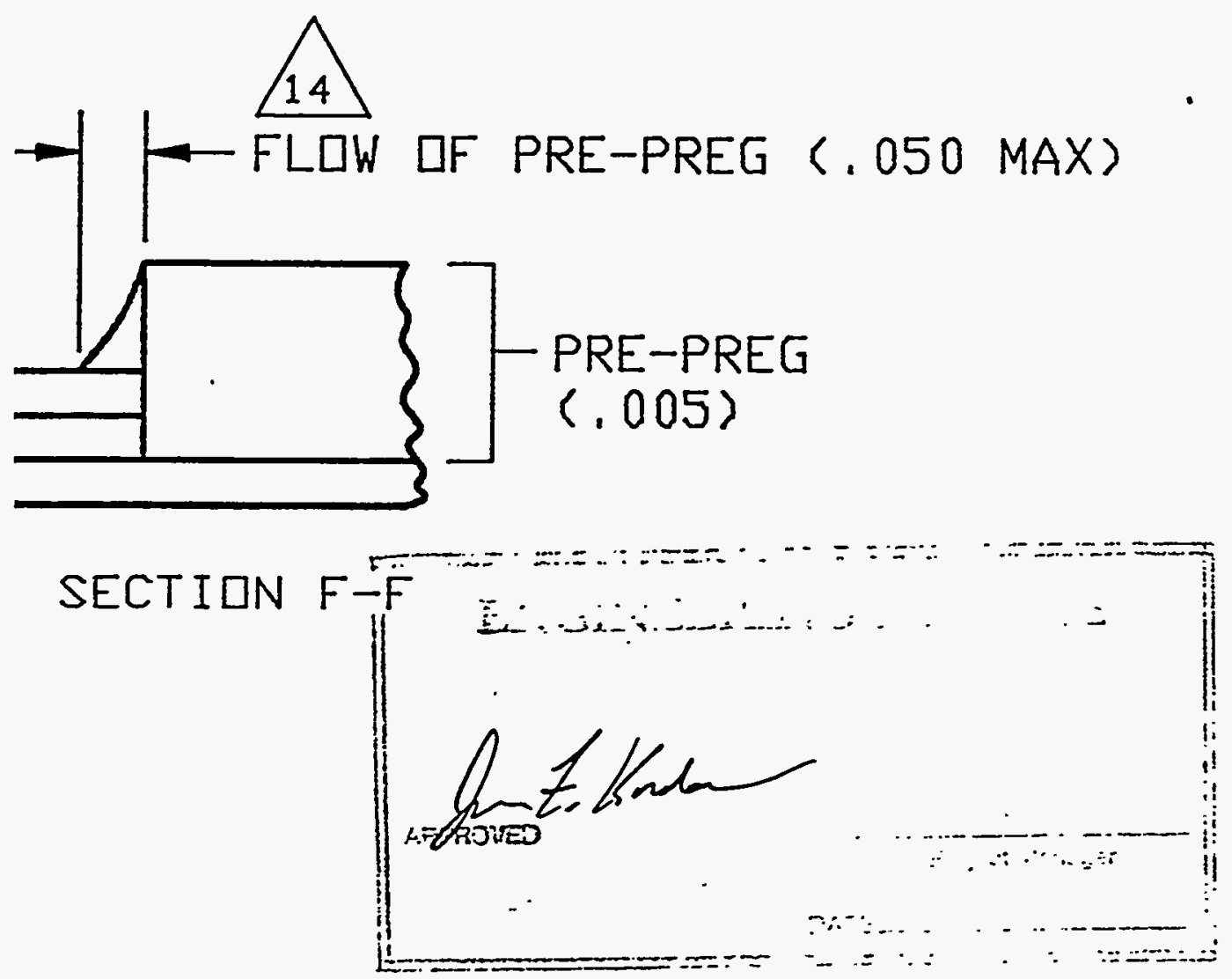

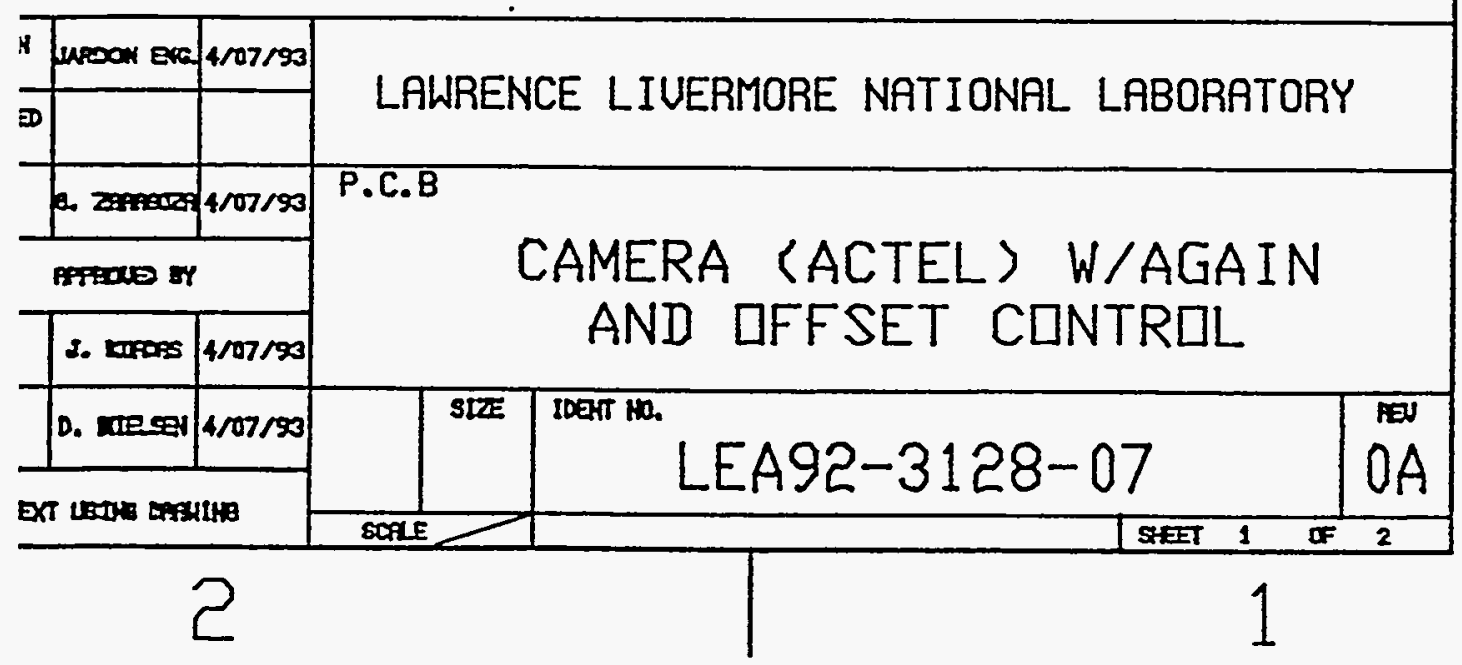



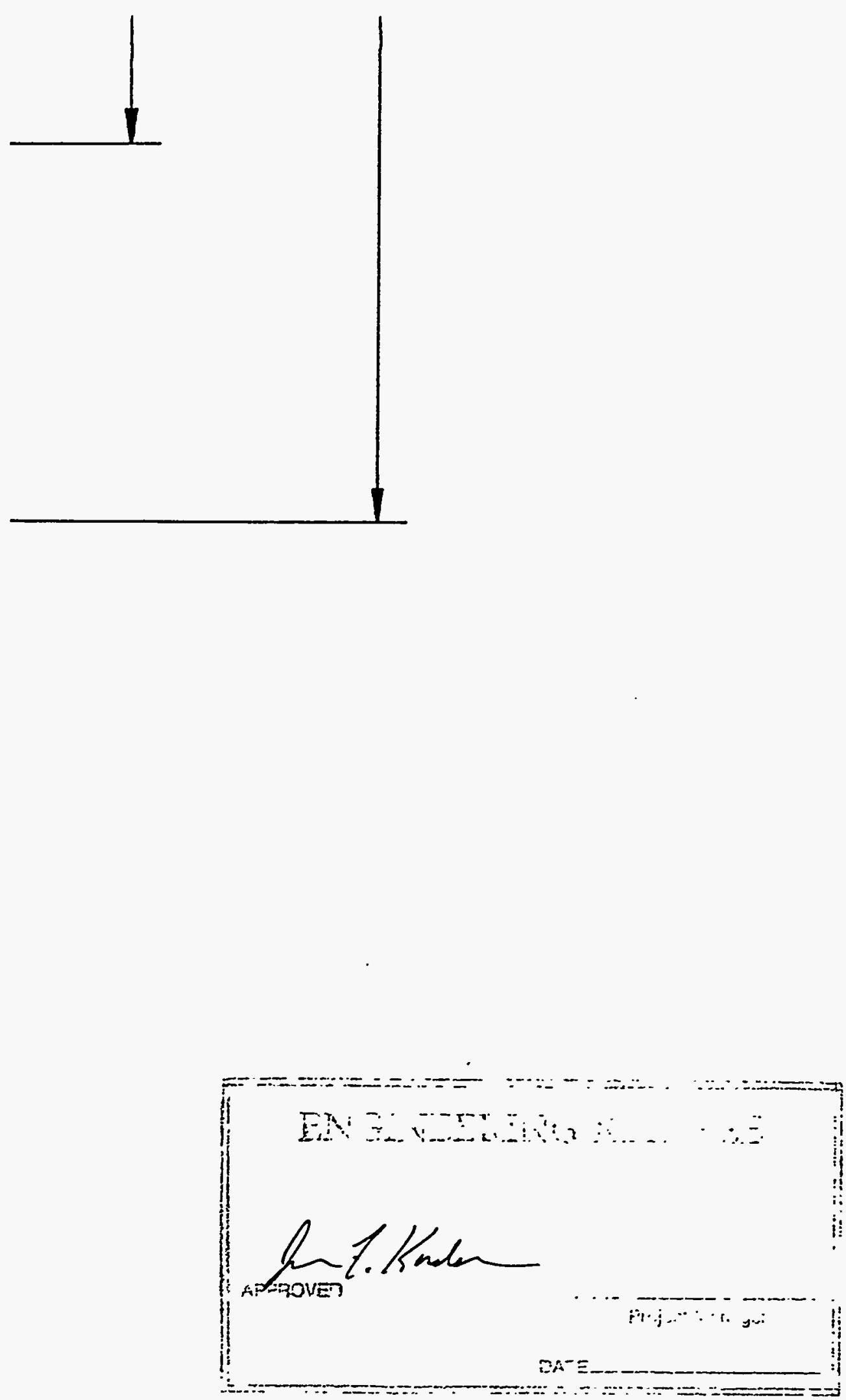

$A$

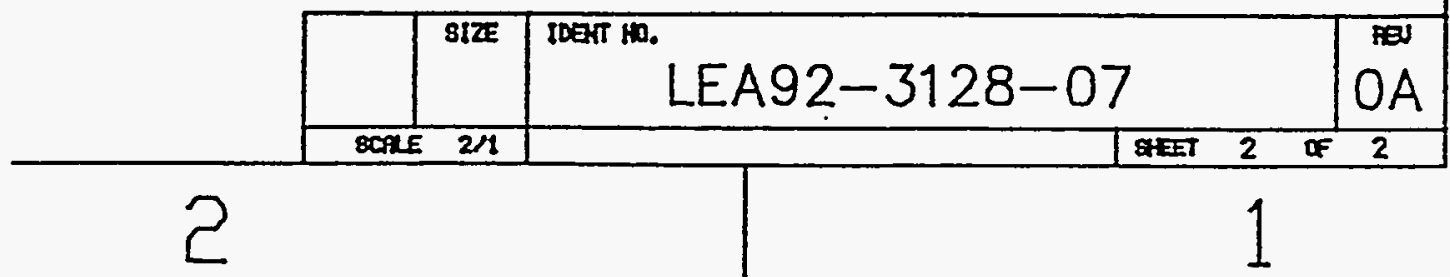


. 


\section{Appendix H.2.7 .}

\section{Electronic Test Data}




\section{Appendix H.2.7.1 \\ Electronic Test Procedure: Actel Camera, PWA with Gain and Offset Control}




\section{Electronic Test Procedure}

\section{Actel Camera, PWA with Gain and Offset Control}

SN\# $\frac{O 4-010}{\text { (ST1 configured) }}$

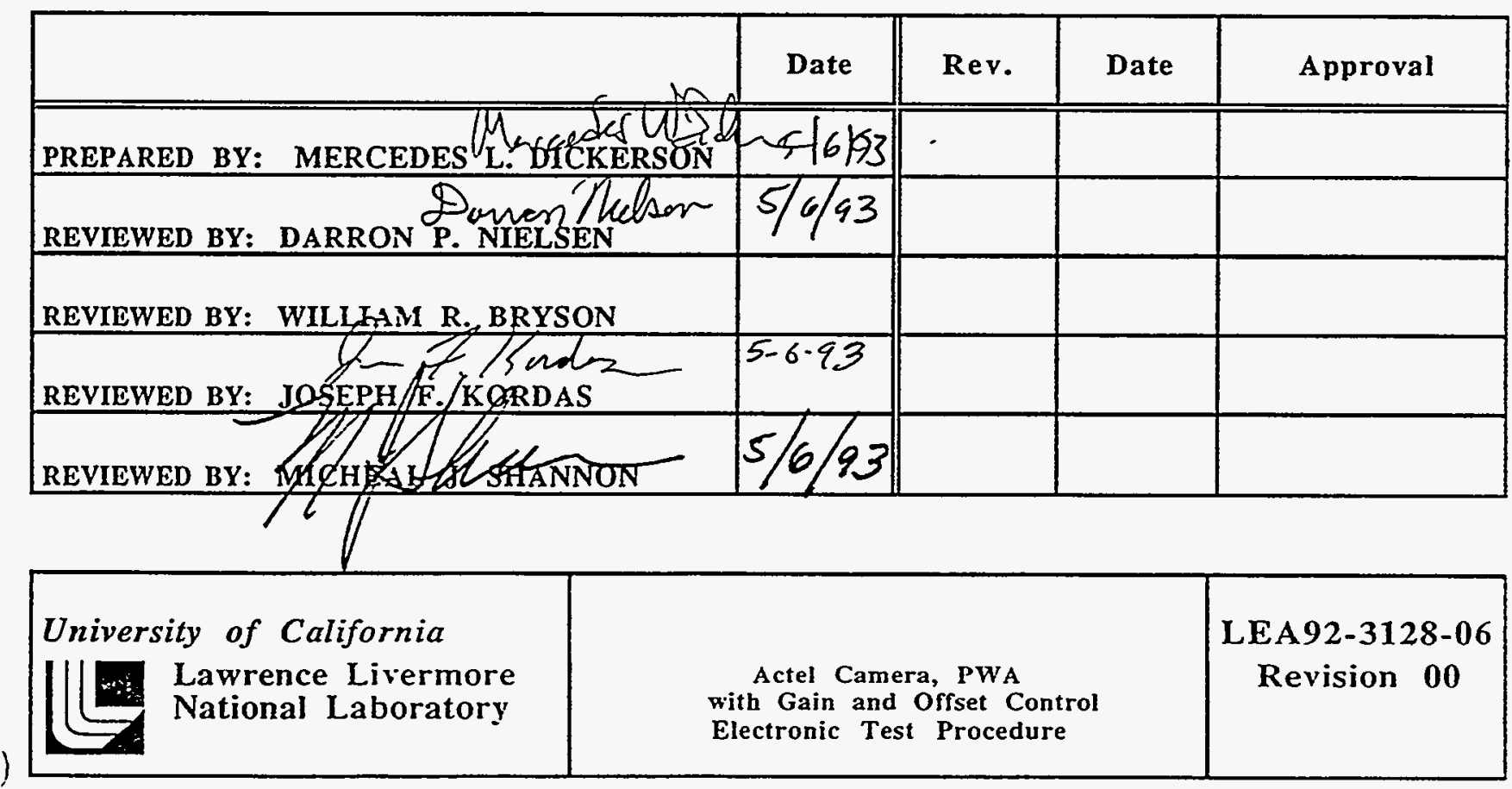




\section{Table of Contents}

1. Scope

2. Required Documents and Test Equipment

2.1 Required Documents

2.2 Required Test Equipment

3. Conditions and Requirements

3.1 Precaurions

3.4 Cleanliness and Environment

3.5 Quality Assurance (QA) Provisions

4. SUN Test Station Setup

5. Printed Wiring Assembly Specificity

5.1 Inspection

5.2 Power Plane Resistance Measurements

5.3 Power Plane Voltage Measurements

5.4 CCD Bias Voltage Measurements

5.5 Reference Voltage Measurements

5.6 Video Clamping Voltage Measurements

5.7 DC Steady State Current Measurements

5.8 Offset Digital-To-Analog (D/A) Verification

5.9 Gain Selection Verification

6. Video Amplifier Gain Verifications

6.1 Test Board Configuration

6.2 HP4194 Analyzer Configuration and Connection.

6.3 Gain and $3 \mathrm{~dB}$ Bandwith Acquisition.

7. Clocking Measurements (with CCD installed)

$7.1 \quad \varnothing \mathrm{L} 2, \varnothing \mathrm{L} 1$

$7.2 \varnothing \mathrm{L} 2, \varnothing \mathrm{R}$, and $\varnothing \mathrm{RFET}$

$7.3 \quad \varnothing \mathrm{P} 1, \varnothing \mathrm{P} 3$

$7.4 \quad \varnothing \mathrm{P} 1, \varnothing \mathrm{P} 2$

$7.5 \varnothing \mathrm{P} 1, \varnothing \mathrm{P} 4$

7.6 P1A, P3

7.7 P1A, P2

7.8 P1A, P4

7.9 P1A, P1B

8. Double Correlated Sampling Functionality Verification

9. Analog to Digital (A/D) Converter

10. Video Interface Timing Confirmation

10.1 Logic Analyzer Setup

10.2 Timing acquisitions

11. Dark Noise Measurement 


\section{Table of Contents cont.}

12. Thermal Test

12.1. Thermal Test Setup

12.2 Thermal Measurement Acquisition

12.3 Thermal Data and Graphs

13. Flat Field Linearity Test

13.1. Linearity Test Setup

13.2 Linearity Measurement Acquisition

13.3 Linearity Data Collection.

13.4 Linearity Data Processing

14. Offset Linearity Test

14.1. Offset Linearity Test Setup

14.2 Offset Linearity Measurement Acquisition

14.3 Offset Linearity Data and Graph

15. Laser Test

16. Tests Required after Conformal Coating 
1. Scope.

This document specifies equipment and procedures required to verify the electrical performance of the ACTEL Camera Printed Wiring Assembly (LEA92-3128-02) in the startracker configuration.

Oscilloscope camera photos and graphs should be attached to the test procedure. Other printer data should be placed in a document protector and inserted in this certification log.

Section 16 describes those tests that are required after conformal coating.

2. Required Documents and Test Equipment.

2.1 Required Documents:

Actel Camera PWB Schematic, LEA92-3128-01-0C OR LEA92-3128-11-OC

Actel Camera PWB Assembly Drawing, LEA92-3128-03

SUN DatacubeTest Station

A Shor Guide o Running hspcube ，C1-S1-002

\subsection{Required Test Equipment:}

SUN DatacubeTert Station includer Protomax Interface

S1/S2 Data Interface Power Supply, AIT EE-0090-10

Engineering TH7883 CCD for test purposes

Digital volumeter such as Fluke model 77

AM 503 Current Probe (2ea) powered by a TM502A Power Supply

Tektronix 2465B Analog Oscilloscope with P6106A probes (4ea)

Oscilloscope recording camera

Tektronix TDS540 Digital Oscilloscope

Hewlett Packard Desk Jet 500 Printer

HP 4194 Impedance Gain-Phase Analyzer, with probe and RG 58 cabling

Tektronix HCi00 color plotter

Philips PM 3585, 200 MHz Logic Analyzer

TV Optoliner Model K-4000 (with neutral density (ND) filters) and Lamphead

HeNe Laser, $1 \mathrm{~mW}$ ar $632.8 \mathrm{~nm}$ (with ND filters)

Surface mount testing probes,

Tektronix 20-pin and 44-pin SMQK1 PLCC

Actel Camera board carrier mount, to prevent carrier/pc card flexing

PC board holder/clamp

Video Copier Procescor Tektronix Model HCO2

Environmental chamber

Timer

Black cloth or an opaque cover for the CCD

Packing Foam

Breakout Connector. 51 contact miniD

The above listed test equipment MUST have calibration dates within one year of test integration. Calibration records should also be available for inspection.

Any fabricated testing hardware, such as the 51-pin breakout connector,MUST have quality assurance tagging and records stating such. 


\section{Conditions and Requirements}

\subsection{Precautions}

(1) Responsibility for Safety. All personnel are responsible for maintaining a safe work environment. The Test Conductor or cognizant operator shall assure that appropriate safe practices are implemented during these operations, and that operations are performed in a proper order.

(2) ESDS Equipment. The test specimen contains electrostatic- sensitive devices which are exposed at the electrical interfaces. Therefore, it shall be handled per MLL-STD1686 Class 1 . The test specimen, the test operator (using wrist straps), and related electrical test equipment shall be connected to a common ground before any electrical mating or de-mating operations, and during the use of any electrical test equipment probes. There shall be no "hot-plugging" of the test specimen with any test equipment.

(3)Examine Connectors. Before mating any flight connector, examine the connector and the connector with which it is to be mated, to assure that there are no interferences at the pin interface. Connector savers will be used at all times.

\subsection{Cleanliness and Environment}

(1) Standard laboratory conditions of atmospheric temperature, pressure, and humidity are acceptable for the testing defined herein.

(2) Normal housekeeping standards will be required. If appropriate, the unit may be cleaned prior to installation into the next assembly, or prior to return to storage.

\subsection{Quality Assurance (QA) Provisions}

QA provisions operative during activities defined in this procedure shall be as specified in the project's QA Plan. This section identifies the interfaces between QA and test personnel. QA and test personnel are jointly responsible for the effectiveness of these interfaces in implementing the QA provisions.

(1) QA shall be notified, in advance, of performance of any activities described in this procedure. A QA Inspector may monitor those activities as is deemed necessary or appropriate, in accordance with the project QA Plan. The inspector shall verify that the proper revision of this procedure is used, and that the required Certification Log is in proper order. QA will then give the "OK to Test" prior to the start of test activities.

(2) The QA Inspector shall verify: that calibration is current for all measuring equipment used in these operations, and will not expire prior to completion of these operations; that applicable project-specific electrical support test equipment (STE) has been properly certified and tagged; and that applicable lifting and handling STE has been propérly proof tested and tagged. 


\section{Qualiţ Assurance (QA) Provisions (continuation)}

(3) The QA Inspector may assist in assuring that the precautionary and environmental requirements stated in 3.1 and 3.2 are met. He shall also, at his discretion, assist in the inspection of test setups prior to application of power to a test specimen, and prior to any mechanism-assisted lifts or moves.

(4) Upon the occurrence of a test anomaly (any event that deviates from the planned procedures, exceeds normal variations, or generates unexpected data), operation of the test article shall be stopped immediately. All other test conditions and parameters shall be maintained (except as those conditions may pose an immediate hazard). The QA Inspector shall be notified that a test anomaly has occurred.

(5) The QA Inspector or Test Conductor (with QA concurrence) shall note each test anomaly on the Failure Reporting And Corrective Action System (FRACAS). The Inspector and the Test Conductor shall review the anomaly. Minor troubleshooting may be done to determine the cause of the anomaly; however, no disassembly or other actions that present a risk to the test article shall be allowed. If the anomaly is found to result from human error or test equipment problems that have not affected the test article, corrective action shall be taken and testing may continue. All troubleshooting steps and results shall be recorded on the FRACAS. The Test Conductor shall supervise any troubleshooting or retesting required in resolving test anomalies.

(6) If a test anomaly cannot be resolved as described above, the Project Engineer shall be notified. If the action indicates that a rework or repair may be required, the anomaly and troubleshooting results shall be noted in the Action Item List (AIL) portion of the Certification Log, Fracus report and a Material Discrepancy Report (MDR) shall be initiated (if required) and processed as prescribed in the QA Plan.

(7) The QA Inspector shall stamp log entries as appropriate, attesting to the proper completion of these operations as previously approved in this procedure document. 


\section{SUN DatacubeTest Station}

The LLNL SUN Test Station layout looks like this:

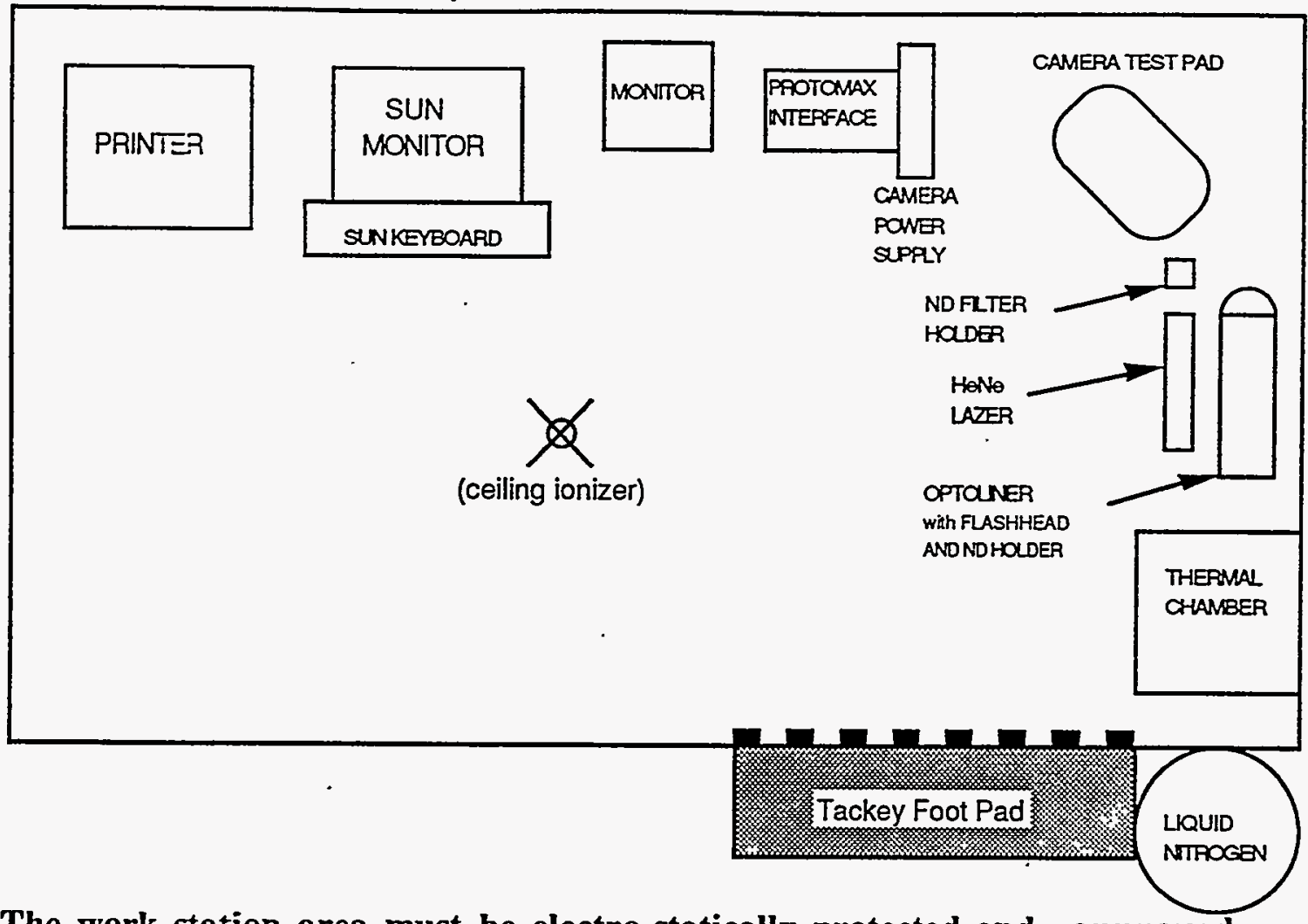

The work station area must be electro-statically protected and approved.

A Short Guide to Running hspcube, C1-S1-002, by Ray Aley, Hye-Sook Park, and Eric Parker explains the Sun 3 Computer-Datacube workstation and the software imaging options for the Startracker (S1), UV-Visible (S2), and Lidar (S4) modes.

\section{Printed Wiring Assembly Specificity}

\subsection{Inspection}

Inspect the carrier mounted Actel board for any conflict with the configuration table, assembly drawing or obvious fabrication flaws. Inspect the action item list of the certification log for any anomalies. NOTE!! The camera board should remain attached to the carrier mount until ultimately bent and housed.!!

SN\# $04-010 \quad$ Inspection completed By $\frac{\Delta \times a}{\text { initials }}$

Date $5 / 6 / 93$ 
5.2 Power Plane Resistance Measurements

Measure potwer plane resistances at $\mathbf{J 1}$.

$$
\text { pin\# }
$$

DVM(common)

5 (AGND)

20 (DGND)

us

pin

DVM(signal)

39 (+15VDC)

4 (-15VDC)

37 (+5VDC)

38 (+5VDC)

3 (-5VDC)

40 (+5VIN)

5

39

37

38

3

40

$39(+15 V D C) \quad-\quad 4$

37

38

3

40

$4(-15 V D C) \quad-\quad 37$

38

3

40

$37(+5 V D C) \quad-\quad 38$

3

40

$3(-5 V D C)$
NOTE: NO cable attached!

expected $\Omega$

measured $\Omega$

$\geq 2 \mathrm{M} \Omega$

$\geq 2 \mathrm{M} \Omega$

$=479 \Omega$

$\approx 479 \Omega$

$\approx 1.54 \mathrm{k} \Omega$

$=2.9 \mathrm{k} \Omega$

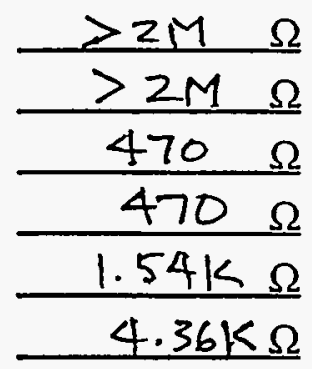

$\approx .2 \Omega$

$>2 \mathrm{M} \Omega$

- $3 \Omega$

$\approx 468 \Omega$

$\approx 468 \Omega$

$\approx 1.5 \mathrm{k} \Omega$

$\approx 3 K \Omega$

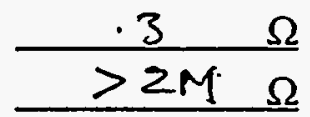

$470 \Omega$

$\geq 11 \mathrm{~K} \Omega$

$\geq 2 M \Omega$

$\geq 2 M \Omega$

$\geq 2 \mathrm{M} \Omega$

$\geq 2 \mathrm{M} \Omega$

$470 \Omega$

$1.54 \mathrm{~K} \Omega$

$4.37 \Omega$

$>2 \mathrm{M} \Omega$

$>2 M \Omega$

$>2 M \Omega$

$>2 \mathrm{M} \Omega$

$12 K \Omega$

$>2 M \Omega$

$\approx .3 \Omega$

$\approx 2 \mathrm{k} \Omega$

$>3 \mathrm{~K} \Omega$

$\approx 4.5 \mathrm{k} \Omega$
$72 M \Omega$

$>2 M \Omega$

$72 M \Omega$
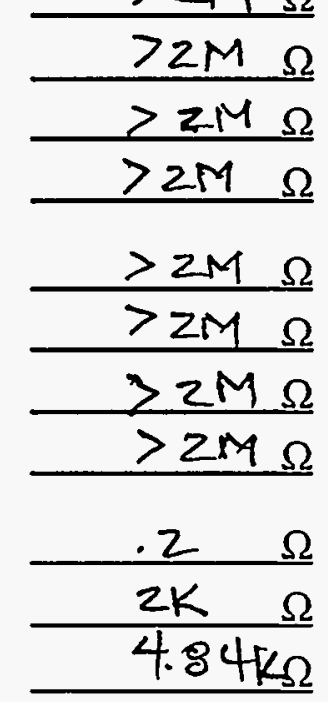

$5.01 \mathrm{~K} \Omega$ 


\subsection{Power Plane Voltage Measurements}

Using a flight cerrified breakout connector, verify power voltages at camera connector before attaching it to the camera board. Complete the table below, then turn off the power. Use J1-pin 20 for DVMi ground.

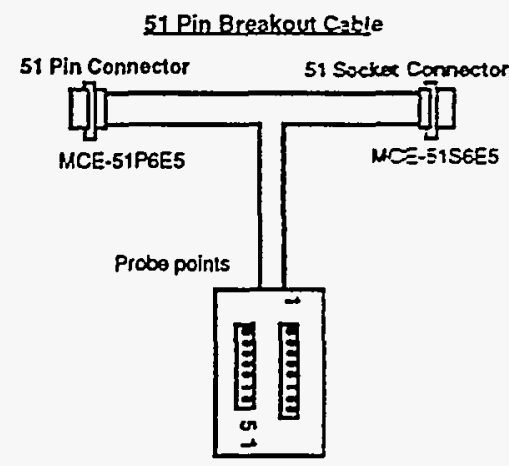

$\mathrm{J} 1 \mathrm{pin}$
39
4
37,38
3
40

P. $\$$. $\$ 3$ Expected V Measured V

Cable voltages satisfied, now measure the power plane voltages. Connect camera side of the breakout connector to the camera board. Once the breakout is attached to the camera board, leave it in place throughout the testing procedure to save the board's connector.

Power up the camera board and record the voltages between single point ground (SPG) or TP1 and indicated volrage points:

$$
\begin{aligned}
& \text { PRIMARY SIDE } \\
& \text { 土. . V V } \\
& \text { U12-pin } 16 \quad 5.02 \mathrm{~V} \\
& \text { U25-pin } 16 \quad 5.02 \mathrm{~V}
\end{aligned}
$$

$$
\begin{aligned}
& \text { SECONDARY SIDE } \\
& +\mathrm{C} 10 \\
& 5.02 v \\
& \text { U2-pins 4, 9, } \\
& 15,16,5,02 \text { v } \\
& \text { U26-pins } 3,14 \text {, } \\
& 16,25,35,5.02 \mathrm{~V} \\
& \begin{array}{ll}
\text { U5-pin } 22 \frac{5.02 v}{5.02 v} \\
\text { U6-pin } 16 \frac{5.02 v}{\text { U7-pin } 16}
\end{array}
\end{aligned}
$$

$$
\begin{aligned}
& \pm 5.0 \mathrm{VA} \\
& + \text { C11 } \\
& 4.91=
\end{aligned}
$$

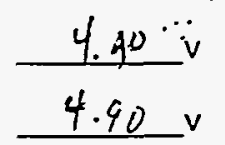$$
\text { U32-pin14 }
$$$$
4.20 \mathrm{~V}
$$ 
PRIMARY SIDE

\begin{tabular}{|c|c|}
\hline$\frac{-5.0 V A}{-C 12}$ & $-5.31 \mathrm{v}$ \\
\hline U1-pin 4 & $-5.31 v$ \\
\hline U24-pin 4 & -5.31 \\
\hline Q1-pin 4 & $-5.31 \mathrm{v}$ \\
\hline Q4-pins 4 & $-5.31 v$ \\
\hline $\pm 15.0 \mathrm{~V}$ & \\
\hline Q2-pin 3 & $15 \cdot 18$ \\
\hline U17-pin 1 & 15.23 \\
\hline U14-pin 7 & 1518 \\
\hline
\end{tabular}

$-15.0 \mathrm{~V}$

U14-pin $4 \quad-15.27 v$

\subsection{CCD Bias Voltage Measurements}

$$
\begin{aligned}
& \text { St- }=0 \mathrm{~V} \mathrm{VSS} \\
& \text { S2 \& S4- }=-3.0 \mathrm{~V} \text { VSS } \\
& \text { U19-pins } 1,10 \\
& \text { and } 17 \\
& \text { O v } v \\
& \begin{aligned}
\mathrm{St} & \frac{\equiv 1.5 \mathrm{v} \mathrm{VgS}}{\mathrm{S} 2 \mathrm{S4}} \\
\text { U19-pin } 20 & \frac{\equiv 2.5 \mathrm{v} \mathrm{VSS}}{1.5 \mathrm{v}}
\end{aligned} \\
& \frac{\approx 13.0 \mathrm{v} V \mathrm{dr}}{\text { U19-pin } 18} \quad 13.13 \mathrm{v} \\
& \equiv 15.0 \mathrm{~V} \mathrm{Vdd} \\
& \text { U19-pins 5, } \\
& \text { and15 } 15 \cdot 18 v
\end{aligned}
$$

\begin{tabular}{|c|c|}
\hline$-C 52$ & $-15.28 v$ \\
\hline U3-pin 4 & $-15 \cdot 28$ \\
\hline U27-pin 4 & $-15.28 v$ \\
\hline
\end{tabular}

\section{SECONDARY SIDE}

$$
\begin{array}{ll}
\text { Q9-pin } 4 & \frac{-5.30 v}{} \\
\text { Q10-pin } 4 & \frac{-5.30 v}{-5.30 v} \\
\text { Q11-pin } 4 & \frac{-5.30}{1}
\end{array}
$$$$
+C 9 \quad 15.17 v
$$$$
\text { U18-pin } 1 \quad 75,2 v
$$$$
\text { U27-pin } 8 \quad 15, m v
$$$$
\text { U3-pin } 8 \quad 15 \% 17 v
$$$$
\text { D3-pin } 2 \quad 15.7 v
$$

U3-pin 1

U3-pin $7 \quad 13 \cdot 12 v$ 
PRIMARY SIDE

5.5 Reference Voltage Measurements

$10.0 \mathrm{~V}$ ref

0.1V DARK REF

10.7VA clocking ref (ØL1, ØR, ØRFET)

U17-pin $3 \quad 10.83 v$

U11-pin $6 \quad 10.82 v$

U30-pin $6 \quad 10.83 v$

10.7VB clocking ref. (P, $\varnothing P)$
SECONDARY SIDE

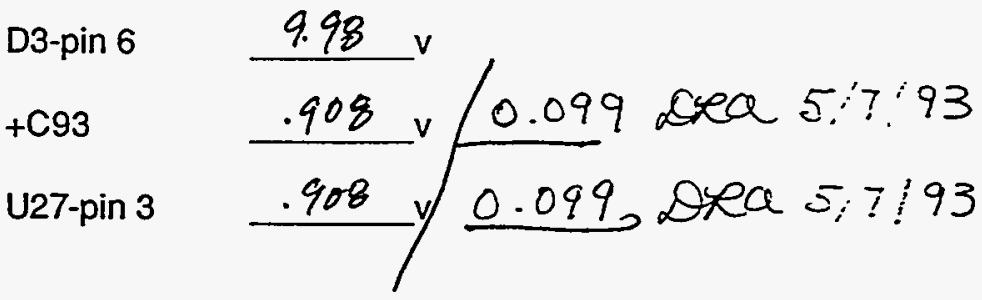

$\begin{array}{ll}\text { U18-pin } 3 & \frac{10.67}{10.67 v} \\ \text { U9-pin } 6 & \frac{10.67 v}{10.67 v} \\ \text { U10-pin } 6 & \text { U22-pin 6 } \\ \text { U23-pin 6 } & \text { 10.67v }\end{array}$

Analog to digital (A/D) converter reference voltages: $=2.5 \mathrm{~V} A / D$ reff

$$
\text { expected volts U27-pin } 5 \quad \frac{2.492 \mathrm{v}}{\text { measured volts }}
$$

U8-pin 6

U8-pin 22

U8-pin 9

5.6 Video Clamping Voltage Measurements

$$
\begin{aligned}
& =0.620 \mathrm{v} \\
& \approx 1.245 \mathrm{v} \\
& \approx 1.875 \mathrm{v}
\end{aligned}
$$

expected volts

U1-pin 8

U24-pin 8

U1-pin 5

U24-pin 5

Turn off the test ilxture.

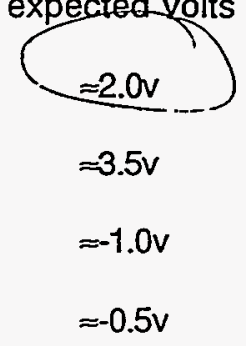

$2.492 \mathrm{v}$

measured volts

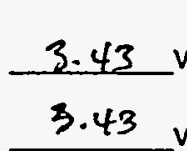
OKAT GS: $-1.048 \mathrm{~V}$

$-.545 v$ 


$$
\begin{array}{r}
\text { EIRlos CURREN } \\
\text { STISN } \$ \text { OA-10 }
\end{array}
$$
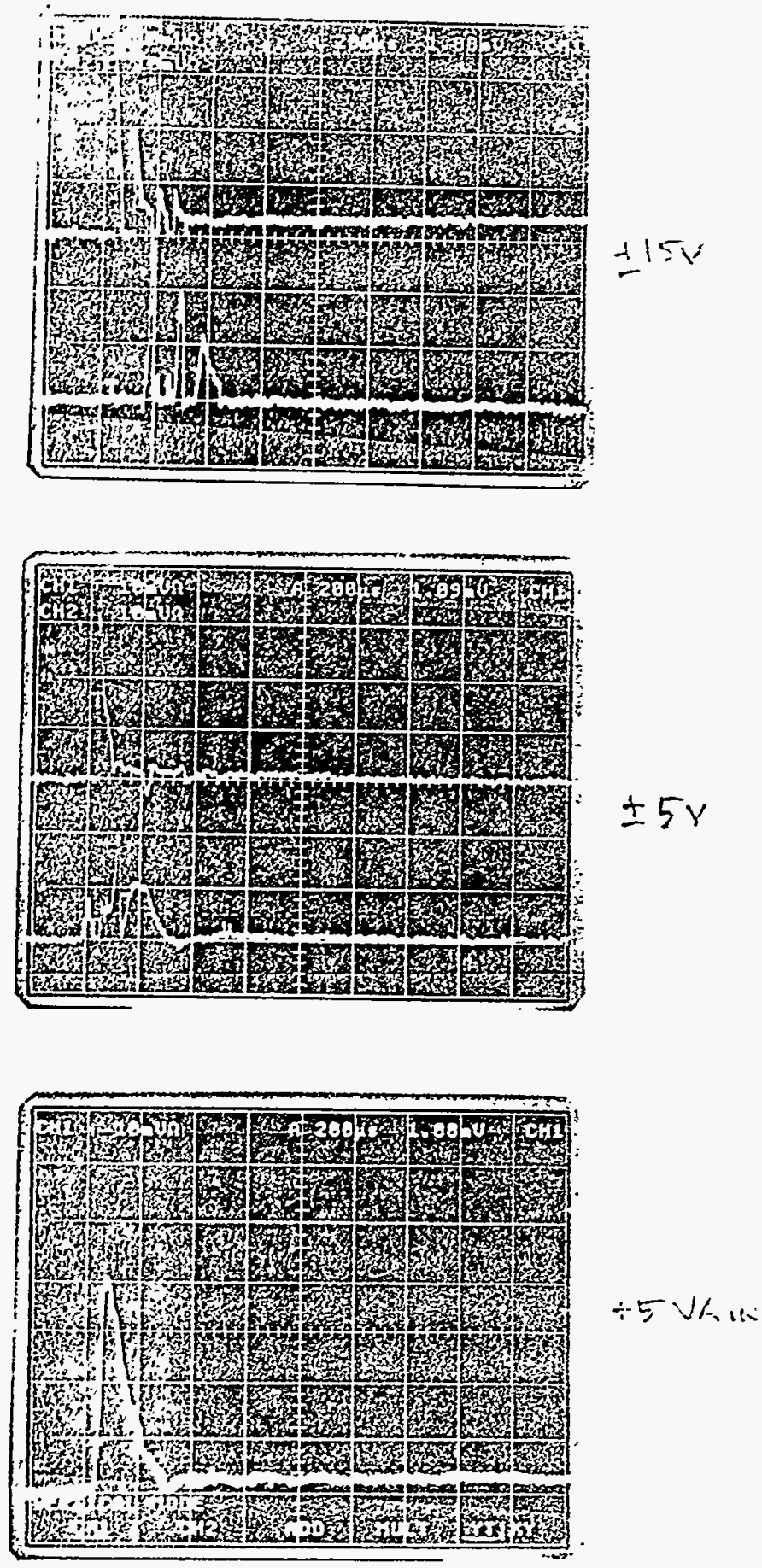


\subsection{Steady State Current Measurements:}

These measurements require an oscilloscope and the AM503 Current Probe powered by a TM502A.

Operation of the AM 503 requires that the oscilloscope be set at $10 \mathrm{mV} /$ div and that the probe be in the locked position.

Isolate and label the camera wiring harness with respect to the individual power voltages. Note!! There are two +5VDC wires\#37\&38 so isolate these wires together.

Power up the camera board. Using the appropriate menu based on the camera board's configuration (Startracker) disable the Video bus. Consult A Short Guide to Running hspcube, C1-S1-002 for the necessary SASI or SUN keyboard commands.

With the Probe and Oscilloscope functional, attach the current probe around each input voltage wire and in the case of the $+5 \mathrm{VDC}$ the wire pair, each time acquiring and recording the oscilloscope display. Note the units/div used at the AM503 so that the current can be calculated.

Consult $A$ Short Guide to Running hspcube, C1-S1-002 for the necessary SASI command to enable the Video bus. Repeat the current measurements. Each time acquiring and recording the oscilloscope display and recording the units/div used at the AM503 so that the current can be calculated.

Calculate the currents under each Video bus state and complete the table below.

\begin{tabular}{|c|c|c|c|}
\hline Voltages & $\begin{array}{c}\text { AM503 } \\
\text { units/div }\end{array}$ & $\begin{array}{c}\text { Calculated } \\
\text { Current Video } \\
\text { Bus Disabled }\end{array}$ & $\begin{array}{c}\text { Calculated } \\
\text { Current Video } \\
\text { Bus Enabled }\end{array}$ \\
\hline \hline$+15 \mathrm{~V}$ & $20 \mathrm{ma}$ & 101 & 101 \\
\hline$-15 \mathrm{~V}$ & $2 \mathrm{ma}$ & 13.76 & 13.76 \\
\hline$+5 \mathrm{VDC}$ & $10 \mathrm{~mA} / 50 \mathrm{~mA}$ & $50.5 \mathrm{~mA}$ & $309 \mathrm{~mA}$ \\
\hline$-5 \mathrm{~V}$ & $10 \mathrm{~mA}$ & $42.7 \mathrm{~mA}$ & $\frac{41.2}{29 \mathrm{~A} A}$ \\
\hline$+5 \mathrm{VAIN}$ & $20 \mathrm{~mA}$ & 107.4 & 105 \\
\hline
\end{tabular}

REMEMBER to attach your recorded documentation to this test procedure! (A document protector is advised) 


\subsection{Offset Digital-to-Analog (D/A) Verification}

To verify data transfer and D/A output voltage, a Fluke 77 or voltmeter is needed.

Within the appropriate menu select and send the indicated offset data via the SASI . Measure the output voltage of U32, AD558TE pins 19, 20. Record the results in the table below.

IMPORTANT: All readings must meet indicated tolerances!

\begin{tabular}{|c|c|c|}
\hline $\begin{array}{c}\text { Decimal } \\
\text { Data Input }\end{array}$ & Expected Voltage & $\begin{array}{c}\text { Measured } \\
\text { Voltage Out }\end{array}$ \\
\hline 00 & $0.0 \mathrm{~V} \pm 10 \mathrm{mV}$ & $.05 \mathrm{l}$ \\
\hline 01 & $80 \mathrm{mV} \pm 10 \mathrm{mV}$ & .080 \\
\hline 02 & $160 \mathrm{mV} \pm 10 \mathrm{mV}$ & .160 \\
\hline 04 & $320 \mathrm{mV} \pm 10 \mathrm{mV}$ & .320 \\
\hline 08 & $640 \mathrm{mV} \pm 10 \mathrm{mV}$ & -640 \\
\hline 16 & $1.28 \mathrm{~V} \pm 10 \mathrm{mV}$ & 1.280 \\
\hline 20 & $1.61 \mathrm{~V} \pm 10 \mathrm{mV}$ & 1.599 \\
\hline 26 & $2.09 \mathrm{~V} \pm 10 \mathrm{mV}$ & 2.079 \\
\hline 31 & $2.49 \mathrm{~V} \pm 10 \mathrm{mV}$ & 2.479 \\
\hline
\end{tabular}

\begin{tabular}{|c|c|}
\hline $04-910$ & $B y M D / D A$ \\
\hline
\end{tabular}




\subsection{Gain Selection Verification}

To verify proper data transfer of gain setting, use a Fluke 77 voltmeter.

Within the appropriate menu select and send the indicated gain data via the SASI. Measure the voltage at Q11,Q10 and Q9 gates. Record the results in the table below.

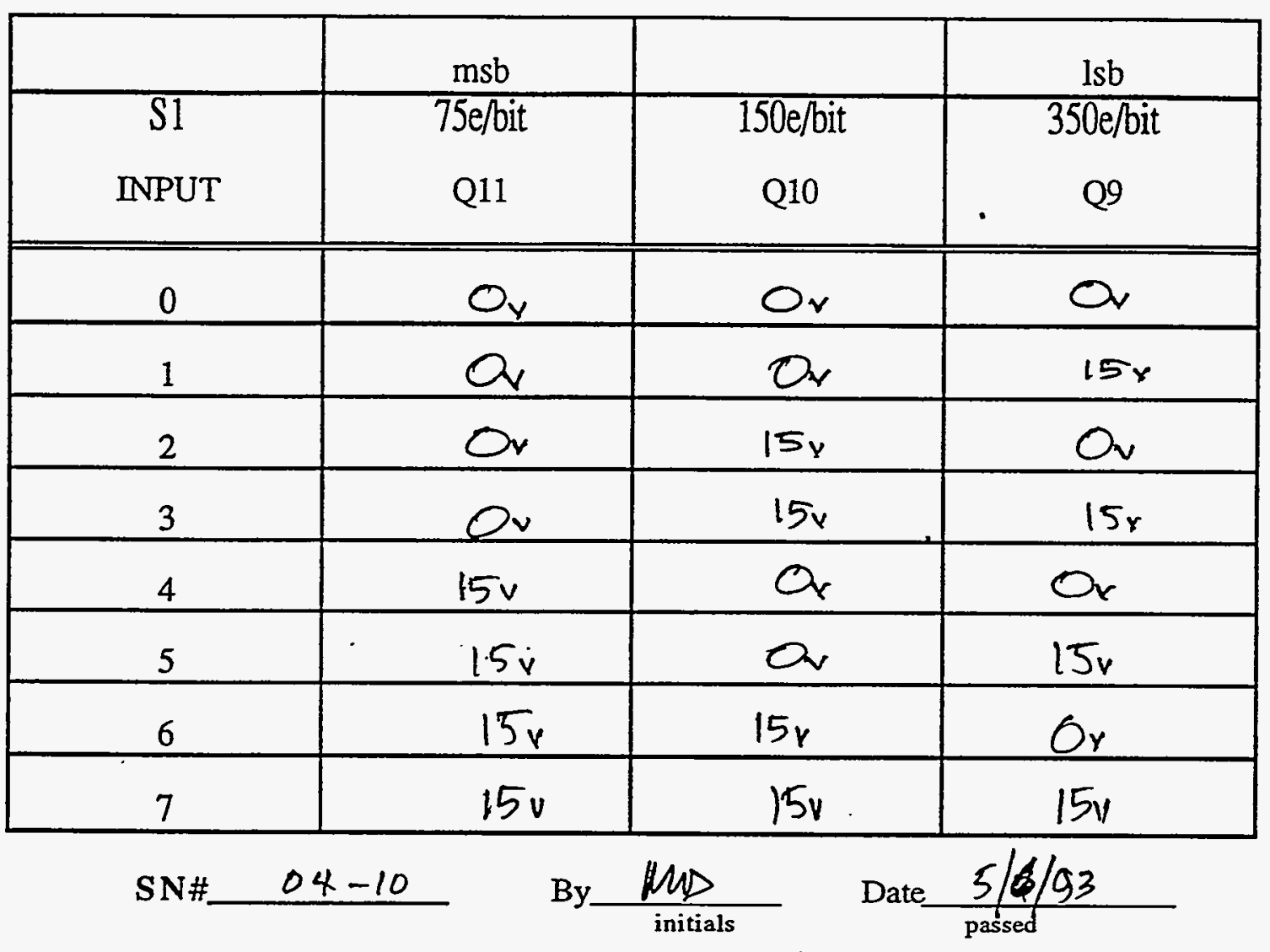


$A: T / R(d B) B: \quad \theta$

$A$ MAX 40.00

$B$ MAX 180.0

O MKR

$d B$

GA IN

$5 \quad 01 \frac{1}{35} 872.34896$

$\mathrm{Hz}$ deg PHASE.

$\checkmark B$
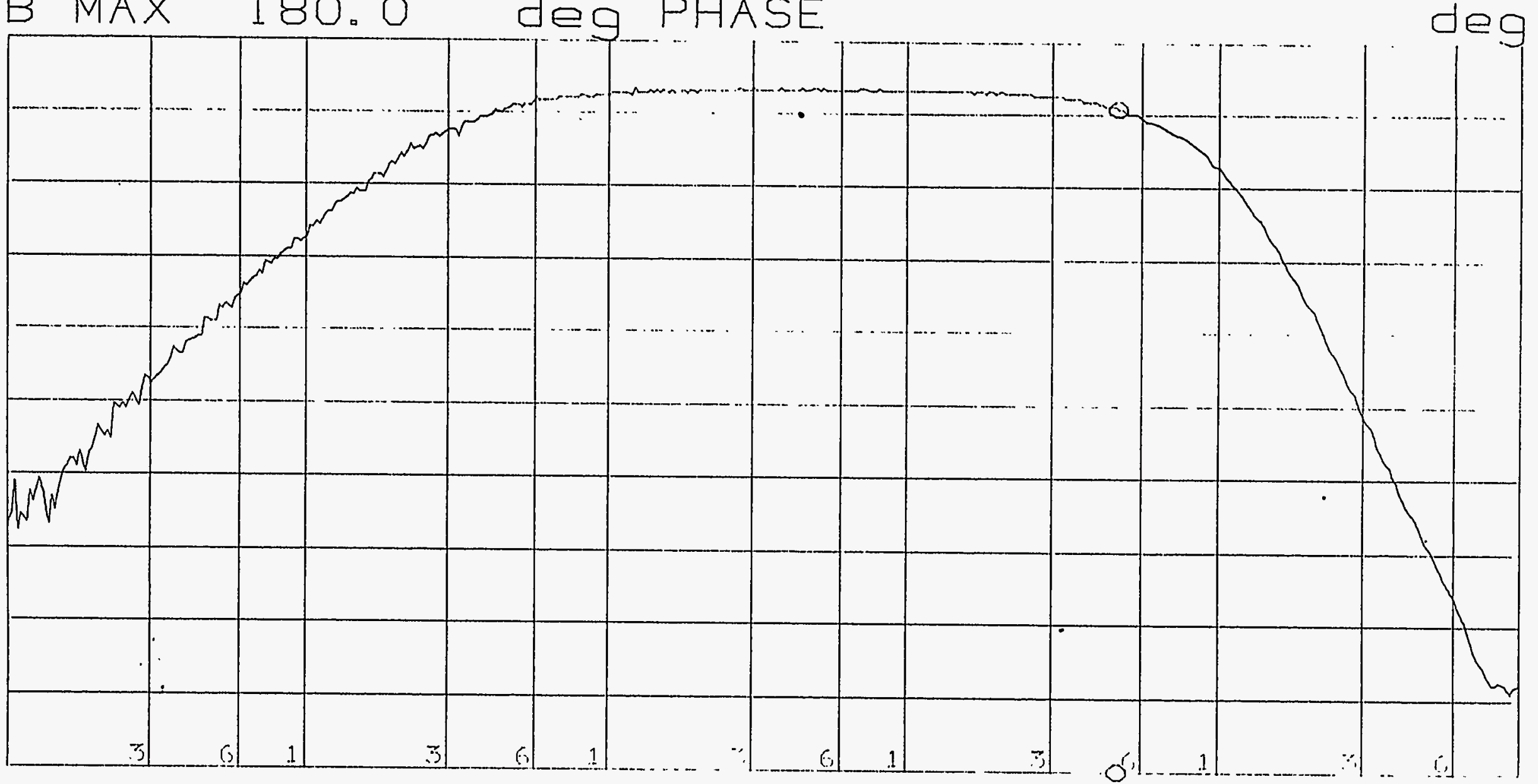

A/DIV 5.000 AB START $1000.0001 \%$

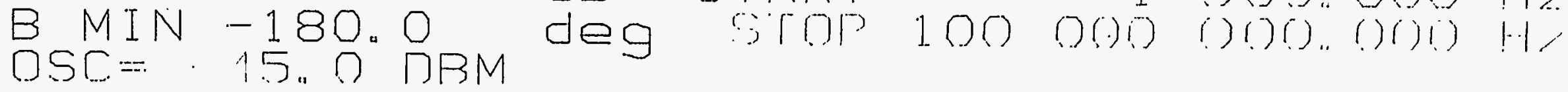

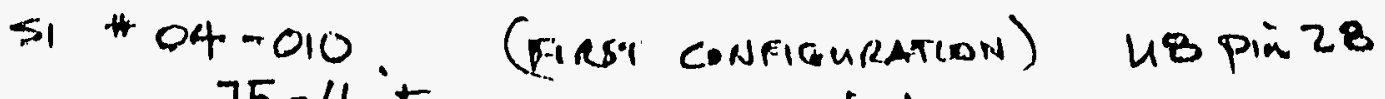

75 elbit 
•

• 


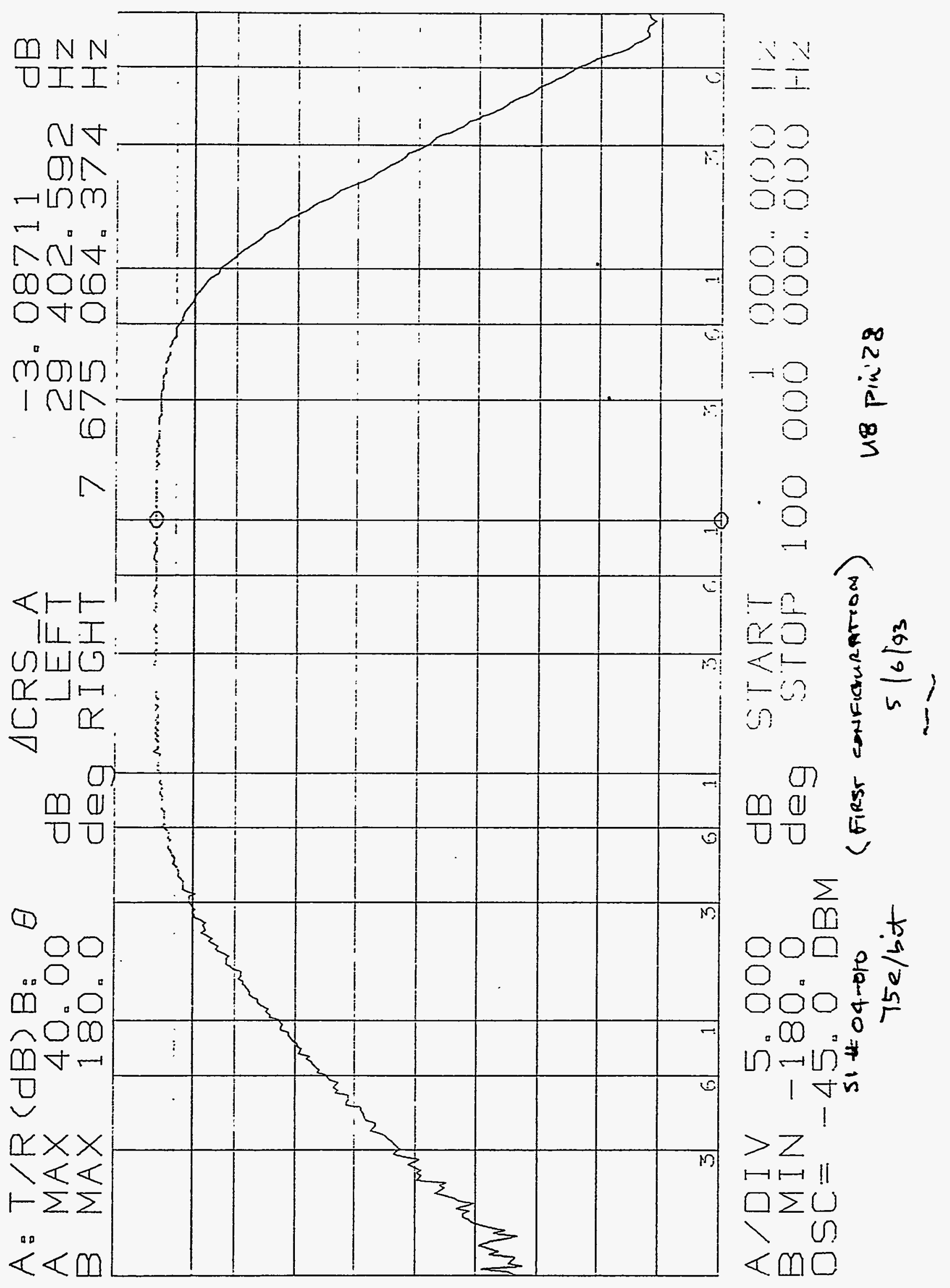




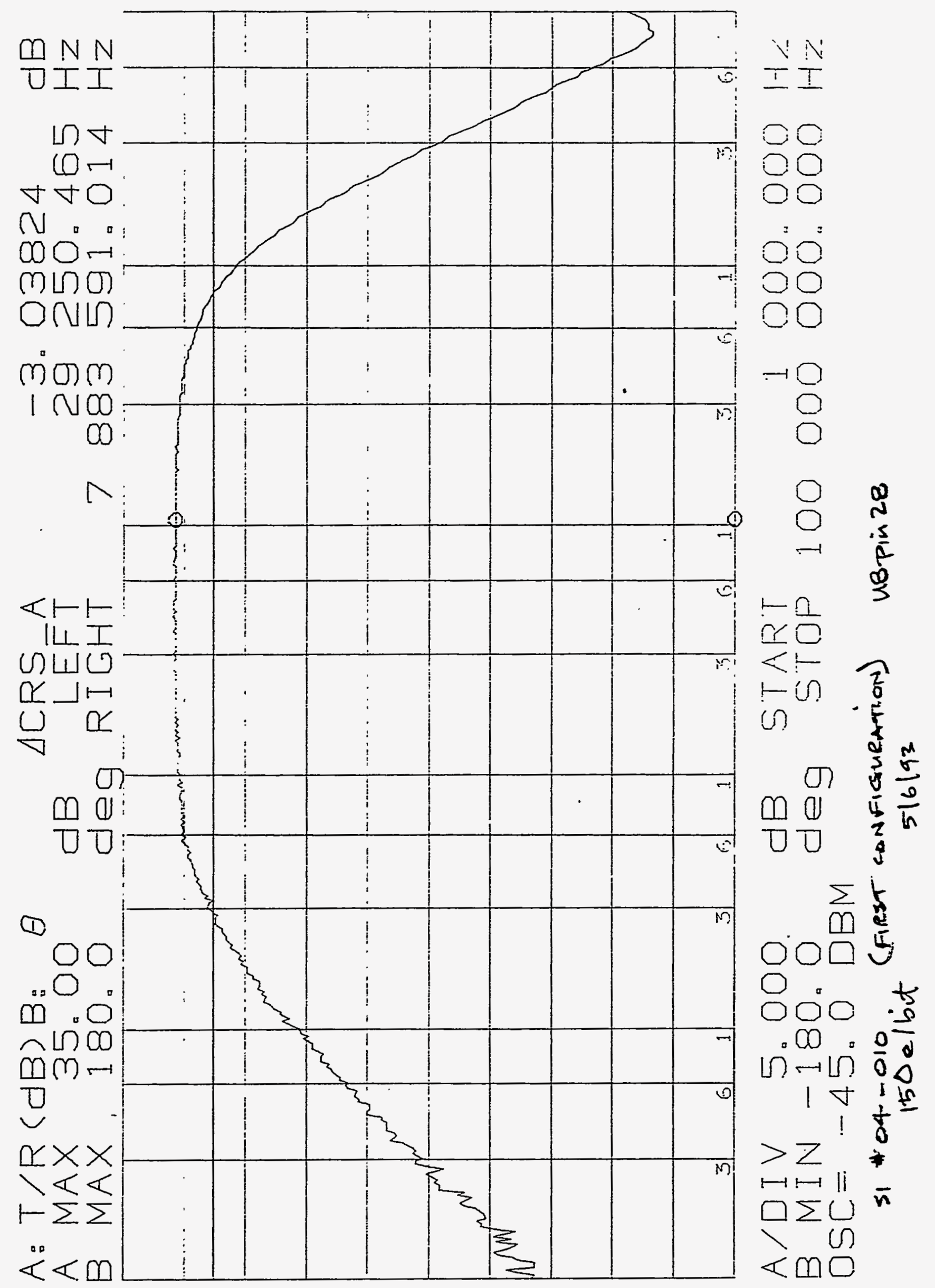




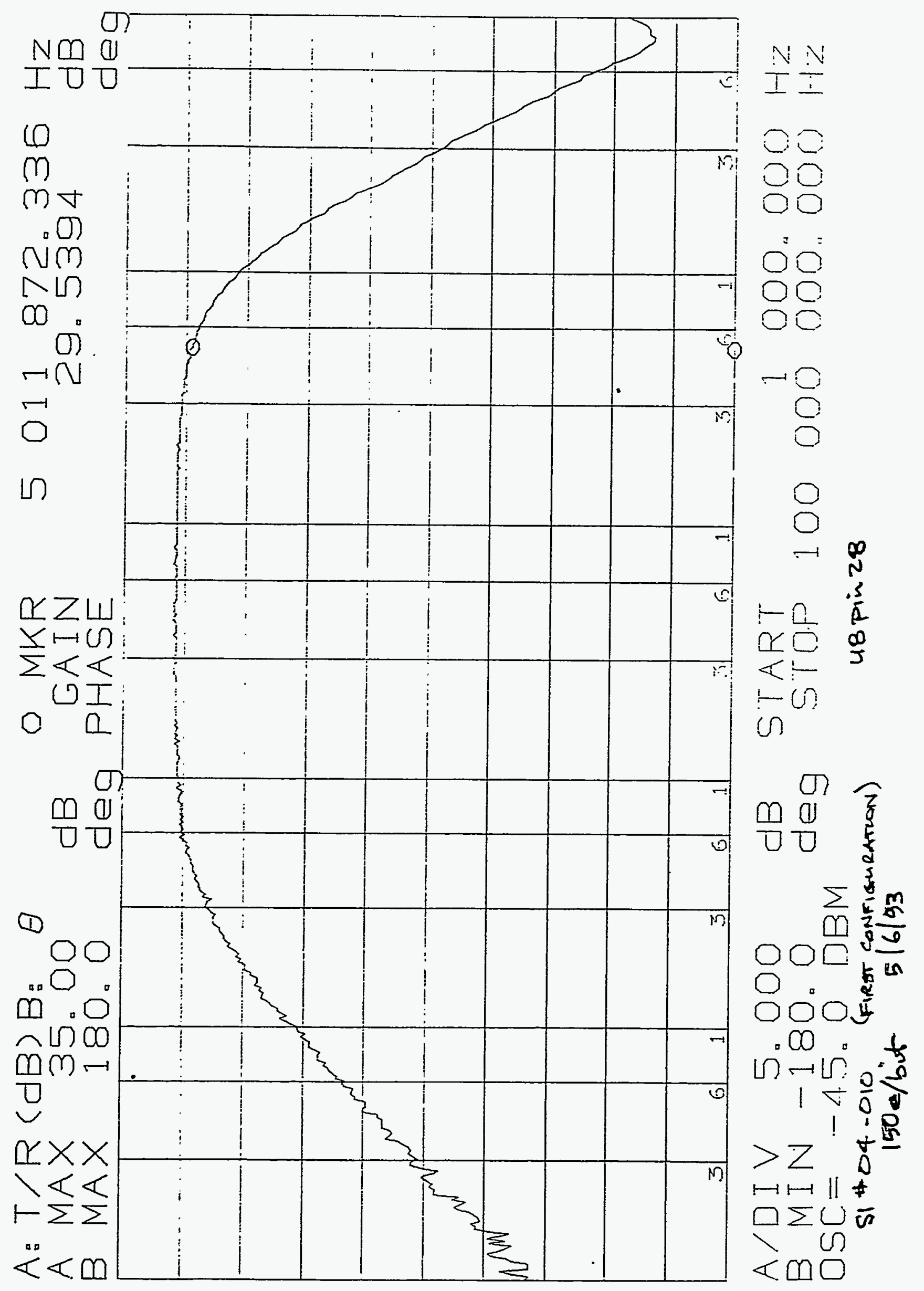


• 


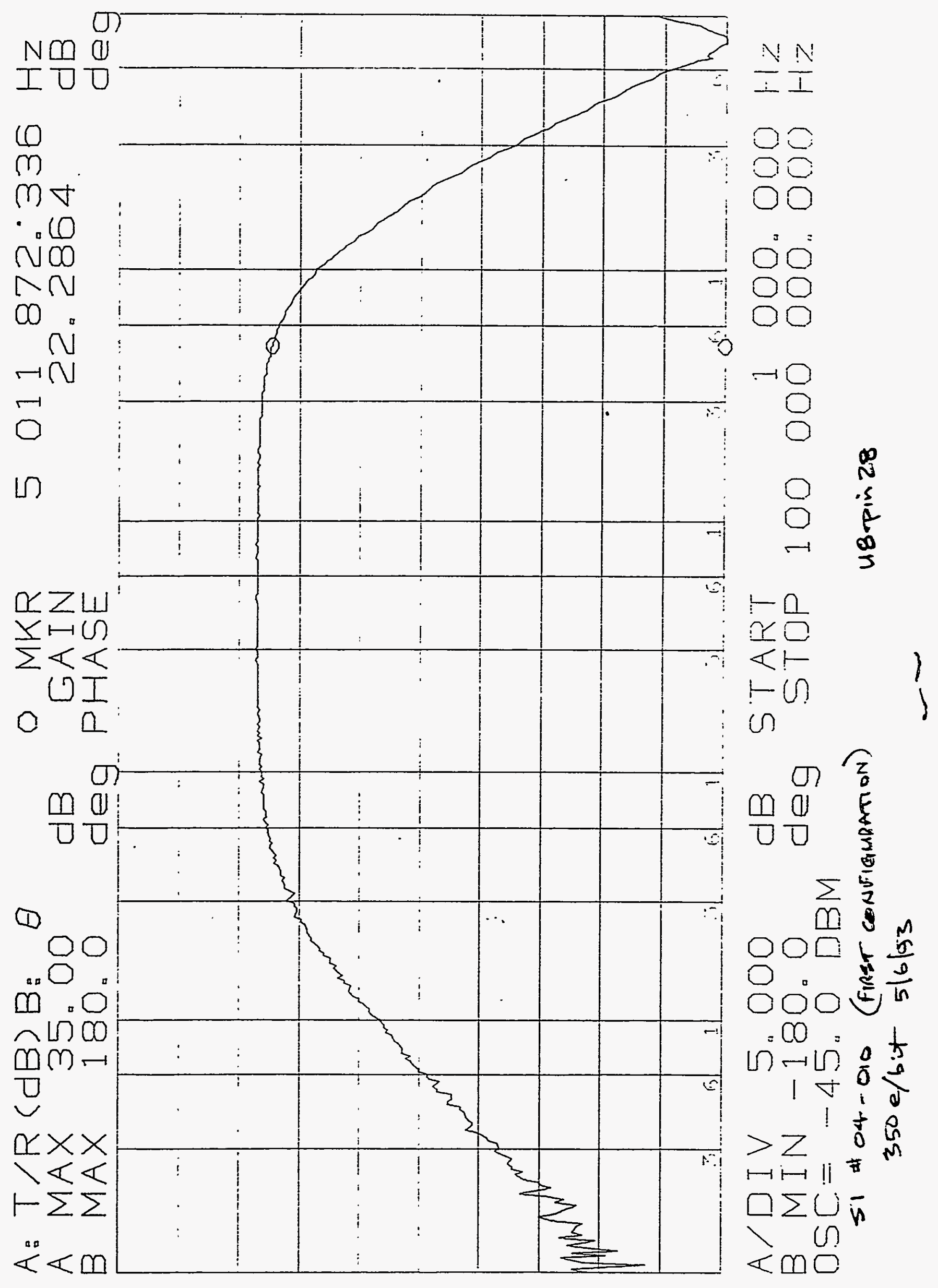


-

(1) 


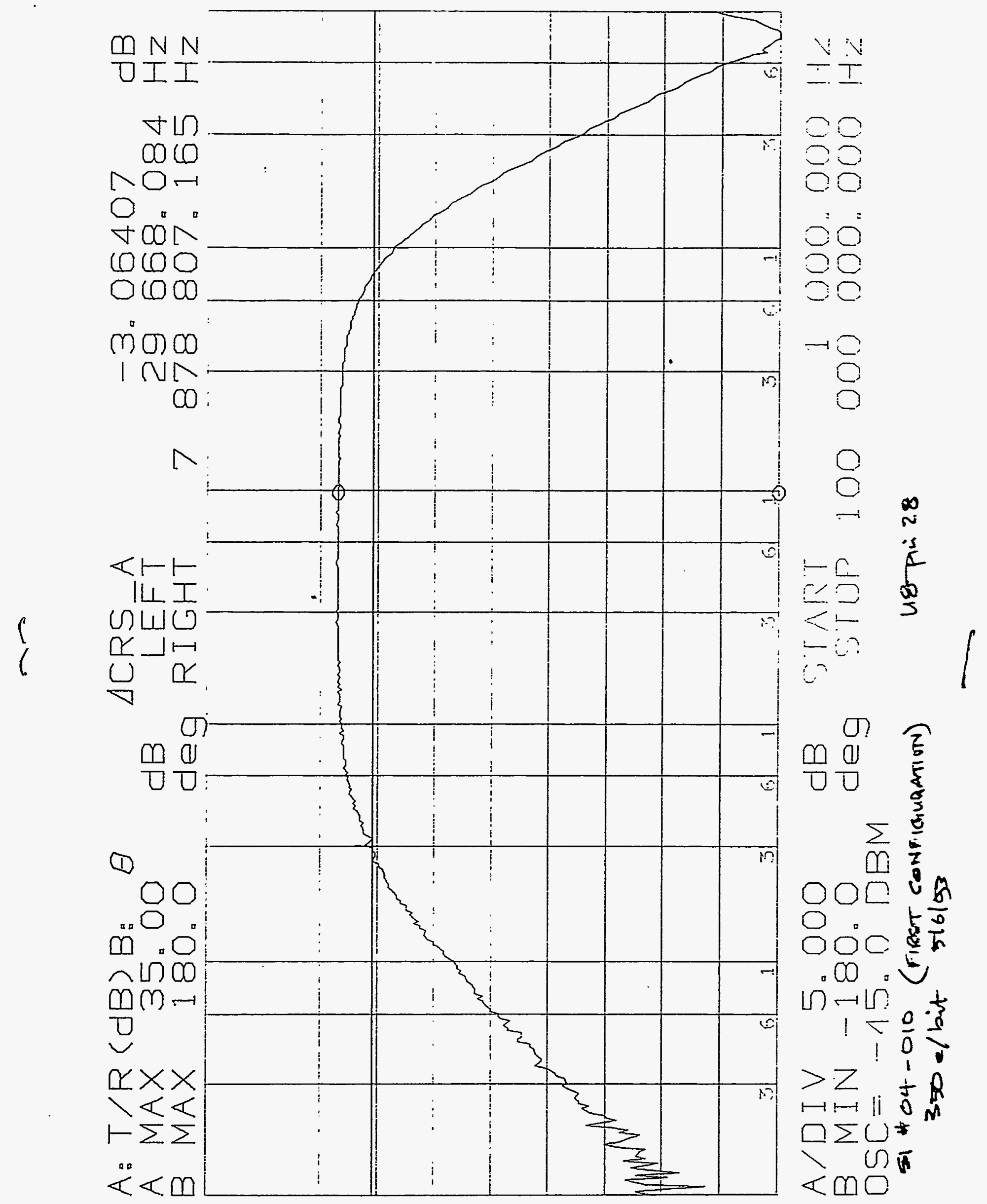




\subsection{Video Amplifier Gain Verifications.}

The video gain measurements require use of the HP4194 Impedance Gain/Phase Analyzer.

\subsection{Test Board Configuration}

Configure the board under test as follows:

Replace R49 with a $1.0 \mathrm{Kohm} 1 \%$ resistor.

Remove R128 and connect R128's outermost pad with C123's outermost pad. This grounds Q1 and Q4 gates.

Disable the $20 \mathrm{MHz}$ oscillator by connecting U5 pins 5 and 23 together.

\subsection{HP4194 Analyzer Configuration and Connection.}

Configure the HP4194 Analyzer as follows:

Gain/Phase measurement,

A Scale linear and AutoScale,

Log Sweep, $1 \mathrm{KHz}$ to $100 \mathrm{MHz}$,

Oscillaror Level equal to $-45 \mathrm{dBm}$.

Insert a $1 \mathrm{Kohm}$ resistor from U19 pin 18 to U19 pin 16. Attach the HP4194 oscillator output to U19 pin 16 and its ground to the ground test point.

\subsection{Gain and 3dB Bandwith Acquisition.}

Measure and store the reference level. Then measure the gain at $5 \mathrm{MHz}$ and $3 \mathrm{~dB}$ frequency at U8 pin 28 for all three gain settings. Record the measured values in the following table and attach the data plots in a document protector.

\begin{tabular}{|c|c|c|c|c|}
\hline $\begin{array}{c}\text { Gain } \\
\text { Setting }\end{array}$ & $\begin{array}{c}\text { Expected } \\
\text { Gain dB }\end{array}$ & $\begin{array}{c}\text { Measured } \\
\text { Gain dB }\end{array}$ & $\begin{array}{c}\text { Expected } \\
\text { 3dB } \\
\text { bandwidth(MHz) }\end{array}$ & $\begin{array}{c}\text { Measured } \\
\text { 3dB } \\
\text { bandwidth(MHz) }\end{array}$ \\
\hline 4 & $35.5 \pm 0.5$ & 35.38 & $7.5 \pm 0.5$ & $7.675 \mathrm{M} / \mathrm{tz}$ \\
\hline 2 & $29.5 \pm 0.5$ & 29.5 & $7.5 \pm 0.5$ & $7.883 \mathrm{MHt}$ \\
\hline 1 & $22.2 \pm 0.5$ & 22.28 & $7.5 \pm 0.5$ & 7.878 \\
\hline \multicolumn{5}{|c|}{ SN\# $04-10$} \\
\hline
\end{tabular}


7. Clocking Measurements with CCD installed

Verify that $\mathrm{L} 19$ pin 16 is not shorted to ground.

Measured $4.3 \mathrm{M} \Omega(>1 \mathrm{M} \Omega)$

Insert the appropriate prototype TH7883 CCD into location U19.

\section{Carefully Check CCD Orientation!!}

7.1 Acquire and record the $\emptyset \mathrm{L} 2$ and $\emptyset \mathrm{L} 1$ clocks:

Make these scope probe connection:

\begin{tabular}{c|c} 
Probe & Location \\
\hline Channel 1 & U19 pin 2 \\
Channel 2 & U19 pin 3
\end{tabular}

Change the scope horizontal sweep frequency to 50ns per division.
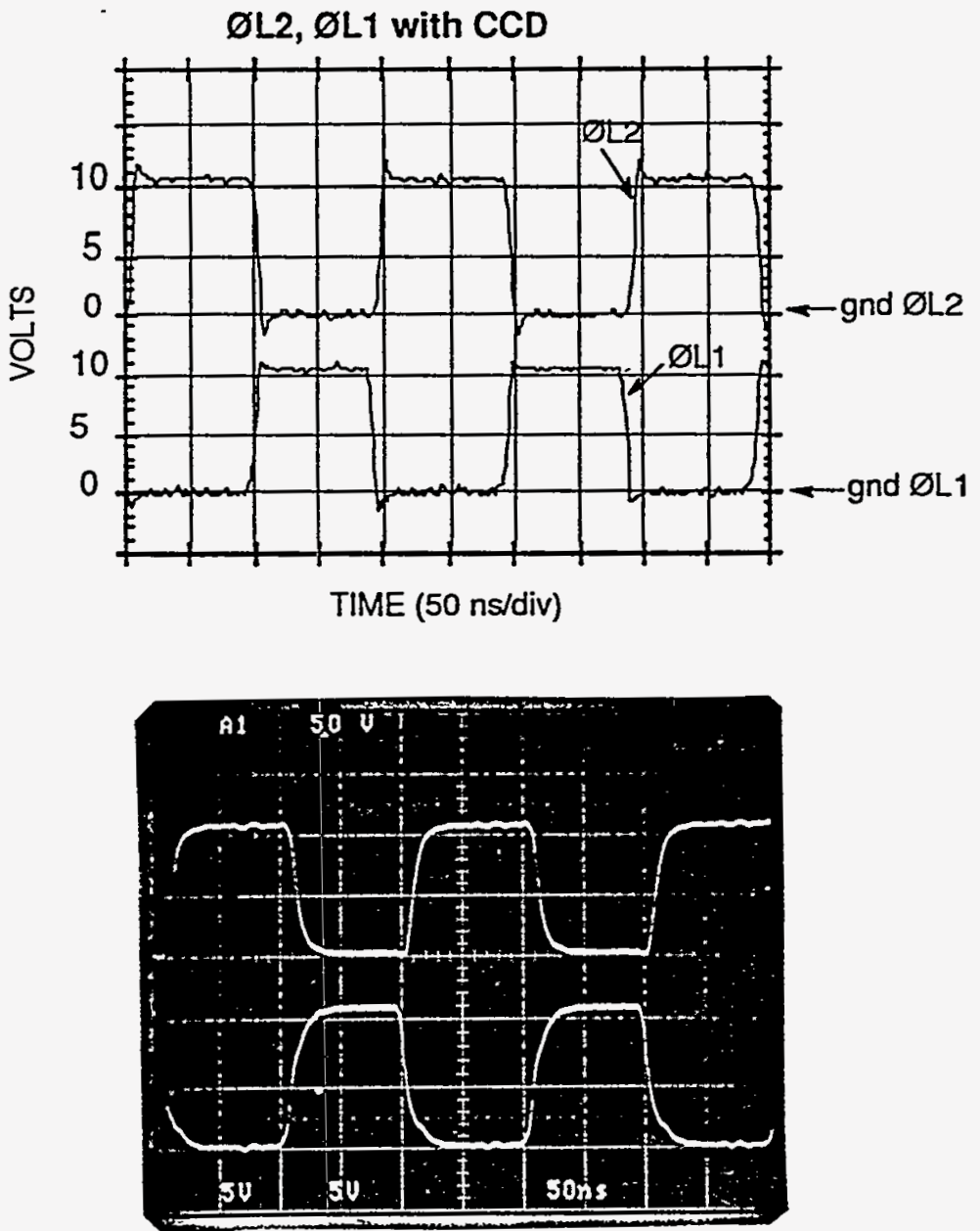
7.2. Acquire and record the $\emptyset \mathrm{L} 2, \emptyset \mathrm{R}$, and $\emptyset \mathrm{RFET}$ clocks:

Move the scope $\emptyset \mathrm{R}$, and $\emptyset \mathrm{RFET}$ probe to these locations:

\begin{tabular}{c|c} 
Probe & Location \\
\hline Channel 2 & U19 pin 19 \\
Channel 3 & R128 Q1 gate side
\end{tabular}
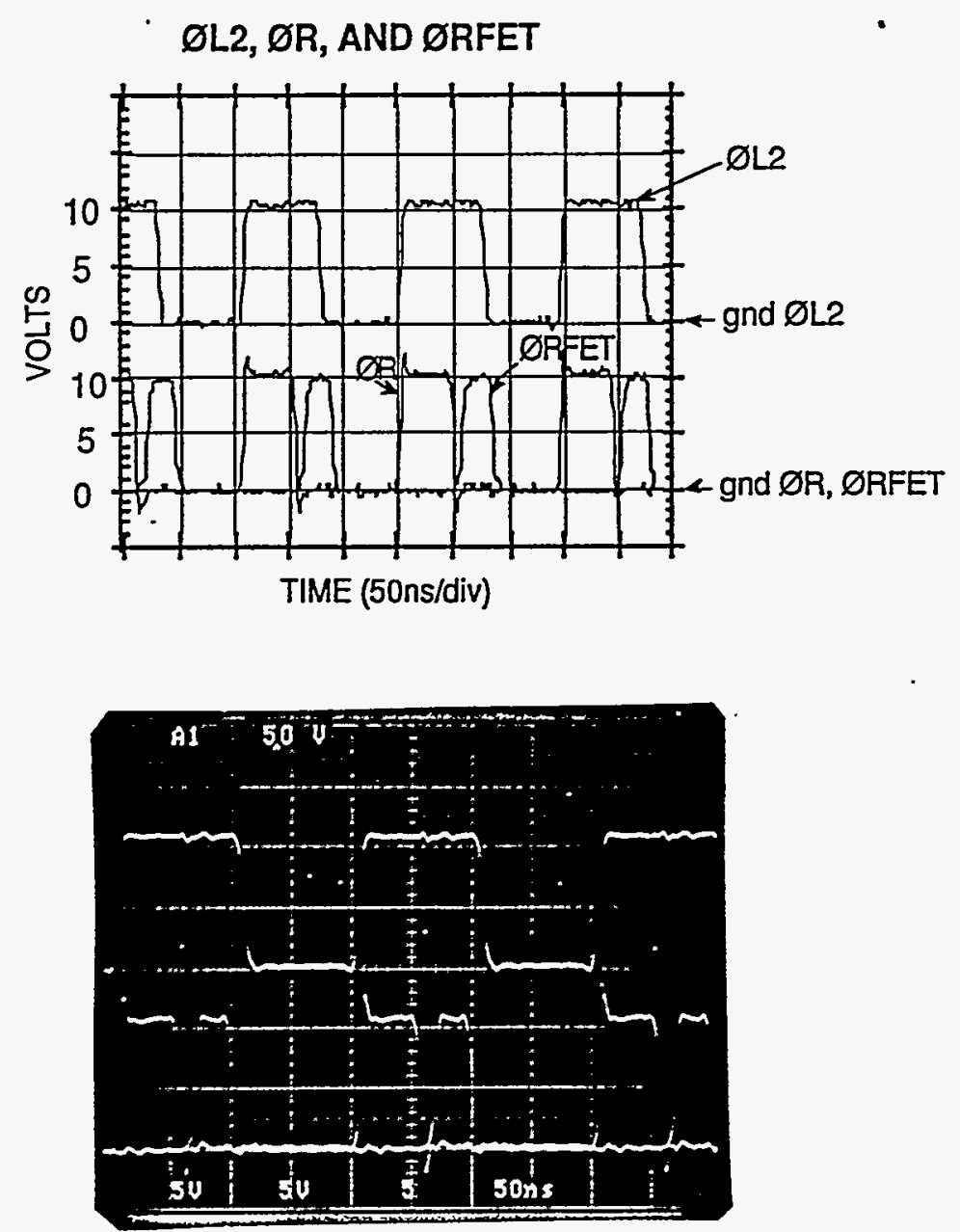
7.3 Acquire and record the ØР1, and ØР3 clocks:

Move the scope probes to these locations:

\begin{tabular}{c|c} 
Probe & Location \\
\hline Channel 1 & U19 pin 14 \\
Channel 2 & U19 pin 13
\end{tabular}

Shift the horizontal sweep frequency to $200 \mathrm{~ns}$ per division.
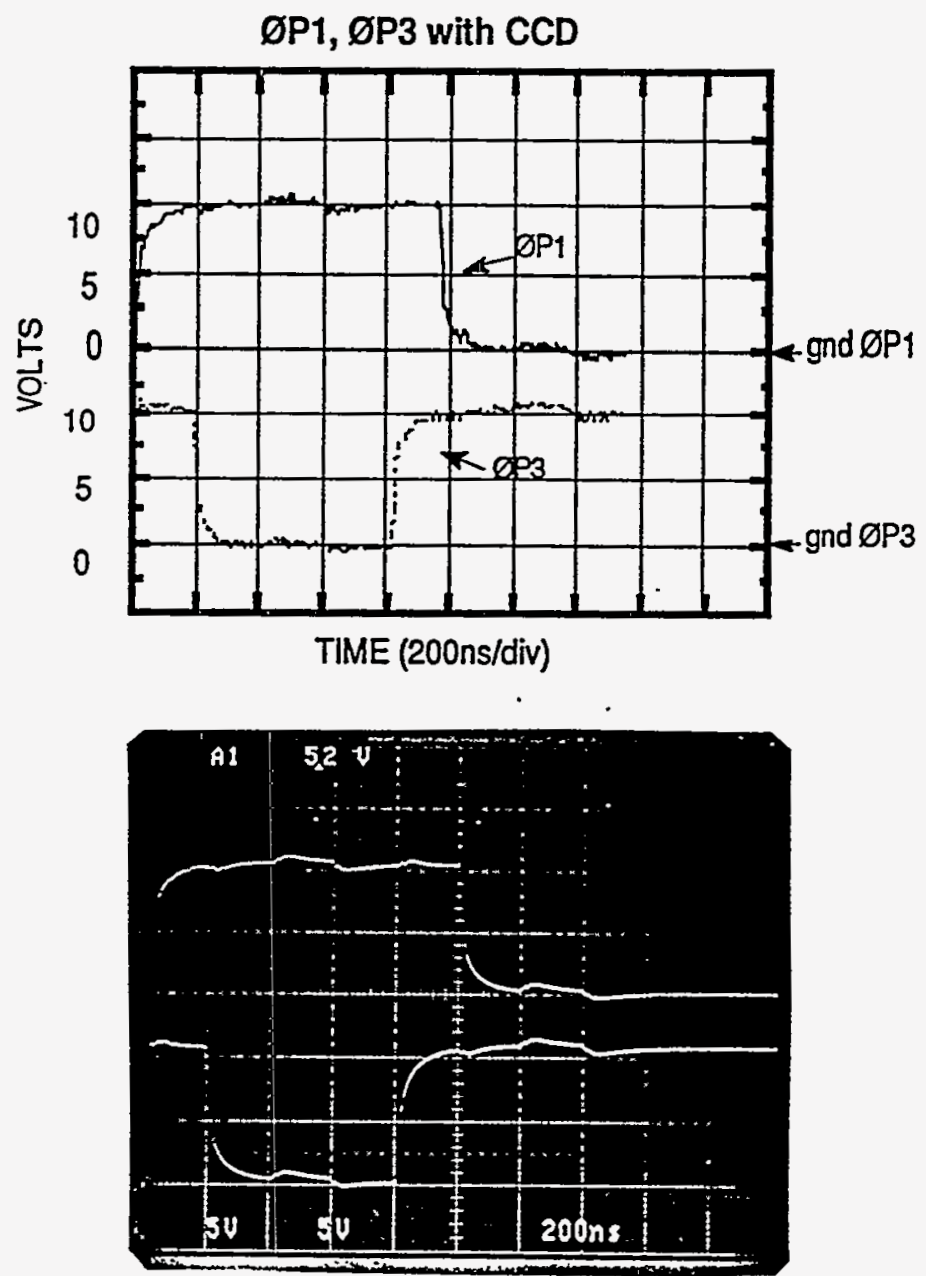
7.4 Acquire and record the ØР1, and ØР2 clocks:

Move the scope probe to this location:

\begin{tabular}{c|c} 
Probe & Location \\
\hline Channel 2 & U19 pin 12
\end{tabular}
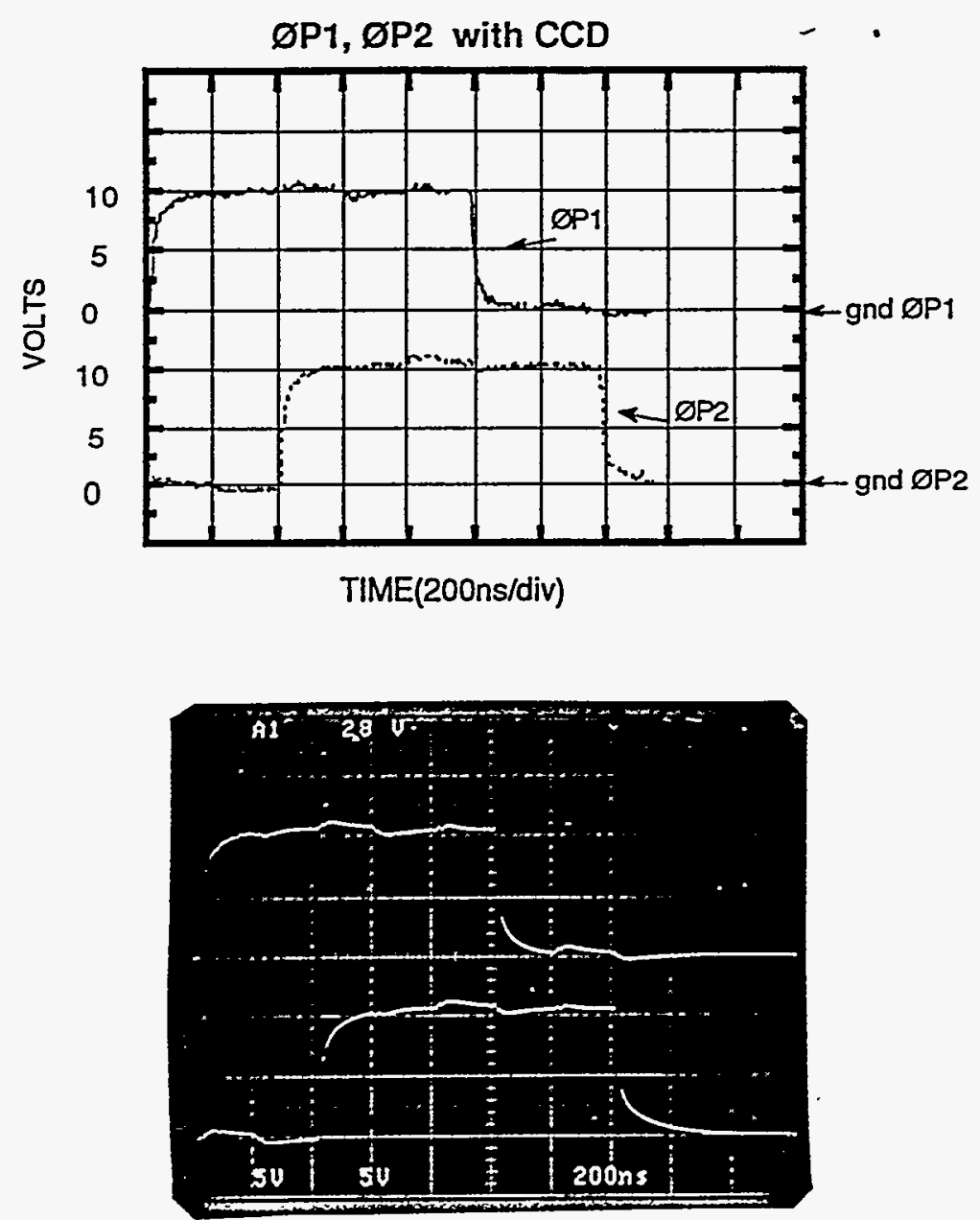
7.5 Acquire and record the $\emptyset P 1$, and $\emptyset P 4$ clocks:

Move the scope probe to the location indicated:

\begin{tabular}{c|c} 
Probe & Location \\
\hline Channel 2 & U19 pin 11
\end{tabular}
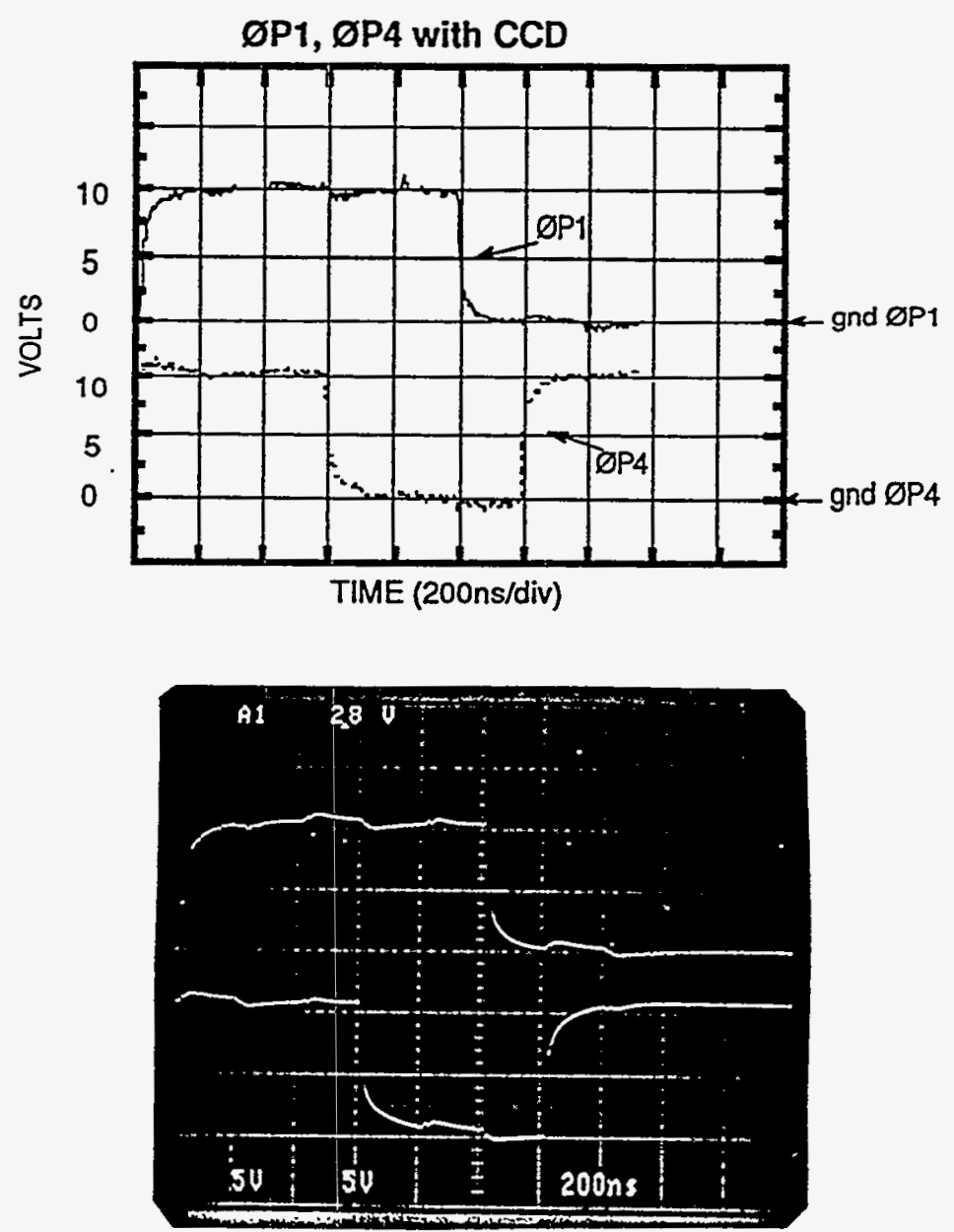
7.6 Acquire and record the P1A, and P3 clocks:

Move the sccpe probes to these locations:

\begin{tabular}{c|c} 
Probe & Location \\
\hline Channel 1 & U19 pin 9 \\
Channel 1 & U19 pin 8
\end{tabular}
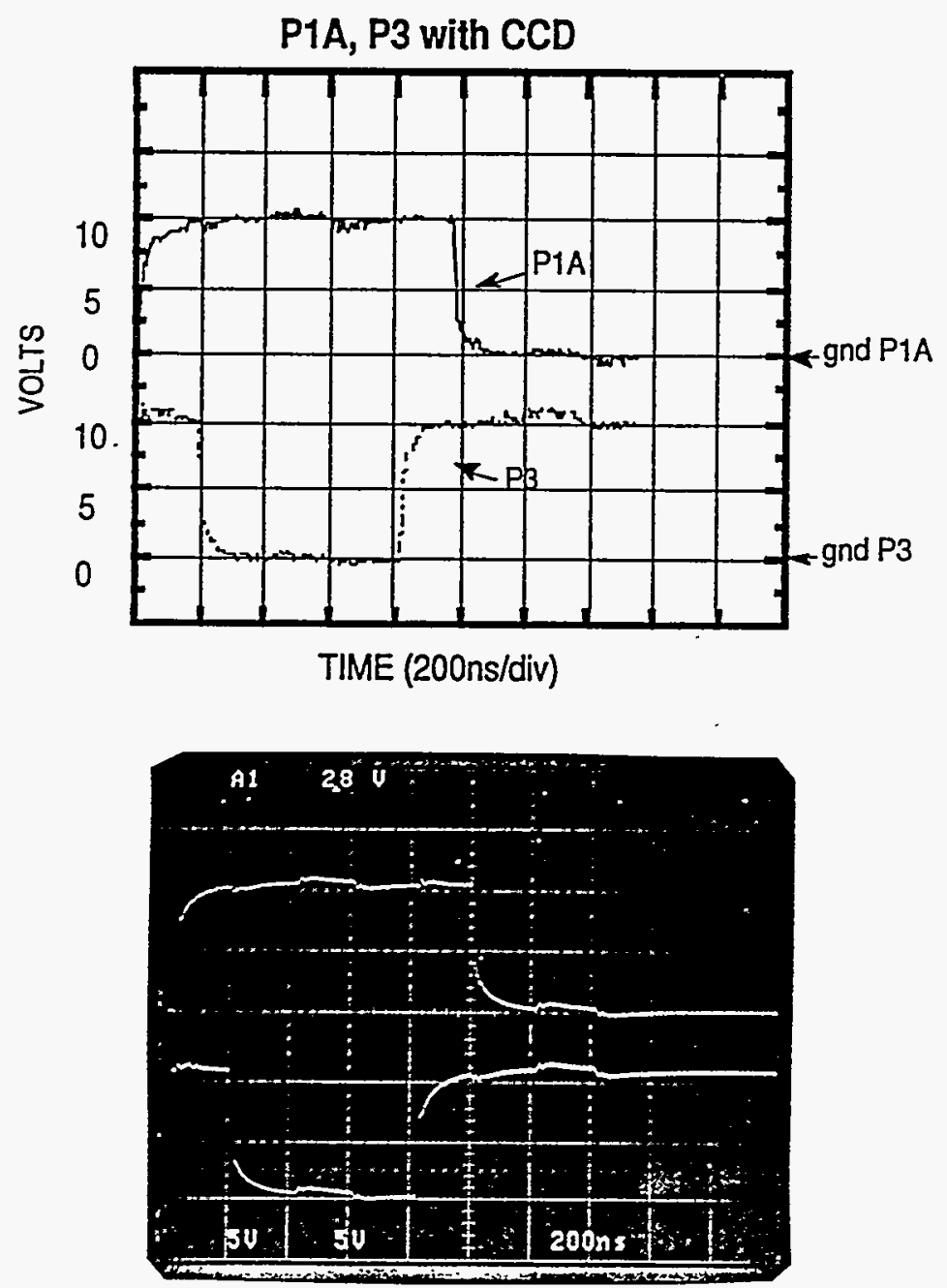
7.7 Acquire and record the P1A, and P2 clocks:

Move the scope probe to this location:

\begin{tabular}{c|c} 
Probe & Location \\
\hline Channel 2 & U19 pin 7
\end{tabular}
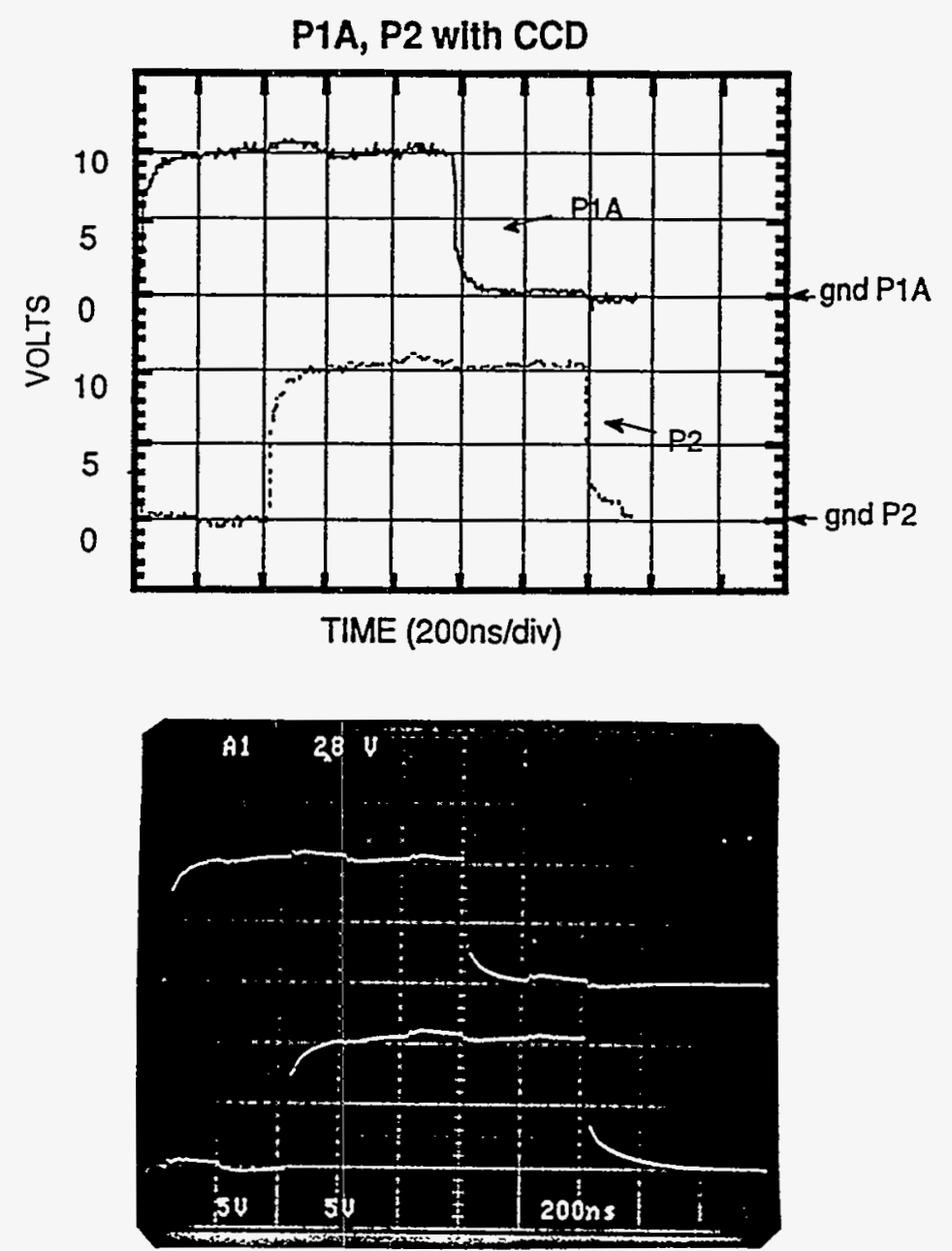
7.8 Acquire and record the P1A, and P4 clocks:

Move the scope probe to this location:.

\begin{tabular}{c|c} 
Probe & Location \\
\hline Channel 2 & U19 pin 6
\end{tabular}
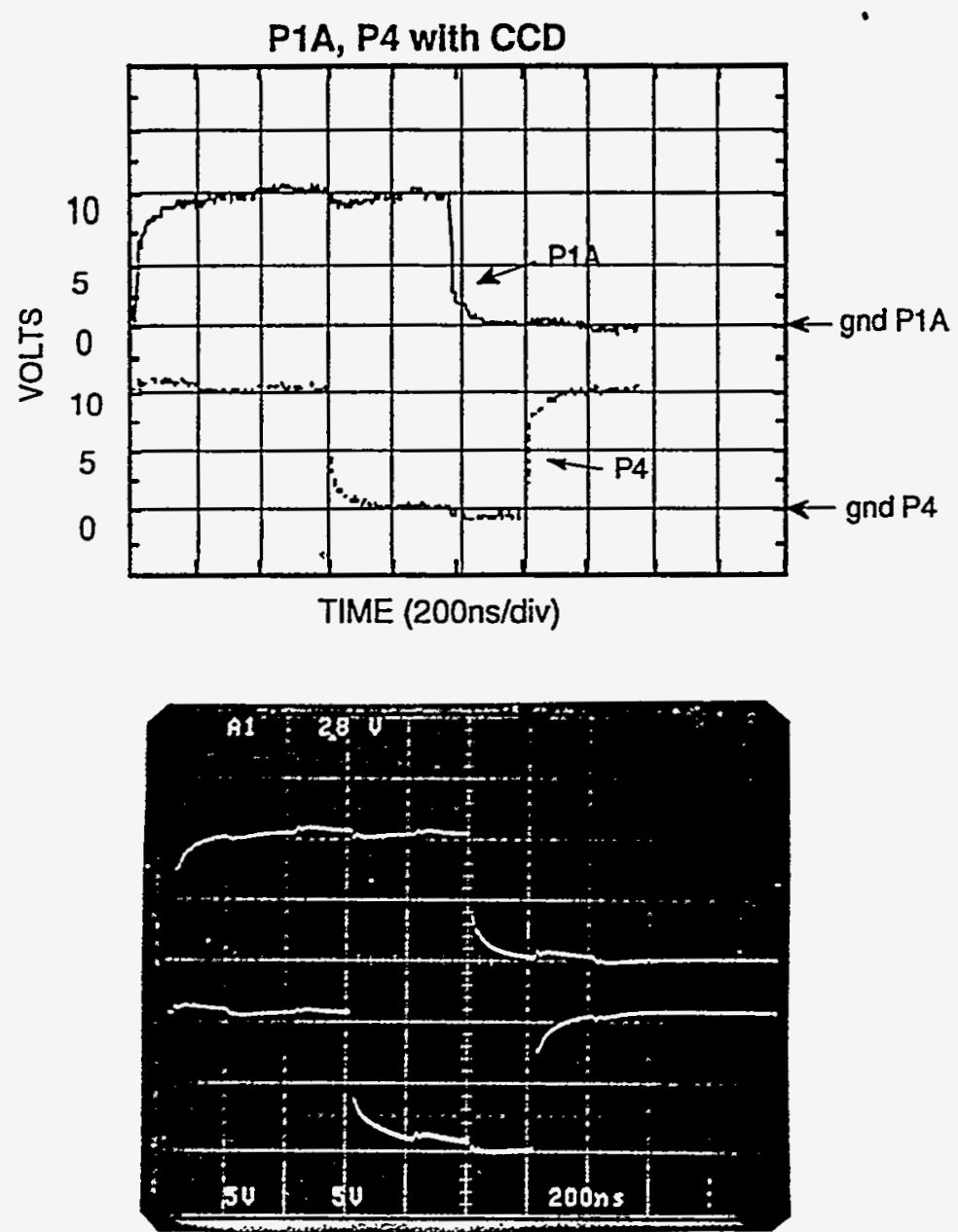
7.9 Acquire and record the P1A, and P1B clocks:

Move the scope probe to this location:

\begin{tabular}{c|c} 
Probe & Location \\
\hline Channel 2 & U19 pin 4
\end{tabular}
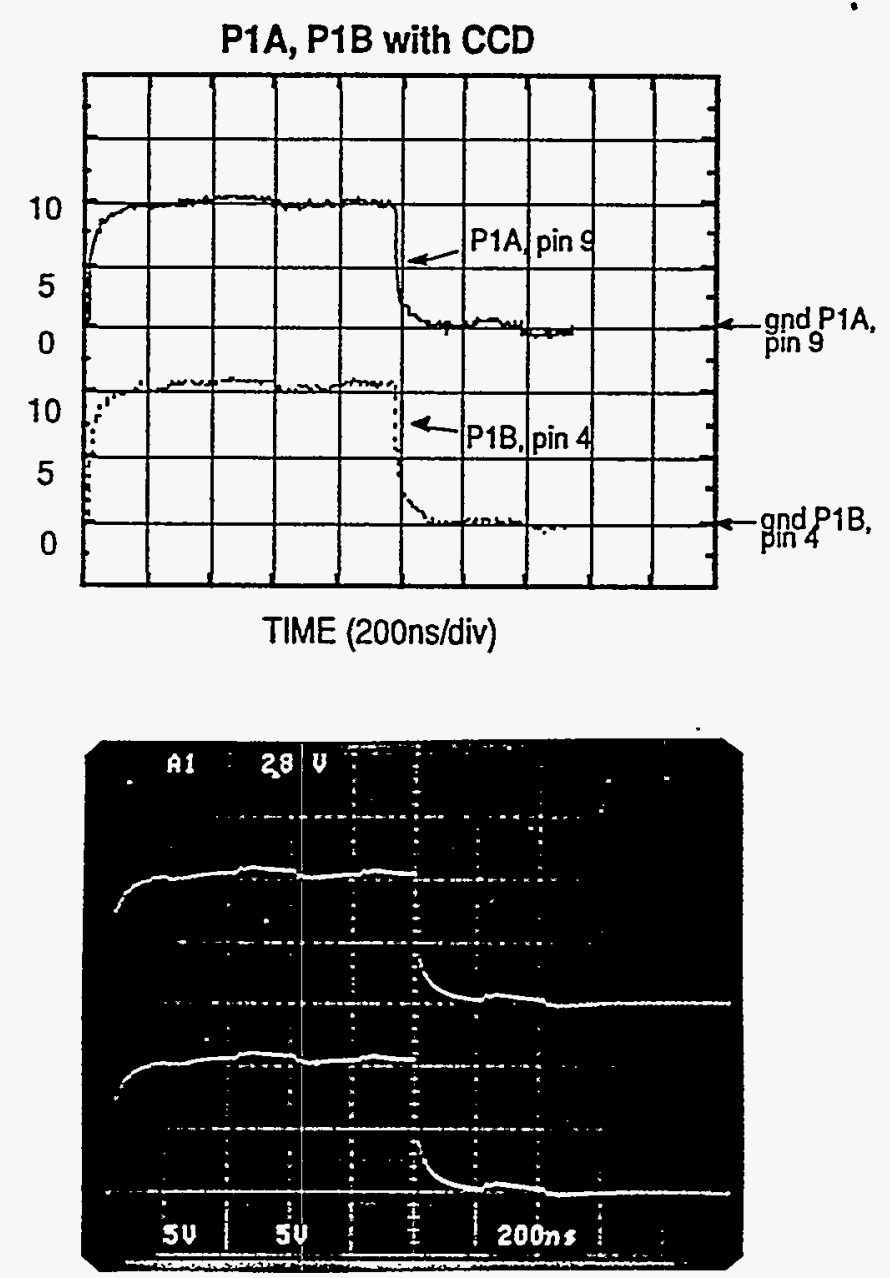


$$
8.4
$$

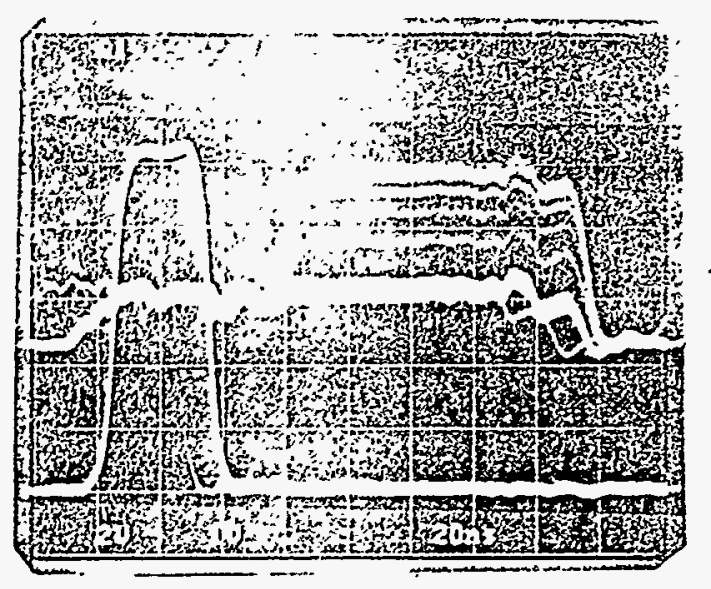

$350 ; \cdots$

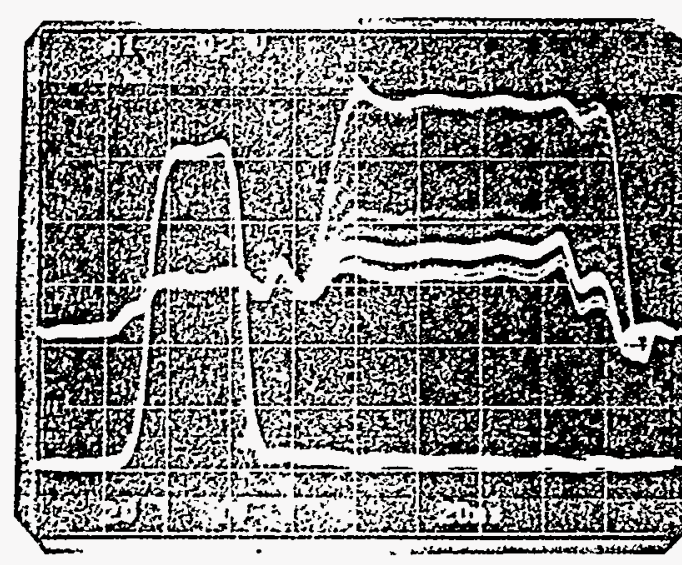

158 ei:

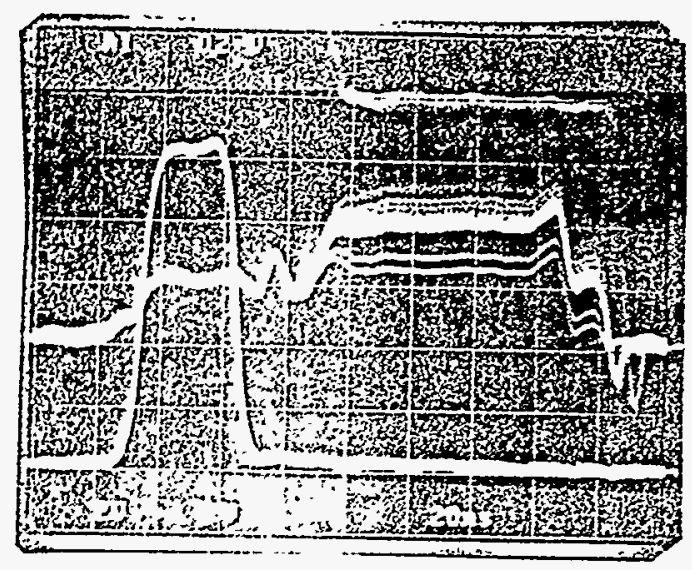

$75 c: \therefore$ 
$\ldots$ .... 


\section{Double Correlated Sampling Functionality Verification}

This measurement requires the use of a Tektronix 2465B—or like—oscilloscope.

Verify the gain of the camera is $150 \mathrm{e} / \mathrm{bit}$ via the SASI.

Make these scope probe connection:

\begin{tabular}{c|c} 
Probe & Location \\
\hline Channel 2 & U24 pin 3 \\
Channel 3 & R128 Q1 gate side .
\end{tabular}

Adjust the time base to $20 \mathrm{~ns}$ per division.

Acquire and record the $\mathrm{Q} 1$ or ØRFET vs Video signals:

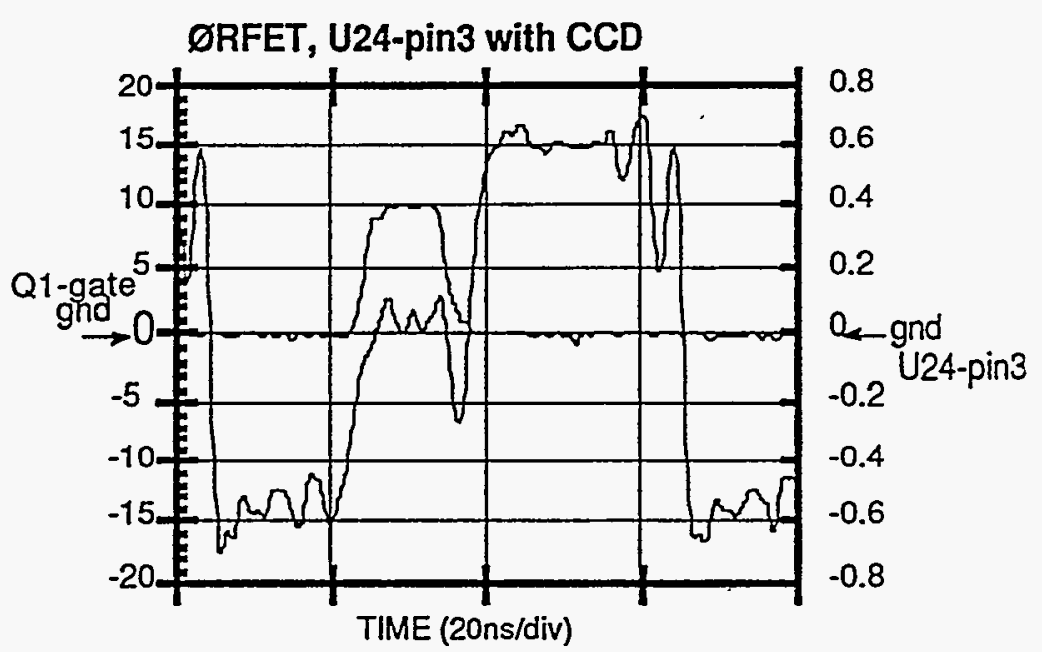

Make the same measurement at 350e/bit and 1000e/bit.

Cote: During the Q1 or ØRFET pulse, the video signal should be $=0 \mathrm{v}$ or ground. At high gains, the sensor may require cool down by non-operation and/or an opaque covering to actuire this measurement. 


\section{Analog to Digital (A/D) Converter Clock vs U24-pin 6 \& U\&-pin 28}

This measurement requires the Tektronix 2465B analog-or like-oscilloscope.

Set the scope to trigger on channel 1.

Set the horizontal sweep to 50ns/division.

Move the scope probes to these locations:

\begin{tabular}{c|c|c} 
Probe & Location & Vertical Gain \\
\hline Channel 1 & U8 pin 1 & 2 V/division \\
Channel 2 & U8 pin 28 & $500 \mathrm{mV} /$ division
\end{tabular}
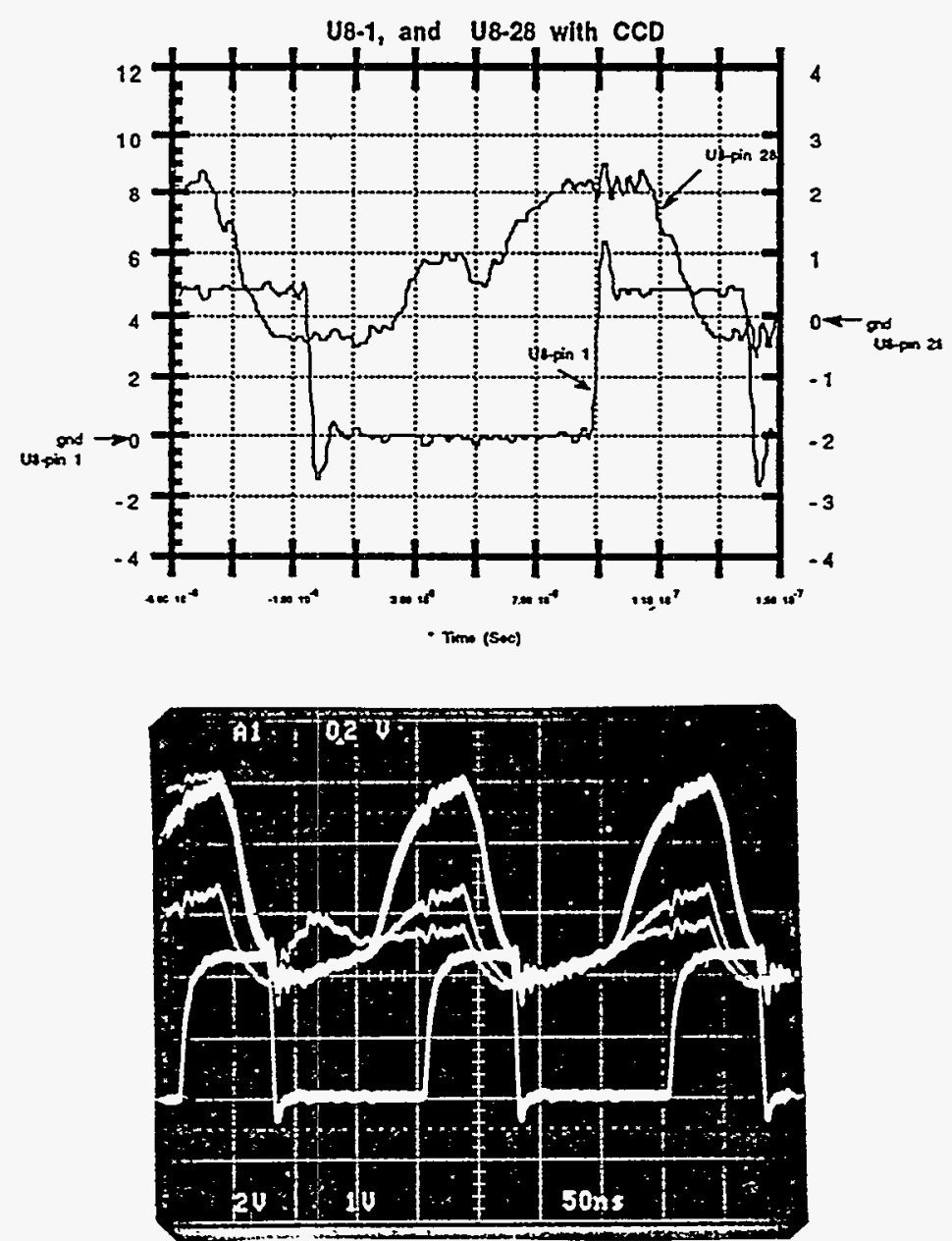


\section{Video Interface Timing Confirmation}

This test requires the use of the Phillips PM 3585 Logic Analyzer.

\subsection{Logic Analyzer Setup}

Move the analyzer pod probes to the following locations at the Datacube interface card connectors designated as $\mathrm{P} 9$ and $\mathrm{P} 10$ :

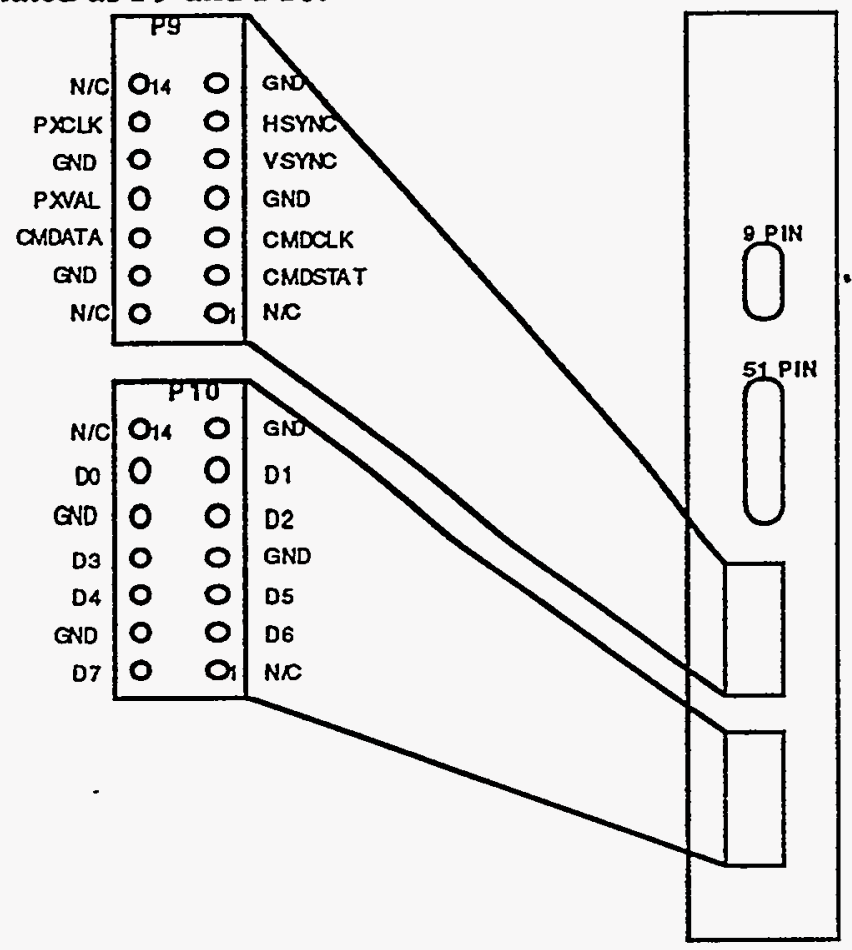

channel 1-CMDCLK

channel 2-CMDDATA

channel 3-CMDSTAT

channel 4-VSYNC

channel 5-PIXVAL

channel 6-PIXCLK

channel 7-HSYNC

channel 9-16-DATA BUS

Attach the pod ground to any of the GND pins indicated.

\subsection{Timing acquisitions:}

Pixclk vs Data

Vsync vs Pixvalid (condensed and expanded at the beginning of line \& frame)

(condensed and expanded at the end of line \& frame)

SASI Command (this is CMDDATA while a SASI is sent from the SUN kestroari)

Rising and falling edges at Vsync vs Pixclk

Rising and falling edges at Pixval vs Pixclk

REMEMBER to attach your recorded documentation to this test procedure?

(A document protector is advised) 


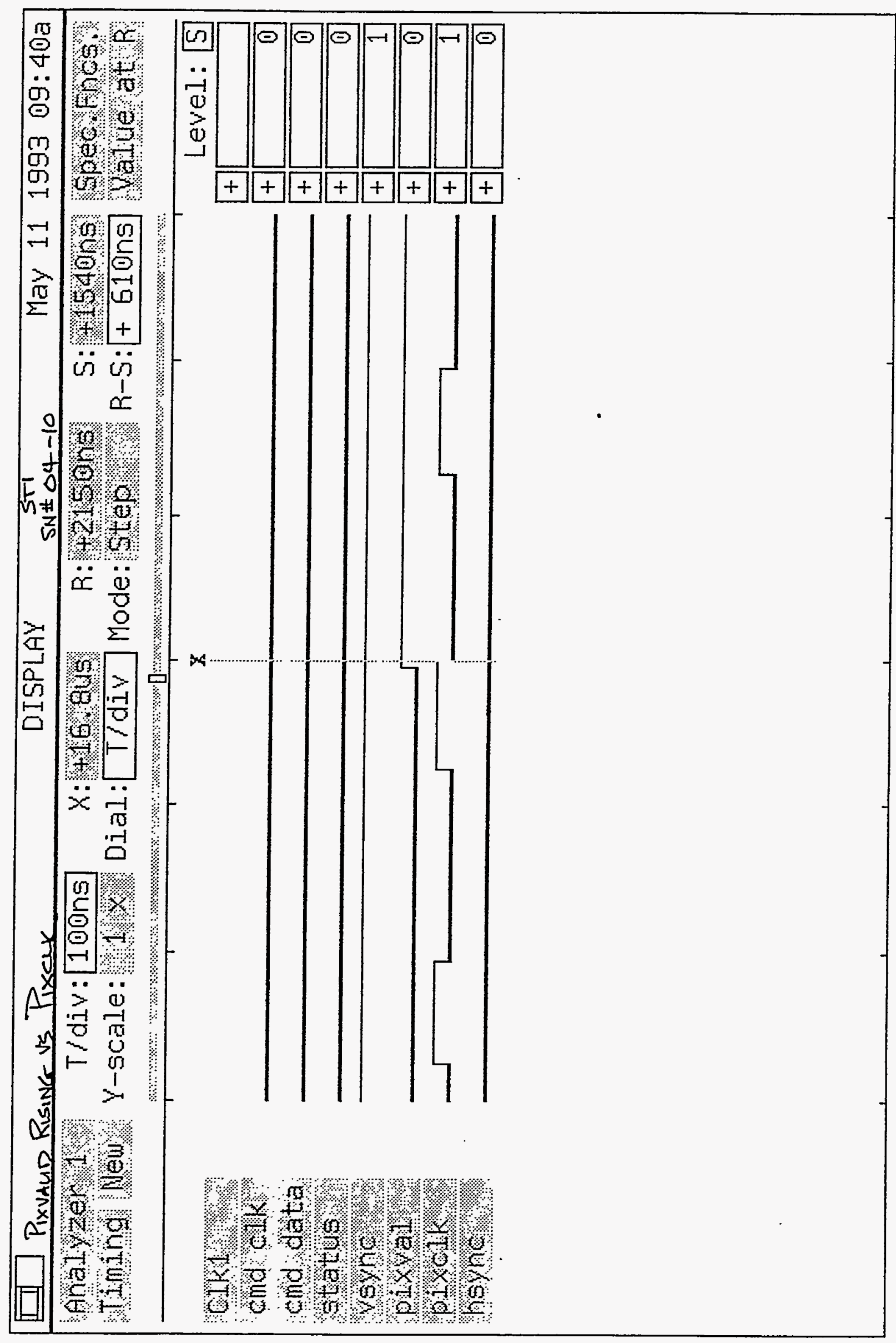




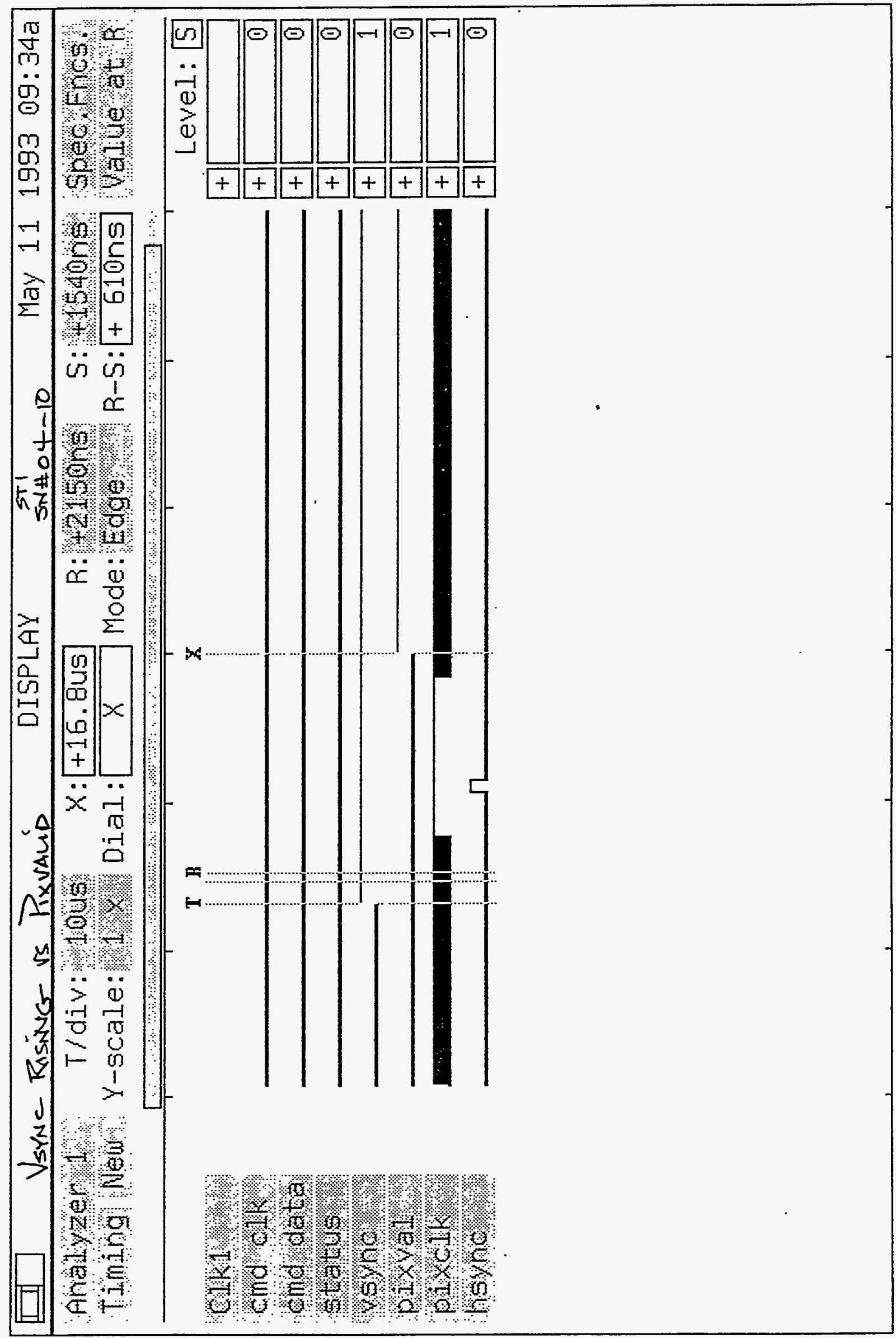




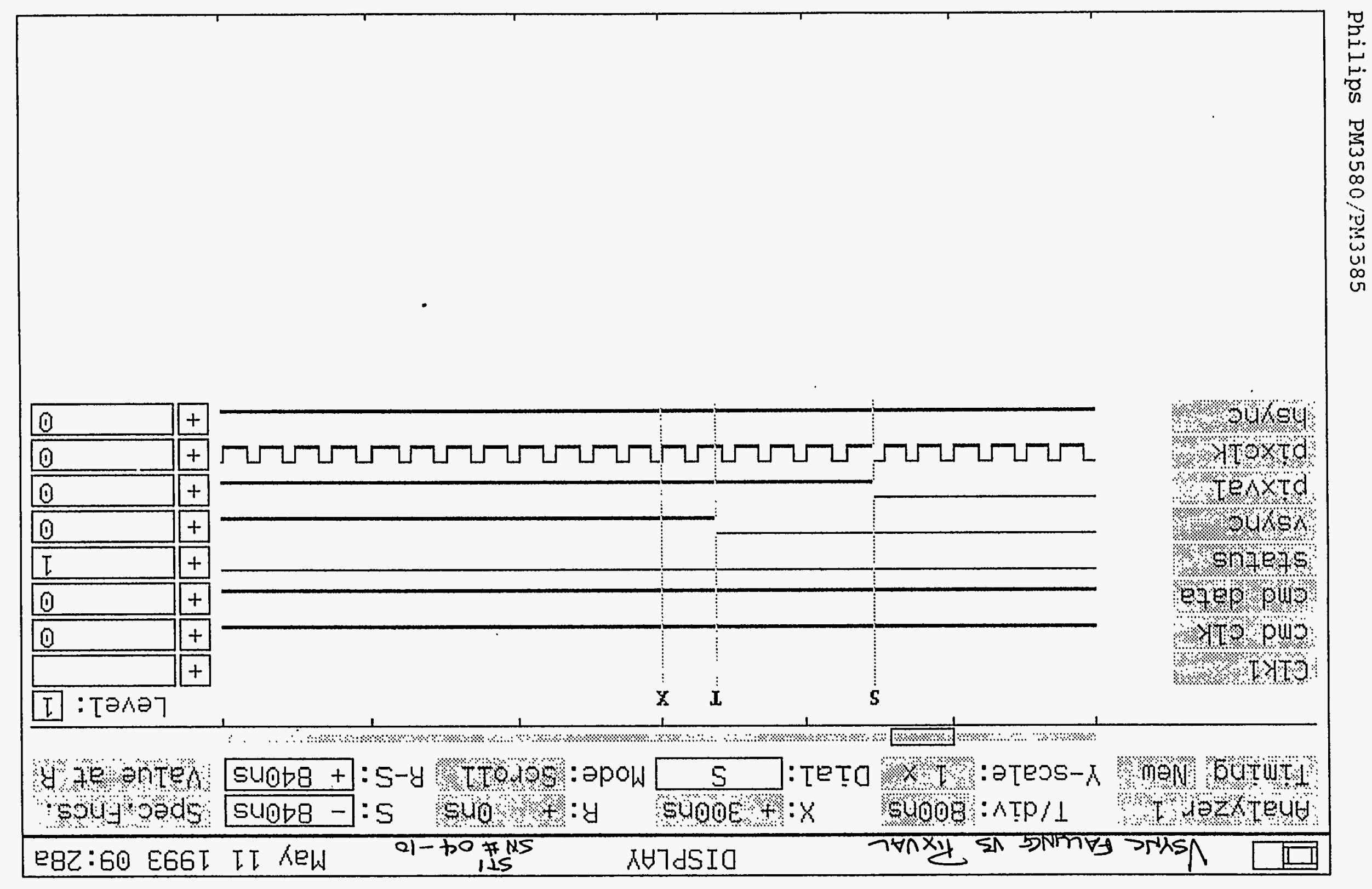




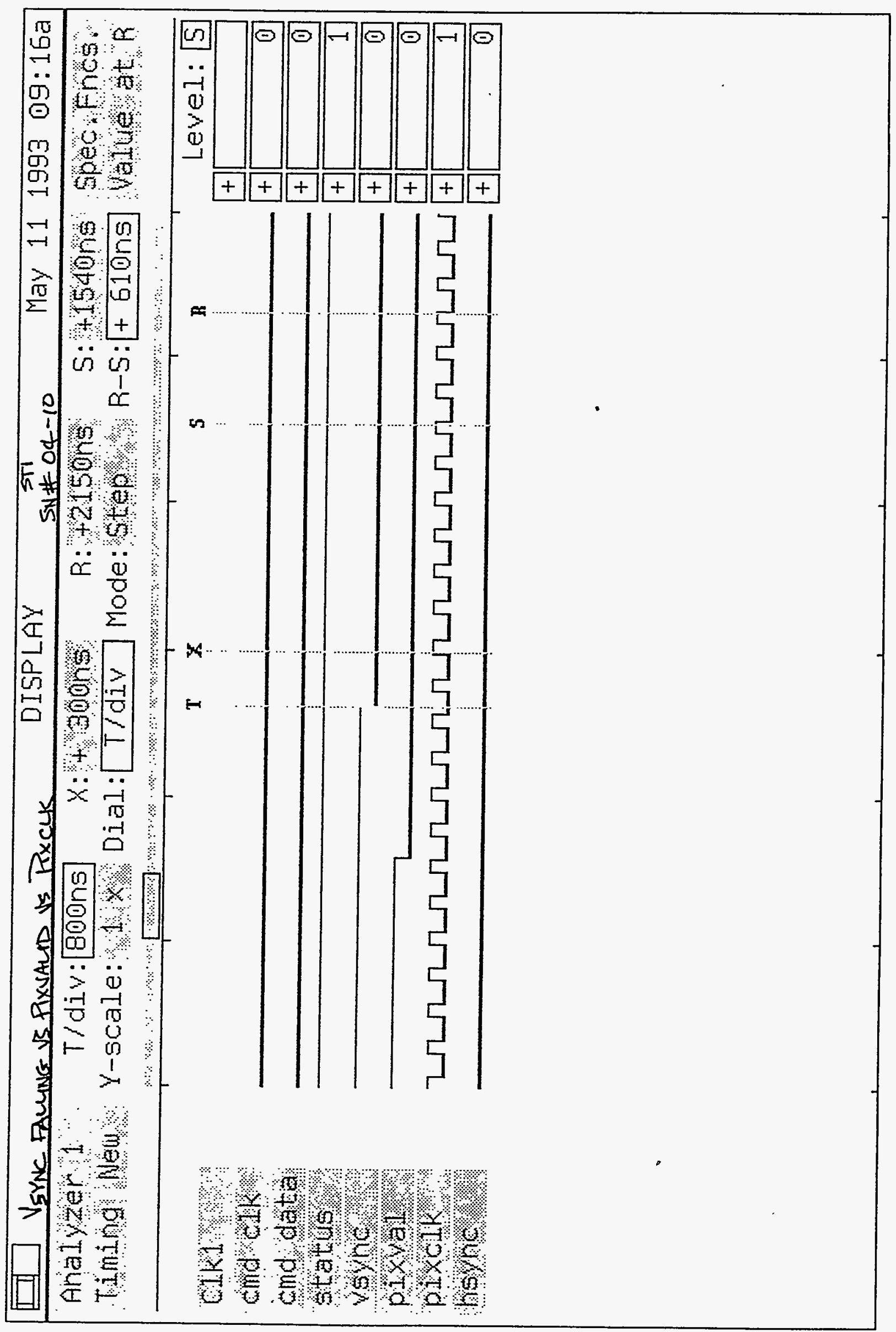


Philips PM3580;?M3585

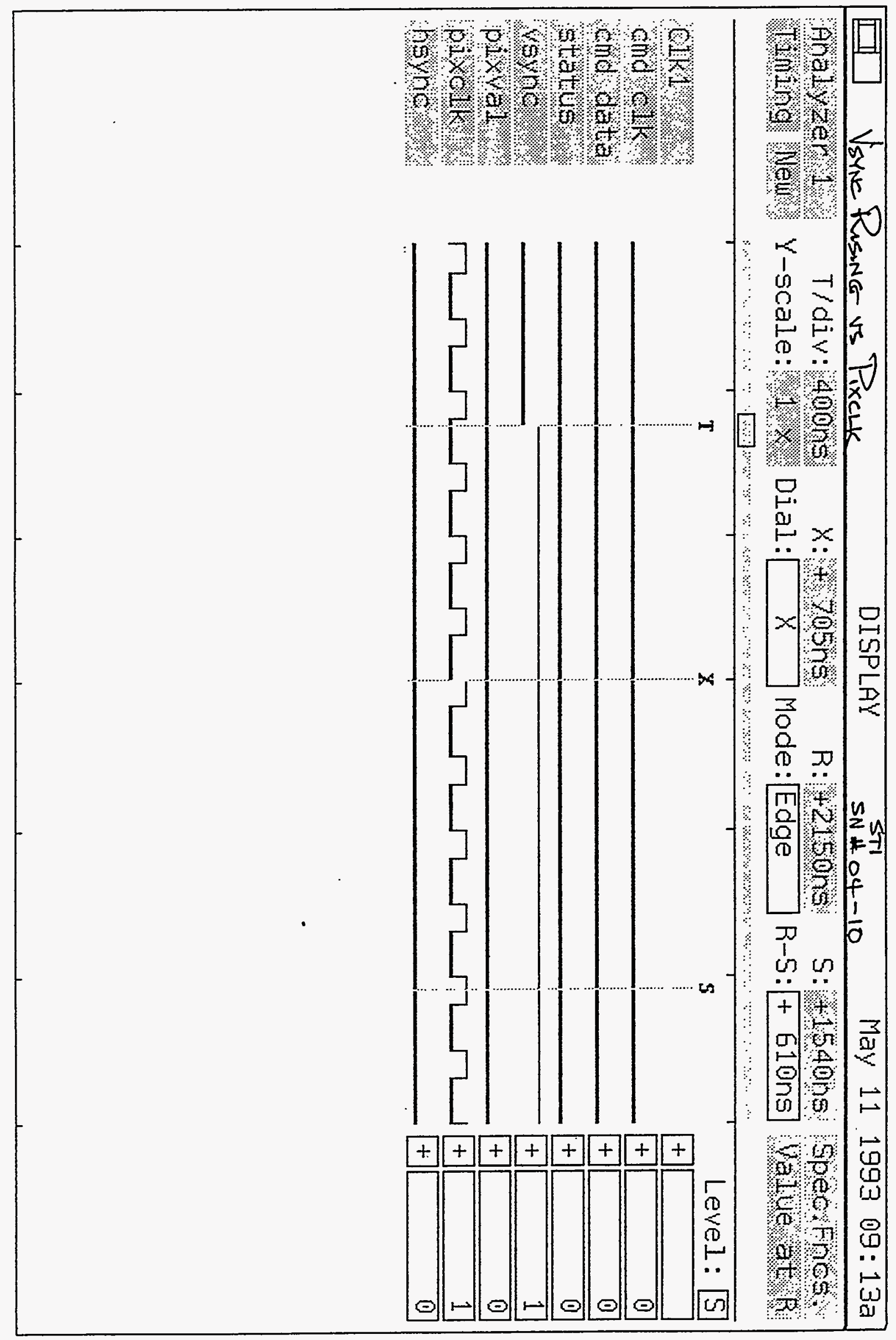




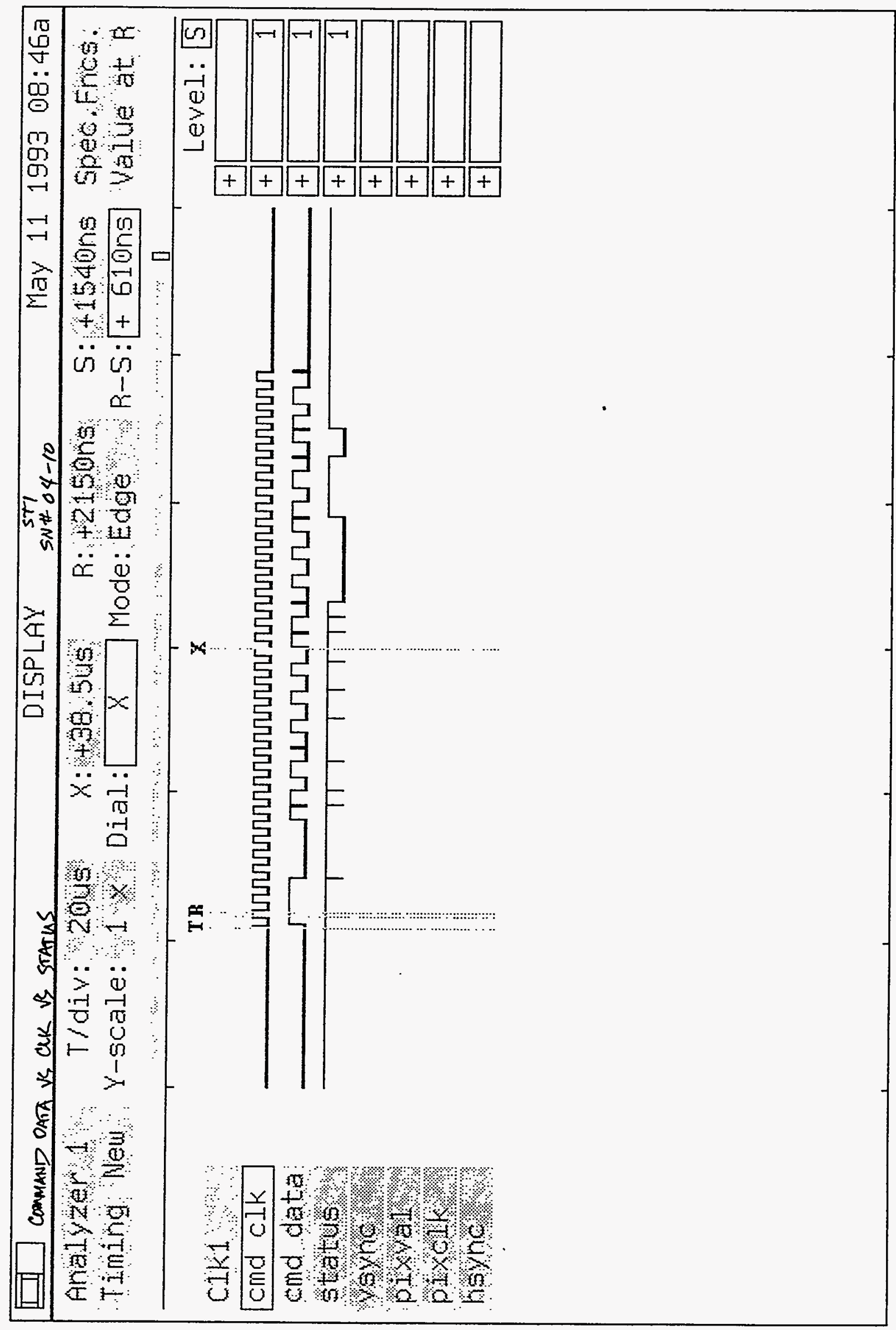




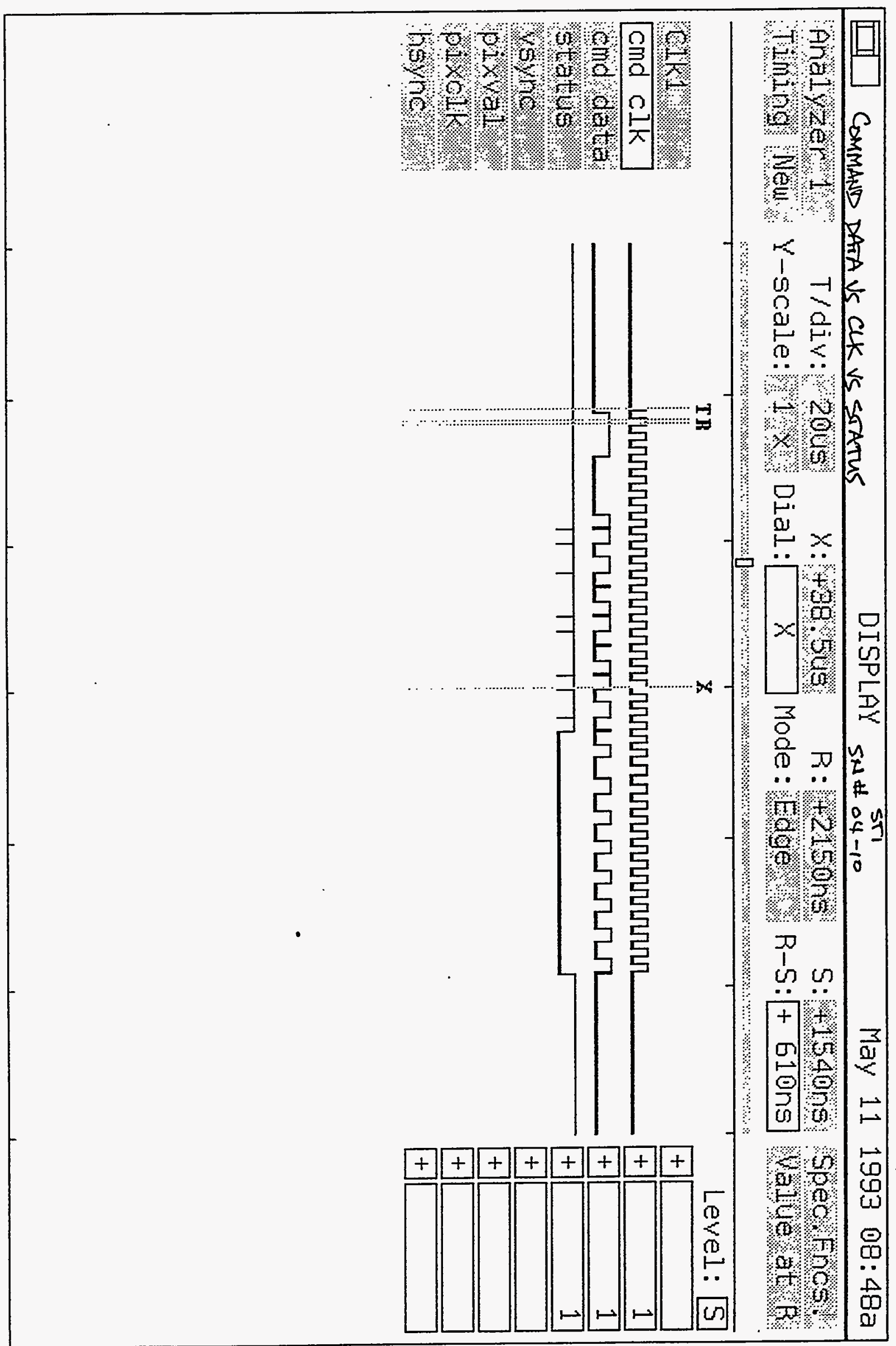




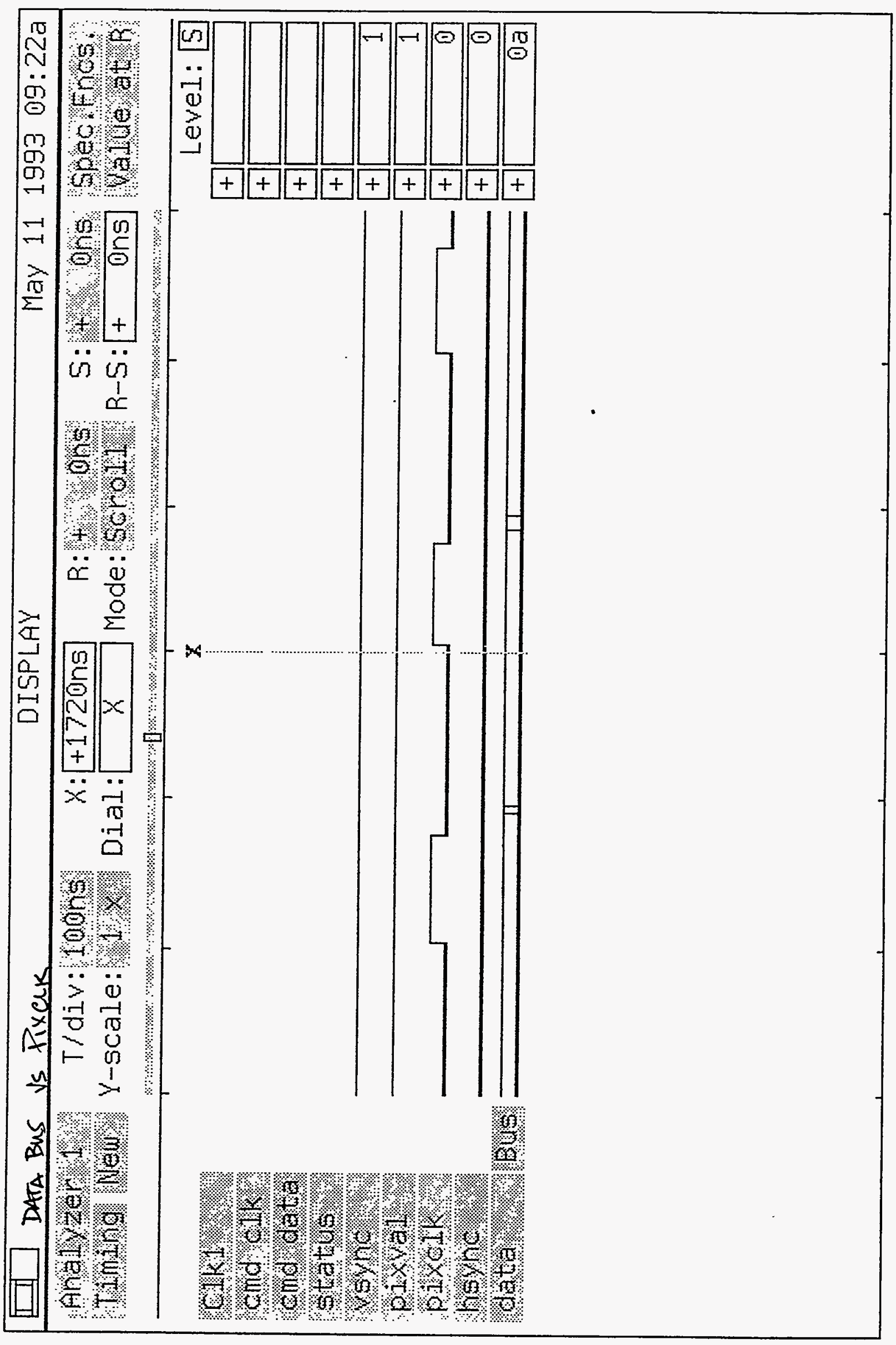


Prectitane wh $F=0$

ST Camera: ST1 \#04-10: int_time=50ms, offset= 0, gain=2 (150 e/bit) Mon May 10 13:s6:45 1993 Pixel Values Min 91 Max 99 Mean 93.2 Sigma $0.65 \times 10^{3}$

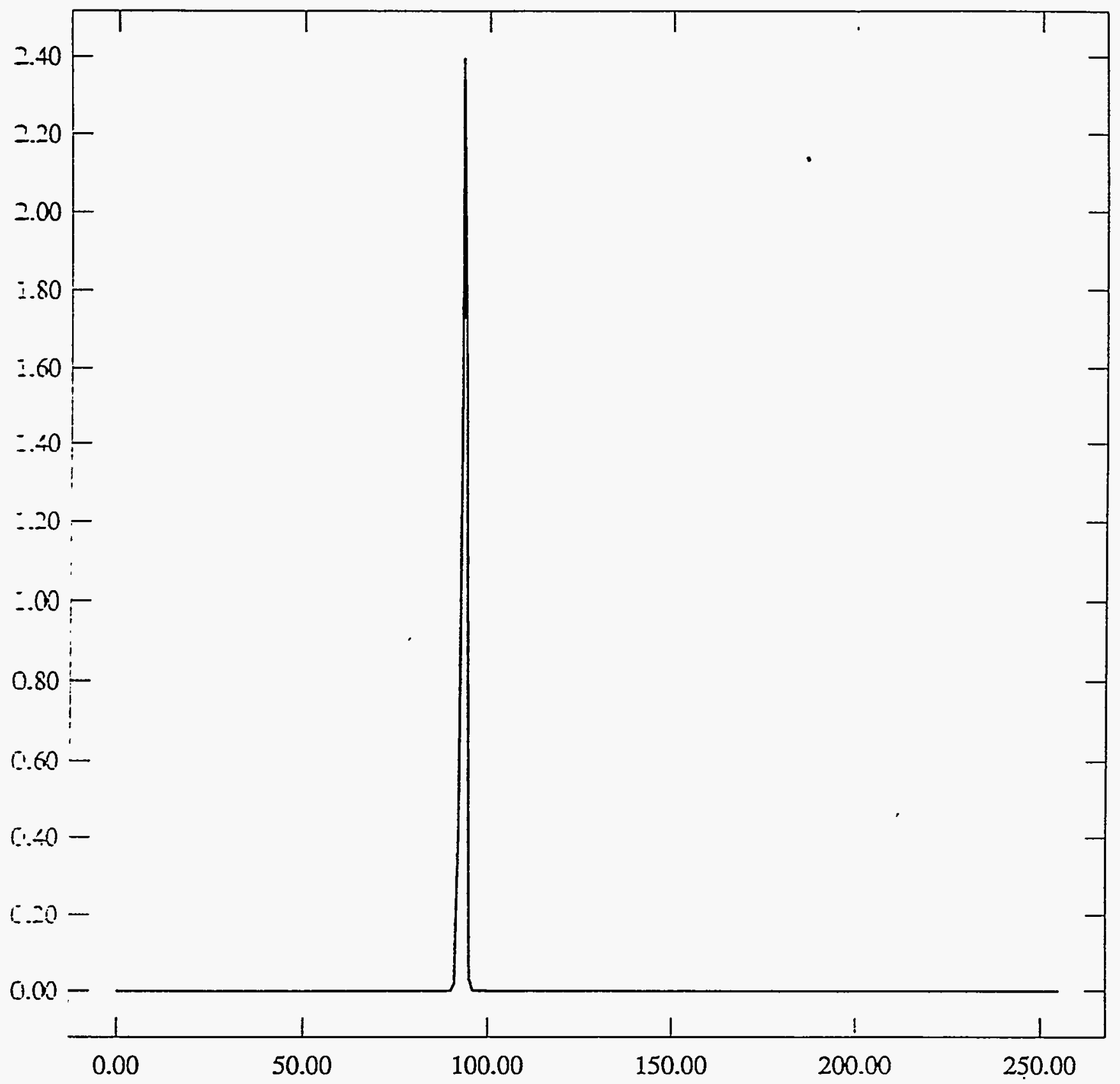


ST Camera: ST1 \#04-10: int_time= 50ms, offset= 0, gain=1 ( 350 e/bit) Mon Mas 10 13:s6:03 1993 Pixel Values Min 44 Max 48 Mean 45.1 Sigma $0.43 \times 10^{3}$

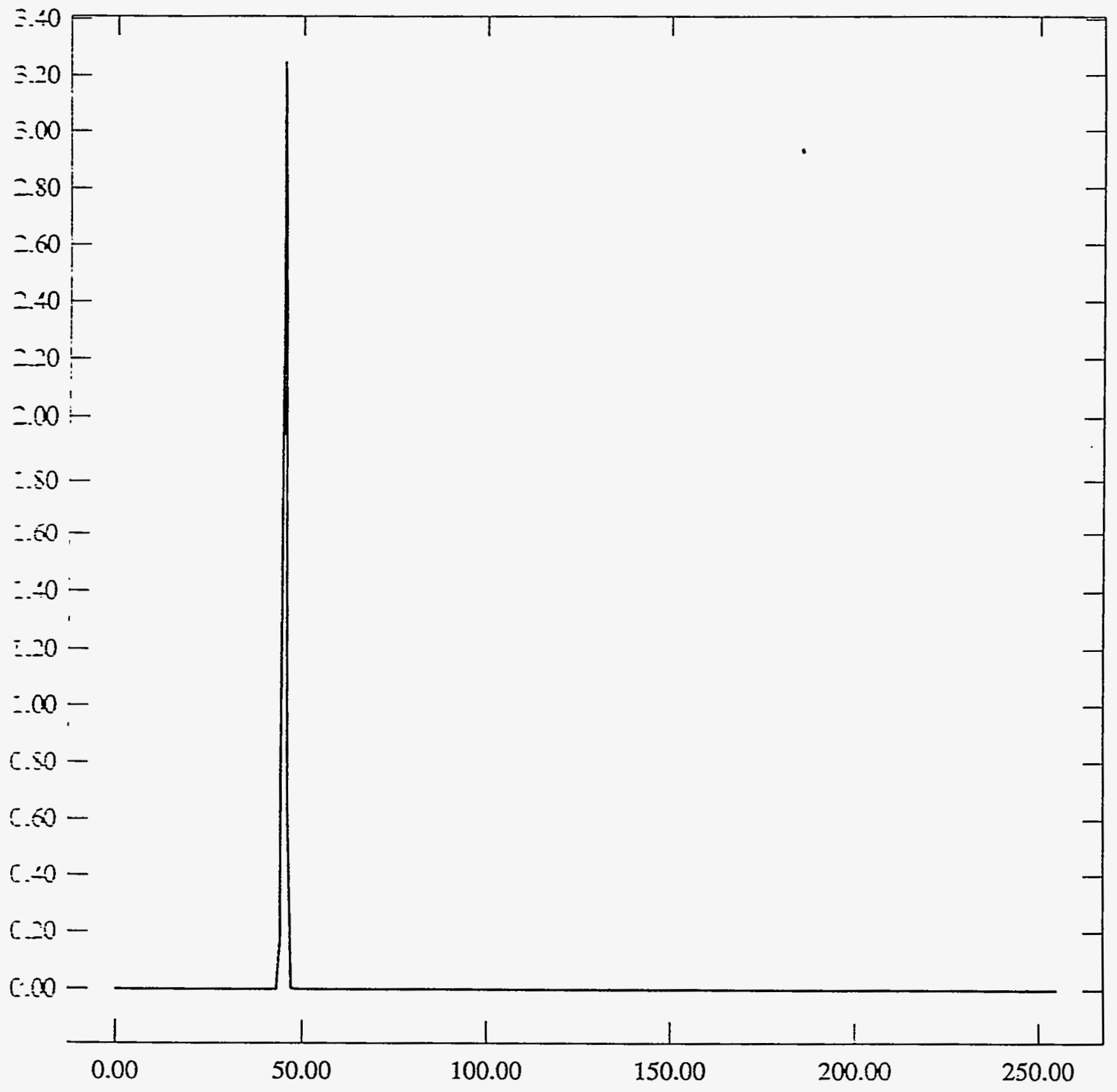


ST Camera: ST1 \#04-10: int_time= 50ms, offset= 0, gain=4 ( 75 e/bit) Mon Mą 10 13:s7:21 1993

Pixel Values Min $170 \mathrm{Max} 187$ Mean 175.4 Sigma $1.55 \times 10^{3}$

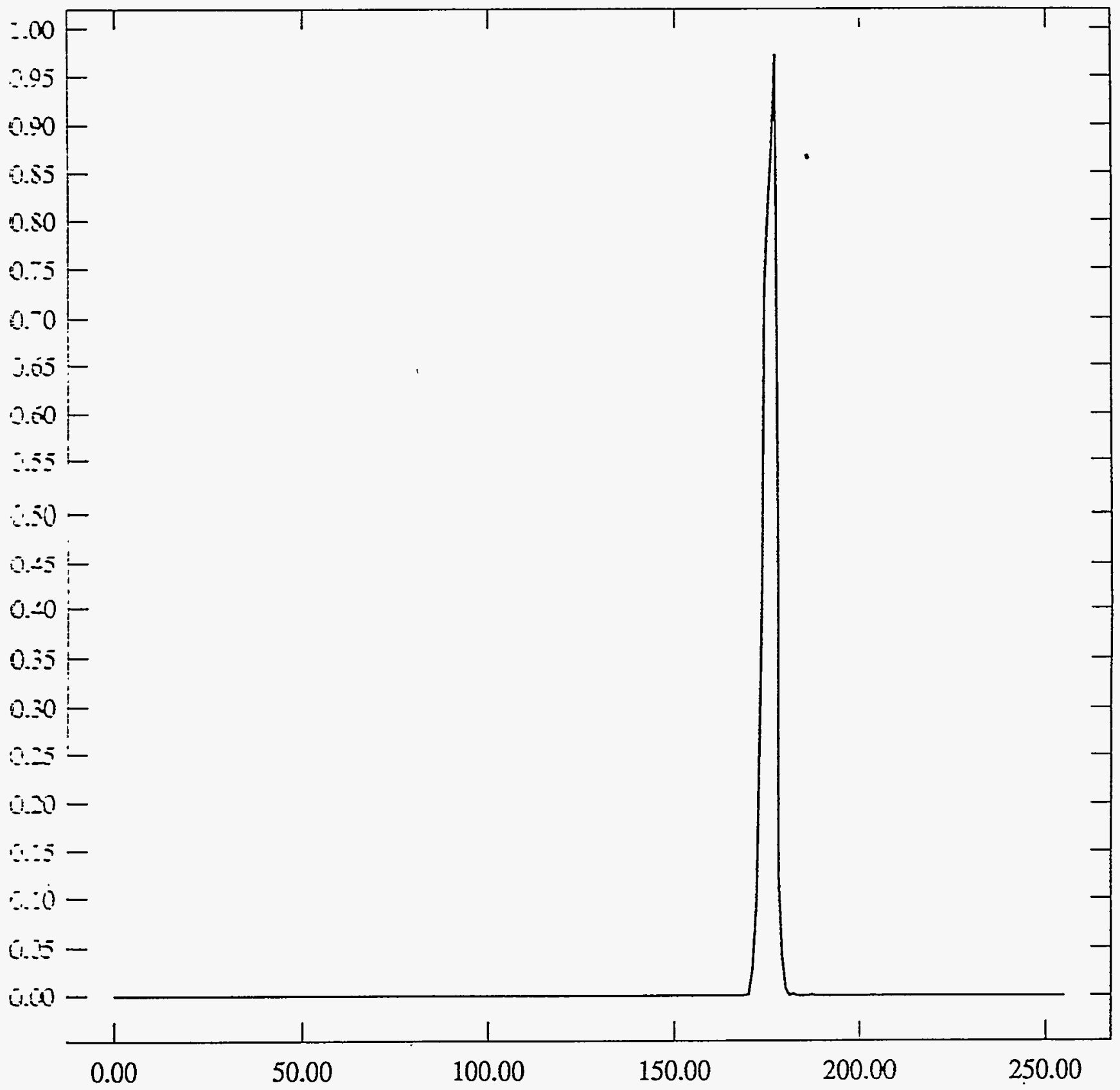




\section{Dark Noise Measurements.}

This measurement requires only the SUN Datacube Test Station and its image processing capabilities and an opaque covering.

Remove all test probes and place an opaque cover over the test CCD. turn the camera on and collect the dark frames as quickly as possible and record histograms.

Verify the gain of the camera is $4(75 \mathrm{e} / \mathrm{bit})$ and the integration time is $50 \mathrm{msec}$ and offset is 0 via the SASI.

Make the same measurement at gain level 2(150e/bit) and 1(350e/bit).

Fill in the Mu/Sigma values in the table below:

\begin{tabular}{|c|c|c|c|c|}
\hline Gain (e/Bit) & $\begin{array}{c}\text { Expected } \\
\text { Average } \\
\text { Black Level }\end{array}$ & $\begin{array}{c}\text { Measured } \\
\text { Average } \\
\text { Black Level }\end{array}$ & $\begin{array}{c}\text { Expected } \\
\text { Histogram } \\
\text { Sigma }\end{array}$ & $\begin{array}{c}\text { Measured } \\
\text { Histogram } \\
\text { Sigma }\end{array}$ \\
\hline $4(75 \mathrm{e} / \mathrm{bit})$ & 160 & 1.2 & \\
\hline $2(150 \mathrm{e} / \mathrm{bit})$ & 750 & & 0.7 & \\
\hline $1(350 \mathrm{e} / \mathrm{bit})$ & 32 & 44.1 & 0.5 & 43 \\
\hline
\end{tabular}

SN\#_ O4-06 By $\frac{M D}{\text { initials }}$ Date $\frac{51,010=}{\text { passed }}$

Turn off the test fixture.

REMEMBER to attach your recorded documentation to this test procedure!

(A document protector is advised) 


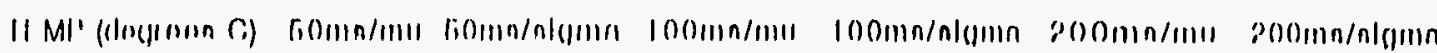

\begin{tabular}{|c|c|c|c|c|c|c|c|}
\hline .20 & 150.00 & 0.12 & 150.10 & 0.72 & 150.40 & 0.72 & $5 / 10 / 93$ \\
\hline .10 & 148.20 & 0.78 & 148.70 & 0.71 & 149.90 & 0.70 & Flight F.0. CCD\#1 \\
\hline 0 & 147.70 & 0.84 & 149.10 & 0.66 & 152.10 & 0.94 & \\
\hline 10 & 149.80 & 0.70 & 154.00 & 1.17 & 163.10 & 1.16 & $75 \theta / b i t$ \\
\hline 20 & 159.00 & 0.99 & 169.60 & 1.33 & 190.70 & 2.26 & $R 49=100 \Omega$ \\
\hline 30 & 185.10 & 1.26 & 211.60 & 2.44 & & & \\
\hline
\end{tabular}

NOIIS: 
ST Camera: ST1\#04-10 -20C: int_time= 50ms, offset= 0, gain=4 ( 75 e/bit) Mon May 10 15:4s:16 1993 Pixel Values Min 147 Max 152 Mean 150.0 Sigma $0.72 \times 10^{3}$

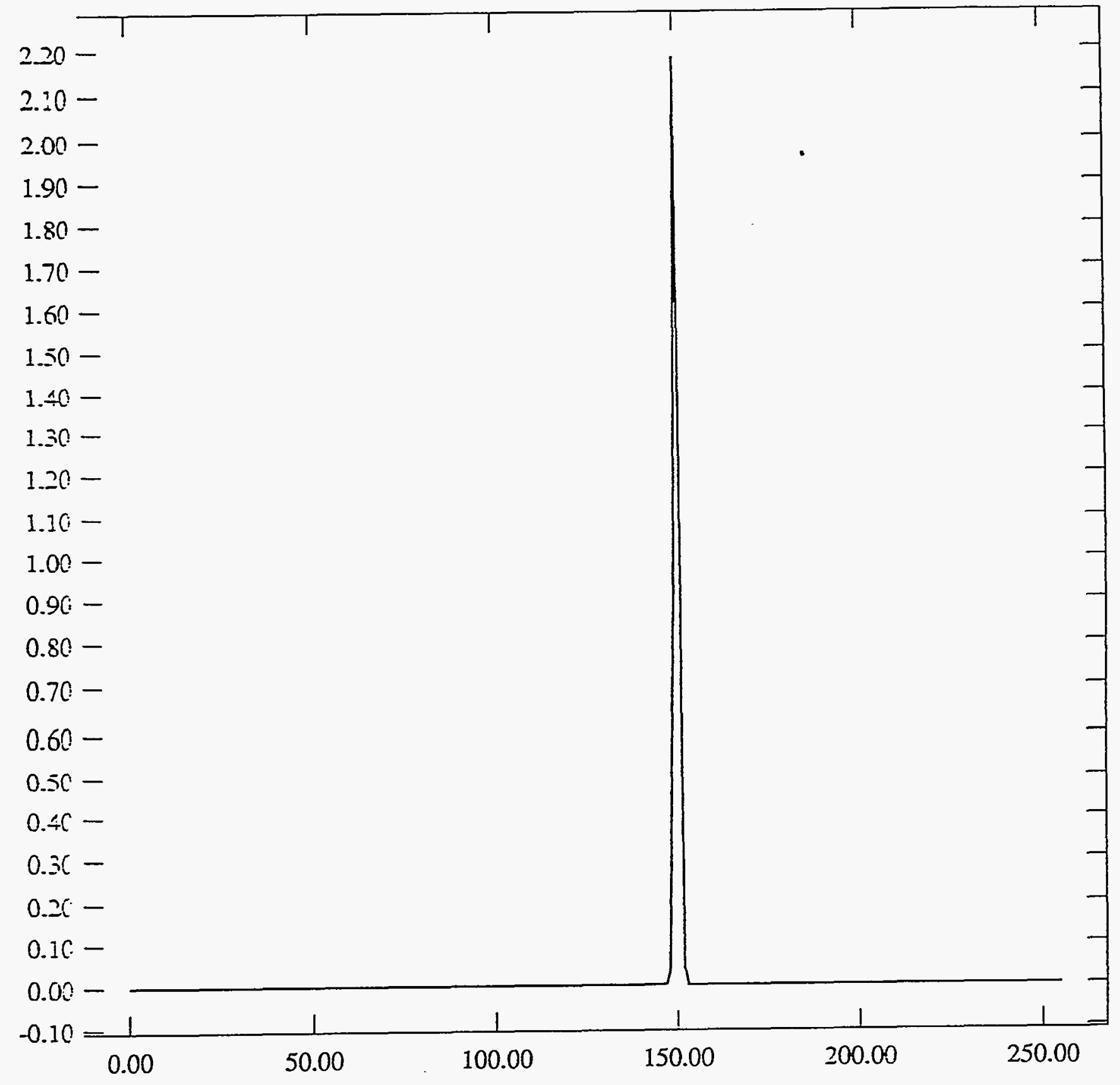


ST Camera: ST1\#04-10 -20C: int_time=100ms, offset= 0, gain=4 ( 75 e/bit) Mon May 10 15:4S:46 1993 Pixel Values Min 147 Max 153 Mean 150.1 Sigma $0.72 \times 10^{3}$

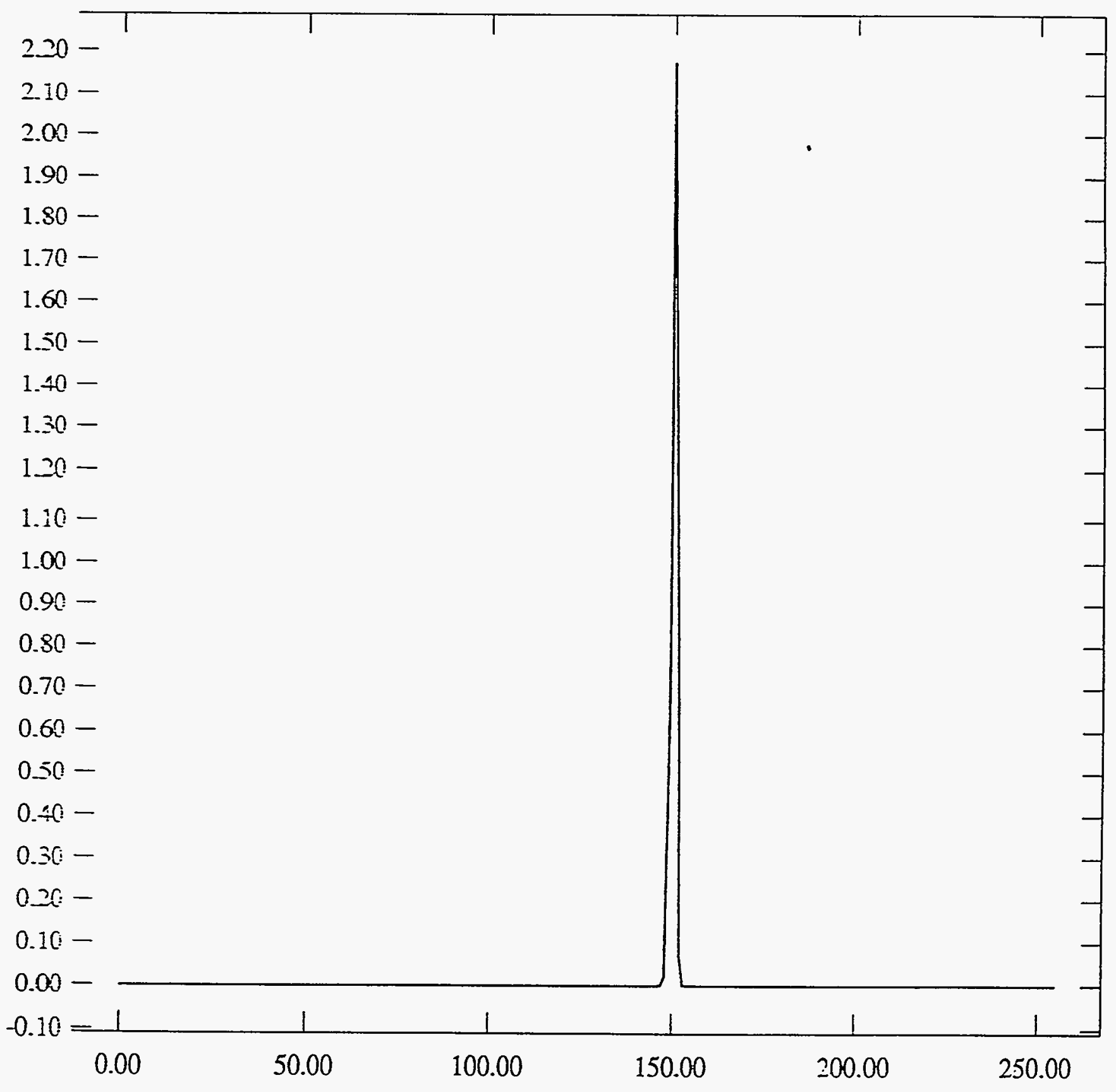


ST Camera: ST1\#04-10 -20C: int_time=200ms, offset= 0, gain=4 ( 75 e/bit) Mon May 10 15:49:18 1993 Pixel Values Min 148 Max 153 Mean 150.4 Sigma $0.72 \times 10^{3}$

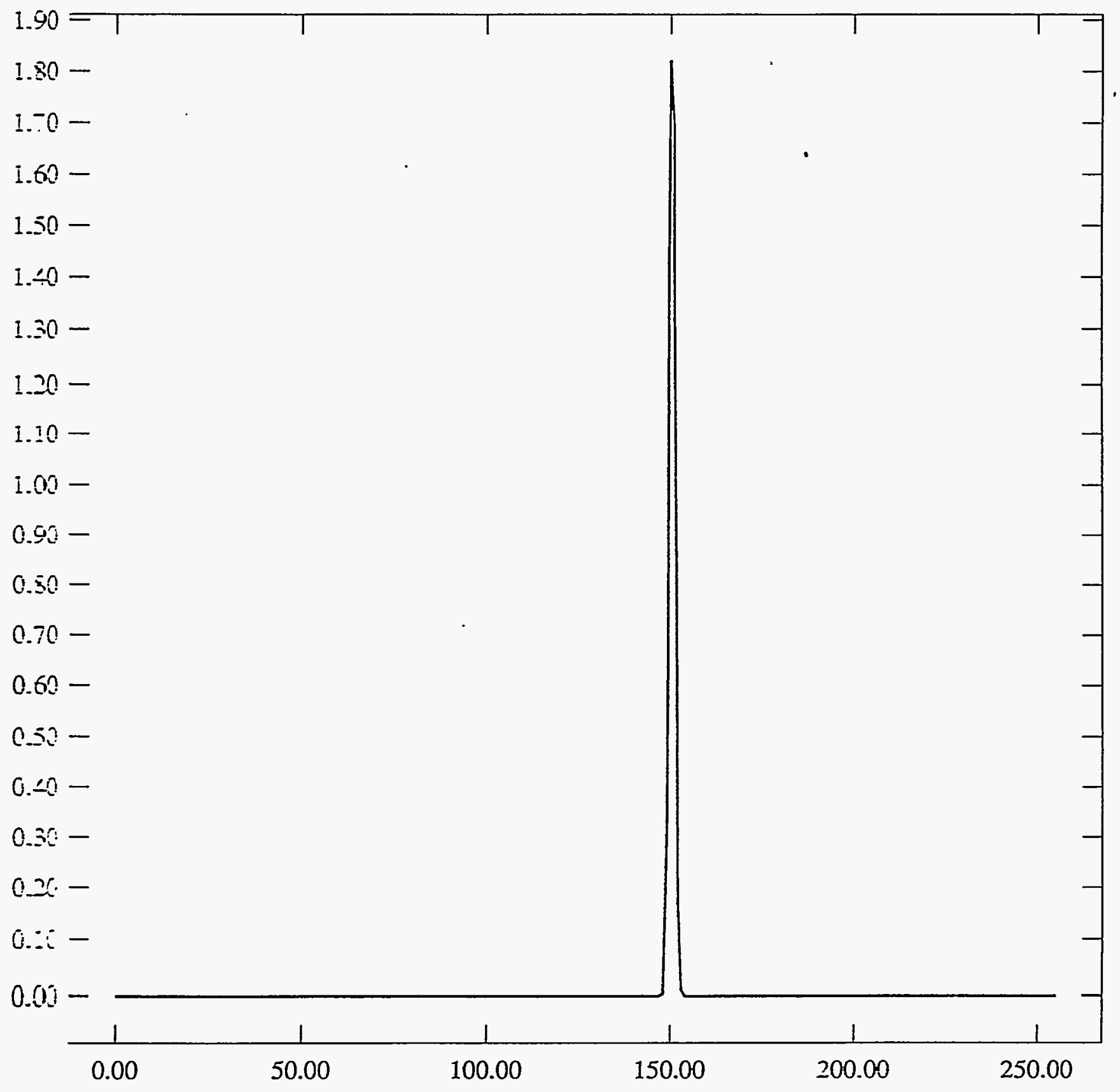


ST Camera: ST1\#04-10 -10C: int_time= 50ms, offset= 0, gain=4 ( 75 e/bit) Mon May 10 16:12:44 1993 Pixel Values Min 146 Max 150 Mean 148.2 Sigma $0.78 \times 10^{3}$

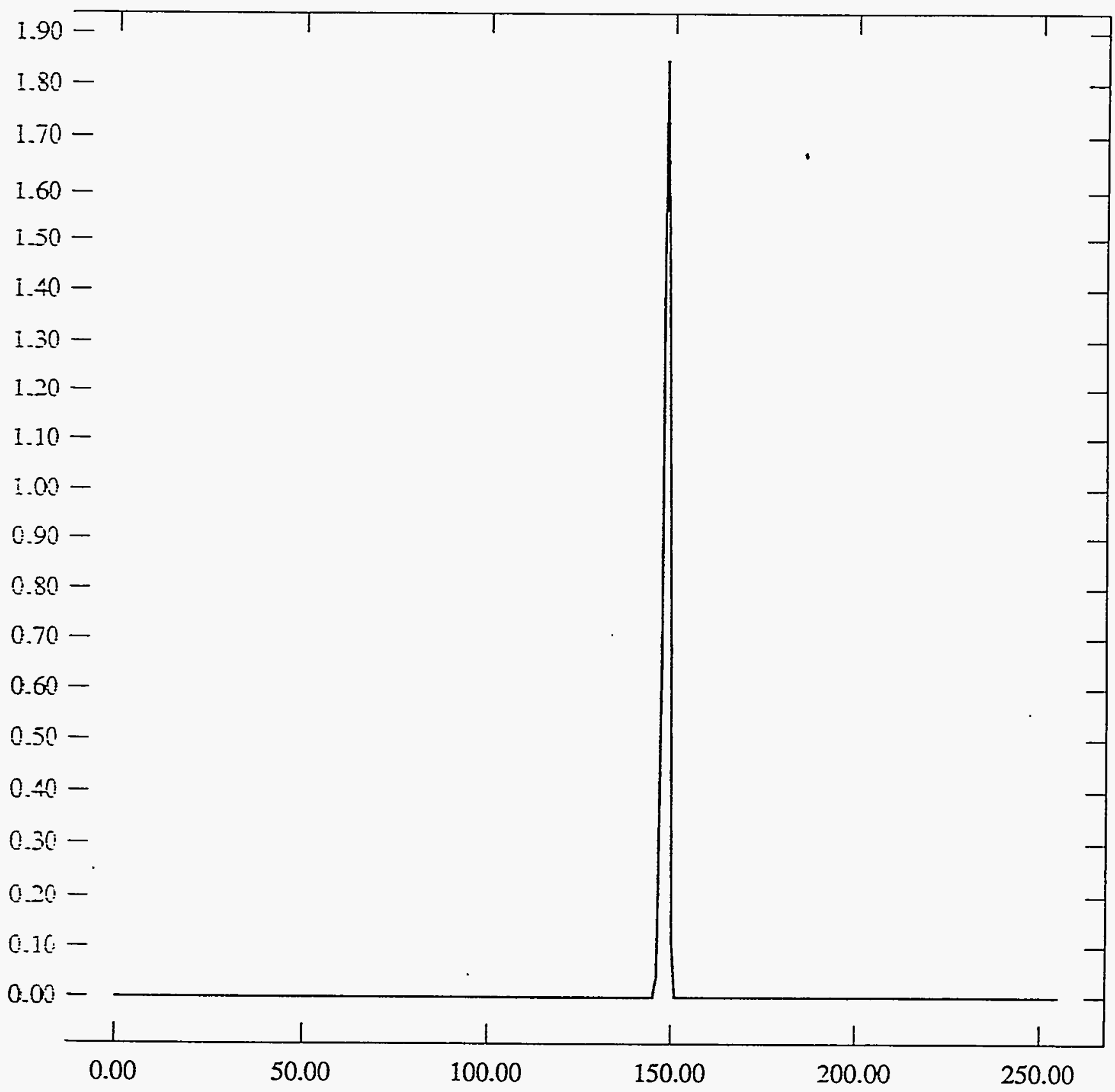


ST Camera: ST1\#04-10 -10C: int time=100ms, offset=0, gain=4 ( 75 e/bit) Mon Mar 10 16:13:24 1993 Pixel Values Min $146 \mathrm{Max} 151$ Mean 148.7 Sigma $0.71 \times 10^{3}$

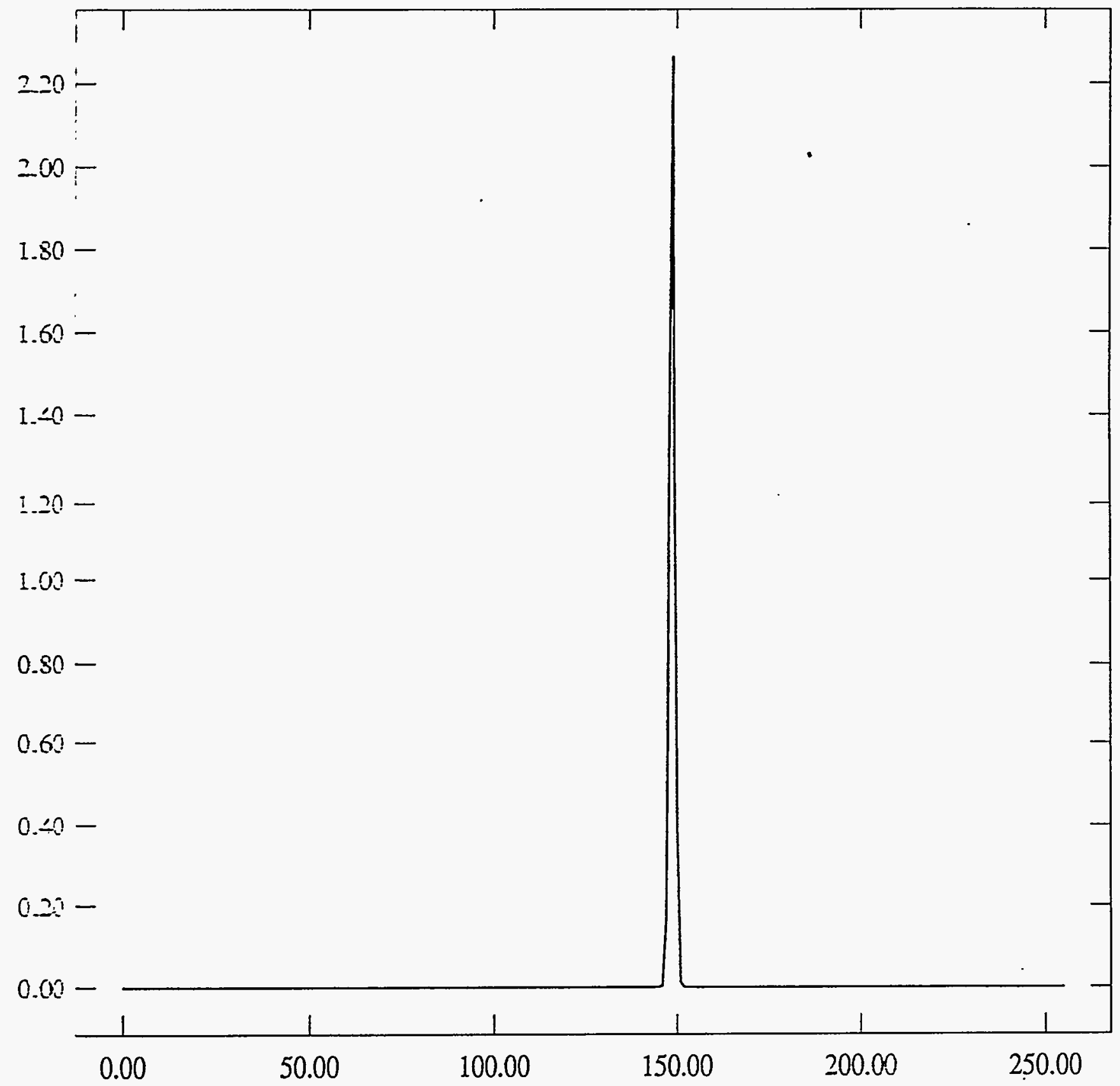


ST Camera: ST1\#04-10 -10C: int_time=200ms, offset= 0, gain=4 ( 75 e/bit) Mon May 10 16:14:04 1993 Pixel Values Min 147 Max 152 Mean 149.9 Sigma $0.70 \times 10^{3}$

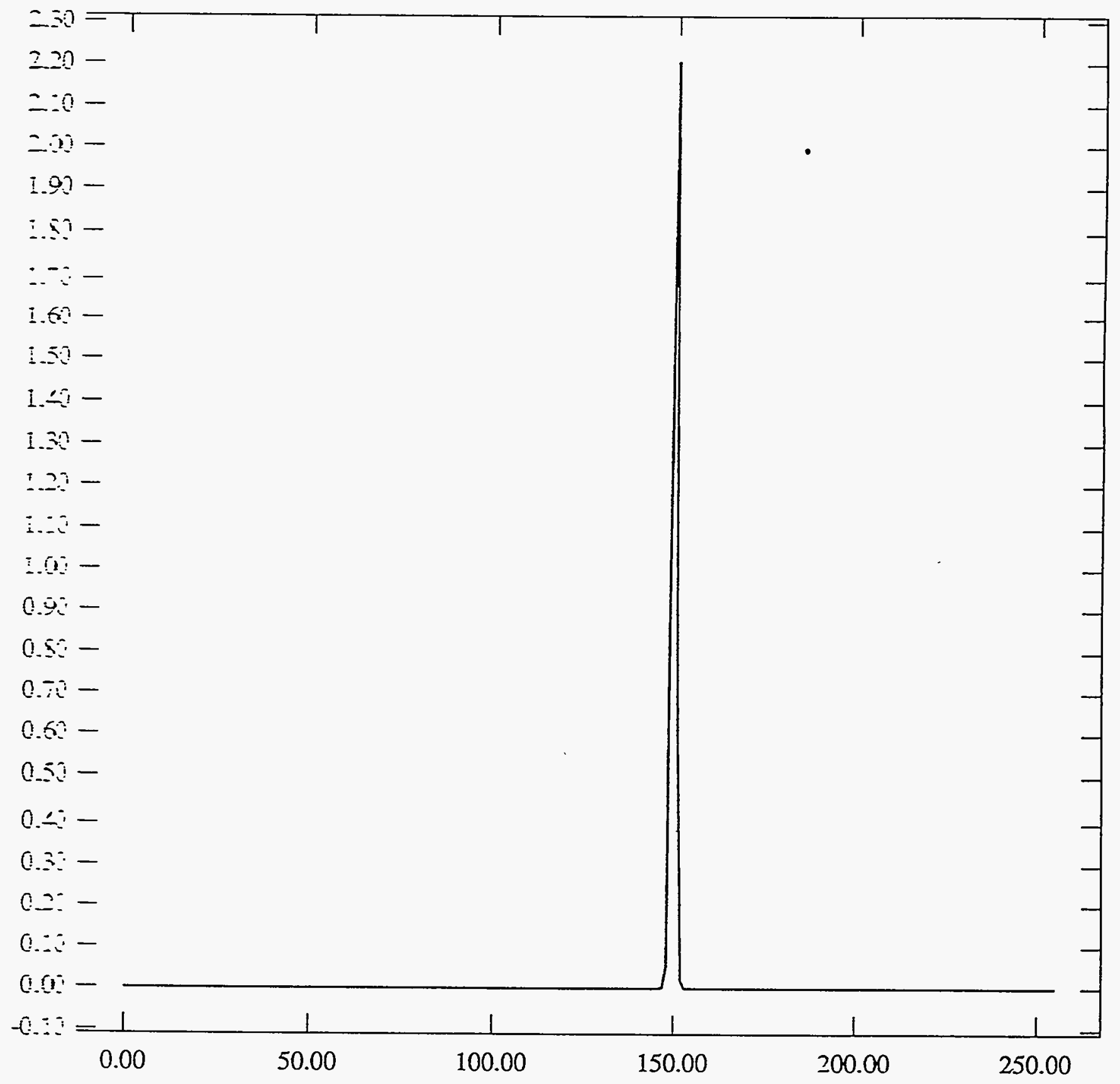


ST Camera: ST1\#04-10 0C: int_time= 50ms, offset= 0, gain=4 ( 75 e/bit) Mon May 10 16:43:29 1993

Pixel Values Min 144 Max 150 Mean 147.7 Sigma $0.84 \times 10^{3}$

$1.70-$

i. $60-$

$50-$

1.0

$1.31-$

$1.20-$

$1.10-$

$1.00-$

$0.9-$

$0.50^{-}-$

e.j-

$0.67-$

$050-$

$0 . \div-$

$0.3-$

Q

a-2 -

$0.01-$

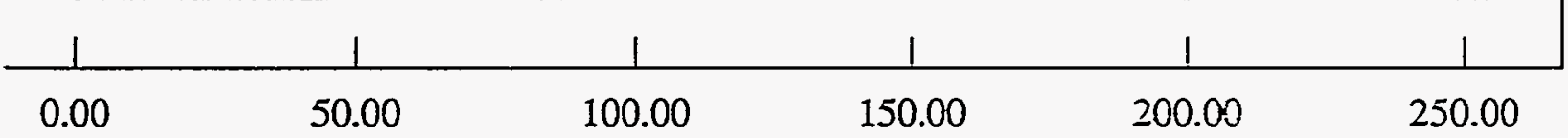


ST Camera: ST1\#04-10 0C: int time=100ms, offset= 0, gain=4 ( 75 e/bit) Mon May 10 16:14:01 1993 Pixel Values Min $146 \overline{\mathrm{M}}$ ax 152 Mean 149.1 Sigma $0.66 \times 10^{3}$

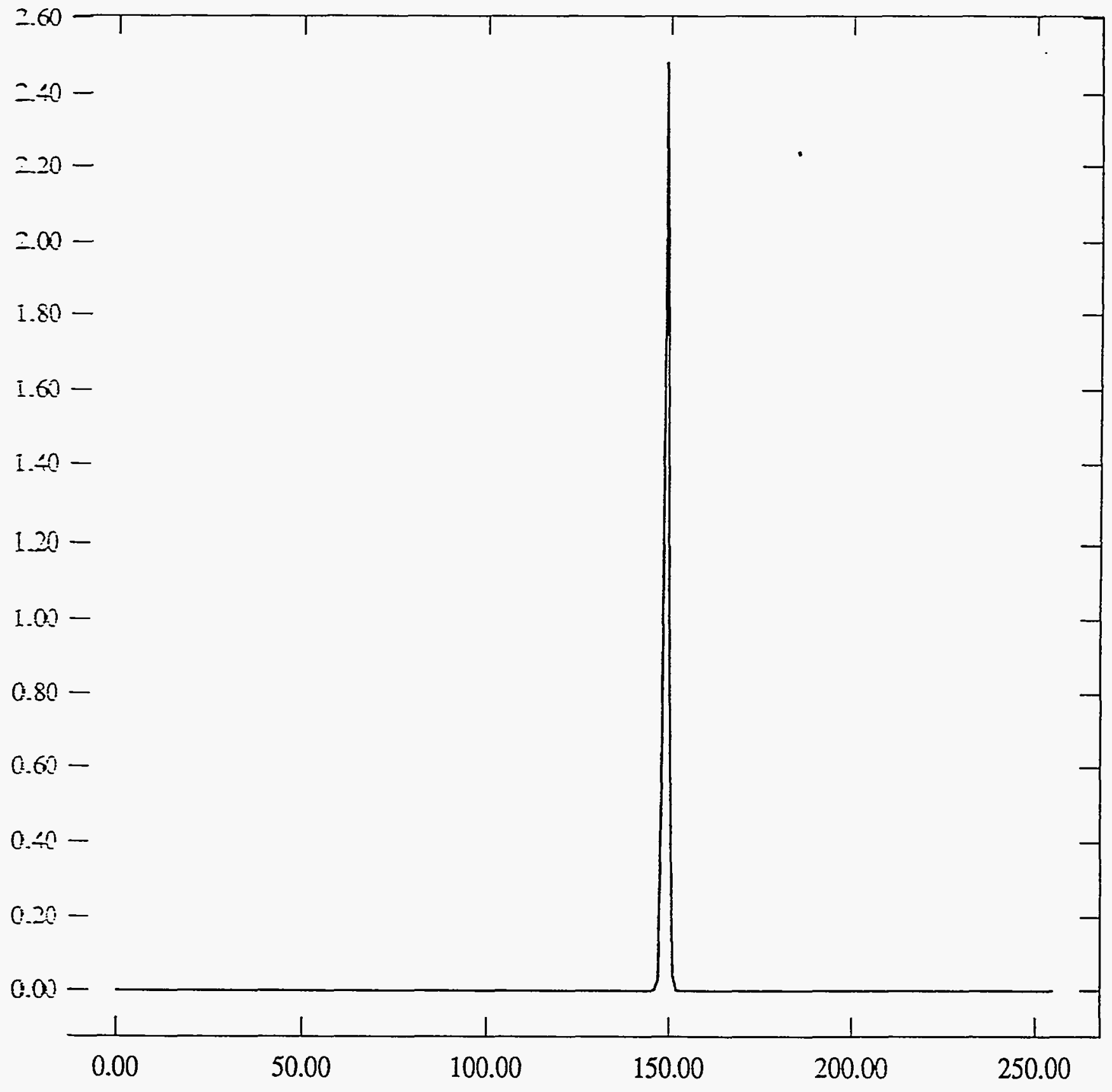


ST Camera: ST1\#04-10 0C: int time=200ms, offset= 0, gain=4 ( $75 \mathrm{e} / \mathrm{bit}$ ) Mon May 10 16:44:32 1993 Pixel Values Min 149 Max 159 Mean 152.1 Sigma $0.94 \times 10^{3}$

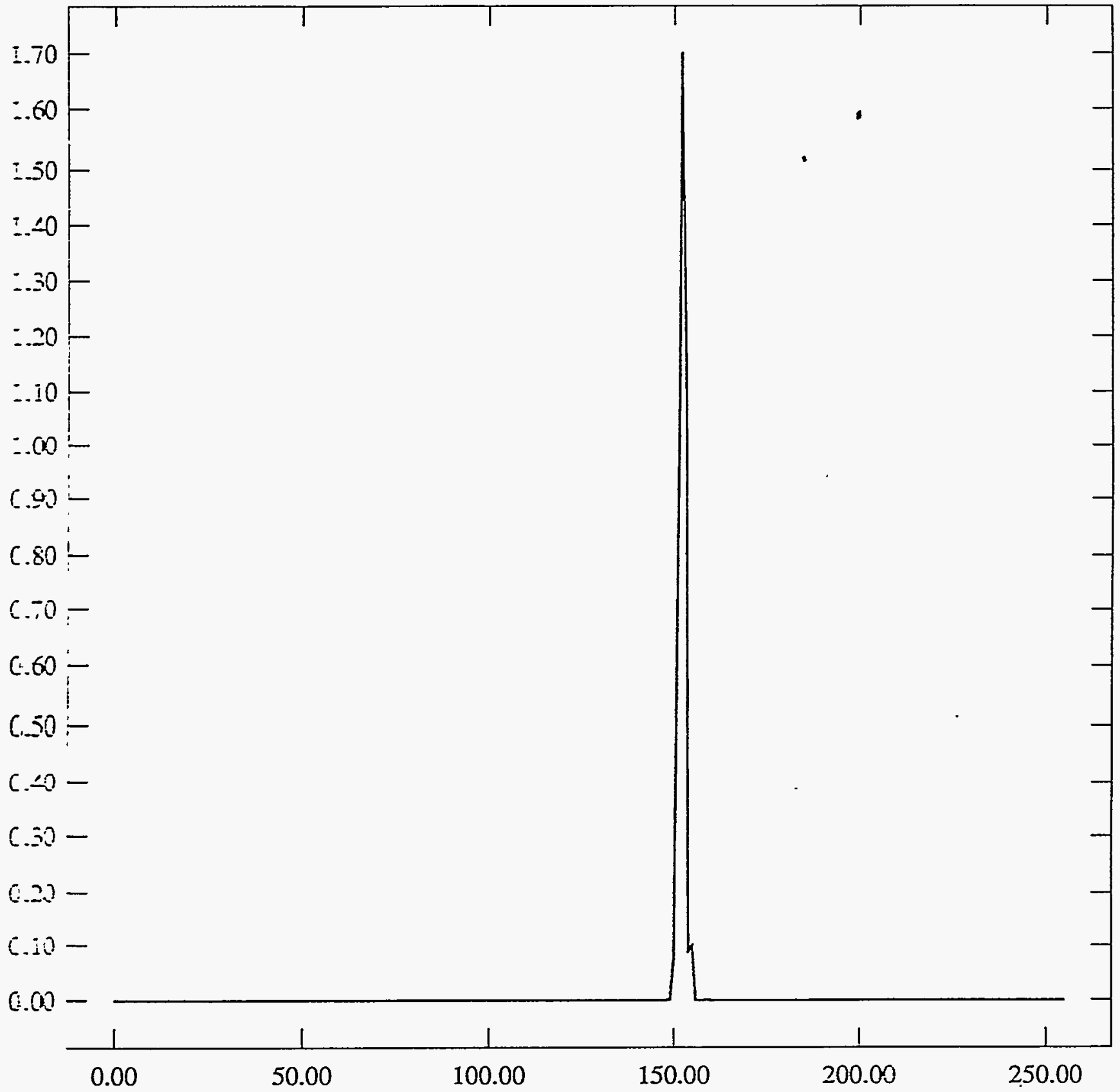


ST Camera: ST1\#04-10 10C: int_time=50ms, offset= 0, gain=4 ( 75 e/bit) Mon .May 10 17:06:57 1993 Pixel Values Min 147 Max 153 Mean 149.8 Sigma $0.70 \times 10^{3}$

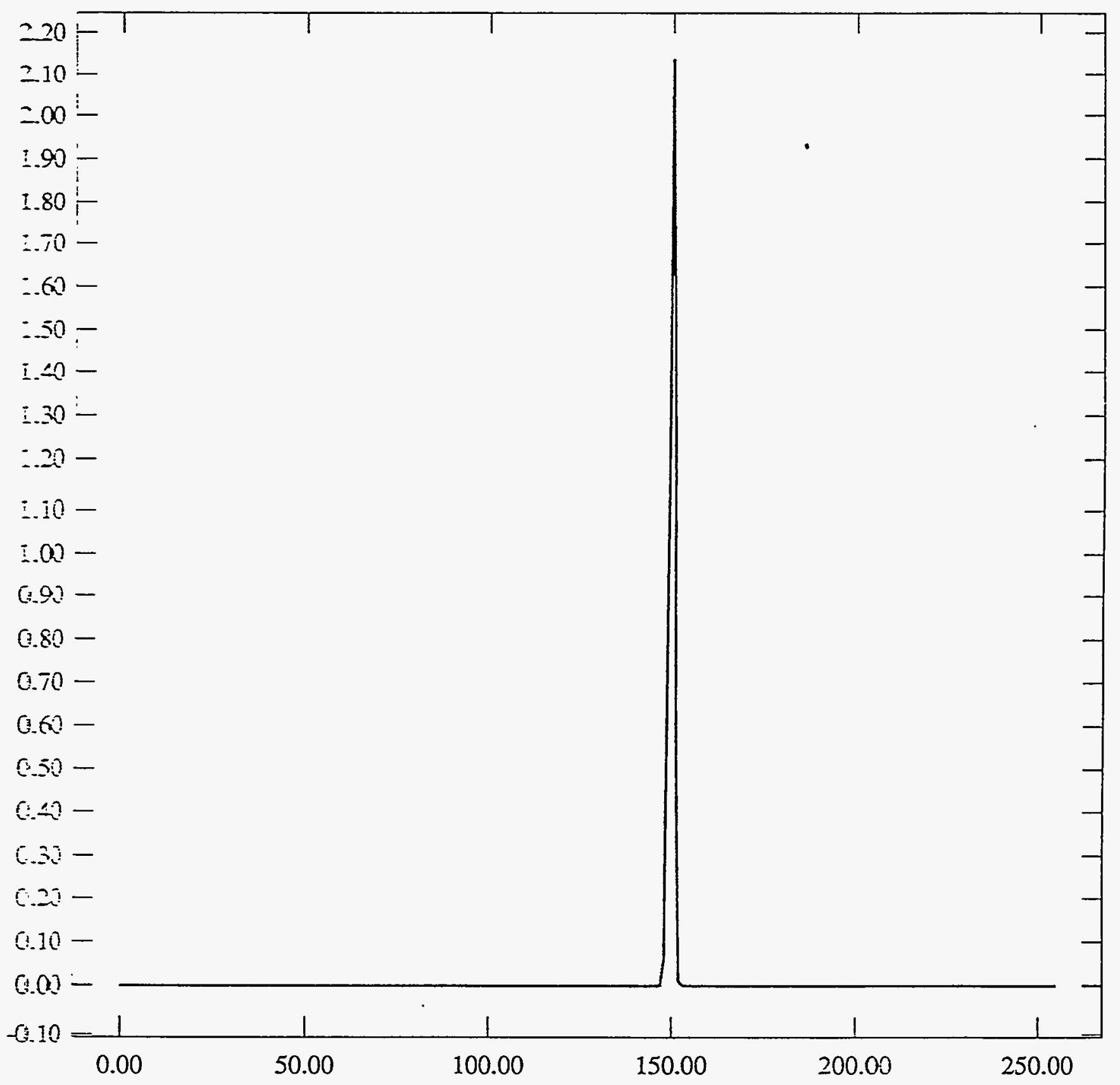


ST Camera: ST1\#04-10 10C: int_time=100ms, offset= 0, gain=4 ( 75 e/bit) Mon :May 10 17:08:39 1993 Pixel Values Min 151 Max 161 Mean 154.0 Sigma $1.17 \times 10^{3}$

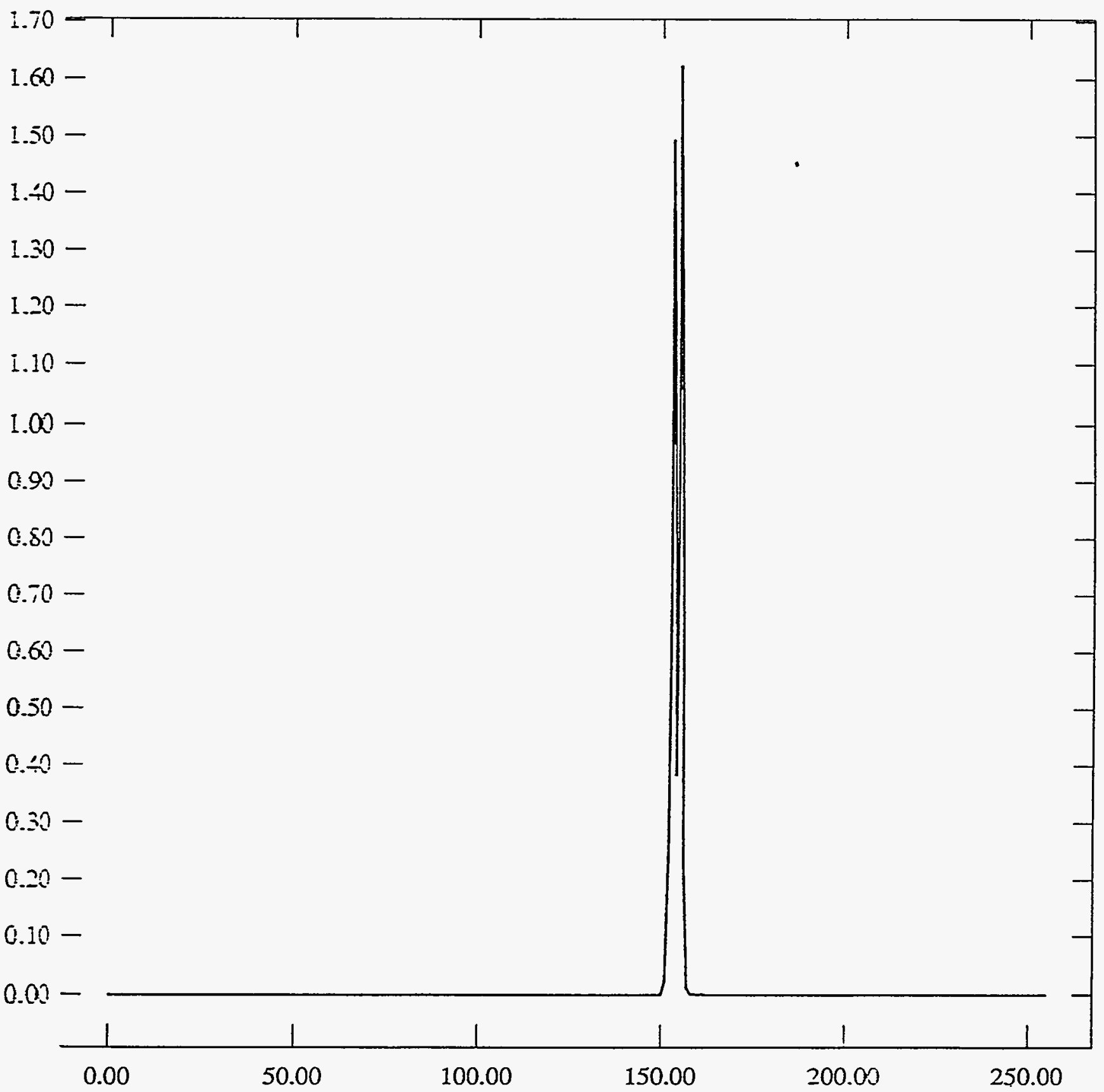


ST Camera: ST1 \#04-10 10C: int_time=200ms, offset= 0, gain=4 ( 75 e/hit) Mon May 10 17:11:04 1993 Pixel Values Min 159 Max 179 Mean 163.1 Sigma $1.16 \times 10^{3}$

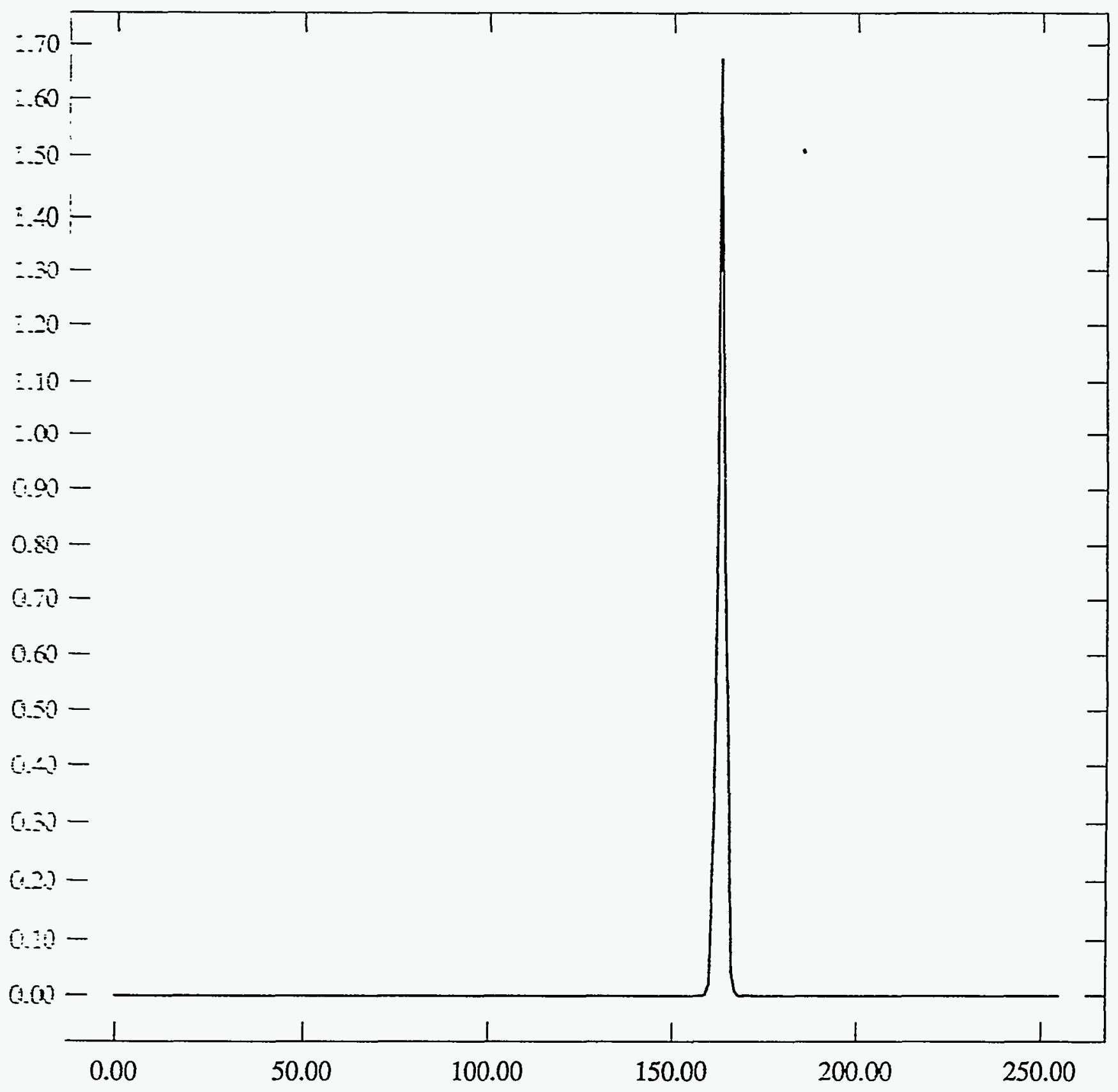


ST Camera: ST1\#04-10 20C: int_time= 50ms, offset= 0, gain=4 ( 75 e/bit) Mon May 10 17:25:21 1993 Pixel Values Min $156 \mathrm{Max} 167$ Mean 159.0 Sigma $0.99 \times 10^{3}$

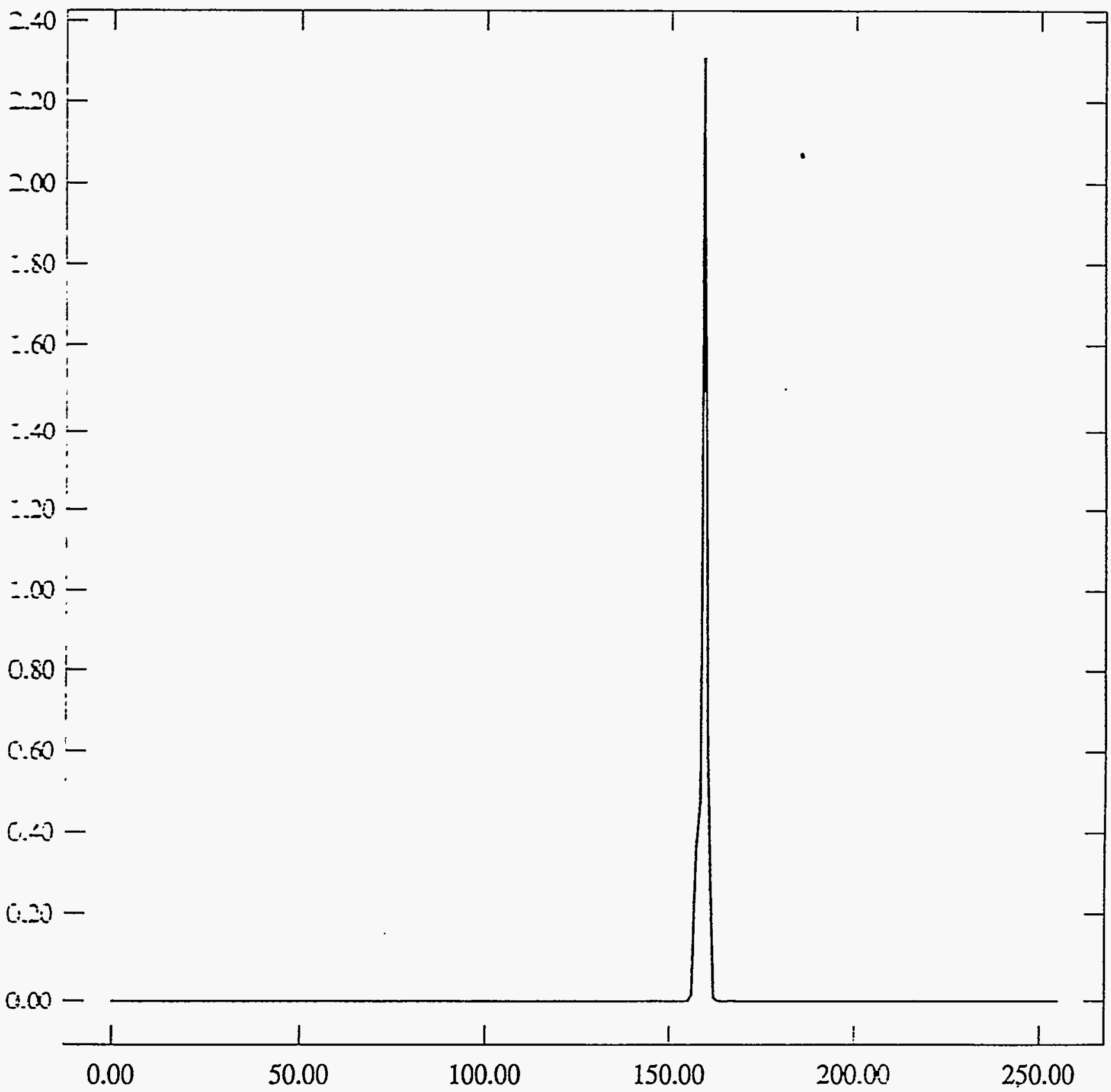


ST Camera: ST1\#04-10 20C: int_time=100ms, offset=0, gain=4 ( 75 e/bit) Mon Maş 10 17:25:53 1993 Pixel Values Min 165 Max 187 Mean 169.6 Sigma $1.33 \times 10^{3}$

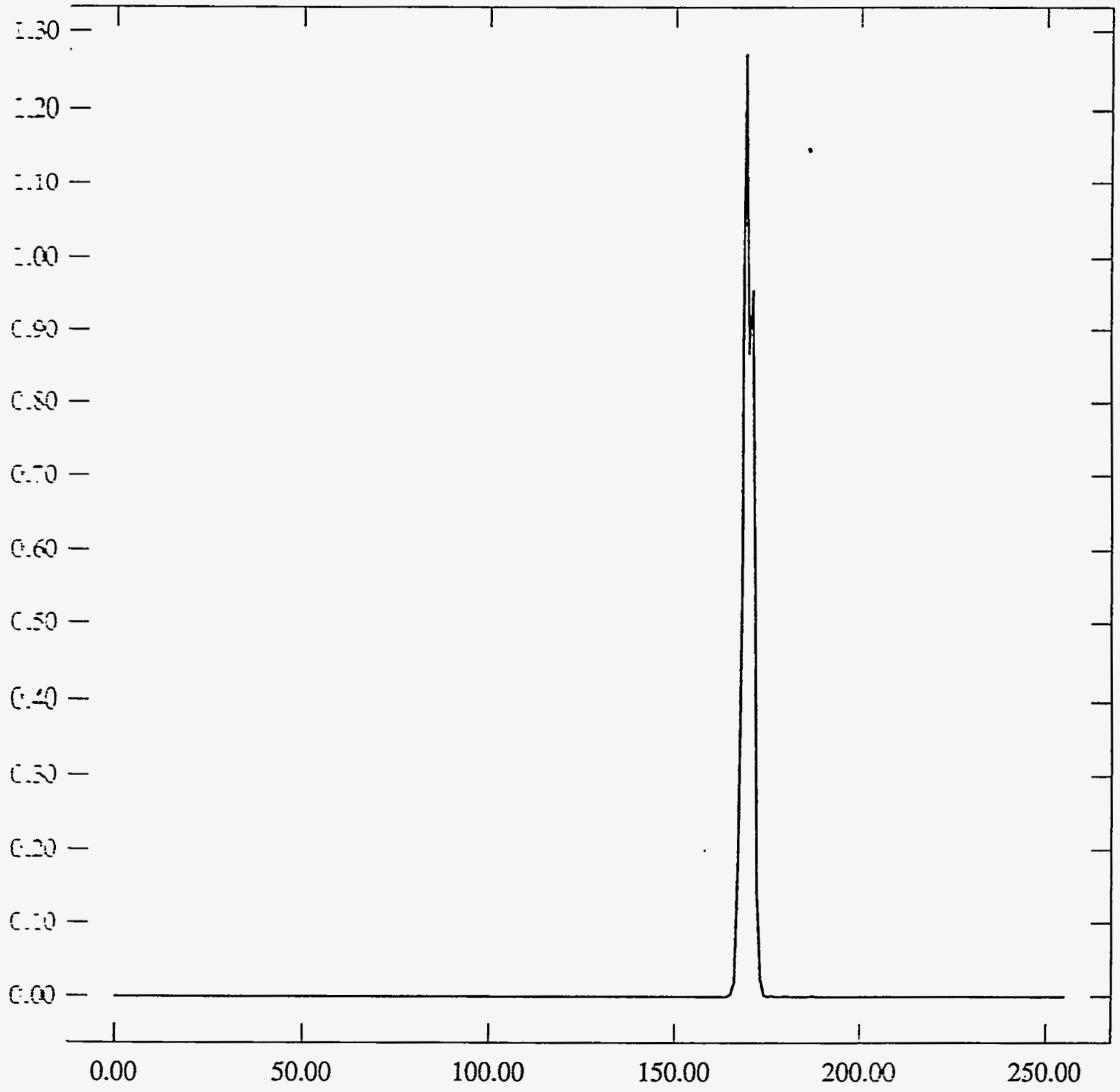


ST Camera: ST1\#04-10 20C: int_time=200ms, offset= 0, gain=4 ( 75 e/bit) Mon Mas 10 17:26:31 1993 Pixe! Values Min 184 Max 224 Mean 190.7 Sigma 2.26

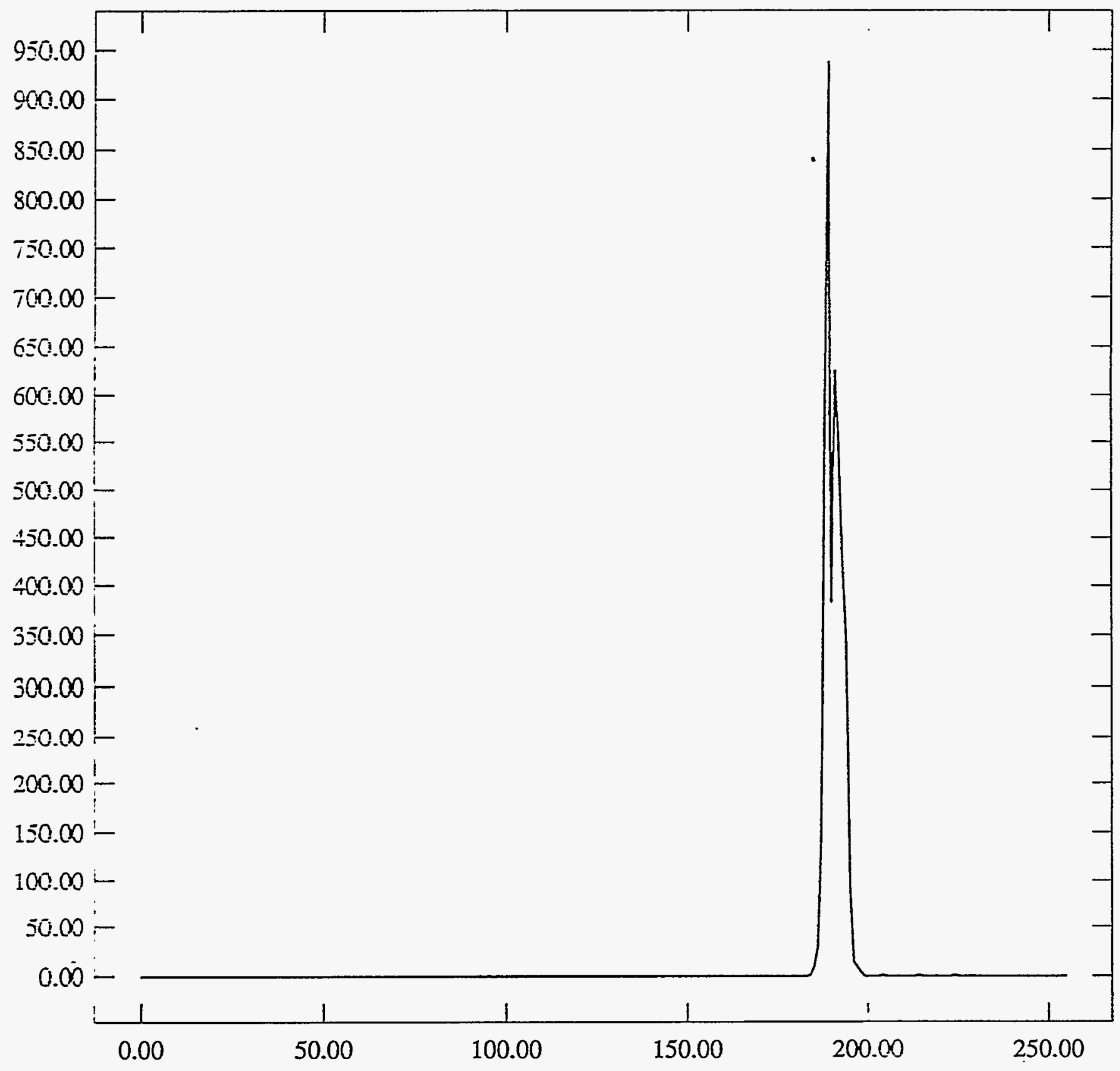


ST Camera: ST1\#04-10 30C: int_time= 50ms, offset= 0, gain=4 ( $75 \mathrm{e} / \mathrm{bit}$ ) Mon Maฐ 10 17:58:33 1993 Pixel Values Min $181 \mathrm{Max} 200$ Mean 185.1 Sigma $1.26 \times 10^{3}$

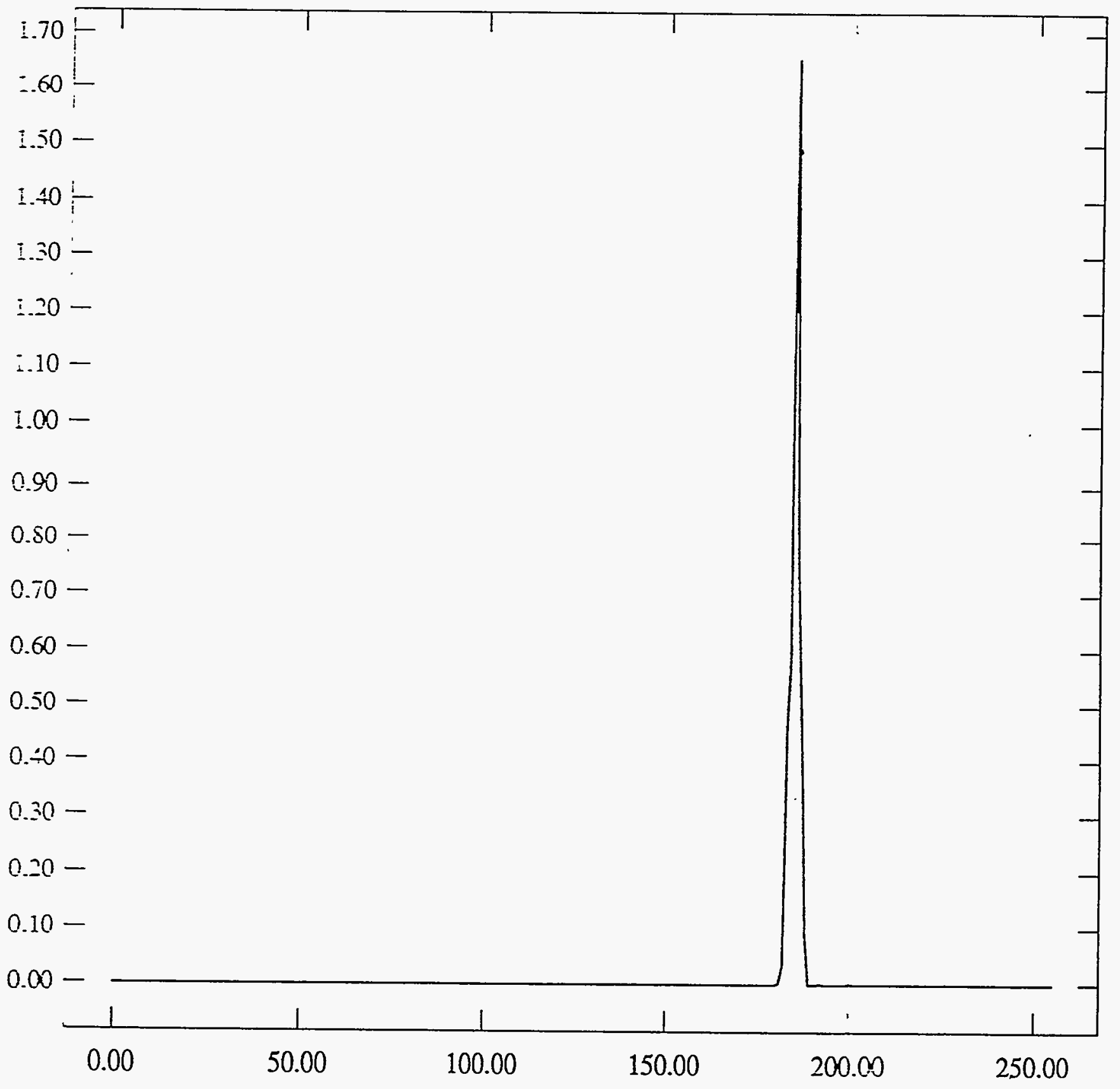


ST Camera: ST1\#04-10 30C: int_time=100ms, offset= 0, gain=4 ( 75 e/bit) Mon Mas 10 17:59:20 1993 Pix:: Values Min 204 Max 244 Mean 211.6 Sigma 2.44

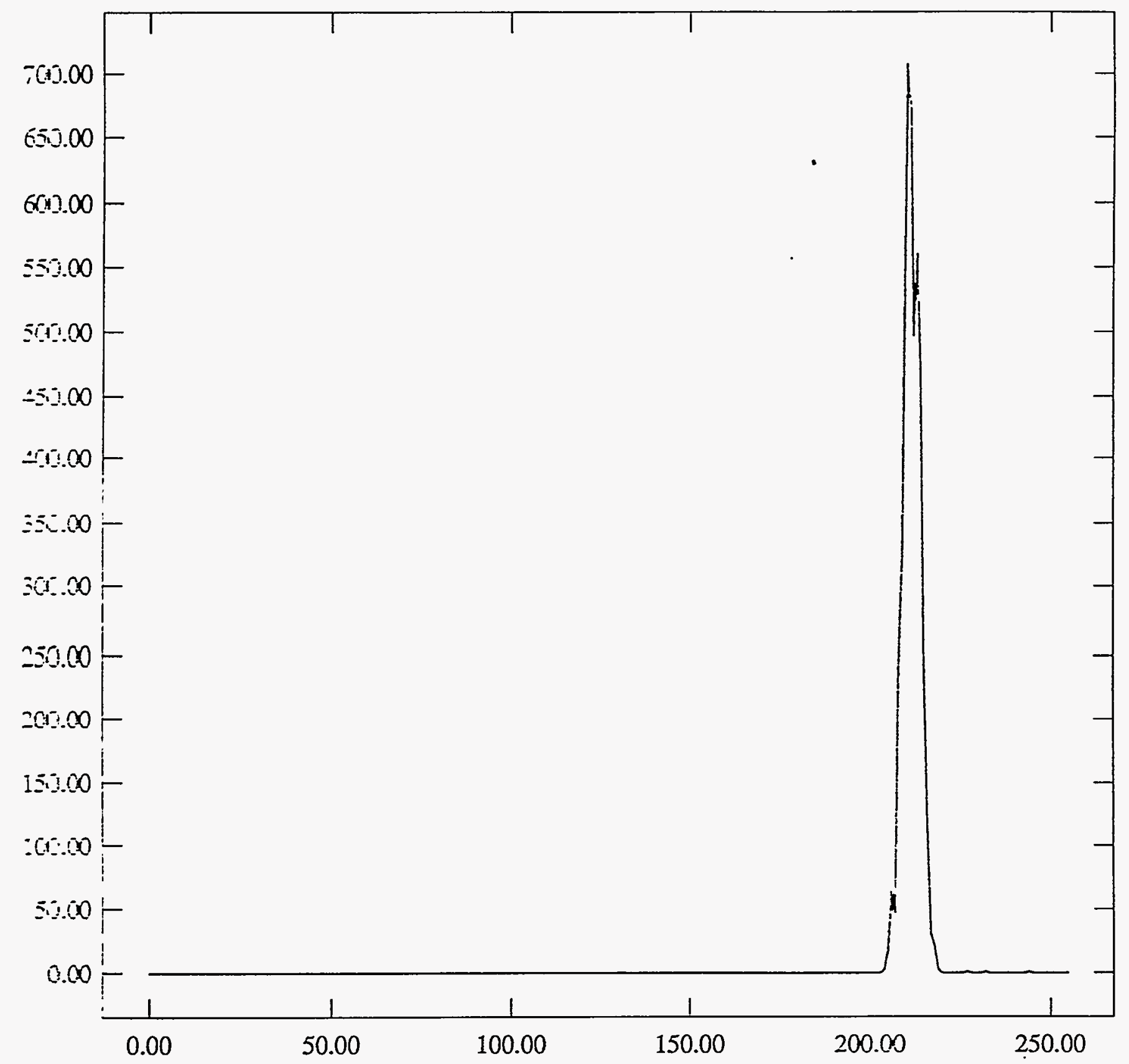


ST Camera: ST1\#04-10 30C: int_time=200ms, offset= 0, gain=4 ( 75 e/bit) Mon Mas 10 18:00:09 1993 Pixel Values Min 250 Max 255 Mean 255.0 Sigma $0.15 \times 10^{3}$

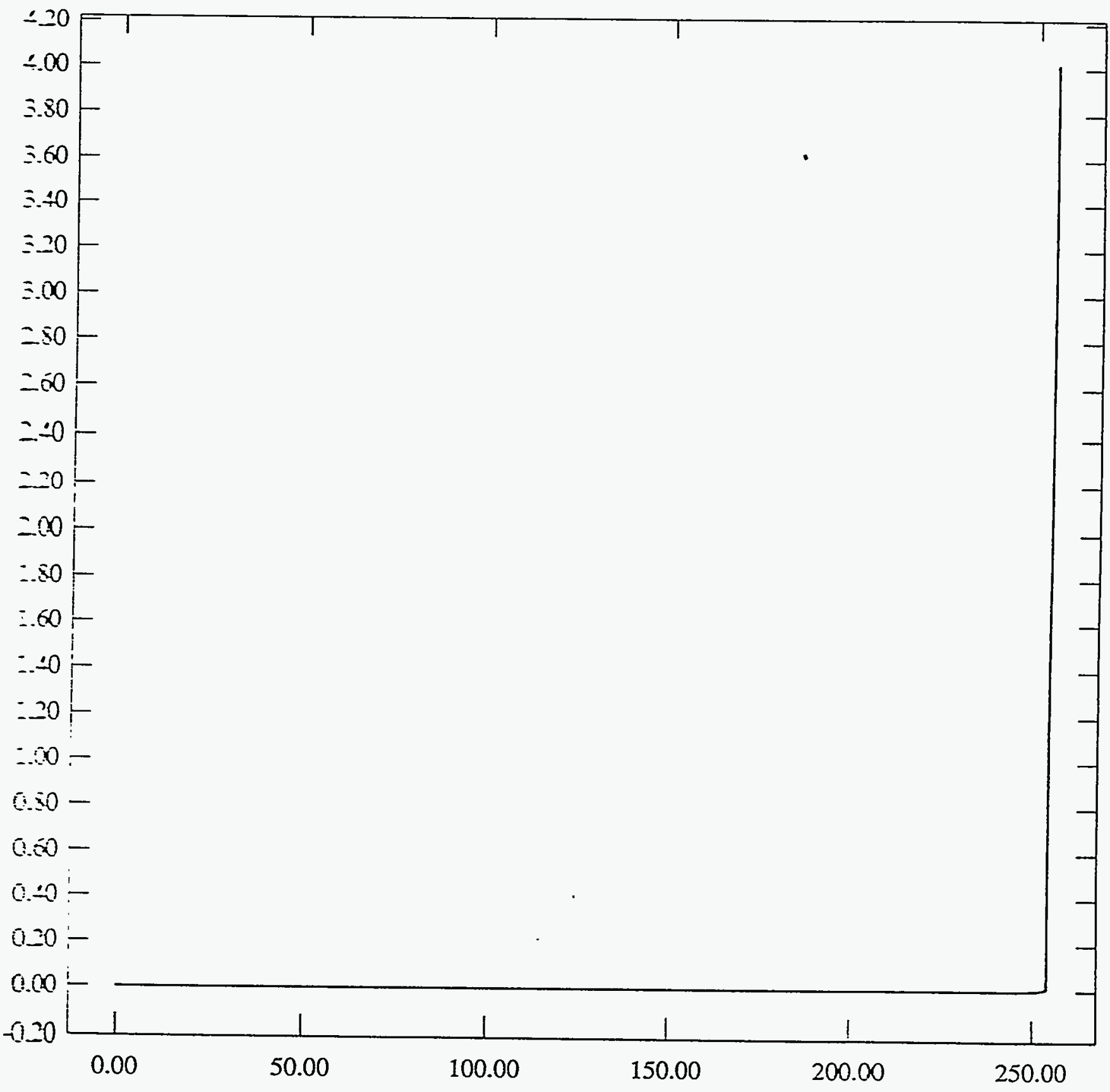




\section{ST1 \#04-10 75e/bit Mu ${ }^{\circ} \mathrm{C}$ Graph}

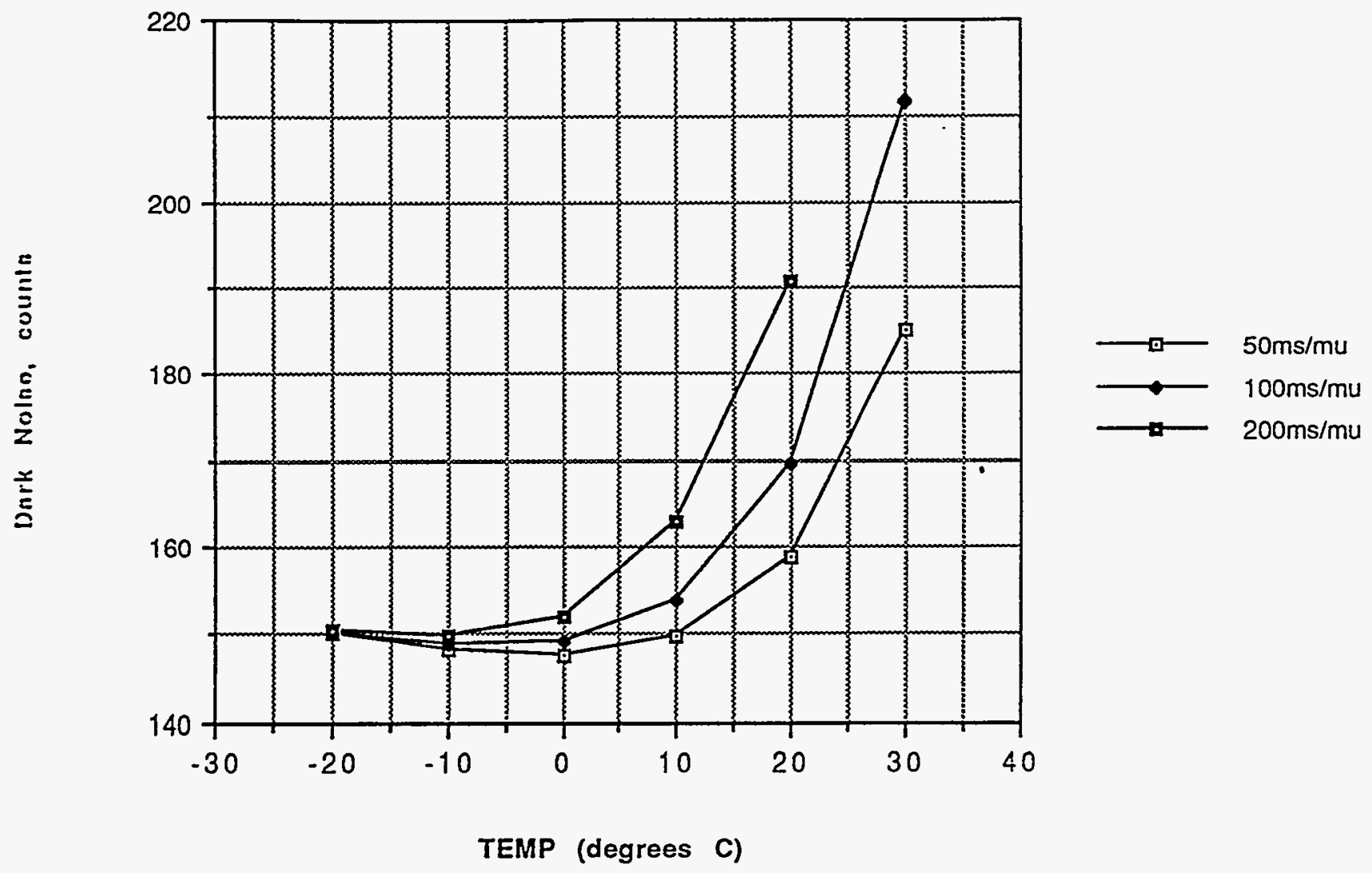

ST1\#04-10 75e/bit Sigma ${ }^{\circ} \mathrm{C}$ Graph

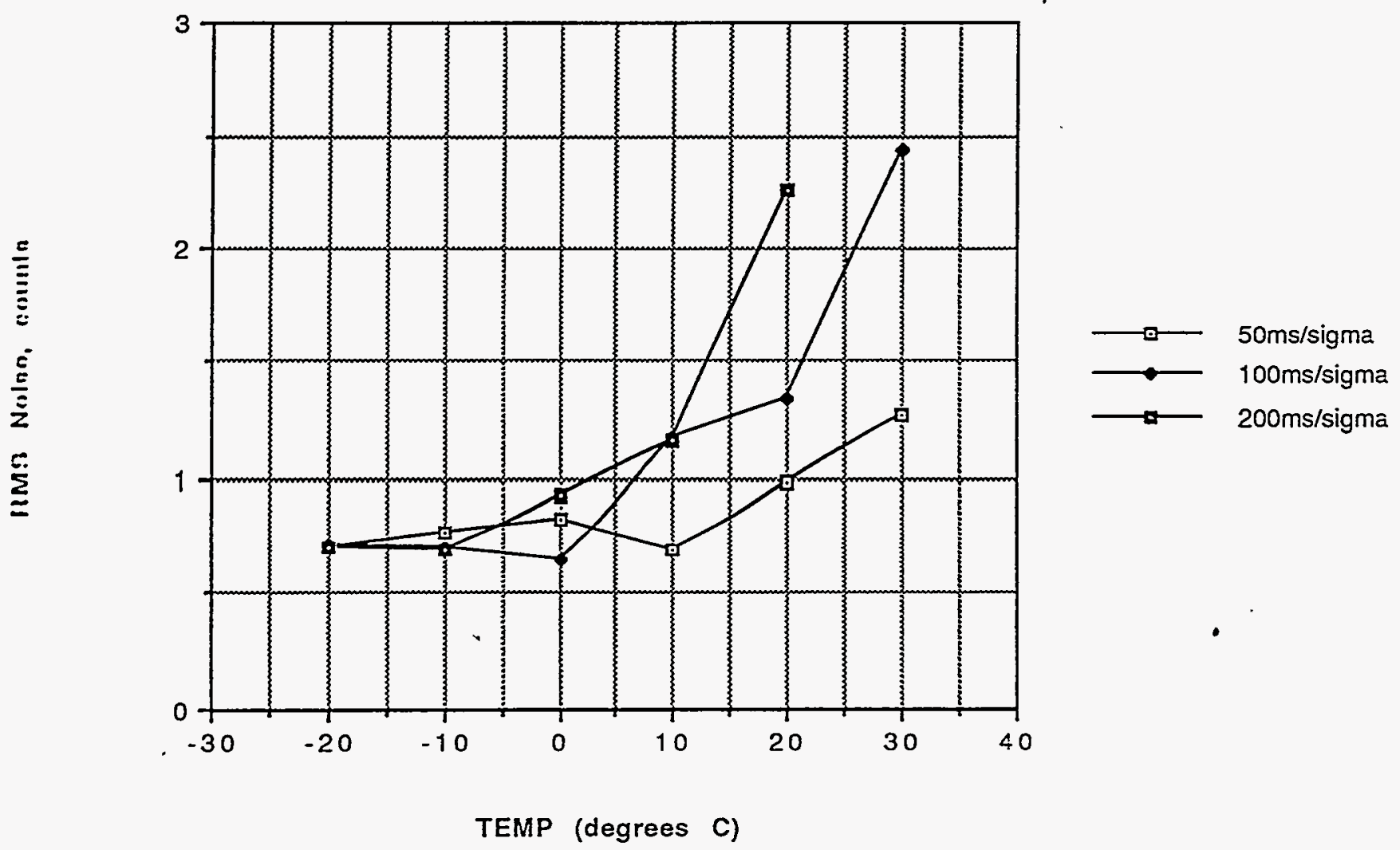




$$
\text { - }
$$




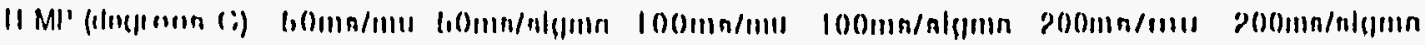

.20

$-10$

0

10

20

30

$\begin{array}{lll}\text { u(.). } & 0.63 & \text { (1).50 } \\ 79.70 & 0.59 & 79.90 \\ 79.40 & 0.66 & 80.00 \\ 80.50 & 0.52 & 82.40 \\ 84.90 & 0.55 & 89.90 \\ 97.90 & 0.85 & 111.50\end{array}$

0.62
0.51
0.45
0.55
0.78
1.23

80.70

80.40

81.50

86.90

100.80

138.40

0.51

0.52

0.55

0.70

1.13
2.14

N()II:

$5 / 10 / 93$

Flight F.0. CCD\#1

$150 \mathrm{e} / \mathrm{bit}$

$R 49=100 \Omega$ 
ST Camera: ST1\#04-10 -20C: int_time= 50ms, offset= 0, gain=2 (150 e/bit) Mon Mas 10 15:46:30 1993 Pixel Values Min 79 Max 82 Mean 80.5 Sigma $0.53 \times 10^{3}$

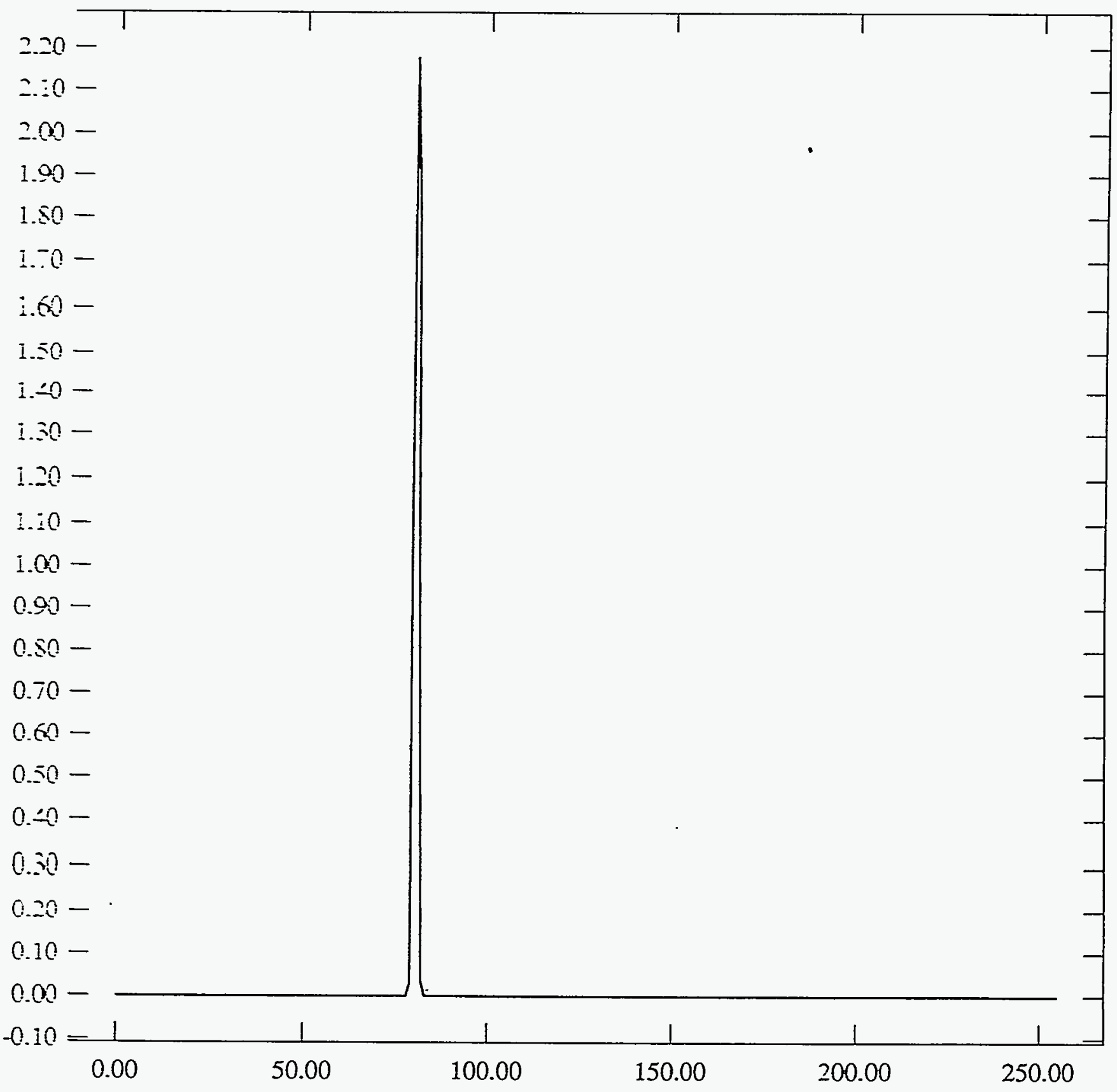


ST Camera: ST1\#04-10 -20C: int_time=100ms, offset= 0, gain=2 (150 e/bit) Mon May 10 15:47:07 1993 Pixel Values Min 79 Max 82 Mean 80.5 Sigma $0.52 \times 10^{3}$

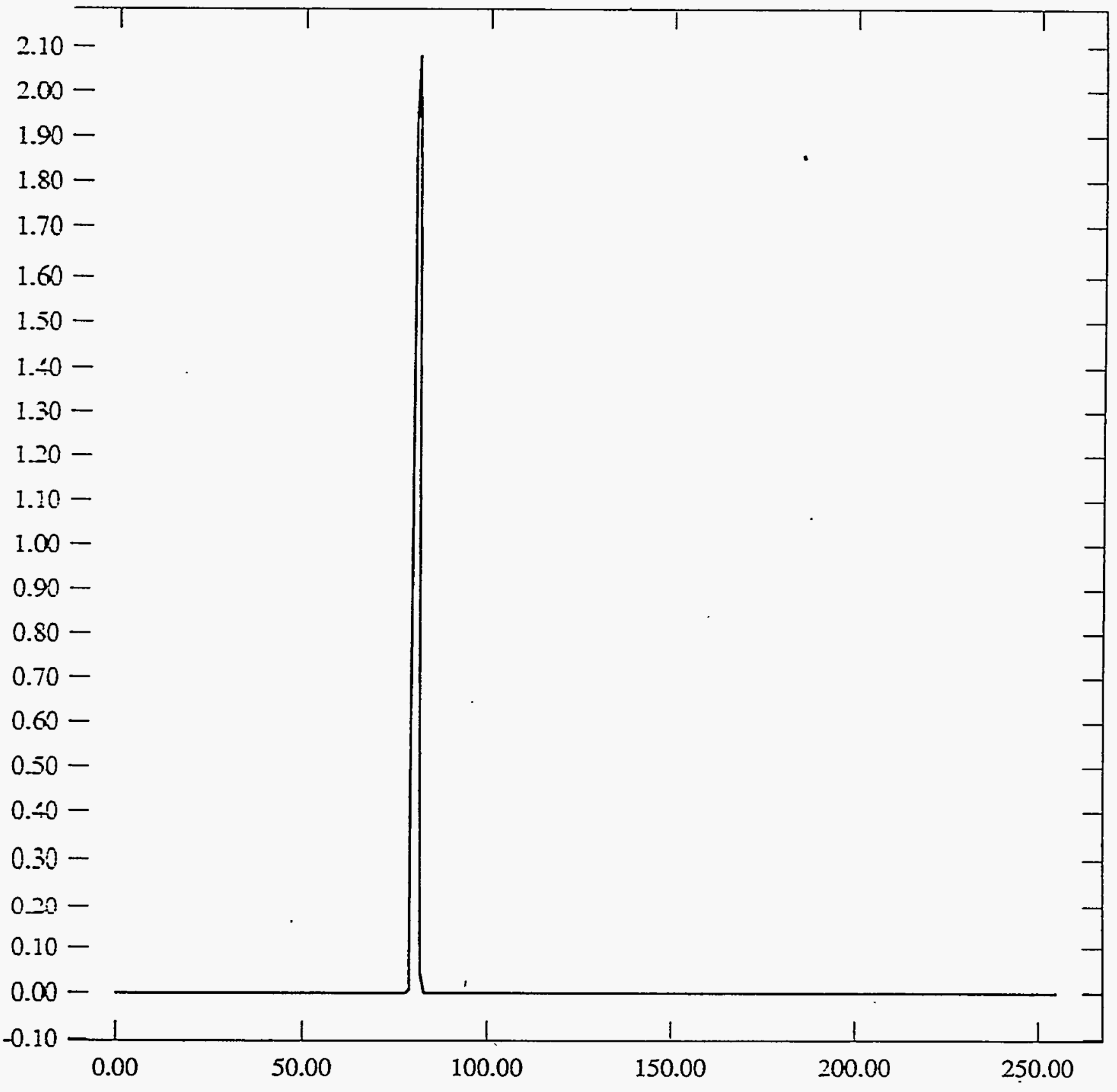


ST Camera: ST1\#04-10 -20C: int_time=200ms, offset= 0, gain=2 ( $150 \mathrm{e} / \mathrm{bit}$ ) Mon May 10 15:47:44 1993 Pixel Values Min 79 Max 82 Mean 80.7 Sigma $0.51 \times 10^{3}$

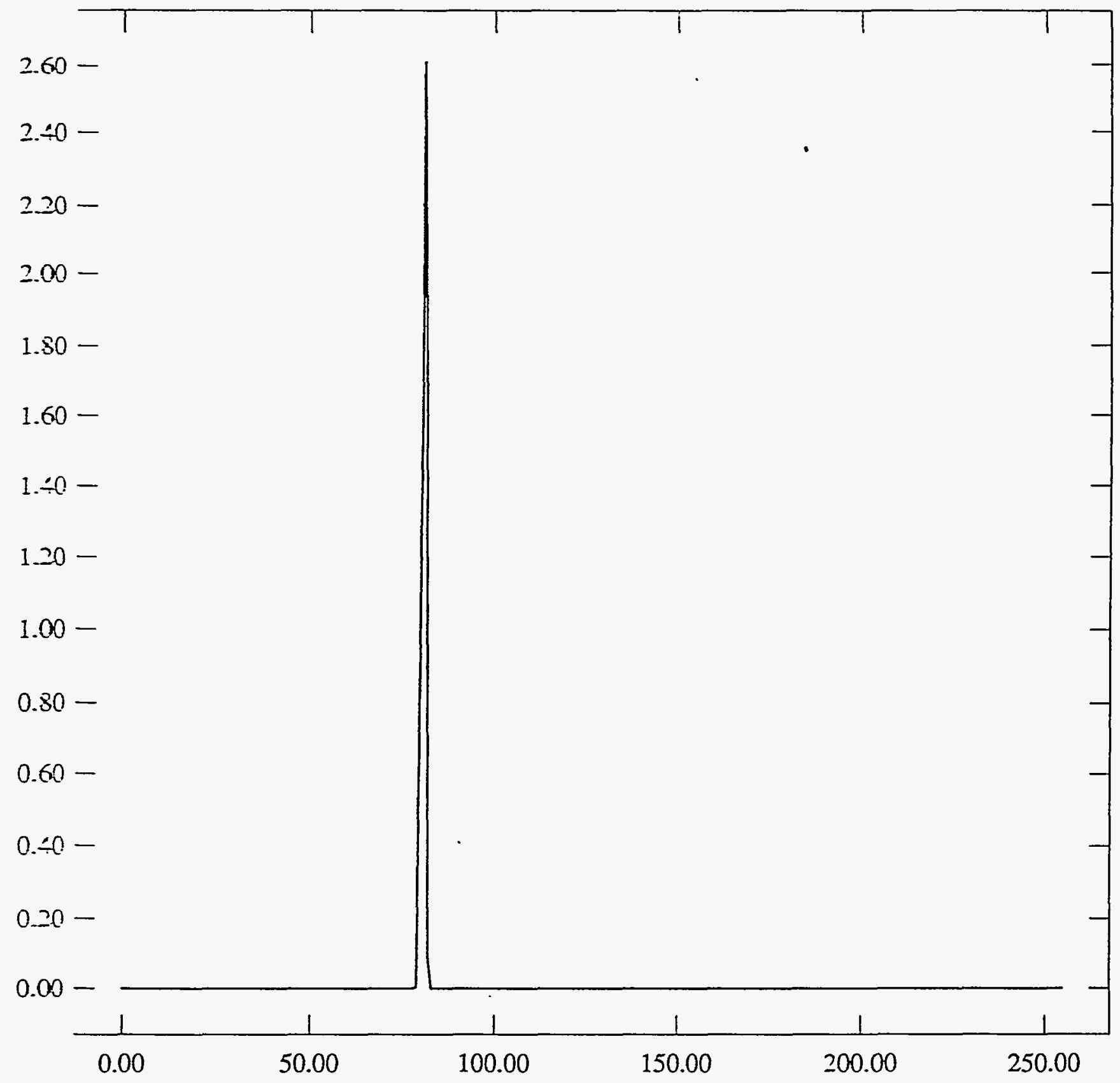


ST Camera: ST1\#04-10 -10C: int_time= 50ms, offset= 0, gain=2 (150 e/bit) Mon May 10 16:11:10 1993

Pixel Values Min 77 Max 81 Mean 79.7 Sigma $0.59 \times 10^{3}$

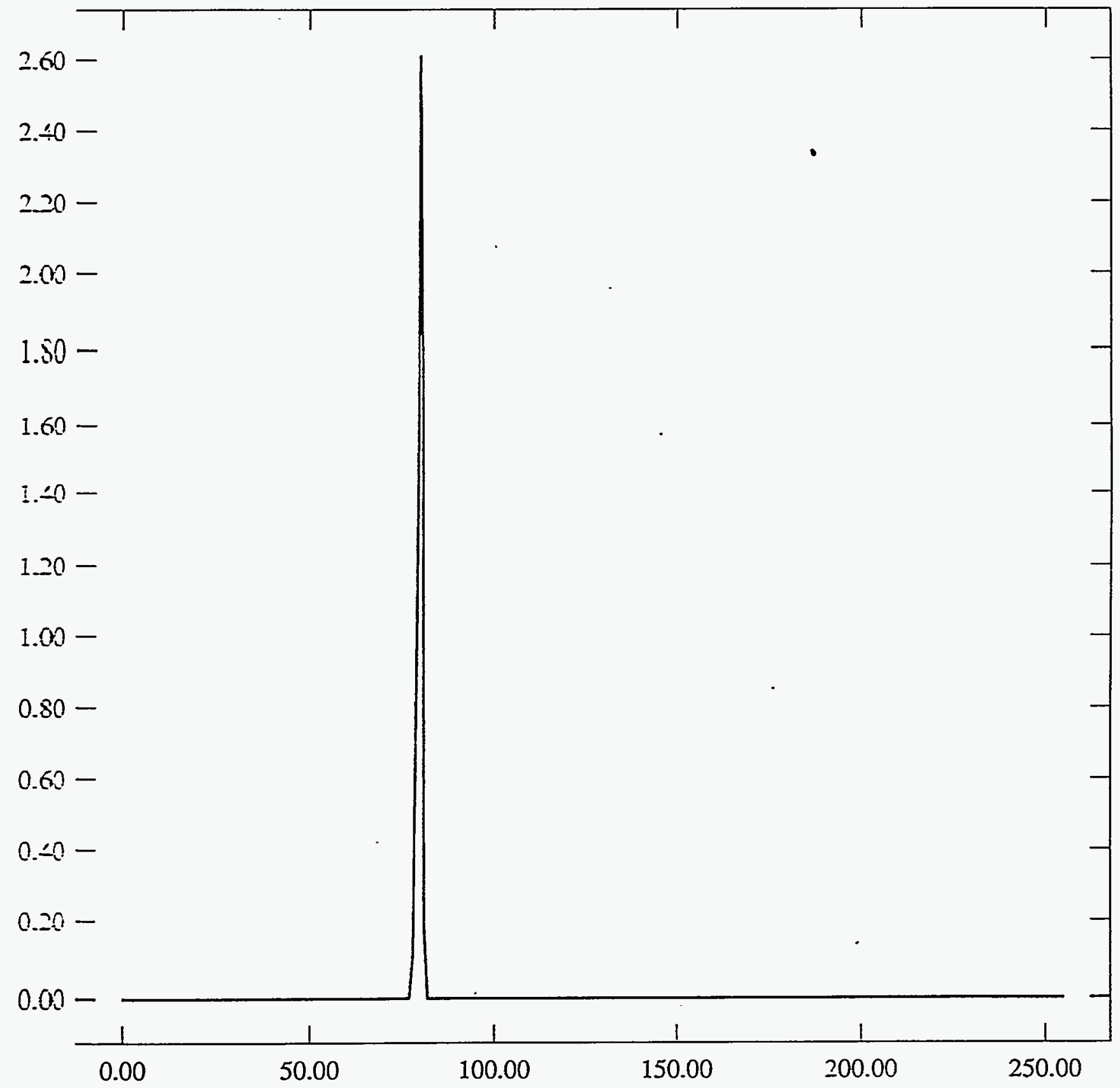


ST Camera: ST1\#04-10 -10C: int_time=100ms, offset= 0, gain=2 (150 e/bit) Mon May 10 16:11:40 1993 Pixel Values Min 78 Max 81 Mean 79.9 Sigma $0.51 \times 10^{3}$

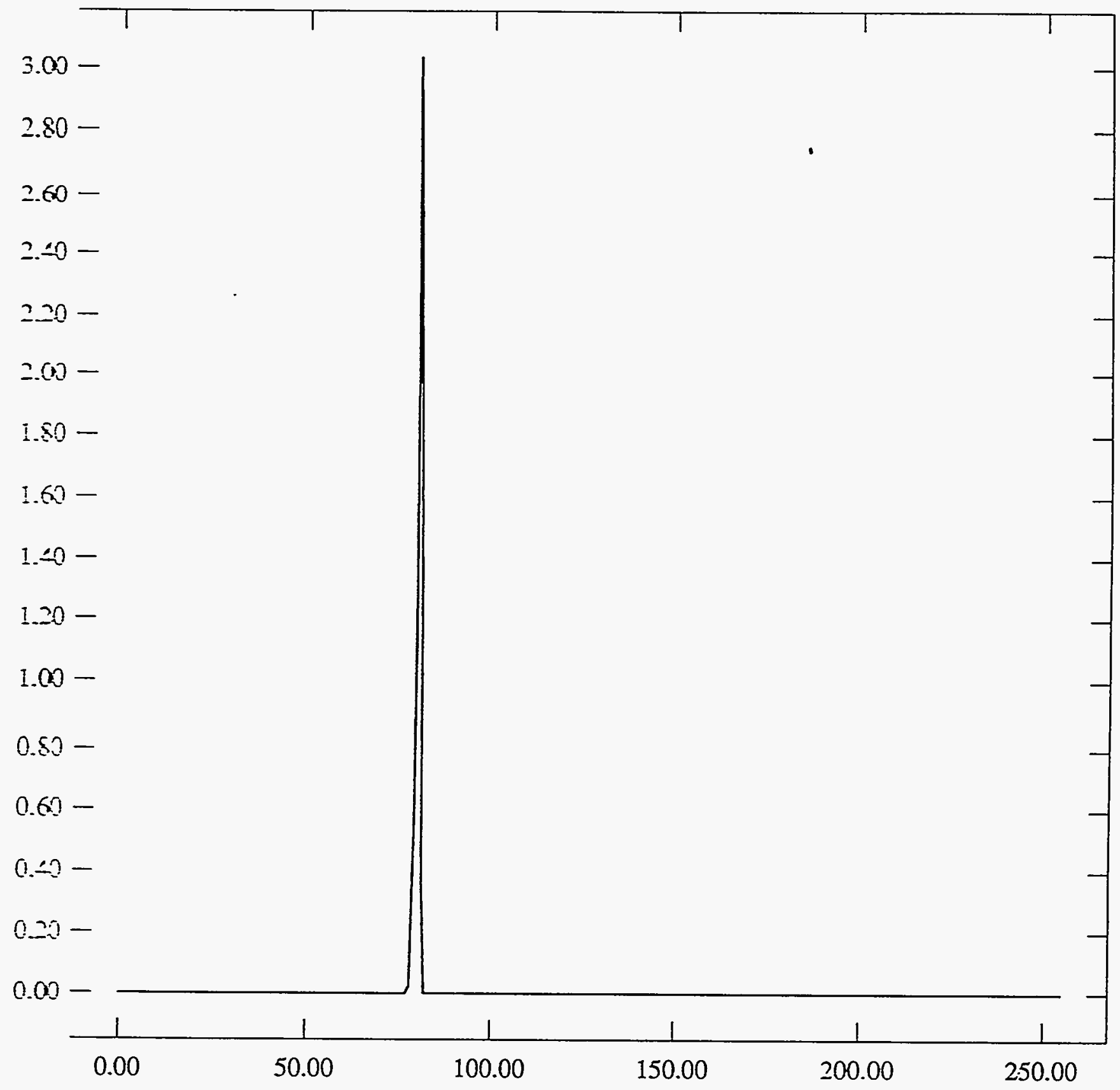


. $8 *$

ST Camera: ST1\#04-10 -10C: int_time=200ms, offset= 0, gain=2 ( $150 \mathrm{e} / \mathrm{bit}$ ) Mon May 10 16:12:11 1993 Pixel Values Min 79 Max 82 Mean 80.4 Sigma $0.52 \times 10^{3}$

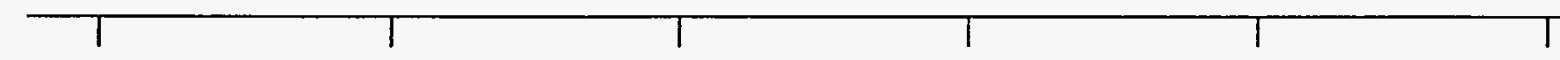

$2.0-0-$

$220-$

$2.00-$

$1.80-$

$1.60-$

$1 . \div 0-$

i.2x-

$1.00-$

$0.80-$

$0.60-$

$0 . \div-$

$0.25-$

$0.00-$

\begin{tabular}{cccccc}
1 & 1 & 1 & 1 & 1 & 1 \\
\hline 0.00 & 50.00 & 100.00 & 150.00 & 200.00 & 250.00
\end{tabular}


ST Camera: ST1\#04-10 0C: int_time=50ms, offset= 0, gain=2 (150 e/bit) Mon May $1016: 41: 231993$ Pixel Values Min 78 Max 81 Mean 79.4 Sigma $0.66 \times 10^{3}$

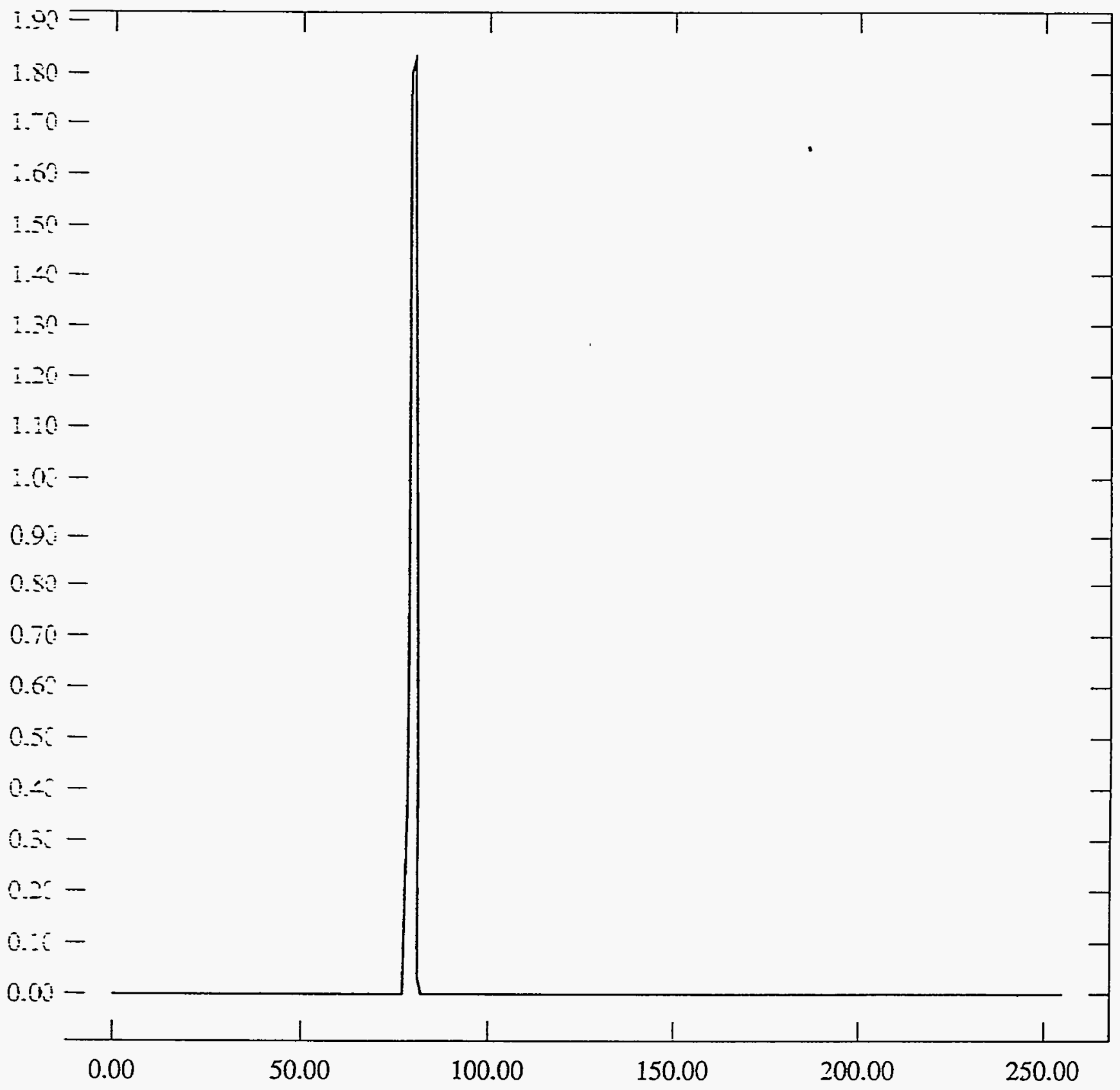




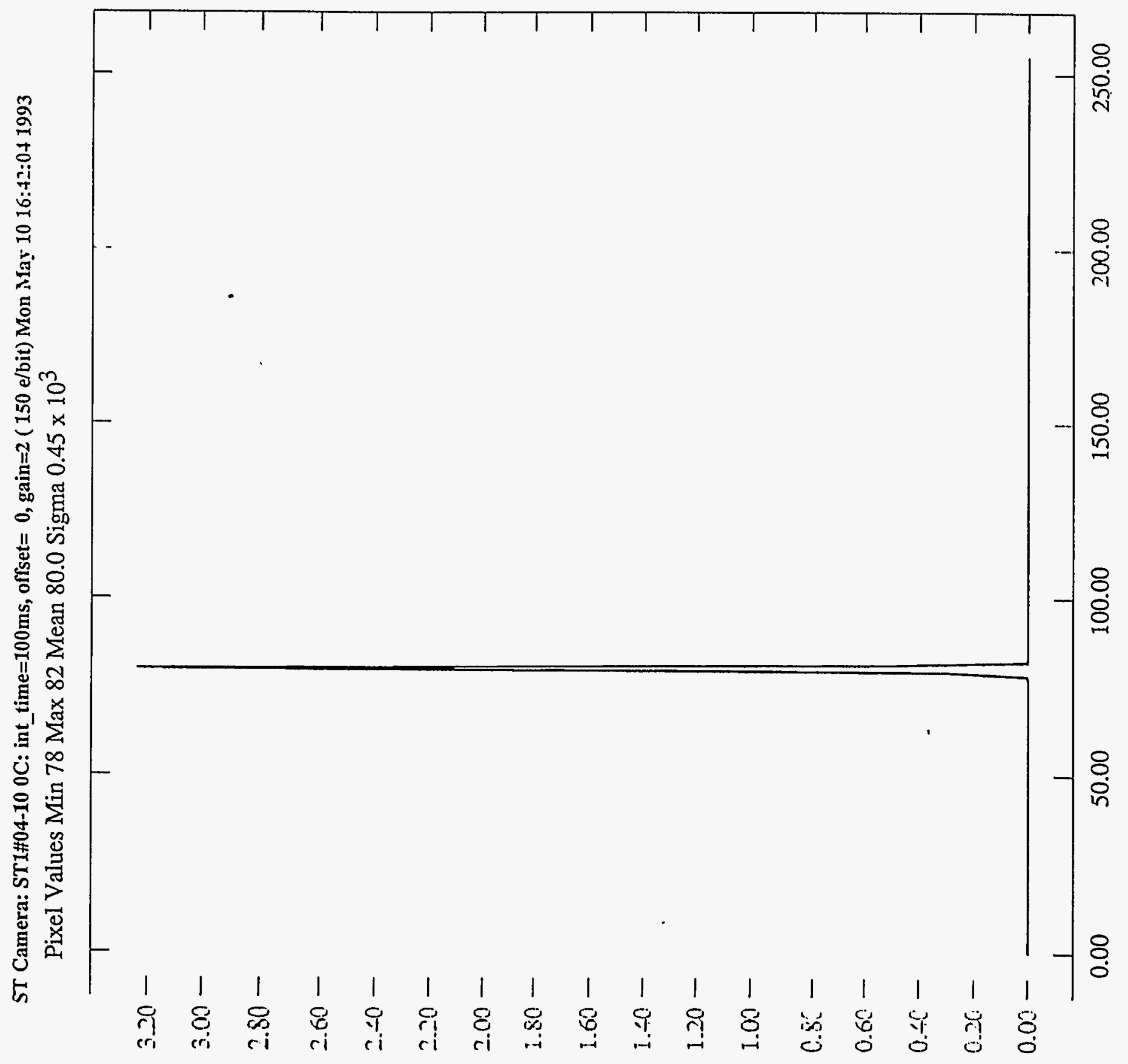


ST Camera: ST1\#04-10 0C: int_time=200ms, offset= 0, gain=2 (150 e/bit) Mon May 10 16:42:49 1993 Pixel Values Min 80 Max 85 Mean 81.5 Sigma $0.55 \times 10^{3}$

$$
2: 0-
$$

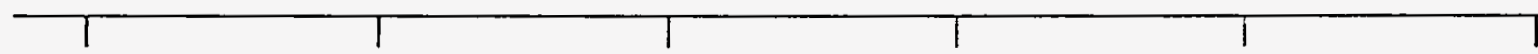

$200-$

$1.90-$

$1.30-$

$1.70-$

$1.60-$

$1.50-$

$1 . \div 0-$

$1.30-$

$1.20-$

i.:0 -

$1.00-$

$0.90-$

$0.80-$

$0.70-$

$0.60-$

$0.50-$

$0.40-$

$0.30-$

$0.20-$

$0.20-$

$0.00-$

$-0.10$

$\frac{1}{0.00}$

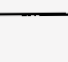


ST Camera: ST1\#04-10 10C: int_time= 50ms, offset= 0, gain=2 (150 e/bit) Mon May 10 17:04:43 1993

Pixel Values Min 79 Max 82 Mean 80.5 Sigma $0.52 \times 10^{3}$

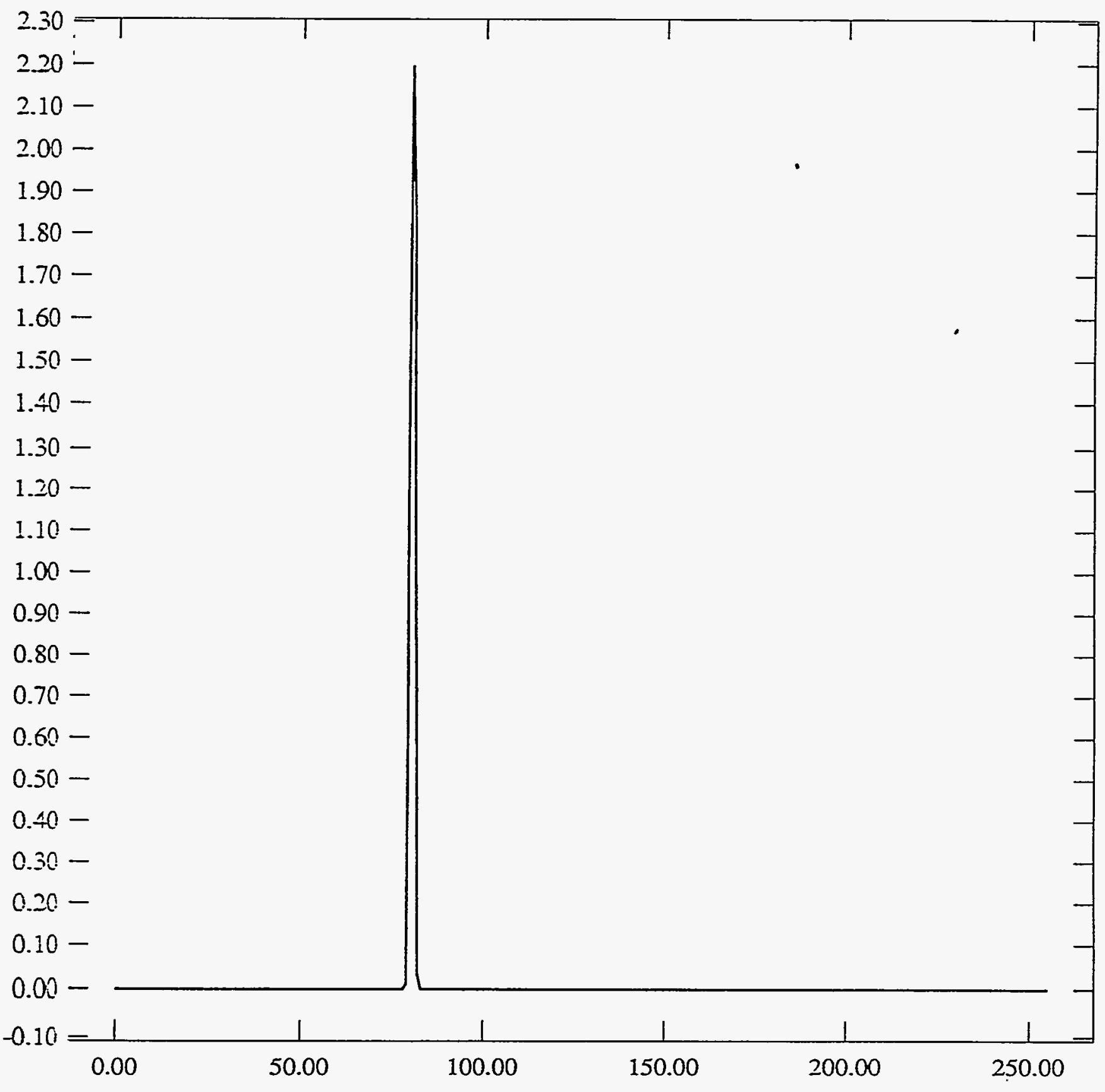


ST Camera: ST1\#04-10 10C: int_time=100ms, offset= 0, gain=2 (150 e/bit) Mon May 10 17:05:13 1993 Pixel Values Min 81 Max 86 Mean 82.4 Sigma $0.55 \times 10^{3}$

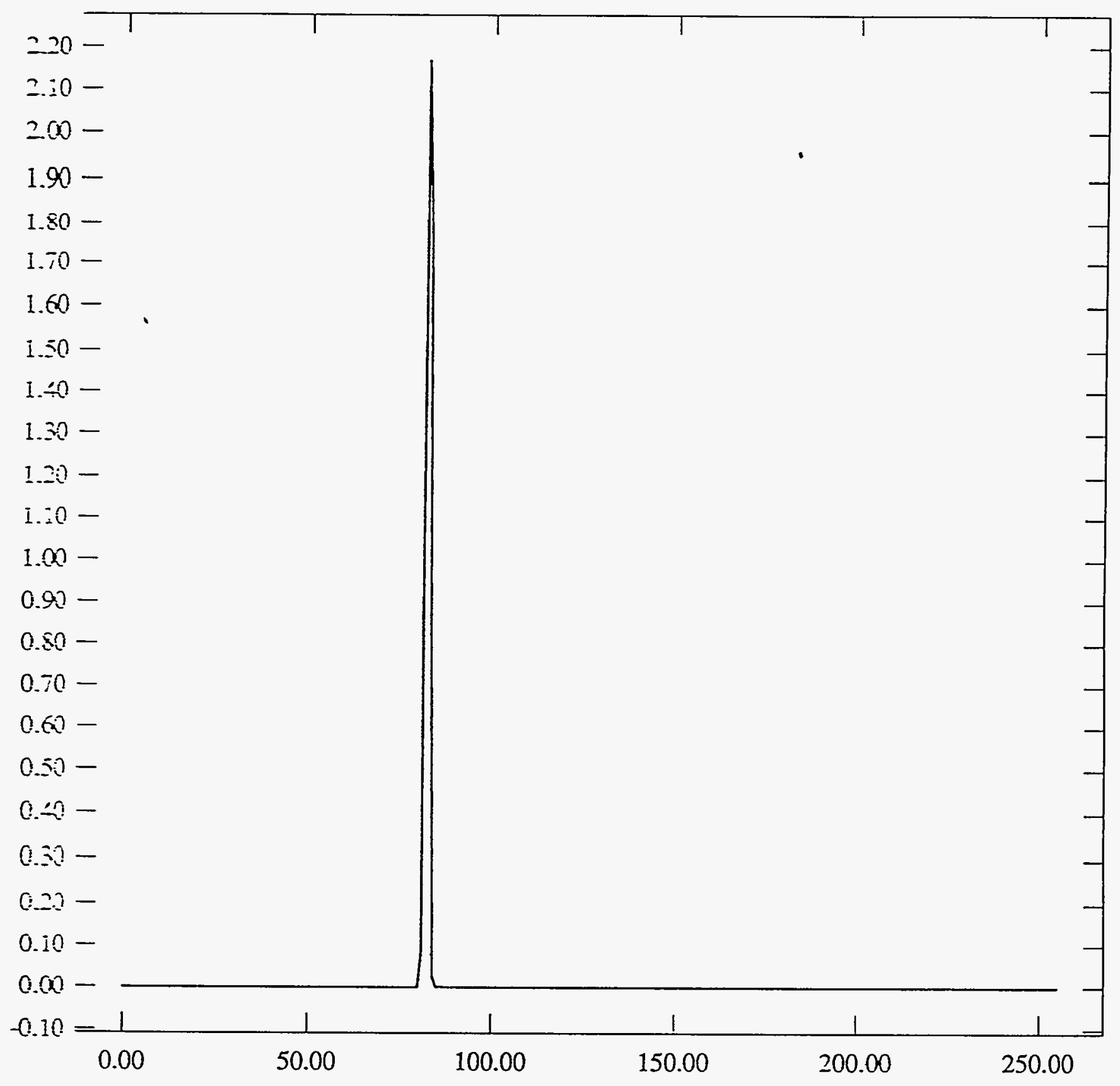


ST Camera: ST1\#04-10 10C: int_time=200ms, offset= 0, gain=2 (150 e/bit) Mon May 10 17:06:24 1993 Pixel Values Min 85 Max 95 Mean 86.9 Sigma $0.70 \times 10^{3}$

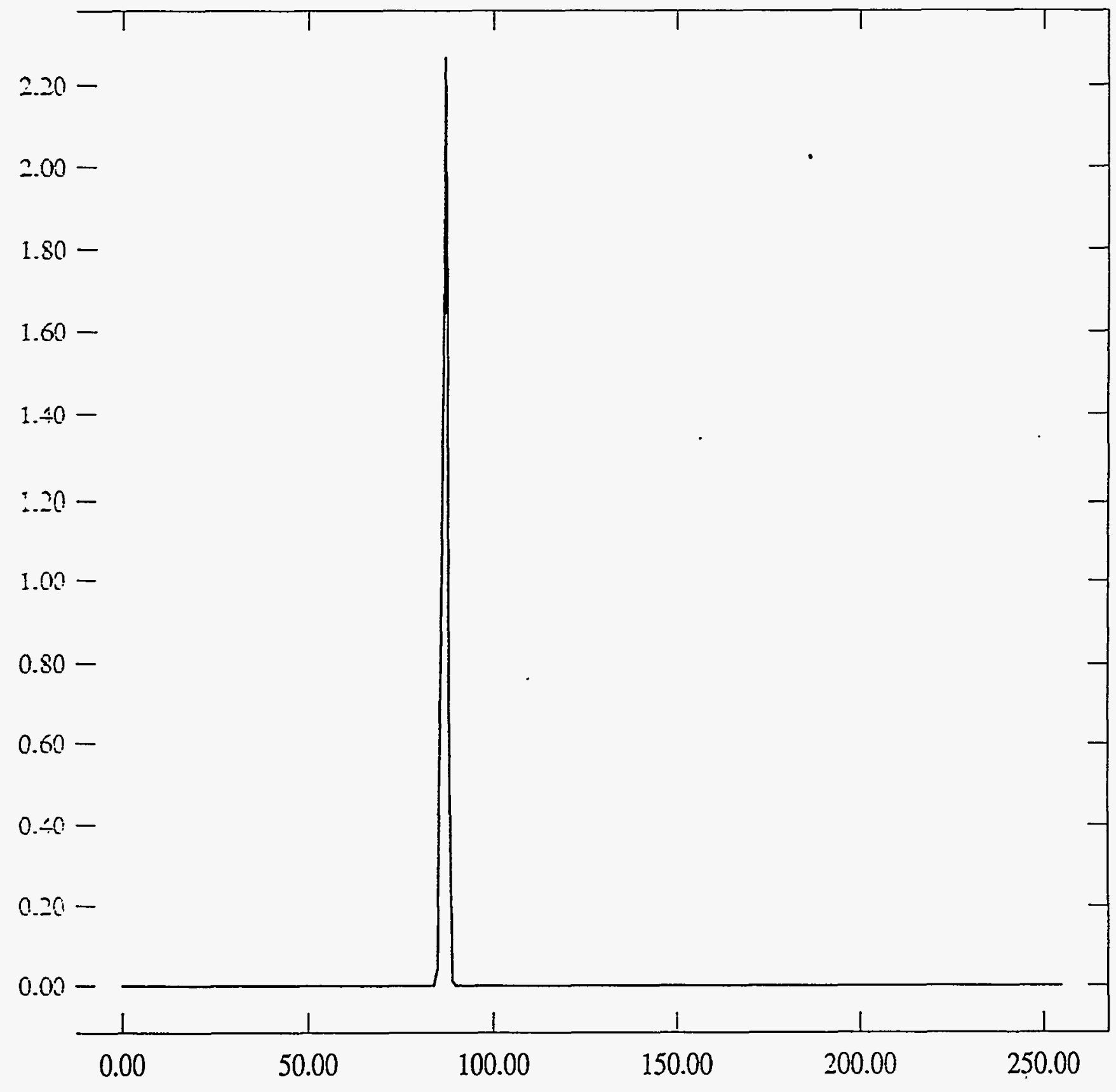


ST Camera: ST1\#04-10 20C: int_time= 50ms, offset= 0, gain=2 (150 e/bit) Mon May 10 1 ::23:53 1993 Pixel Values Min 83 Max 89 Mean 84.9 Sigma $0.55 \times 10^{3}$

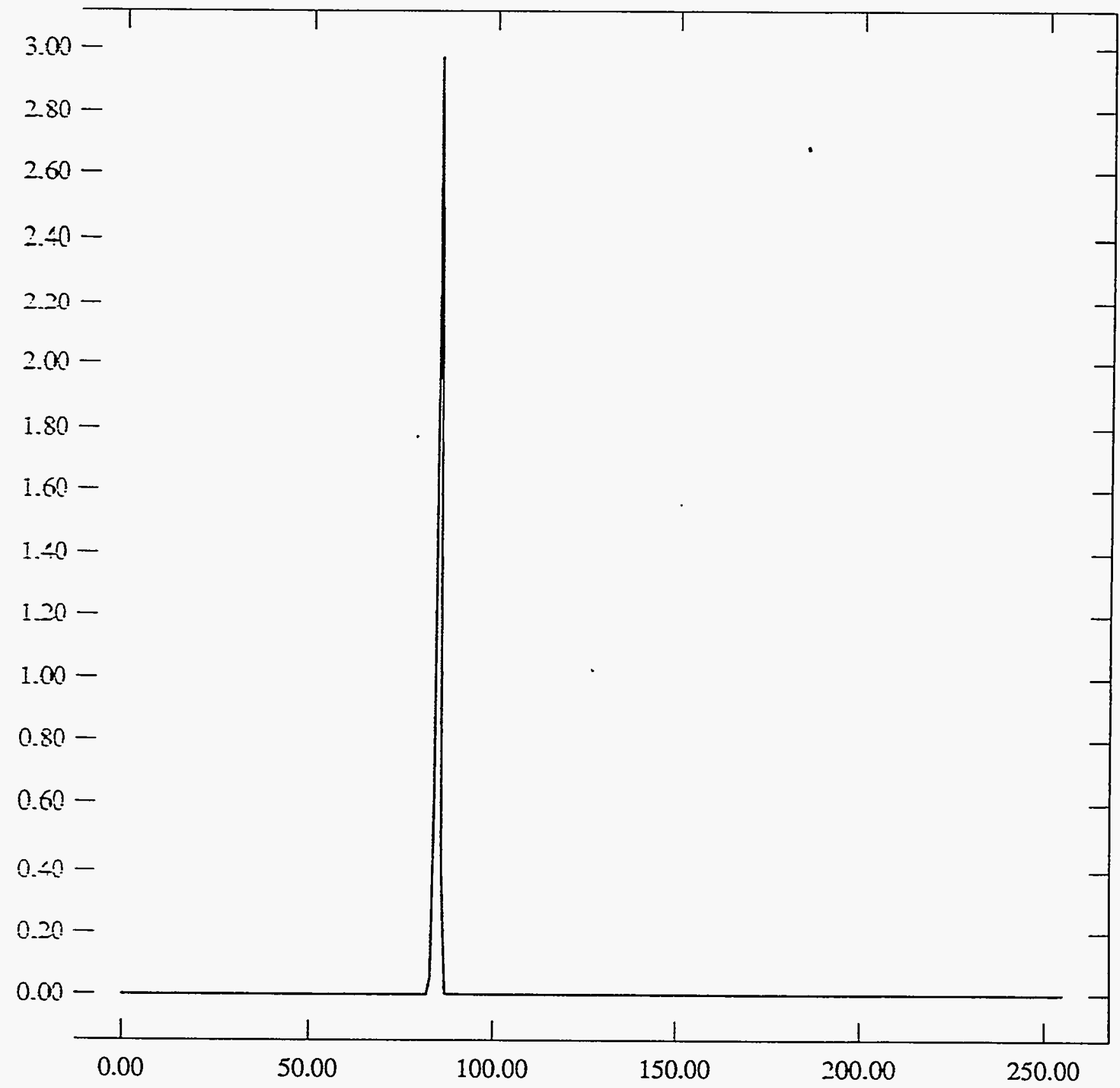


ST Camera: ST1\#04-10 20C: int_time=100ms, offset= 0, gain=2 ( $150 \mathrm{e} / \mathrm{bit}$ ) Mon May 10 17:24:21 1993

Pixel Values Min 88 Max 98 Mean 89.9 Sigma $0.78 \times 10^{3}$

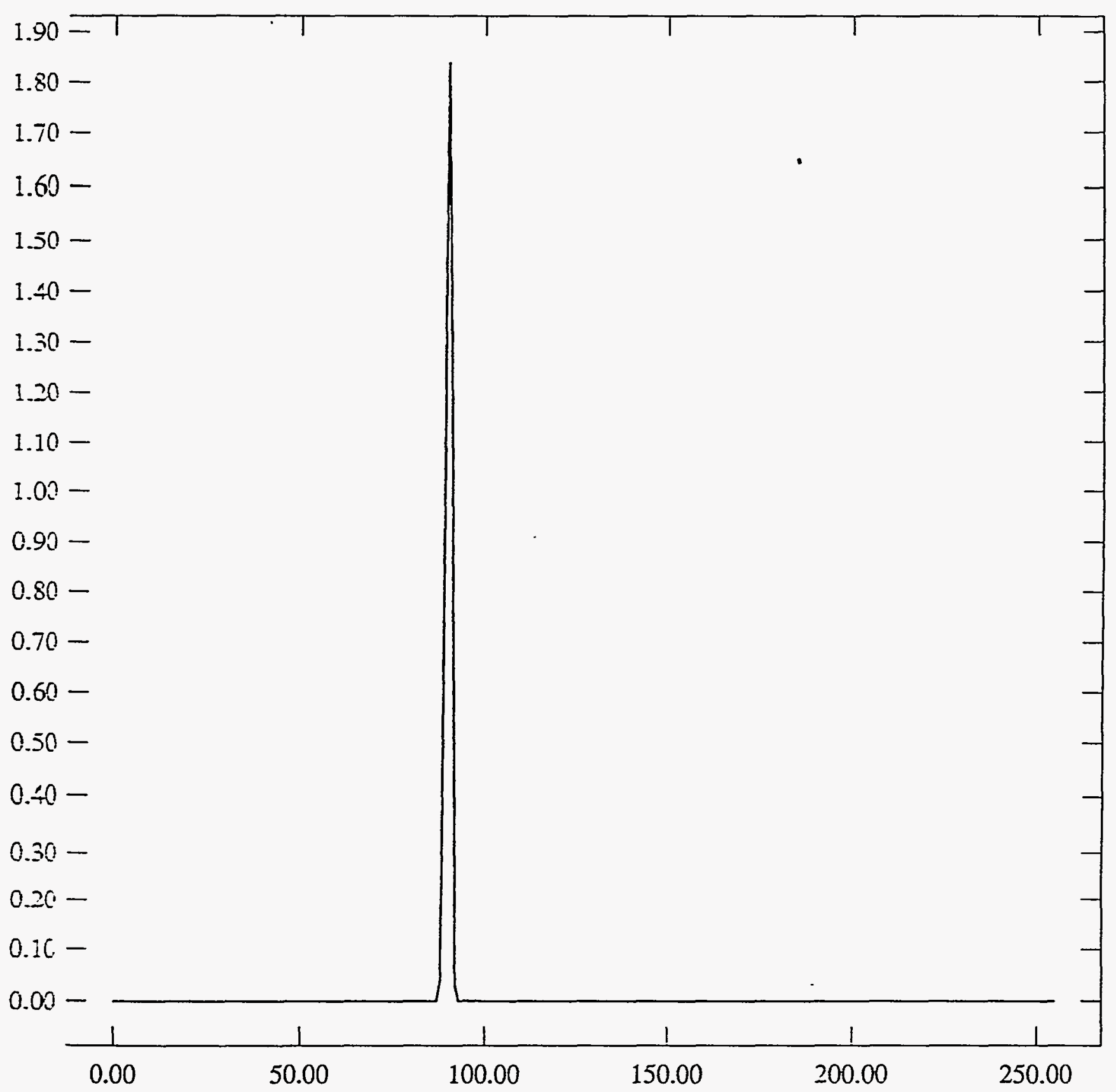


ST Camera: ST1\#04-10 20C: int_time=200ms, offset= 0, gain=2 (150 e/bit) Mon May 10 17:24:52 1993 Pixel Values Min 97 Max 120 Mean 100.8 Sigma $1.13 \times 10^{3}$

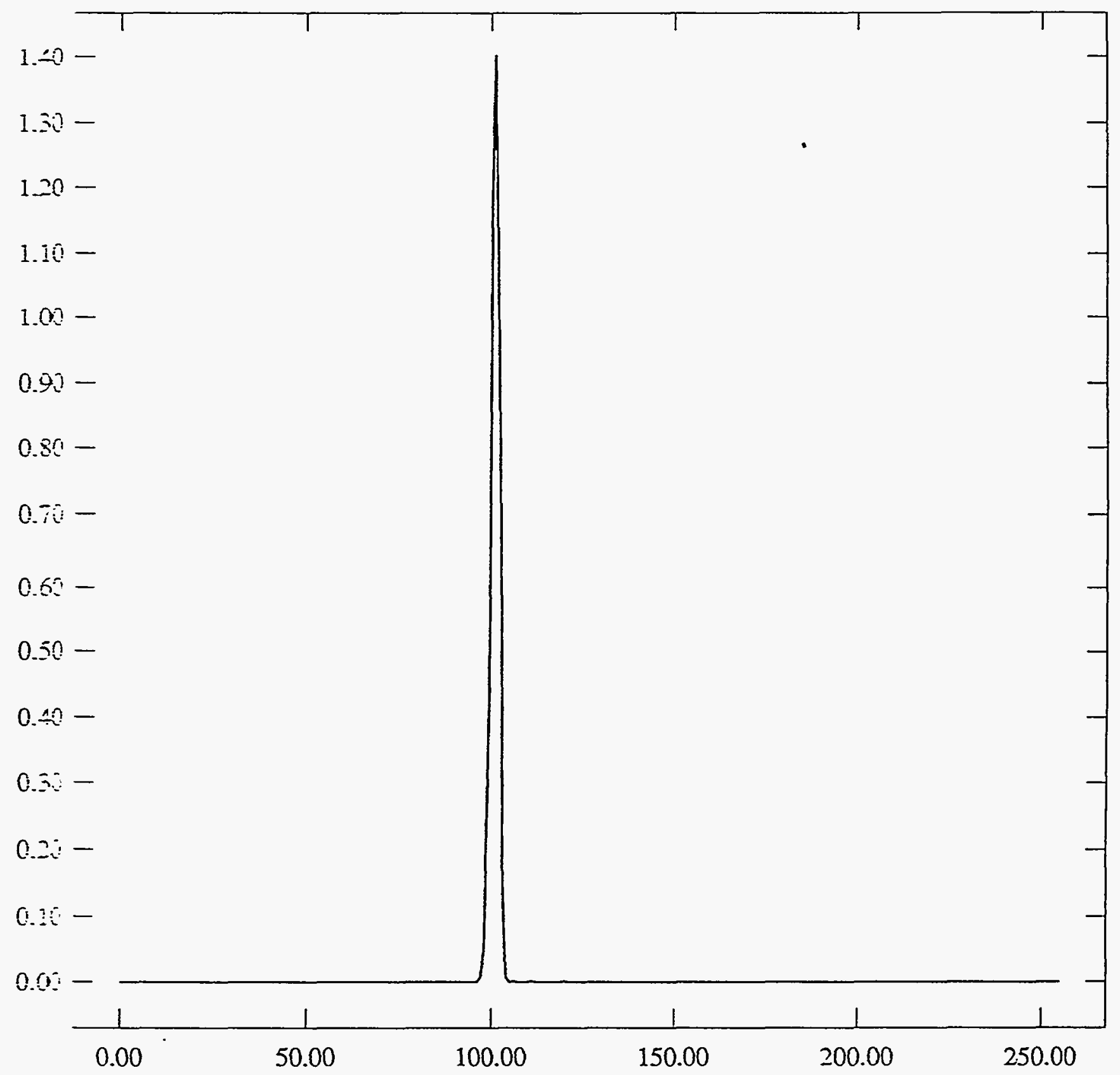


ST Camera: ST1\#04-10 30C: int_time= 50ms, offset= 0, gain=2 (150 e/bit) Mon May 10 17:56:00 1993

Pixel Values Min 96 Max 105 Mean 97.9 Sigma $0.85 \times 10^{3}$

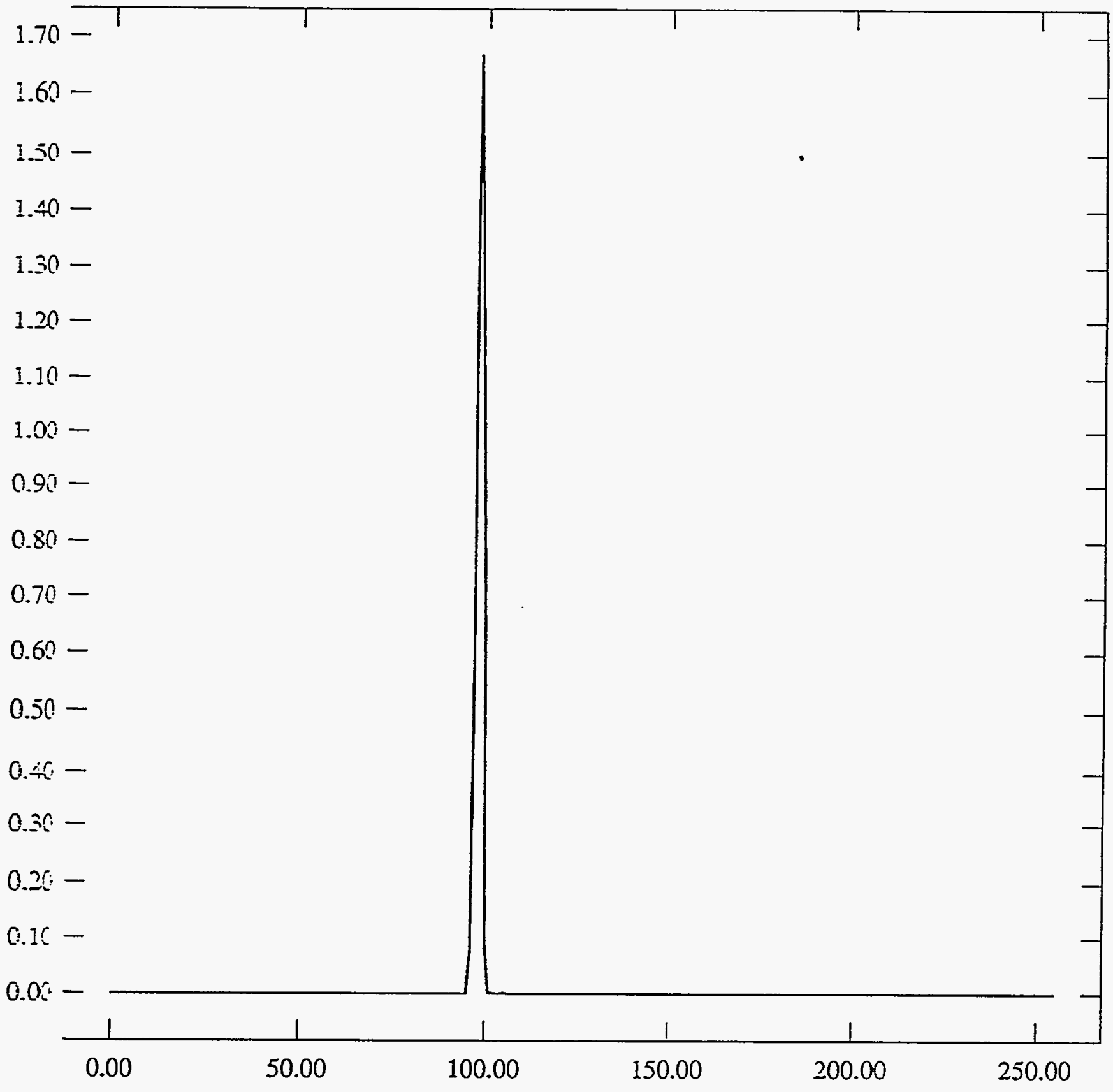


ST Camera: ST1\#04-10 30C: int_time=100ms, offset= 0, gain=2 (150 e/bit) Mon May 10 17:57:16 1993 Pixel Values Min 108 Max 128 Mean 111.5 Sigma $1.23 \times 10^{3}$

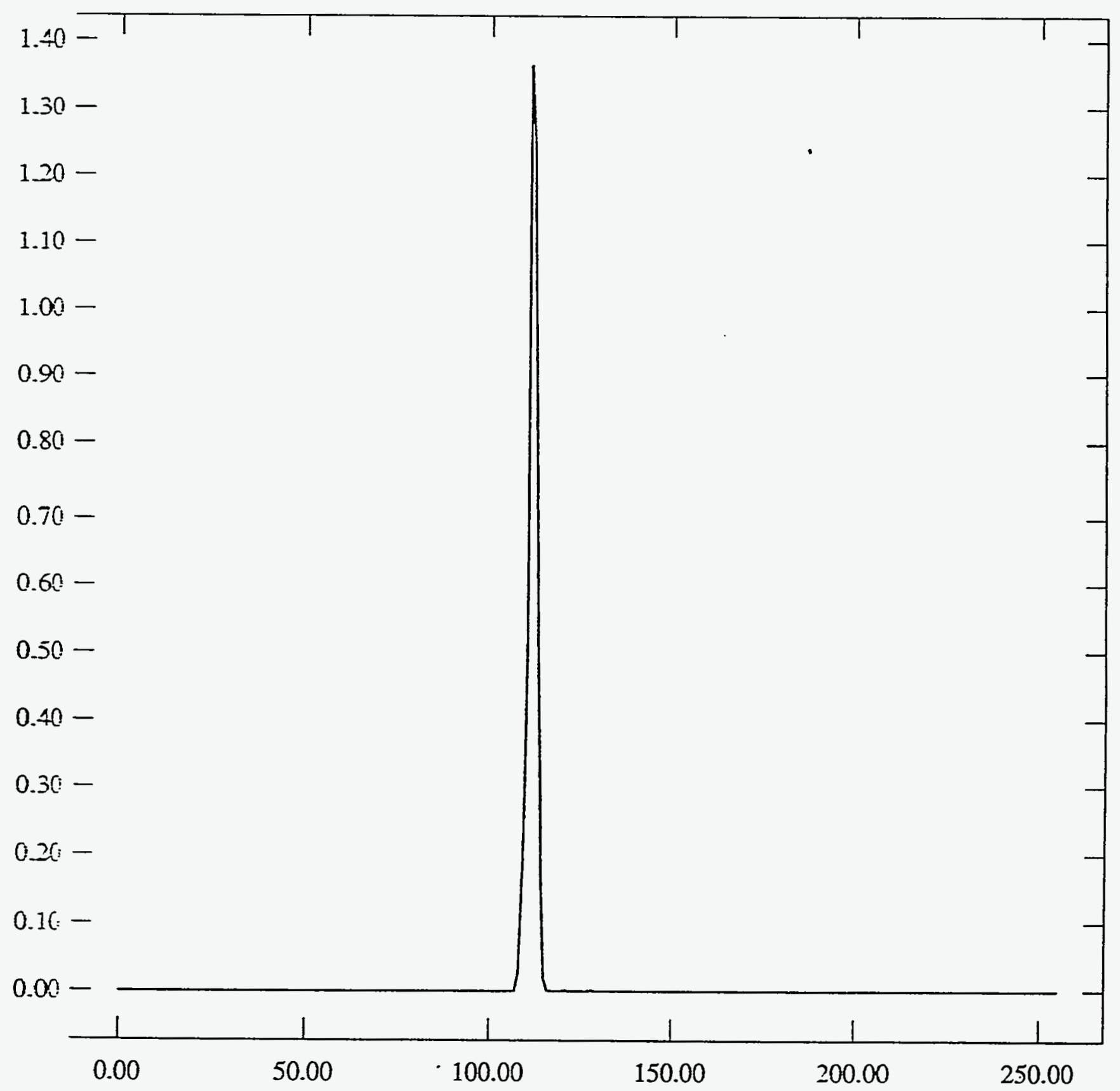


ST Camera: ST1\#04-10 30C: int_time=200ms, offset= 0, gain=2 (150 e/bit) Mon May 10 17:ミs:02 1993 Pixel Vejues Min 131 Max 172 Mean 138.4 Sigma 2.14

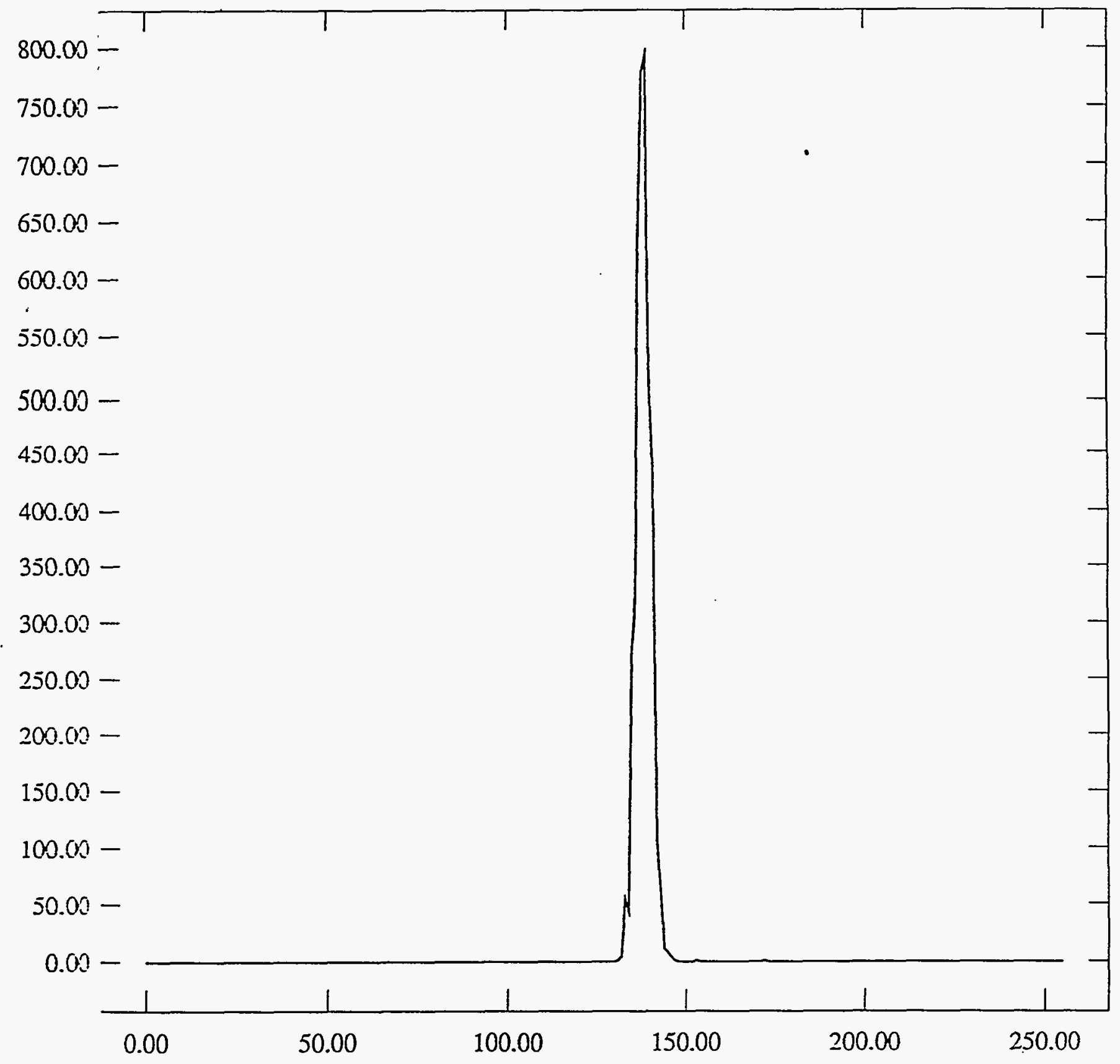




\section{ST1 \#04-10 150e/bit $\mathrm{Mu}{ }^{\circ} \mathrm{C}$ Graph}

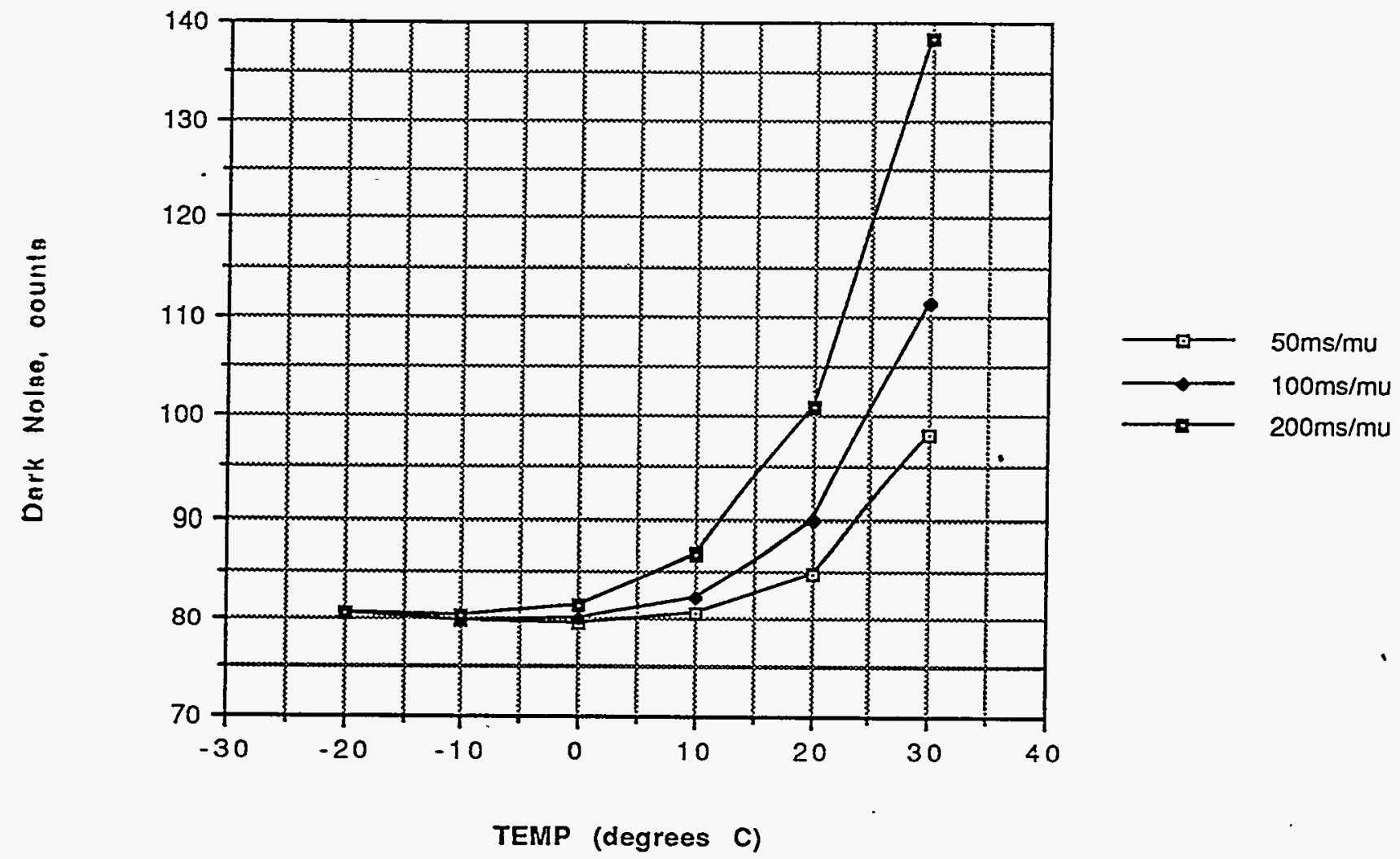

ST1 \#04-10 150e/bit Sigma ${ }^{\circ} \mathrm{C}$ Graph

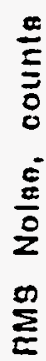

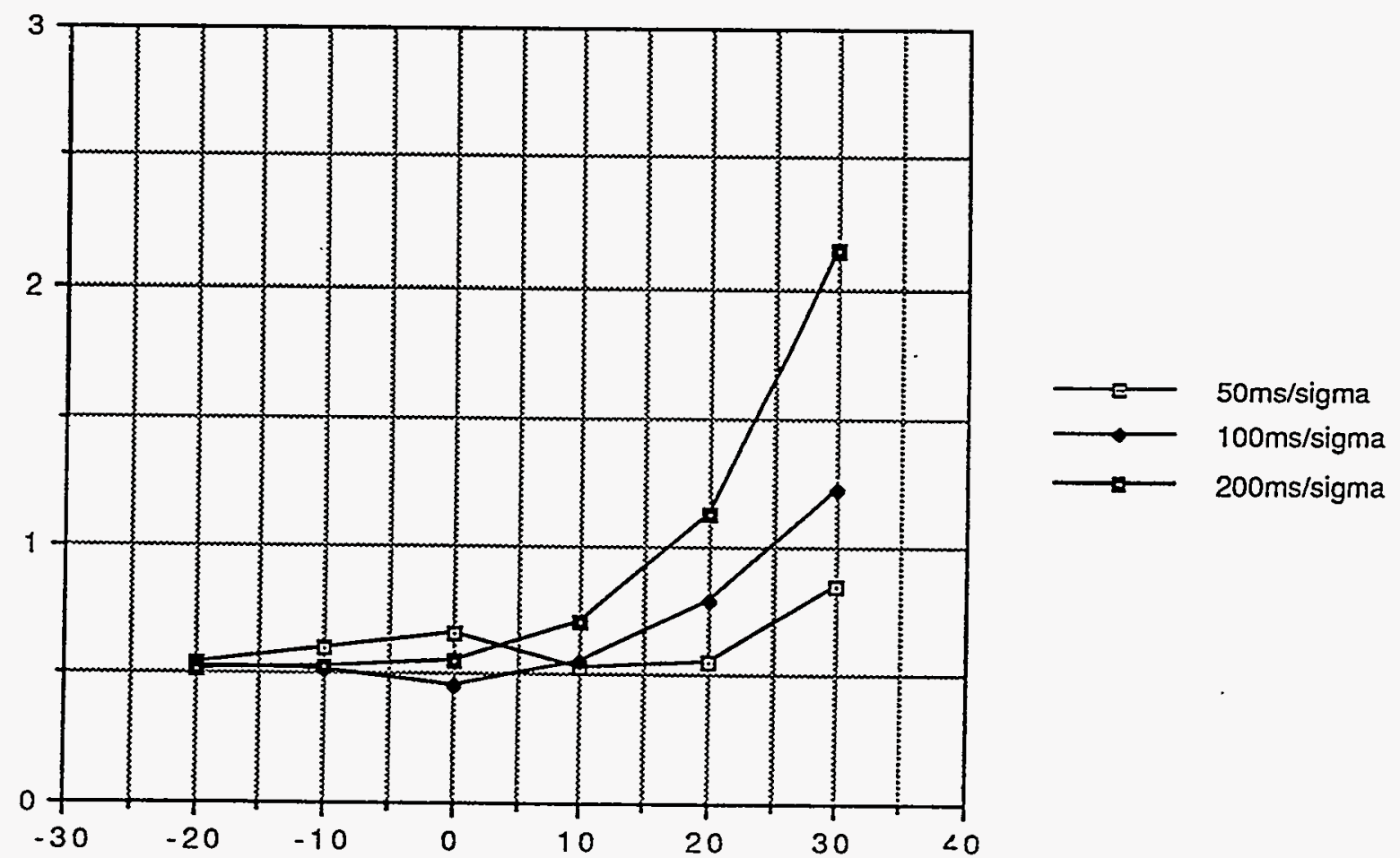

TEMP (degrees C) 


\section{Thermal Test}

This test :2quires the SUN Datacube and its image processing capabilities, an environmental chamber with limit rate controls, and a timer.

\section{Carefully Insert The Flight CCD Into The Test Board. Check Its Orientation}

\subsection{Thermal Test Setup}

Secure the carrier mounted Actel board in a PC board holder and place the holder in the environmental chamber. Care should be taken so that the board does not short to chamber walls.

Attach the camera cable harness to the Actel board via a feed-through hole. Wrap a piece of foam around the cable harness. Squeeze the wrapped harness into the feed-through so that the hole is sealed and there is no strain on the inside/outside cabling.

Place an opaque cover over the CCD.

Power-up and confirm a functioning camera/acquisition system by capturing a frame. At room temperature this should resemble the dark measurement histogram acquired in SECTION 11.

Turn-off the camera board under test

Seal the environmental chamber.

Set chamber temperature ramp rate at $2^{\circ} \mathrm{C} / \mathrm{min}$.

Set chamber temperature deviation limit to $2^{\circ} \mathrm{C}$.

Set chamber soak time to 20 minutes.

Start the thermal sequence at $-20^{\circ} \mathrm{C}$ or at a ${ }^{\circ} \mathrm{C}$ determined by your requester. 


\subsection{Thermal Measurement Acquisition}

The Guide to running hspcube, C1-S1-002 explains a Fast 9 image capture. This program module automatically grabs a $50 \mathrm{~ms}, 100 \mathrm{~ms}$ and $200 \mathrm{~ms}$ integration time images at all three gains. It then does a histogram of those images using a region of interest specified by the use-

Repeat Fast 9 completing your needed temperature range.

Fill in the Table below.

\begin{tabular}{|c|c|c|c|c|c|c|}
\hline & $50 \mathrm{~ms}$ & $50 \mathrm{~ms}$ & $100 \mathrm{~ms}$ & $100 \mathrm{~ms}$ & $200 \mathrm{~ms}$ & $200 \mathrm{~ms}$ \\
\hline Temm & $\mathrm{Mu}$ & Sigma & Mu & Sigma & Mu & Sigma \\
\hline \hline$-20^{\circ} \mathrm{C}$ & & & & & & \\
\hline$-10^{\circ} \mathrm{C}$ & & & & & & \\
\hline $0^{\circ} \mathrm{C}$ & & & & & & \\
\hline $10^{\circ} \mathrm{C}$ & & & & & & \\
\hline $20^{\circ} \mathrm{C}$ & & & & & & \\
\hline $30^{\circ} \mathrm{C}$ & & & & & & \\
\hline
\end{tabular}




\subsection{Thermal Data and Graphs}

Graphing techniques will vary with software. However, if you use Cricketgraph, use the "line" griph format.

Plot Mu rs Temperaure as below:

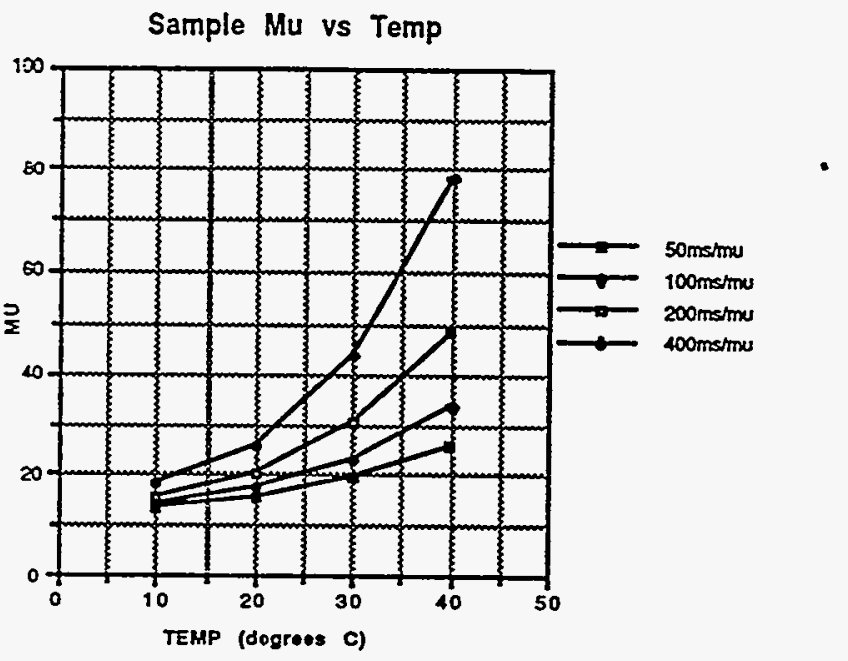

Plot Sigma vs Temperature like this:

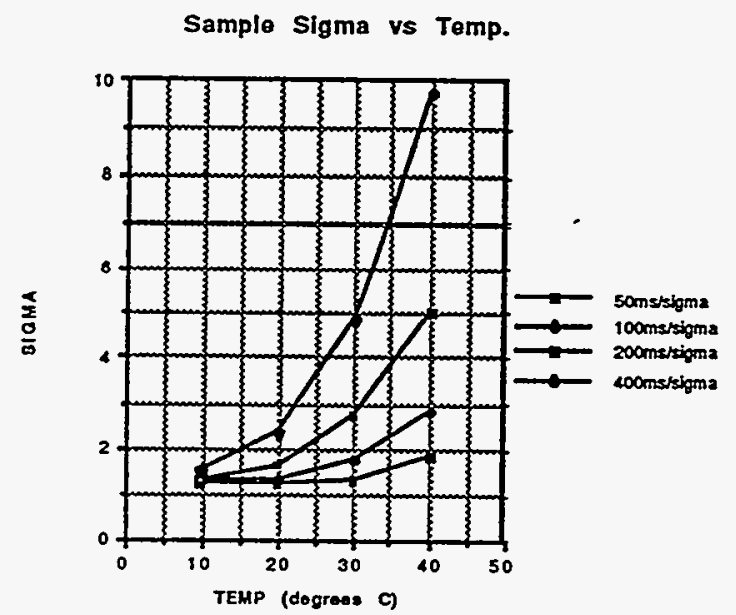

SN\# By $\frac{5^{4}-10}{\text { initials }}$ Date $\frac{5 / 10 / 93}{\text { passed }}$

Remember to attach graphs and associated data to test procedure! (a document protector is advised) 
13. Flat Field Linearity Test

This test requires the use of the SUN Datacube and its image processing capabilities, a TV Optoline- Model K-4000 with neutral density(ND) filters ranging from 0.8 to 2.8 , and a resolution chart for focusing.

\subsection{Linearity Test Setup}

Using alcohol and $Q$-ips clean the installed CCD.

Verify a properly connected camera acquisition system by acquiring an image. Always use a connectcr saver.

Turn on the test fixture.

Put the SLN Datacube in the Acquire mode, see Guide to Running hspcube-C1-S1-002.

Install a total 0.8ND filter and test pattern in the T.V. Optoliner.

Adjust the camera board so that the test pattern image is centered and focused on the CCD.

NOTE: Once focused, neither the camera nor the optoliner can be moved. Allow the T.V. Optoliner and camera to warm up under continuous operation for $\approx 1$ hour before proceeding. Keeping the camera's environmental temperature constant and allowing a long warm up requires only one background histogram for linearity computation.

Remove the test pattern and replace with a flat field image.

With $0.8 \mathrm{ND}$ filtering installed in the optoliner, adjust the T.V. Optoliner lamp voltage so that you get a Mu count between 235 and 250 .

\subsection{Linearity Measurement Acquisition}

Use the SUN Datacube "Acquire and build histogram Sequence " to capture a frame and process a defined region of interest. Then obtain its histogram. 


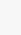


TEMP (degrees C) $50 \mathrm{~ms} / \mathrm{mu} 50 \mathrm{~ms} / \mathrm{sigma} 100 \mathrm{~ms} / \mathrm{mu} 100 \mathrm{~ms} / \mathrm{sigma} 200 \mathrm{~ms} / \mathrm{mu} 200 \mathrm{~ms} / \mathrm{sigma}$

$\begin{array}{ll}40.70 & 0.44 \\ 40.00 & 0.36 \\ 39.40 & 0.50 \\ 40.00 & 0.36 \\ 41.70 & 0.46 \\ 47.40 & 0.55\end{array}$

40.80

40.00

39.80

40.90

43.80

52.90
0.42
0.35
0.42
0.27
0.13
0.64
40.80

40.30

40.60

42.70

13.50

64.10
0.41

0.47

0.50

0.48

0.58

1.09
NOTES:

$5 / 10 / 93$

Flight F.0. CCD\#1

$3500 / \mathrm{bit}$

$1140-10011$ 
ST Camera: ST1 ${ }^{2} 0+10-20 \mathrm{C}$ : int_time $=50 \mathrm{~ms}$, offset= 0, gain=1 ( $350 \mathrm{e} / \mathrm{bit}$ ) Mon May 10 15:44:43 1993 Pixel Values Min $\div 0$ Max 42 Mean 40.7 Sigma $0.44 \times 10^{3}$

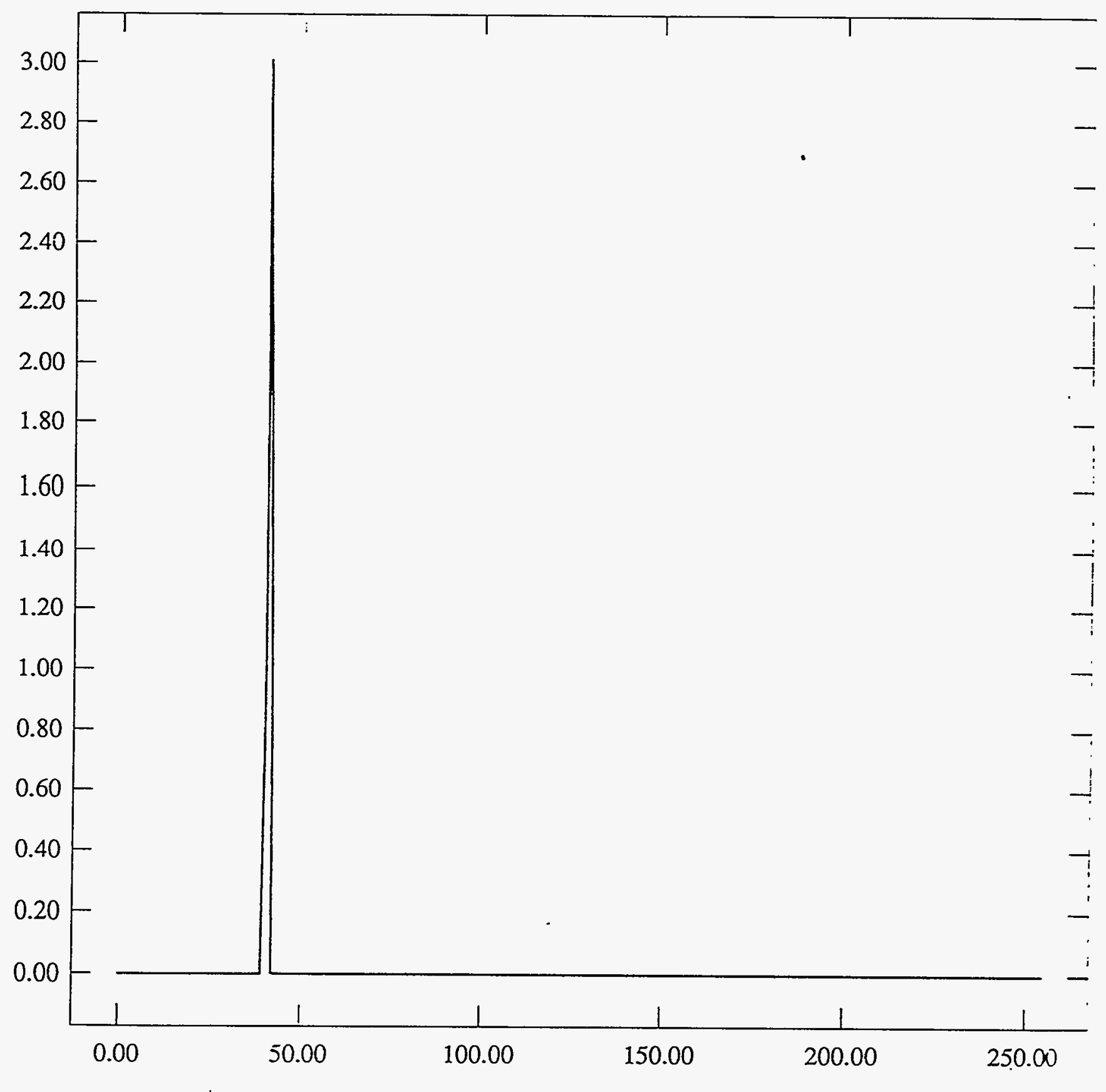


ST Camera: ST1 Pixel Values Min 40 Max 42 Mean 40.8 Sigma $0.42 \times 10^{3}$

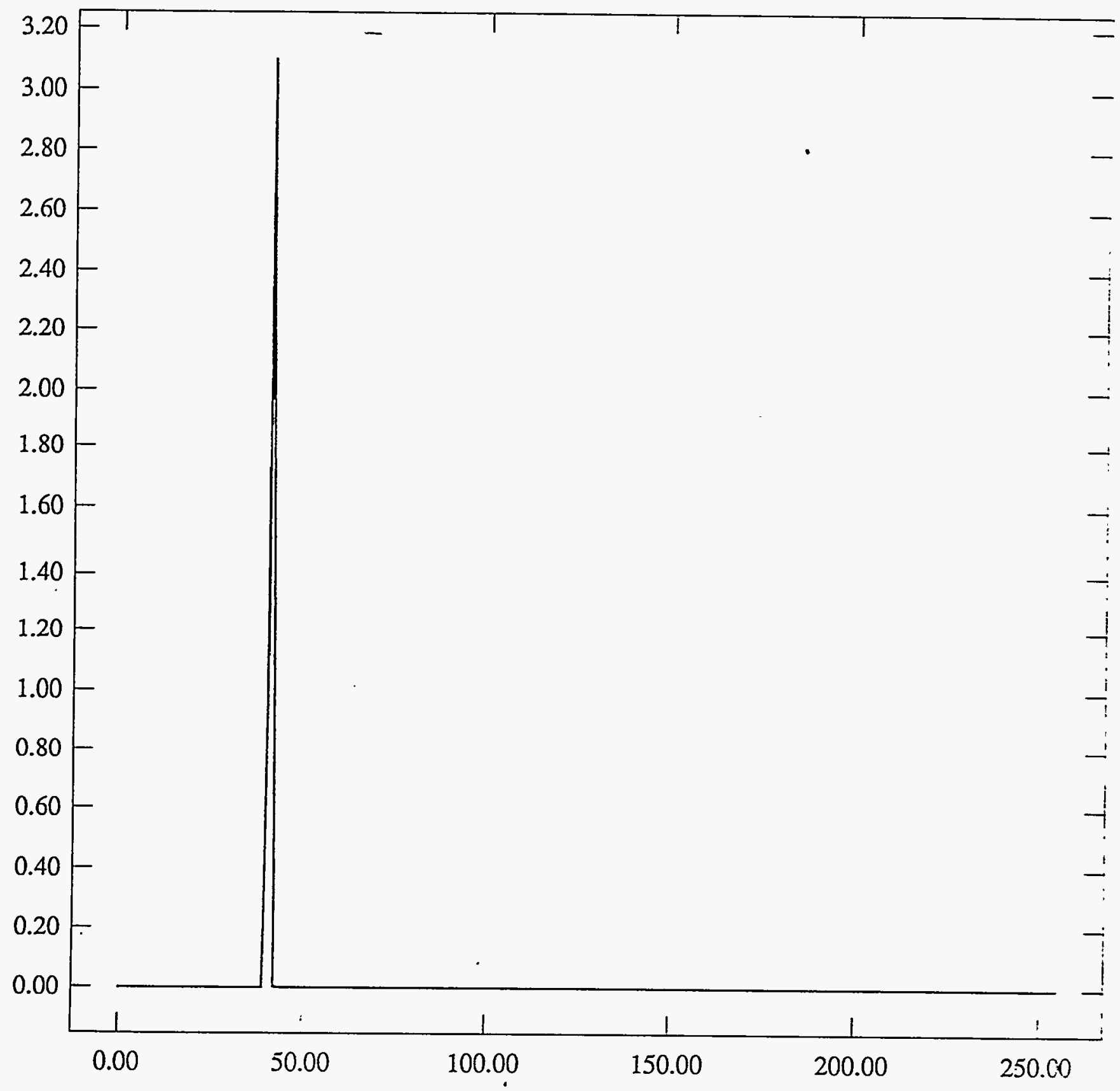


ST Camera: ST1 $04-10-20 \mathrm{C}$ : int_time=200ms, offset= 0, gain=1 ( $350 \mathrm{e} / \mathrm{bit}$ ) Mon May 10 15:45:58 1993 Pixel Values Min 40 Max 42 Mean 40.8 Sigma $0.41 \times 10^{3}$

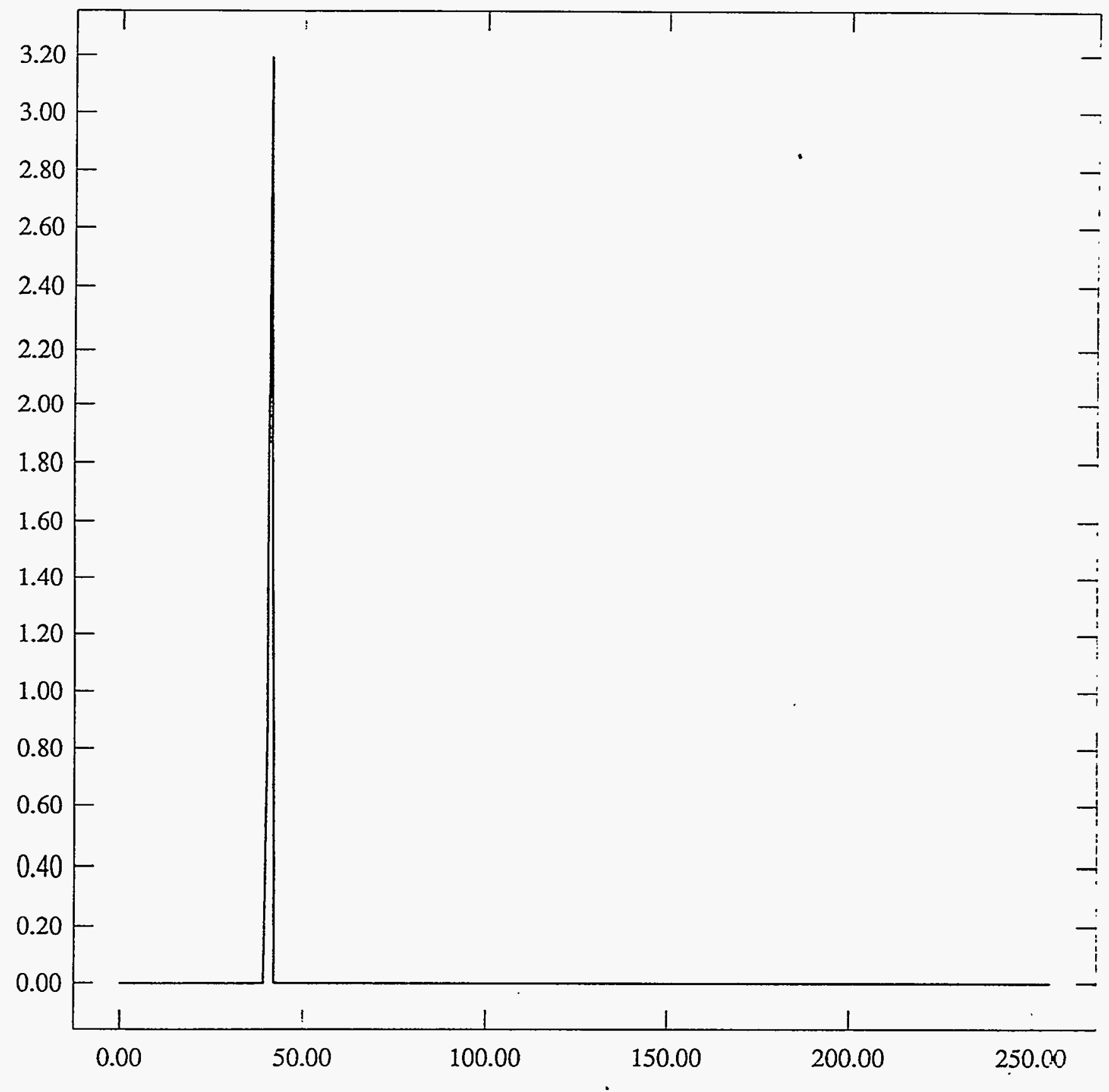


ST Camera: ST1 $=0+10$-10C: int_time= 50ms, offset= 0, gain=1 ( $350 \mathrm{e} / \mathrm{bit}$ ) Mon May 10 16:09:13 1993 Pixel Values Min 39 Max 41 Mean 40.0 Sigma $0.36 \times 10^{3}$

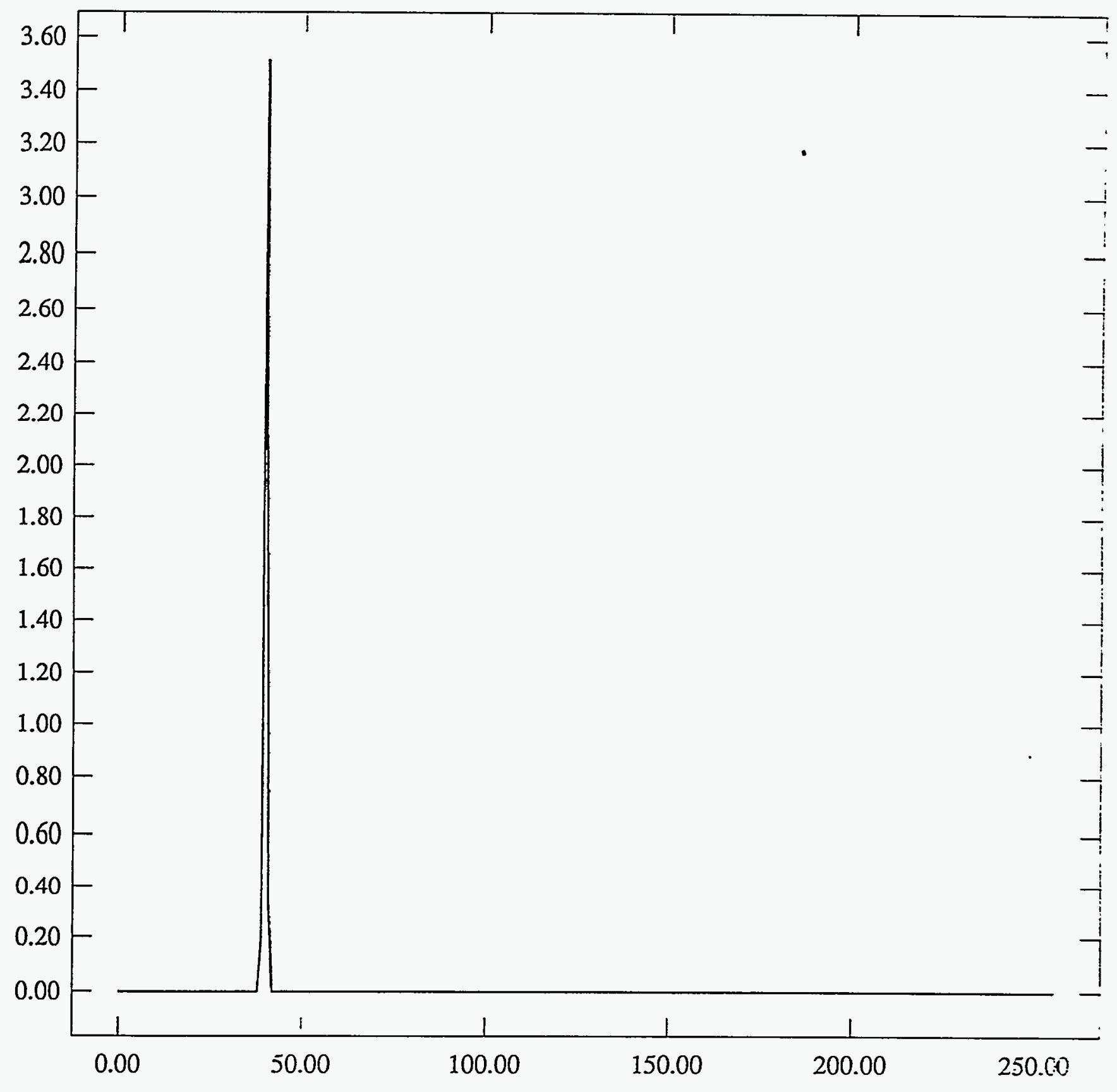


ST Camera: ST1 $\dot{7} 04-10$-10C: int_time $=100 \mathrm{~ms}$, offset= 0, gain=1 (350 e/bit) Mon May 10 16:10:09 1993 Pixel Values Min 39 Max 41 Mean 40.0 Sigma $0.35 \times 10^{3}$

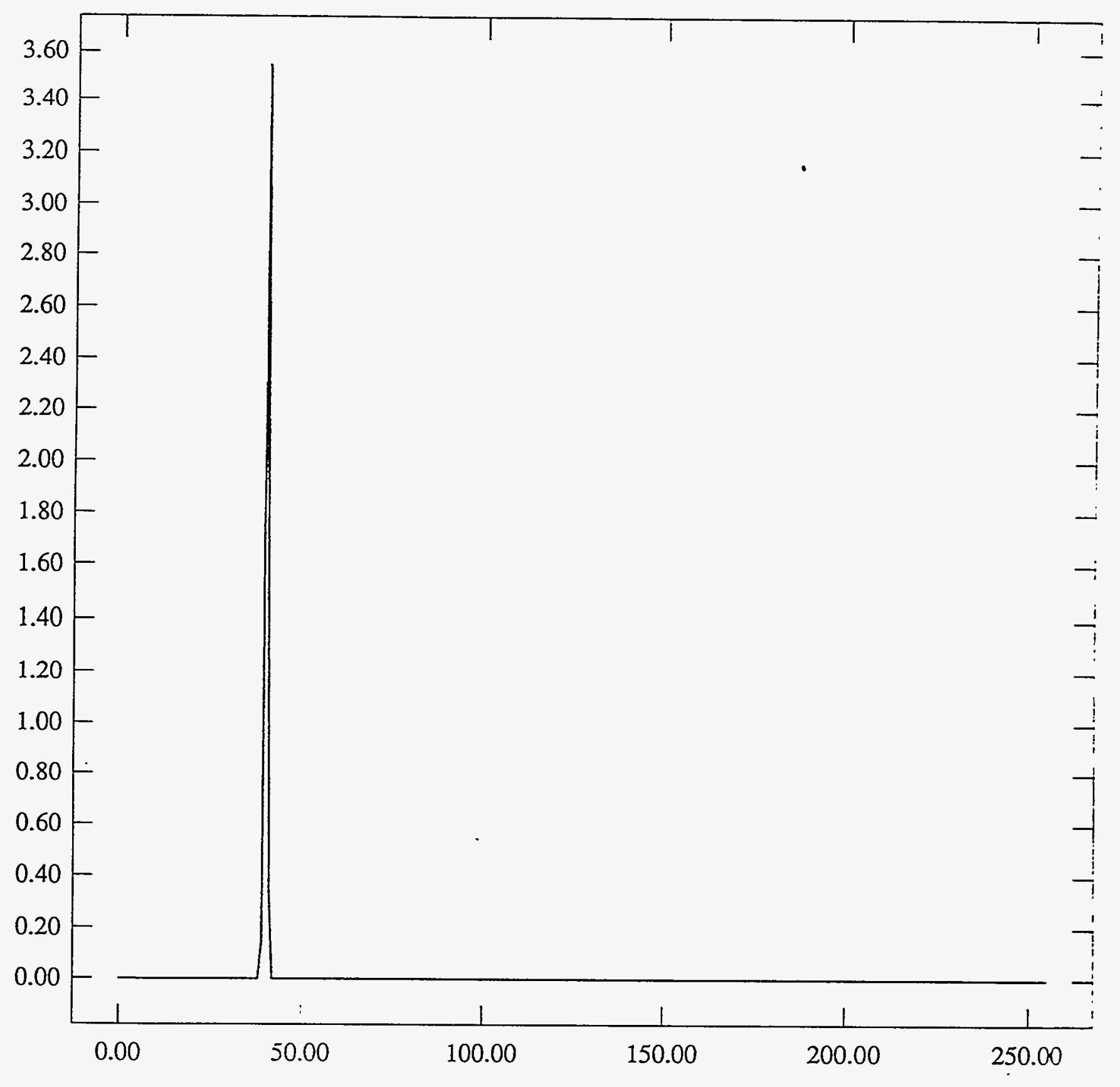


ST Camera: ST1 0 04-10 -10C: int_time=200ms, offset= 0, gain=1 ( $350 \mathrm{e} / \mathrm{bit})$ Mon May 10 16:10:41 1993 Pixel Values Min 39 Max 41 Mean 40.3 Sigma $0.47 \times 10^{3}$

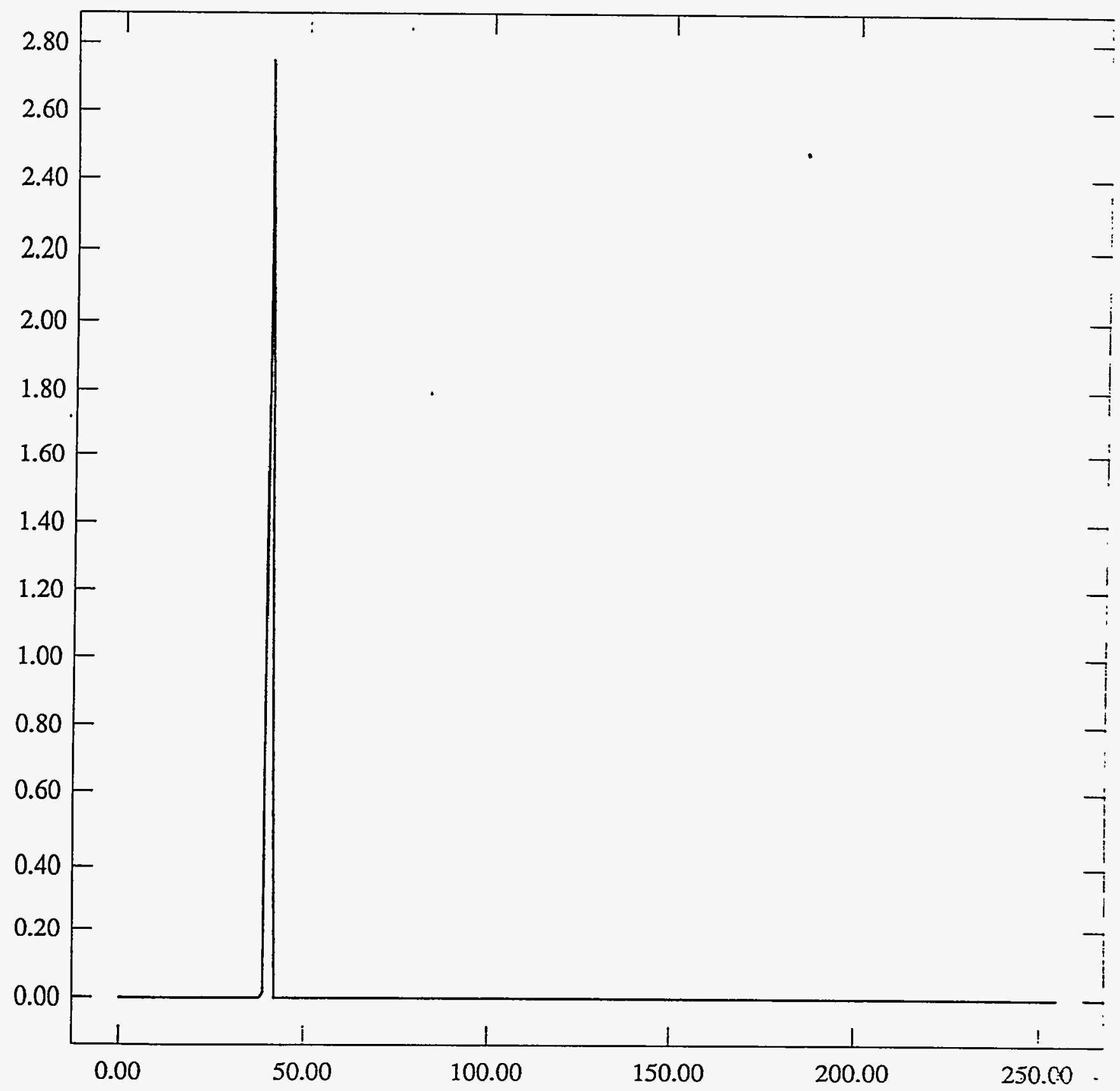


ST Camera: ST1 $=04-10$ OC: int_time= 50ms, offset= 0, gain=1 ( $350 \mathrm{e} / \mathrm{bit})$ Mon May 10 16:39:37 1993 Pixel Values Min 38 Max 41 Mean 39.4 Sigma $0.50 \times 10^{3}$

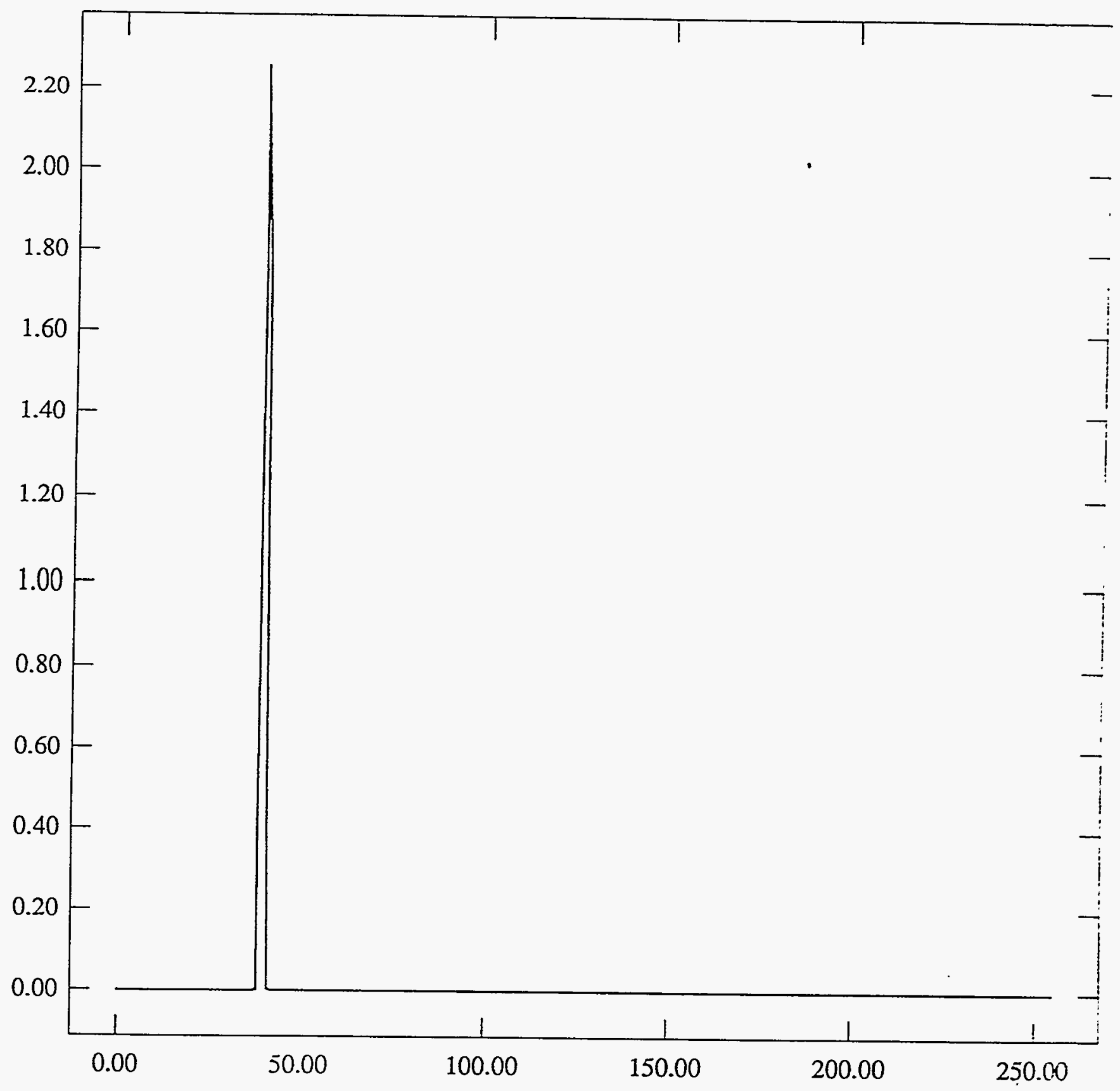


ST Camera: ST1 Pixel Values Min 39 Max 41 Mean 39.8 Sigma $0.42 \times 10^{3}$

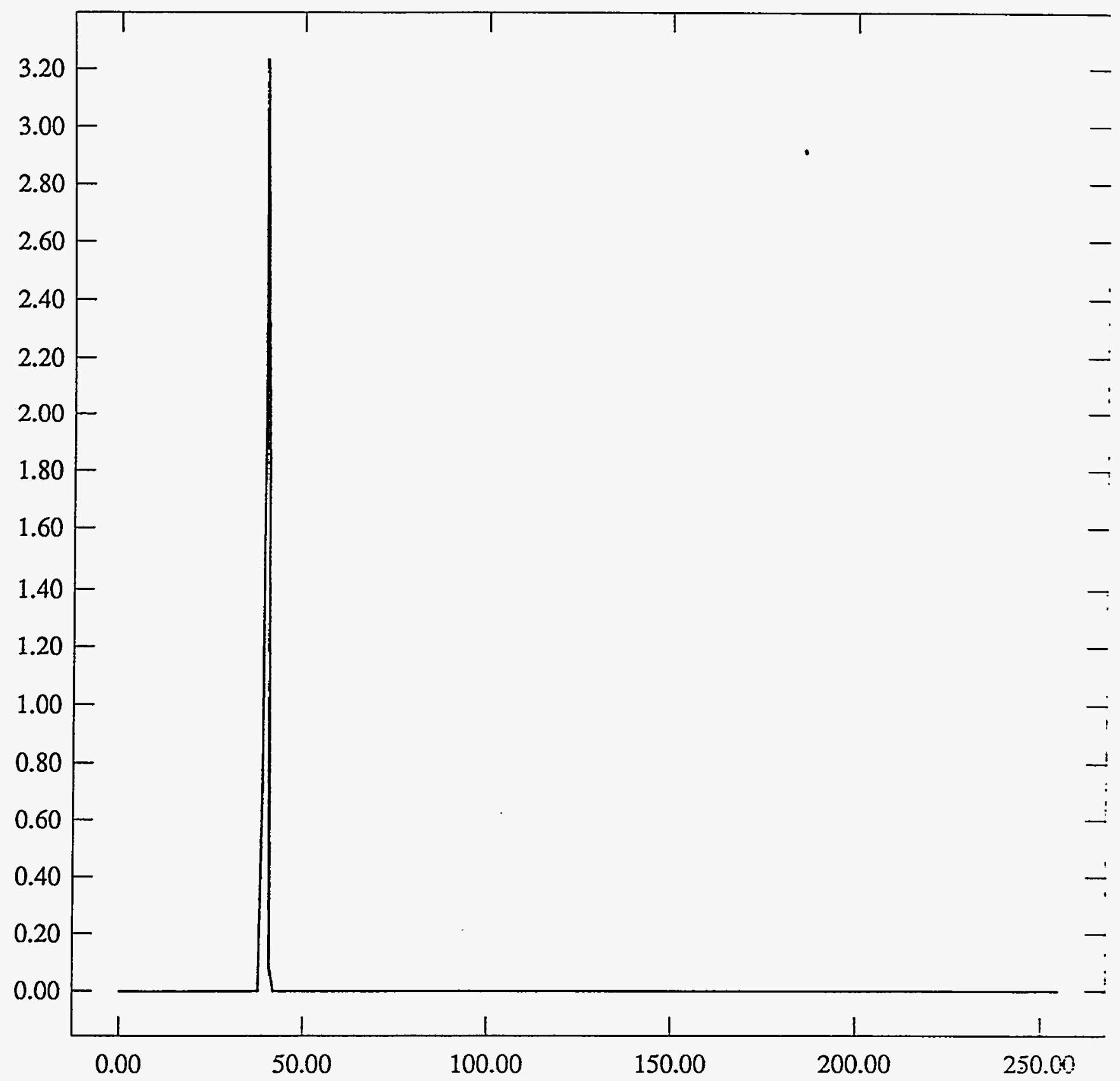


ST Camera: ST1 $=04-10$ 0C: int_time $=200 \mathrm{~ms}$, offset= 0, gain=1 ( $350 \mathrm{e} / \mathrm{bit}$ ) Mon May 10 16:40:55 1993 Pixel Values Min 39 Max 42 Mean 40.6 Sigma $0.50 \times 10^{3}$

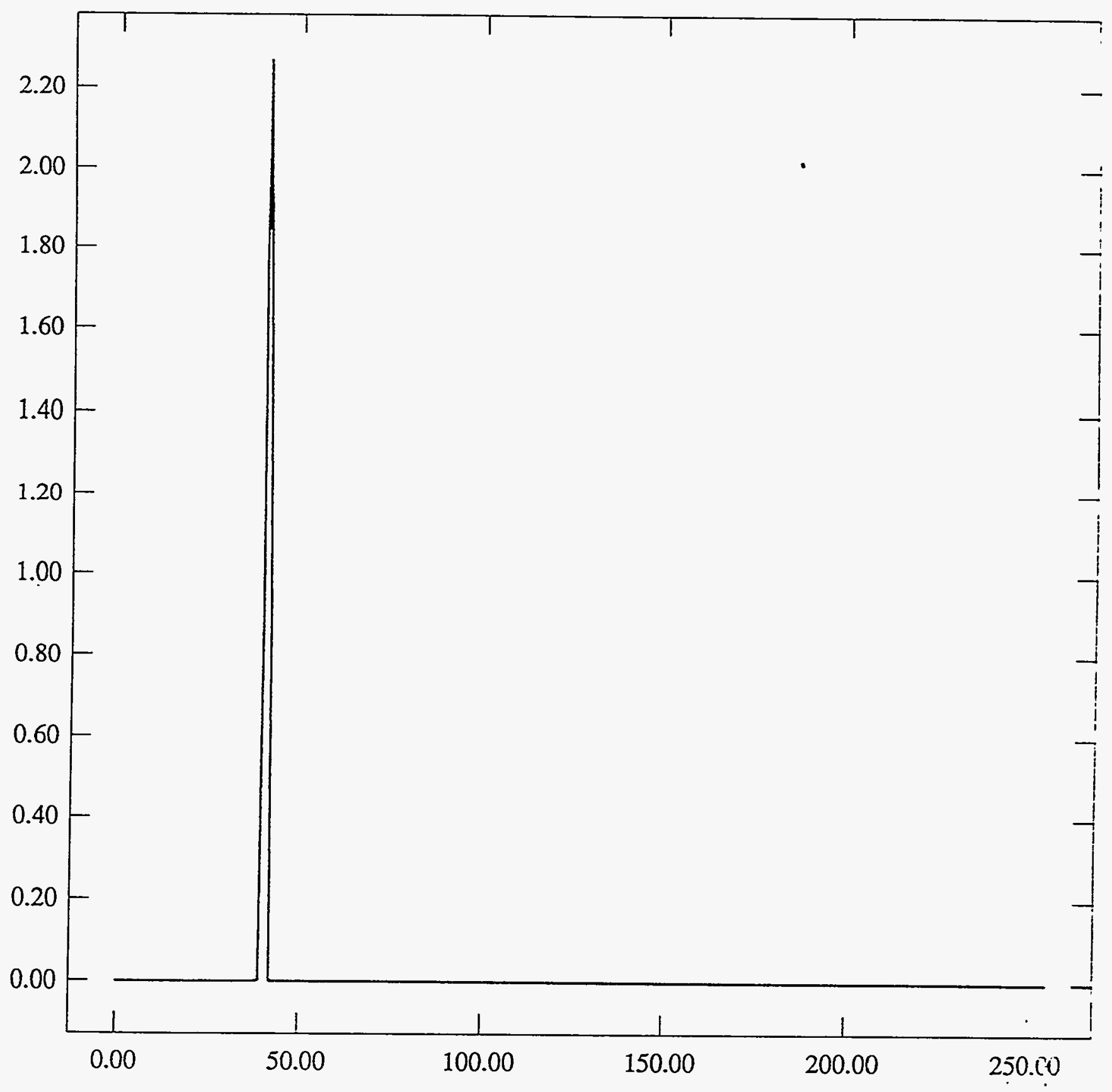


ST Camera: ST1 Pixel Values Min 39 Max 41 Mean 40.0 Sigma $0.36 \times 10^{3}$

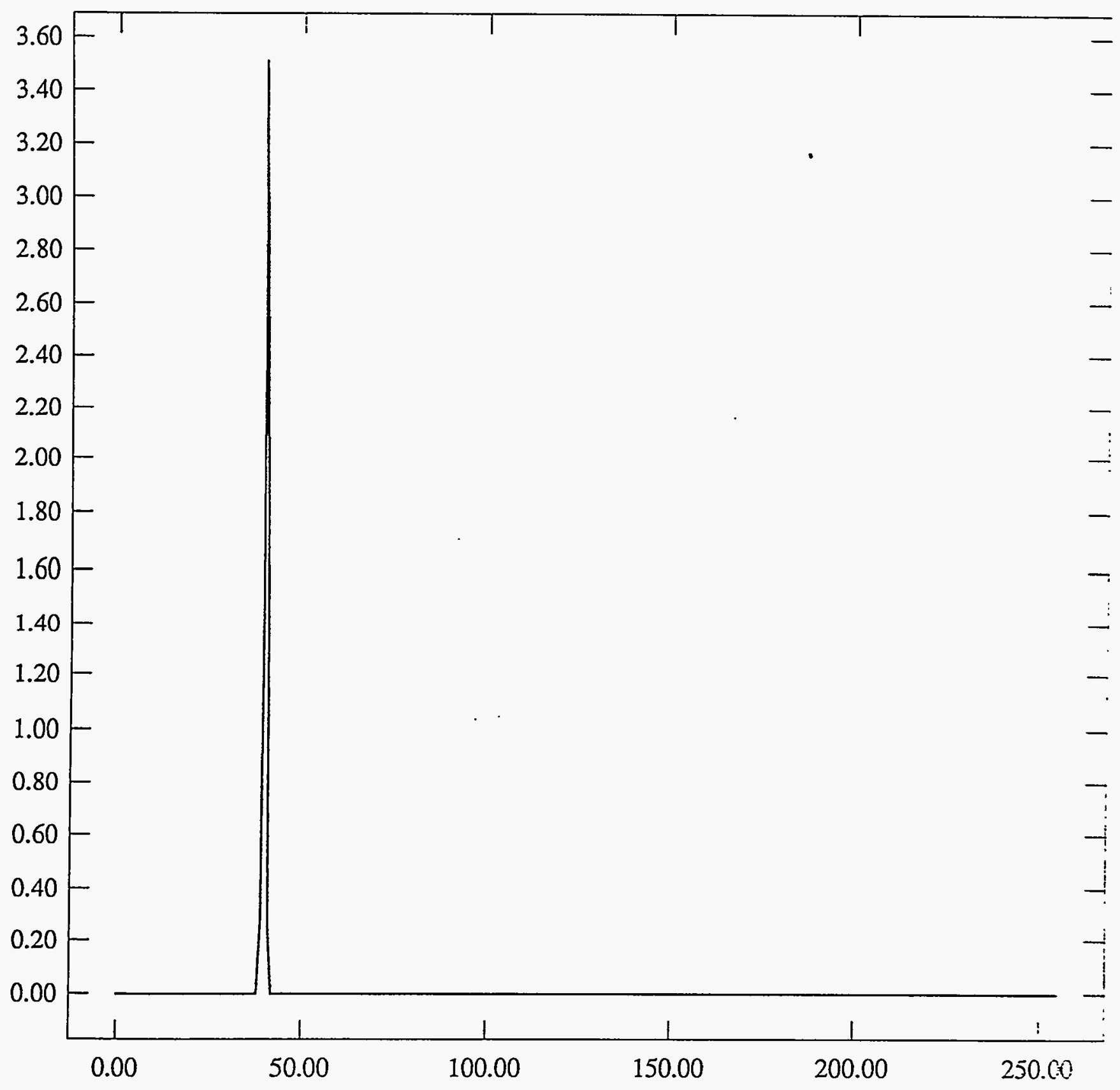


ST Camera: ST1 Pixel Values Min 40 Max 42 Mean 40.9 Sigma $0.27 \times 10^{3}$

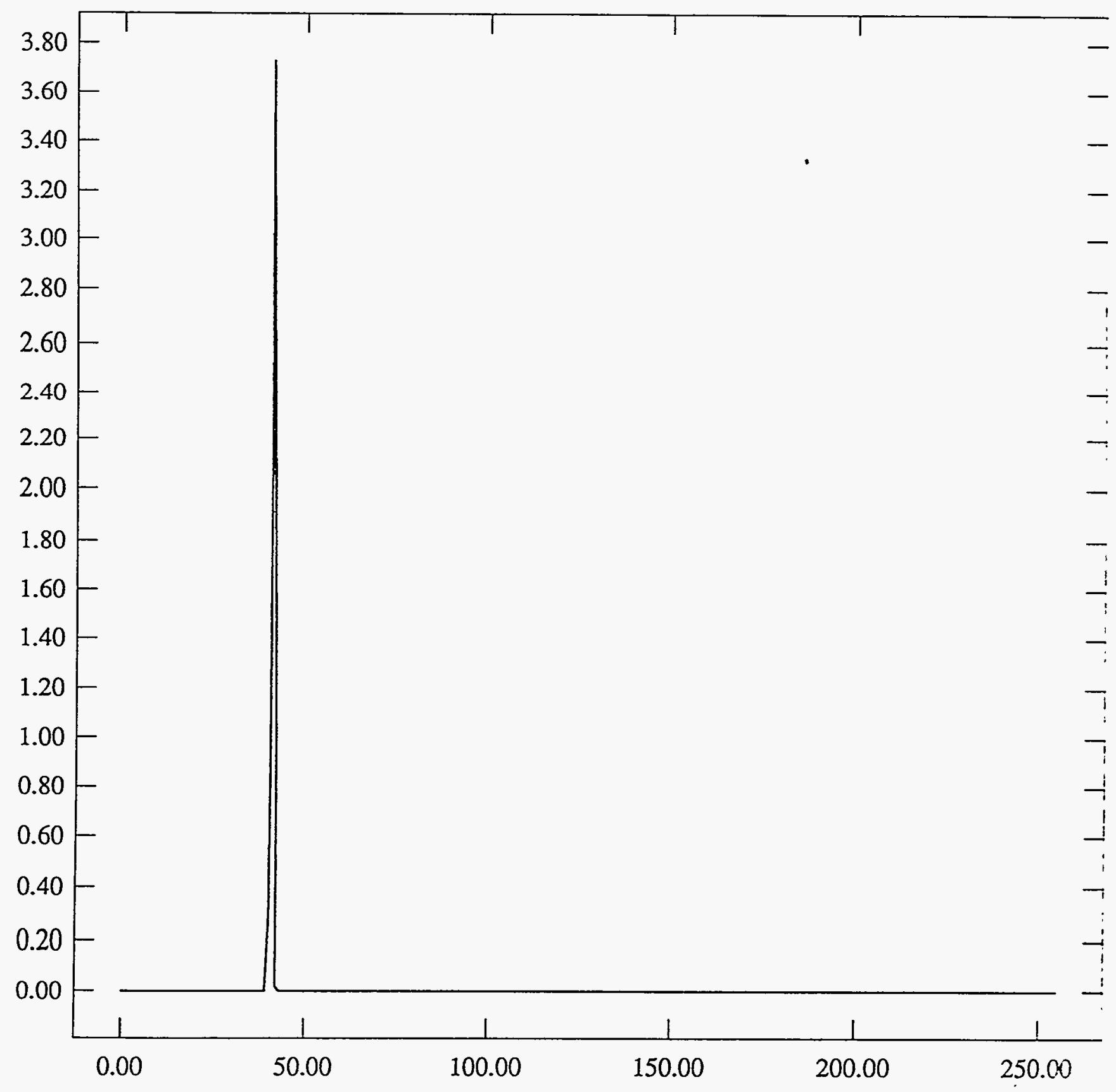


ST Camera: ST1 Pixel Values Min 41 Max 46 Mean 42.7 Sigma $0.48 \times 10^{3}$

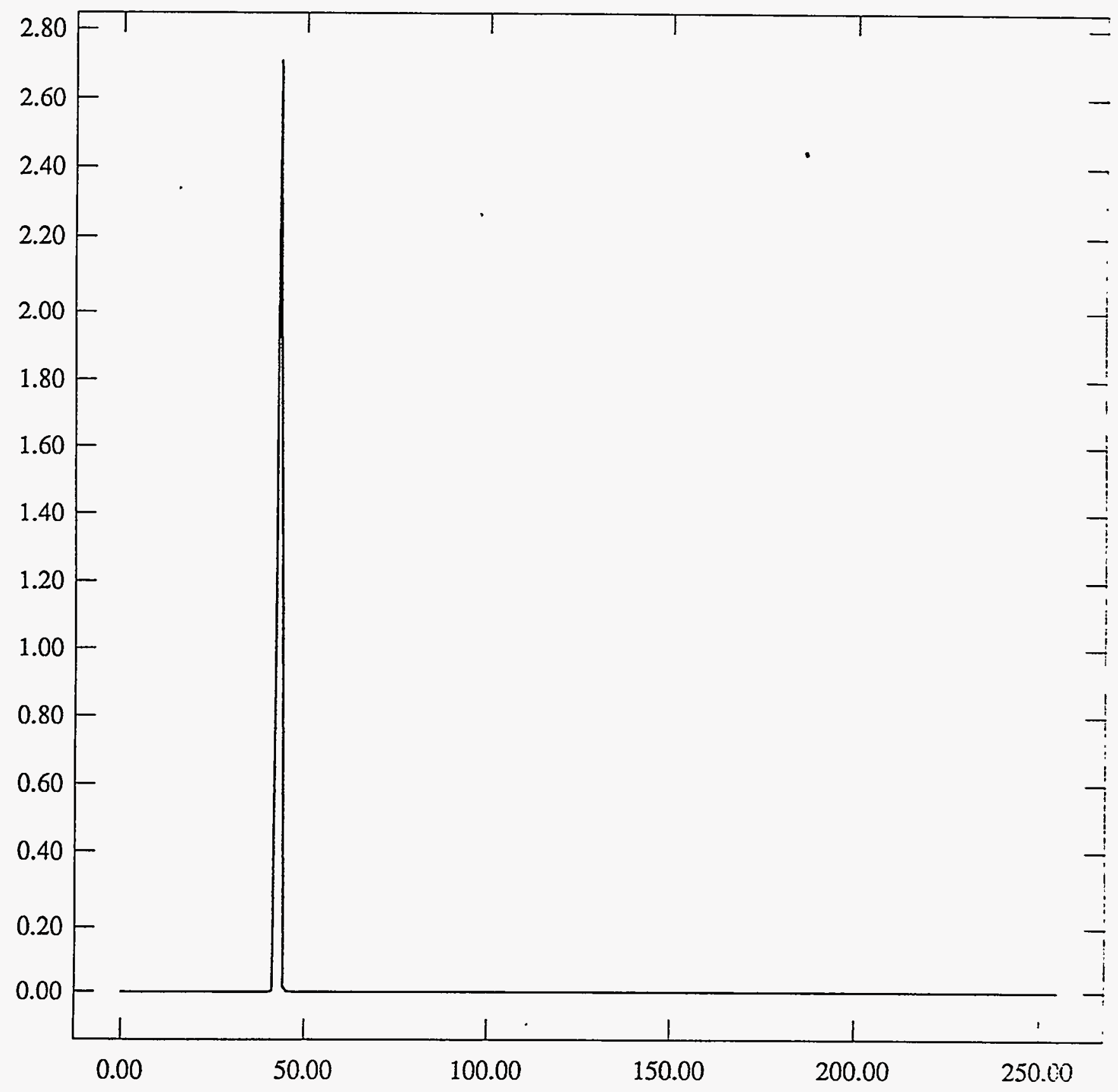


ST Camera: ST1 Pixel Values Min 41 Max 43 Mean 41.7 Sigma $0.46 \times 10^{3}$

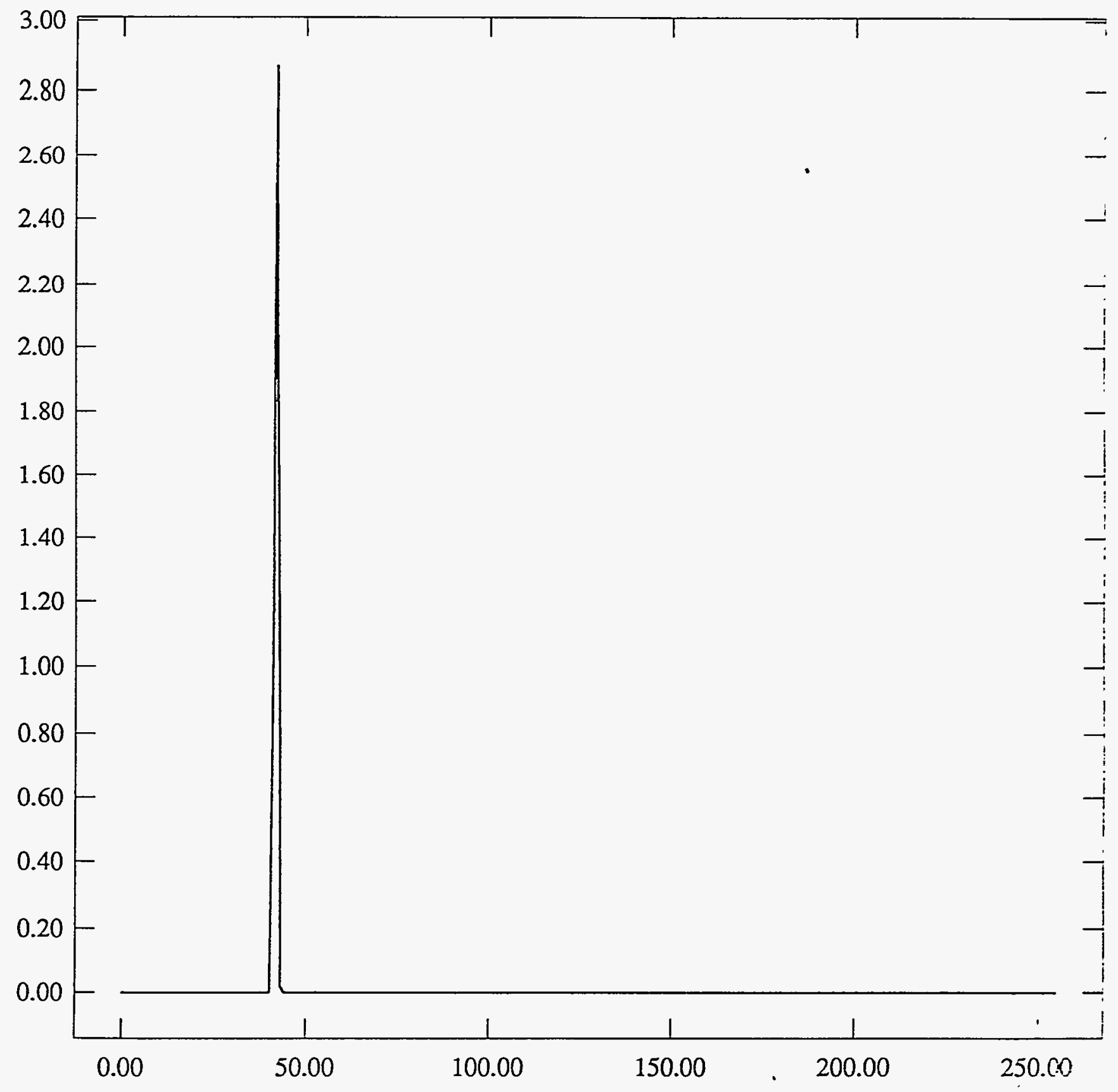


ST Camera: ST1菂04-10 20C: int_time=100ms, offset= 0, gain=1 ( $350 \mathrm{e} / \mathrm{bit}$ ) Mon May 10 17:22:46 1993 Pixel Values Min $43 \mathrm{Max} 48$ Mean 43.8 Sigma $0.43 \times 10^{3}$

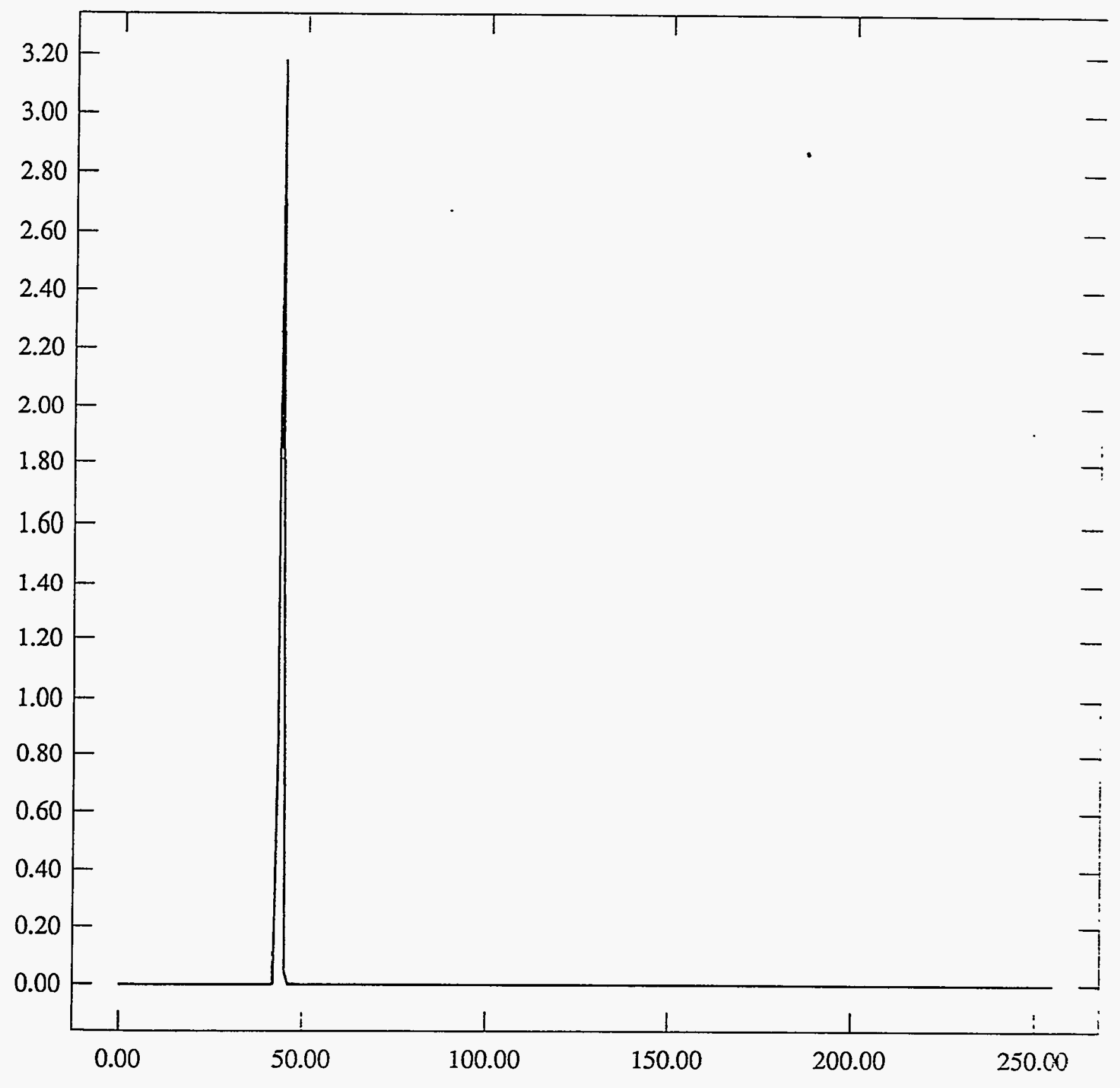


ST Camera: ST1 $=04-10$ 20C: int_time $=200 \mathrm{~ms}$, offset= 0, gain=1 (350 e/bit) Mon May 10 17:23:23 1993 Pixel Values Min 47 Max 56 Mean 48.5 Sigma $0.58 \times 10^{3}$

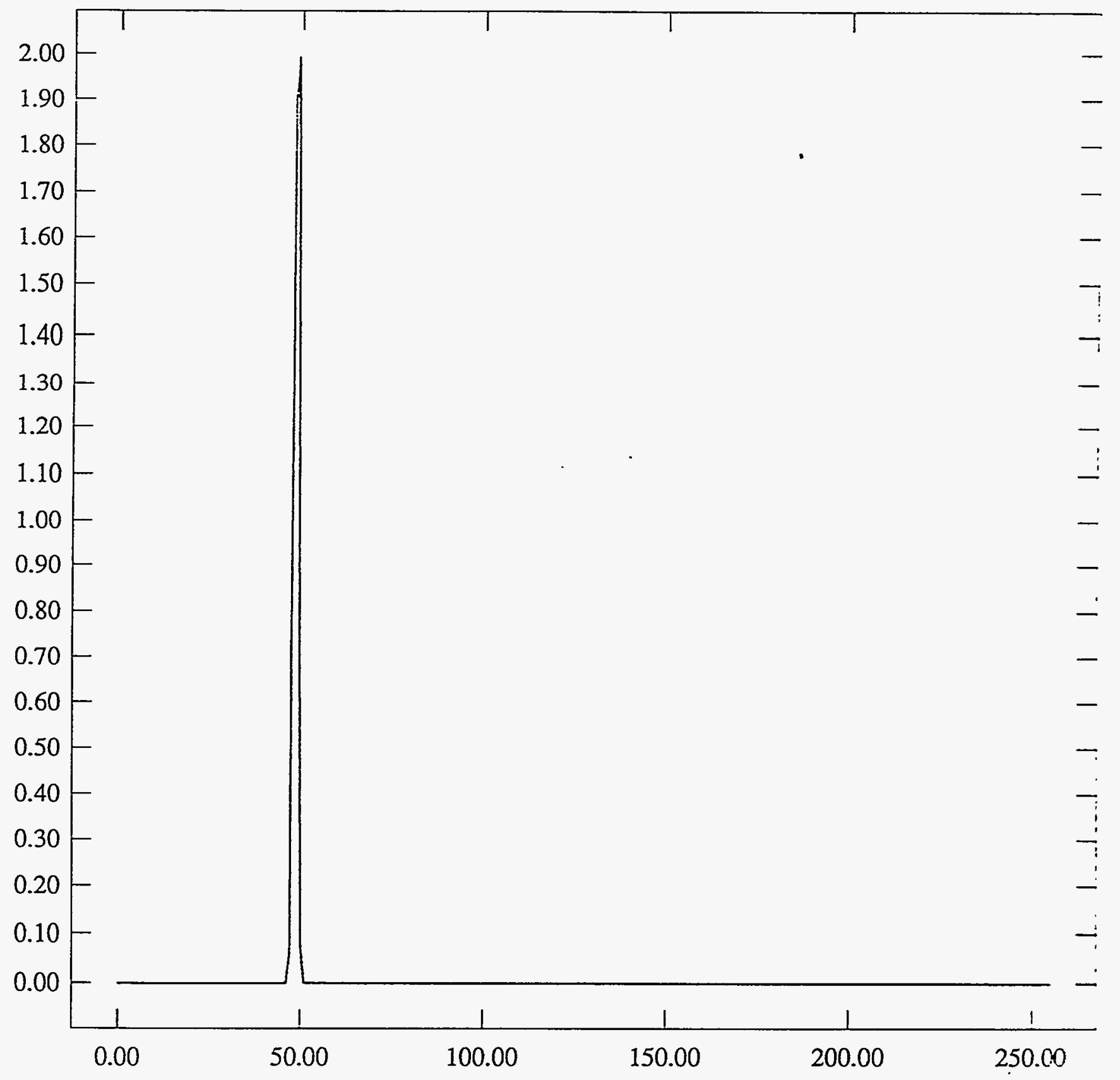


ST Camera: ST1 $\div 0410$ 30C: int_time $=50 \mathrm{~ms}$, offset= 0, gain=1 ( $350 \mathrm{e} / \mathrm{bit})$ Mon May 10 17:53:32 1993 Pixel Values Min 46 Max 51 Mean 47.4 Sigma $0.55 \times 10^{3}$

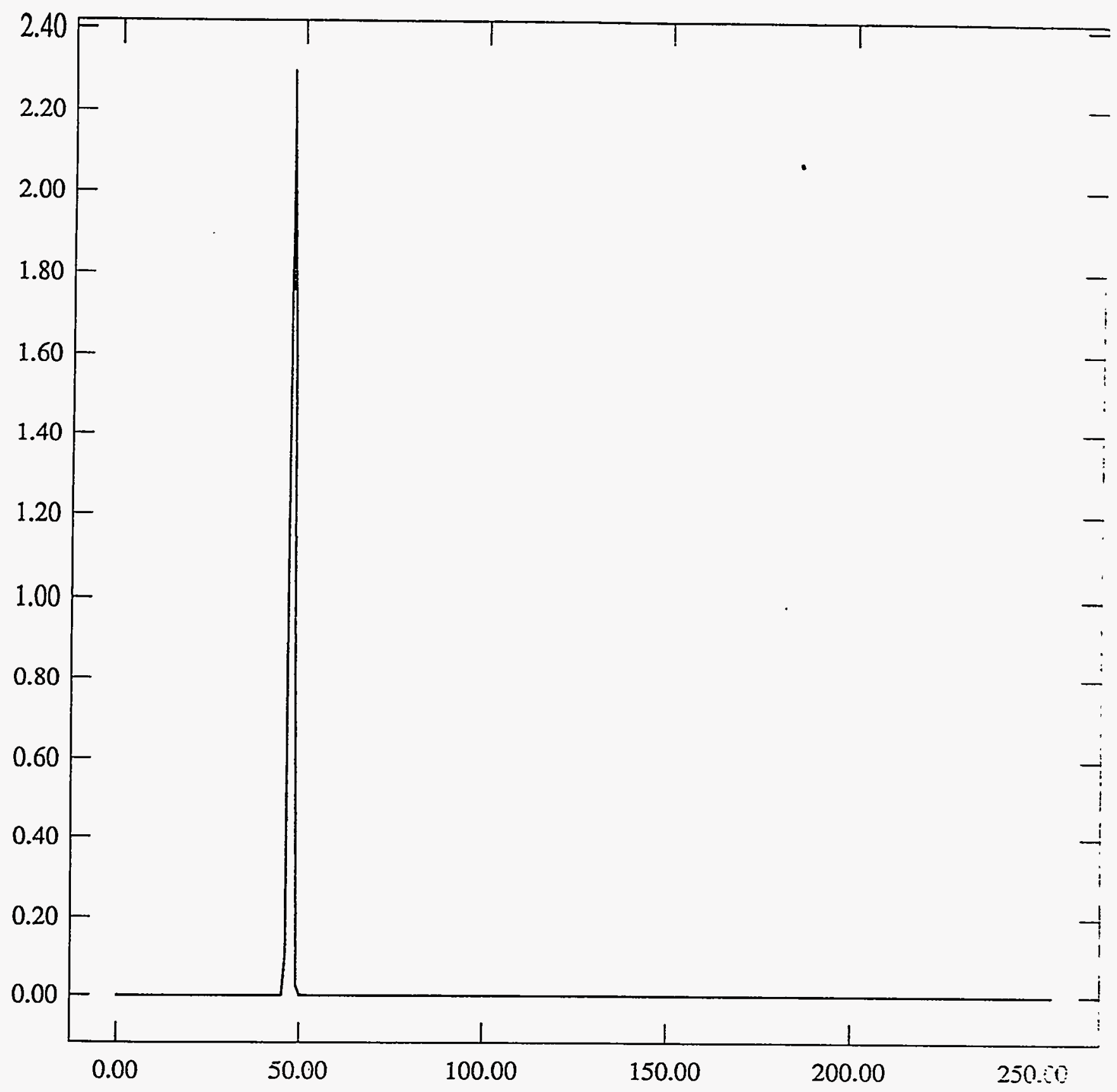


ST Camera: ST1 $\frac{\pi}{\mathrm{r} 04-10} 30 \mathrm{C}$ : int_time $=100 \mathrm{~ms}$, offset=0, gain=1 ( $350 \mathrm{e} / \mathrm{bit}$ ) Mon May 10 17:54:46 1993 Pixel Values Min 51 Max 59 Mean 52.9 Sigma $0.64 \times 10^{3}$

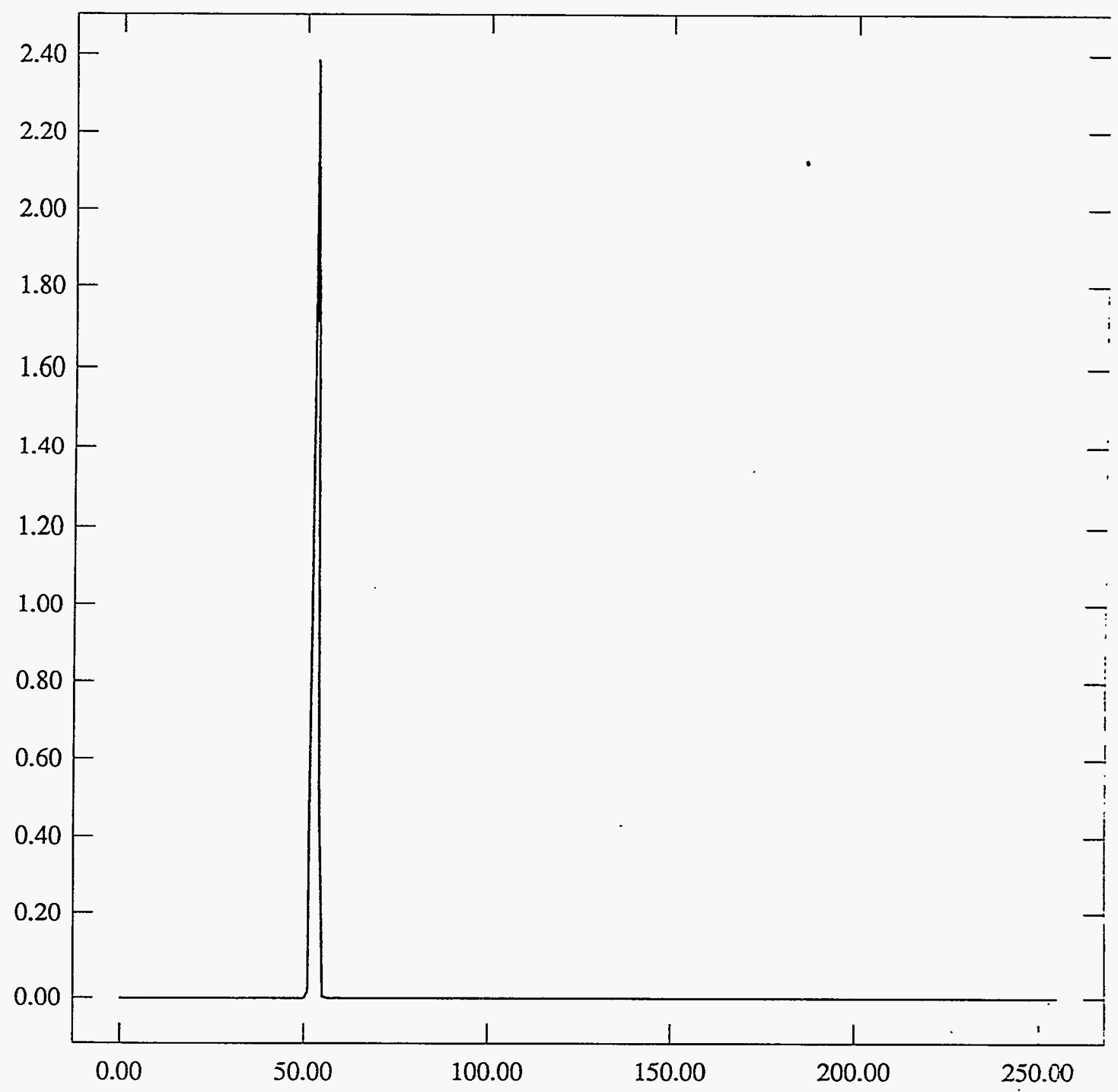


ST Camera: ST1 Pixel Values Min 61 Max 78 Mean 64.1 Sigma $1.09 \times 10^{3}$

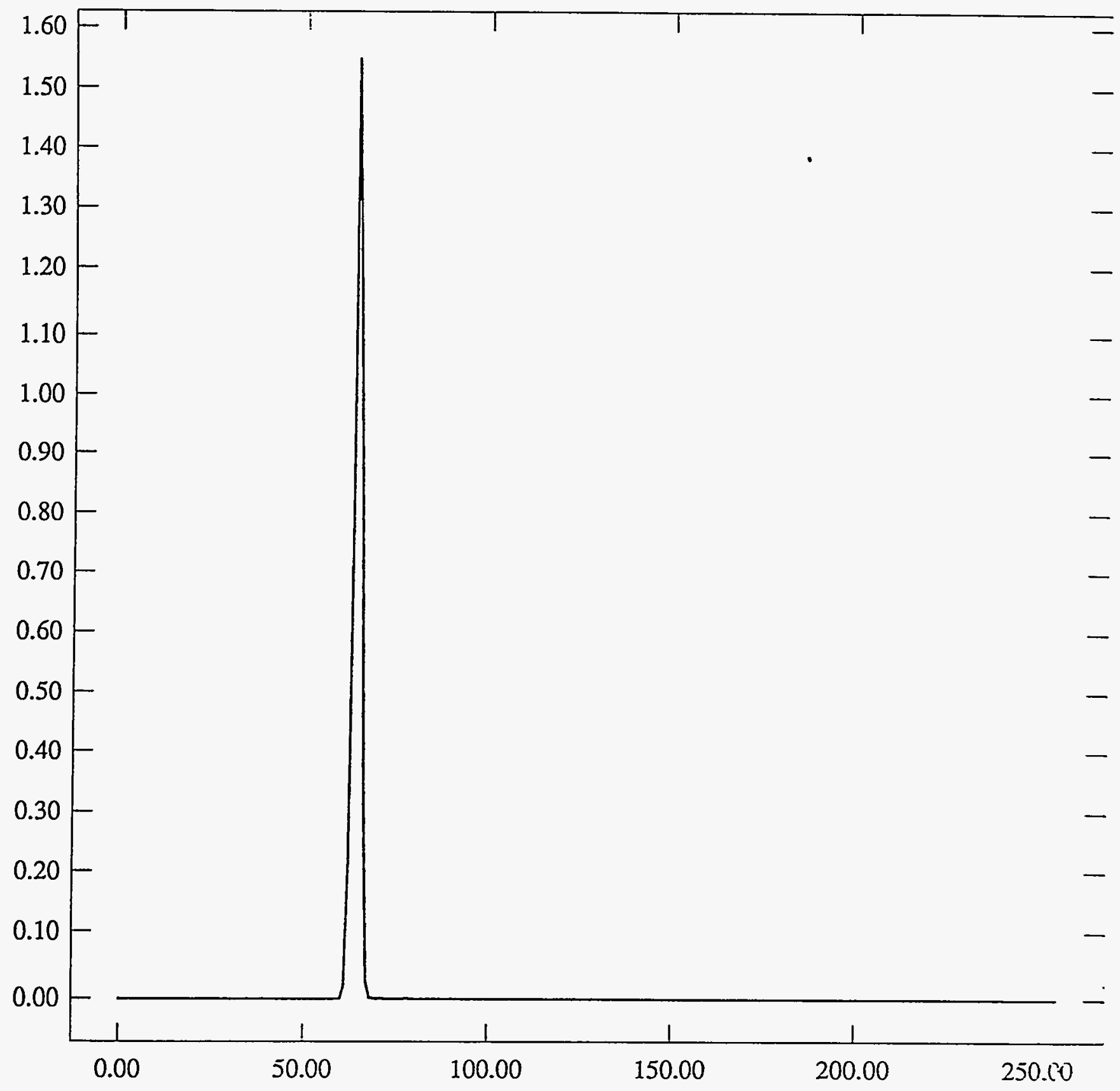


ST1\#04-10 350e/bit Mu ${ }^{\circ} \mathrm{C}$ Graph

$\frac{0}{5}$
5
0
0
05
$\frac{0}{0}$
2
$\frac{1}{2}$
$\frac{1}{5}$
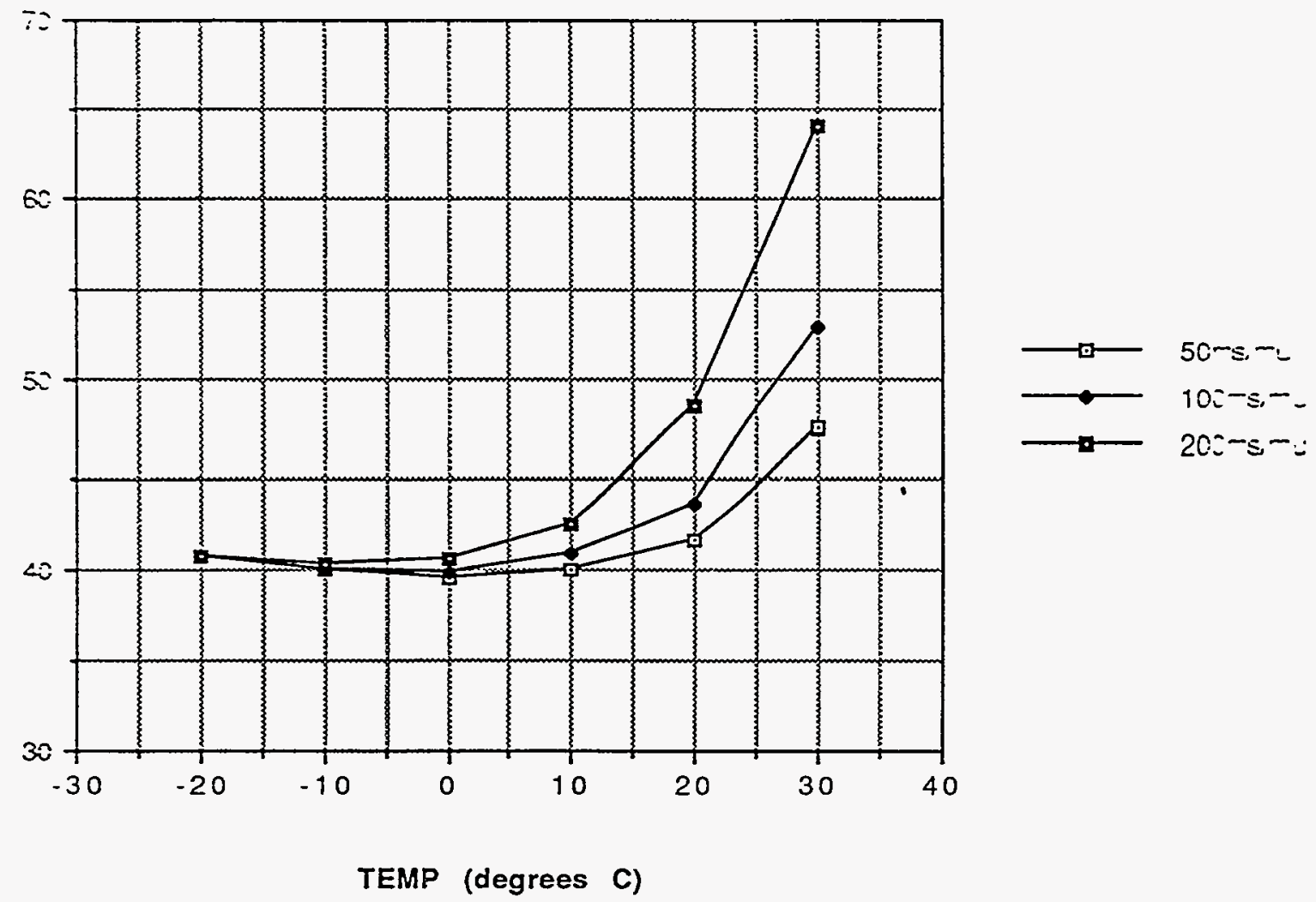

ST1\#04-10 350e/bit Sigma ${ }^{\circ} \mathrm{C}$ Graph

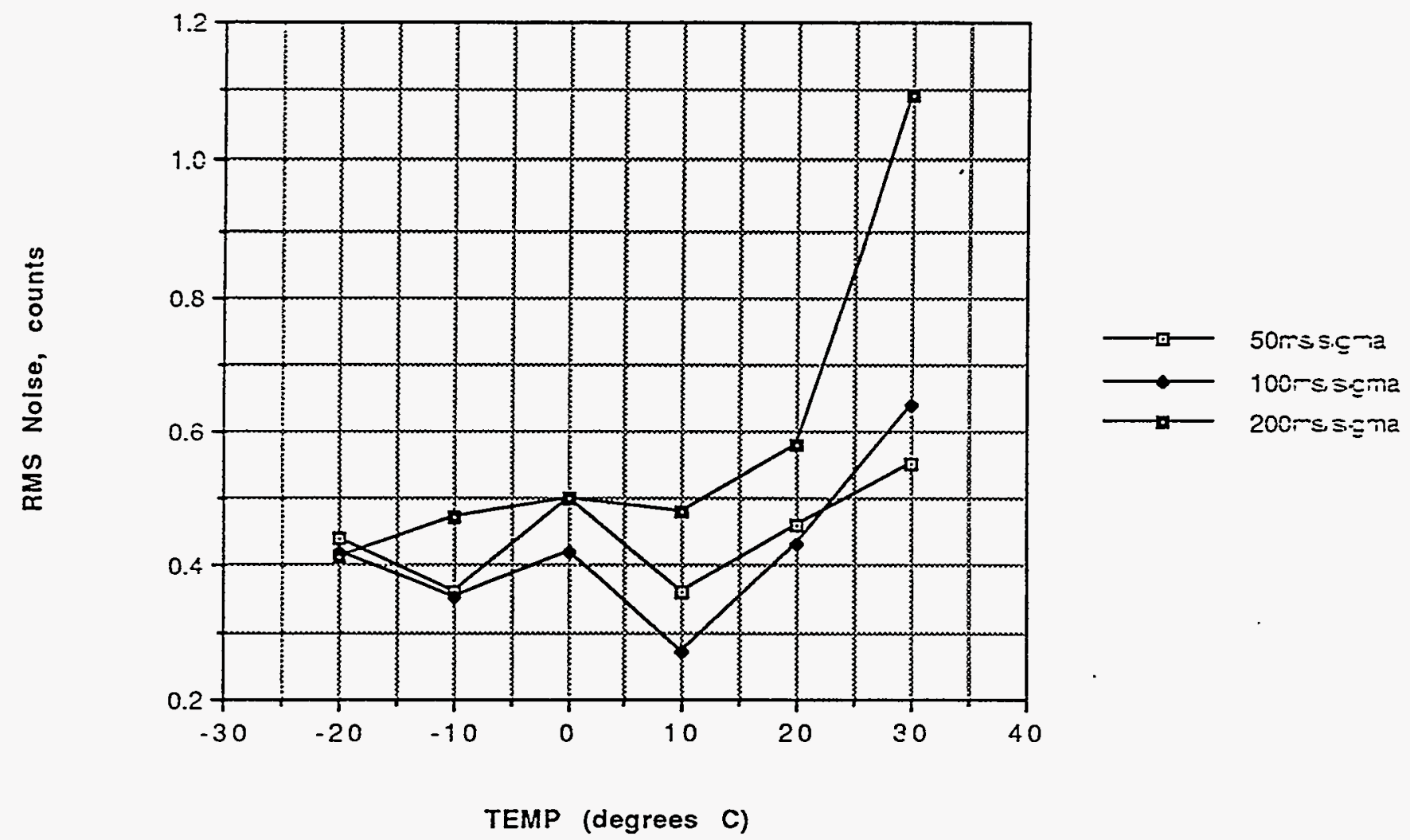



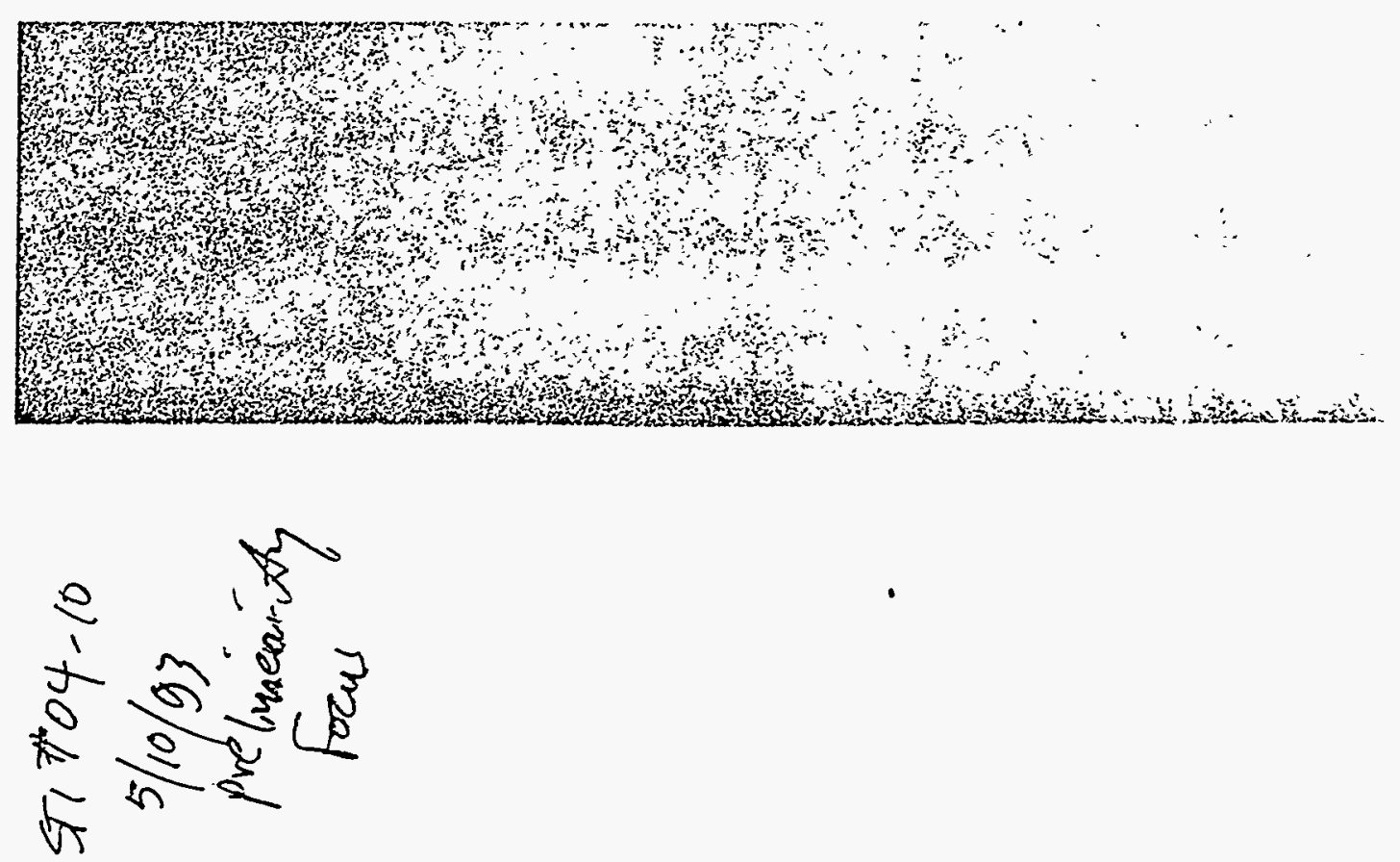

Mry 


\section{•}




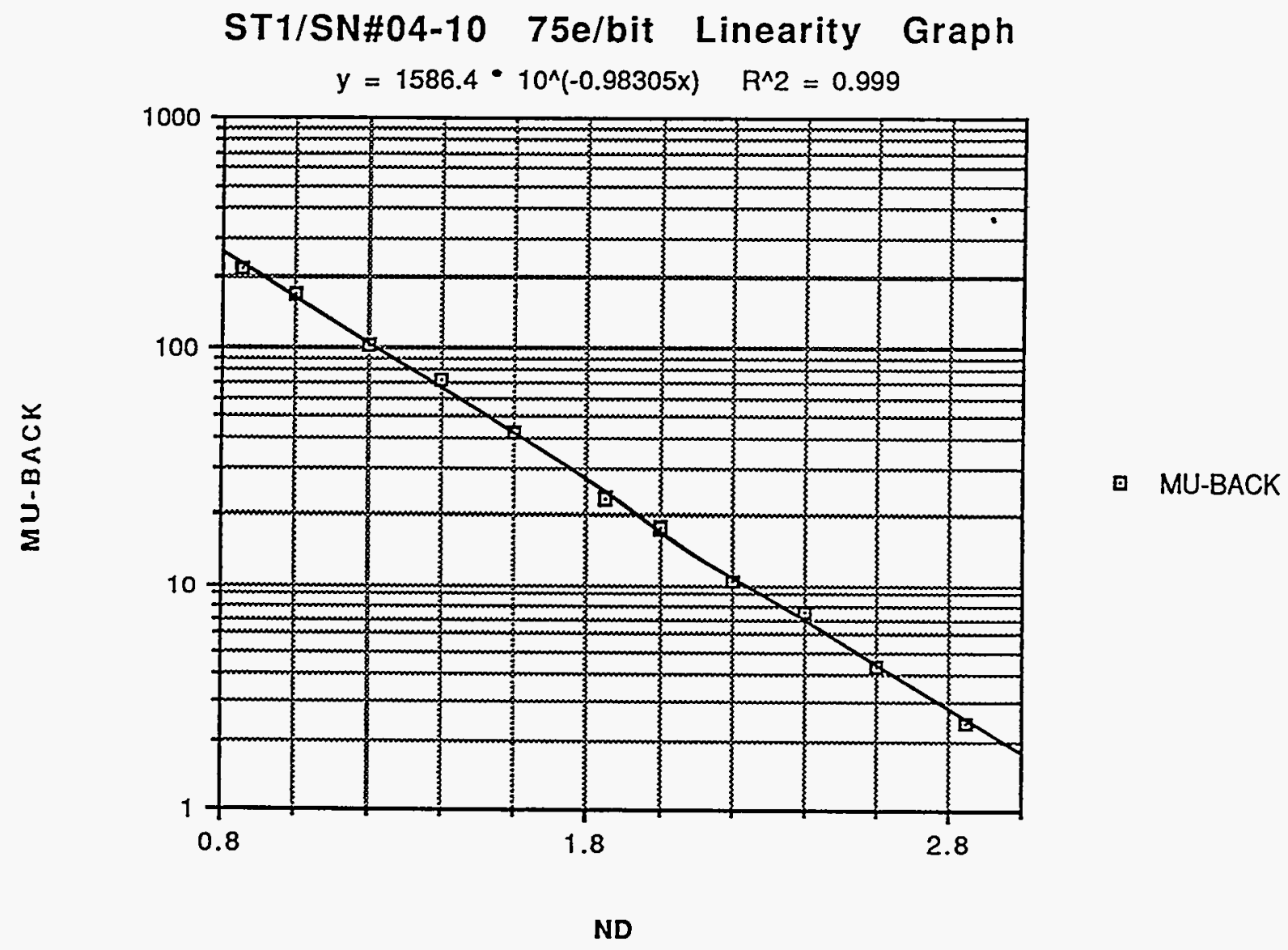


ST1/SN\#04-10/75e/LNDT

N

MN

0.85

1.00

1.20

1.40

1.60

1.85

2.00

2.20

2.40

2.60

2.85
BACK

27.02

27.02

27.02

27.02

27.02

27.49

27.49

27.49

27.49
27.49

$\begin{array}{lll}29.93 & 27.49 & 2.44\end{array}$
MU-BACK

Colu

216.30

172.10

104.27

71.61

42.52

22.68

17.54

10.45

7.47

4.37 $\begin{array}{lll}29.93 & 27.49 & 2.44\end{array}$
Wed, May 12, 1993 9:24 AM

$$
\text { NOTES: }
$$

\author{
$5 / 10 / 93$ \\ ST1 SN\#04-10 \\ $11.3 v$
}

SUNDATACUBE

offset $=24$

$75 \mathrm{e} / \mathrm{bit}$

P.S.\#5008

HEAD\#4163 


\subsection{Linearity Data Collection.}

Select the first gain setting.

Begin by taking a background level. Use an ND of 8.0 for background. Adjust the Offset so that the black level is equal to 20 counts and readjust the lamp voltage so that the average is equal to $240-250$ counts with an ND of 0.85 .

Starting with $0.8 \mathrm{ND}$, increment the ND filter value with 0.2 steps until MU almost equals the background. Acquire, build histogram, and record mu/sigma information for each ND value. Repeat this sequence for all 3 Gain settings.

Turn off power.

Sample data table:

Actual data table for gain of $4 \quad 7^{5 e}$

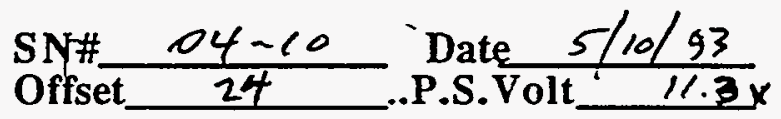

\begin{tabular}{|c|c|c|c|}
\hline ND & Mu & Backgnd & Mu-Back \\
\hline 0.85 & 249 & 82 & 167 \\
\hline 1.0 & 211 & 82 & 129 \\
\hline 1.2 & 159 & 82 & 77 \\
\hline 1.4 & 136 & 82 & 54 \\
\hline 1.6 & 113 & 82 & 31 \\
\hline 1.85 & 99 & 82 & 17 \\
\hline 2.0 & 95 & 82 & 13 \\
\hline 2.2 & 90 & 82 & 8 \\
\hline 2.4 & 87 & 82 & 5 \\
\hline 2.6 & 85 & 82 & 3 \\
\hline 2.85 & 84 & 82 & 2 \\
\hline
\end{tabular}

\begin{tabular}{|c|c|c|c|}
\hline ND & Mu & Backgnd & Mu-Back \\
\hline 0.85 & & & \\
\hline 1.0 & 243.32 & 27.02 & \\
\hline 1.2 & 199.12 & & \\
\hline 1.4 & 98.29 & & \\
\hline 1.6 & 69.54 & & \\
\hline 1.85 & 50.17 & 27.49 & \\
\hline 2.0 & 45.03 & & \\
\hline 2.2 & 37.94 & & \\
\hline 2.4 & 34.96 & & \\
\hline 2.6 & 31,86 & & \\
\hline 2.85 & 29.93 & & \\
\hline
\end{tabular}





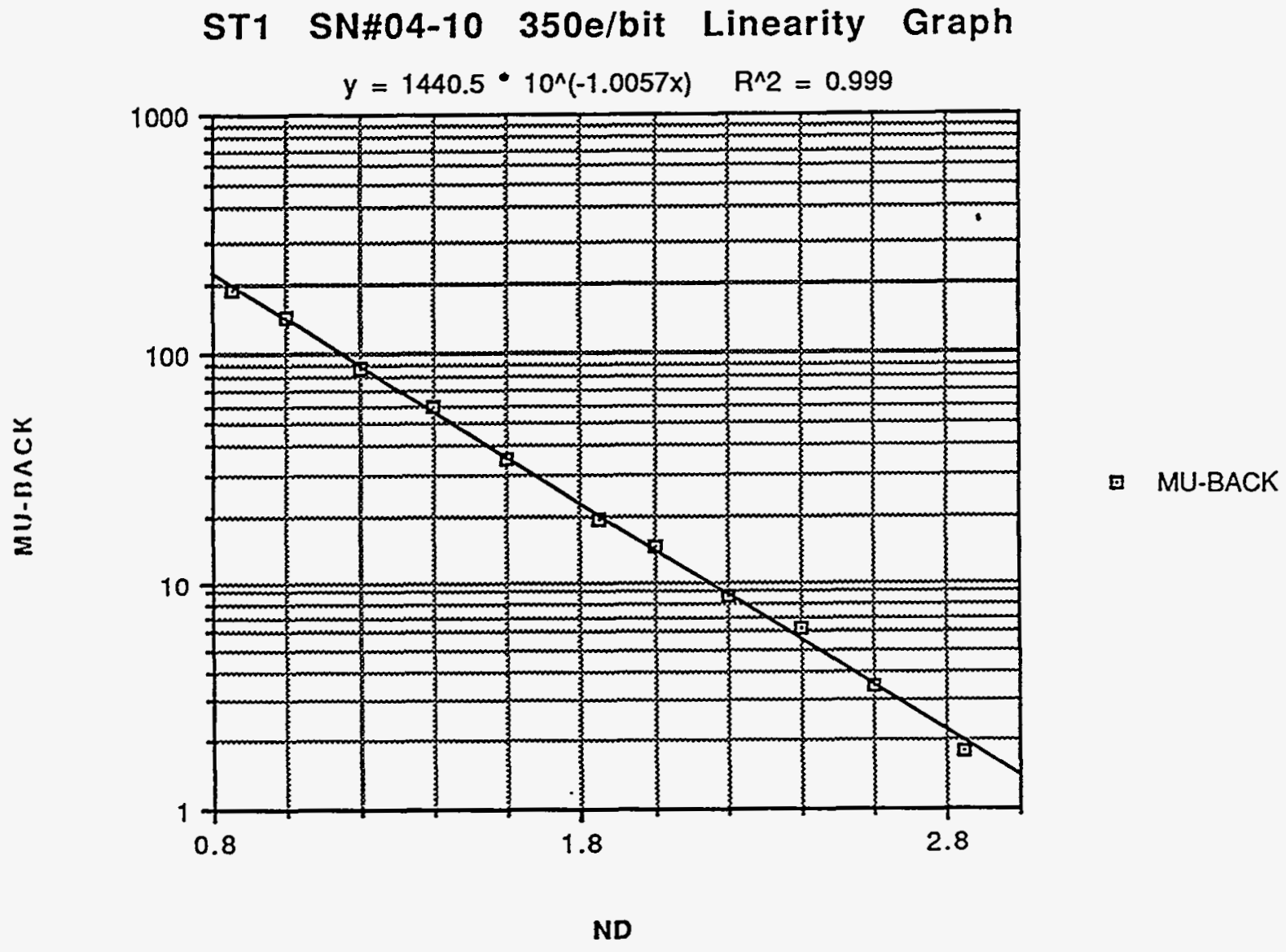


ST1/SN\#04-10/350e/LNDT

ND

0.85

1.00

1.20

1.40

1.60

1.85

2.00

2.20

2.40

2.60

2.85
M

217.72

173.06

115.02

87.86

62.51

46.55

42.09

36.24

33.81

31.02

29.37
BACK

27.54

27.54

27.54

27.54

27.56

27.56

27.56

27.56

27.56

27.56

27.56
MU-BACK

190.18

145.52

87.48

60.32

34.95

18.99

$14.53^{-}$

8.68

6.25

3.46

1.81
Wed, May 12, 1993 11:40 AR

NOTES:

$5 / 10 / 93$

ST1 SN\#04-10

$14.0 \mathrm{~V}$

SUNDATACUBE

offset $=3$

$350 \mathrm{e} / \mathrm{bit}$

P.S.\#5008

HEAD\#4163 


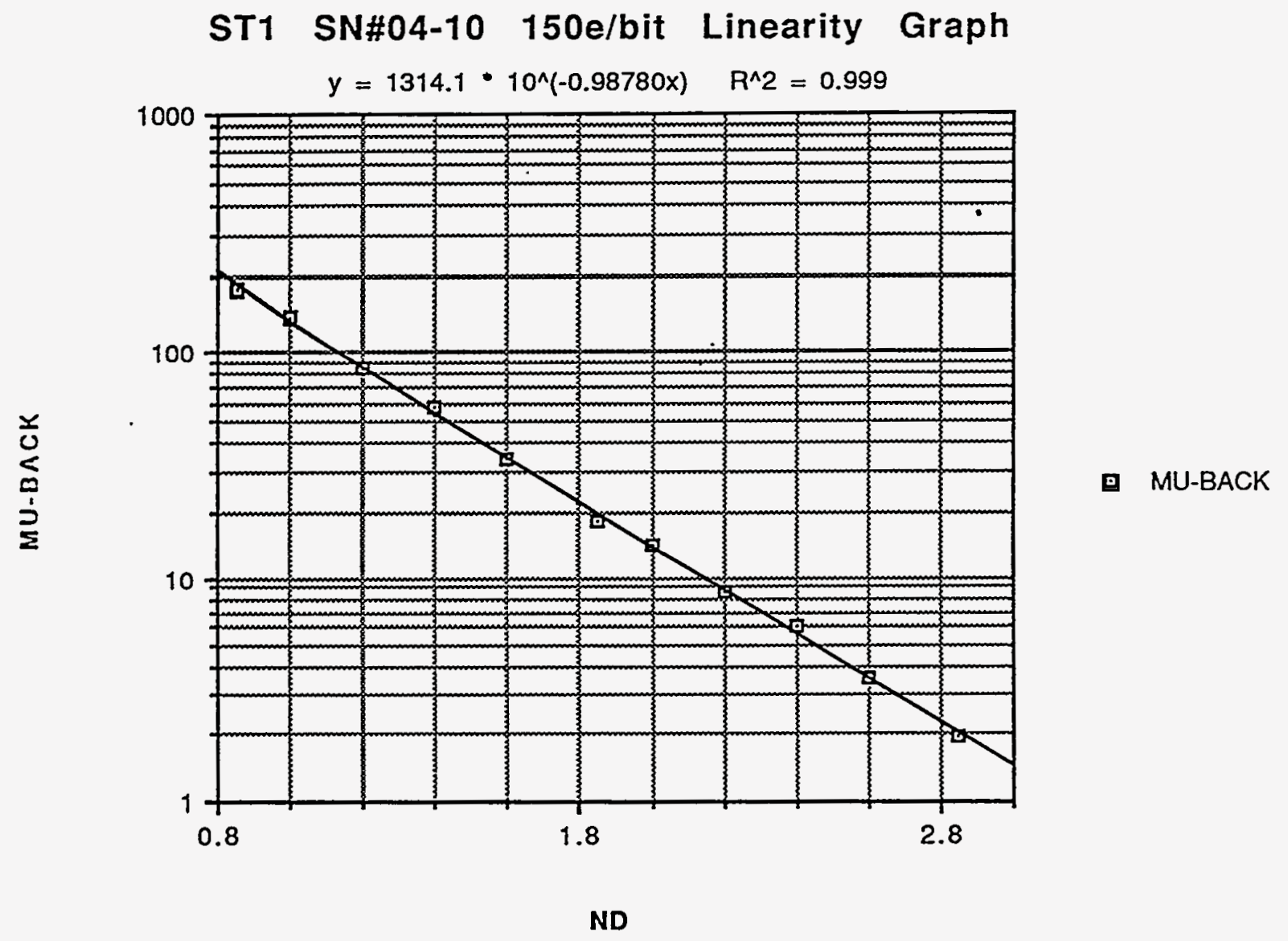


ST1/SN\#04-10/150e/LNDT

BACK

23.44

23.44

23.44

23.44

23.44

23.44

23.44

23.47

23.47

23.47

23.47

182.79

139.77

84.44

58.45

33.95

18.23

14.14

8.53

6.09

3.53

1.96
Wed, May 12, 1993 11:24 Al

MU-BACK Colu NOTES:

\author{
$5 / 10 / 93$ \\ ST1 SN\#04-10 \\ $12.0 \mathrm{~V}$ \\ SUNDATACUBE \\ offset $=11$ \\ $150 \mathrm{e} / \mathrm{bit}$ \\ P.S.\#5008 \\ HEAD\#4163
}


Actual data table for gain of 21500 $s x=\frac{04-10}{11}$ Date $5 / 10 / 93$

\begin{tabular}{|c|c|c|c|}
\hline ND & Mu & Backgnd & Mu-Back \\
\hline 0.85 & 206.23 & 23.44 & \\
\hline 1.0 & 163.21 & & \\
\hline 1.2 & 107.88 & & \\
\hline 1.4 & 81.89 & & \\
\hline 1.6 & 57.39 & & \\
\hline 1.85 & 41.67 & & \\
\hline 2.0 & 37.58 & 23.47 & \\
\hline 2.2 & 32.08 & & \\
\hline $2 . \div$ & 29.56 & & \\
\hline 2.6 & 27.00 & & \\
\hline 2.85 & 25.43 & & \\
\hline
\end{tabular}

Actual data table for gain of $1 \quad 350 \mathrm{e}$

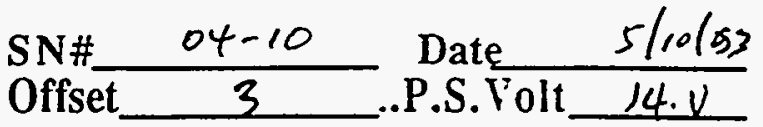

\begin{tabular}{|c|c|c|c|}
\hline ND & Mu & Backgnd & Mu-Back \\
\hline 0.85 & 217.72 & 27.54 & \\
\hline 1.0 & 173.06 &. & \\
\hline 1.2 & 115.02 & & \\
\hline 1.4 & 87.86 & & \\
\hline 1.6 & 67.51 & 27.56 & \\
\hline 1.85 & 46.55 & & \\
\hline 2.0 & 42.09 & & \\
\hline 2.2 & 36.24 & & \\
\hline 2.4 & 33.81 & & \\
\hline 2.6 & 31.02 & & \\
\hline 2.85 & 29.37 & & \\
\hline
\end{tabular}




\subsection{Linearity Data Processing}

Graphing techniques will vary with software. If you use Cricketgraph, select the "scatter" graph format. Note: $\mathrm{Y}$ axis $=\mathrm{Mu}-\mathrm{Back}$; $\mathrm{X}$ axis $=\mathrm{ND}$.

Choose a logarithmic $\mathrm{Y}$ axis and an exponential curve fit.

Here is a flat field linearity graph using Cricketgraph:

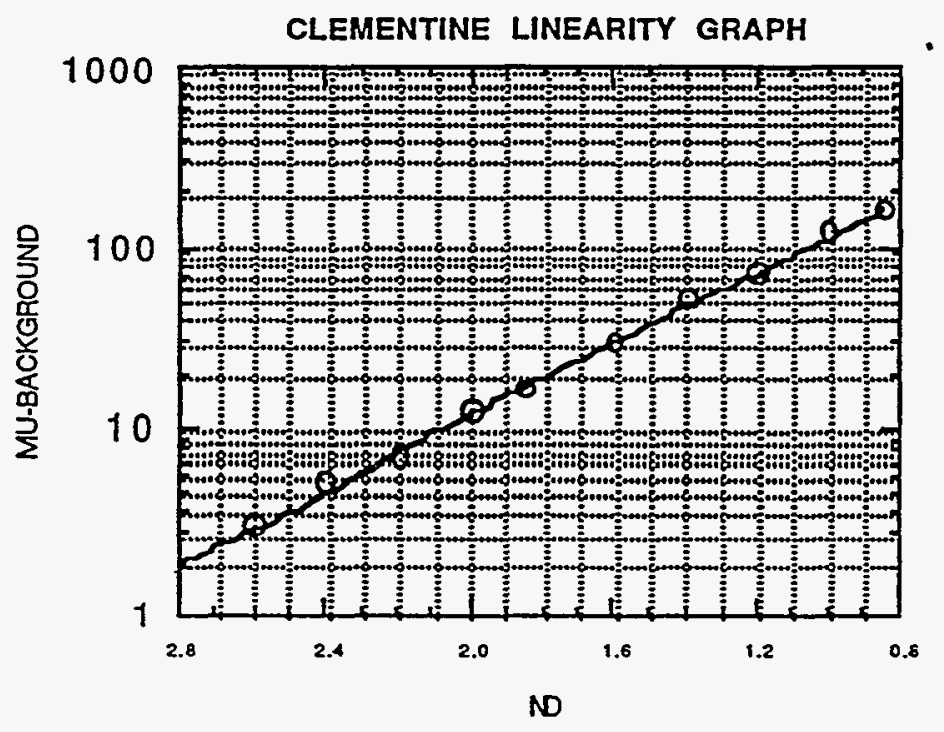

Confirm your linear results:

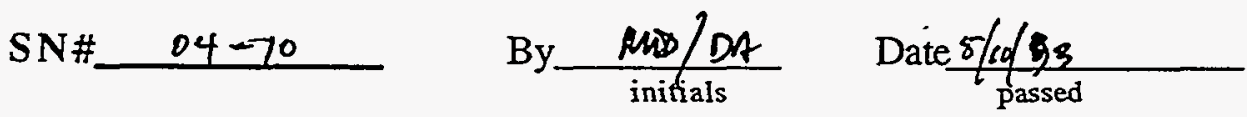

REMEMBER to include your recorded documentation in the test procedure! (a cixument protector is advised) 


\title{
14. Offset Linearity Test
}

This test requires the use of the SUN Datacube and its image processing capabilities, a TV Optoliner Model $\mathrm{K}-4000$ with neutral density(ND) filters ranging up to 1.8, and a resolution chart for focusing.

\subsection{Offset Linearity Test Setup}

Using alcohol and Q-tips, clean the installed CCD.

Verify a properly connected camera acquisition system.

Power up the test fixture.

Put the frame grabber in the grab mode.

Install a total 0.8 Neutral Density (ND) filter and test pattern in the T.V. Optoliner.

Adjust the camera board so that the test pattern image is focused on the $\mathrm{CCD}$.

NOTE: With the focal plane now established, neither the camera nor the optoliner can be moved.

Remove test pattern for a flat field image.Set the board gain to gain setting of 2 .

Remove all ND (ND =0.0) and input a HEX offset of 00 .

Adjust the T.V. Optoliner lamp voltage so that you get a $M U$ of $\approx 250$ counts.

\begin{abstract}
Allow the T.V. Optoliner and camera to warm up under continuous operation for $\approx 1$ hour before proceeding. Keeping the camera's environmental temperature constant and allowing a long warm up requires only one background histogram for linearity computation.
\end{abstract}




\section{-}




\section{ST1 SN\#04-10 OffSET LINEARITY GRAPH}

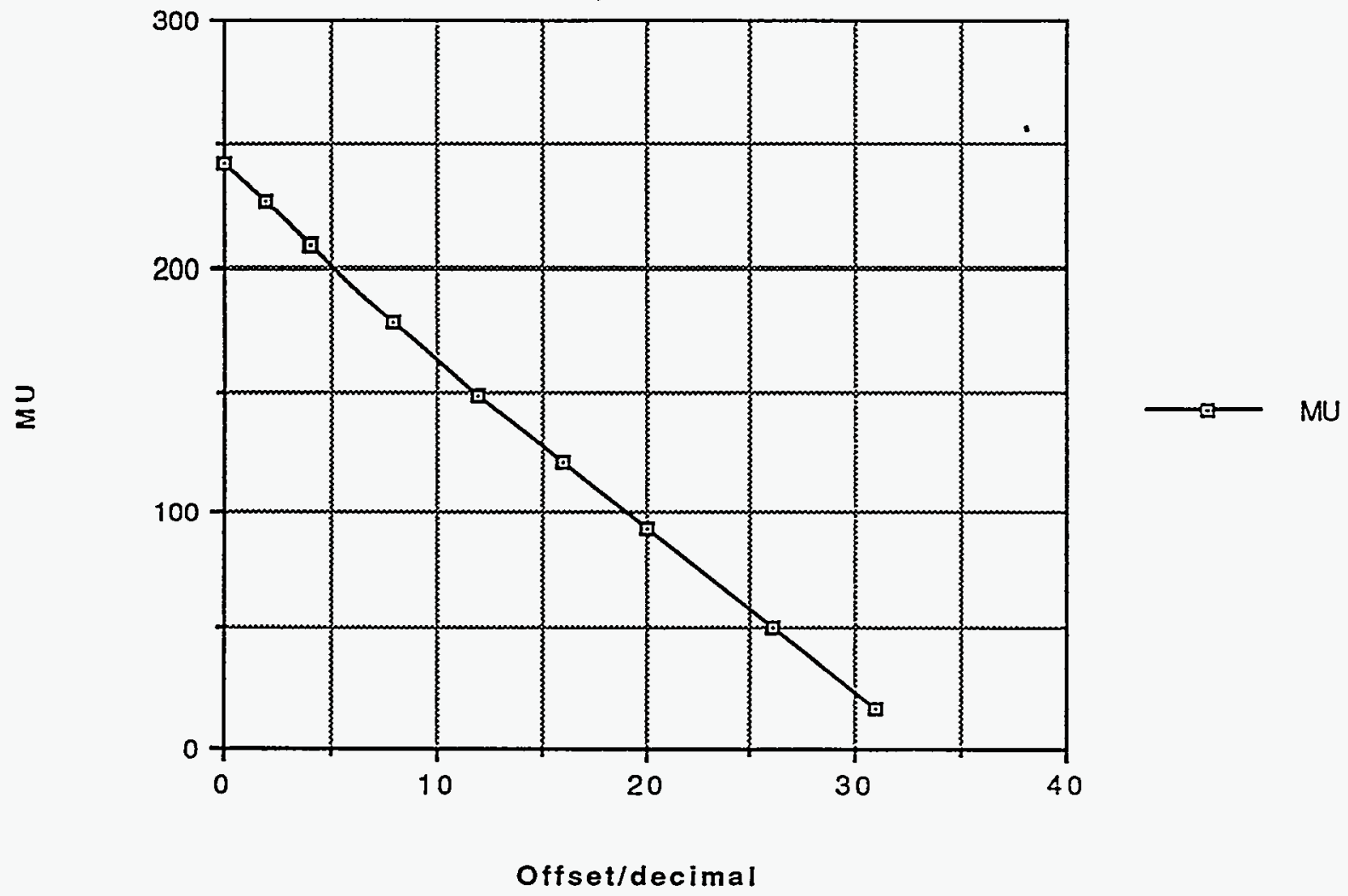


ST1/SN\#04-10/OfFLNDT

MU Colum Column 4

1

$2 \quad 0 \quad 241.41$

3225.41

$\begin{array}{lll}4 & 4 & 209.25\end{array}$

$\begin{array}{lll}5 & 8 & 178.47\end{array}$

$\begin{array}{lll}6 & 12 & 149.11\end{array}$

$\begin{array}{lll}7 & 16 & 121.53\end{array}$

$8 \quad 20 \quad 92.65$

$9 \quad 26 \quad 50.91$

$10 \quad 31$

17.35

$5 / 10 / 93$

ST1 SN\#04-10

P. S. $=14.0 \mathrm{~V}$

CCD\#8846

SUNDATACUBE

$350 \mathrm{e} / \mathrm{bit}$

P.S. \#5008

HEAD\#4163
Wed, May 12, 1993 9:13 AN 


\subsection{Offset Linearity Measurement Acquisition}

Use the SUN Datacube " Acquire and build histogram Sequence " to capture a frame and process a defined region of interest and to analyze for mu/sigma histograms.

\subsection{Offset Linearity Data and Graph}

Begin by taking a background level. Use an ND of 8.0 for background.

Input the offset values listed in the table below recording a histogram of the defined region of interest each time.

Power down the test fixture.

\begin{tabular}{|c|c|c|c|}
\hline Offset & Mu & Backgnd & Mu-Back \\
\hline 00 & 241.41 & 52.12 & \\
\hline 02 & 225.41 & & \\
\hline 04 & 209.25 & & \\
\hline 08 & 178.47 & & \\
\hline 12 & 149.11 & & \\
\hline 16 & 121.53 & & \\
\hline 20 & 92.65 & & \\
\hline 26 & 50.91 & & \\
\hline 31 & 17.35 & & \\
\hline
\end{tabular}


Graphing techniques will vary with software. If you use Cricketgraph, select the "scatter" graph format. Plot MU-BACKGROUND vs OFFSET

Choose a linear $\mathrm{Y}$ axis and linear curve fit.

Here is an offset linearity graph using Cricketgraph:

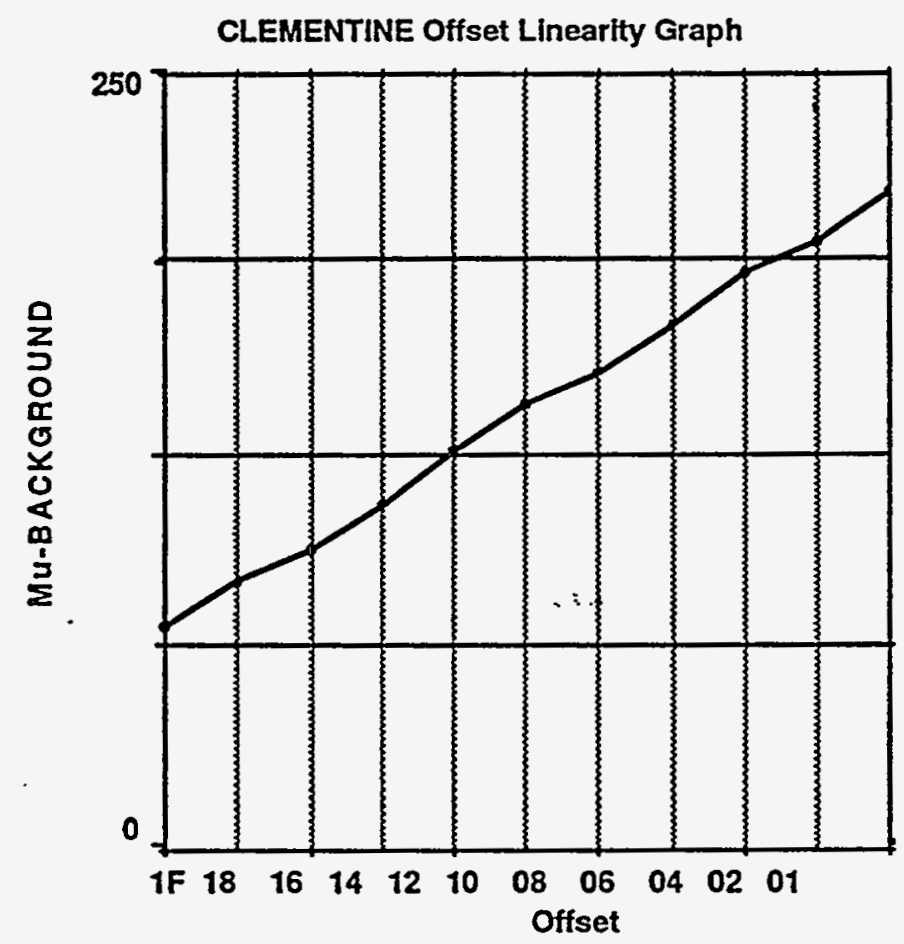

SN\#_ $04-10$
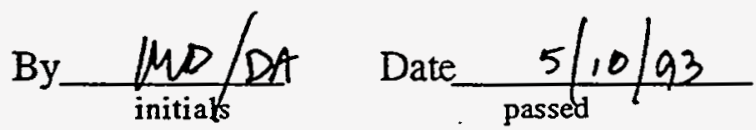

REMEMBER to include your recorded documentation in the test procedure!

(a document protector is advised) 


\section{ST1 \#04-10 LASER TEST 5/11/93}

Pixel Value

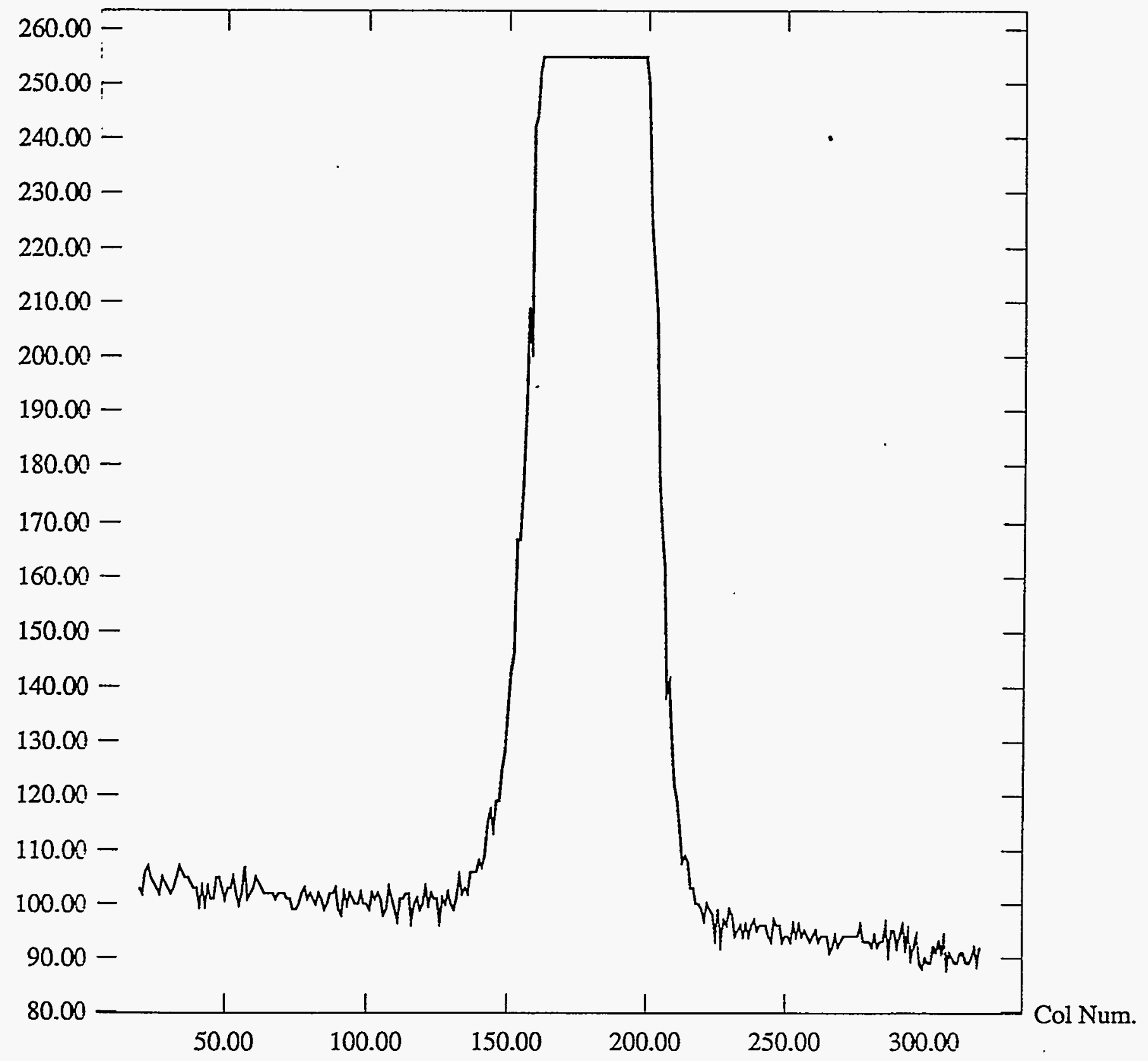



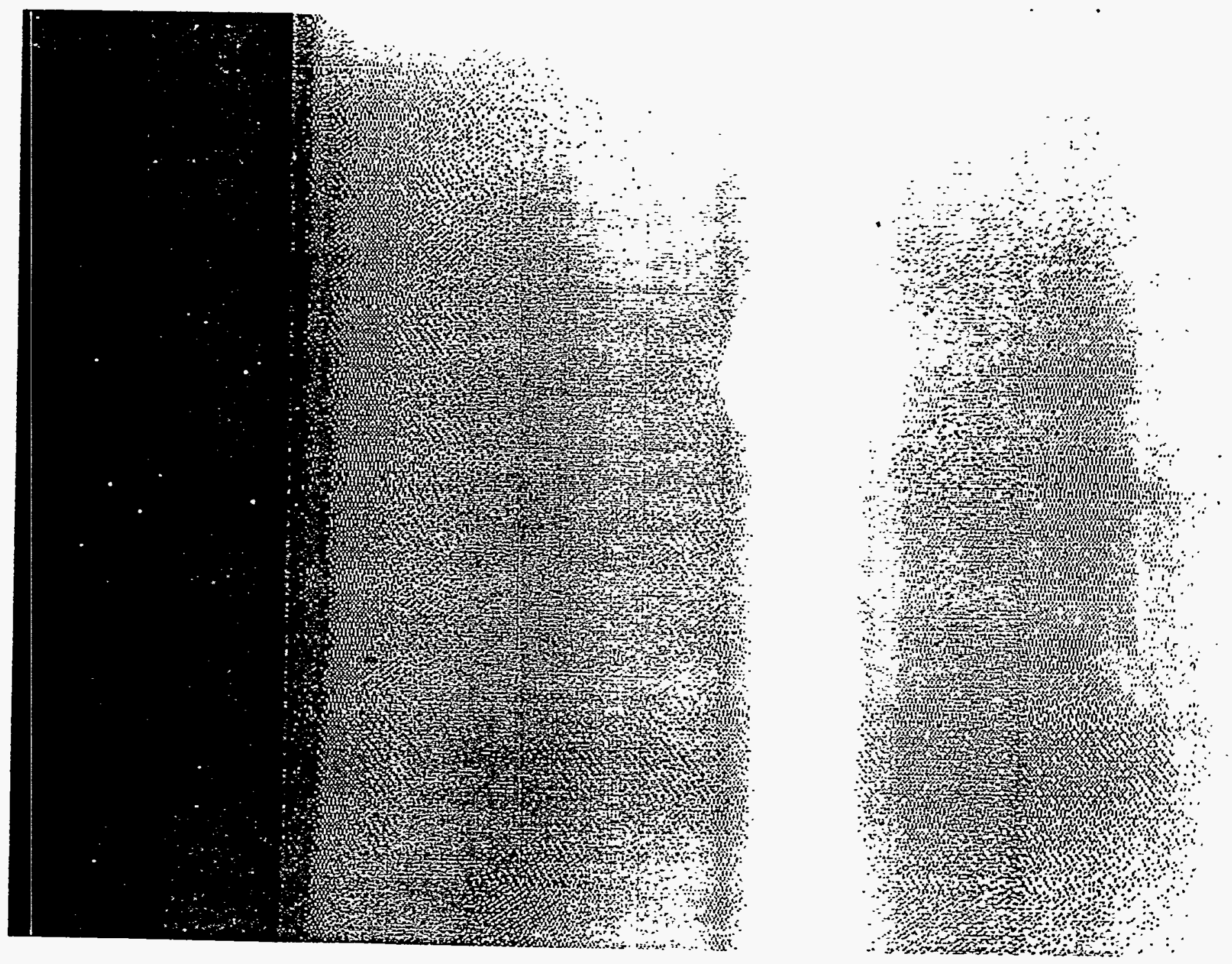
ST Camera: right side: int_time $=50 \mathrm{~ms}$, offset $=31$, gain=2 ( 150 e/bit $)$ Tue May 11 10:31:24 1993 Pixel Values Min 82 Max 96 Mean 87.6 Sigma 1.99

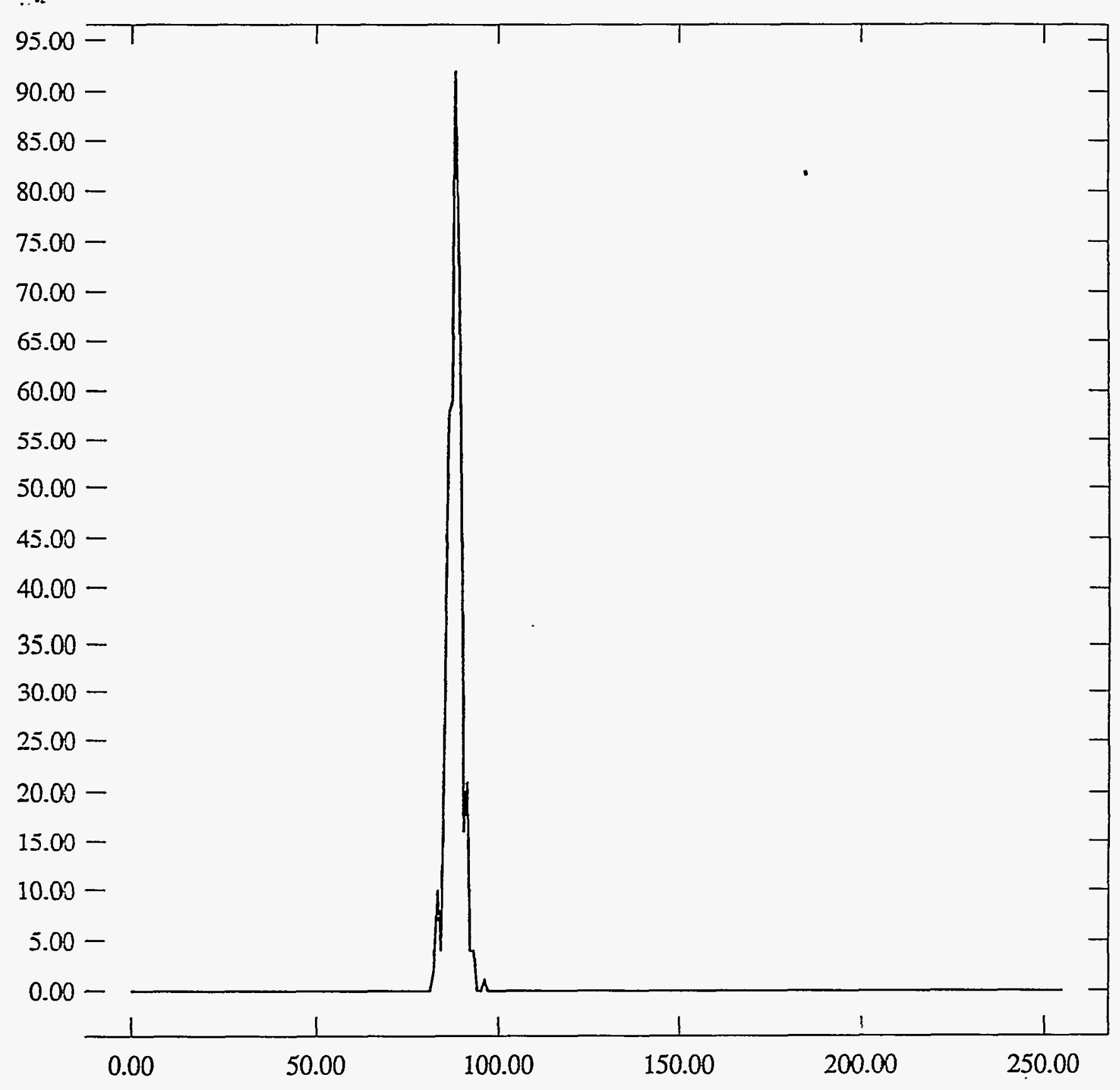


ST Camera: Left side: int time $=50 \mathrm{~ms}$, offset $=31$, gain=2 (150 e/bit) Tue May 11 10:30:21 1993

Pixel Values Min 88 Max 97 Mean 92.5 Sigma 1.89

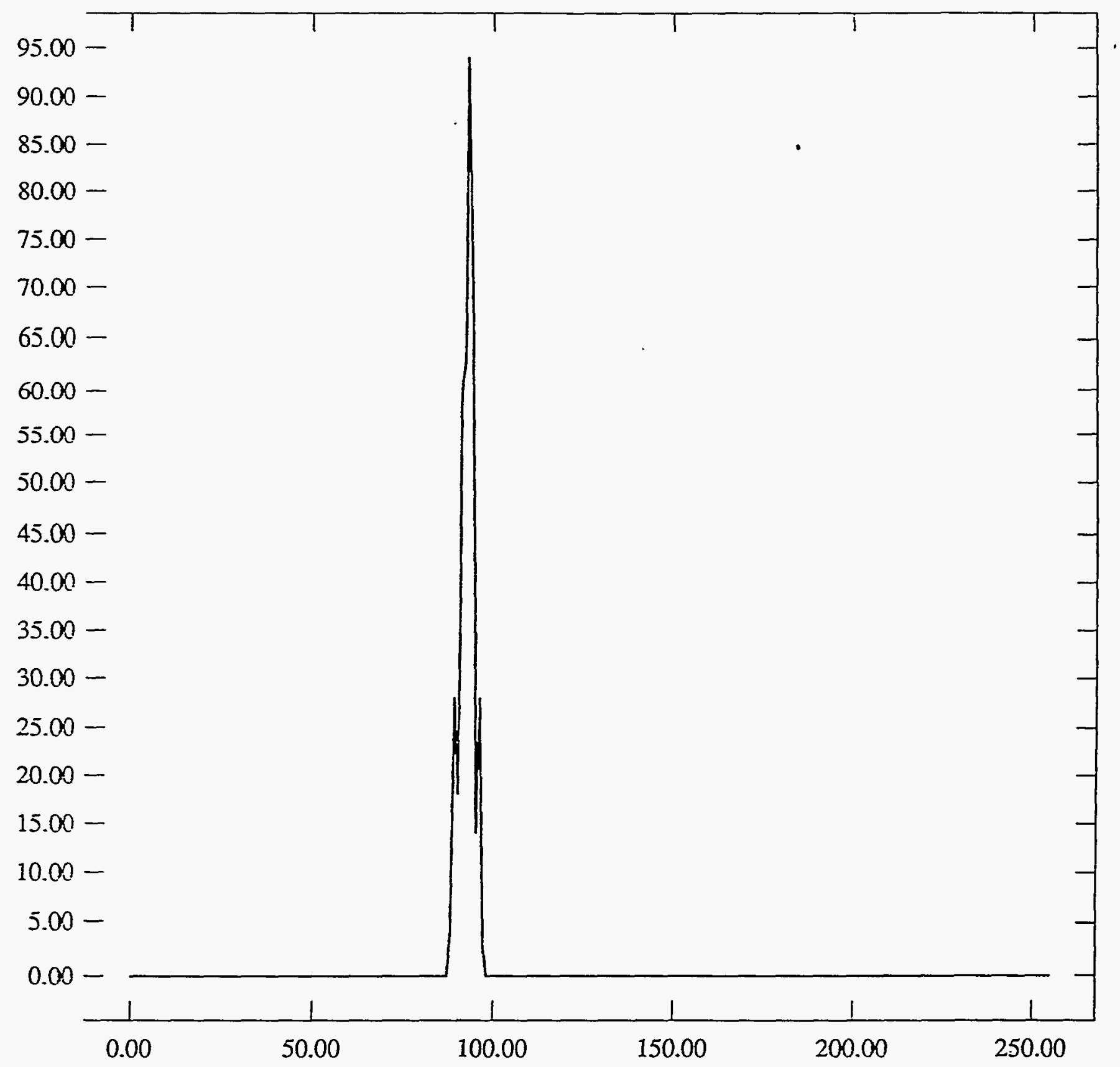




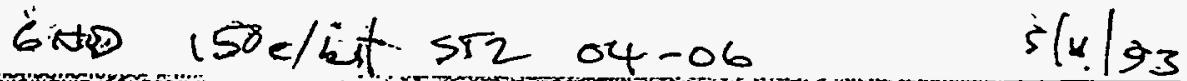

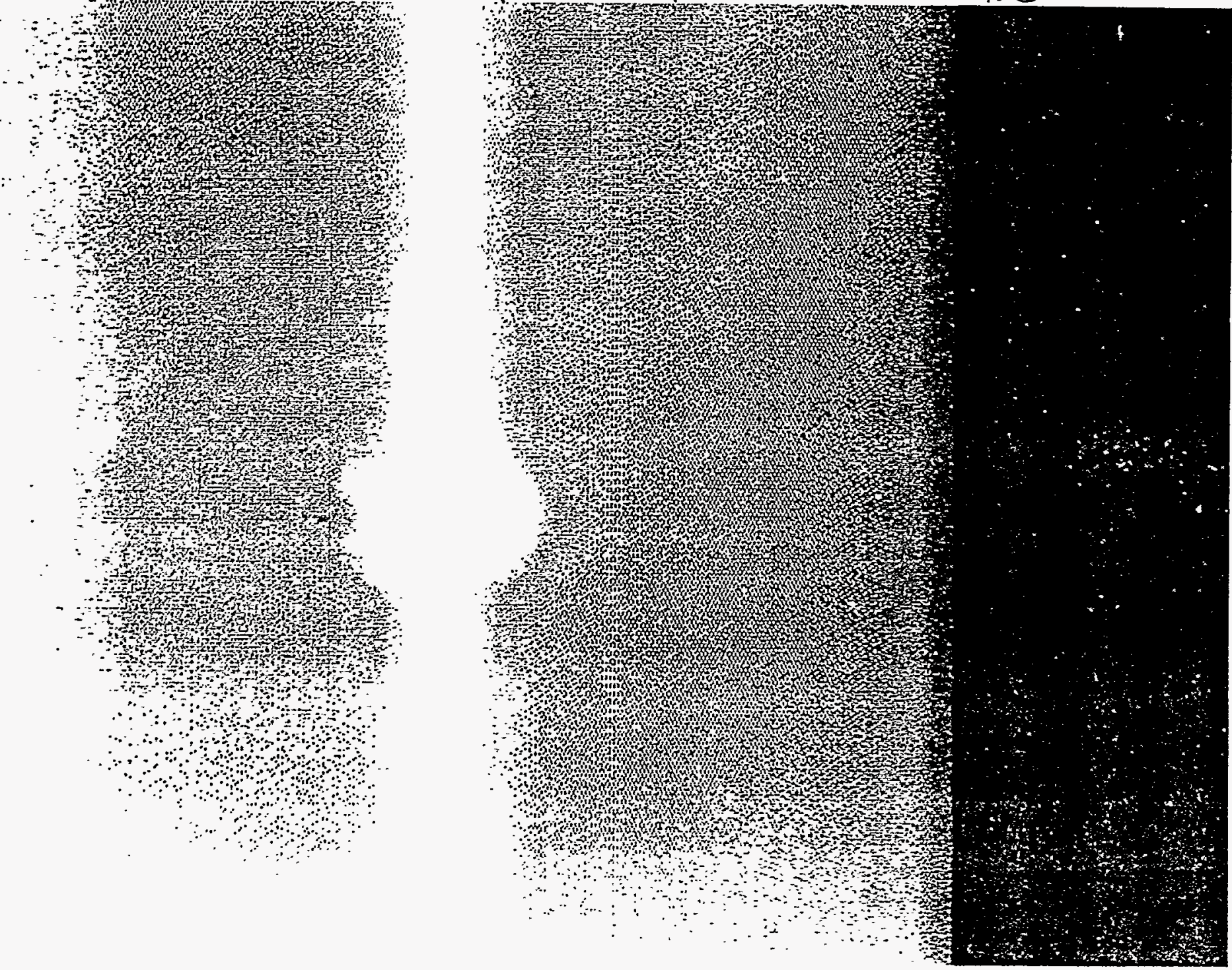


-... 
Row Lineout Row 239

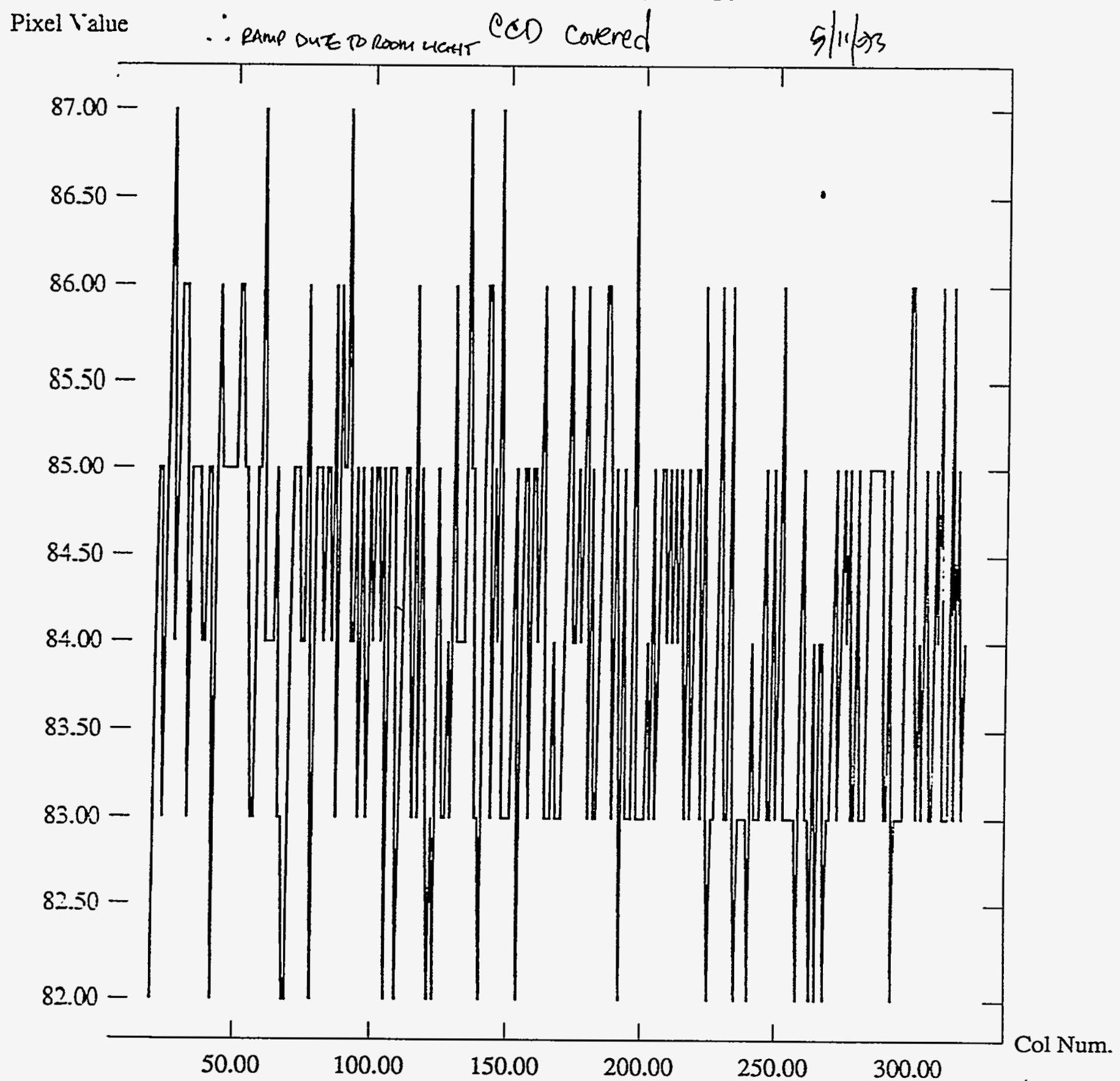




$$
\ldots
$$




\section{Row Lineout Row 239}

Pixel Value CCD NoS CORERED

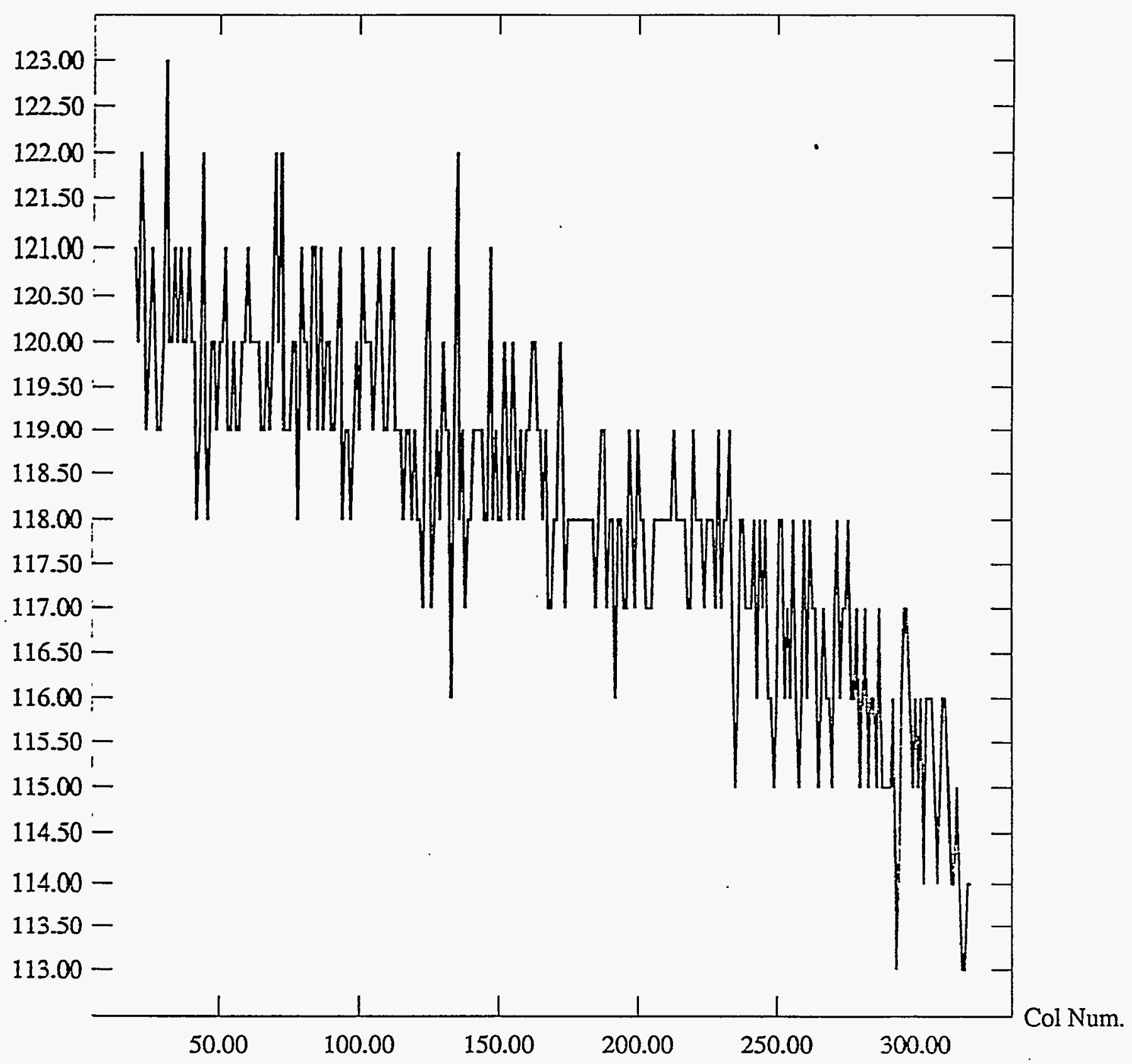




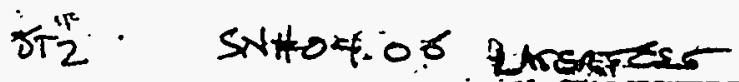

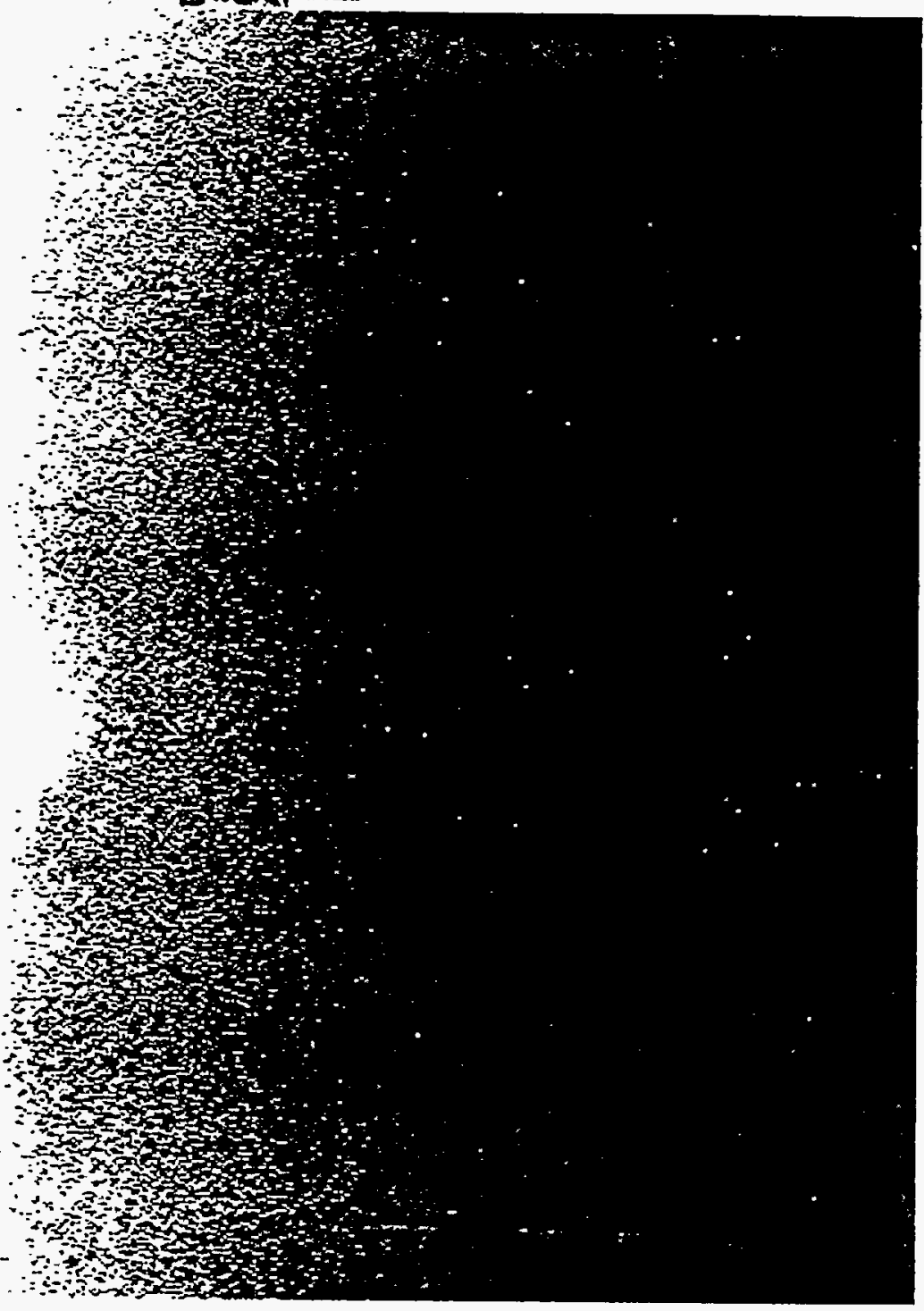




\section{Laser Test}

This test requires the use of the SUN Datacube and its image processing capabilities, a HeNe Laser, $1 \mathrm{~mW}$ at $632.8 \mathrm{~nm}$ appropriate ND filters ranging from 2.0 to 6.0 or combinations equaling such.

Verify a working camera system.

Turn off camera power.

Position a HeNe Laser on the approximate center of the CCD.

Place an optical ND filter holder in the path of the laser beam.

Power the camera:

Place the SUN Datacube in the Acquire mode.

Do a Print Pixel-see Guide to Running hspcube, CI-S1-002-to check pixel values of illuminated area.

Install sufficient optical ND to reduce the intensity of the laser light to the saturation level of the CCD or 255 counts.

Do a Get Row Lineout plot-see Guide to Running hspcube,C1-S1-002-through the illuminate area.

Note: There should be no oscillations or tailing around the saturated spot.

Use the video copier to record the non-oscillating saturated laser spot image.

$S N \# \quad 04-16$
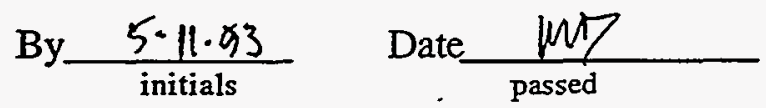

REMEMBER to include your recorded documentation in the test procedure!

(a document protector is advised) 
16. Tests Required after Conformal Coating

Archive/record a post conformal coat:

1) Dark Noise Measurement (Section 11).

2) A focused test pattern image using the TV Optoliner.

SN\#

By__ initials

Date $\frac{}{\text { passed }}$

REMEMBER to include your recorded documentation in the test procedure! (a document protector is advised) 

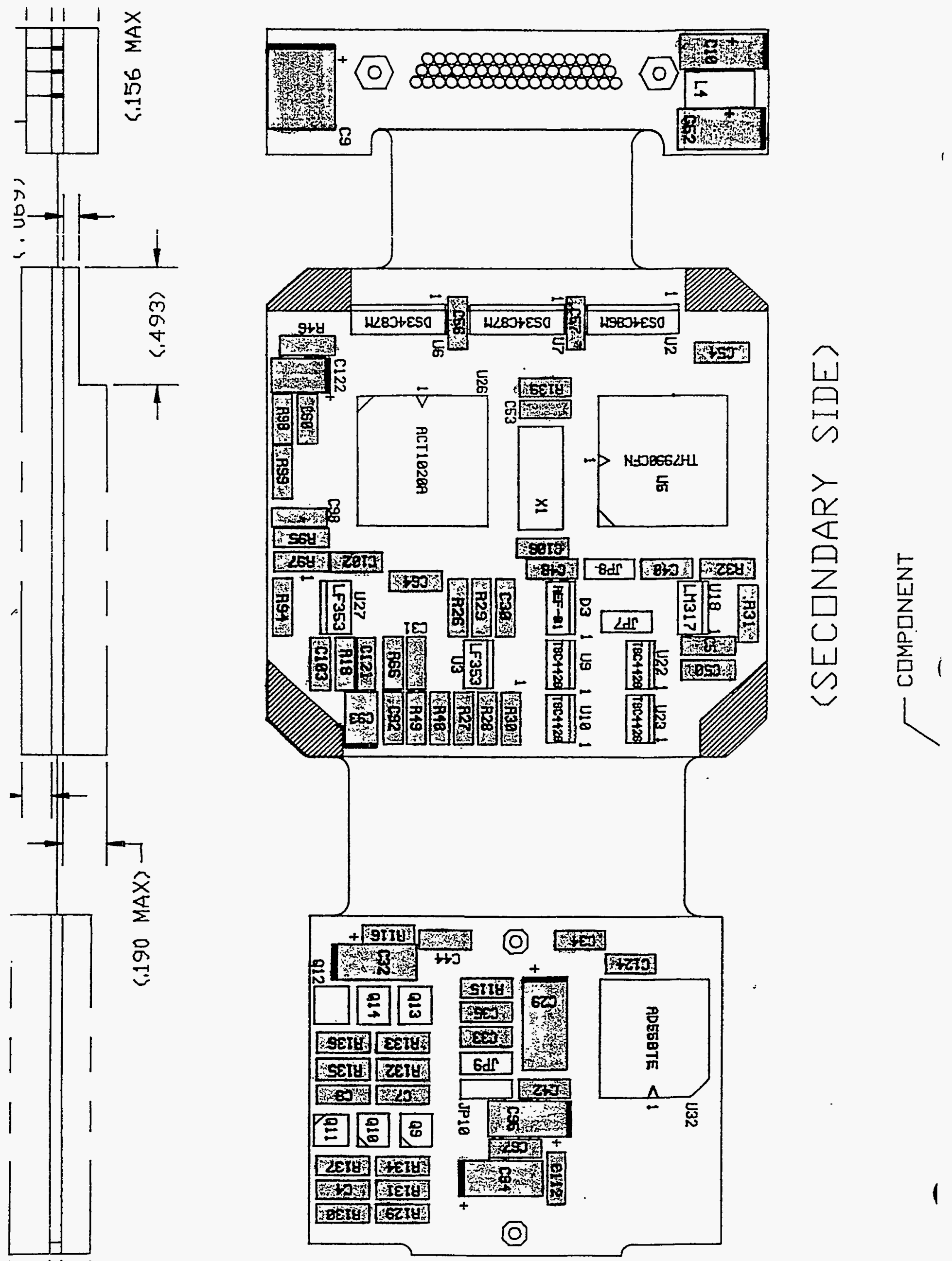


\section{Appendix H.3}

Mechanical Assembly Log 


\section{Appendix H.3.1 Operations Sheet}


$\therefore$

..... 


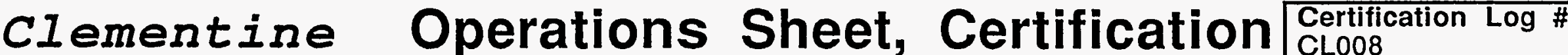

\begin{tabular}{|c|c|c|c|c|c|c|c|}
\hline \multirow{2}{*}{\multicolumn{2}{|c|}{\begin{tabular}{|l|} 
Part Number \\
C1-AAA92-106282 TAB02 \\
Next Assembly / Deliver To: \\
None \\
\end{tabular}}} & \begin{tabular}{|l} 
Serial No. \\
ST314
\end{tabular} & \multirow{3}{*}{\multicolumn{2}{|c|}{ 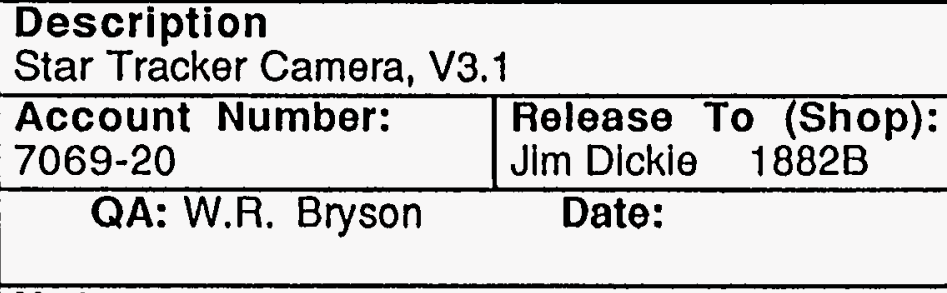 }} & \multirow{2}{*}{\multicolumn{3}{|c|}{ 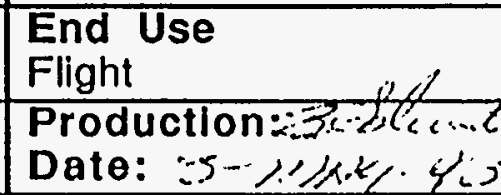 }} \\
\hline & & & & & & & \\
\hline \multicolumn{3}{|c|}{$\begin{array}{lc}\text { Prepared By: } & \text { Date: } \\
\text { Kathy Coatney } & 3 \text { May } 93 \\
\end{array}$} & & & \multicolumn{3}{|c|}{$\begin{array}{l}\text { Approved By: } \\
\text { Date }\end{array}$} \\
\hline \multicolumn{3}{|c|}{ Associated Documentation: } & \multicolumn{5}{|l|}{ Notes: } \\
\hline \multicolumn{8}{|l|}{ Assembly Log, } \\
\hline \multicolumn{8}{|c|}{ Document Tree, C1-AAA92-106282 Tab 02-00 } \\
\hline \multicolumn{8}{|c|}{ Assembly Procedure, C1-S1-012 } \\
\hline \multicolumn{8}{|c|}{ Assembly Drawing, AAA92-106277-00 } \\
\hline \multicolumn{8}{|l|}{ Test Procedure, } \\
\hline \\
\hline \multicolumn{8}{|c|}{ Change Verlfication Record or Engineering Change Notice Record } \\
\hline $\begin{array}{l}\text { Parts List or } \\
\text { Dwg Number }\end{array}$ & $\begin{array}{c}\text { Dwg Chg } \\
\text { Letter }\end{array}$ & $\begin{array}{c}\text { Eco } \\
\text { Number }\end{array}$ & Descri & on or Remarks & & Opr & $\overline{Q A}$ \\
\hline & & & & • & & & \\
\hline & & & & & & & \\
\hline & & & & & & & \\
\hline & & & & & & & \\
\hline & & & & & & & \\
\hline
\end{tabular}




$$
\ldots
$$


Appendix H.3.2

\section{Work Sheets}


$\ldots$ . - . - . 


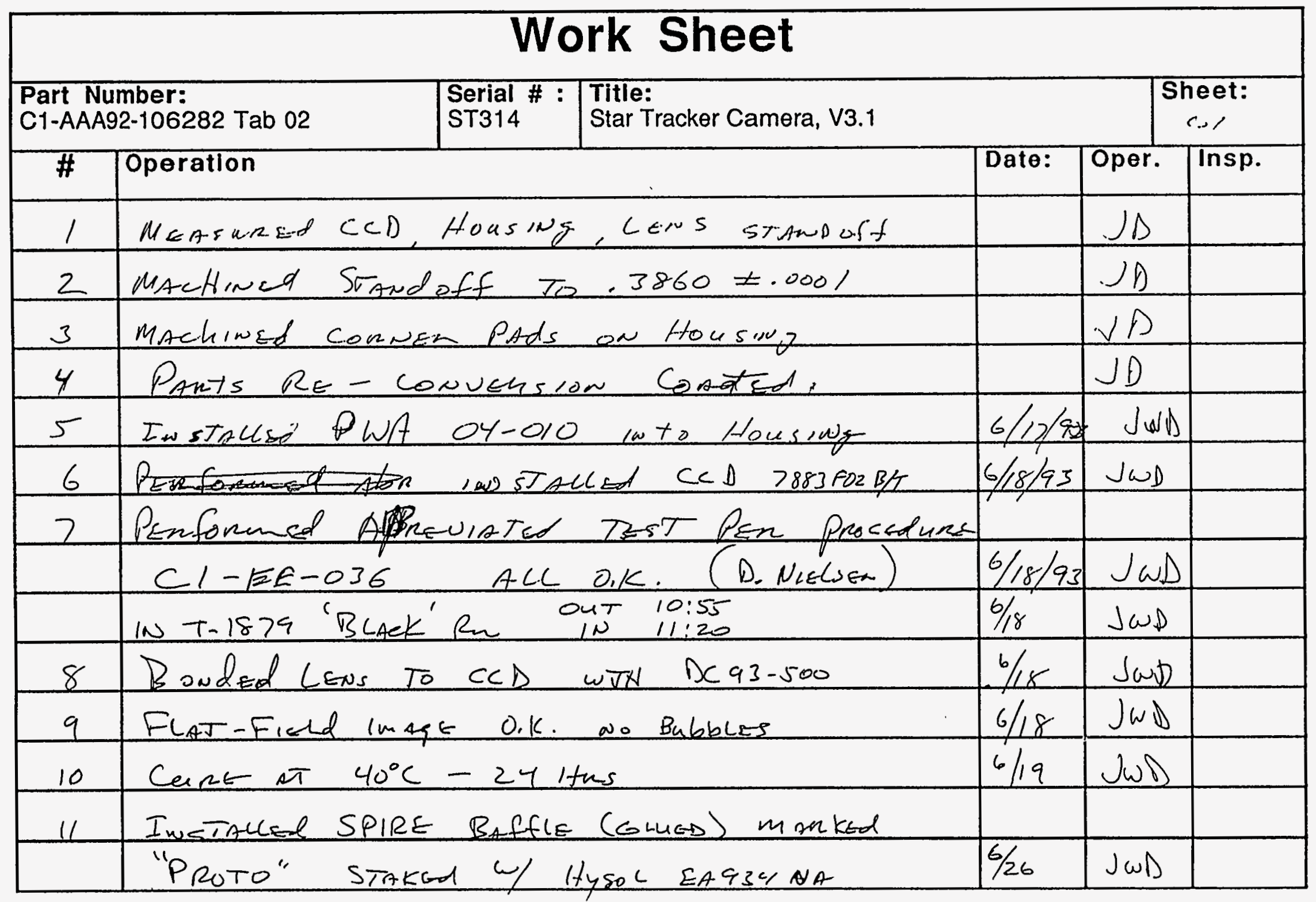




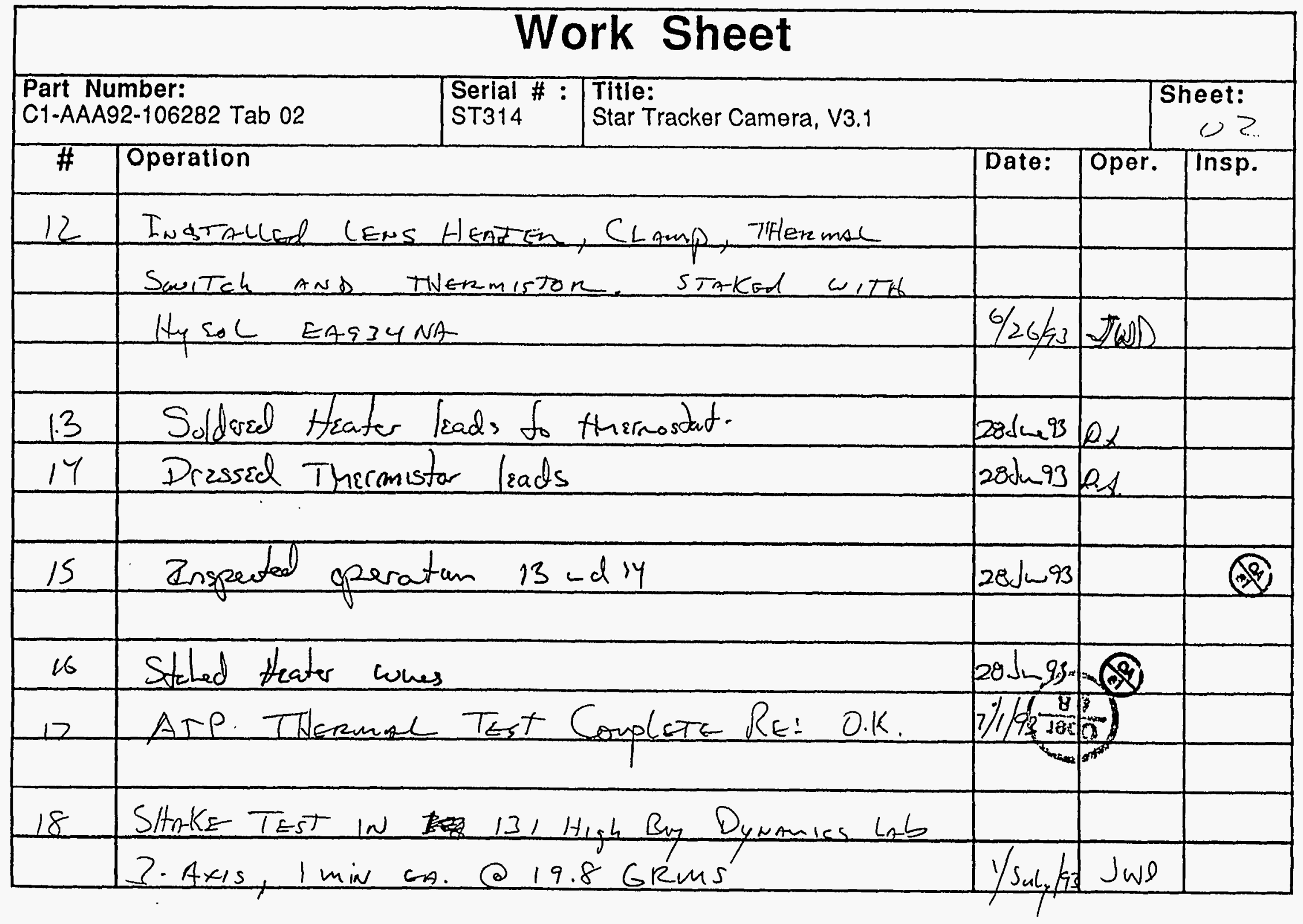




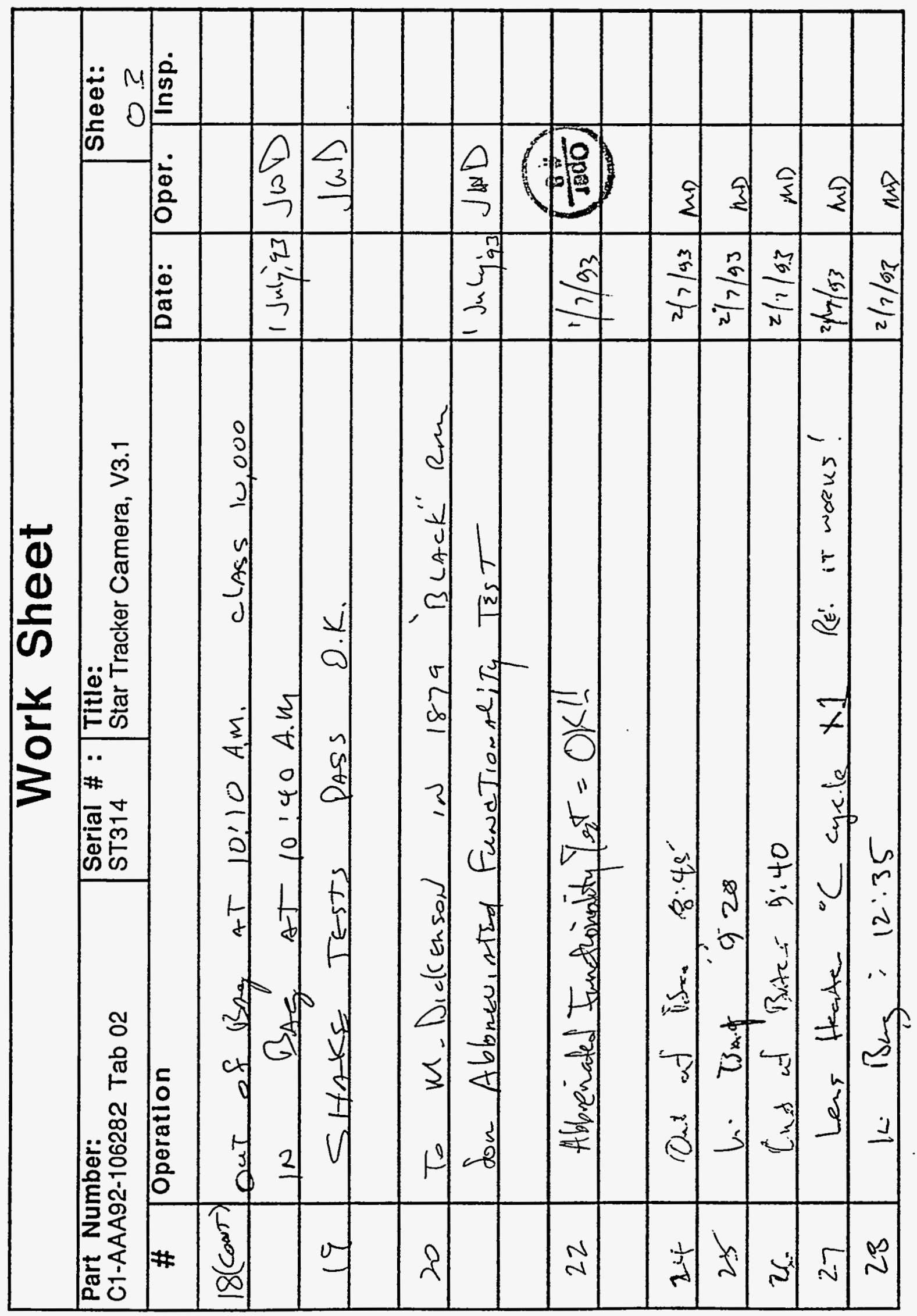




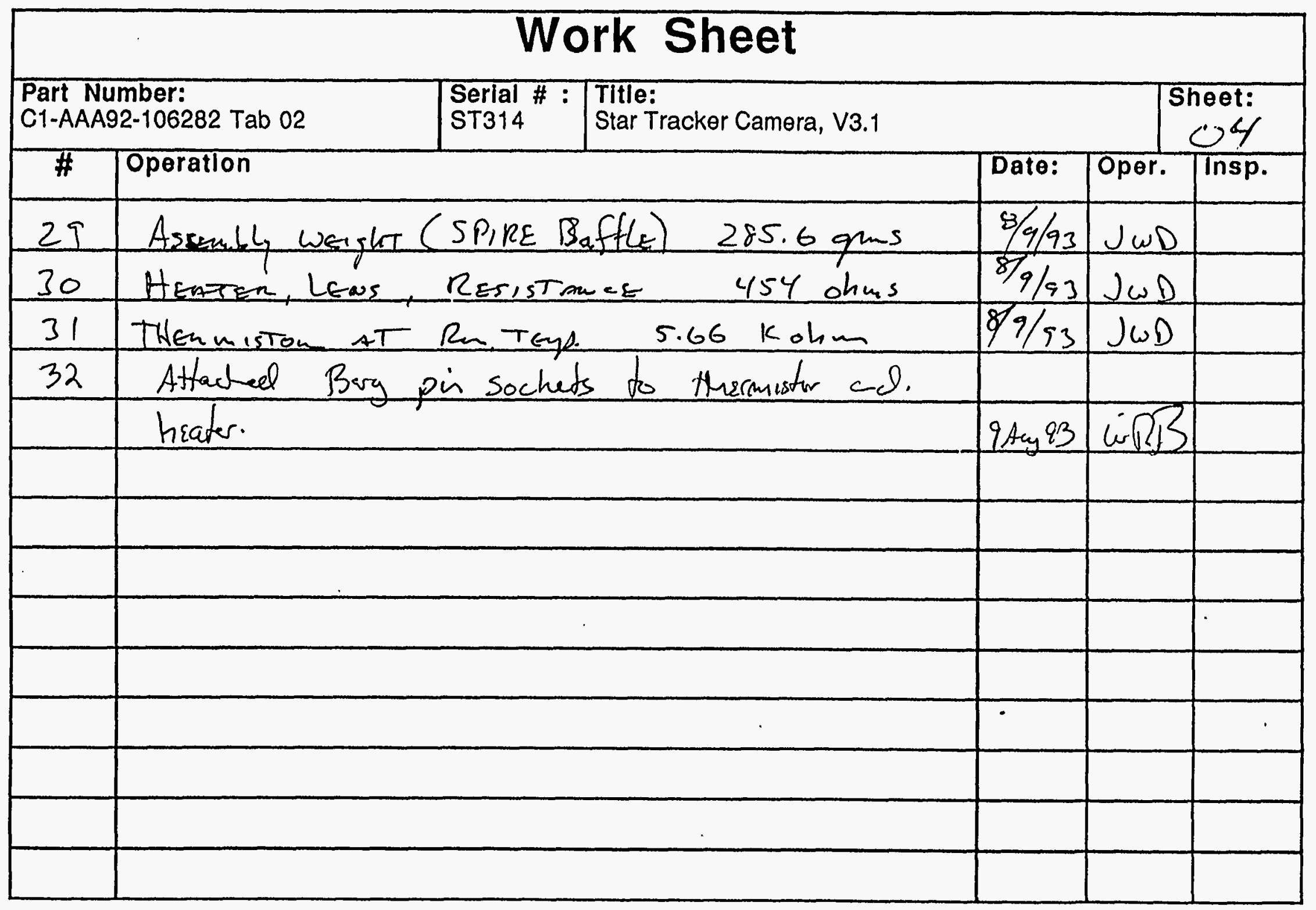




\section{Appendix H.3.3}

\section{Bill of Materials}




\section{Clementine Configuration Management}

\begin{tabular}{ll|}
\hline Document Tree \#: & C1-AAA92-106282 TAB02-00 \\
Title: & Star Tracker Camera Assy, V3.1 \\
Next Higher Tree: & None \\
\hline
\end{tabular}

Serial Number:

File Name:

Software/Op. System: Excel 4.0/Macintosh
S1

Star Tracker Camera -

\section{Comments:}

Star Tracker Camera C1-AAA92-106282 Tab02 uses a ST2A Camera Board

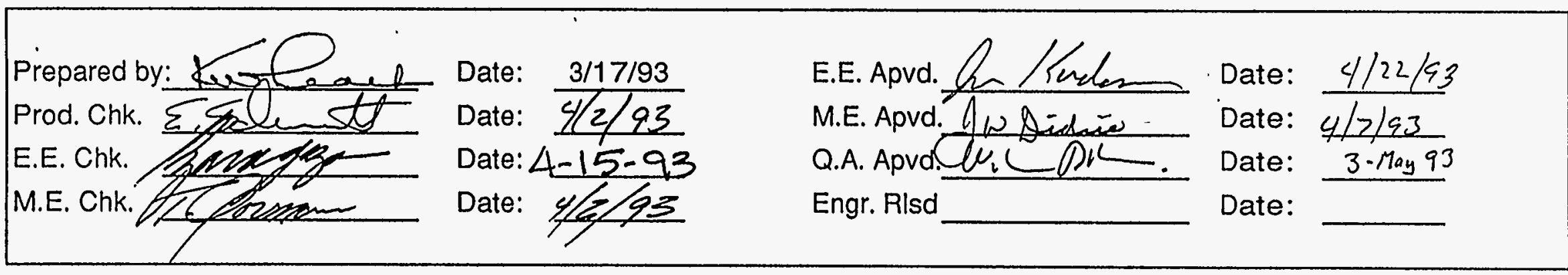

\begin{tabular}{|c||c|c|c|c|c|c|c|c|c|c|c|}
\hline \multicolumn{9}{|c|}{ REVISION HISTORY } & & & \\
\hline Level & 00 & & & & & & & & & \\
\hline Date & $\cdot$ & & & & & & & & & & \\
\hline & & & & & & & & & & \\
\hline
\end{tabular}




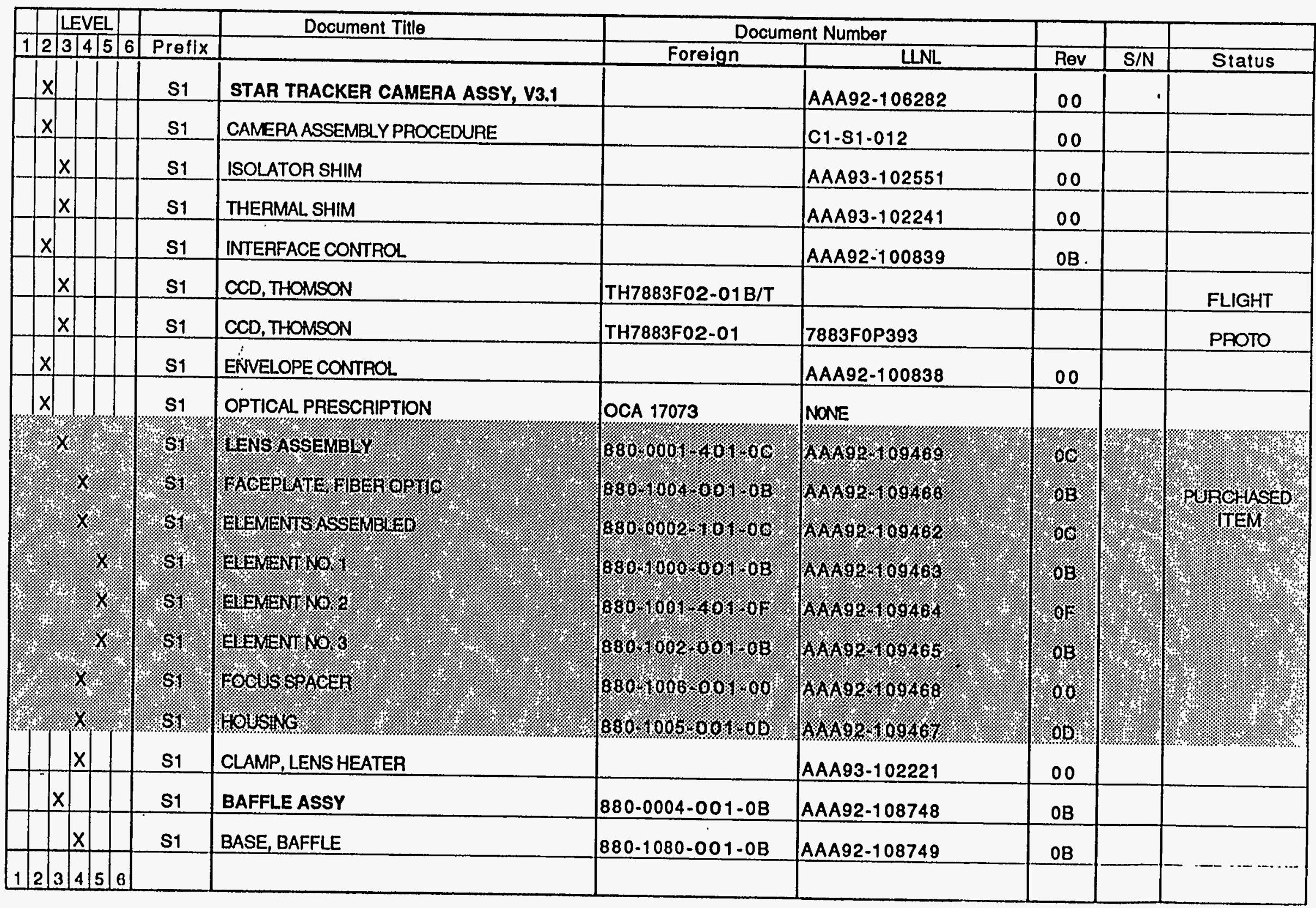




\begin{tabular}{|c|c|c|c|c|c|c|c|c|c|}
\hline \multicolumn{3}{|c|}{ LEVEL } & & Document Title & \multicolumn{2}{|c|}{ Document Number } & & & \\
\hline 12 & \begin{tabular}{|l|l|l|}
3 & 4 & 5 \\
\end{tabular} & \begin{tabular}{|l|l|}
5 & 6 \\
\end{tabular} & Prefix & & Foreign & LLNL & Rev & $S / N$ & Status \\
\hline & $x$ & & S1 & COVER & & AAA93-102598 & 00 & - & \\
\hline & $x$ & & s1 & VANE NO. 1 & 880.1021 .001 & AAA92-108747 & 00 & & \\
\hline & $x$ & & ș1 & VANE NO. 2 & $880-1022.001$ & AAAQ2-108748 & 00 & & \\
\hline & $x$ & & s1 & VANE NO. 3 & 880.1023 .001 & AAA $92-108745$ & 00 & & \\
\hline & $x$ & & s1 & VANE NO. 4 & $880-1024-001$ & AAA92-108744 & 00 & & \\
\hline & $\mathrm{x}$ & & s1 & CAMERA ASSY & & AAA92-106277 & 00 & & \\
\hline & $x$ & & S1 & CAMERAHOUSING & & AAA92-106258 & OC & & \\
\hline & $x$ & & s1 & BUSHING, JACKPOST, MDM CONN. & & AAA93-101167 TABO8 & 00 & & \\
\hline & $x$ & & s1 & CIRCUIT BOARD PAD & $800-3068$ & AAA92-104621 & 00 & & \\
\hline & $x$ & & S1 & END COVER & & AAA92-106249 & $O A$ & & \\
\hline & $x$ & & S1 & SHIM, LOWER, END COVER & & AAA93-102610 & 00 & & \\
\hline & $x$ & & s1 & SHIM, UPPER, END COVER & & AAA93-102609 & $O A$ & & \\
\hline & $x$ & & s1 & CONNECTORBRACKET & & AAA92-106257 & $O A$ & & \\
\hline & $\mathrm{x}$ & & S1 & PAD, CCD THERMAL & & AAA93-102243 & 00 & & \\
\hline & $x$ & & s1 & ICD, CAMERA & & AAA92-104603 & OE & & \\
\hline & $x$ & & S1 & ST2A CAMERA ASSY, W. GAIN \& OFFSET CON & & LEA92-3128-13 & $O A$ & & IN FILE \\
\hline & $\mathrm{x}$ & & S1 & SCHEMATIC, CAMERA, ST2A & & LEA92-3128-11 & OB & & IN FILE \\
\hline & & $x$ & S1 & ARTWORK & & LEA92.3128.02 & 00 & & IN FILE \\
\hline & & $x$ & s1 & BILL OF MATERIALS & & LEA92-3128.04 & OC & & IN FILE \\
\hline 1.2 & $3 \mid 4: 5$ & \begin{tabular}{l|l}
5 & 6 \\
\end{tabular} & & & & & & & \\
\hline
\end{tabular}




\begin{tabular}{|c|c|c|c|c|c|c|c|c|c|c|}
\hline \multicolumn{3}{|c|}{ LEVEL } & & & Document Title & \multicolumn{2}{|c|}{ Document Number } & & & \\
\hline $1 / 2$ & $2 \sqrt[3]{4}$ & 45 & 6 & Prefix & & Foraign & LINL & Rev & $S / N$ & Status \\
\hline & & & $x$ & s1 & SPACER (CONN. STANDOFF) & & AAA92-104616-TAB01 & OC & - & \\
\hline & & & $x$ & si & MTG. HAROWARE & $800-3043$ & AAA92-104607-TABO1 & 00 & & \\
\hline & & & $\underline{x}$ & $\mathbf{S 1}$ & NUT, PCB RETAINER & & AAAQ2.109126 & $O A$ & & \\
\hline & & $x$ & & s1 & ASSEMBLYY PAOCEDURE & & LEA92-3128-05 & OB & & IN FILE \\
\hline & & $x$ & & S1 & TEST PROCEDURE & & LEA92-3128-16 & 00 & & N/A \\
\hline & & $x$ & & s1 & FAB DRAWING & & LEA92-3128-07' & $O A$ & & IN FILE \\
\hline & & $x$ & & s1 & ARRAY DOCUMENTATHN-U26 & & LEA92-3128-18 & 00 & & NOT SIGNED \\
\hline & $x$ & & & s1 & THERMISTER, FENWALL & 137-562-ZXT-DO2 & & & & \\
\hline & $x$ & & & S1 & LENS STANDOFF & & AAA93-102550 & $O A$ & & \\
\hline 1$] 2$ & 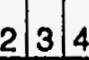 & 45 & 6 & & & & & & & \\
\hline
\end{tabular}


Appendix H.3.4

Assembly Procedures 
" 


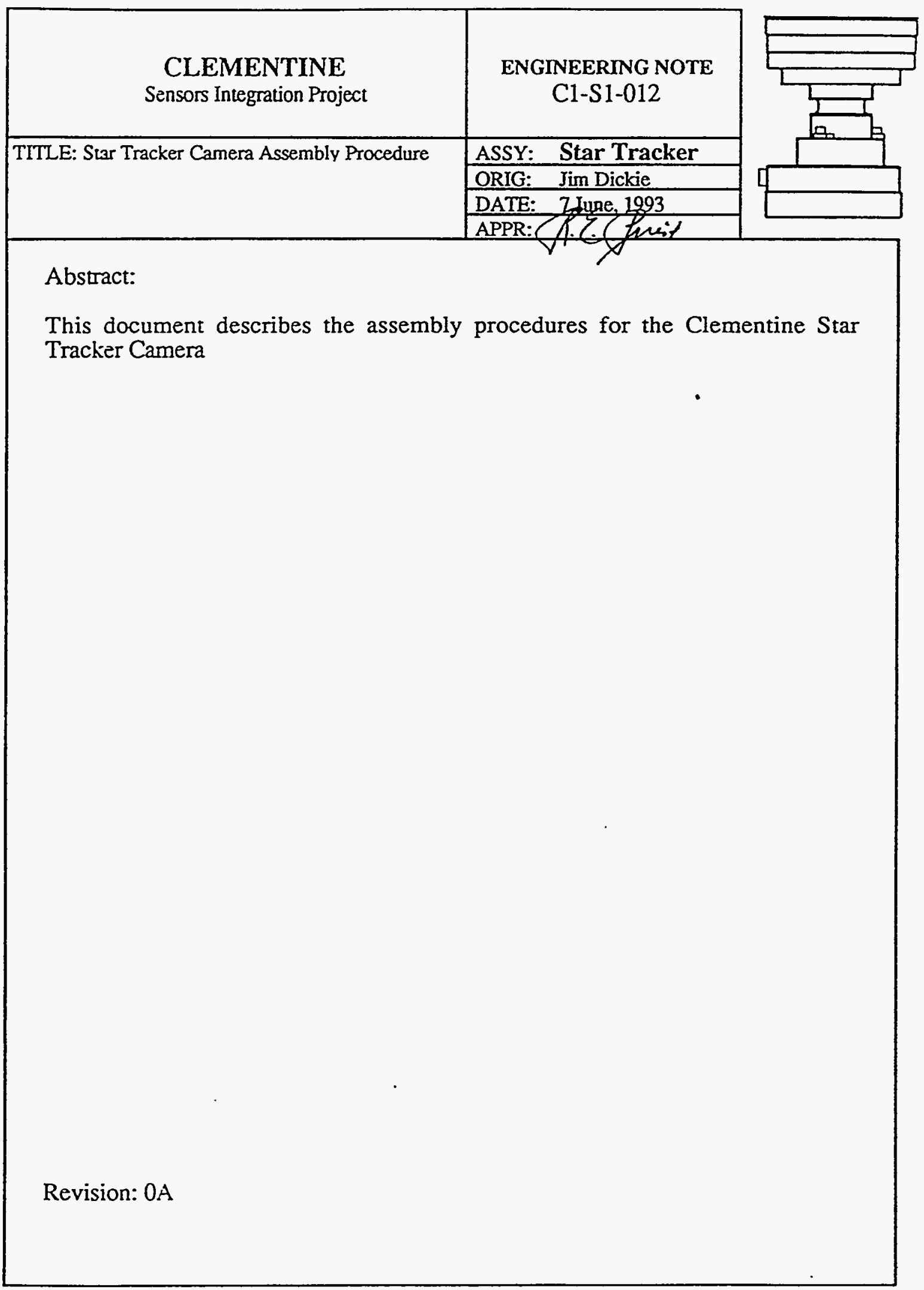




\section{Engineering Note \\ C1-S1-012}

\section{CLEMENTINE}

Star Tracker Camera

Assembly Procedures

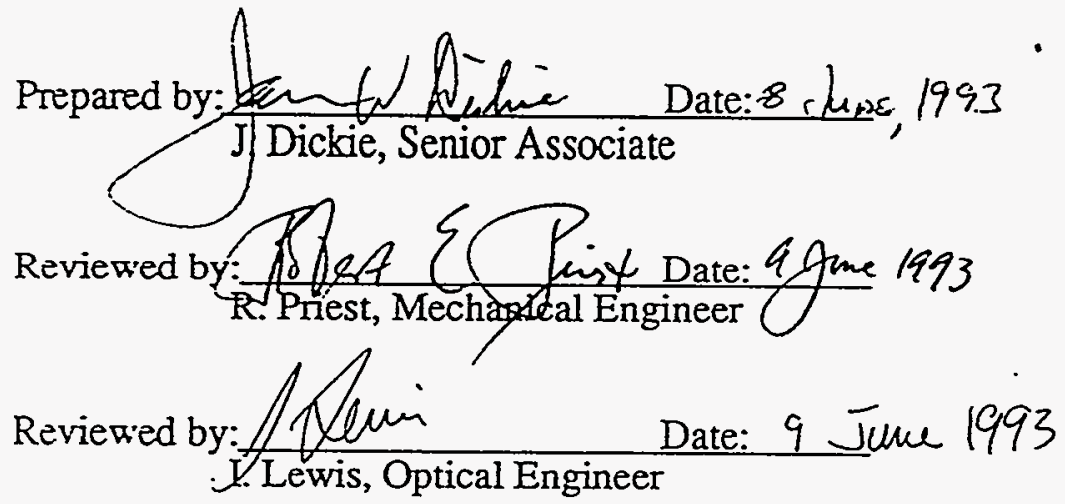

Reviewed by: $\mathrm{W} / \mathrm{C}-1 / \mathrm{K}$ Date:/ Whe 83

W. Bryson, Quality Assurance

Reviewed by: Nex Date: $610-23$

W. Rice, Quality Assurance

Reviewed by: .

E. Schmitt, Production

Reviewed by: If K Then Date: 10 Junp 1993 Kordasy STC Sensor Engineer

Approved bo : Date: $14 \mathrm{mB}$ 


\subsection{General}

1.1 Scope

This document details steps required to assemble the Clementine Star Tracker Camera (STC).

\subsection{Description}

The STC consists of an Actel electronics PWA, a Thomson TïH7883-FO2-01 $\mathrm{B} / \mathrm{T} \mathrm{CCD}$ (Flight cameras only, prototype cameras will utilize a non-B/T TH7883-F02-01 unit), mechanical hardware that encases the PWA and CCD, a mini-concentric Wide Field of View (WFOV) lens, and a light baffle. The camera is used for imaging stars to determine the position of a vehicle in space.

Assembly includes general mechanical assembly, testing to verify quality of optical couplant between the CCD and the lens fiber optic field flattener, measurement and possibly adjustment of the optical axis normal to the camera mounting surfaces, abbreviated electrical function testing prior to final staking, and final staking.

\subsection{Reference Documents and Drawings}

1.3.1 C1-ME-008, Clementine Sensors General Contamination Control Plan.

1.3.2 C1-S0-TBD, Clementine ESD Protection Plan.

1.3.3 C1-S1-TBD, STC Abbreviated Electronic Function Test Procedure.

1.3.4 MLL-STD-1686, Handling of ESD Sensitive Equipment.

1.3.5 MIL-STD-1246B, Product Cleanliness Levels and Contamination Control Plan.

1.3.6 C1-S0-005, Adhesives, Compounds, and Optical Couplants.

1.3.7 C1-S0-TBD, Clementine Quality Assurance Program Plan

\subsection{Deviations}

Procedural deviations or changes from specified procedures which do not affect the physical assembly may be made at the discretion of the responsible engineer. Deviations or changes which require any mechanical or electronic change may be made only after review and approval by a suitable Material Discrepancy Review Board as defined in the Clementine QA Program Plan.

\subsection{Electro-Static Discharge Control Requirements}

The STC contains electrostatic-sensitive devices which are exposed on the PWA and $C C D$ prior to assembly closure and at the electrical interfaces after assembly closure. Therefore, it shall be handled per MIL-STD-1686 Class 1. All work shàll be performed in an approved electrostatic discharge control area as defined by the Clementine Quality Assurance Group.

The STC, the test operator (using wrist straps), and related electrical test equipment shall be connected to a common ground before any electrical mating or de-mating operations, and during the use of any electrical test equipment probes. There shall be no "hot-plugging" of the test specimen with any test equipment. 
All electrostatic sensitive parts shall be stored in approved antistatic storage bags when not in use.

\subsection{Cleanliness and Contamination Control Requirements}

All assembly work shall be performed in a Class 100 laminar flow hood located within a Class 10,000 environment as defined in LLNL document 'Clementine Sensors General Contamination Control Plan'.

Handling of all parts shall be with clean lint-free gloves. Personnel shall wear face and hair protective smocks when handling exposed oftics.

\subsection{Photographs}

Photographs shall be taken of the unit at major subassembly steps and of the final assembled unit. A suitable ruler shall be used to provide scale.

\subsection{Disassembly Contingency}

Due to the optical bonding of the CCD to the lens fiberoptic, and the time required to dissolve this bond line, there is no disassembly of an STC allowed beyond step 4.3.5, with the special exception noted in step 4.3.9. If any camera is found to be defective at any point beyond step 4.3 .5 , a total restart of this assembly procedure is required.

\subsection{Parts List}

2.1 From the kitted assembly, where applicable, record all part serial numbers for this camera into the table below.

\begin{tabular}{|c|c|c|c|c|}
\hline$\underline{\text { Item }}$ & Description & Reference No. & Serial No. & Quantity \\
\hline 1 & Camera Housing & $92-106258$ & 04 & 1 \\
\hline 2 & Lens Standoff & $93-102550$ & 314 & 1 \\
\hline 3 & End Cover & $92-106249$ & 04 & 1 \\
\hline 4 & Baffle Assembly & $92-108748$ & & 1 \\
\hline 5 & WFOV Lens Assembly & $92-109469$ & 006 & 1 \\
\hline \multirow[t]{2}{*}{6} & $\begin{array}{l}\text { Actel PWA Assembly } \\
\text { Includes: }\end{array}$ & LEA92-3128-03 & $04-010$ & 1 \\
\hline & $\begin{array}{l}\text { Spacer, Tab-01 } \\
\text { Nut, 2-56 } \\
\text { Nut, PEM, 2-56 } \\
\text { Thermistor, Fenwal }\end{array}$ & $\begin{array}{l}\text { 92-104616 } \\
\text { NAS \#671-C02 } \\
\text { CRES } \\
\text { 137-562-ZXT-D02 }\end{array}$ & $\begin{array}{l}\mathrm{n} / \mathrm{a} \\
\mathrm{n} / \mathrm{a} \\
\mathrm{n} / \mathrm{a} \\
\mathrm{n} / \mathrm{a}\end{array}$ & $\begin{array}{l}2 \\
2 \\
2 \\
1\end{array}$ \\
\hline 7 & Jackpost, Tab-08 & $93-101167$ & $\mathrm{n} / \mathrm{a}$ & 2 \\
\hline 8 & CCD, Thomson & $\begin{array}{l}\text { TH7883-FO2-01 } \\
\text { (Prototype Cameras) }\end{array}$ & $A / A$ & 1 \\
\hline
\end{tabular}




\begin{tabular}{|c|c|c|c|c|}
\hline 9 & CCD, Thomson & $\begin{array}{l}\text { TH7883-FO2-01 B/T } \\
\text { (Flight Camera Only) }\end{array}$ & 3350 & -31 \\
\hline 10 & Pad, Circuit Board & $92-104621$ & $\mathrm{n} / \mathrm{a}$ & 1 \\
\hline 11 & Pad, CCD Thermal & $93-102243$ & $\mathrm{n} / \mathrm{a}$ & 1 \\
\hline 12 & Connector Bracket & $92-106257$ & $\mathrm{n} / \mathrm{a}$ & 1 \\
\hline 13 & $\begin{array}{l}\text { Socket head cap } \\
\text { screw, } 2-56 \times .187 \text { lg. }\end{array}$ & NAS \#1352-N02-3 & $\mathrm{n} / \mathrm{a}$ & 14 \\
\hline 14 & $\begin{array}{l}\text { Socket head cap } \\
\text { screw, } 2-56 \times .250 \mathrm{lg} \text {. }\end{array}$ & NAS \#1352-N02-4 & $\mathrm{n} / \mathrm{a}$ & 6 \\
\hline 15 & $\begin{array}{l}\text { Socket head cap } \\
\text { screw, } 2-56 \times .375 \mathrm{lg} \text {. }\end{array}$ & NAS \#1352-N02-6 & $\mathrm{n} / \mathrm{a}$ & 3 \\
\hline 16 & $\begin{array}{l}\text { Socket head cap } \\
\text { screw, } 2-56 \times .50 \mathrm{lg} \text {. }\end{array}$ & NAS \#1352-N02-8 & $\mathrm{n} / \mathrm{a}$ & 2 \\
\hline 17 & Washer, \#2, Ø0.25 & NAS \#620-N02 & $\mathrm{n} / \mathrm{a}$ & 8 \\
\hline 18 & Washer, Thermal & $93-102551$ & $\mathrm{n} / \mathrm{a}$ & 6 \\
\hline 19 & Thermistor, Fenwal & 534-31AG04-562 & $\mathrm{n} / \mathrm{a}$ & 1 \\
\hline 20 & Clamp, Lens Heater & $93-102221$ & $\mathrm{n} / \mathrm{a}$ & 1 \\
\hline 21 & Heater, Lens, Minco & HK17402-9311 & $\mathrm{n} / \mathrm{a}$ & 1 \\
\hline 22 & Switch, Sundstrand & $974-0014-774$ & $\mathrm{n} / \mathrm{a}$ & 1 \\
\hline 23 & Tape, Reflective & Sheldahl & $\mathrm{n} / \mathrm{a}$ & $\mathrm{a} / \mathrm{r}$ \\
\hline 24 & Shim, End, Upper & $93-102609$ & $\mathrm{n} / \mathrm{a}$ & 2 \\
\hline 25 & Shim, End, Lower & $93-102610$ & $\mathrm{n} / \mathrm{a}$ & 2 \\
\hline
\end{tabular}

Parts logged into assembly by: K Koxtugy Date: $6 / 93$

\subsection{Required Tools}

2.2.1 As part of this procedure, the following tools, with current calibration certificates, are required for assembly.

1. Torque wrench, capable of reading 0 to 10 inch-pounds minimum, with $0.1 \mathrm{in}-\mathrm{lb}$ resolution.

2. 0-1 inch Micrometer with 0.0001 inch resolution.

3. 0-1 inch Depth micrometer with 0.0001 inch resolution. 


\subsection{Adhesives, Couplants, Staking Compounds}

3.1 For additional information on all compounds, refer to Clementine Engineering Note C1-S0-005, 'Adhesives, Compounds, and Optical Couplants'

\begin{tabular}{|c|c|c|c|c|c|}
\hline Item & Description & PotLife & Cure & Lot No. & Exp. Dats \\
\hline 1 & $\begin{array}{l}\text { Staking Compound } \\
\text { Hysol EA934NA }\end{array}$ & $30 \mathrm{~min}$. & 2 hrs.@50C & & 7194 \\
\hline 2 & $\begin{array}{l}\text { Optical Couplant } \\
\text { DC 93-500 }\end{array}$ & $2 \mathrm{hrs}$. & 24 hrs.@50 C & & 5194 \\
\hline 3 & $\begin{array}{l}\text { Thermal Epoxy } \\
\text { BA-2151 }\end{array}$ & $30 \mathrm{~min}$. & 3 hrs.@50 $\mathrm{C}$ & & 5194 \\
\hline 4 & $\begin{array}{l}\text { Silver Epoxy } \\
\text { BA-2902 }\end{array}$ & $30 \mathrm{~min}$. & 3 hrs. @ 50 C & - & $12 / 93$ \\
\hline 5 & $\begin{array}{l}\text { Thermal Grease } \\
\text { DC- } 340\end{array}$ & $\mathrm{n} / \mathrm{a}$ & $\mathrm{n} / \mathrm{a}$ & - & -1 \\
\hline
\end{tabular}

\subsection{Assembly Procedure}

Initials / Date

4.1 PWA Installation Into Camera Housing

4.1.1 Remove the Actel Camera PWA, P/N LEA92-306703 , from the carrier per procedure C1-S0-TBD.

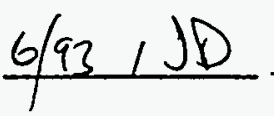

4.1.2 -Using-a-certified-micrometer-accurate-to-0.0001-inches, measure the PWA thickness at the four thermal pads as shown in figure 1. Record these measurements to 4 significant figures (nominal is .046 \pm .005 ).
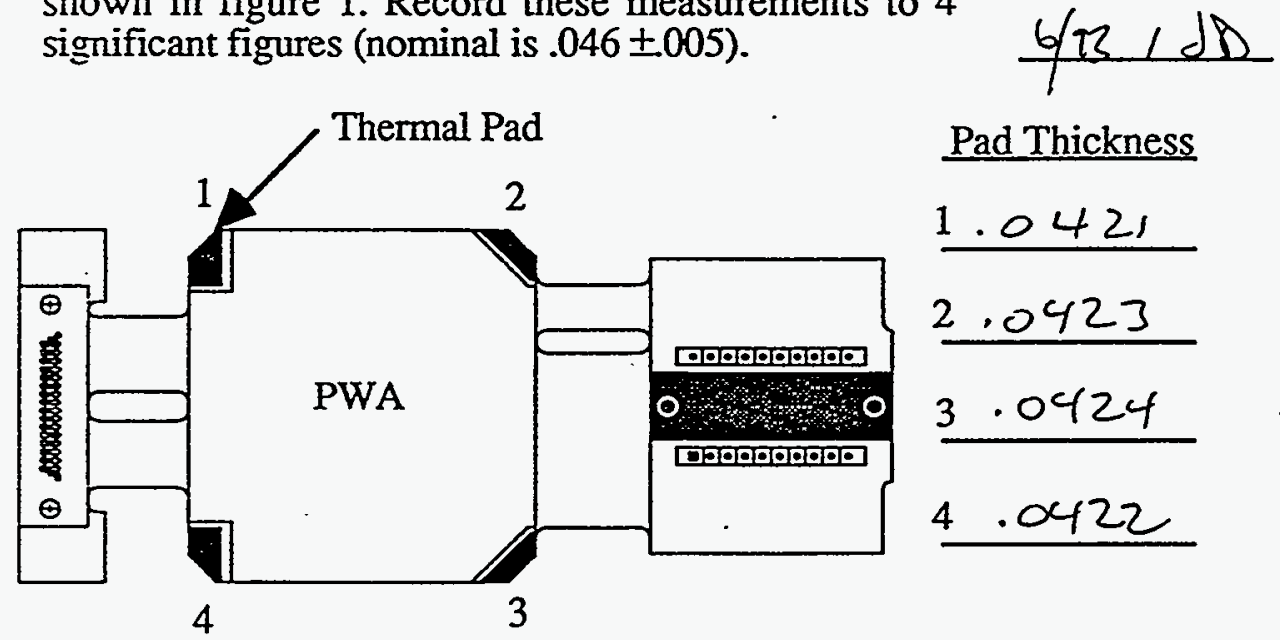

FIGURE 1

4.1.3 Place PWA in oven set to $50^{\circ} \mathrm{C}$ for 20 minutes. Remove PWA from oven and while still hot, bend to shape as shown in Circuit Board ICD drawing No. 92-104603 and figure 2.

\section{$\underline{\text { Pad Thickness }}$}

1.0421

2.0423

$3 \cdot 0424$

4.0422 


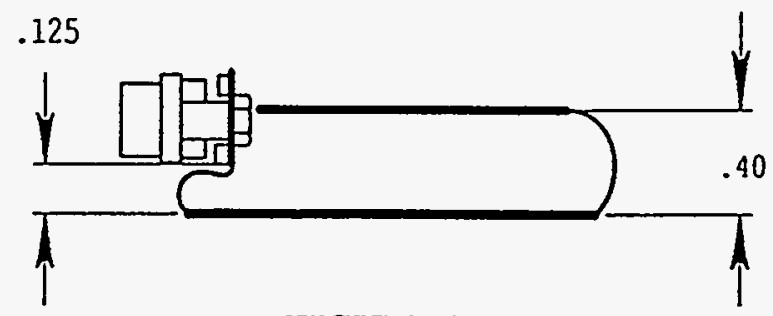

FIGURE 2

4.1.4 Using the optical comparator with the $100 \mathrm{X}$ objective for maximum sensitivity, measure the step height at the four corners for PWA mounting on the Camera Housing $\mathrm{P} / \mathrm{N}$ 92-106258 as shown in Figures 3 and 5 (nominal is $.050+.000,-.005$ ). Record these measurements to 4 significant figures. This step should be $0.0005 \pm 0.0001$ less then the measured thickness of the PWA at the corresponding thermal pad areas as recorded in step 4.1.1. If correction is required, have the camera housing reprocessed, and the 2-56 threaded inserts installed before proceeding to step 4.1.5.
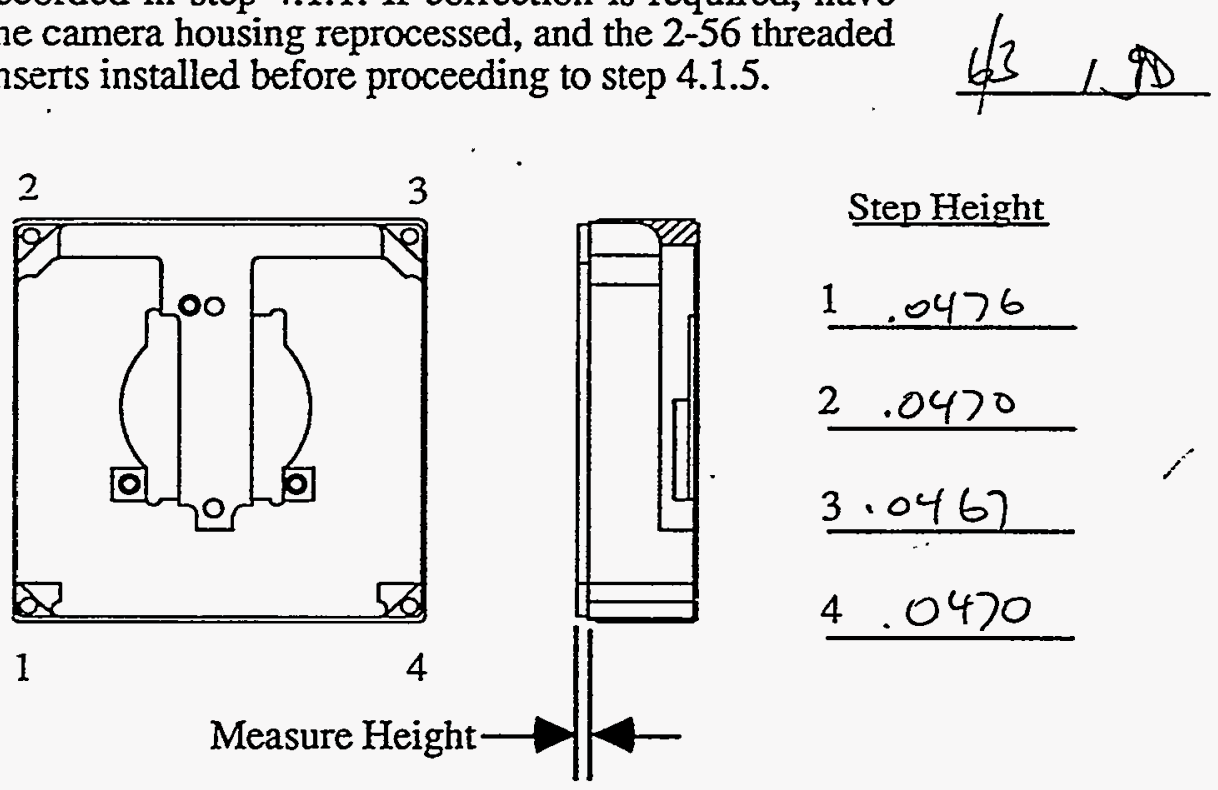

FIGURE 3

4.1.5 Remove and discard the 2 screws holding the PWA connector to spacers. Install Connector Bracket P/N 92-106257 over connector. See figure 4.

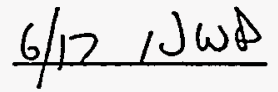


4.1.6 Install PWA board into Camera Housing with Circuit Board Pad P/N 92-104621 and 2-56 washers installed between PWA assembly and housing heat sink. Important, apply a thin layer (.001 in. thick, max.) of DC-340 thermal grease to both sides of the circuit board pad prior to installation.

Secure connector and connector bracket with 2 each, Jackposts P/N 92-104607-Tab 01. Torque to $3.5 \pm 0.1$ in-lb.

The thermistor fits in the slot on the finger of the Camera Housing as shown in figure 4. Be careful not to pinch the thermistor leads.

Secure PWA with 2 each, 2-56 x .25 long socket head cap screws. Torque to $3.5 \pm 0.1 \mathrm{in}-\mathrm{lb}$.

Stake thermistor with BA-2151 thermal Compound.

Stake fasteners with EA934NA. Cure for $3 \mathrm{hrs}$ at 50 ${ }^{\circ} \mathrm{C}$.
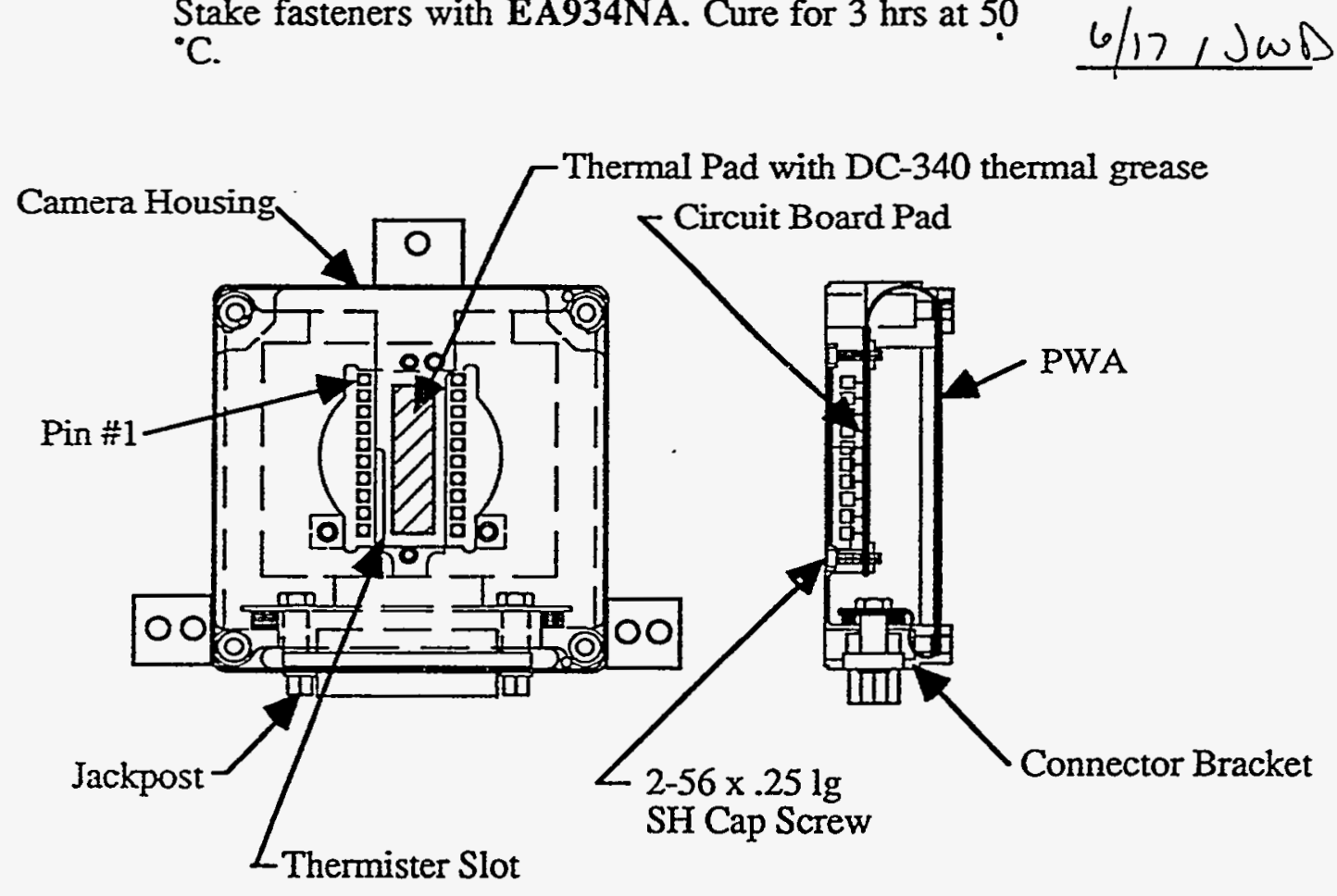

FIGURE 4

4.1.7 Apply a thin (.002 in. thick, max.) layer of BA-2902 Silver Epoxy to 4 thermal contact pads at internal corners of End Cover P/N 92-106249. Place End Cover Shims, P/N 93-102609 and 93-102610 in position on corresponding end cover pads. Cure for 3 hours at $50^{\circ} \mathrm{C}$.

4.1.8 Apply a thin (.001 in. thick, max.) layer of DC-340 thermal grease to both sides of the four PWA thermal contact areas at corners of camera body, and the mating corners of the end cover/shim assembly.

Install end cover and secure with 4 each, 2-56 x .25 long socket head cap screws. Torque to $3.5 \pm 0.1 \mathrm{in}-1 \mathrm{~b}$. Do not stake fasteners at this time.

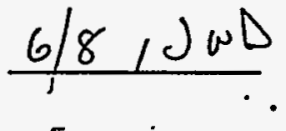

$6 / 77 / J w 0$ 
4.2 CCD Installation Into Camera Housing

4.2.1 Prior to installation of $\mathrm{CCD}$ into camera, with extreme caution so the fiberoptic is not scratched, measure the overall thickness of the CCD to 4 significant figures using the optical comparator with the $100 \mathrm{X}$ objective for maximum sensitivity. Record this measurement to 4 significant figures.

CCD Thickness_. . 3393

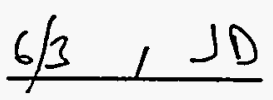

\subsubsection{Install Thomson TH7883-FO2-01 CCD (TH7883-} FO2-01 B/T for flight cameras only) into PWA connector, being careful to install CCD Thermal Pad $\mathrm{P} / \mathrm{N}$ 93-102243 between $\mathrm{CCD}$ and housing. IMPORTANT: be sure to apply a thin (.001 in. thick, max.) layer of DC-340 thermal grease to both surfaces of the thermal pad during installation. See figure 4.

IMPORTANT: Verify location of pin \#1 with socket $\ddot{* 1}$ prior to installation of $\mathrm{CCD}$ (see fig. 4).

Visually inspect assembly to verify $\mathrm{CCD}$ is completely and evenly seated onto thermal pad.

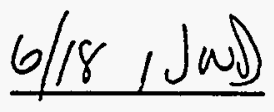

4.2.3 Perform abbreviated PWA board/CCD electronic functionality test per procedure $\mathrm{C} 1-\mathrm{S} 1-(\mathrm{TBD})$, and verify good thermal contact between $C C D$ and heat sink Record results. Pass/No Pass PASS

4.2.4 If pass, proceed with assembly section 4.3. If no pass, stop assembly procedure until problem has been identified and corrected, and camera passes abbreviated electronics functionality test.
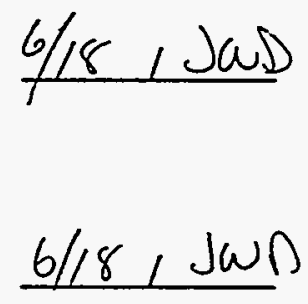

\subsection{Lens Standoff Installation}

4.3.1 Using the optical comparator with the $100 \mathrm{X}$ objective for maximum sensitivity, measure the step height from the lens standoff mounting ring to the thermal finger surface in the camera body. Record this measurement to 4 significant figures. See Figure 5.

Housing Step Depth

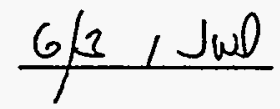




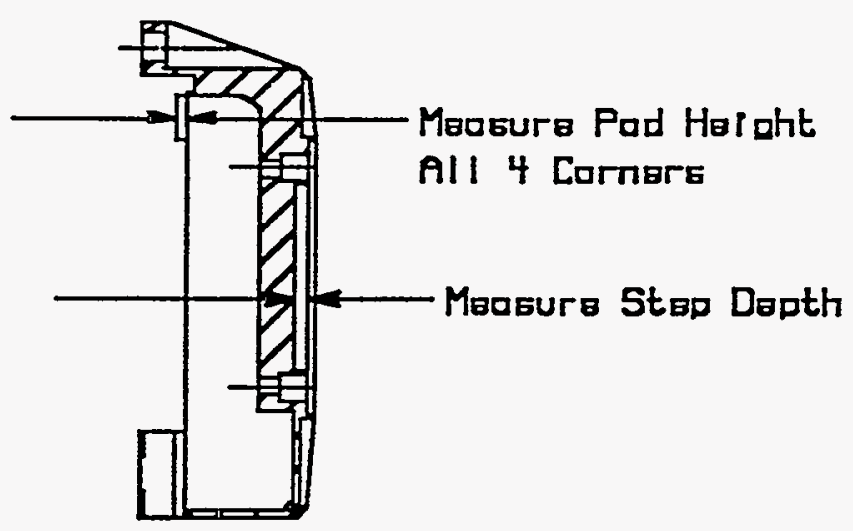

FIGURE 5

4.3.2 From the inspection data provided with WFOV Lens P/N 92-109469, obtain the recorded depth from the face of the fiberoptic to the three mounting tabs (nominal is 0.125 ). Record these measurements to 4 significant figures.
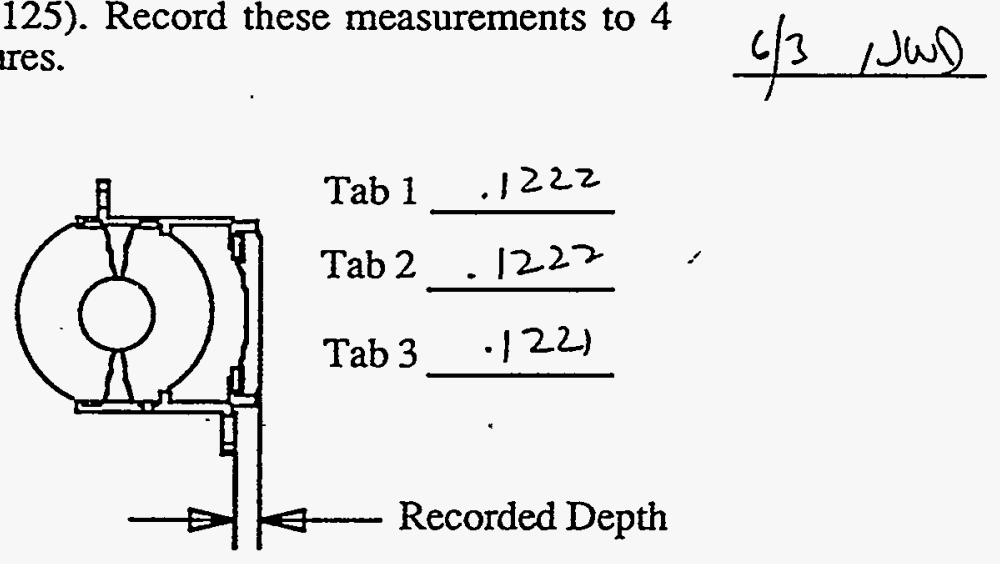

\section{FIGURE 6}

4.3.3 Calculate average depth to face of lens fiberoptic to 4 significant figures and record answer. Average Depth .1222 

W. $150 \pm .005$ ₹ $.110 \pm .005$
THESE HOLES ONLY

From farsiose- DO

$$
\because \because \text { WOT BREAK TIINH }
$$
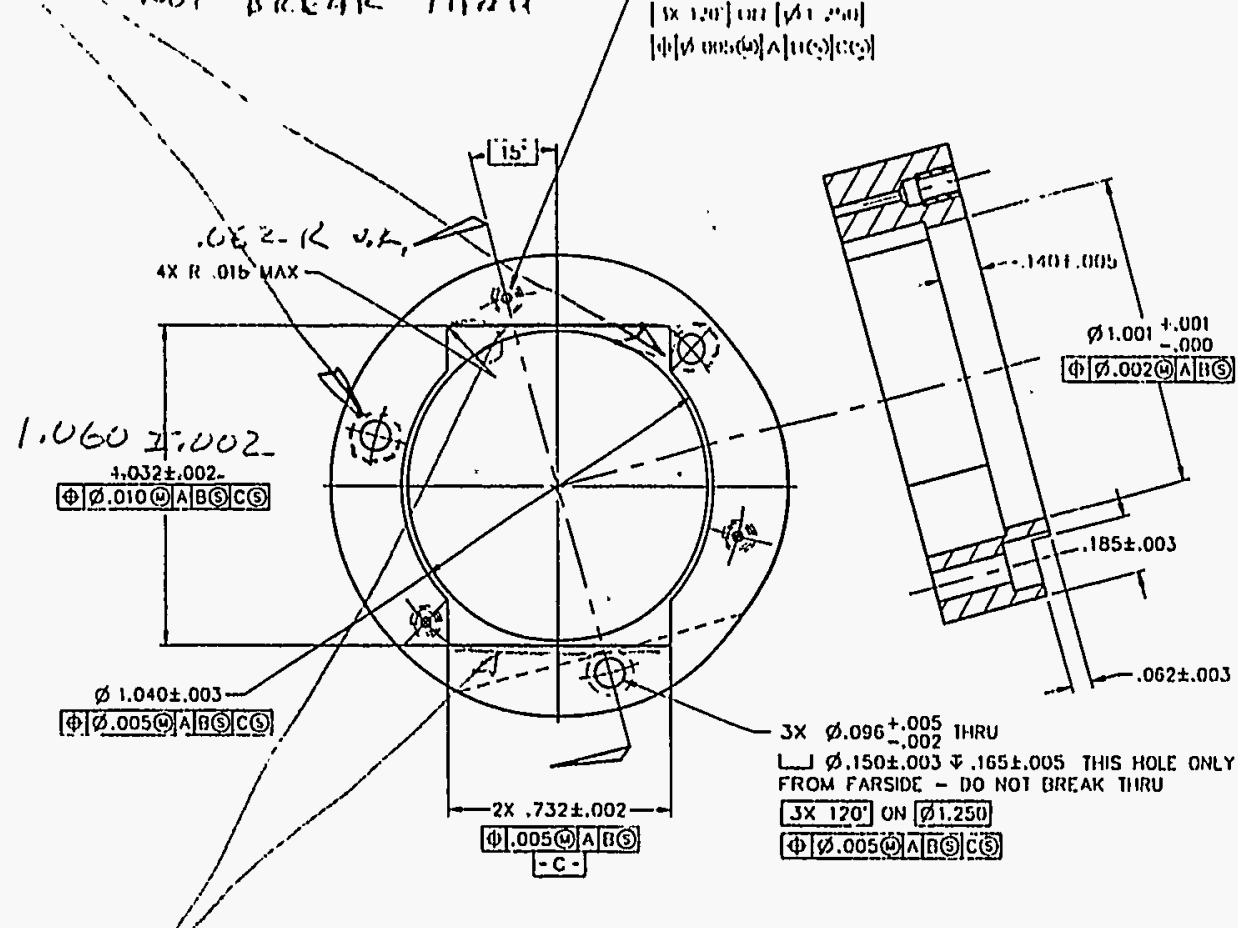

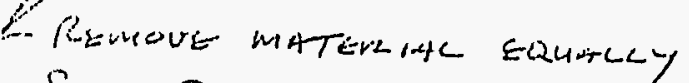
from Bortt ends to achievis 1.060 Dim. Do NOT RELISUE CORNAM. 1,

$$
\begin{aligned}
& \quad 57-31 \% \\
& \text { Floglit } \pi z
\end{aligned}
$$

NOIES

1. All DIMENSIONS ARE IN INCHES.

2. DIMENSIONING AND TOLERANCING PER ANSI YI 4.SM-IOB2.

PER ANSI B46.1-1978.

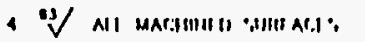

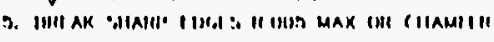

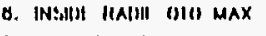

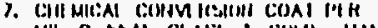

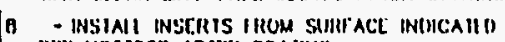

\begin{tabular}{|c|c|c|c|c|c|}
\hline & \multicolumn{2}{|l|}{3} & \multicolumn{3}{|c|}{ INSERT, SCREW LOCKING, CRES, 2-56 X .129L LS21209-C0215) 2} \\
\hline & & & \multirow{2}{*}{\multicolumn{2}{|c|}{$\begin{array}{l}\text { AL ALY MPE 6061-T651 } \\
\text { DESCAIPIION / MAIEAIAI }\end{array}$}} & $00-1-250 / 1$ \\
\hline \multirow[t]{4}{*}{ HO Rta } & \multicolumn{2}{|l|}{ PANT I IIINI SIK NO } & & & SPIC NO \\
\hline & OWH Tom Qumam & $\frac{2 / 2 / 103}{2 / 8}$ & \multirow{4}{*}{ 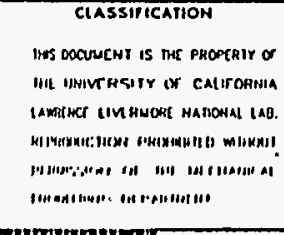 } & \multicolumn{2}{|c|}{ STAR TRACKER CAMERA ASSY, V3,1 } \\
\hline & arvo & $\frac{31 / 3}{3 / 29}$ & & \\
\hline & & & & \multicolumn{2}{|c|}{ LENS STANDOFT } \\
\hline \multicolumn{3}{|c|}{ 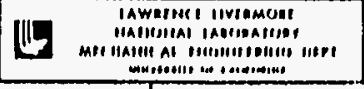 } & & \multirow{2}{*}{\multicolumn{2}{|c|}{ 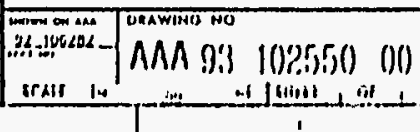 }} \\
\hline & & & ||[!||||||||||| & & \\
\hline
\end{tabular}

9. WRAP IN CLEAN UNT-FREE MAIERIAL

DO NOT MARK ON PART.

$$
\text { 17: }
$$




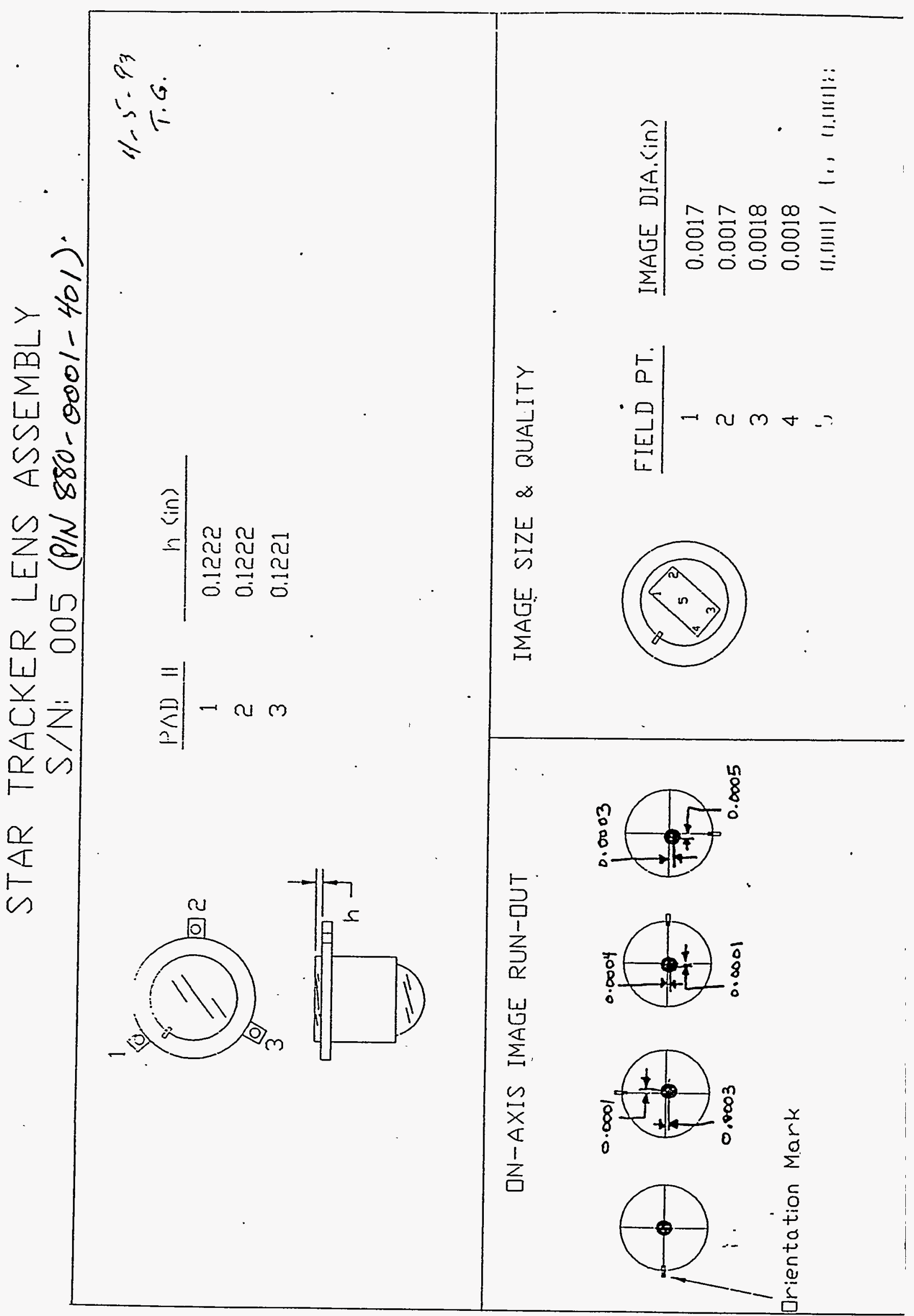




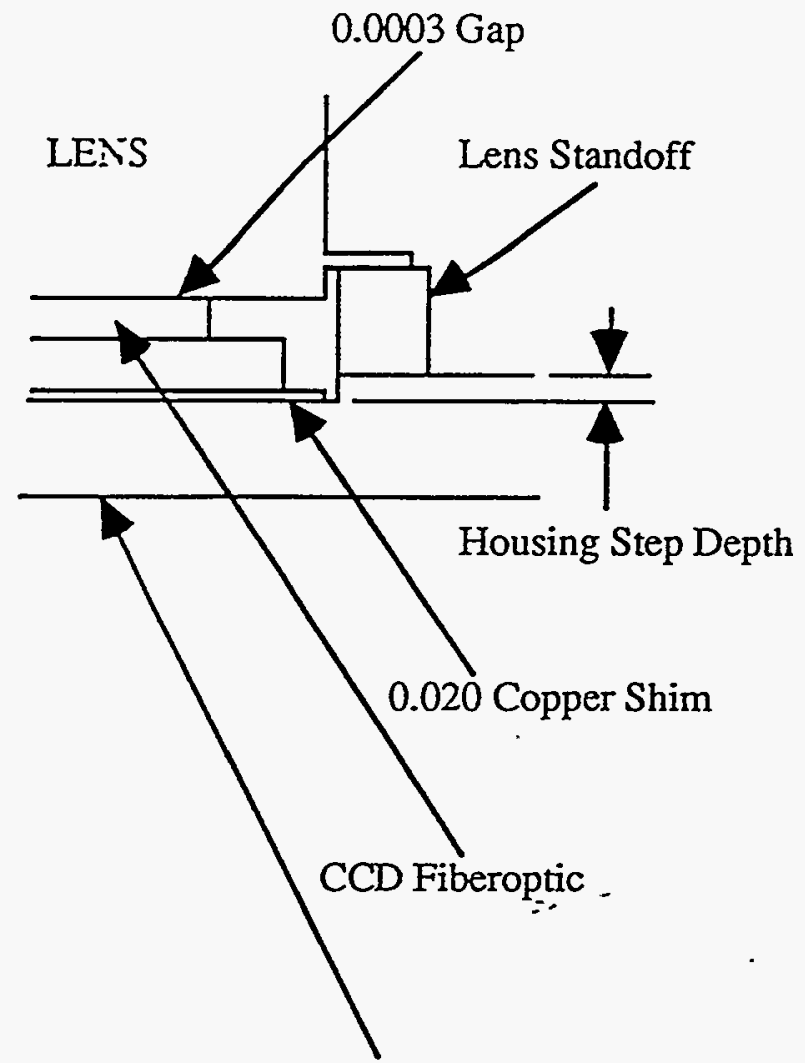

Housing Thermal Finger
Add The Following:

$\begin{array}{ll}\text { Lens Tab Depth } & \frac{.1222}{13393} \\ \text { CCD Thickness }\end{array}$

0.020 Copper Shim $\quad 0.020$

0.0003 Gap $\quad 0.0003$

0.001 Epoxy Fill $\quad 0.001$

Sub-Total: .4830

Subtract The Following:

Housing Step Depth .0970

Total is Lens

Standoff Thickness .3860

\section{FIGURE 7}

4.3.7 Perform the arithmetic as shown in Figure 7.

4.3.8 Remove the lens standoff and reprocess the bottom surface to achieve the thickness \pm 0.0001 , recorded from the arithmetic in Figure 7.

4.3.4 Apply a thin layer (.001 in. thick, max.) of DC-340 thermal grease to the standoff-to-camera body mechanical interface areas.

Install lens standoff to camera body with 1 each, 2-56 $\times .375$ long and 2 each $2-56 \times .50$ long socket head cap screws. Torque to $3.5 \pm 0.1 \mathrm{in}-\mathrm{lb}$.

4.3.5 Using the optical comparator with the $100 \mathrm{X}$ objective for maximum sensitivity, measure distance from top of lens standoff to top of CCD fiberoptic at 4 positions (1-4) to verify that the fiberoptic surface is parallel to the top of the lens standoff to within 0.0001 inches as shown in figures 8 and 9 , and matches the lens-to-tab depth recorded in the inspection data from the vendor +0.0003 inches. If not, reposition the CCD to correct any error.
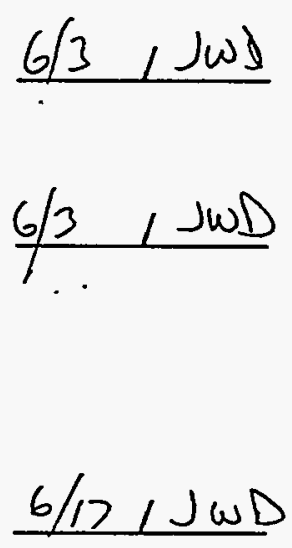

$6 / 01 \mathrm{Jw0}$ 


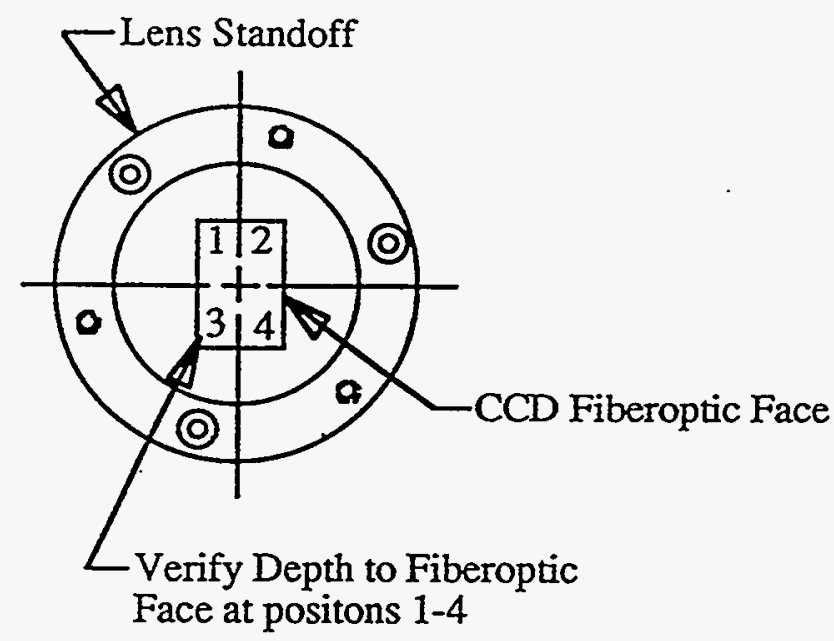

FIGURE 8

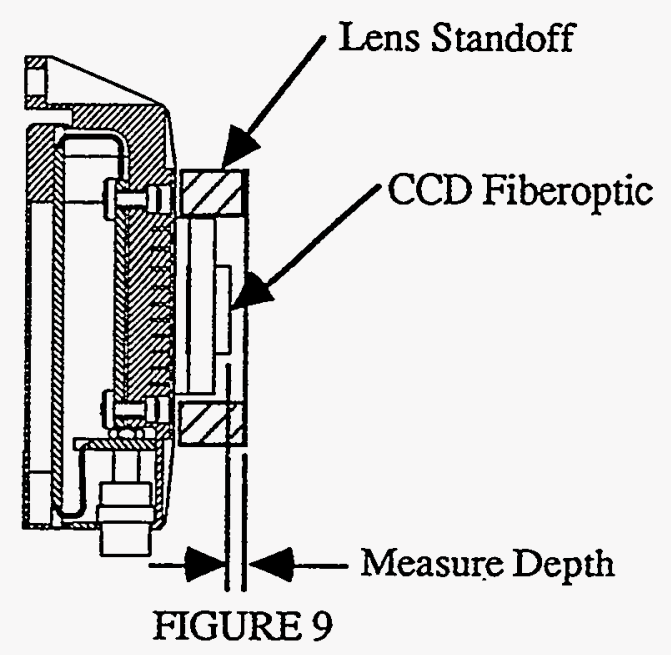

4.3.6 Stake fasteners with EA934NA Staking Compound. Cure at $60^{\circ} \mathrm{C}$ for $3 \mathrm{Hr}$.

4.3.7 Do not proceed to assembly section 4.4 unless there is a single time span of at least 8 hours available to complete all steps of section 4.4 .

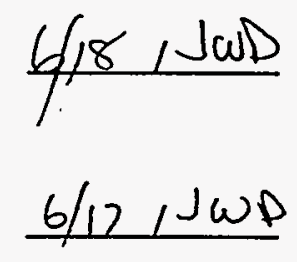

4.4 Lens Installation

4.4.1 Mix a small quantity of DC 93-500 encapsulant and degas. Place one drop of the degassed encapsulant on top center of the CCD fiberoptic interface surface as indicated in figure 10.

Apply a thin layer (.001 in. thick, max.) of DC-340 thermal grease to the mechanical interface between the lens standoff and the WFOV lens mount tabs.

Using extreme care to avoid any contact with the thermal grease, except at the mount points, place the WFOV lens into the lens standoff. 
At this point, verify the lens/CCD orientation. Visually inspect the optical interface through the lens to ensure that the encapsulant is evenly spread over the CCD/lens interface with no bubbles evident.

Secure the lens to the lens standoff with 3 each, $2-56 \mathrm{x}$ .187 long socket head cap screws with \#2 $\times \varnothing 0.25$ CRES washers. Torque all 3 fasteners evenly 1/4 turn at a time to $2.9 \pm 0.1 \mathrm{in}-\mathrm{lb}$.
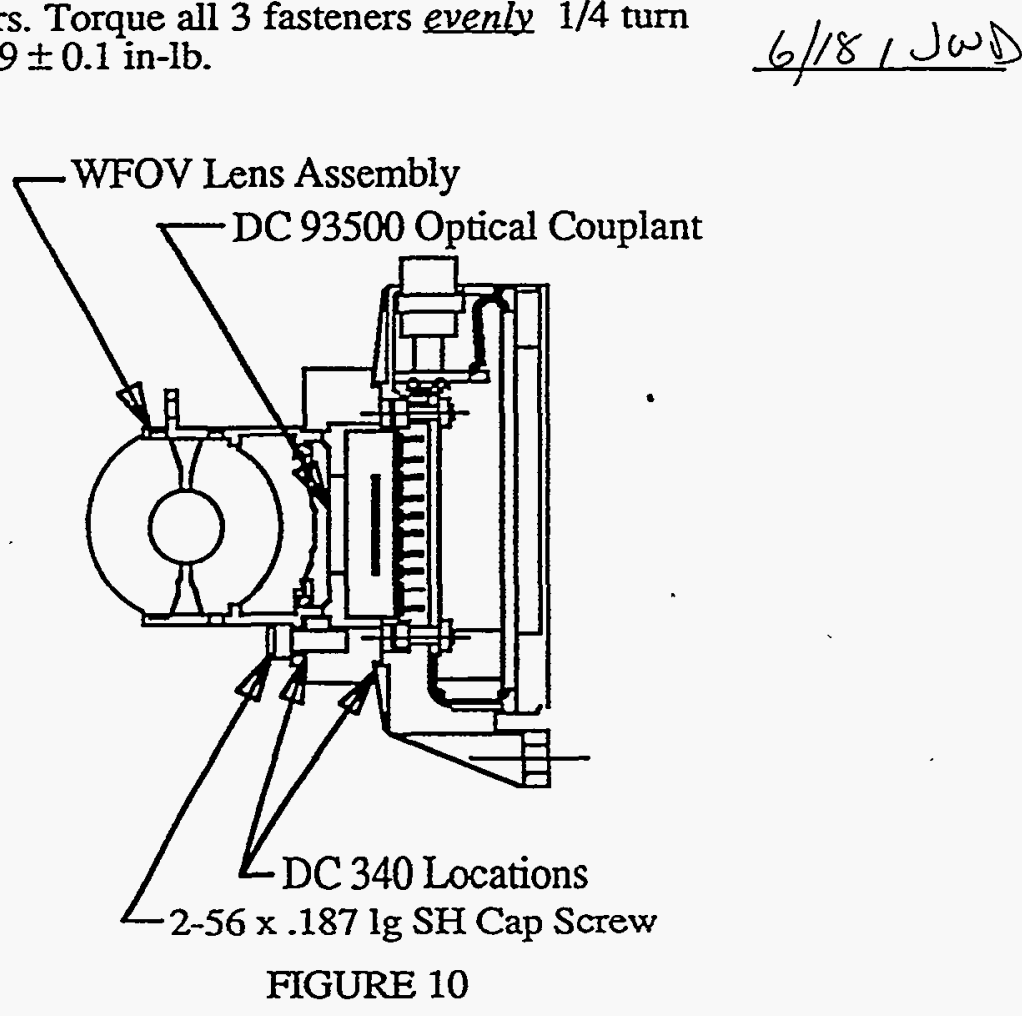

4.4.2 Within one hour of the procedures completed in step 4.4.1, perform an abbreviated camera electronic functionality test per procedure $\mathrm{Cl}-\mathrm{S} 1$-(TBD).

Record results. Pass/No Pass

PASS

If pass, proceed to step 4.4.3

If no pass, immediately proceed to step 4.4 .4

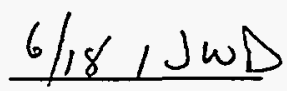

4.4.3 Within one hour of the test performed in step 4.4.2, perform a flat field optical test to look for bubbles and even distribution at the fiberoptic interface between the lens and $\mathrm{CCD}$.

Record results. Pass/No Pass PASS

If pass, proceed to assembly section 4.5

If no pass, immediately proceed to step 4.4 .4

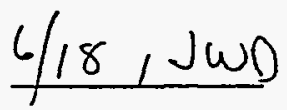


4.4.4 NOTE: This step is to be taken only as an emergency measure, and only if a $B / T C C D$ is being used. If the camera fails either of the tests required in steps 4.4 .2 or 4.4.3, immediately disassemble the lens from the camera housing, remove the $\mathrm{CCD}$, and carefully remove any residual couplant from all optical surfaces to ensure that both the lens and the B/T CCD can be salvaged for reuse.

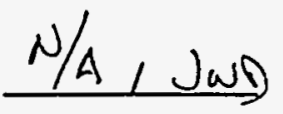

4.4.5 If step 4.4.4 is performed, the assembly procedure is aborted at this point and must be re-started.

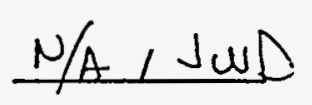

4.5 Baffle Installation

4.5.1 Install Baffle Assembly P/N 92-108748 onto the WFOV lens mounting tabs using 3 each, 2-56 x.187 long socket head cap screws and 6 each, Thermà Isolation Washers, $\mathrm{P} / \mathrm{N}$ 93-102551. Do not torque fasteners beyond finger tight at this time. Ensure that the baffle assembly is evenly centered on the front of the WFOV lens by observing the gap between the lens and the baffle. For maximum thermal resistance, minimize metal-to-metal contact around this interface and between fasteners and mounting tabs.

See Figure 11.
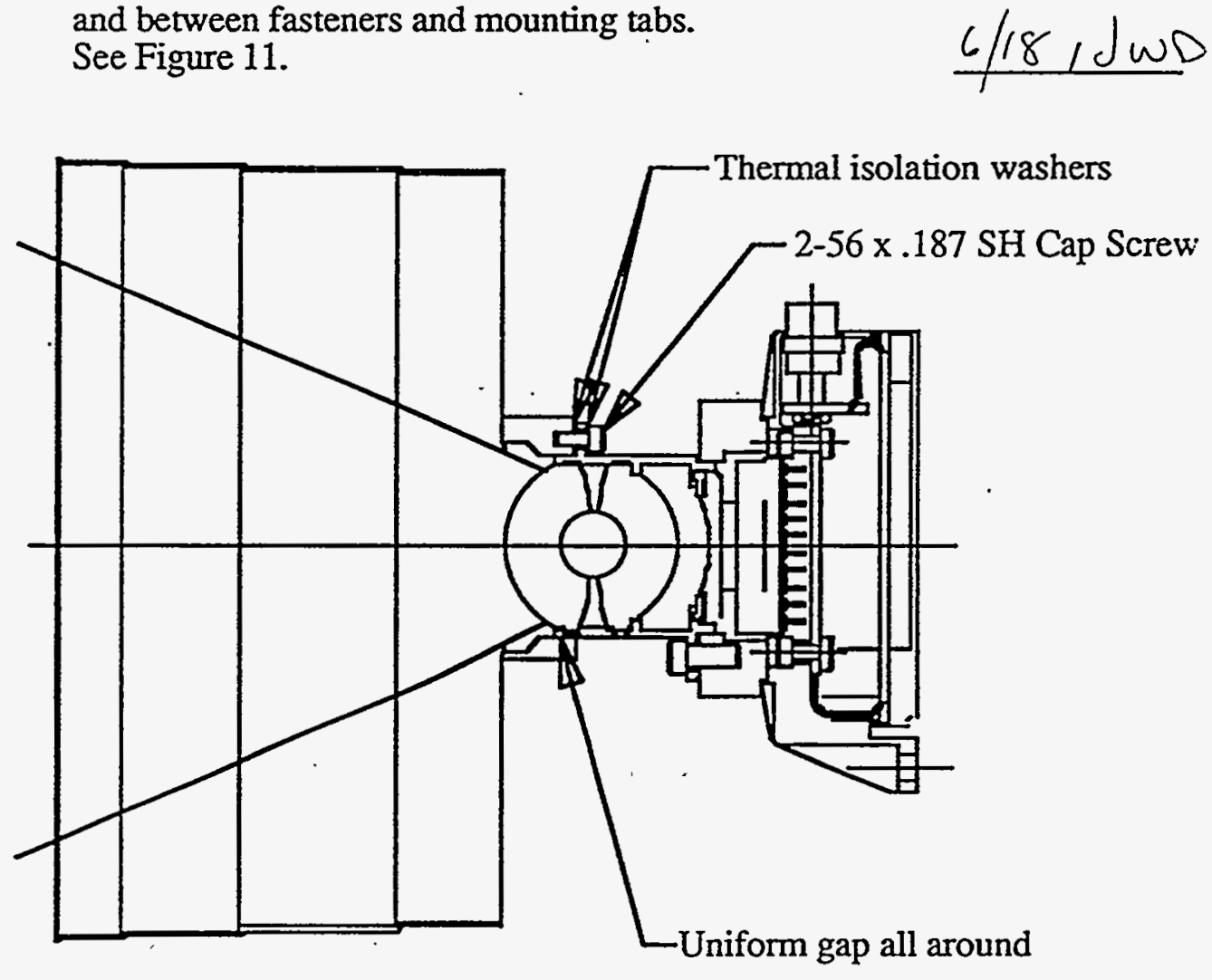

FIGURE 11

4.5.2 Perform abbreviated camera electronic functionality test per procedure $\mathrm{C} 1-\mathrm{S} 1$-(TBD). Record results. Pass/No Pass
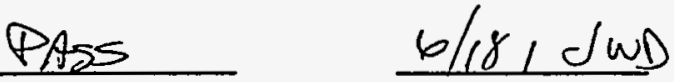
4.5.3 Angular orientation of the rectangular baffle cutout to the camera CCD is critical. Total angular tolerance is $0.3^{\circ}$ rotation. Visually verify orientation as shown in Figure 12, also verify by imaging with the camera and looking for any obscuration at the corners. If baffle is within tolerance, torque fasteners to $2.0 \pm 0.1 \mathrm{in}-\mathrm{lb}$.

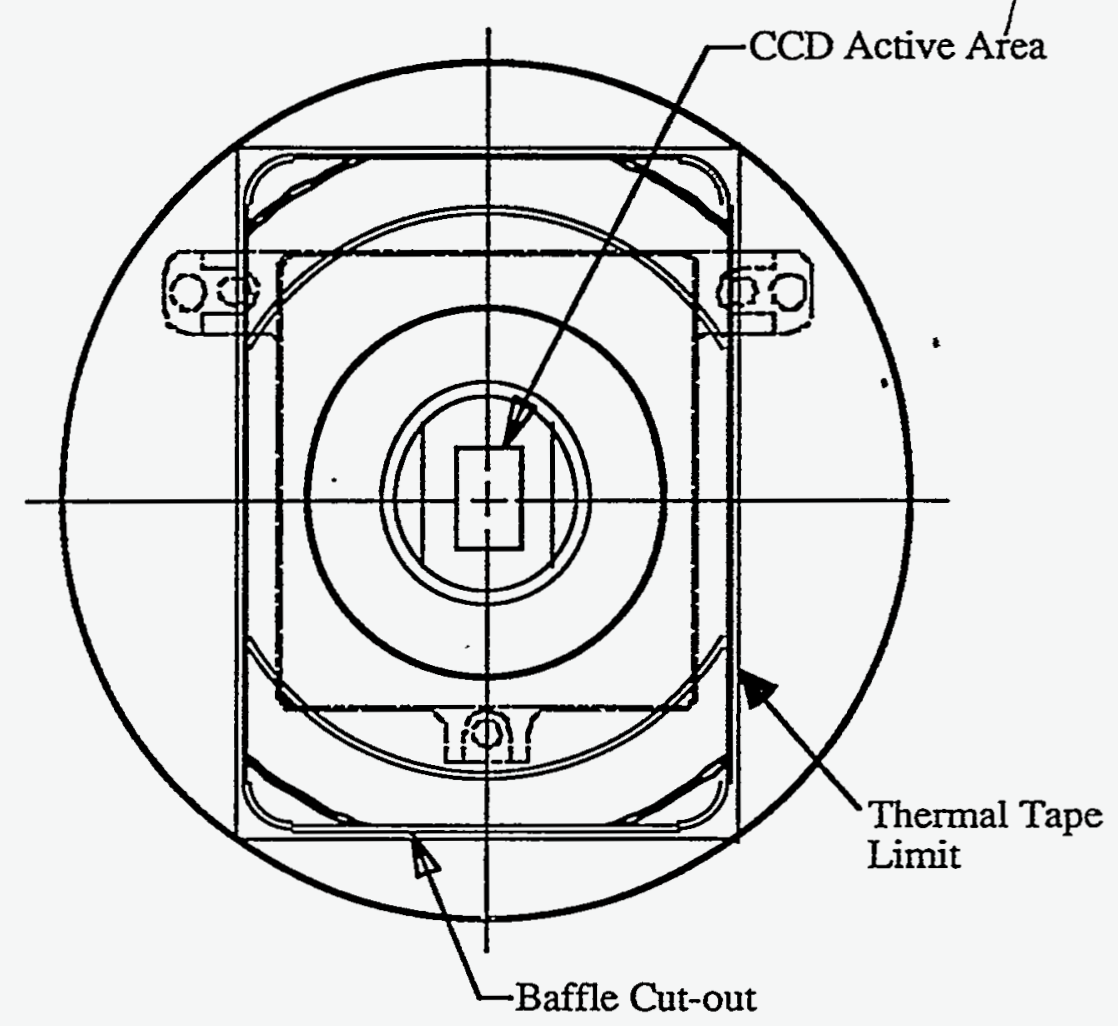

FIGURE 12

\subsubsection{If camera/baffle assembly has passed all functionality} tests, stake all lens, baffle, and camera end cover fasteners with EA934NA. Cure for $3 \mathrm{hrs}$. at $50{ }^{\circ} \mathrm{C}$. Apply Sheldahl thermal tape to front of baffle vane. Trim to baffle outside diameter. IMPORTANT: Do not apply tape within 0.060 inches of the vane edge. See Figure 12.

$6 / 20 / J \omega)$ 


\subsection{Lens Heater Installation}

4.6.1 Install Lens Heater Clamp, P/N 93-102221, and Lens Heater Strip, Minco P/N HK17402-9311, onto the WFOV lens barrel using 2 each, 2-56 x .187 long socket head cap screws. Be careful when routing the heater wires out of clamp to avoid damage to wires. Install temperature control switch onto lens heater clamp using 2 each, 2-56 x .187 long socket head cap screws. Place a small drop of BA-2151 thermal epoxy under center of switch prior to installation to ensure good thermal contact. Torque all fasteners to $3.5 \pm 0.1$ in-lb.

Stake heater wires and fasteners with EA934NA. Cure for $3 \mathrm{hrs}$ at $50^{\circ} \mathrm{C}$.

4.6.2 Bond Thermistor, Fenwal P/N 534-31AG04-562, to side of lens heater clamp with BA-2151 epoxy. Cure for 3 hrs. at $50^{\circ} \mathrm{C}$.
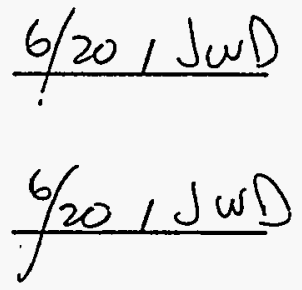
Appendix H.3.5

Test Procedures 


\section{Abbreviated Functional}

\section{Test Procedure}

for

Sub and Fully Housed

Clementine Camera, PWAs

with Gain and Offset Control

$$
6 / 18 / 93
$$

ST 314

Prior to cens Boud

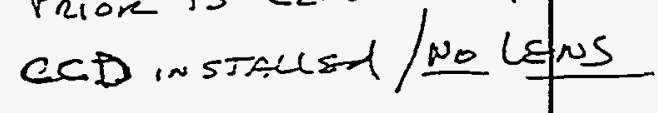

THIS is A ST-1 Cenere!

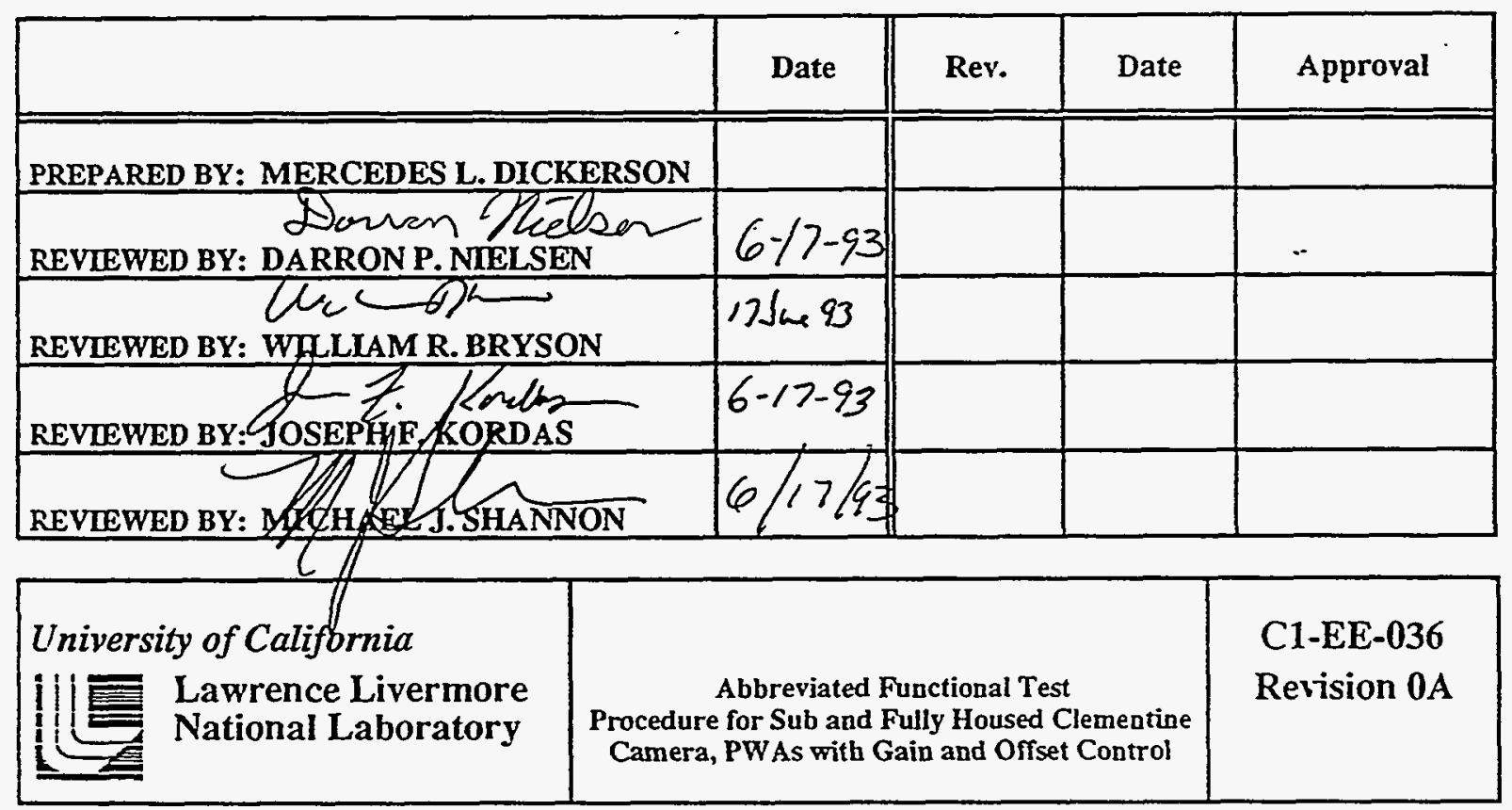




\section{Sub and Final Assembly Resistance and Voltage Specificity prior to Power-un}

Inspect the camera for connector saver and shorting plug. If one or both of these are not present obtain them. A 51 -contact breakout should be attached to the connector saver to perform this test. The 51-contact shorting plug should be attached to the connector saver for transport or storage once this test is complete. Using a flight certified breakout connector-

51 Pin Breakout Cable

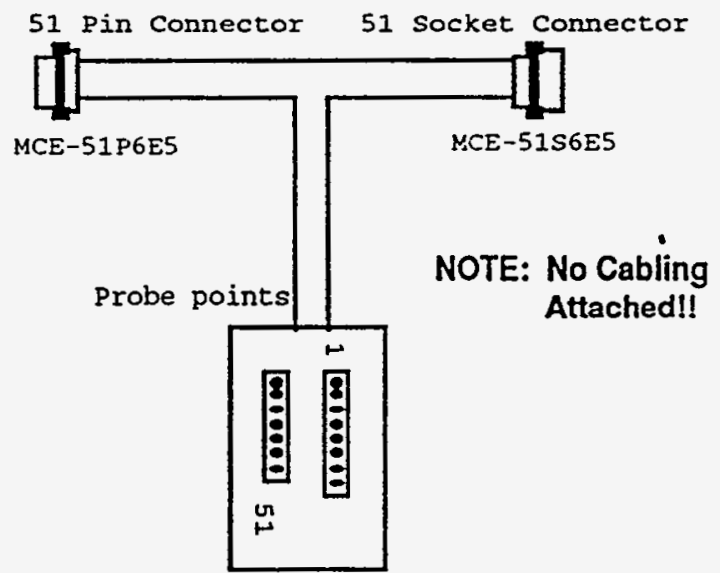

-Verify these resistances:

pin\#

DVM(common)

5 (AGND)

20 (DGND)

20 (DGND)

$39(+15 V D C)$ vs
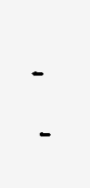

$-$

$-$

$-$

$$
-
$$

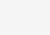

\section{pin\# DVM(signal)}

39 (+15VDC)

4 (-15VDC)

37 (+5VDC)

38 (+5VDC)

$3 \quad(-5 \mathrm{VDC})$

$40 \quad(+5 \mathrm{VIN})$

5

39

37

38

3

40

\section{4}

37

38

3

40 


\begin{tabular}{|c|c|c|c|c|}
\hline \multirow[t]{4}{*}{$4(-15 V D C)$} & - & 37 & $>12 K \Omega$ & $13.2 \mathrm{~K} \Omega$ \\
\hline & - & 38 & $>12 K \Omega$ & $13.2 K \Omega$ \\
\hline & - & 3 & $>13 K \Omega$ & $14.8 \mathrm{k} \Omega$ \\
\hline & - & 40 & $>13 K \Omega$ & $17.6 \mathrm{k} \Omega$ \\
\hline \multirow[t]{3}{*}{$37(+5 \mathrm{VDC})$} & - & 38 & $\leq 1 \Omega$ & 0 \\
\hline & - & 3 & $>2 k \Omega$ & $2 K \Omega$ \\
\hline & - & 40 & $>4 K \Omega$ & $4,9 k \Omega$ \\
\hline $3(-5 \mathrm{VDC})$ & - & 40 & $>5 \mathrm{k} \Omega$ & $5.9 / \mathrm{C}$ \\
\hline \multirow[t]{8}{*}{2 (CGND) } & - & 51 & $\leq 4 \Omega$ & $0 \Omega$ \\
\hline & - & 36 & $\infty$ & $\sim \Omega$ \\
\hline & - & 5 & $\infty$ & $\sim \Omega$ \\
\hline & - & 37 & $\infty$ & $1 / \Omega$ \\
\hline & - & 39 & $\infty$ & $\leftarrow \Omega$ \\
\hline & - & 40 & $\infty$ & $\sim \Omega$ \\
\hline & - & 4 & $\infty$ & $\sim \Omega$ \\
\hline & - & 3 & $\infty$ & $\sim \Omega$ \\
\hline
\end{tabular}

Using a flight certified breakout connector, verify power voltages at cable connector-camera end-before attaching it to the camera board. Use J1-pin 20 for multimeter ground and complete the following table.

$\begin{array}{rcc}\text { J1 pin \# } & \text { Expected V } & \text { Measured V } \\ 39 & +15 \mathrm{~V} & +15,3 \\ 4 & -15 \mathrm{~V} & -15.3 \\ 37,38 & +5 \mathrm{VDC} & +5.1 \\ 3 & -5 \mathrm{~V} & -5.4 \\ 40 & +5 \mathrm{VAIN} & +5.1\end{array}$

Tum off the power. Specificity verified, the camera and cabling are ready for power-up.

$$
\begin{aligned}
& \text { SN\# ST 314 } \\
& \text { By } \frac{\text { Wuid }}{\text { initials }} \\
& \text { Fanctionshity TEFT prior } \\
& \text { T.O Lens Bording } \\
& \text { Date } \frac{6 / 18: 5=}{\text { passed. }}
\end{aligned}
$$

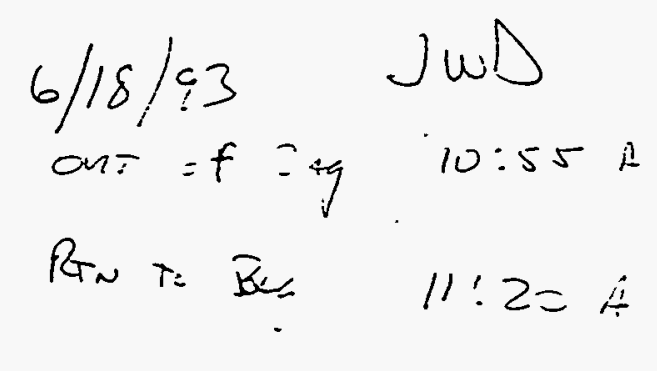




\section{Room Temperature Dark Measurement Data}

Connect a quality assured data acquisition system and cabling with the resistance verified camera to be tested.

Acquire dark images at all three gain values-1,2, and 4-using a 50ms integration time and 0 offset.

Turn off power.

Using the same region of interest for each acquired image, process a histogram resulting in MU and SIGMA values. These values should correspond to those taken at $=20^{\circ} \mathrm{C}$ during the Thermal Test. Therefore, review the $50 \mathrm{~ms}$ data for all three gains at $20^{\circ} \mathrm{C}$. NOTE: This assumes the thermal test was performed with the same CCD now housed.

$$
\text { SN\# ST 314 }
$$

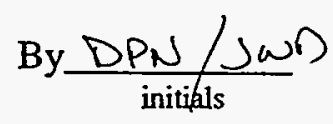

Date $\frac{6 / 18 / 93}{\text { passed }}$

\section{Imaging Verification}

With adequate lensing, capture an image with the Startracker or UV-Vis camera and verify that it does image.

Place an image-on-clear or text-on-clear transparency against the Lidar intensifier and gate the intensifier appropriately to capture a Lidar image.
SN\# ST 314
By JWD
Date $\frac{6 / 18 / 95}{\text { passed }}$

REMEMBER to attach your recorded documentation to this test procedure!

(A document protector is advised) 


\section{Appendix H.3.5.1 \\ Calibration Data Files}




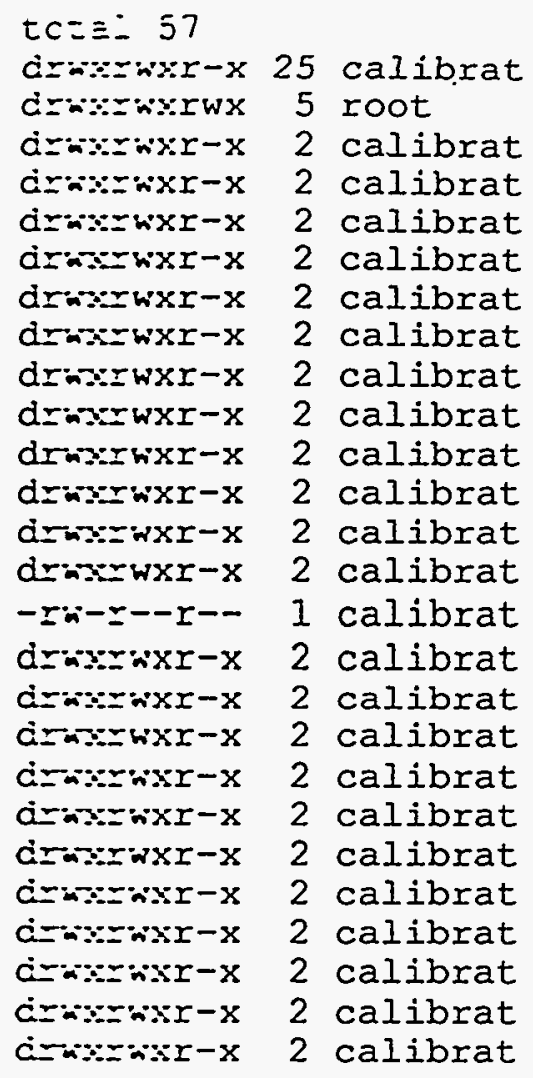

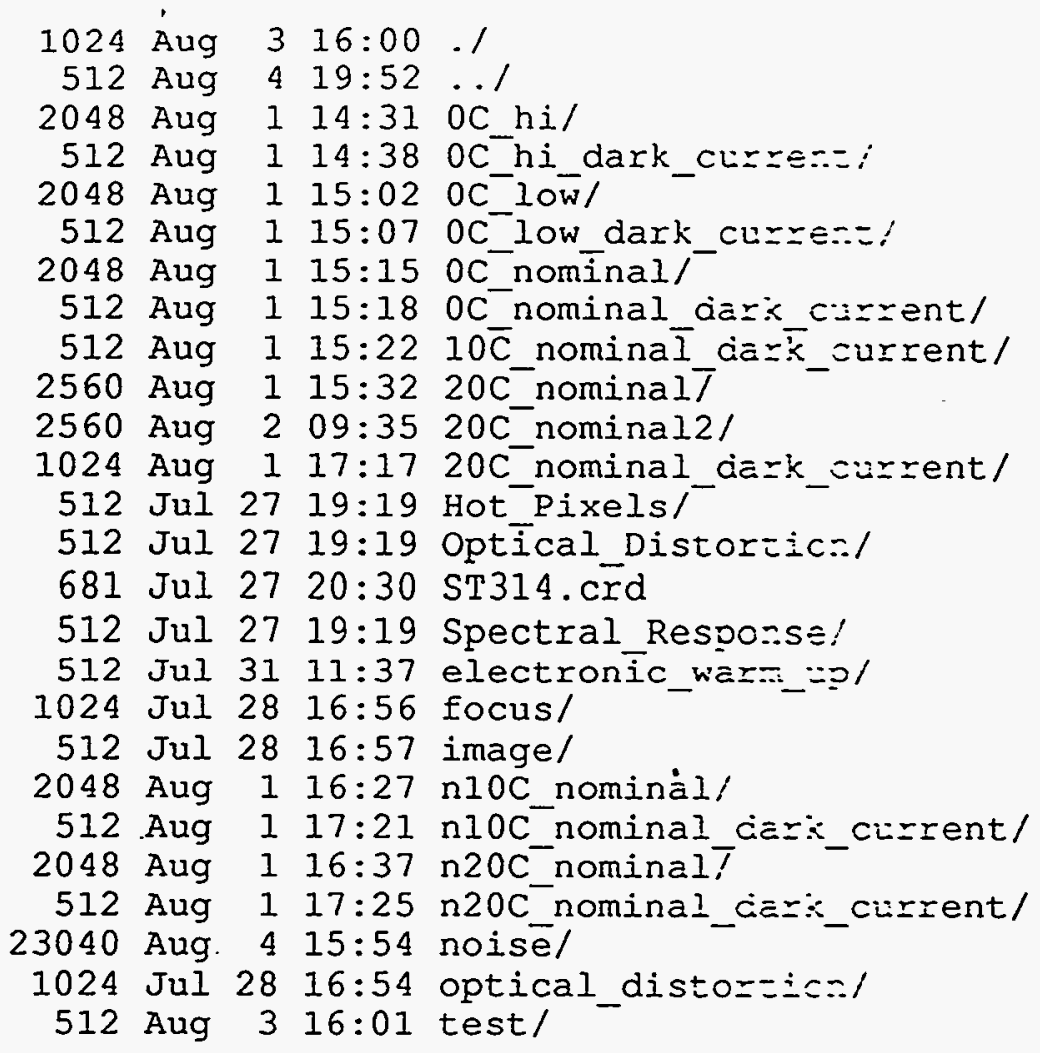


- $\ldots .$.

-

$\ldots$ 


\section{Appendix H.3.5.2 \\ Environmental Acceptance Test Procedures}



- 


\section{Appendix H.3.5.2.1}

Random Vibration Test Data 


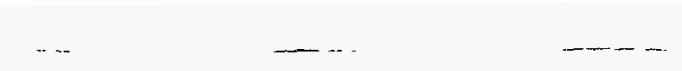




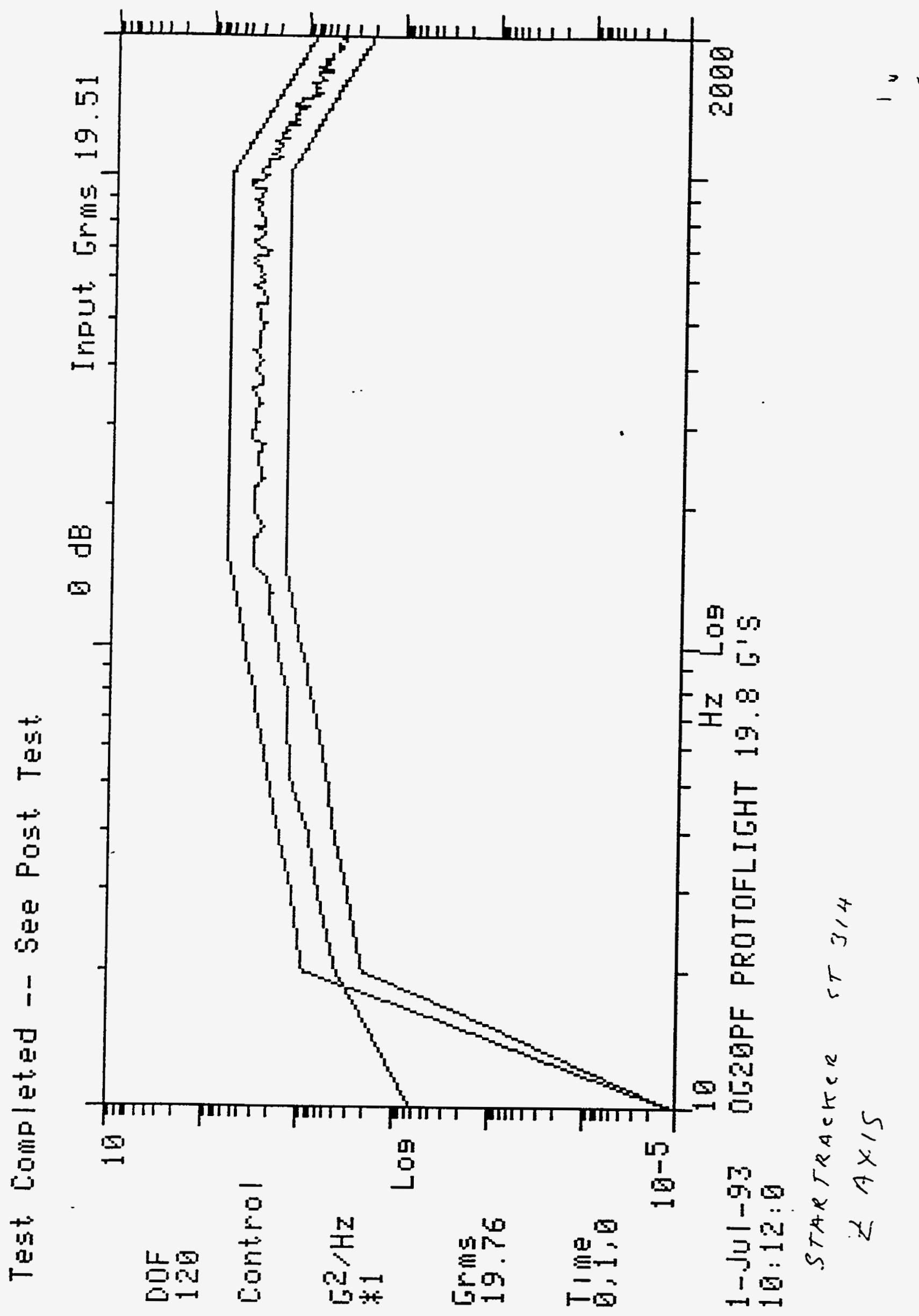



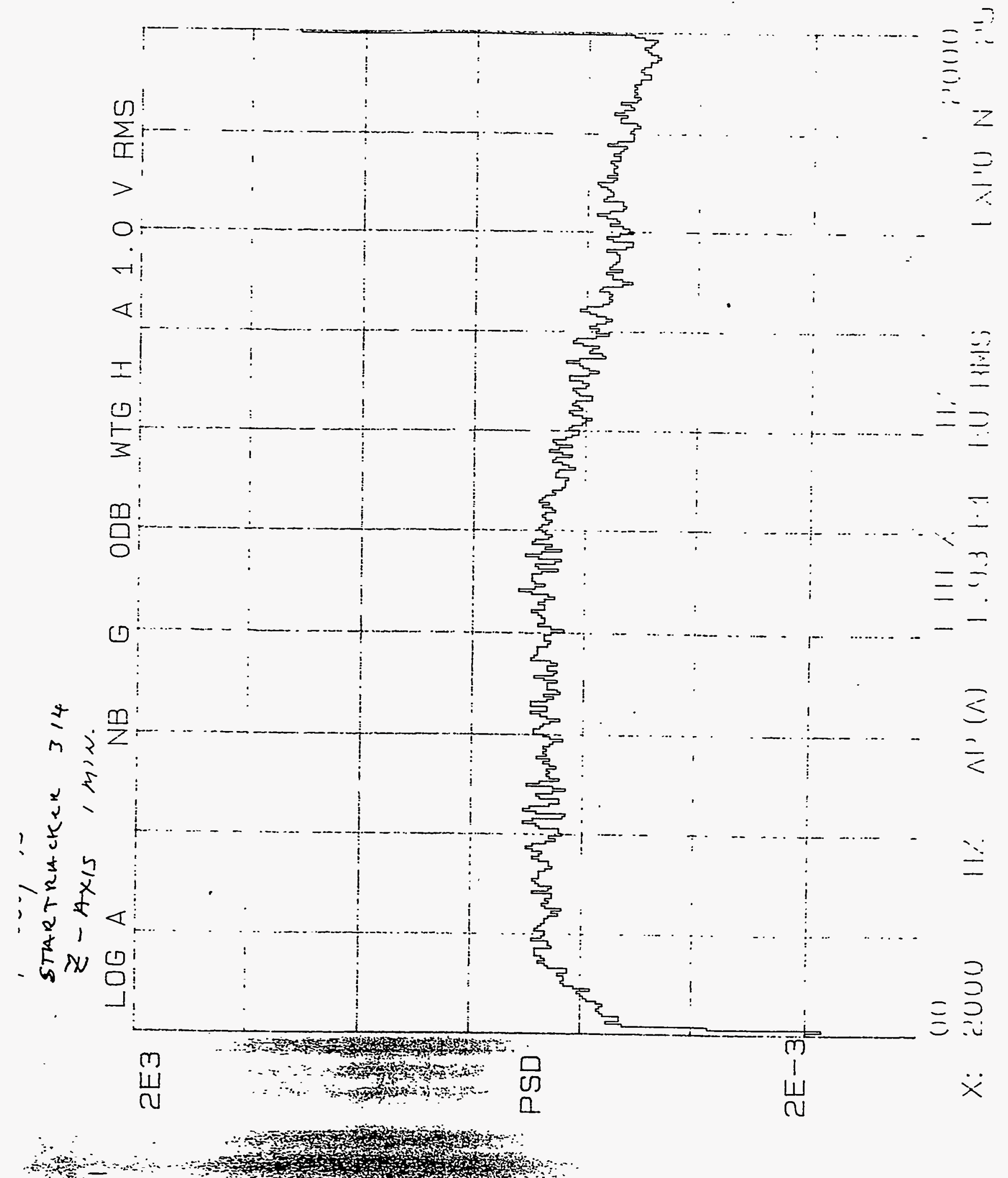


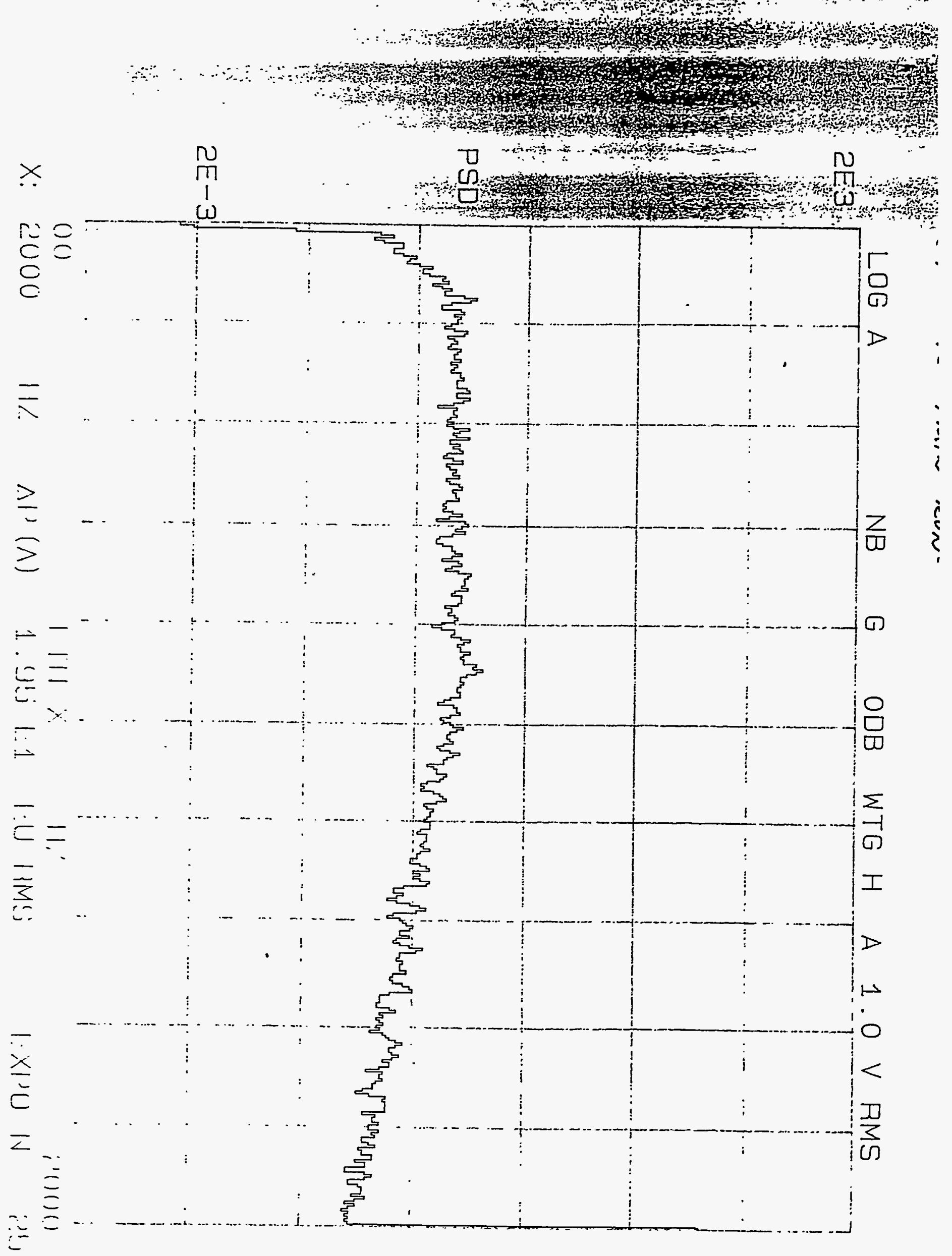




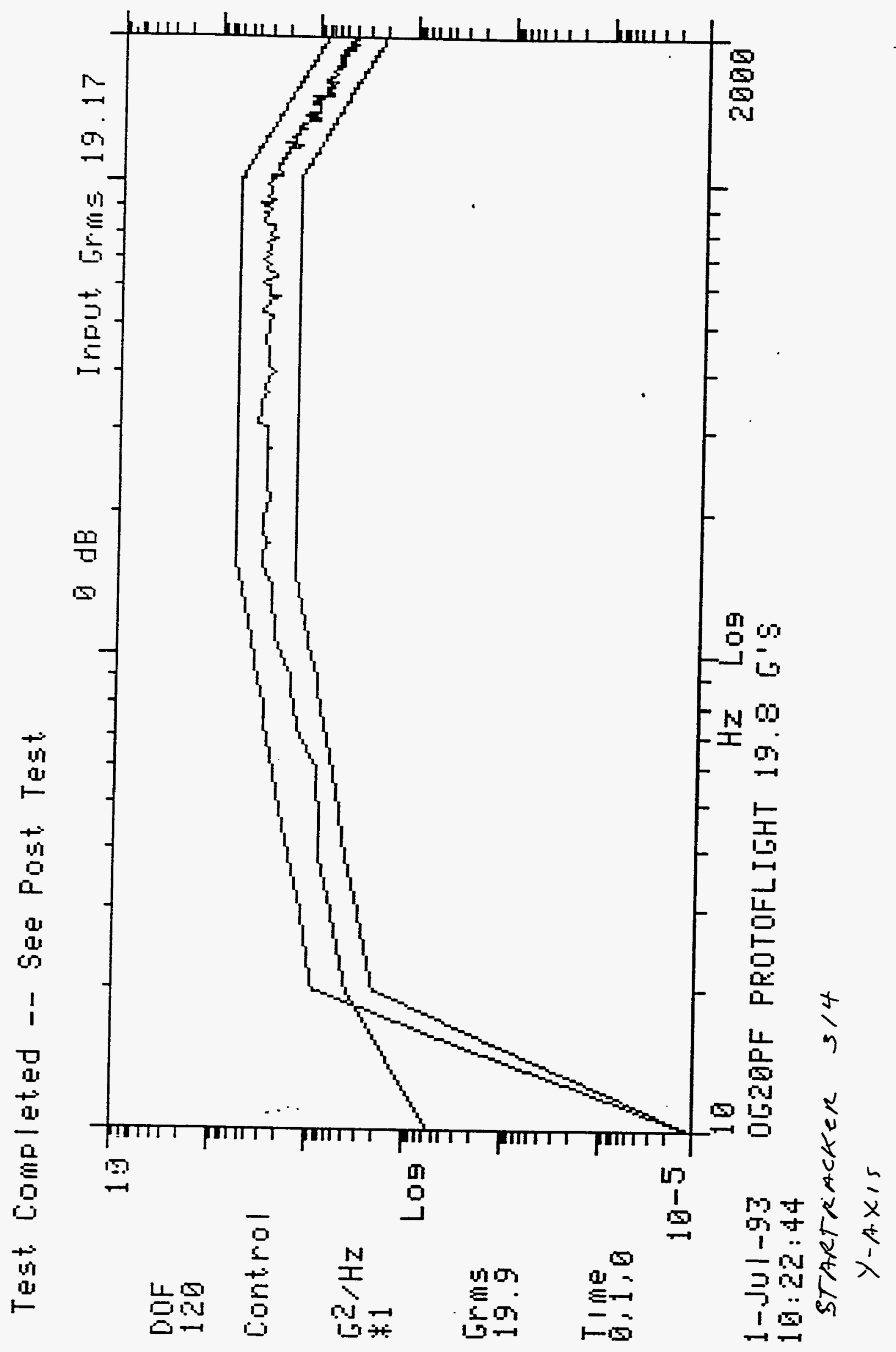




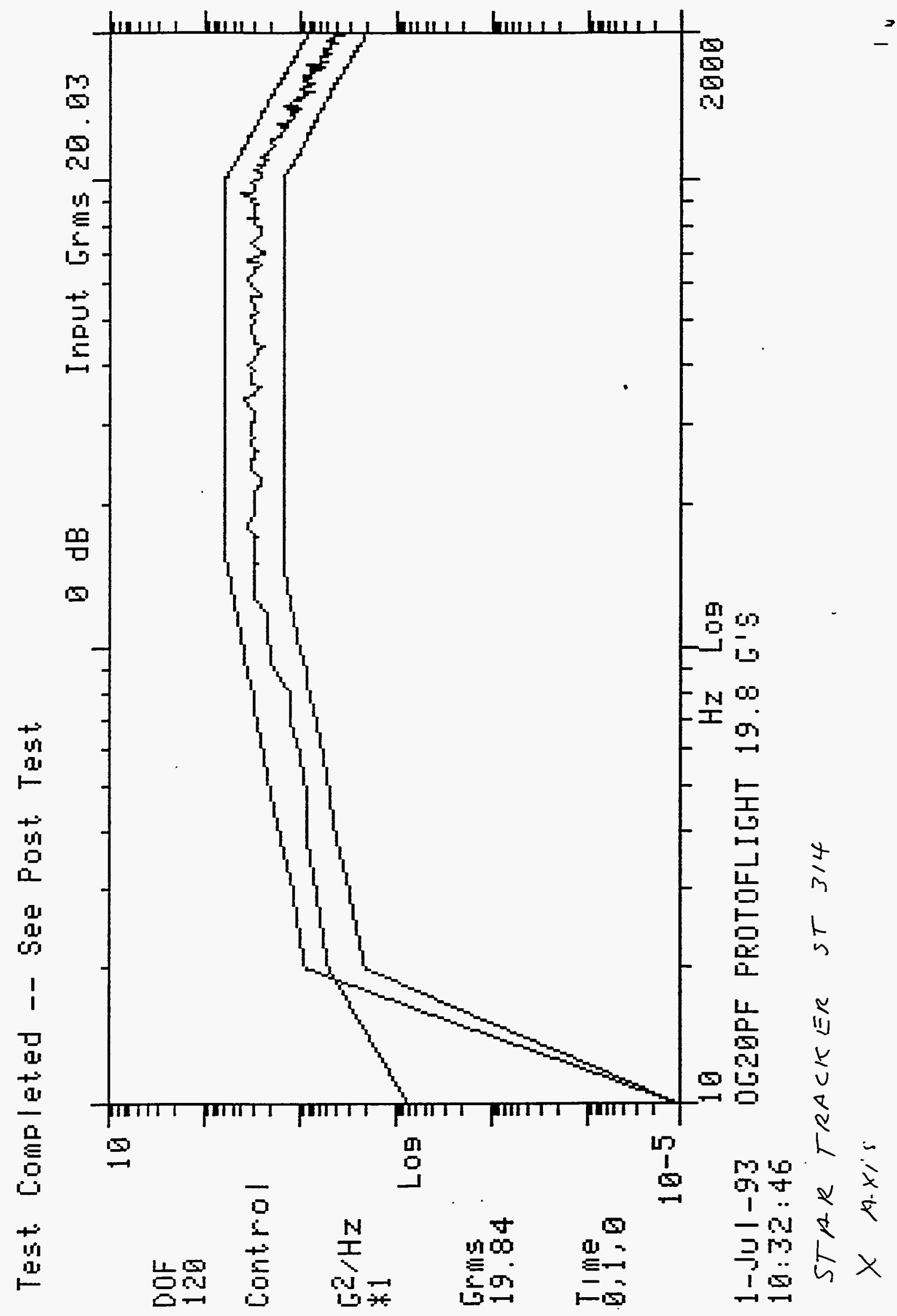



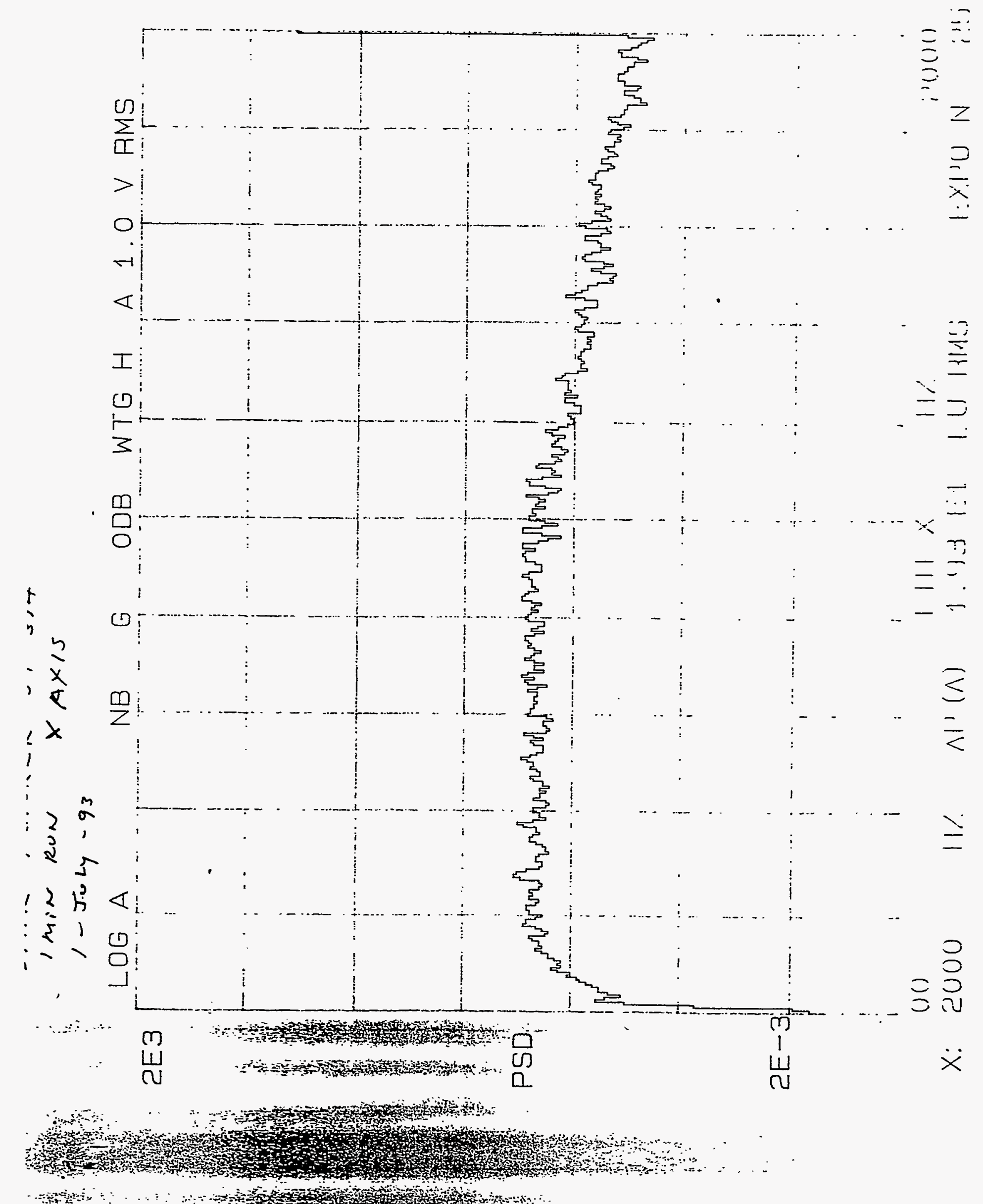

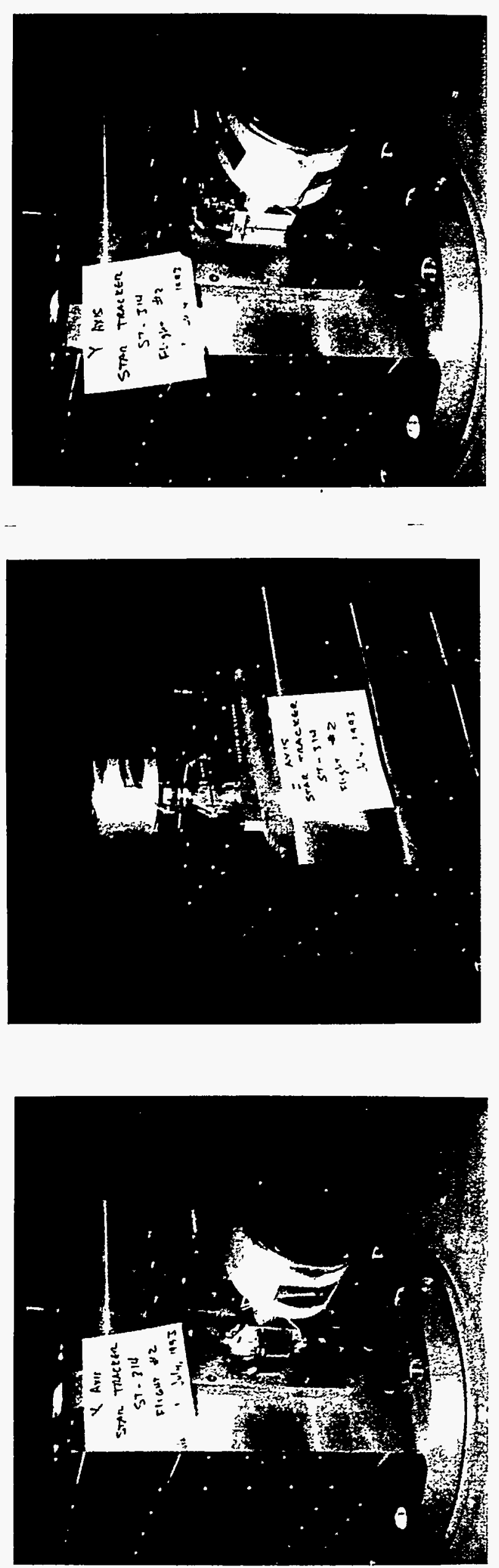
- 


\section{$7 \cdot 153$ \\ PKT SHALE? SXIPOCL}

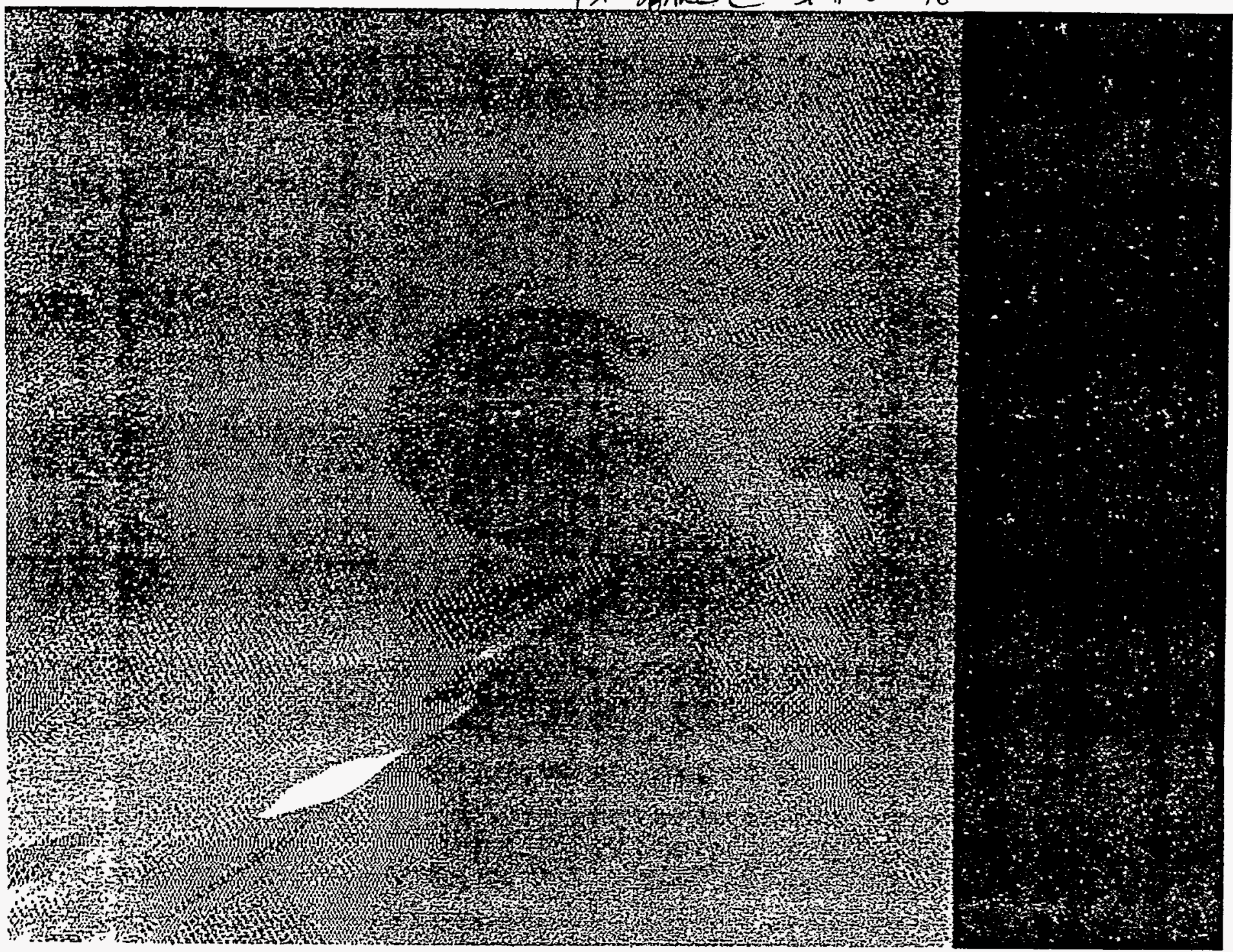




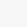


ST Camera: st314: int_time $=50 \mathrm{~ms}$, offset= 0, gain=4 ( 75 e/bit) Fri Jun 18 11:17:13 1993 Pixel Values Min 164 Max 176 Mean 168.2 Sigma $1.33 \times 10^{3}$

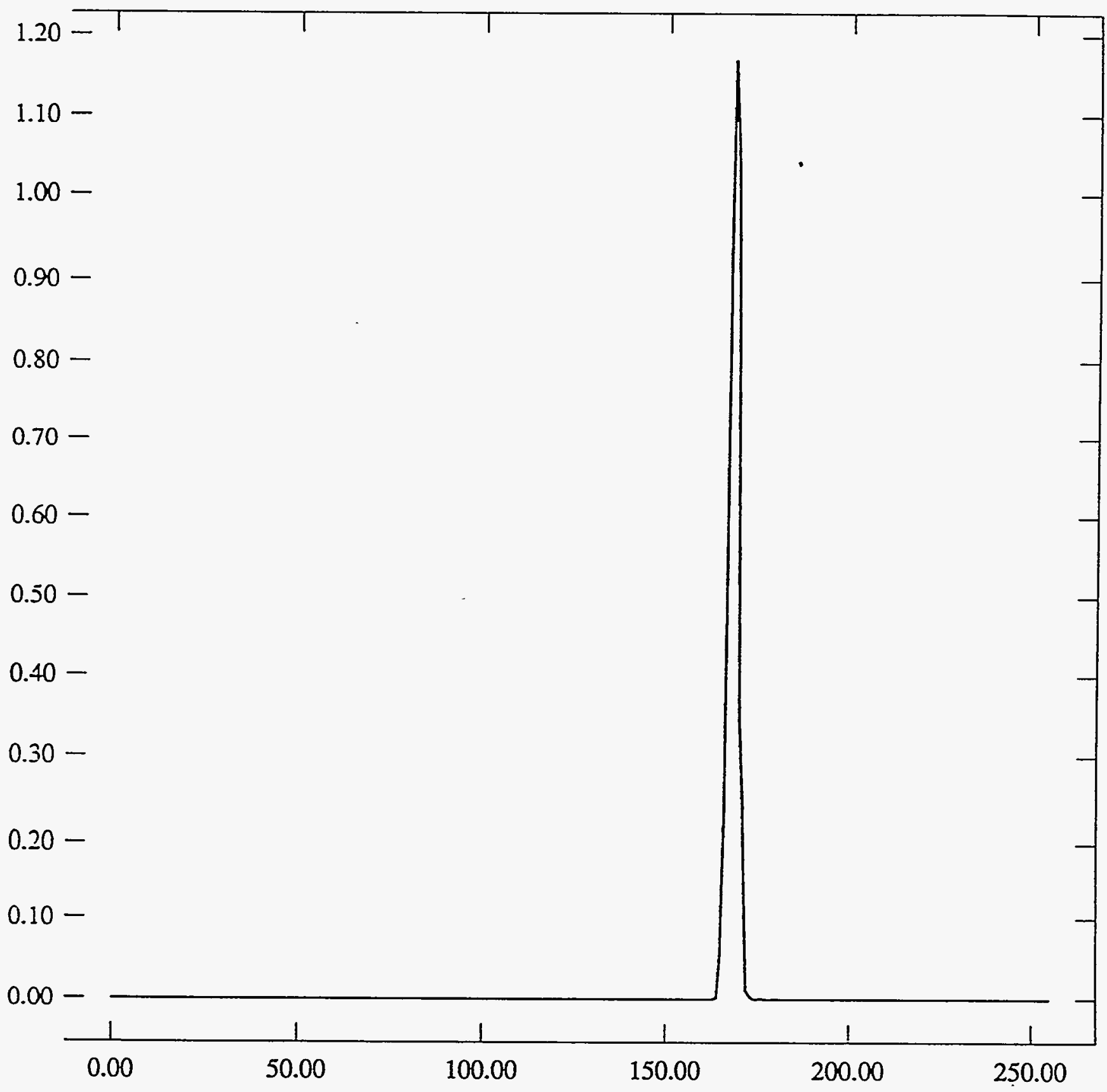


ST Camera: st314: int_time $=50 \mathrm{~ms}$, offset= 0, gain=2 ( $150 \mathrm{e} / \mathrm{bit}$ ) Fri Jun 18 11:15: $\mathbf{3} 1993$ Pixel Values Min 88 Max 94 Mean 90.7 Sigma 0.78 x $10^{3}$

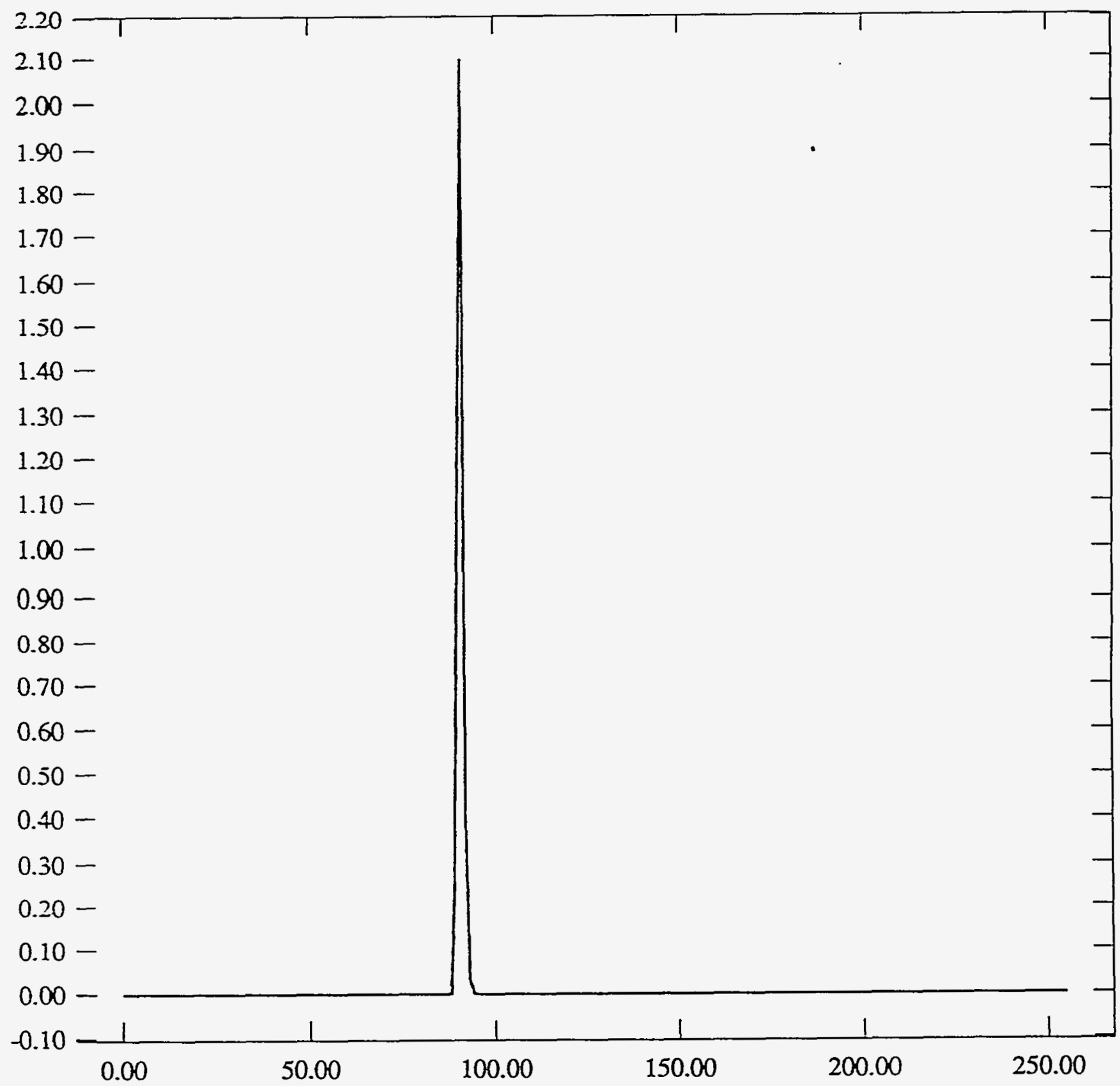


ST Camera: st314: int_time $=50 \mathrm{~ms}$, offset $=0$, gain=1 (350 e/bit) Fri Jun 18 11:14:58 1993

Pixel Values Min 43 Max 47 Mean 44.2 Sigma $0.41 \times 10^{3}$

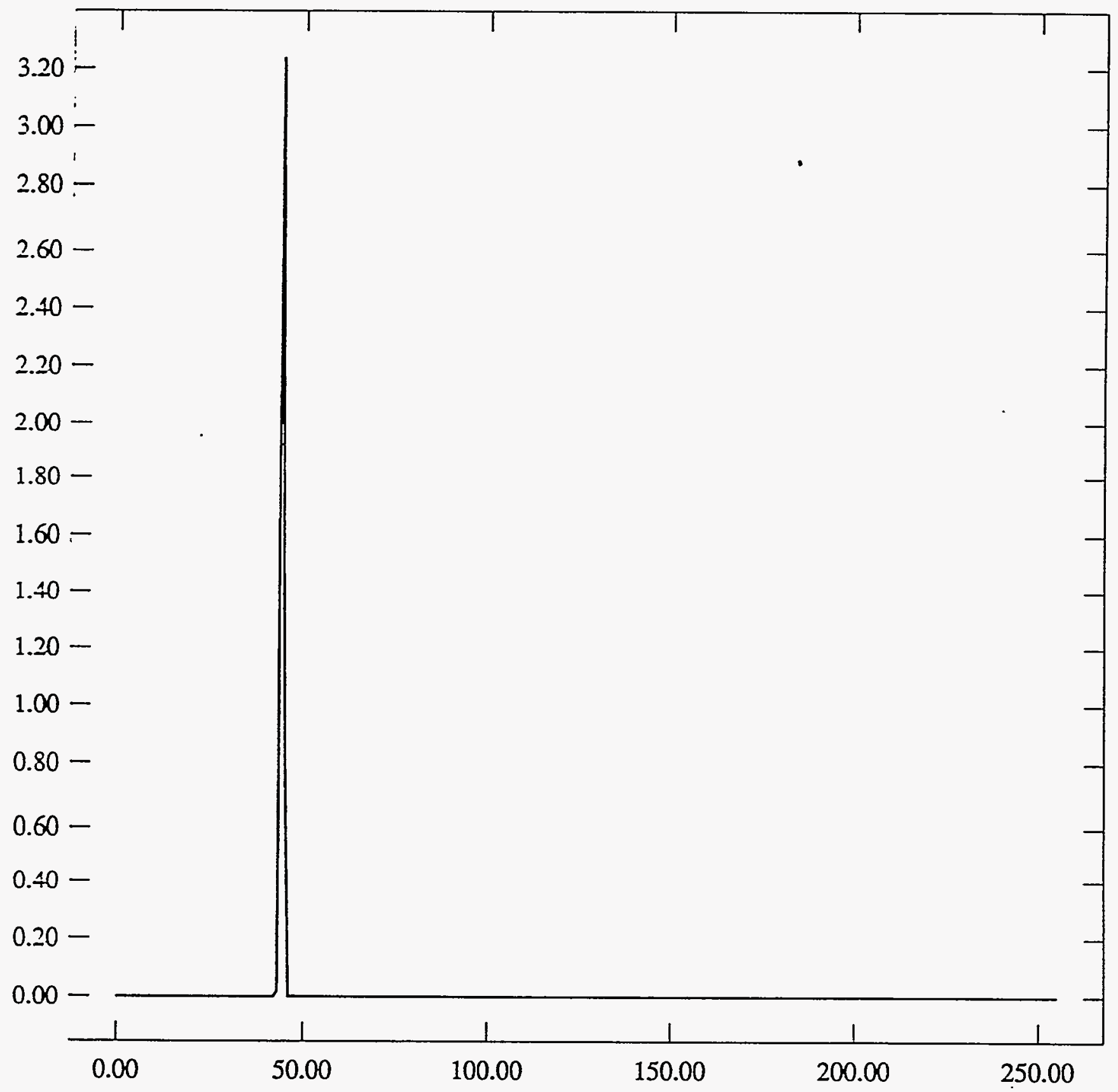




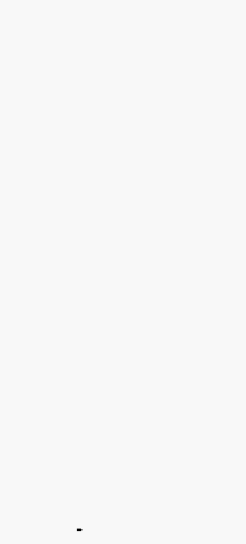

$\therefore \quad-\quad \ldots \ldots$

( 


\section{Abbreviated Functional Test Procedure for Sub and Fully Housed Clementine Camera, PWAs with Gain and Offset Control}

$\cdots \cdot 7 \cdot 93$

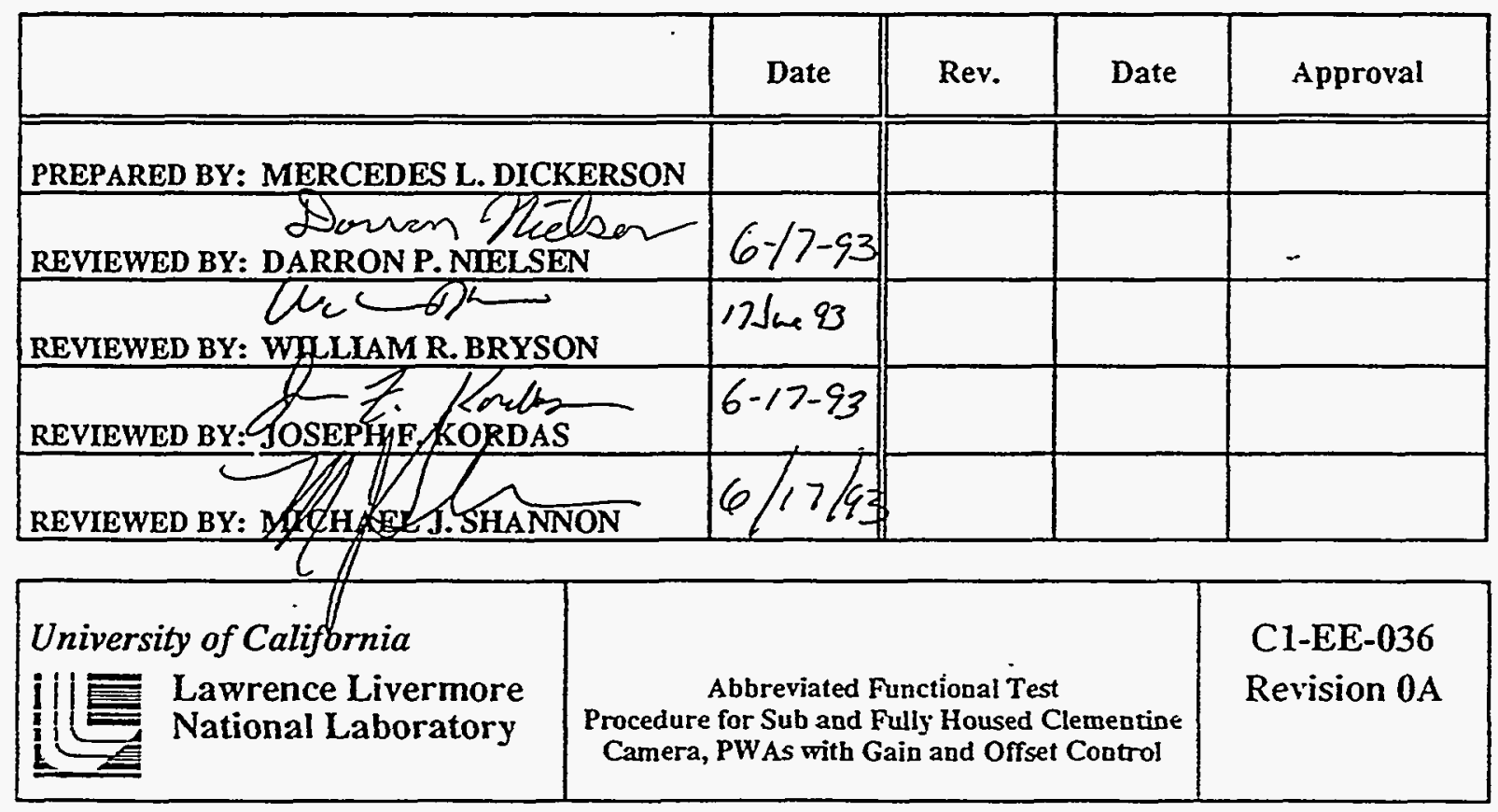




\section{Sub and Final Assembly Resistance and Voltage Specificity prior to Power-un}

Inspect the camera for connector saver and shorting plug. If one or both of these are not present obtain ther A 51-contact breakout should be attached to the connector saver to perform this test. The 51-contact shorti plug should be attached to the connector saver for transport or storage once this test is complete. Using a flight certified breakout connector-

51 Pin Breakout cable

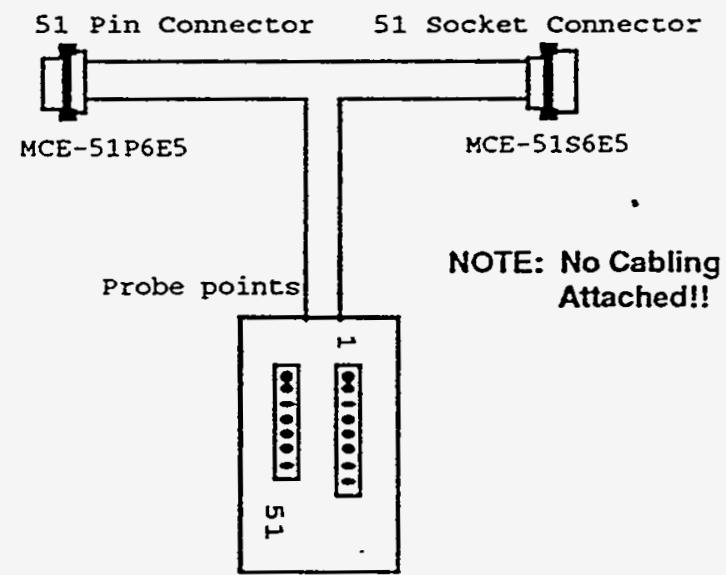

-Verify these resistances: pin\# vs DVM(common) 5 (AGND)

20 (DGND)

$\begin{array}{ccc} & - & 39 \\ & - & 37 \\ & - & 38 \\ & - & 3 \\ 39(+15 \vee D C) & - & 40 \\ & - & 4 \\ & - & 37 \\ & - & 38 \\ & - & 3 \\ & - & 40\end{array}$

\begin{tabular}{|c|c|}
\hline expected & asure \\
\hline$>400 \Omega$ & $\$ 81 \Omega$ \\
\hline$>12 K \Omega$ & $12 k \Omega$ \\
\hline$>400 \Omega$ & $-469 \Omega$ \\
\hline$>400 \Omega$ & $469 \Omega$ \\
\hline$>1 \mathrm{k} \Omega$ & $(.5410 \Omega$ \\
\hline$>4 \mathrm{k} \Omega$ & $4.37 \mathrm{~K} \Omega$ \\
\hline$\leq 1 \Omega$ & $.3 \Omega$ \\
\hline$>400 \Omega$ & $48 \Gamma \Omega$ \\
\hline$>400 \Omega$ & $469 \Omega$ \\
\hline$>400 \Omega$ & $469 \Omega$ \\
\hline$>1 \mathrm{k} \Omega$ & $1.54 K \Omega$ \\
\hline$>4 K \Omega$ & $4.37 k \Omega$ \\
\hline$>11 K \Omega$ & $11.9 \mathrm{~K} \Omega$ \\
\hline$>10 \mathrm{~K} \Omega$ & $946 \Omega$ \\
\hline$>10 \mathrm{~K} \Omega$ & $946 \Omega$ \\
\hline$>13 K<2$ & $2.0 K \Omega$ \\
\hline$>15 K \Omega 2$ & $4.8 k \Omega 2$ \\
\hline
\end{tabular}




\begin{tabular}{|c|c|c|c|}
\hline \multirow[t]{4}{*}{4 (-15VDC) } & 37 & $>12 K \Omega$ & $13.53 \times 12$ \\
\hline & 38 & $>12 K \Omega$ & $13.53 k \Omega$ \\
\hline & 3 & $>13 K \Omega$ & $14.61 \mathrm{~K} \Omega$ \\
\hline & 40 & $>13 K \Omega$ & $17.42 k \Omega$ \\
\hline \multirow[t]{3}{*}{37 (+5VDC) } & 38 & $\leq 1 \Omega$ & $.3 \Omega$ \\
\hline & 3 & $>2 \mathrm{k} \Omega$ & $2 \gamma \quad \Omega$ \\
\hline & 40 & $>4 K \Omega$ & $4.85 K \Omega$ \\
\hline $3(-5 V D C)$ & 40 & $>5 \mathrm{k} \Omega$ & $5.92 \times \Omega$ \\
\hline \multirow[t]{8}{*}{2 (CGND) } & 51 & $\leq 1 \Omega$ & $.3 \Omega$ \\
\hline & 36 & $\infty$ & $\infty \quad \Omega$ \\
\hline & 5 & $\infty$ & $\infty \Omega$ \\
\hline & 37 & $\infty$ & $\infty \Omega$ \\
\hline & 39 & $\infty$ & $\infty \quad \Omega$ \\
\hline & 40 & $\infty$ & $\infty \quad \Omega$ \\
\hline & 4 & $\infty$ & $\infty \quad \Omega$ \\
\hline & 3 & $\infty$ & $\infty \quad \Omega$ \\
\hline
\end{tabular}

Using a flight certified breakout connector, verify power voltages at cable connector-camera end-before attaching it to the camera board. Use J1-pin 20 for multimeter ground and complete the following table.

$\begin{array}{rcc}\text { J1 pin \# } & \text { Expected V } & \text { Measured V } \\ 39 & +15 \mathrm{~V} & \frac{15.31}{-15.79} \\ 4 & -15 \mathrm{~V} & \frac{5.11}{37,38} \\ 3 & +5 \mathrm{VDC} & -5.4 \\ 40 & -5 \mathrm{~V} & \frac{5.11}{} \\ & +5 \mathrm{VAIN} & \end{array}$

Tum off the power. Specificity verified, the camena andicabling are ready for power-up.

SN\#_ OY

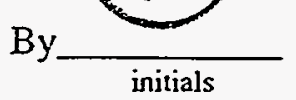

Date $\frac{7.1 .93}{\text { passed }}$ 


\section{Room Temperature Dark Measurement Data}

Connect a quality assured data acquisition system and cabling with the resistance verified camera to be tested.

Acquire dark images at all three gain values-1,2, and 4-using a 50ms integration time and 0 offset.

Turn off power.

Using the same region of interest for each acquired image, process a histogram resulting in $\mathrm{MU}$ and SIGMA values. These values should correspond to those taken at $=20^{\circ} \mathrm{C}$ during the Thermal Test. Therefore, review the $50 \mathrm{~ms}$ data for all three gains at $20^{\circ} \mathrm{C}$. NOTE: This assumes the thermal test was performed with the same CCD now housed.

$$
\text { SN\#_ } 34-10 \quad \text { By_ } \underbrace{\left(\frac{8 \#}{1000}\right)}_{\text {initjals }} \text { Date } \frac{7.91}{1 \cdot 9{ }^{2}}
$$

\section{Imaging Verification}

With adequate lensing, capture an image with the Startracker or UV-Vis camera and verify that it does image.

Place an image-on-clear or text-on-clear transparency against the Lidar intensifier and gate the intensifier apprópriatêly to capture a Lidar image.
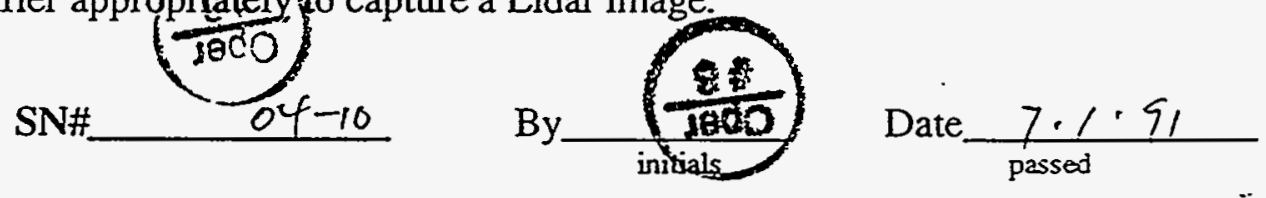

REMEMBER to attach your recorded documentation to this test procedure!

(A document protector is advised) 
ST Camera: ST1\#04-10pstshk2: int_time= 50ms, offset= 0, gain=1 (350 e/bit) Thu Jul 1 14:25:18 1993 Pixel Values Min 40 Max 43 Mean 40.8 Sigma $0.39 \times 10^{3}$

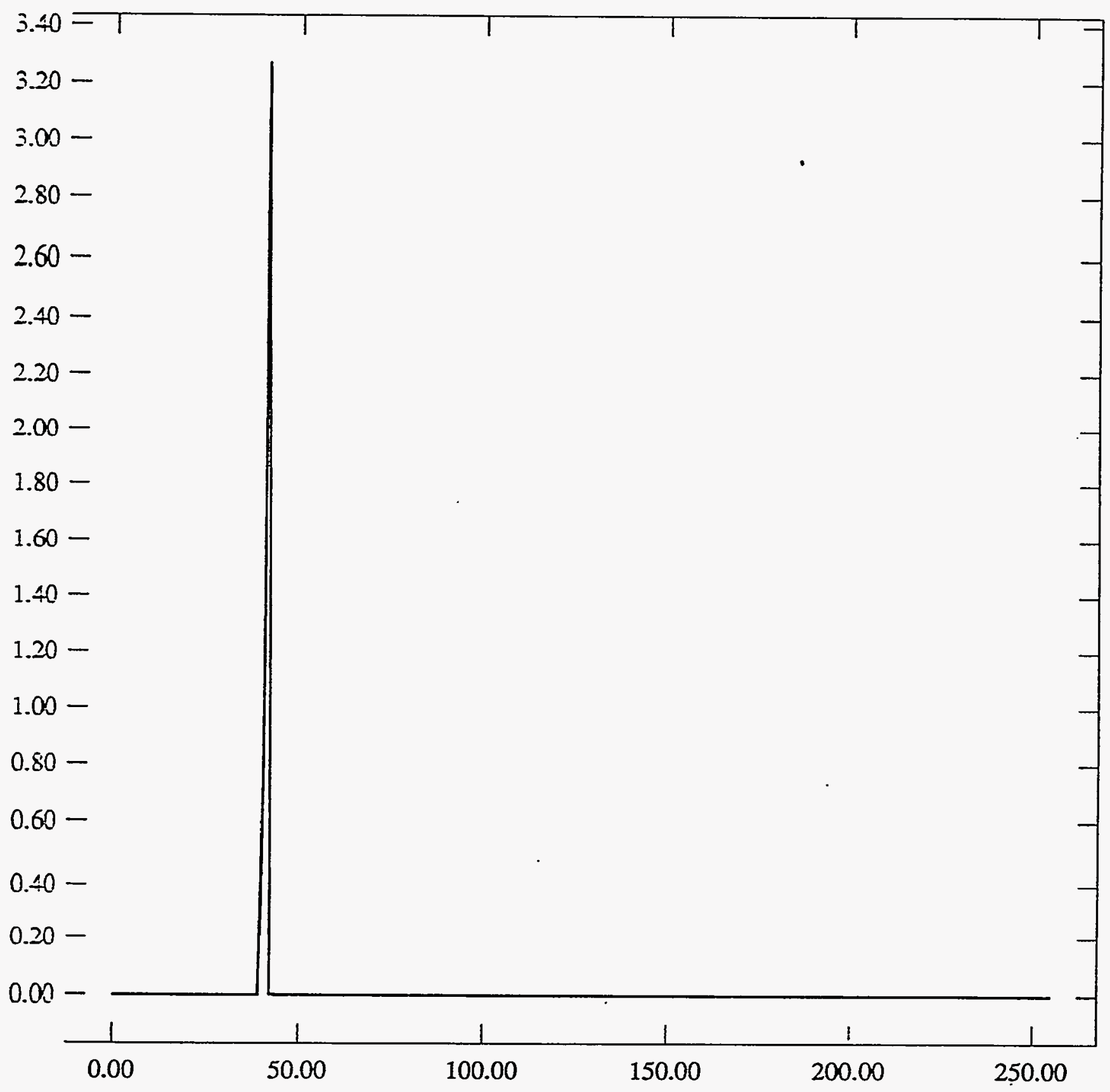


ST Camera: ST1\#04-10pstshk2: int time= 50ms, offset= 0, gain=2 (150 e/bit) Thu Jul 1 14:25:45 1993 Pixel Values Min 80 Max 87 Mean 82.1 Sigma $0.57 \times 10^{3}$

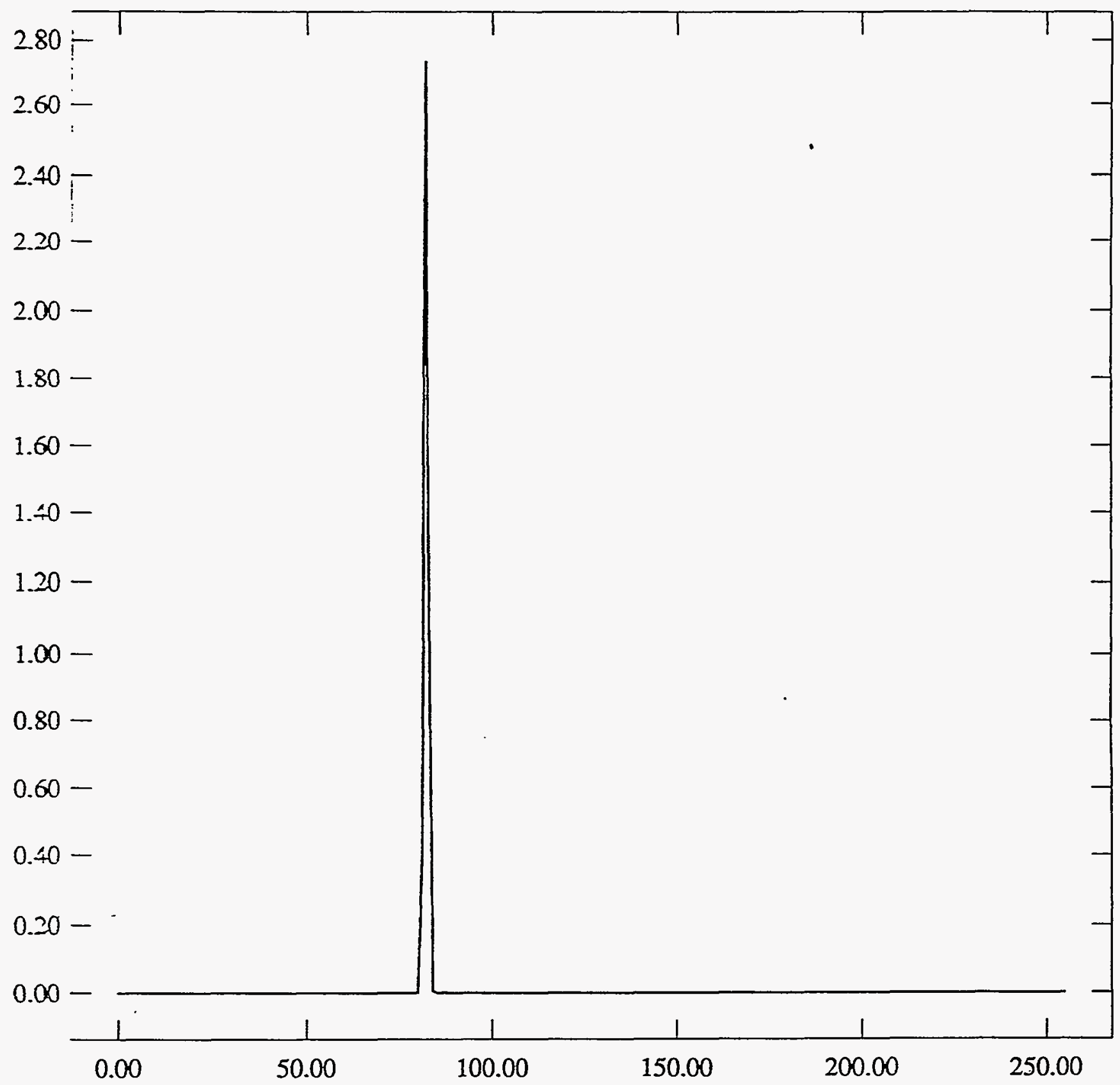


ST Camera: ST1\#04-10pstshk2: int_time= 50ms, offset= 0, gain=4 ( $75 \mathrm{e} / \mathrm{bit}$ ) Thu Jul 114:26:06 1993 Pixel Values Min 148 Max 161 Mean 151.1 Sigma $0.91 \times 10^{3}$

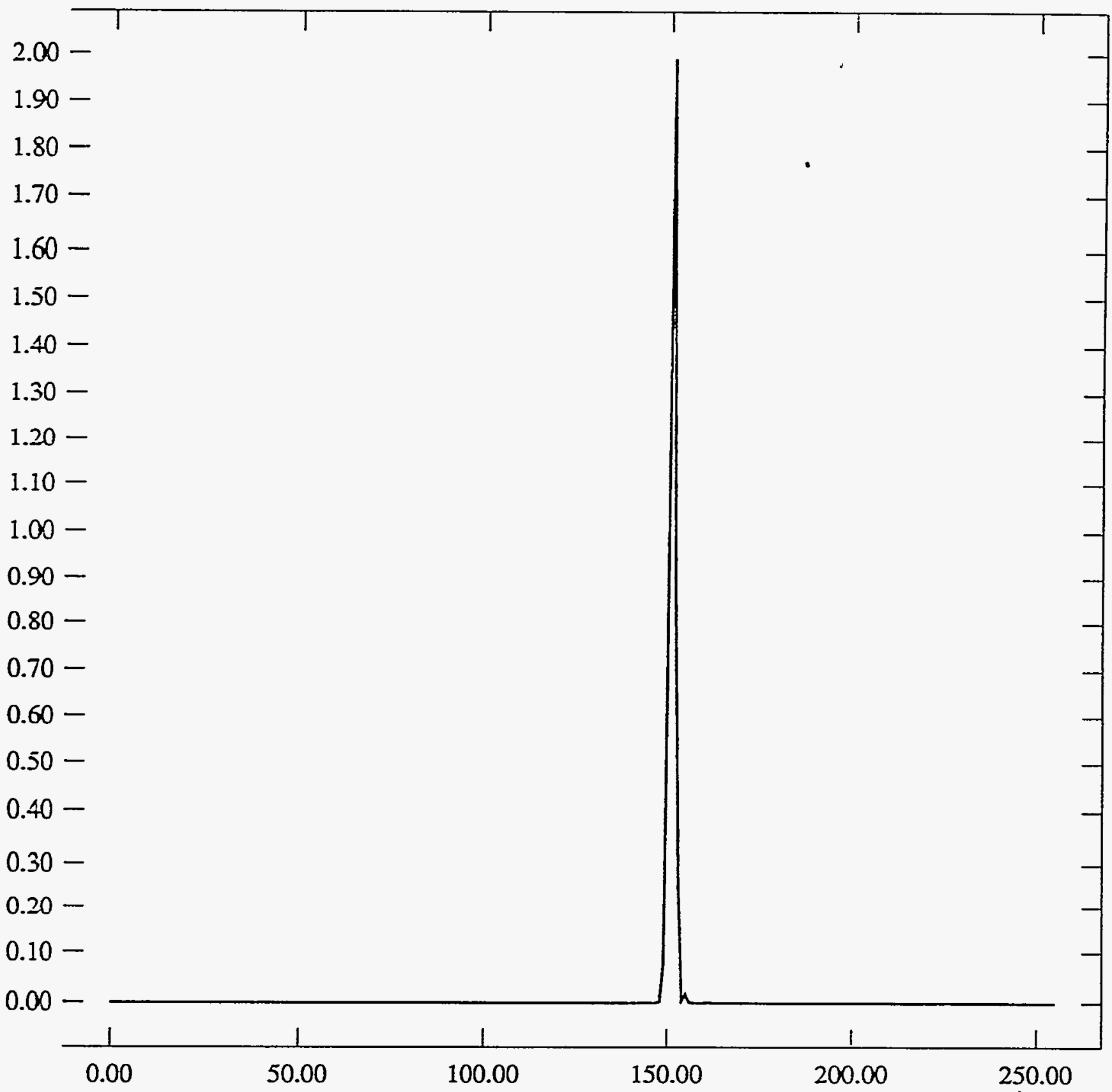


$\ldots$

.....

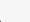


Appendix H.3.5.2.2

Thermal Cycle Test Data 


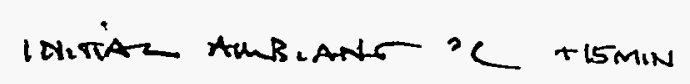

ST Camera: ST1\#04-10 : int_time= 50ms, offset= 0, gain=1 ( 350 e/bit) Wed Jun 30 05:17:12 1993

Pixel Values Min 41 Max 43 Mean 41.9 Sigma $0.28 \times 10^{3}$

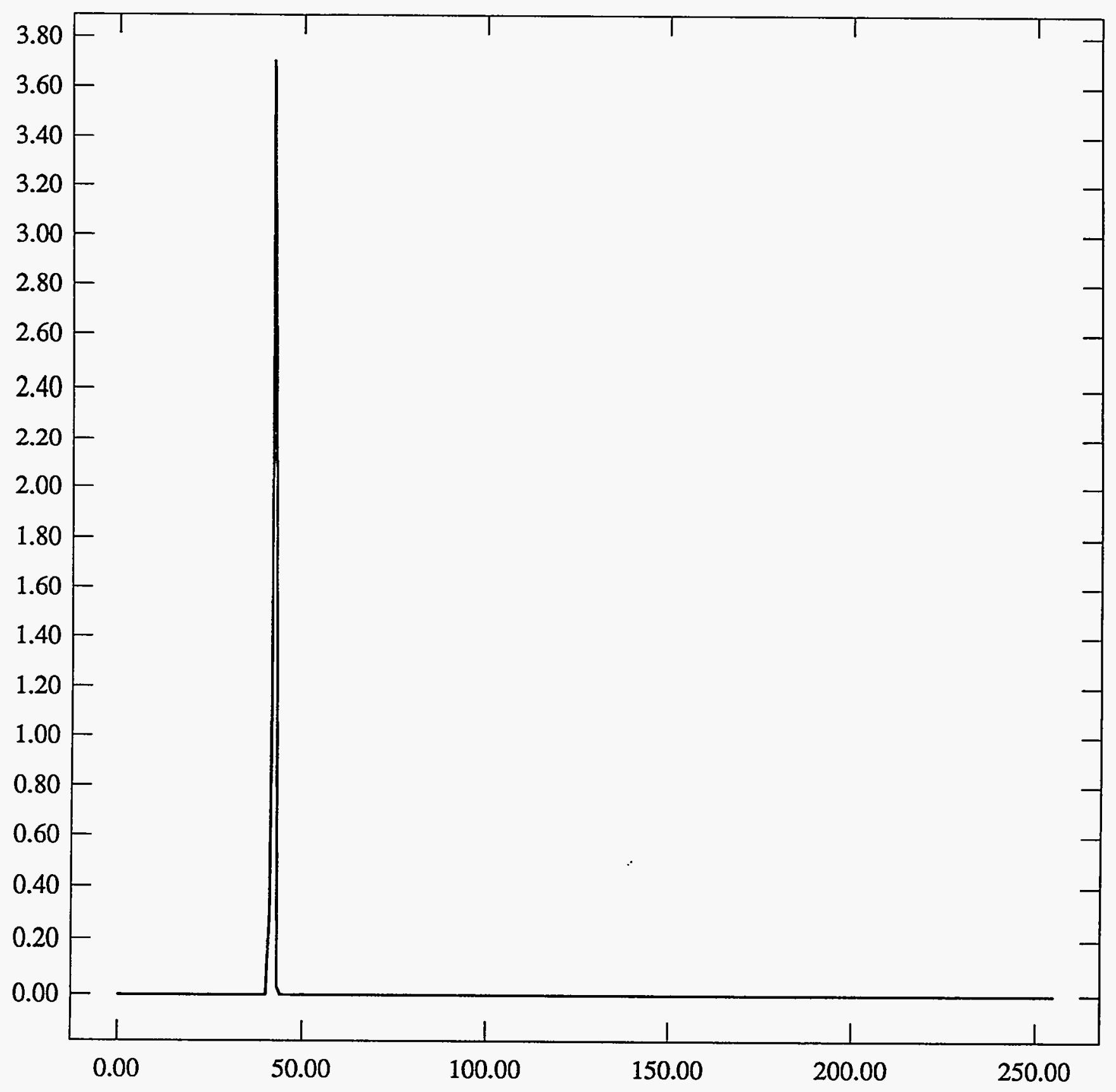


ST Camera: ST1\#04-10 : int_time=100ms, offset= 0, gain=1 ( 350 e/bit) Wed Jun 30 05:17:54 1993

Pixel Values Min 41 Max 43 Mean 41.9 Sigma $0.36 \times 10^{3}$

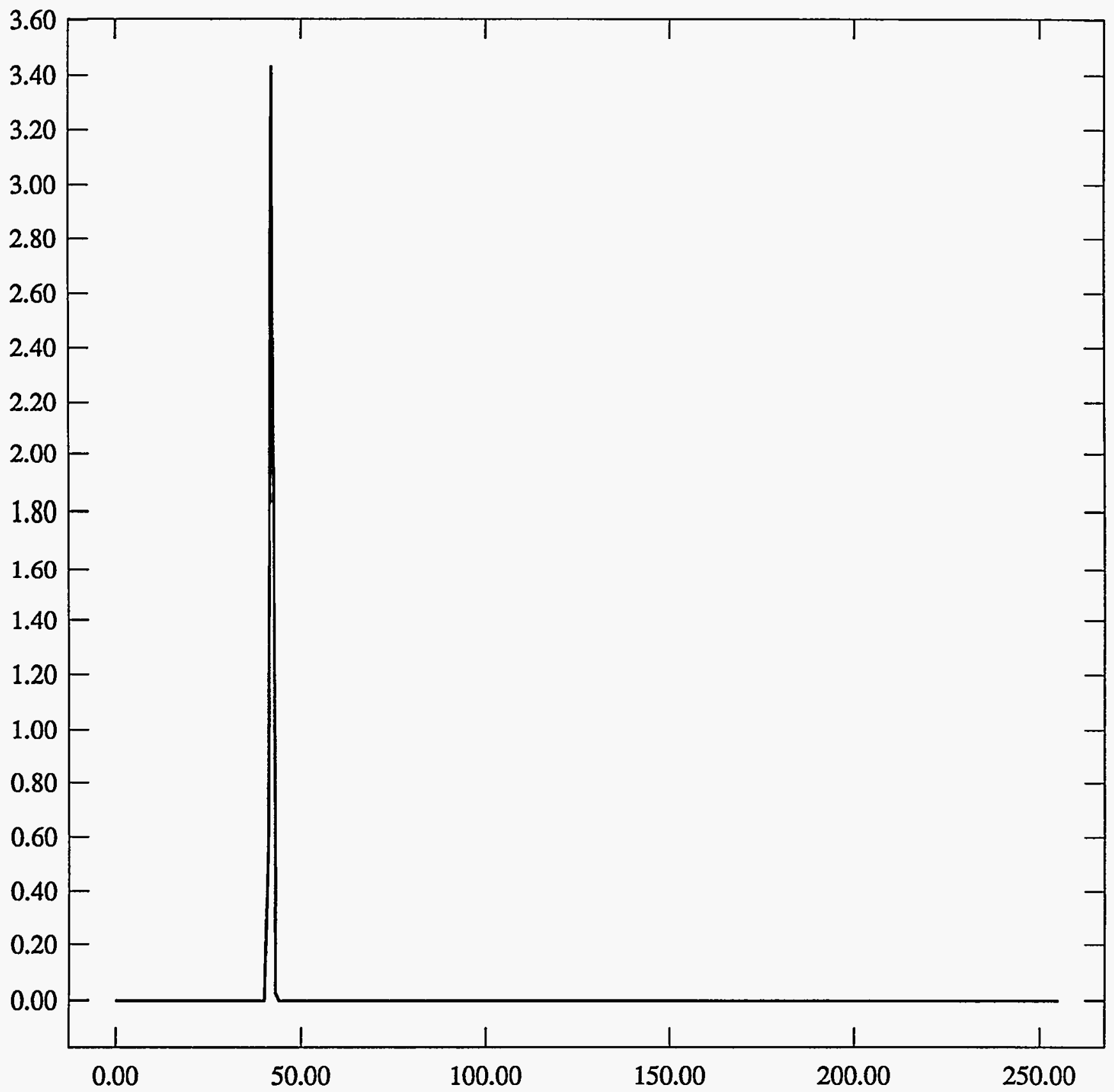


ST Camera: ST1 \#04-10: int_time=200ms, offset= 0, gain=1 ( 350 e/bit) Wed Jun 30 05:18:34 1993

Pixel Values Min 41 Max 43 Mean 41.8 Sigma $0.40 \times 10^{3}$

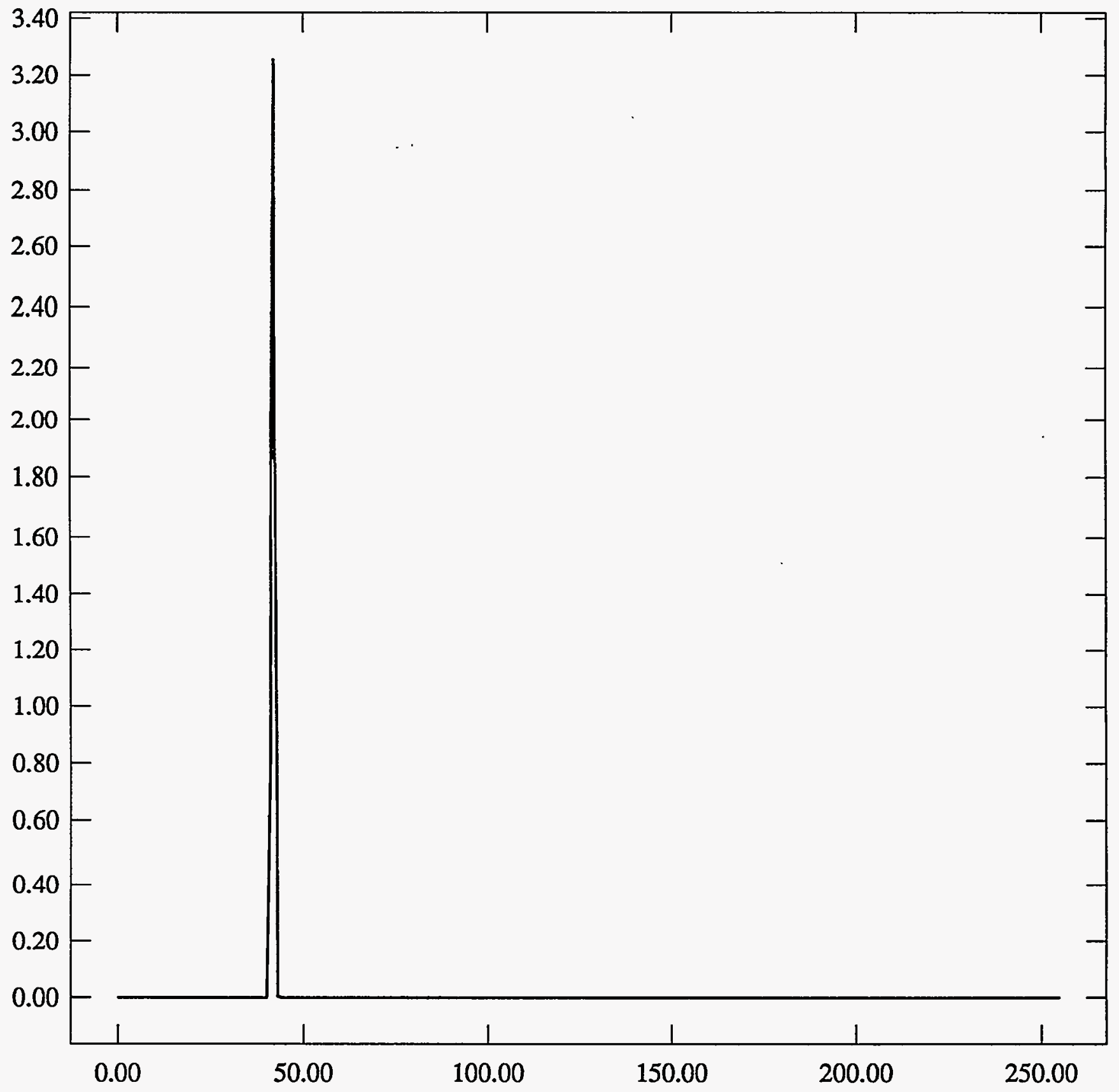


ST Camera: ST1\#04-10: int_time= 50ms, offset= 0, gain=2 (150 e/bit) Wed Jun 30 05:19:02 1993

Pixel Values Min 82 Max 86 Mean 84.1 Sigma $0.73 \times 10^{3}$

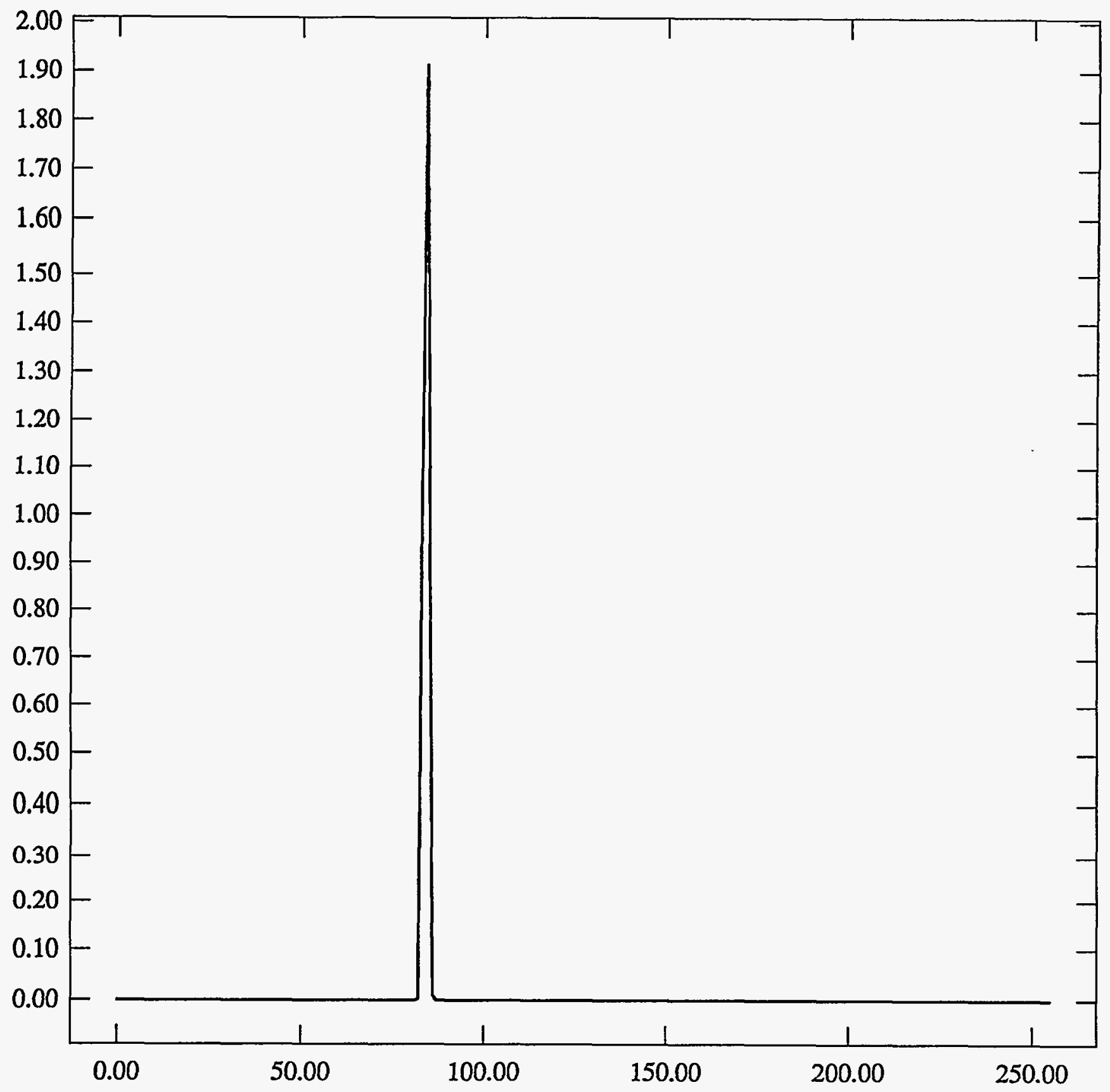


ST Camera: ST1\#04-10: int_time=100ms, offset= 0, gain=2 ( $150 \mathrm{e} / \mathrm{bit}$ ) Wed Jun 30 05:19:32 1993 Pixel Values Min 82 Max 86 Mean 83.9 Sigma $0.75 \times 10^{3}$

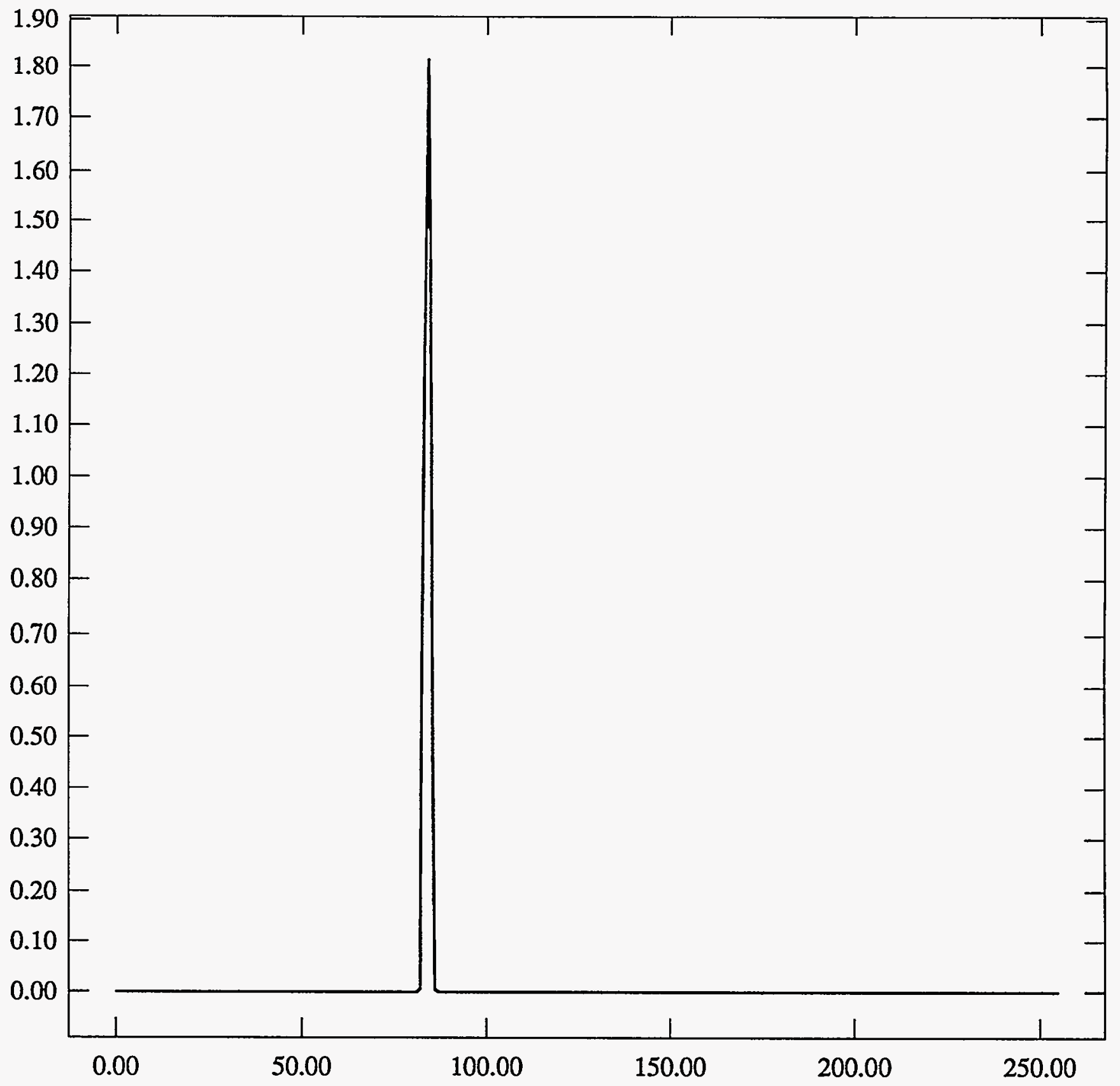


ST Camera: ST1\#04-10: int_time=200ms, offset= 0, gain=2 (150 e/bit) Wed Jun 30 05:19:59 1993

Pixel Values Min 82 Max 87 Mean 83.7 Sigma $0.75 \times 10^{3}$

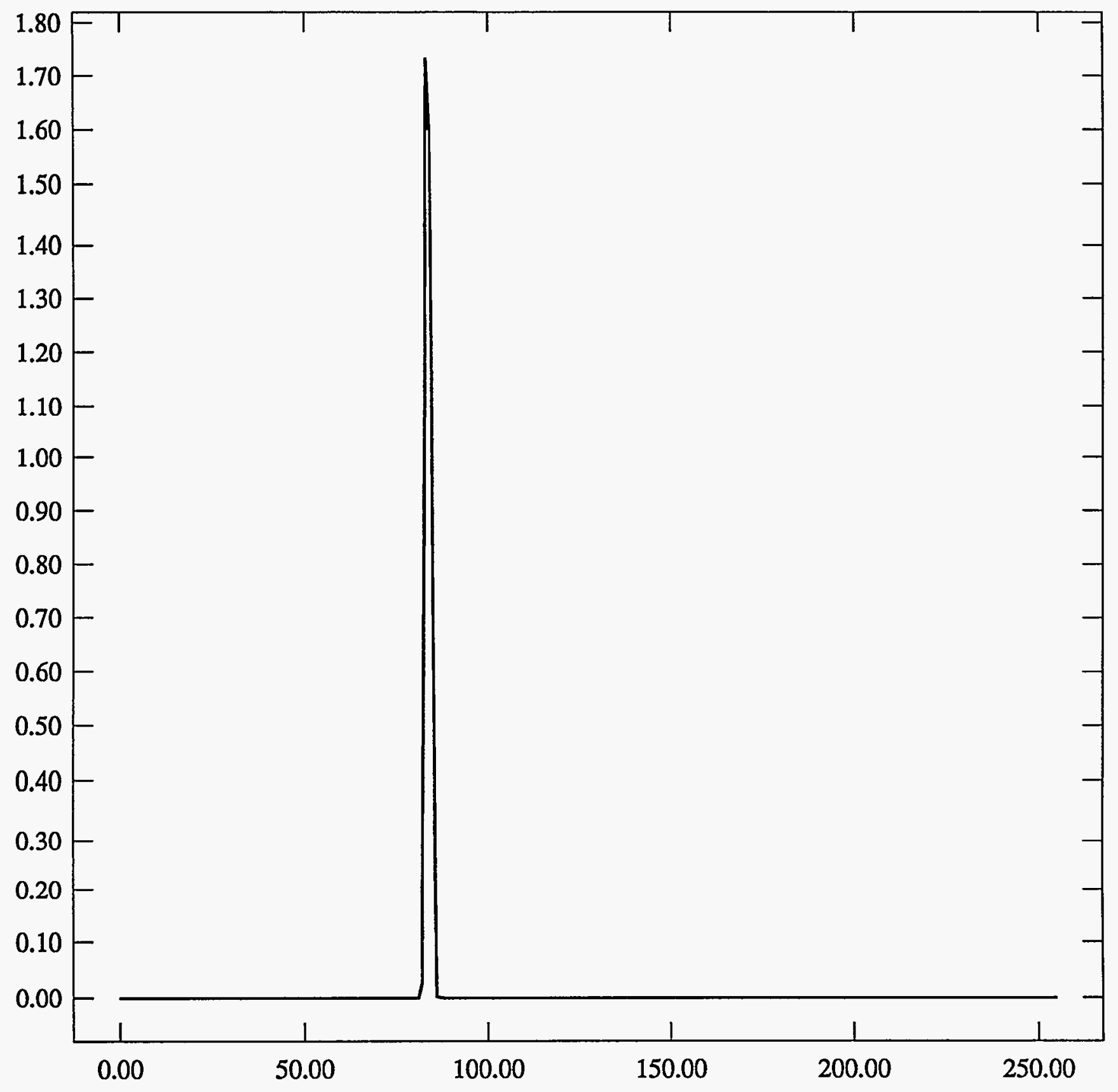


ST Camera: ST1\#04-10: int_time = 50ms, offset= 0, gain=4 ( $75 \mathrm{e} / \mathrm{bit}$ ) Wed Jun 30 05:20:28 1993 Pixel Values Min 150 Max 157 Mean 152.9 Sigma 1.09 x $10^{3}$

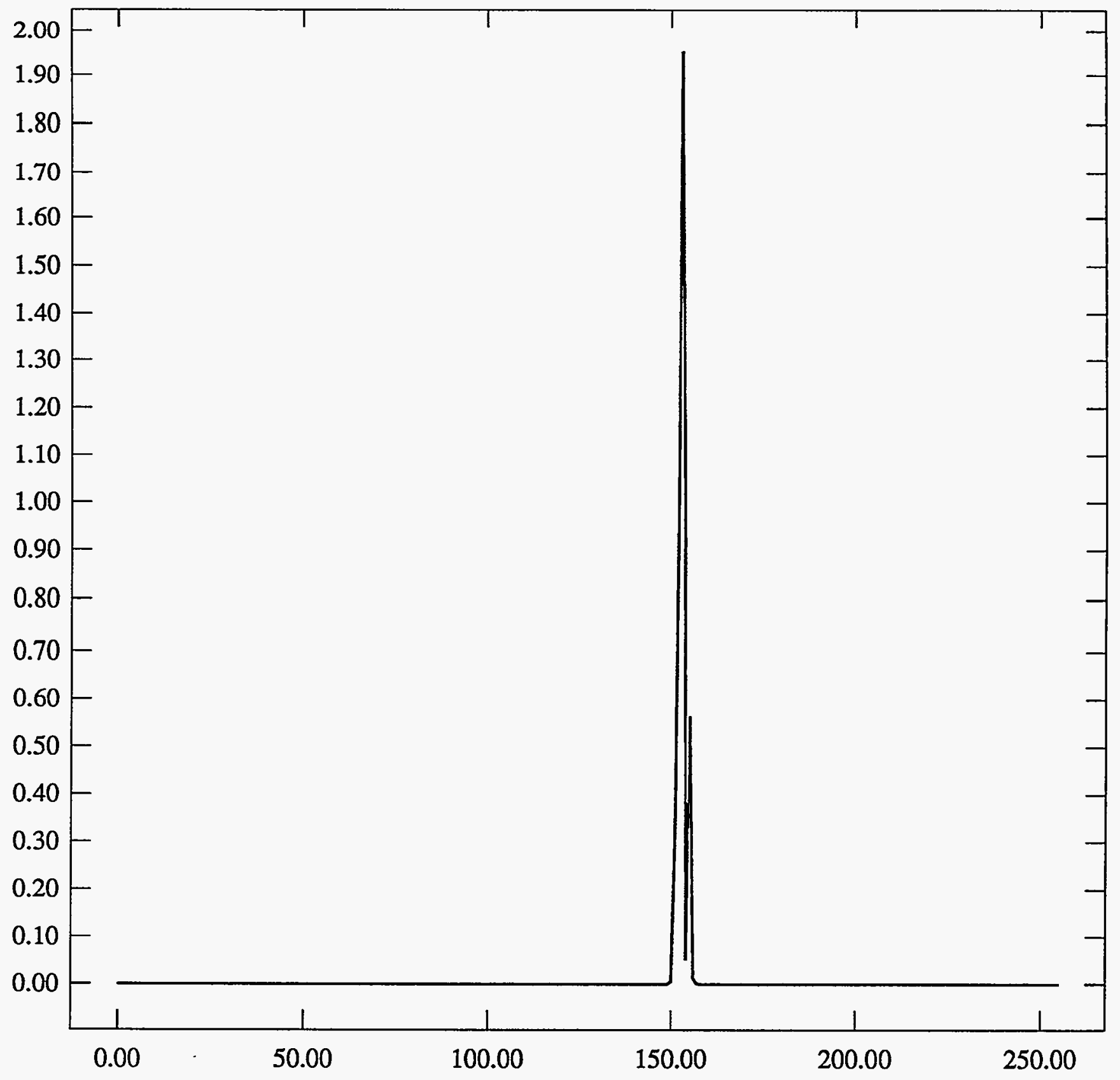


ST Camera: ST1 $\$ 04-10:$ int time=100ms, offset= 0, gain=4 ( 75 e/bit) Wed Jun 30 05:21:00 1993

Pixel Values Min 150 Max 156 Mean 152.7 Sigma $1.04 \times 10^{3}$

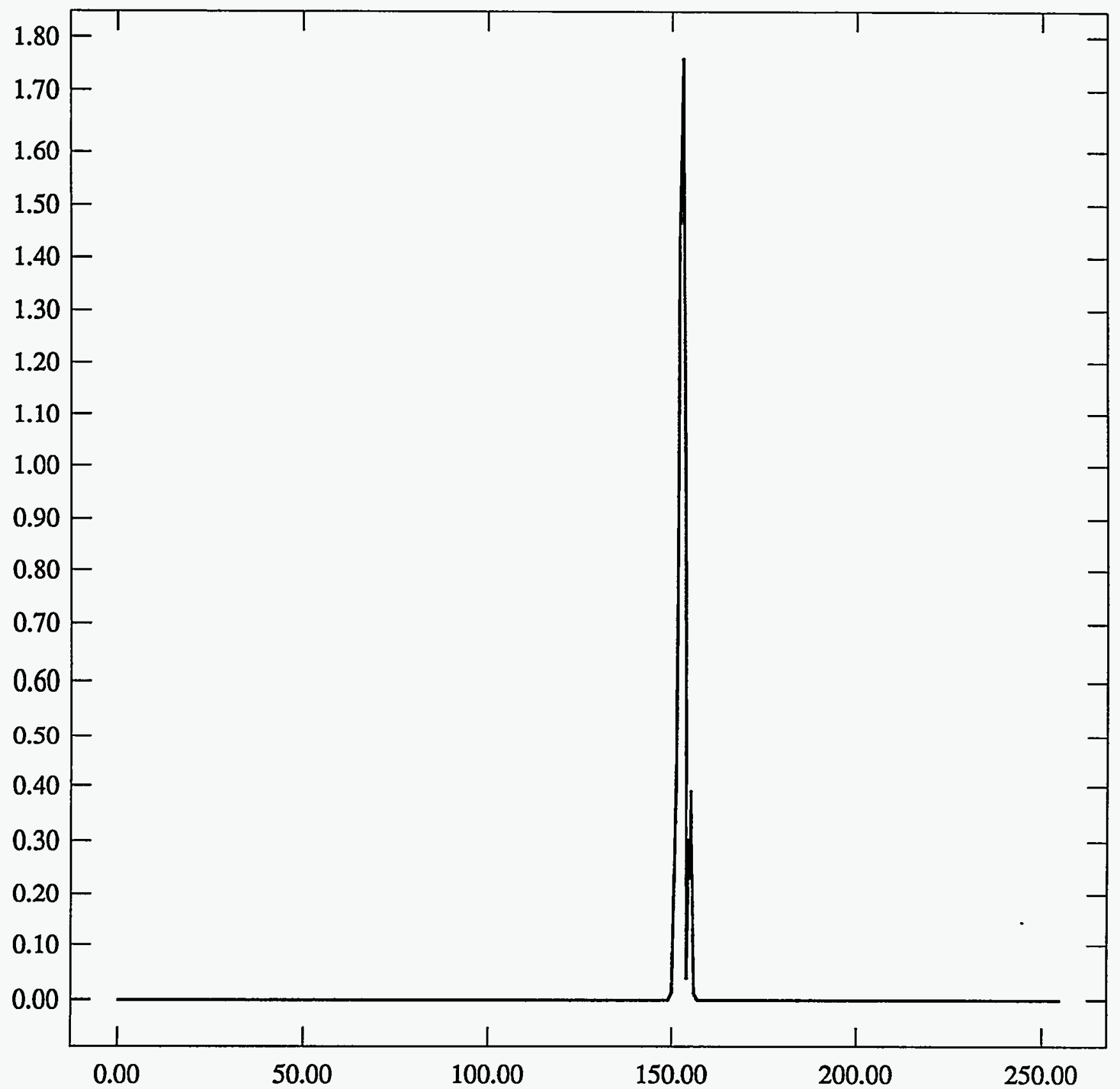


ST Camera: ST1\#04-10: int_time=200ms, offset= 0, gain=4 ( $75 \mathrm{e} / \mathrm{bit}$ ) Wed Jun 30 05:21:47 1993 Pixel Values Min 149 Max 156 Mean 152.4 Sigma $1.01 \times 10^{3}$

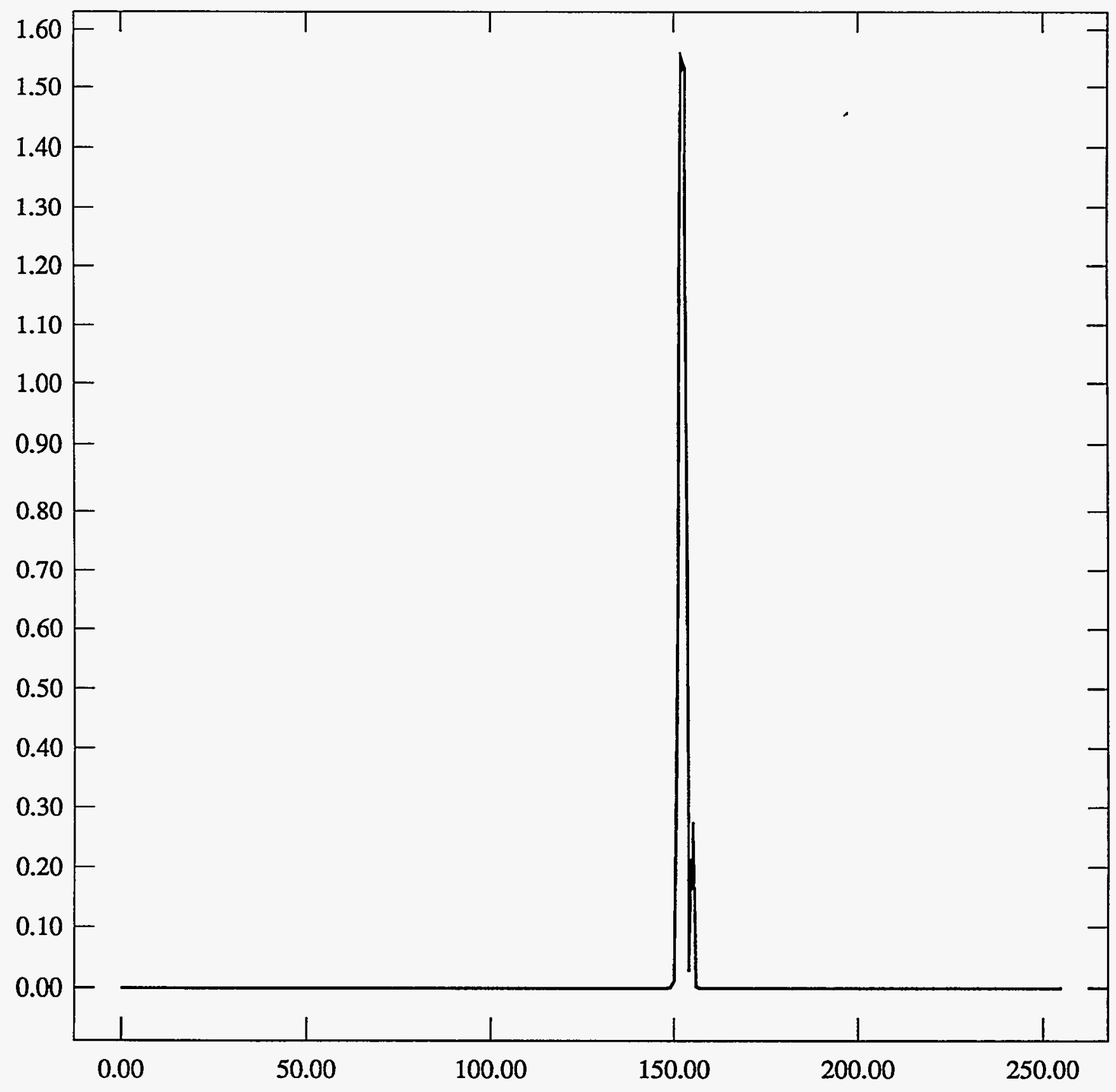


$2+1-30$ (2) $15 \min$

ST Camera: ST1\#04-10 -30C \#1: int_time= 50ms, offset= 0, gain=1 ( 350 e/bit) Wed Jun 30 06:03:25 1993 Pixel Values Min 39 Max 41 Mean 39.9 Sigma $0.34 \times 10^{3}$

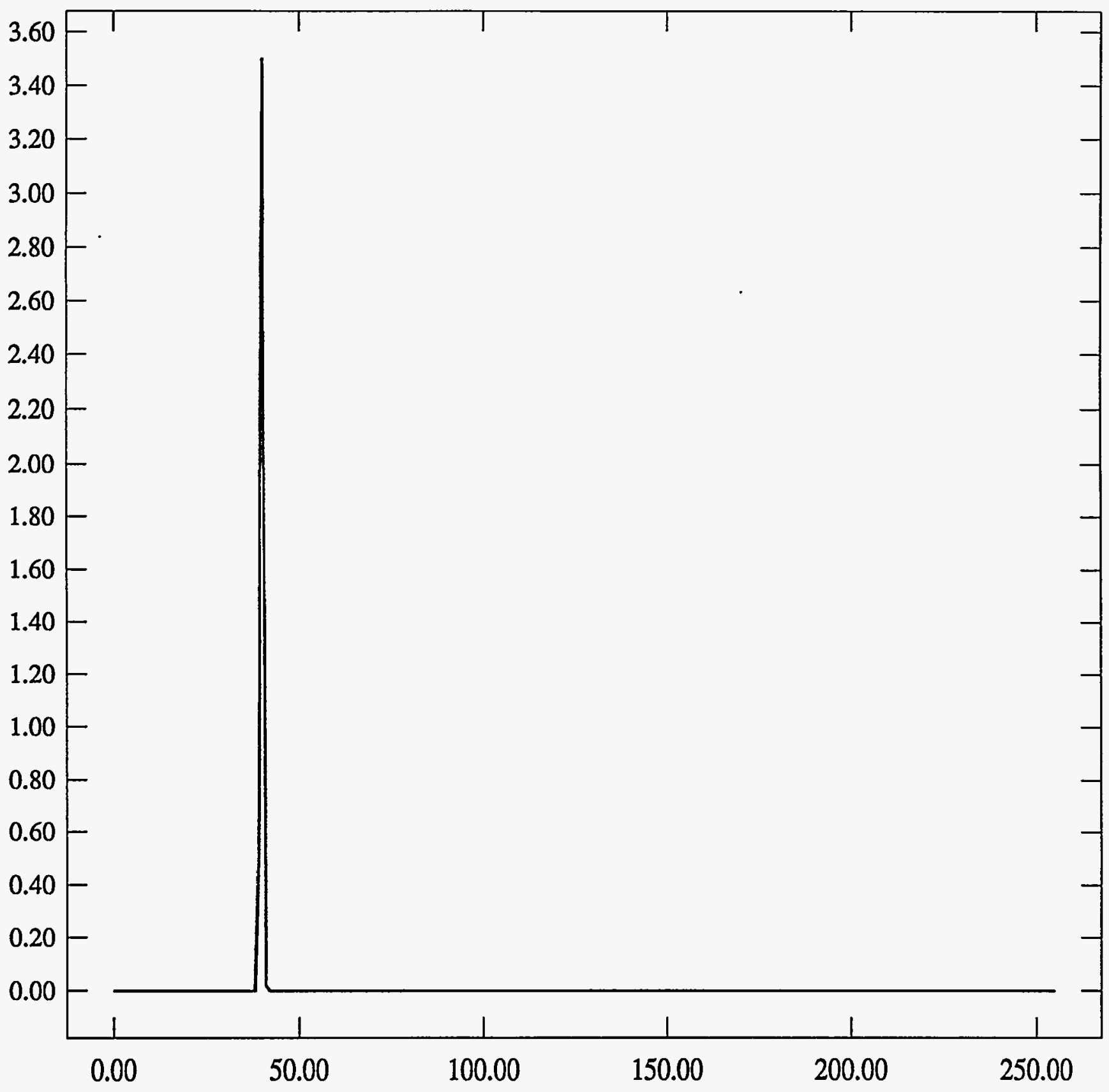


ST Camera: ST1\#04-10 -30C \#1: int_time=100ms, offset= 0, gain=1 ( 350 e/bit) Wed Jun 30 06:04:38 1993 Pixel Values Min 39 Max 41 Mean 39.9 Sigma 0.34 x $10^{3}$

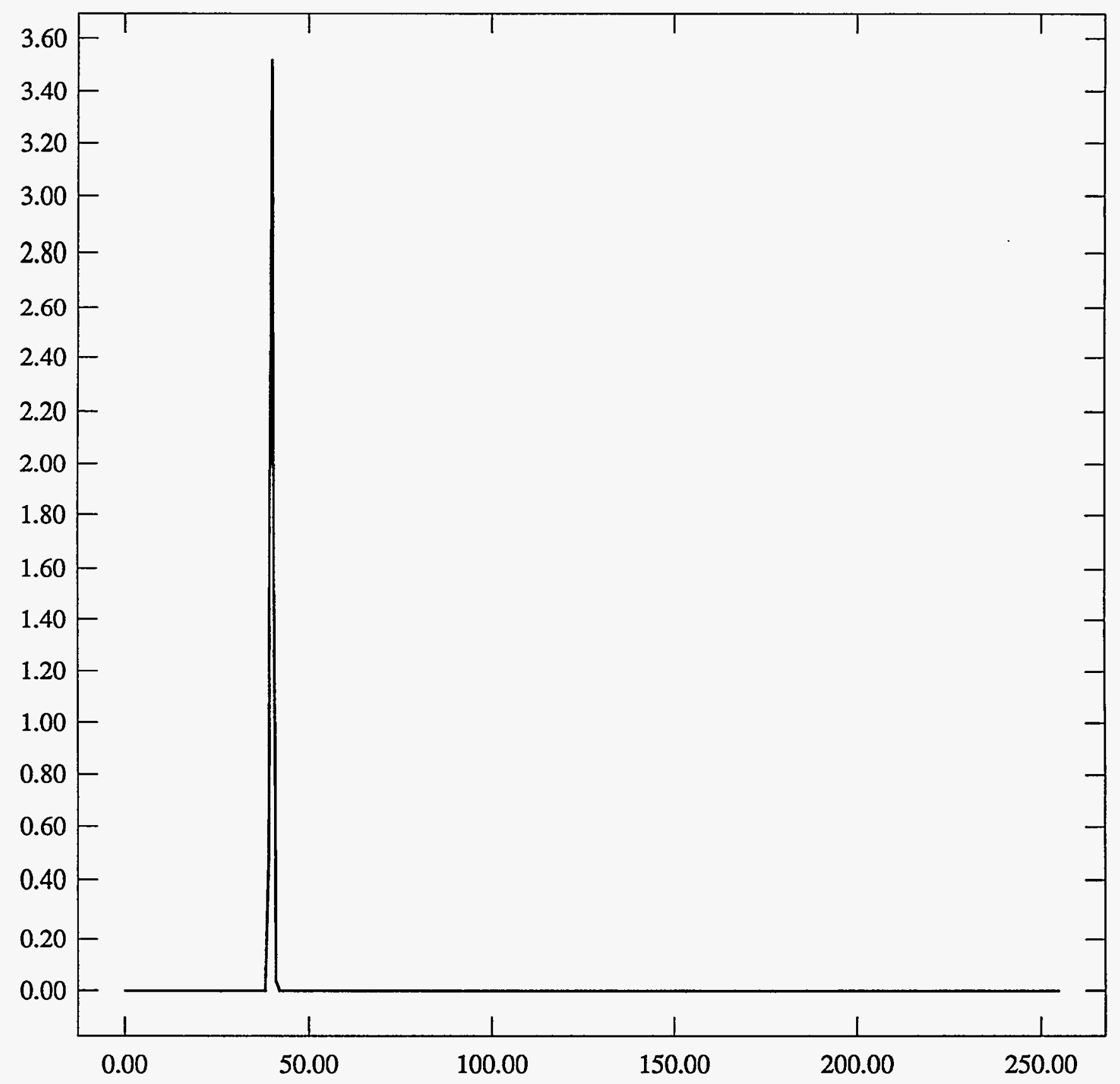


ST Camera: ST1\#04-10 -30C \#1: int_time=200ms, offset= 0, gain=1 ( $350 \mathrm{e} / \mathrm{bit}$ ) Wed Jun 30 06:05:23 1993 Pixel Values Min 39 Max 41 Mean 39.9 Sigma $0.33 \times 10^{3}$

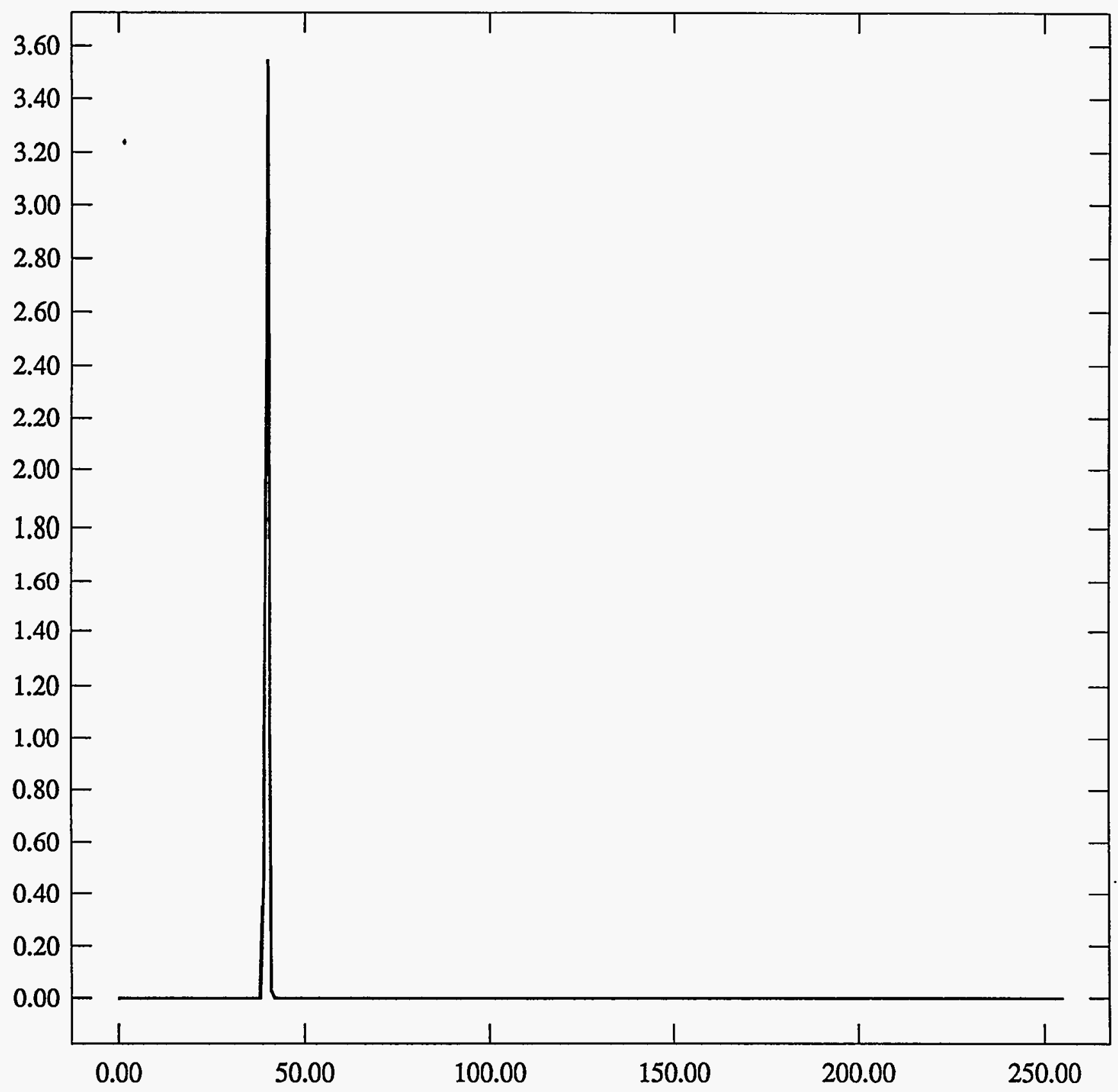


ST Camera: ST1\#04-10 -30C \#1: int_time= 50ms, offset= 0, gain=2 (150 e/bit) Wed Jun 30 06:06:27 1993 Pixel Values Min 78 Max 80 Mean 79.2 Sigma $0.58 \times 10^{3}$

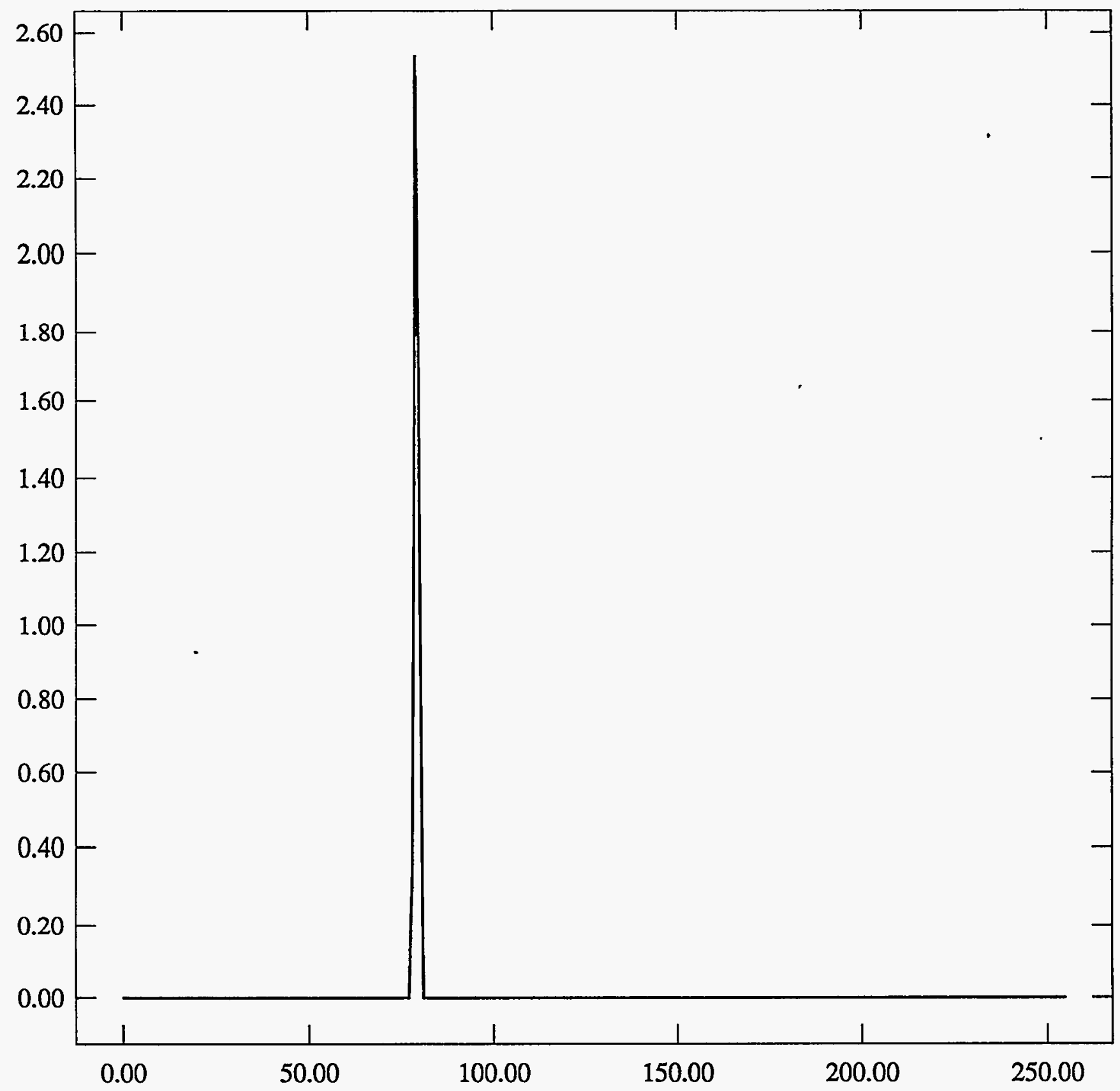


ST Camera: ST1\#04-10 -30C \#1: int_time=100ms, offset= 0, gain=2 (150 e/bit) Wed Jun 30 06:06:54 1993 Pixel Values Min 78 Max 80 Mean 79.2 Sigma $0.57 \times 10^{3}$

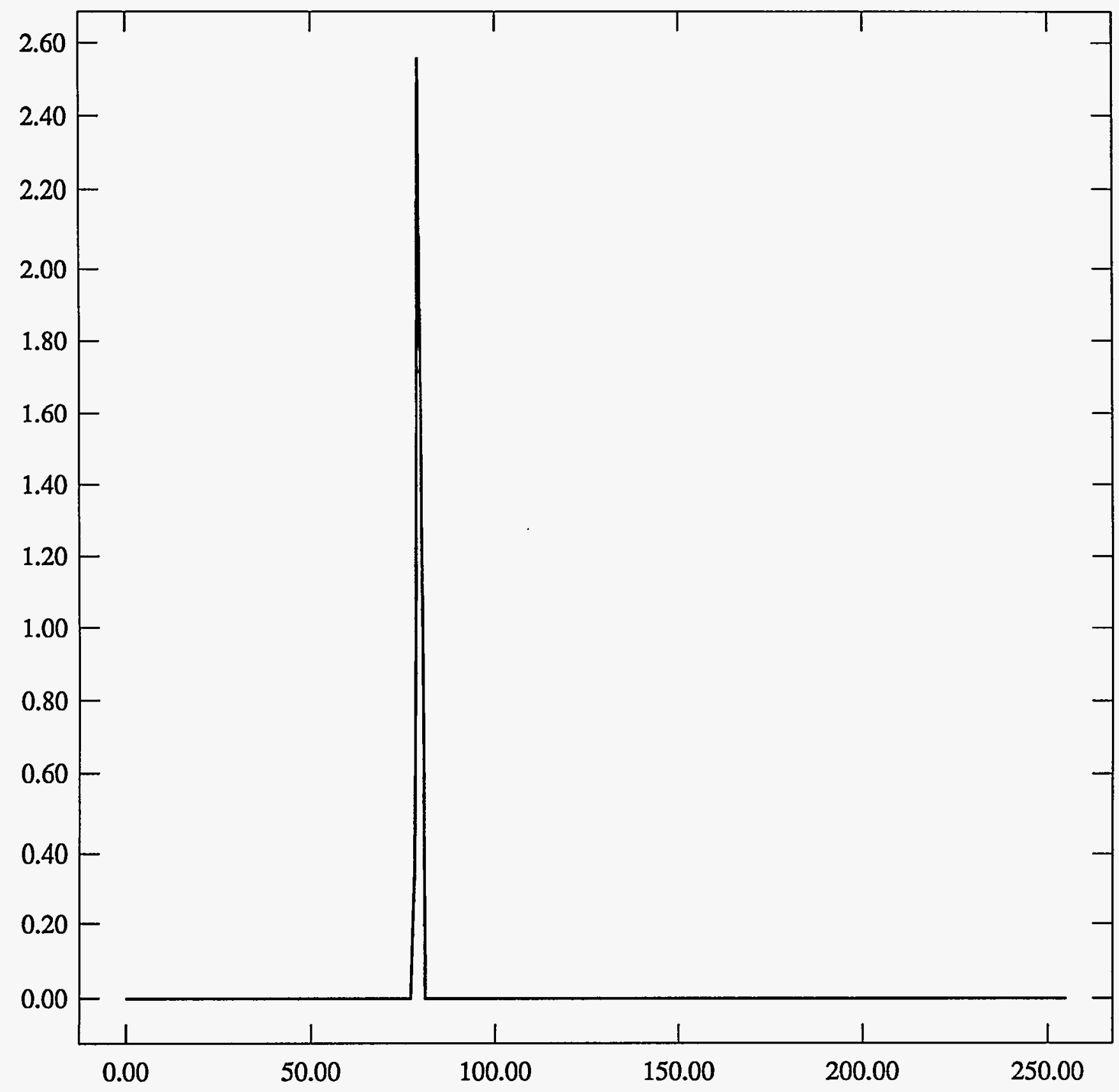


ST Camera: ST1\#04-10 -30C \#1: int_time=200ms, offset= 0, gain=2 (150 e/bit) Wed Jun 30 06:08:14 1993 Pixel Values Min 78 Max 81 Mean 79.2 Sigma $0.58 \times 10^{3}$

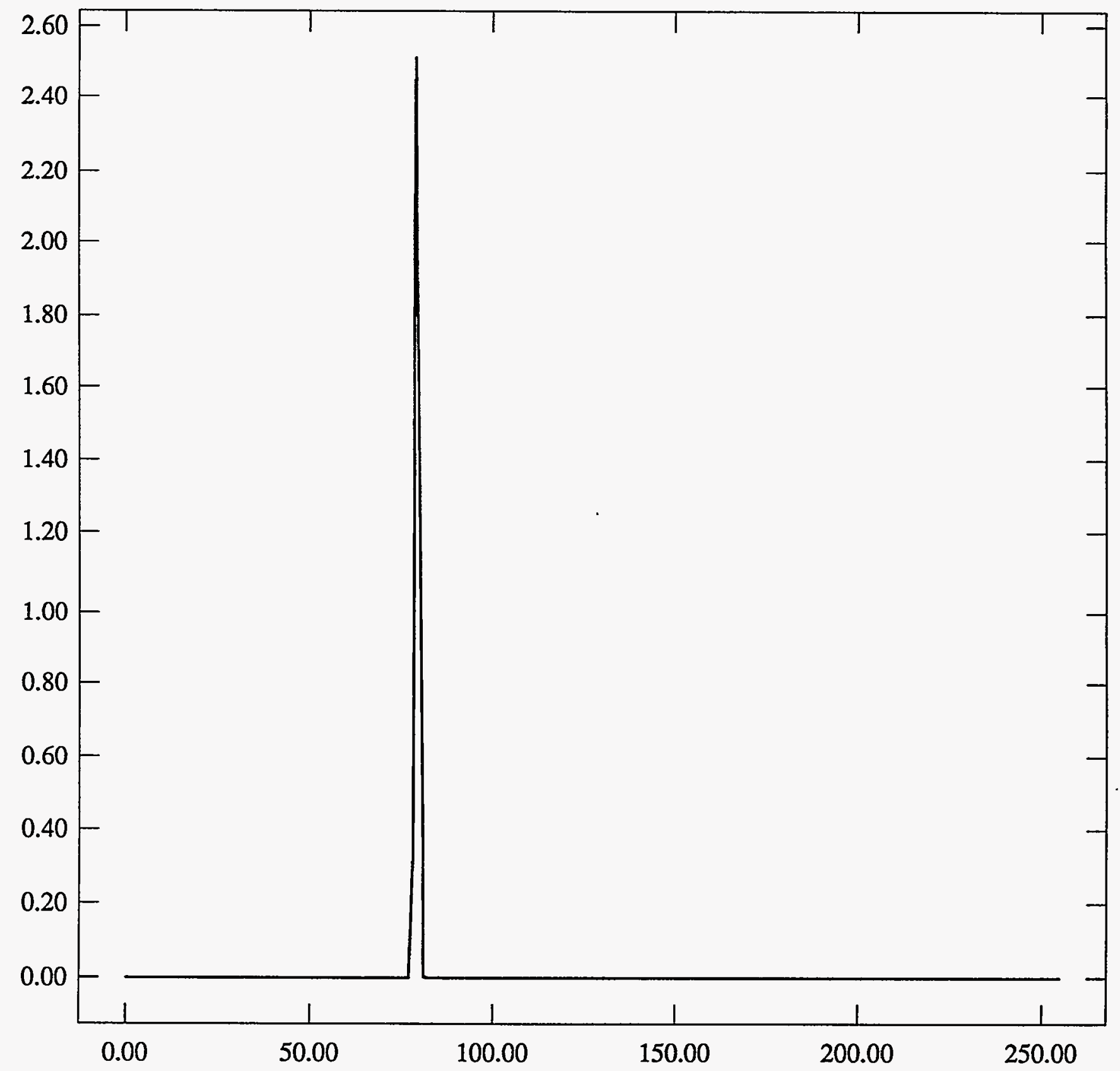


ST Camera: ST1\#04-10 -30C \#1: int_time= 50ms, offset= 0, gain=4 ( 75 e/bit) Wed Jun 30 06:08:38 1993 Pixel Values Min 145 Max 149 Mean 146.8 Sigma $0.69 \times 10^{3}$

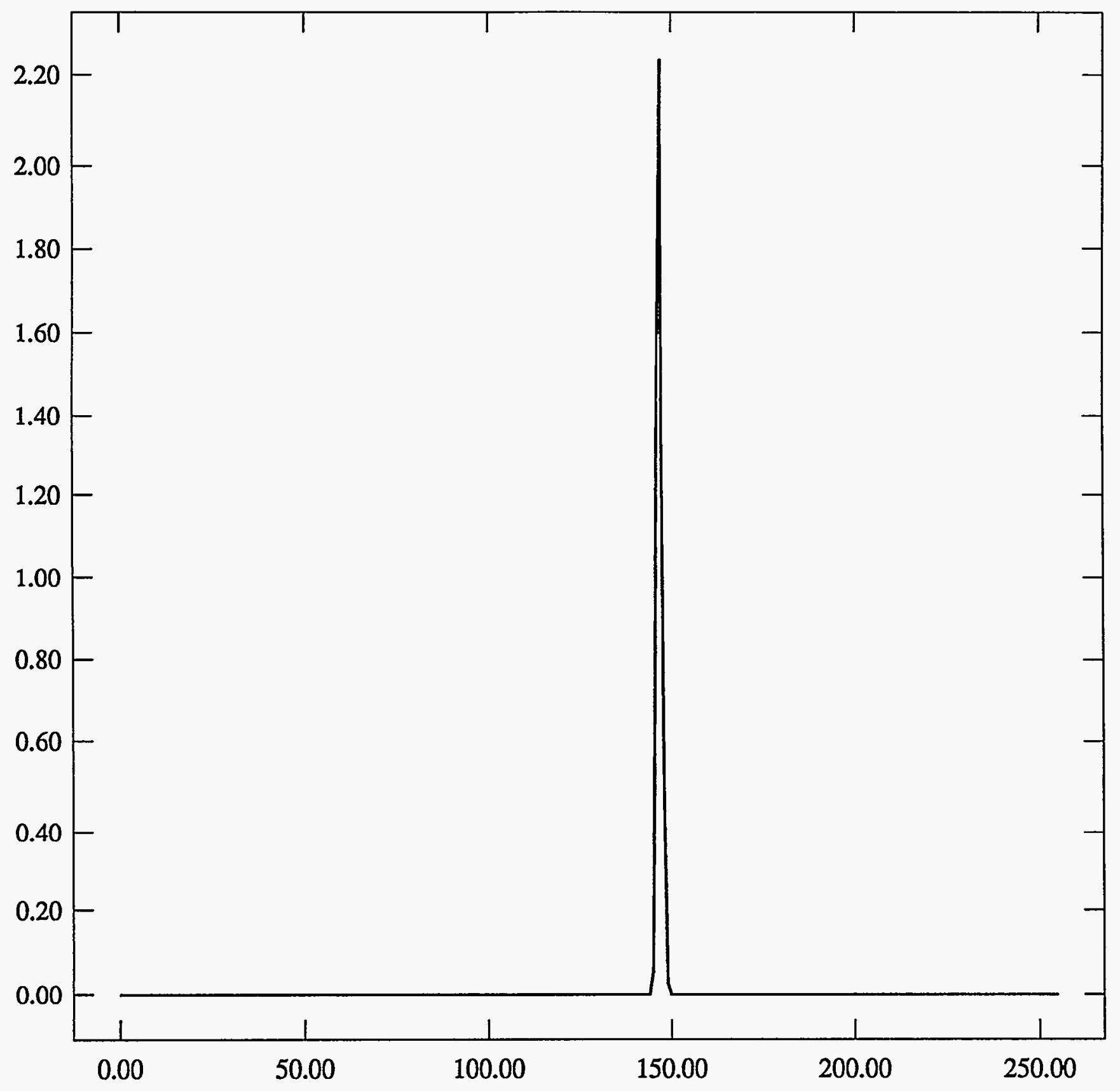


ST Camera: ST1\#04-10 -30C \#1: int_time=100ms, offset= 0, gain=4 ( 75 e/bit) Wed Jun 30 06:09:12 1993 Pixel Values Min 145 Max 149 Mean 146.9 Sigma $0.69 \times 10^{3}$

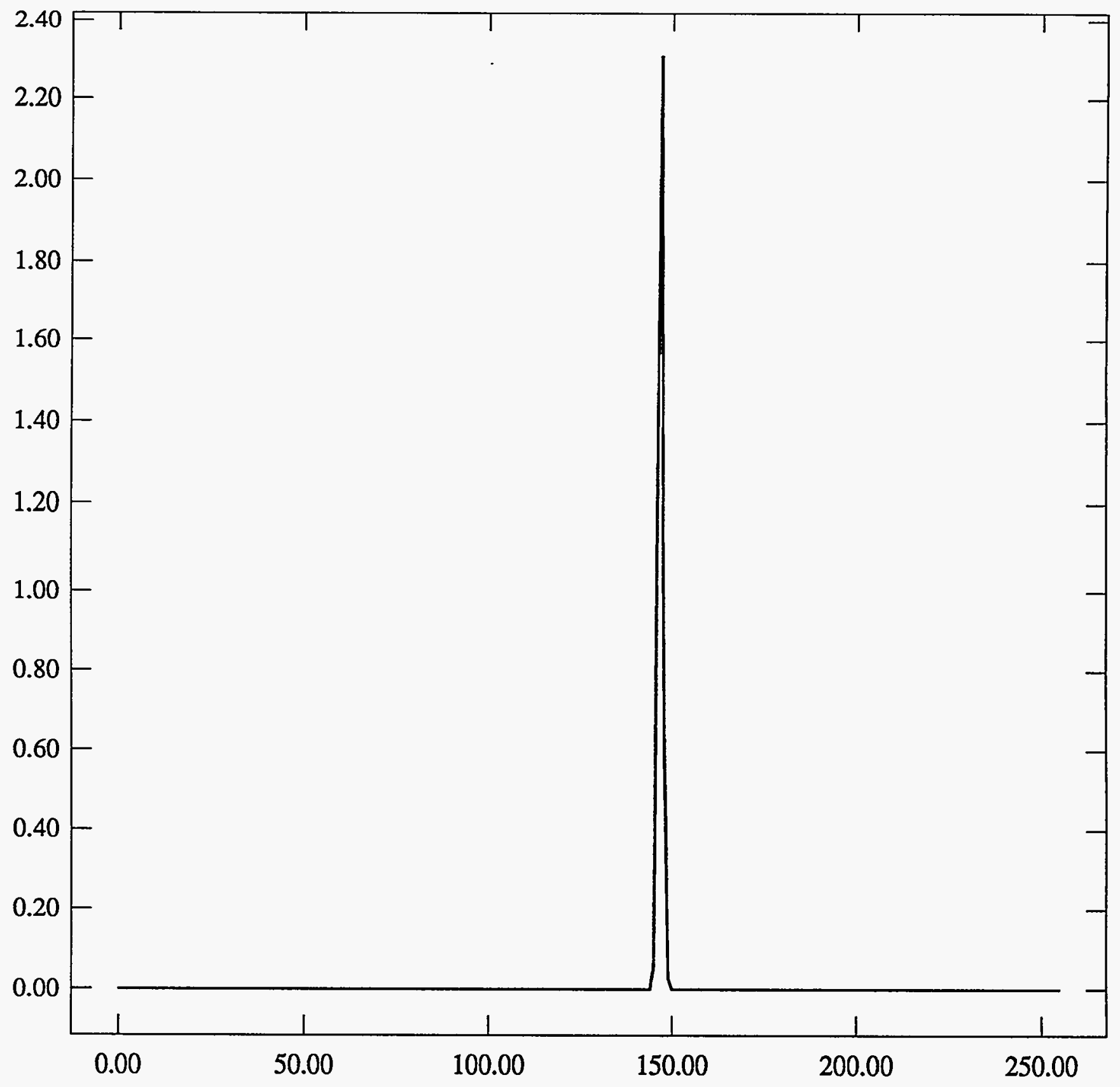


ST Camera: ST1\#04-10 -30C \#1: int_time=200ms, offset= 0, gain=4 ( 75 e/bit) Wed Jun 30 06:09:43 1993 Pixel Values Min 145 Max 149 Mean 146.9 Sigma $0.69 \times 10^{3}$

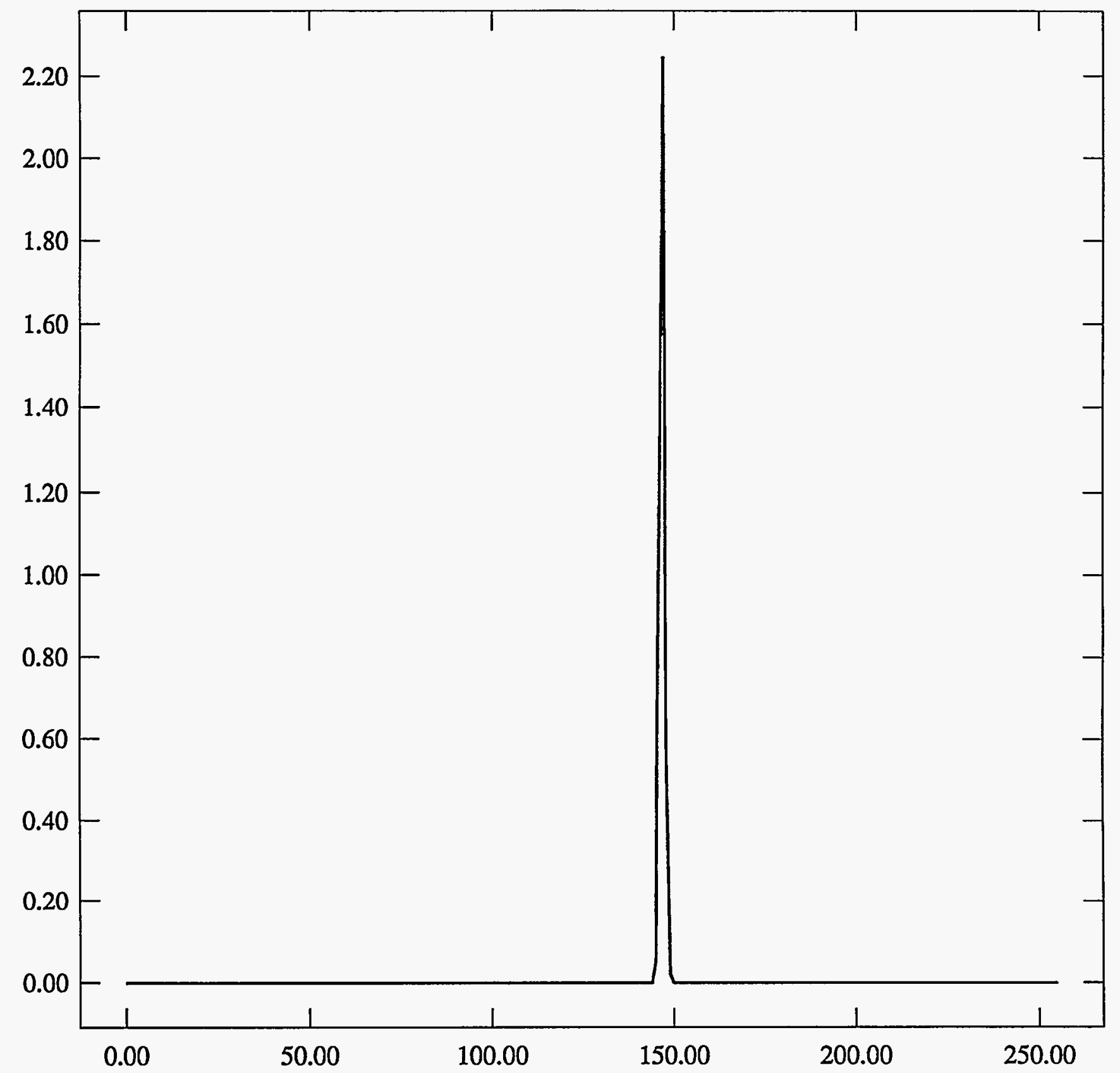


*1-30 Exs of CYCaE.

ST Camera: ST1\#04-10 -30C \#1: int_time= 50ms, offset= 0, gain=1 ( 350 e/bit) Wed Jun 30 06:48:28 1993 Pixel Values Min 39 Max 41 Mean 39.7 Sigma $0.46 \times 10^{3}$

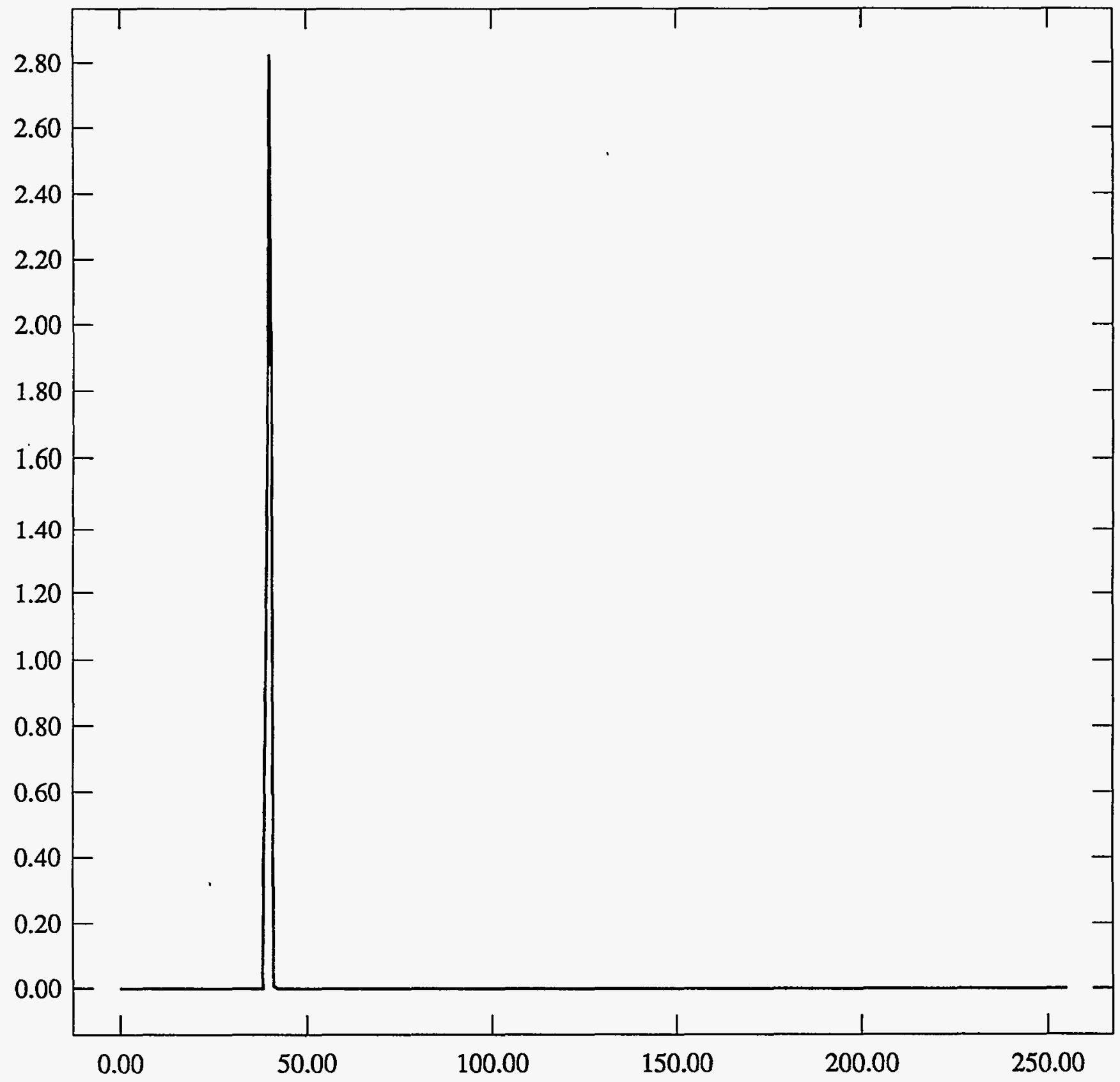


ST Camera: ST1\#04-10 -30C \#1: int_time=100ms, offset= 0, gain=1 ( $350 \mathrm{e} / \mathrm{bit}$ ) Wed Jun 30 06:48:50 1993 Pixel Values Min 39 Max 41 Mean 39.7 Sigma $0.47 \times 10^{3}$

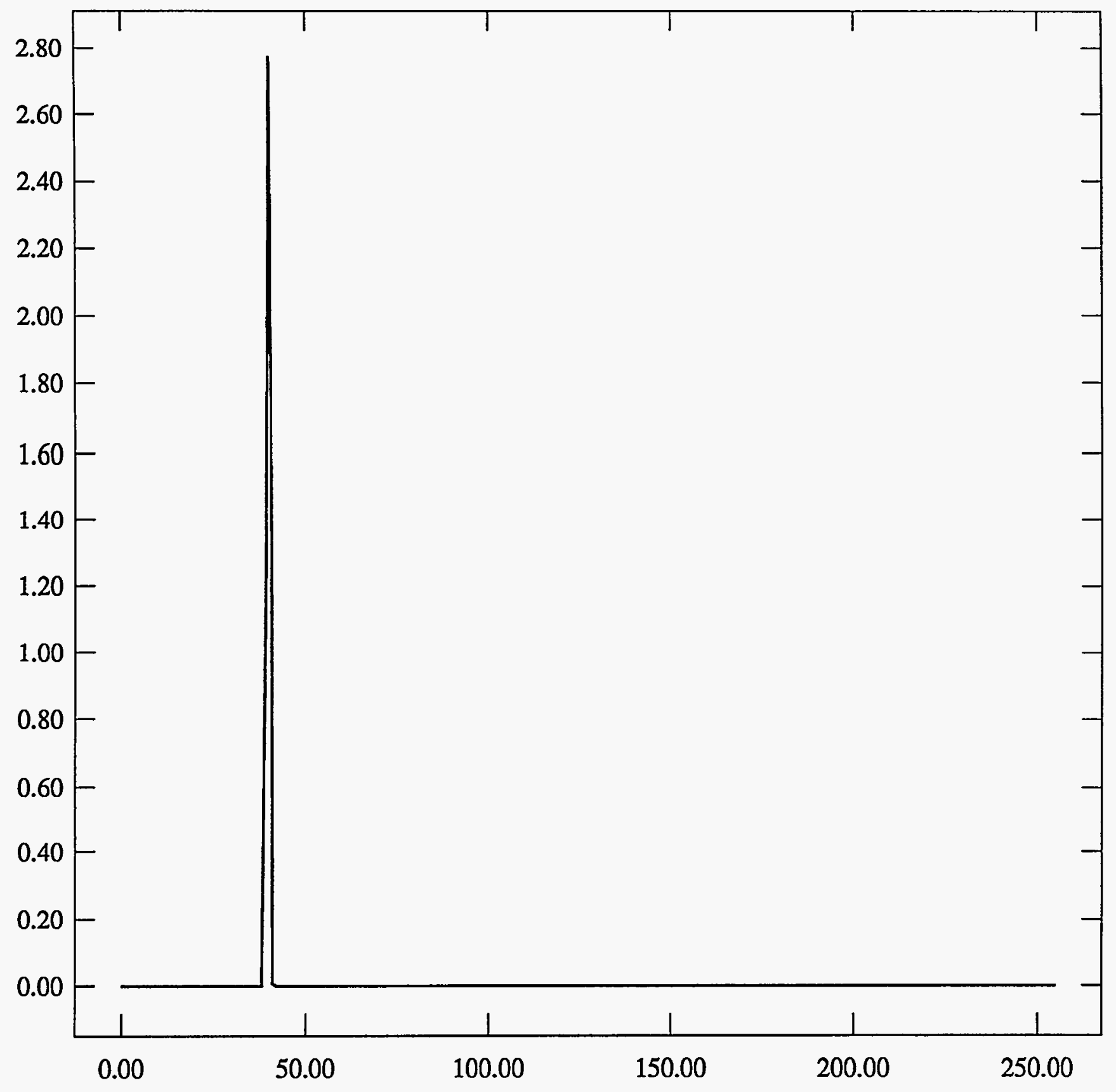


ST Camera: ST1\#04-10 -30C \#1: int_time=200ms, offset= 0, gain=1 ( $350 \mathrm{e} / \mathrm{bit})$ Wed Jun 30 06:49:31 1993 Pixel Values Min 39 Max 41 Mean 39.7 Sigma $0.48 \times 10^{3}$

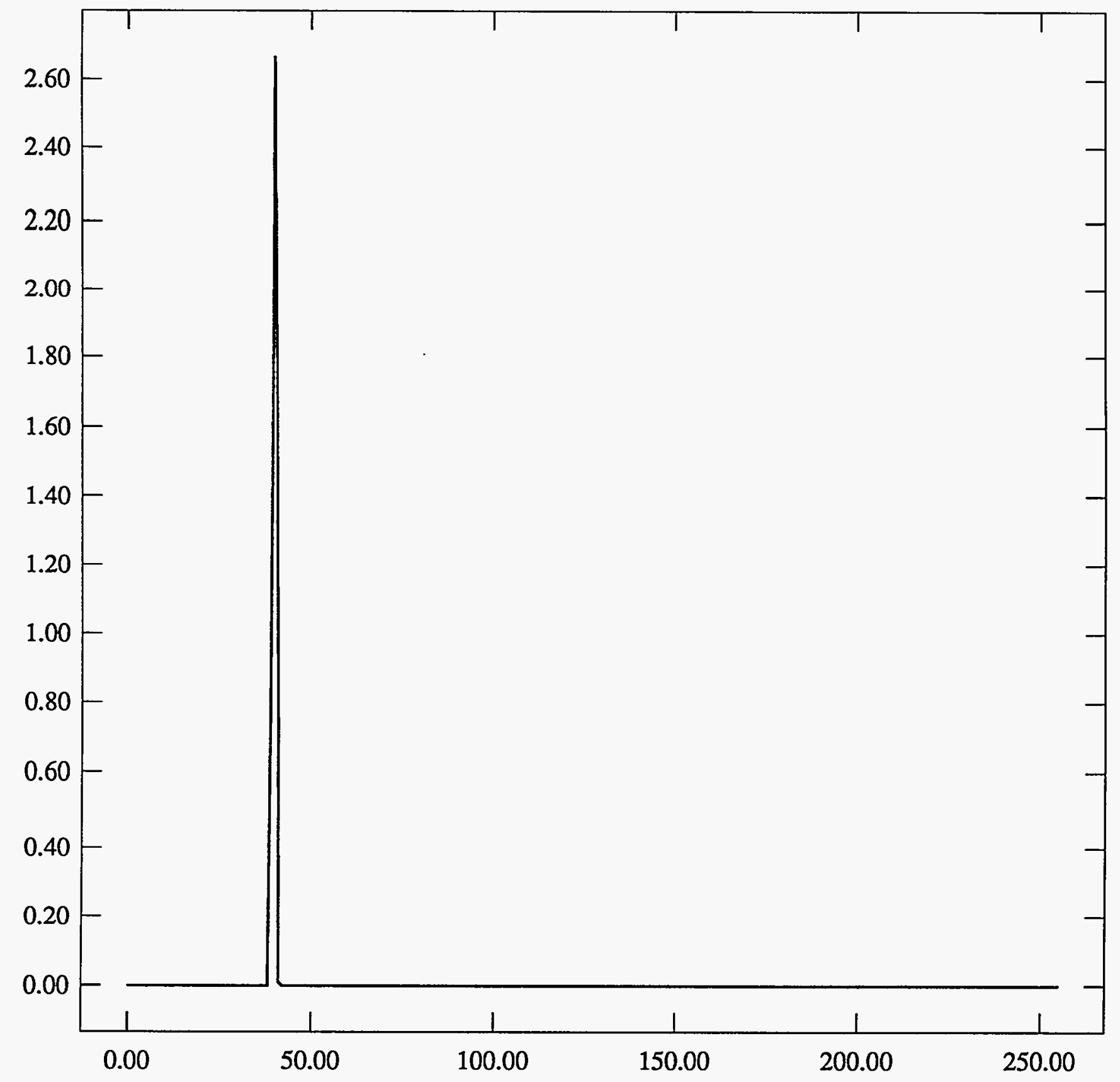


ST Camera: ST1\#04-10 -30C \#1: int_time=200ms, offset= 0, gain=1 (350 e/bit) Wed Jun 30 06:49:31 1993 Pixel Values Min 39 Max 41 Mean 39.7 Sigma $0.48 \times 10^{3}$

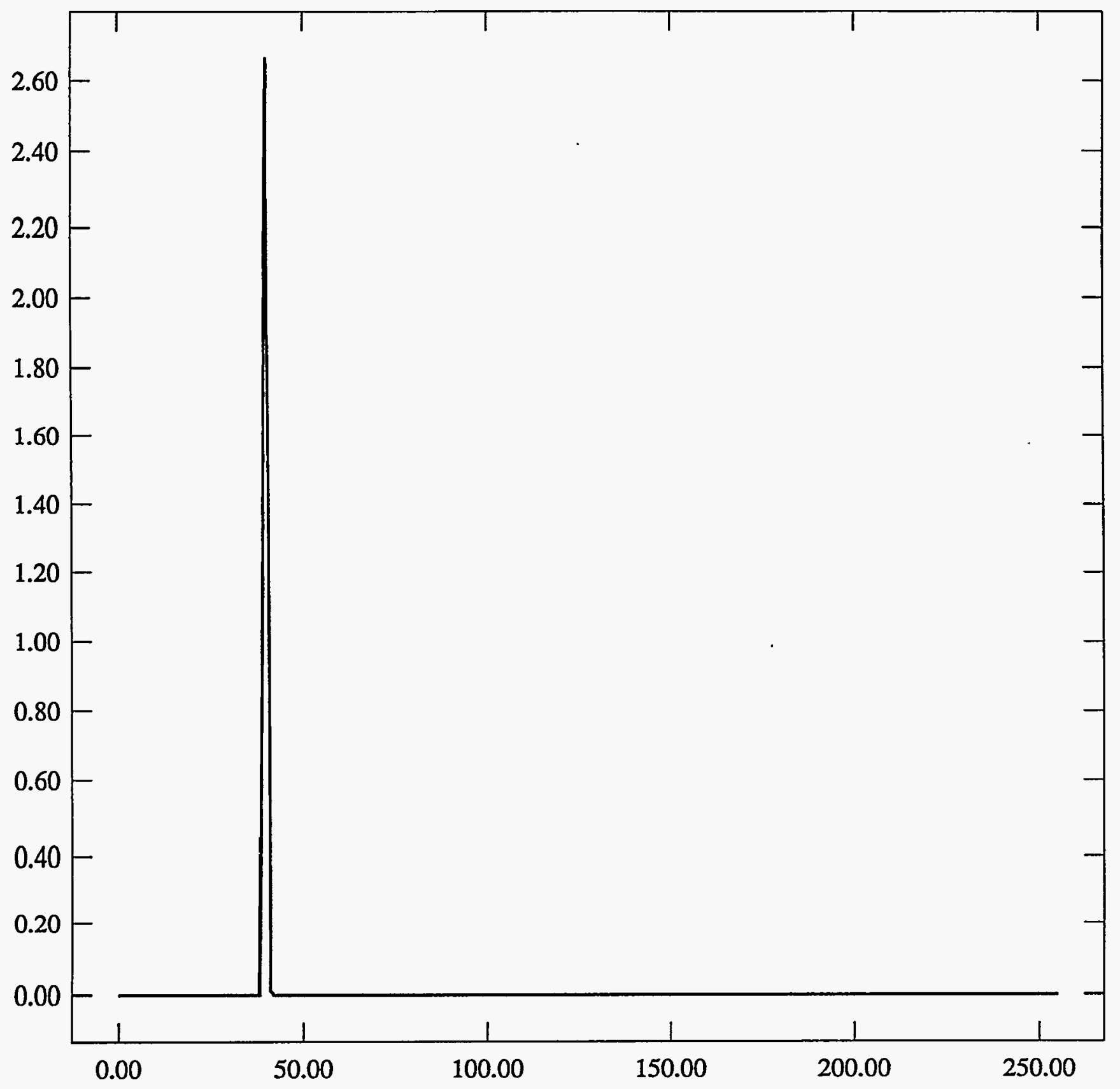


ST Camera: ST1\#04-10 -30C \#1: int_time= 50ms, offset= 0, gain=2 (150 e/bit) Wed Jun 30 06:50:08 1993 Pixel Values Min 77 Max 80 Mean 78.9 Sigma $0.57 \times 10^{3}$

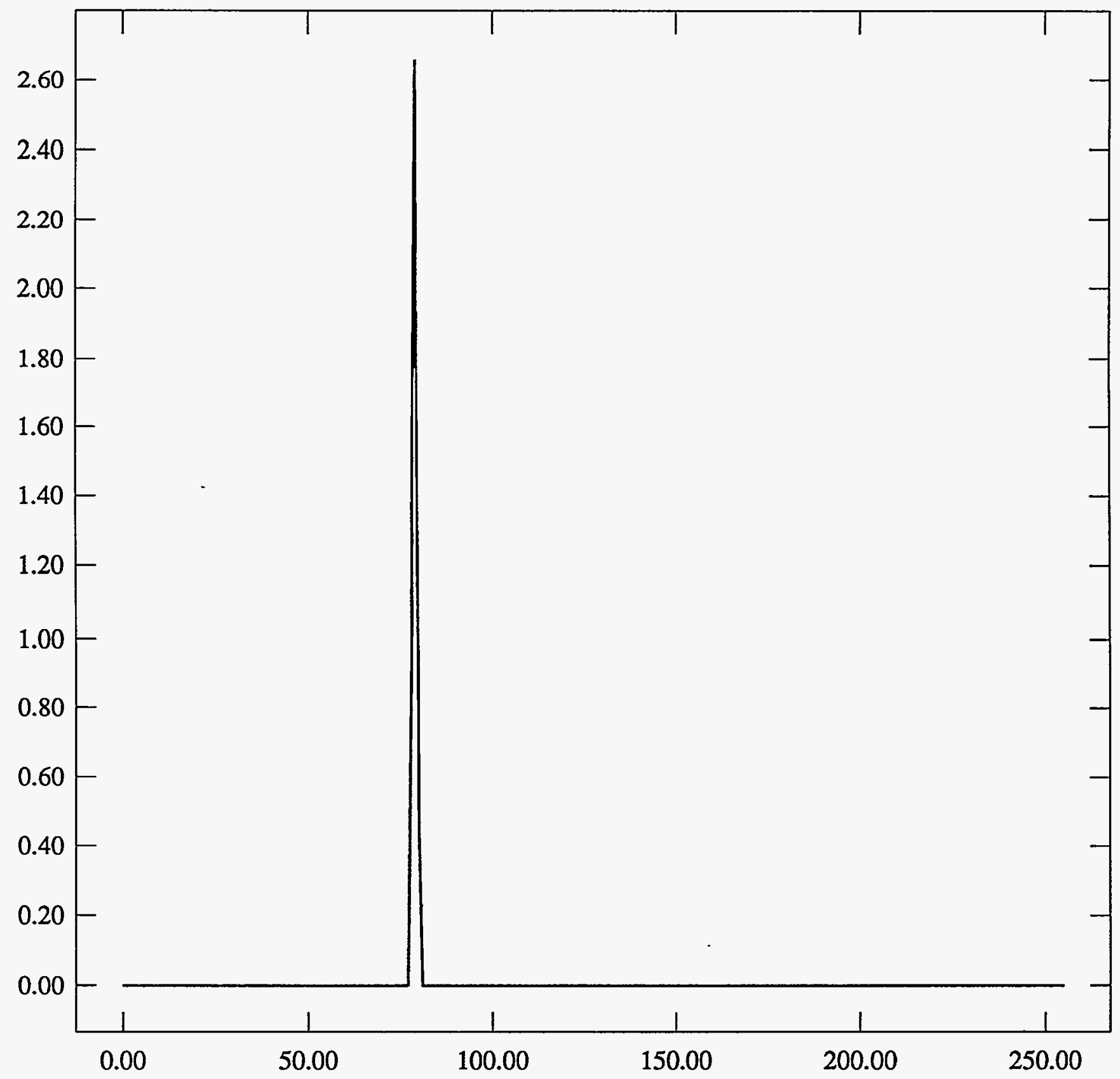


ST Camera: ST1\#04-10 -30C \#1: int_time=100ms, offset= 0, gain=2 (150 e/bit) Wed Jun 30 06:51:06 1993 Pixel Values Min 78 Max 80 Mean 78.8 Sigma $0.58 \times 10^{3}$

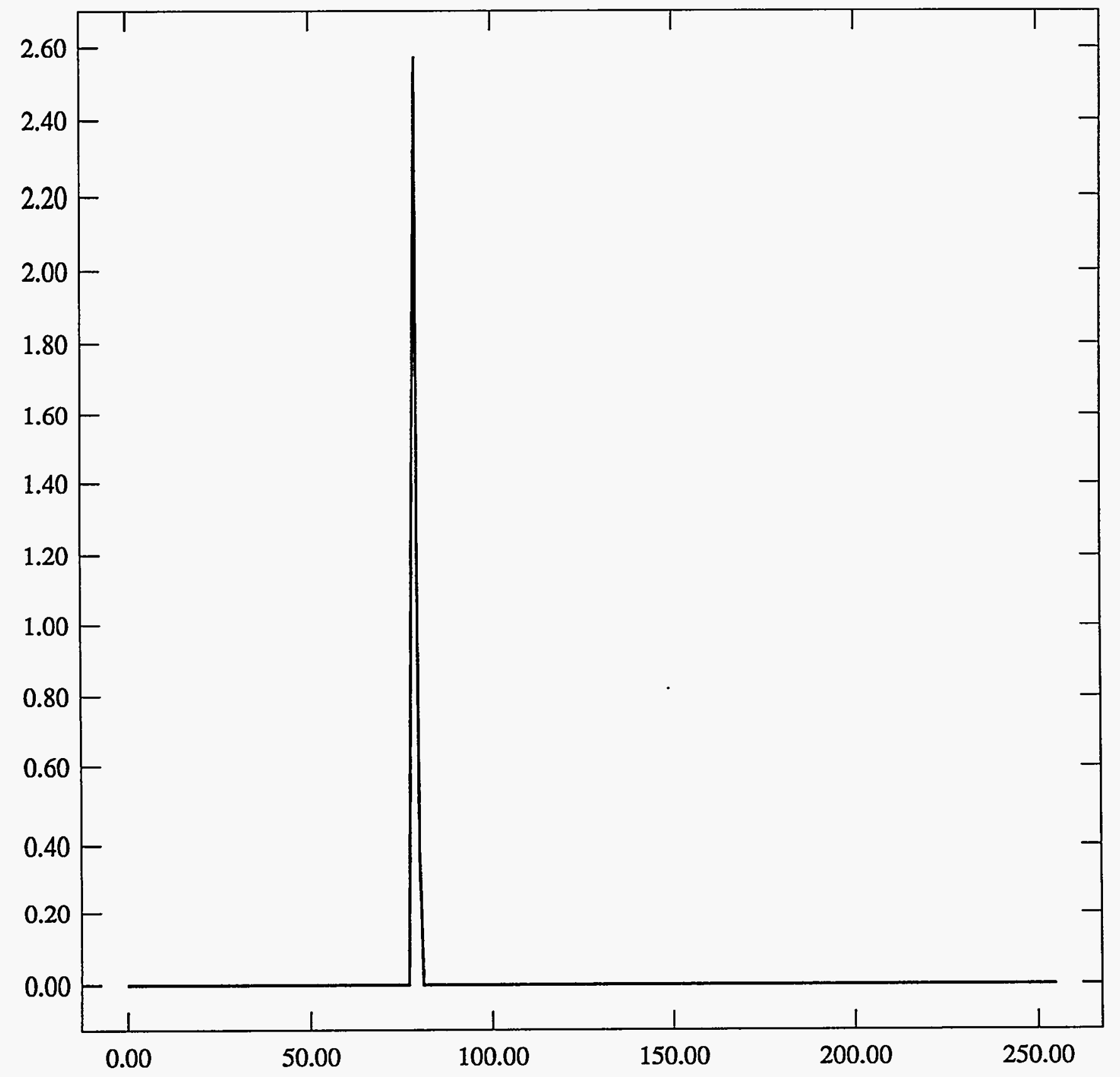


ST Camera: ST1\#04-10 -30C \#1: int_time=200ms, offset= 0, gain=2 (150 e/bit) Wed Jun 30 06:51:36 1993 Pixel Values Min 77 Max 80 Mean 78.8 Sigma $0.58 \times 10^{3}$

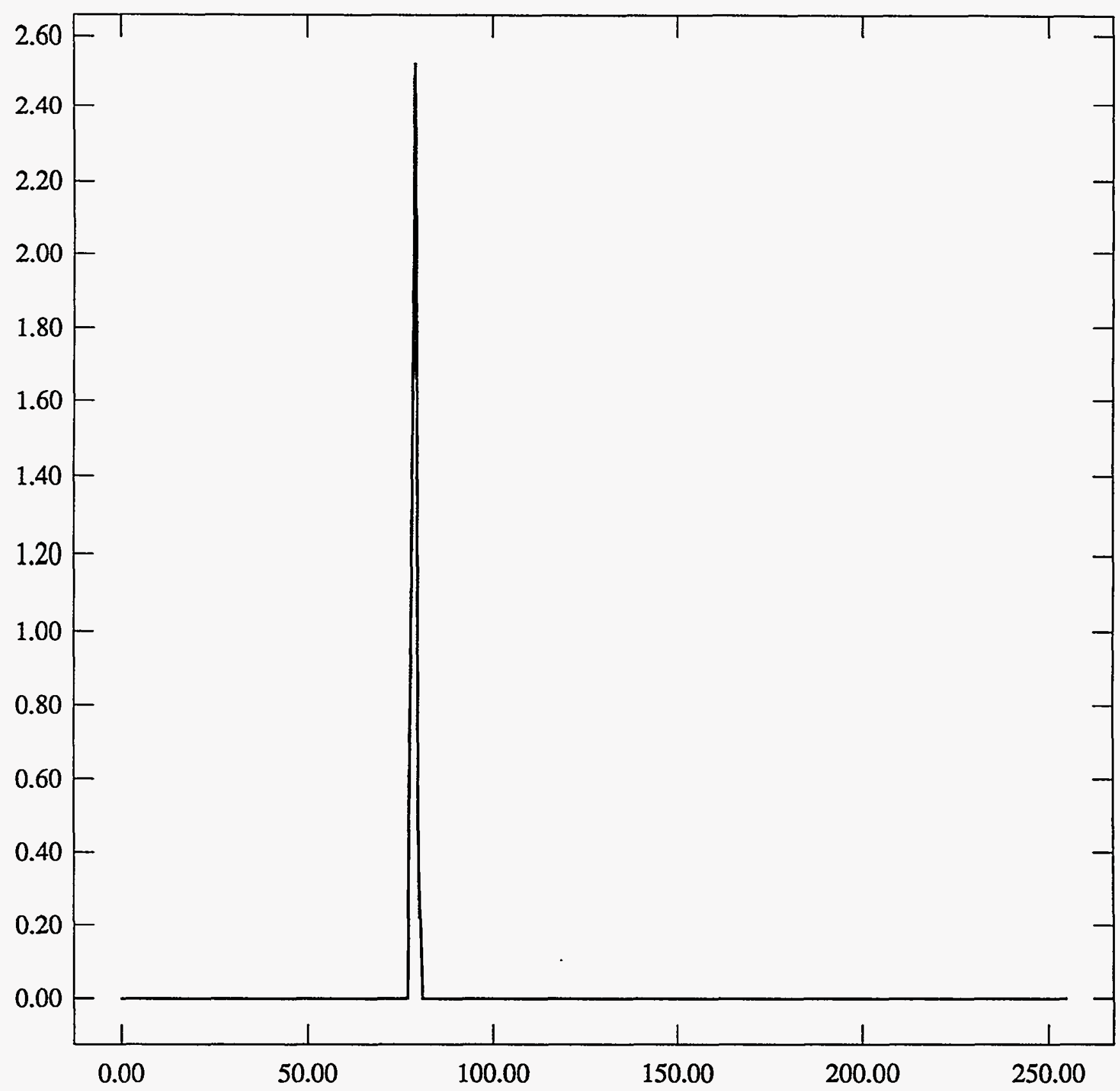


ST Camera: ST1\#04-10 -30C \#1: int_time= 50ms, offset= 0, gain=4 ( 75 e/bit) Wed Jun 30 06:52:09 1993 Pixel Values Min 144 Max 148 Mean 146.2 Sigma $0.68 \times 10^{3}$

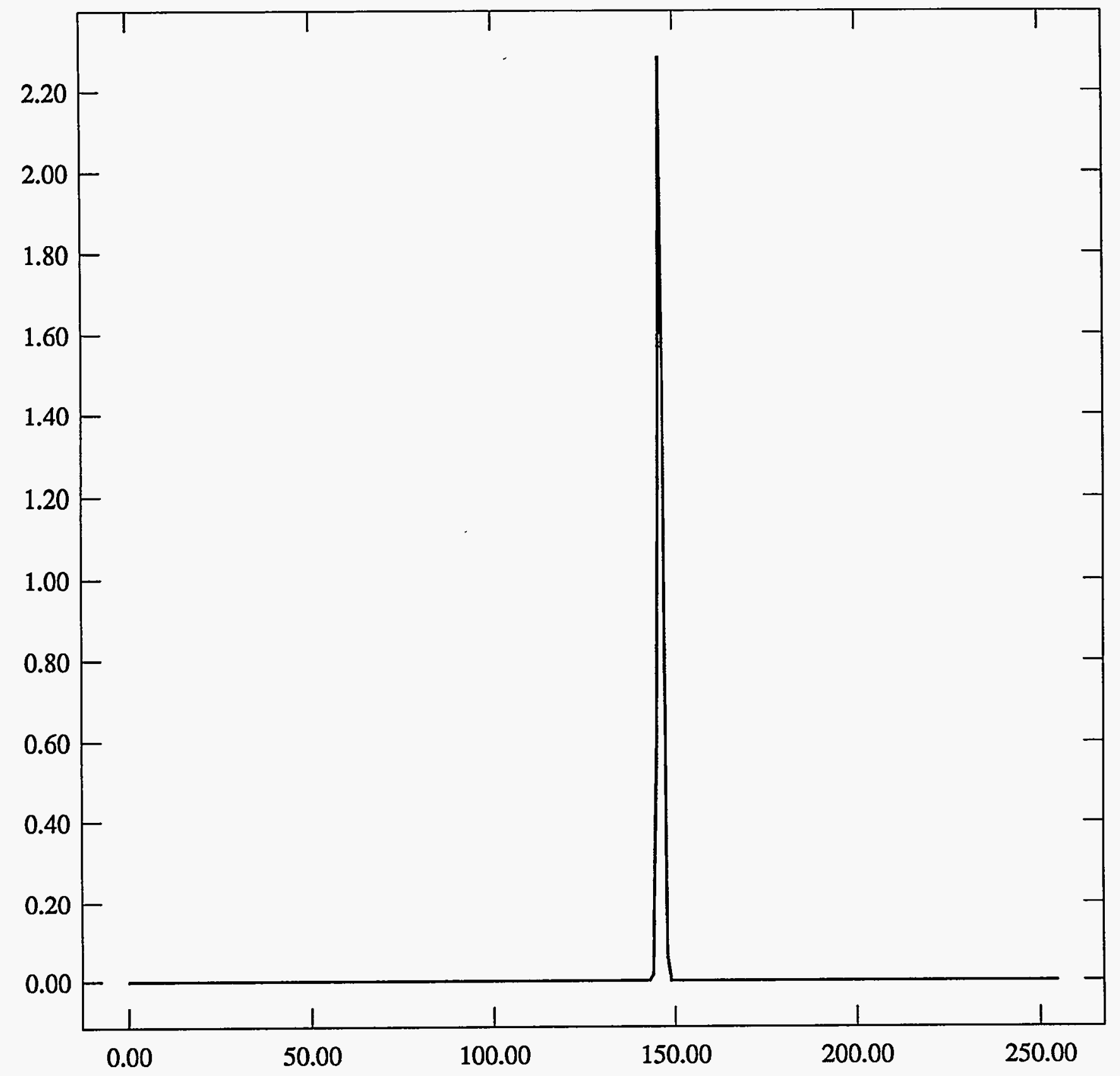


ST Camera: ST1\#04-10 -30C \#1: int_time=100ms, offset= 0, gain=4 ( $75 \mathrm{e} / \mathrm{bit}$ ) Wed Jun 30 06:52:40 1993 Pixel Values Min 144 Max 149 Mean 146.1 Sigma $0.68 \times 10^{3}$

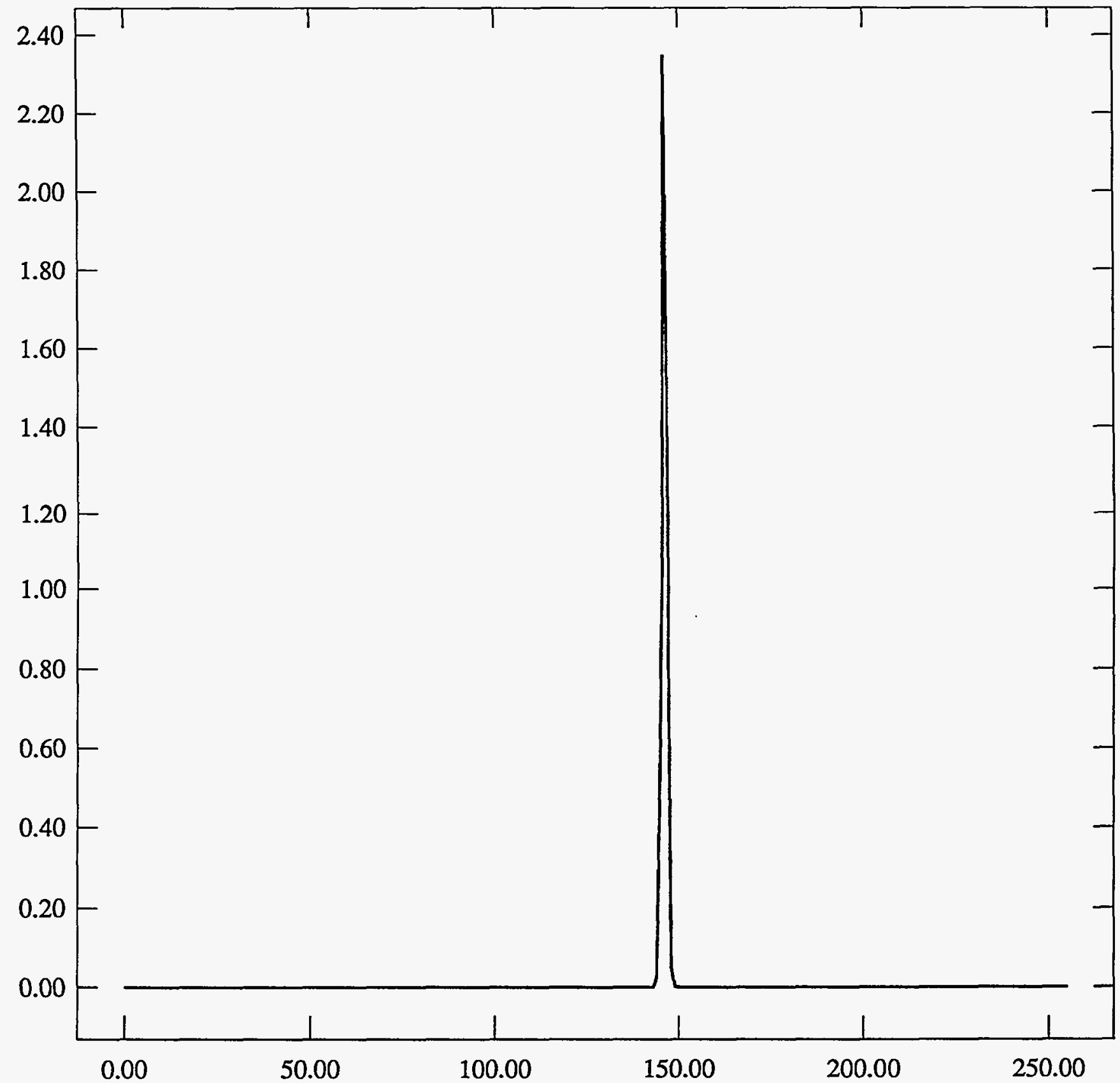


ST Camera: ST1\#04-10 -30C \#1: int_time=200ms, offset= 0, gain=4 ( 75 e/bit) Wed Jun 30 06:53:17 1993 Pixel Values Min 144 Max 148 Mean 146.0 Sigma $0.67 \times 10^{3}$

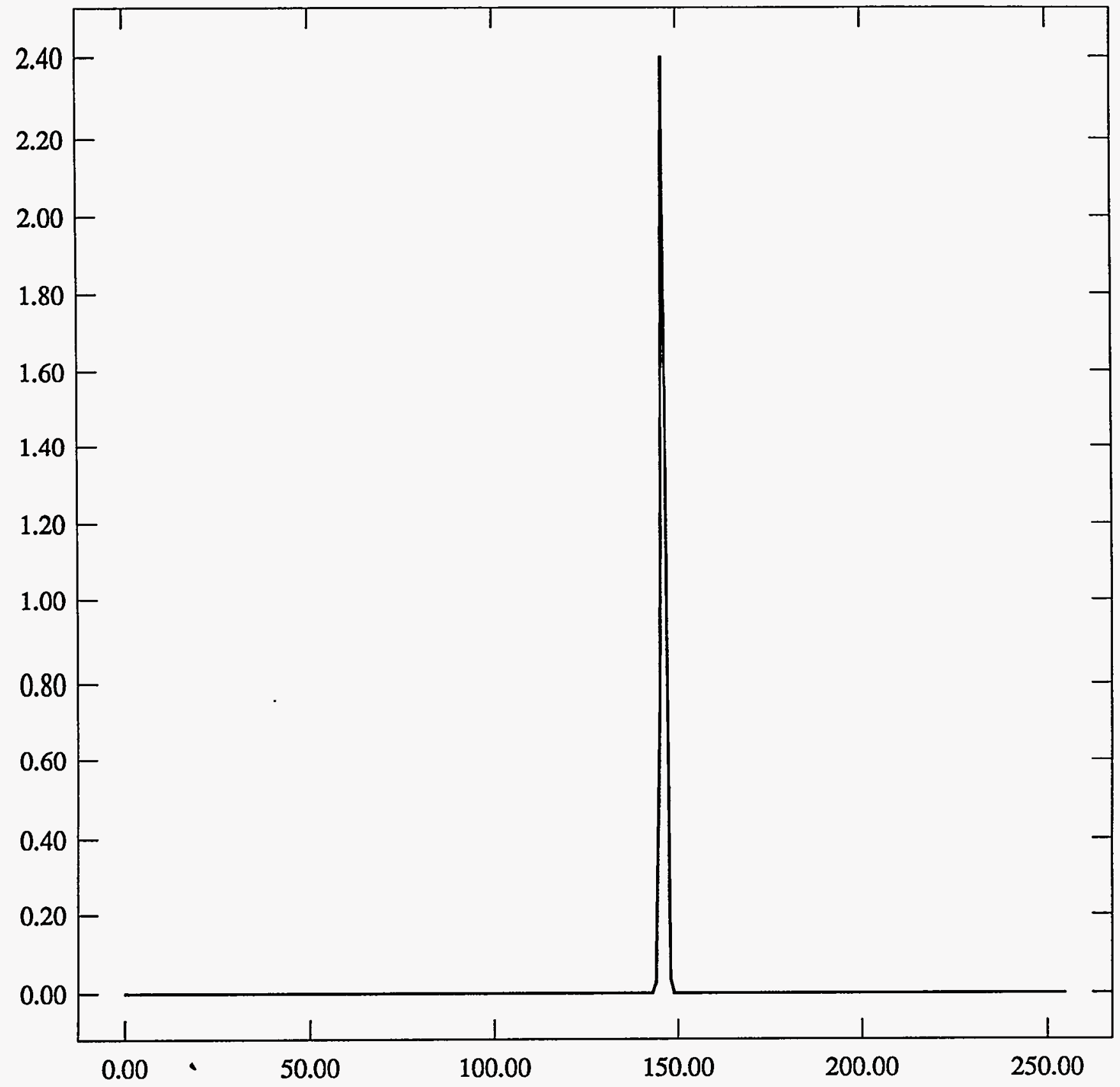


$\Rightarrow 120^{\circ} \mathrm{C}+15 \mathrm{MIN}$

ST Camera: ST1\#04-10 20C \#1: int_time= 50ms, offset= 0, gain=1 ( 350 e/bit) Wed Jun 30 07:19:50 1993 Pixel Values Min $39 \operatorname{Max} 40$ Mean 39.4 Sigma $0.49 \times 10^{3}$

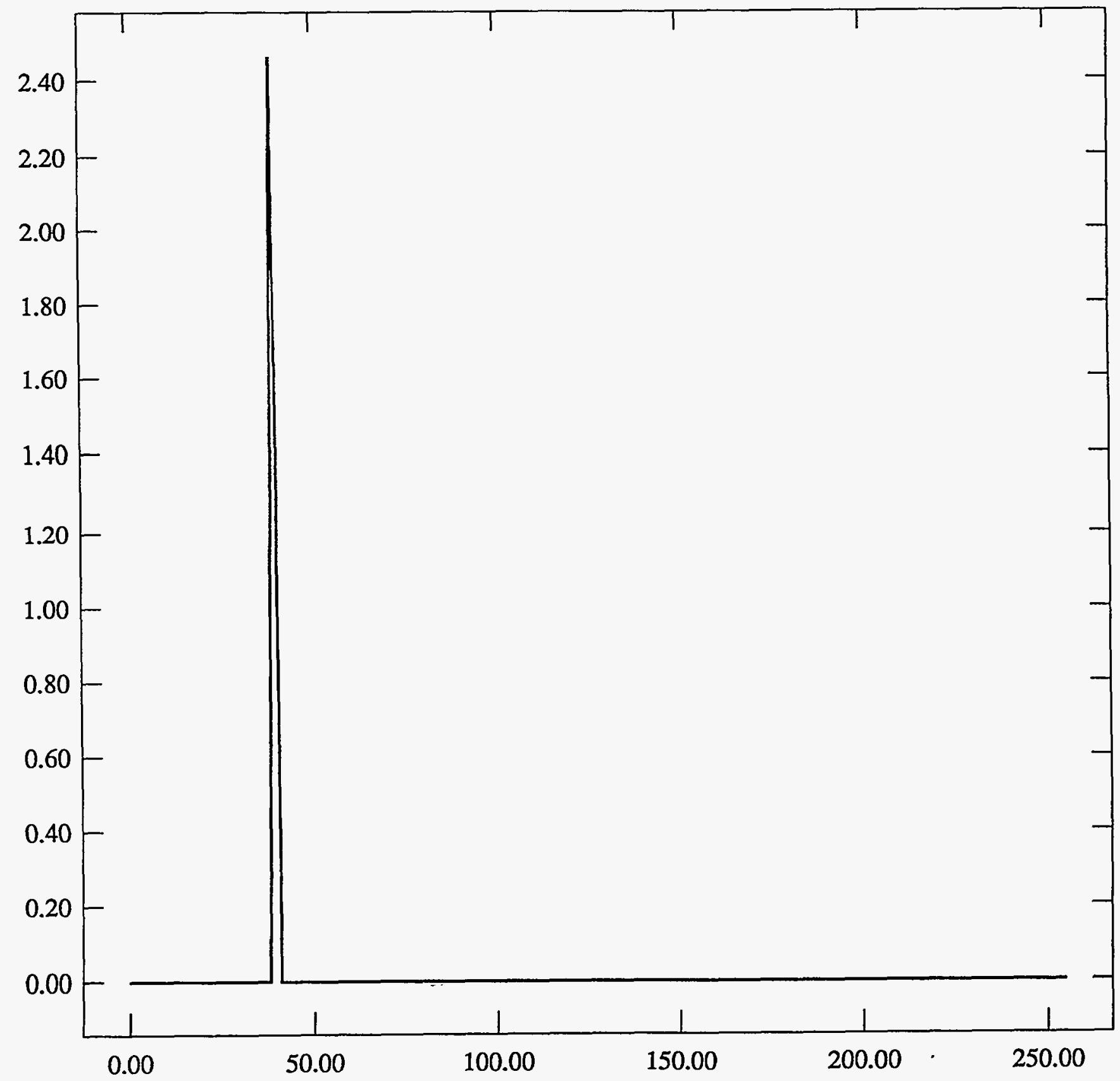


ST Camera: ST1\#04-10 20C \#1: int_time=100ms, offset= 0, gain=1 ( 350 e/bit) Wed Jun 30 07:20:31 1993 Pixel Values Min 38 Max 41 Mean 39.4 Sigma $0.49 \times 10^{3}$

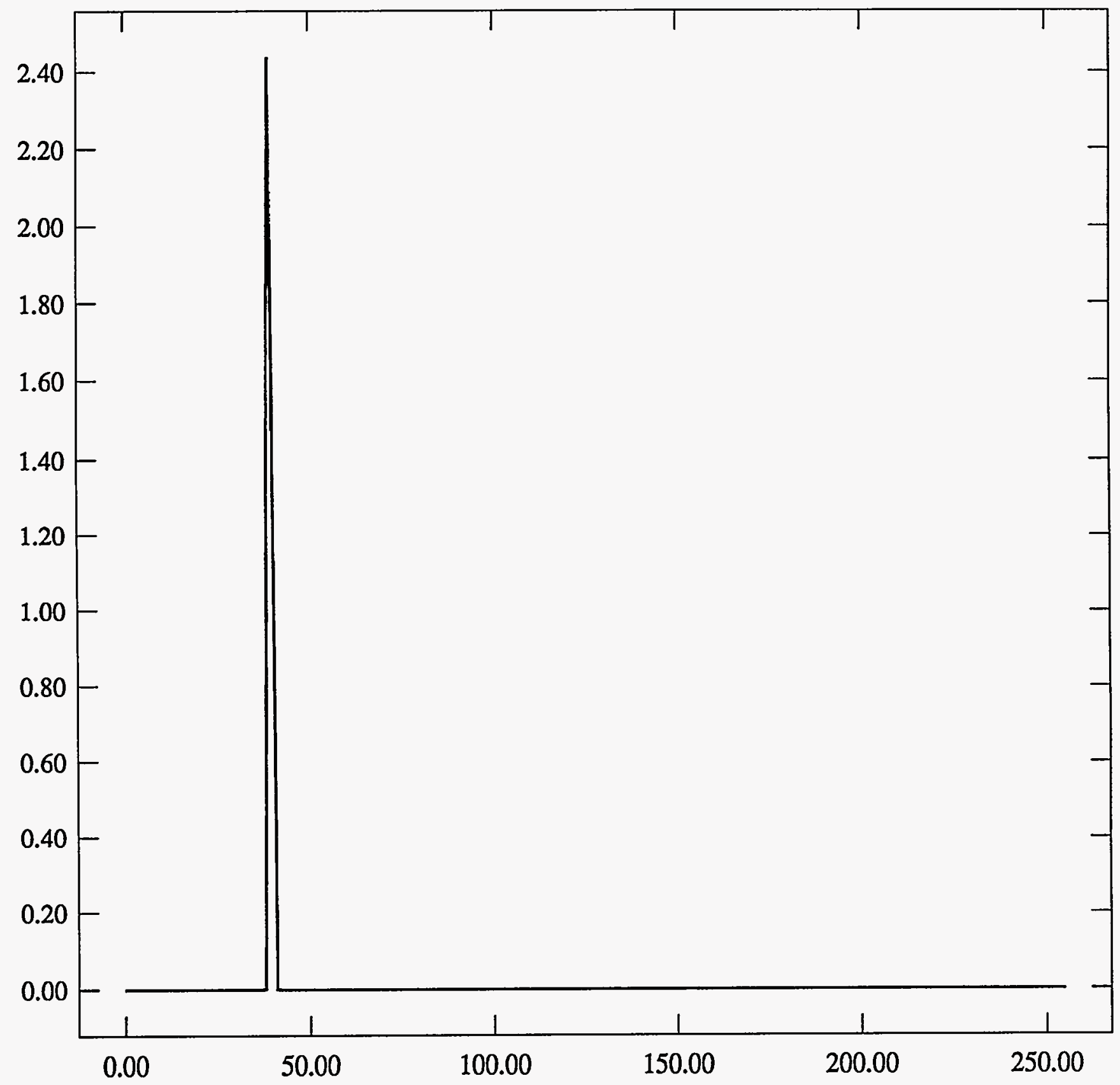


ST Camera: ST1\#04-10 20C \#1: int_time=200ms, offset= 0, gain=1 (350 e/bit) Wed Jun 30 07:21:00 1993 Pixel Values Min 39 Max 41 Mean 39.4 Sigma $0.49 \times 10^{3}$

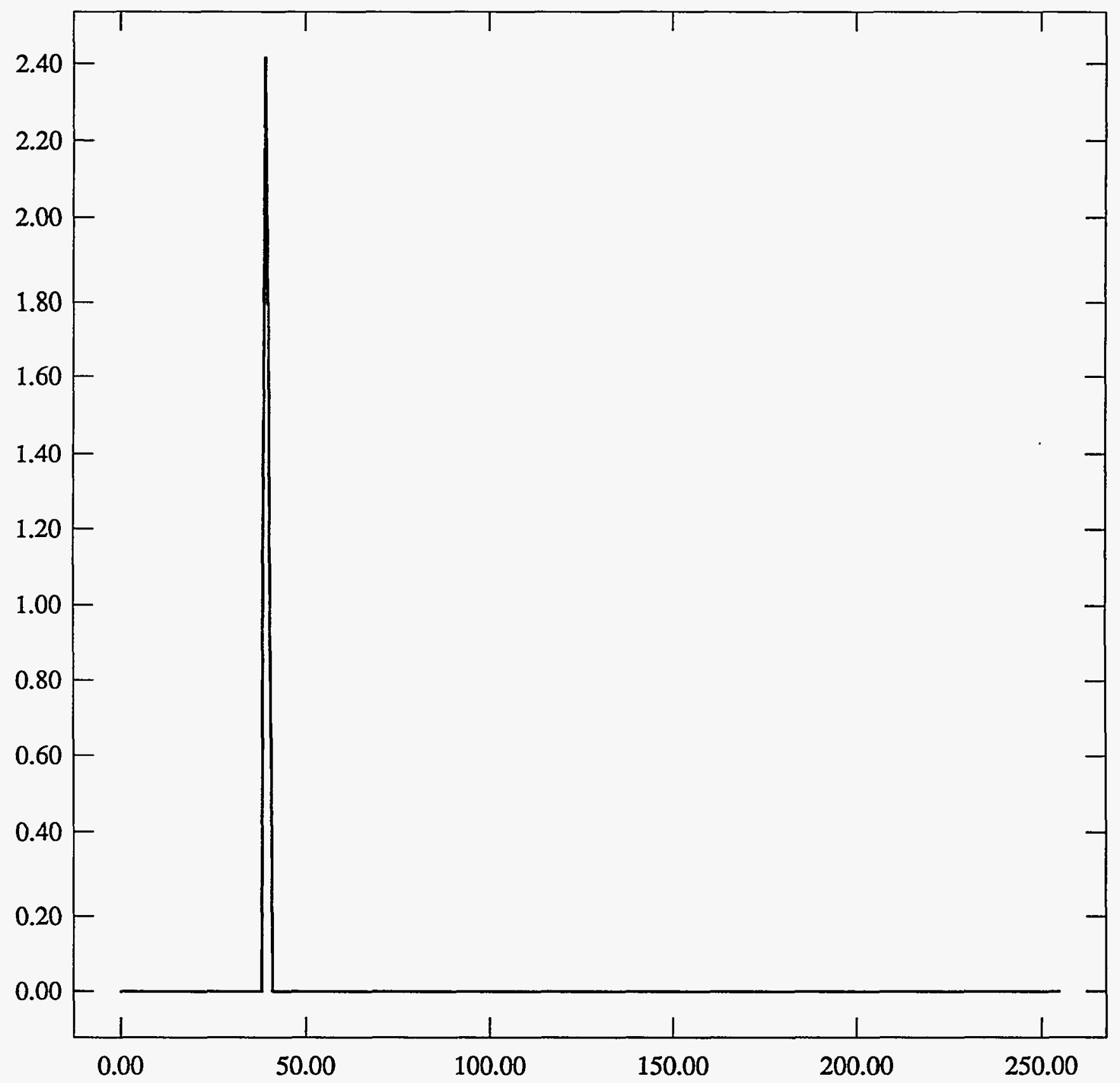


ST Camera: ST1\#04-10 20C \#1: int_time= 50ms, offset= 0, gain=2 (150 e/bit) Wed Jun 30 07:21:50 1993 Pixel Values Min 77 Max 81 Mean 79.1 Sigma $0.78 \times 10^{3}$

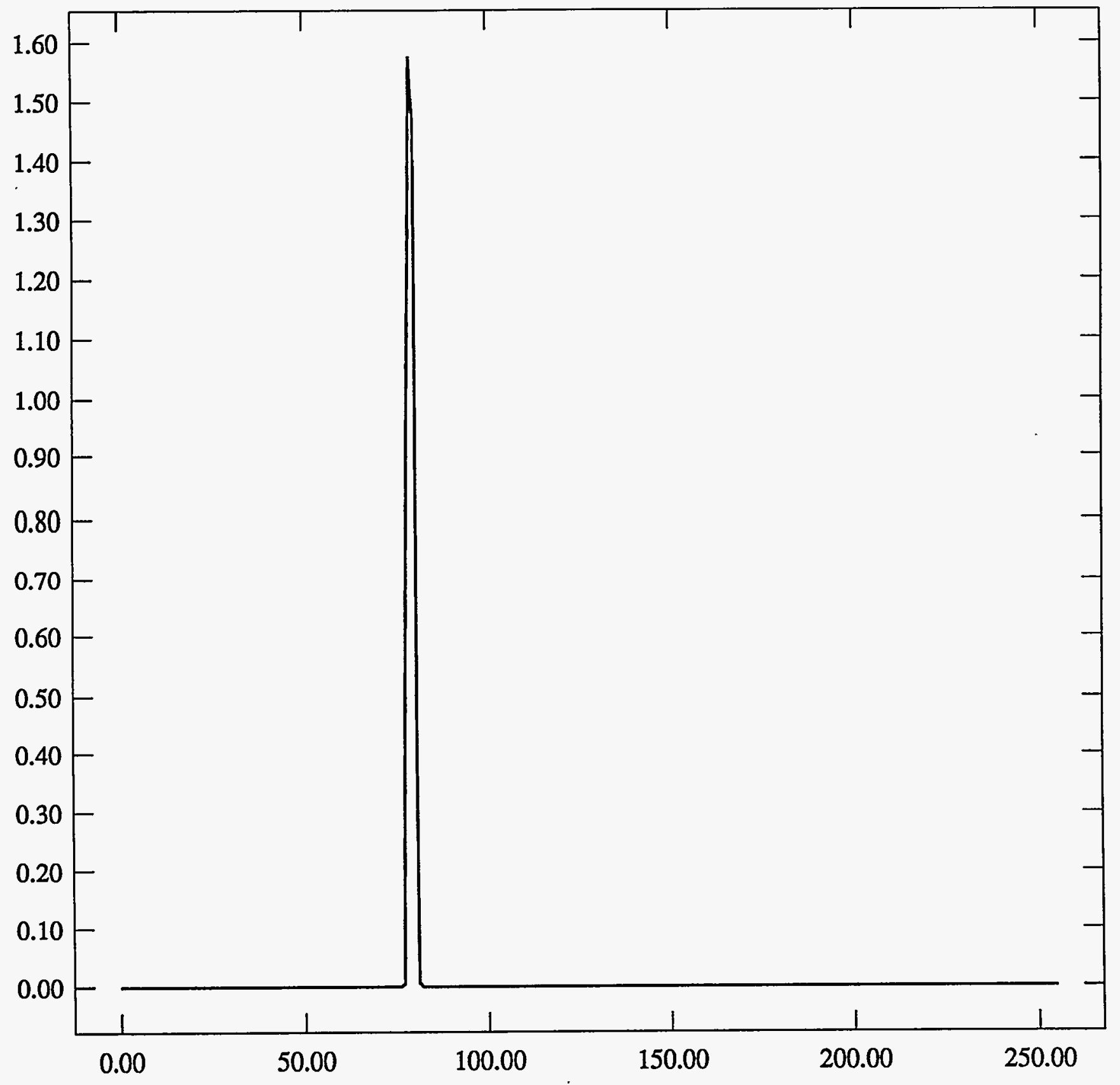


ST Camera: ST1\#04-10 20C \#1: int_time=100ms, offset= 0, gain=2 ( 150 e/bit) Wed Jun 30 07:22:45 1993 Pixel Values Min 77 Max 81 Mean 79.1 Sigma $0.77 \times 10^{3}$

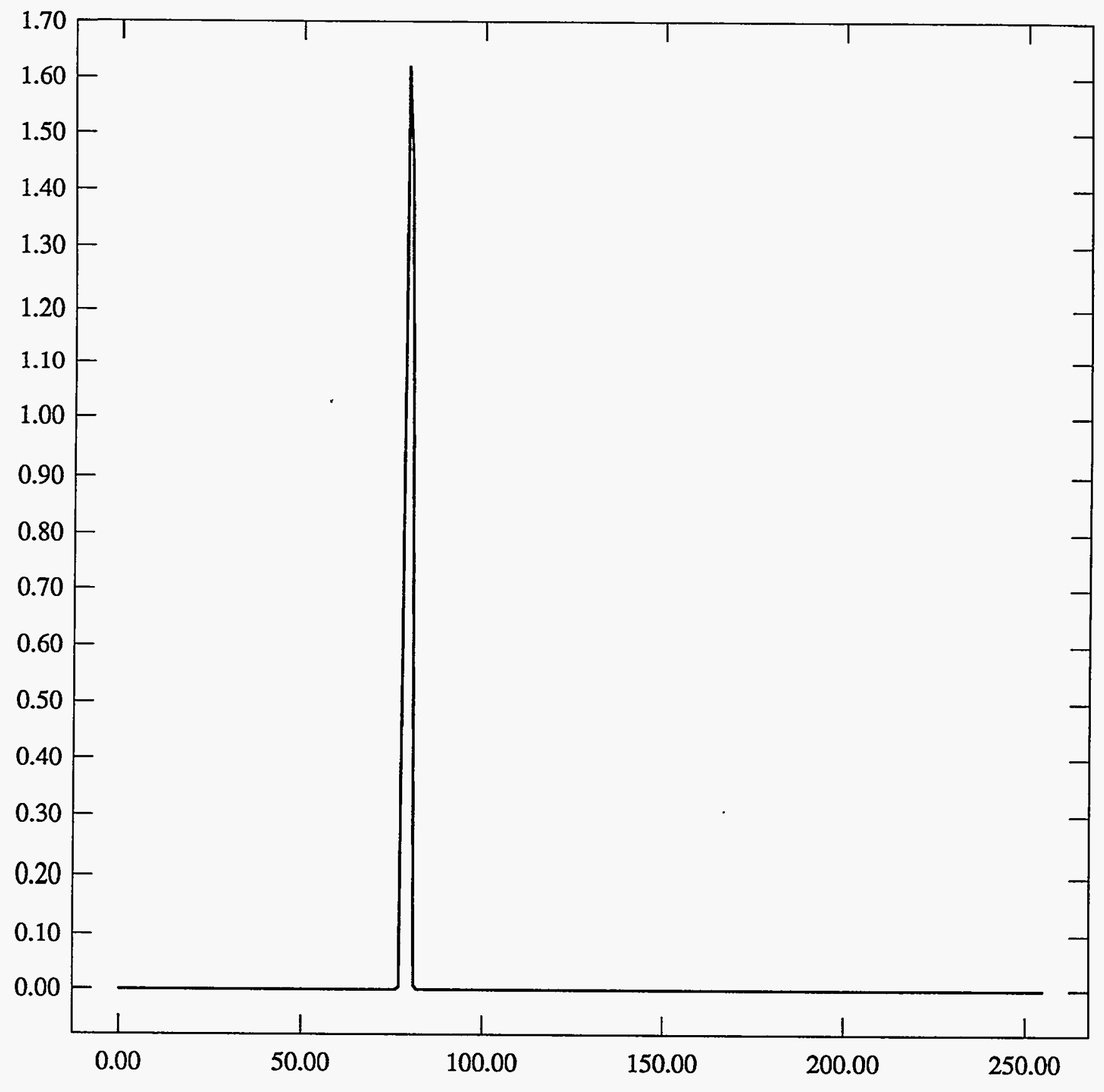


ST Camera: ST1\#04-10 20C \#1: int_time=200ms, offset= 0, gain=2 (150 e/bit) Wed Jun 30 07:23:07 1993 Pixel Values Min 77 Max 81 Mean 79.1 Sigma $0.79 \times 10^{3}$

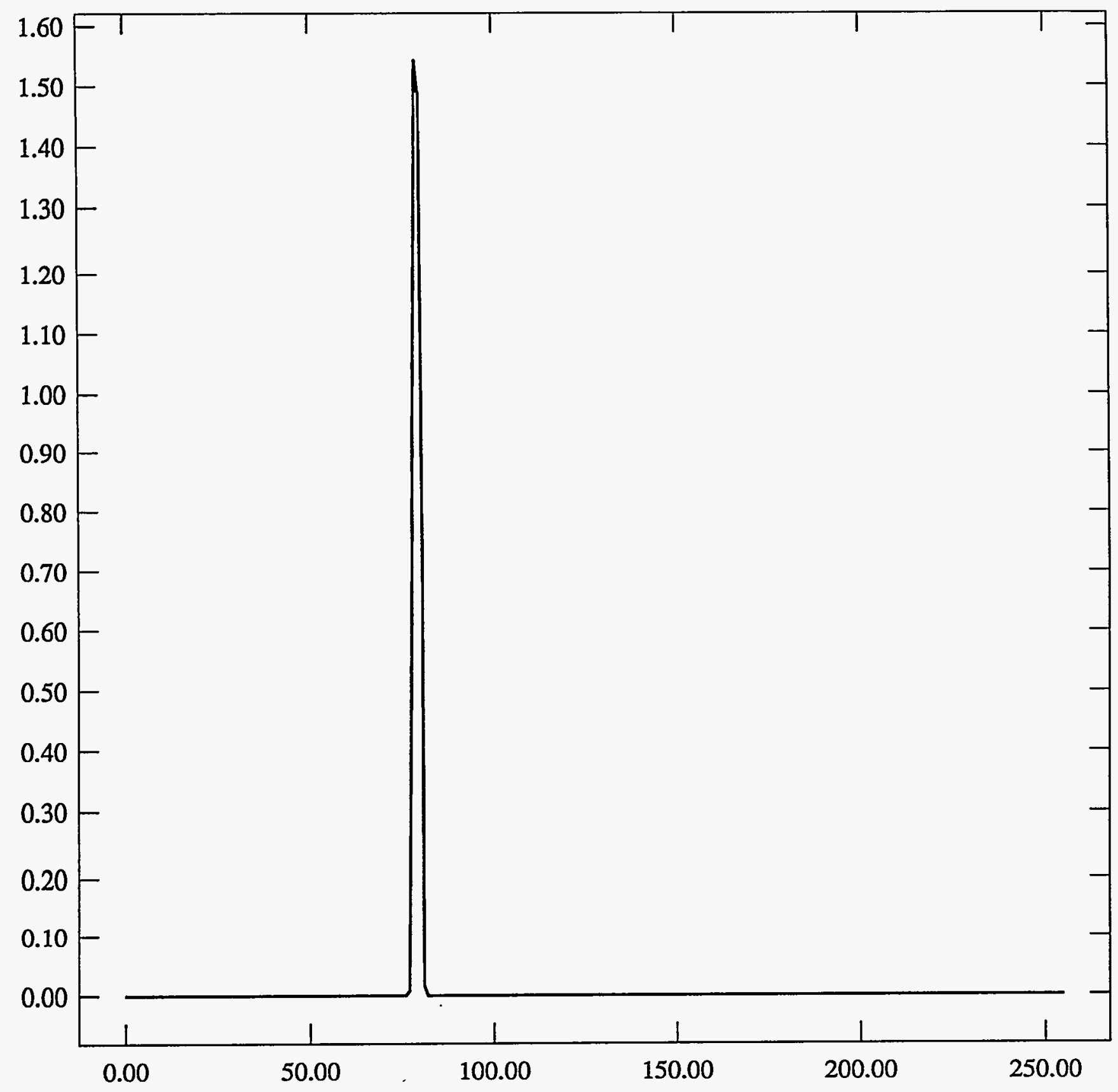


ST Camera: ST1\#04-10 20C \#1: int_time= 50ms, offset= 0, gain=4 ( $75 \mathrm{e} / \mathrm{bit}$ ) Wed Jun 30 07:23:33 1993 Pixel Values Min 142 Max 148 Mean 144.9 Sigma $0.82 \times 10^{3}$

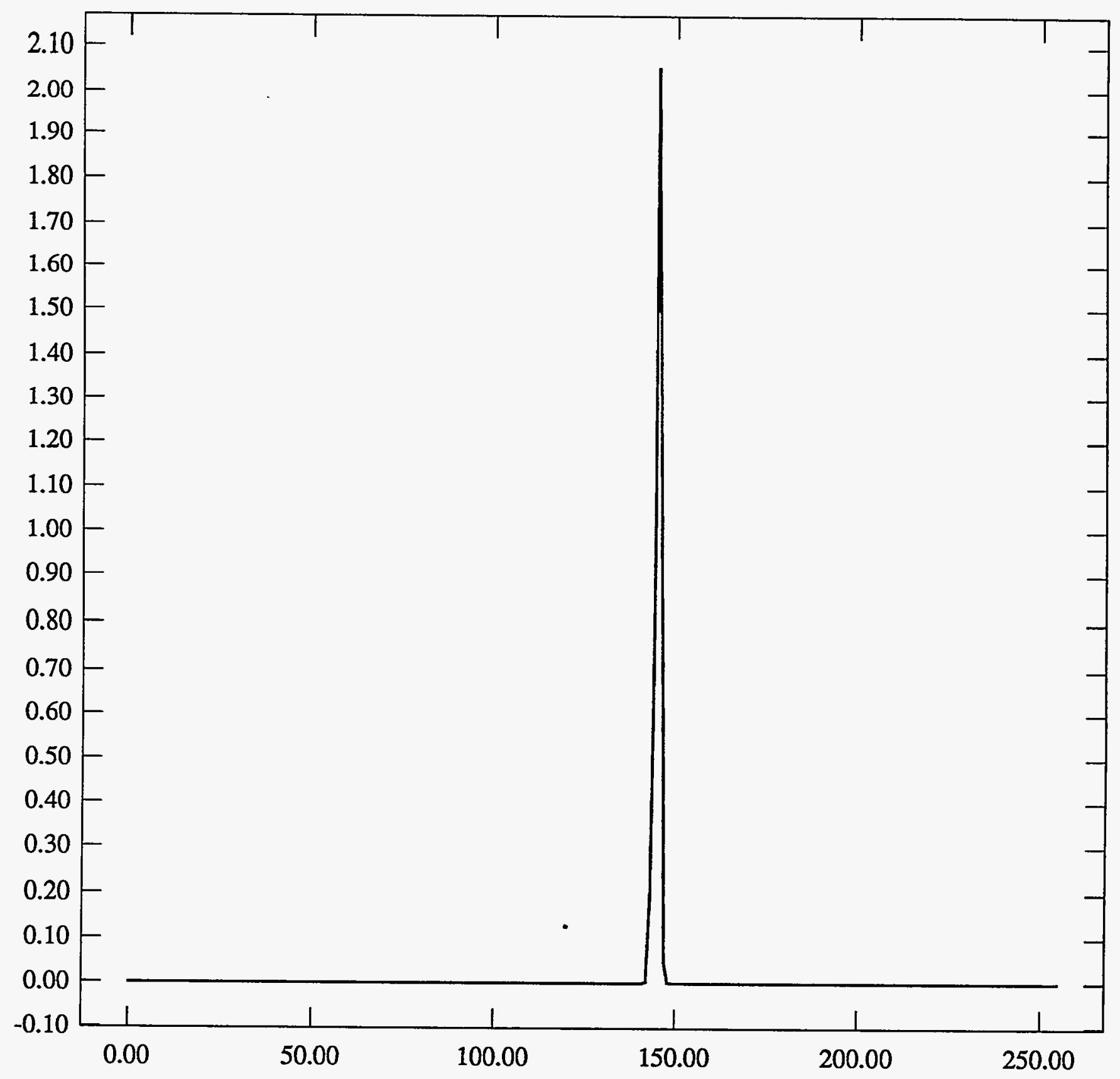


ST Camera: ST1\#04-10 20C \#1: int_time=100ms, offset= 0, gain=4 ( 75 e/bit) Wed Jun 30 07:24:02 1993 Pixel Values Min 142 Max 147 Mean 144.9 Sigma 0.78 x $10^{3}$

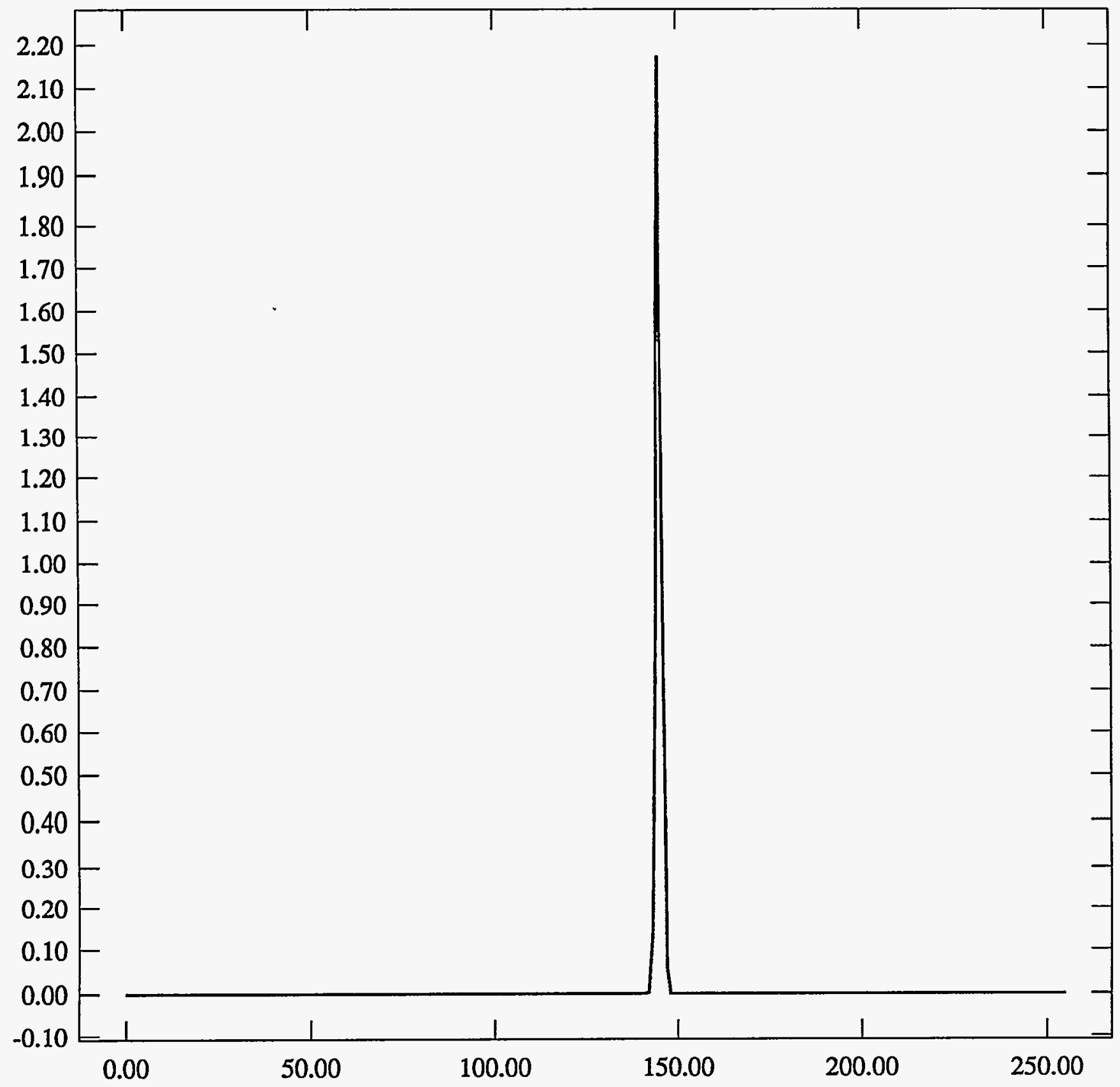


ST Camera: ST1\#04-10 20C \#1: int_time=200ms, offset= 0, gain=4 ( 75 e/bit) Wed Jun 30 07:24:32 1993 Pixel Values Min 142 Max 148 Mean 144.8 Sigma $0.83 \times 10^{3}$

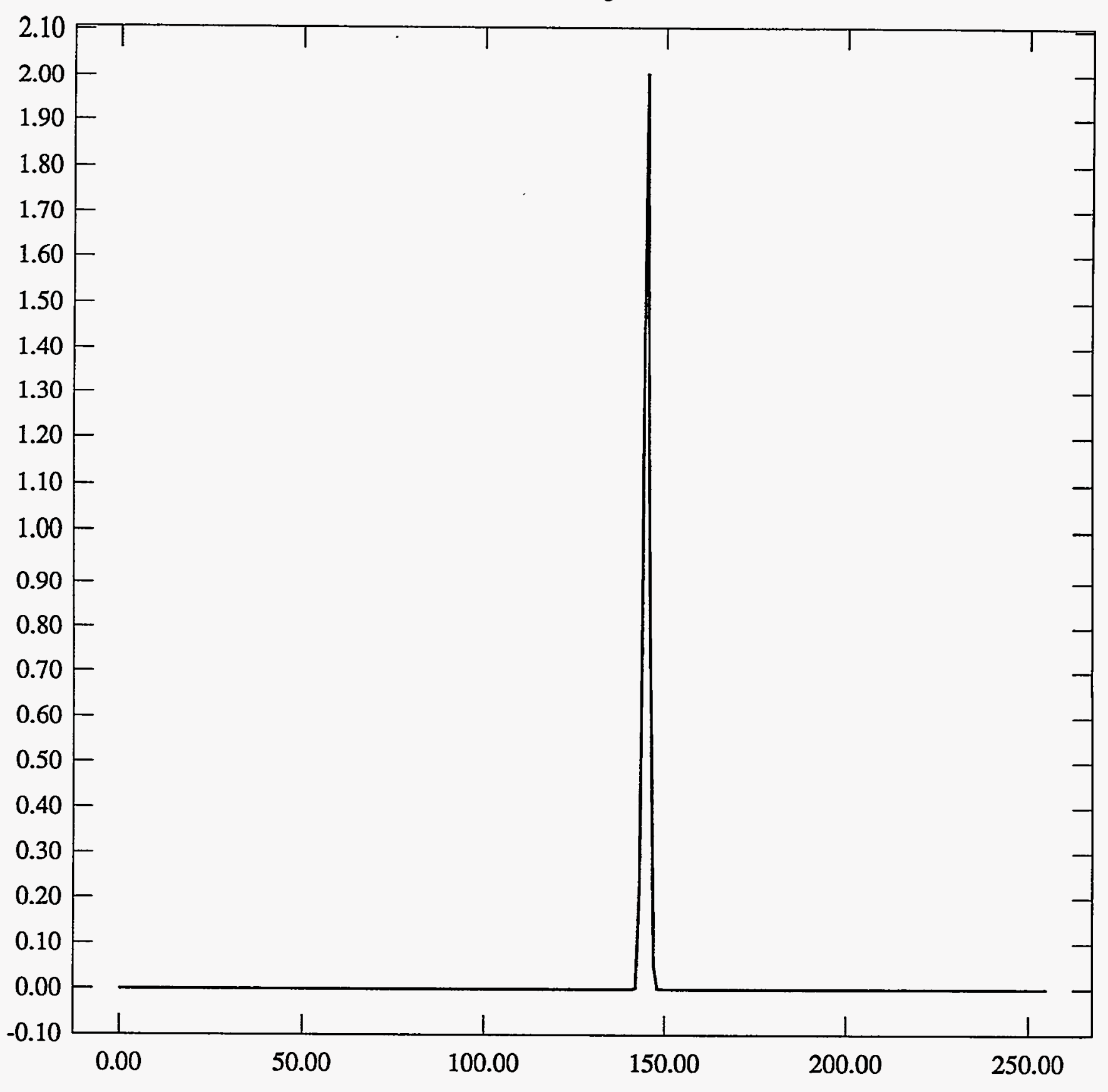


H1 20 Dend af eyale

ST Camera: ST1\#04-10 20C \#1: int_time= 50ms, offset= 0, gain=1 ( $350 \mathrm{e} / \mathrm{bit}$ ) Wed Jun 30 07:59:47 1993 Pixel Values Min $39 \operatorname{Max} 40$ Mean 39.4 Sigma $0.49 \times 10^{3}$

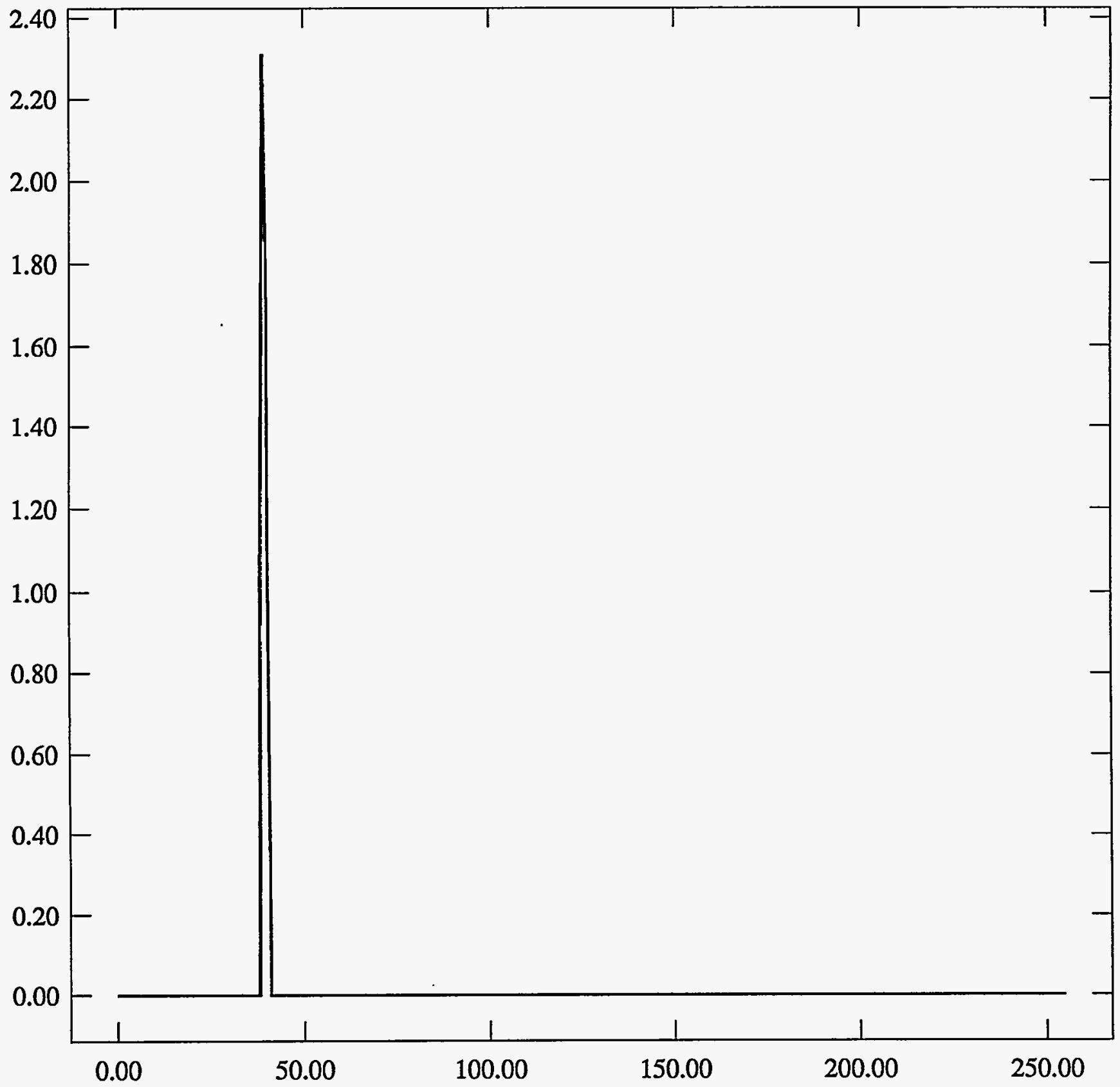


ST Camera: ST1\#04-10 20C \#1: int_time=100ms, offset= 0, gain=1 ( 350 e/bit) Wed Jun 30 08:00:06 1993 Pixel Values Min 38 Max 41 Mean 39.4 Sigma $0.50 \times 10^{3}$

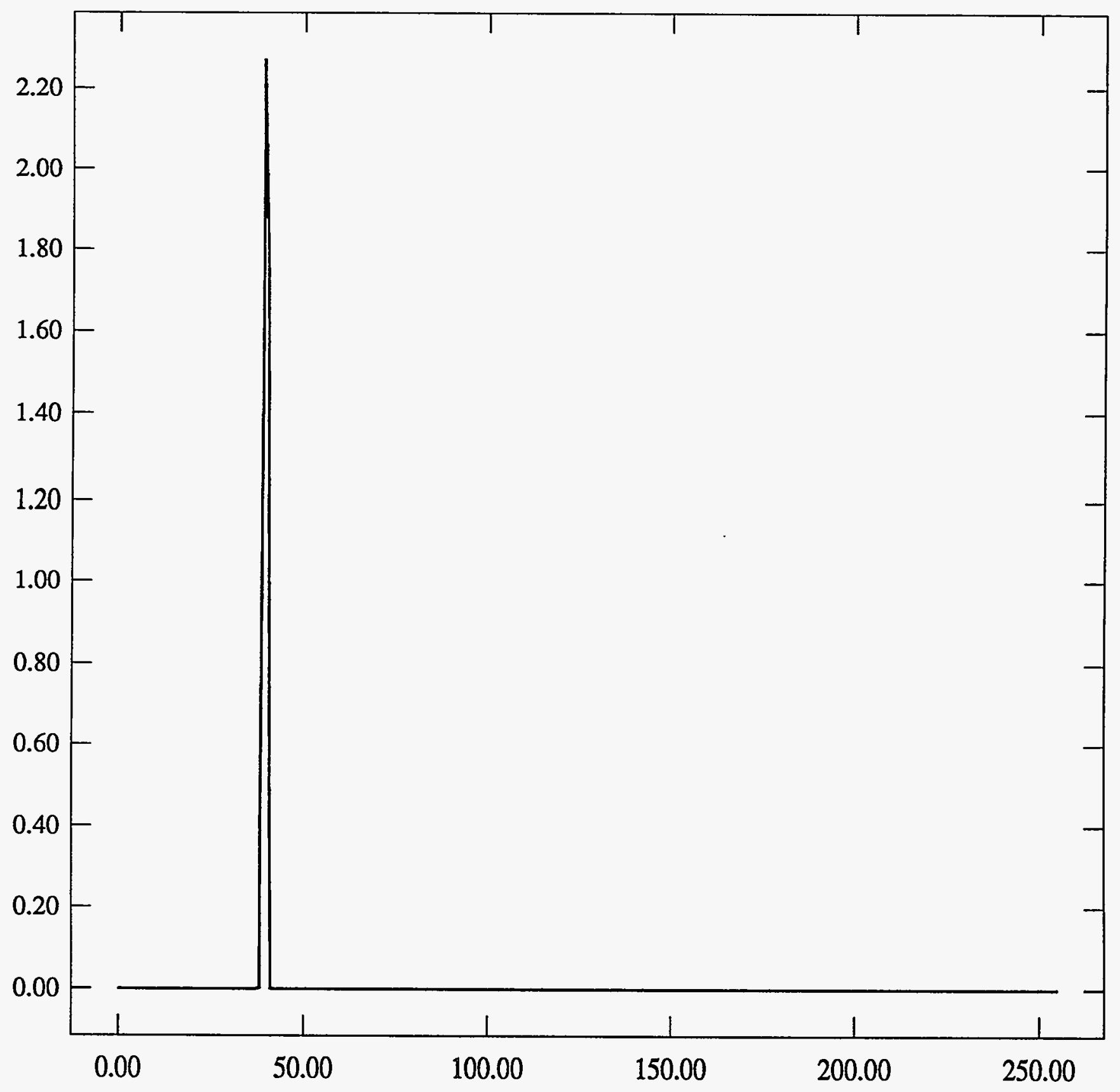


ST Camera: ST1\#04-10 20C \#1: int_time=200ms, offset= 0, gain=1 ( $350 \mathrm{e} / \mathrm{bit}$ ) Wed Jun 30 08:00:42 1993 Pixel Values Min 39 Max 41 Mean 39.4 Sigma $0.49 \times 10^{3}$

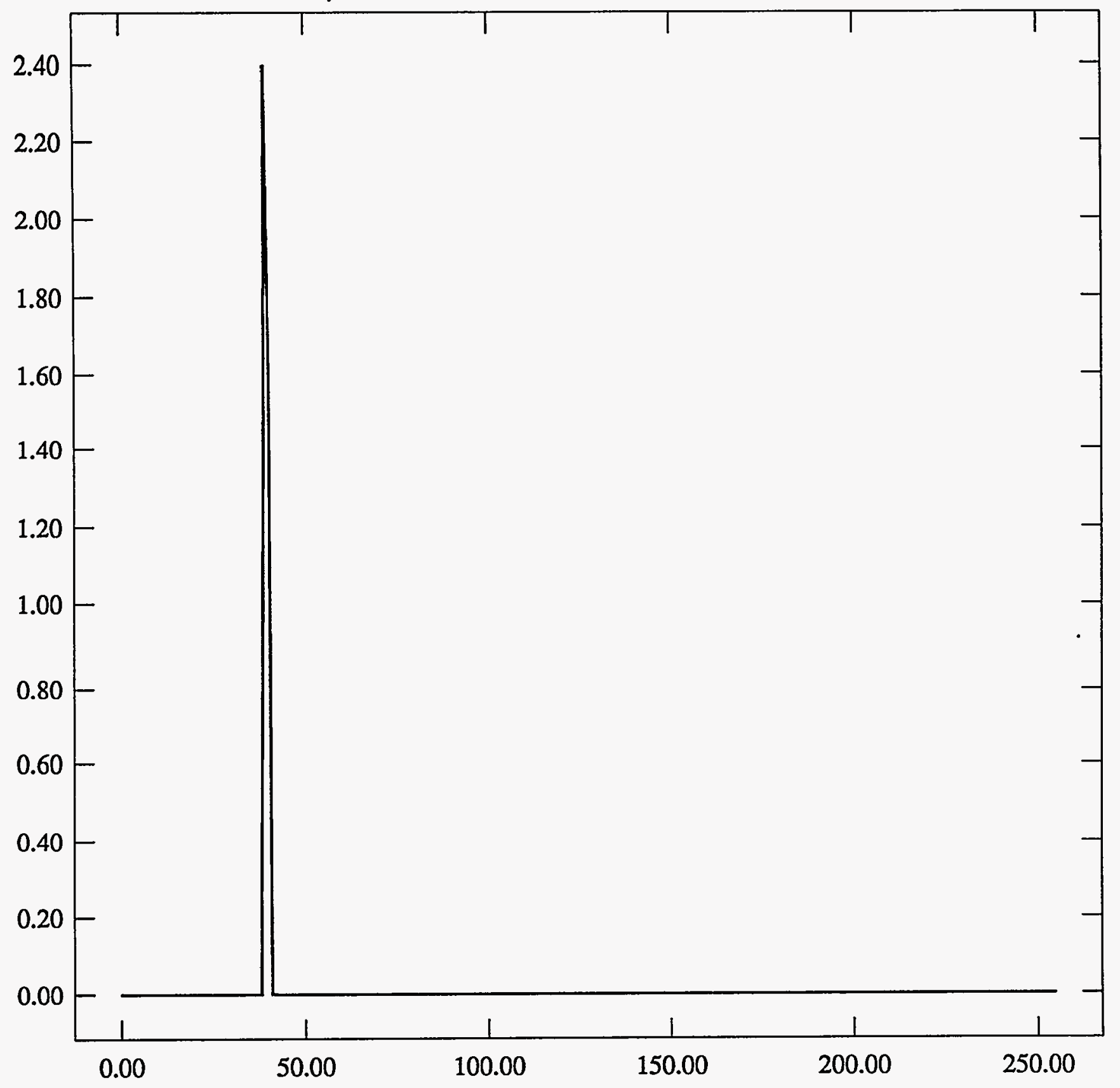


ST Camera: ST1\#04-10 20C \#1: int_time= 50ms, offset= 0, gain=2 (150 e/bit) Wed Jun 30 08:01:52 1993 Pixel Values Min 77 Max 82 Mean 79.2 Sigma $0.78 \times 10^{3}$

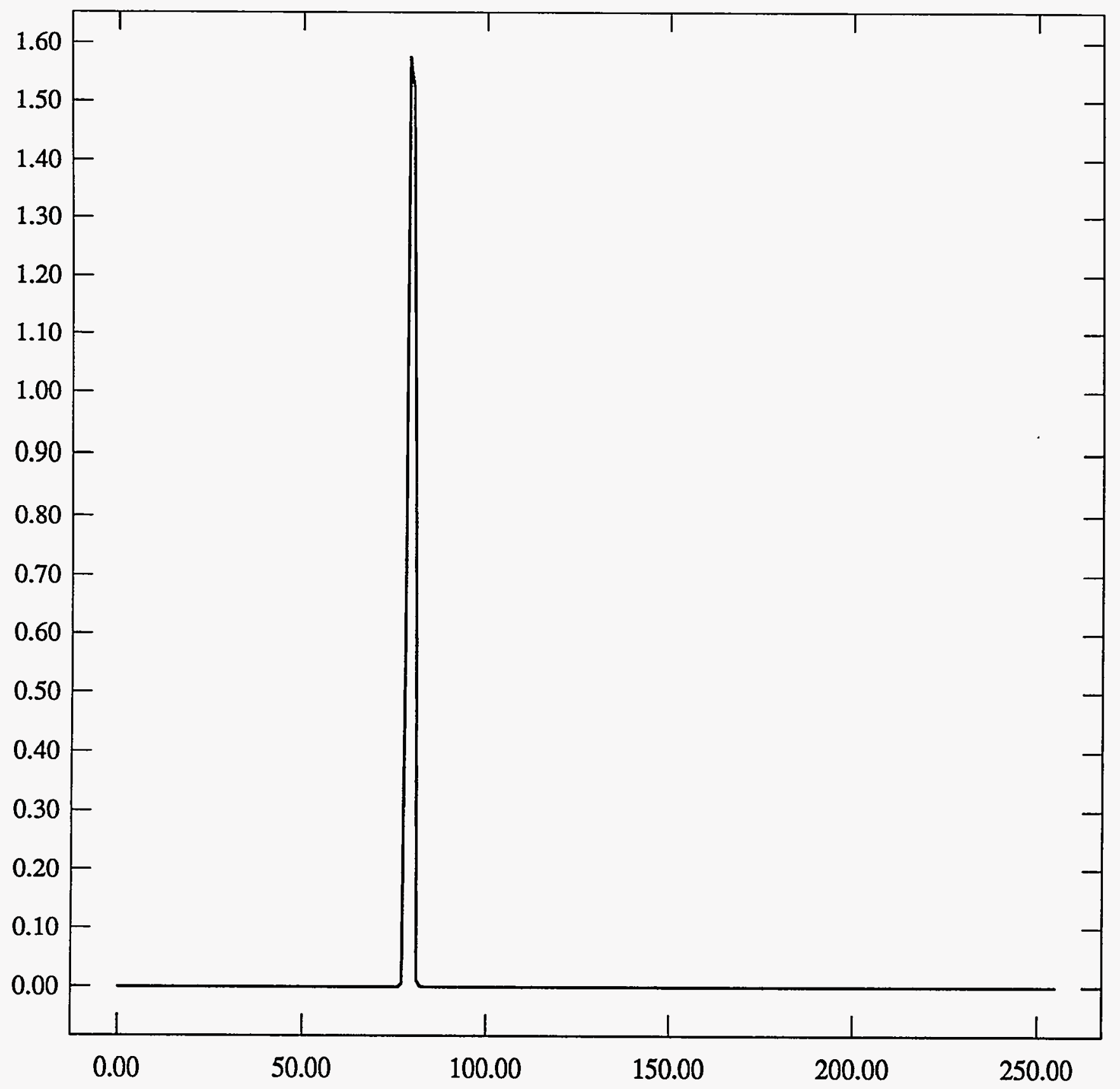


ST Camera: ST1\#04-10 20C \#1: int_time=100ms, offset= 0, gain=2 ( $150 \mathrm{e} / \mathrm{bit})$ Wed Jun 30 08:02:59 1993 Pixel Values Min 77 Max 81 Mean 79.1 Sigma $0.76 \times 10^{3}$

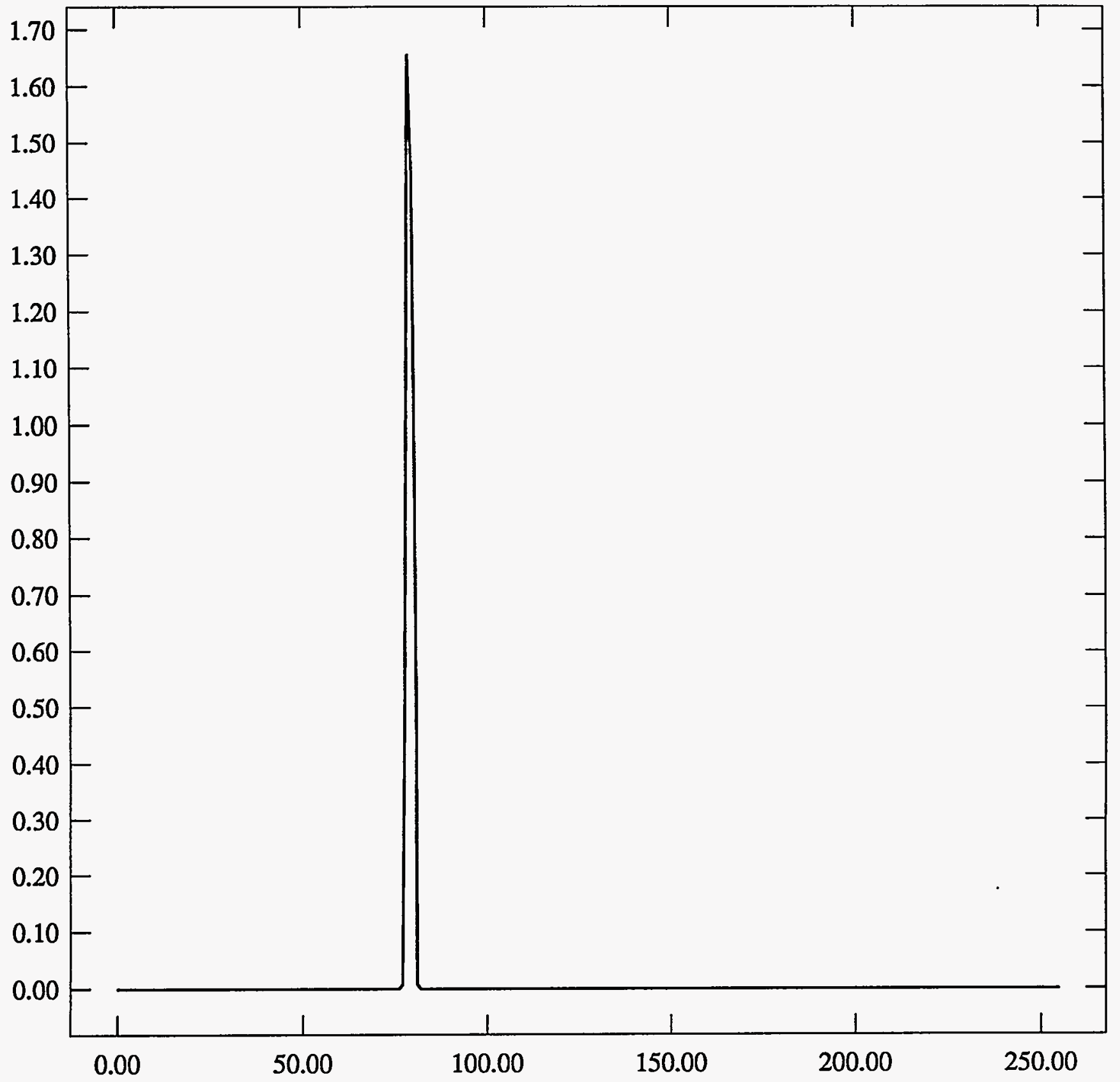


ST Camera: ST1\#04-10 20C \#1: int_time=200ms, offset= 0, gain=2 (150 e/bit) Wed Jun 30 08:03:27 1993 Pixel Values Min 77 Max 81 Mean 79.1 Sigma $0.76 \times 10^{3}$

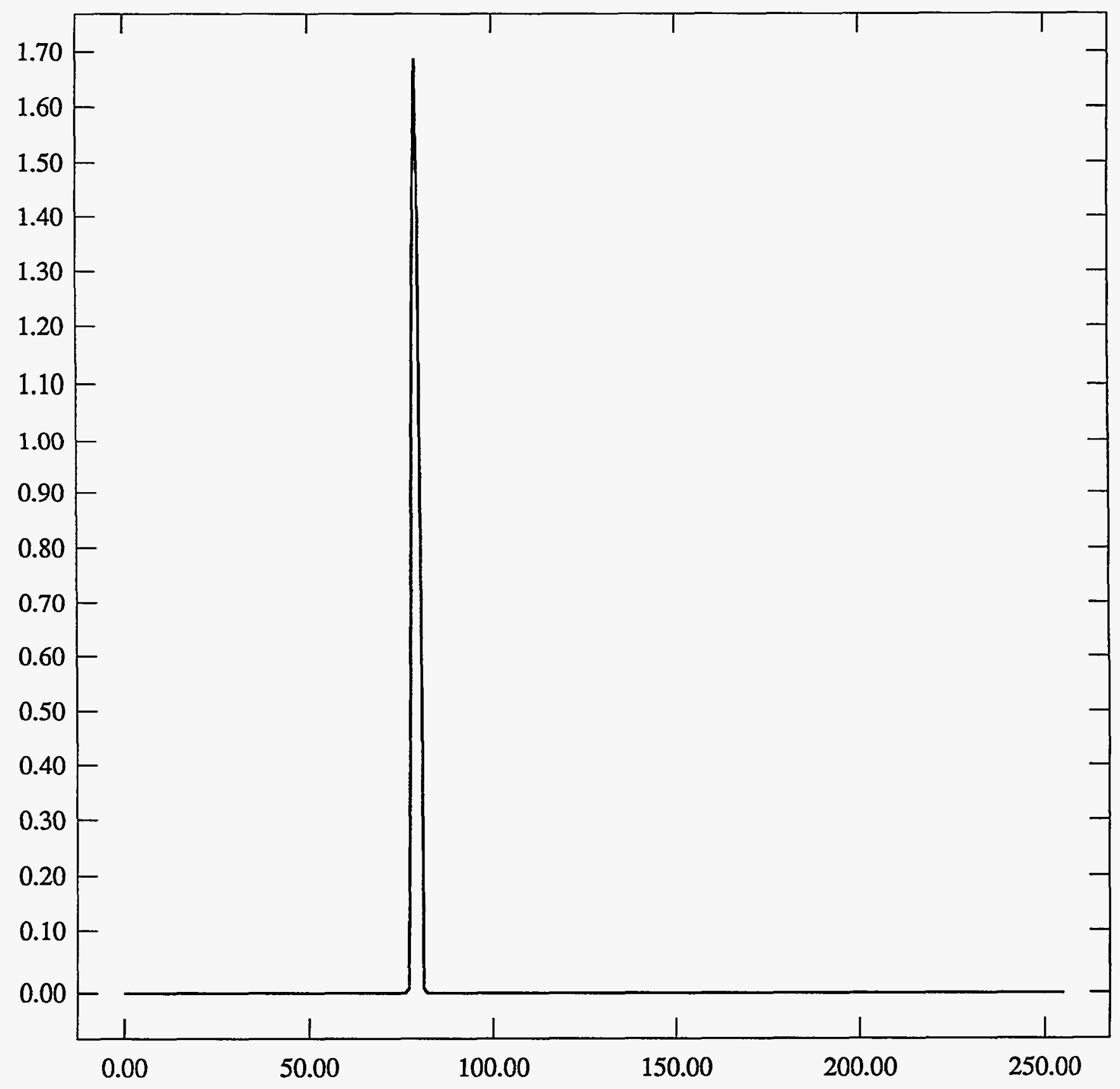


ST Camera: ST1\#04-10 20C \#1: int_time= 50ms, offset= 0, gain=4 ( $75 \mathrm{e} / \mathrm{bit}$ ) Wed Jun 30 08:03:52 1993

Pixel Values Min 142 Max 147 Mean 144.8 Sigma $0.80 \times 10^{3}$

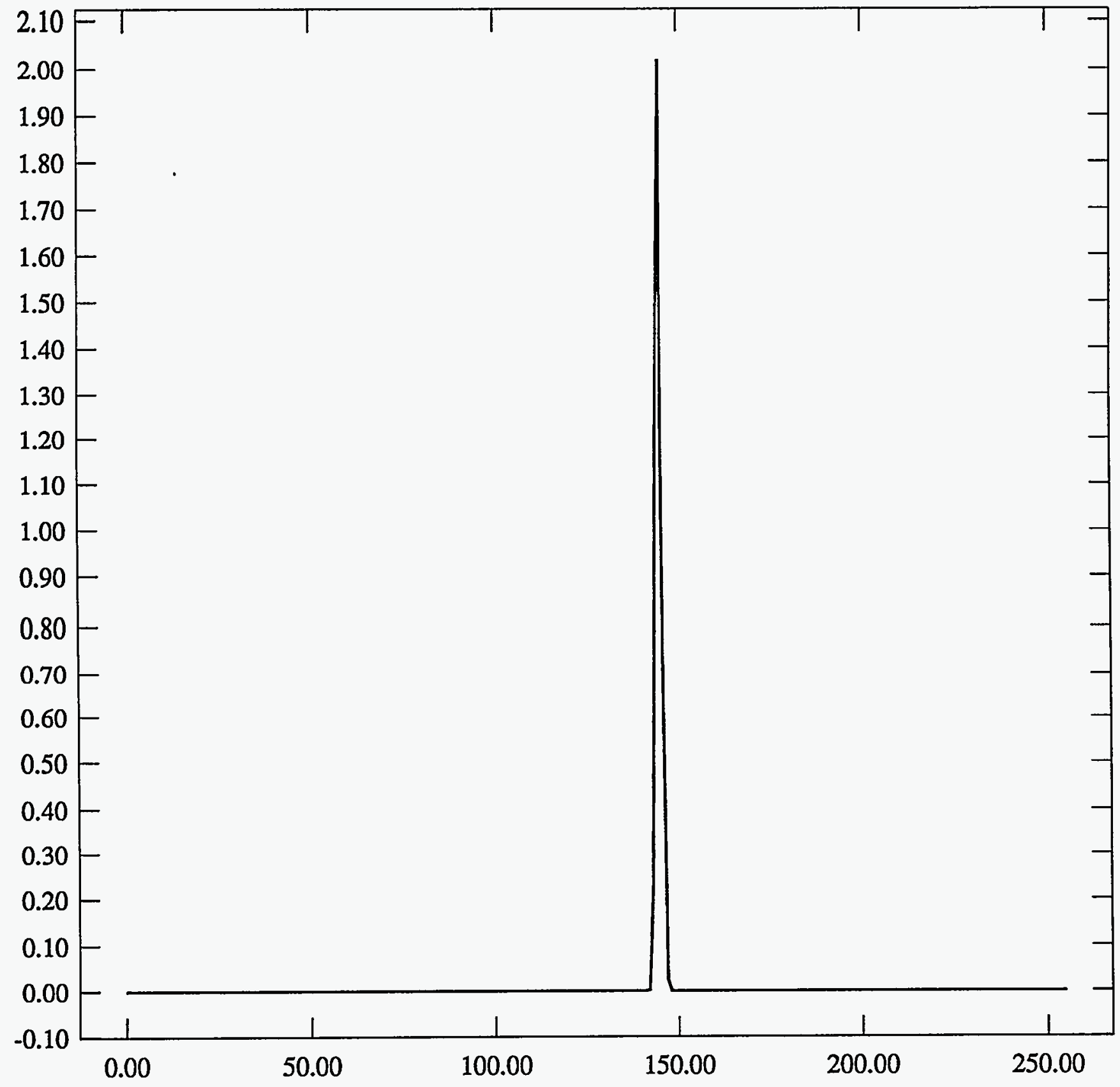


ST Camera: ST1\#04-10 20C \#1: int_time=100ms, offset= 0, gain=4 ( 75 e/bit) Wed Jun 30 08:04:29 1993 Pixel Values Min 142 Max 148 Mean 145.0 Sigma $0.83 \times 10^{3}$

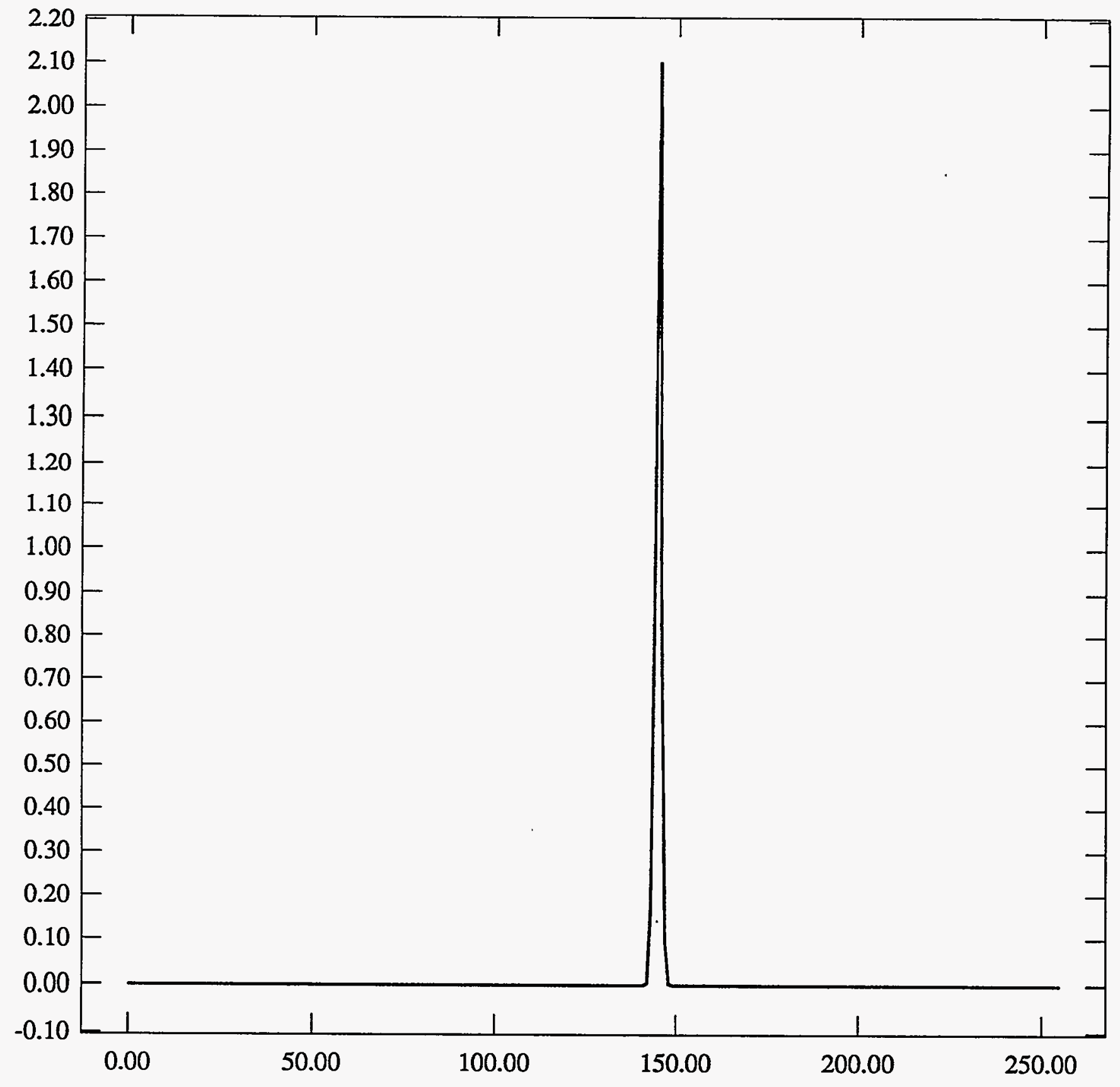


ST Camera: ST1\#04-10 20C \#1: int_time=200ms, offset= 0, gain=4 ( 75 e/bit) Wed Jun 30 08:05:10 1993 Pixel Values Min 142 Max 148 Mean 145.0 Sigma $0.80 \times 10^{3}$

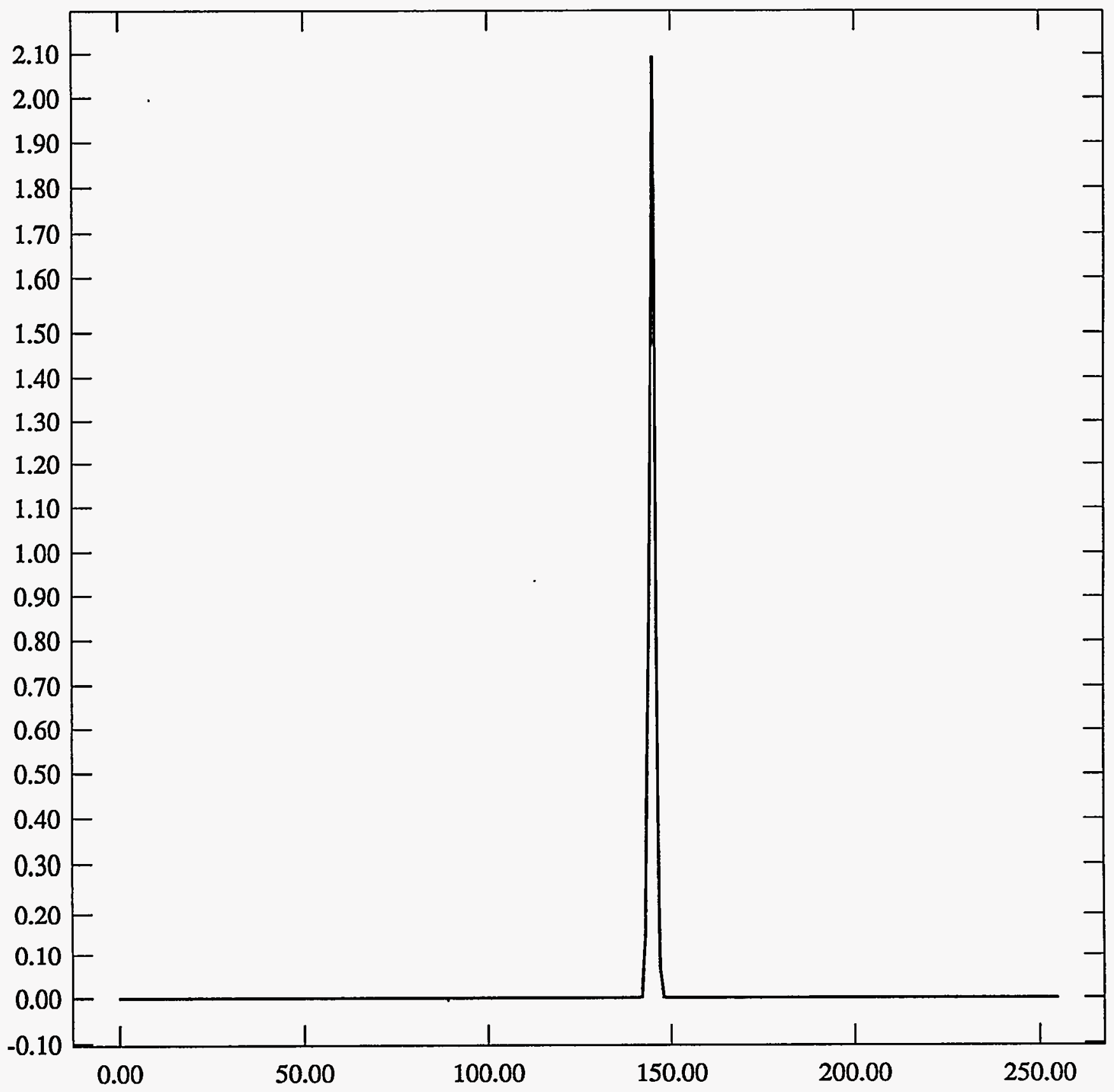


*2. $-30 \quad 15$ MiN

ST Camera: ST1\#04-10 -30C \#2: int_time= 50ms, offset= 0, gain=1 ( $350 \mathrm{e} / \mathrm{bit}$ ) Wed Jun 30 08:36:01 1993 Pixel Values Min 39 Max 41 Mean 39.9 Sigma $0.32 \times 10^{3}$

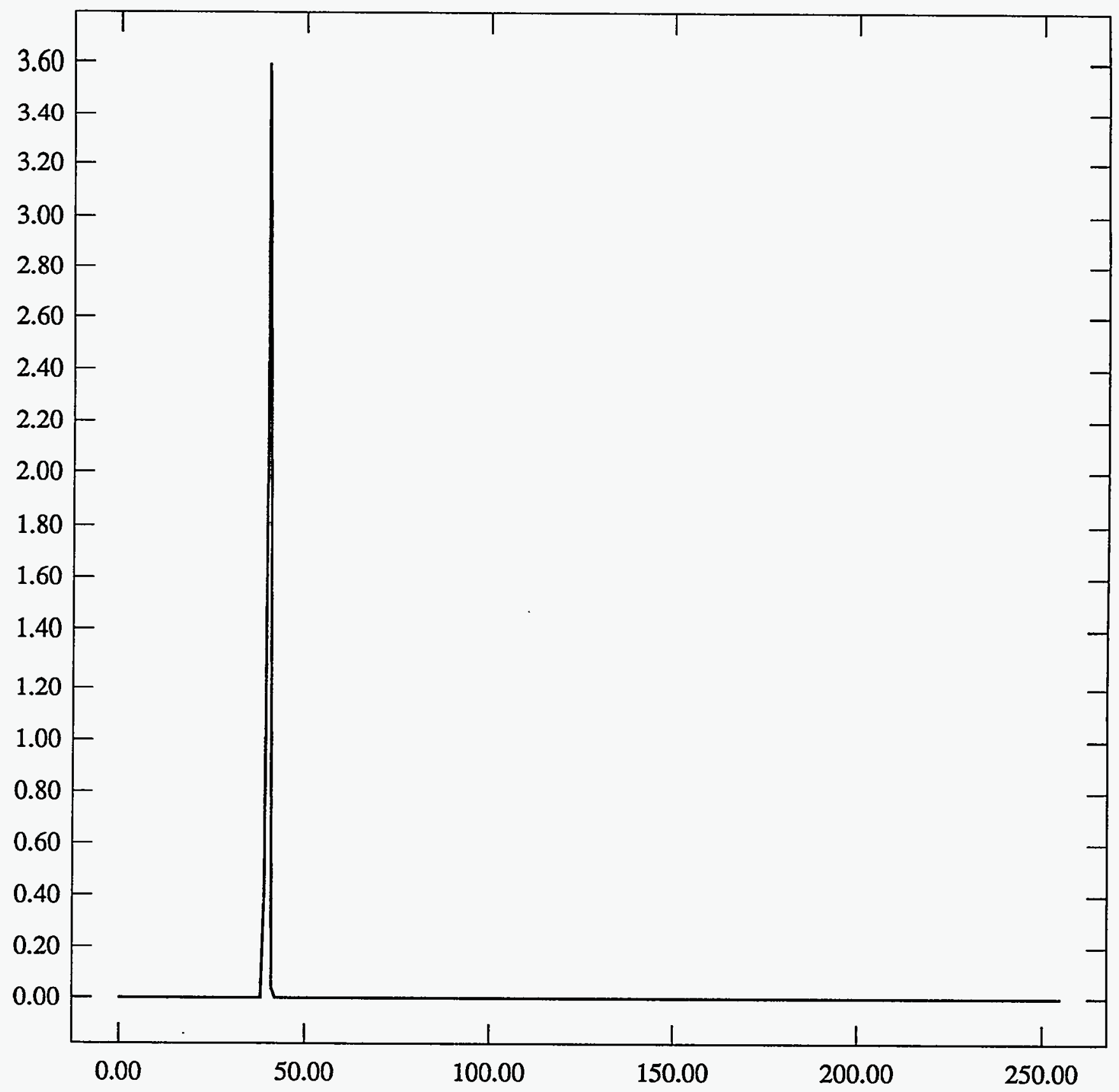


ST Camera: ST1\#04-10 -30C \#2: int_time=100ms, offset= 0, gain=1 ( $350 \mathrm{e} / \mathrm{bit}$ ) Wed Jun 30 08:36:26 1993 Pixel Values Min 39 Max 41 Mean 39.9 Sigma $0.30 \times 10^{3}$

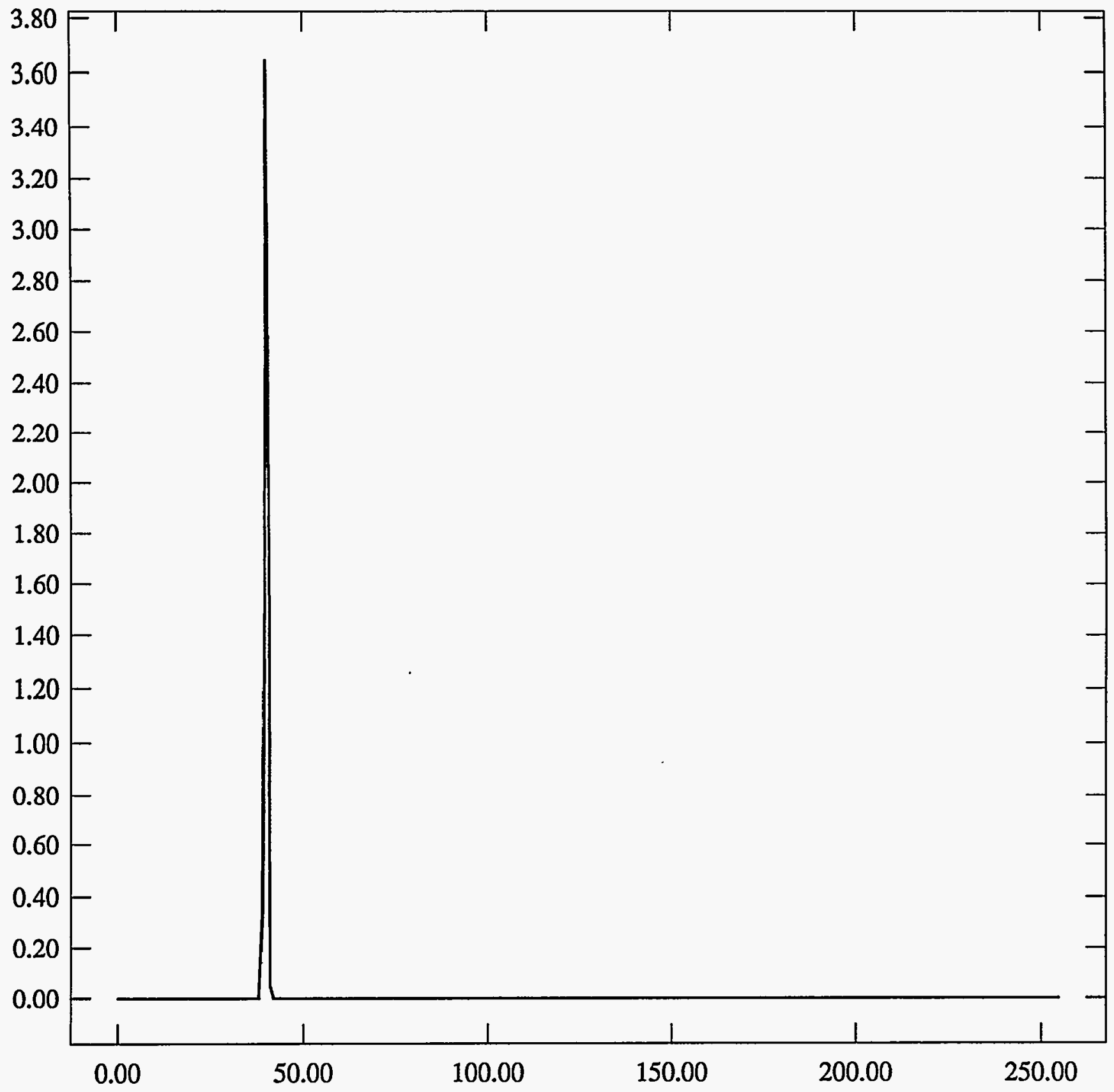


ST Camera: ST1 $\$ 04-10-30 \mathrm{C} \# 2$ : int_time=200ms, offset= 0, gain=1 ( $350 \mathrm{e} / \mathrm{bit}$ ) Wed Jun 30 08:36:48 1993 Pixel Values Min 39 Max 41 Mean 39.9 Sigma $0.30 \times 10^{3}$

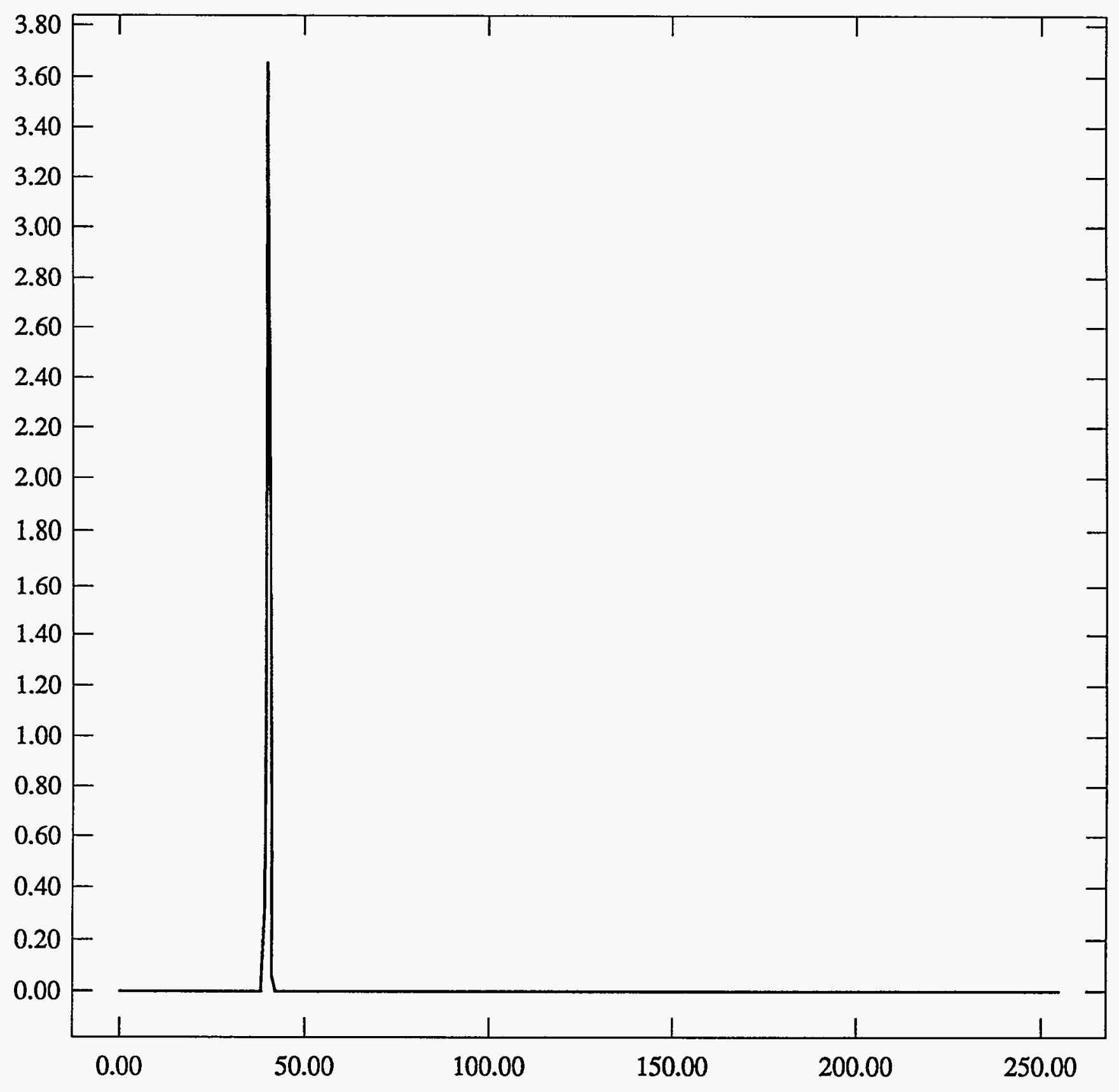


ST Camera: ST1\#04-10 -30C \#2: int_time= 50ms, offset= 0, gain=2 ( 150 e/bit) Wed Jun 30 08:37:19 1993 Pixel Values Min 78 Max 80 Mean 79.3 Sigma 0.57 x $10^{3}$

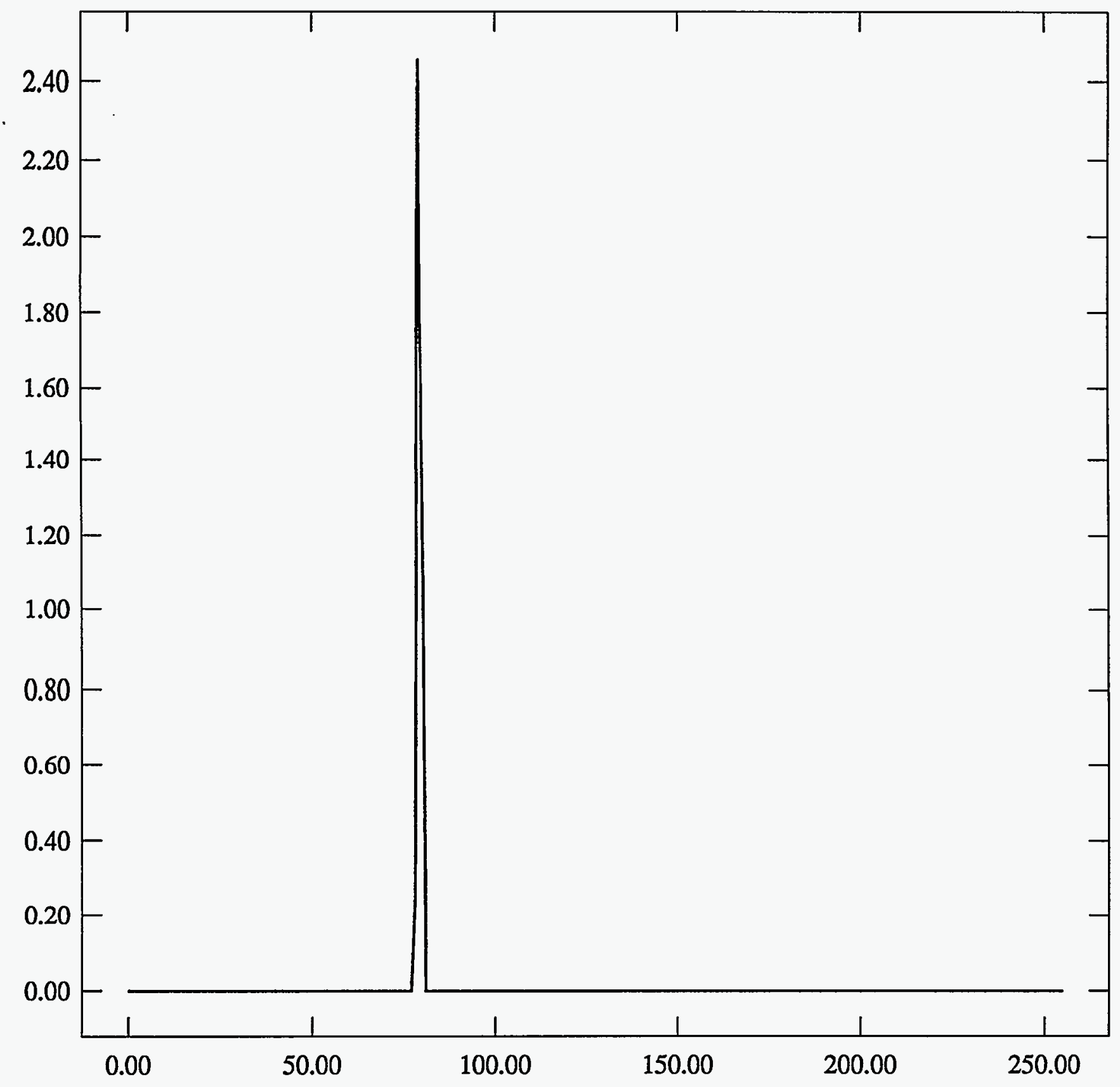


ST Camera: ST1\#04-10 -30C \#2: int_time=100ms, offset= 0, gain=2 (150 e/bit) Wed Jun 30 08:38:02 1993 Pixel Values Min 78 Max 81 Mean 79.3 Sigma $0.57 \times 10^{3}$

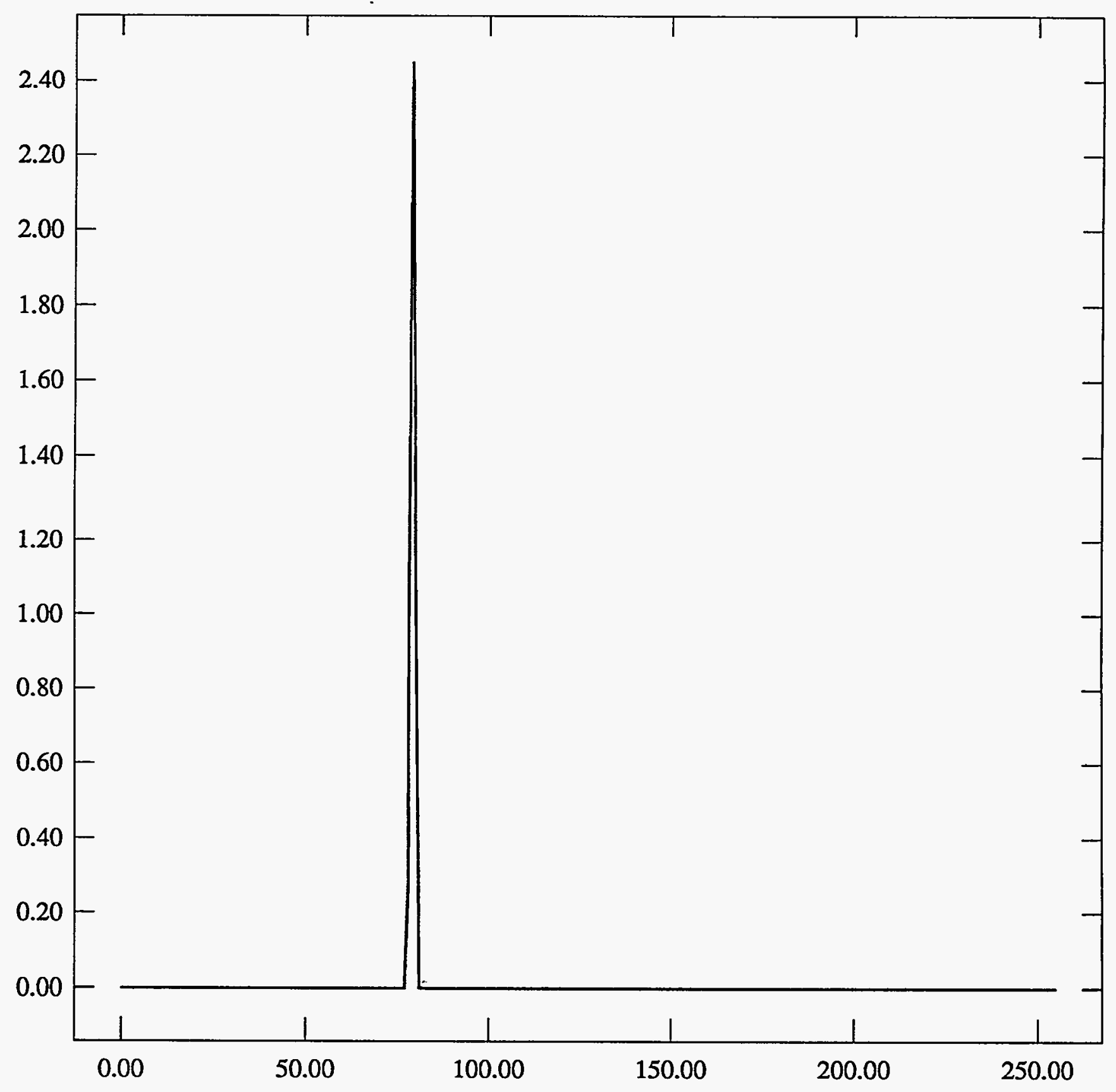


ST Camera: ST1\#04-10 -30C \#2: int_time=200ms, offset= 0, gain=2 (150 e/bit) Wed Jun 30 08:38:36 1993 Pixel Values Min 78 Max 80 Mean 79.3 Sigma $0.57 \times 10^{3}$

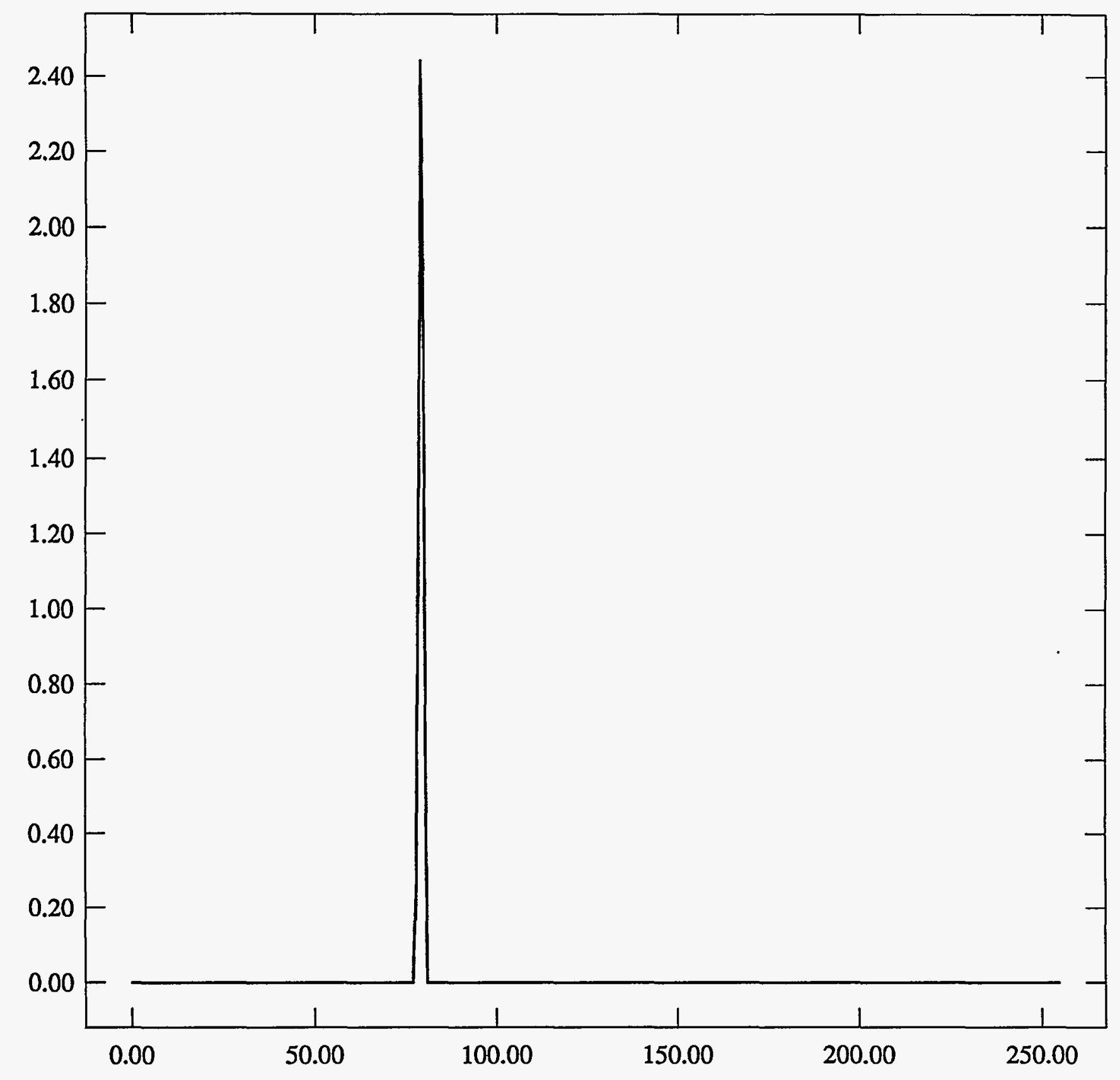


ST Camera: ST1\#04-10 -30C \#2: int_time= 50ms, offset= 0, gain=4 ( 75 e/bit) Wed Jun 30 08:39:45 1993 Pixel Values Min 145 Max 149 Mean 146.9 Sigma $0.72 \times 10^{3}$

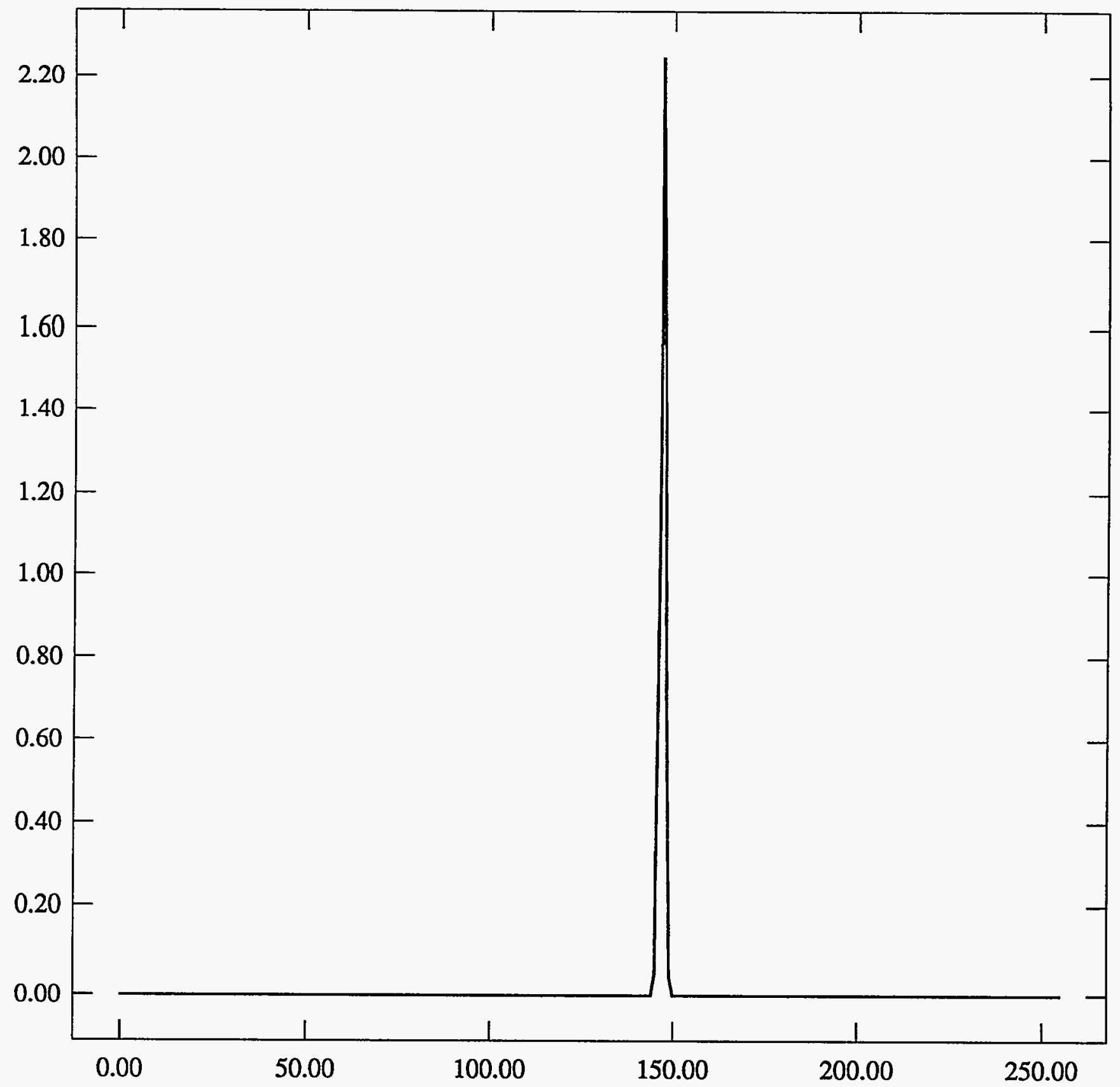


ST Camera: ST1\#04-10 -30C \#2: int_time=100ms, offset= 0, gain=4 ( 75 e/bit) Wed Jun 30 08:40:38 1993 Pixel Values Min 144 Max 149 Mean 146.9 Sigma $0.72 \times 10^{3}$

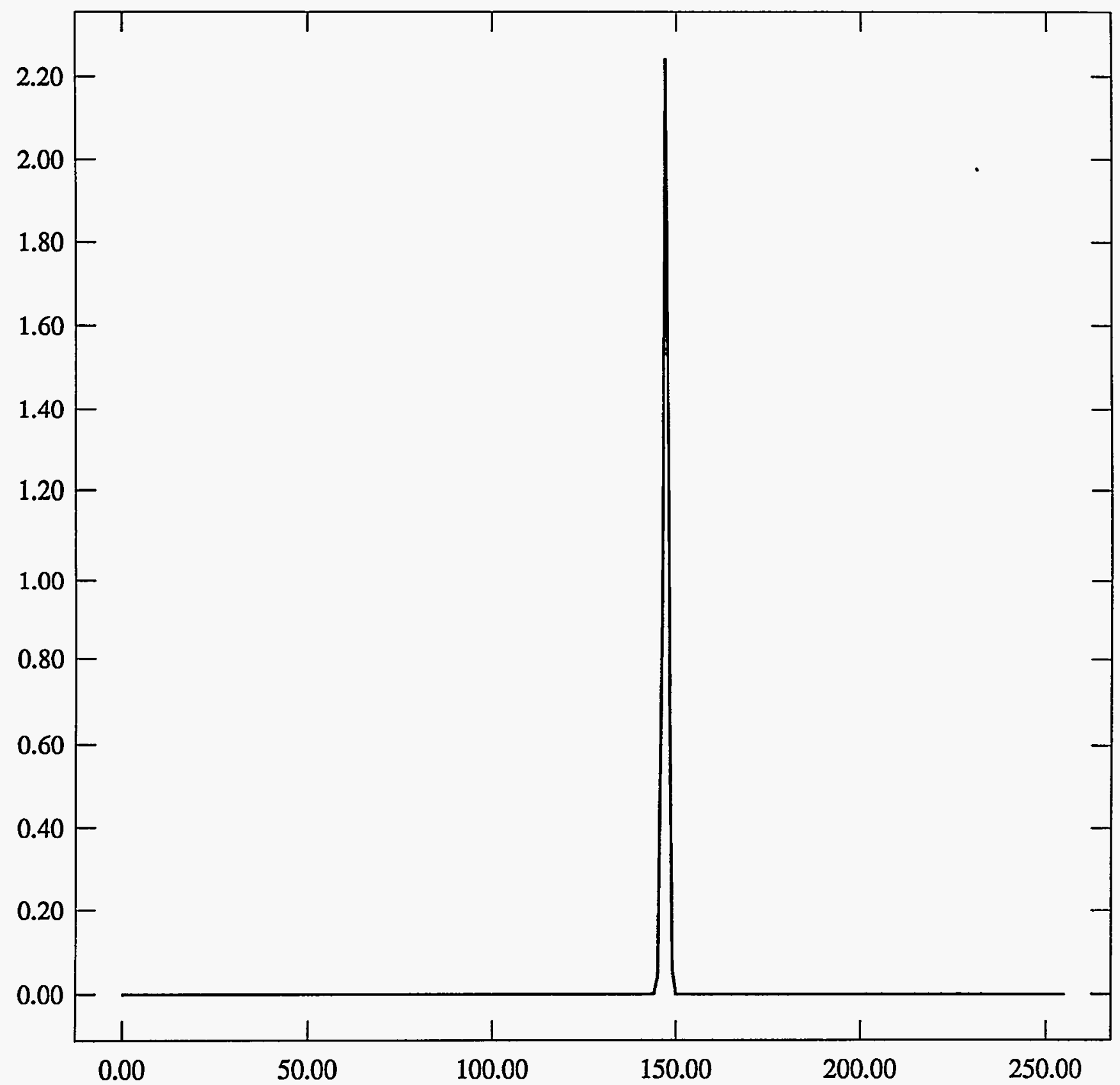


ST Camera: ST1\#04-10 -30C \#2: int_time=200ms, offset= 0, gain=4 ( 75 e/bit) Wed Jun 30 08:41:48 1993 Pixel Values Min 145 Max 149 Mean 146.9 Sigma $0.74 \times 10^{3}$

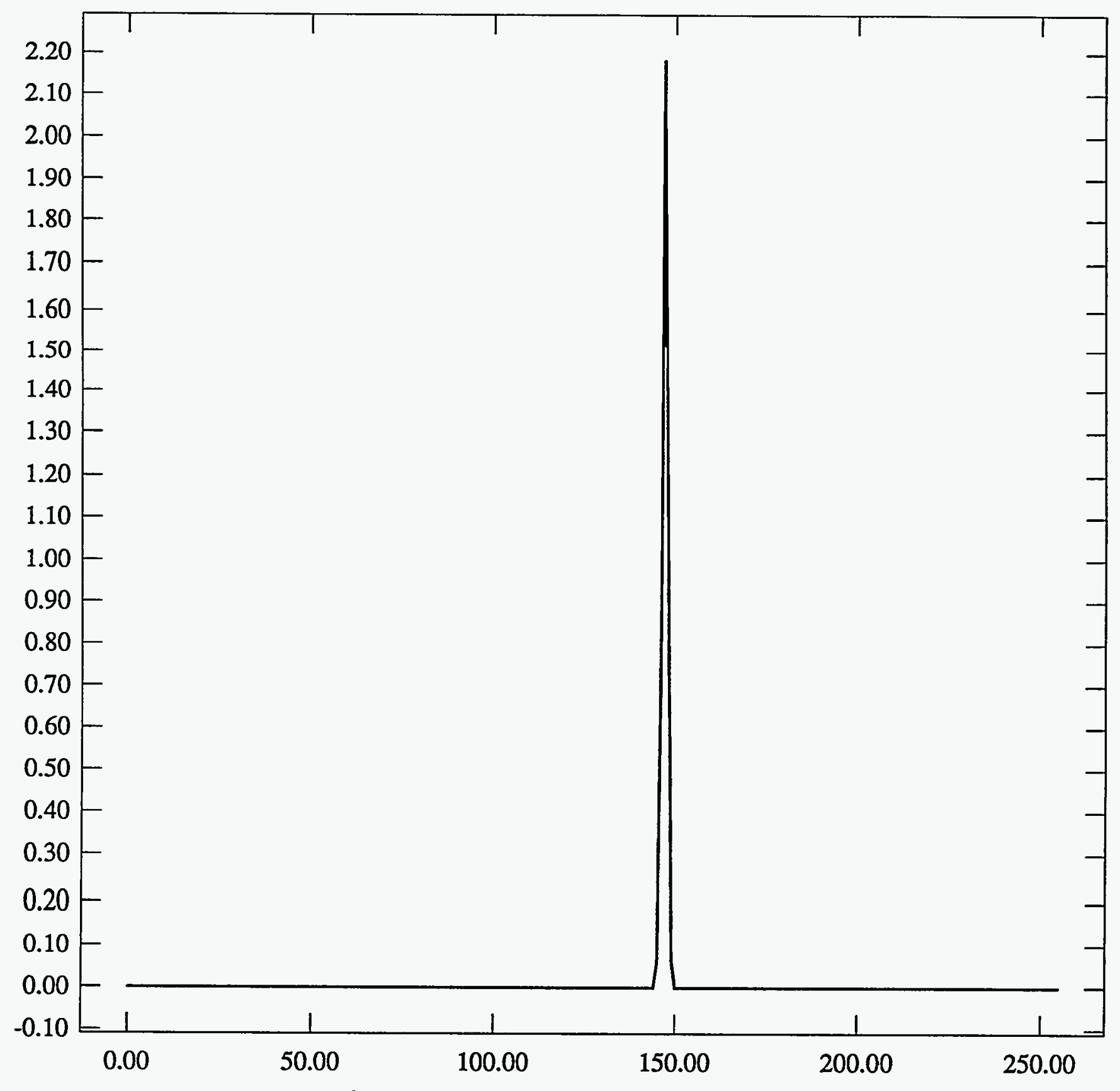


t2-30 2 NO

ST Camera: ST1\#04-10 -30C \#2: int_time= 50ms, offset= 0, gain=1 ( 350 e/bit) Wed Jun 30 09:17:47 1993 Pixel Values Min 39 Max 41 Mean 39.9 Sigma $0.33 \times 10^{3}$

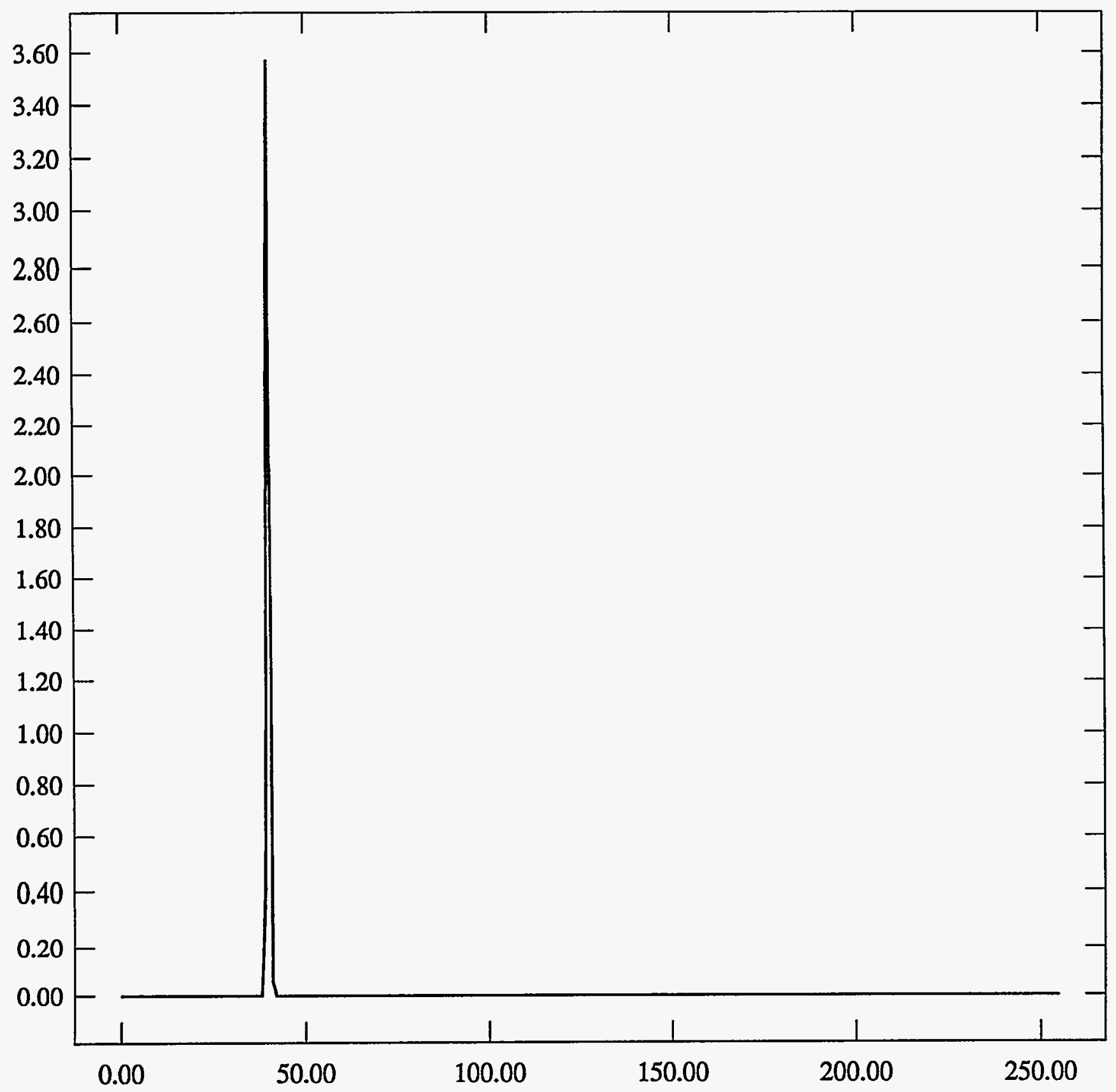


ST Camera: ST1\#04-10 -30C \#2: int_time=100ms, offset= 0, gain=1 ( 350 e/bit) Wed Jun 30 09:18:08 1993 Pixel Values Min $39 \operatorname{Max} 41$ Mean 39.9 Sigma $0.31 \times 10^{3}$

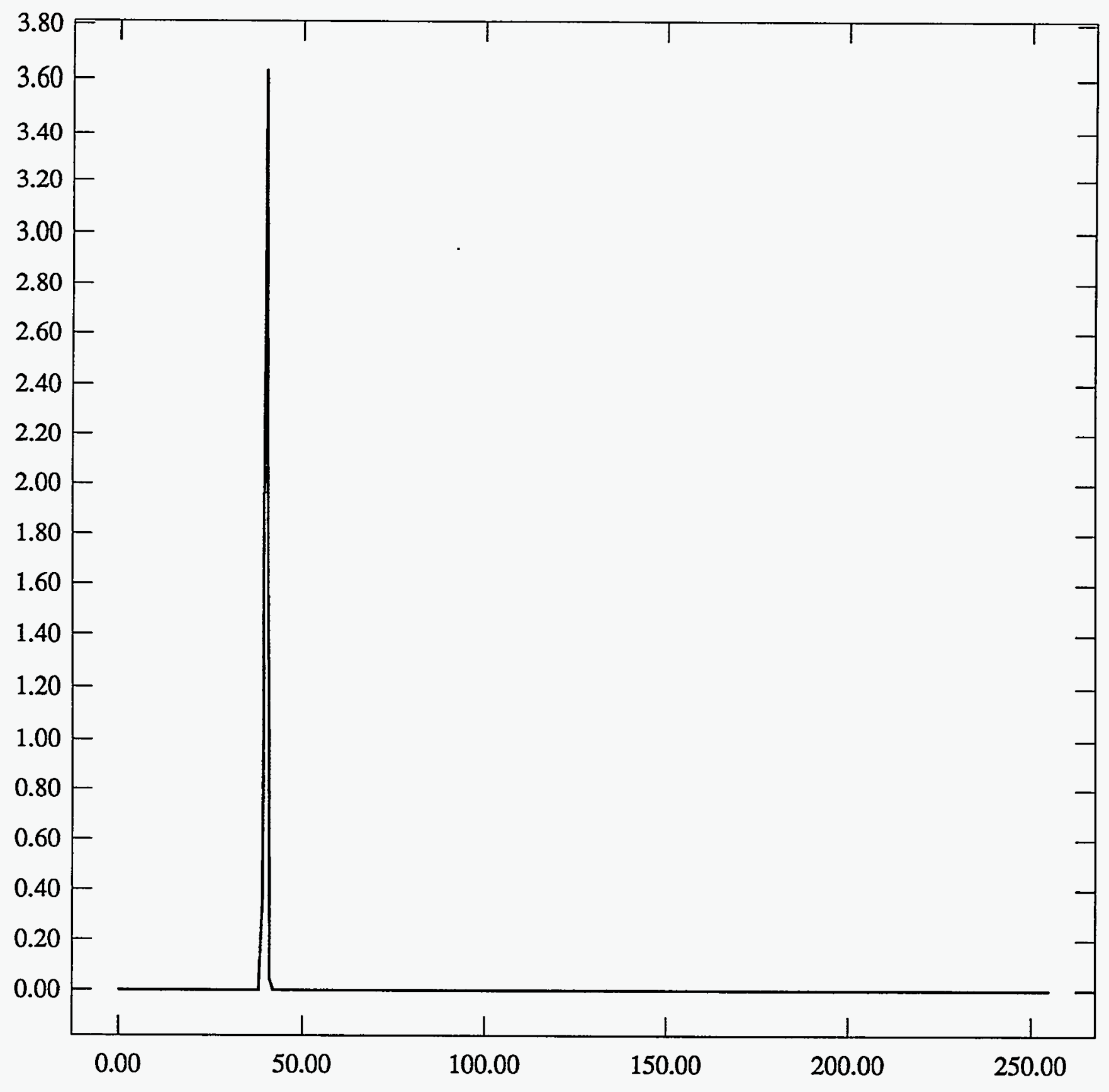


ST Camera: ST1\#04-10 -30C \#2: int_time=200ms, offset= 0, gain=1 ( 350 e/bit) Wed Jun 30 09:18:37 1993 Pixel Values Min 39 Max 41 Mean 39.9 Sigma $0.32 \times 10^{3}$

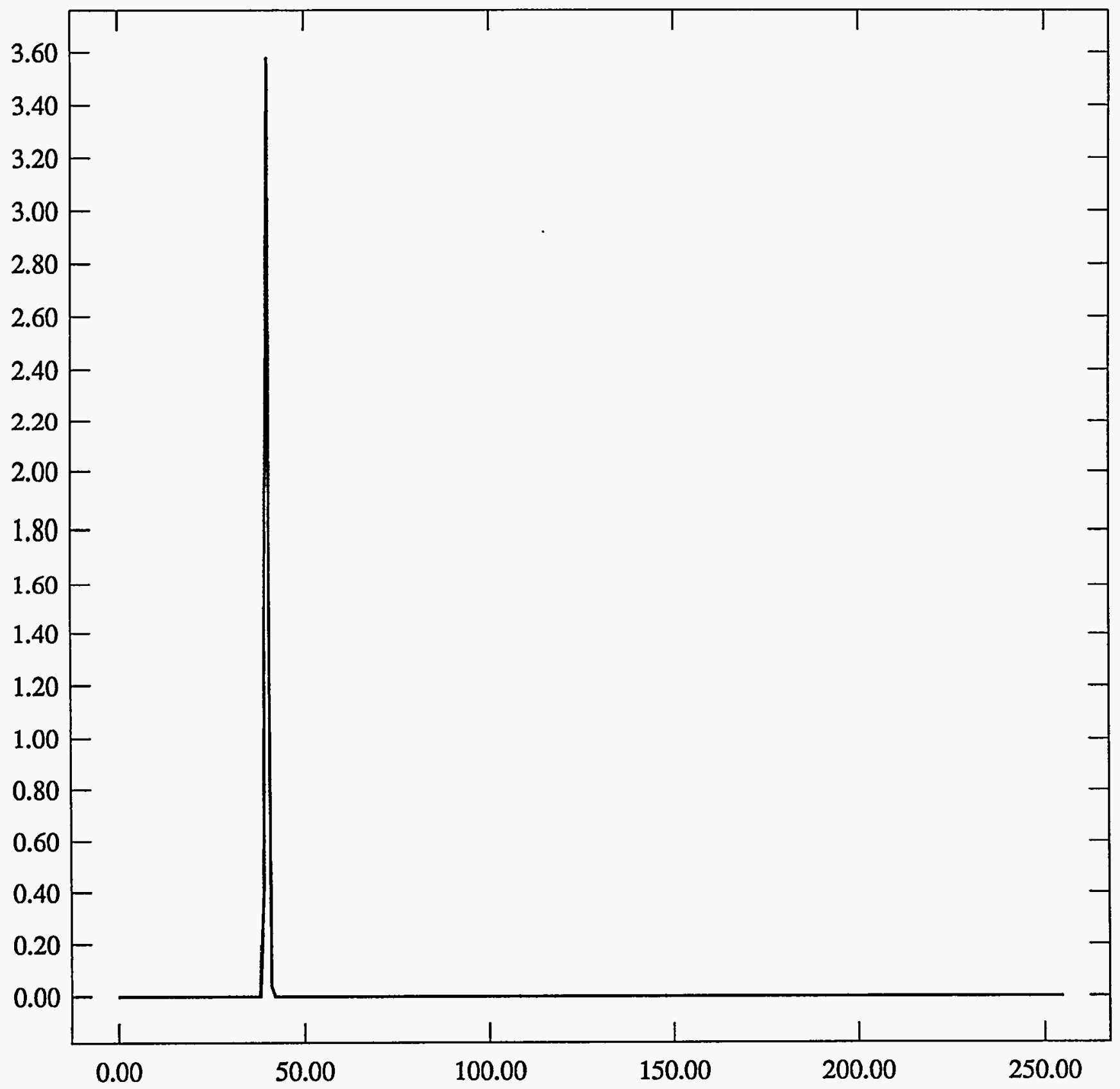


ST Camera: ST1\#04-10 -30C \#2: int_time= 50ms, offset= 0, gain=2 (150 e/bit) Wed Jun 30 09:18:58 1993 Pixel Values Min 78 Max 81 Mean 79.2 Sigma $0.58 \times 10^{3}$

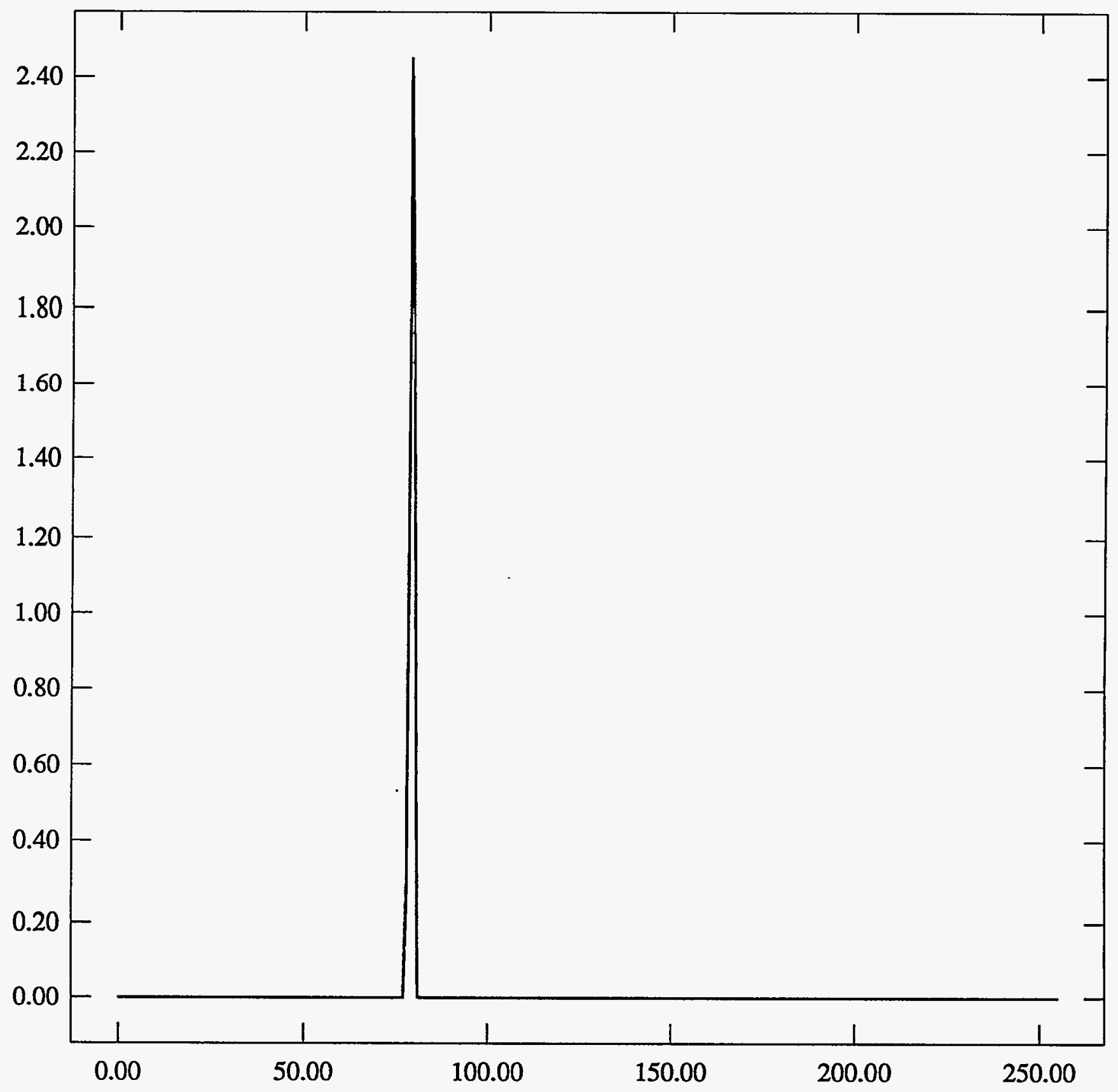


ST Camera: ST1\#04-10 -30C \#2: int_time=100ms, offset= 0, gain=2 ( $150 \mathrm{e} / \mathrm{bit}$ ) Wed Jun 30 09:19:20 1993 Pixel Values Min 78 Max 80 Mean 79.3 Sigma $0.59 \times 10^{3}$

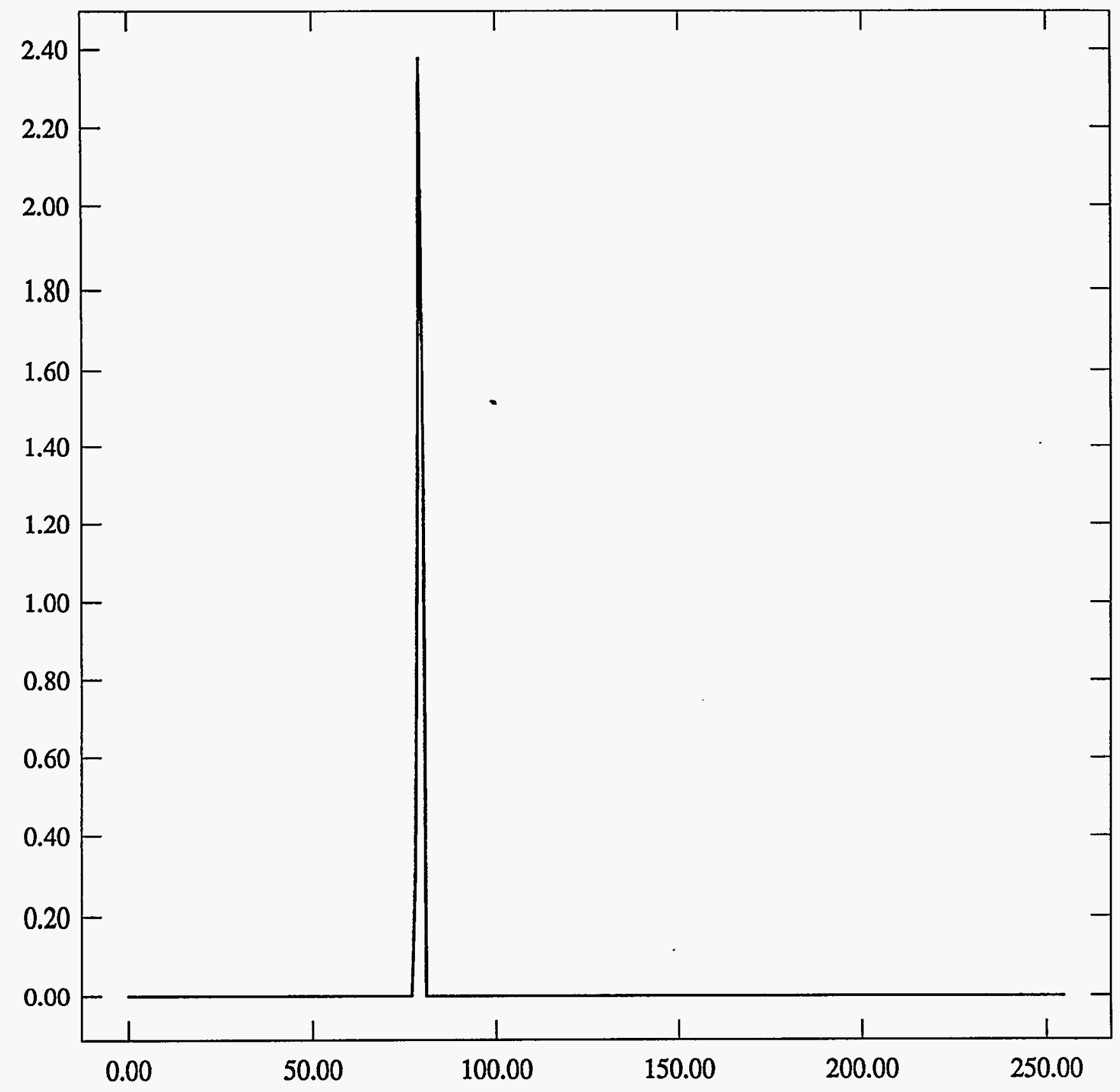


ST Camera: ST1\#04-10 -30C \#2: int_time=200ms, offset= 0, gain=2 ( $150 \mathrm{e} / \mathrm{bit}$ ) Wed Jun 30 09:19:45 1993 Pixel Values Min 78 Max 80 Mean 79.3 Sigma $0.58 \times 10^{3}$

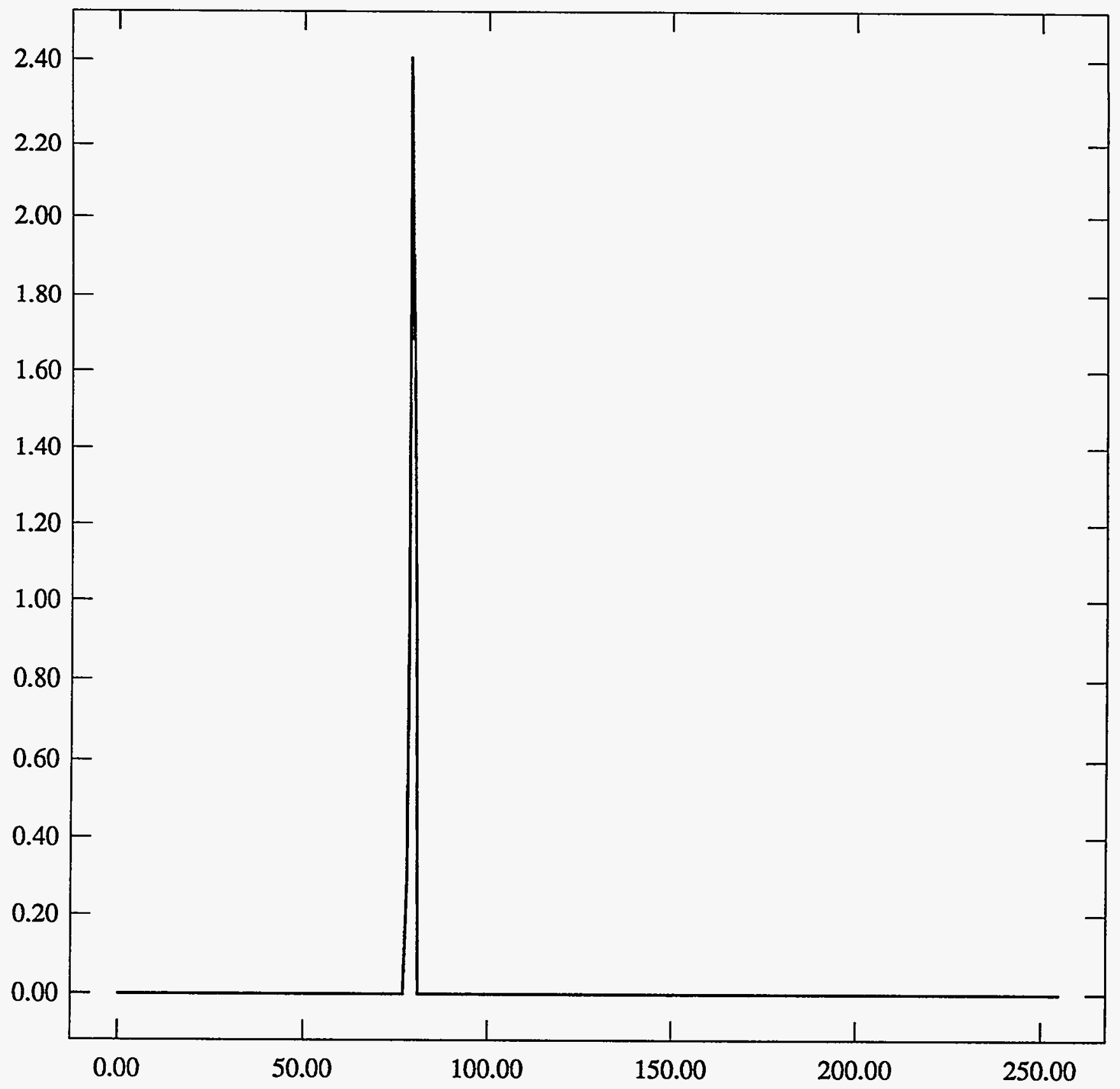


ST Camera: ST1\#04-10 -30C \#2: int_time= 50ms, offset= 0, gain=4 ( 75 e/bit) Wed Jun 30 09:20:05 1993 Pixel Values Min 145 Max 149 Mean 146.9 Sigma 0.73 x $10^{3}$

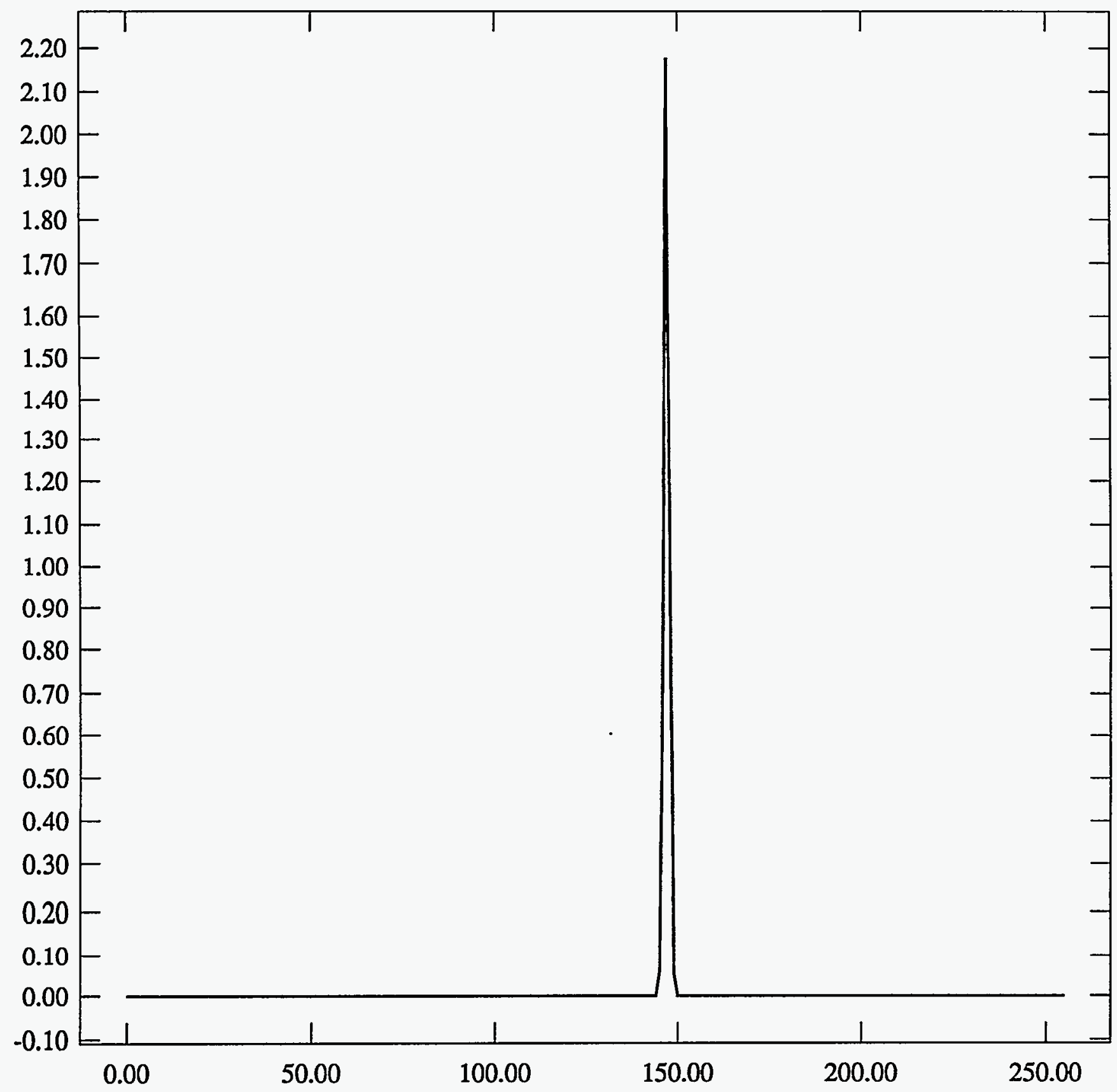


ST Camera: ST1\#04-10 -30C \#2: int_time=100ms, offset= 0, gain=4 ( 75 e/bit) Wed Jun 30 09:20:30 1993 Pixel Values Min 145 Max 149 Mean 146.9 Sigma $0.71 \times 10^{3}$

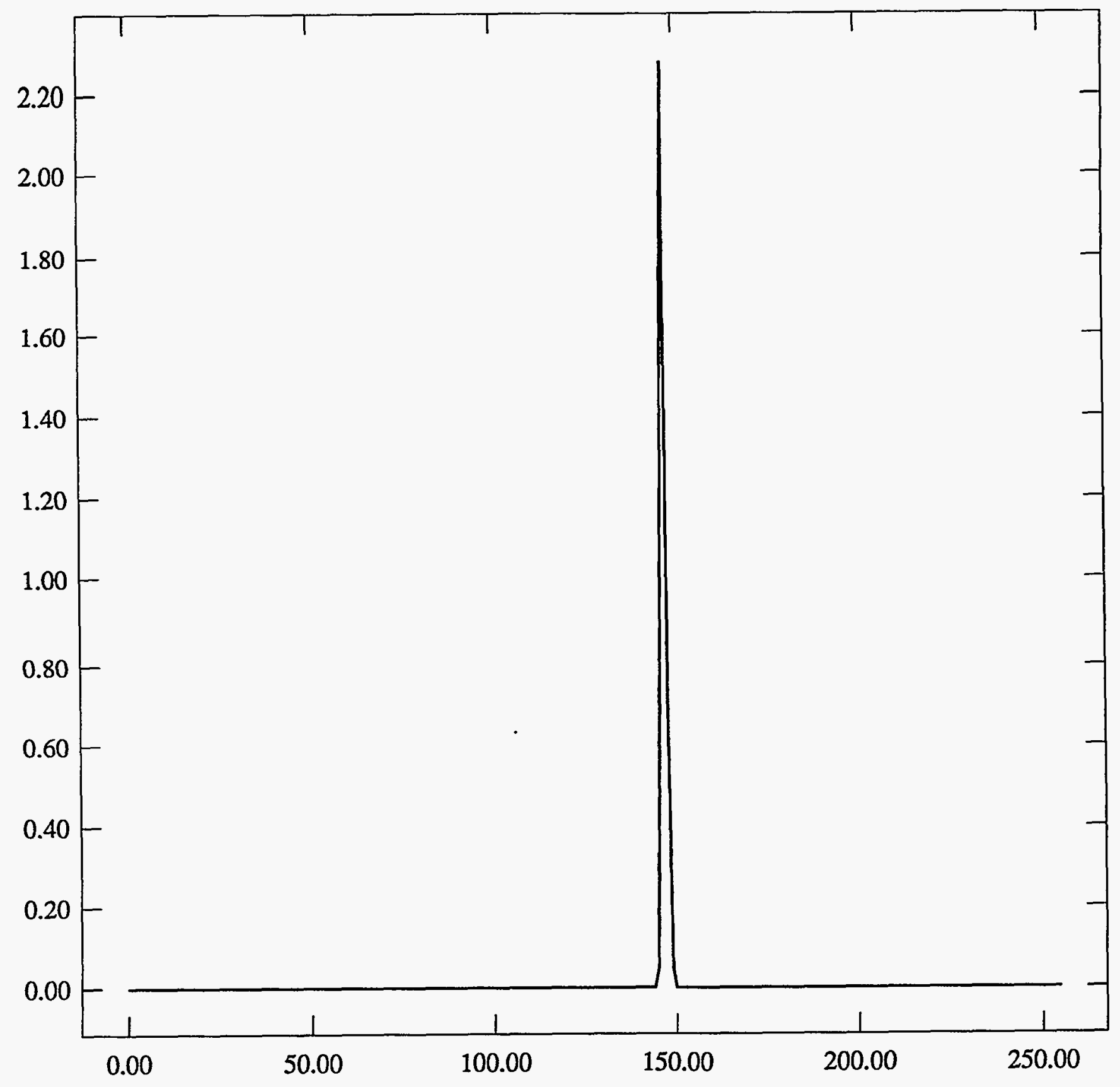


ST Camera: ST1\#04-10 -30C \#2: int_time=200ms, offset= 0, gain=4 ( 75 e/bit) Wed Jun 30 09:20:57 1993 Pixel Values Min 144 Max 149 Mean 146.9 Sigma $0.69 \times 10^{3}$

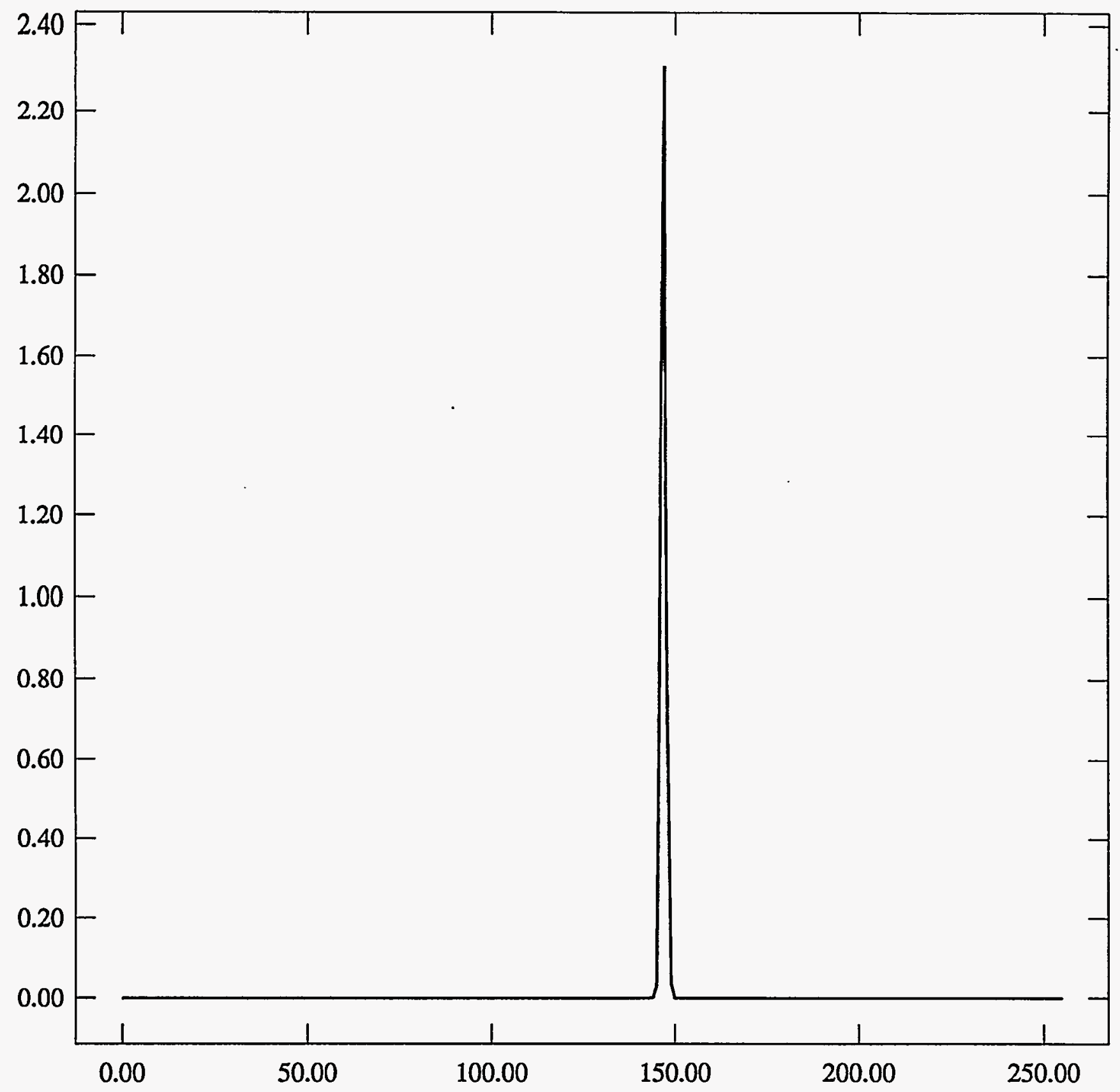




$$
E \geq 20=15 \mathrm{mmin}
$$

ST Camera: ST1\#04-10 20C \#2: int_time= 50ms, offset= 0, gain=1 ( $350 \mathrm{e} / \mathrm{bit}$ ) Wed Jun 30 09:52:21 1993 Pixel Values Min 39 Max 41 Mean 39.5 Sigma $0.50 \times 10^{3}$

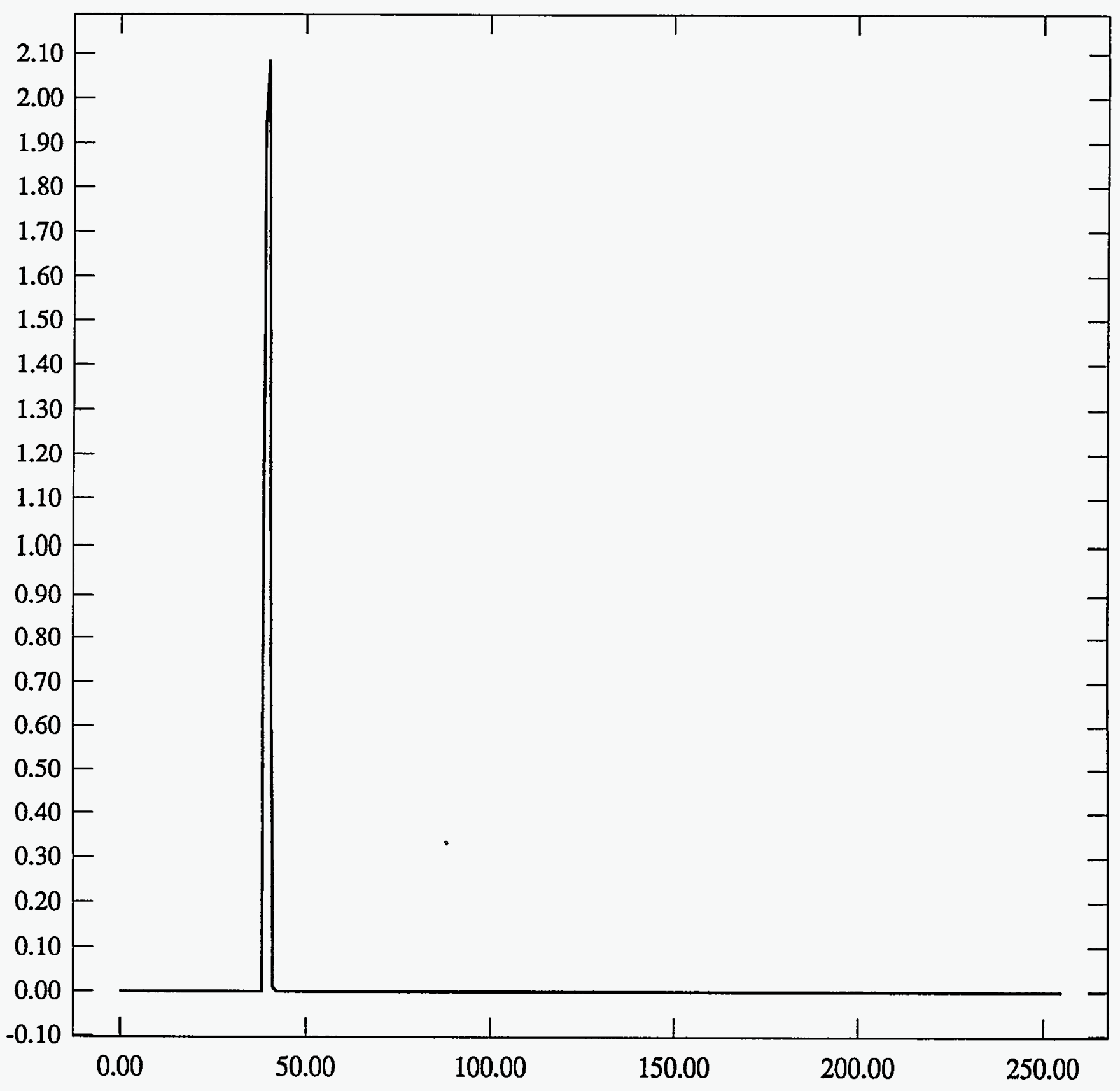


ST Camera: ST1\#04-10 20C \#2: int_time=100ms, offset= 0, gain=1 ( 350 e/bit) Wed Jun 30 09:52:37 1993 Pixel Values Min 39 Max 41 Mean 39.5 Sigma $0.50 \times 10^{3}$

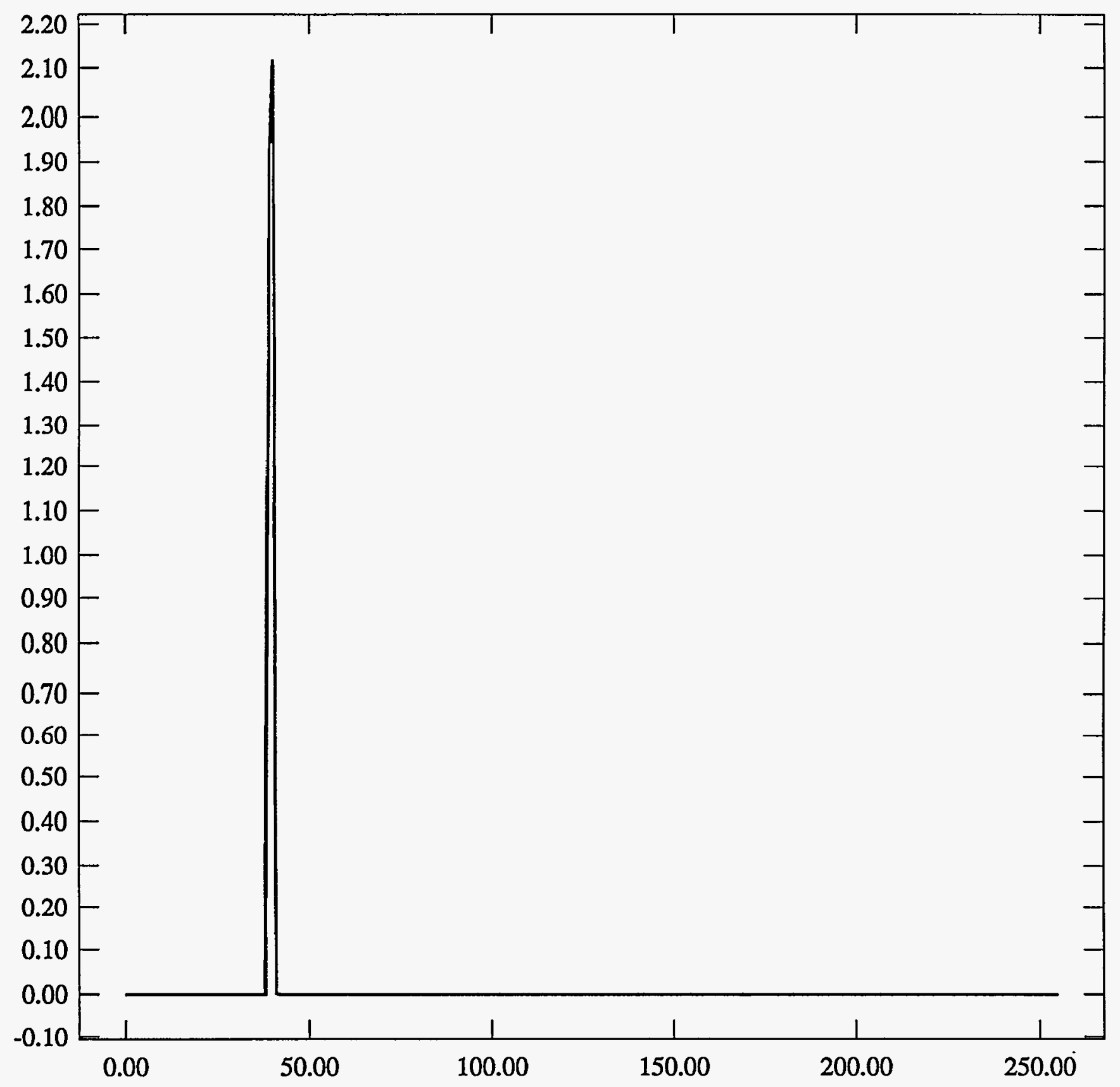


ST Camera: ST1\#04-10 20C \#2: int_time=200ms, offset= 0, gain=1 (350 e/bit) Wed Jun 30 09:52:56 1993 Pixel Values Min 39 Max 41 Mean 39.5 Sigma $0.50 \times 10^{3}$

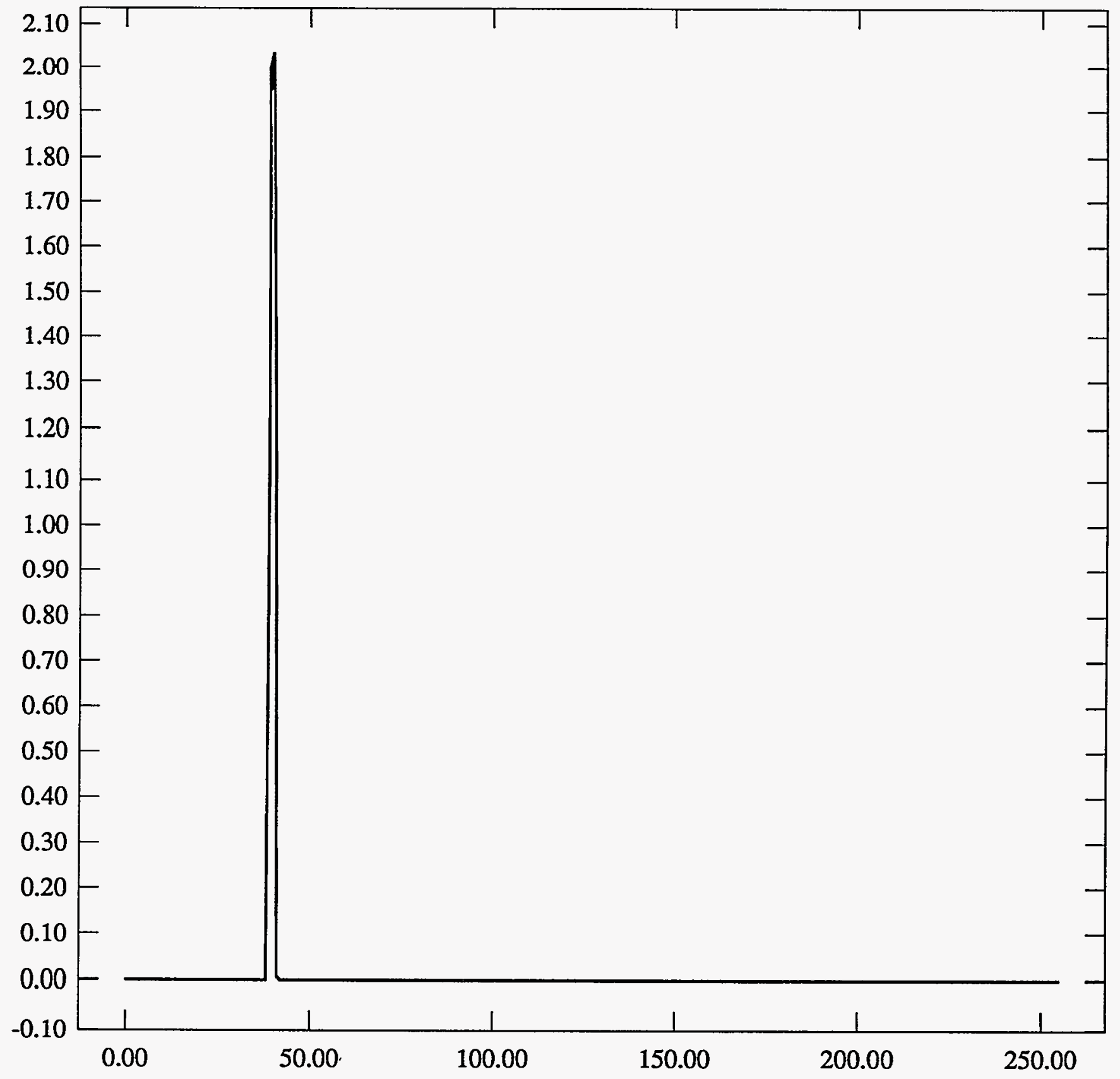


ST Camera: ST1\#04-10 20C \#2: int_time= 50ms, offset= 0, gain=2 (150 e/bit) Wed Jun 30 09:53:35 1993

Pixel Values Min 77 Max 81 Mean 79.3 Sigma $0.77 \times 10^{3}$

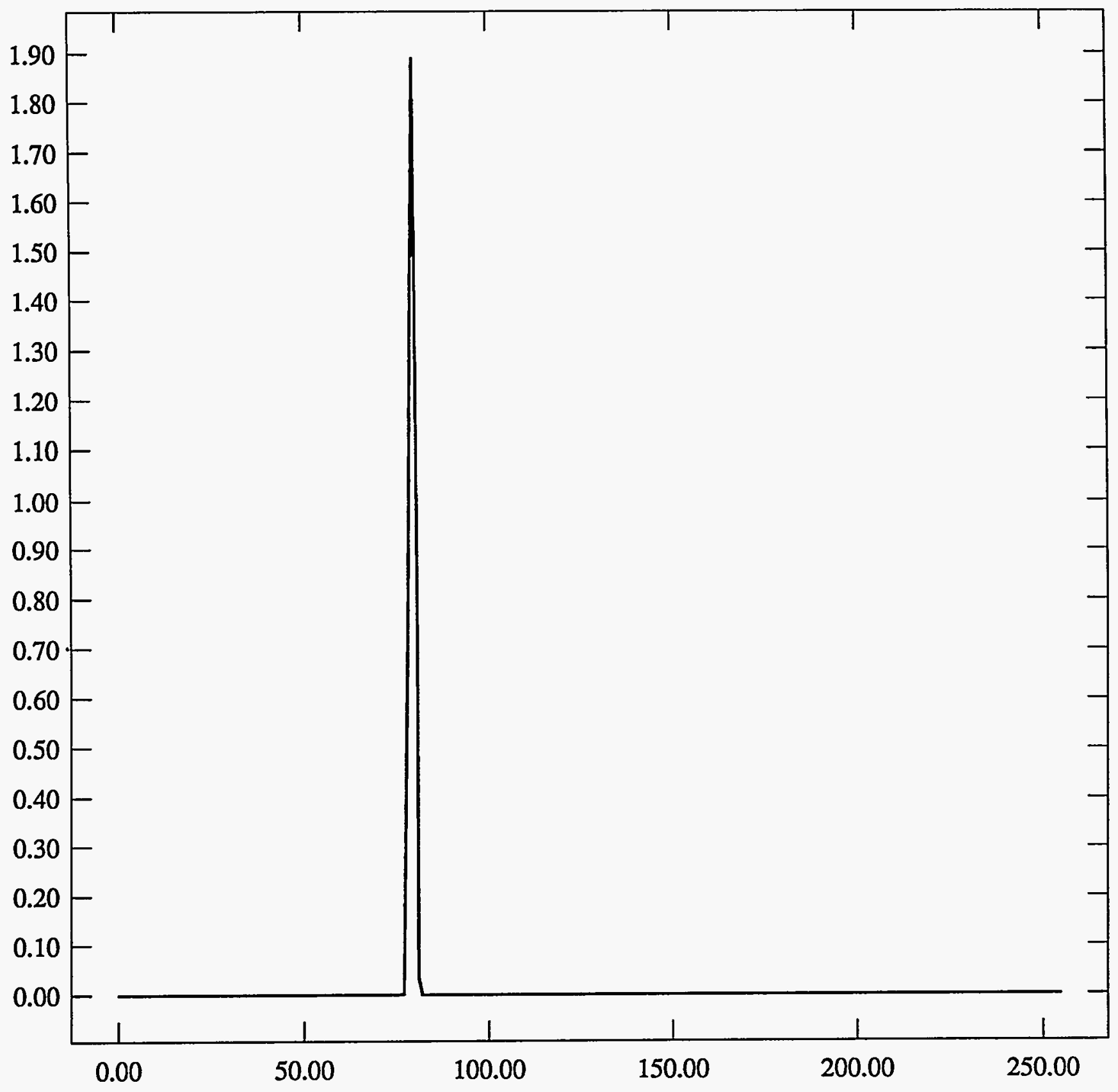


ST Camera: ST1\#04-10 20C \#2: int_time=100ms, offset= 0, gain=2 ( 150 e/bit) Wed Jun 30 09:53:54 1993 Pixel Values Min 77 Max 81 Mean 79.3 Sigma $0.76 \times 10^{3}$

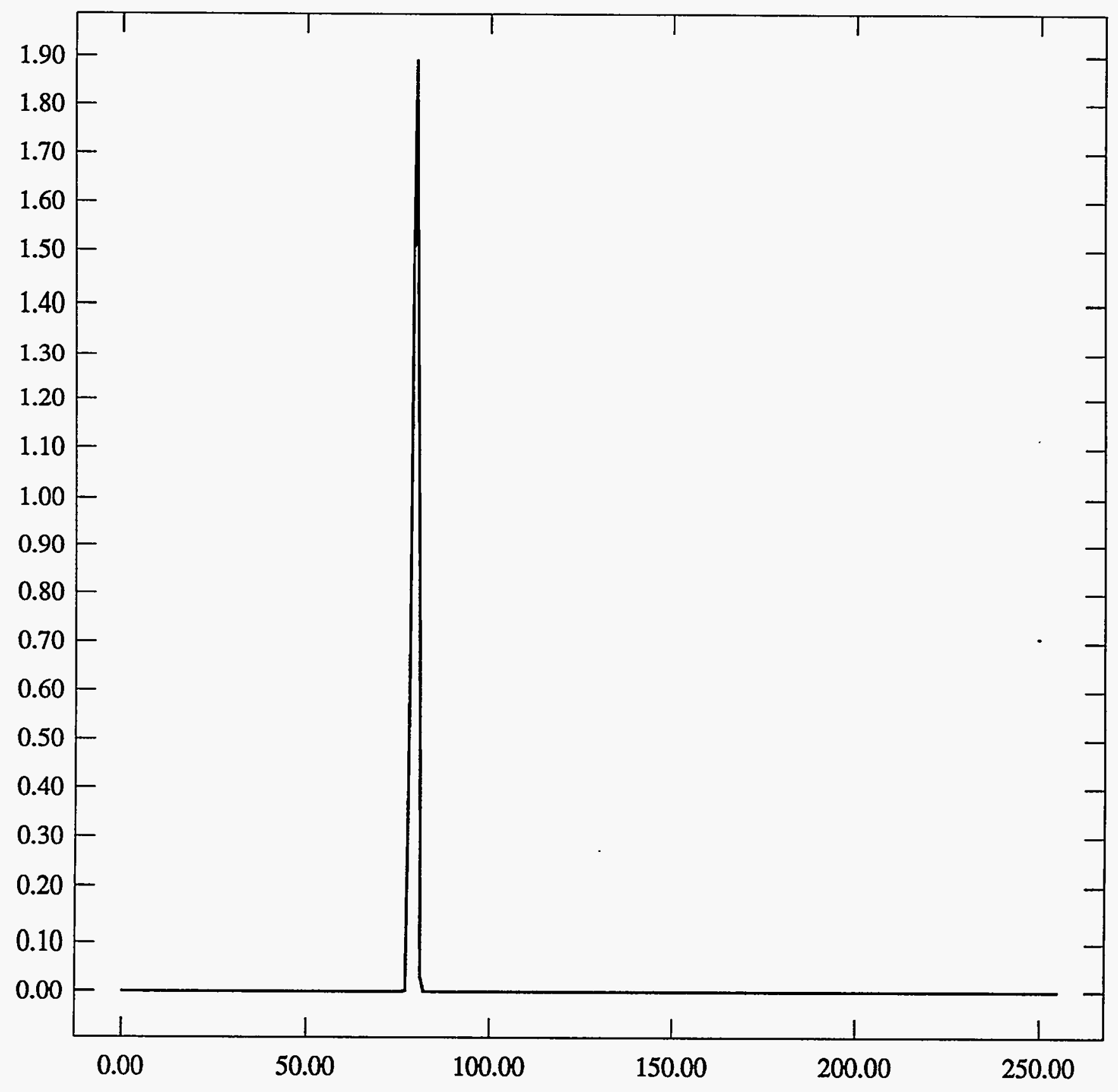


ST Camera: ST1\#04-10 20C \#2: int_time=200ms, offset= 0, gain=2 (150 e/bit) Wed Jun 30 09:54:15 1993 Pixel Values Min 77 Max 81 Mean 79.3 Sigma $0.77 \times 10^{3}$

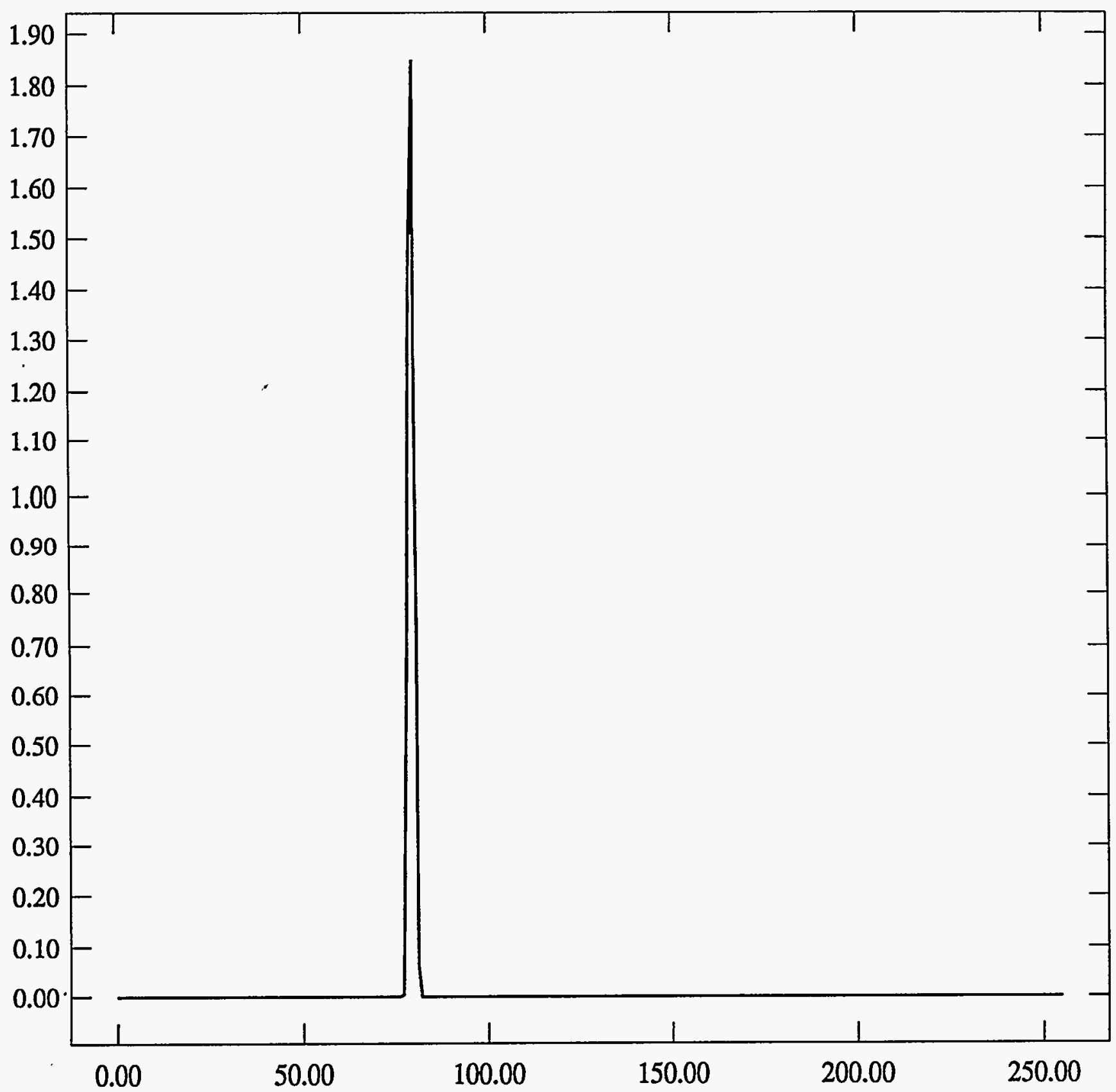


ST Camera: ST1\#04-10 20C \#2: int_time= 50ms, offset= 0, gain=4 ( $75 \mathrm{e} / \mathrm{bit}$ ) Wed Jun 30 09:54:36 1993 Pixel Values Min 142 Max 148 Mean 145.2 Sigma $0.80 \times 10^{3}$

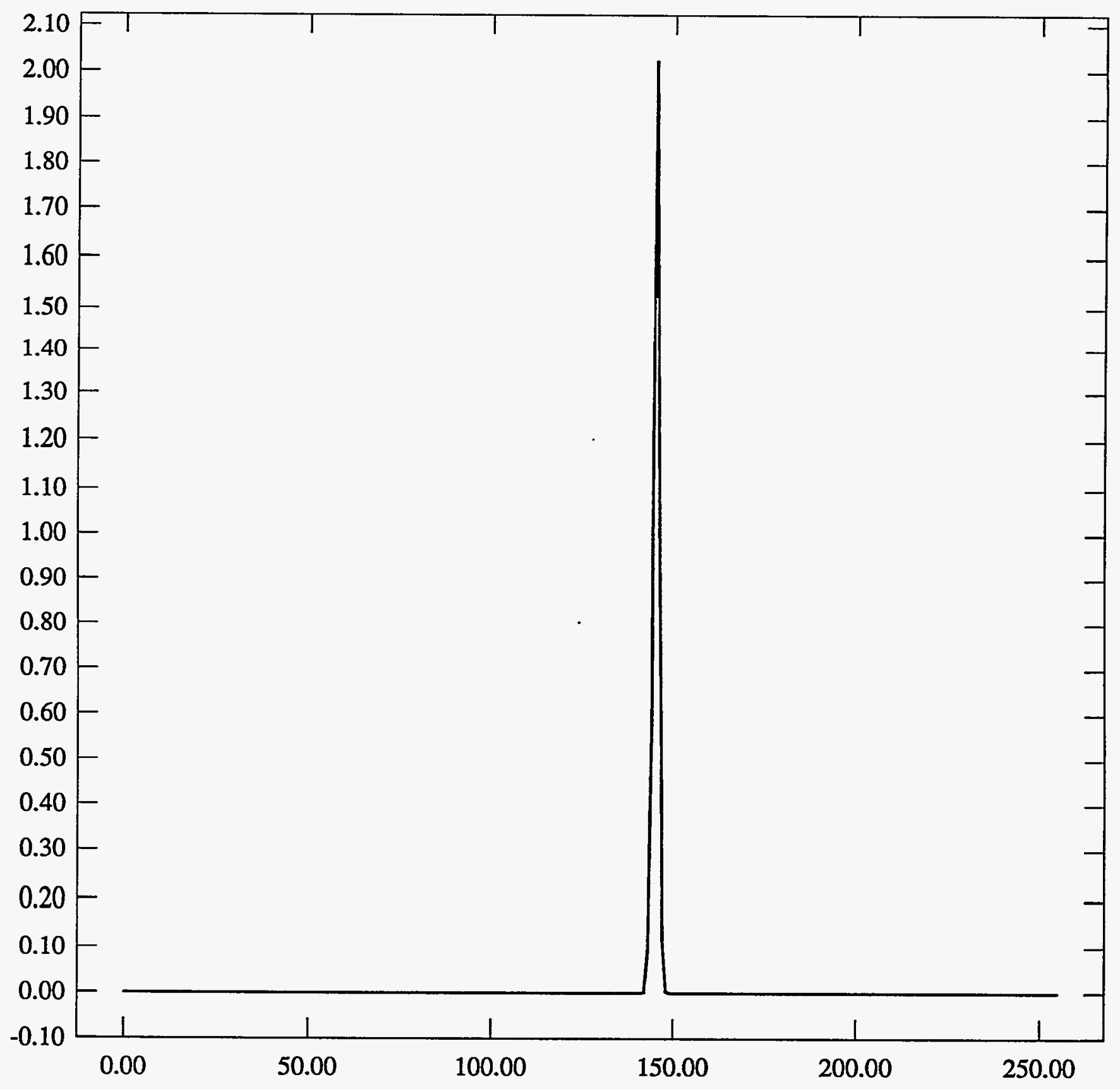


ST Camera: ST1\#04-10 20C \#2: int_time=100ms, offset= 0, gain=4 ( 75 e/bit) Wed Jun 30 09:55:00 1993 Pixel Values Min 143 Max 148 Mean 145.2 Sigma $0.75 \times 10^{3}$

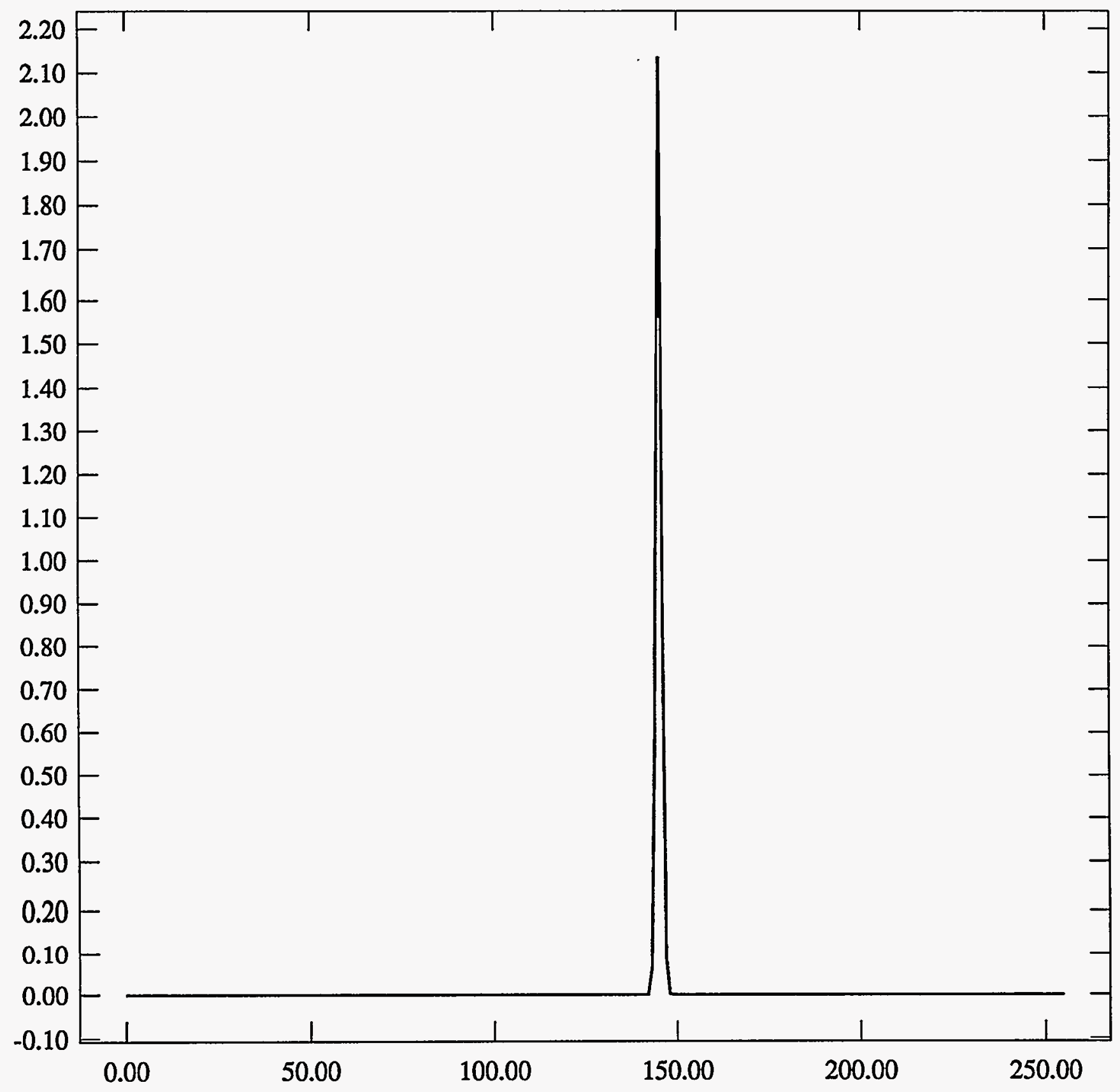


ST Camera: ST1\#04-10 20C \#2: int_time=200ms, offset= 0, gain=4 ( 75 e/bit) Wed Jun 30 09:55:21 1993 Pixel Values Min 143 Max 148 Mean 145.2 Sigma $0.76 \times 10^{3}$

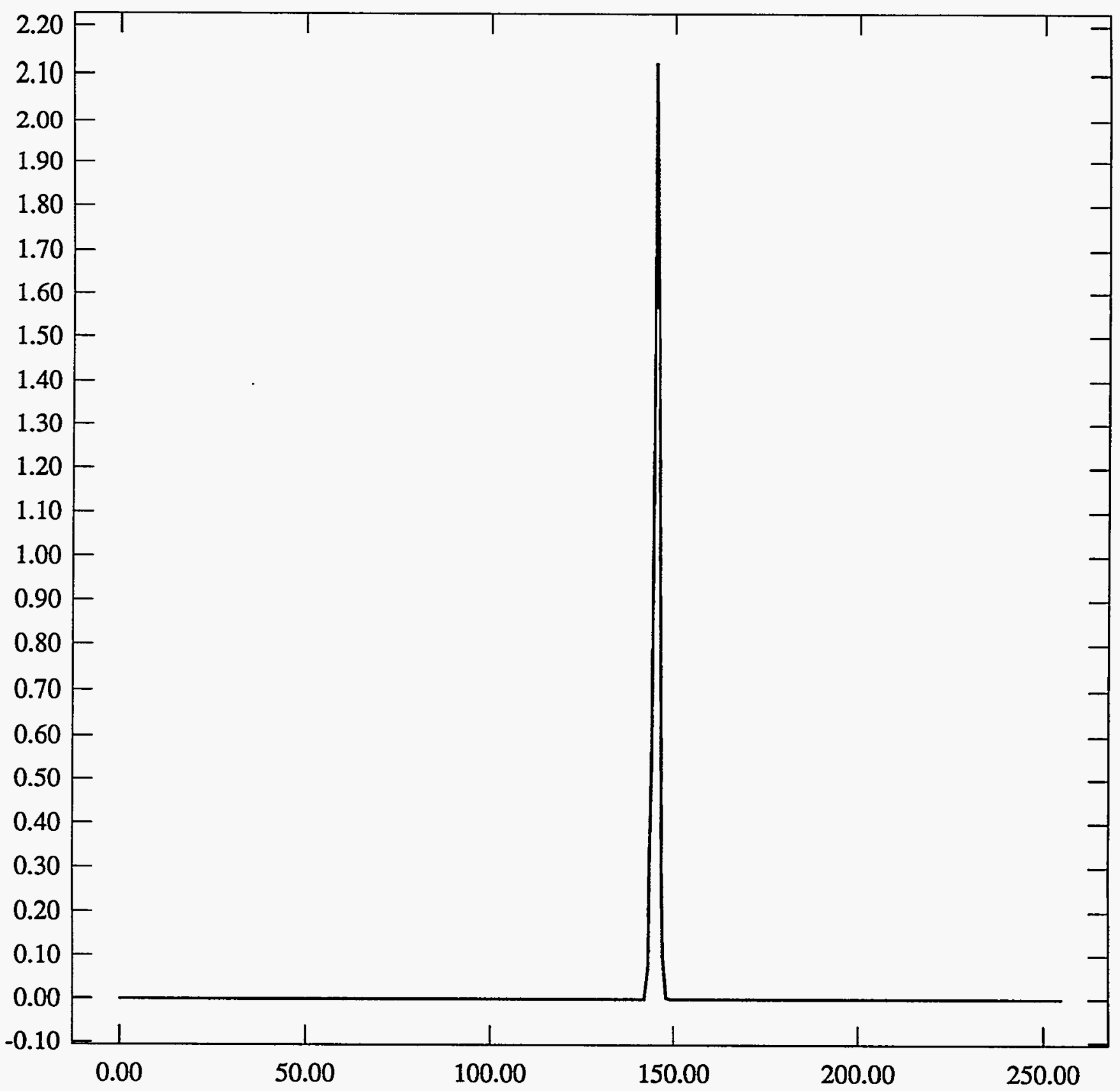




$$
\text { \#26 zoc END ofCLue }
$$

ST Camera: ST1\#04-10 20C \#2: int_time= 50ms, offset= 0, gain=1 (350 e/bit) Wed Jun 30 10:33:49 1993 Pixel Values Min 39 Max 41 Mean 39.4 Sigma $0.49 \times 10^{3}$

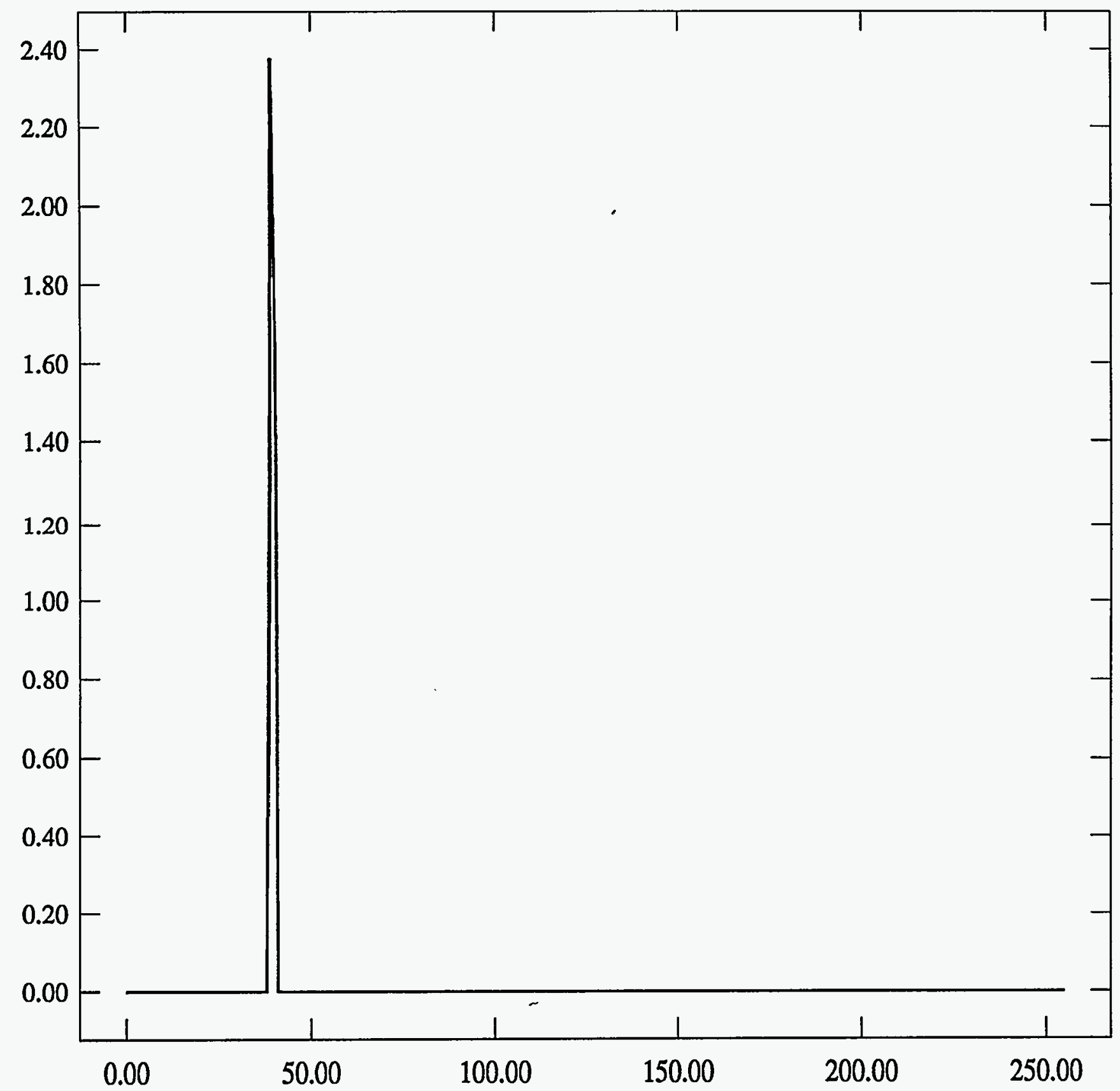


ST Camera: ST1\#04-10 20C \#2: int_time=100ms, offset= 0, gain=1 ( $350 \mathrm{e} / \mathrm{bit}$ ) Wed Jun 30 10:34:06 1993 Pixel Values Min 39 Max 41 Mean 39.4 Sigma $0.50 \times 10^{3}$

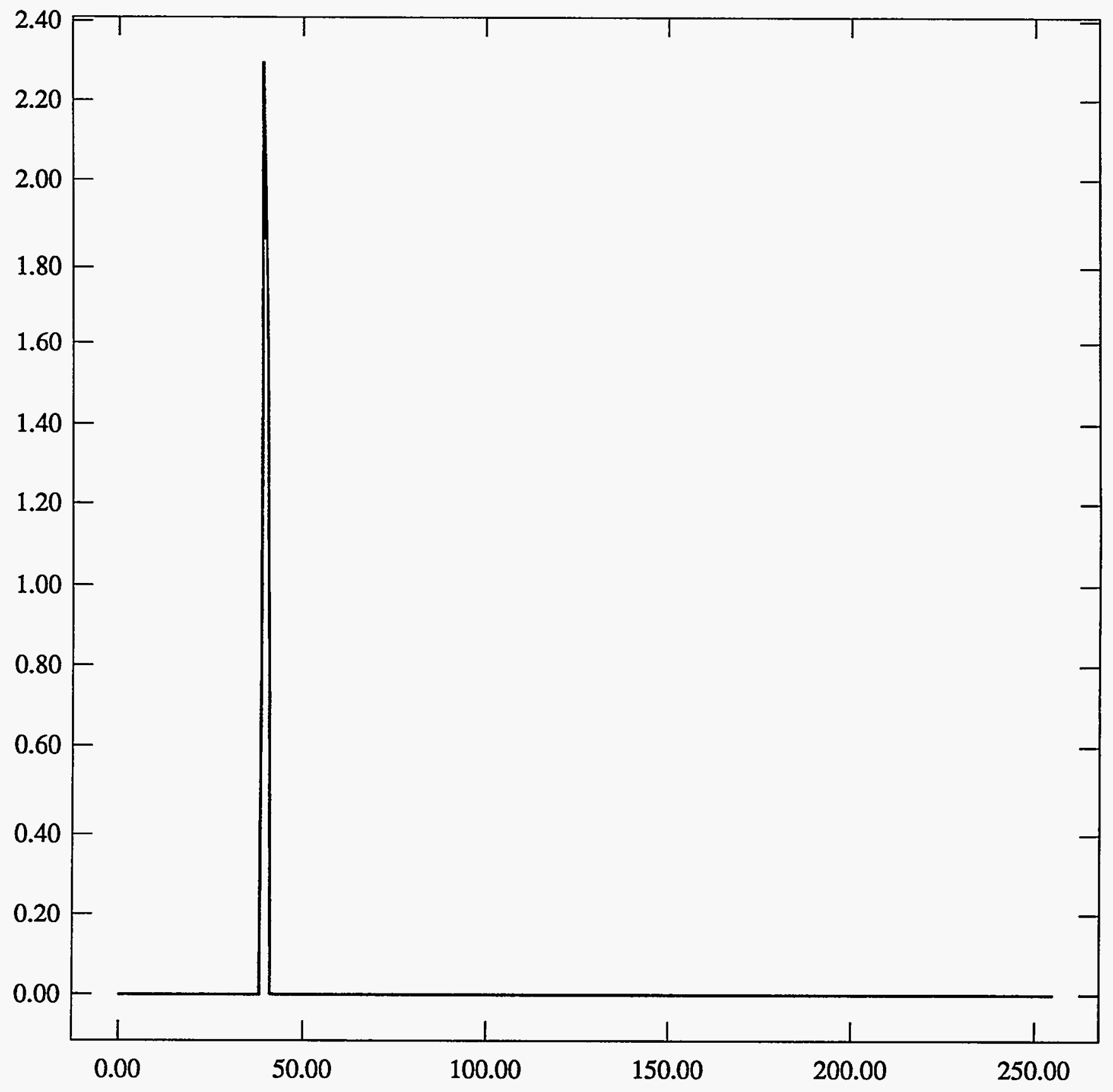


ST Camera: ST1\#04-10 20C \#2: int_time=200ms, offset= 0, gain=1 (350 e/bit) Wed Jun 30 10:34:23 1993 Pixel Values Min 39 Max 41 Mean 39.4 Sigma $0.49 \times 10^{3}$

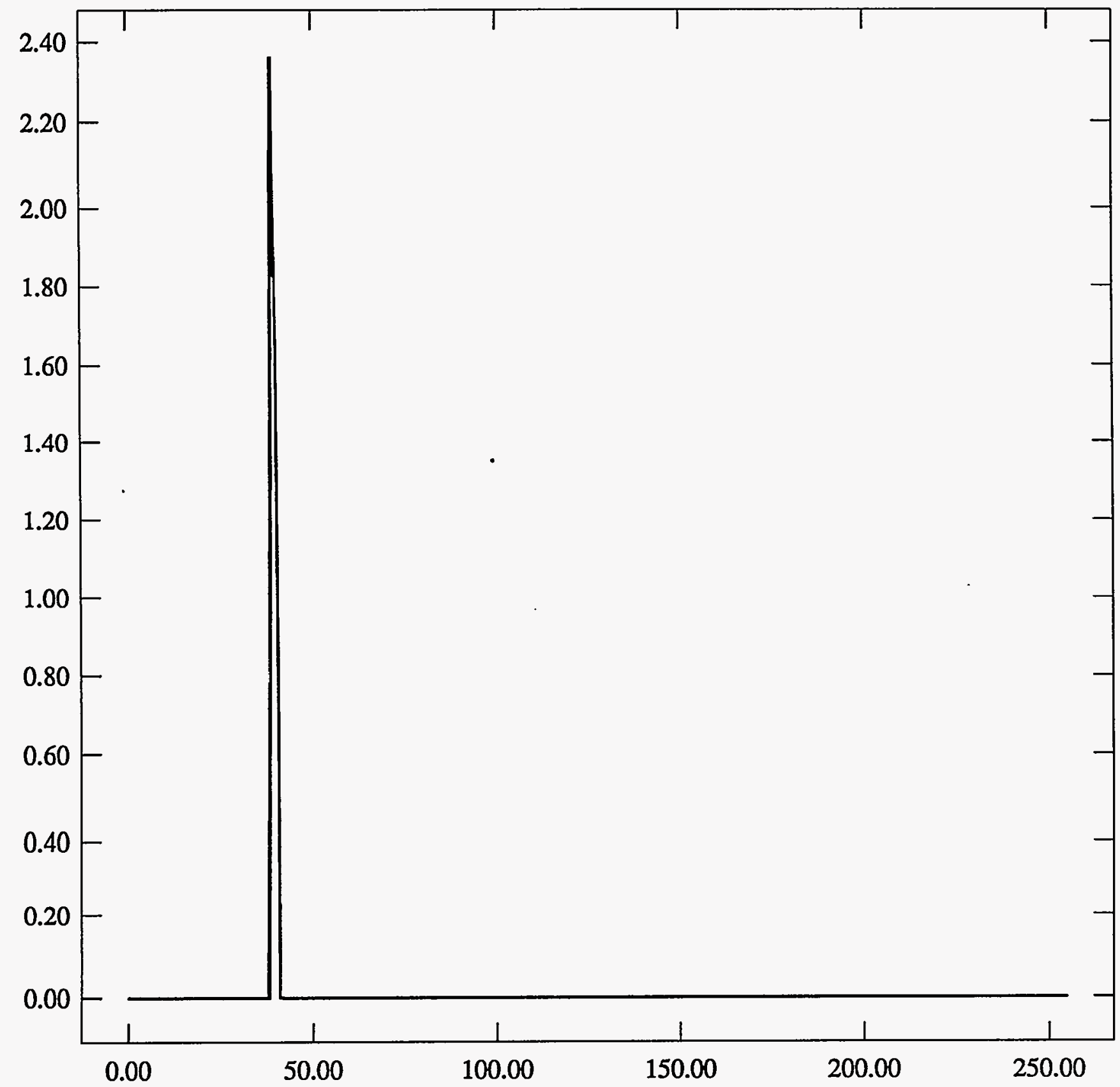


ST Camera: ST1\#04-10 20C \#2: int_time= 50ms, offset= 0, gain=2 (150 e/bit) Wed Jun 30 10:34:49 1993 Pixel Values Min 77 Max 81 Mean 79.2 Sigma 0.77 x $10^{3}$

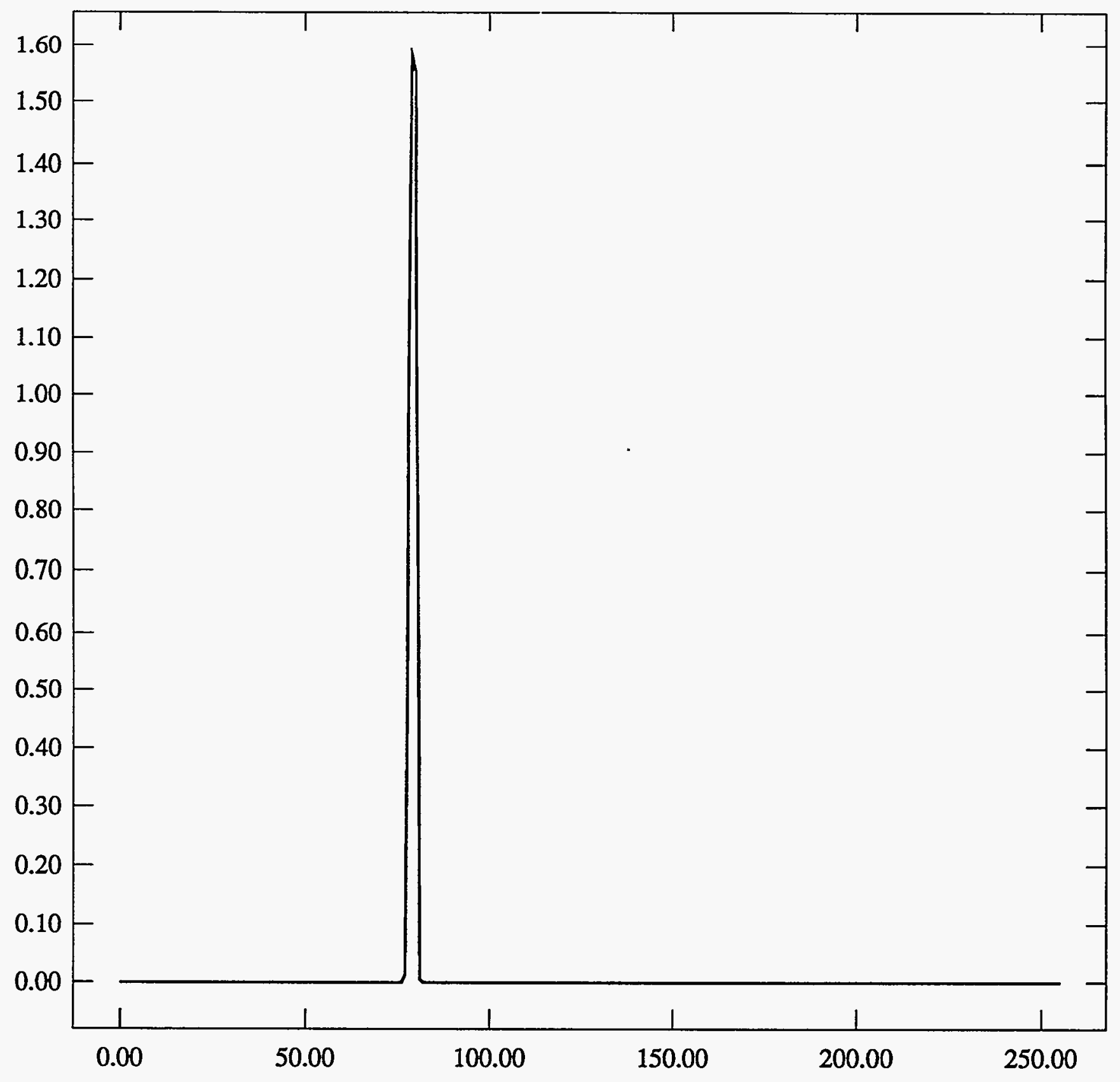


ST Camera: ST1\#04-10 20C \#2: int_time=100ms, offset= 0, gain=2 (150 e/bit) Wed Jun 30 10:35:13 1993 Pixel Values Min 77 Max 81 Mean 79.2 Sigma $0.77 \times 10^{3}$

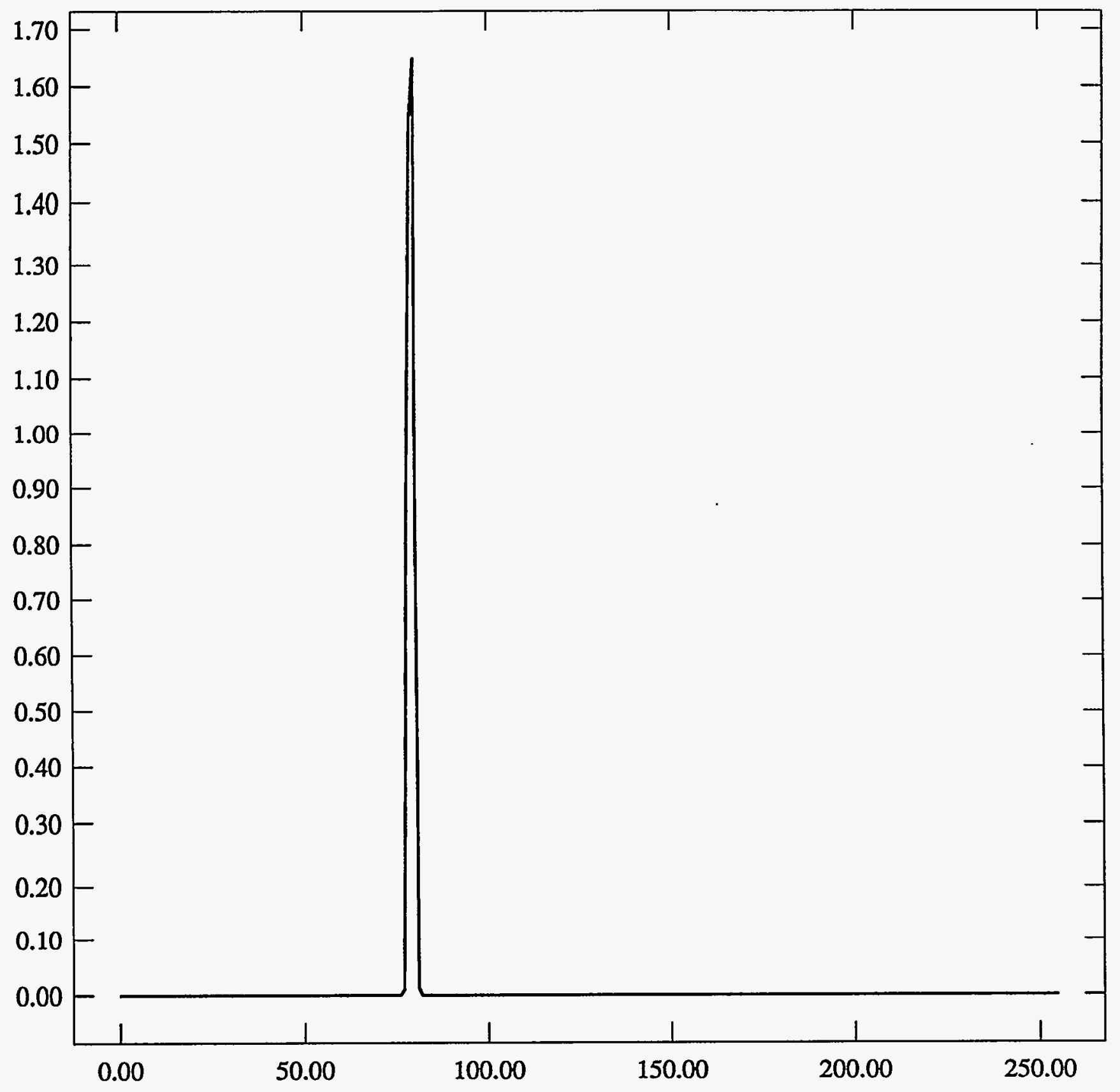


ST Camera: ST1 $\$$ 04-10 20C \#2: int_time=200ms, offset= 0, gain=2 (150 e/bit) Wed Jun 30 10:35:30 1993 Pixel Values Min 77 Max 81 Mean 79.2 Sigma $0.78 \times 10^{3}$

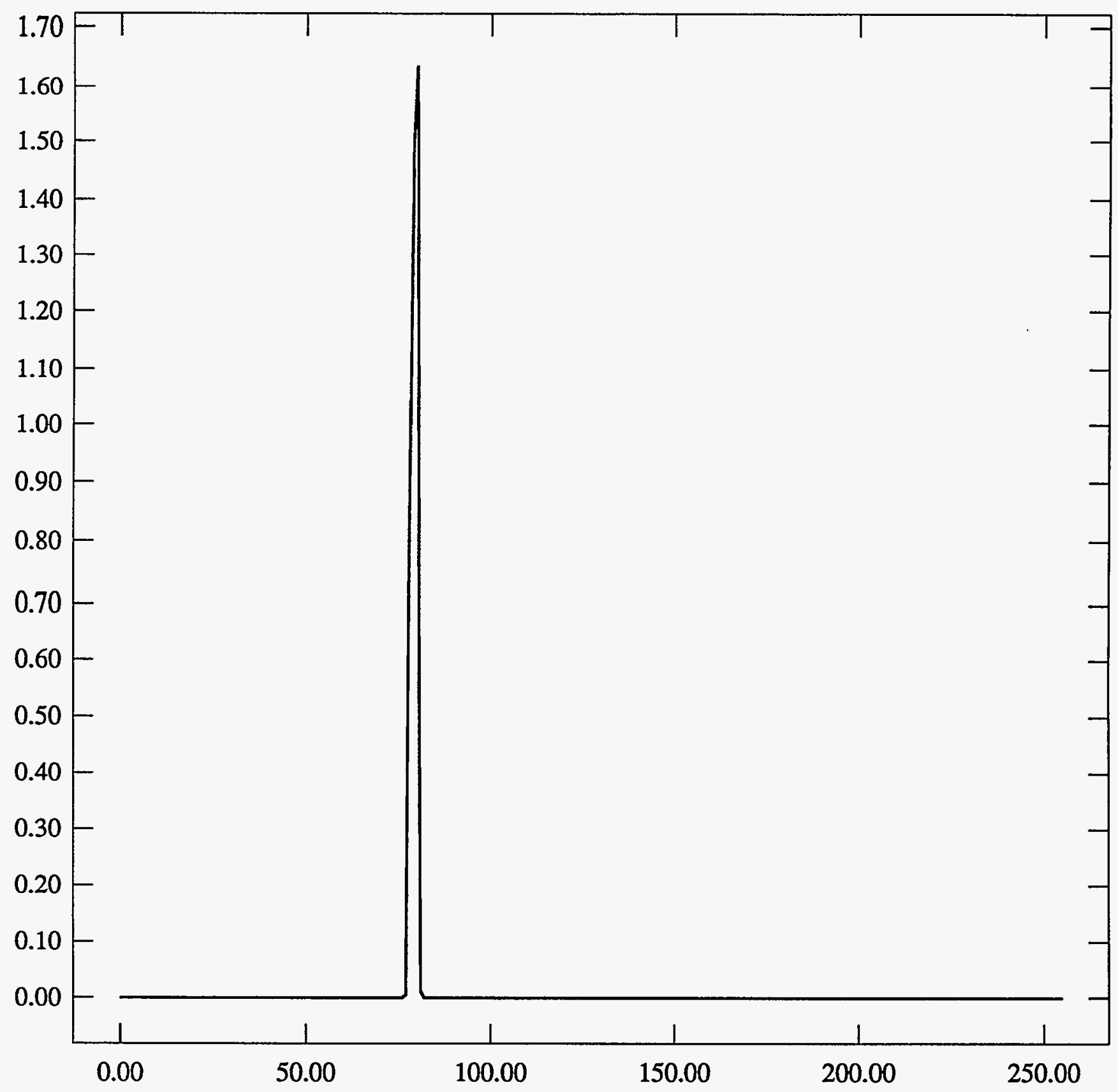


ST Camera: ST1\#04-10 20C \#2: int_time= 50ms, offset= 0, gain=4 ( 75 e/bit) Wed Jun 30 10:35:52 1993 Pixel Values Min 143 Max 147 Mean 145.0 Sigma $0.76 \times 10^{3}$

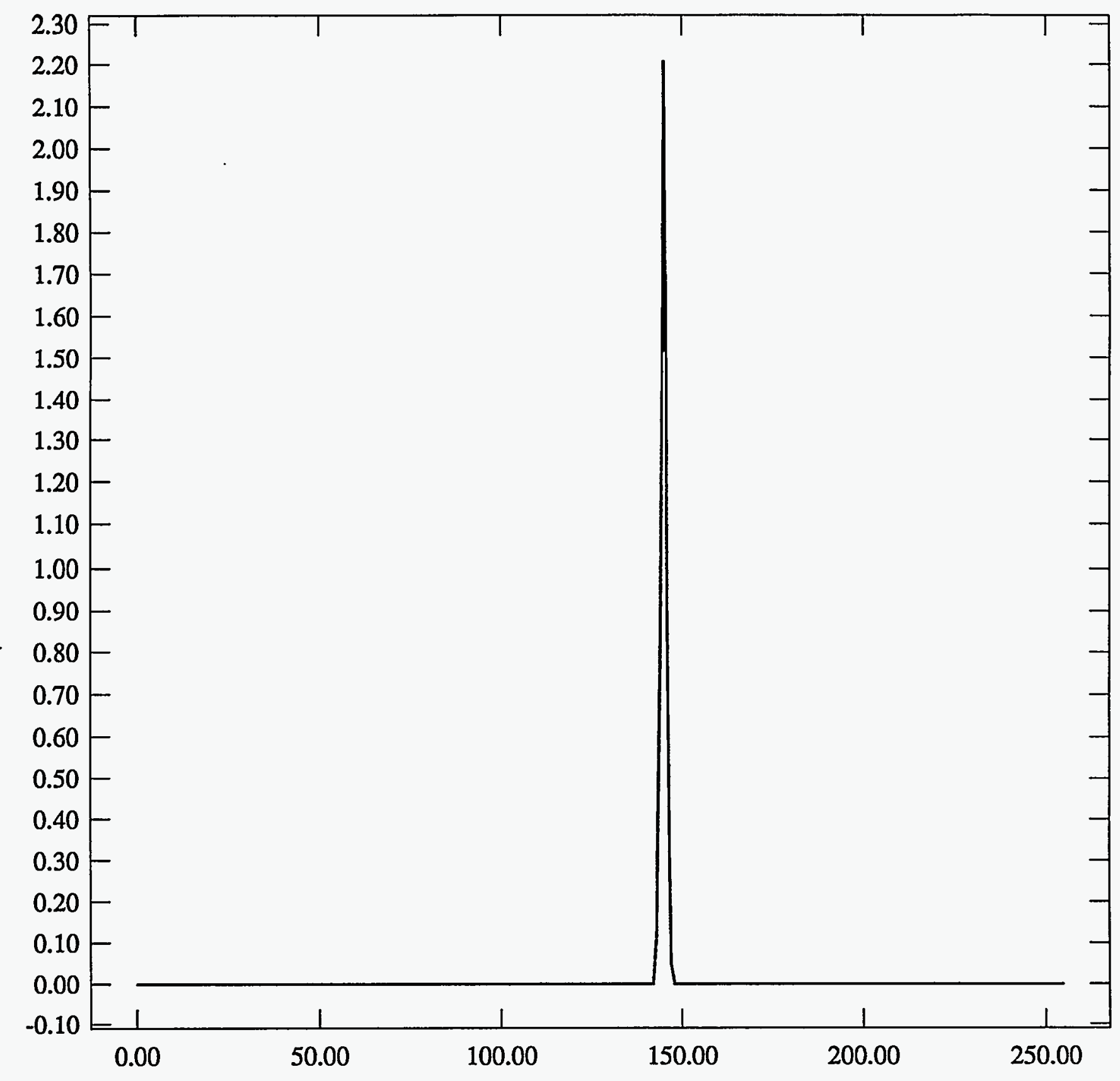


ST Camera: ST1\#04-10 20C \#2: int_time=100ms, offset= 0, gain=4 ( $75 \mathrm{e} / \mathrm{bit}$ ) Wed Jun 30 10:36:11 1993 Pixel Values Min 142 Max 148 Mean 145.0 Sigma $0.76 \times 10^{3}$

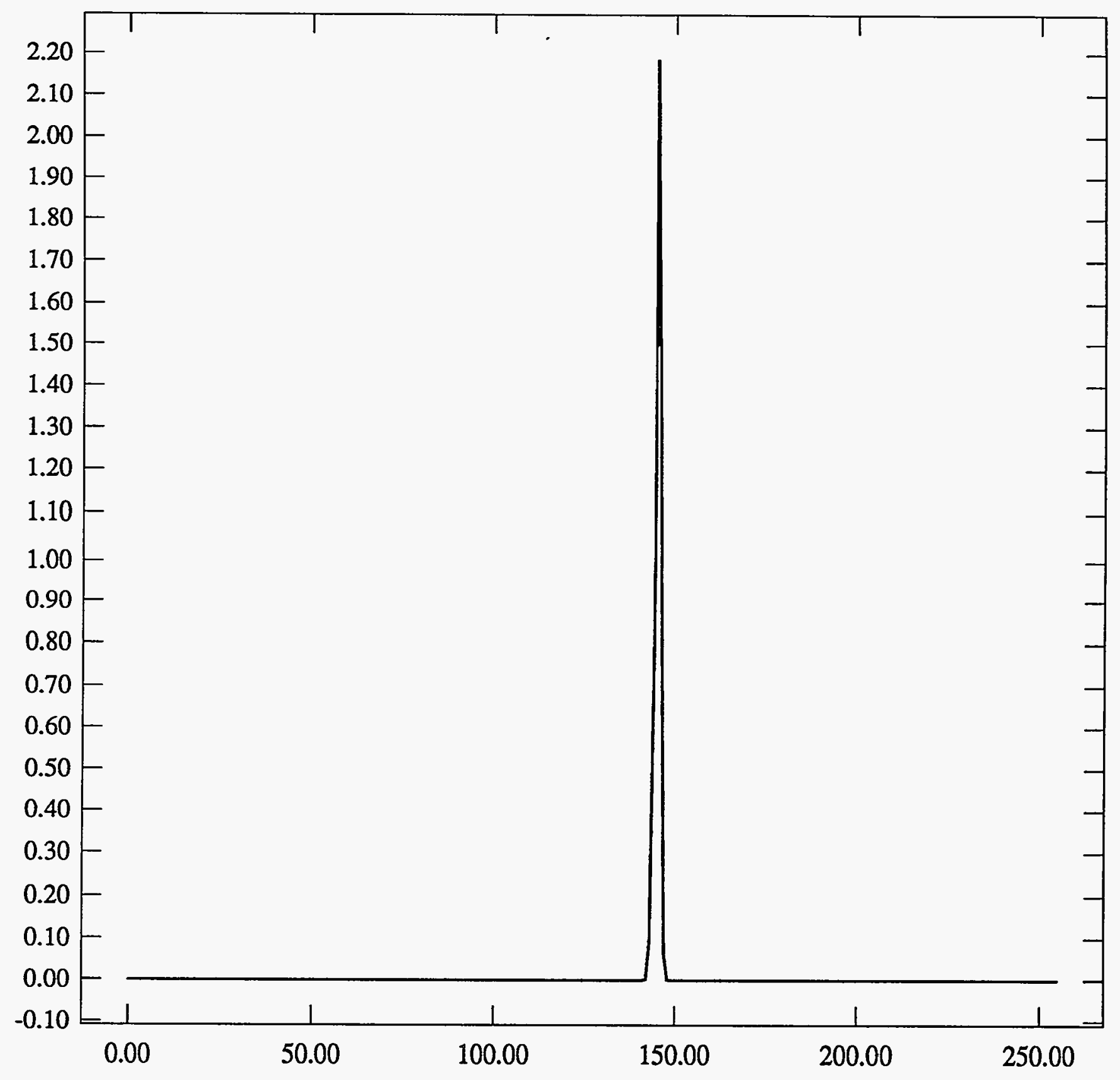


ST Camera: ST1\#04-10 20C \#2: int_time=200ms, offset= 0, gain=4 ( 75 e/bit) Wed Jun 30 10:36:28 1993 Pixel Values Min 142 Max 148 Mean 145.0 Sigma 0.77 x $10^{3}$

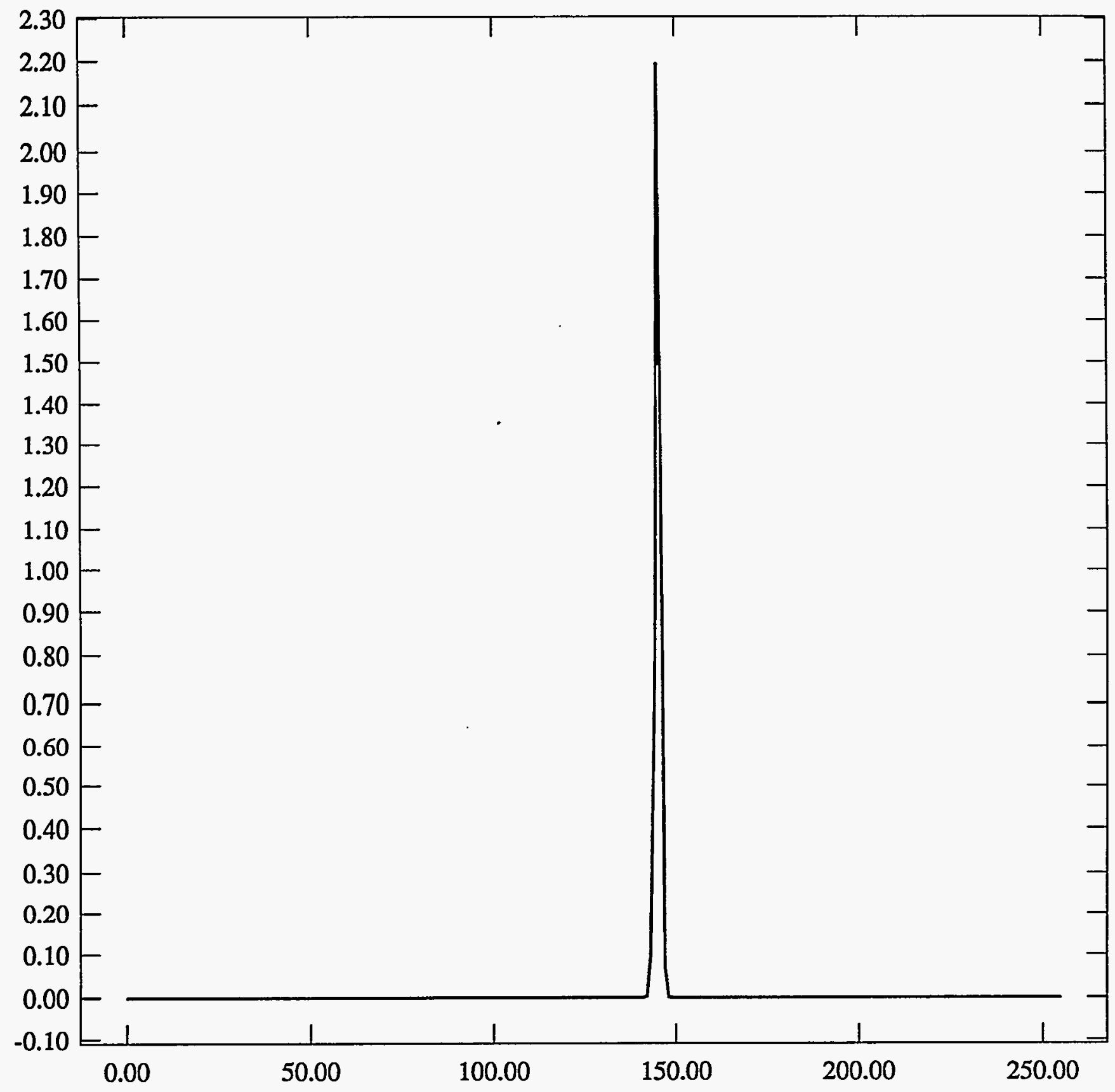


$\$ 3-30<15$ min

ST Camera: ST1\#04-10 -30C \#3: int_time= 50ms, offset= 0, gain=1 (350 e/bit) Wed Jun 30 11:09:37 1993 Pixel Values Min 39 Max 41 Mean 39.9 Sigma $0.28 \times 10^{3}$

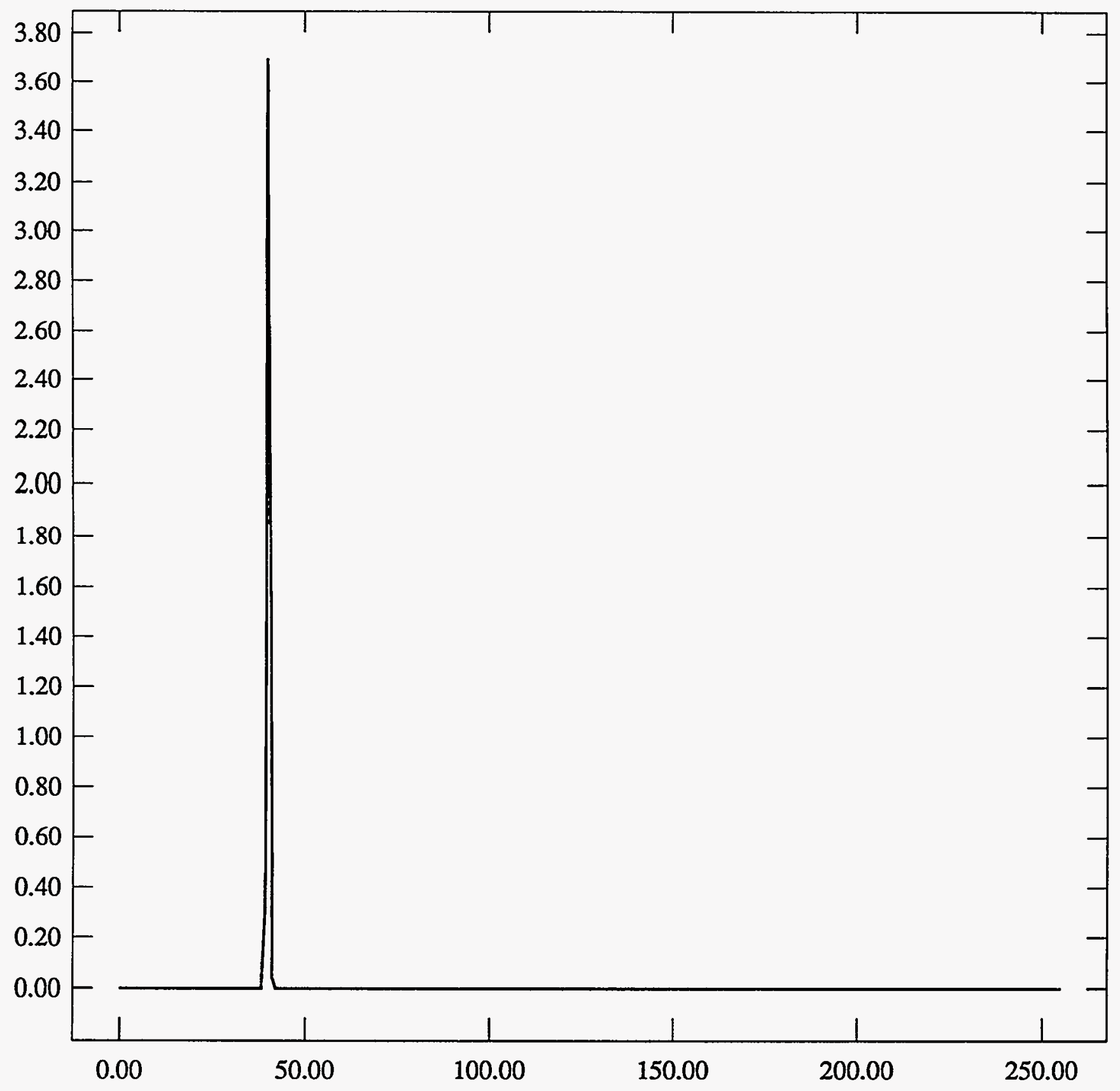


ST Camera: ST1\#04-10 -30C \#3: int_time=100ms, offset= 0, gain=1 ( $350 \mathrm{e} / \mathrm{bit}$ ) Wed Jun 30 11:09:54 1993 Pixel Values Min 39 Max 41 Mean 39.9 Sigma $0.28 \times 10^{3}$

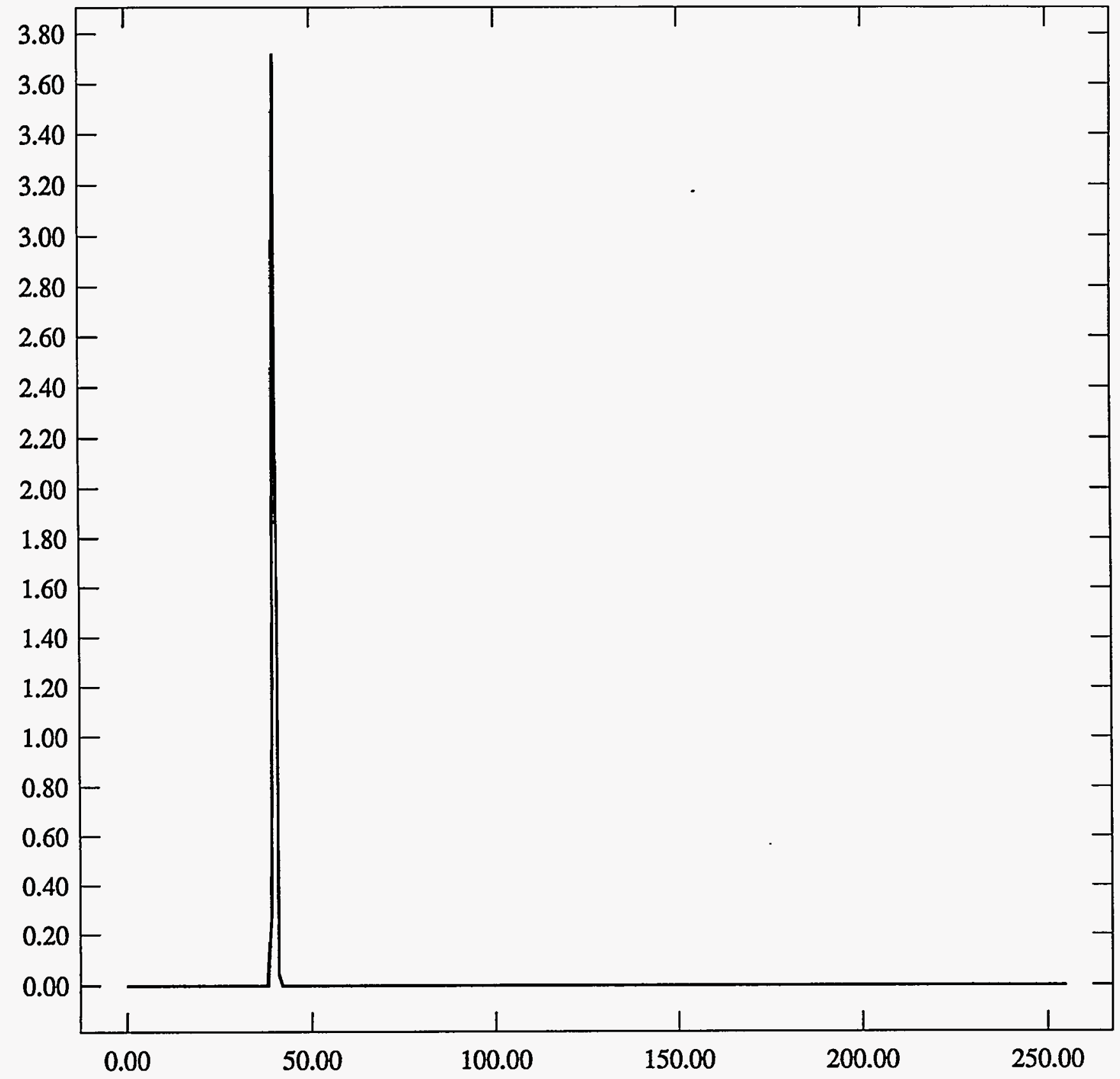


ST Camera: ST1\#04-10 -30C \#3: int_time=200ms, offset= 0, gain=1 ( $350 \mathrm{e} / \mathrm{bit}$ ) Wed Jun 30 11:10:10 1993 Pixel Values Min 39 Max 41 Mean 39.9 Sigma $0.29 \times 10^{3}$

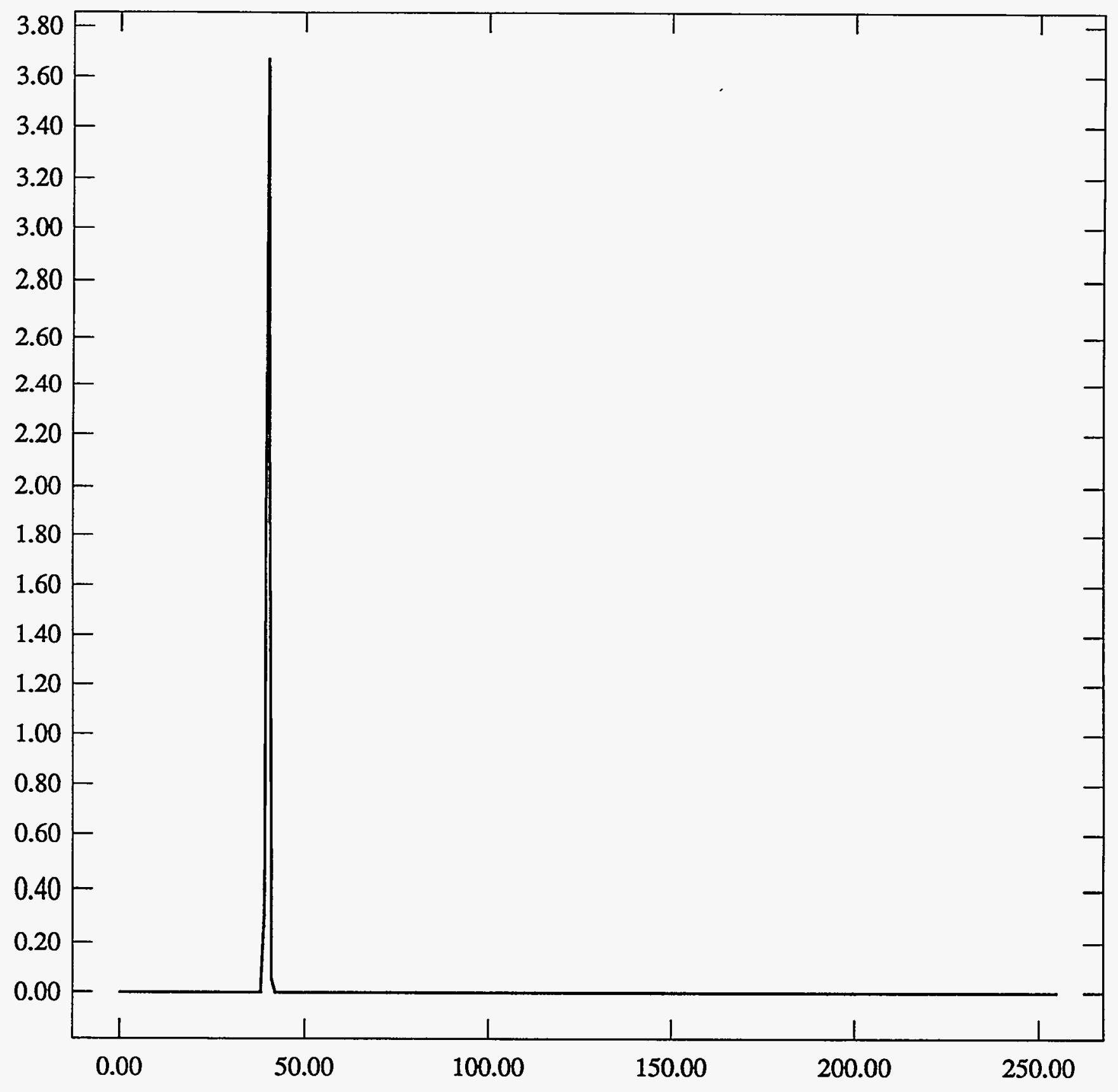


ST Camera: ST1\#04-10 -30C \#3: int_time= 50ms, offset= 0, gain=2 (150 e/bit) Wed Jun 30 11:10:30 1993 Pixel Values Min 78 Max 81 Mean 79.3 Sigma $0.58 \times 10^{3}$

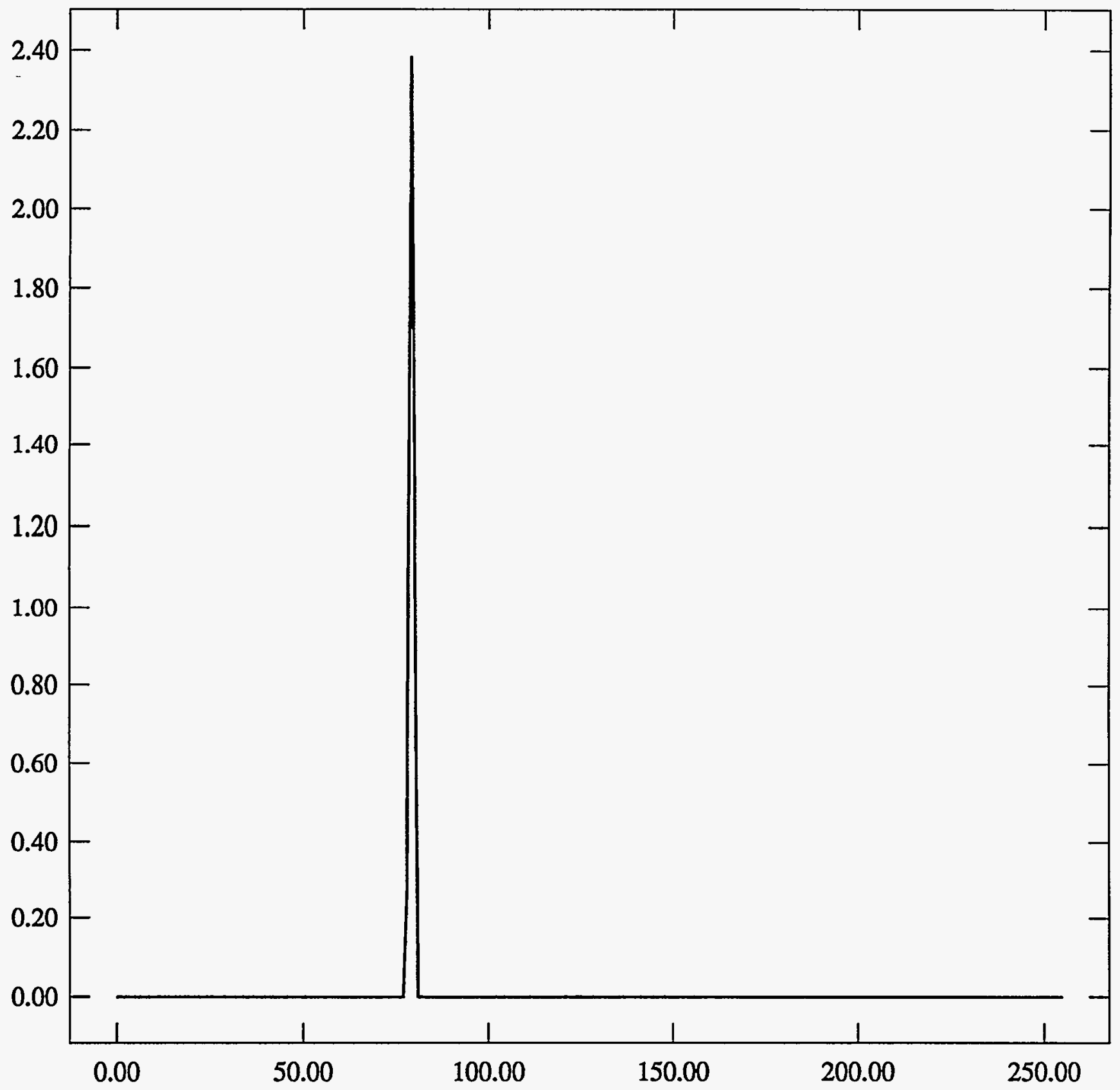


ST Camera: ST1\#04-10 -30C \#3: int_time=100ms, offset= 0, gain=2 (150 e/bit) Wed Jun 30 11:10:54 1993 Pixel Values Min 78 Max 81 Mean 79.3 Sigma $0.57 \times 10^{3}$

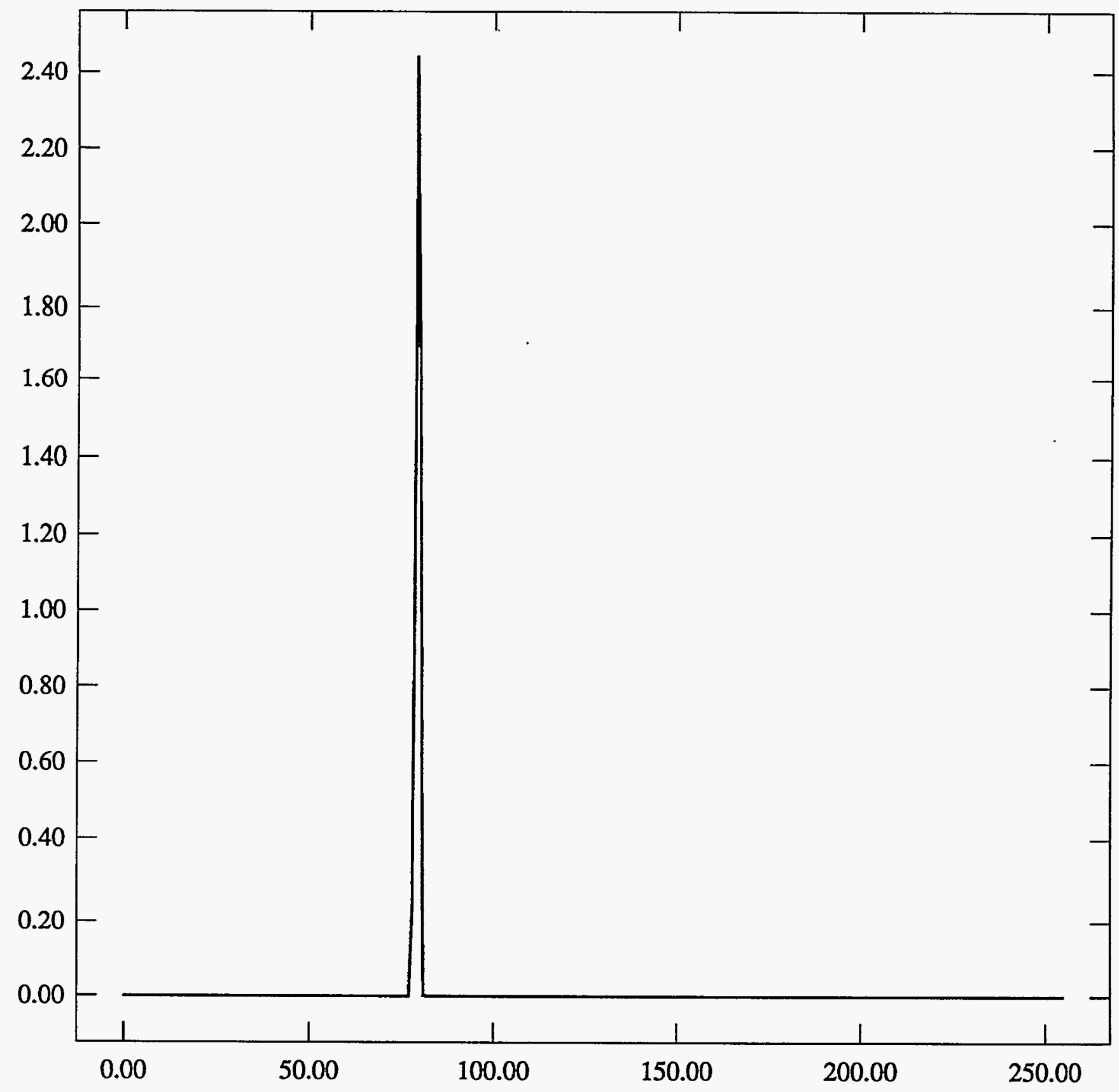


ST Camera: ST1\#04-10 -30C \#3: int_time=200ms, offset= 0, gain=2 ( 150 e/bit) Wed Jun 30 11:11:10 1993 Pixel Values Min 78 Max 81 Mean 79.3 Sigma $0.61 \times 10^{3}$

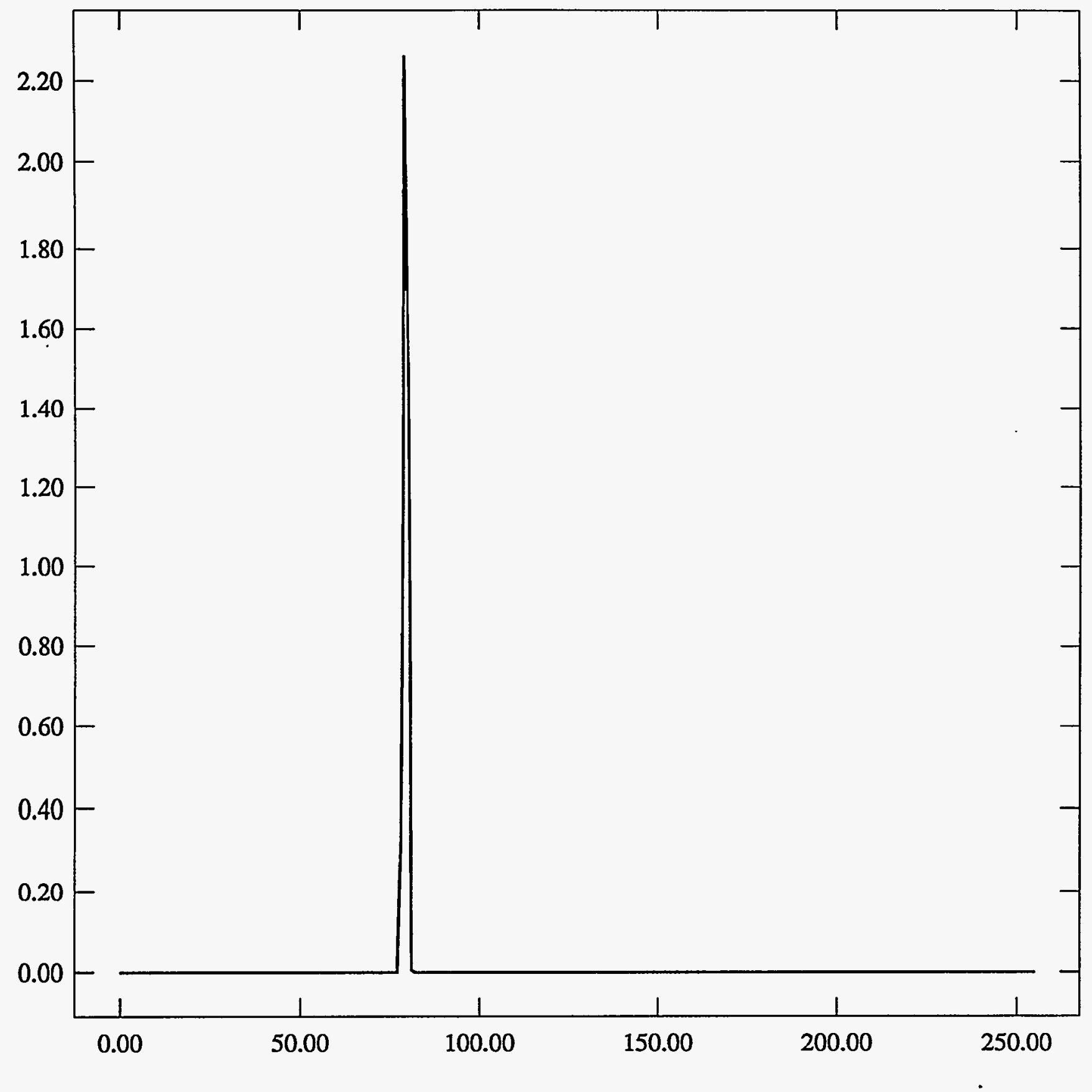


ST Camera: ST1\#04-10 -30C \#3: int_time= 50ms, offset= 0, gain=4 ( 75 e/bit) Wed Jun 30 11:11:26 1993 Pixel Values Min 145 Max 149 Mean 147.0 Sigma $0.68 \times 10^{3}$

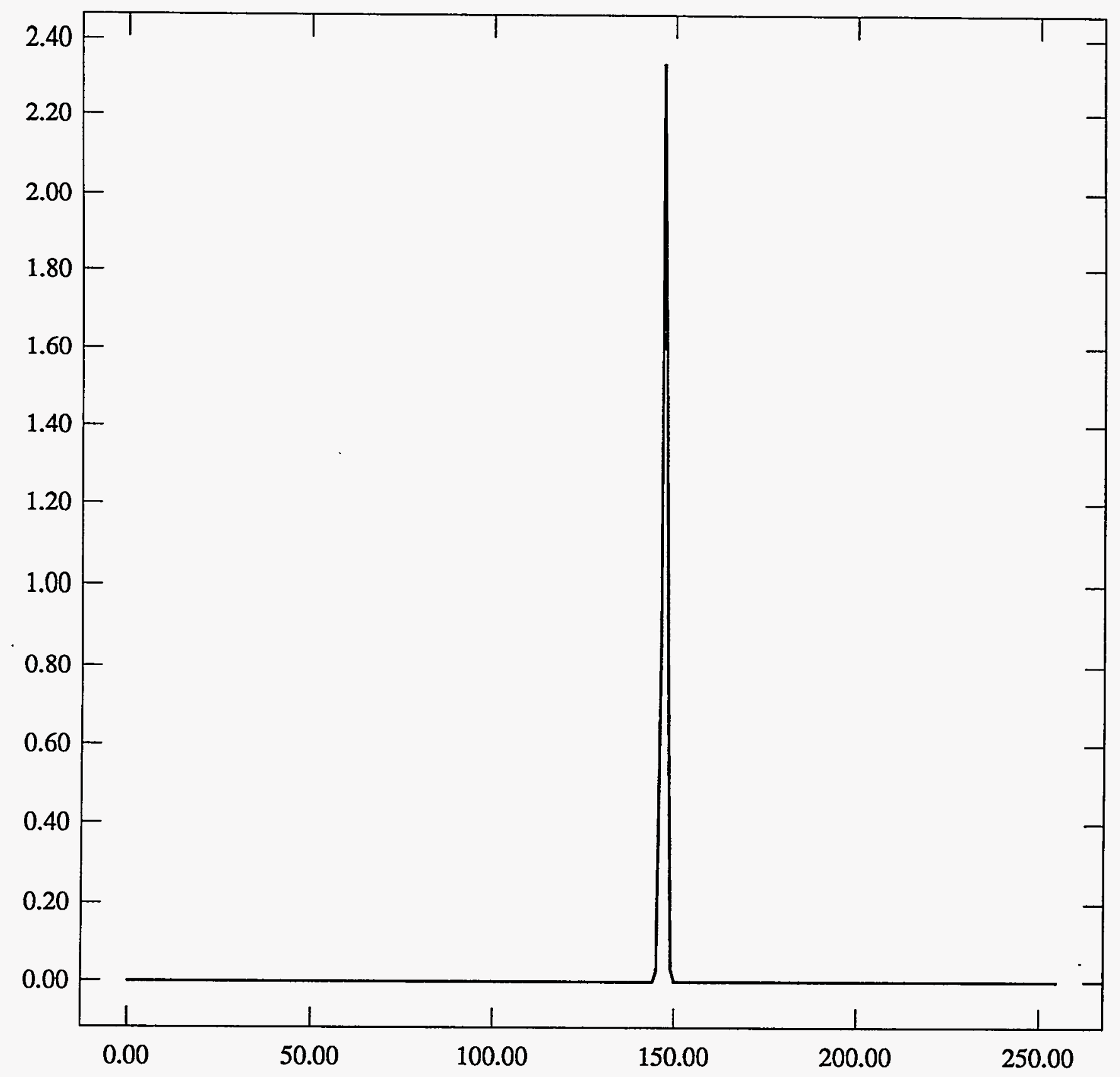


ST Camera: ST1\#04-10 -30C \#3: int_time=100ms, offset= 0, gain=4 ( 75 e/bit) Wed Jun 30 11:11:43 1993 Pixel Values Min 145 Max 149 Mean 147.0 Sigma $0.70 \times 10^{3}$

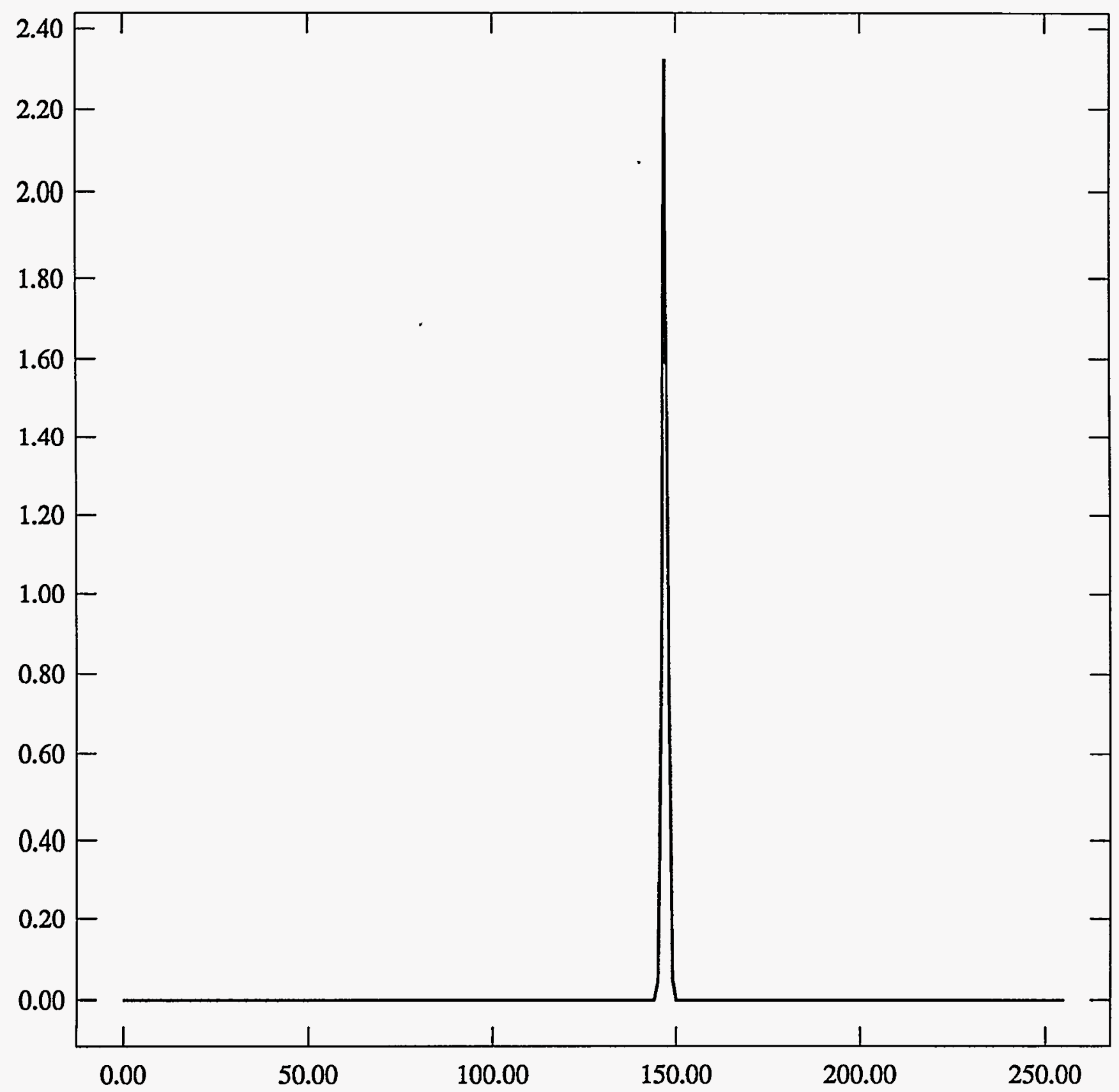


ST Camera: ST1\#04-10 -30C \#3: int_time=200ms, offset= 0, gain=4 ( 75 e/bit) Wed Jun 30 11:12:01 1993 Pixel Values Min 145 Max 150 Mean 147.0 Sigma $0.70 \times 10^{3}$

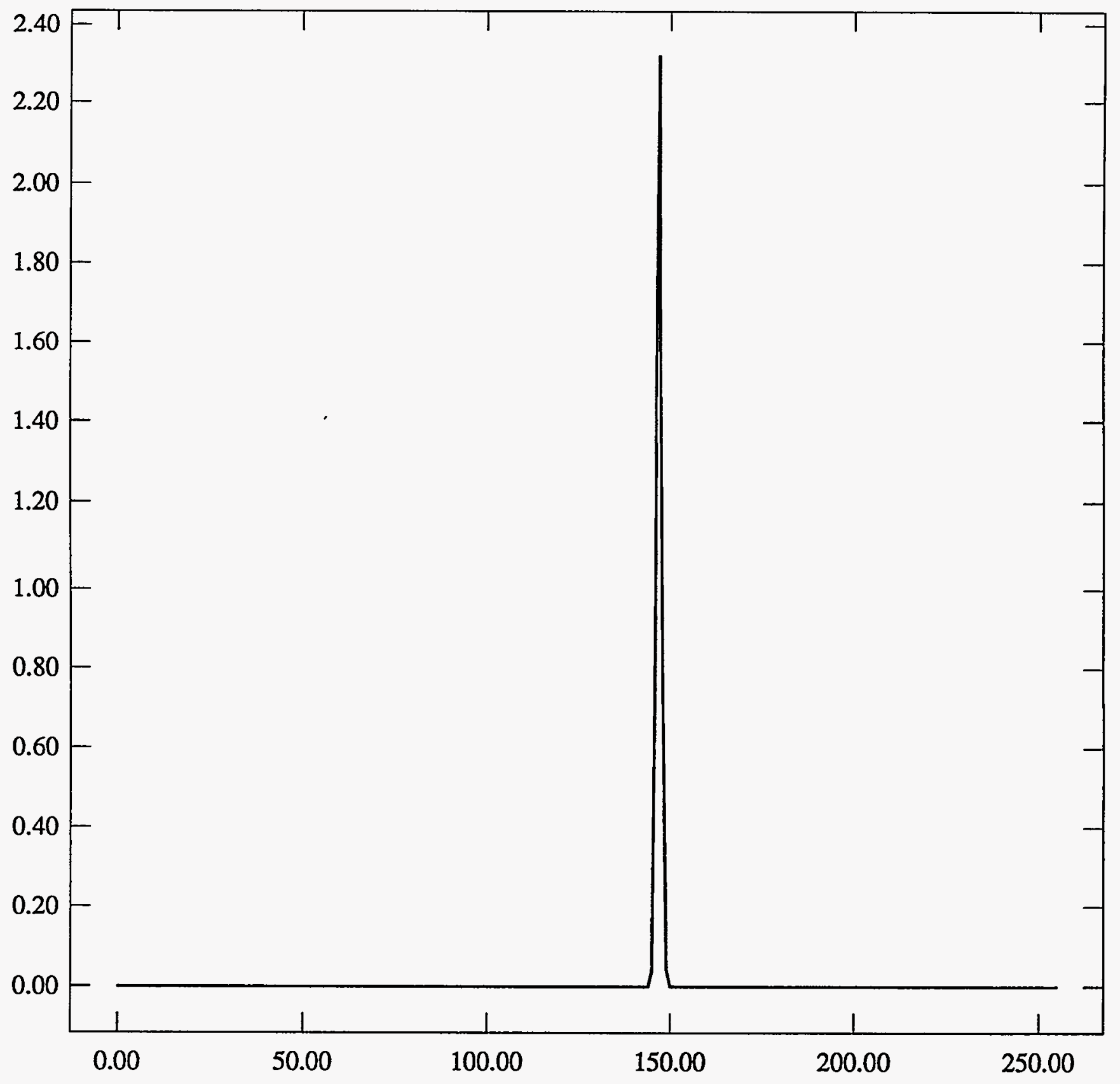


$\$ 3-30$ END

ST Camera: ST1\#04-10 -30C \#3: int_time= 50ms, offset= 0, gain=1 (350 e/bit) Wed Jun 30 11:51:38 1993 Pixel Values Min 39 Max 41 Mean 39.9 Sigma $0.30 \times 10^{3}$

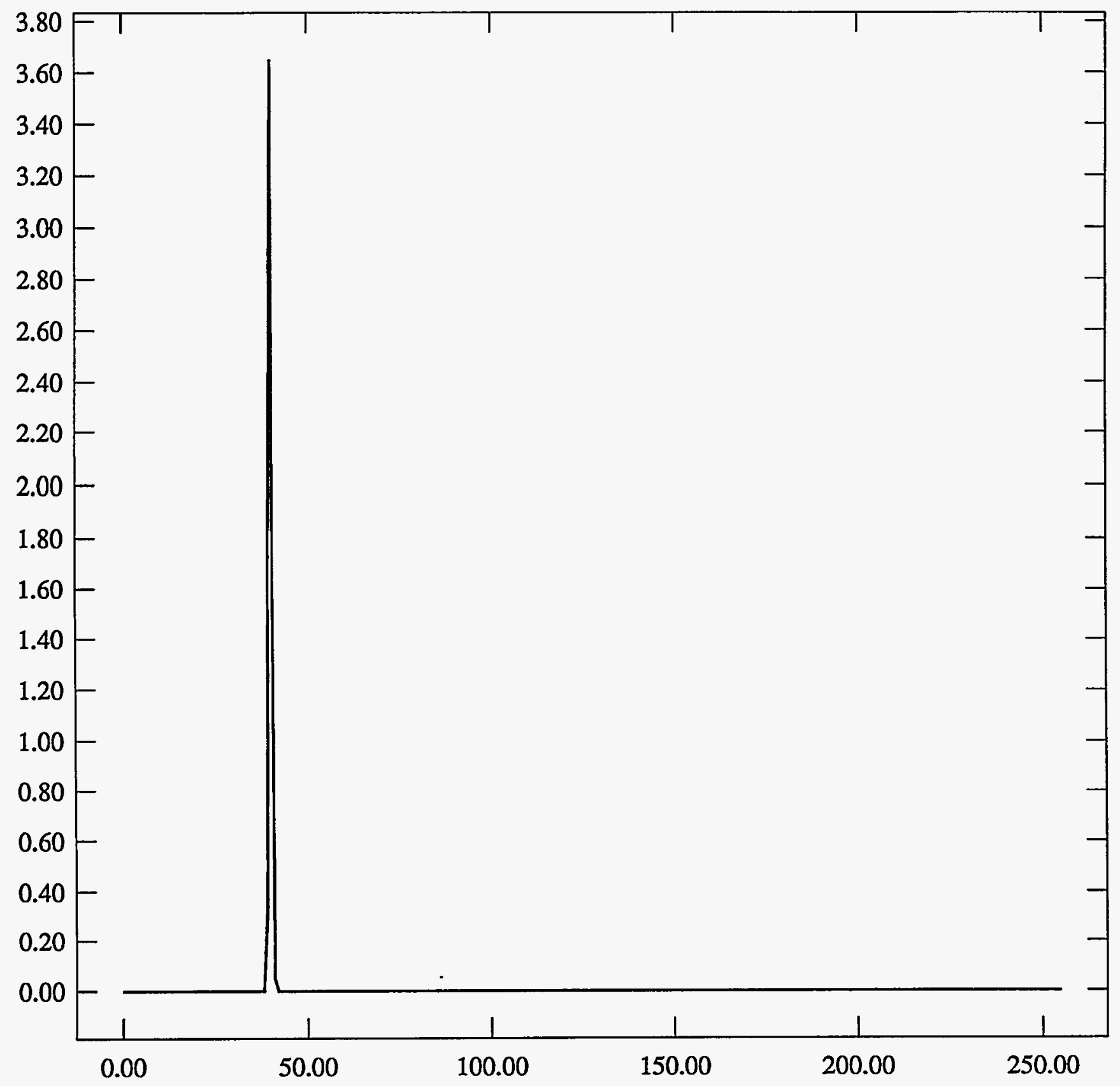


ST Camera: ST1\#04-10 -30C \#3: int_time=100ms, offset= 0, gain=1 ( $350 \mathrm{e} / \mathrm{bit}$ ) Wed Jun 30 11:52:07 1993 Pixel Values Min 39 Max 41 Mean 39.9 Sigma $0.35 \times 10^{3}$

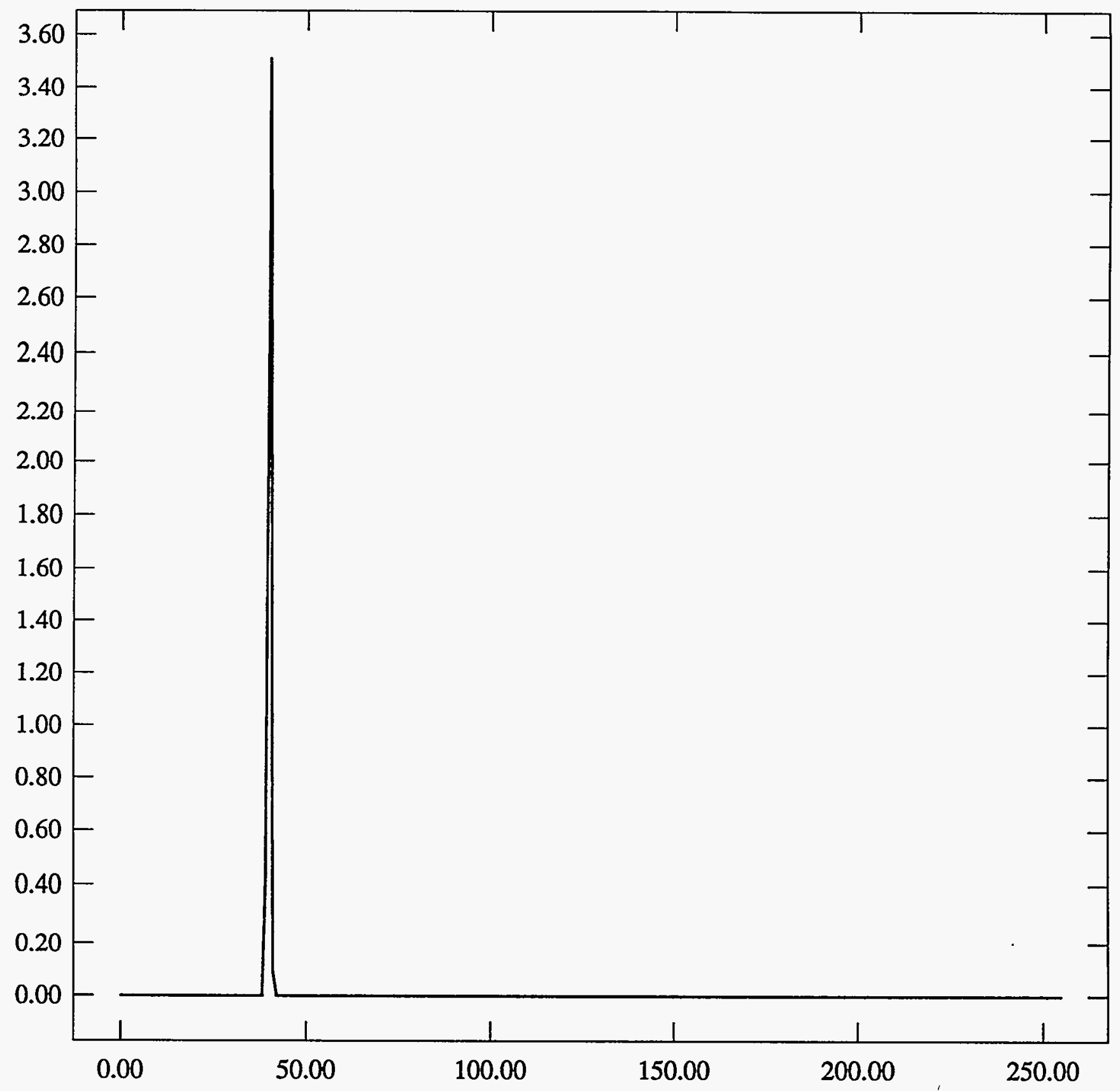


ST Camera: ST1\#04-10 -30C \#3: int_time=200ms, offset= 0, gain=1 ( 350 e/bit) Wed Jun 30 11:52:27 1993 Pixel Values Min 39 Max 41 Mean 39.9 Sigma 0.35 x 10 3

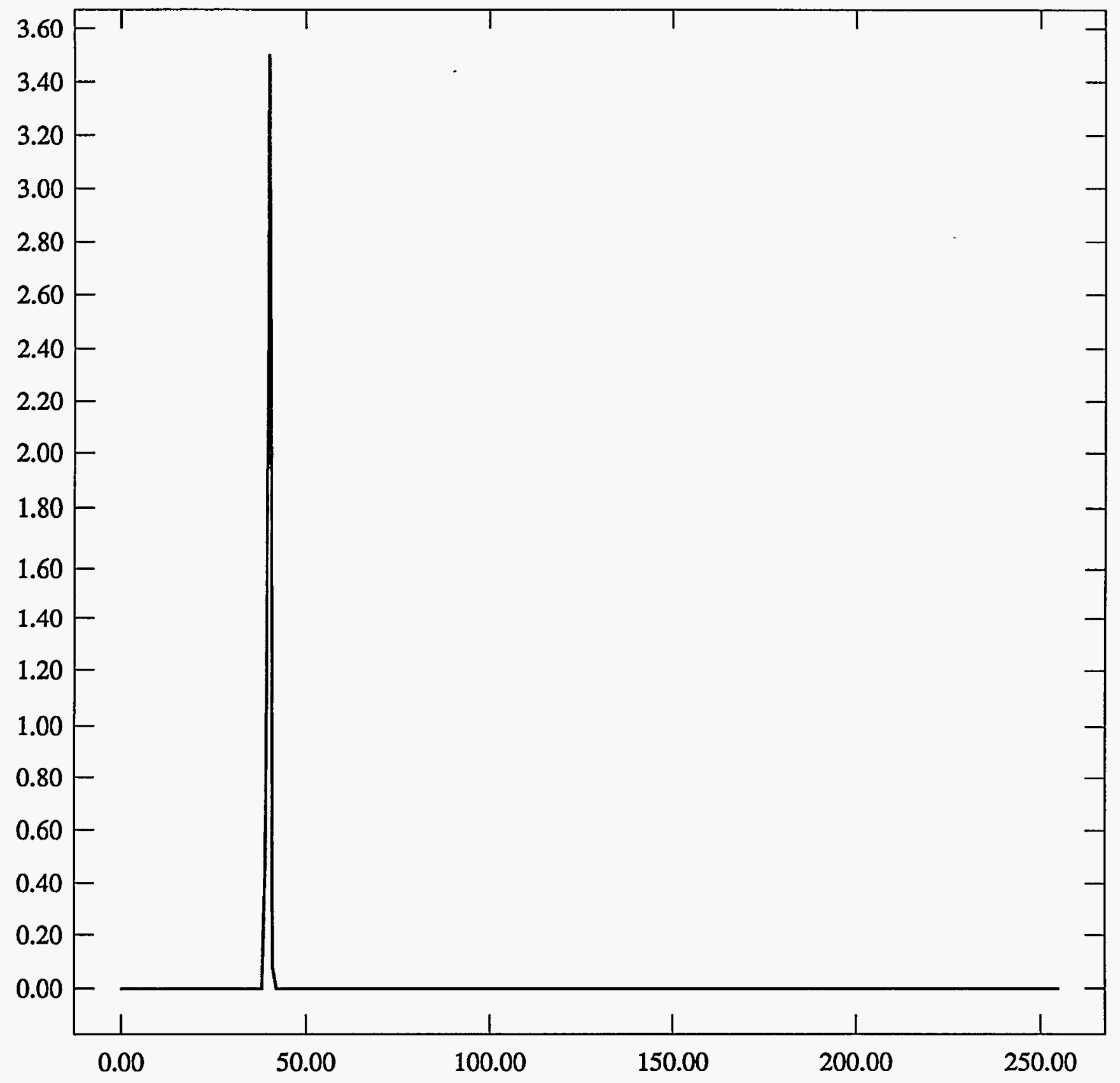


ST Camera: ST1\#04-10 -30C \#3: int_time= 50ms, offset= 0, gain=2 (150 e/bit) Wed Jun 30 11:52:42 1993 Pixel Values Min 78 Max 81 Mean 79.3 Sigma $0.58 \times 10^{3}$

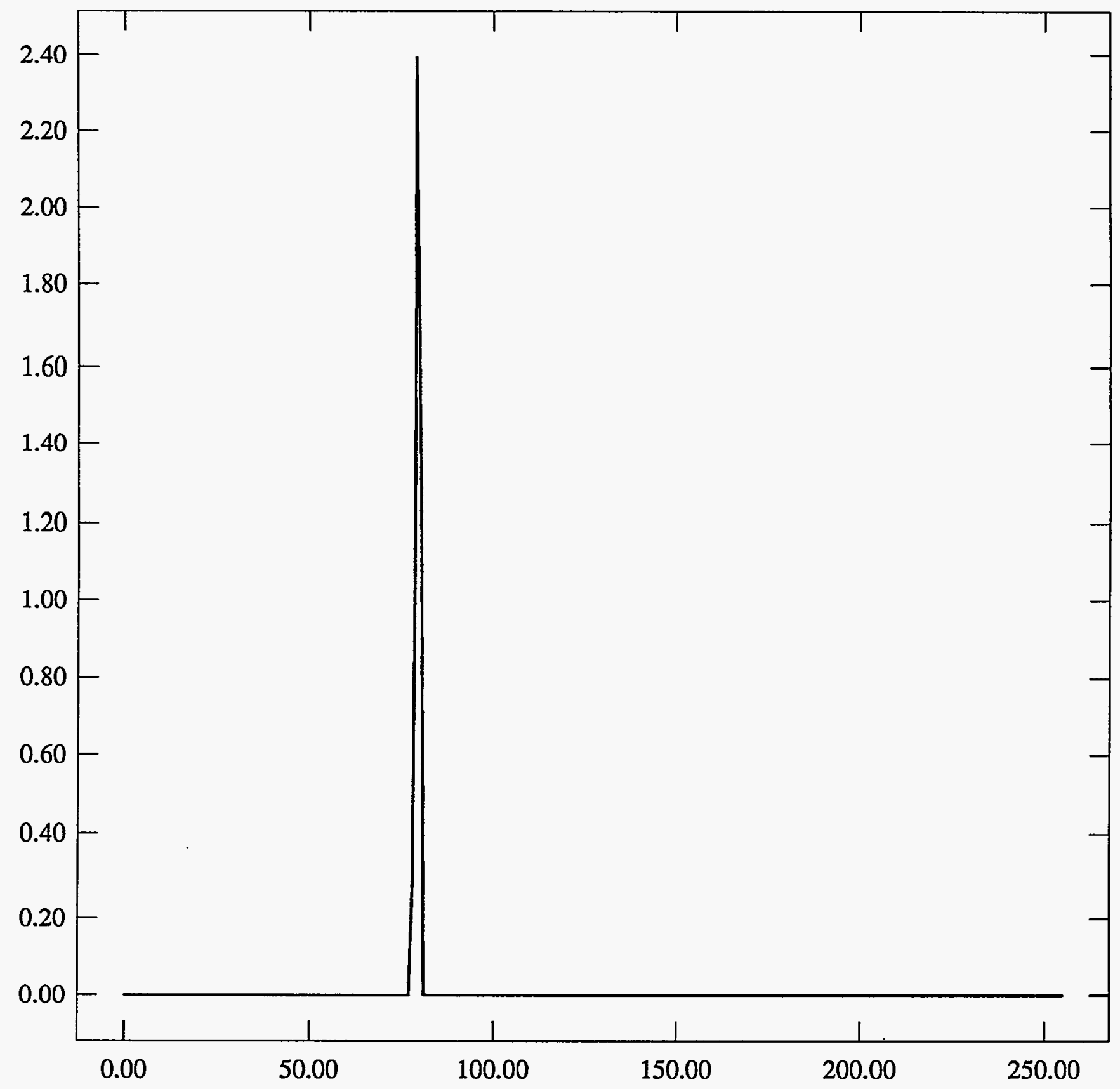


ST Camera: ST1\#04-10 -30C \#3: int_time=100ms, offset= 0, gain=2 ( 150 e/bit) Wed Jun 30 11:53:11 1993 Pixel Values Min 78 Max 80 Mean 79.3 Sigma $0.58 \times 10^{3}$

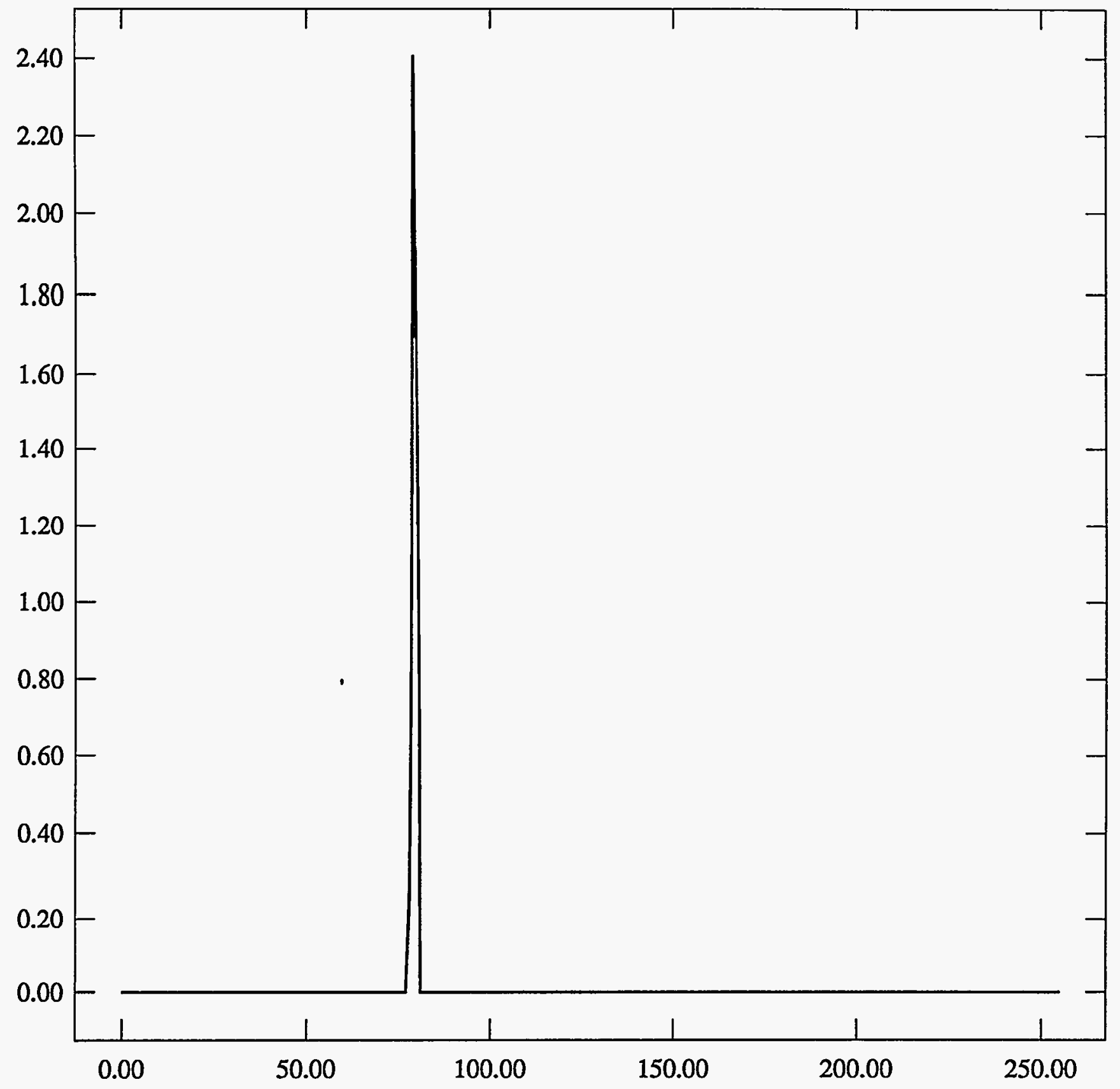


ST Camera: ST1\#04-10 -30C \#3: int_time=200ms, offset= 0, gain=2 (150 e/bit) Wed Jun 30 11:53:28 1993 Pixel Values Min 78 Max 81 Mean 79.3 Sigma $0.58 \times 10^{3}$

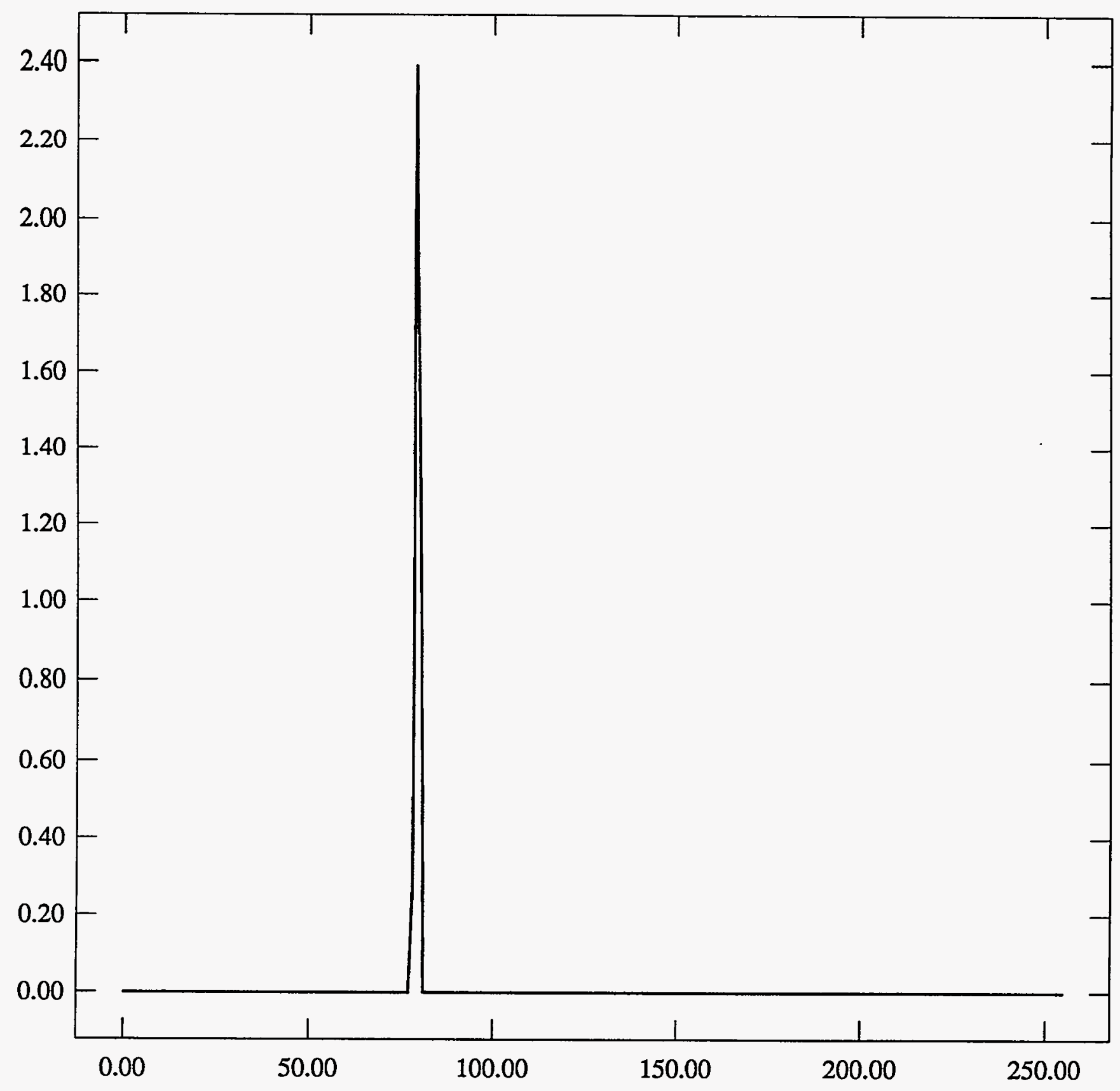


ST Camera: ST1\#04-10 -30C \#3: int_time= 50ms, offset= 0, gain=4 ( 75 e/bit) Wed Jun 30 11:53:49 1993 Pixel Values Min 145 Max 149 Mean 146.9 Sigma $0.68 \times 10^{3}$

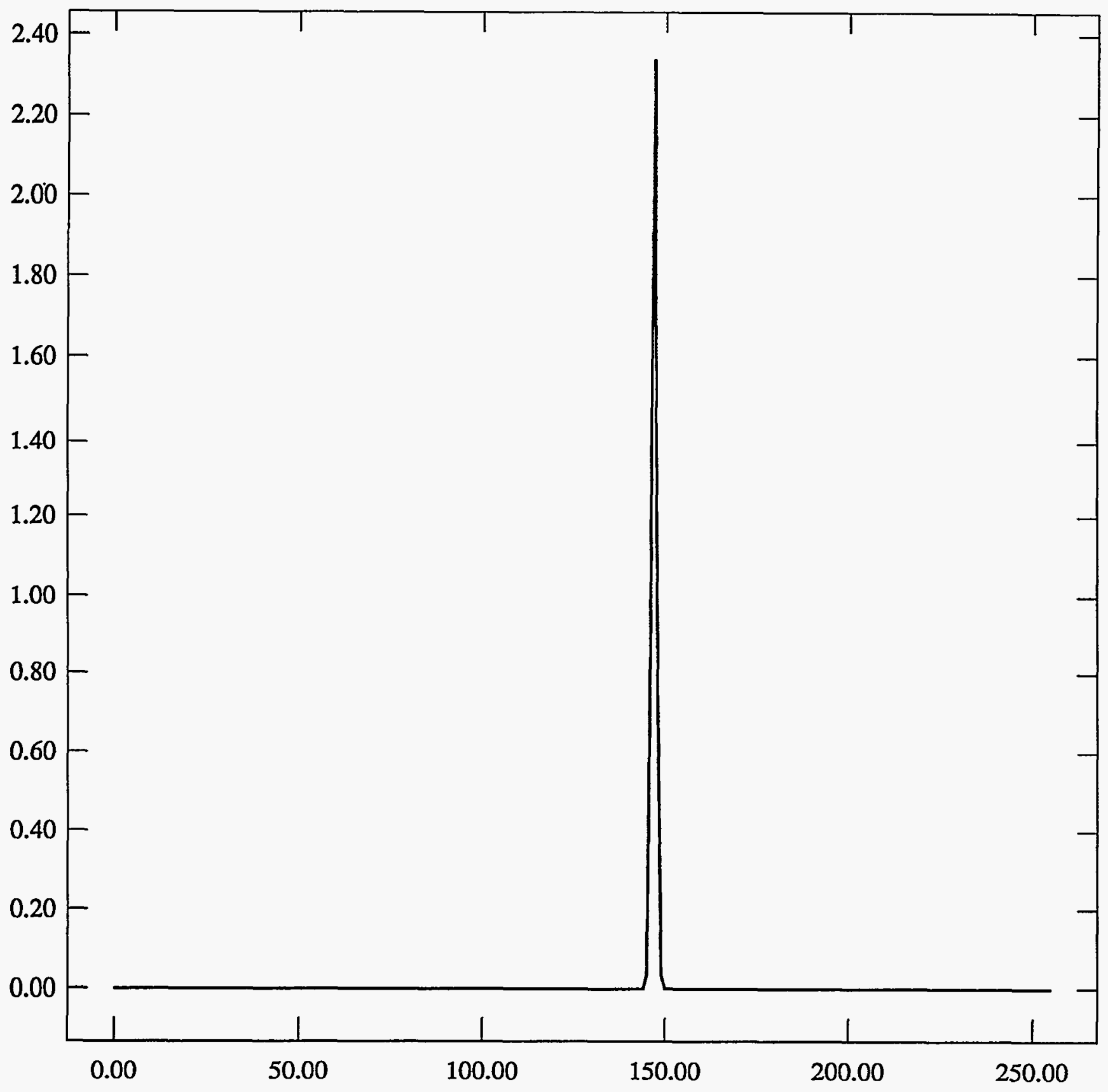


ST Camera: ST1\#04-10 -30C \#3: int_time=100ms, offset= 0, gain=4 ( 75 e/bit) Wed Jun 30 11:54:11 1993 Pixel Values Min 145 Max 149 Mean 146.9 Sigma $0.70 \times 10^{3}$

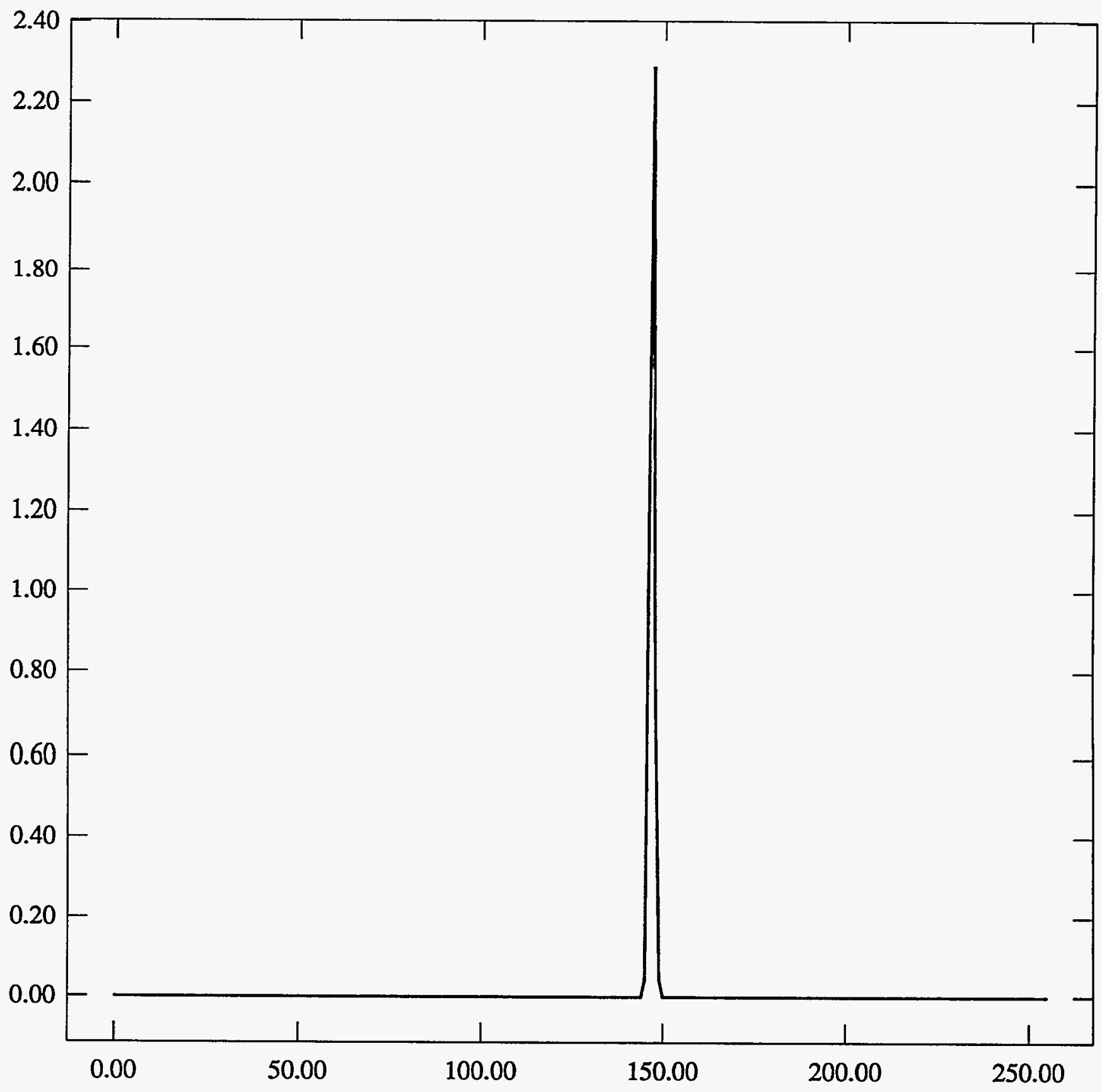


ST Camera: ST1\#04-10 -30C \#3: int_time=200ms, offset= 0, gain=4 ( 75 e/bit) Wed Jun 30 11:54:29 1993 Pixel Values Min 145 Max 150 Mean 146.9 Sigma $0.70 \times 10^{3}$

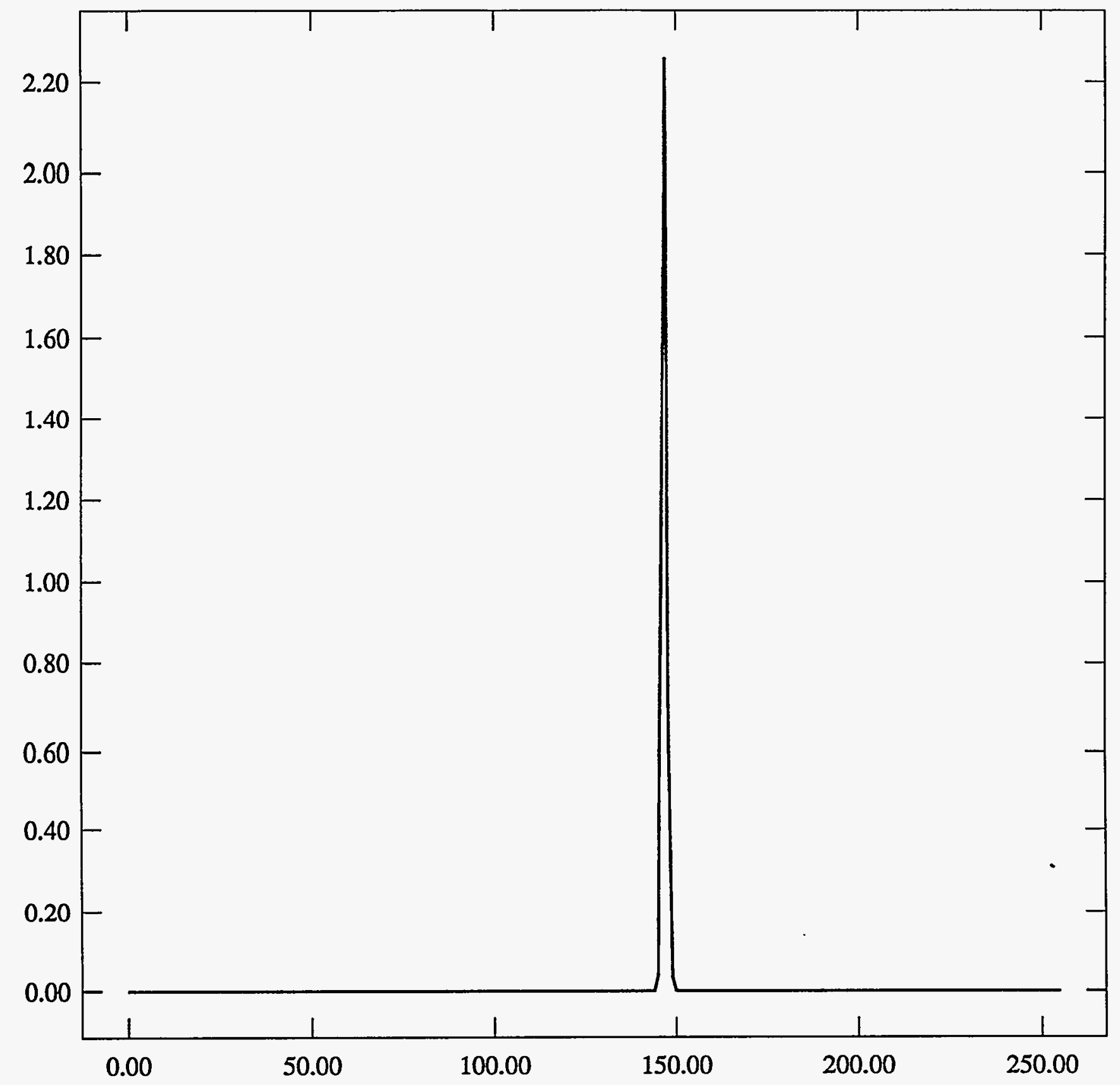


H3 20cis ismins

ST Camera: ST1\#04-10 20C \#3: int_time= 50ms, offset= 0, gain=1 ( 350 e/bit) Wed Jun 30 12:25:32 1993 Pixel Values Min 39 Max 41 Mean 39.6 Sigma $0.50 \times 10^{3}$

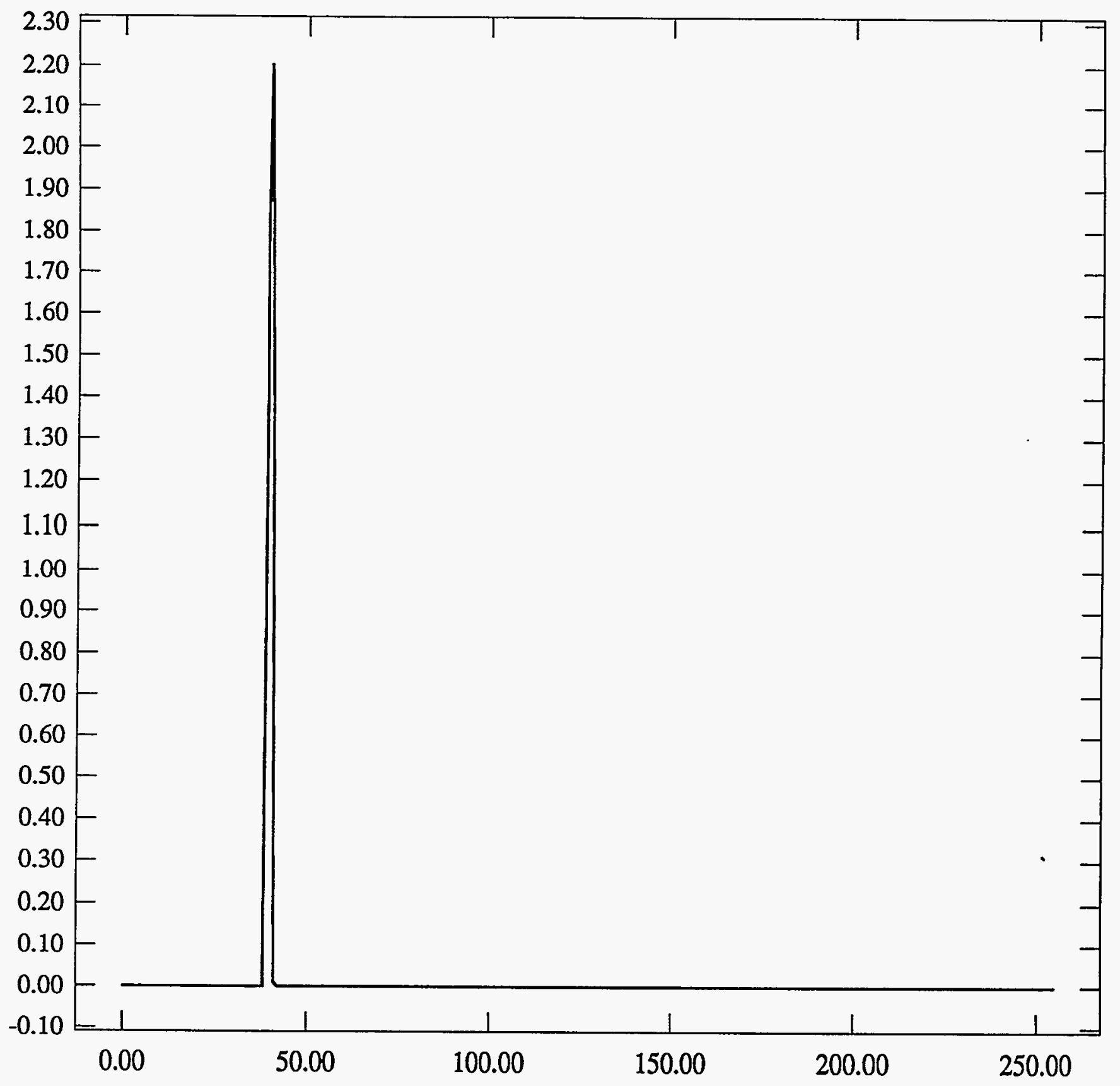


ST. Camera: ST1\#04-10 20C \#3: int_time=100ms, offset= 0, gain=1 ( 350 e/bit) Wed Jun 30 12:25:47 1993 Pixel Values Min 39 Max 41 Mean 39.5 Sigma $0.50 \times 10^{3}$

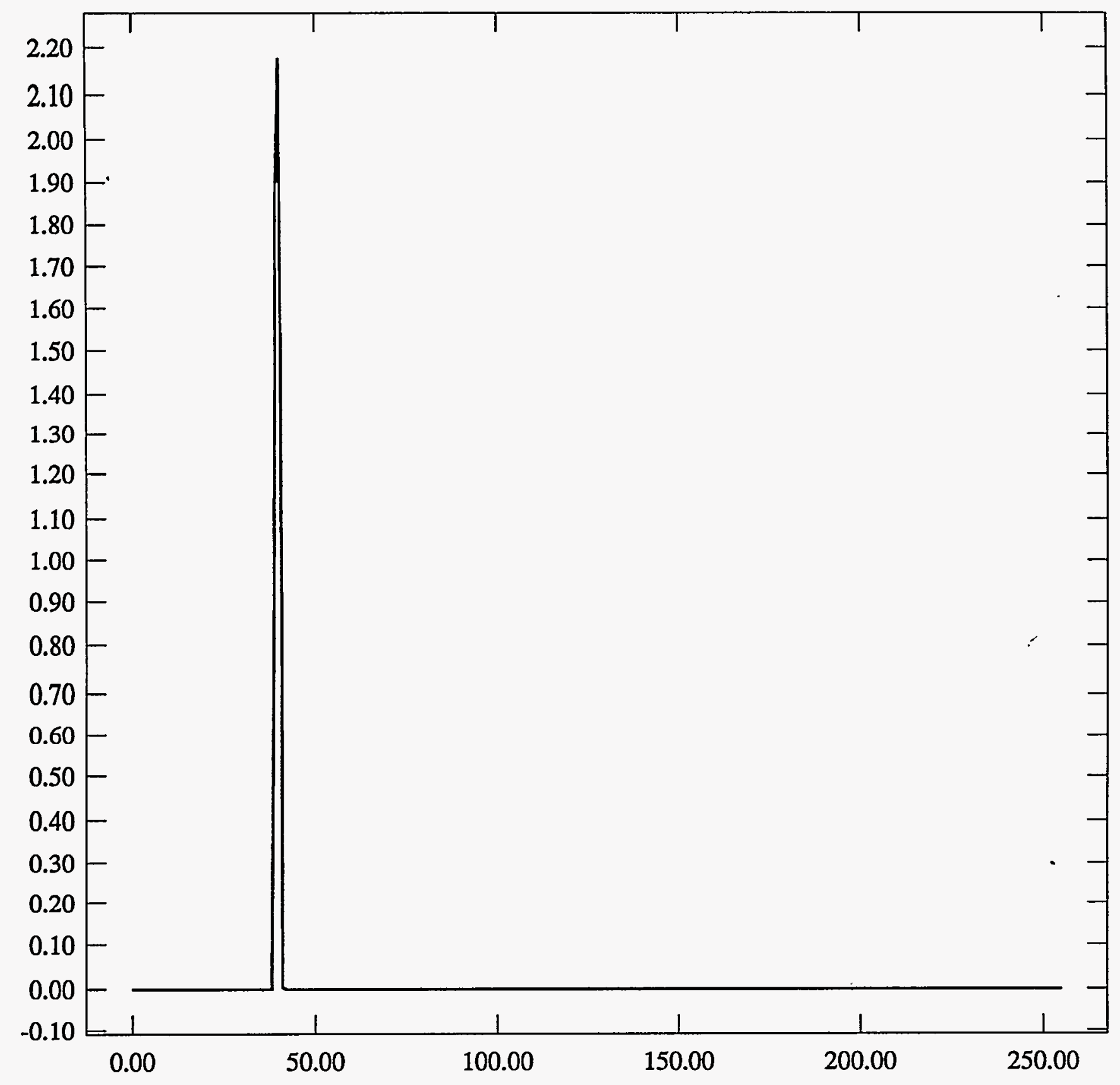


ST Camera: ST1\#04-10 20C \#3: int_time=200ms, offset= 0, gain=1 ( 350 e/bit) Wed Jun 30 12:26:05 1993 Pixel Values Min 39 Max 41 Mean 39.5 Sigma $0.50 \times 10^{3}$

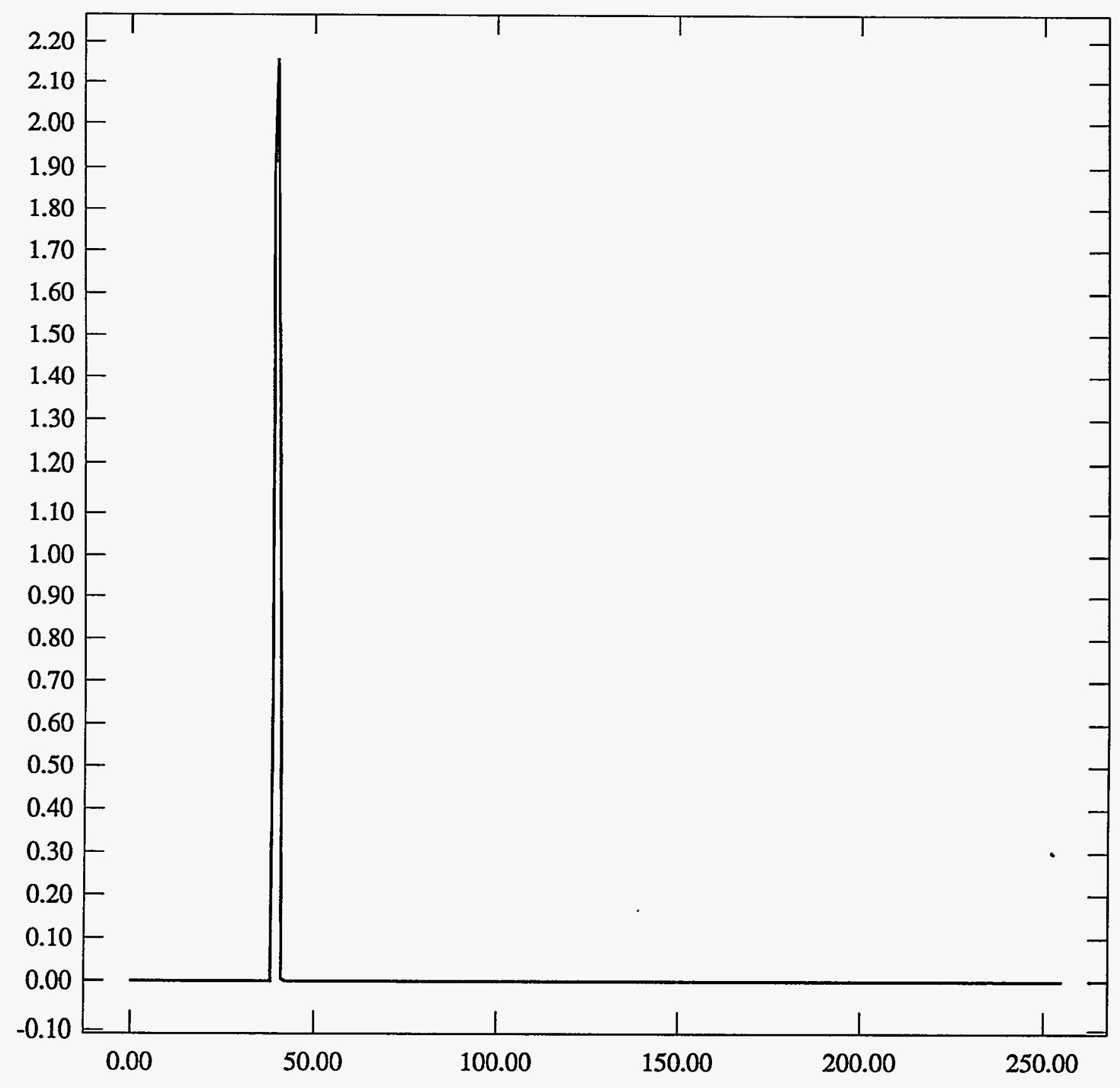


ST Camera: ST1\#04-10 20C \#3: int_time= 50ms, offset= 0, gain=2 (150 e/bit) Wed Jun 30 12:26:23 1993 Pixel Values Min 77 Max 81 Mean 79.4 Sigma $0.75 \times 10^{3}$

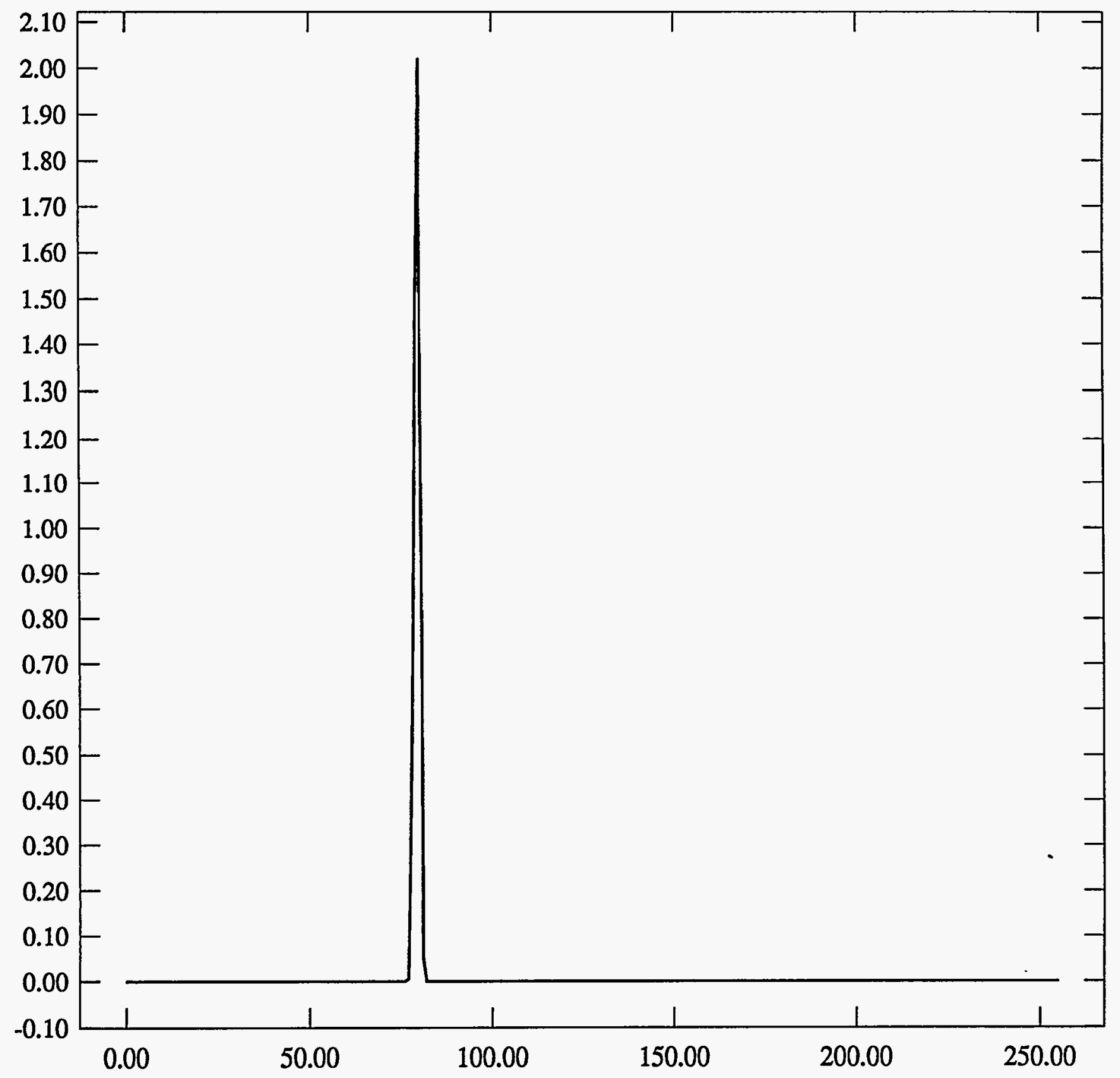


ST Camera: ST1\#04-10 20C \#3: int_time=100ms, offset= 0, gain=2 ( $150 \mathrm{e} / \mathrm{bit}$ ) Wed Jun 30 12:26:38 1993 Pixel Values Min 78 Max 81 Mean 79.4 Sigma $0.75 \times 10^{3}$

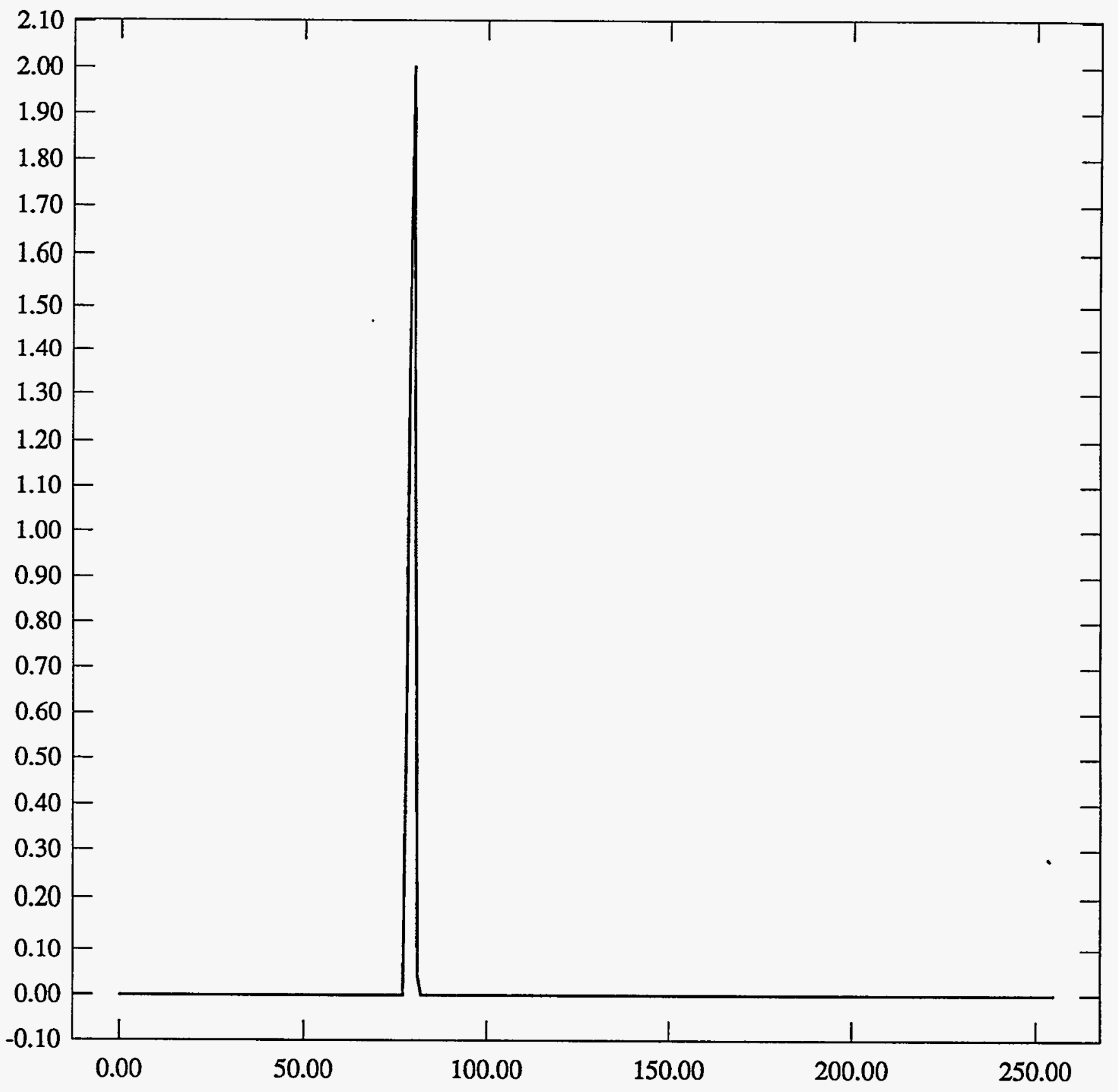


ST Camera: ST1\#04-10 20C \#3: int_time=200ms, offset= 0, gain=2 ( 150 e/bit) Wed Jun 30 12:26:54 1993 Pixel Values Min 77 Max 81 Mean 79.3 Sigma $0.75 \times 10^{3}$

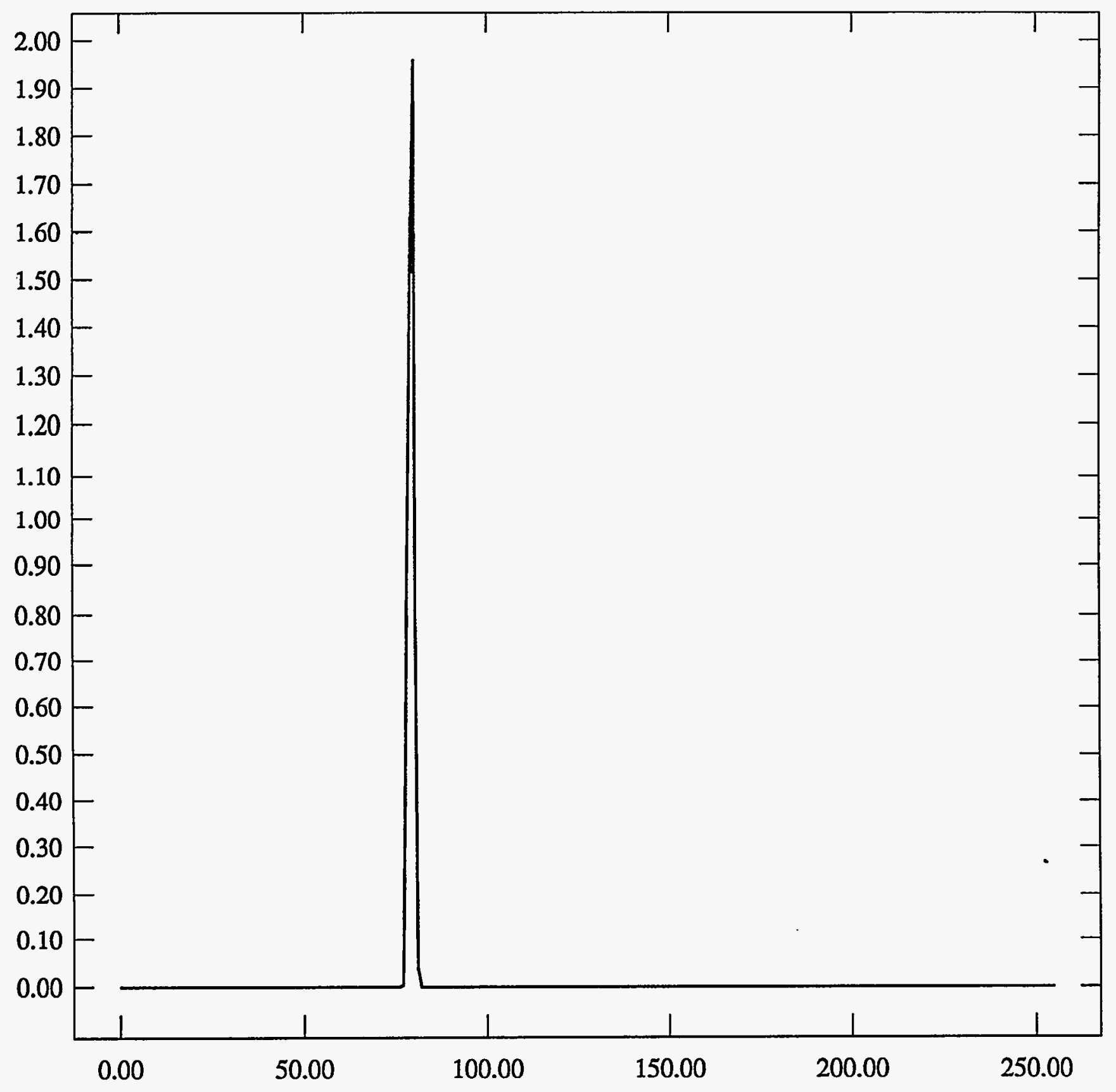


ST Camera: ST1\#04-10 20C \#3: int_time= 50ms, offset= 0, gain=4 ( 75 e/bit) Wed Jun 30 12:27:12 1993 Pixel Values Min 142 Max 148 Mean 145.2 Sigma $0.76 \times 10^{3}$

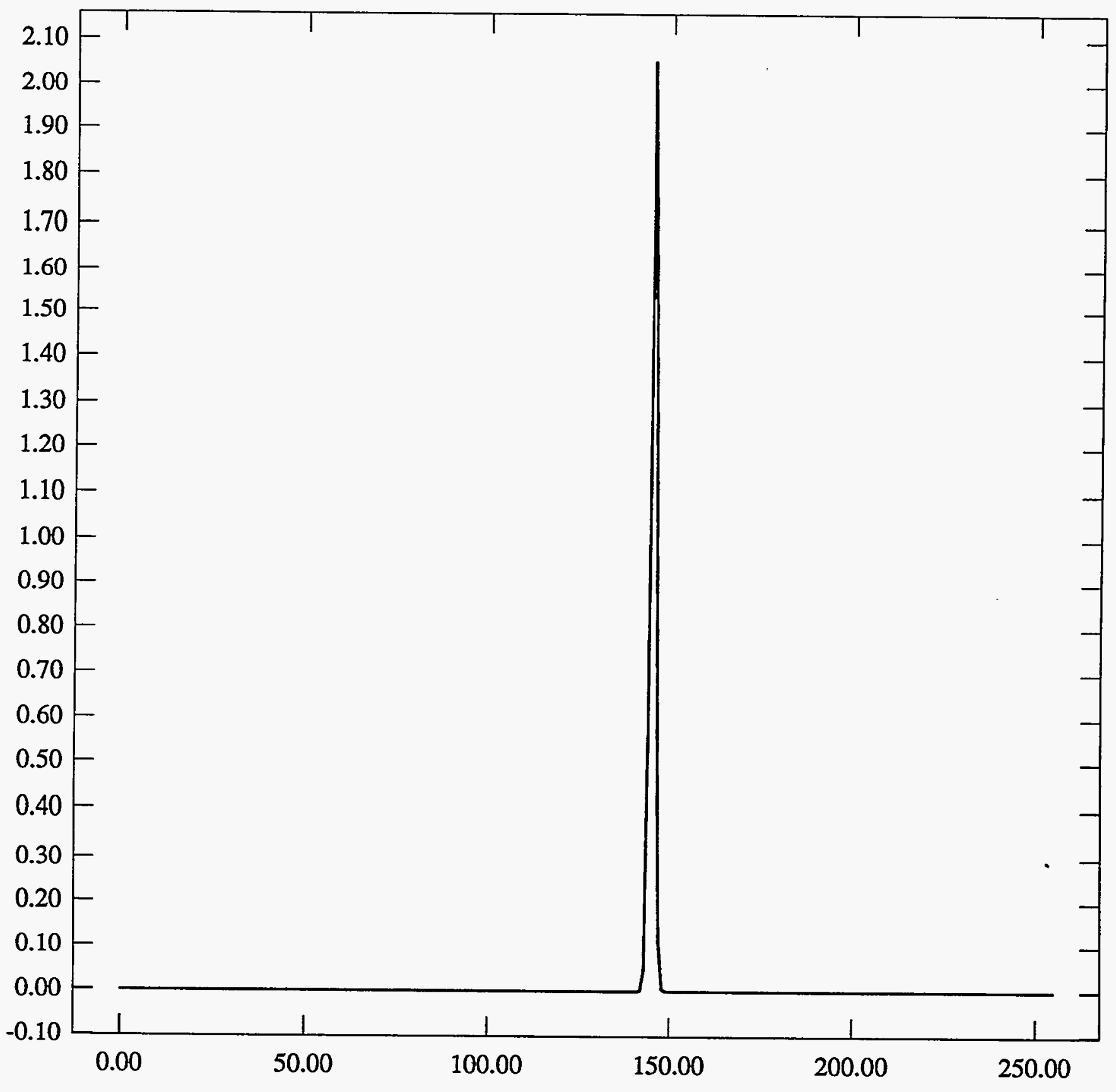


ST Camera: ST1\#04-10 20C \#3: int_time=100ms, offset= 0, gain=4 ( 75 e/bit) Wed Jun 30 12:27:32 1993 Pixel Values Min 142 Max 147 Mean 145.3 Sigma $0.76 \times 10^{3}$

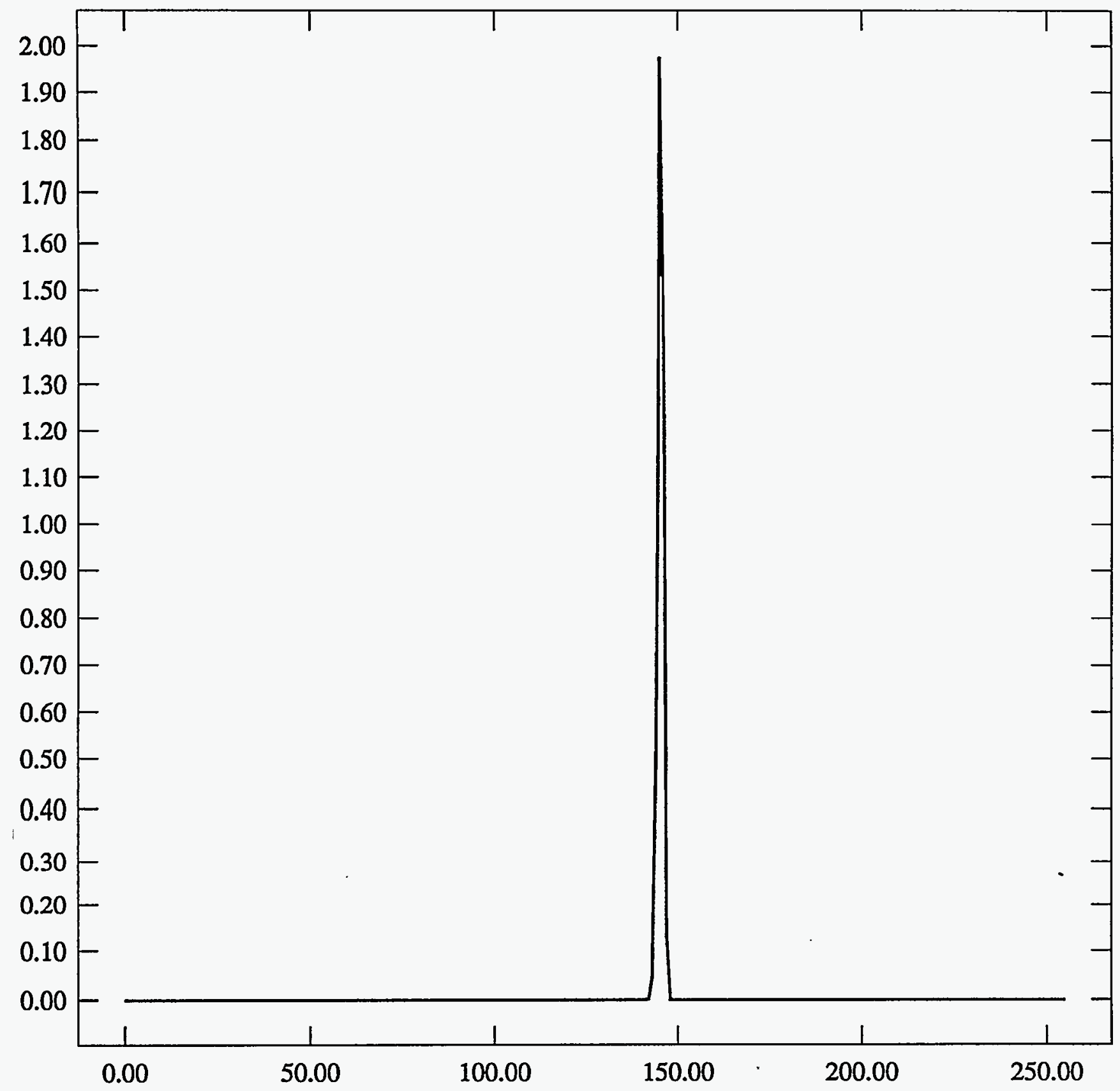


ST Camera: ST1\#04-10 20C \#3: int_time=200ms, offset= 0, gain=4 ( 75 e/bit) Wed Jun 30 12:27:49 1993 Pixel Values Min 142 Max 148 Mean 145.2 Sigma $0.76 \times 10^{3}$

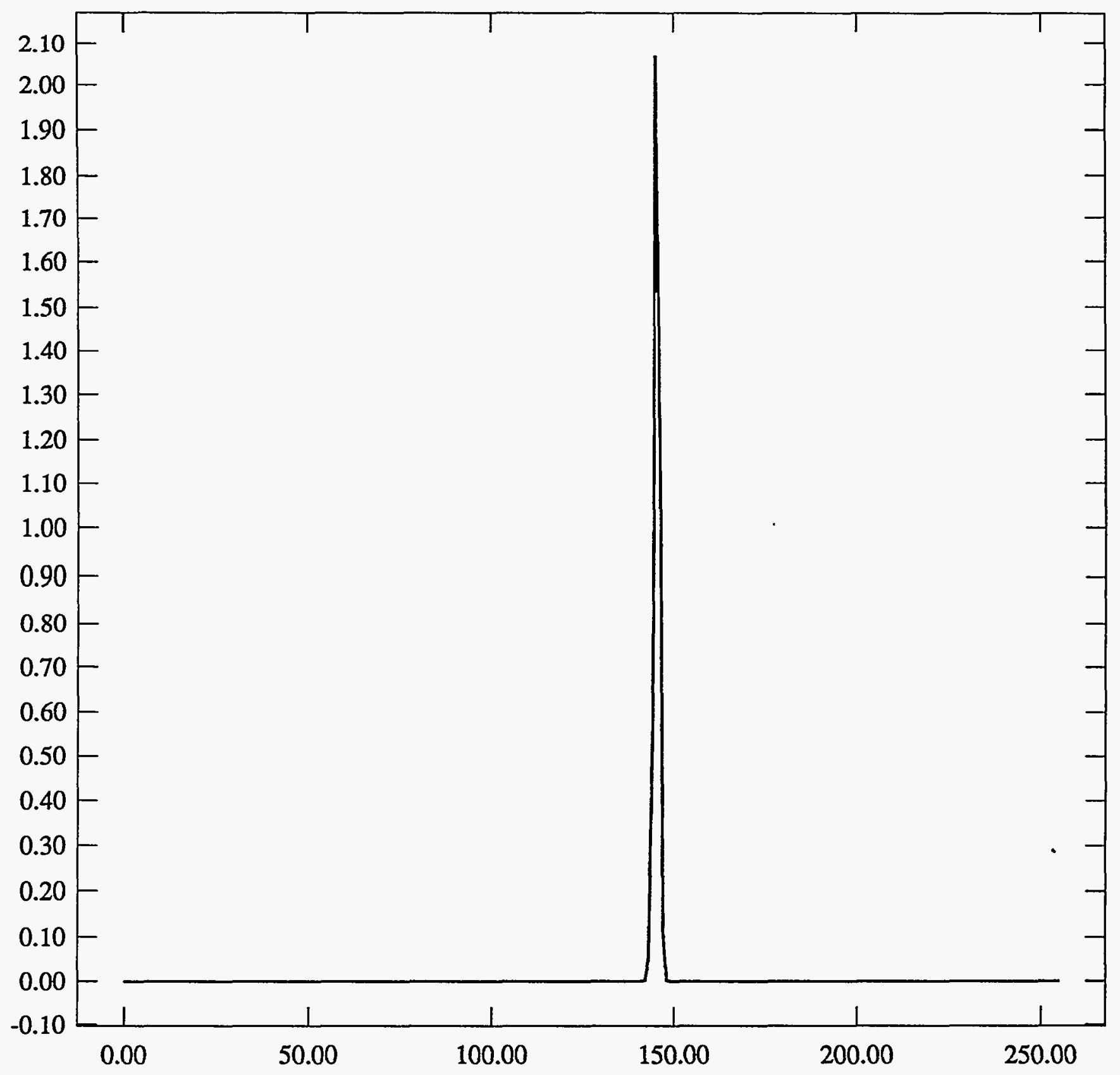


\# $320^{\circ} \mathrm{C}$ End

ST Camera: ST1\#04-10 20C \#3: int_time= 50ms, offset= 0, gain=1 ( 350 e/bit) Wed Jun 30 13:04:43 1993 .Pixel Values Min 39 Max 40 Mean 39.4 Sigma $0.49 \times 10^{3}$

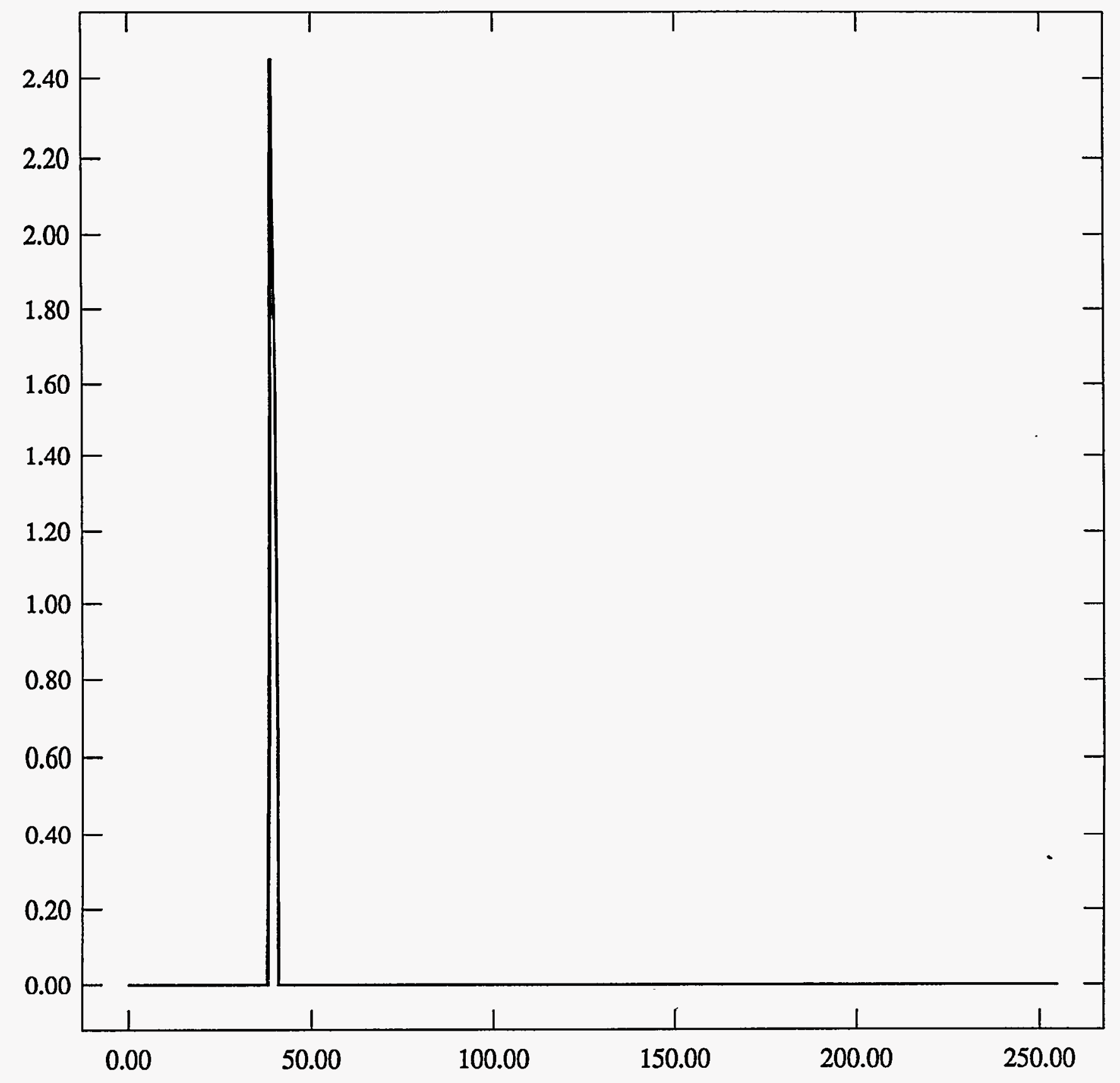


ST Camera: ST1\#04-10 20C \#3: int_time=100ms, offset= 0, gain=1 ( 350 e/bit) Wed Jun 30 13:05:49 1993 Pixel Values Min 39 Max 40 Mean 39.4 Sigma $0.49 \times 10^{3}$

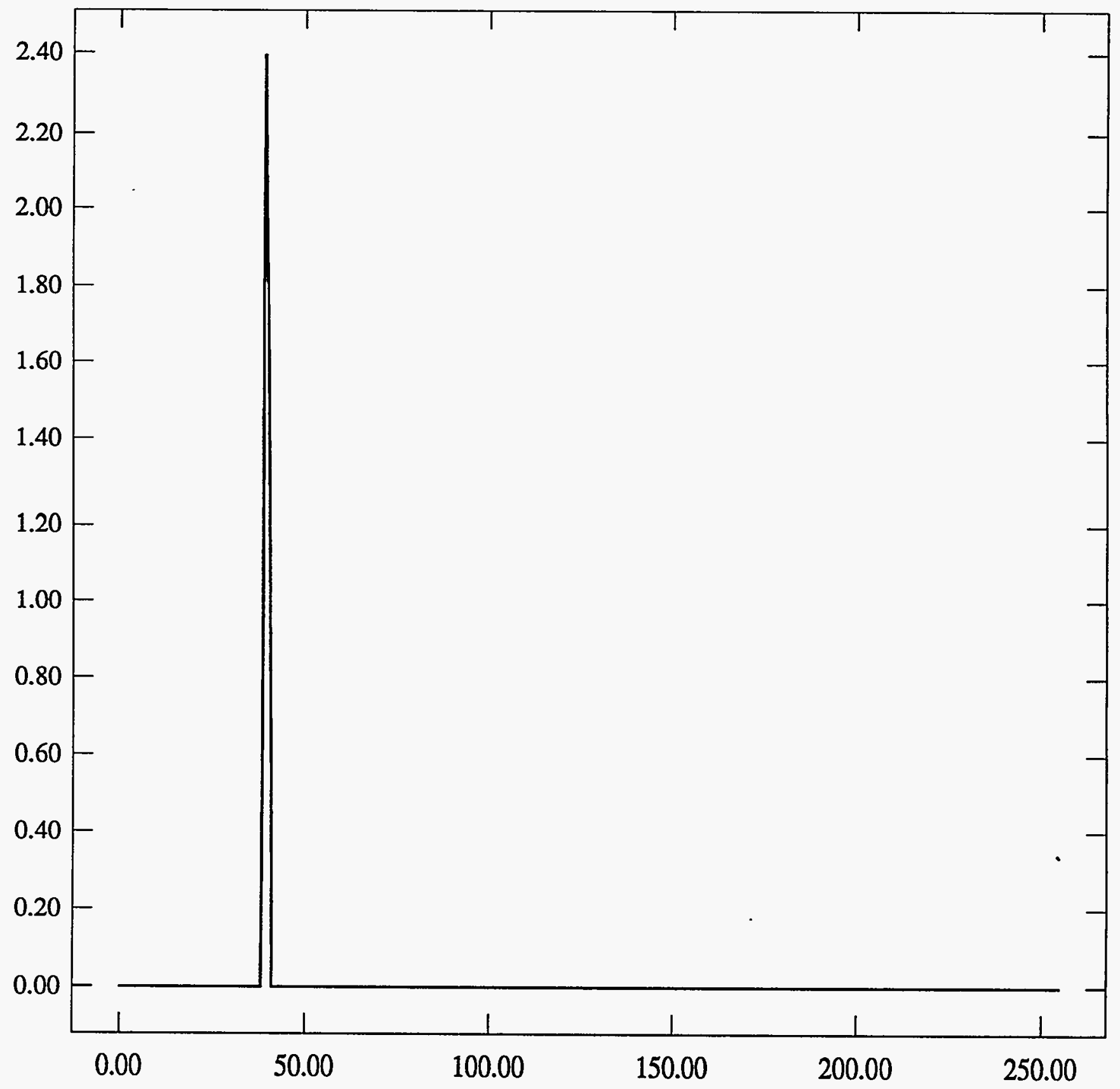


ST Camera: ST1\#04-10 20C \#3: int time=200ms, offset= 0, gain=1 ( $350 \mathrm{e} / \mathrm{bit}$ ) Wed Jun 30 13:06:29 1993 Pixel Values Min 39 Max 40 Mean 39.4 Sigma $0.49 \times 10^{3}$

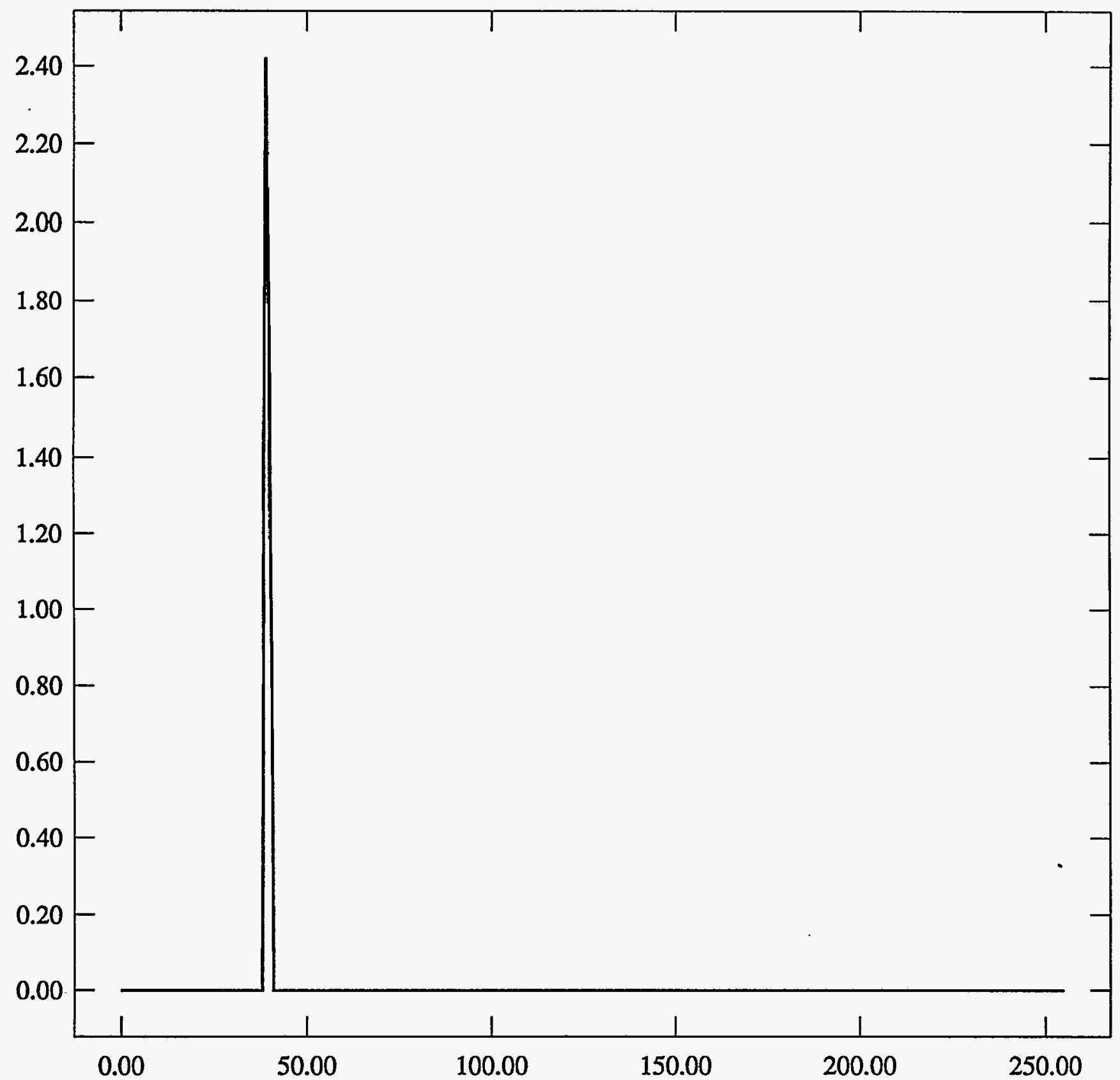


ST Camera: ST1\#04-10 20C \#3: int_time= 50ms, offset= 0, gain=2 (150 e/bit) Wed Jun 30 13:07:11 1993 Pixel Values Min 77 Max 81 Mean 79.1 Sigma $0.77 \times 10^{3}$

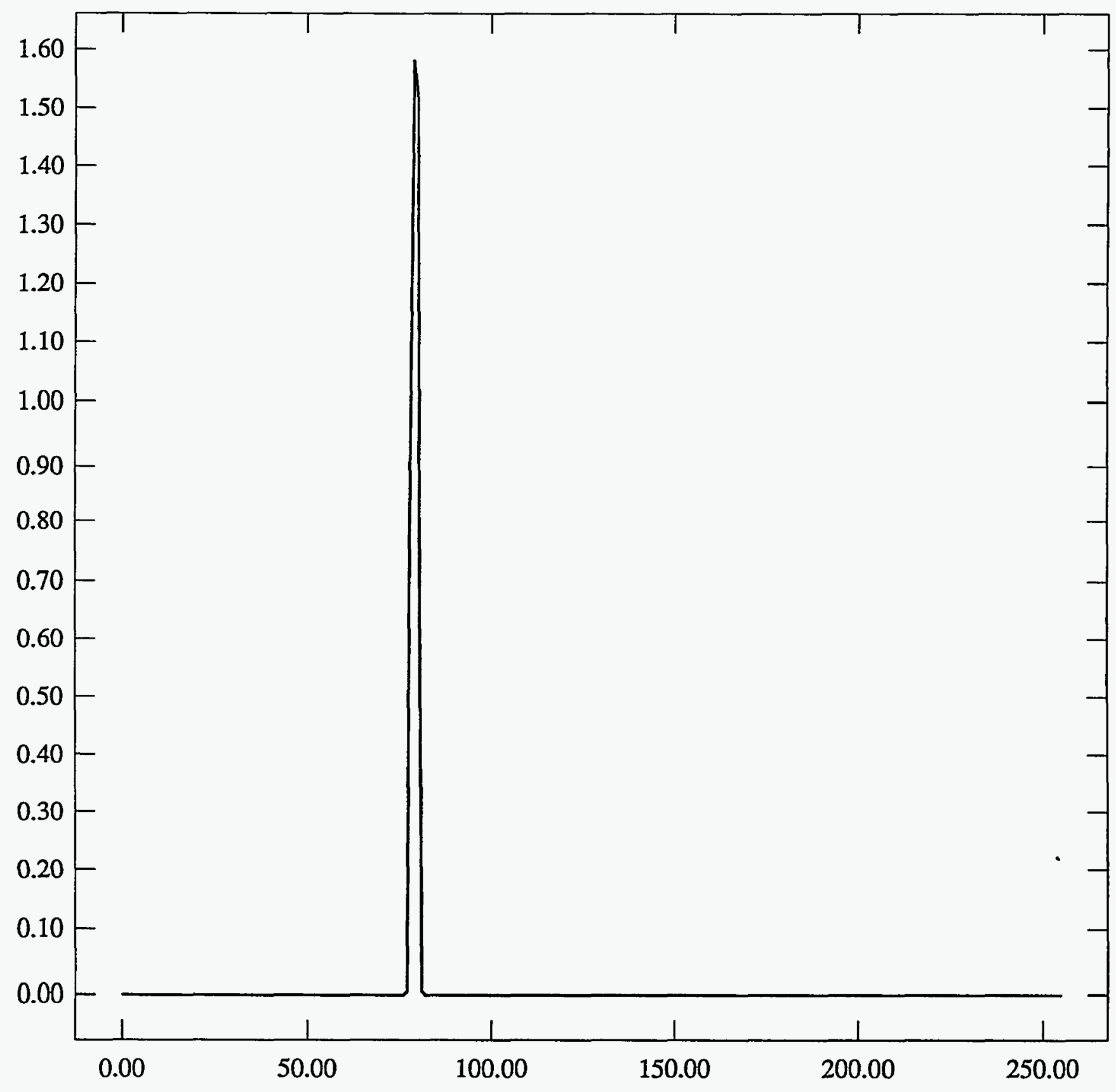


ST Camera: ST1\#04-10 20C \#3: int_time=100ms, offset= 0, gain=2 ( 150 e/bit) Wed Jun 30 13:07:49 1993 Pixel Values Min 77 Max 81 Mean 79.2 Sigma $0.77 \times 10^{3}$

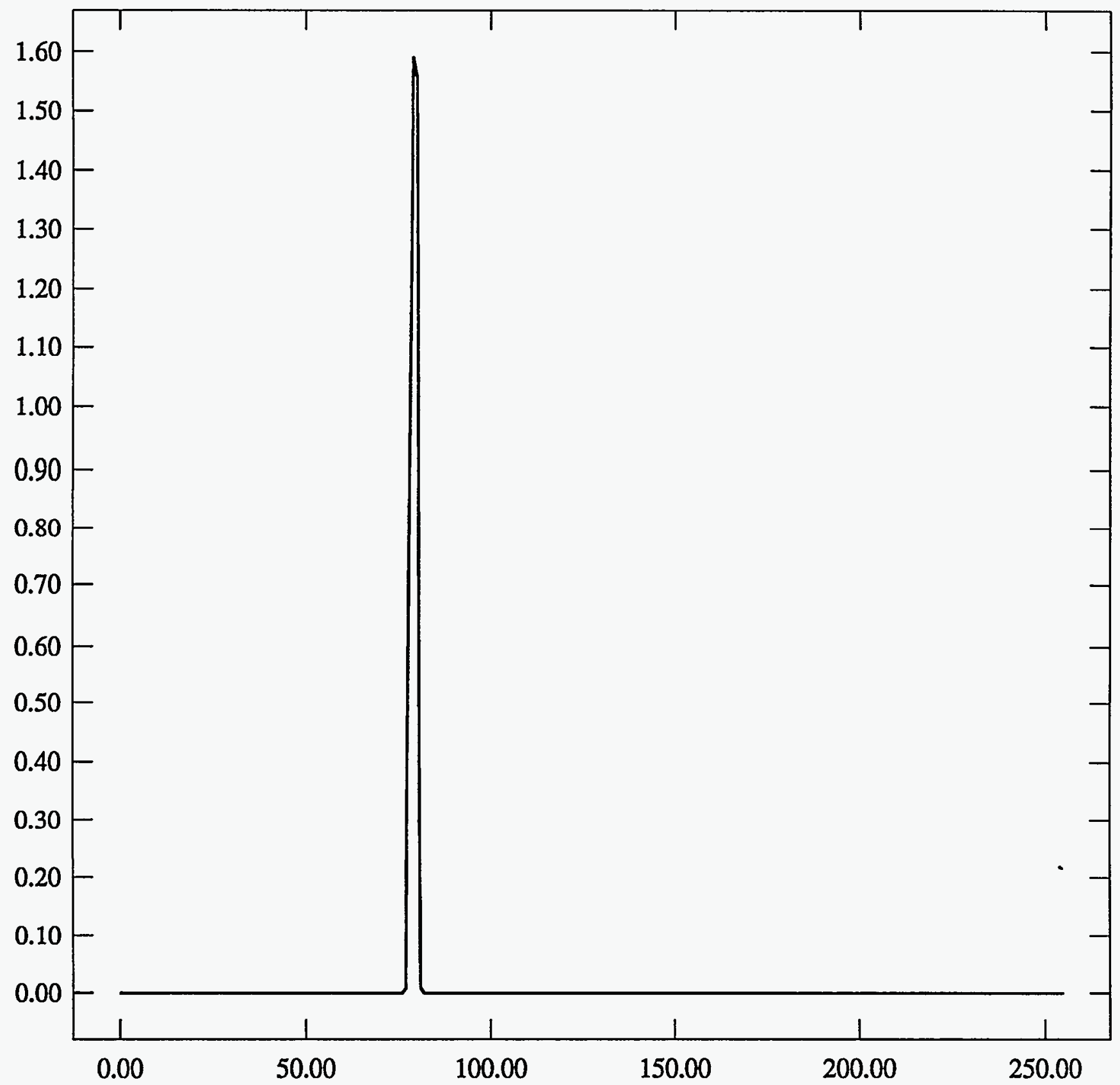


ST Camera: ST1 \#04-10 20C \#3: int_time=200ms, offset= 0, gain=2 ( $150 \mathrm{e} / \mathrm{bit})$ Wed Jun 30 13:08:31 1993 Pixel Values Min 77 Max 81 Mean 79.1 Sigma $0.78 \times 10^{3}$

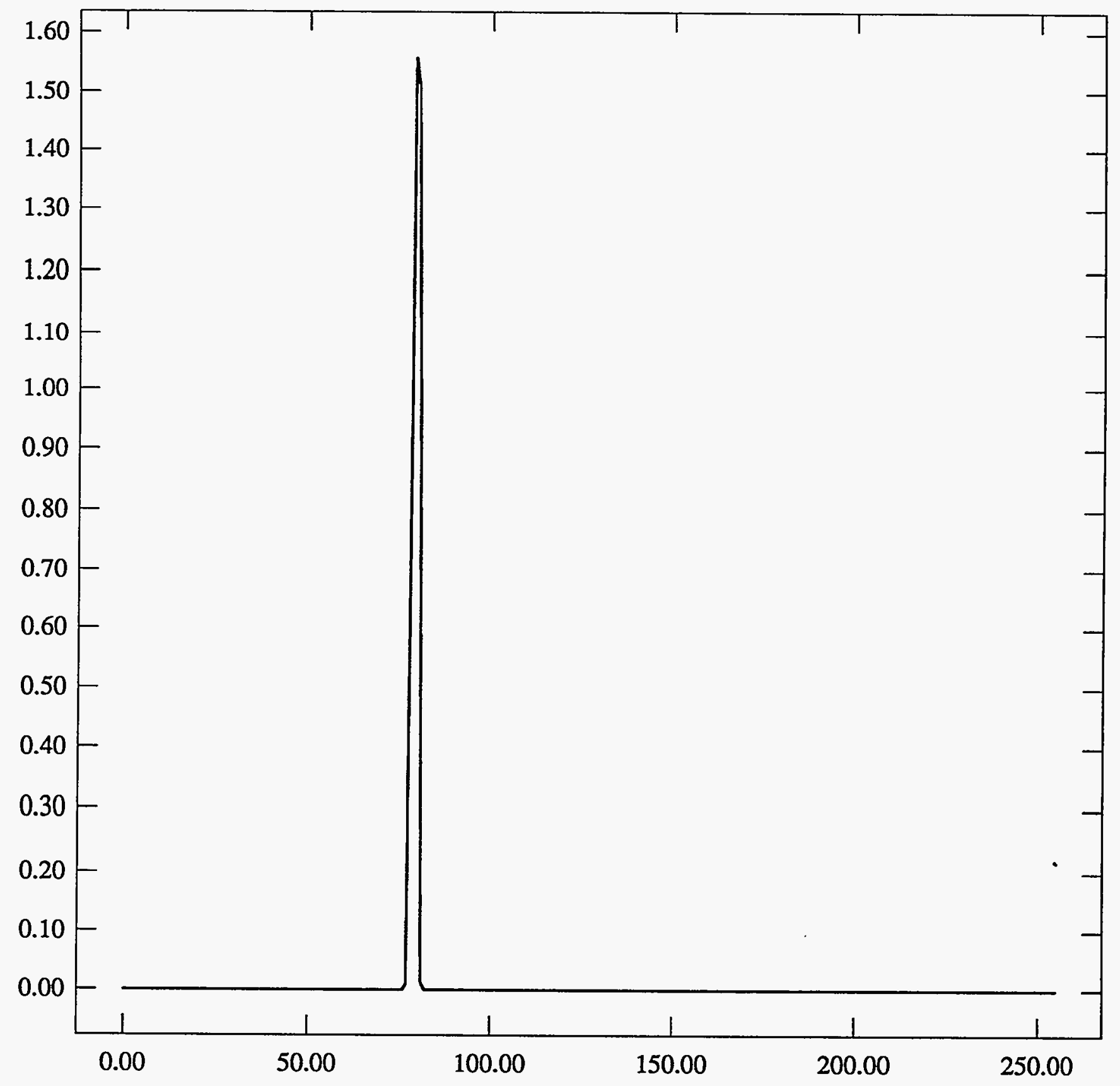


ST Camera: ST1\#04-10 20C \#3: int_time= 50ms, offset= 0, gain=4 ( 75 e/bit) Wed Jun 30 13:09:18 1993 Pixel Values Min 142 Max 148 Mean 145.0 Sigma $0.79 \times 10^{3}$

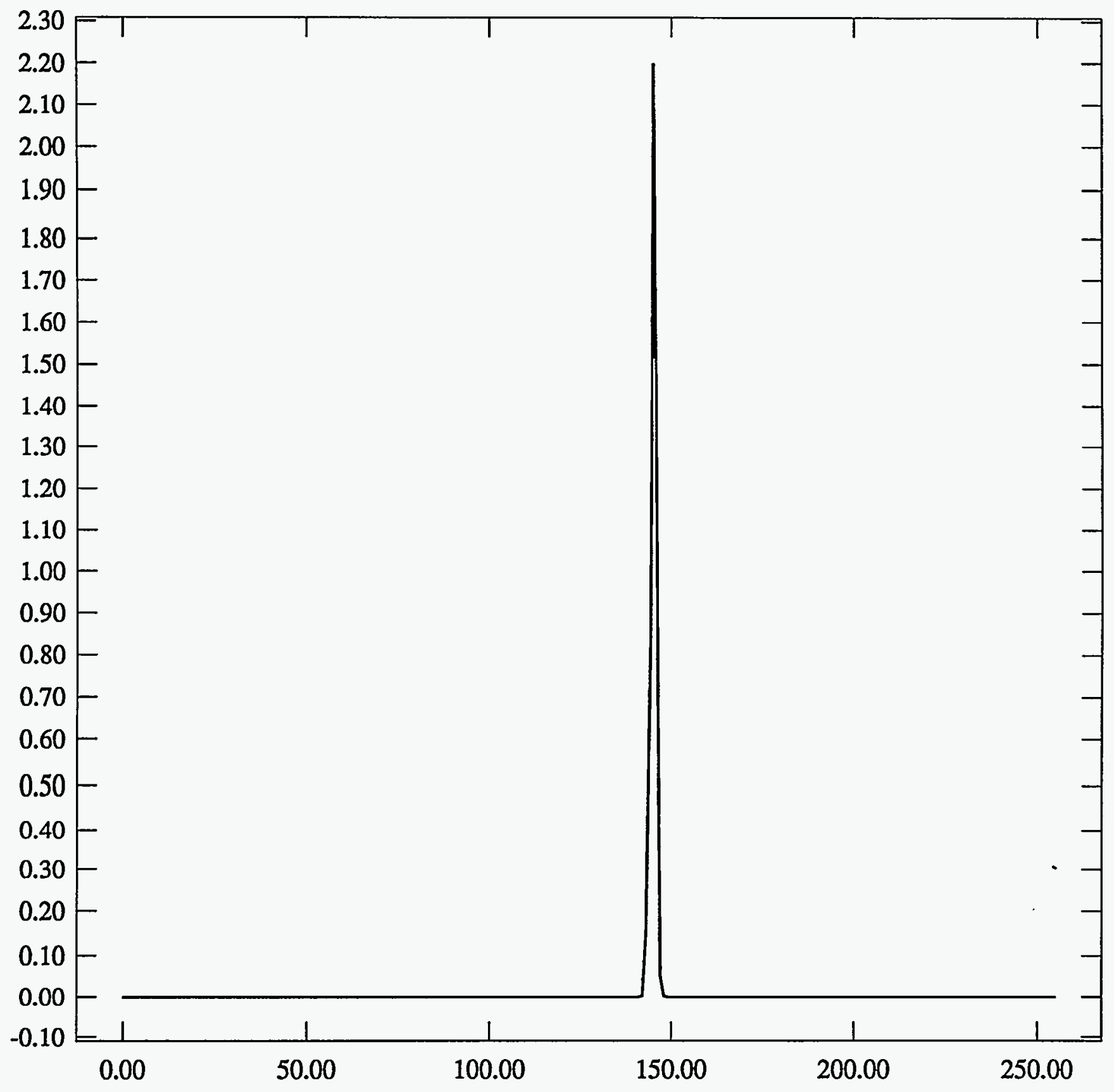


ST Camera: ST1\#04-10 20C \#3: int_time=100ms, offset= 0, gain=4 ( $75 \mathrm{e} / \mathrm{bit}$ ) Wed Jun 30 13:10:01 1993 Pixel Values Min 142 Max 148 Mean 145.0 Sigma $0.79 \times 10^{3}$

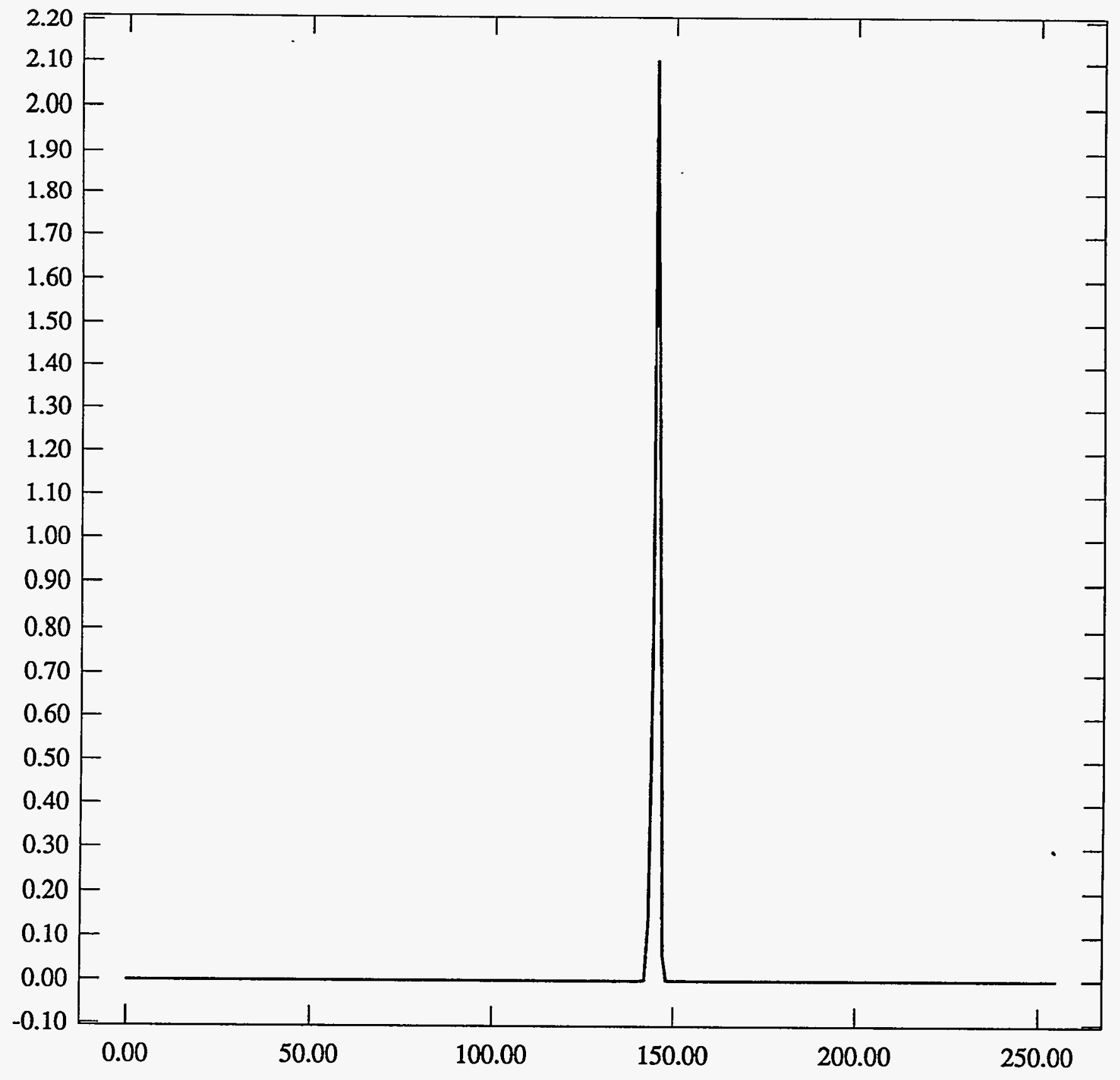


ST Camera: ST1\#04-10 20C \#3: int_time=200ms, offset= 0, gain=4 ( 75 e/bit) Wed Jun 30 13:10:42 1993 Pixel Values Min 142 Max 147 Mean 144.9 Sigma $0.78 \times 10^{3}$

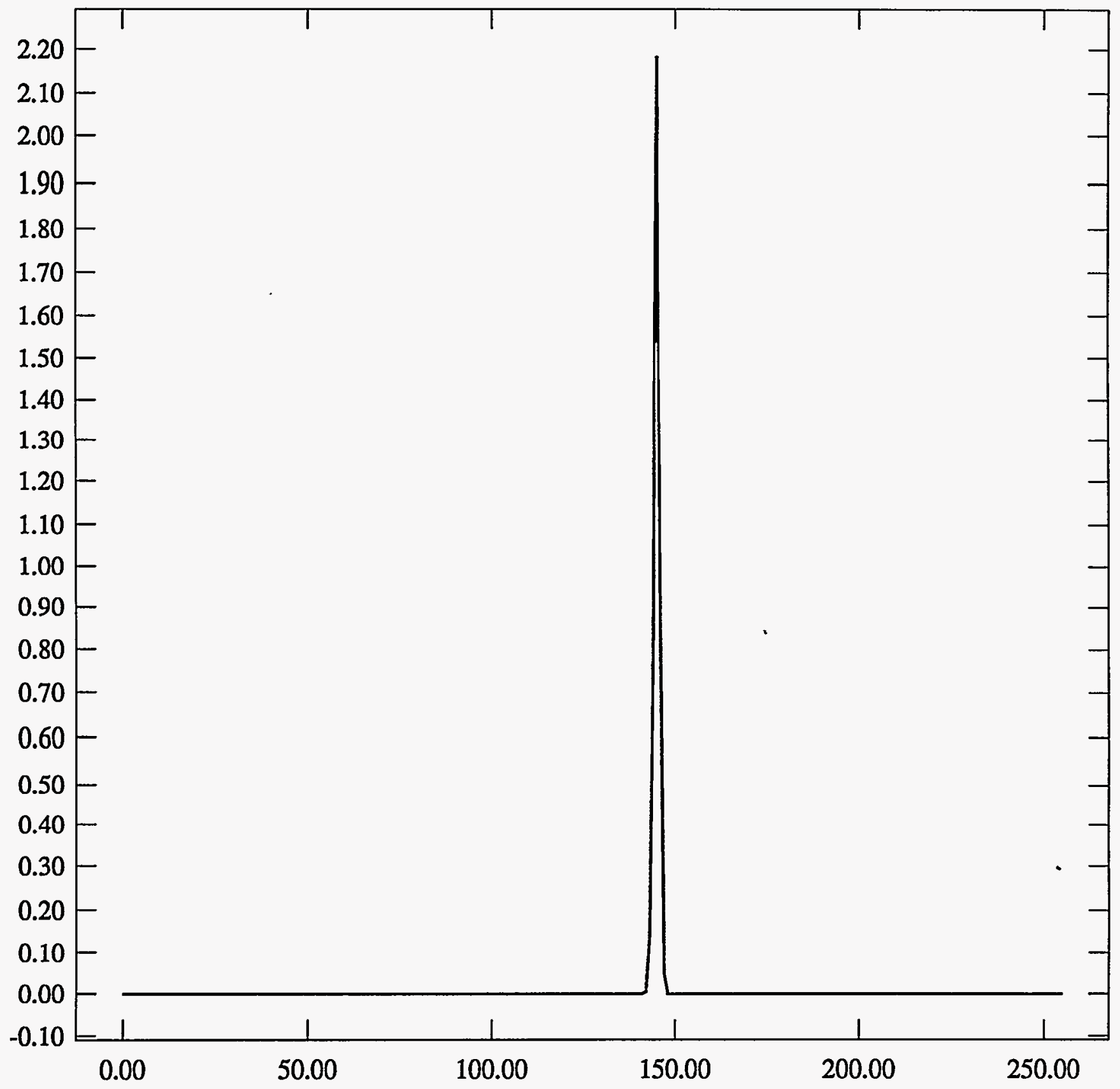


ST Camera: ST1\#04-10 -30C \#4: int_time= 50ms, offset= 0, gain=1 ( 350 e/bit) Wed Jun 30 13:46:20 1993

$$
\begin{array}{r}
-30^{\circ} \mathrm{C} \\
15 \mathrm{~m}
\end{array}
$$
Pixel Values Min 39 Max 41 Mean 39.9 Sigma $0.33 \times 10^{3}$

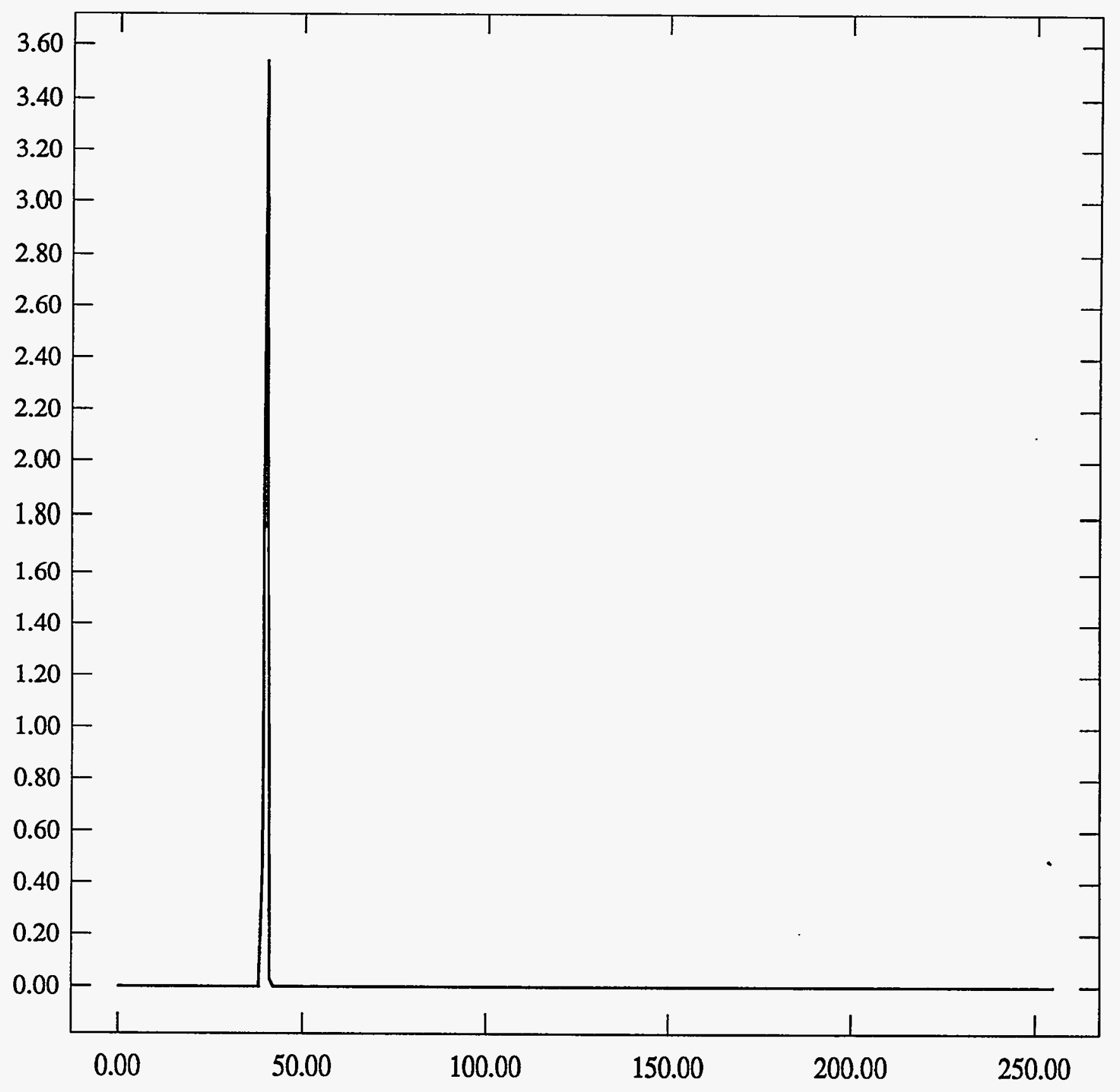


$\eta_{0}$

ST Camera: ST1\#04-10 -30C \#4: int_time=100ms, offset= 0, gain=1 (350 e/bit) Wed Jun 30 13:47:07 1993 Pixel Values Min 0 Max 0 Mean 0.0 Sigma $0.00 \times 10^{3}$

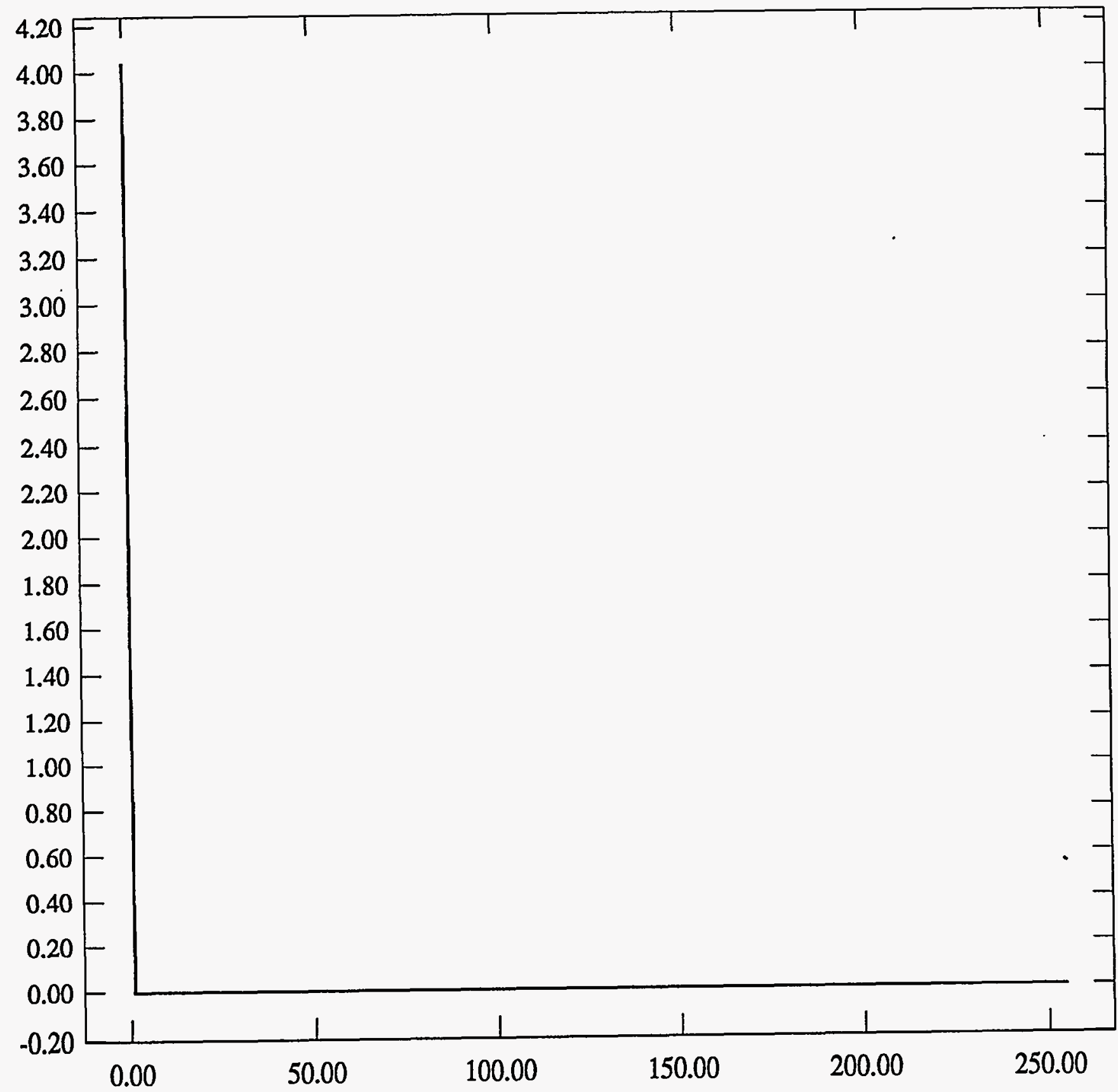


ST Camera: ST1\#04-10 -30C \#4: int_time=200ms, offset= 0, gain=1 ( $350 \mathrm{e} / \mathrm{bit}$ ) Wed Jun 30 13:47:53 1993 Pixel Values Min 39 Max 41 Mean 39.9 Sigma $0.31 \times 10^{3}$

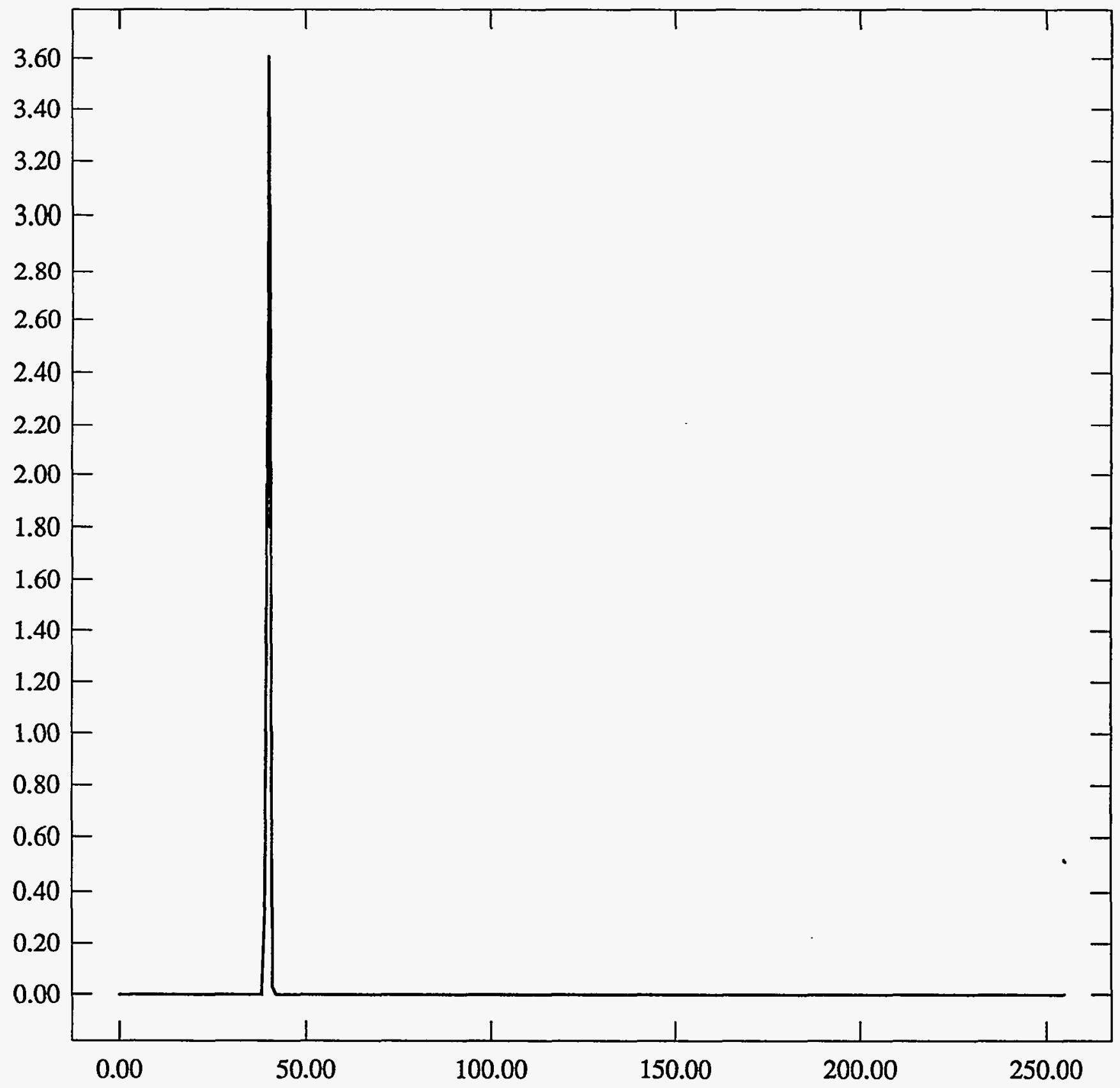


ST Camera: ST1\#04-10 -30C \#4: int_time= 50ms, offset= 0, gain=2 ( 150 e/bit) Wed Jun 30 13:48:39 1993 Pixel Values Min 78 Max 81 Mean 79.2 Sigma $0.60 \times 10^{3}$

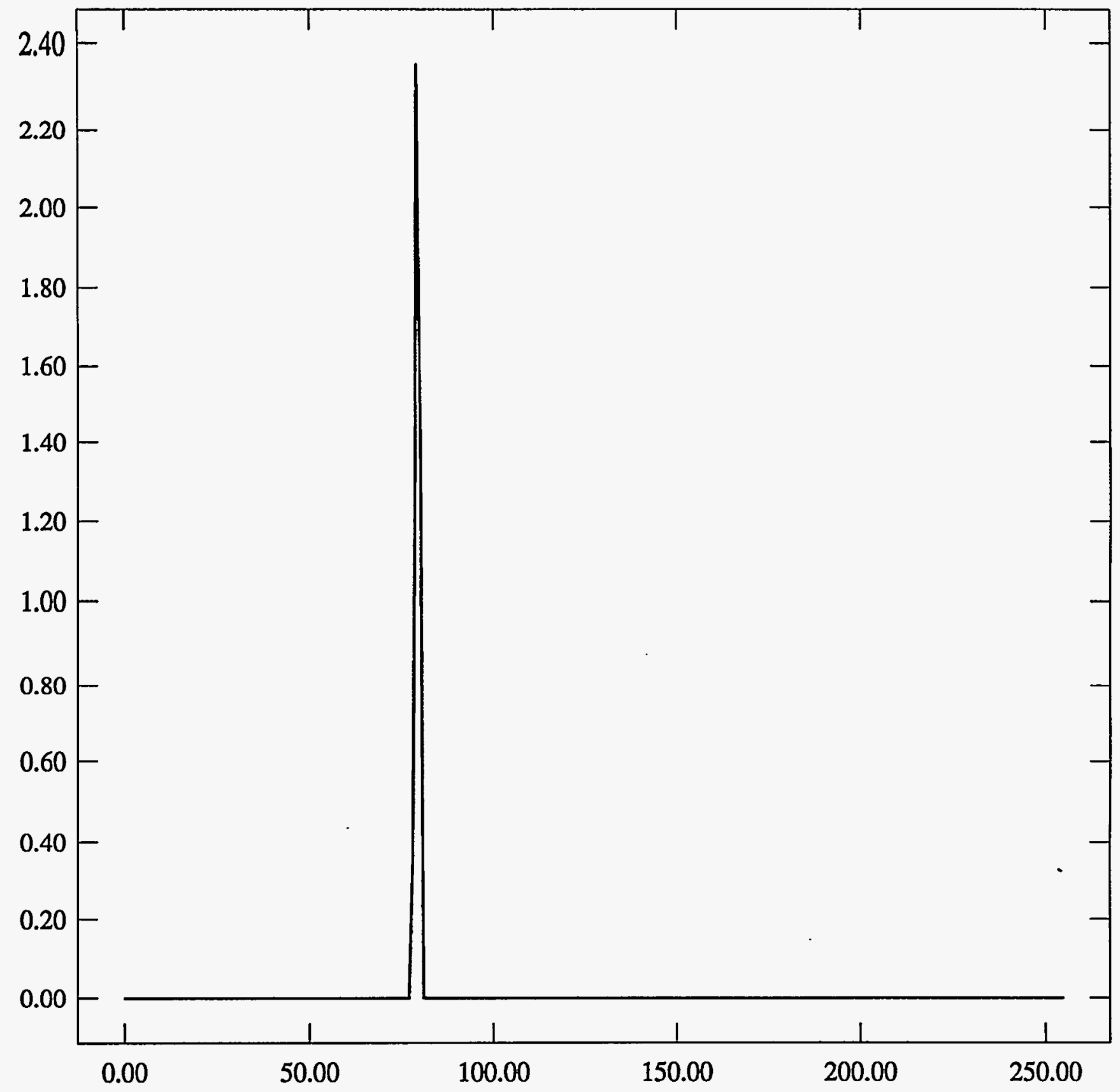


ST Camera: ST1\#04-10 -30C \#4: int_time=100ms, offset= 0, gain=2 ( $150 \mathrm{e} / \mathrm{bit})$ Wed Jun 30 13:49:14 1993 Pixel Values Min 78 Max 80 Mean 79.3 Sigma $0.58 \times 10^{3}$

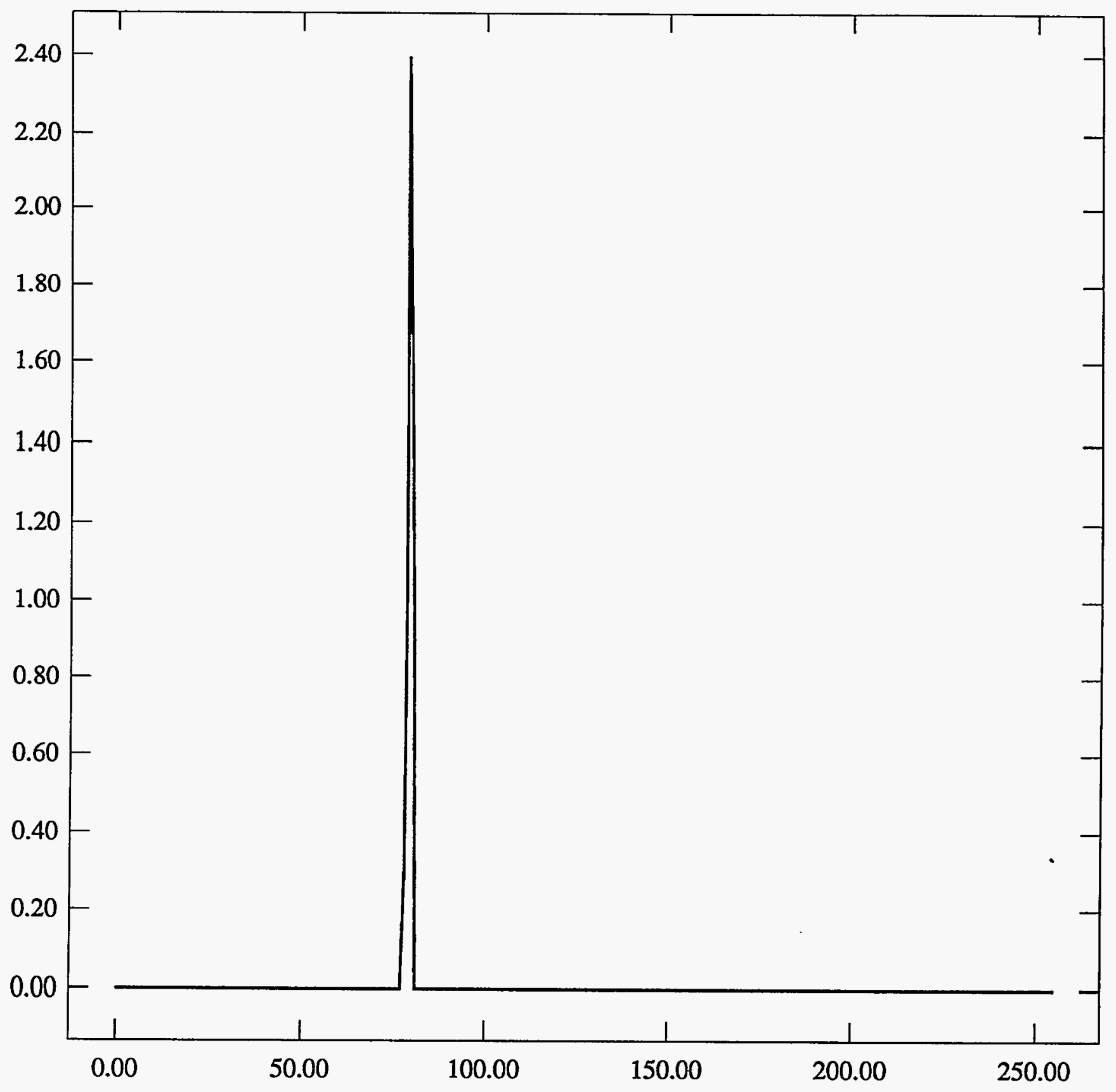


ST Camera: ST1\#04-10 -30C \#4: int_time=200ms, offset= 0, gain=2 (150 e/bit) Wed Jun 30 13:50:01 1993 Pixel Values Min 78 Max 81 Mean 79.3 Sigma 0.61 x $10^{3}$

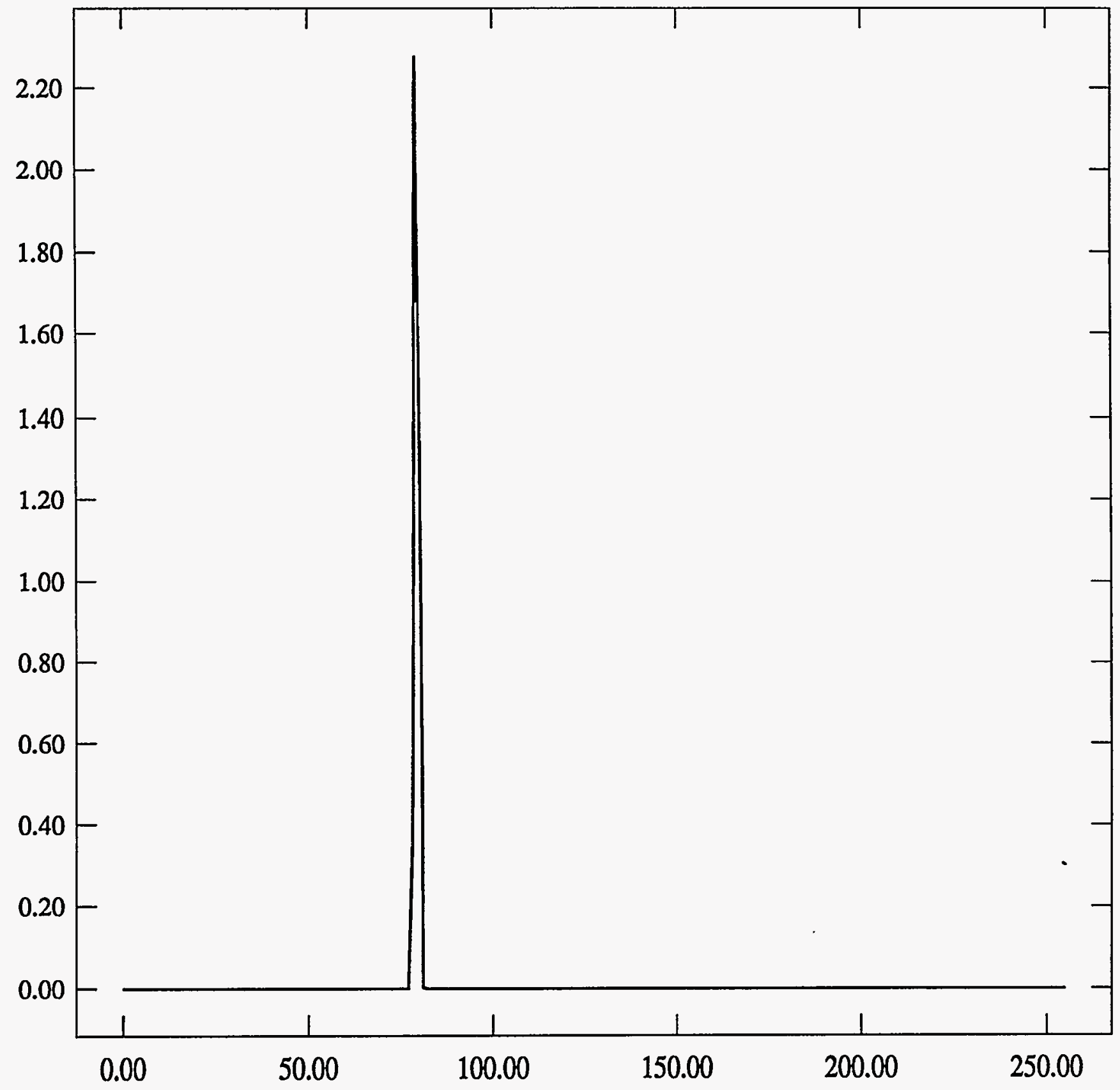


ST Camera: ST1\#04-10 -30C \#4: int_time= 50ms, offset= 0, gain=4 ( 75 e/bit) Wed Jun 30 13:50:43 1993 Pixel Values Min 145 Max 149 Mean 146.9 Sigma $0.69 \times 10^{3}$

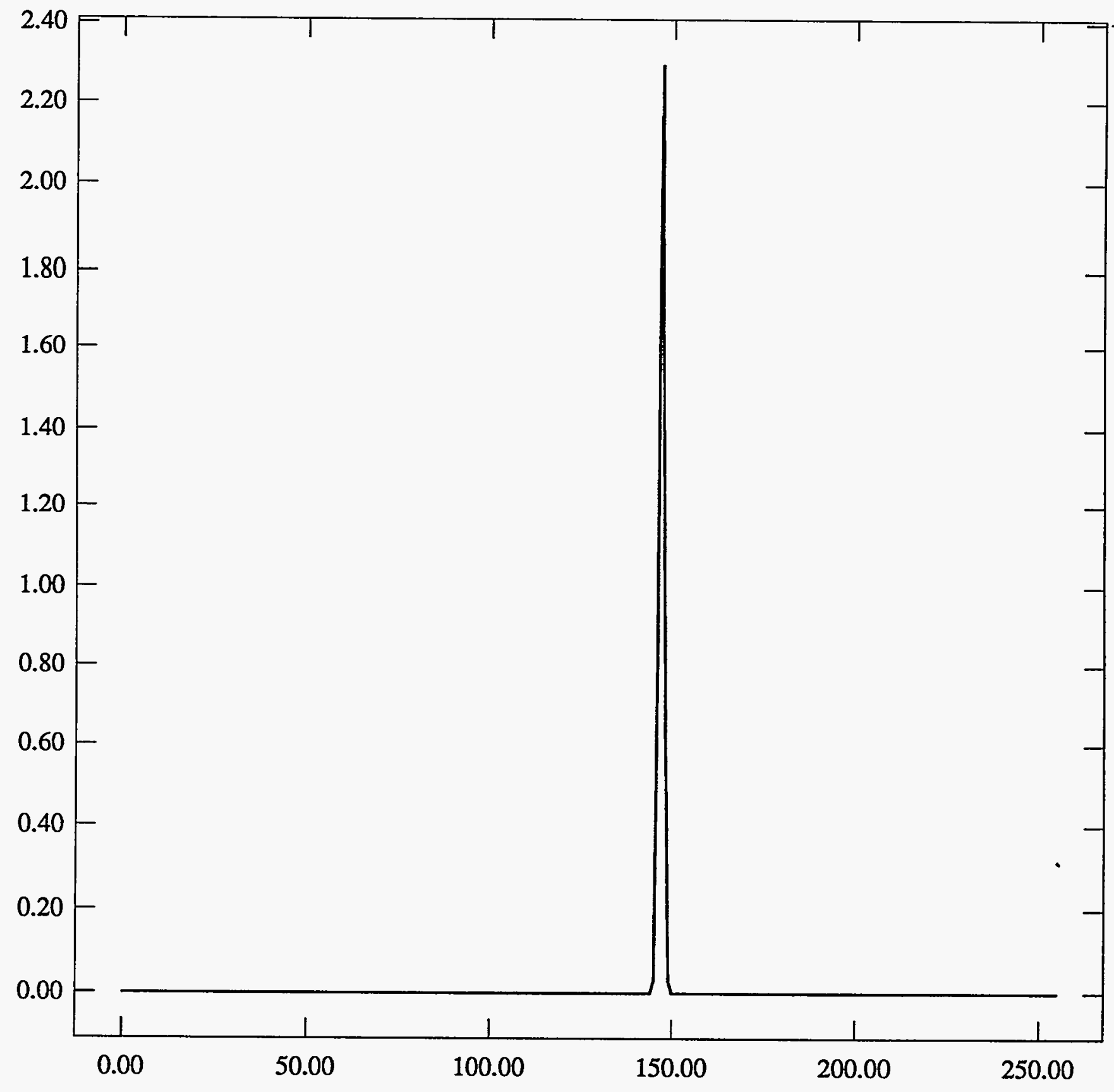


ST Camera: ST1\#04-10 -30C \#4: int_time=100ms, offset= 0, gain=4 ( 75 e/bit) Wed Jun 30 13:51:26 1993 Pixel Values Min 144 Max 149 Mean 146.9 Sigma $0.69 \times 10^{3}$

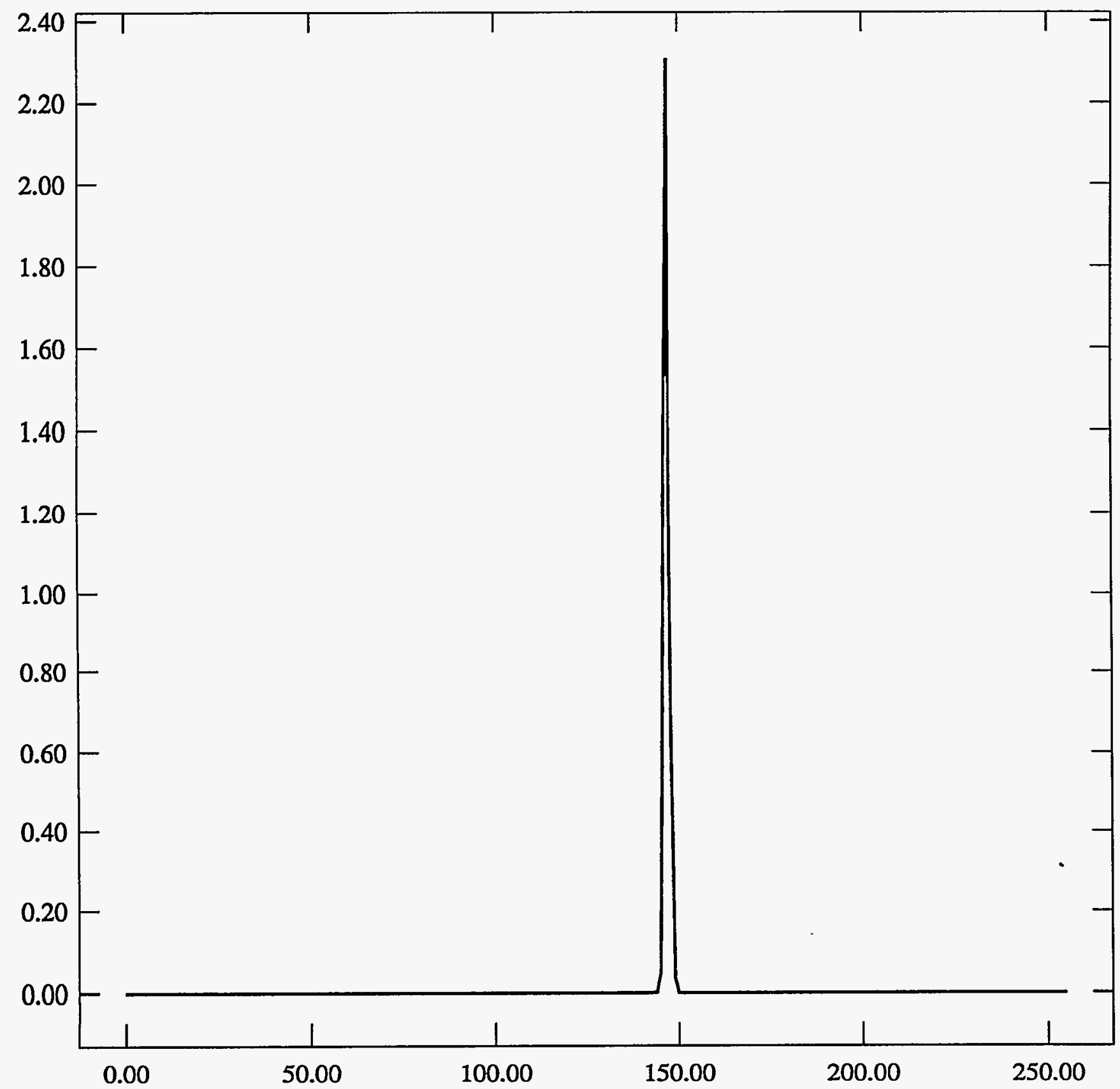


ST Camera: ST1\#04-10 -30C \#4: int_time=200ms, offset= 0, gain=4 ( 75 e/bit) Wed Jun 30 13:52:17 1993 Pixel Values Min 145 Max 149 Mean 146.9 Sigma $0.75 \times 10^{3}$

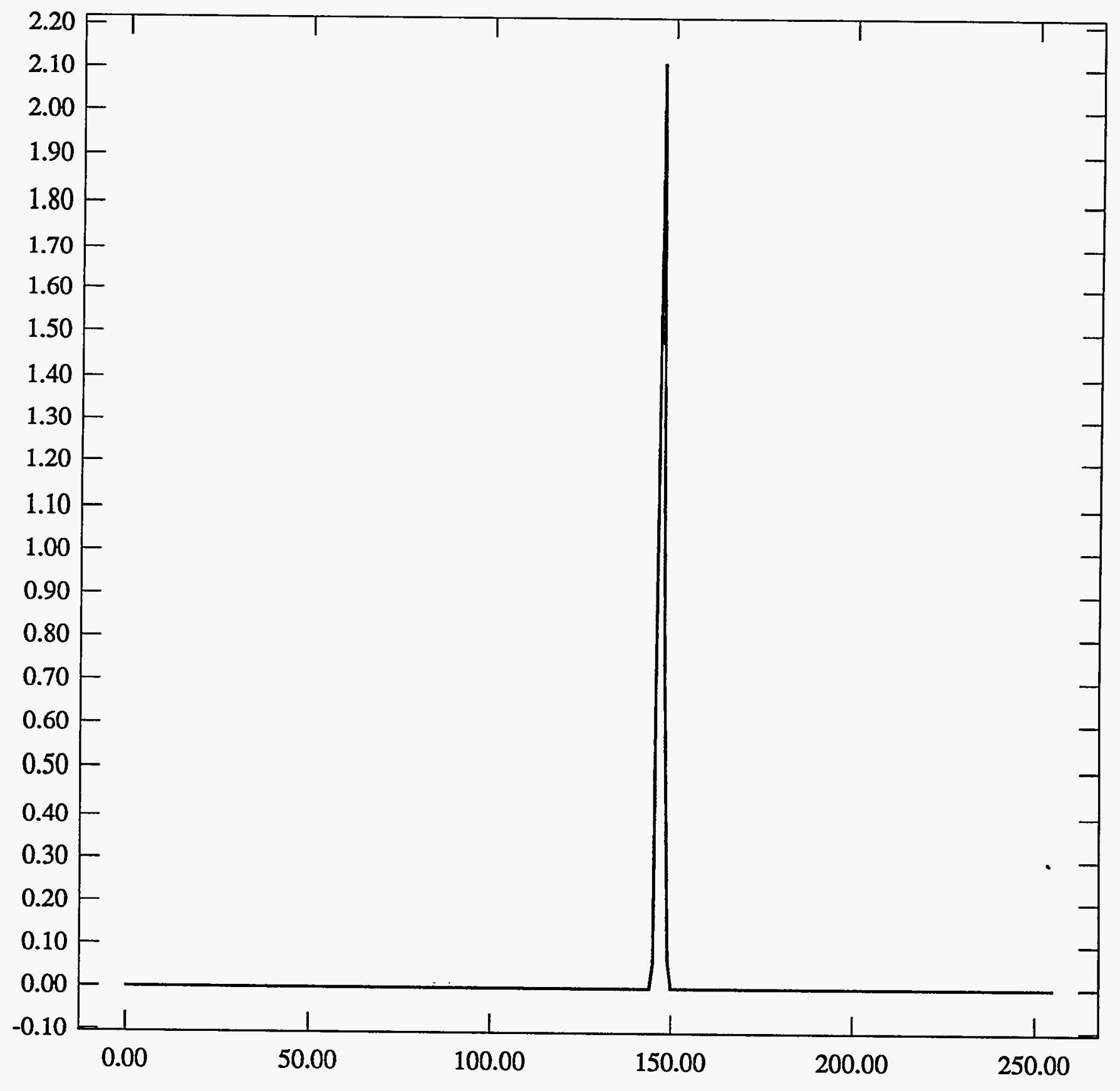




$$
\pm 4-30^{\circ} \mathrm{C} \text { END }
$$

ST Camera: ST1\#04-10 -30C \#4: int_time= 50ms, offset= 0, gain=1 ( $350 \mathrm{e} / \mathrm{bit}$ ) Wed Jun 30 14:21:11 1993 Pixel Values Min $39 \operatorname{Max} 41$ Mean 39.9 Sigma $0.33 \times 10^{3}$

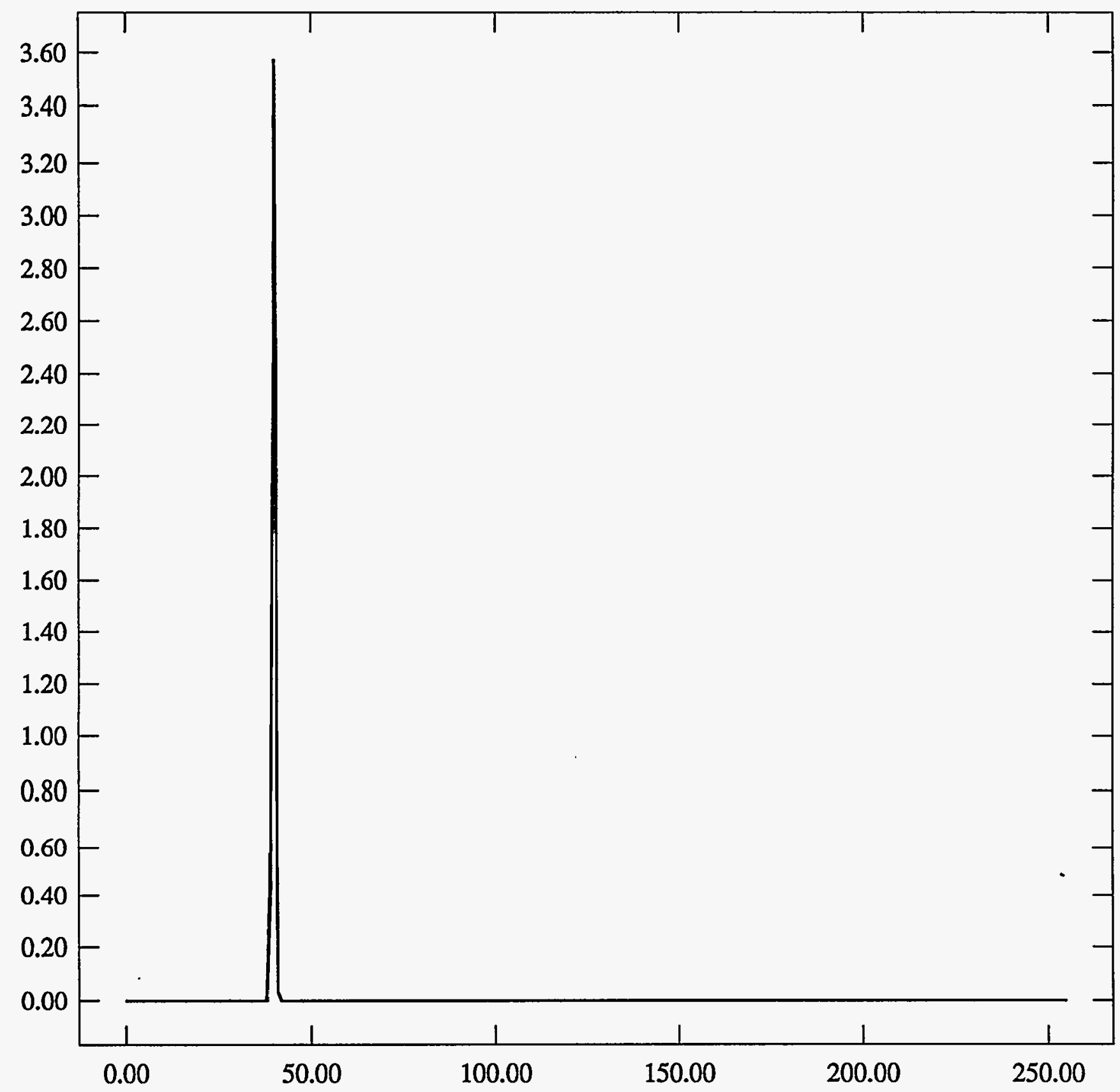


ST Camera: ST1\#04-10 -30C \#4: int_time=100ms, offset= 0, gain=1 ( 350 e/bit) Wed Jun 30 14:21:53 1993 Pixel Values Min 39 Max 41 Mean 39.9 Sigma $0.32 \times 10^{3}$

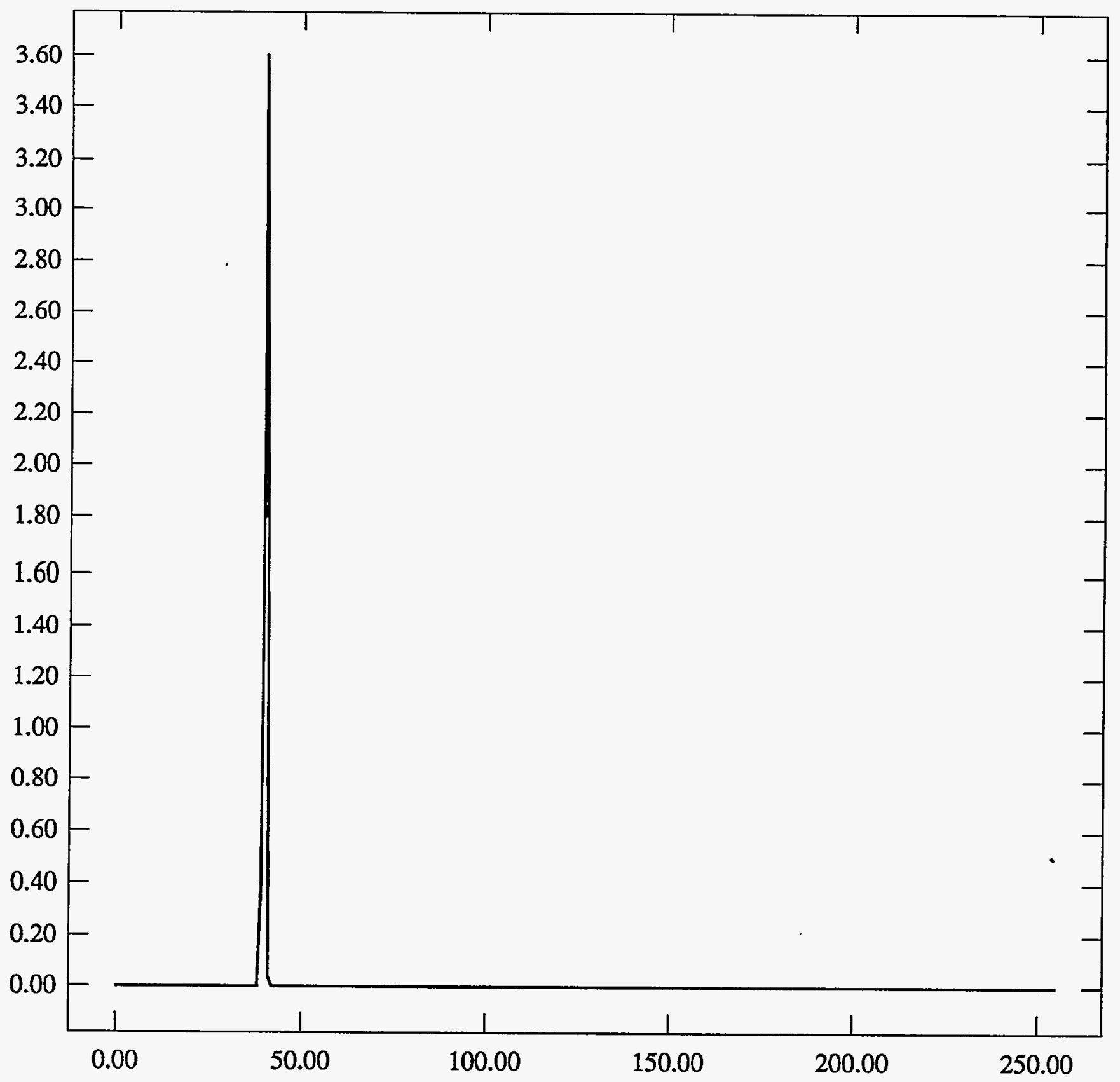


ST Camera: ST1\#04-10 -30C \#4: int_time=200ms, offset= 0, gain=1 (350 e/bit) Wed Jun 30 14:22:48 1993 Pixel Values Min 39 Max 41 Mean 39.9 Sigma 0.33 x $10^{3}$

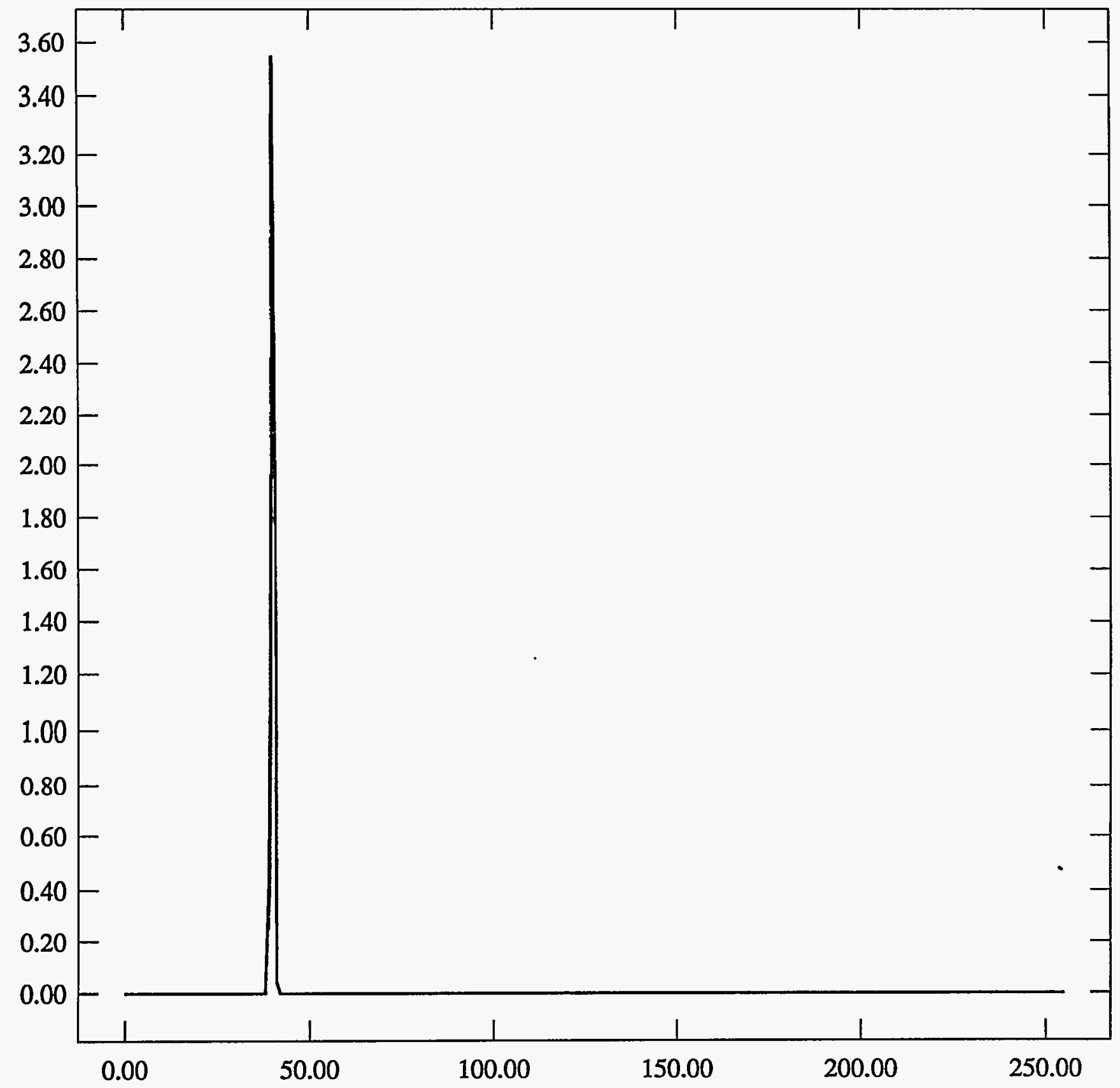


ST Camera: ST1\#04-10 -30C \#4: int_time= 50ms, offset= 0, gain=2 ( $150 \mathrm{e} / \mathrm{bit}$ ) Wed Jun 30 14:23:04 1993 Pixel Values Min 78 Max 81 Mean 79.2 Sigma $0.58 \times 10^{3}$

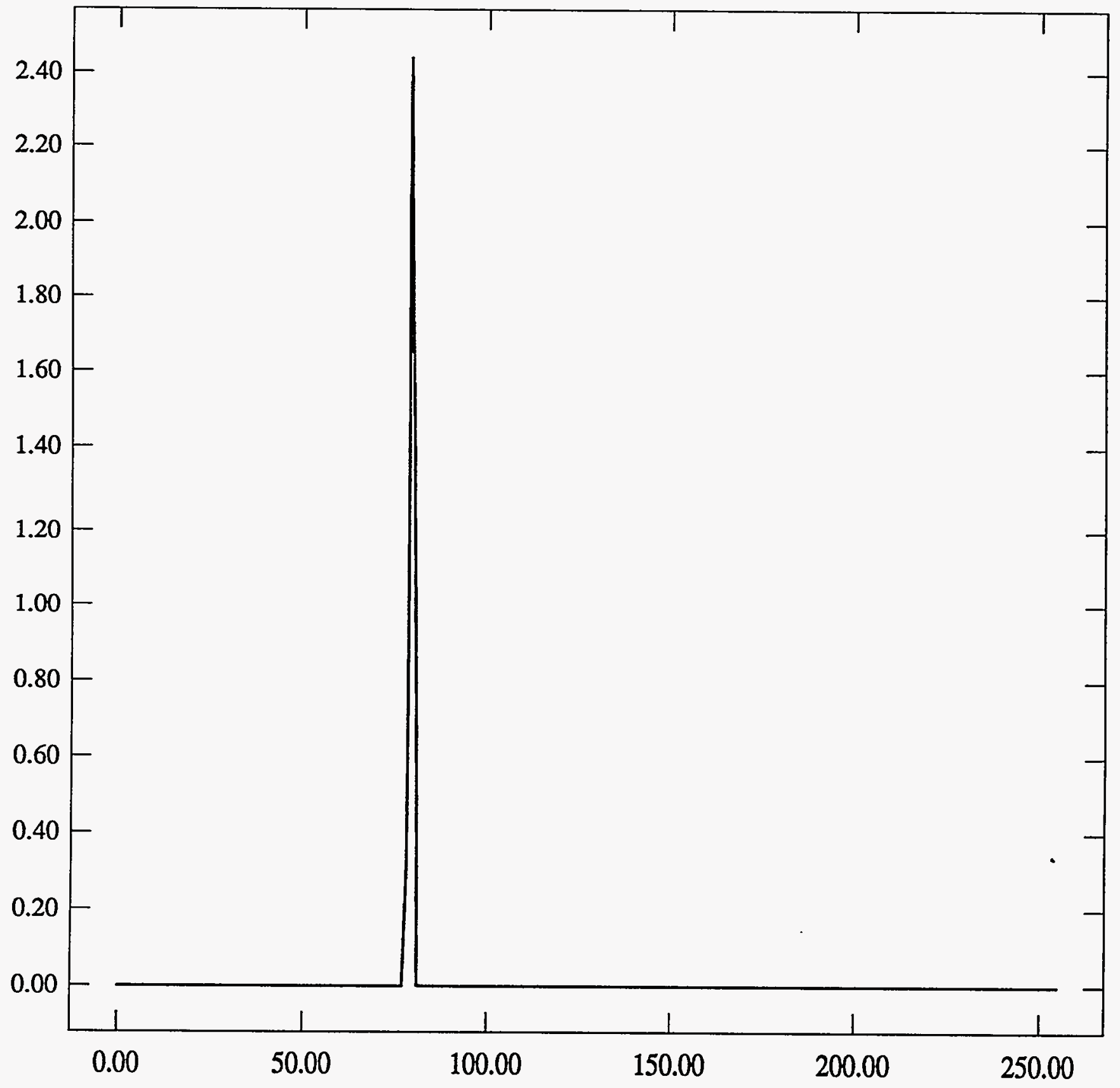


ST Camera: ST1\#04-10 -30C \#4: int_time=100ms, offset= 0, gain=2 ( 150 e/bit) Wed Jun 30 14:23:30 1993 Pixel Values Min 78 Max 80 Mean 79.2 Sigma $0.57 \times 10^{3}$

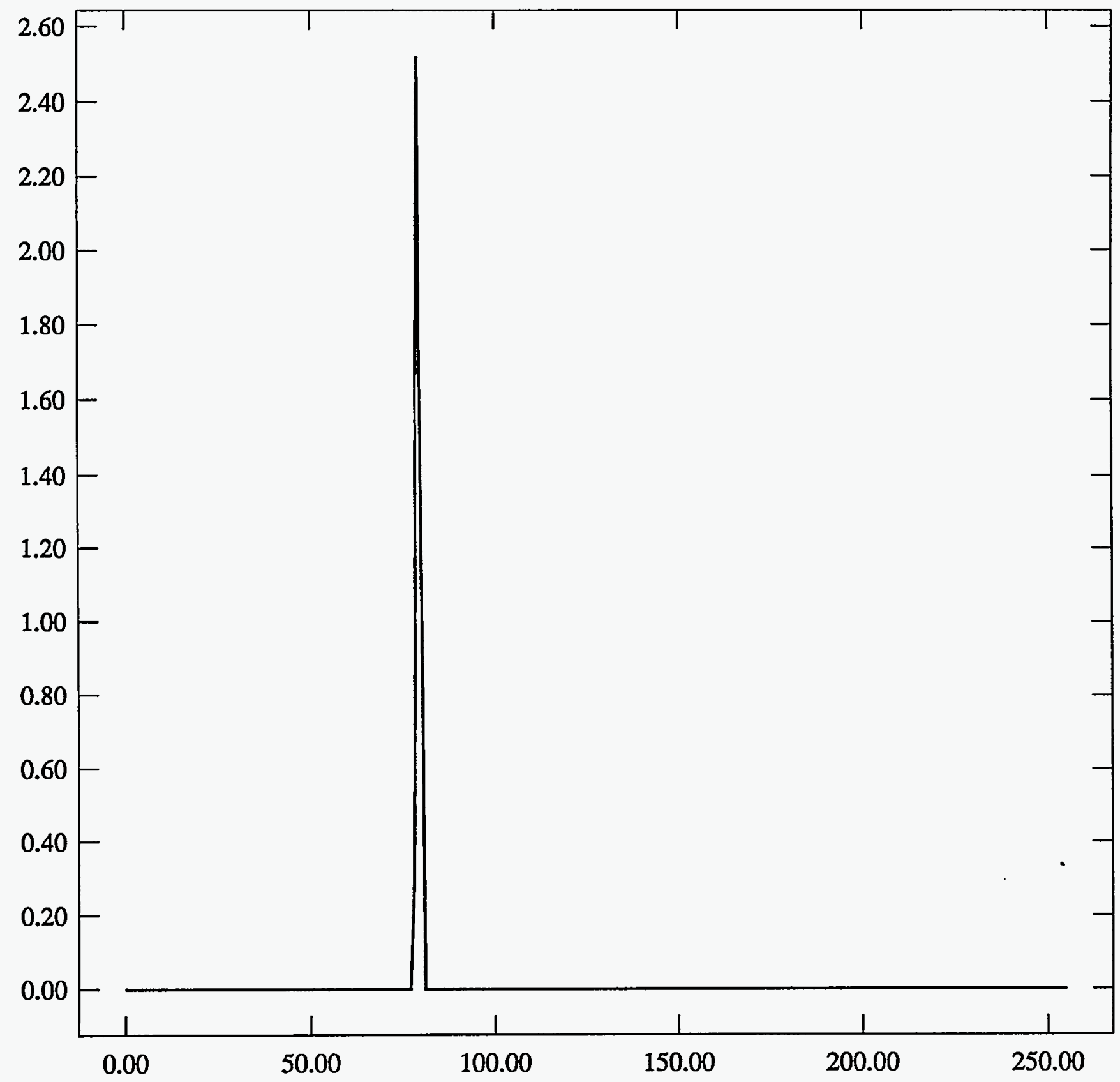


ST Camera: ST1\#04-10 -30C \#4: int_time=200ms, offset= 0, gain=2 ( $150 \mathrm{e} / \mathrm{bit}$ ) Wed Jun 30 14:24:34 1993 Pixel Values Min 78 Max 80 Mean 79.2 Sigma $0.58 \times 10^{3}$

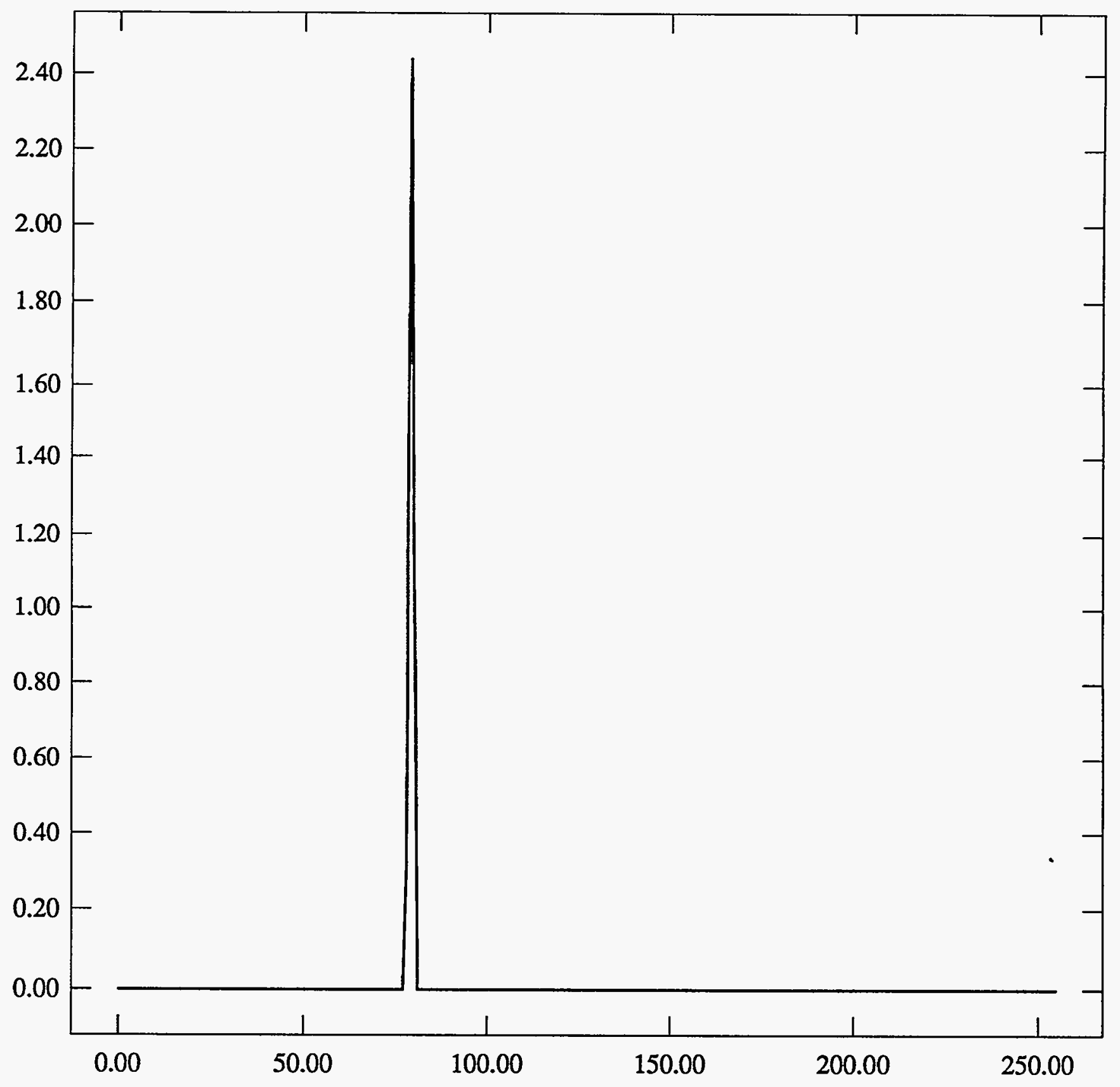


ST Camera: ST1\#04-10 -30C \#4: int_time= 50ms, offset= 0, gain=4 ( 75 e/bit) Wed Jun 30 14:24:50 1993 Pixel Values Min 145 Max 149 Mean 146.9 Sigma $0.69 \times 10^{3}$

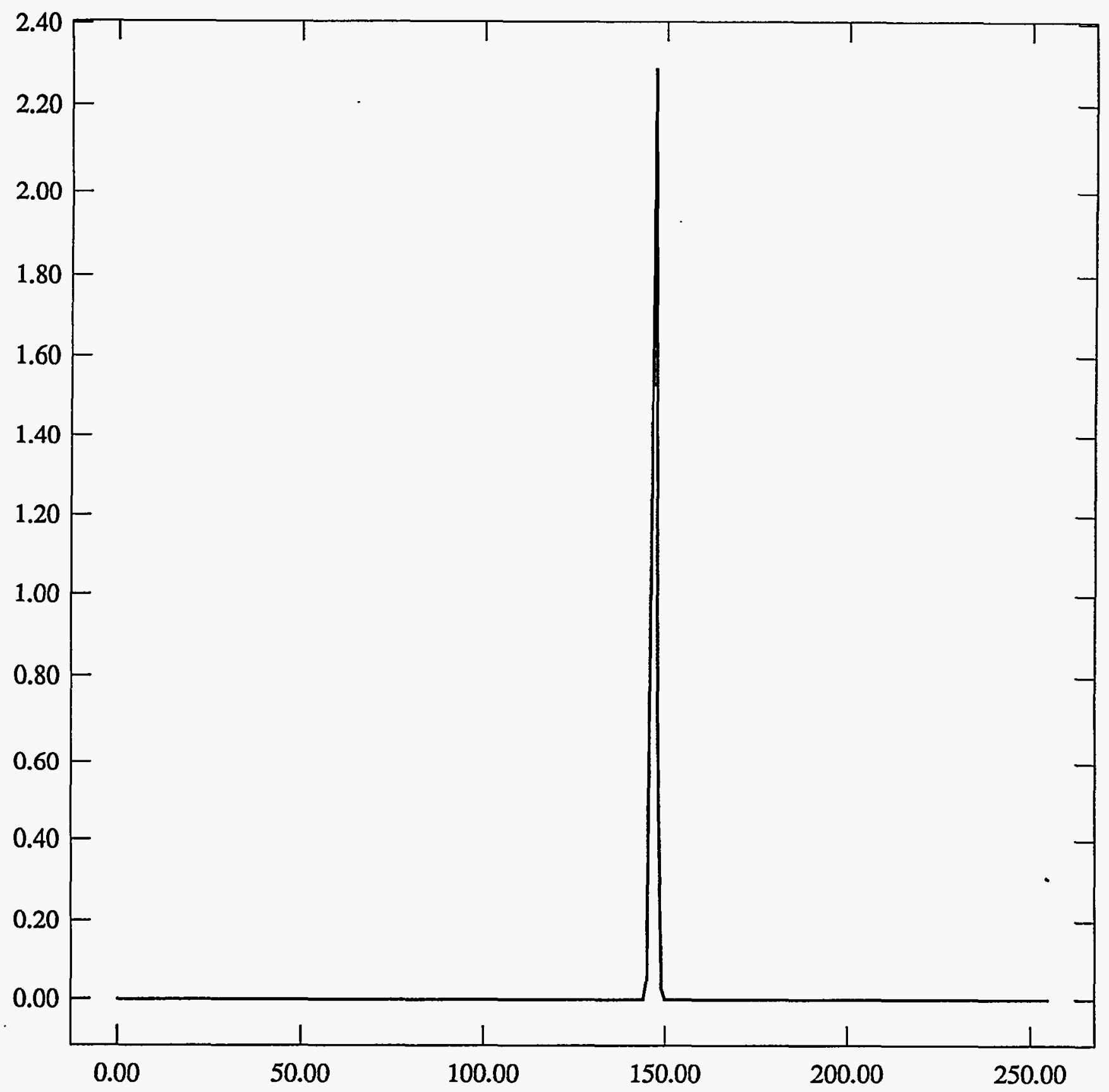


ST Camera: ST1\#04-10 -30C \#4: int_time=100ms, offset= 0, gain=4 ( 75 e/bit) Wed Jun 30 14:25:10 1993 Pixel Values Min 145 Max 149 Mean 146.9 Sigma $0.68 \times 10^{3}$

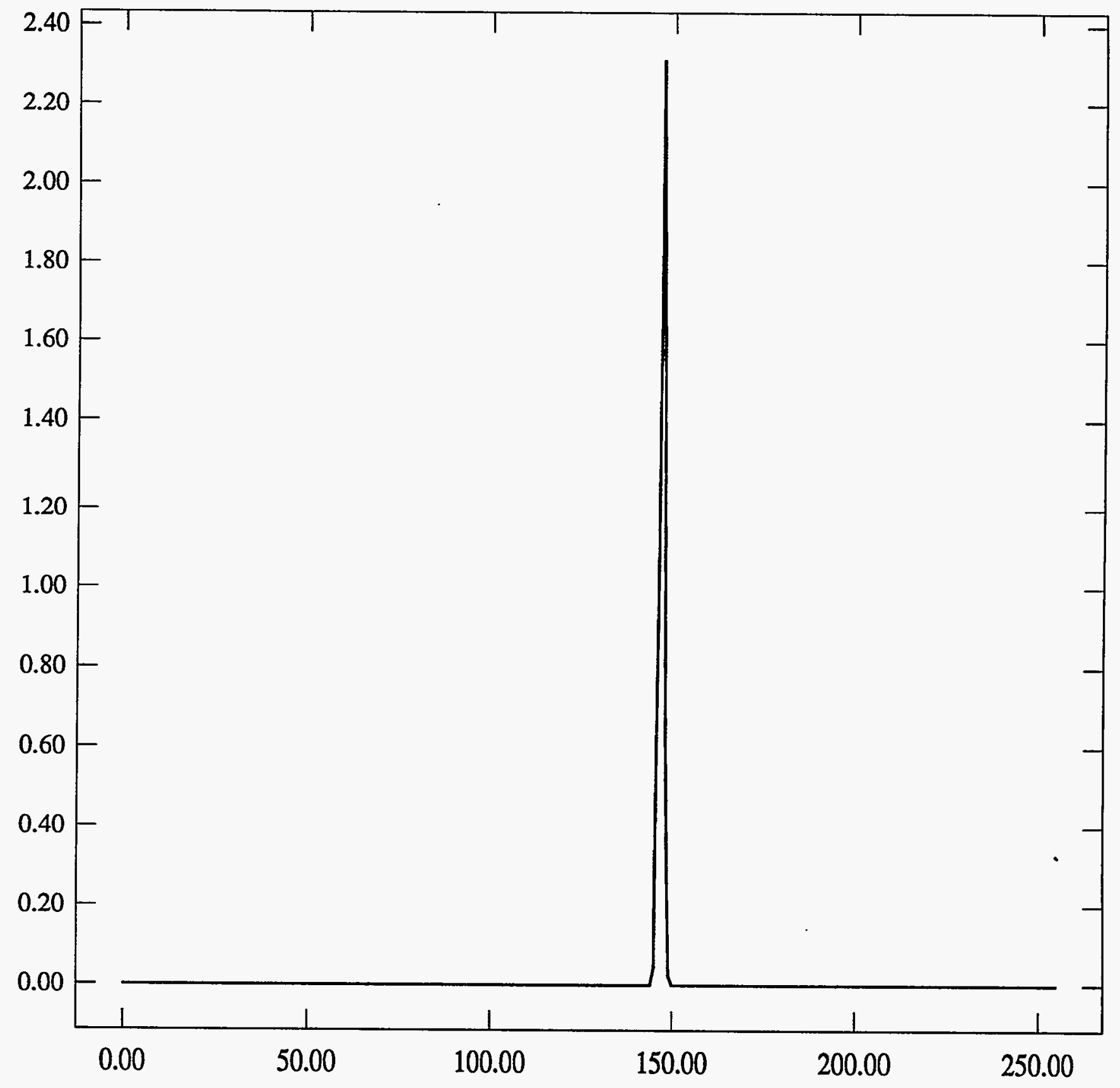


ST Camera: ST1\#04-10 -30C \#4: int_time=200ms, offset= 0, gain=4 ( 75 e/bit) Wed Jun 30 14:25:27 1993 Pixel Values Min 145 Max 149 Mean 146.9 Sigma $0.70 \times 10^{3}$

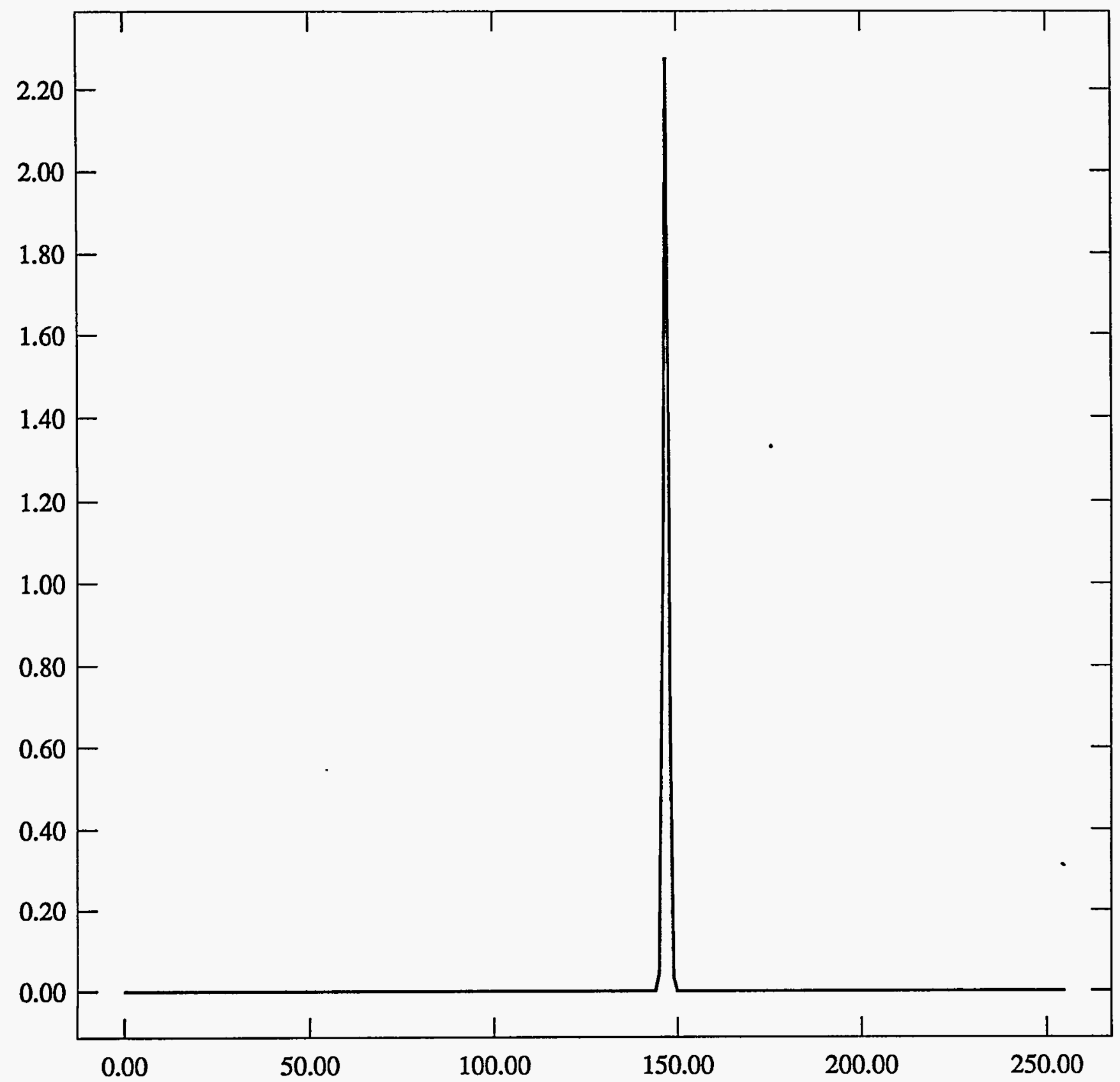


\#420C 15 min

ST Camera: ST1\#04-10 20C \#4: int_time= 50ms, offset= 0, gain=1 ( 350 e/bit) Wed Jun 30 15:01:35 1993 Pixel Values Min 39 Max 41 Mean 39.5 Sigma $0.50 \times 10^{3}$

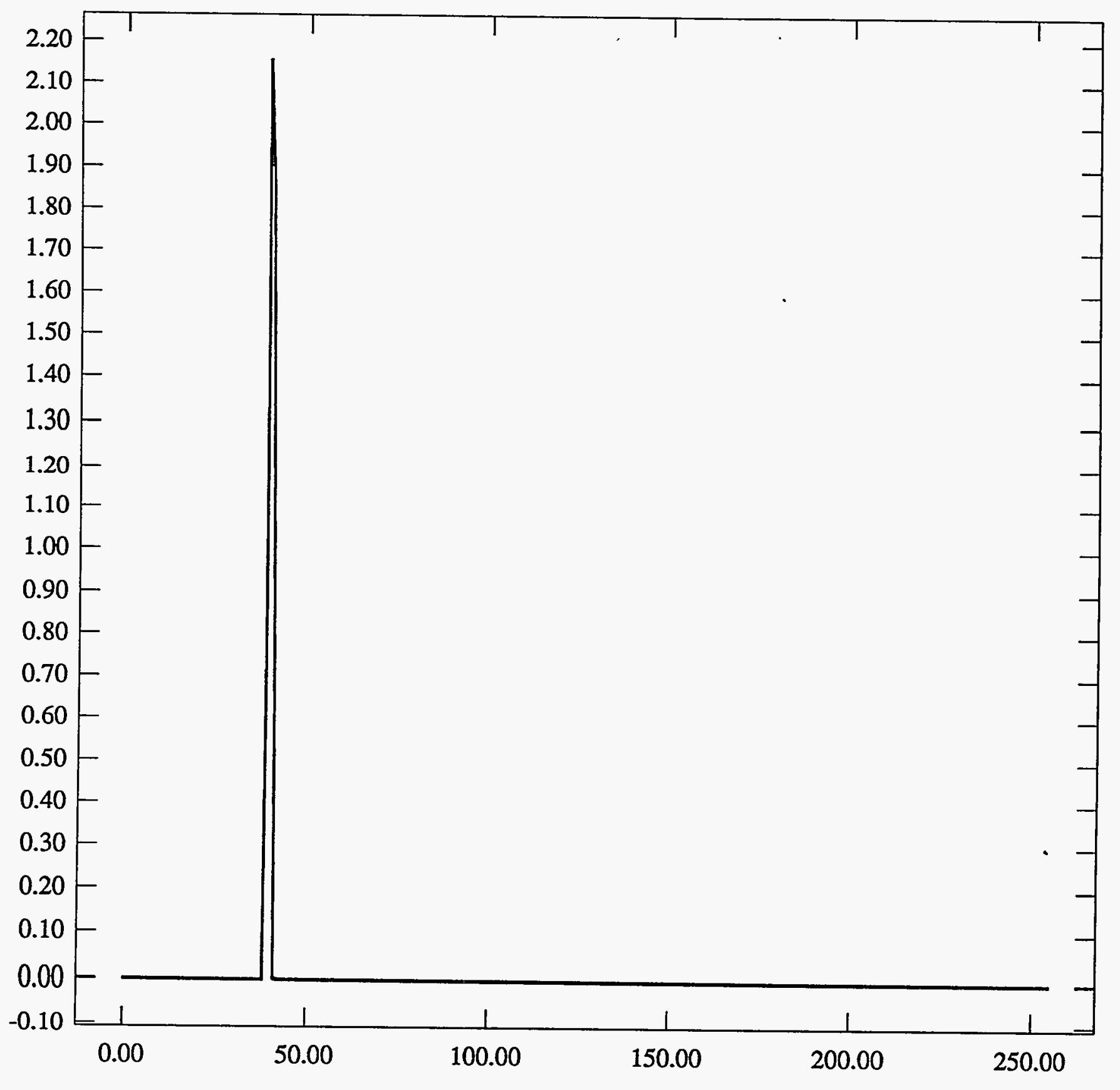


ST Camera: ST1\#04-10 20C \#4: int_time=100ms, offset= 0, gain=1 ( 350 e/bit) Wed Jun 30 15:01:48 1993 Pixel Values Min 38 Max 41 Mean 39.5 Sigma $0.50 \times 10^{3}$

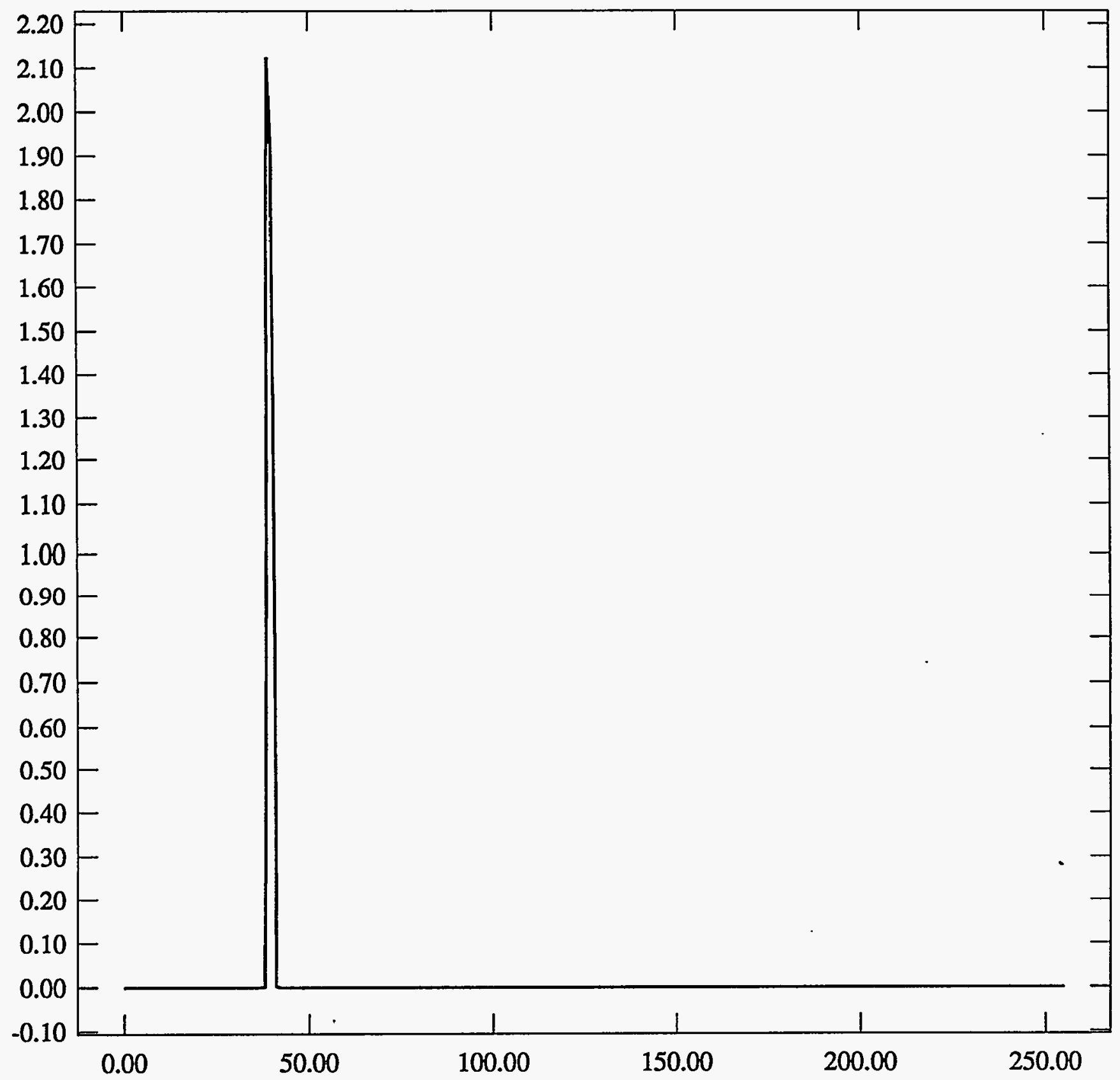


ST Camera: ST1\#04-10 20C \#4: int_time=200ms, offset= 0, gain=1 ( 350 e/bit) Wed Jun 30 15:01:59 1993 Pixel Values Min 39 Max 41 Mean 39.5 Sigma $0.50 \times 10^{3}$

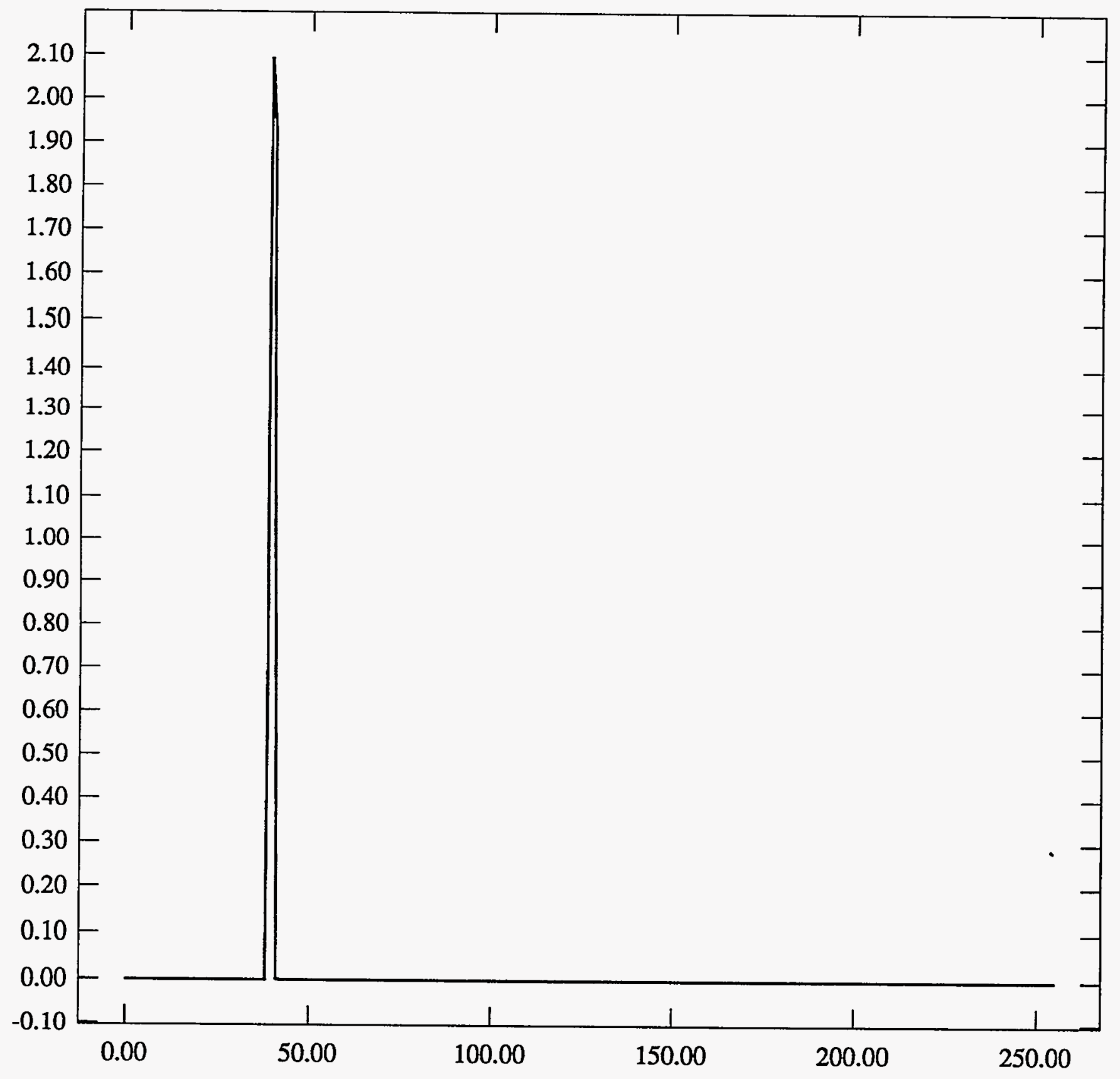


ST Camera: ST1\#0410 20C \#4: int_time= 50ms, offset= 0, gain=2 ( 150 e/bit) Wed Jun 30 15:02:16 1993 Pixel Values Min 77 Max 81 Mean 79.3 Sigma $0.77 \times 10^{3}$

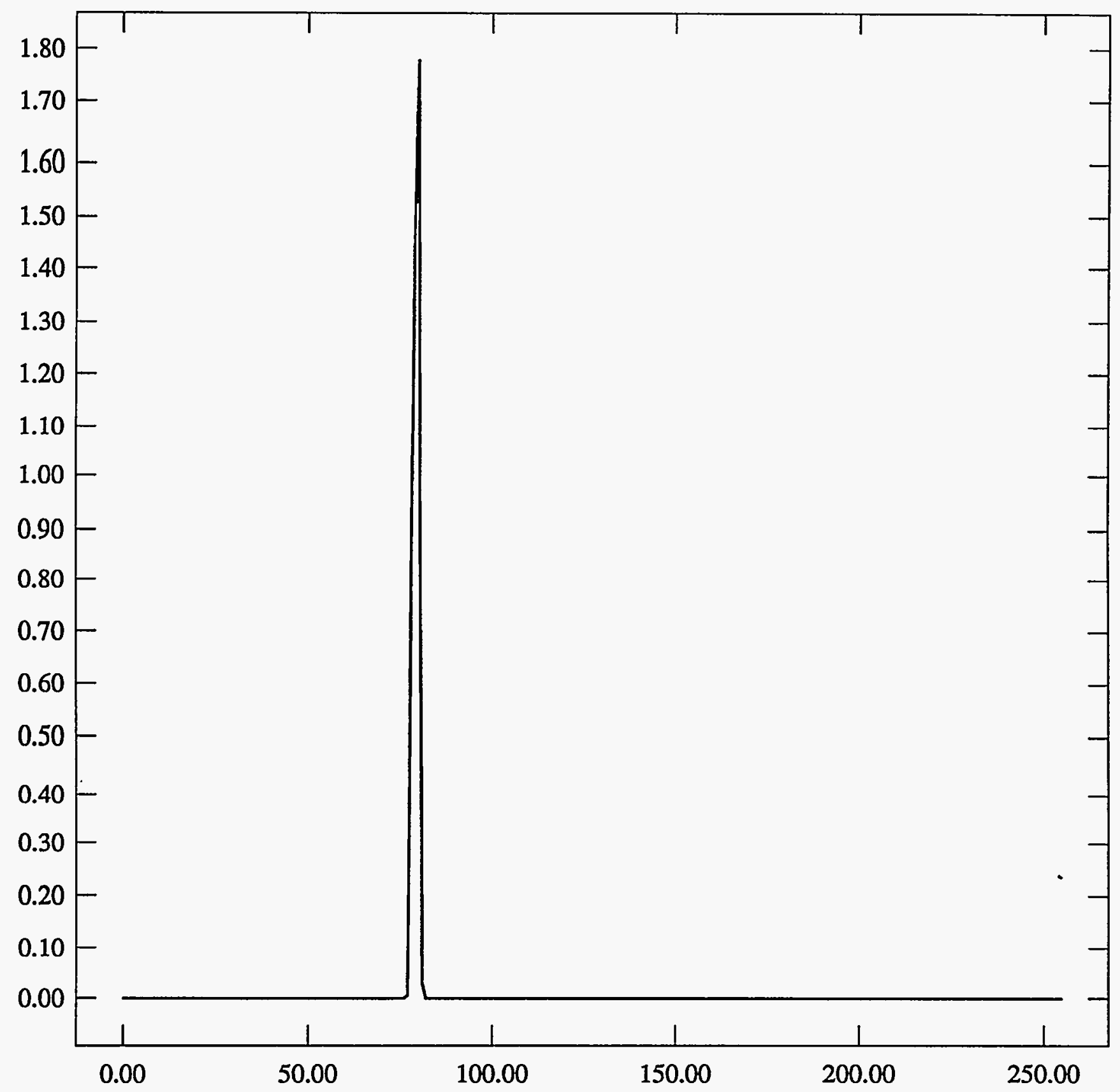


ST Camera: ST1\#04-10 20C \#4: int_time=100ms, offset= 0, gain=2 ( 150 e/bit) Wed Jun 30 15:02:32 1993 Pixel Values Min 77 Max 81 Mean 79.3 Sigma $0.76 \times 10^{3}$

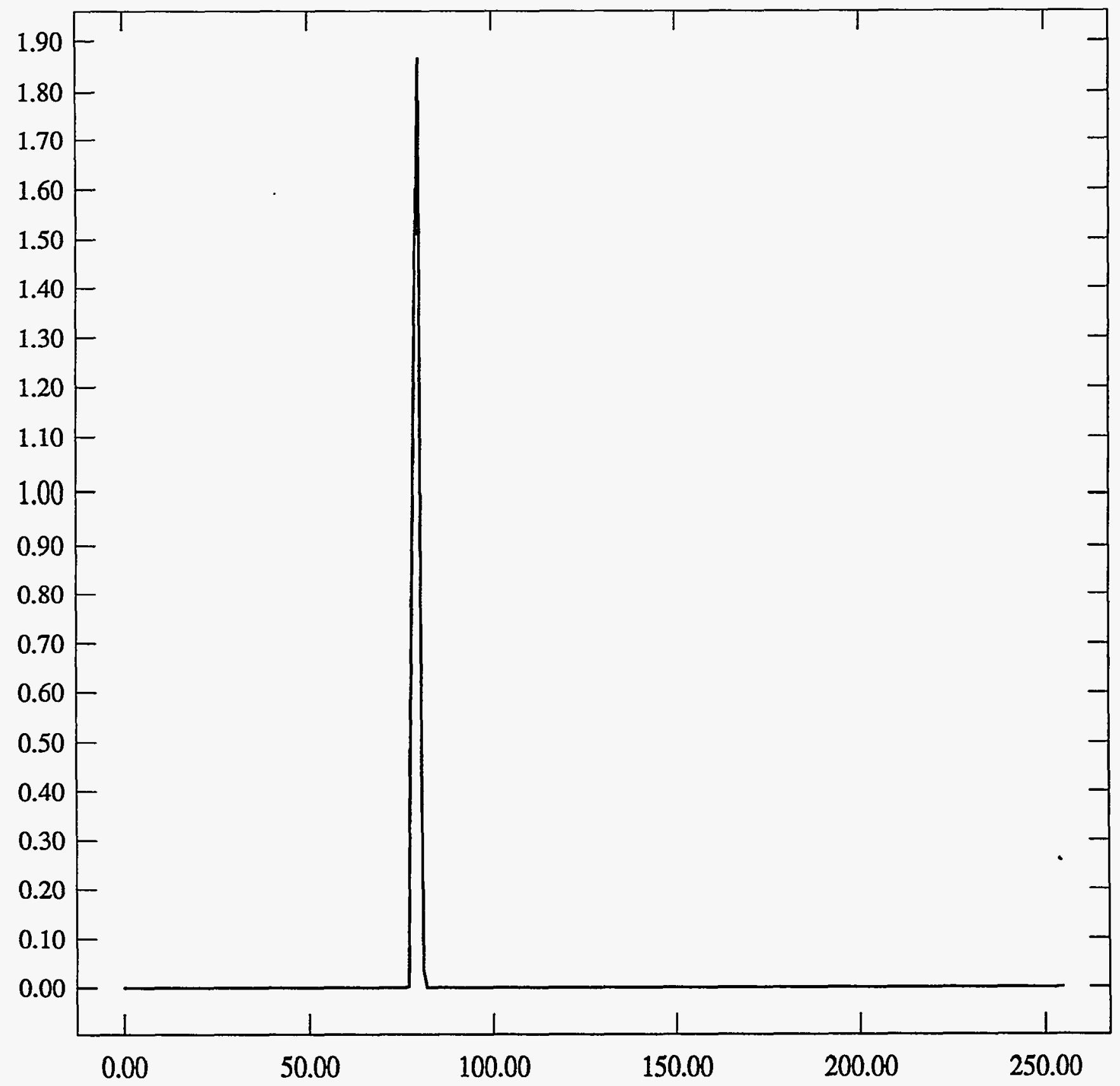


ST Camera: ST1\#04-10 20C \#4: int_time=200ms, offset= 0, gain=2 ( $150 \mathrm{e} / \mathrm{bit}$ ) Wed Jun 30 15:02:44 1993 Pixel Values Min 77 Max 81 Mean 79.2 Sigma $0.76 \times 10^{3}$

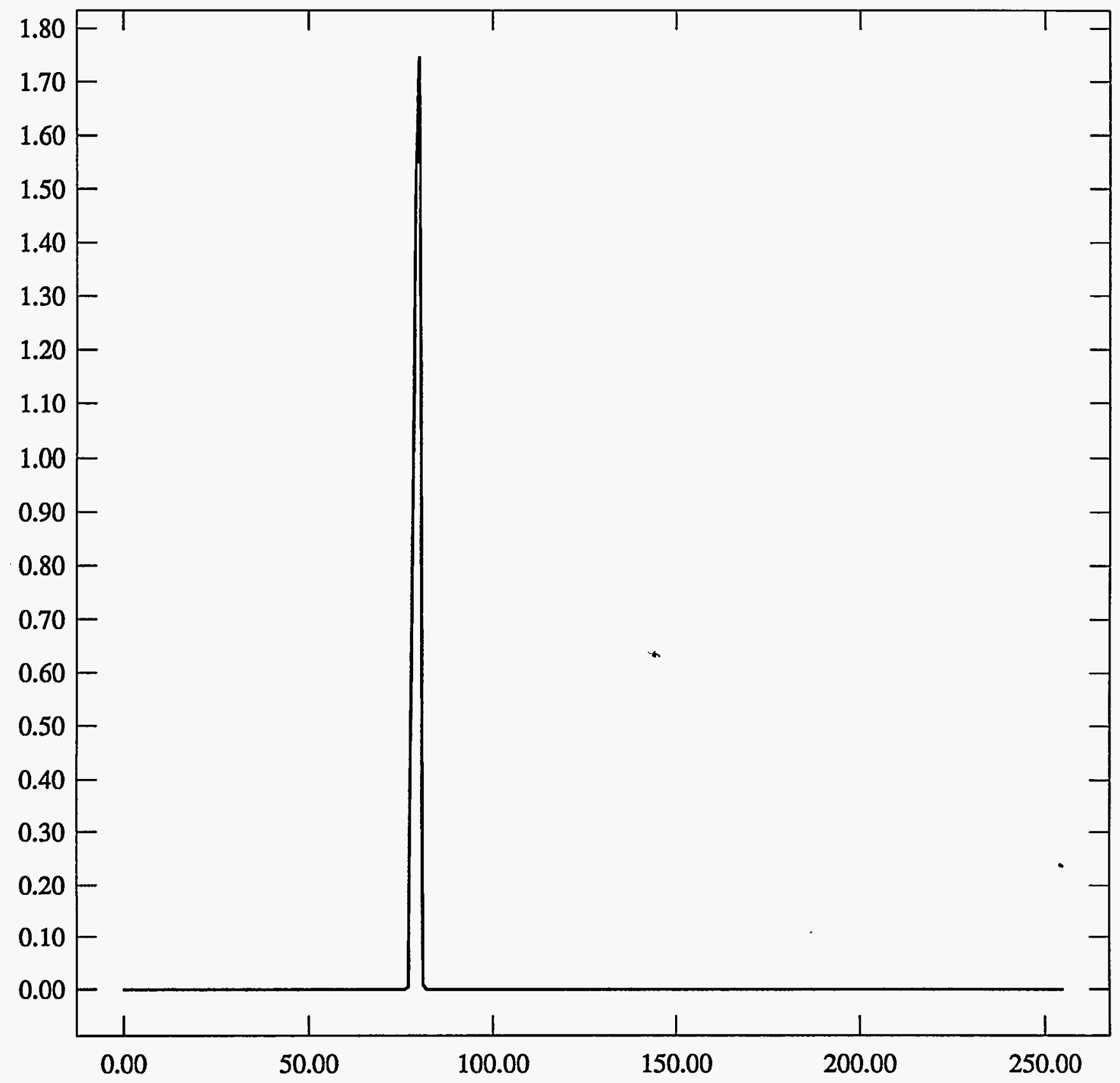


ST Camera: ST1\#04-10 20C \#4: int_time= 50ms, offset= 0, gain=4 ( 75 e/bit) Wed Jun 30 15:03:00 1993 Pixel Values Min 143 Max 148 Mean 145.1 Sigma $0.77 \times 10^{3}$

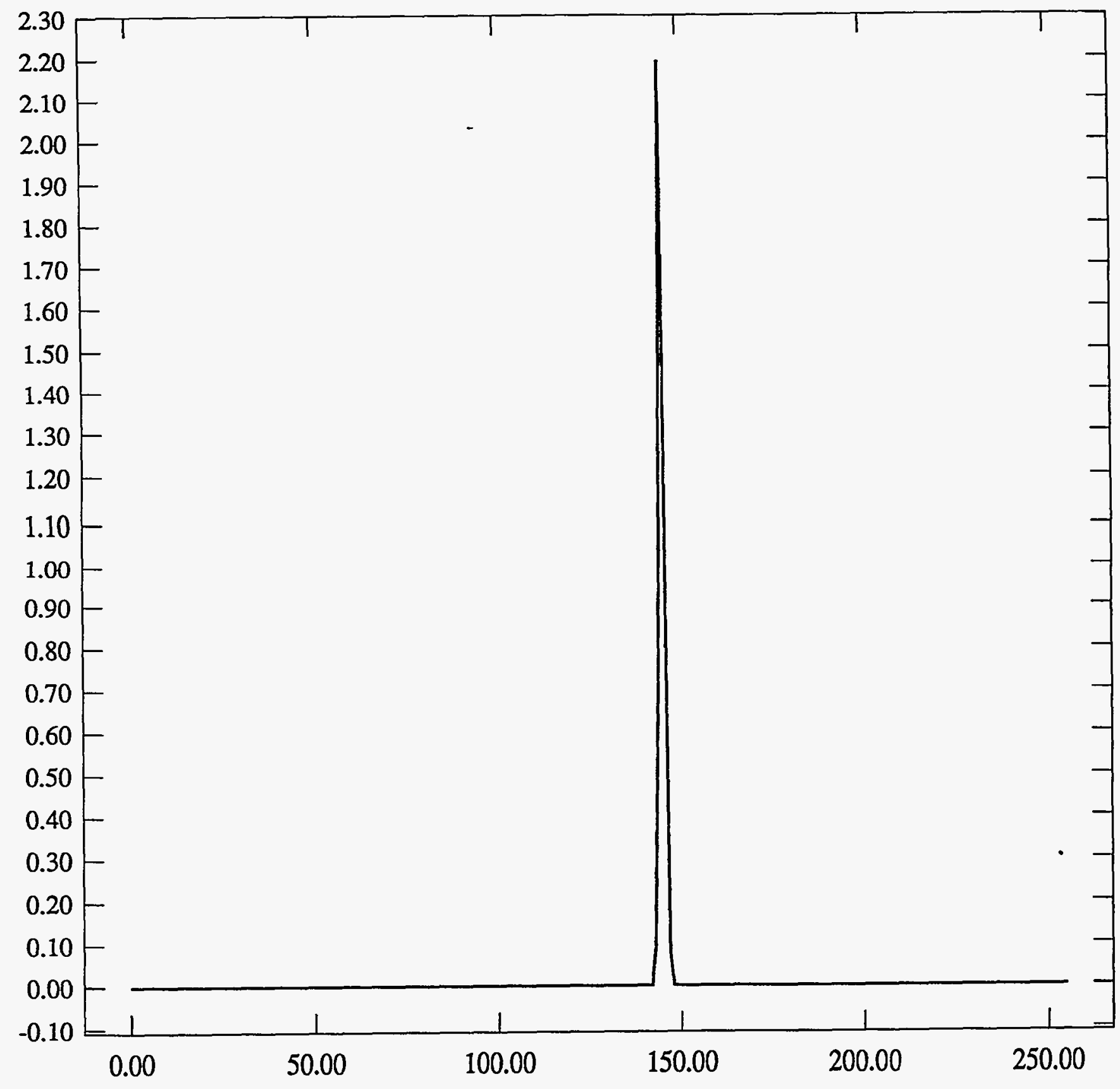


ST Camera: ST1\#04-10 20C \#4: int_time=100ms, offset= 0, gain=4 ( 75 e/bit) Wed Jun 30 15:03:12 1993 Pixel Values Min 143 Max 148 Mean 145.1 Sigma $0.75 \times 10^{3}$

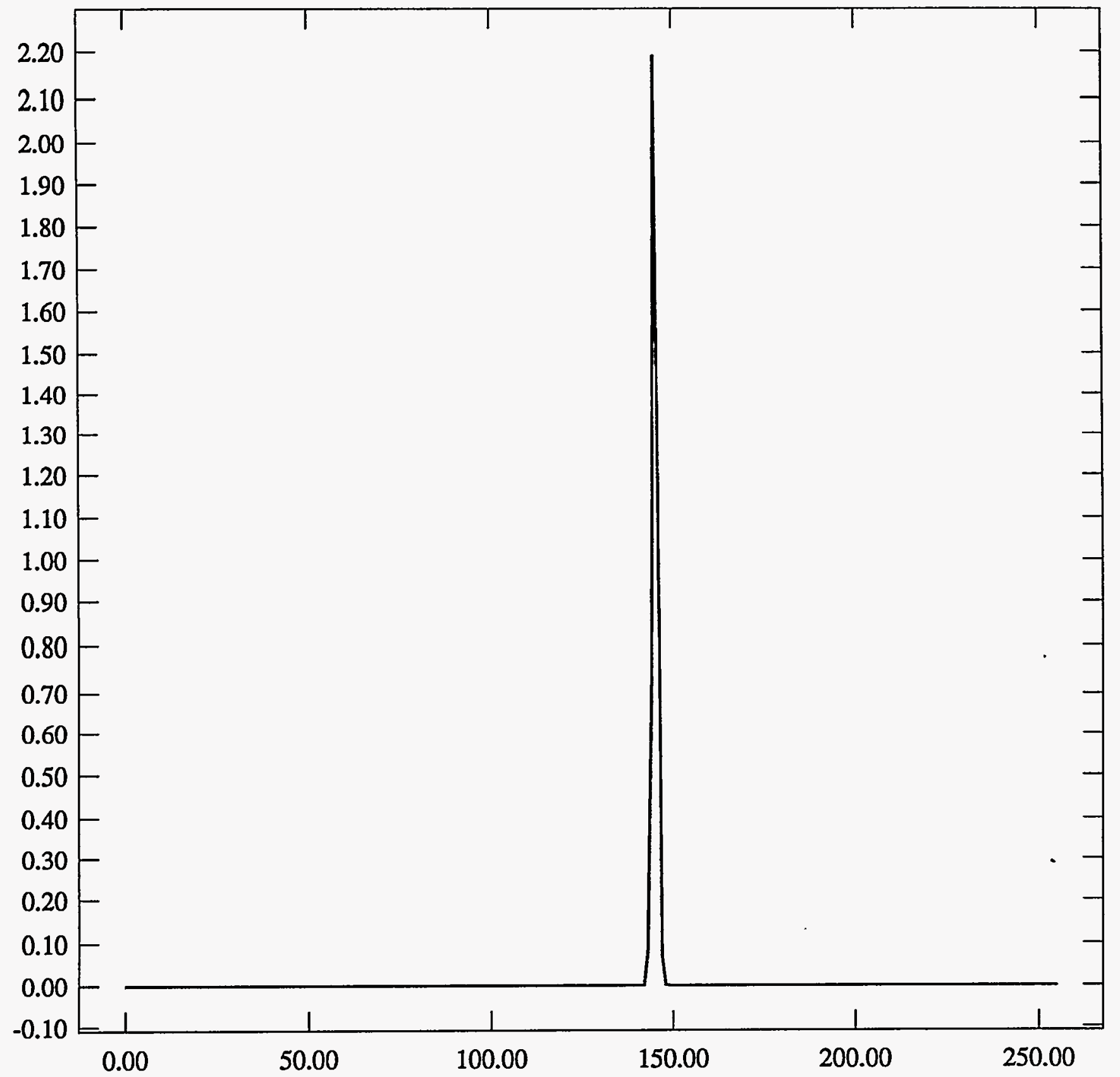


ST Camera: ST1\#04-10 20C \#4: int_time=200ms, offset= 0, gain=4 ( 75 e/bit) Wed Jun 30 15:03:24 1993 Pixel Values Min 142 Max 147 Mean 145.0 Sigma $0.77 \times 10^{3}$

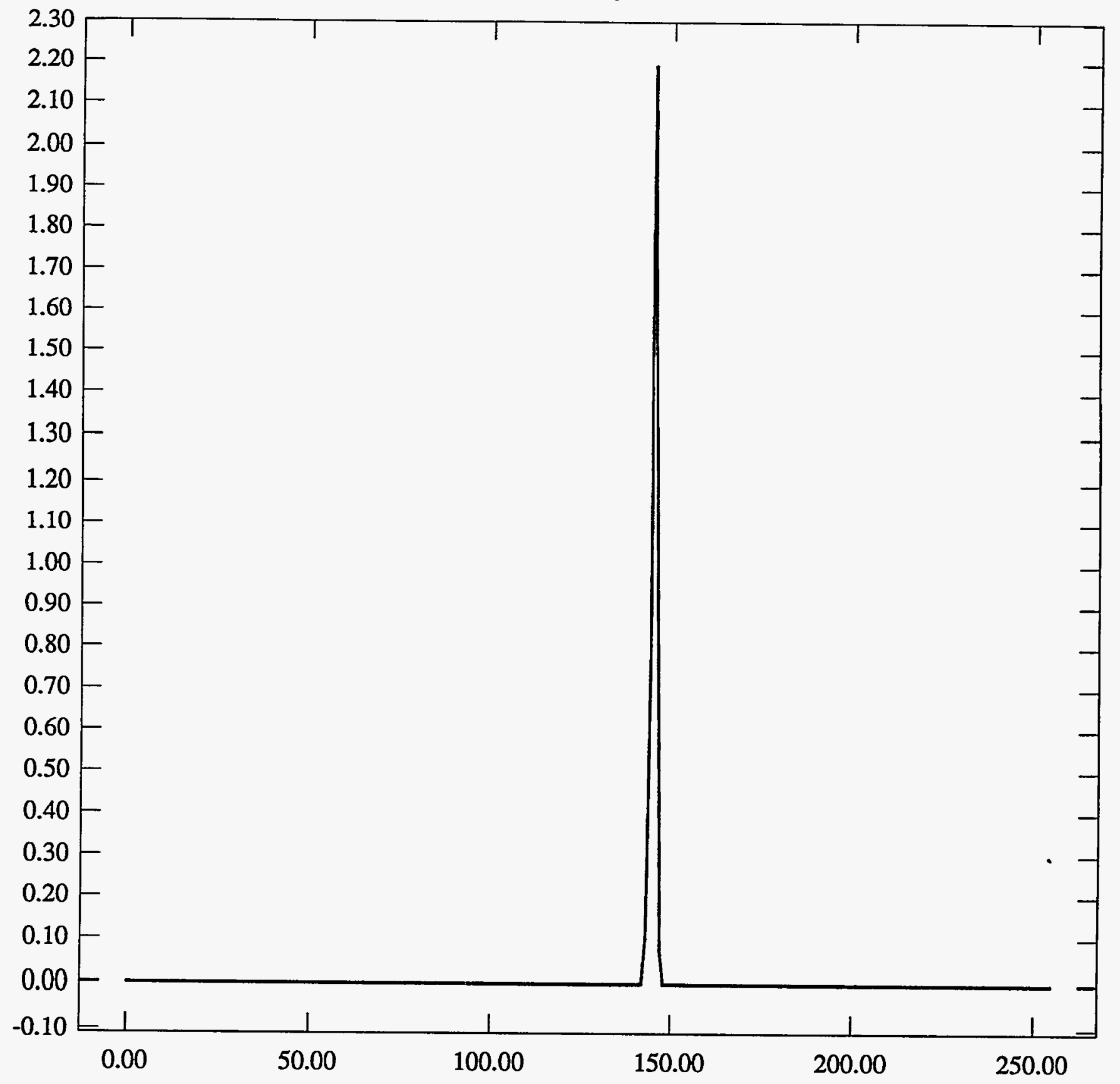


H $20 C$ END ON CYCCE

ST Camera: ST1\#04-10 20C \#4: int_time= 50ms, offset= 0, gain=1 ( $350 \mathrm{e} / \mathrm{bit}$ ) Wed Jun 30 15:41:02 1993

Pixel Values Min 39 Max 41 Mean 39.4 Sigma $0.49 \times 10^{3}$

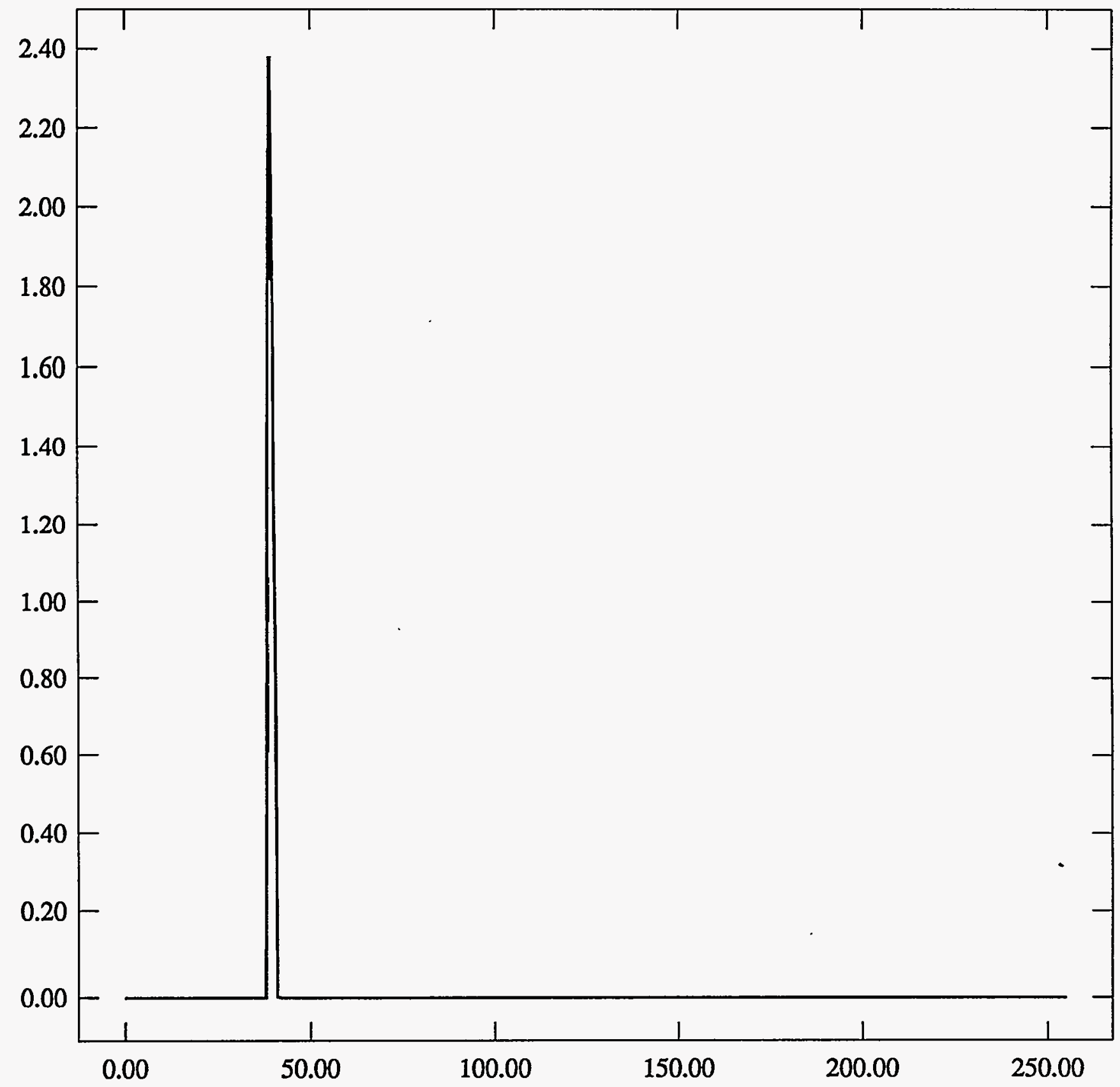


ST Camera: ST1\#04-10 20C \#4: int_time=100ms, offset= 0, gain=1 ( 350 e/bit) Wed Jun 30 15:41:35 1993 Pixel Values Min 39 Max 40 Mean 39.4 Sigma $0.50 \times 10^{3}$

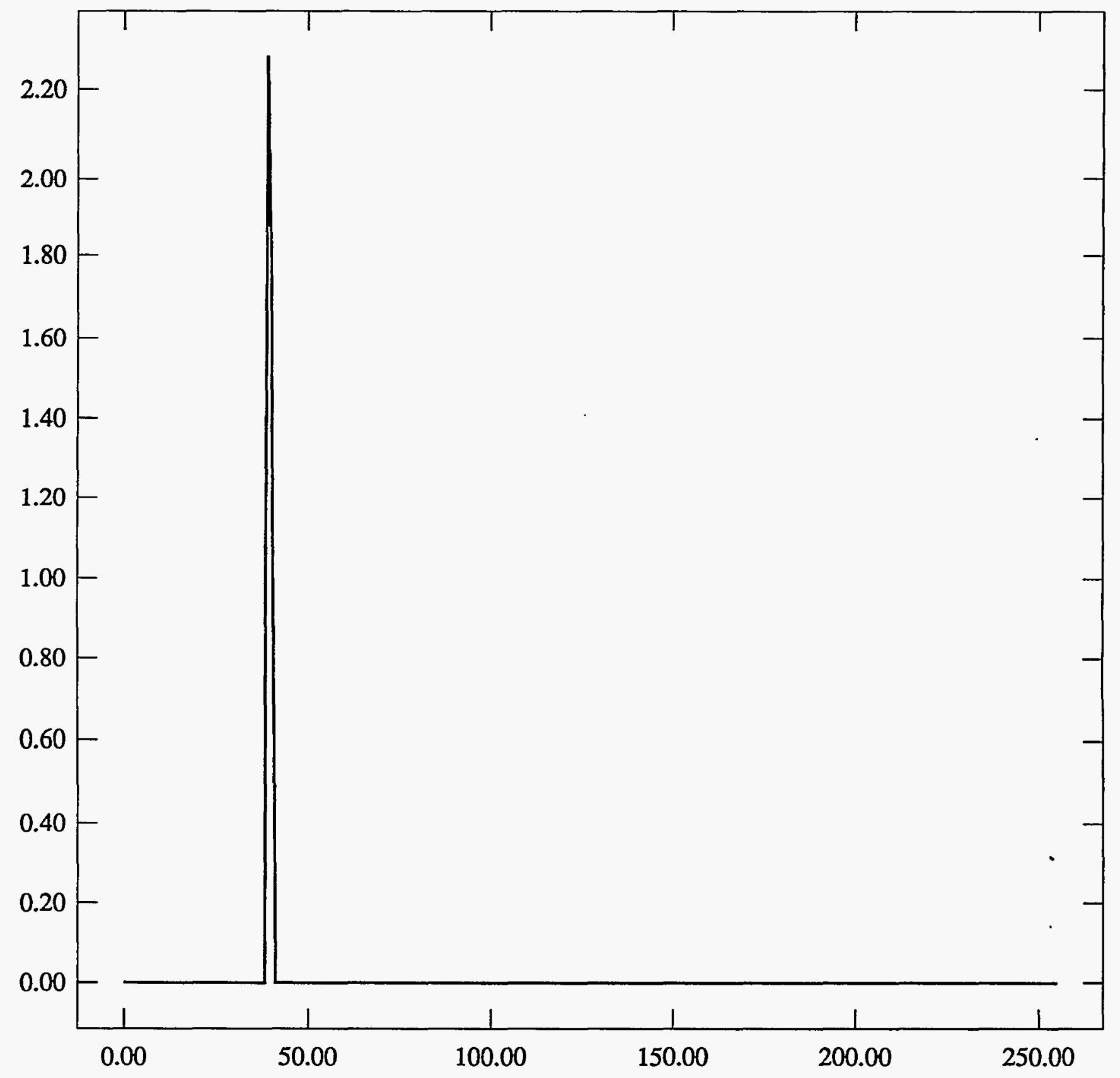


ST Camera: ST1\#04-10 20C \#4: int_time=200ms, offset= 0, gain=1 ( $350 \mathrm{e} / \mathrm{bit}$ ) Wed Jun 30 15:41:46 1993 Pixel Values Min 39 Max 41 Mean 39.4 Sigma $0.49 \times 10^{3}$

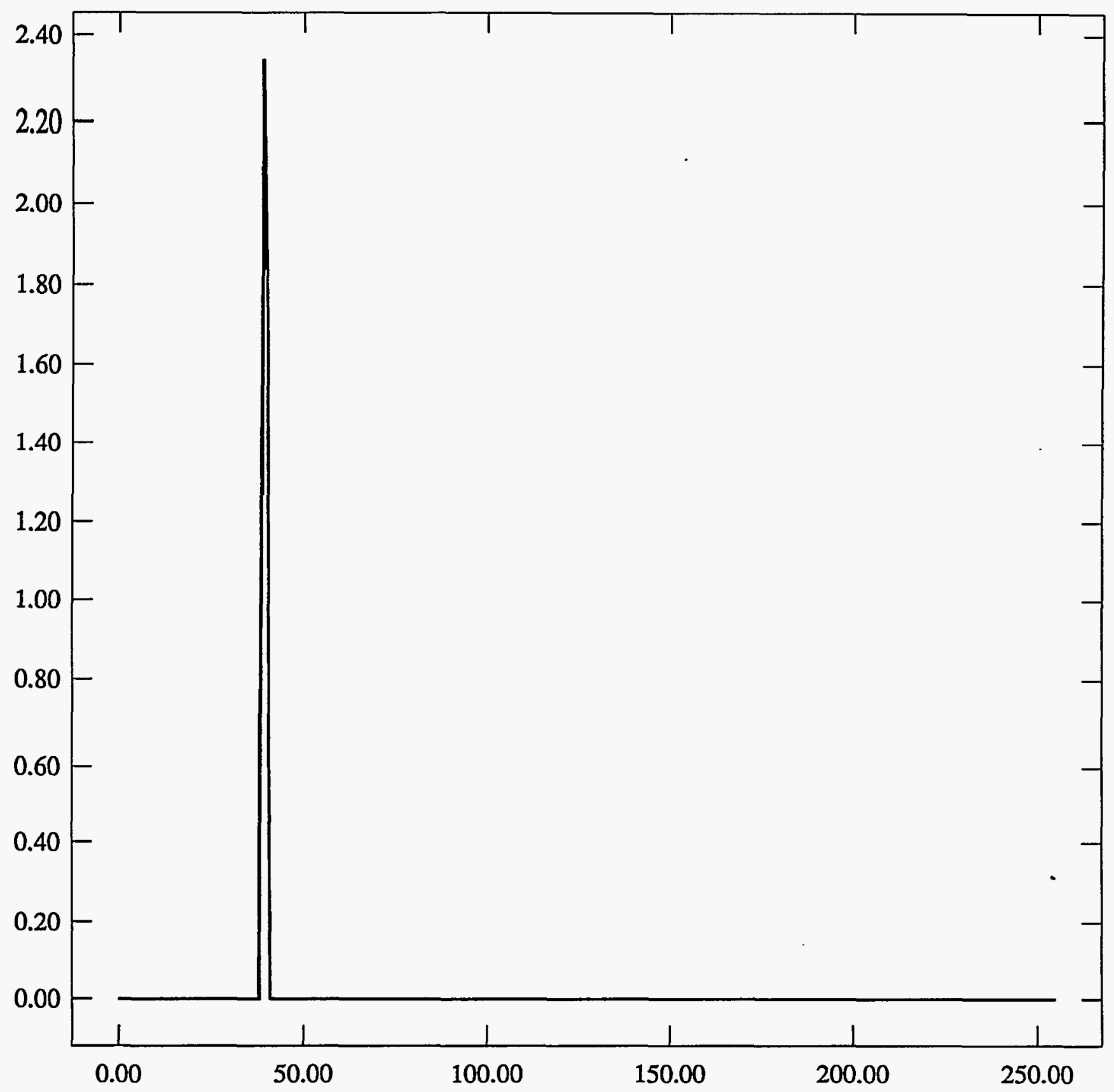


ST Camera: ST1\#04-10 20C \#4: int_time= 50ms, offset= 0, gain=2 ( 150 e/bit) Wed Jun 30 15:42:01 1993 Pixel Values Min 77 Max 81 Mean 79.2 Sigma $0.77 \times 10^{3}$

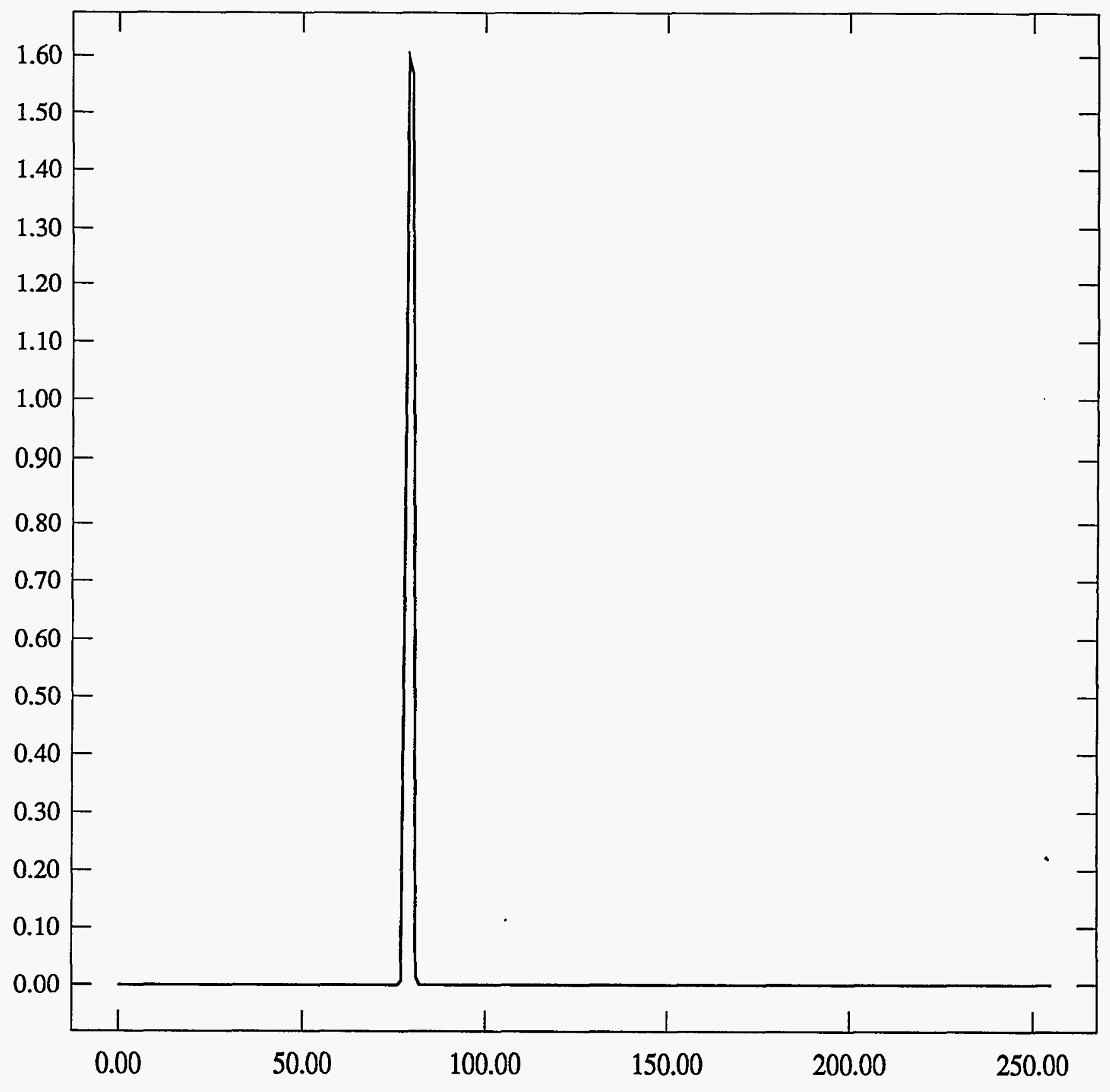


ST Camera: ST1\#04-10 20C \#4: int_time=100ms, offset= 0, gain=2 ( 150 e/bit) Wed Jun 30 15:42:16 1993 Pixel Values Min 77 Max 81 Mean 79.1 Sigma $0.77 \times 10^{3}$

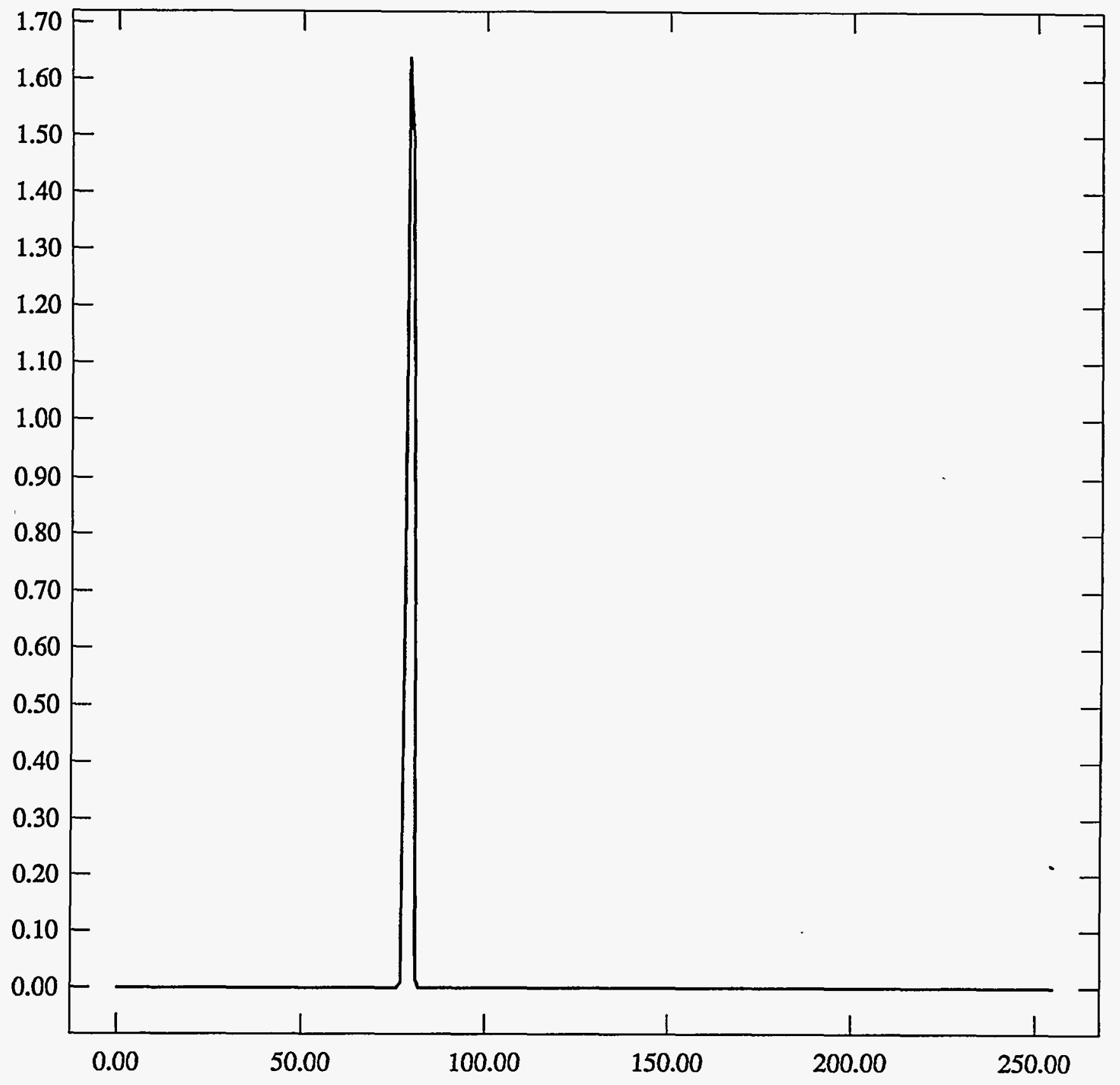


ST Camera: ST1\#04-10 20C \#4: int_time=200ms, offset= 0, gain=2 ( 150 e/bit) Wed Jun 30 15:42:30 1993 Pixel Values Min 77 Max 81 Mean 79.2 Sigma $0.77 \times 10^{3}$

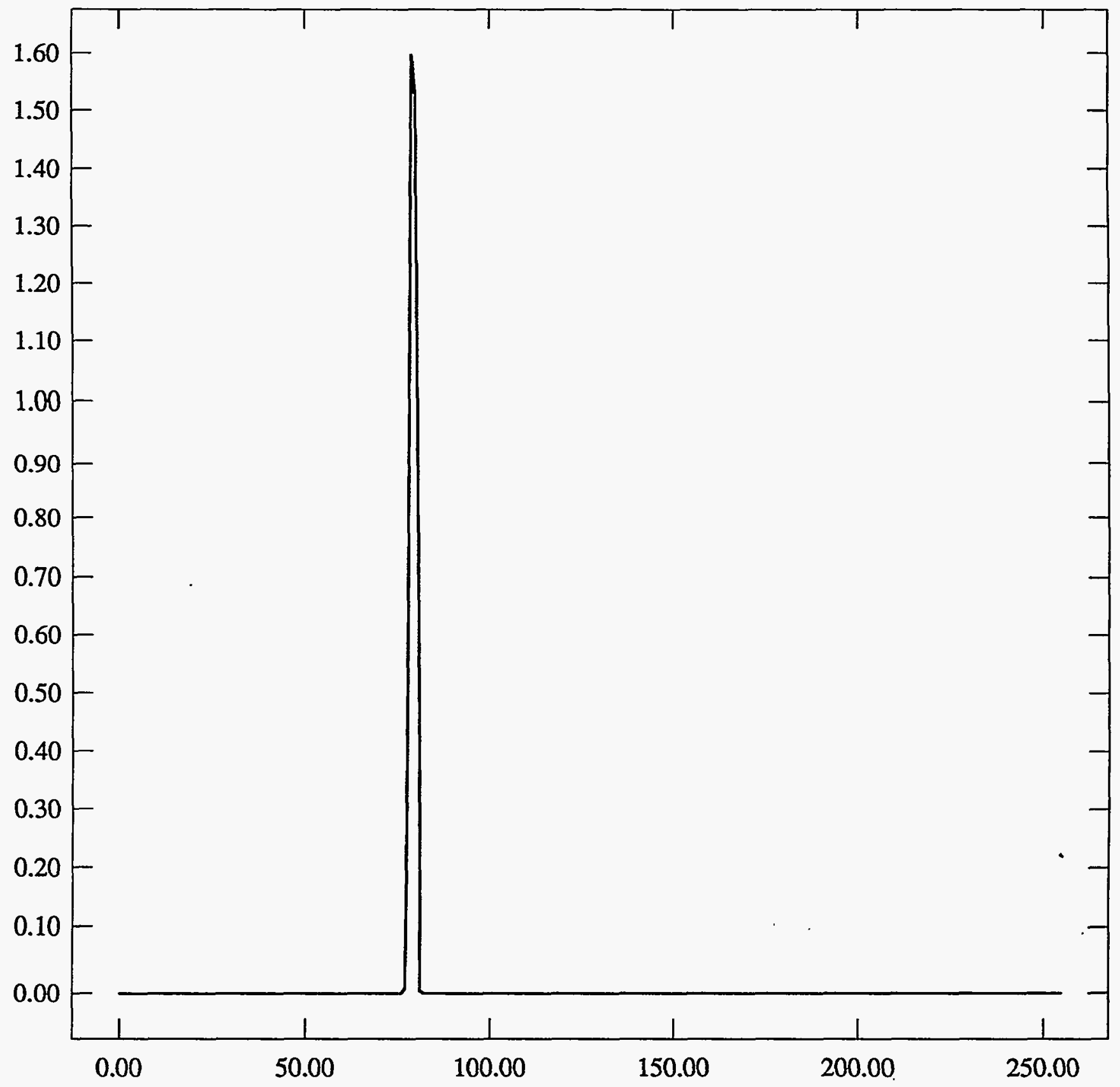


ST Camera: ST1\#04-10 20C \#4: int_time= 50ms, offset= 0, gain=4 ( 75 e/bit) Wed Jun 30 15:42:43 1993 Pixel Values Min 142 Max 148 Mean 144.9 Sigma $0.77 \times 10^{3}$

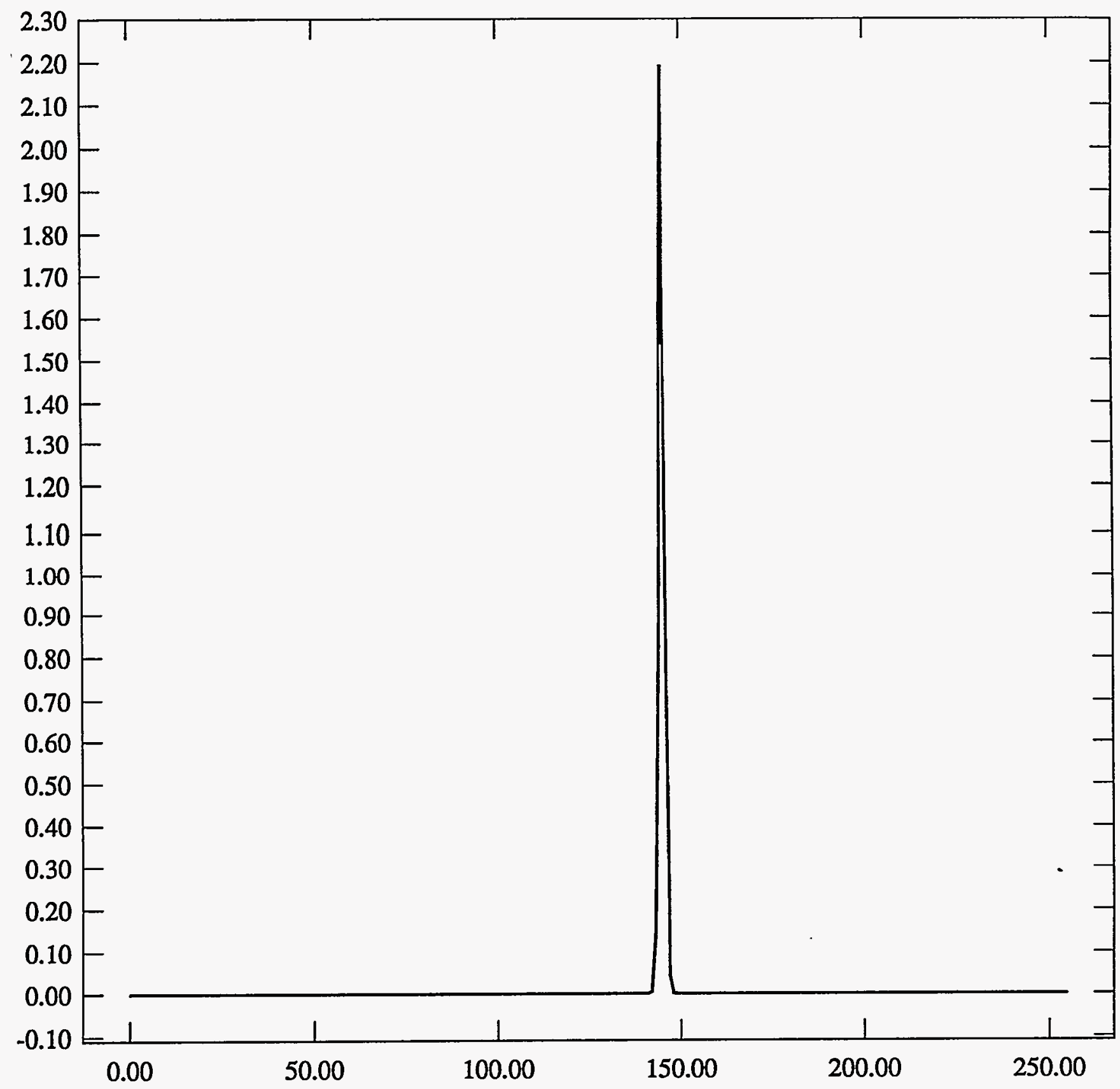


ST Camera: ST1\#04-10 20C \#4: int_time=100ms, offset= 0, gain=4 ( 75 e/bit) Wed Jun 30 15:42:57 1993 Pixel Values Min 142 Max 148 Mean 145.0 Sigma $0.81 \times 10^{3}$

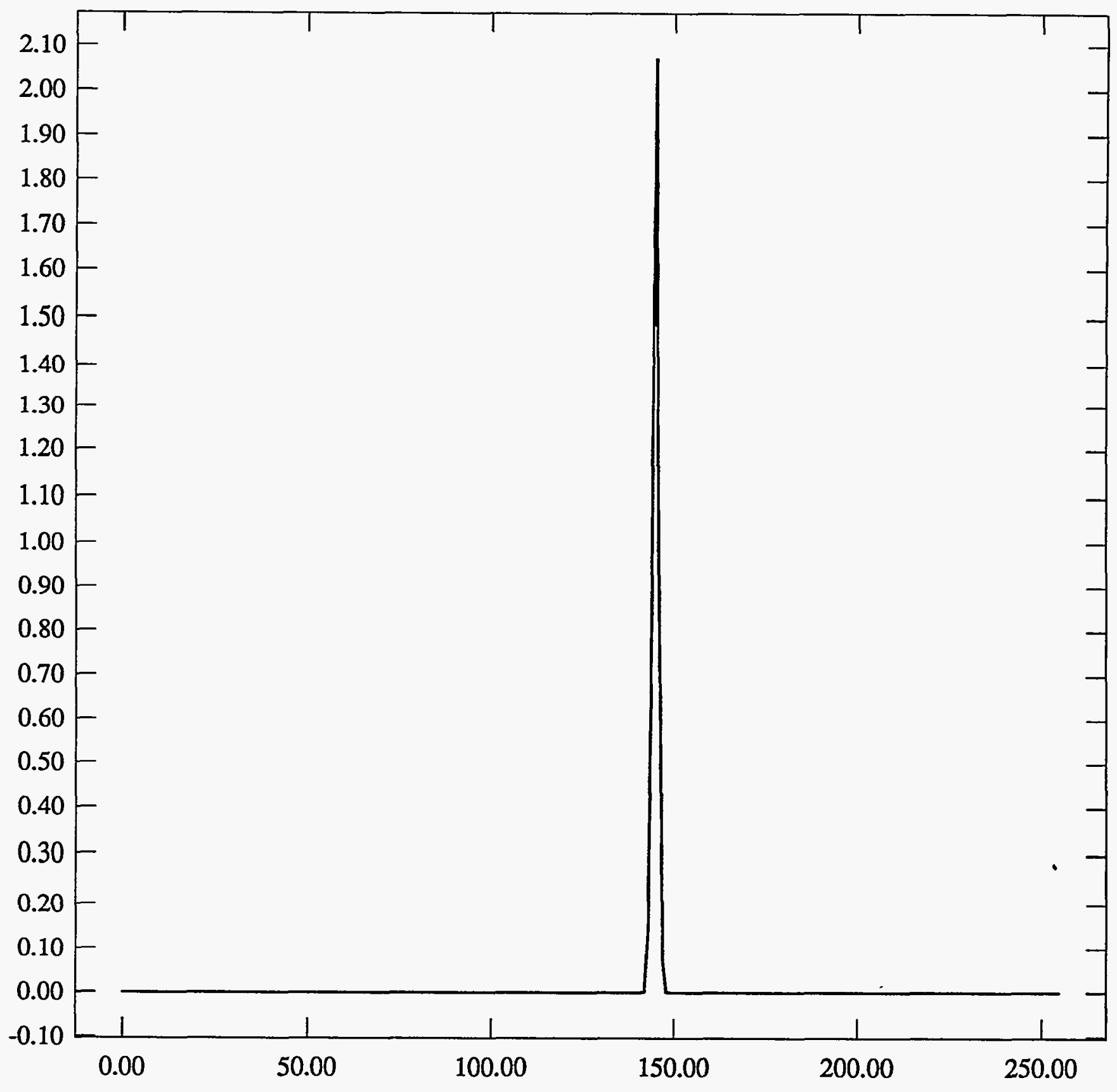


ST Camera: ST1\#04-10 20C \#4: int_time=200ms, offset= 0, gain=4 ( 75 e/bit) Wed Jun 30 15:43:15 1993 Pixel Values Min 143 Max 148 Mean 144.9 Sigma $0.78 \times 10^{3}$

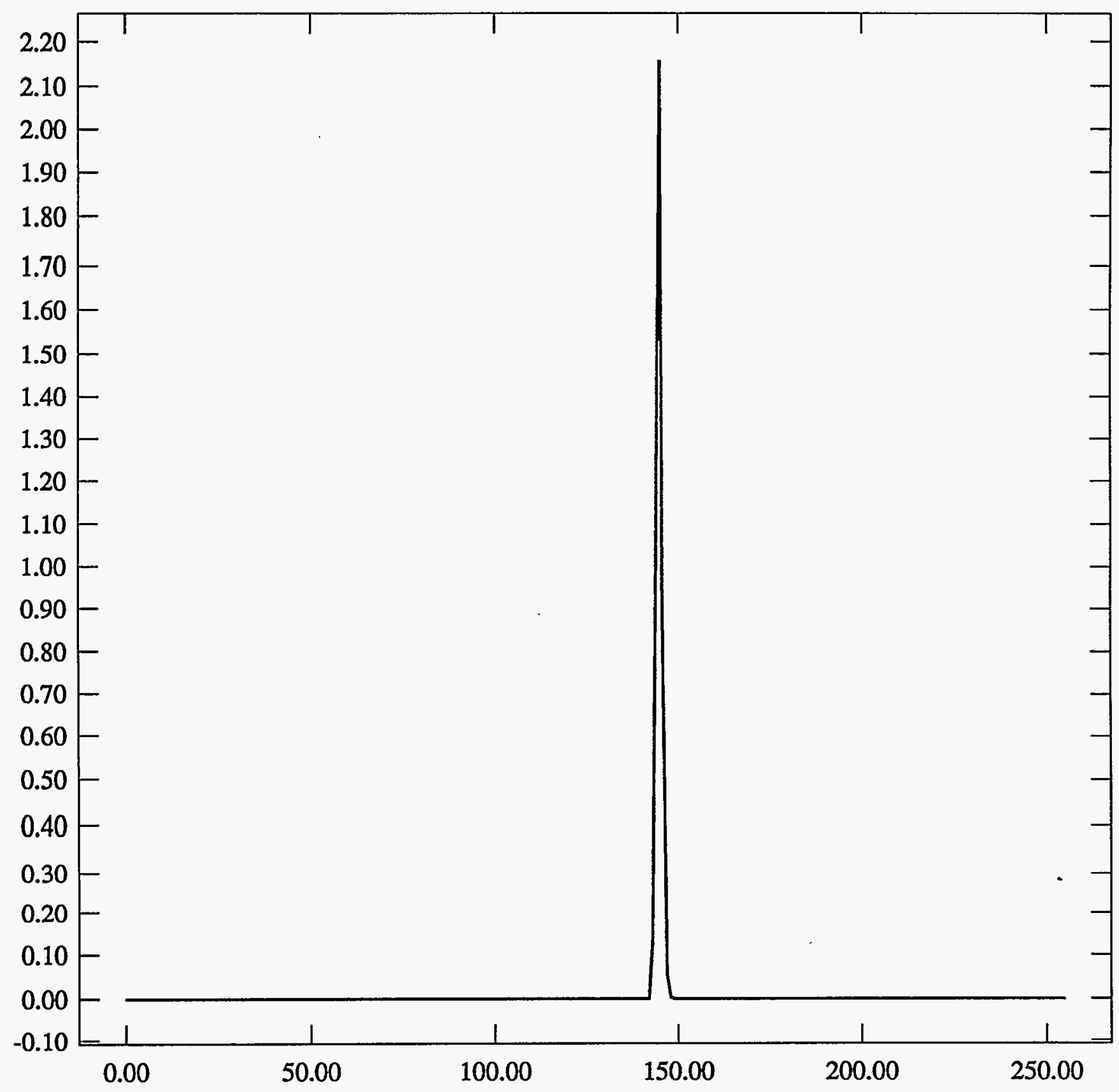




$$
-155-30 \mathrm{C} \quad 15 \mathrm{~min}
$$

ST Camera: ST1\#04-10 -30C \#5: int_time= 50ms, offset= 0, gain=1 (350 e/bit) Wed Jun 30 16:18:50 1993 Pixel Values Min 39 Max 41 Mean 39.9 Sigma $0.37 \times 10^{3}$

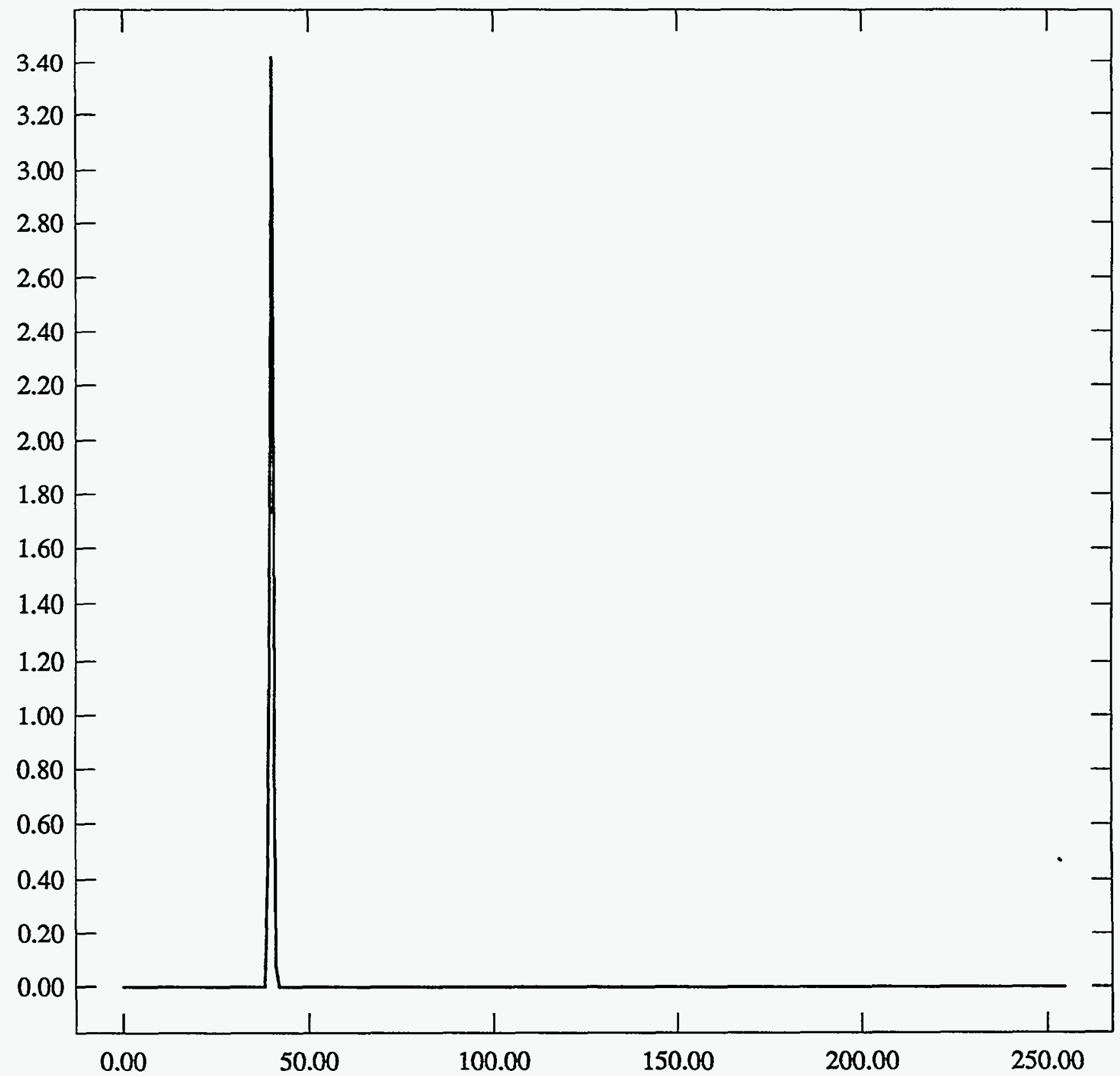


ST Camera: ST1\#04-10 -30C \#5: int_time=100ms, offset= 0, gain=1 (350 e/bit) Wed Jun 30 16:19:06 1993 Pixel Values Min 39 Max 41 Mean 39.9 Sigma $0.36 \times 10^{3}$

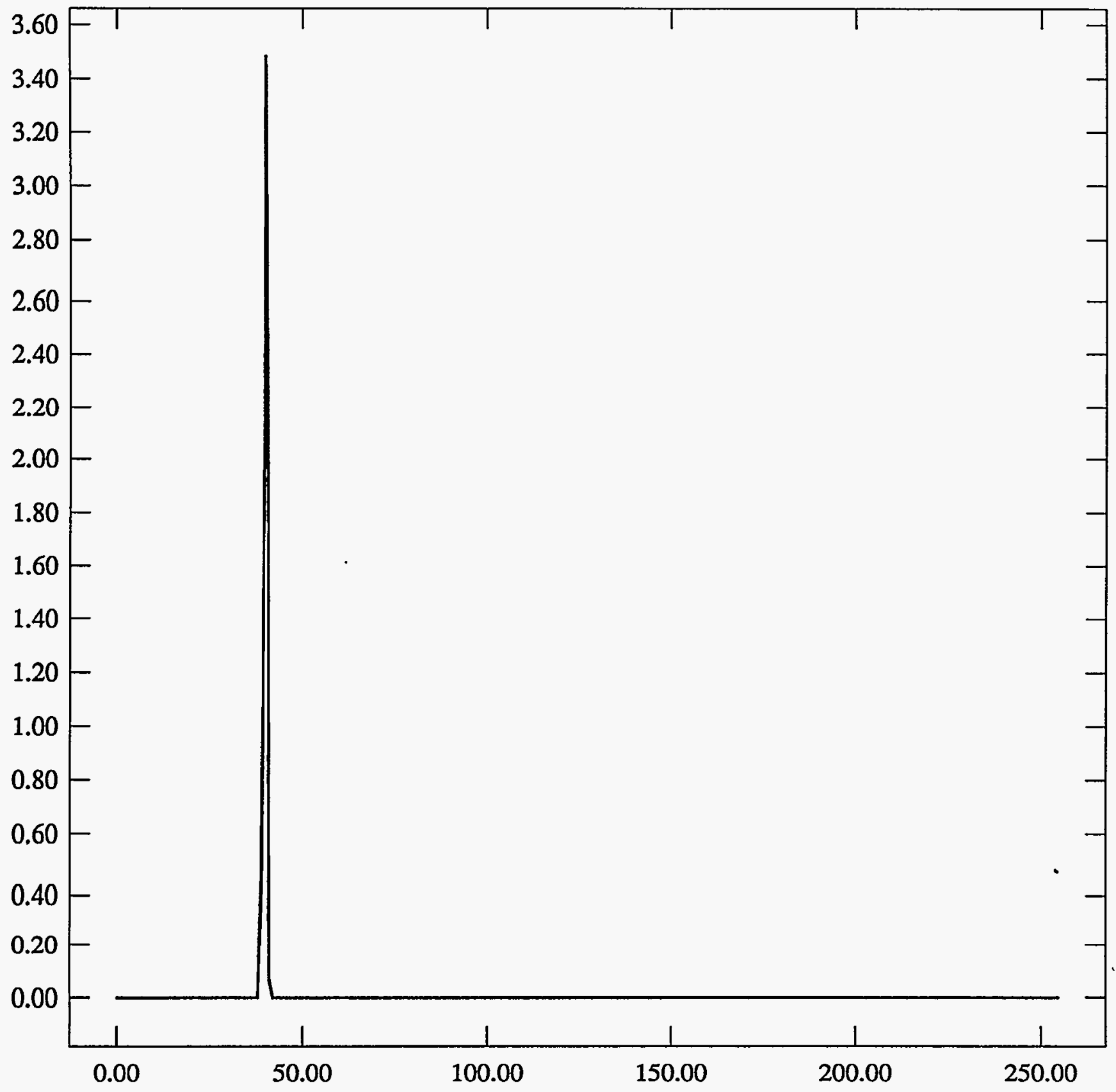


ST Camera: ST1\#04-10 -30C \#5: int_time=200ms, offset= 0, gain=1 (350 e/bit) Wed Jun 30 16:19:17 1993 Pixel Values Min 39 Max 41 Mean 39.9 Sigma $0.31 \times 10^{3}$

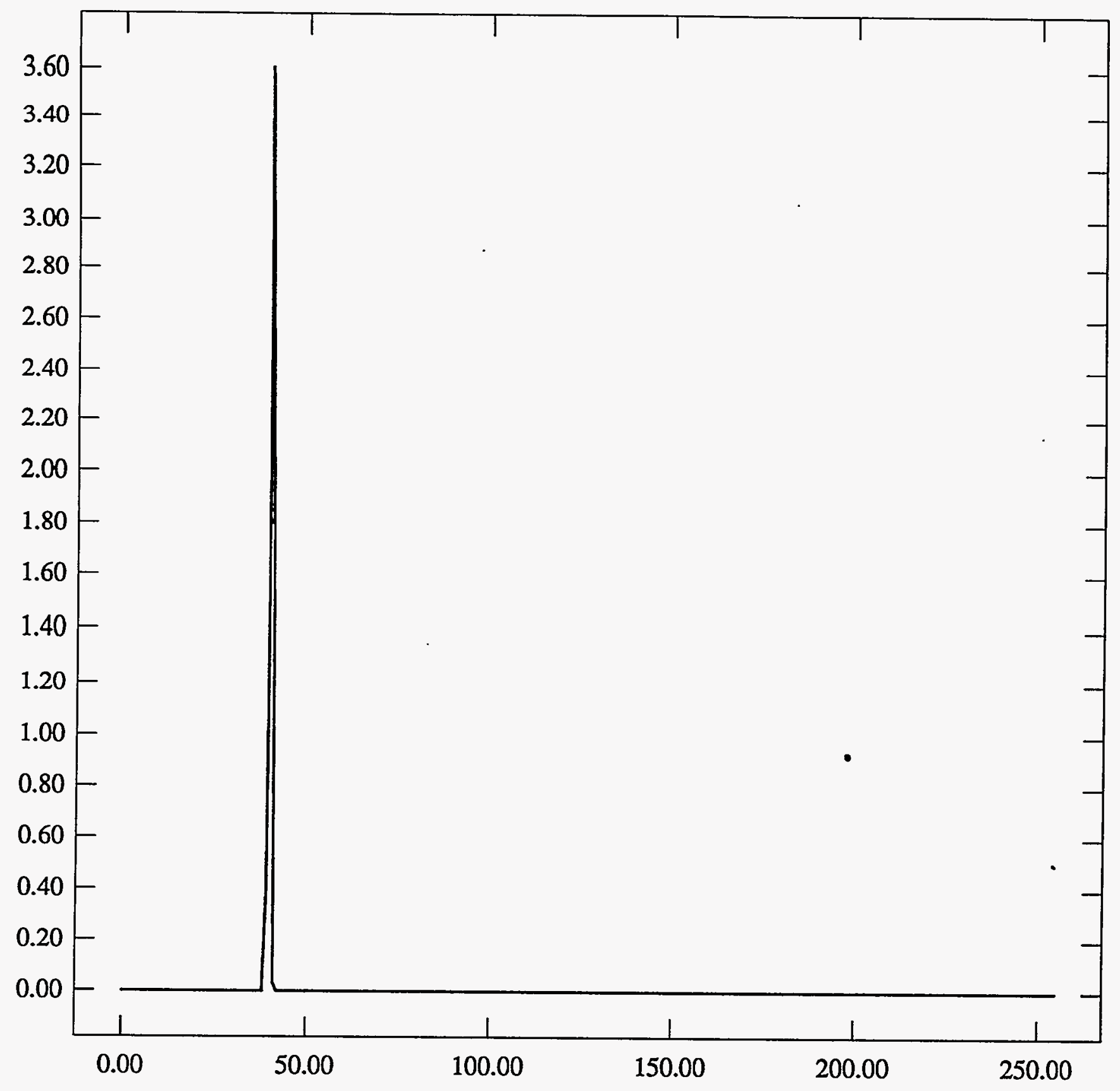


ST Camera: ST1\#04-10 -30C \#5: int_time= 50ms, offset= 0, gain=2 (150 e/bit) Wed Jun 30 16:19:32 1993 Pixel Values Min 78 Max 81 Mean 79.2 Sigma $0.57 \times 10^{3}$

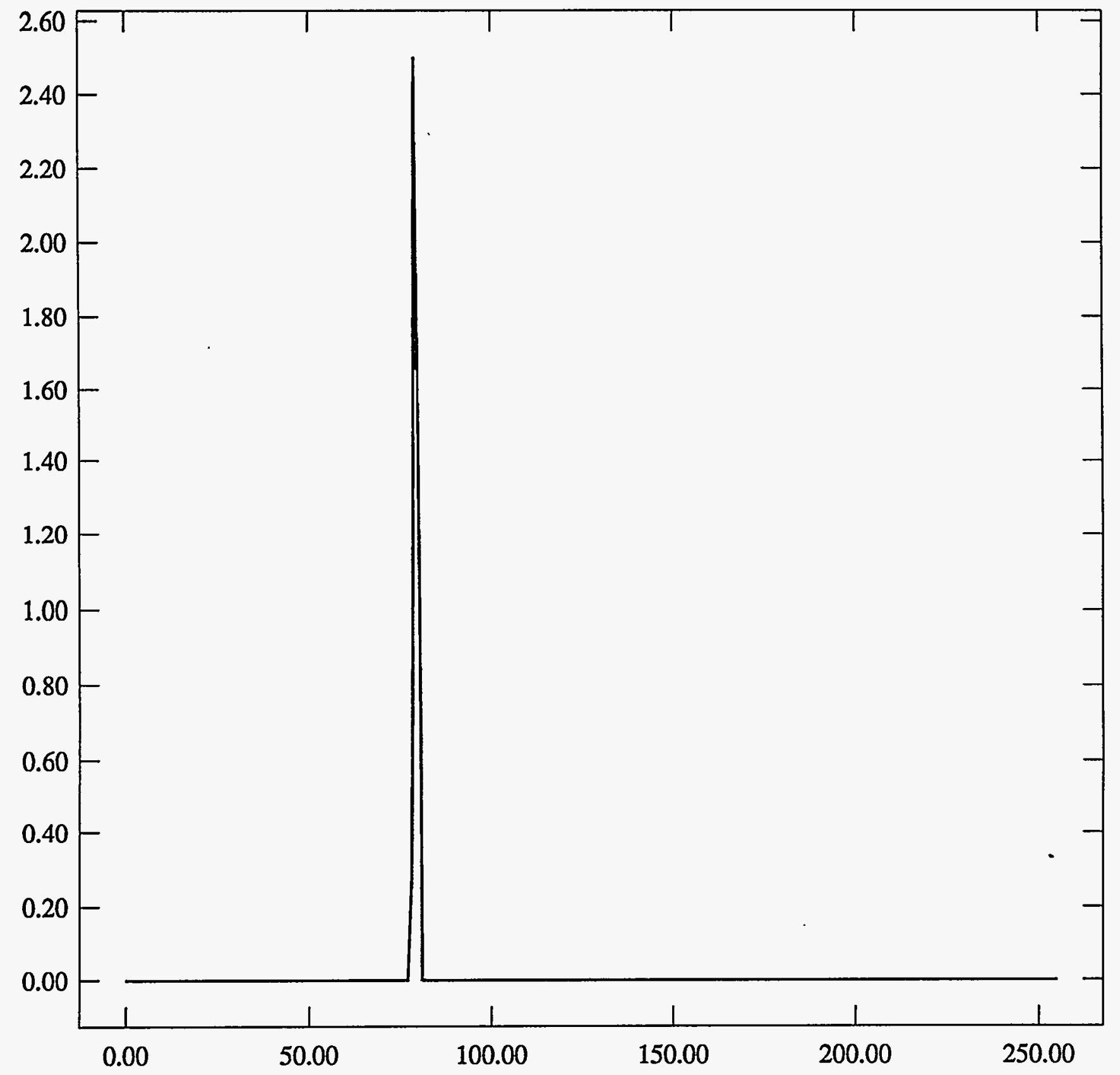


ST Camera: ST1\#04-10 -30C \#5: int_time=100ms, offset= 0, gain=2 (150 e/bit) Wed Jun 30 16:19:47 1993 Pixel Values Min 78 Max 81 Mean 79.2 Sigma $0.59 \times 10^{3}$

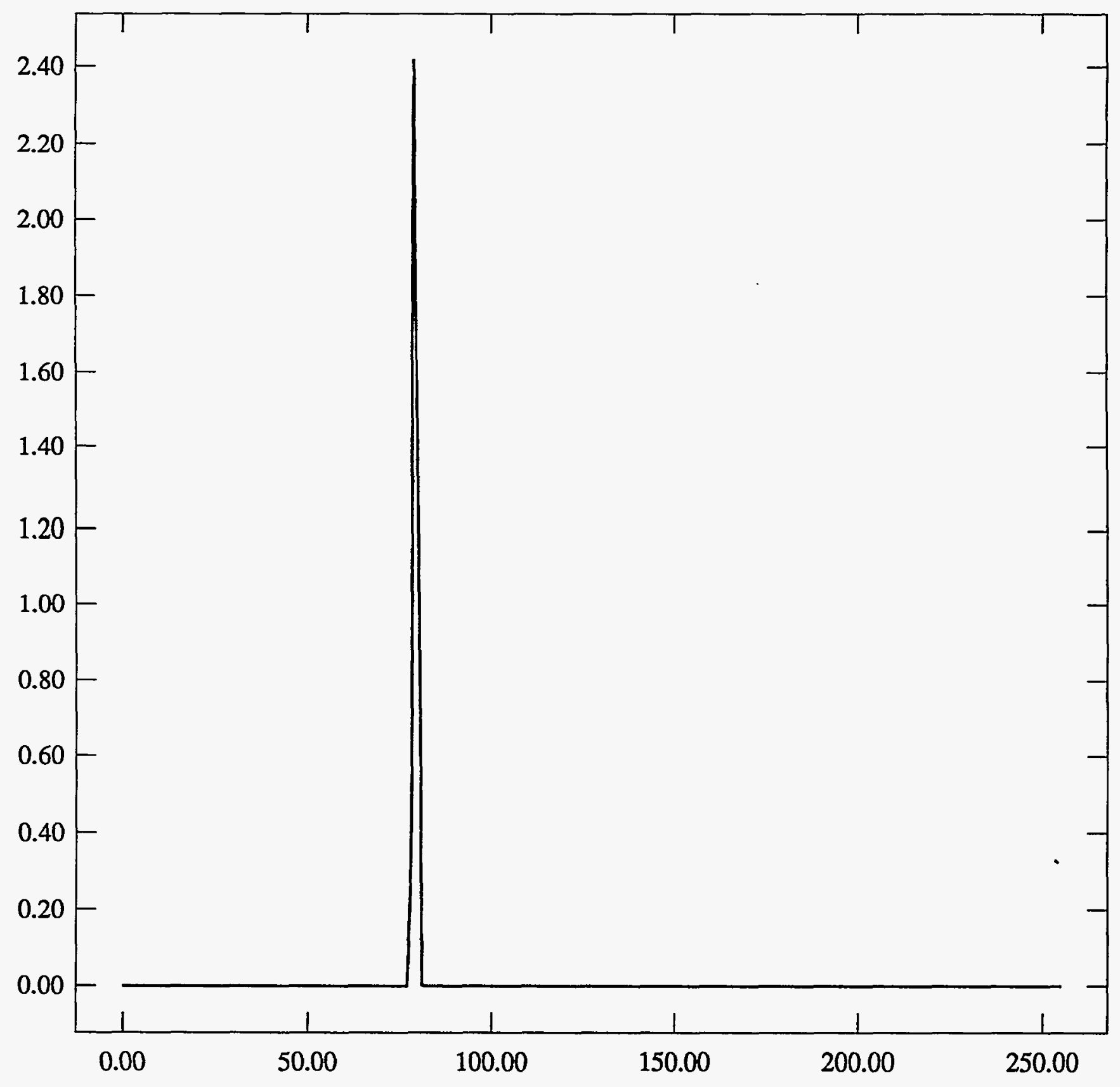


ST Camera: ST1\#04-10 -30C \#5: int_time=200ms, offset= 0, gain=2 (150 e/bit) Wed Jun 30 16:20:04 1993 Pixel Values Min 78 Max 80 Mean 79.3 Sigma $0.57 \times 10^{3}$

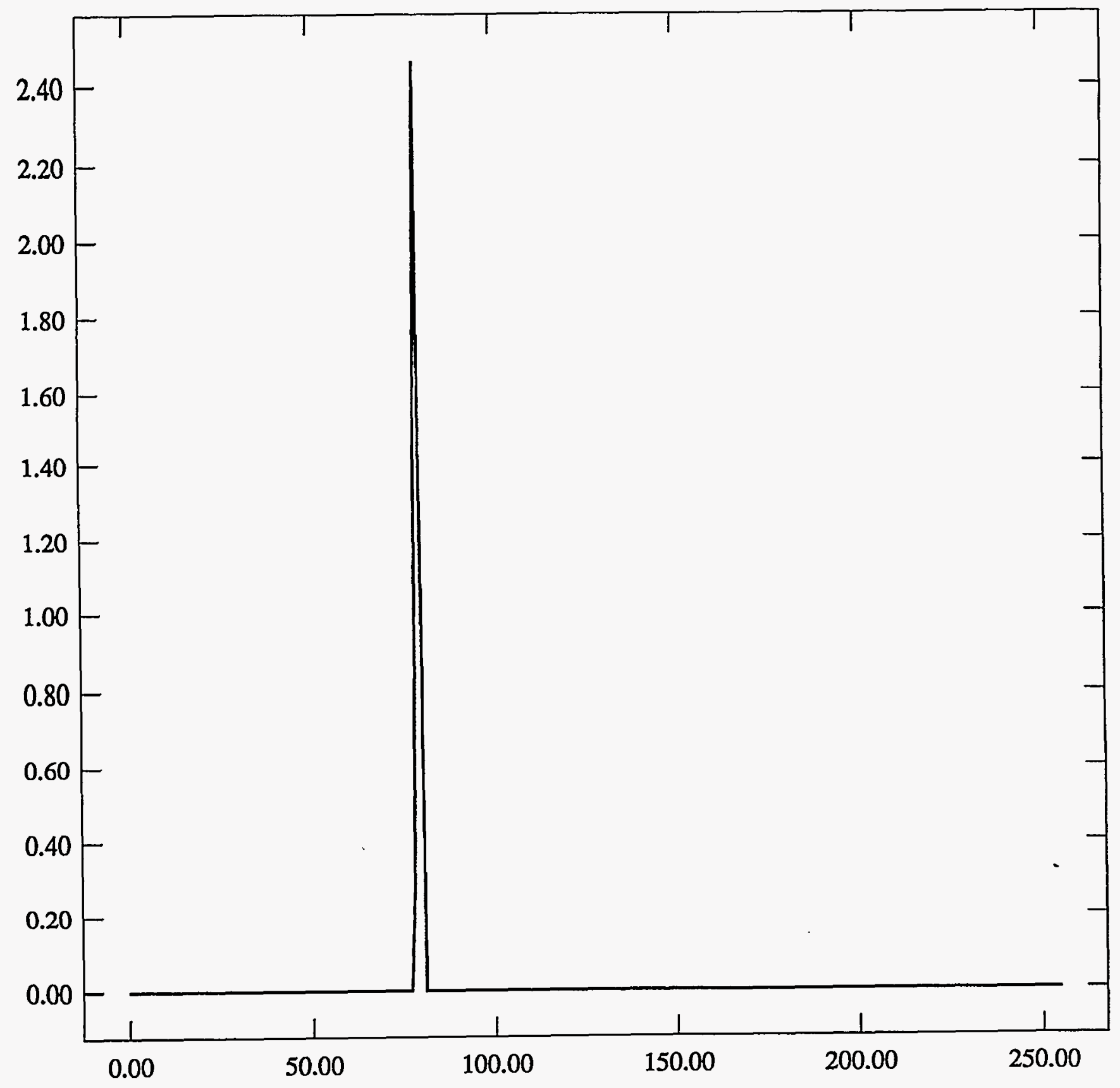


ST Camera: ST1\#04-10 -30C \#5: int_time= 50ms, offset= 0, gain=4 ( 75 e/bit) Wed Jun 30 16:20:16 1993 Pixel Values Min 145 Max 149 Mean 146.9 Sigma $0.69 \times 10^{3}$

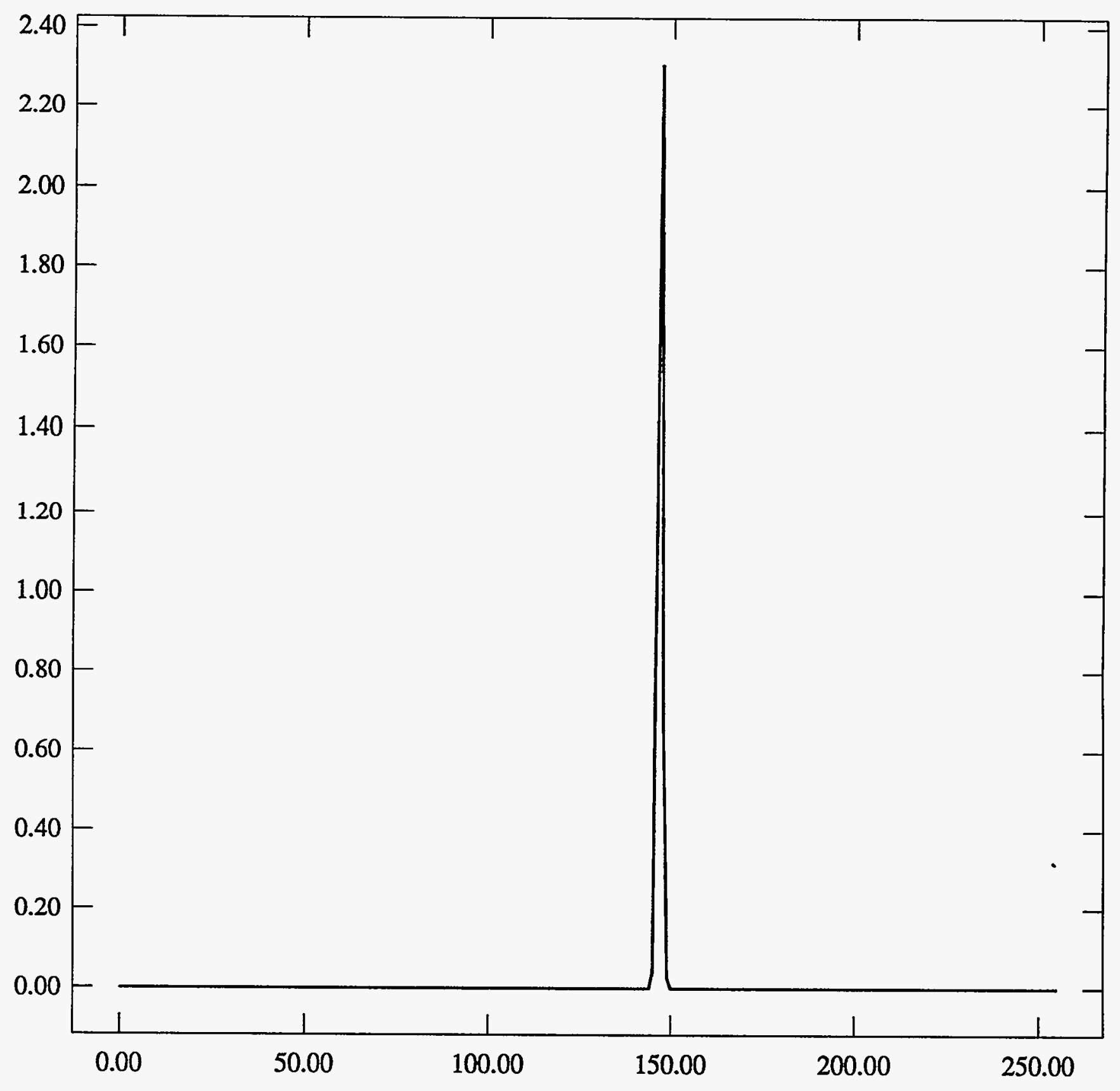


ST Camera: ST1\#04-10 -30C \#5: int_time=100ms, offset= 0, gain=4 ( 75 e/bit) Wed Jun 30 16:20:31 1993 Pixel Values Min 145 Max 149 Mean 146.9 Sigma $0.69 \times 10^{3}$

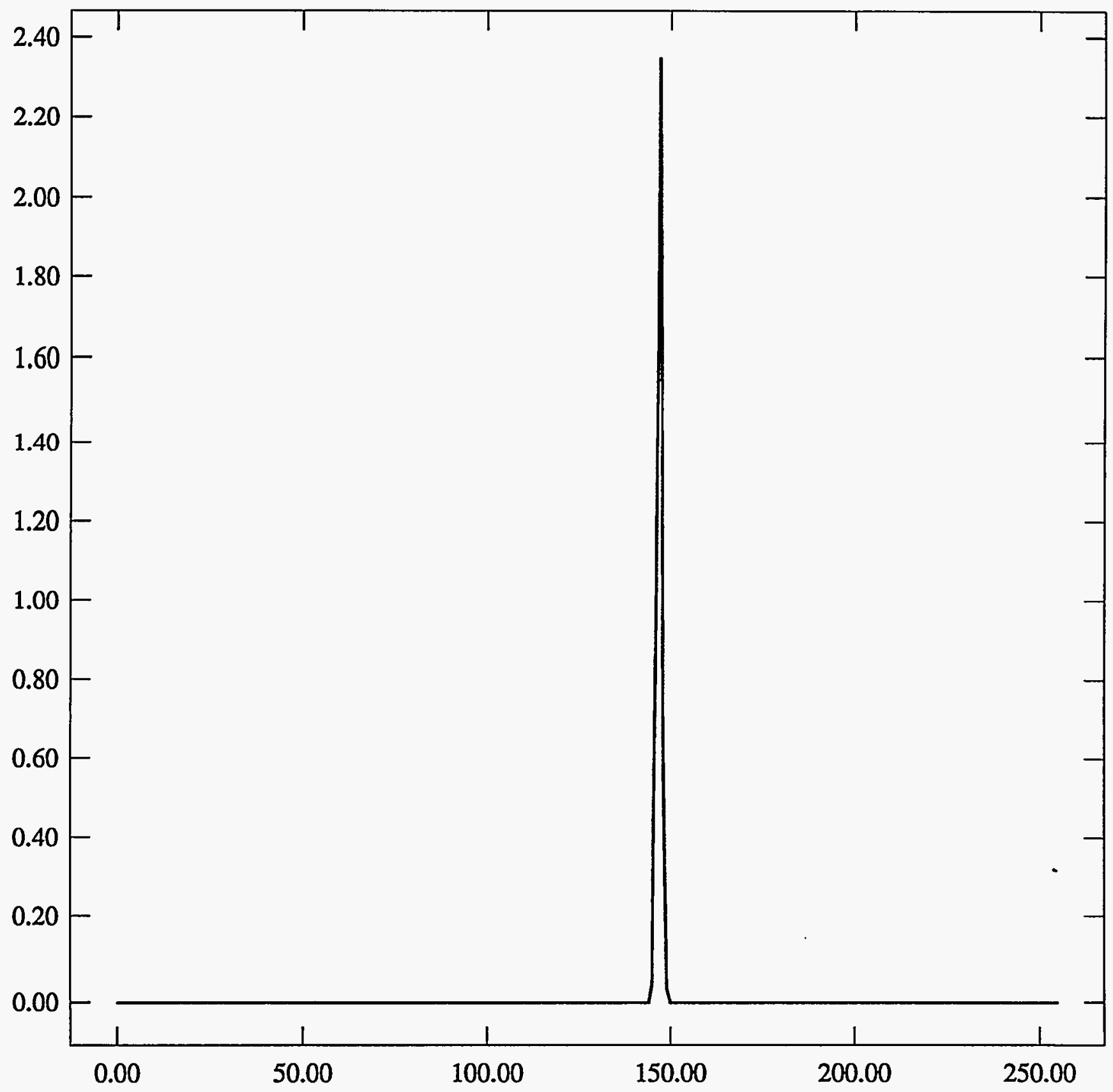


ST Camera: ST1\#04-10 -30C \#5: int_time=200ms, offset= 0, gain=4 ( 75 e/bit) Wed Jun 30 16:20:46 1993 Pixel Values Min 145 Max 149 Mean 146.9 Sigma $0.69 \times 10^{3}$

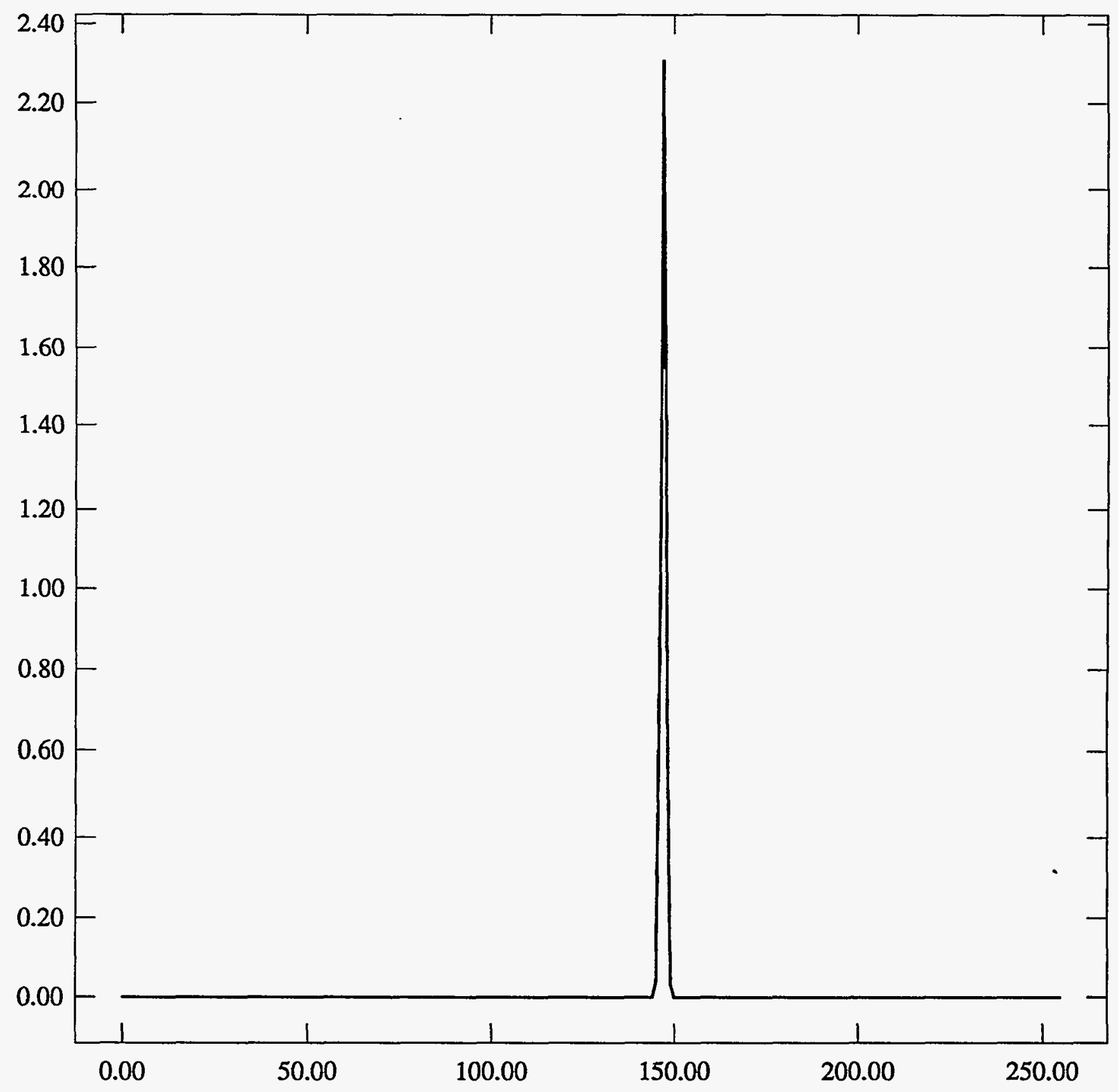




$$
\pm 5-30 c \text { cas }
$$

ST Camera: ST1\#04-10 -30C \#5: int_time= 50ms, offset= 0, gain=1 ( $350 \mathrm{e} / \mathrm{bit}$ ) Wed Jun 30 16:55:59 1993 Pixel Values Min 39 Max 41 Mean 39.9 Sigma $0.36 \times 10^{3}$

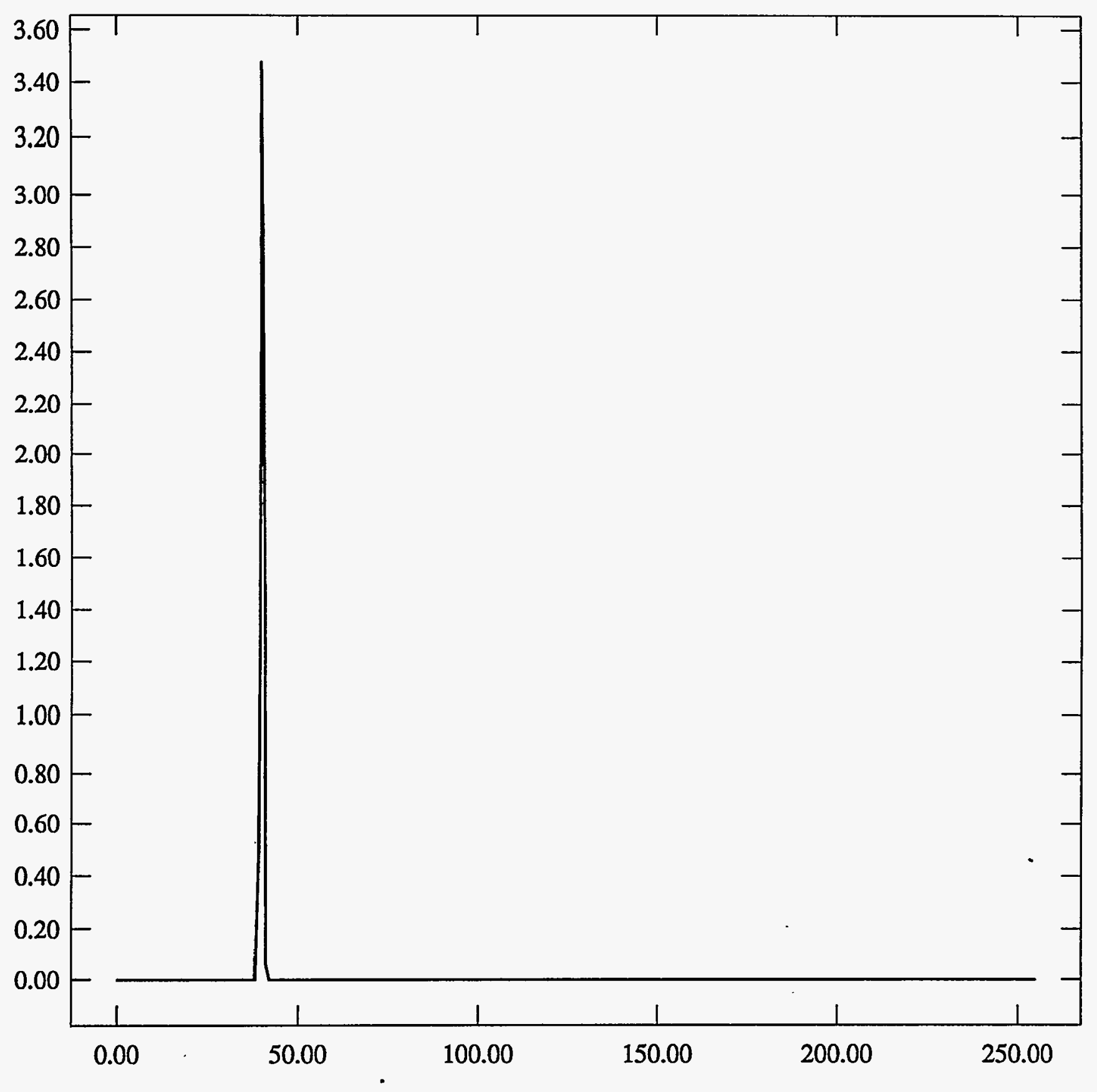


ST Camera: ST1\#04-10 -30C \#5: int_time=100ms, offset= 0, gain=1 ( $350 \mathrm{e} / \mathrm{bit}$ ) Wed Jun 30 16:56:13 1993 Pixel Values Min 39 Max 41 Mean 39.9 Sigma $0.33 \times 10^{3}$

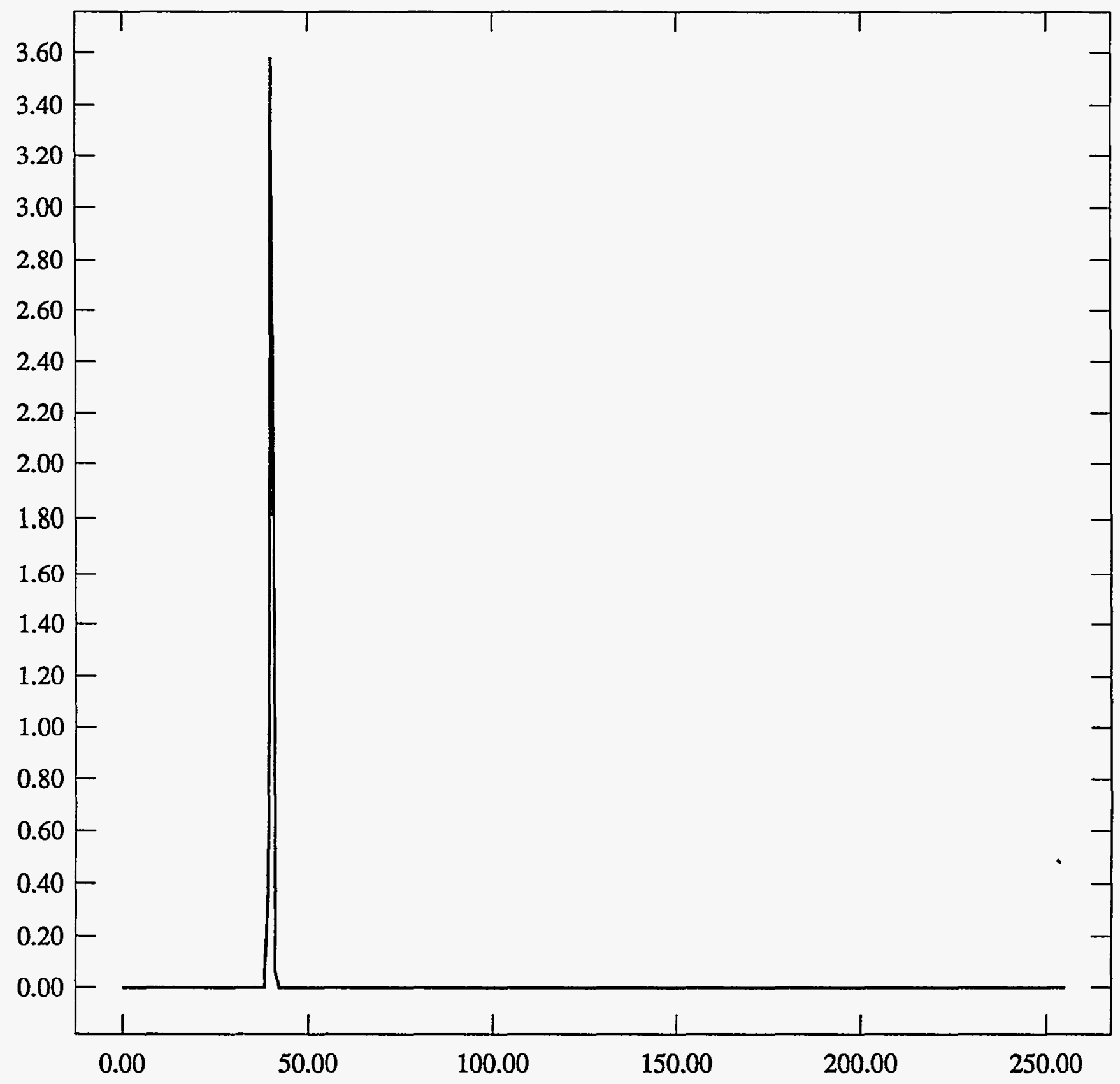


ST Camera: ST1\#04-10 -30C \#5: int_time=200ms, offset= 0, gain=1 ( 350 e/bit) Wed Jun 30 16:56:25 1993 Pixel Values Min 39 Max 41 Mean 39.9 Sigma $0.31 \times 10^{3}$

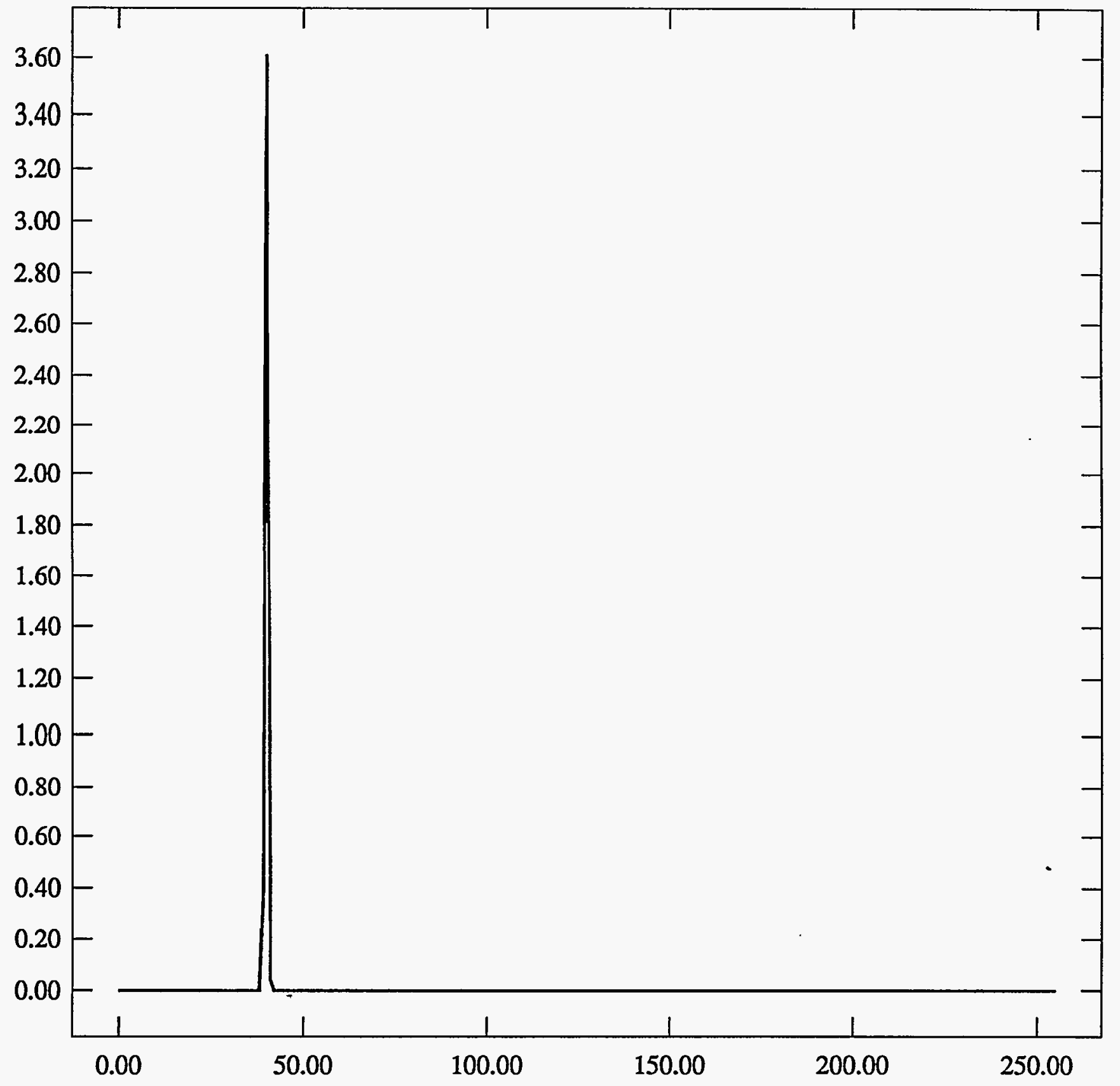


ST Camera: ST1\#04-10 -30C \#5: int_time= 50ms, offset= 0, gain=2 ( 150 e/bit) Wed Jun 30 16:56:39 1993 Pixel Values Min 78 Max 81 Mean 79.3 Sigma $0.58 \times 10^{3}$

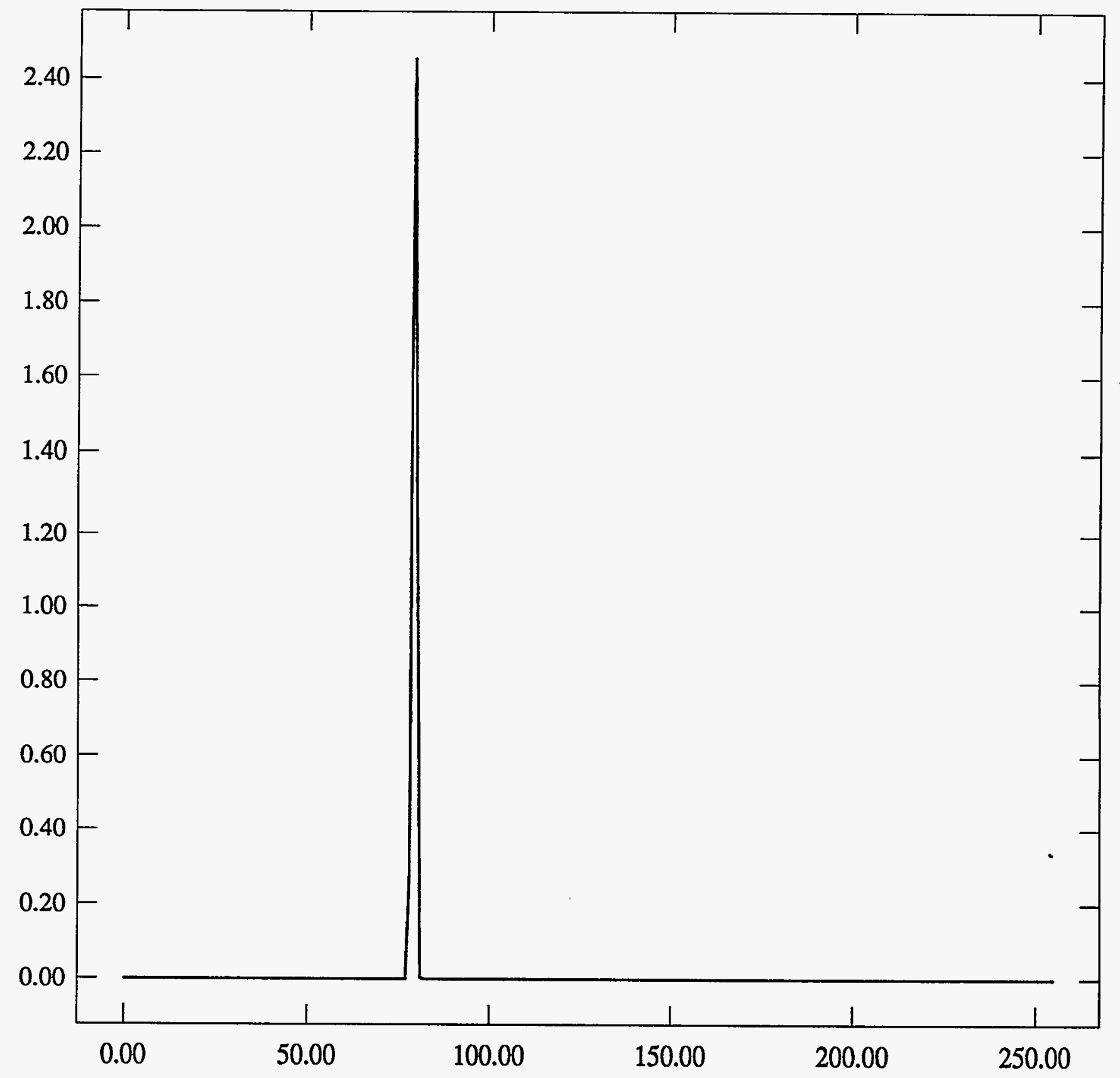


ST Camera: ST1 $¥ 04-10$-30C \#5: int_time=100ms, offset= 0, gain=2 ( $150 \mathrm{e} / \mathrm{bit}$ ) Wed Jun 30 16:56:54 1993 Pixel Values Min 78 Max 80 Mean 79.2 Sigma $0.58 \times 10^{3}$

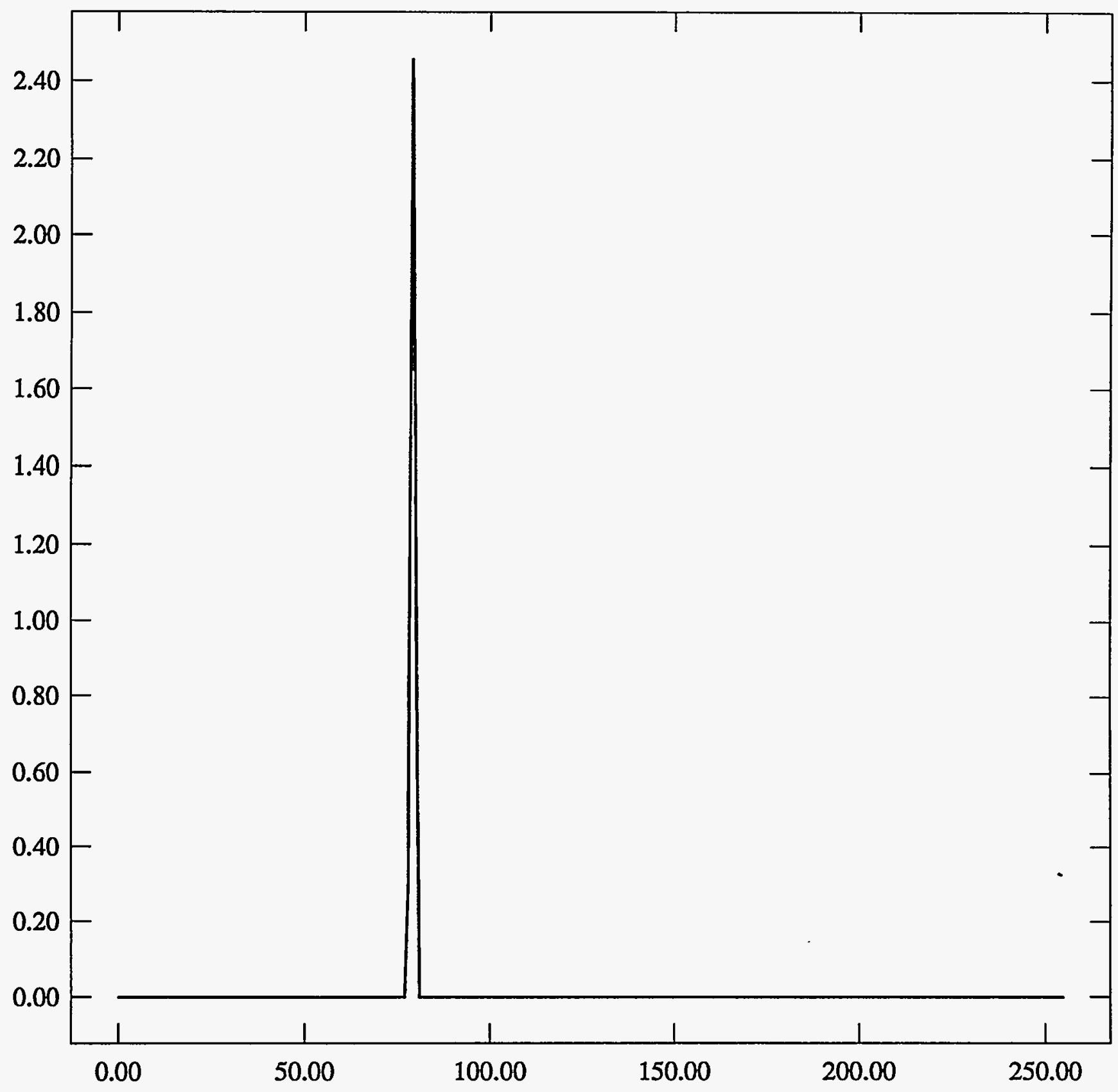


ST Camera: ST1\#04-10 -30C \#5: int_time=200ms, offset= 0, gain=2 ( 150 e/bit) Wed Jun 30 16:57:13 1993 Pixel Values Min 78 Max 81 Mean 79.2 Sigma $0.60 \times 10^{3}$

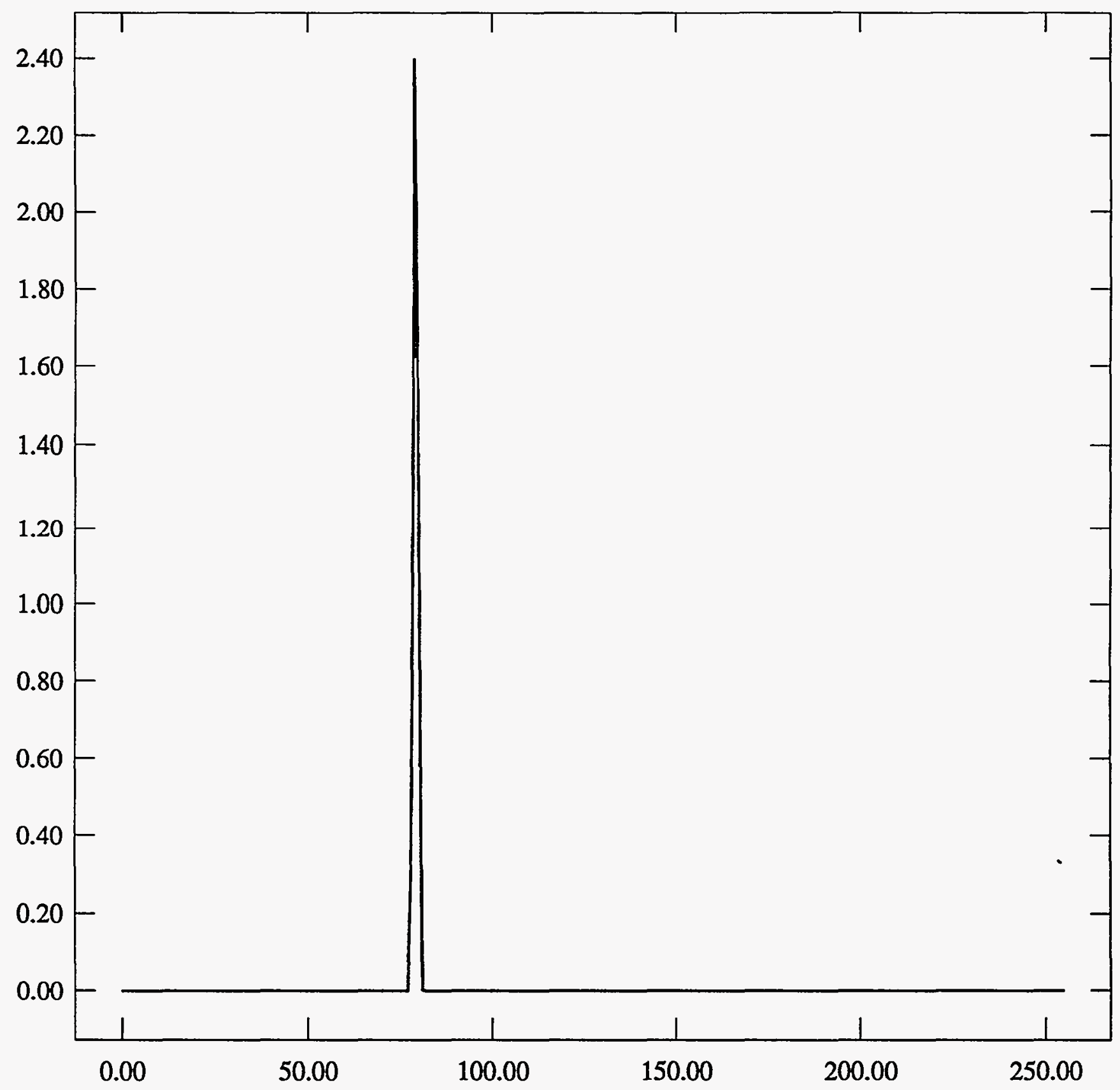


ST Camera: ST1\#04-10 -30C \#5: int_time= 50ms, offset= 0, gain=4 ( $75 \mathrm{e} / \mathrm{bit}$ ) Wed Jun 30 16:57:29 1993 Pixel Values Min 145 Max 149 Mean 146.9 Sigma $0.69 \times 10^{3}$

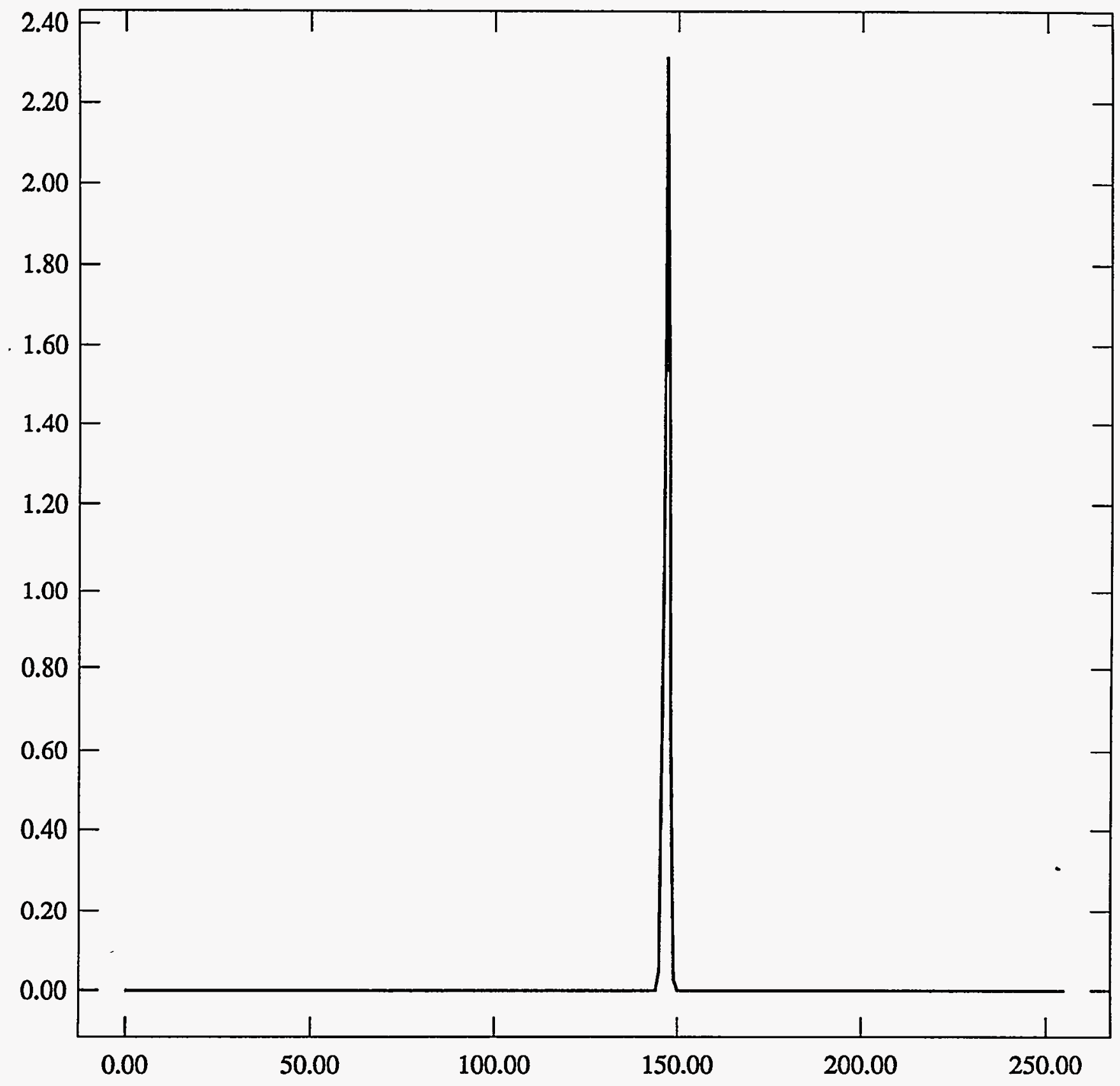


ST Camera: ST1\#04-10 -30C \#5: int time=100ms, offset= 0, gain=4 ( 75 e/bit) Wed Jun $3016: 57: 42$ 1993 Pixel Values Min 145 Max 149 Mean 146.9 Sigma $0.68 \times 10^{3}$

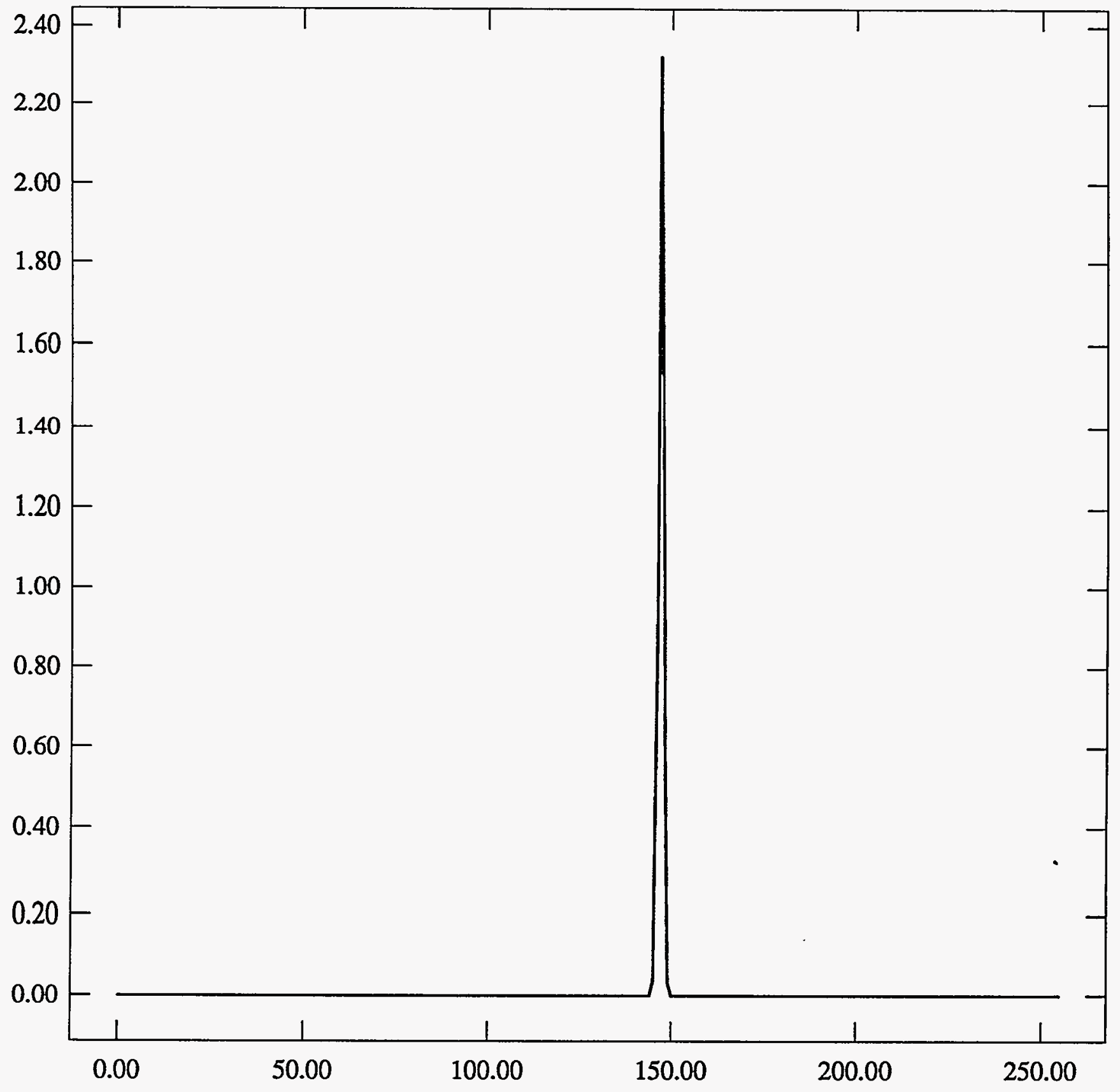


ST Camera: ST1\#04-10 -30C \#5: int_time=200ms, offset= 0, gain=4 ( 75 e/bit) Wed Jun 30 16:57:53 1993 Pixel Values Min 145 Max 149 Mean 146.9 Sigma $0.69 \times 10^{3}$

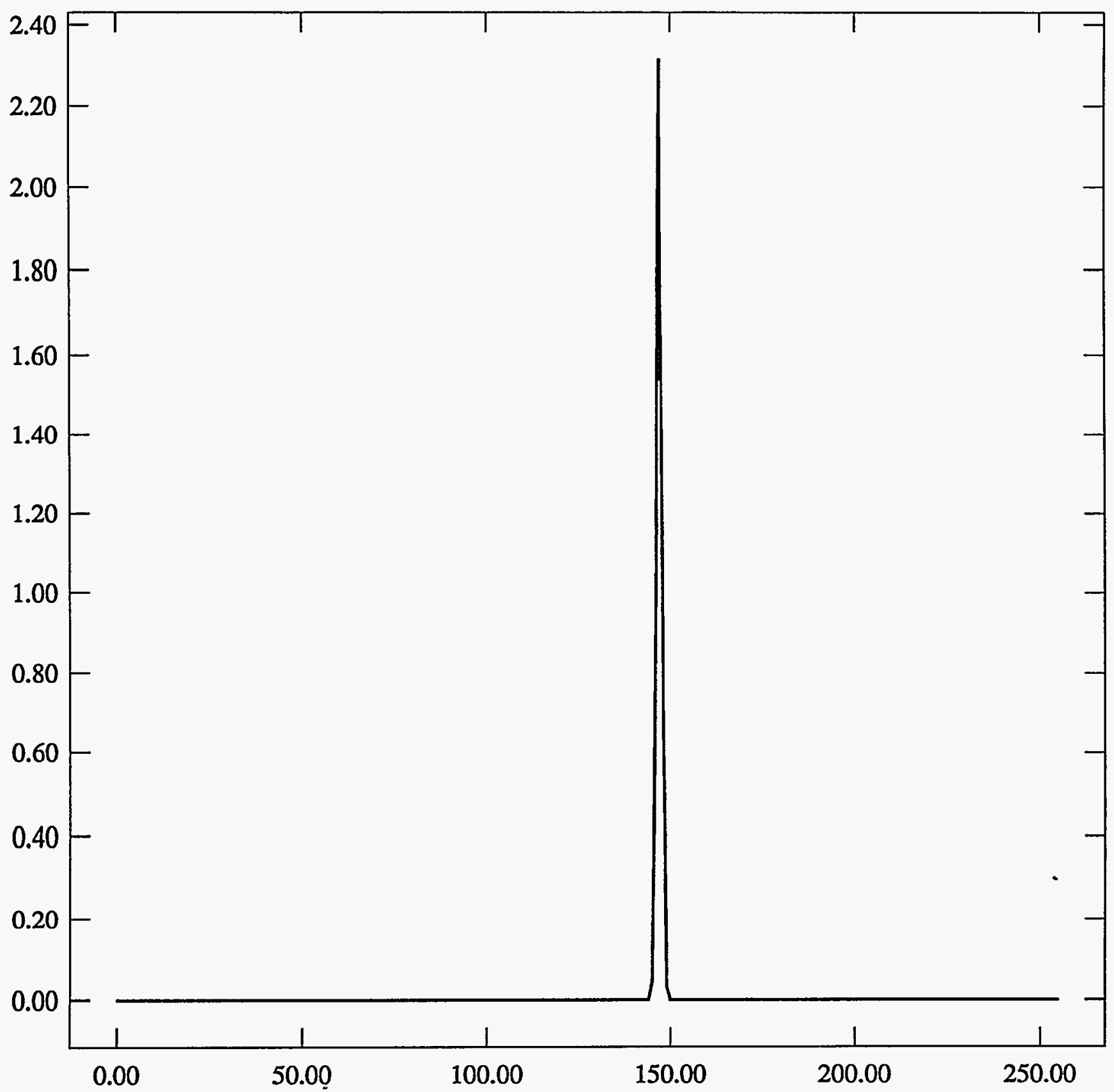


\#5 20C 15 mir

ST Camera: ST1\#04-10 20C \#5: int_time= 50ms, offset= 0, gain=1 ( 350 e/bit) Wed Jun 30 17:34:21 1993 Pixel Values Min 39 Max 41 Mean 39.5 Sigma $0.50 \times 10^{3}$

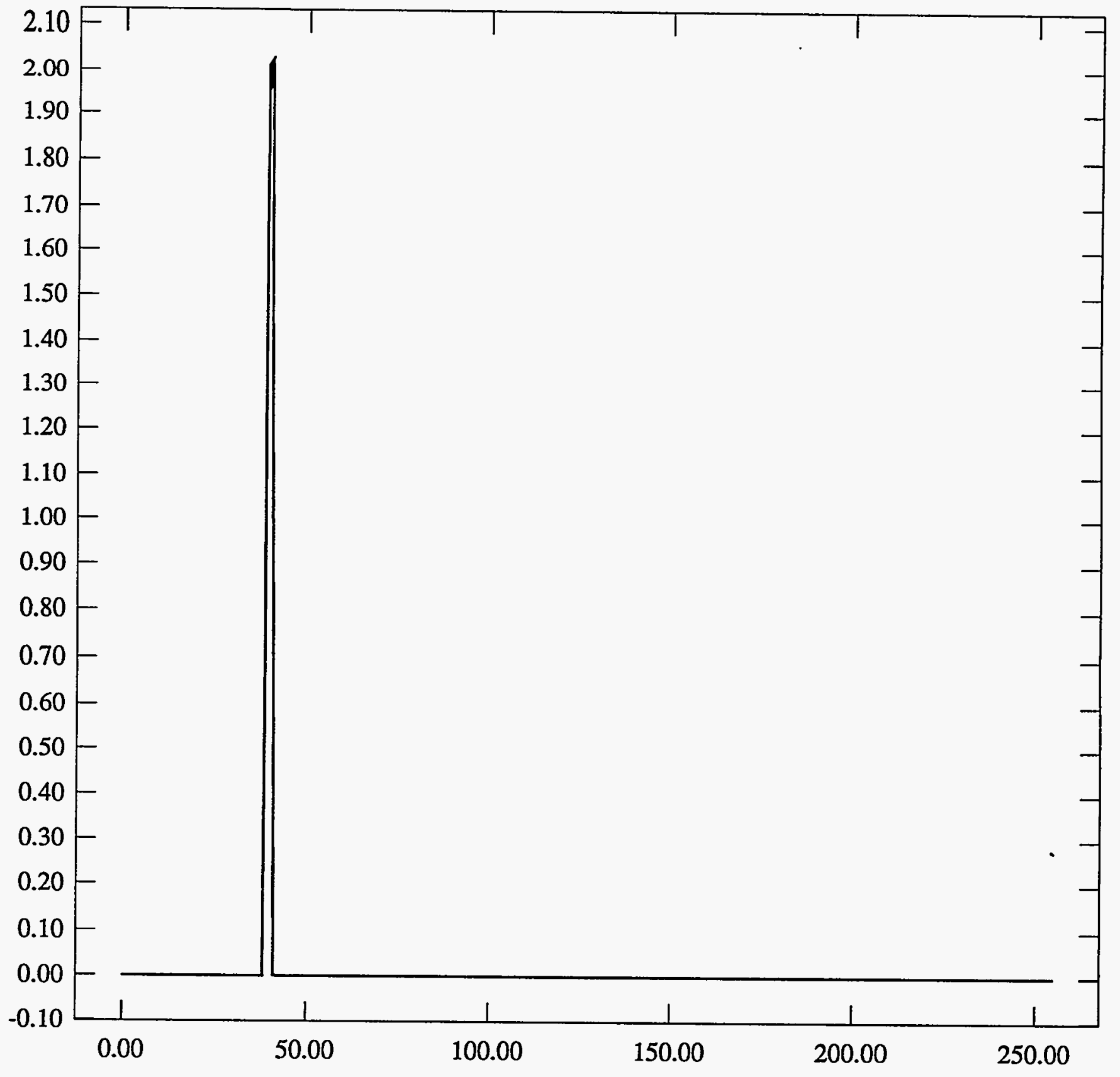


ST Camera: ST1\#04-10 20C \#5: int_time=100ms, offset= 0, gain=1 ( 350 e/bit) Wed Jun 30 17:34:39 1993 Pixel Values Min 39 Max 41 Mean 39.5 Sigma $0.50 \times 10^{3}$

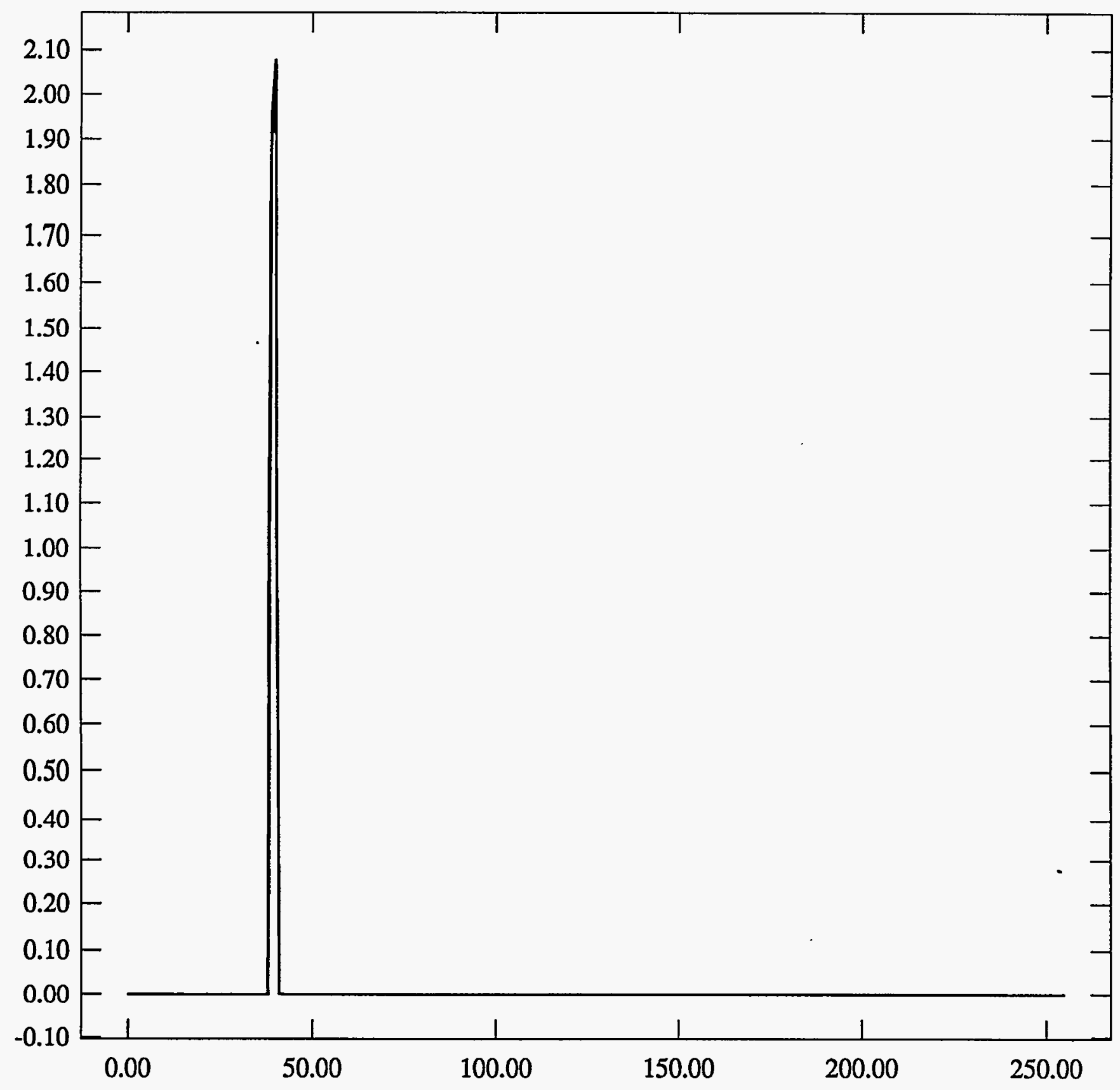


ST Camera: ST1\#04-10 20C \#5: int_time=200ms, offset= 0, gain=1 (350 e/bit) Wed Jun 30 17:34:50 1993 Pixel Values Min 39 Max 40 Mean 39.5 Sigma $0.50 \times 10^{3}$

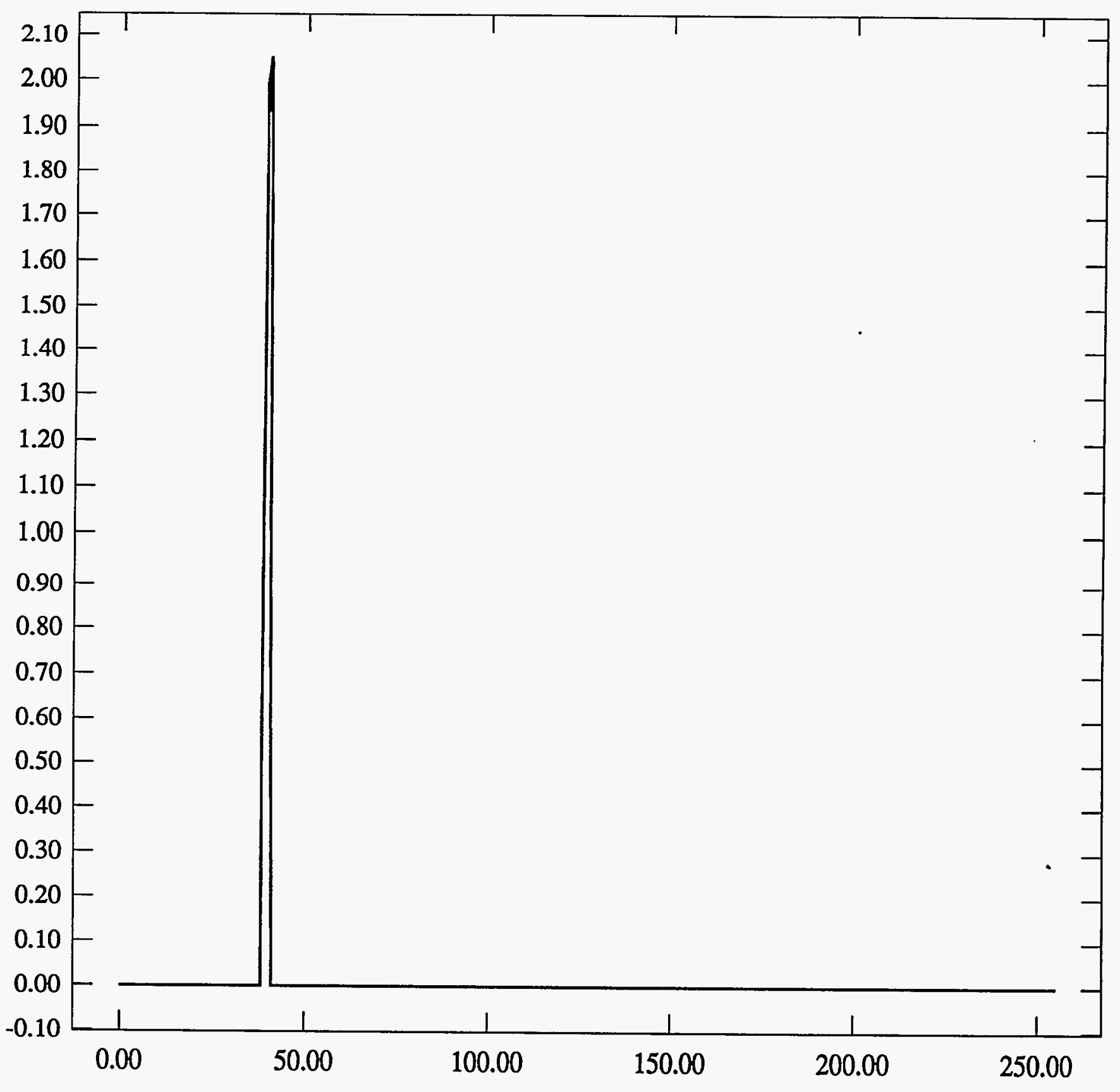


ST Camera: ST1\#04-10 20C \#5: int_time= 50ms, offset= 0, gain=2 (150 e/bit) Wed Jun 30 17:35:06 1993 Pixel Values Min 77 Max 81 Mean 79.3 Sigma $0.77 \times 10^{3}$

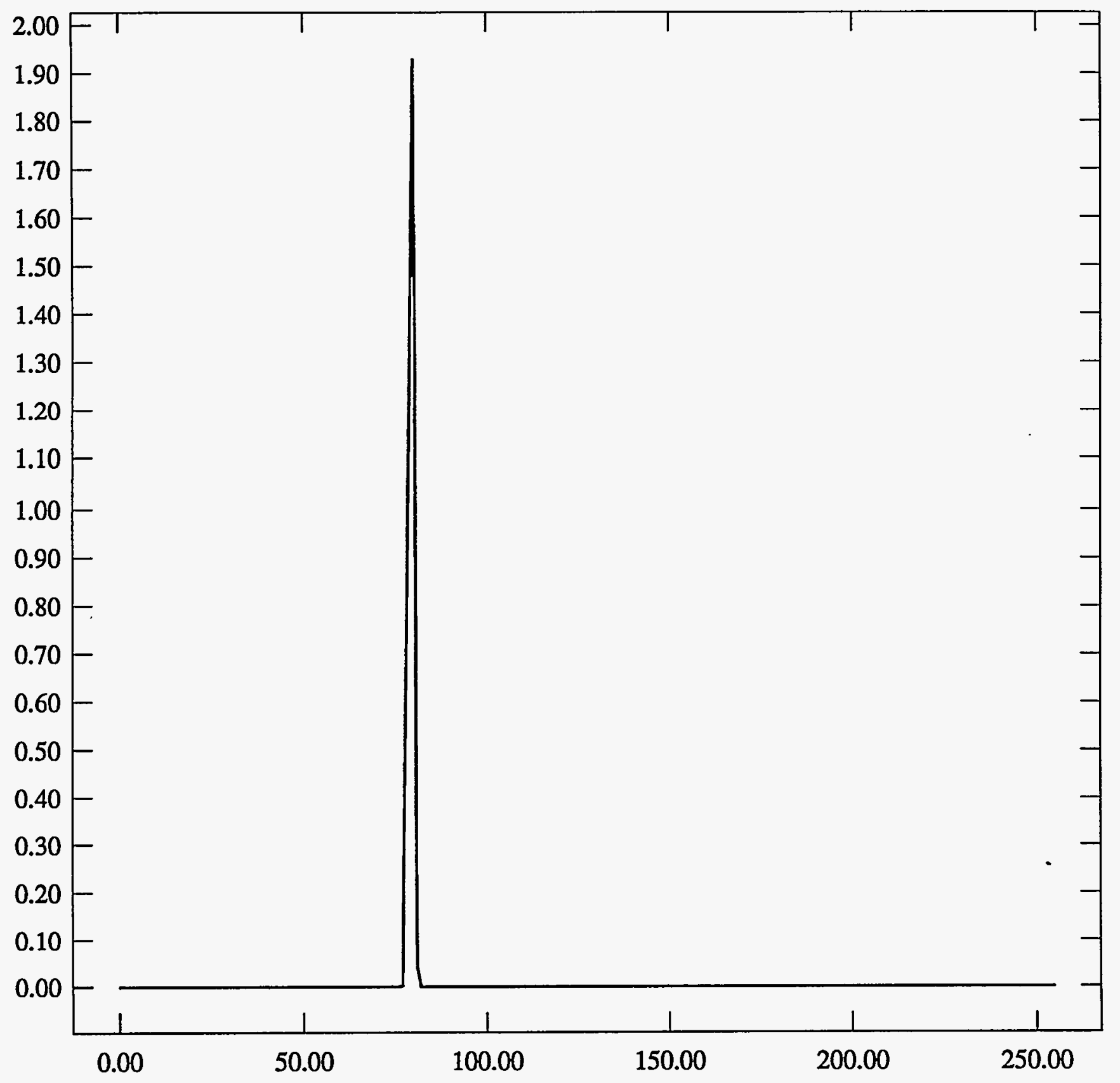


ST Camera: ST1\#04-10 20C \#5: int_time=100ms, offset= 0, gain=2 ( 150 e/bit) Wed Jun 30 17:35:16 1993 Pixel Values Min 77 Max 81 Mean 79.3 Sigma $0.74 \times 10^{3}$

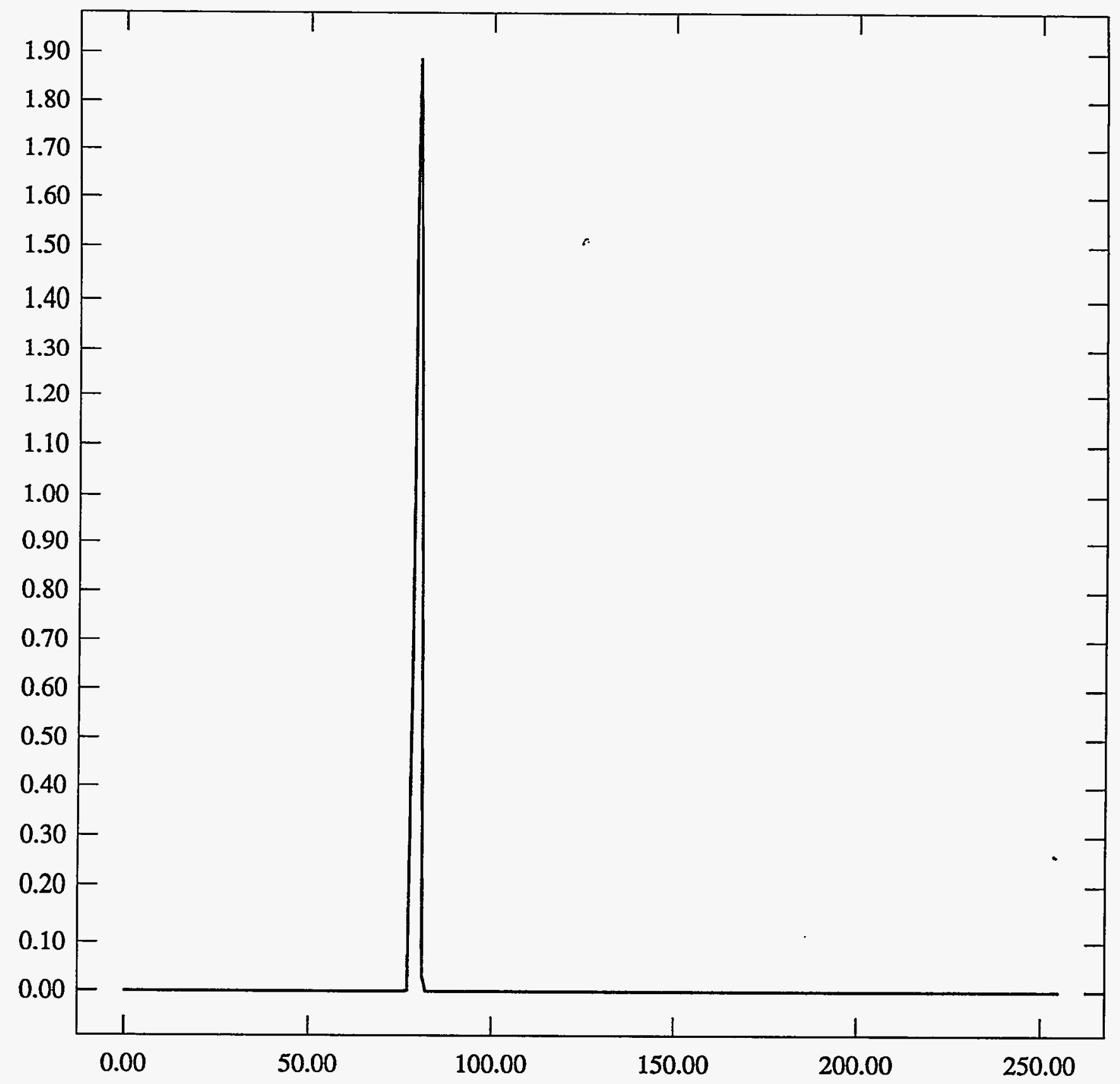


ST Camera: ST1\#04-10 20C \#5: int_time=200ms, offset= 0, gain=2 ( $150 \mathrm{e} / \mathrm{bit}$ ) Wed Jun 30 17:35:30 1993 Pixel Values Min 77 Max 81 Mean 79.3 Sigma $0.75 \times 10^{3}$

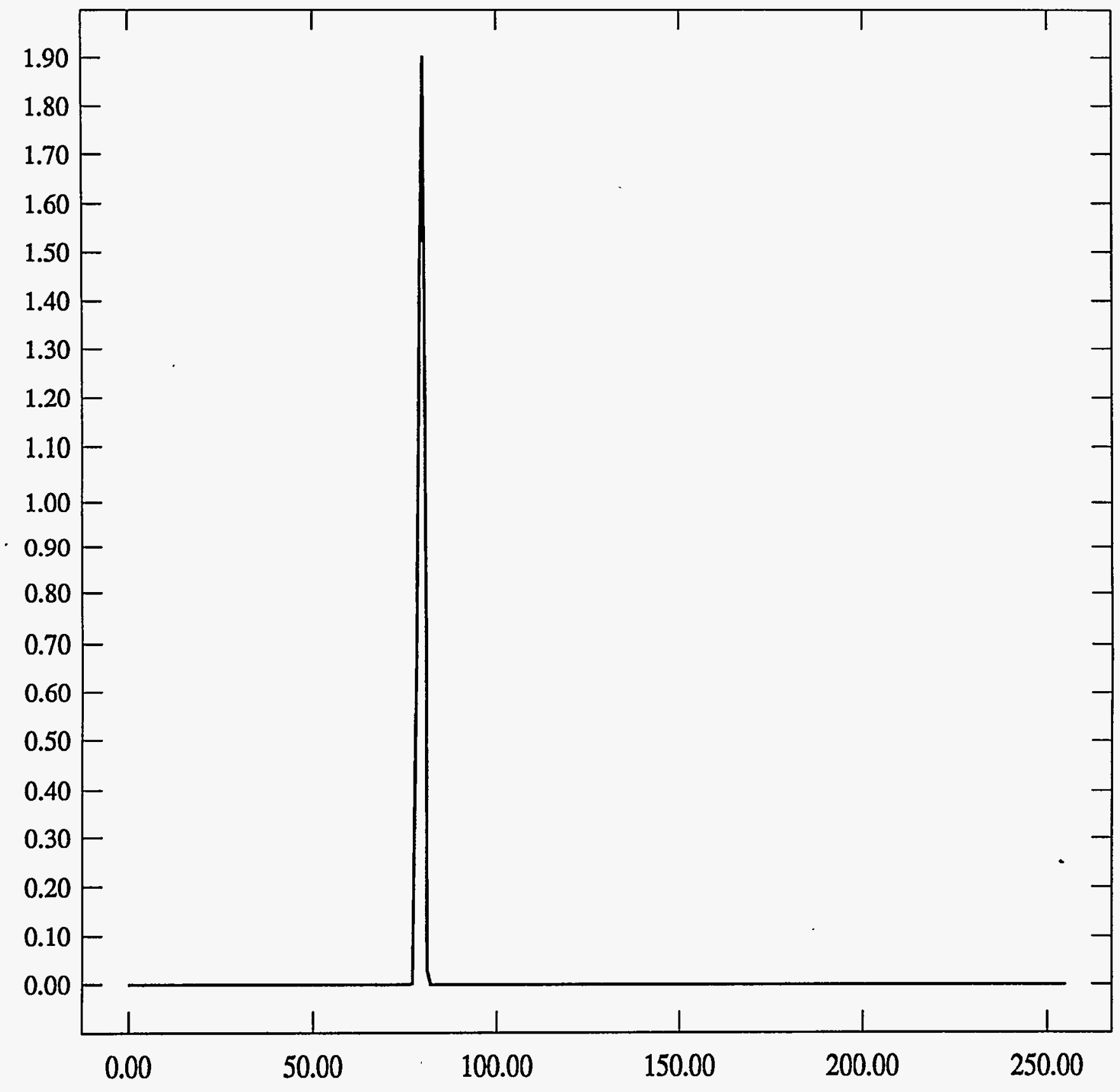


ST Camera: ST1\#04-10 20C \#5: int_time= 50ms, offset= 0, gain=4 ( 75 e/bit) Wed Jun 30 17:35:46 1993 Pixel Values Min 142 Max 148 Mean 145.1 Sigma $0.78 \times 10^{3}$

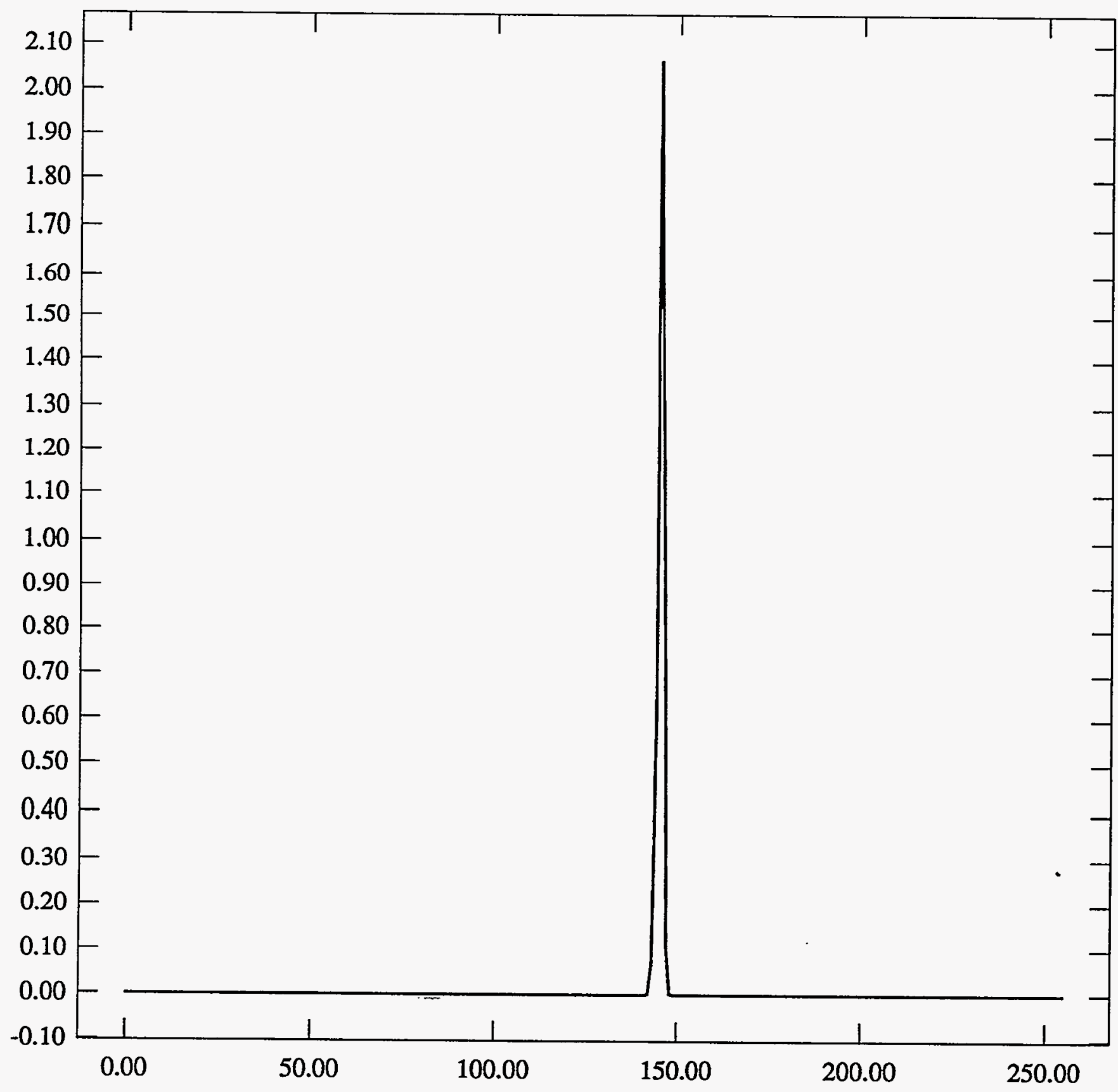


ST Camera: ST1\#04-10 20C \#5: int_time=100ms, offset= 0, gain=4 ( 75 e/bit) Wed Jun 30 17:36:01 1993 Pixel Values Min 143 Max 148 Mean 145.1 Sigma $0.75 \times 10^{3}$

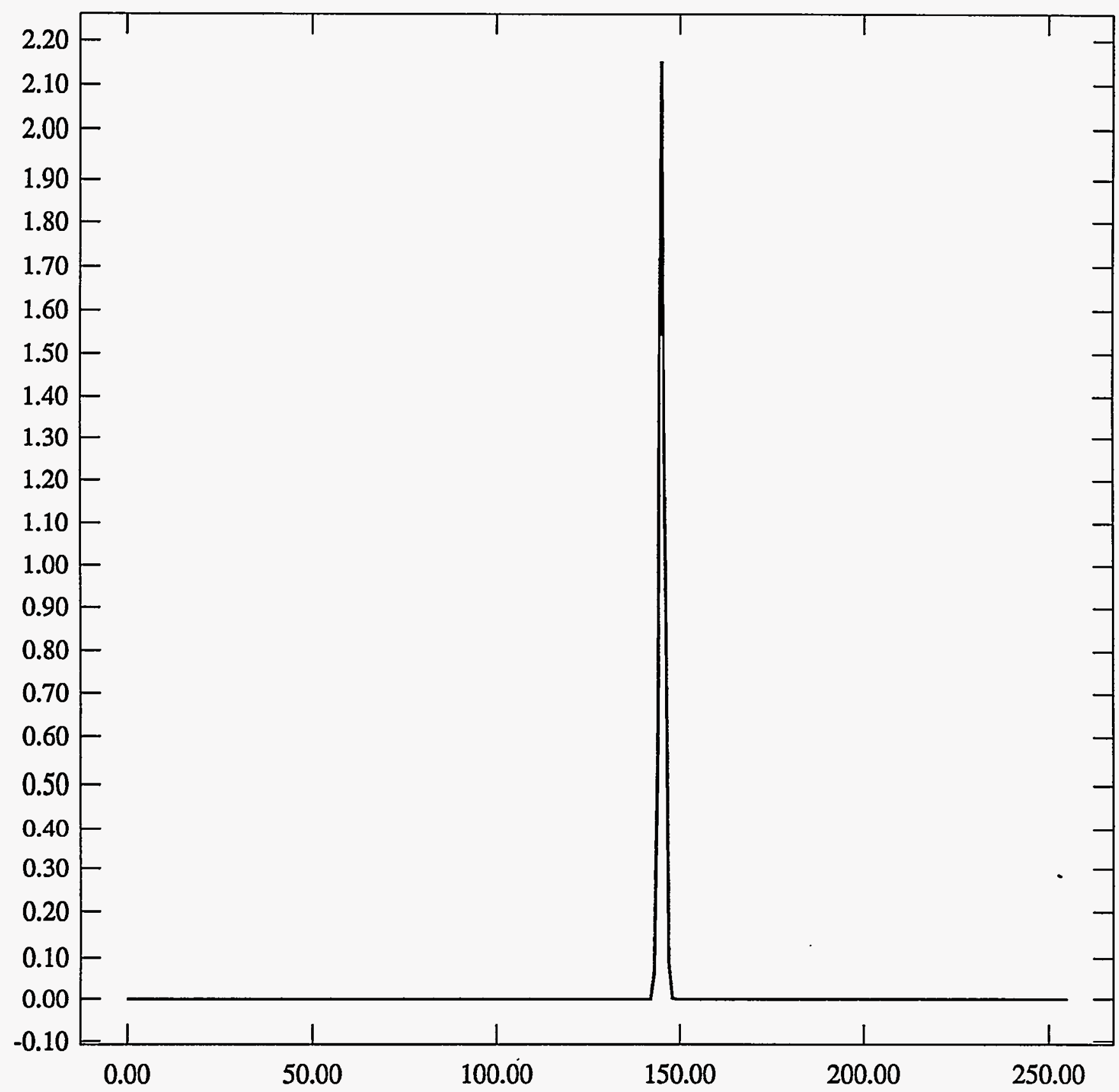


ST Camera: ST1\#04-10 20C \#5: int_time=200ms, offset= 0, gain=4 ( 75 e/bit) Wed Jun 30 17:36:24 1993 Pixel Values Min 142 Max 148 Mean 145.2 Sigma $0.76 \times 10^{3}$

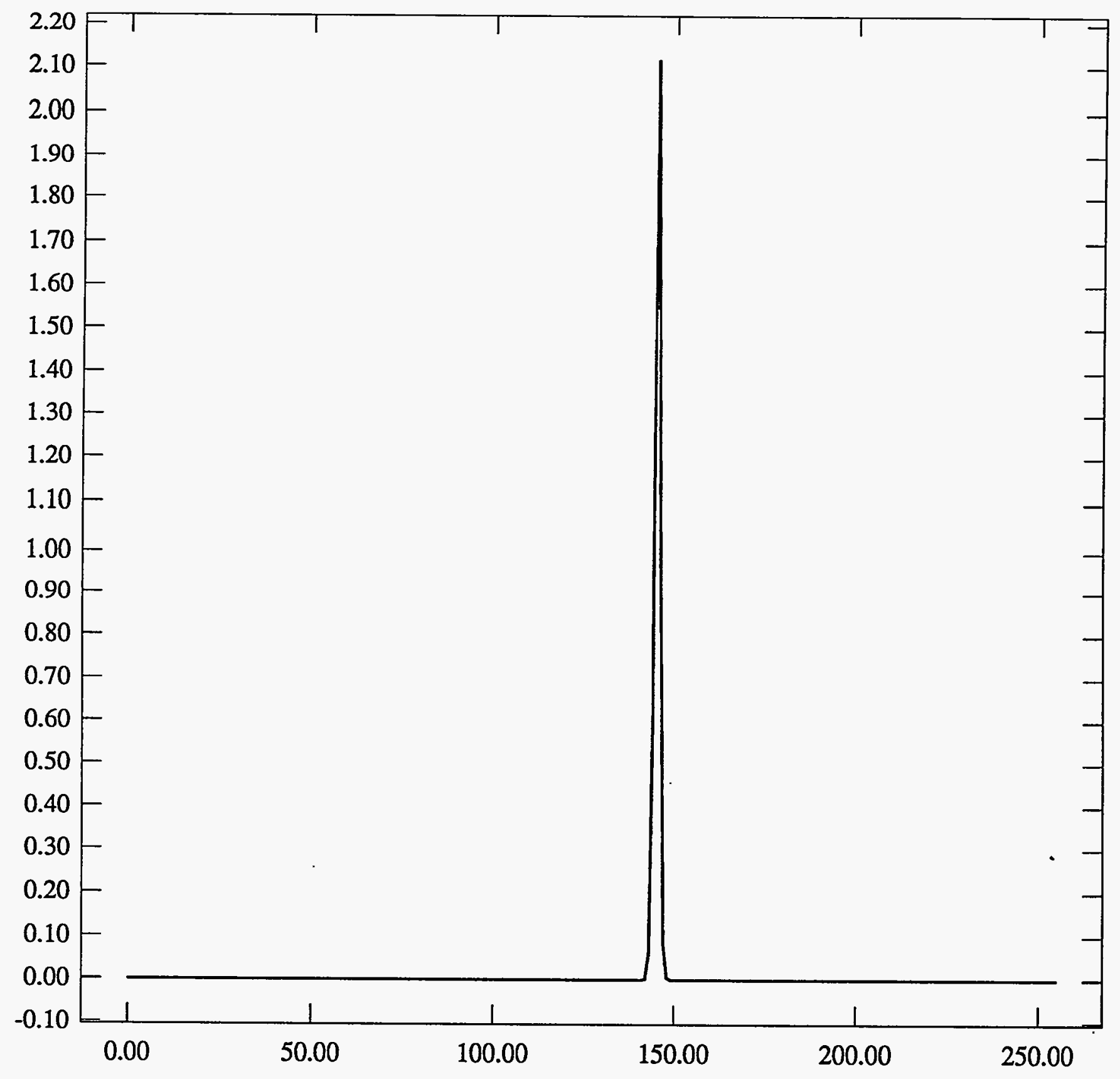




$$
4570 \mathrm{C} \text { ond wicne he }
$$

ST Camera: ST1\#04-10 20C \#5: int_time= 50ms, offset= 0, gain=1 ( 350 e/bit) Wed Jun 30 18:14:31 1993 Pixel Values Min 39 Max 40 Mean 39.4 Sigma $0.48 \times 10^{3}$

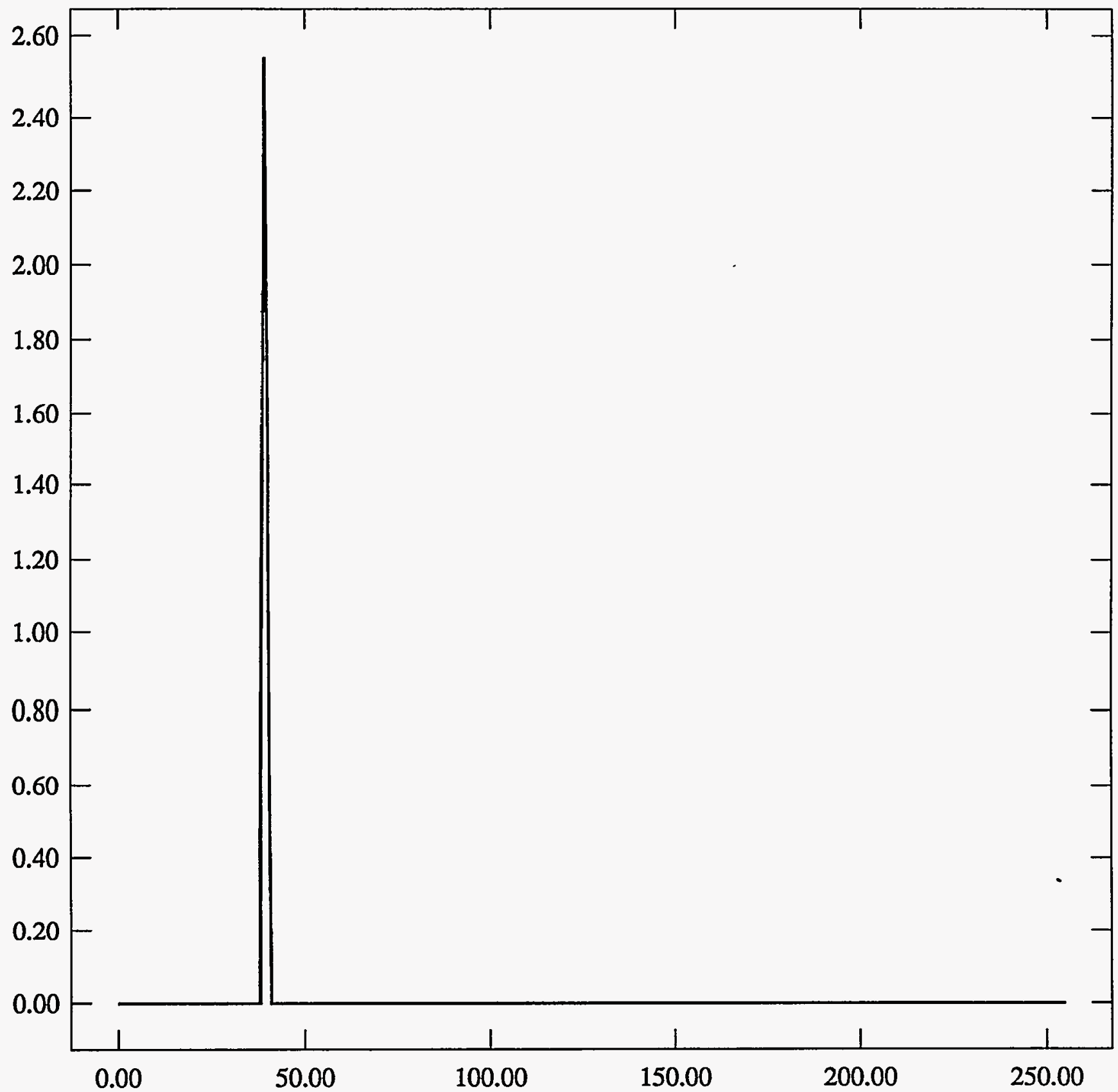


ST Camera: ST1\#04-10 20C \#5: int_time=100ms, offset= 0, gain=1 ( 350 e/bit) Wed Jun 30 18:14:43 1993 Pixel Values Min 39 Max 41 Mean 39.4 Sigma $0.49 \times 10^{3}$

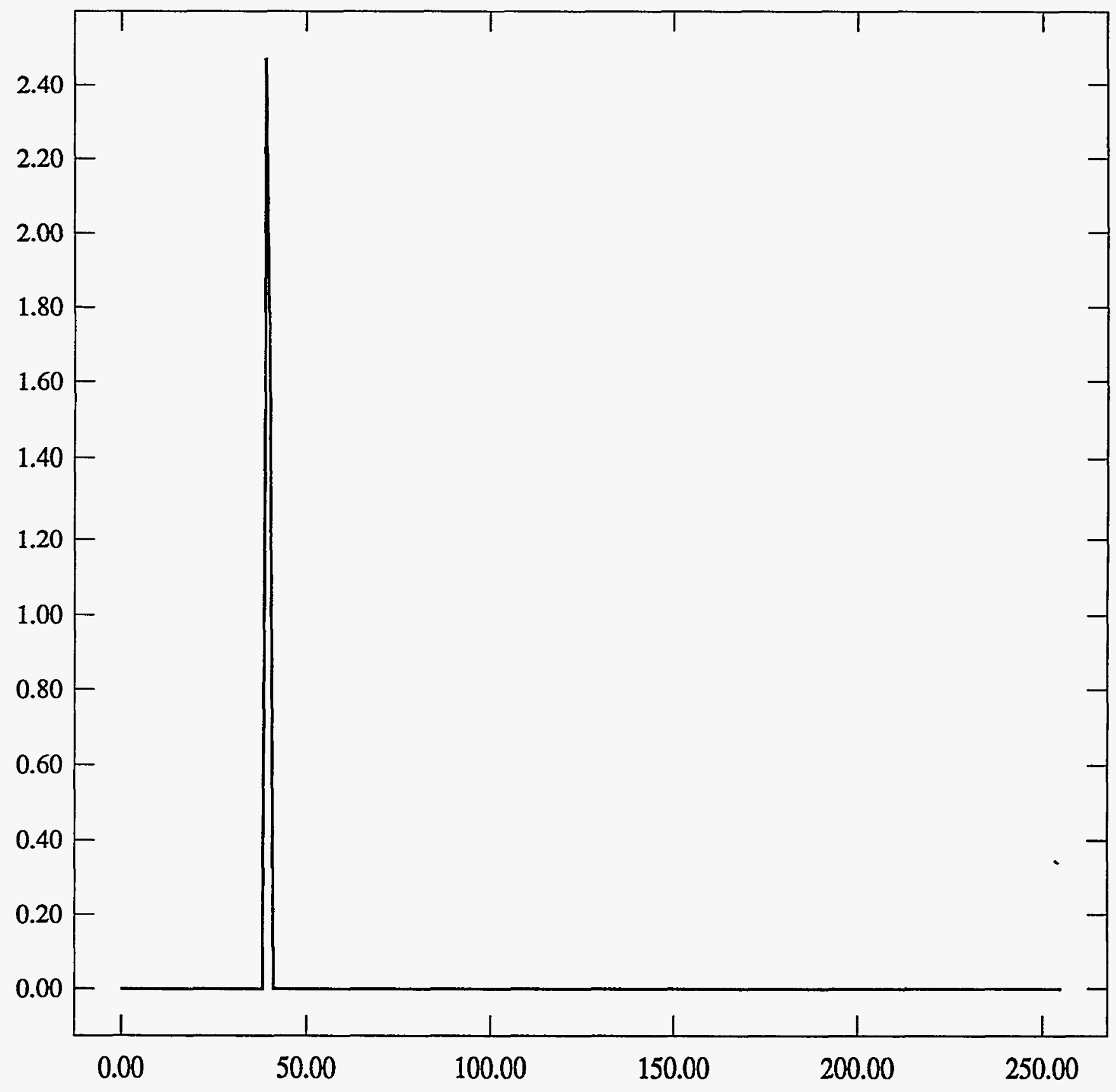


ST Camera: ST1\#04-10 20C \#5: int_time=200ms, offset= 0, gain=1 ( 350 e/bit) Wed Jun 30 18:14:55 1993 Pixel Values Min 38 Max 40 Mean 39.4 Sigma $0.49 \times 10^{3}$

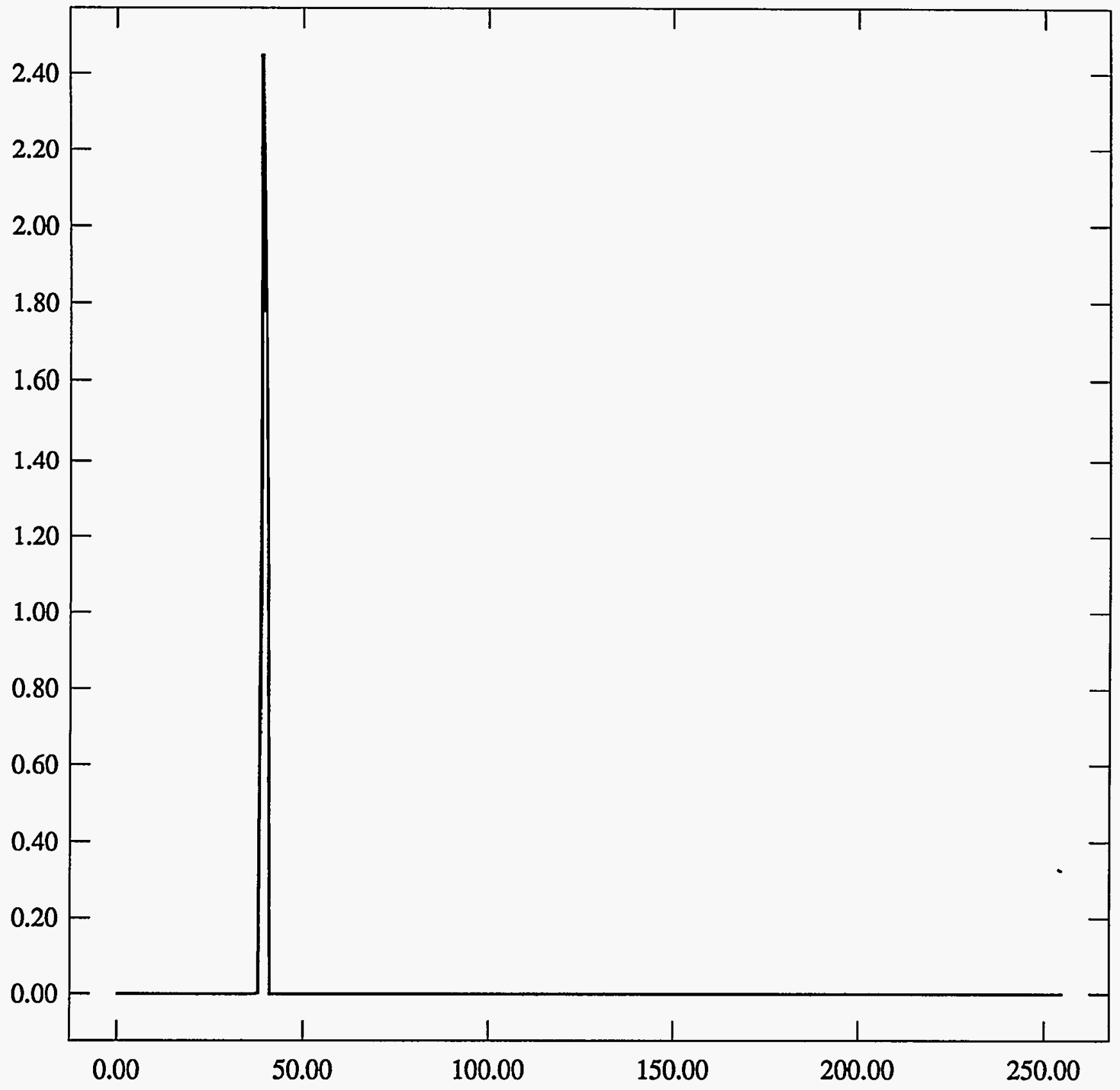


ST Camera: ST1\#04-10 20C \#5: int_time= 50ms, offset= 0, gain=2 (150 e/bit) Wed Jun 30 18:15:07 1993 Pixel Values Min 77 Max 81 Mean 79.1 Sigma $0.76 \times 10^{3}$

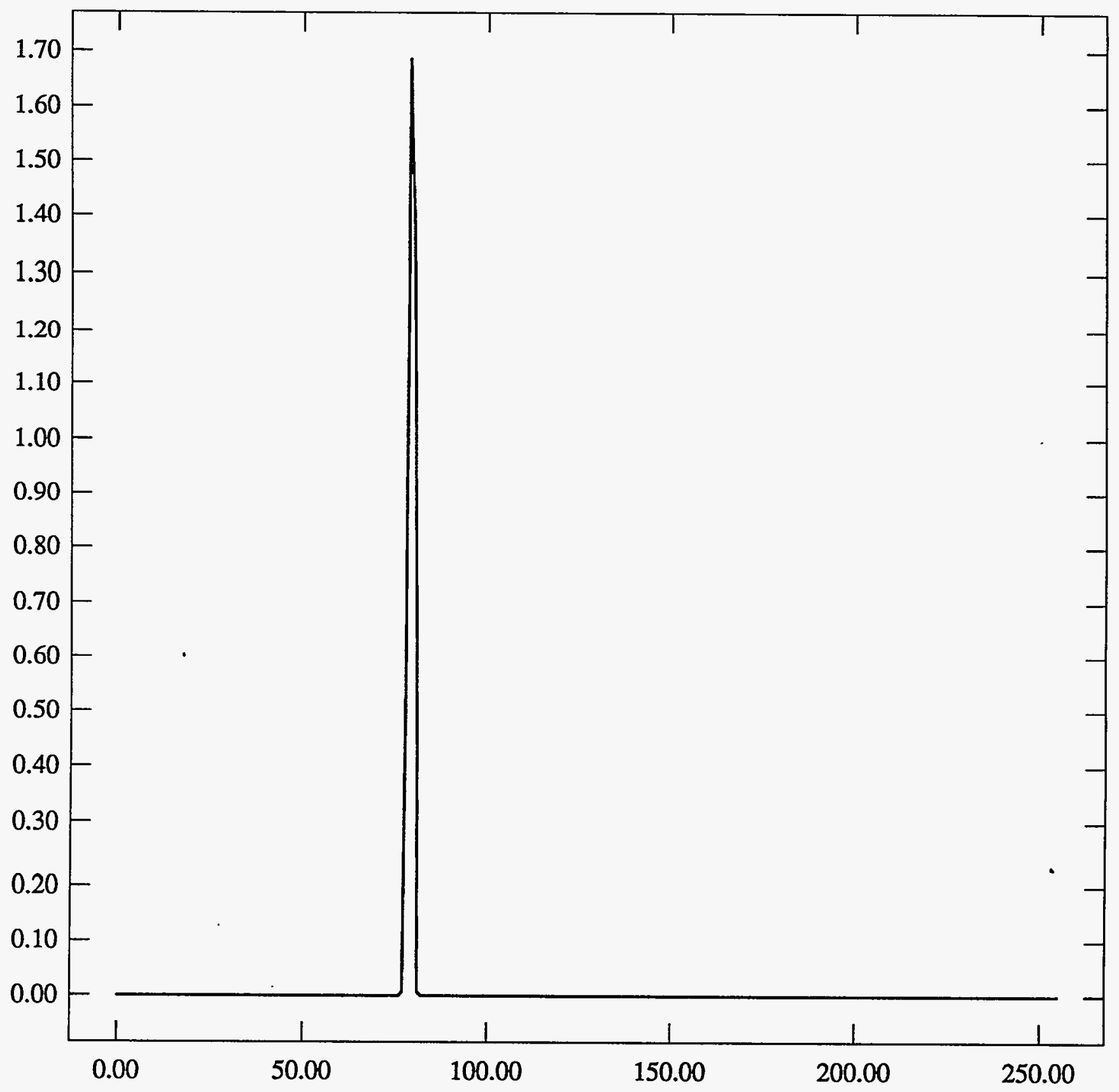


ST Camera: ST1\#04-10 20C \#5: int_time=100ms, offset= 0, gain=2 (150 e/bit) Wed Jun 30 18:15:20 1993 Pixel Values Min 77 Max 81 Mean 79.1 Sigma $0.78 \times 10^{3}$

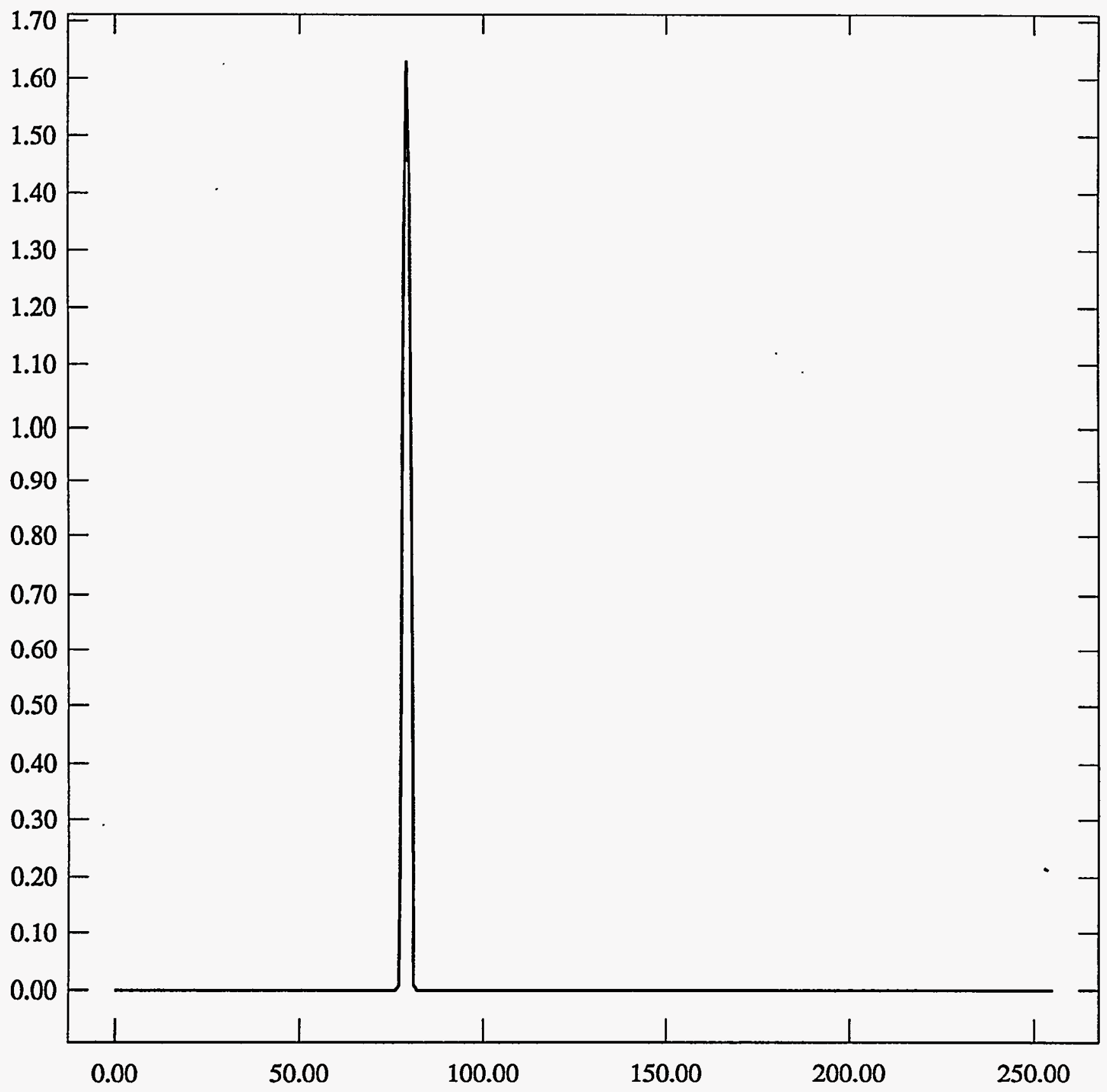


ST Camera: ST1\#04-10 20C \#5: int_time=200ms, offset= 0, gain=2 (150 e/bit) Wed Jun 30 18:15:31 1993 Pixel Values Min 77 Max 81 Mean 79.1 Sigma $0.77 \times 10^{3}$

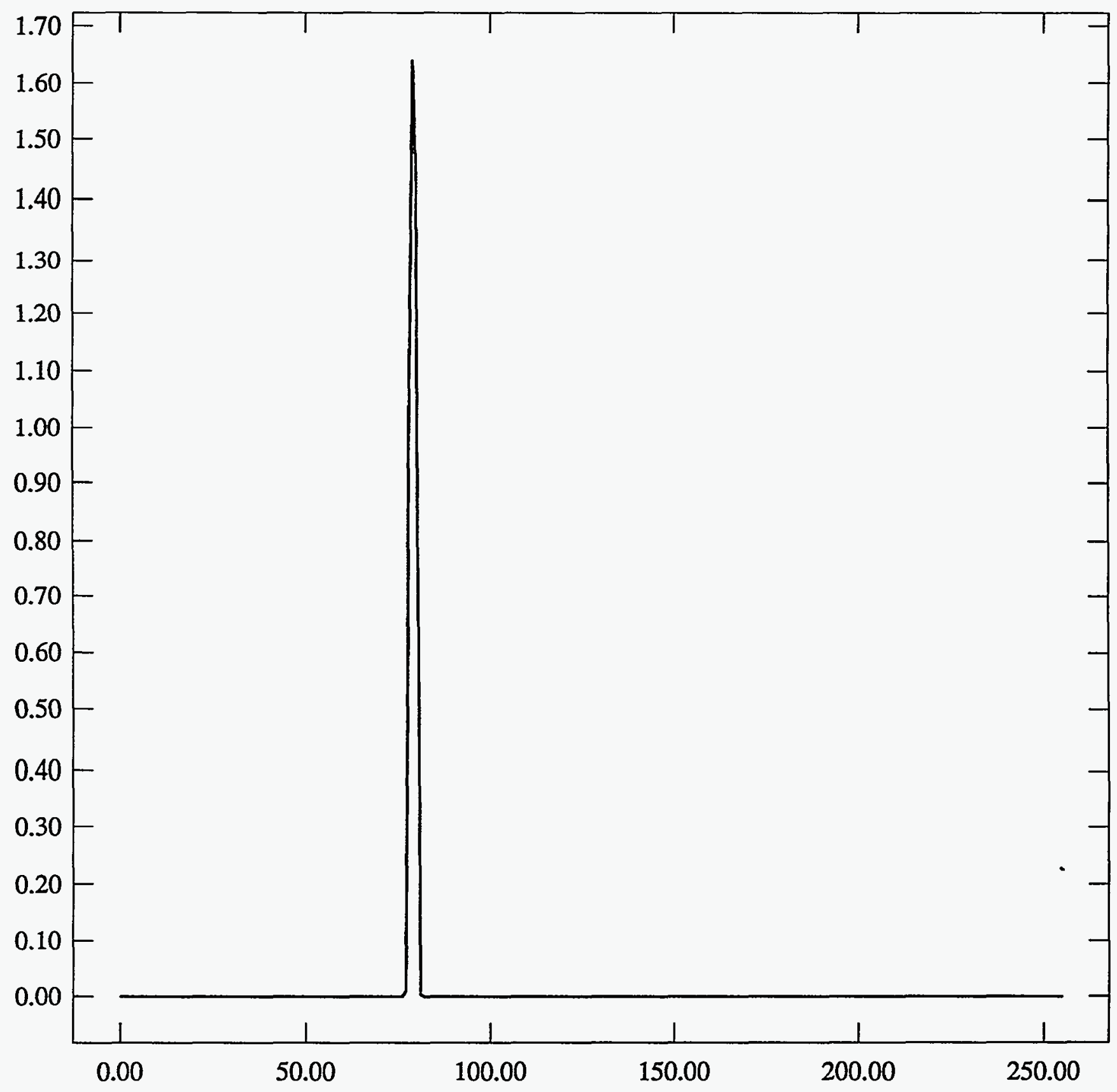


ST Camera: ST1\#04-10 20C \#5: int_time= 50ms, offset= 0, gain=4 ( 75 e/bit) Wed Jun 30 18:15:43 1993 Pixel Values Min 142 Max 148 Mean 144.8 Sigma $0.82 \times 10^{3}$

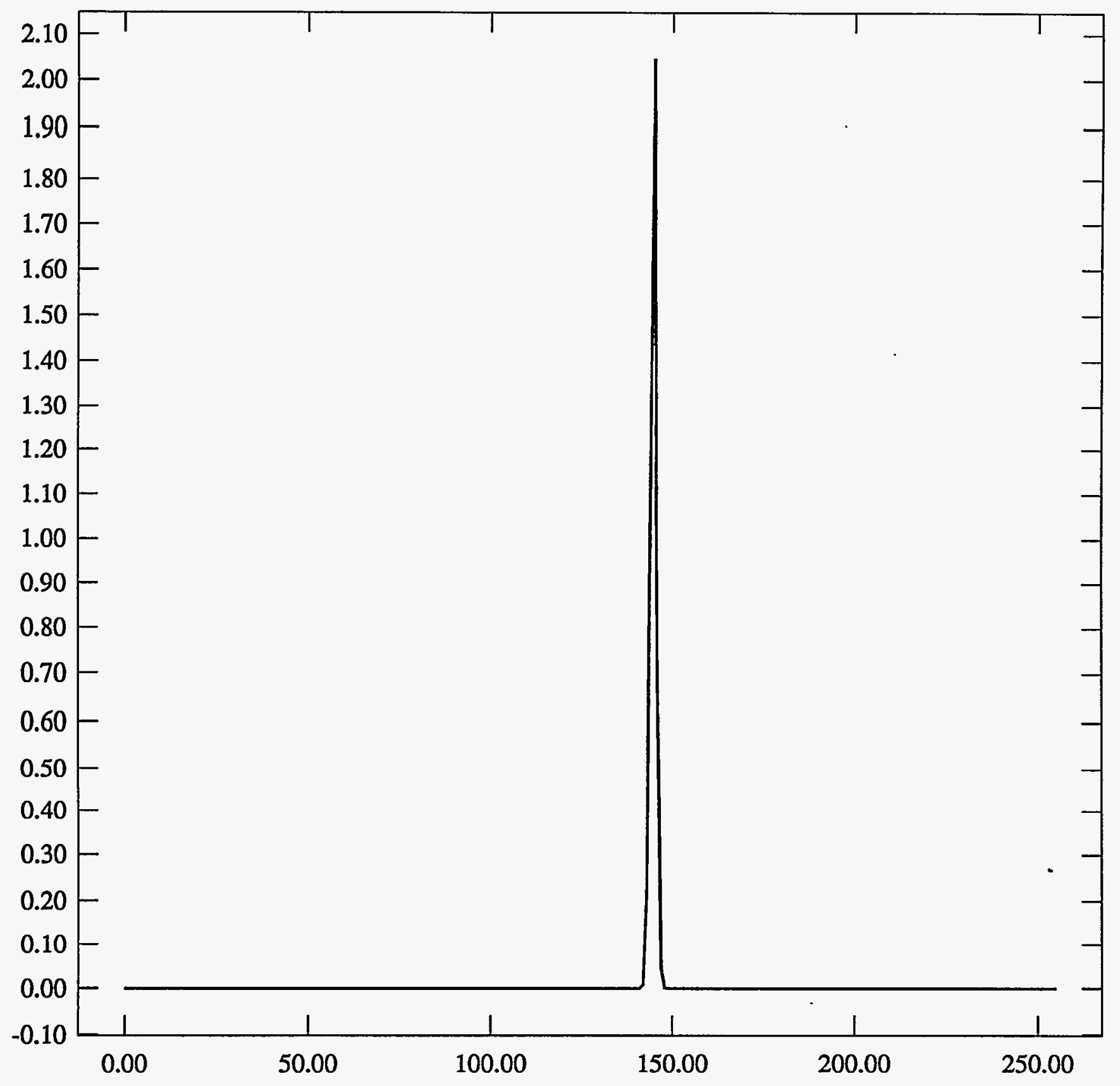


ST Camera: ST1\#04-10 20C \#5: int_time=100ms, offset= 0, gain=4 ( 75 e/bit) Wed Jun 30 18:15:57 1993 Pixel Values Min 142 Max 147 Mean 144.9 Sigma $0.78 \times 10^{3}$

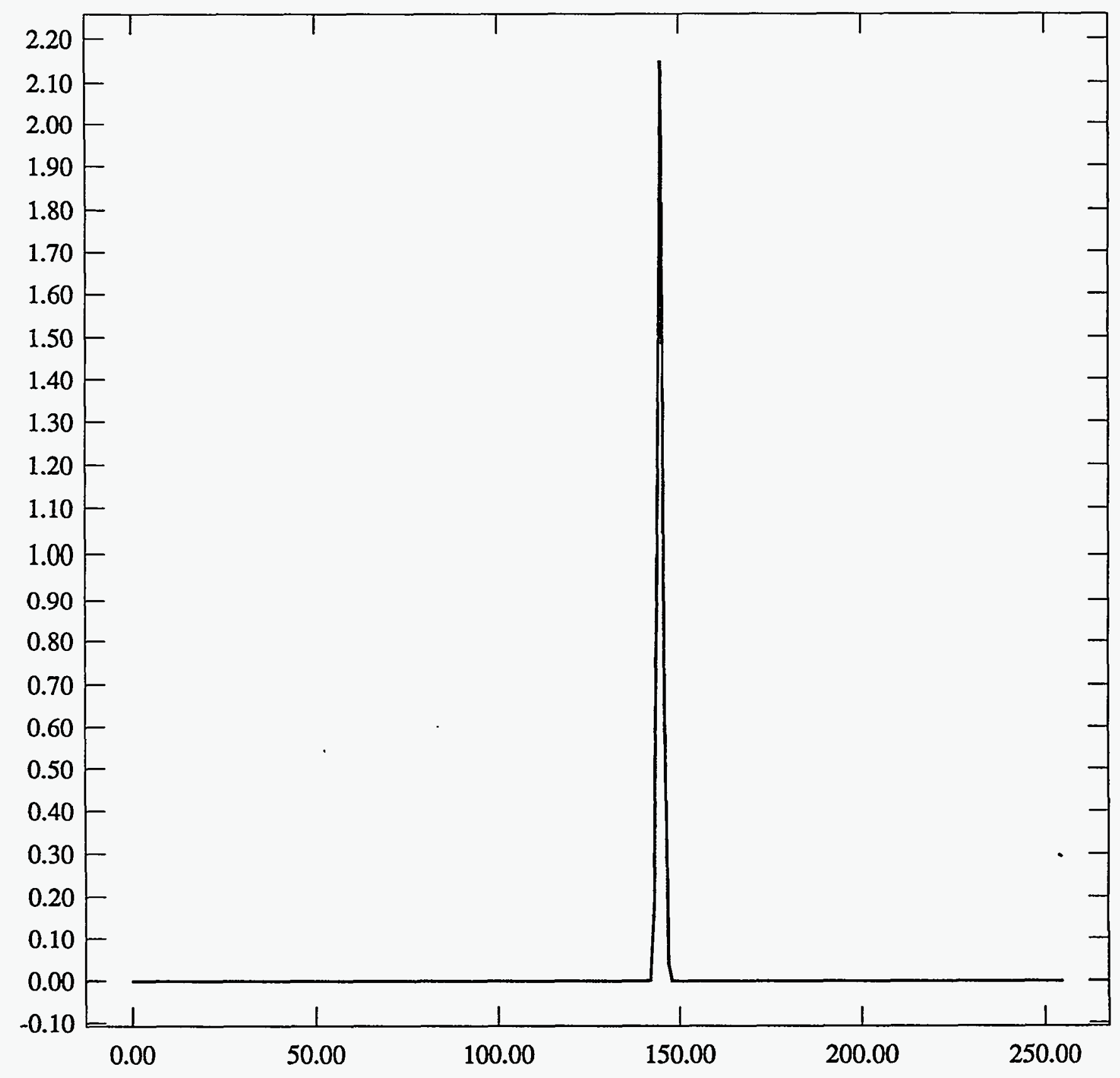


ST Camera: ST1\#04-10 20C \#5: int_time=200ms, offset= 0, gain=4 ( 75 e/bit) Wed Jun 30 18:16:15 1993 Pixel Values Min 142 Max 147 Mean 144.9 Sigma $0.78 \times 10^{3}$

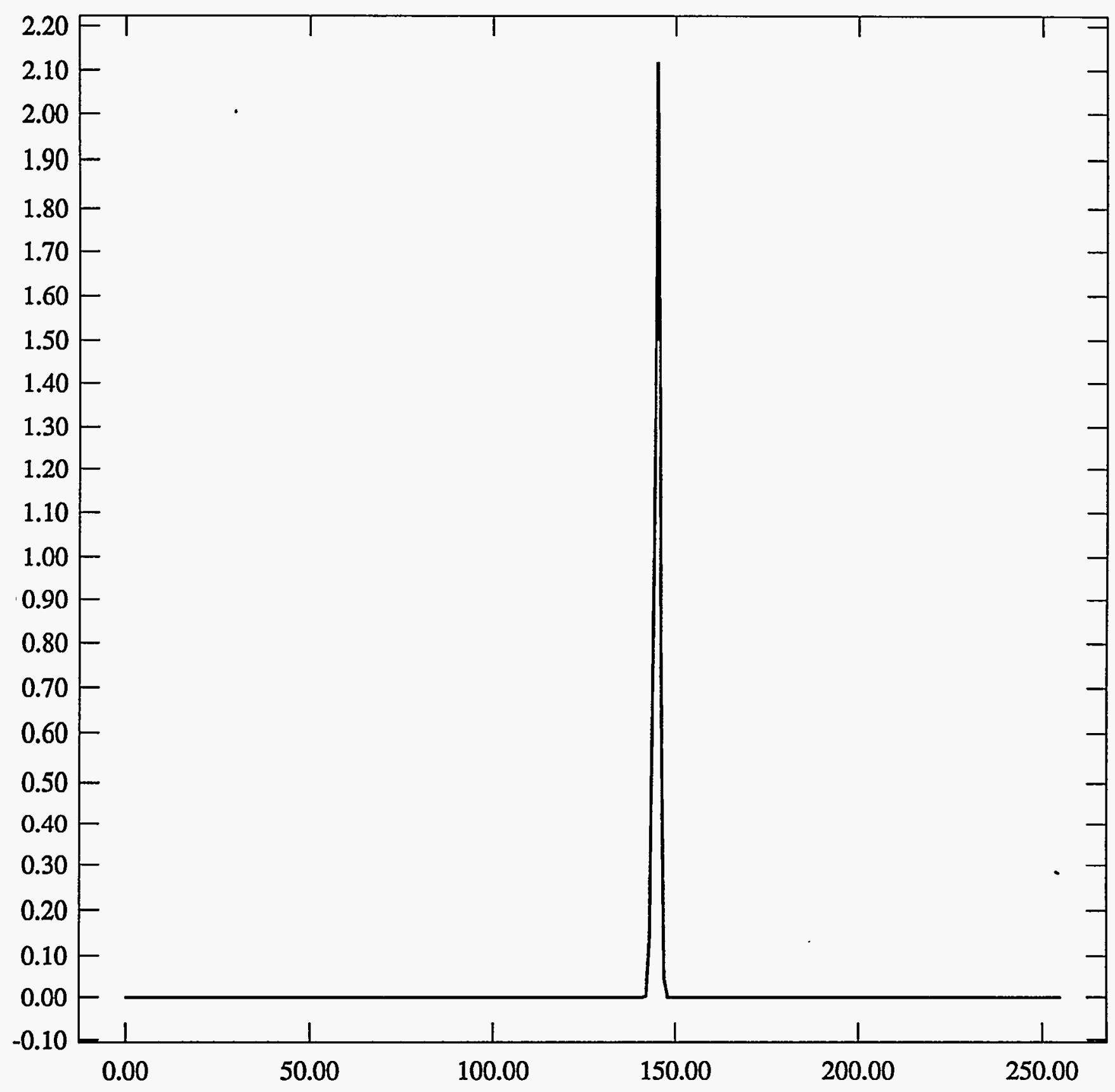


\#6. $30 \mathrm{C} \quad 15 \mathrm{~min}$

ST Camera: ST1\#04-10 -30C \#6: int_time= 50ms, offset= 0, gain=1 ( 350 e/bit) Wed Jun 30 18:53:50 1993 Pixel Values Min 39 Max 41 Mean 39.9 Sigma $0.34 \times 10^{3}$

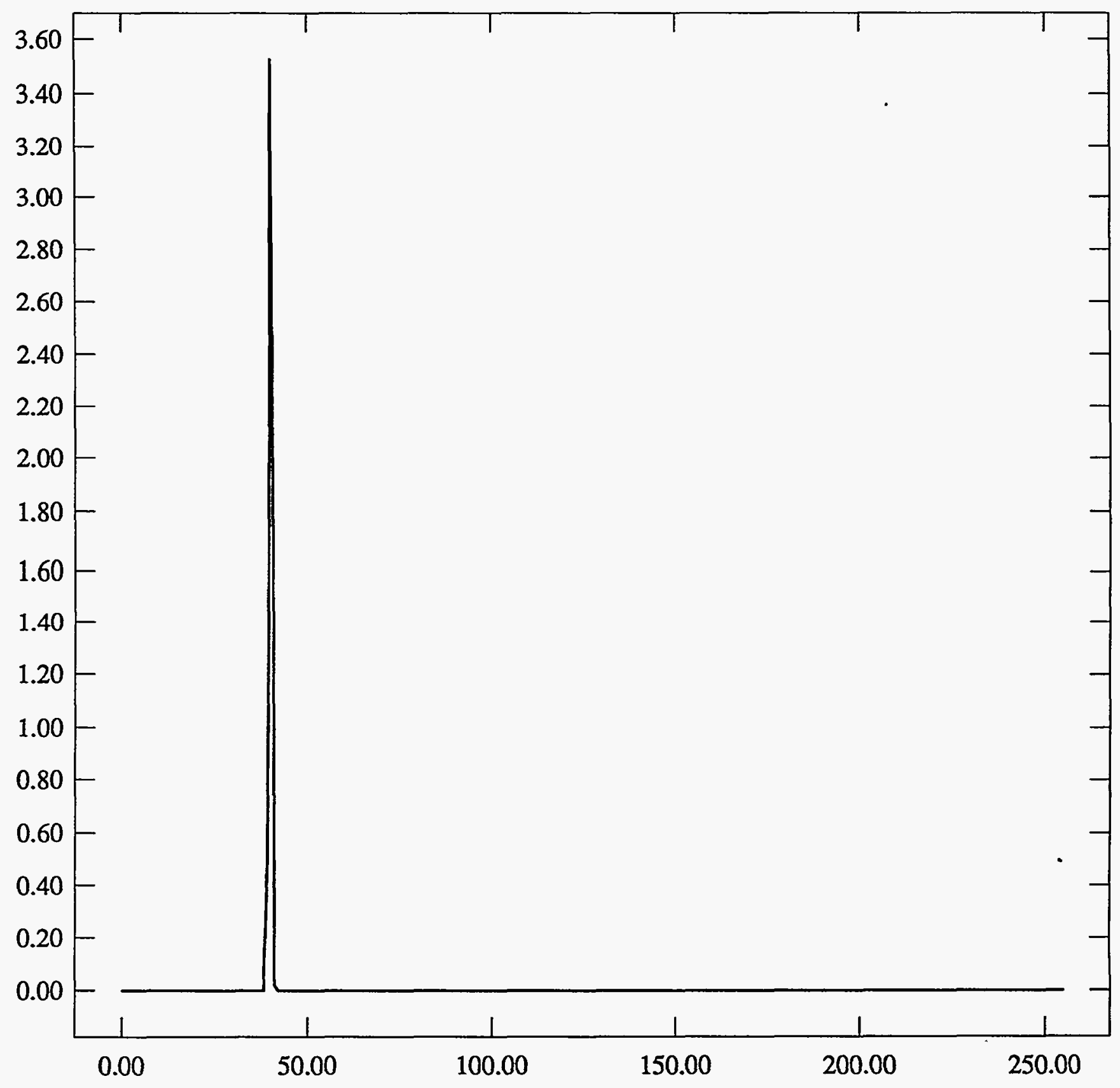


ST Camera: ST1\#04-10 -30C \#6: int_time=100ms, offset= 0, gain=1 ( 350 e/bit) Wed Jun 30 18:54:07 1993 Pixel Values Min 39 Max 41 Mean 39.9 Sigma 0.33 x $10^{3}$

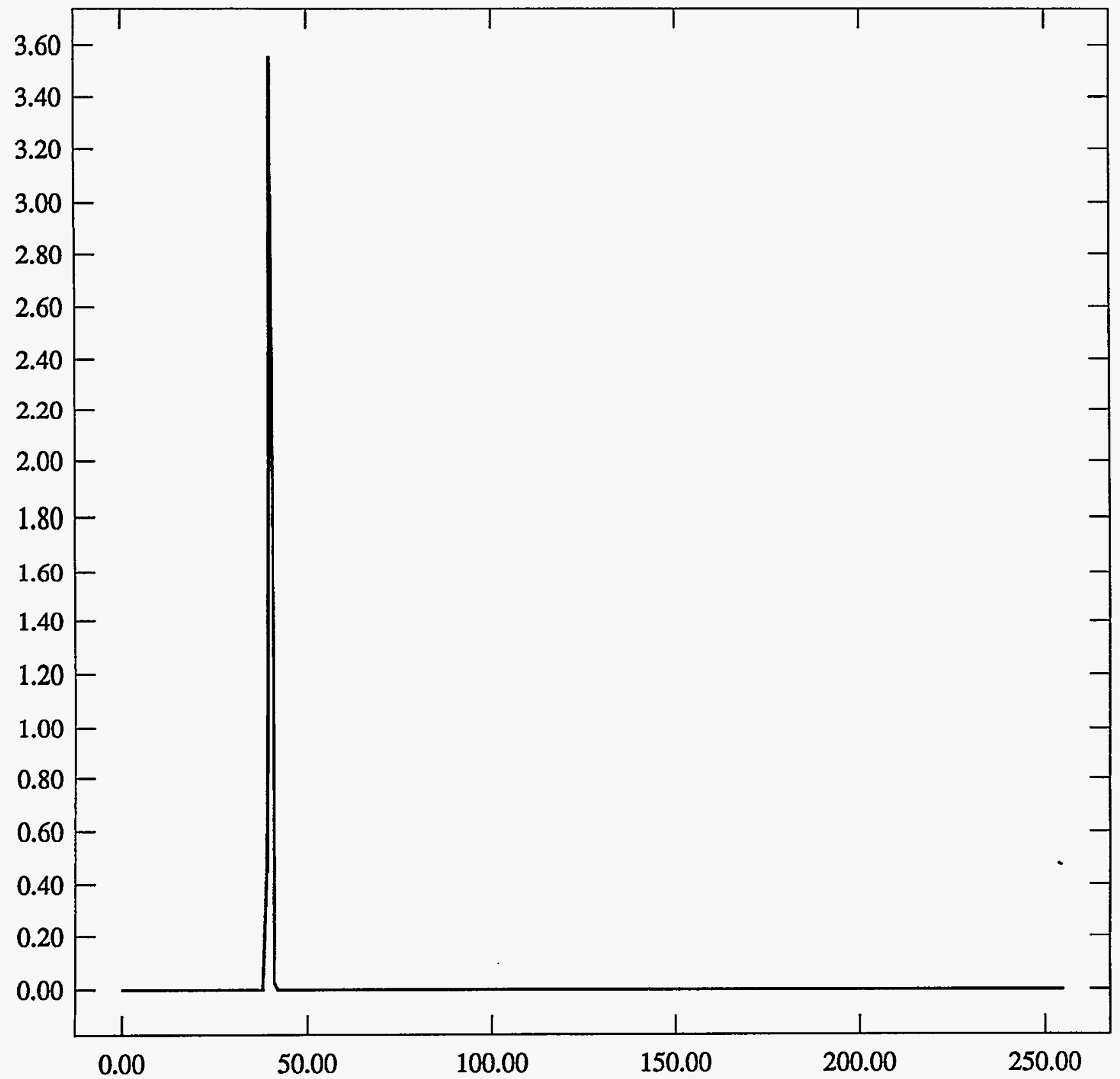


ST Camera: ST1\#04-10 -30C \#6: int_time=200ms, offset= 0, gain=1 ( 350 e/bit) Wed Jun 30 18:54:20 1993 Pixel Values Min 39 Max 41 Mean 39.9 Sigma $0.34 \times 10^{3}$

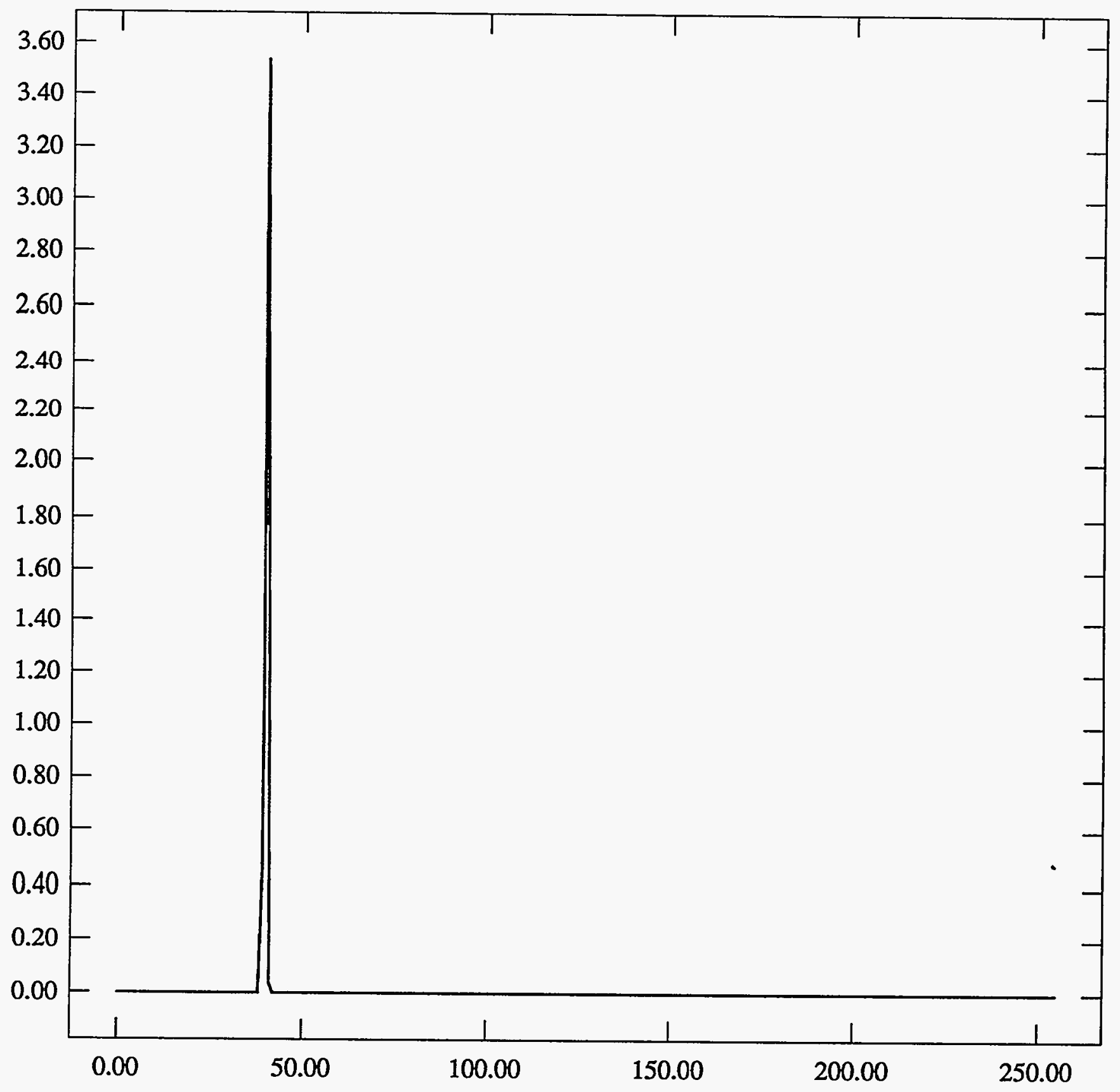


ST Camera: ST1\#04-10 -30C \#6: int_time= 50ms, offset= 0, gain=2 (150 e/bit) Wed Jun 30 18:54:34 1993 Pixel Values Min 78 Max 80 Mean 79.2 Sigma $0.57 \times 10^{3}$

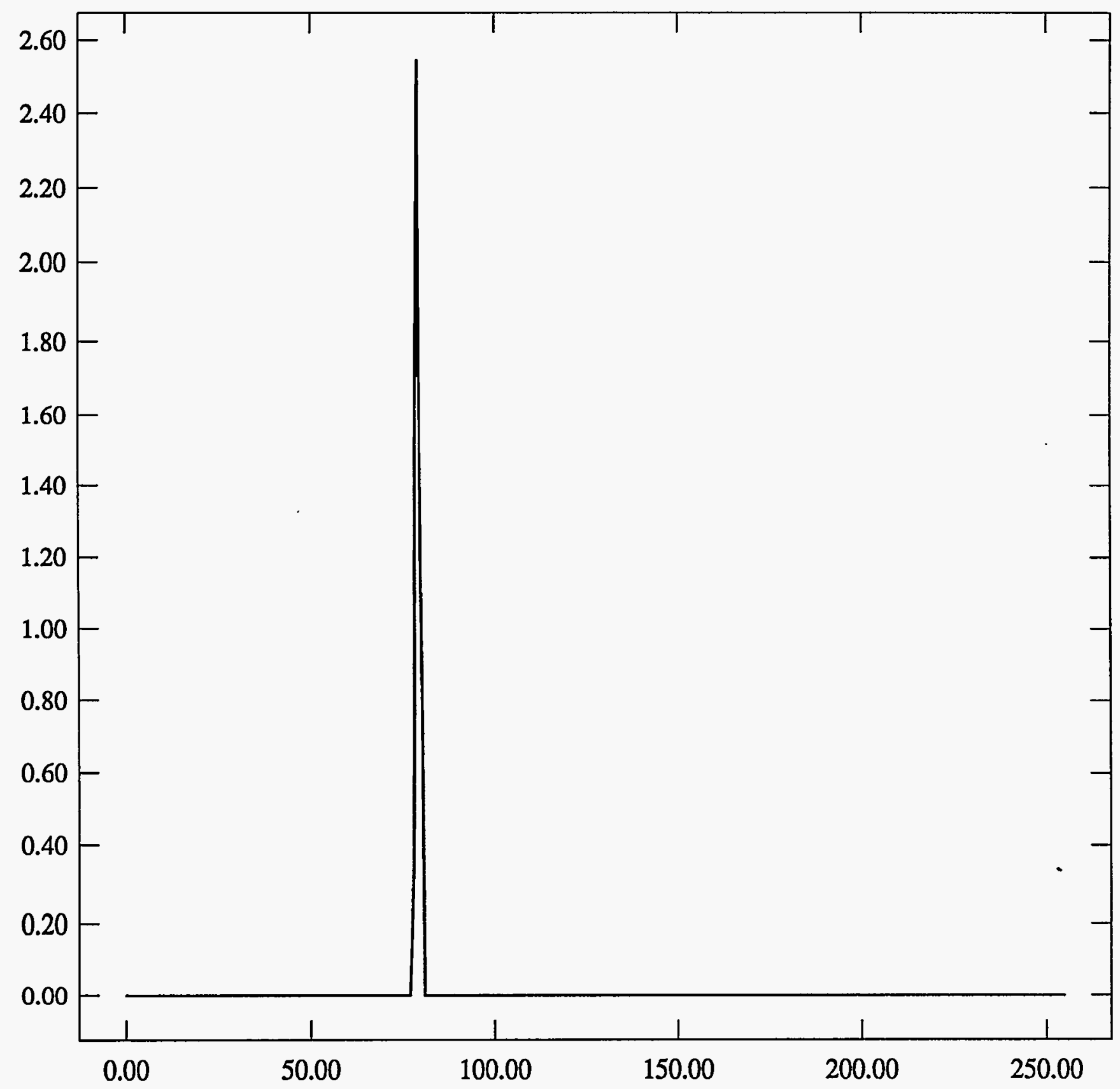


ST Camera: ST1\#04-10 -30C \#6: int_time=100ms, offset= 0, gain=2 (150 e/bit) Wed Jun 30 18:54:46 1993 Pixel Values Min 78 Max 81 Mean 79.2 Sigma $0.58 \times 10^{3}$

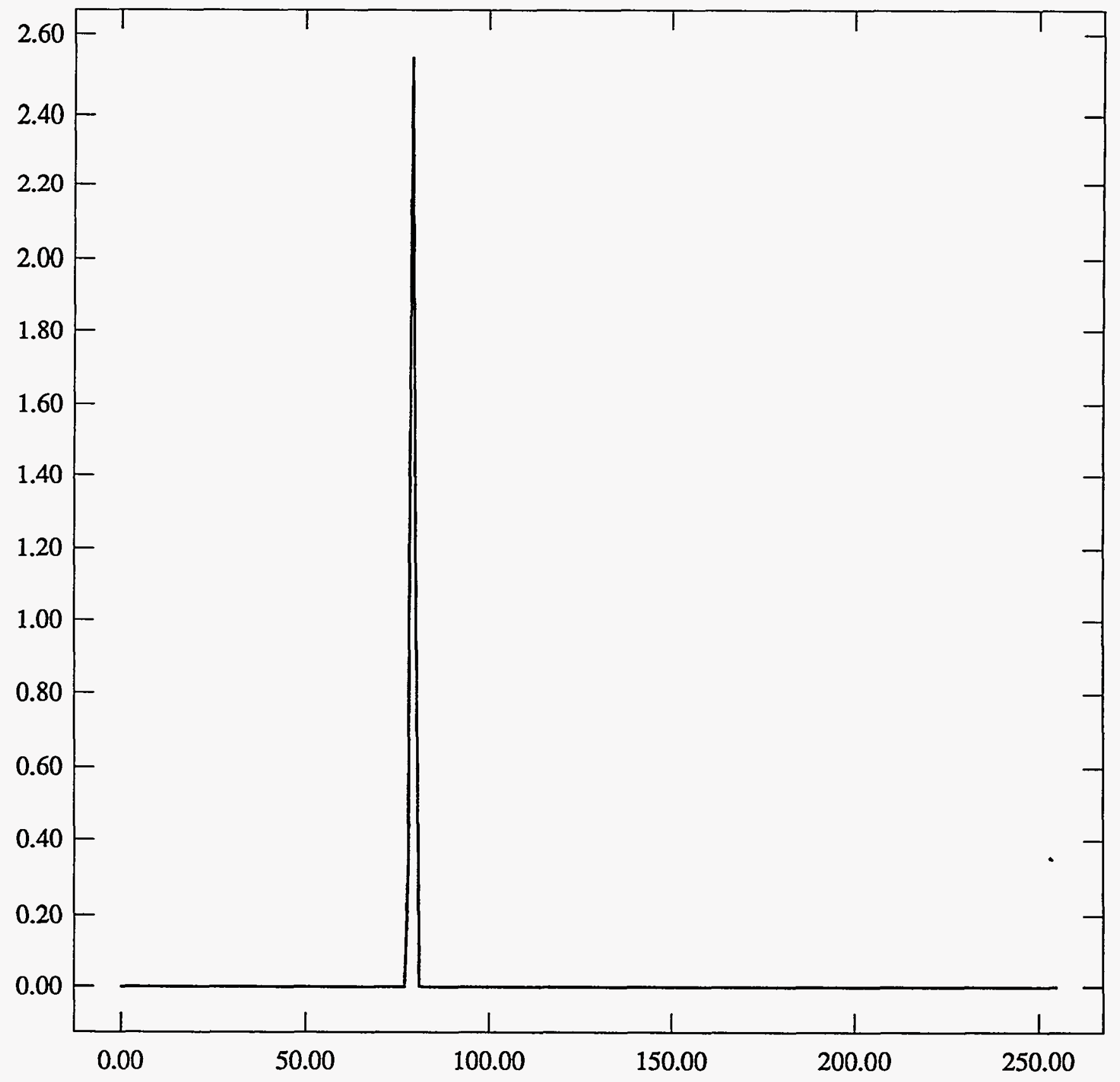


ST Camera: ST1\#04-10 -30C \#6: int_time=200ms, offset= 0, gain=2 ( 150 e/bit) Wed Jun 30 18:55:02 1993 Pixel Values Min 78 Max 80 Mean 79.2 Sigma $0.58 \times 10^{3}$

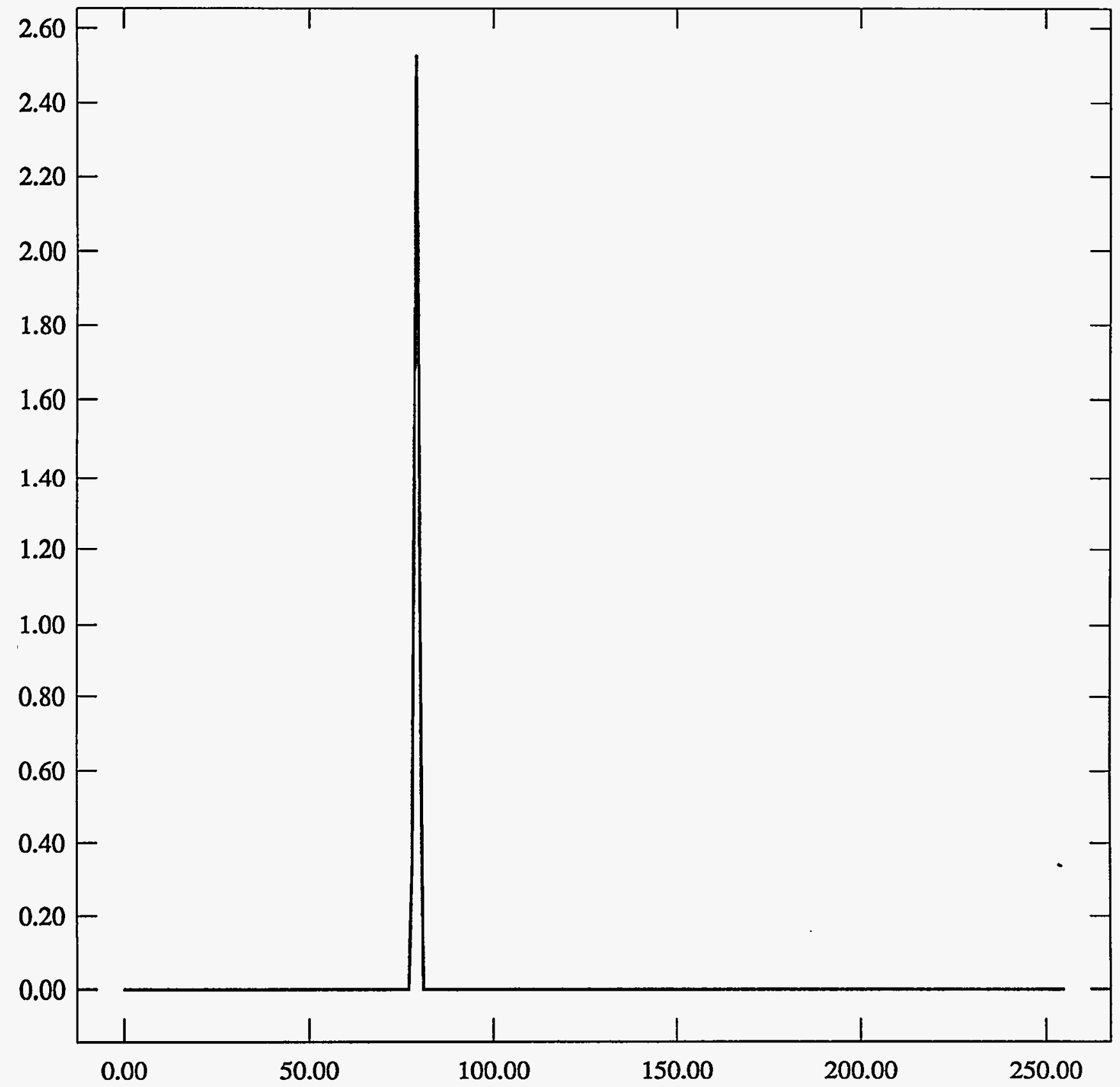


ST Camera: ST1\#04-10 -30C \#6: int_time= 50ms, offset= 0, gain=4 ( 75 e/bit) Wed Jun 30 18:55:14 1993 Pixel Values Min 144 Max 149 Mean 146.8 Sigma $0.69 \times 10^{3}$

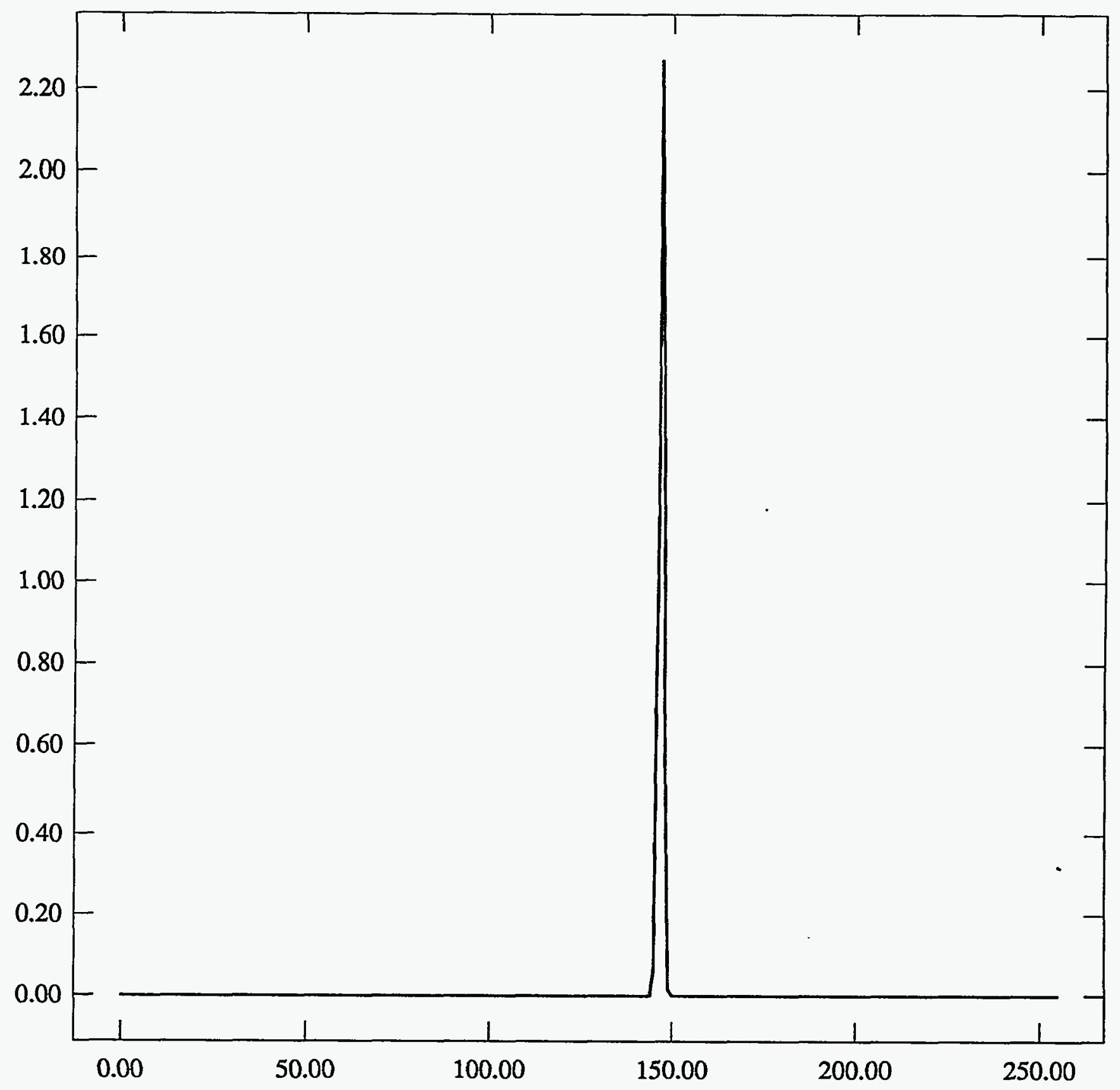


ST Camera: ST1\#04-10 -30C \#6: int_time=100ms, offset= 0, gain=4 ( 75 e/bit) Wed Jun 30 18:55:29 1993 Pixel Values Min 145 Max 149 Mean 146.9 Sigma $0.70 \times 10^{3}$

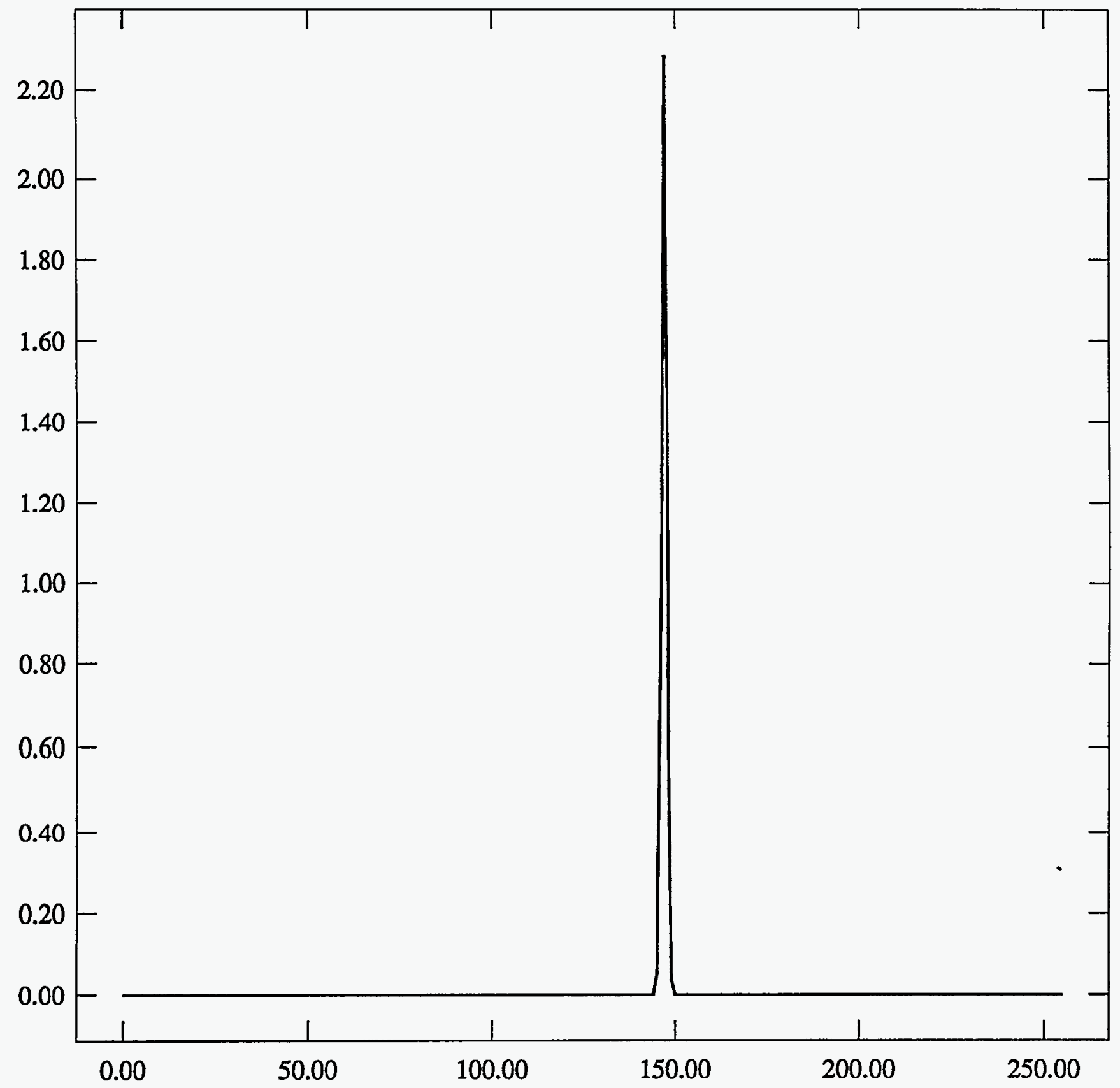


ST Camera: ST1\#04-10 -30C \#6: int_time=200ms, offset= 0, gain=4 ( 75 e/bit) Wed Jun 30 18:55:42 1993 Pixel Values Min 145 Max 149 Mean 146.9 Sigma $0.72 \times 10^{3}$

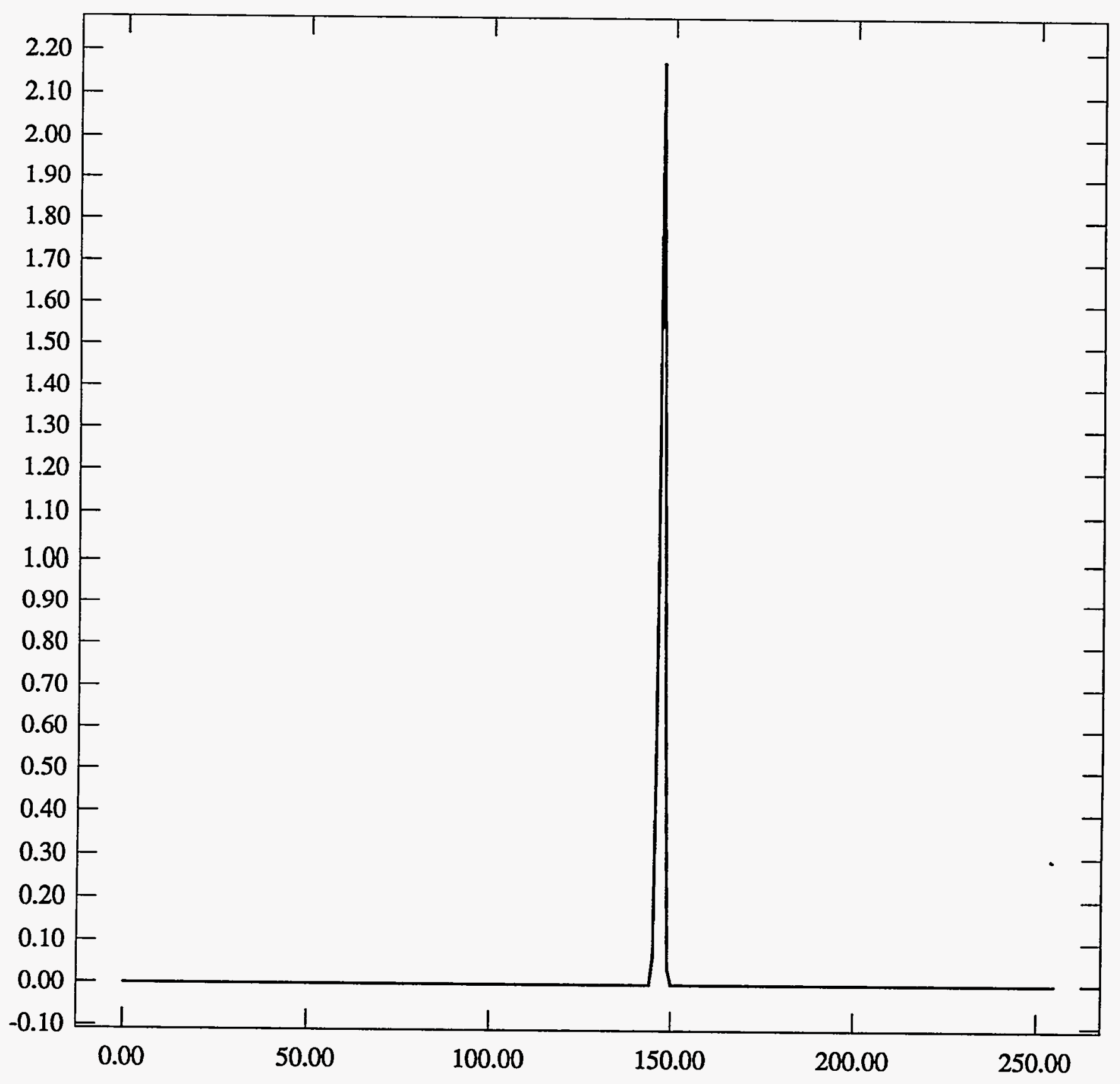




$$
\$ 16-36 C \quad[N, 2
$$

ST Camera: ST1\#04-10 -30C \#6: int_time= 50ms, offset= 0, gain=1 (350 e/bit) Wed Jun 30 19:33:02 1993 Pixel Values Min 39 Max 41 Mean 39.9 Sigma $0.35 \times 10^{3}$

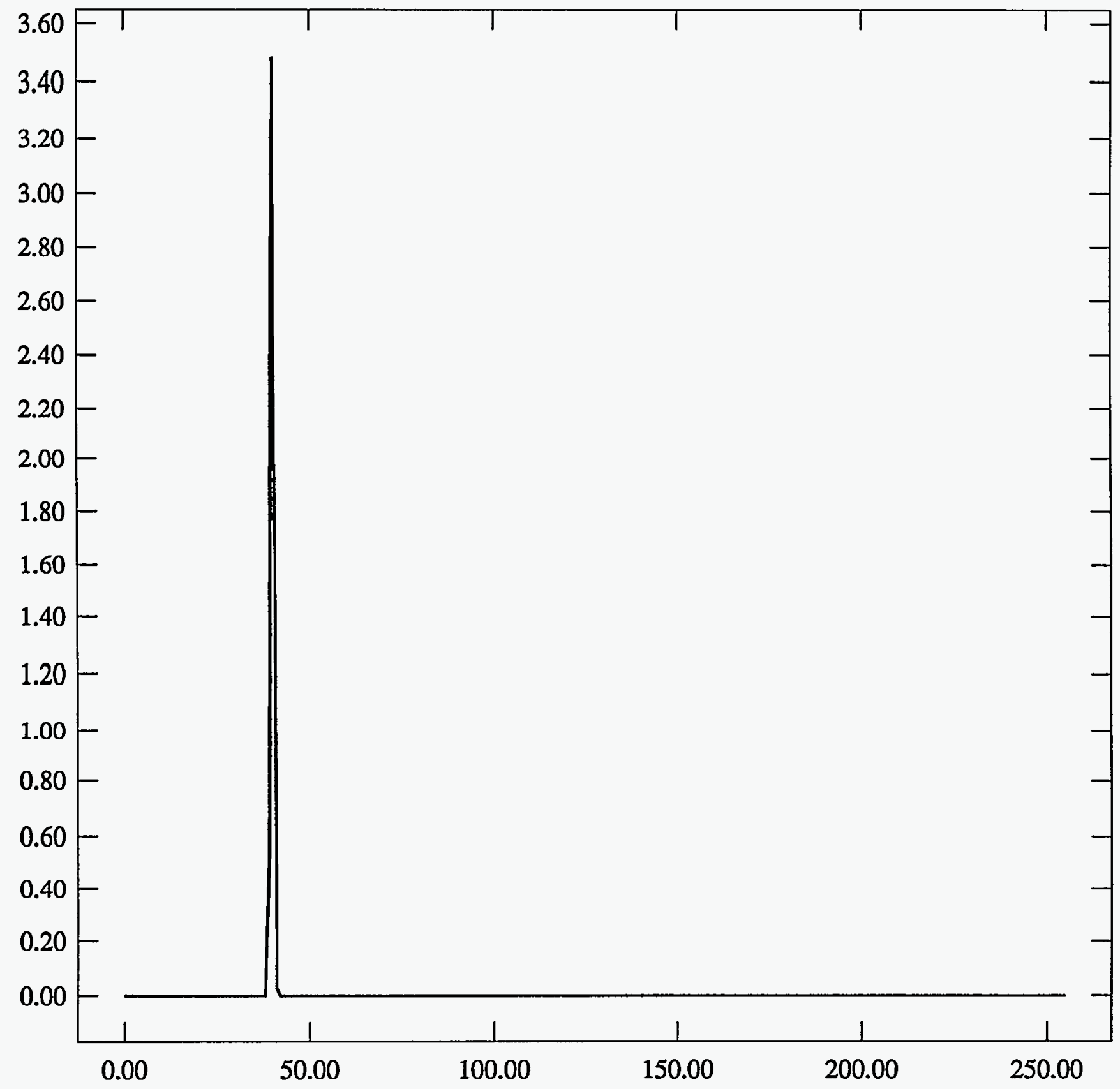


ST Camera: ST1\#04-10 -30C \#6: int_time=100ms, offset= 0, gain=1 ( 350 e/bit) Wed Jun 30 19:33:14 1993 Pixel Values Min 39 Max 41 Mean 39.9 Sigma $0.32 \times 10^{3}$

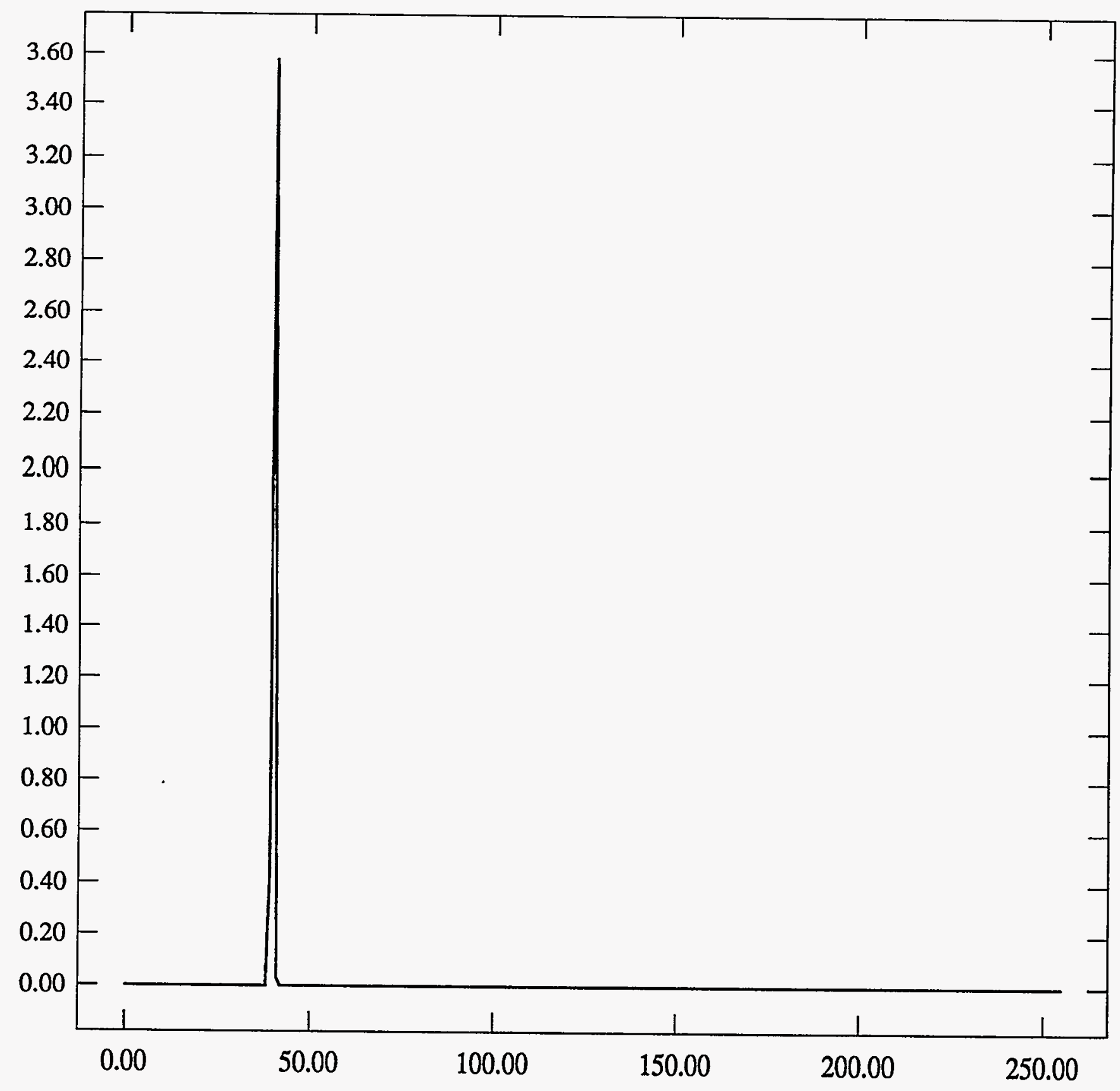


ST Camera: ST1\#04-10 -30C \#6: int_time=200ms, offset= 0, gain=1 ( $350 \mathrm{e} / \mathrm{bit}$ ) Wed Jun 30 19:33:24 1993 Pixel Values Min 39 Max 41 Mean 39.9 Sigma $0.35 \times 10^{3}$

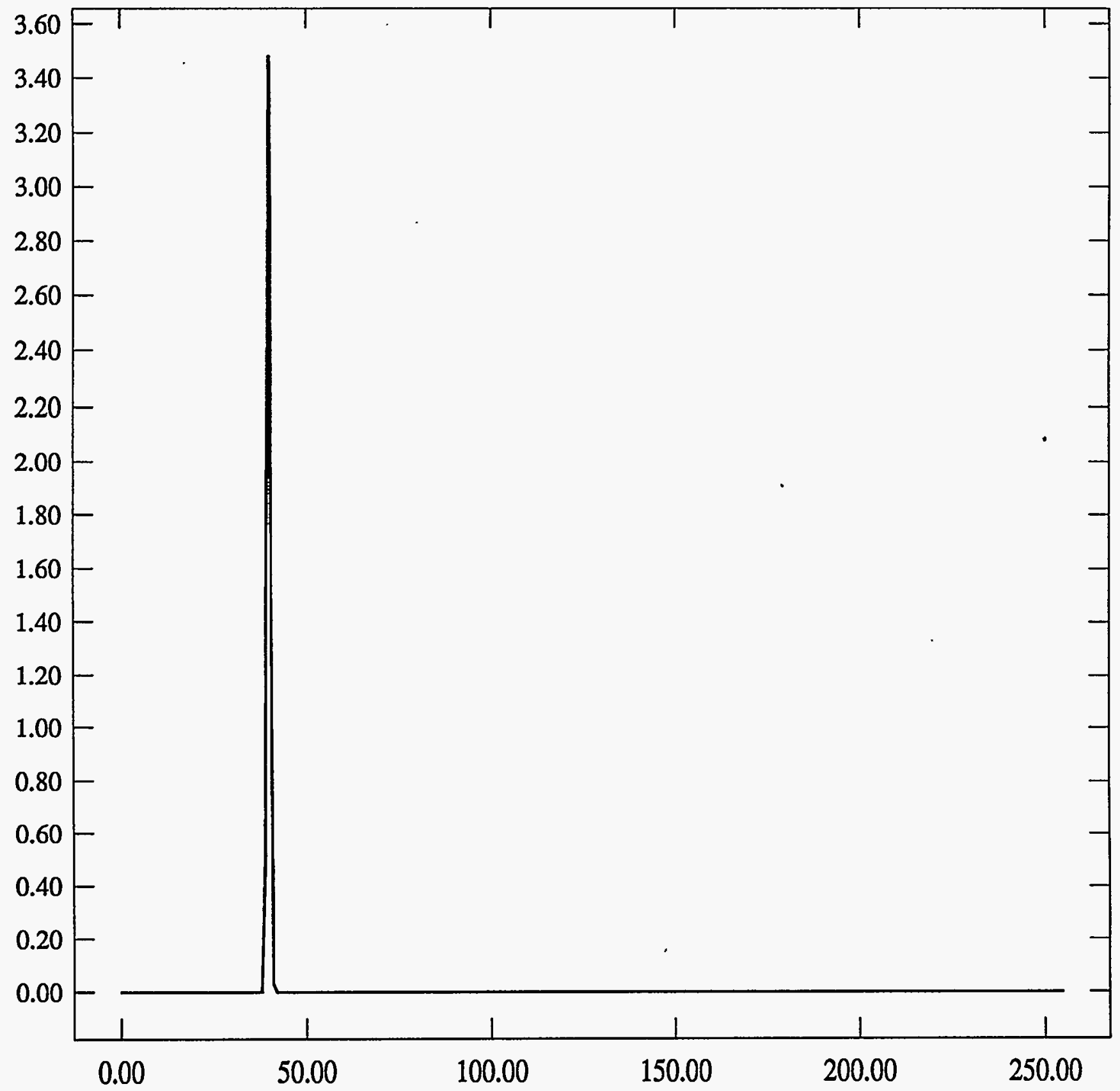


ST Camera: ST1\#04-10 -30C \#6: int_time= 50ms, offset= 0, gain=2 (150 e/bit) Wed Jun 30 19:33:36 1993 Pixel Values Min 78 Max 80 Mean 79.2 Sigma $0.60 \times 10^{3}$

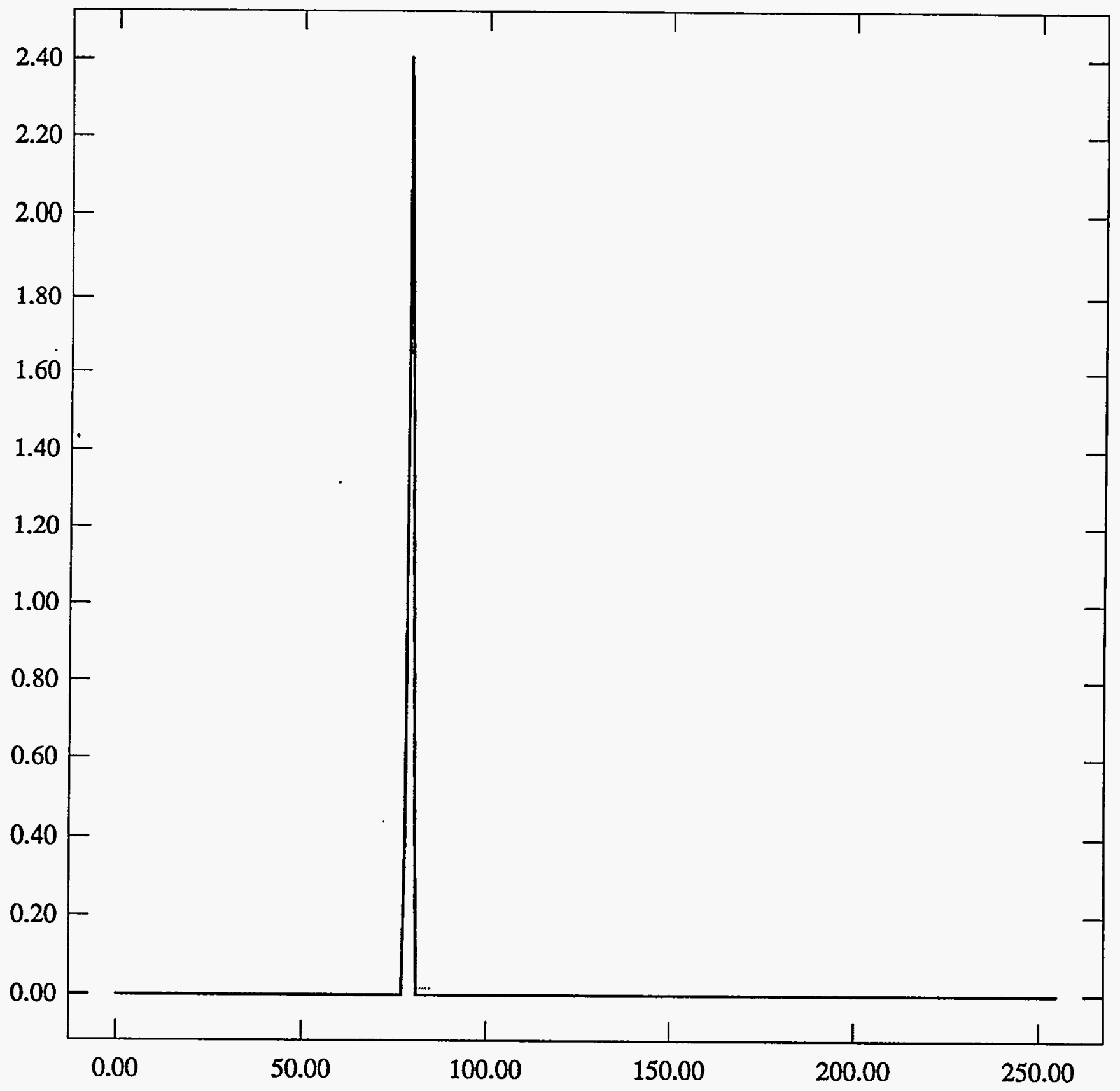


ST Camera: ST1\#04-10 -30C \#6: int_time=100ms, offset= 0, gain=2 (150 e/bit) Wed Jun 30 19:33:48 1993 Pixel Values Min 78 Max 80 Mean 79.2 Sigma $0.57 \times 10^{3}$

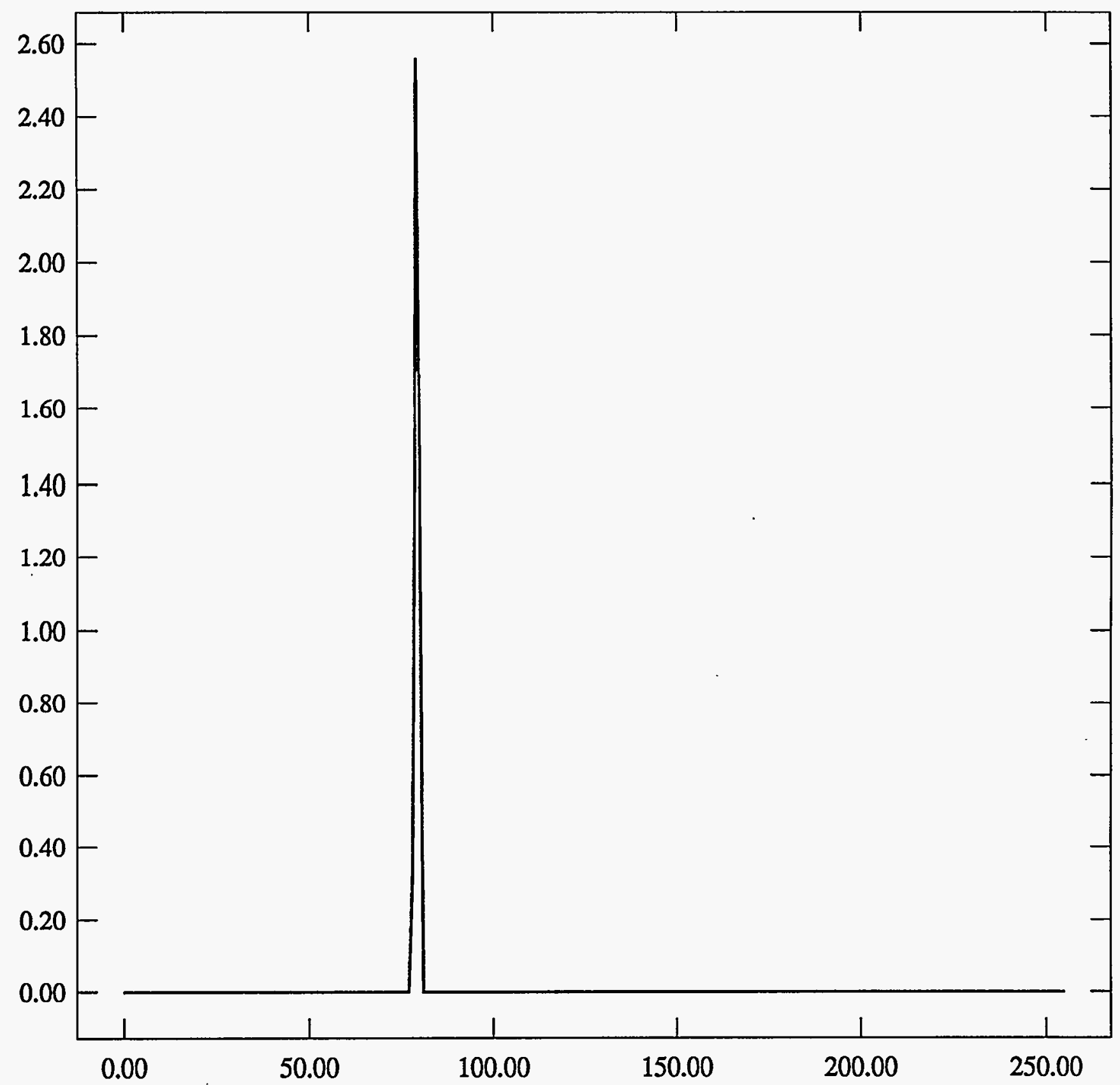


ST Camera: ST1\#04-10 -30C \#6: int_time=200ms, offset= 0, gain=2 ( $150 \mathrm{e} / \mathrm{bit})$ Wed Jun 30 19:33:59 1993 Pixel Values Min 78 Max 80 Mean 79.2 Sigma $0.58 \times 10^{3}$

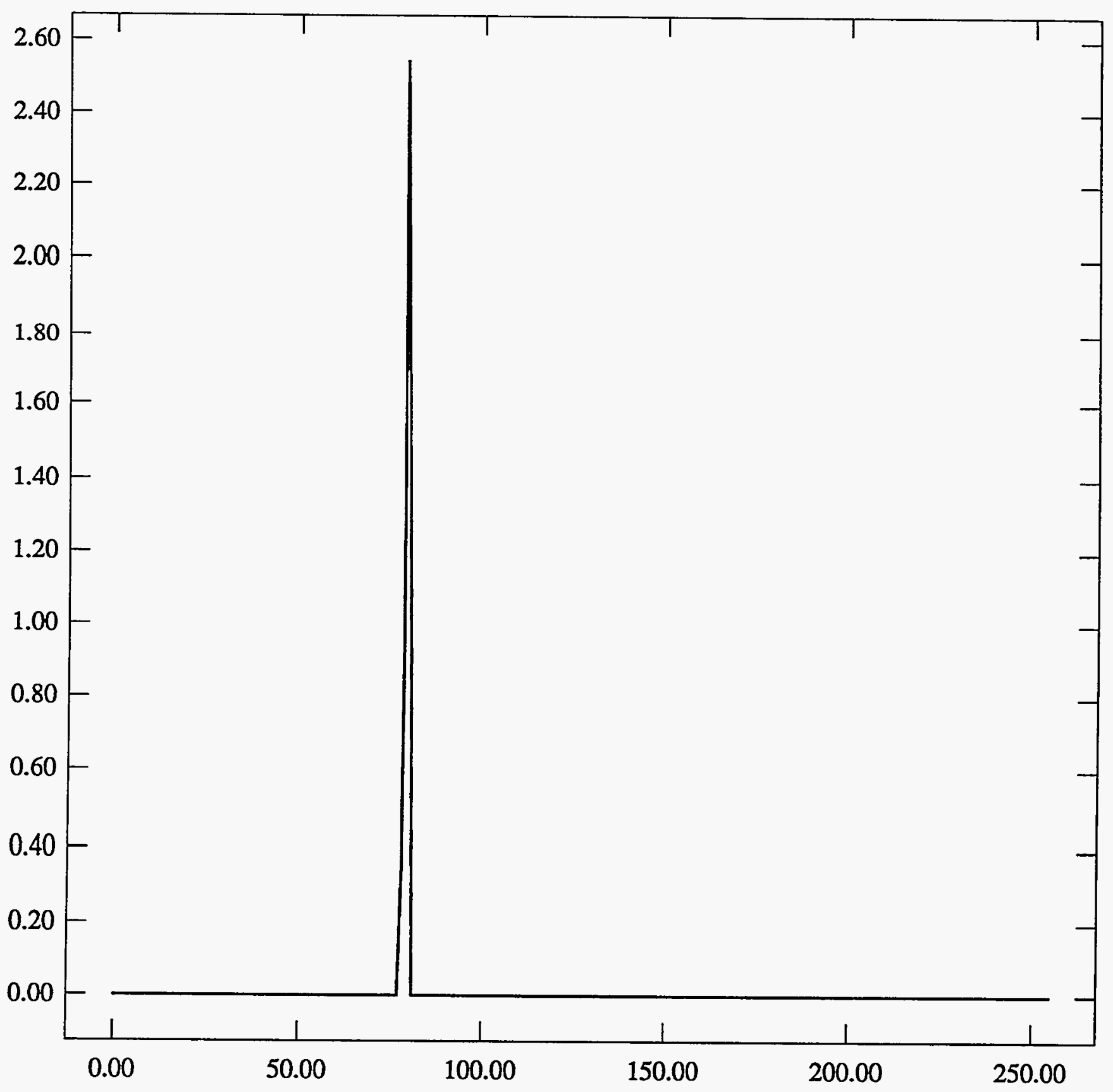


ST Camera: ST1\#04-10 -30C \#6: int_time= 50ms, offset= 0, gain=4 ( 75 e/bit) Wed Jun 30 19:34:10 1993 Pixel Values Min 145 Max 149 Mean 146.9 Sigma $0.70 \times 10^{3}$

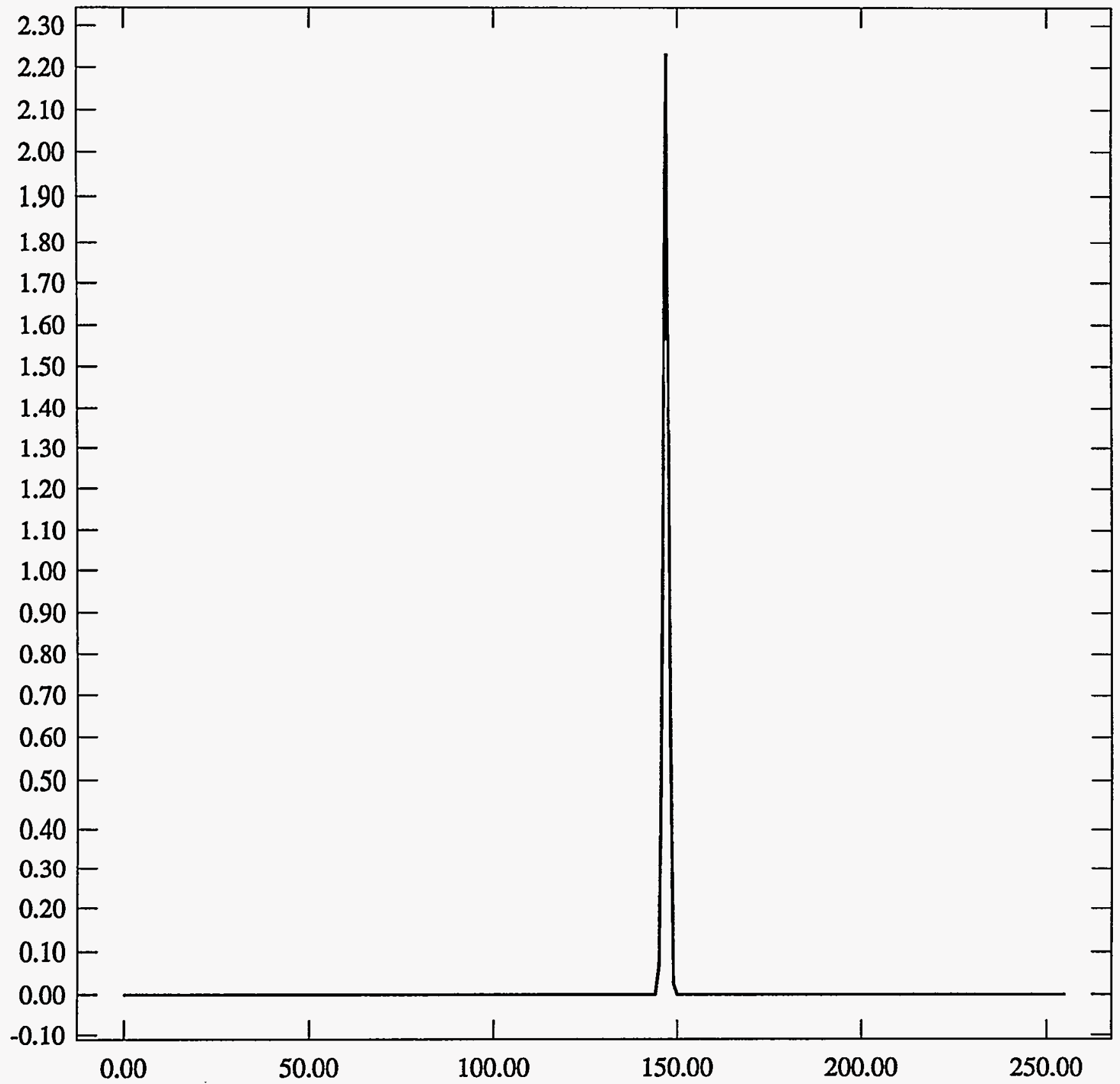


ST Camera: ST1\#04-10 -30C \#6: int_time=100ms, offset= 0, gain=4 ( 75 e/bit) Wed Jun 30 19:34:22 1993 Pixel Values Min 144 Max 149 Mean 146.9 Sigma 0.71 x 1033

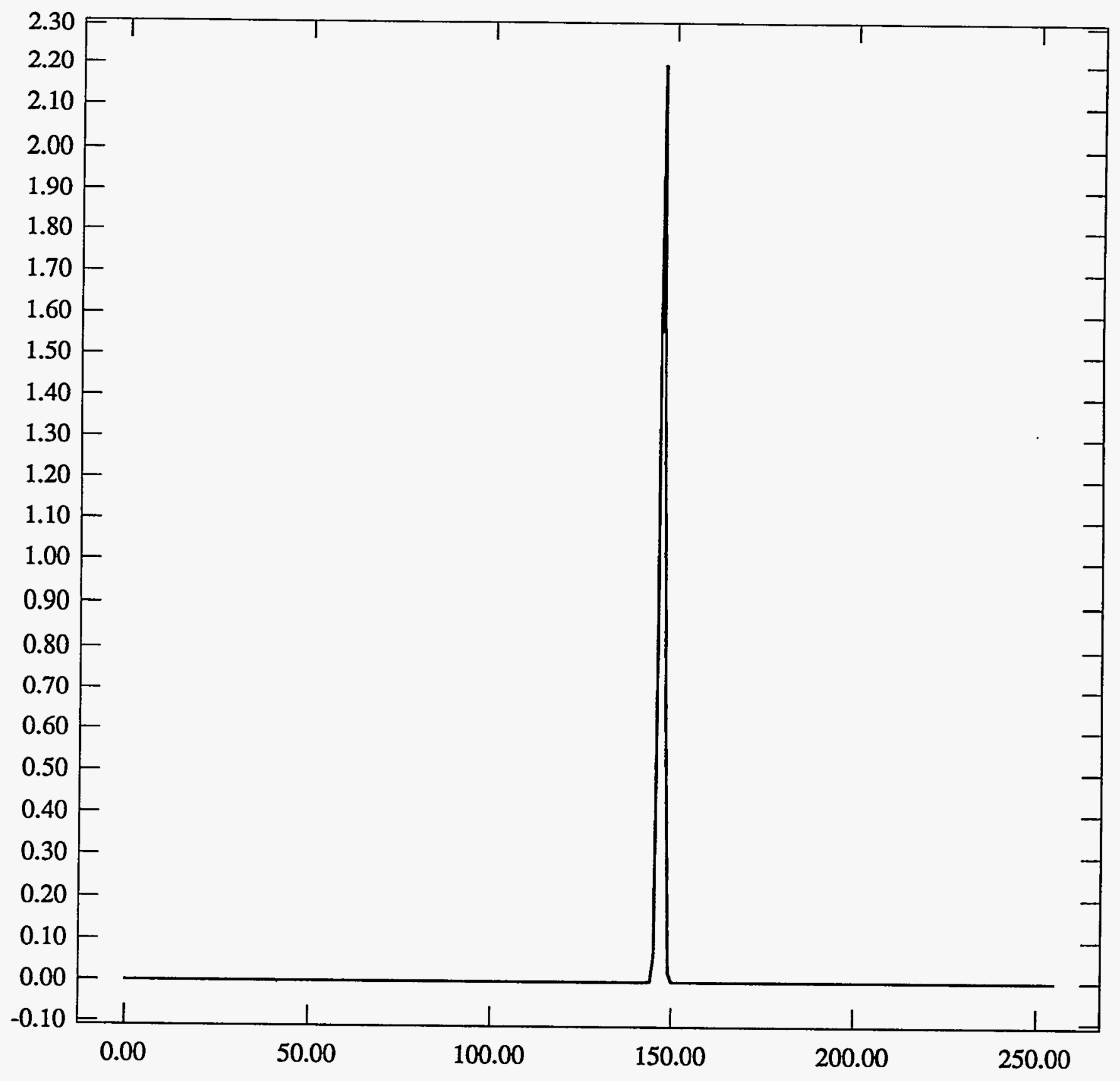


ST Camera: ST1\#04-10 -30C \#6: int_time=200ms, offset= 0, gain=4 ( 75 e/bit) Wed Jun 30 19:34:34 1993 Pixel Values Min 145 Max 149 Mean 146.9 Sigma $0.70 \times 10^{3}$

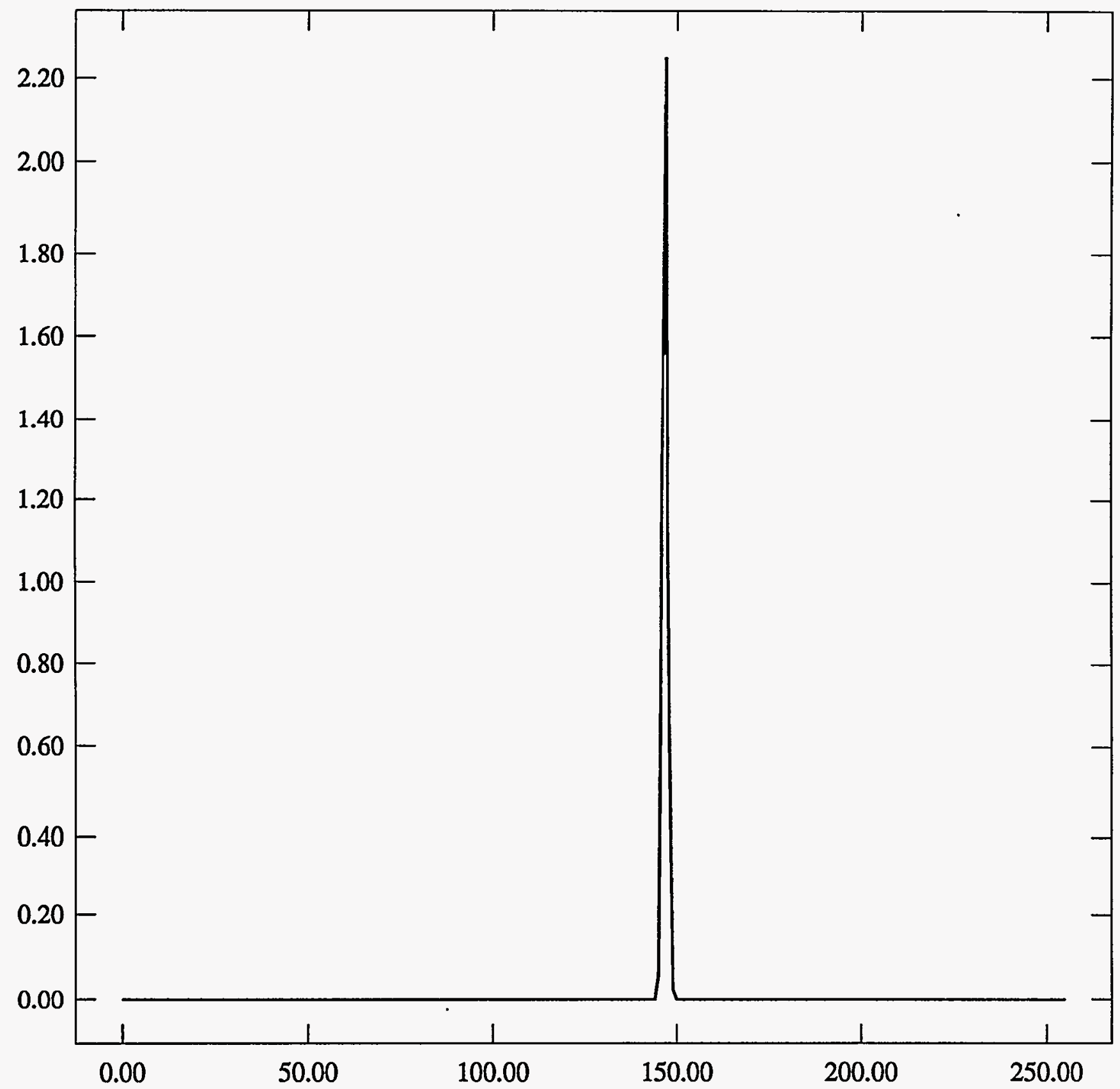


\#20C 15 min

ST Camera: ST1\#04-10 20C \#6: int_time= 50ms, offset= 0, gain=1 ( $350 \mathrm{e} / \mathrm{bit}$ ) Wed Jun 30 20:07:25 1993 Pixel Values Min 39 Max 41 Mean 39.5 Sigma $0.50 \times 10^{3}$

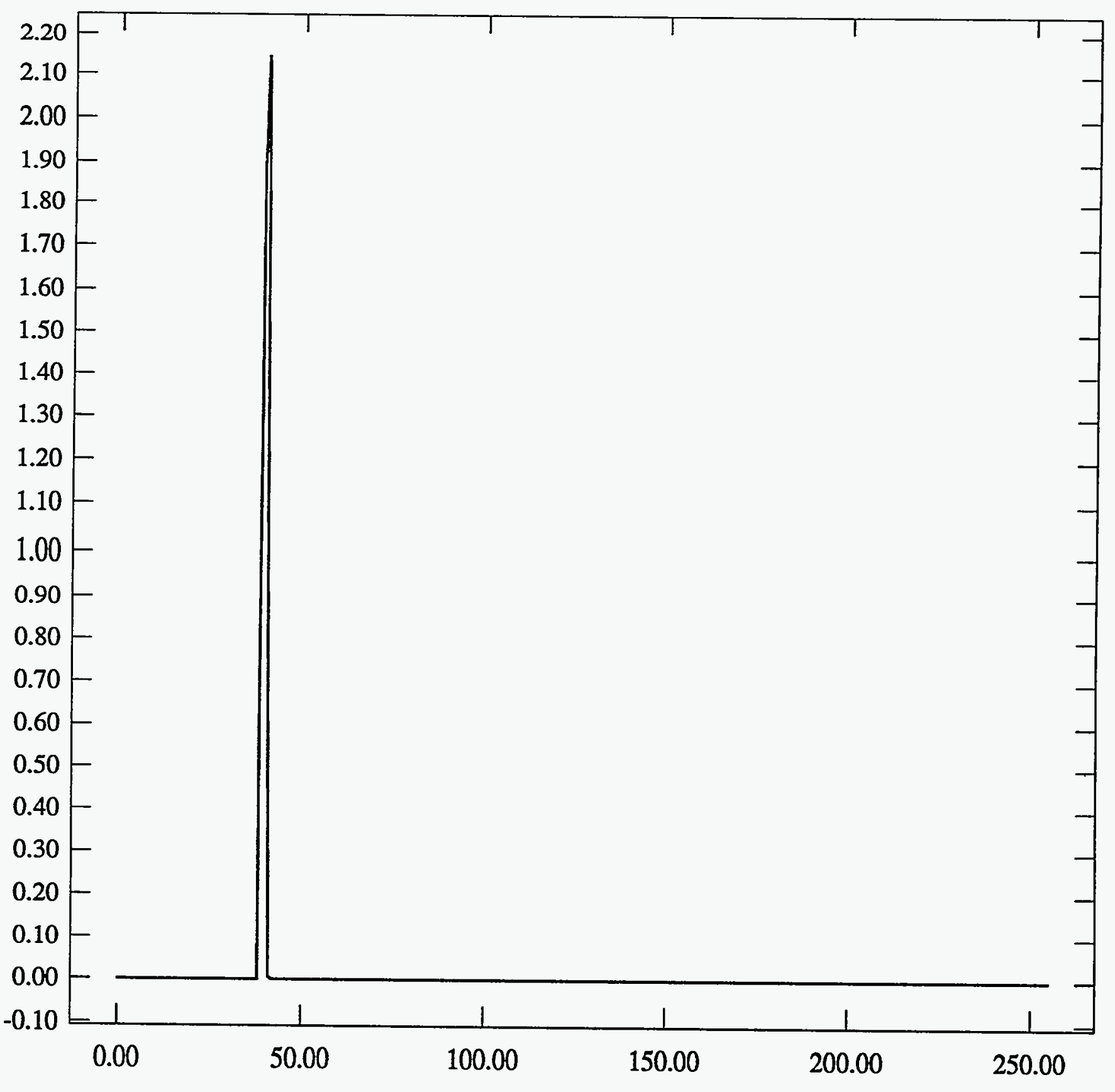


ST Camera: ST1\#04-10 20C \#6: int_time=100ms, offset= 0, gain=1 (350 e/bit) Wed Jun 30 20:07:42 1993 Pixel Values Min 39 Max 41 Mean 39.5 Sigma $0.50 \times 10^{3}$

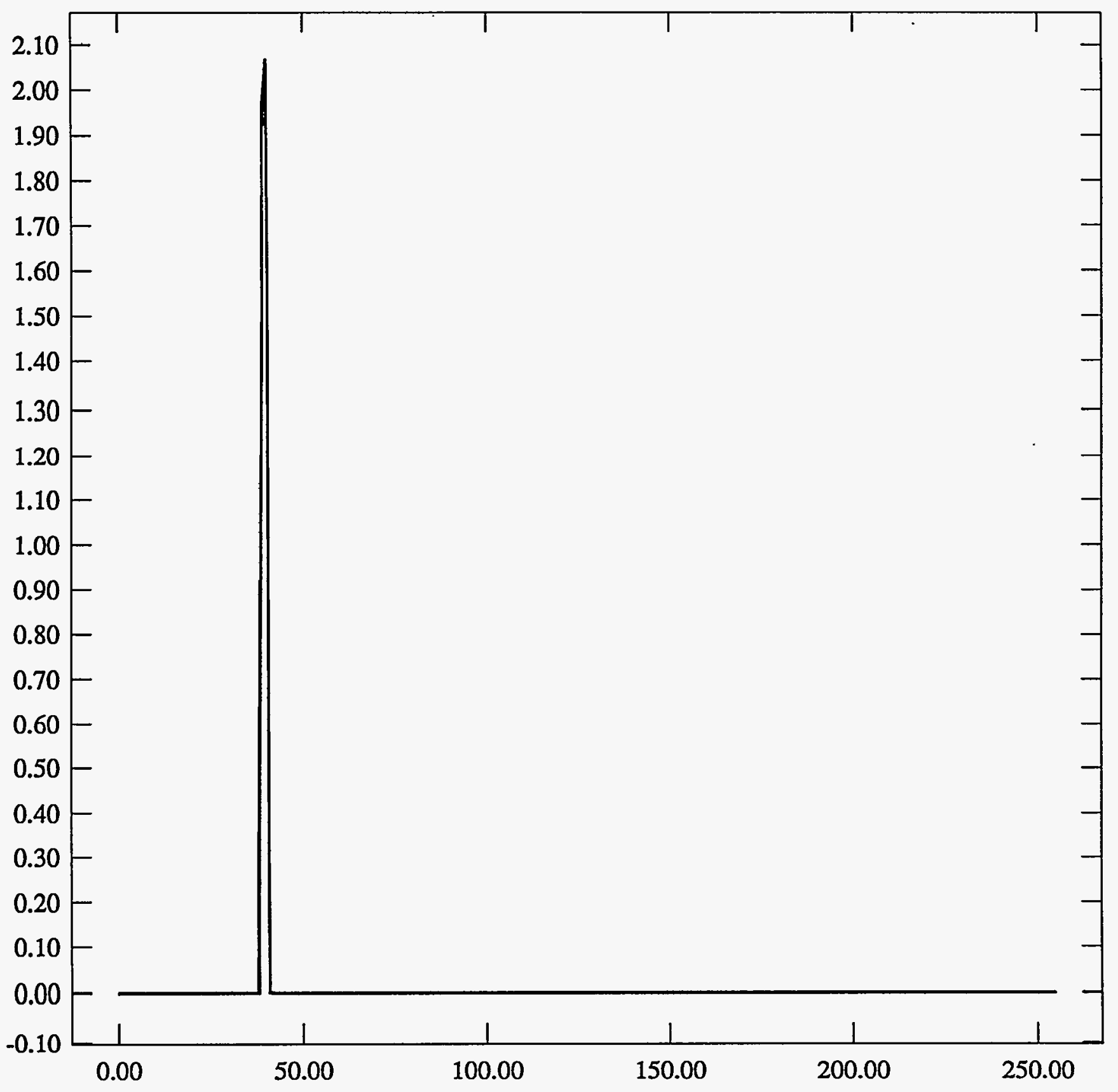


ST Camera: ST1\#04-10 20C \#6: int_time=200ms, offset= 0, gain=1 ( $350 \mathrm{e} / \mathrm{bit}$ ) Wed Jun 30 20:07:54 1993 Pixel Values Min 39 Max 41 Mean 39.5 Sigma $0.50 \times 10^{3}$

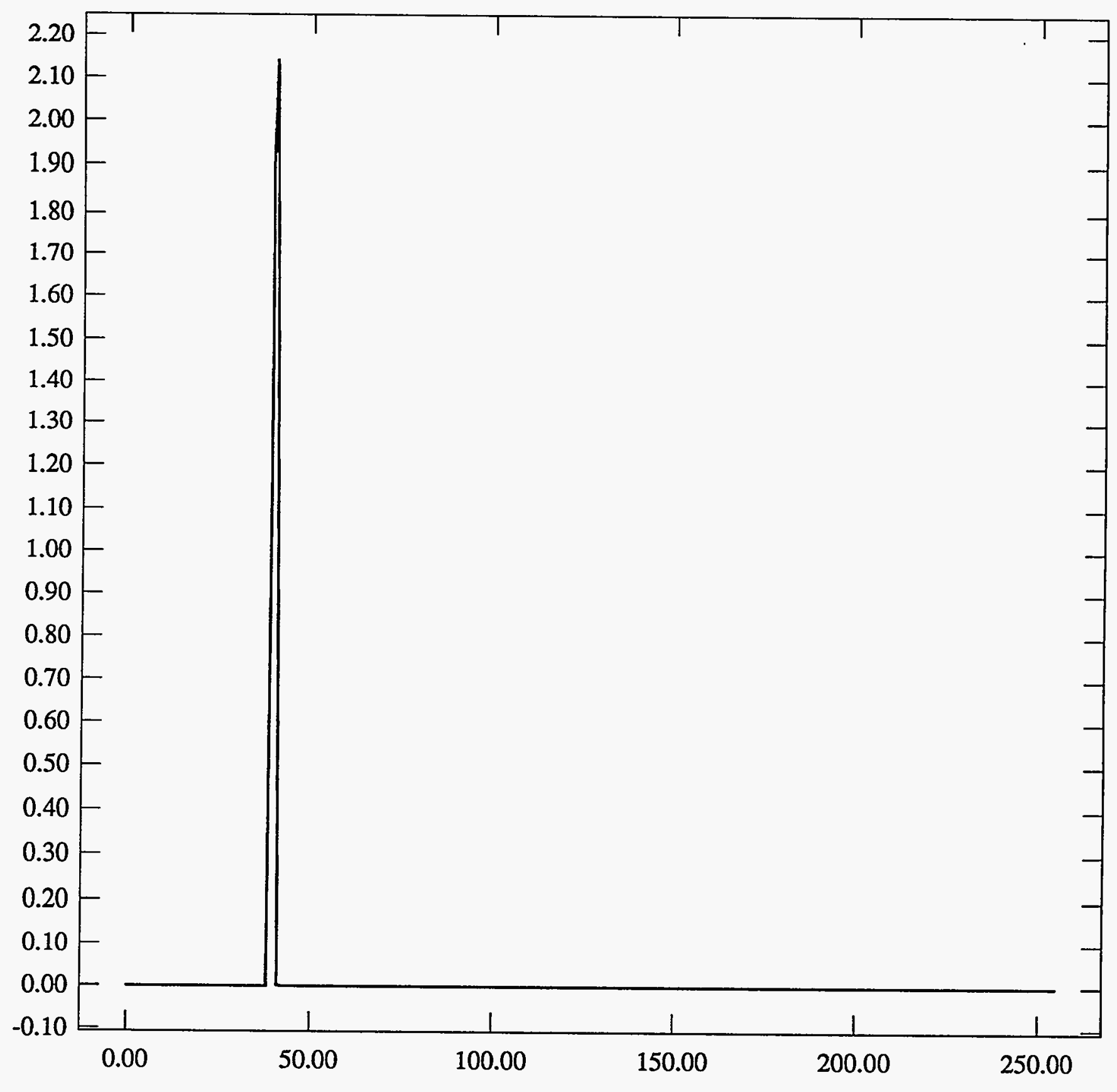


ST Camera: ST1\#04-10 20C \#6: int_time= 50ms, offset= 0, gain=2 (150 e/bit) Wed Jun 30 20:08:10 1993 Pixel Values Min 77 Max 81 Mean 79.4 Sigma $0.74 \times 10^{3}$

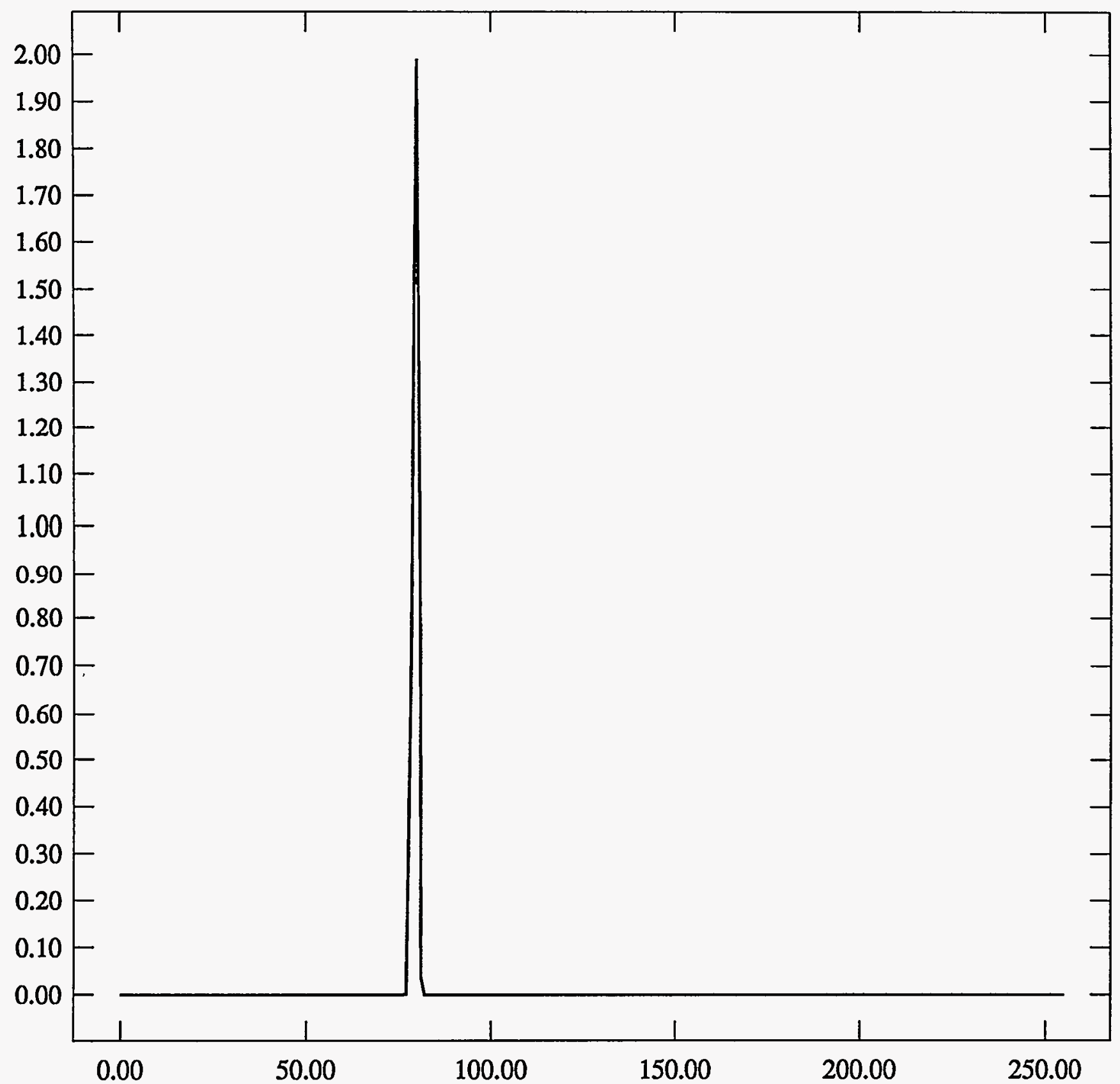


ST Camera: ST1\#04-10 20C \#6: int_time=100ms, offset= 0, gain=2 ( $150 \mathrm{e} / \mathrm{bit}$ ) Wed Jun 30 20:08:21 1993 Pixel Values Min 77 Max 81 Mean 79.4 Sigma 0.77 x $10^{3}$

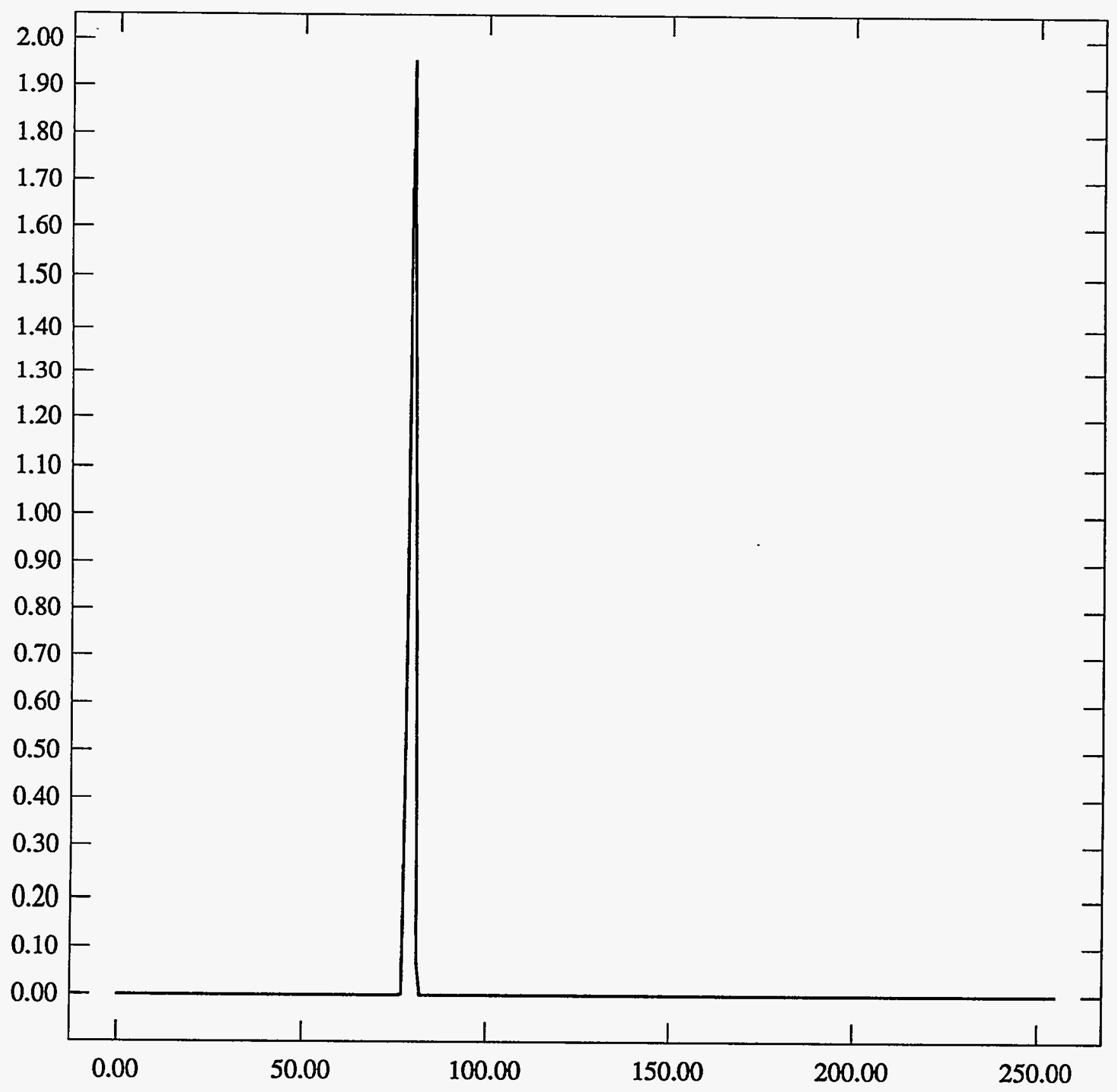


ST Camera: ST1\#04-10 20C \#6: int_time=200ms, offset= 0, gain=2 ( 150 e/bit) Wed Jun 30 20:08:41 1993 Pixel Values Min 77 Max 81 Mean 79.3 Sigma $0.75 \times 10^{3}$

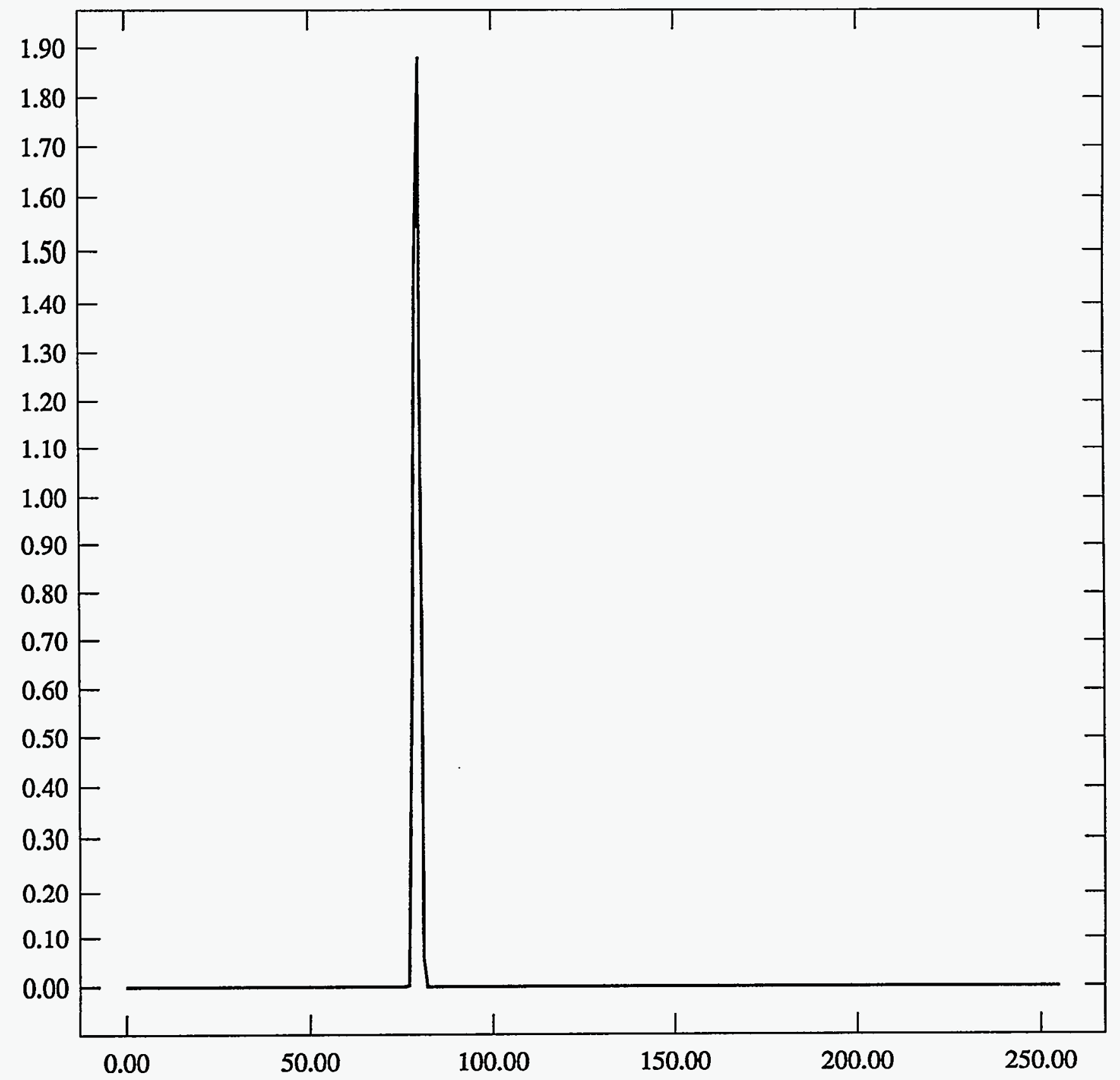


ST Camera: ST1\#04-10 20C \#6: int_time= 50ms, offset= 0, gain=4 ( 75 e/bit) Wed Jun 30 20:08:59 1993 Pixel Values Min 143 Max 148 Mean 145.2 Sigma $0.77 \times 10^{3}$

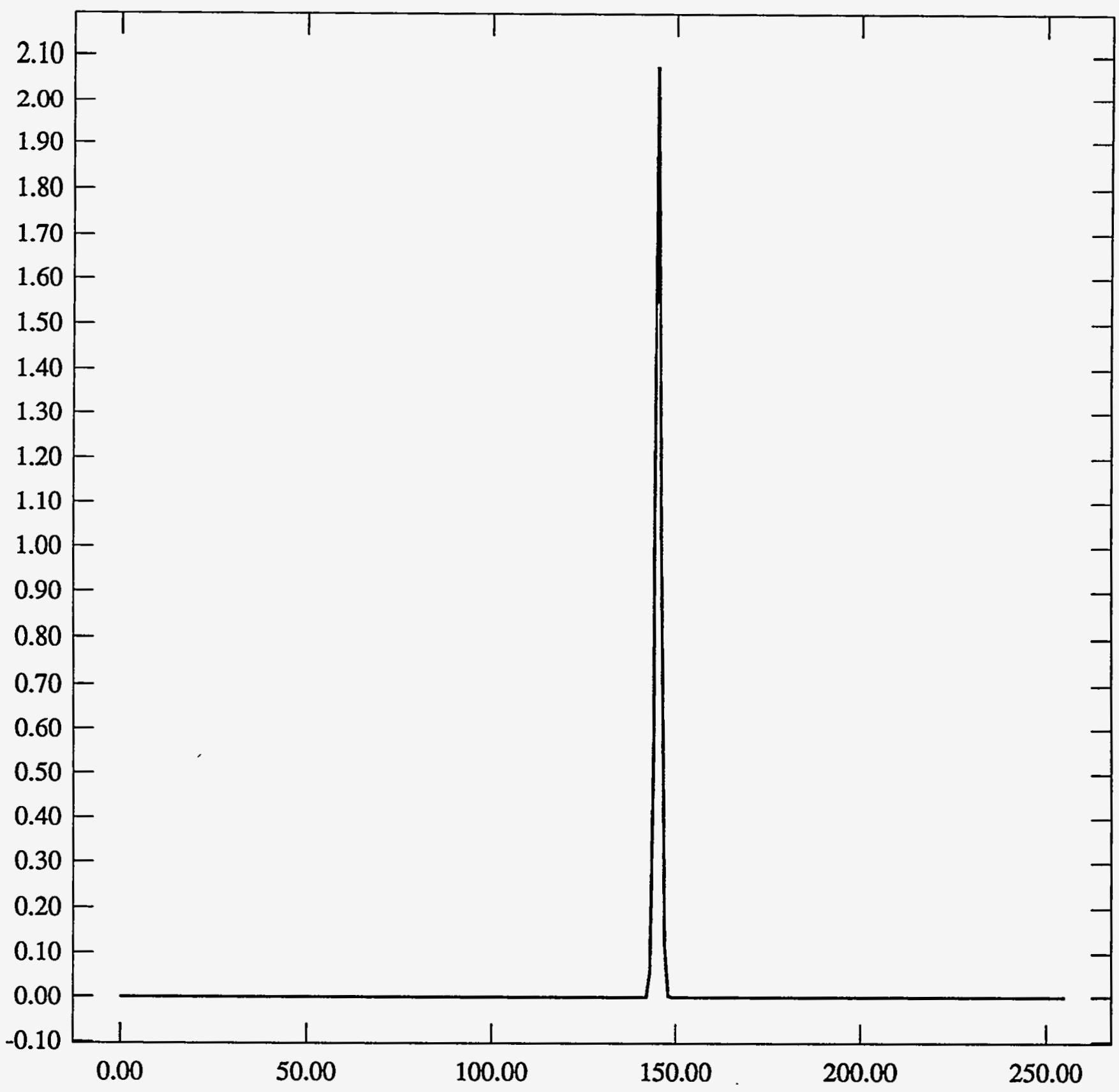


ST Camera: ST1\#04-10 20C \#6: int_time=100ms, offset= 0, gain=4 ( 75 e/bit) Wed Jun 30 20:09:11 1993 Pixel Values Min 143 Max 148 Mean 145.2 Sigma $0.76 \times 10^{3}$

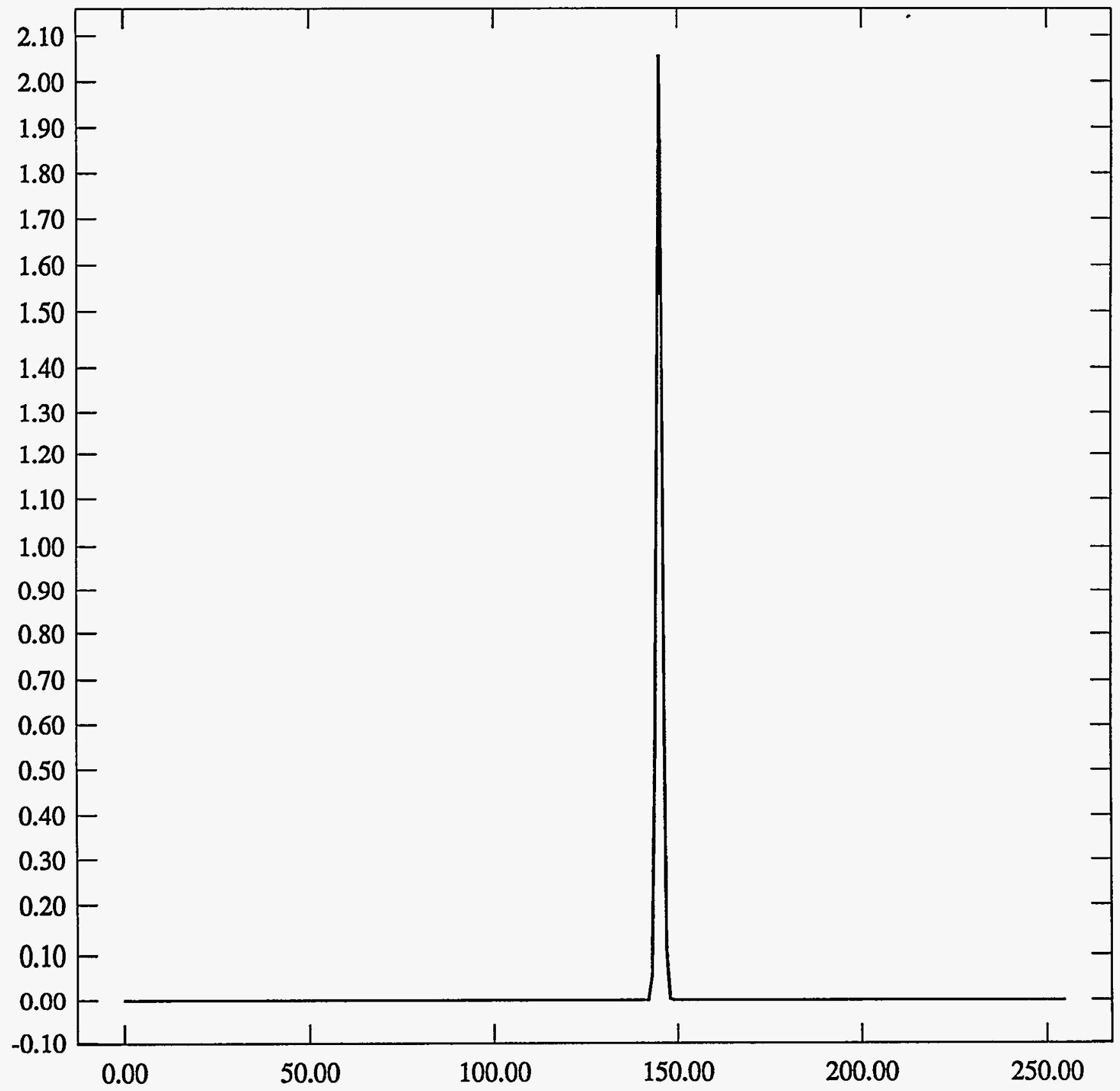


ST Camera: ST1 $\# 04-10$ 20C \#6: int_time=200ms, offset= 0, gain=4 ( 75 e/bit) Wed Jun 30 20:13:04 1993 Pixel Values Min 142 Max 148 Mean 145.1 Sigma $0.77 \times 10^{3}$

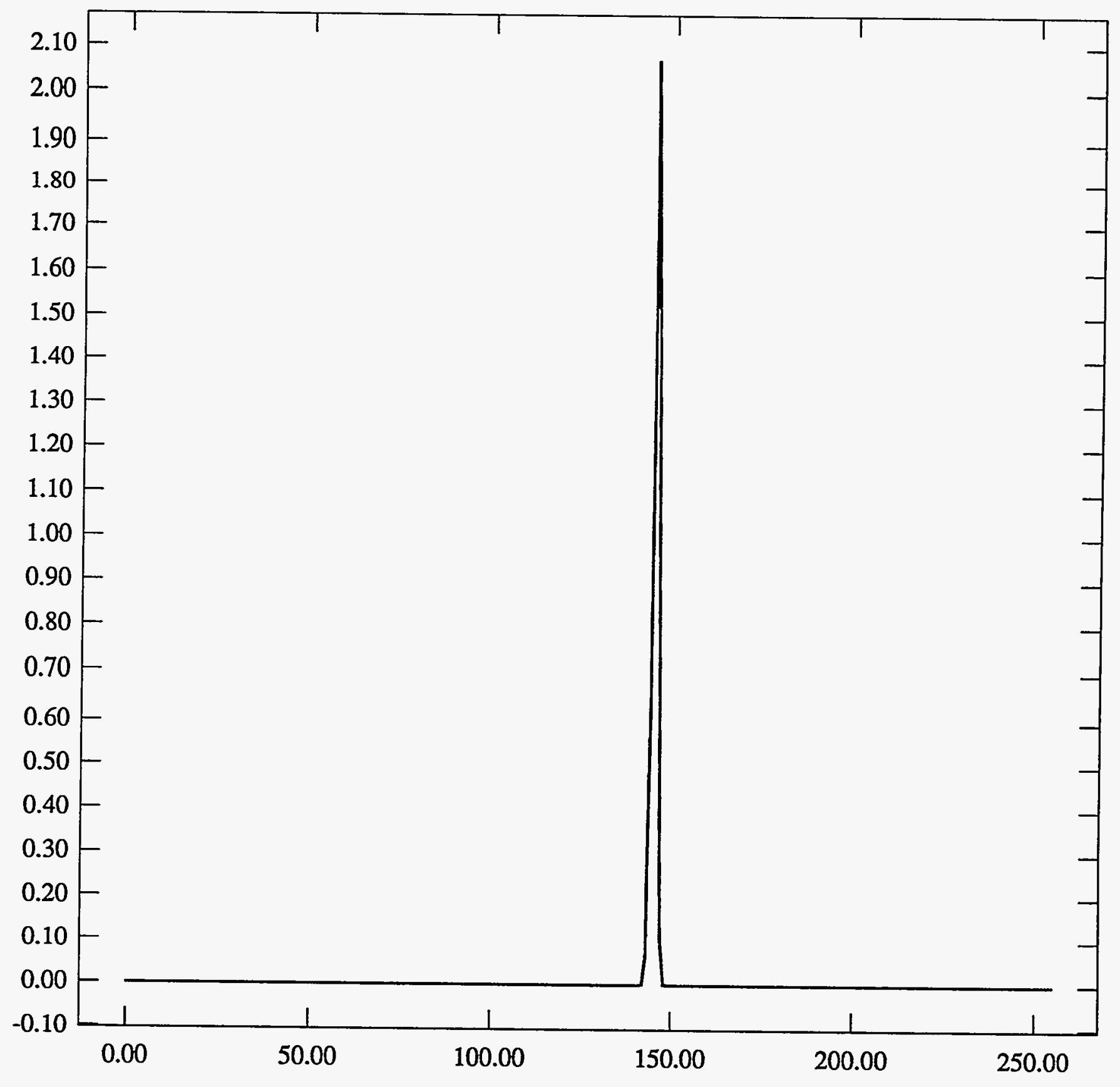


H6 t20 ENA or cYces

ST Camera: ST1\#04-10 20C \#6: int_time= 50ms, offset= 0, gain=1 (350 e/bit) Wed Jun 30 20:48:11 1993 Pixel Values Min 38 Max 40 Mean 39.3 Sigma $0.47 \times 10^{3}$

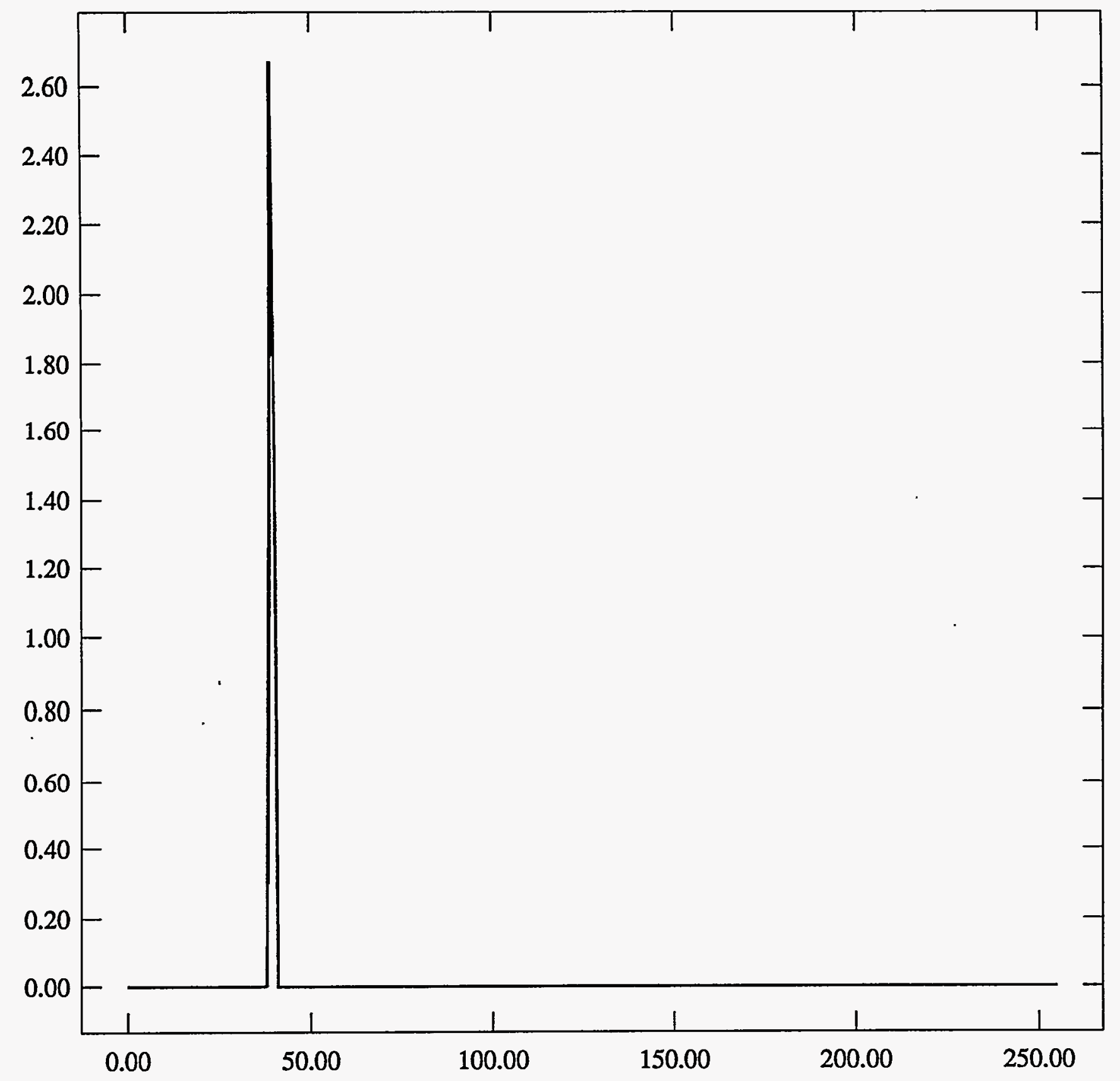


ST Camera: ST1\#04-10 20C \#6: int_time=100ms, offset= 0, gain=1 ( $350 \mathrm{e} / \mathrm{bit}$ ) Wed Jun 30 20:48:24 1993 Pixel Values Min 39 Max 40 Mean 39.3 Sigma $0.46 \times 10^{3}$

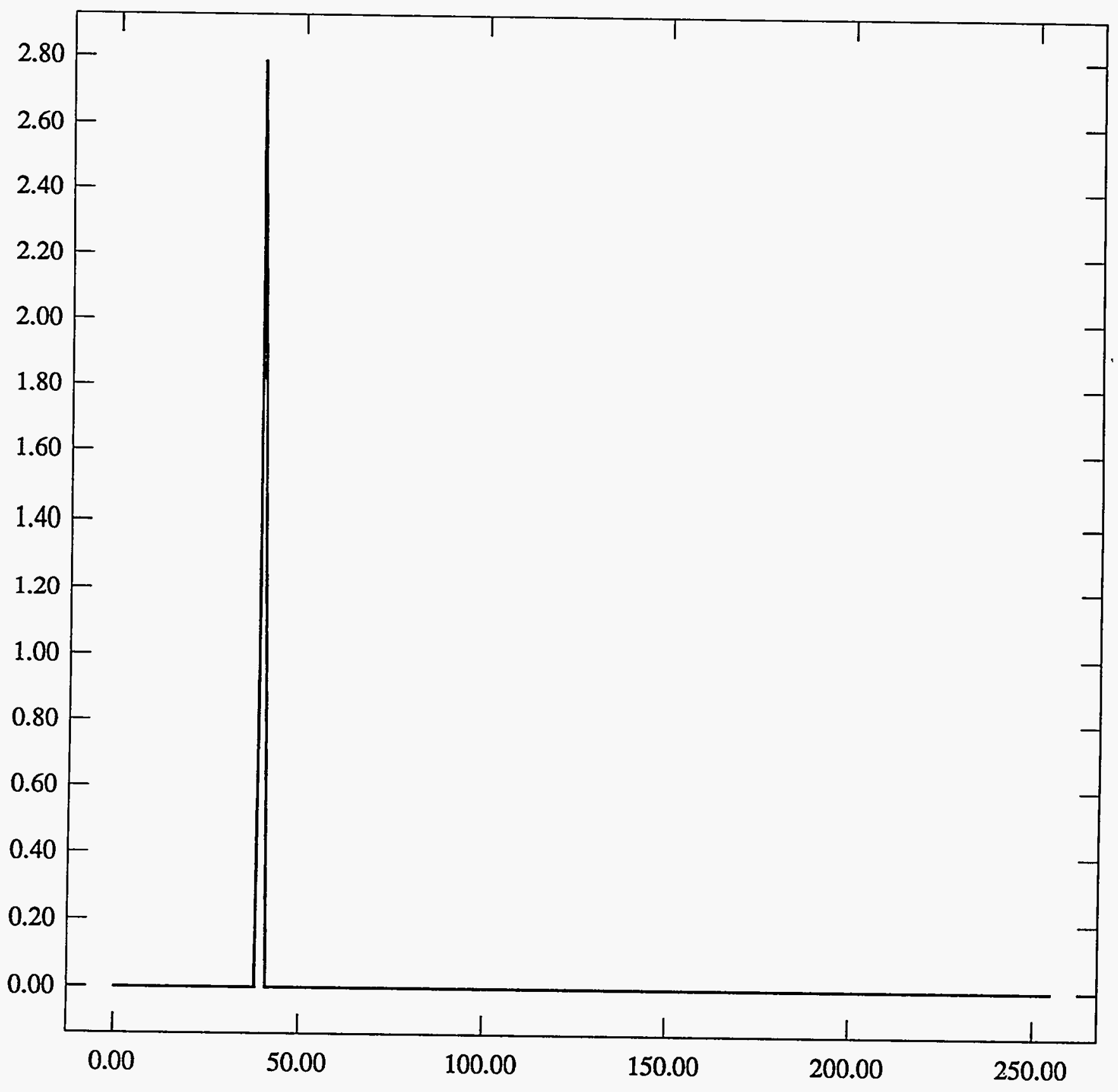


ST Camera: ST1\#04-10 20C \#6: int_time=200ms, offset= 0, gain=1 (350 e/bit) Wed Jun 30 20:48:35 1993 Pixel Values Min 39 Max 40 Mean 39.3 Sigma $0.47 \times 10^{3}$

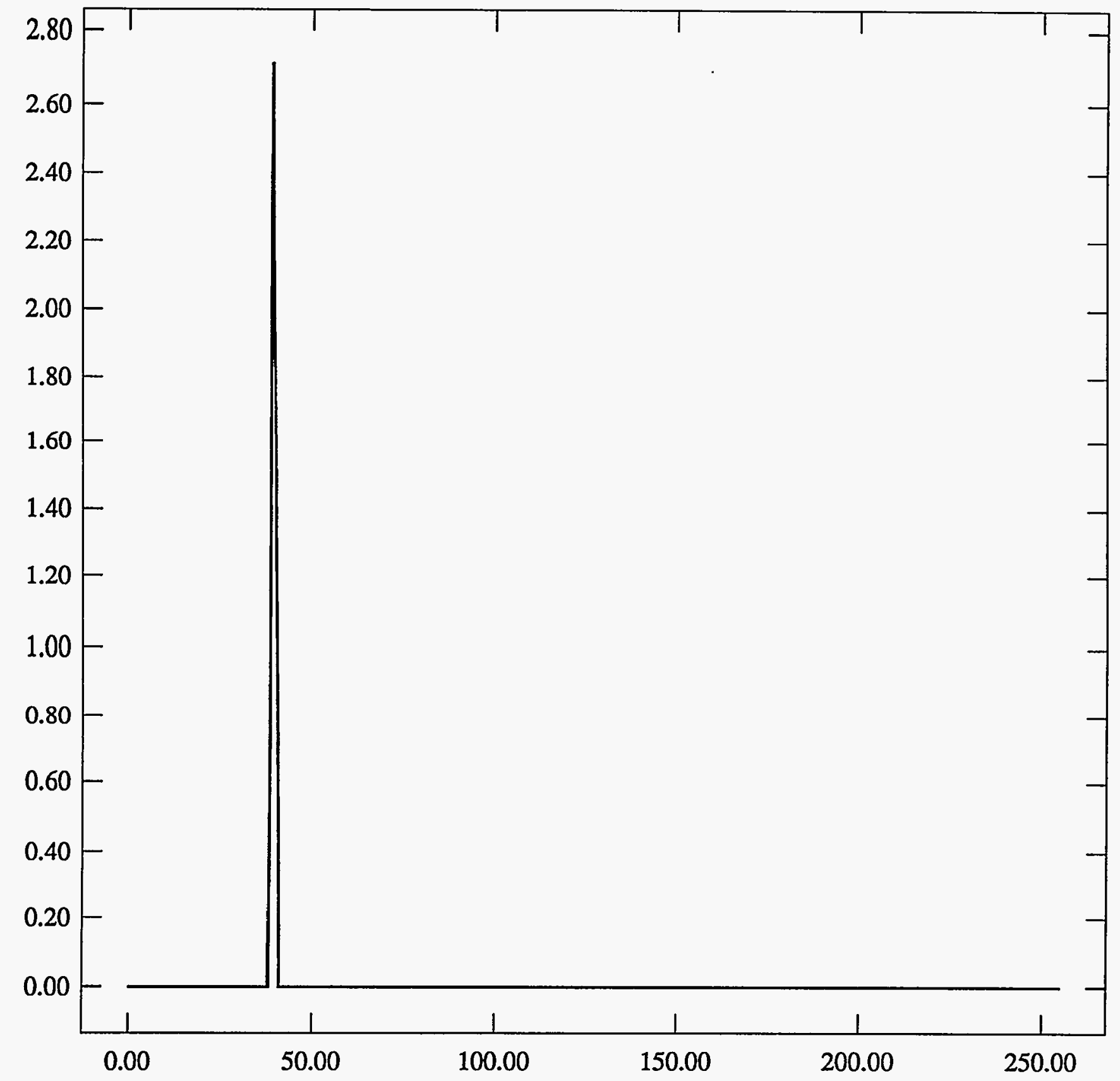


ST Camera: ST1\#04-10 20C \#6: int_time= 50ms, offset= 0, gain=2 (150 e/bit) Wed Jun 30 20:48:47 1993 Pixel Values Min 77 Max 81 Mean 79.0 Sigma $0.77 \times 10^{3}$

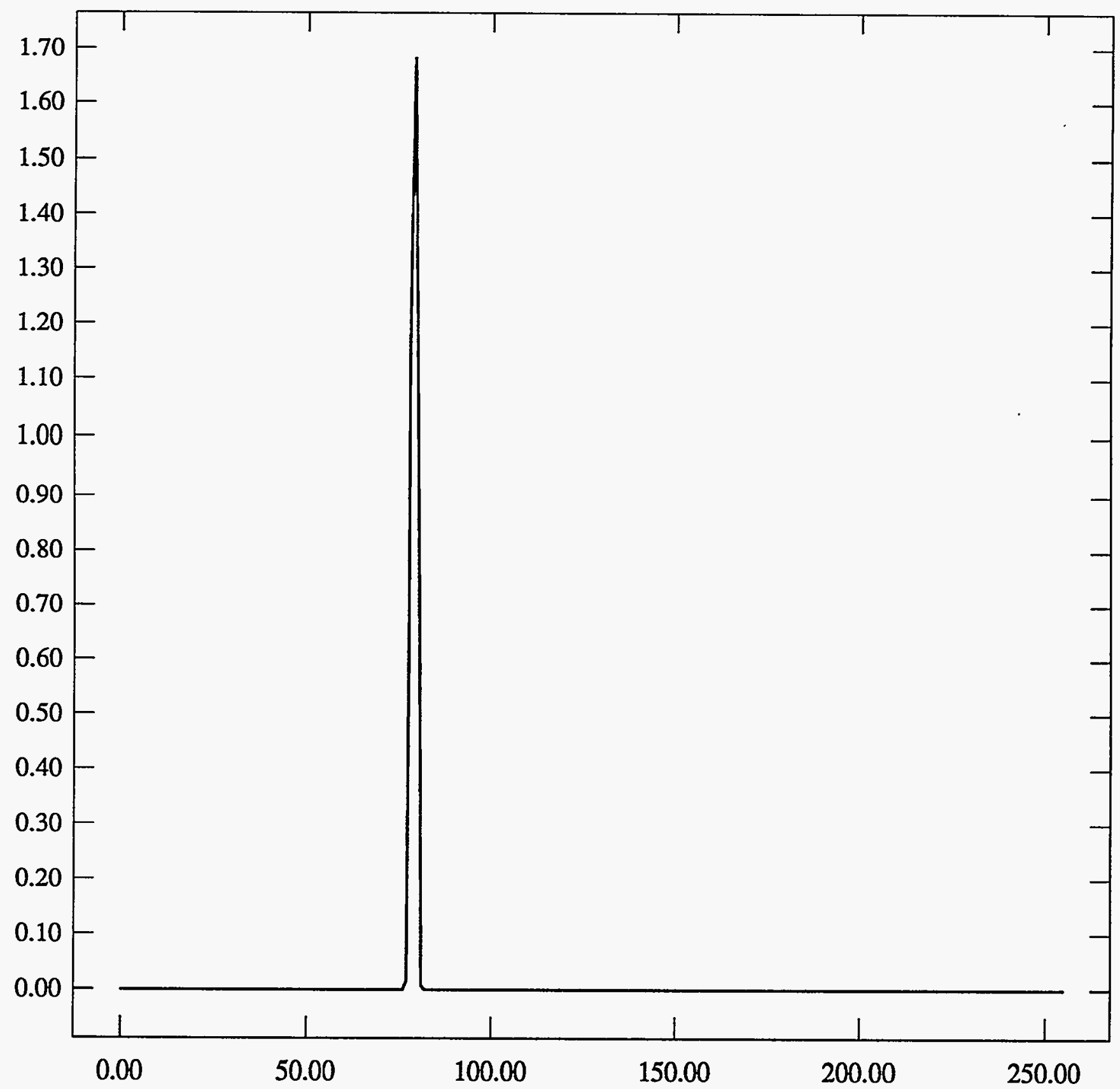


ST Camera: ST1\#04-10 20C \#6: int_time=100ms, offset= 0, gain=2 ( 150 e/bit) Wed Jun 30 20:48:59 1993 Pixel Values Min 77 Max 81 Mean 79.0 Sigma $0.77 \times 10^{3}$

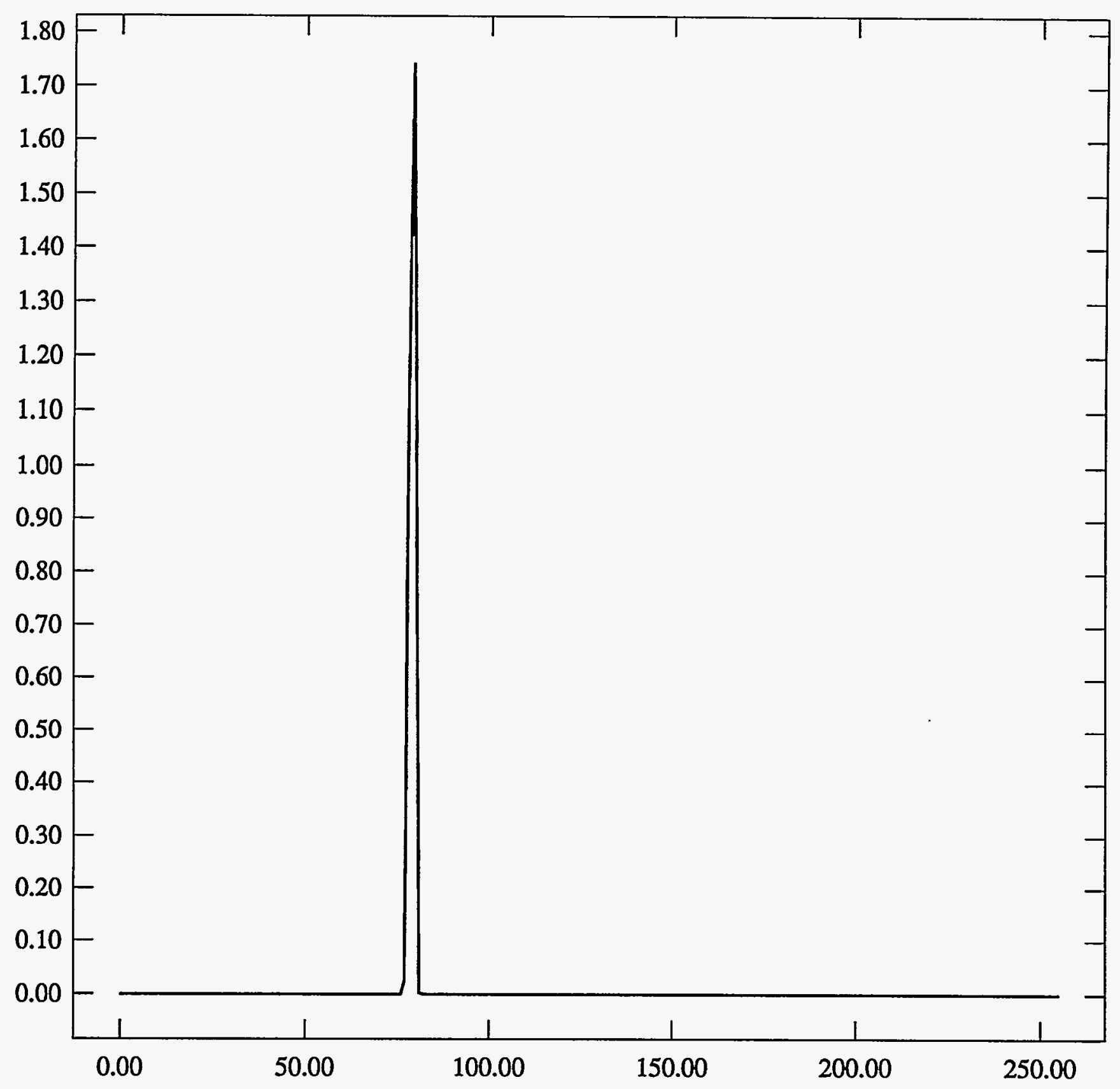


ST Camera: ST1\#04-10 20C \#6: int_time=200ms, offset= 0, gain=2 ( $150 \mathrm{e} / \mathrm{bit}$ ) Wed Jun 30 20:49:11 1993 Pixel Values Min 77 Max 81 Mean 79.0 Sigma $0.79 \times 10^{3}$

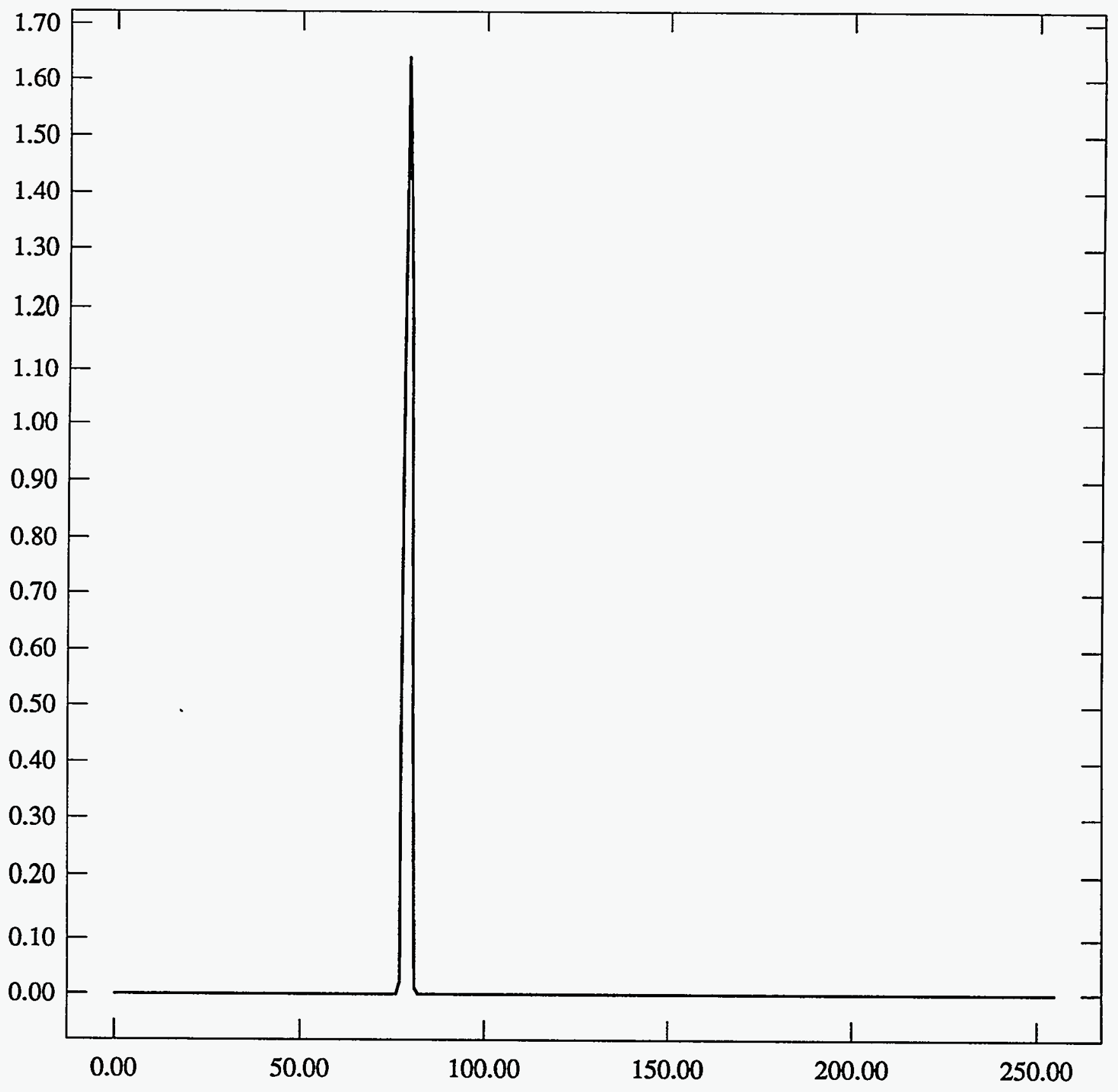


ST Camera: ST1\#04-10 20C \#6: int_time= 50ms, offset= 0, gain=4 ( $75 \mathrm{e} /$ bit) Wed Jun 30 20:49:24 1993 Pixel Values Min 142 Max 147 Mean 144.8 Sigma $0.83 \times 10^{3}$

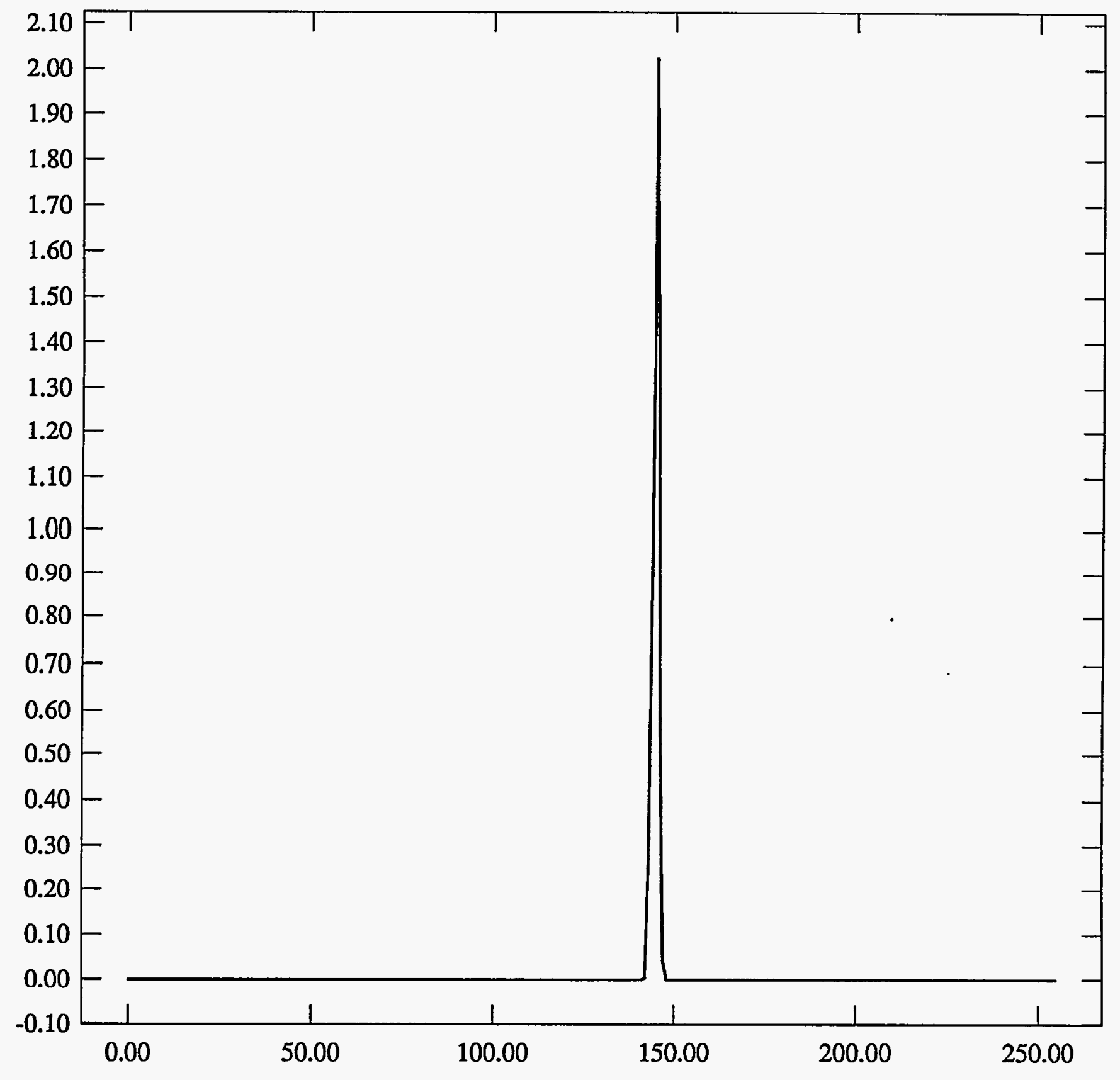


ST Camera: ST1\#04-10 20C \#6: int_time=100ms, offset= 0, gain=4 ( 75 e/bit) Wed Jun 30 20:49:36 1993 Pixel Values Min 141 Max 148 Mean 144.7 Sigma $0.86 \times 10^{3}$

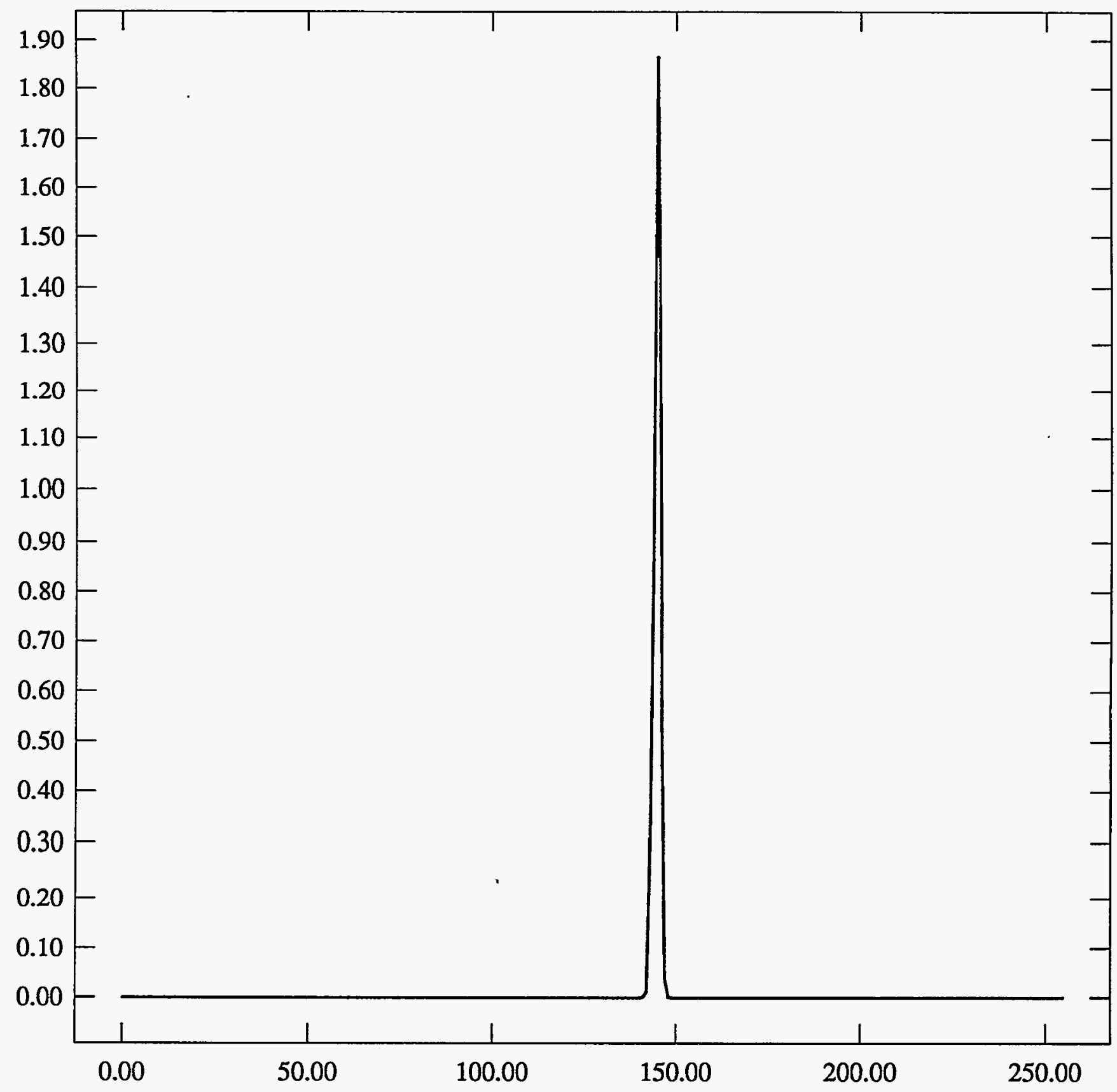


ST Camera: ST1\#04-10 20C \#6: int_time=200ms, offset= 0, gain=4 ( 75 e/bit) Wed Jun 30 20:49:49 1993 Pixel Values Min 142 Max 148 Mean 144.7 Sigma $0.83 \times 10^{3}$

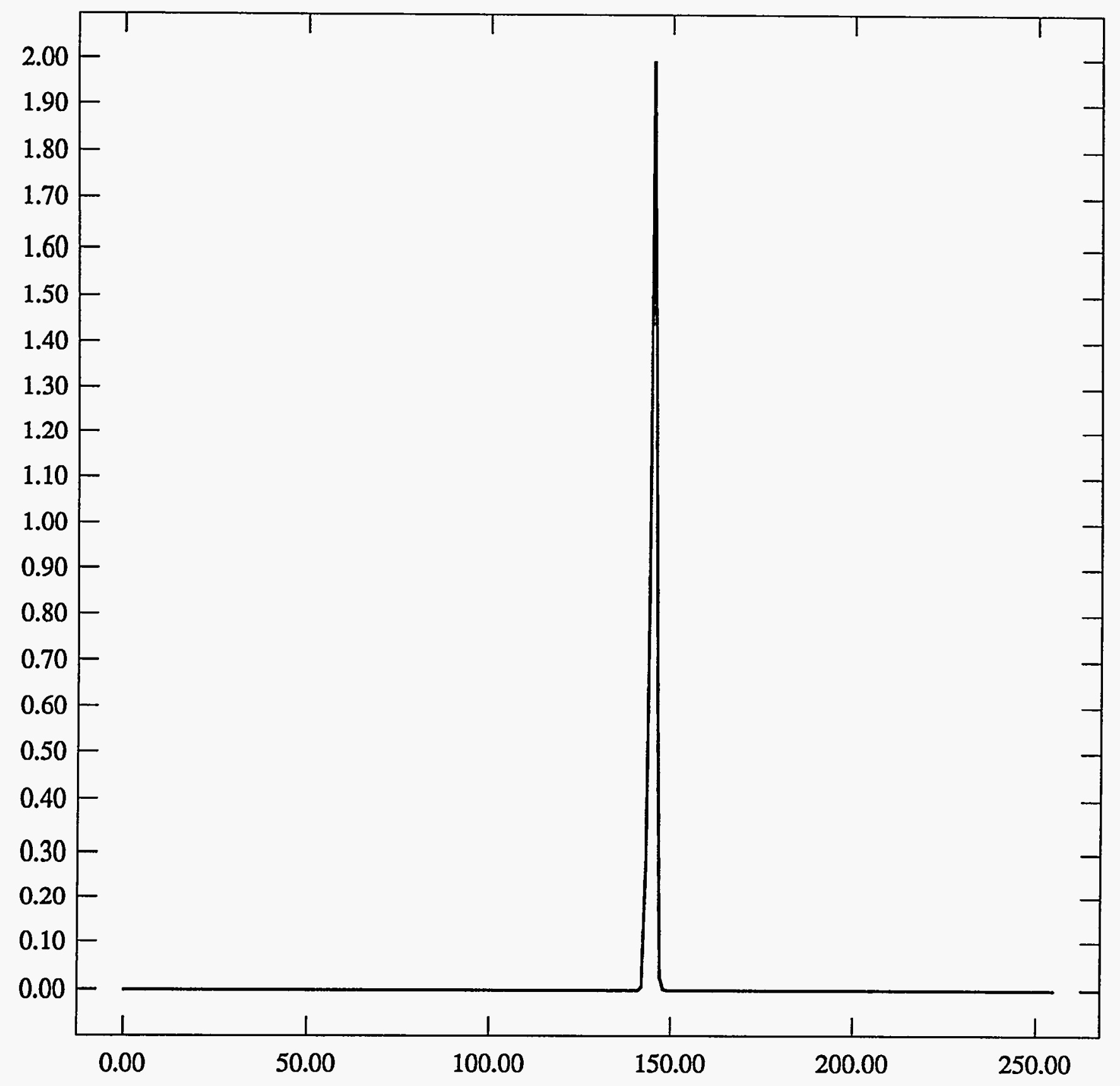


LENS HEATOR

ST Camera: ST1\#4-10 20C: int_time= 50ms, offset= 0, gain=1 ( $350 \mathrm{e} / \mathrm{bit})$ Fri Jul 2 12:22:44 1993

Pixel Values Min 40 Max 44 Mean 41.3 Sigma $0.45 \times 10^{3}$

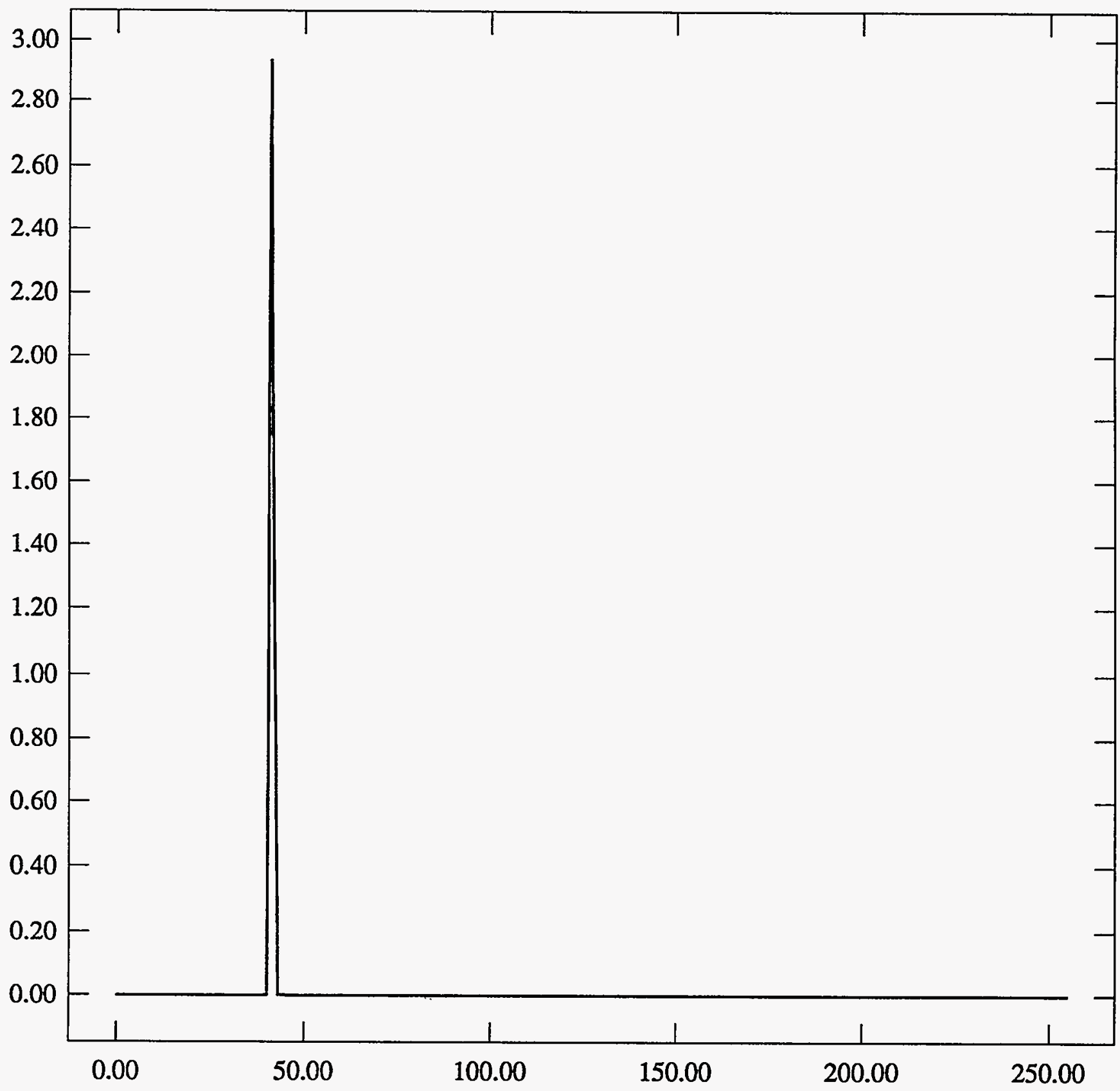


ST Camera: ST1\#4-10 20C: int_time=100ms, offset= 0, gain=1 ( 350 e/bit) Fri Jul 2 12:22:58 1993 Pixel Values Min 43 Max 49 Mean 43.9 Sigma $0.35 \times 10^{3}$

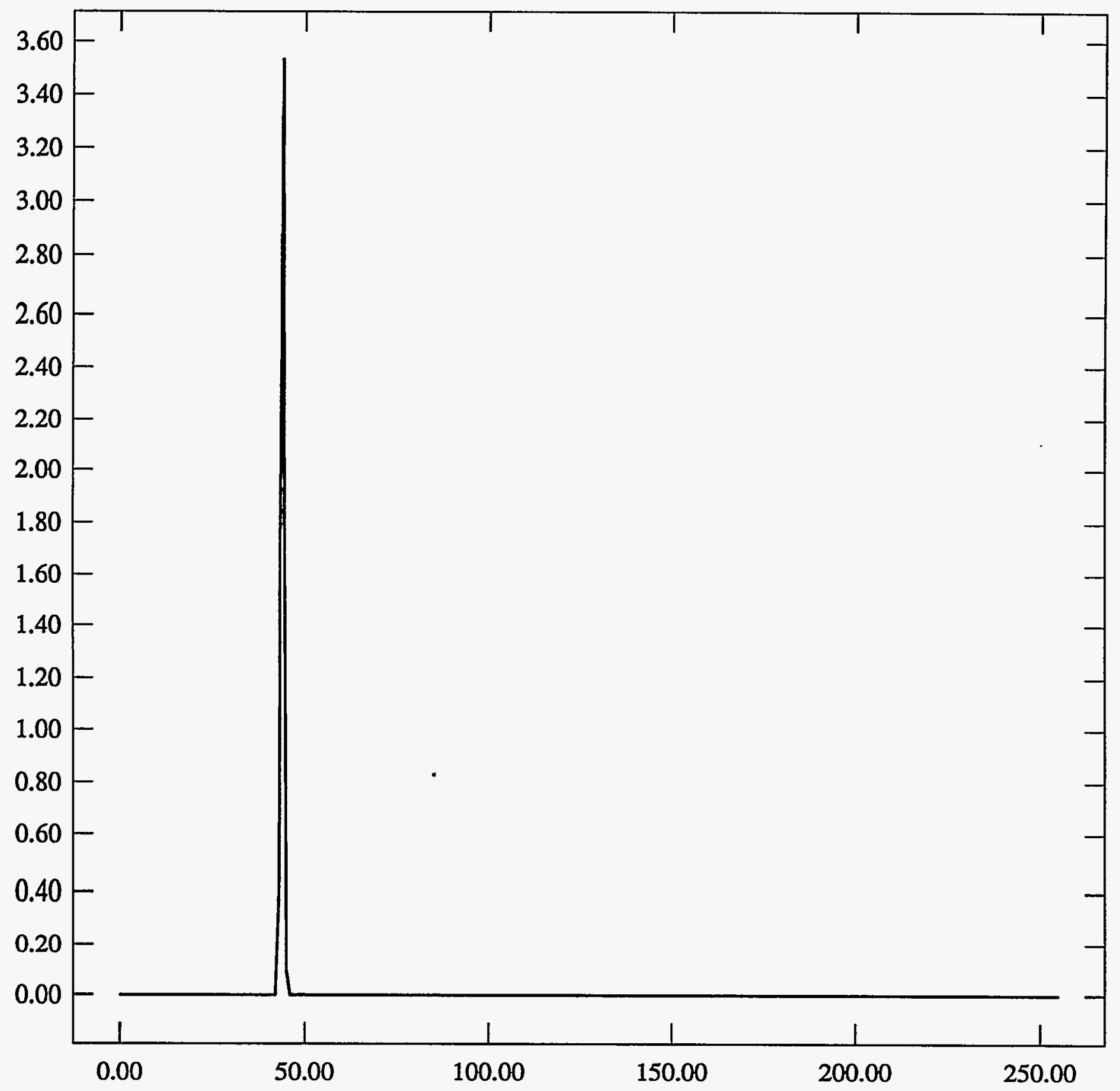


ST Camera: ST1\#4-10 20C: int_time=200ms, offset= 0, gain=1 ( 350 e/bit) Fri Jul 2 12:23:11 1993

Pixel Values Min 48 Max 59 Mean 49.6 Sigma $0.60 \times 10^{3}$

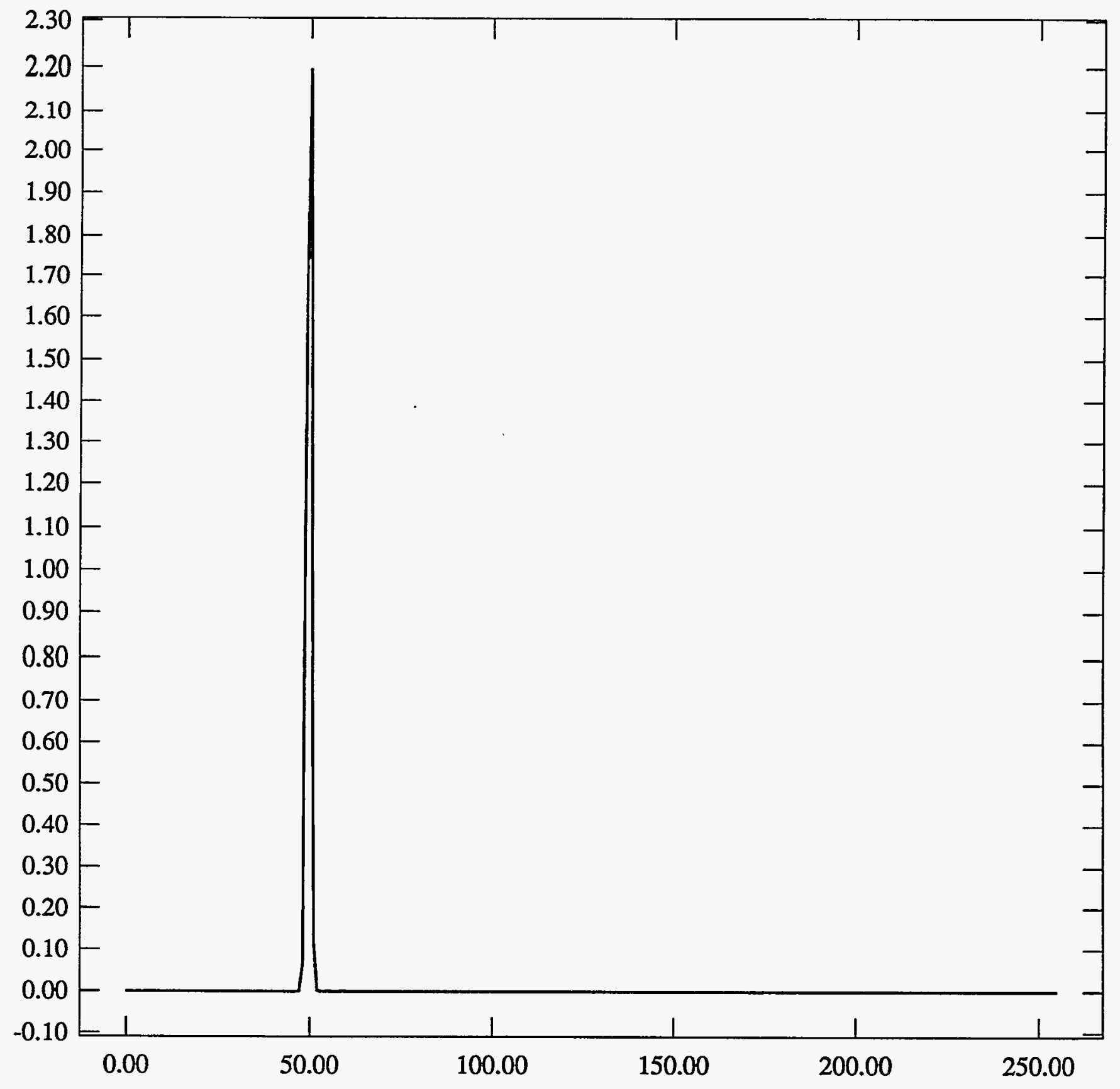


ST Camera: ST1\#4-10 20C: int_time= 50ms, offset= 0, gain=2 ( 150 e/bit $)$ Fri Jul 2 12:23:23 1993 Pixel Values Min 82 Max 88 Mean 83.3 Sigma $0.64 \times 10^{3}$

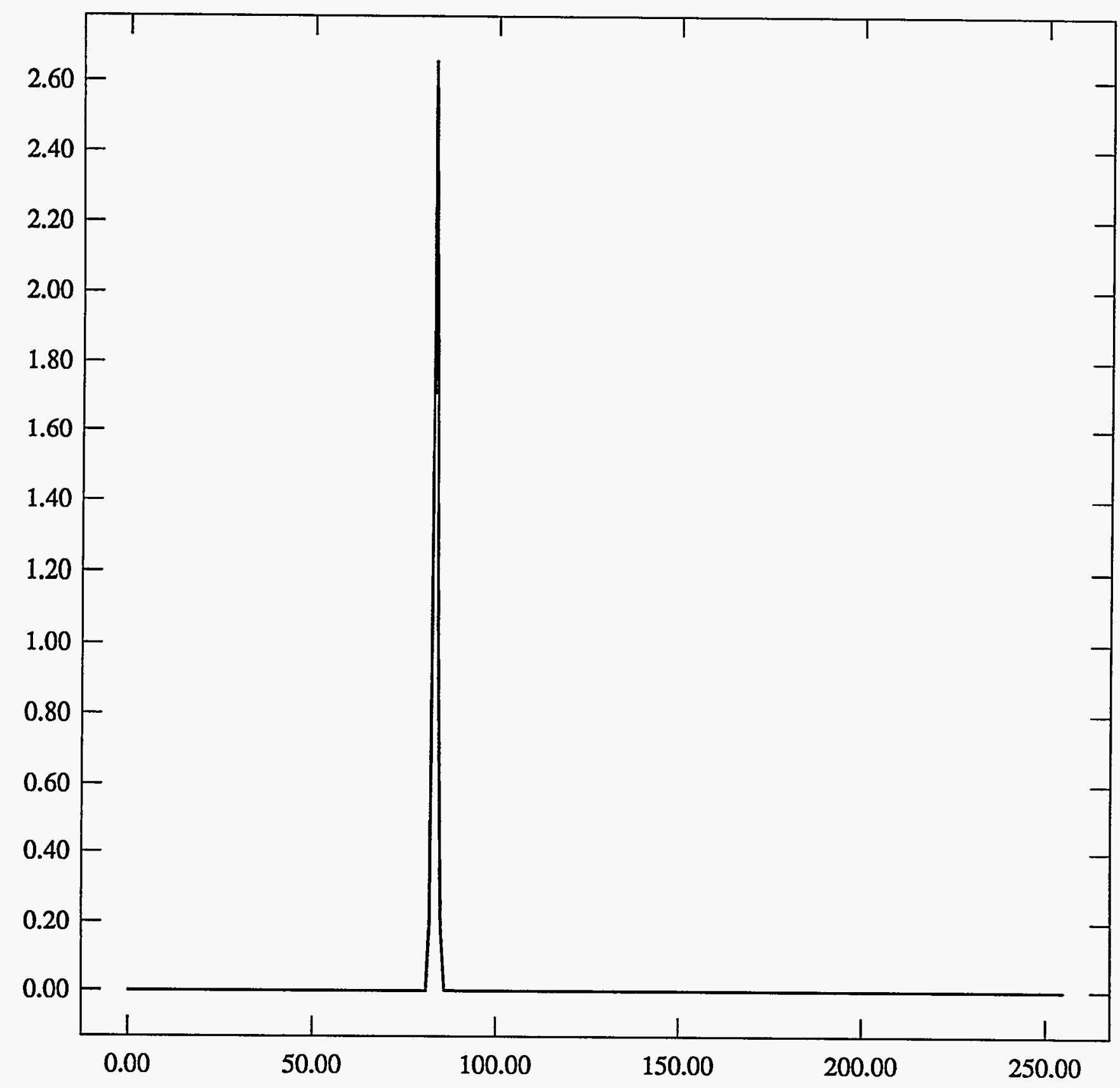


ST Camera: ST1\#4-10 20C: int time=100ms, offset= 0, gain=2 ( 150 e/bit) Fri Jul 2 12:23:33 1993

Pixel Values Min 87 Max 99 Mean 89.4 Sigma $0.77 \times 10^{3}$

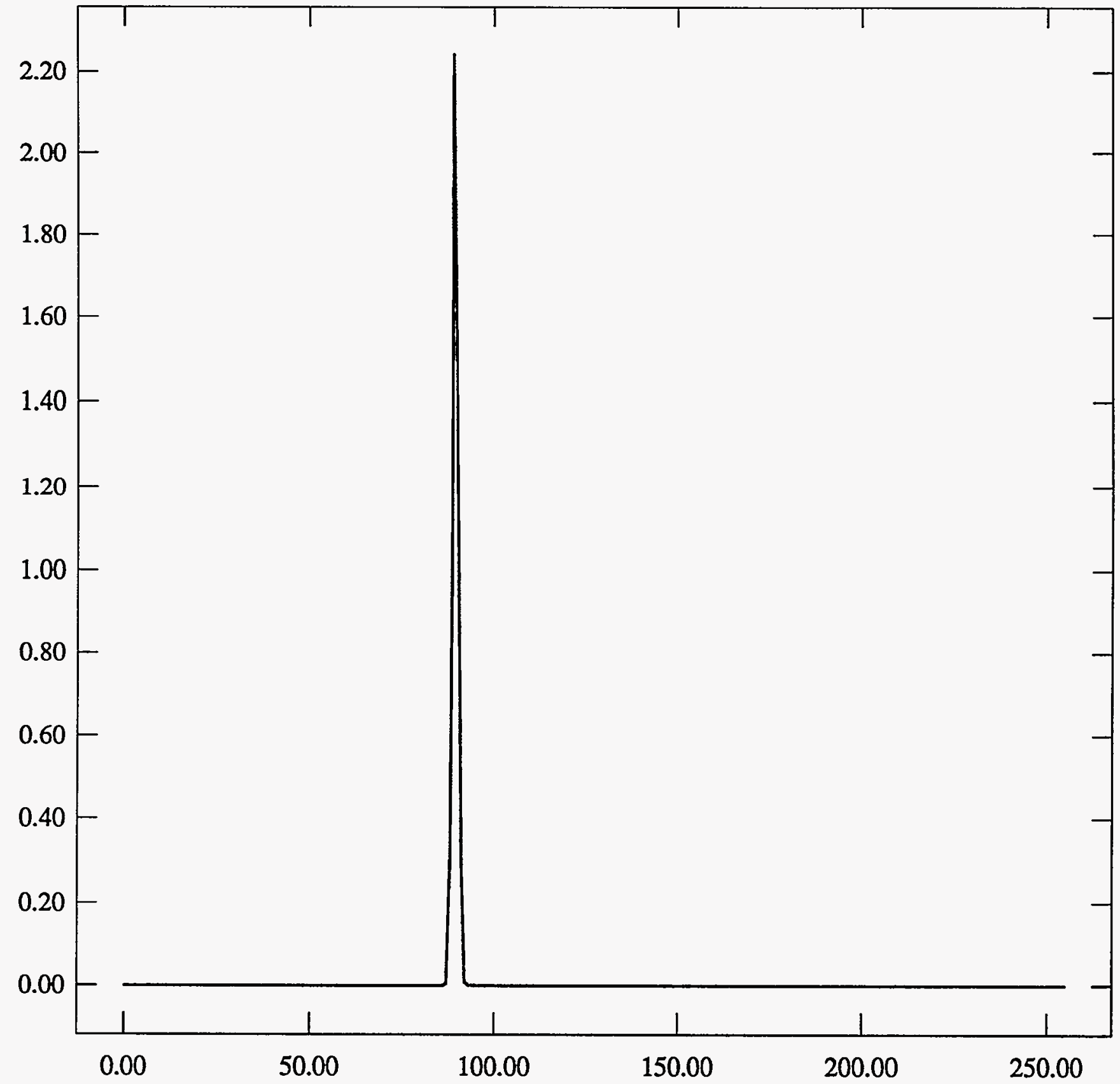


ST Camera: ST1\#4-10 20C: int_time=200ms, offset= 0, gain=2 ( $150 \mathrm{e} / \mathrm{bit}$ ) Fri Jul 2 12:23:45 1993 Pixel Values Min 98 Max 124 Mean 102.1 Sigma $1.24 \times 10^{3}$

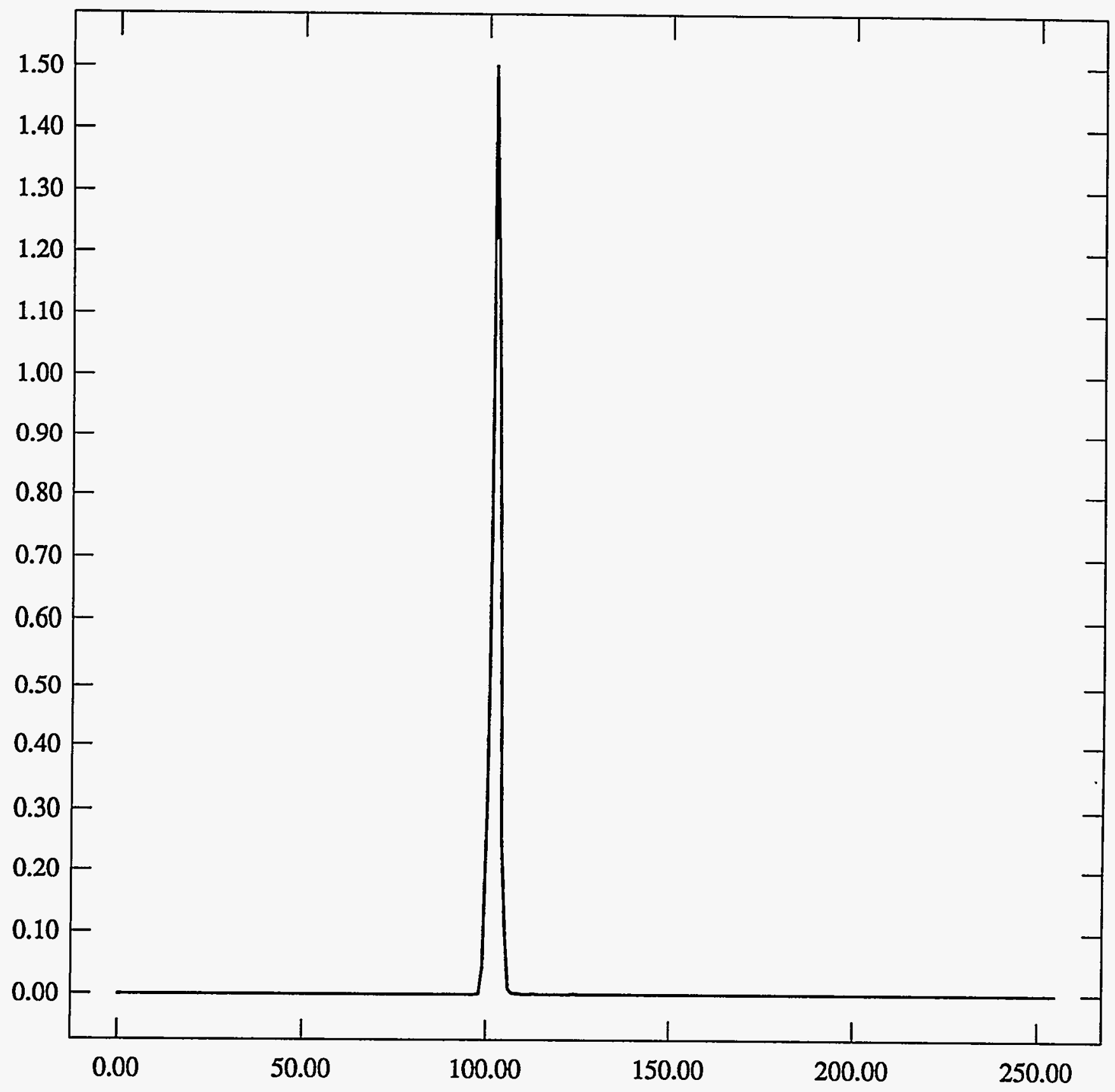


ST Camera: ST1\#4-10 20C: int_time= 50ms, offset= 0, gain=4 ( 75 e/bit) Fri Jul 2 12:24:01 1993

Pixel Values Min 150 Max 163 Mean 152.9 Sigma $1.19 \times 10^{3}$

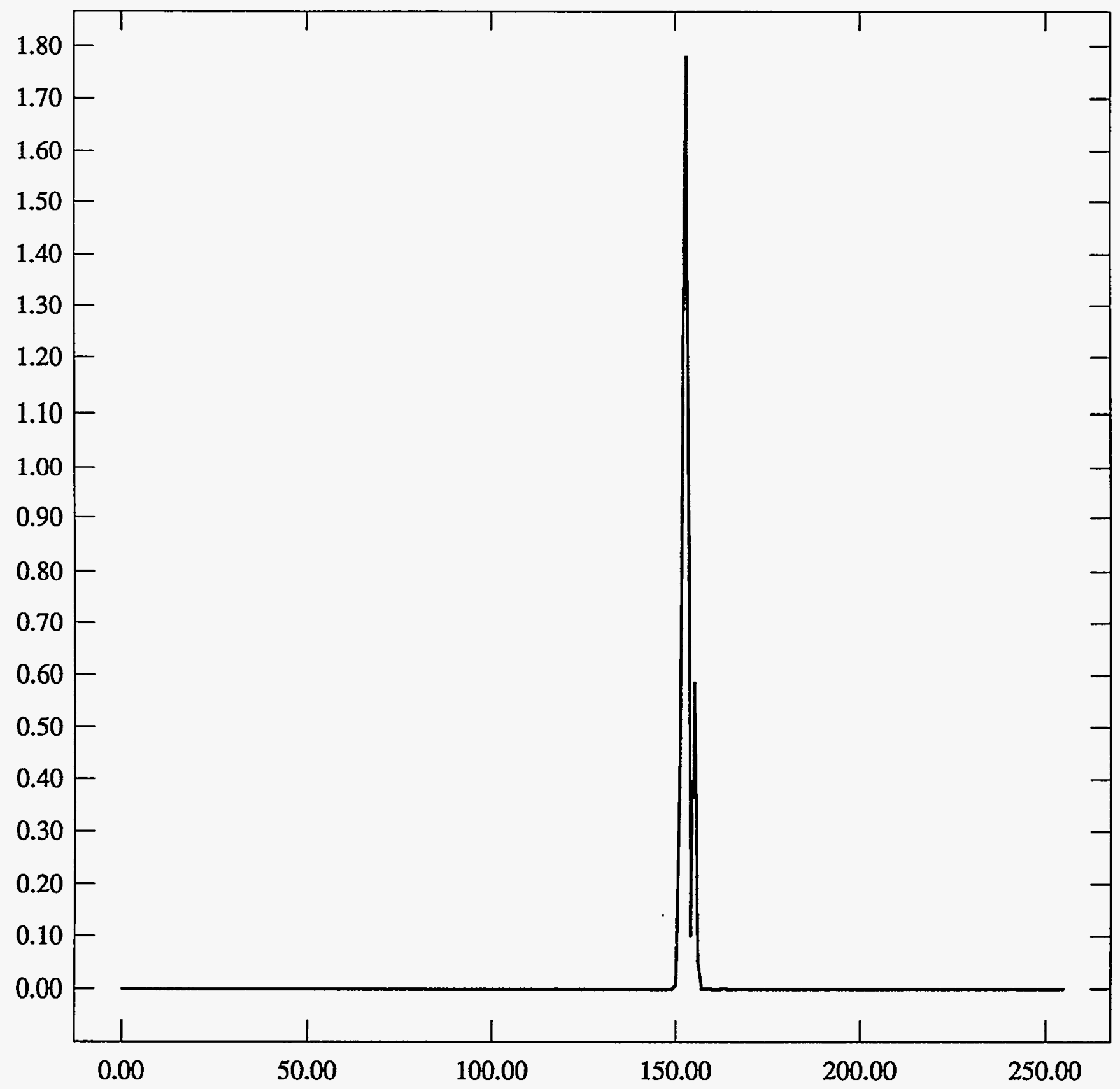


ST Camera: ST1\#4-10 20C: int_time=100ms, offset= 0, gain=4 ( 75 e/bit) Fri Jul 2 12:24:12 1993 Pixel Values Min 161 Max 185 Mean 165.3 Sigma $1.40 \times 10^{3}$

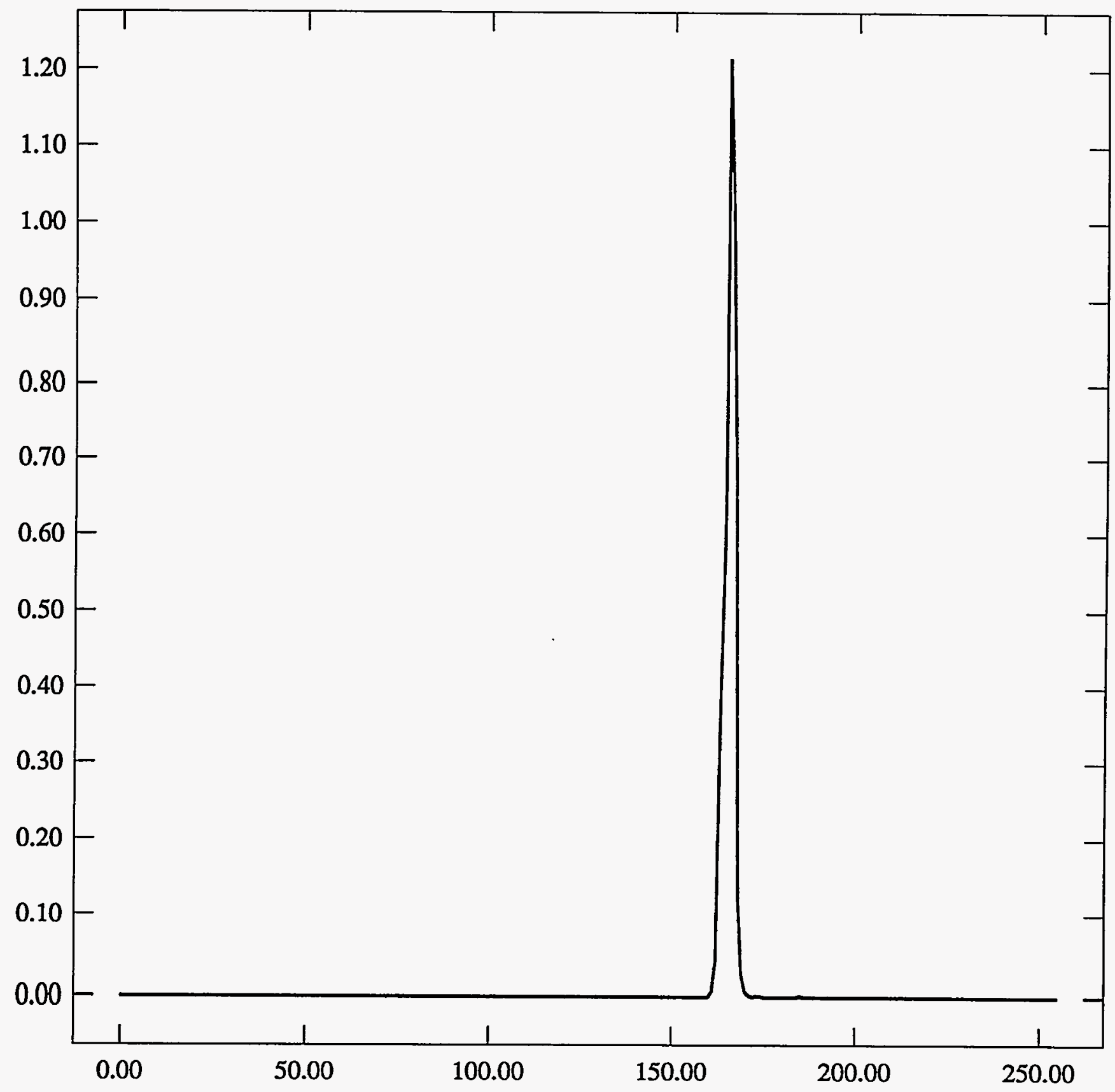


ST Camera: ST1\#4-10 20C: int_time=200ms, offset= 0, gain=4 ( 75 e/bit) Fri Jul 2 12:24:25 1993

Pixel Values Min 183 Max 231 Mean 189.2 Sigma 2.34 x $10^{3}$

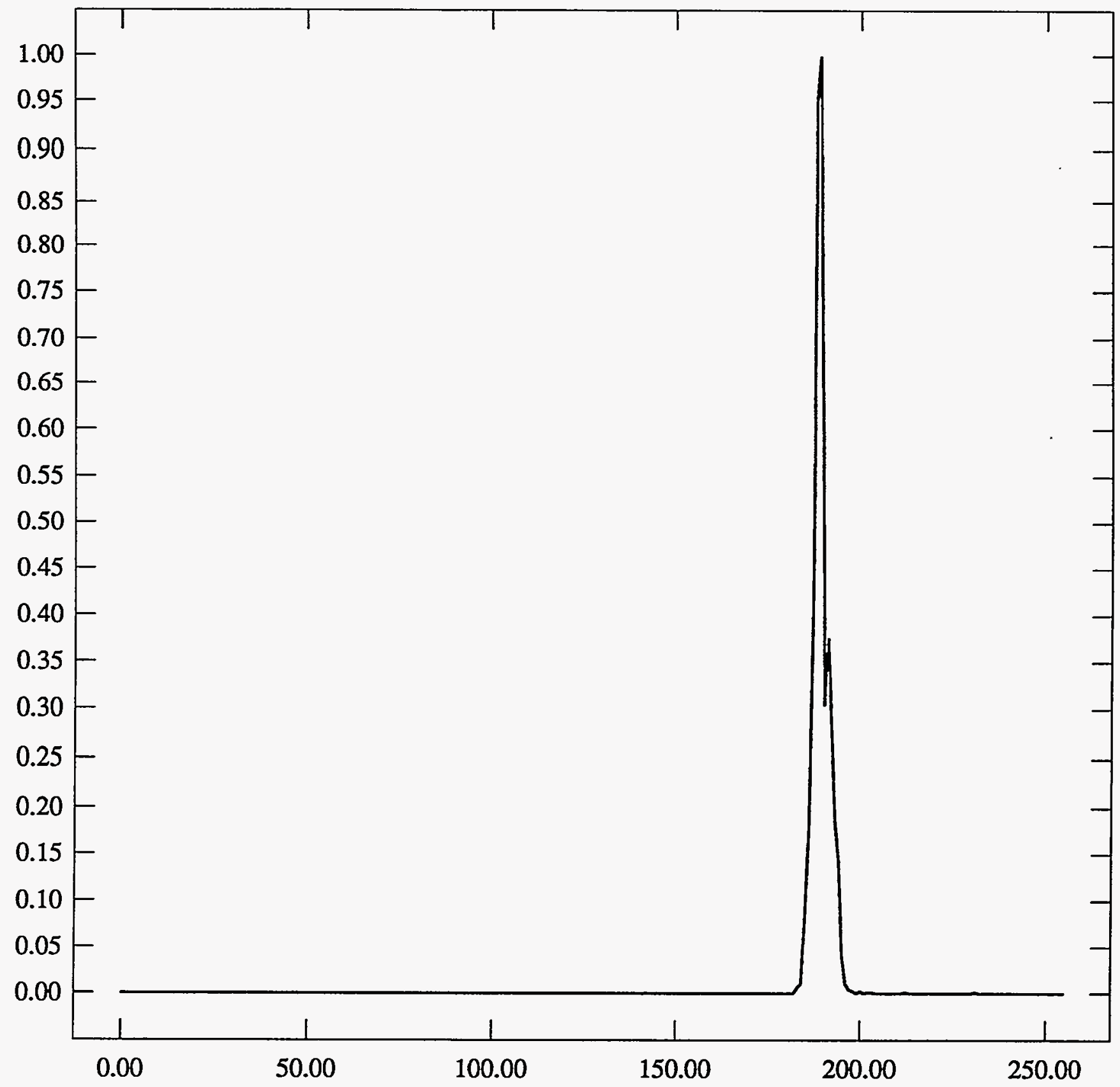


LENS HEATER

$20015 \mathrm{~mm}$ "

ST Camera: ST1\#4-10 20C: int_time= 50ms, offset= 0, gain=1 ( 350 e/bit) Fri Jul 2 11:42:15 1993 Pixel Values Min 41 Max 44 Mean 41.3 Sigma $0.45 \times 10^{3}$

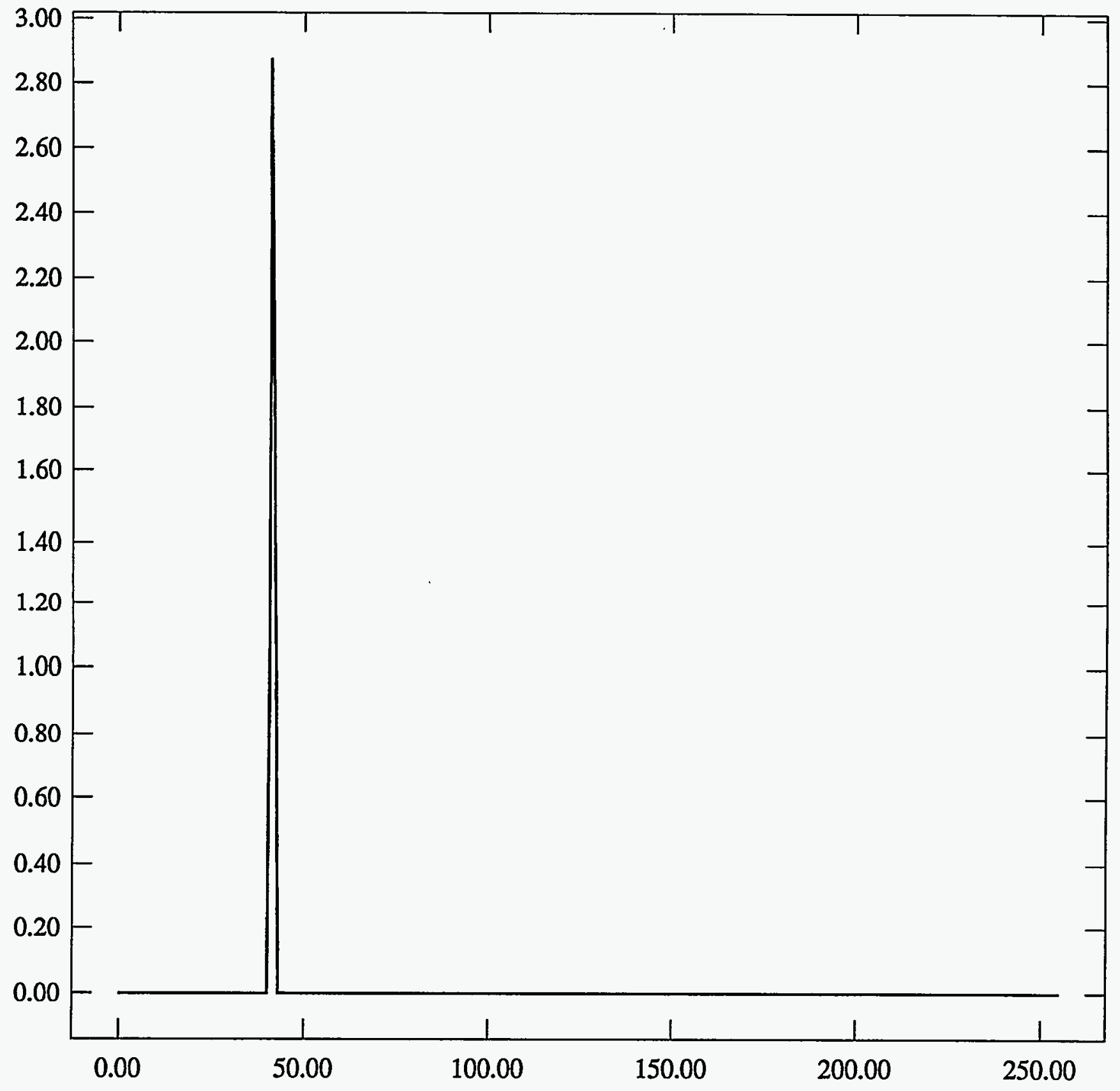


ST Camera: ST1\#4-10 20C: int_time=100ms, offset= 0, gain=1 (350 e/bit) Fri Jul 2 11:42:29 1993 Pixel Values Min 43 Max 49 Mean 43.9 Sigma $0.36 \times 10^{3}$

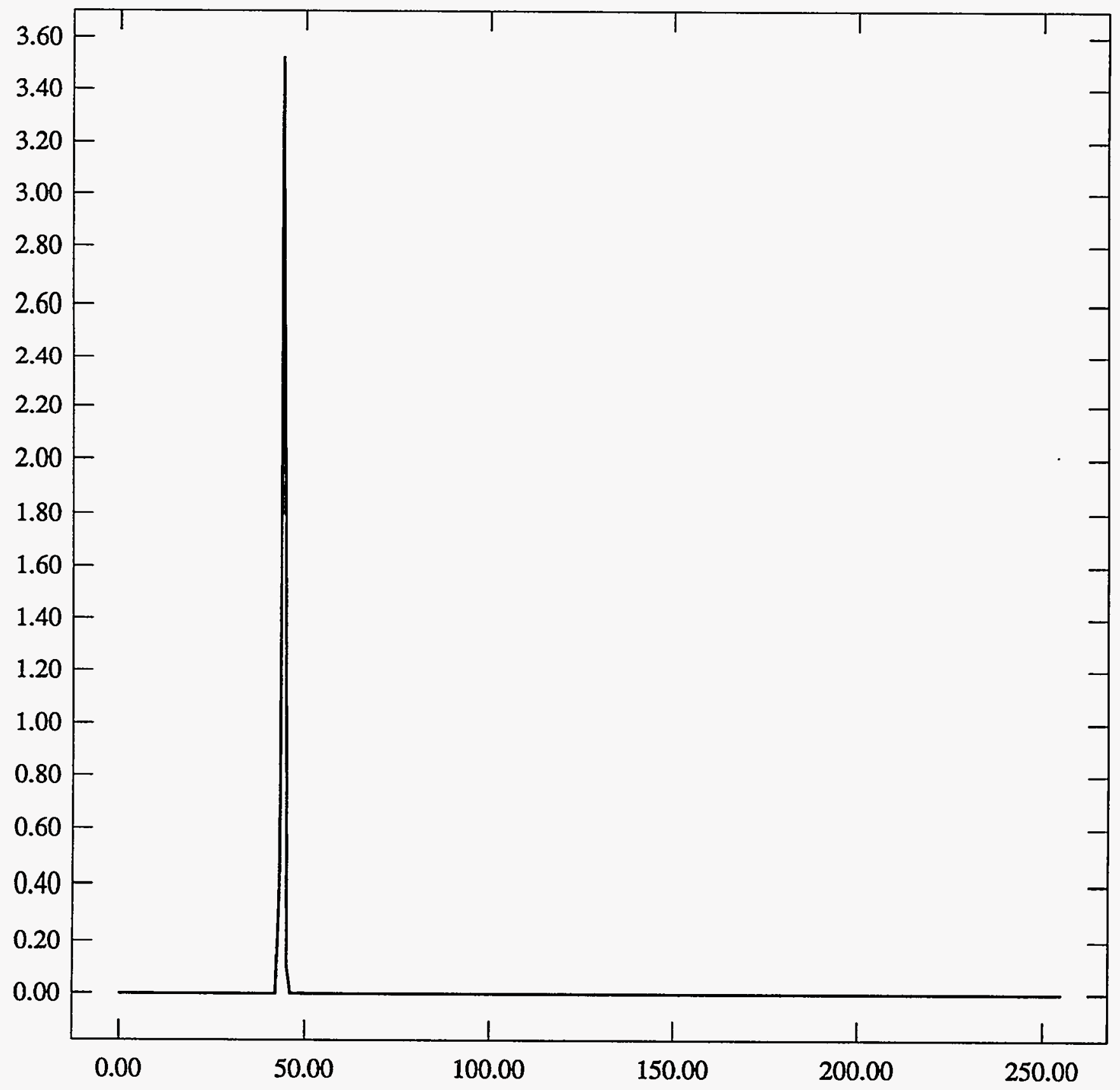


ST Camera: ST1\#4-10 20C: int_time=200ms, offset= 0, gain=1 ( 350 e/bit) Fri Jul 2 11:42:41 1993 Pixel Values Min 48 Max 59 Mean 49.6 Sigma $0.60 \times 10^{3}$

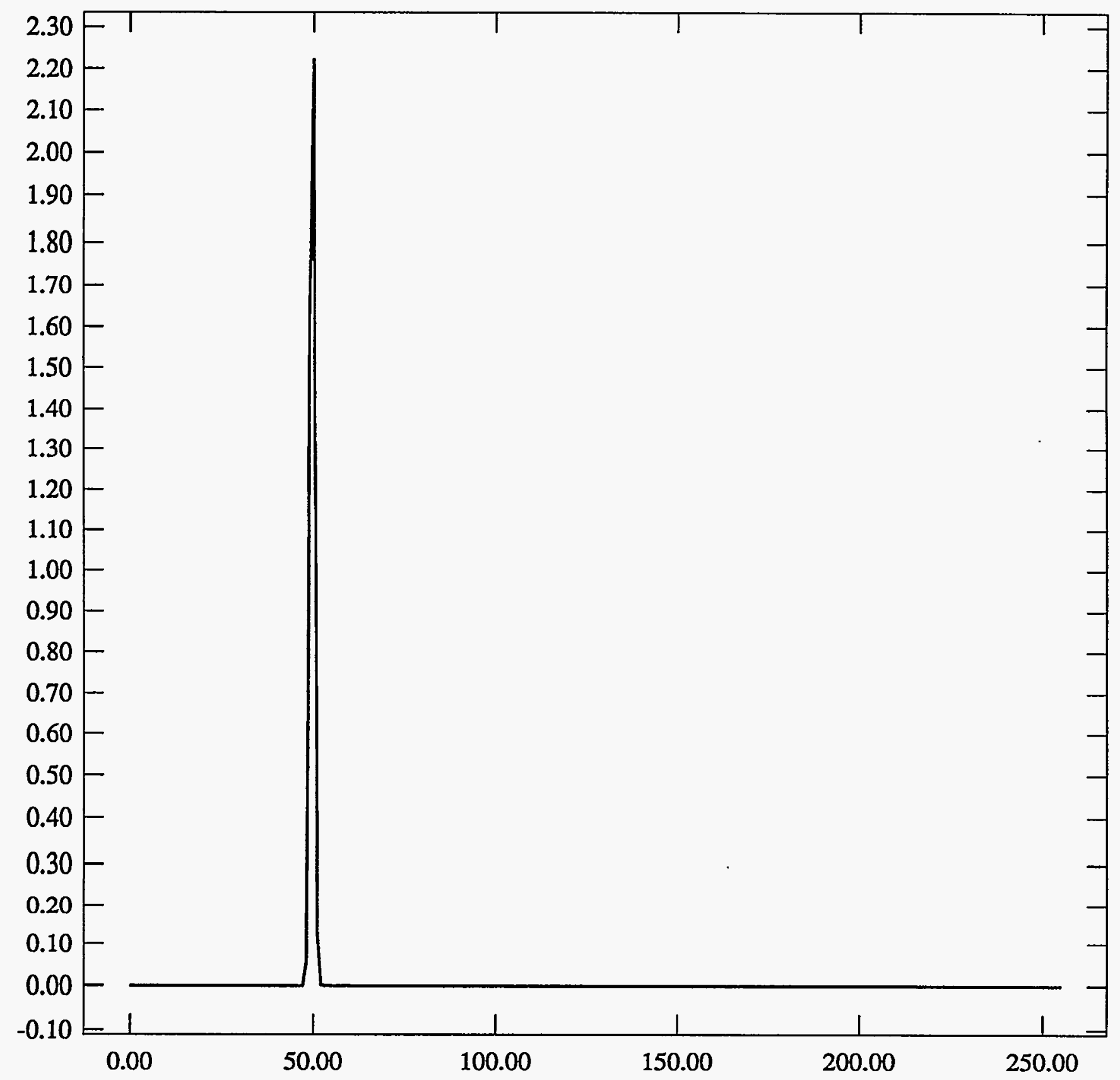


ST Camera: ST1 \#4-10 20C: int_time= 50ms, offset= 0, gain=2 ( $150 \mathrm{e} / \mathrm{bit}$ ) Fri Jul 2 11:43:02 1993

Pixel Values Min 82 Max 89 Mean 83.3 Sigma $0.64 \times 10^{3}$

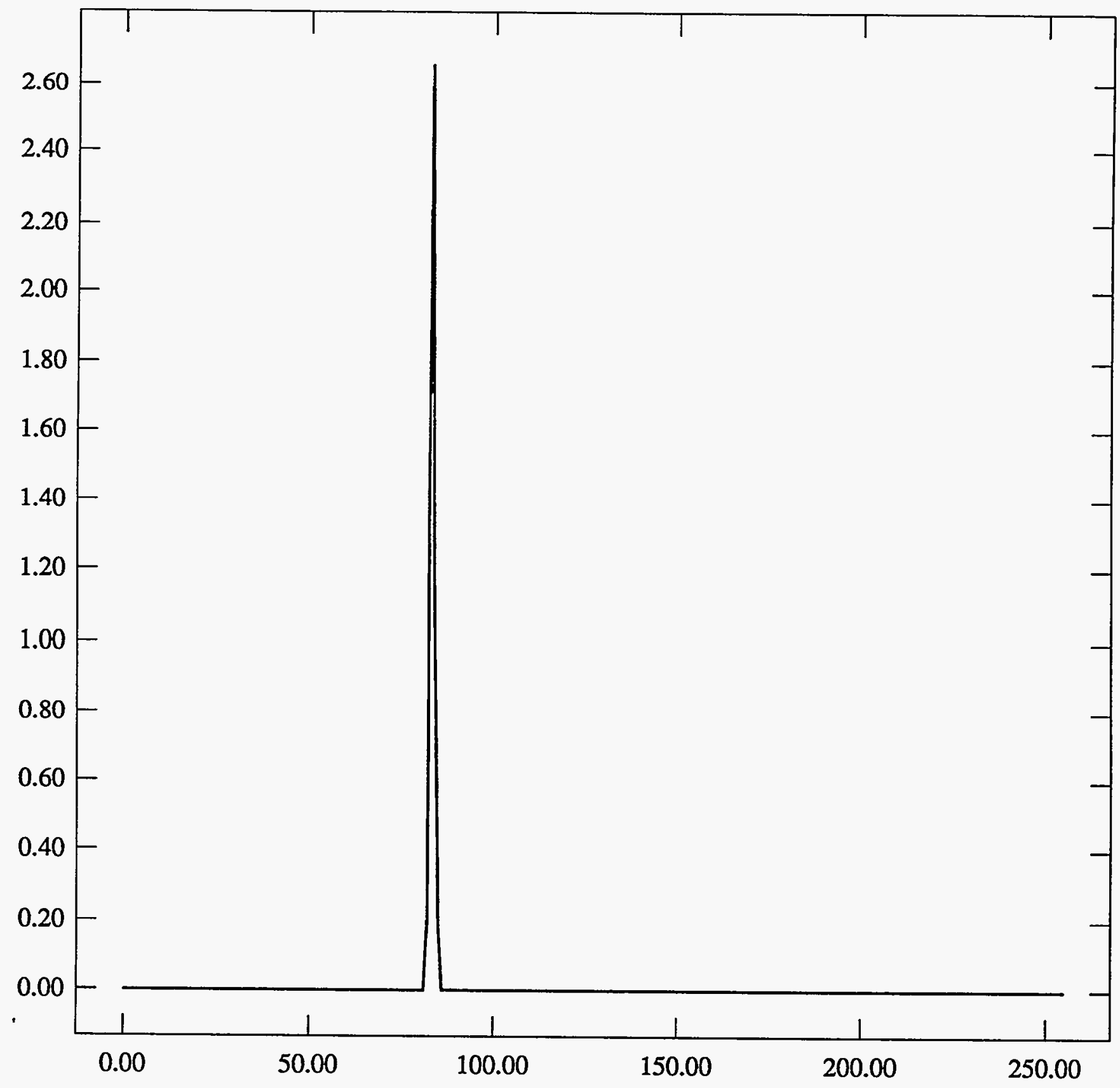


ST Camera: ST1\#4-10 20C: int_time=100ms, offset= 0, gain=2 ( 150 e/bit) Fri Jul 2 11:43:13 1993

Pixel Values Min 87 Max 101 Mean 89.4 Sigma $0.75 \times 10^{3}$

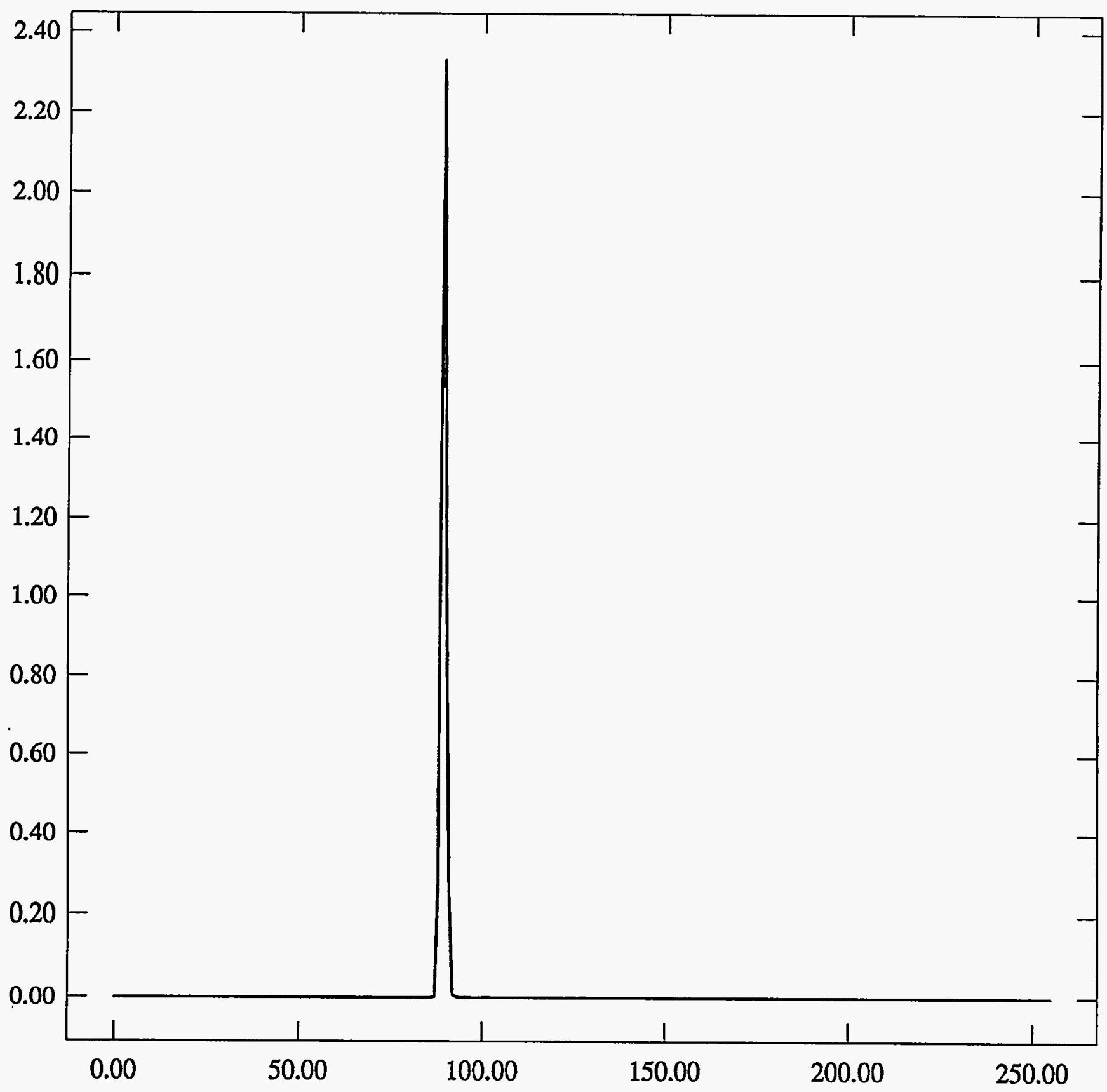


ST Camera: ST1\#4-10 20C: int_time=200ms, offset= 0, gain=2 ( 150 e/bit) Fri Jul 2 11:43:22 1993

Pixel Values Min 98 Max 125 Mean 102.1 Sigma 1.24 x $10^{3}$

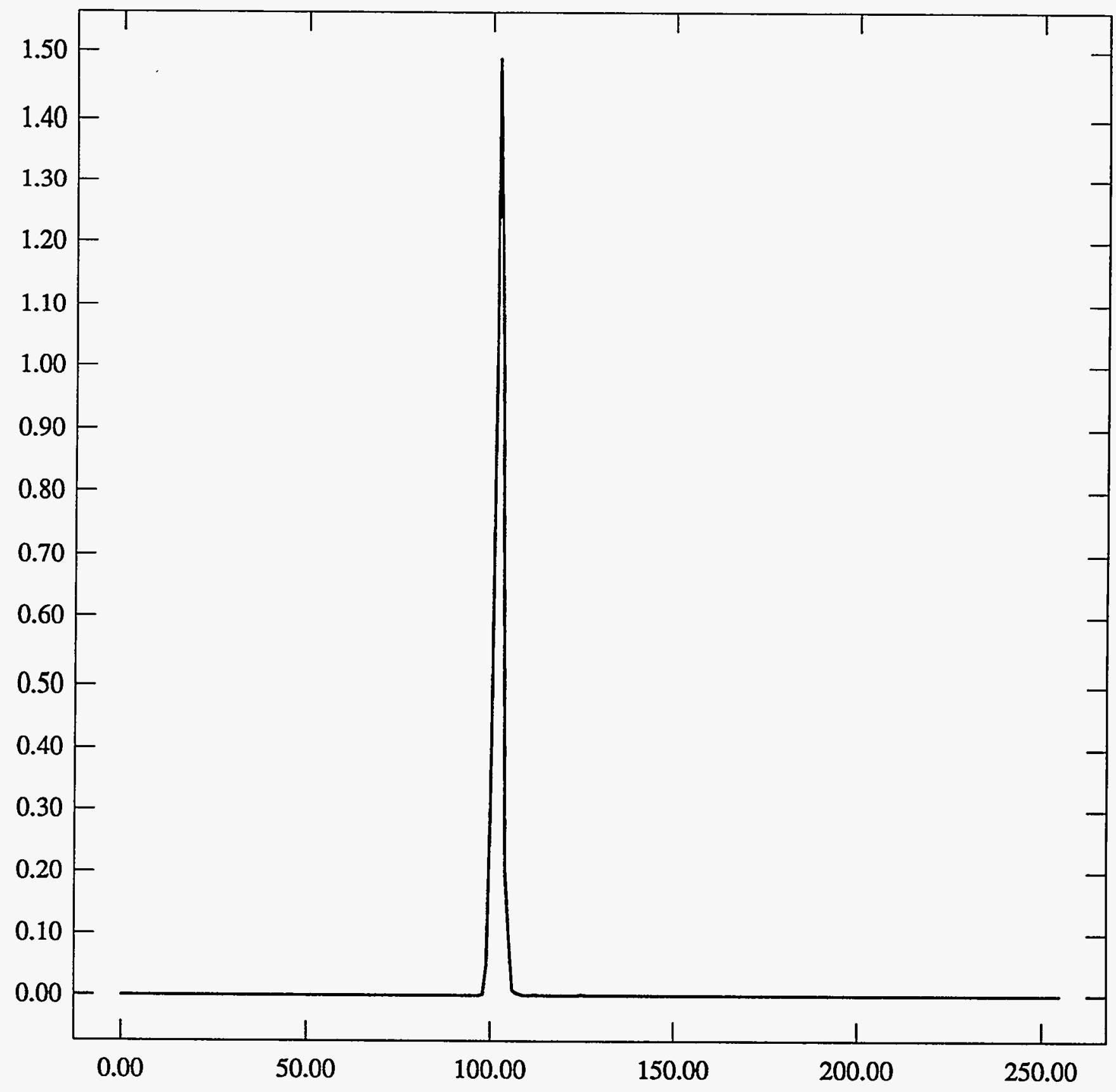


ST Camera: ST1\#4-10 20C: int_time= 50ms, offset= 0, gain=4 ( 75 e/bit) Fri Jul 2 11:43:35 1993

Pixel Values Min 150 Max 164 Mean 152.8 Sigma $1.19 \times 10^{3}$

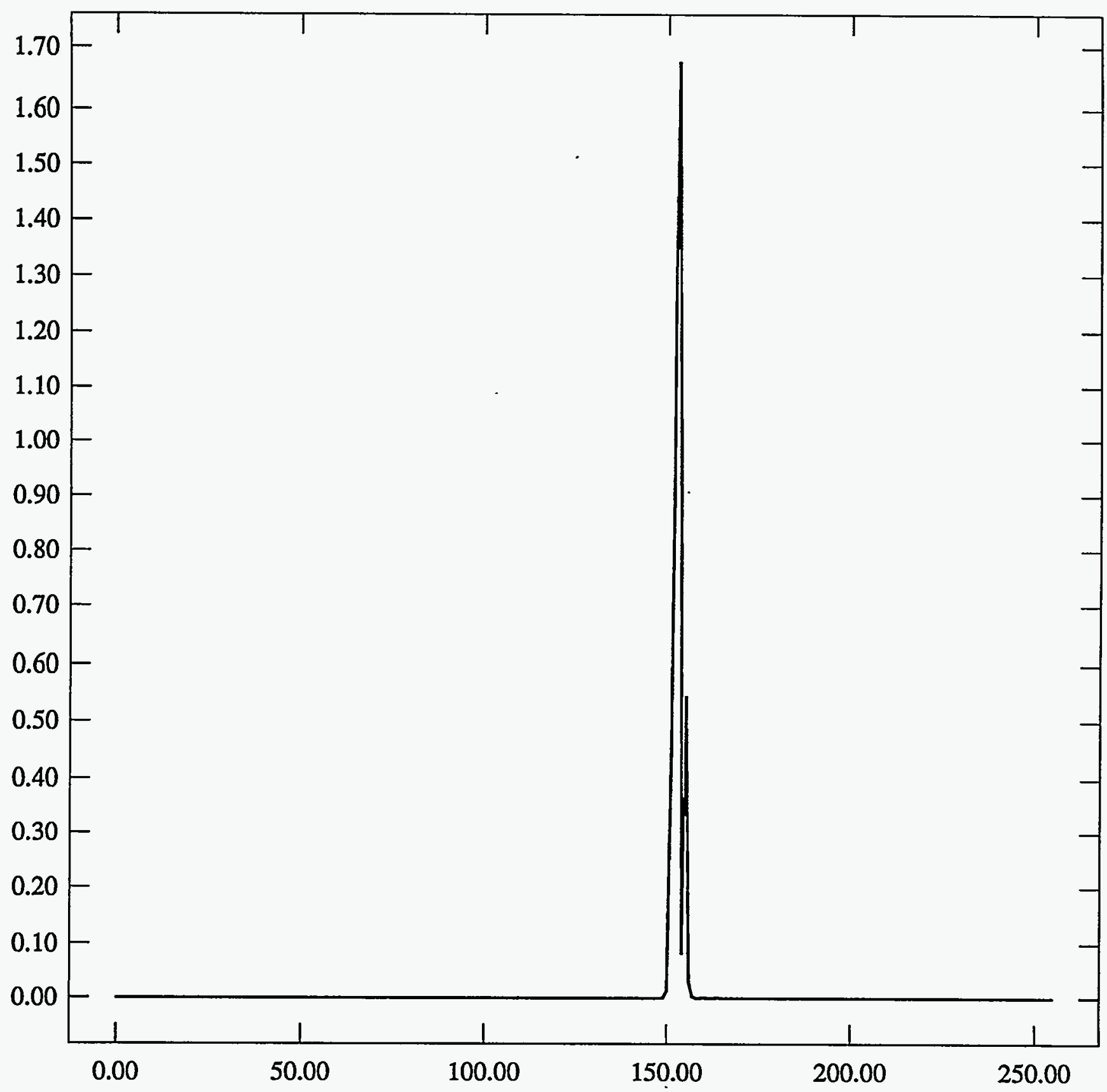


ST Camera: ST1\#4-10 20C: int_time=100ms, offset= 0, gain=4 ( 75 e/bit) Fri Jul 2 11:43:46 1993

Pixel Values Min 161 Max 184 Mean 165.2 Sigma $1.44 \times 10^{3}$

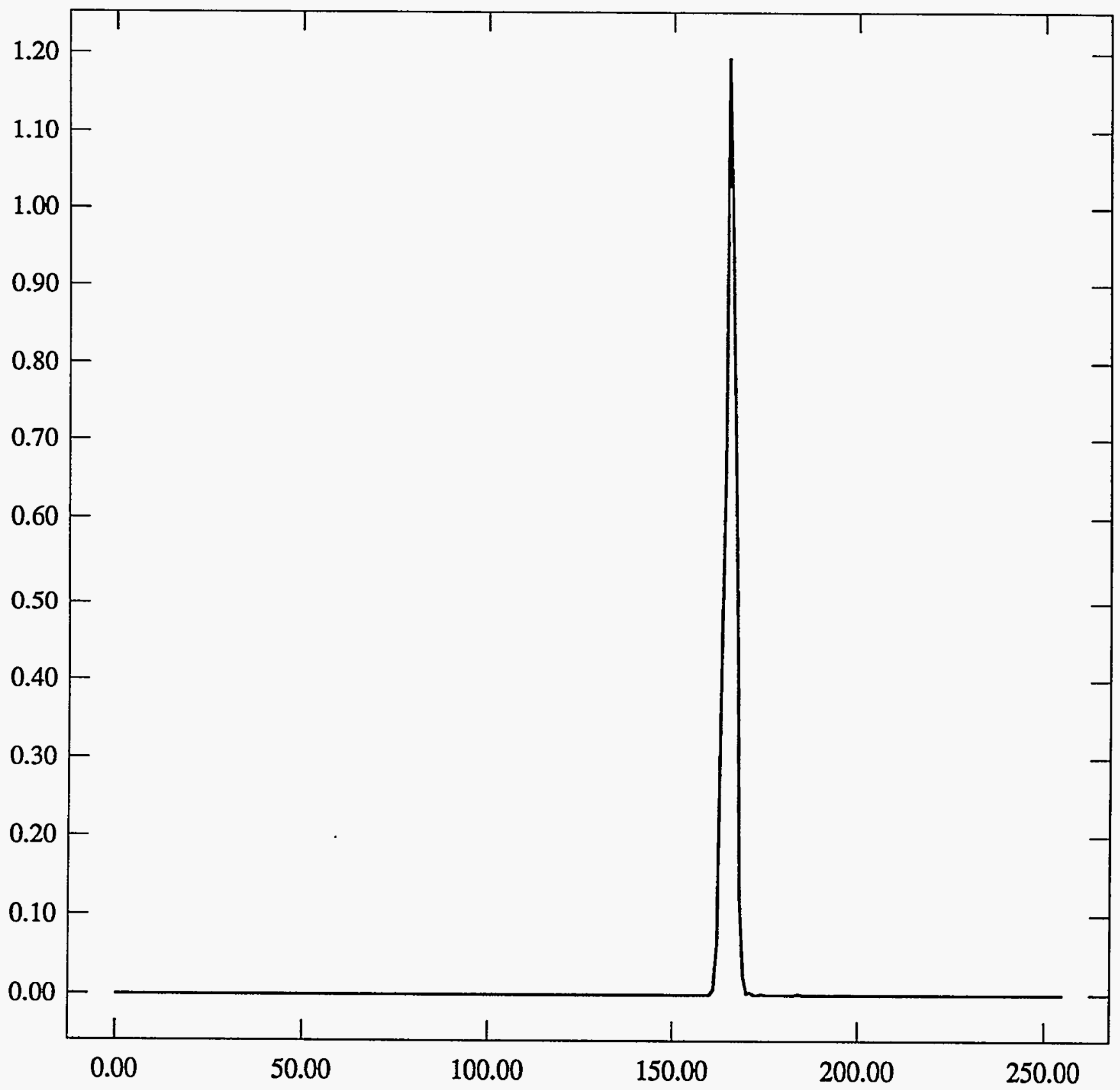


ST Camera: ST1\#4-10 20C: int_time=200ms, offset= 0, gain=4 ( 75 e/bit) Fri Jul 2 11:43:57 1993 Pixel Values Min 183 Max 235 Mean 189.0 Sigma $2.33 \times 10^{3}$

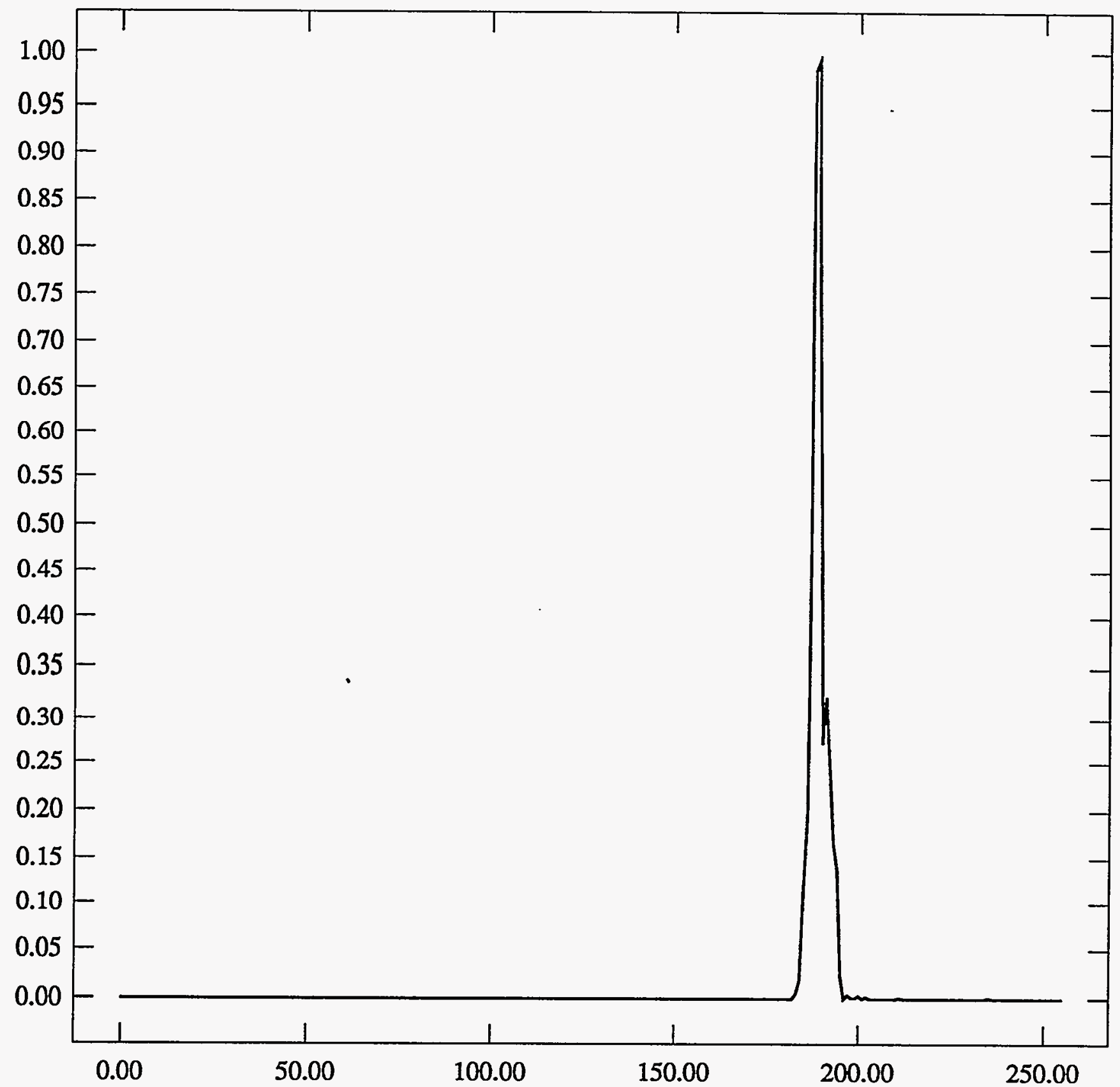


LENS HEATER $\quad-30^{\circ} \mathrm{c}$ end

ST Camera: ST1\#4-10 -30C: int_time= 50ms, offset= 0, gain=1 ( 350 e/bit) Fri Jul 2 11:04:57 1993

Pixel Values Min 39 Max 41 Mean 39.4 Sigma $0.50 \times 10^{3}$

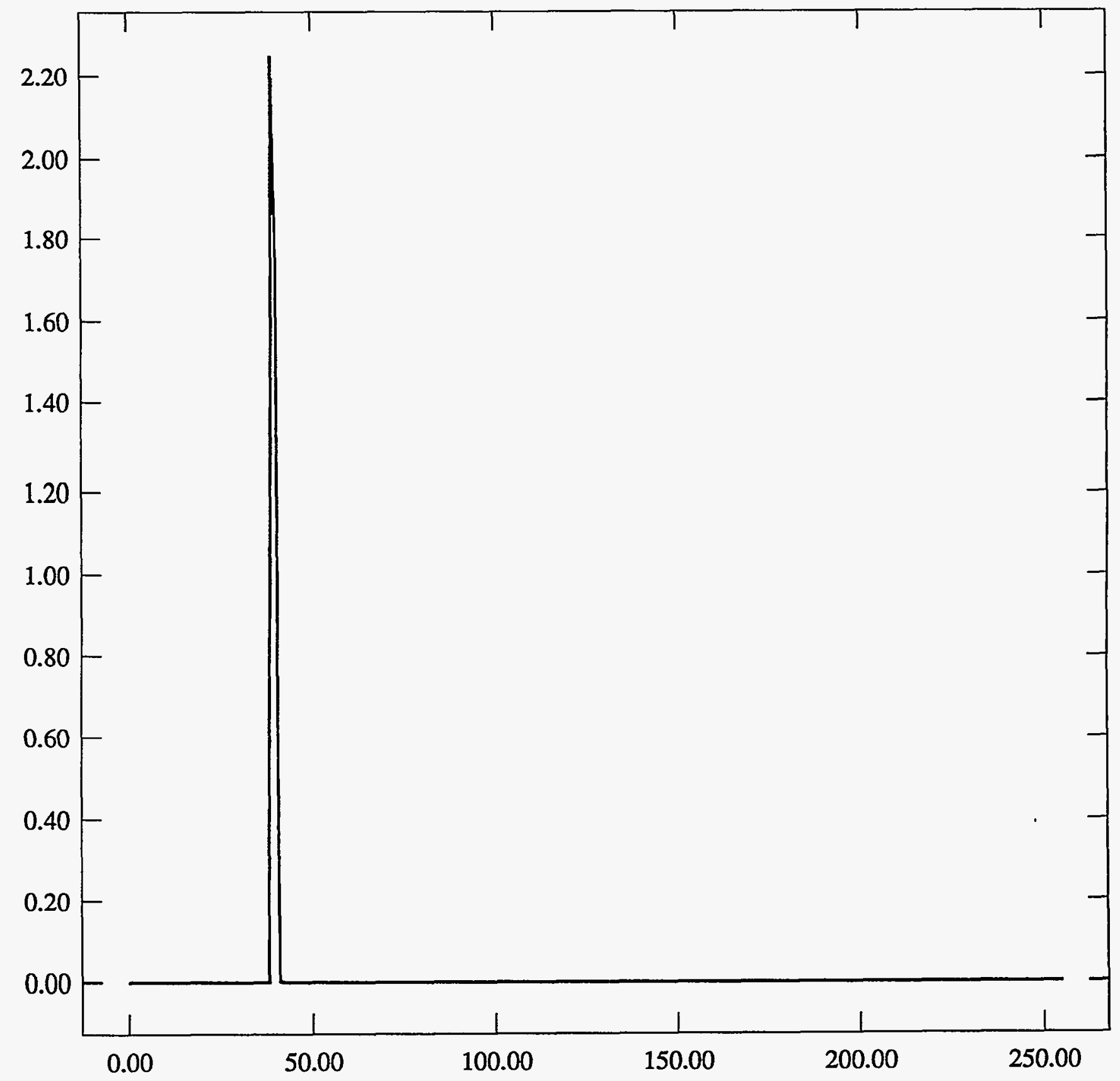


ST Camera: ST1\#4-10 -30C: int_time=100ms, offset= 0, gain=1 ( 350 e/bit) Fri Jul 211:05:09 1993

Pixel Values Min 39 Max 41 Mean 39.5 Sigma $0.50 \times 10^{3}$

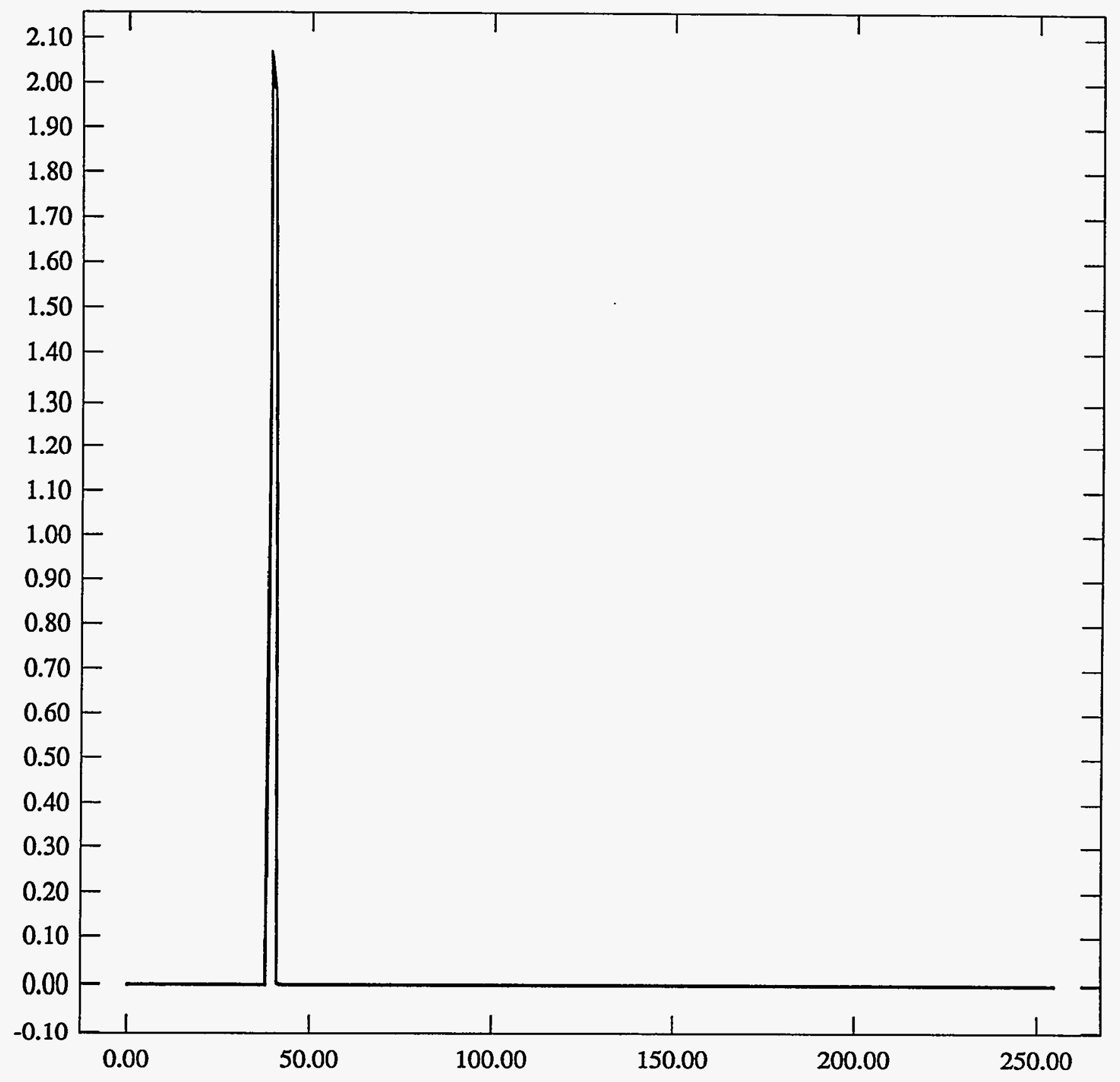


ST Camera: ST1\#4-10 -30C: int_time=200ms, offset= 0, gain=1 ( 350 e/bit) Fri Jul 2 11:05:50 1993

Pixel Values Min 39 Max 41 Mean 39.5 Sigma $0.50 \times 10^{3}$

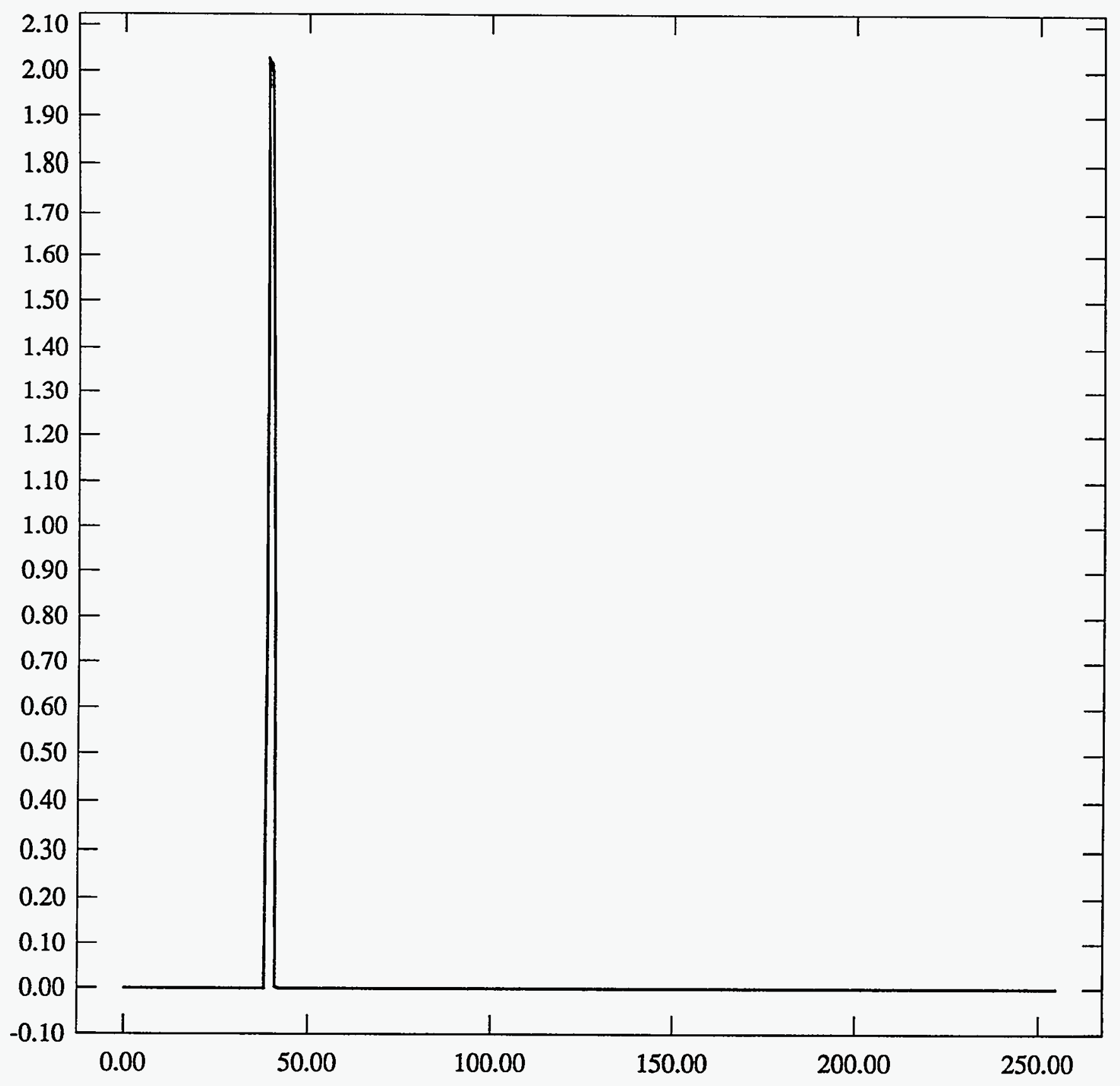


ST Camera: ST1\#4-10 -30C: int_time= 50ms, offset= 0, gain=2 (150 e/bit) Fri Jul 2 11:06:03 1993 Pixel Values Min 77 Max 80 Mean 78.7 Sigma $0.57 \times 10^{3}$

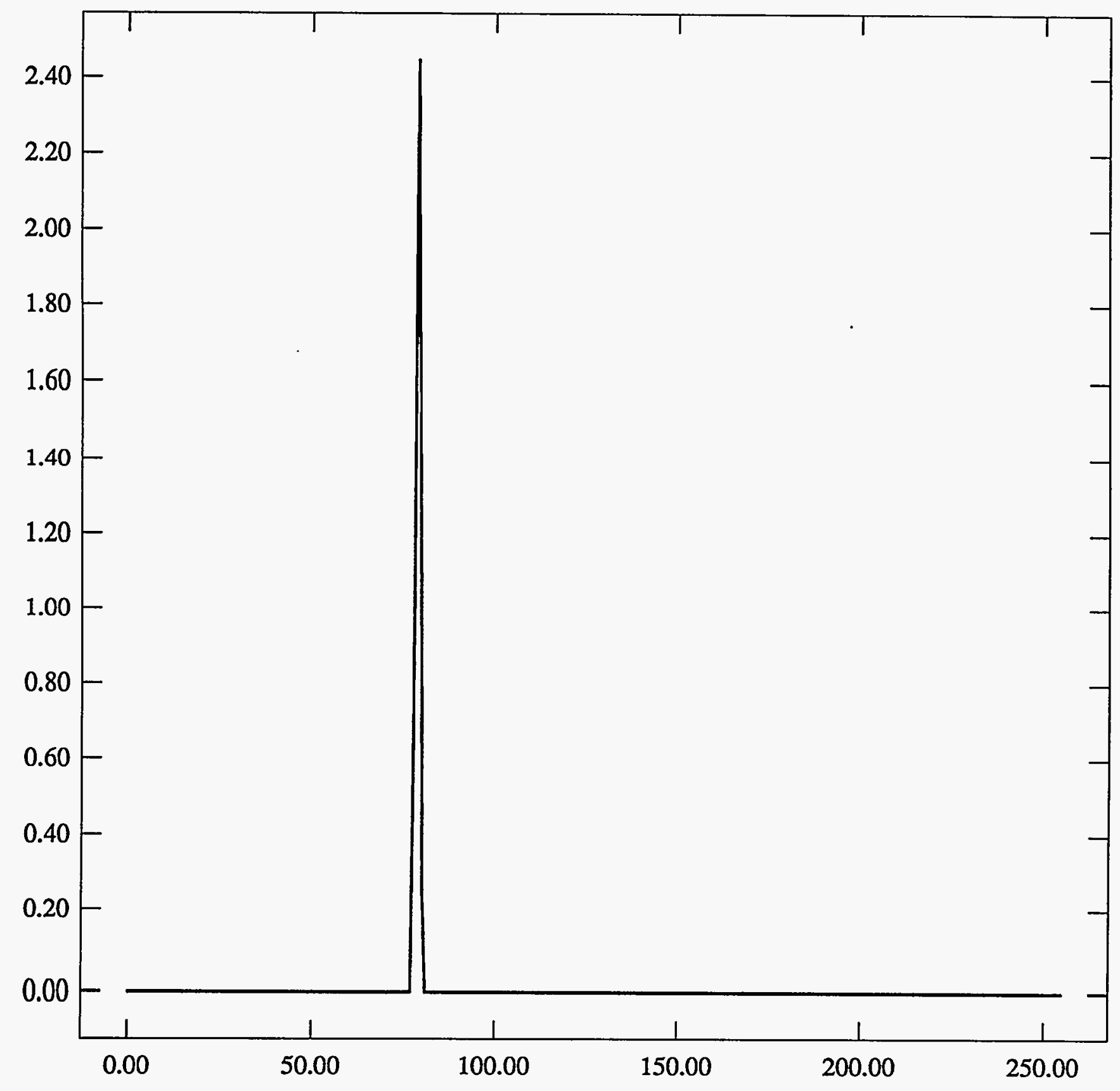


ST Camera: ST1\#4-10 -30C: int_time=100ms, offset= 0, gain=2 ( $150 \mathrm{e} / \mathrm{bit})$ Fri Jul 2 11:06:15 1993 Pixel Values Min 78 Max 80 Mean 78.8 Sigma $0.56 \times 10^{3}$

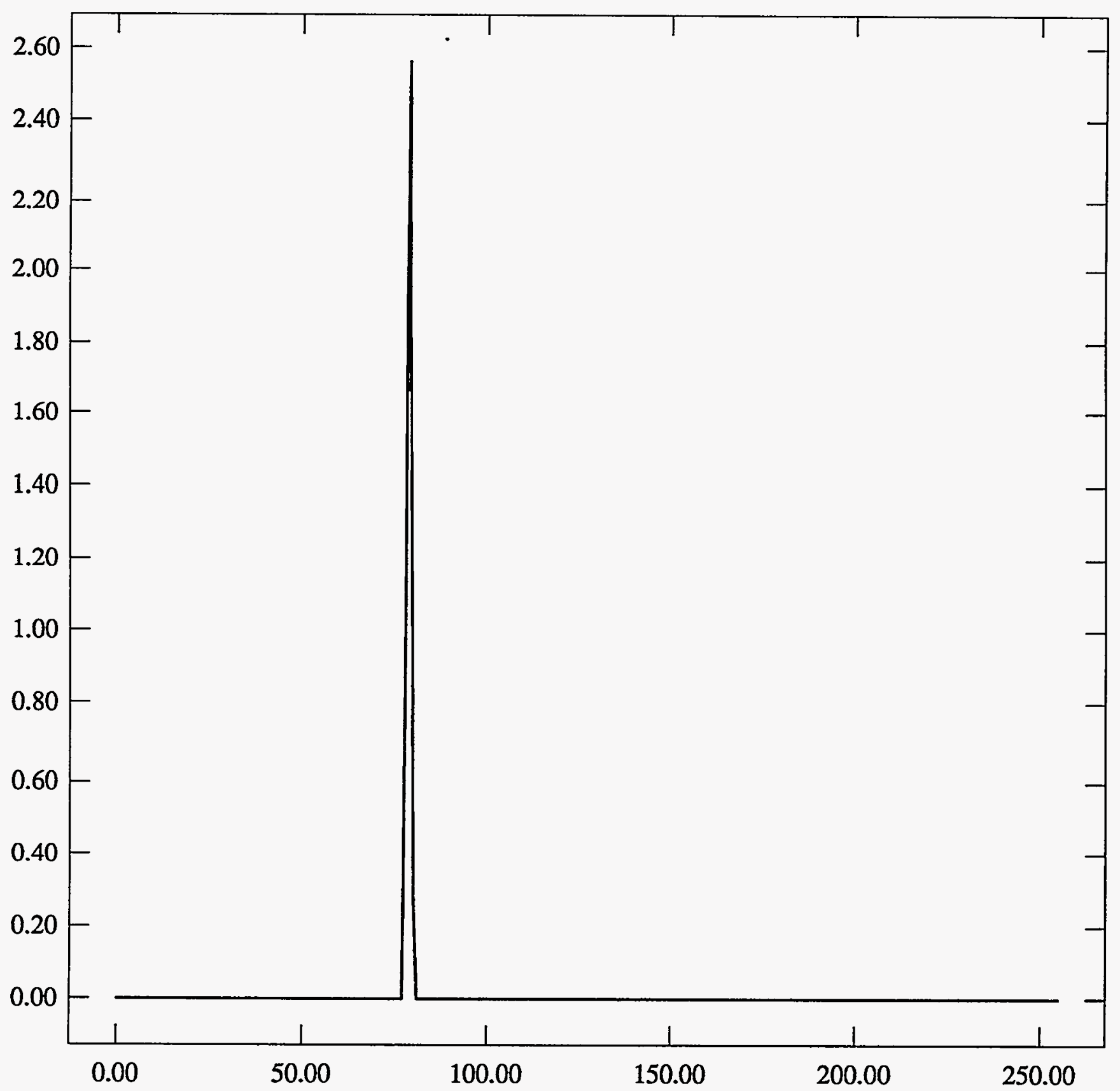


ST Camera: ST1\#4-10 -30C: int_time=200ms, offset= 0, gain=2 ( 150 e/bit) Fri Jul 2 11:06:28 1993 Pixel Values Min 77 Max 80 Mean 78.9 Sigma $0.59 \times 10^{3}$

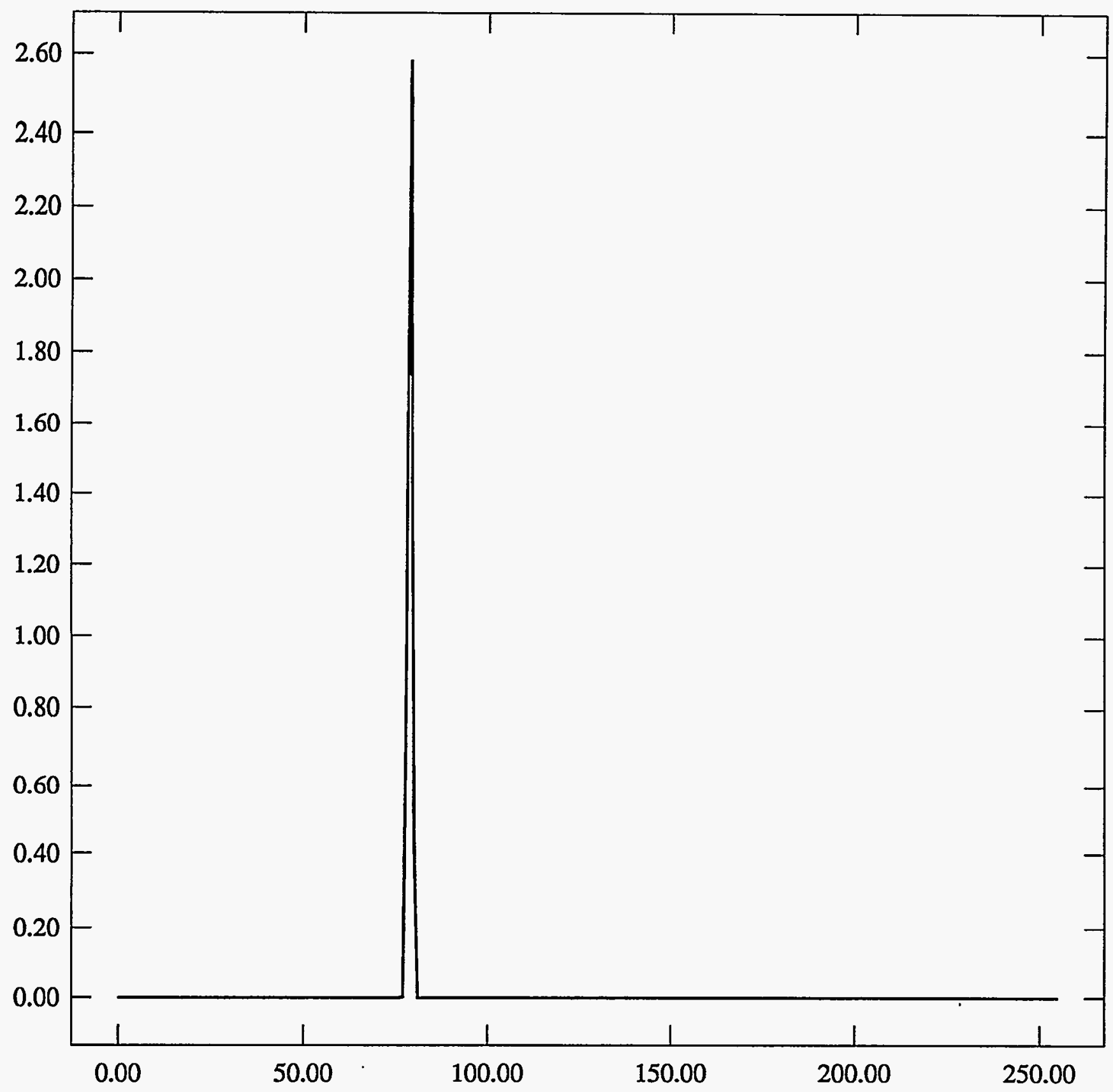


ST Camera: ST1\#4-10 -30C: int_time= 50ms, offset= 0, gain=4 ( 75 e/bit) Fri Jul 2 11:06:39 1993 Pixel Values Min 144 Max 149 Mean 146.2 Sigma $0.70 \times 10^{3}$

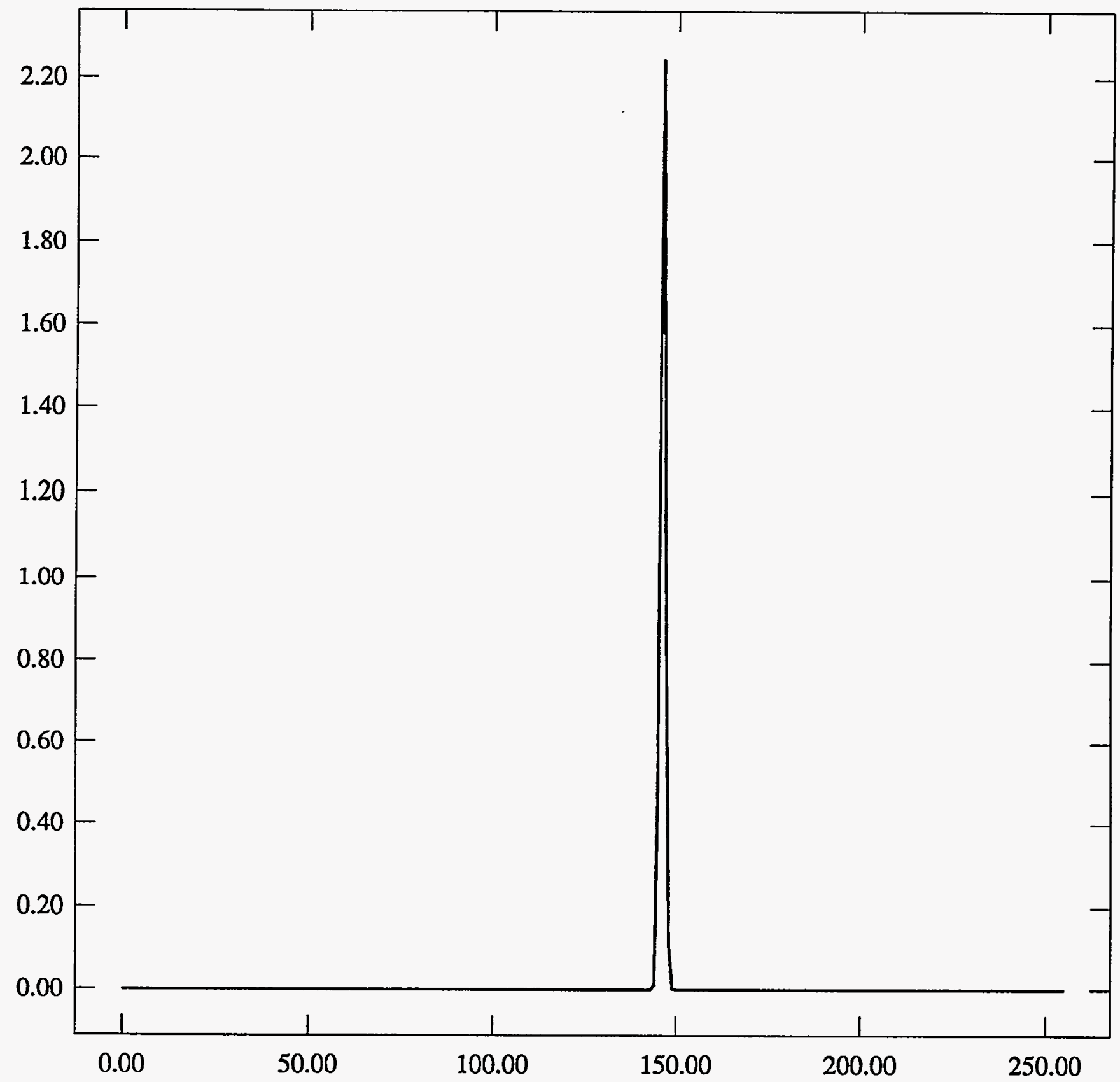


ST Camera: ST1\#4-10 -30C: int_time=100ms, offset= 0, gain=4 ( 75 e/bit) Fri Jul 2 11:06:50 1993 Pixel Values Min 144 Max 149 Mean 146.3 Sigma $0.69 \times 10^{3}$

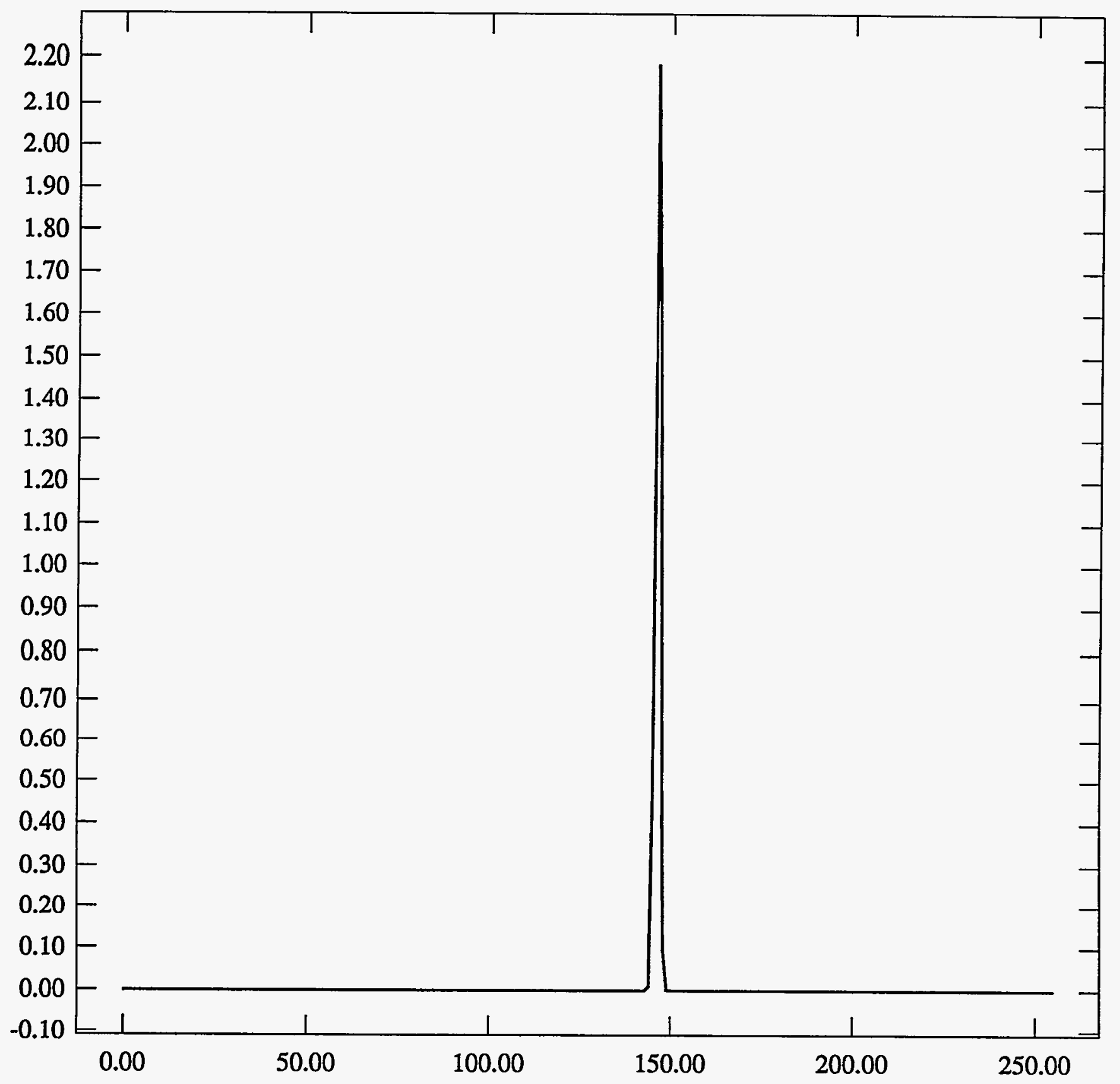


ST Camera: ST1\#4-10 -30C: int_time=200ms, offset= 0, gain=4 ( 75 e/bit) Fri Jul 2 11:07:05 1993 Pixel Values Min 144 Max 149 Mean 146.4 Sigma $0.70 \times 10^{3}$

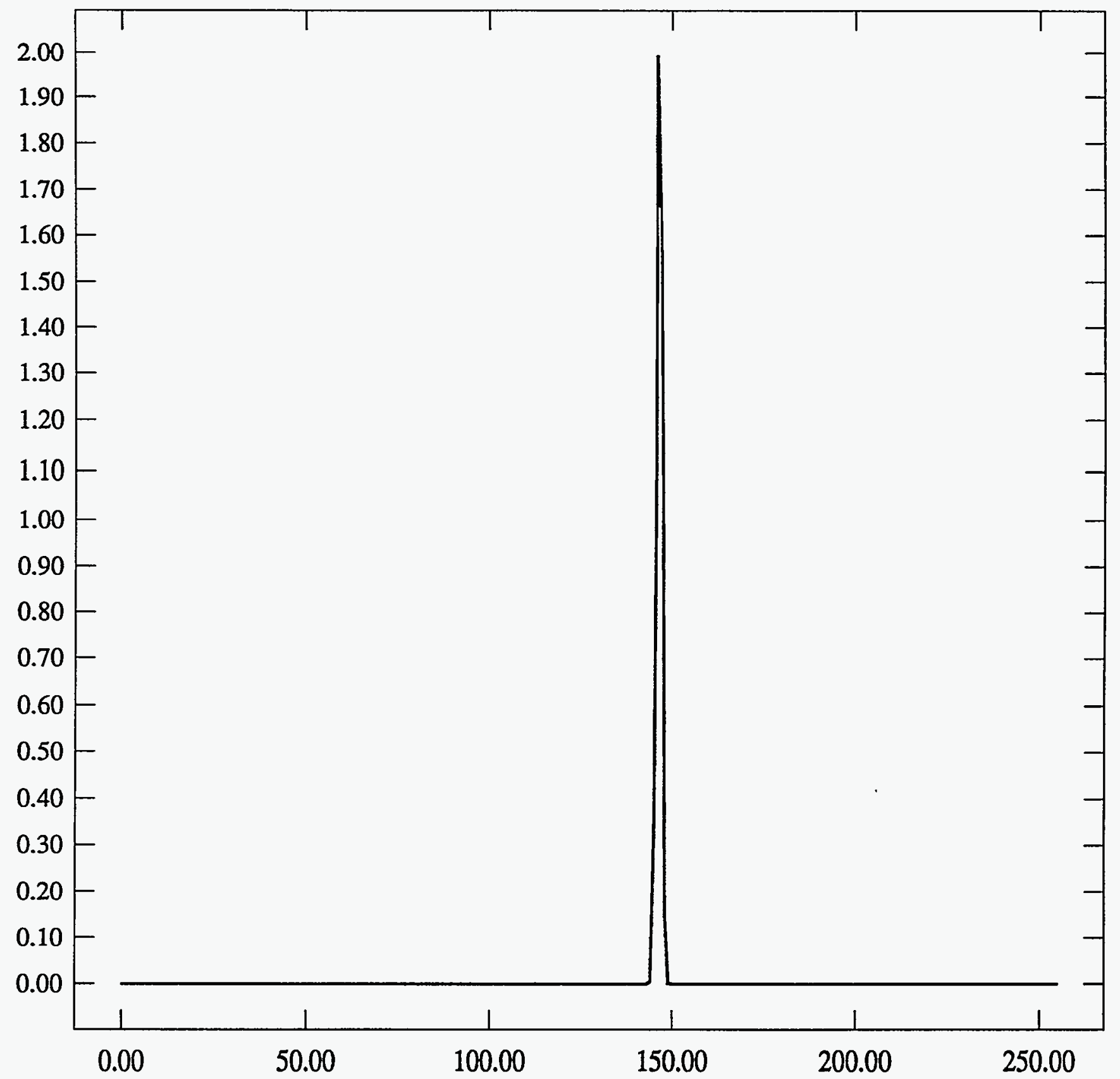




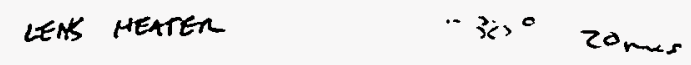

ST Camera: ST1\#4-10 -30C: int_time= 50ms, offset= 0, gain=1 ( $350 \mathrm{e} / \mathrm{bit}$ ) Fri Jul 2 10:32:59 1993

Pixel Values Min 39 Max 41 Mean 39.4 Sigma $0.50 \times 10^{3}$

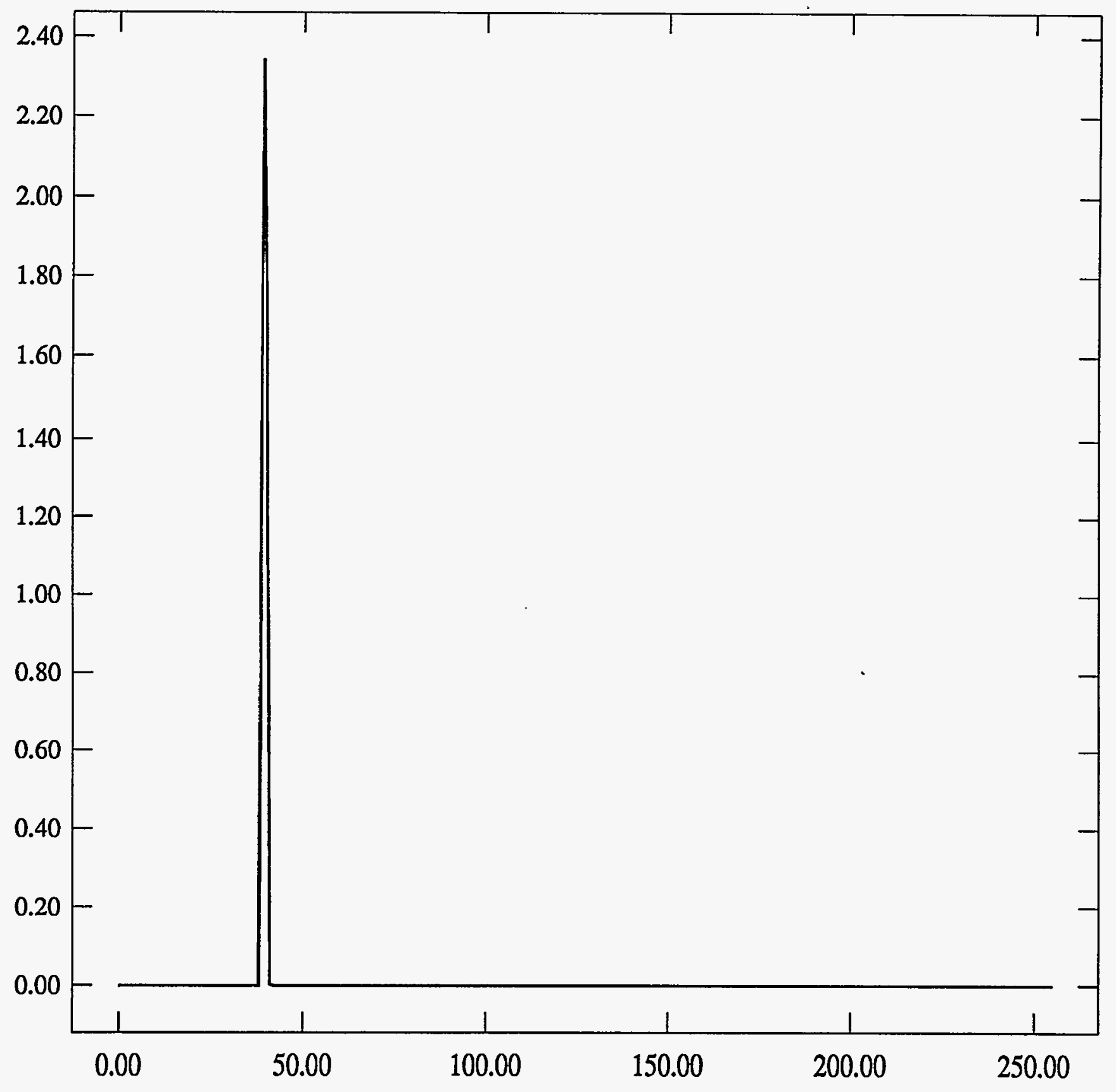


ST Camera: ST1\#4-10 -30C: int_time=100ms, offset= 0, gain=1 ( 350 e/bit) Fri Jul 2 10:33:12 1993 Pixel Values Min 39 Max 41 Mean 39.4 Sigma $0.50 \times 10^{3}$

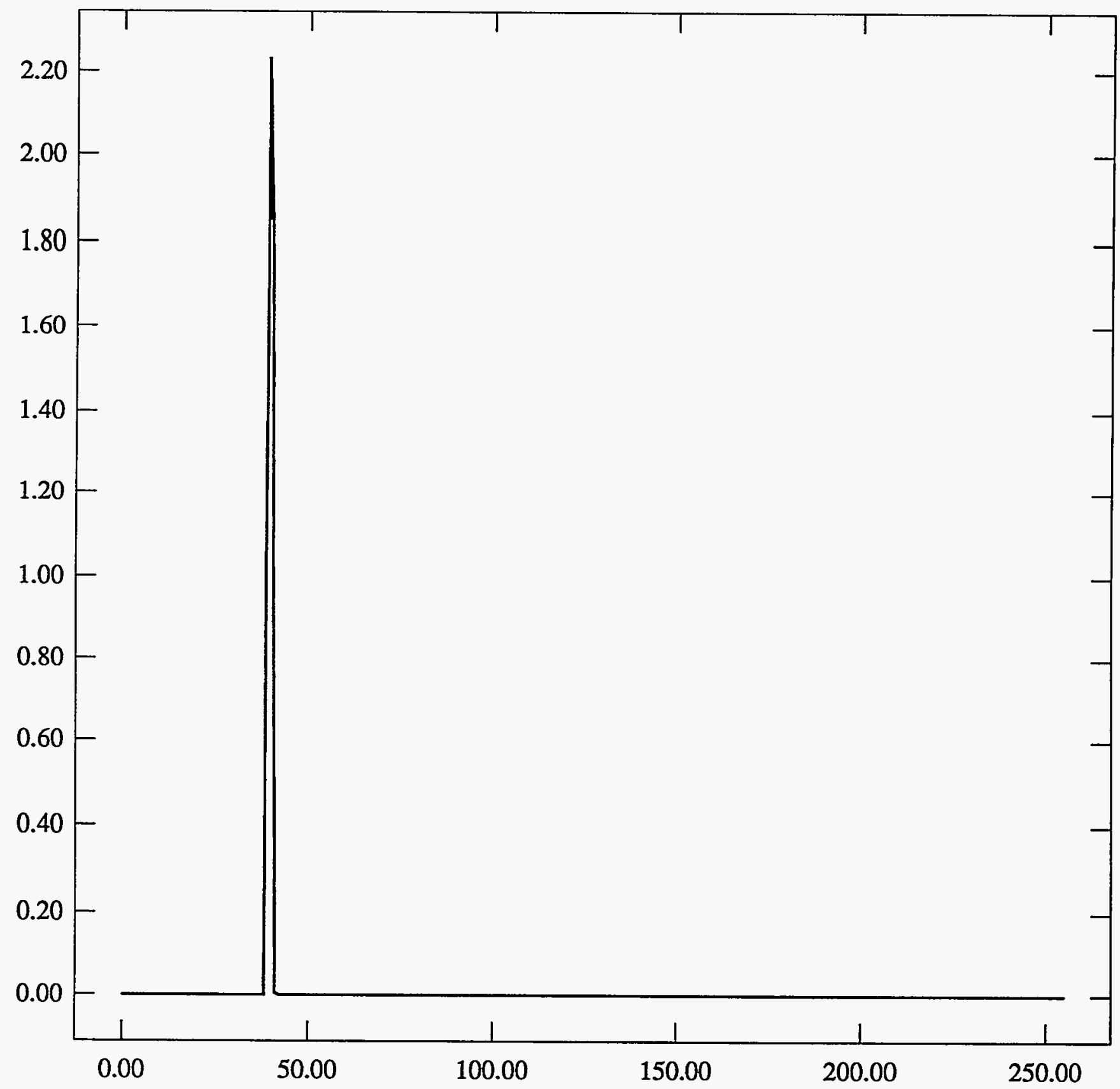


ST Camera: ST1\#4-10 -30C: int_time=200ms, offset= 0, gain=1 ( 350 e/bit) Fri Jul 2 10:33:22 1993 Pixel Values Min 39 Max 41 Mean 39.5 Sigma $0.50 \times 10^{3}$

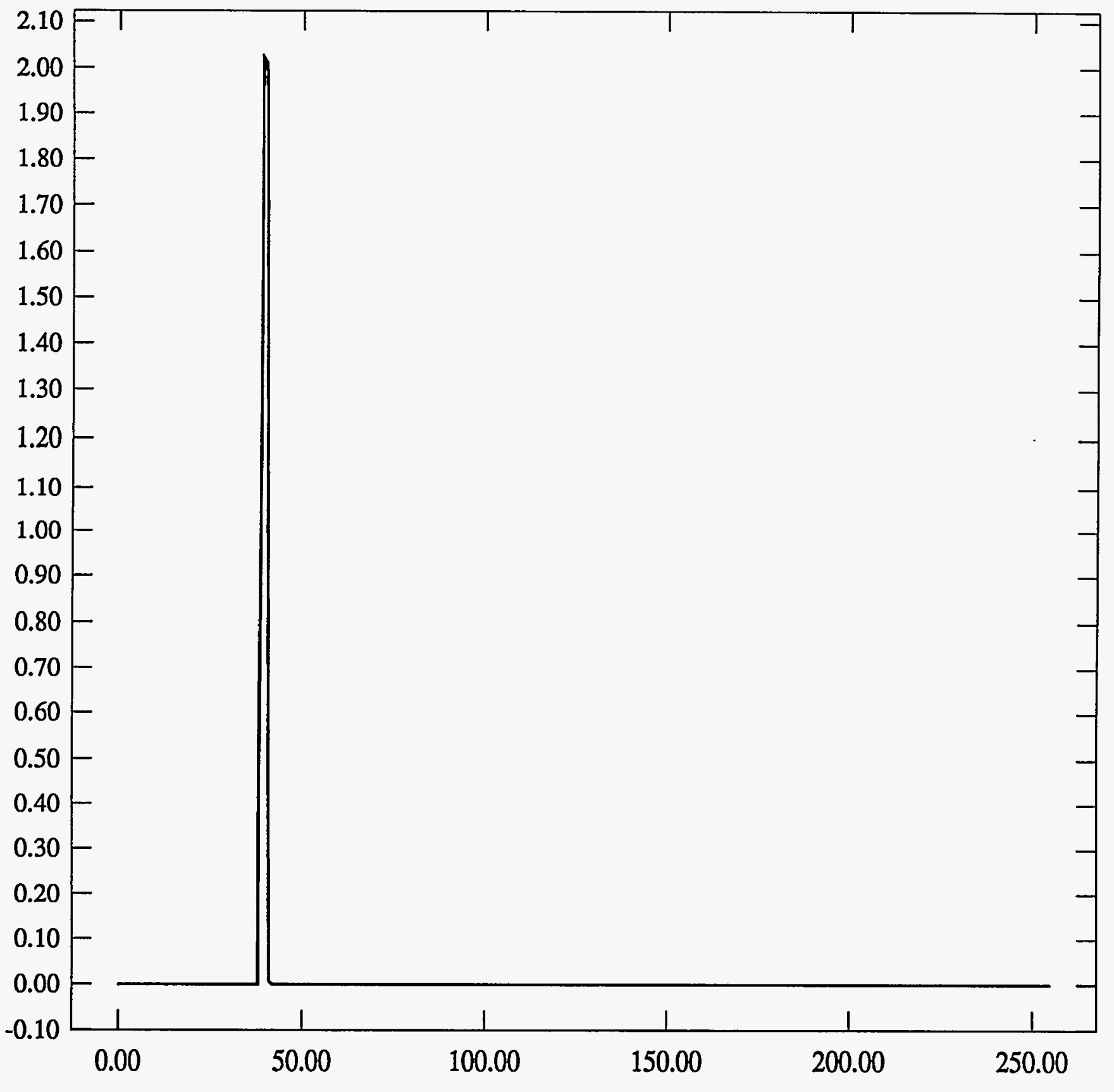


ST Camera: ST1\#4-10 -30C: int_time $=50 \mathrm{ms,} \mathrm{offset=} \mathrm{0,} \mathrm{gain=2} \mathrm{(} 150 \mathrm{e} / \mathrm{bit})$ Fri Jul 2 10:33:37 1993 Pixel Values Min 77 Max 80 Mean 78.7 Sigma $0.57 \times 10^{3}$

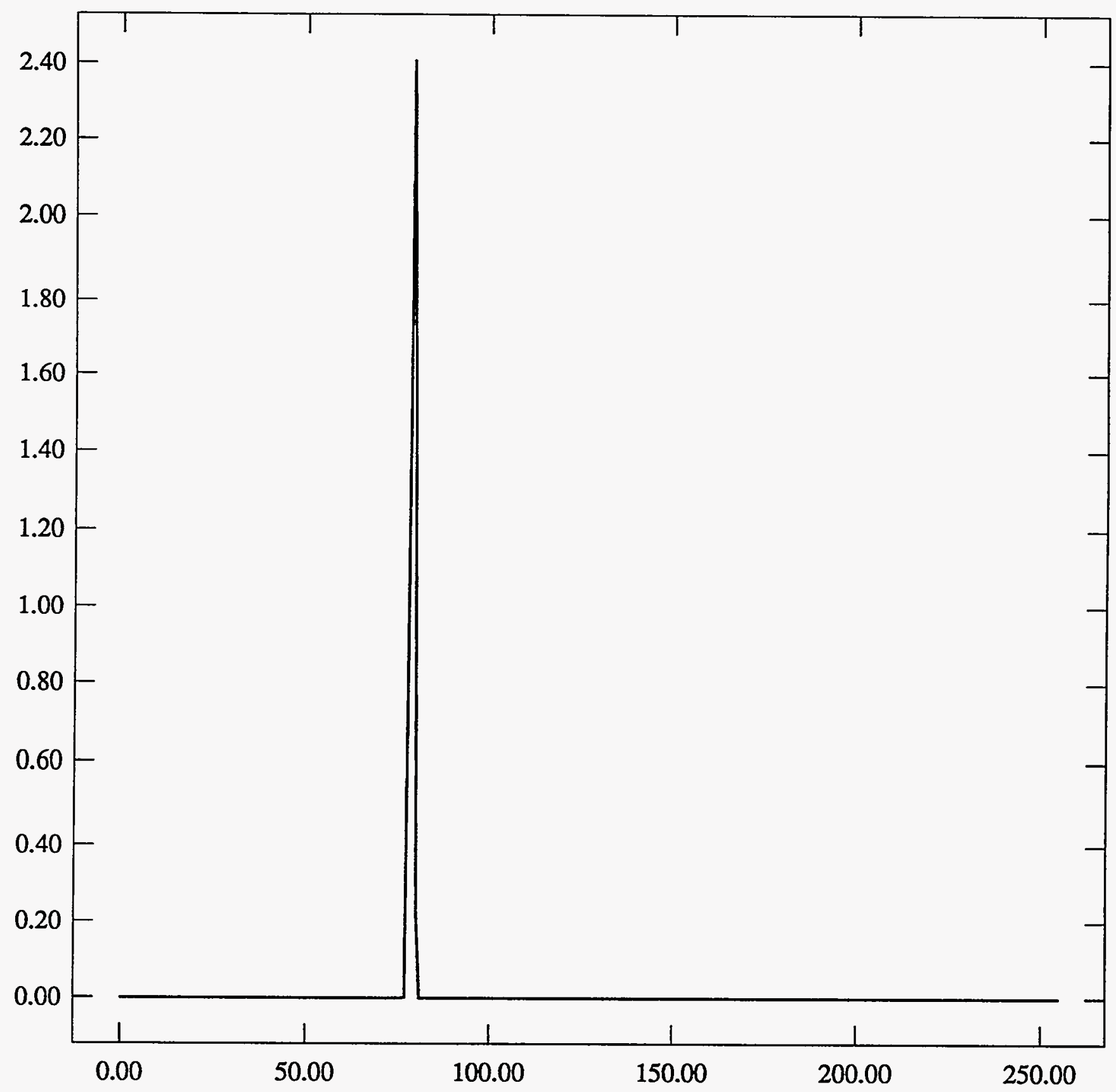


ST Camera: ST1\#4-10 -30C: int_time=100ms, offset= 0, gain=2 ( 150 e/bit) Fri Jul 2 10:33:58 1993 Pixel Values Min 77 Max 80 Mean 78.7 Sigma 0.57 x $10^{3}$

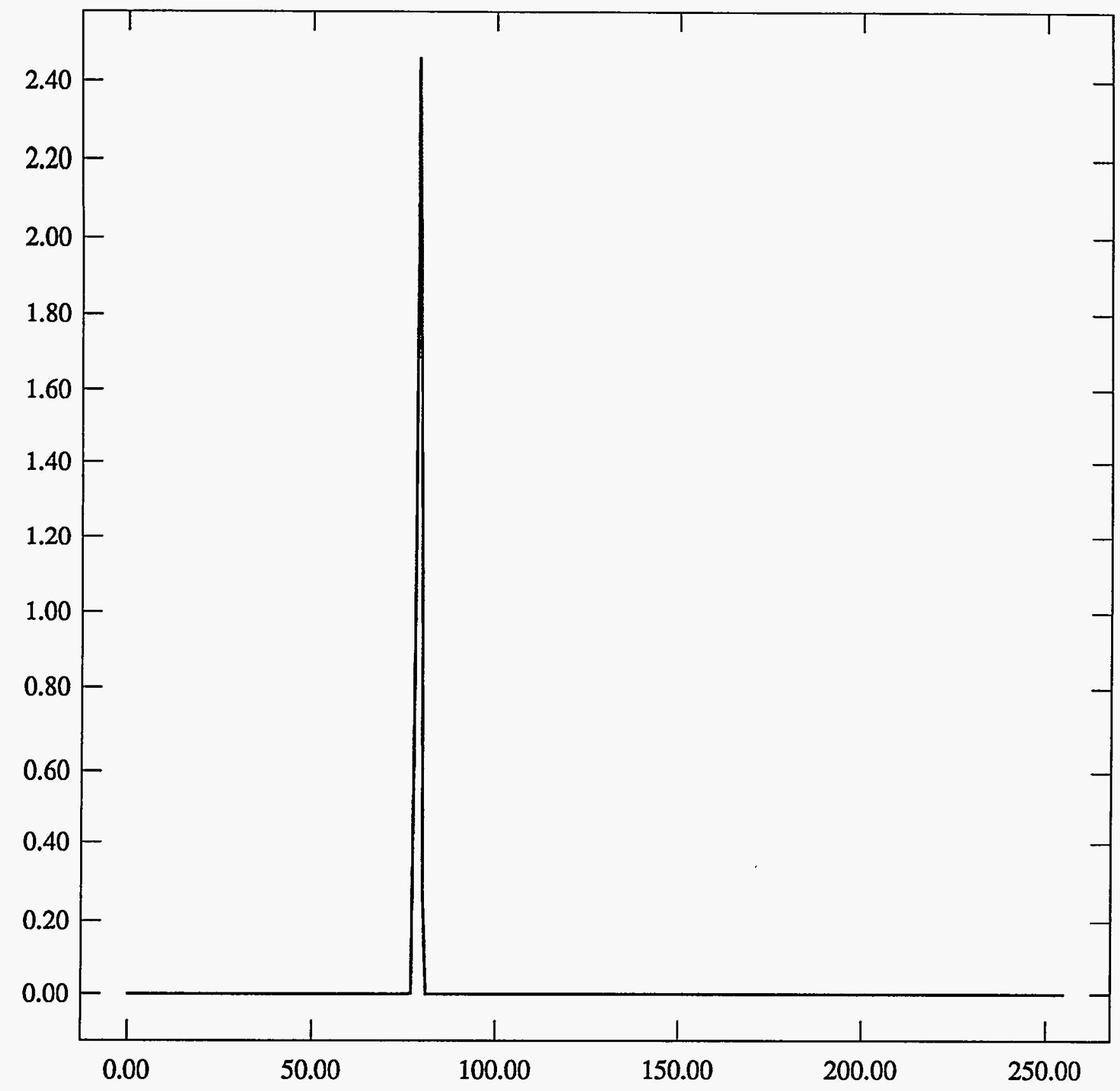


ST Camera: ST1\#4-10 -30C: int_time=200ms, offset= 0, gain=2 ( $150 \mathrm{e} / \mathrm{bit}$ ) Fri Jul 2 10:34:11 1993 Pixel Values Min 77 Max 80 Mean 78.8 Sigma $0.58 \times 10^{3}$

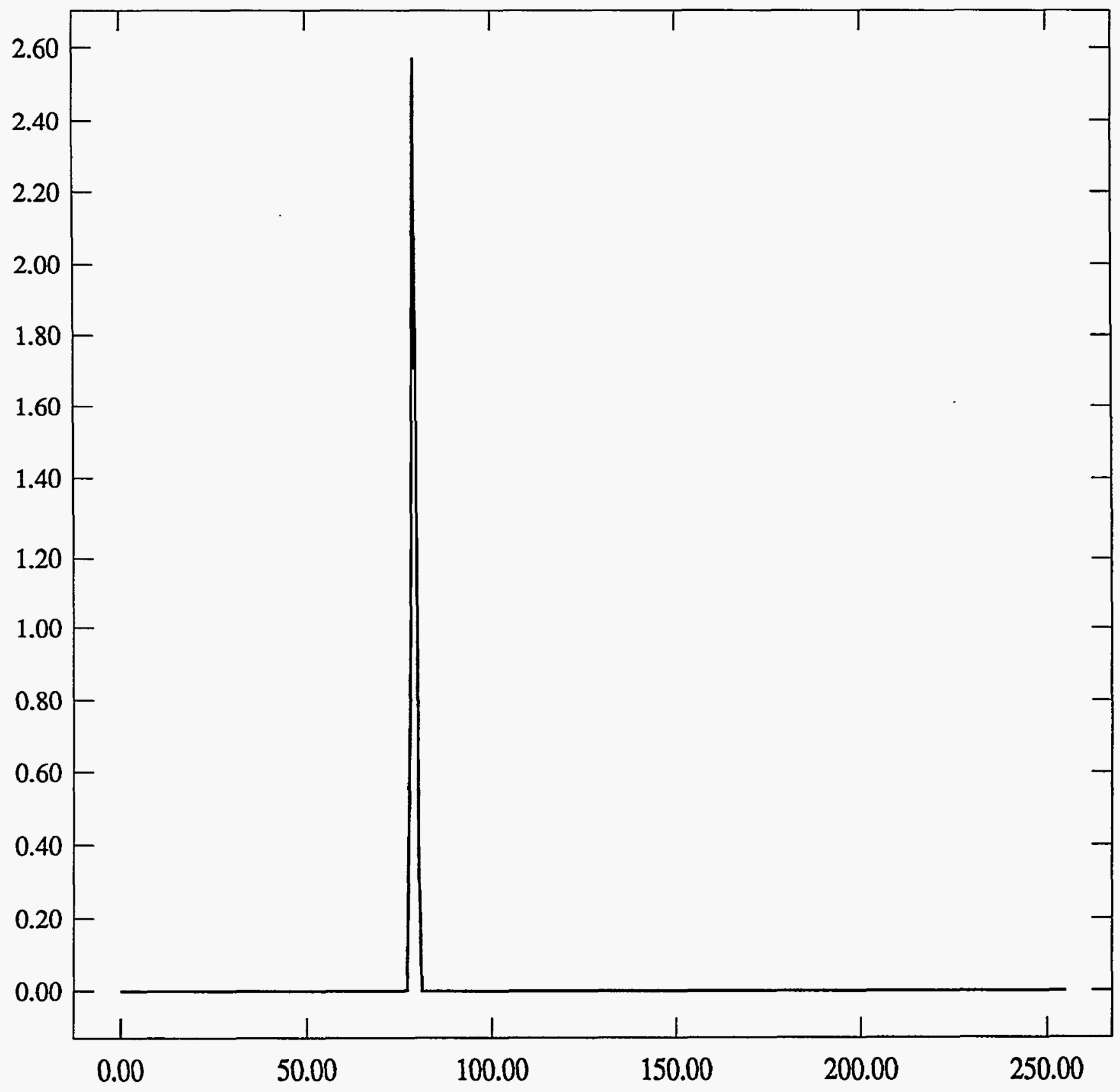


ST Camera: ST1\#4-10 -30C: int_time= 50ms, offset= 0, gain=4 ( 75 e/bit) Fri Jul 2 10:34:29 1993 Pixel Values Min 144 Max 148 Mean 146.2 Sigma $0.72 \times 10^{3}$

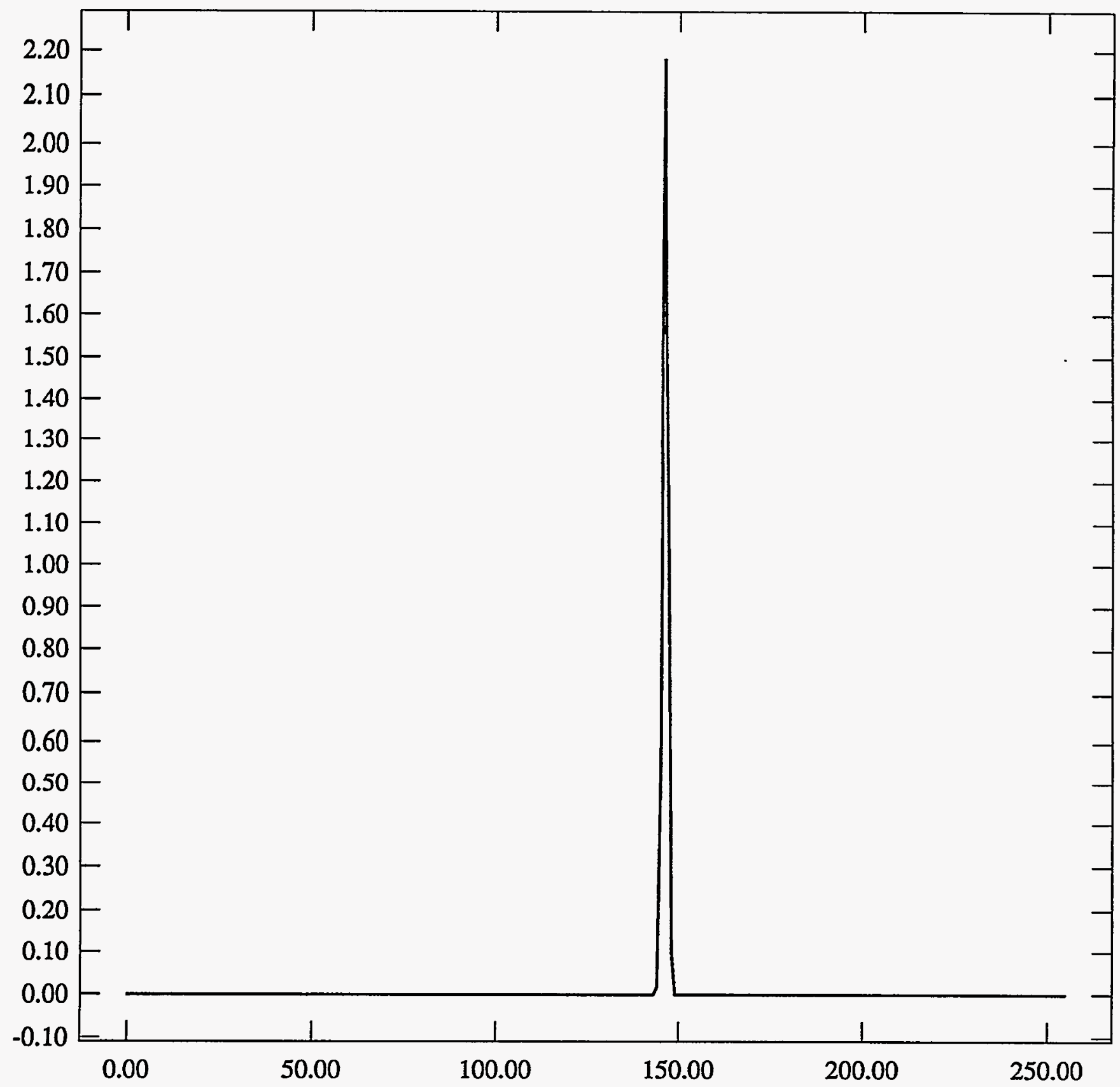


ST Camera: ST1\#4-10 -30C: int_time=100ms, offset= 0, gain=4 ( 75 e/bit) Fri Jul 2 10:34:42 1993

Pixel Values Min 143 Max 149 Mean 146.3 Sigma $0.72 \times 10^{3}$

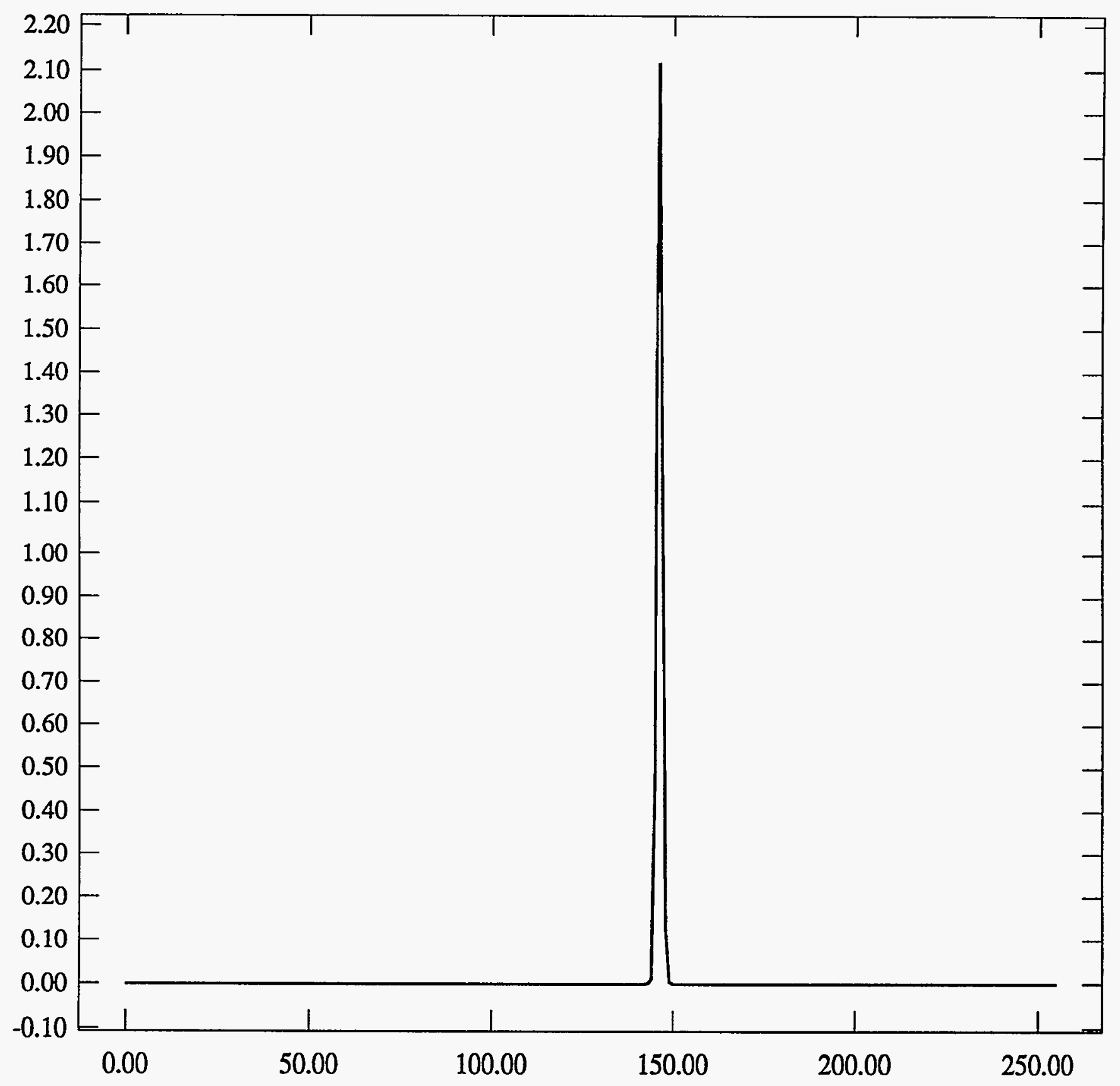


ST Camera: ST1\#4-10 -30C: int_time=200ms, offset= 0, gain=4 ( $75 \mathrm{e} /$ bit) Fri Jul 2 10:34:56 1993 Pixel Values Min 144 Max 149 Mean 146.3 Sigma $0.69 \times 10^{3}$

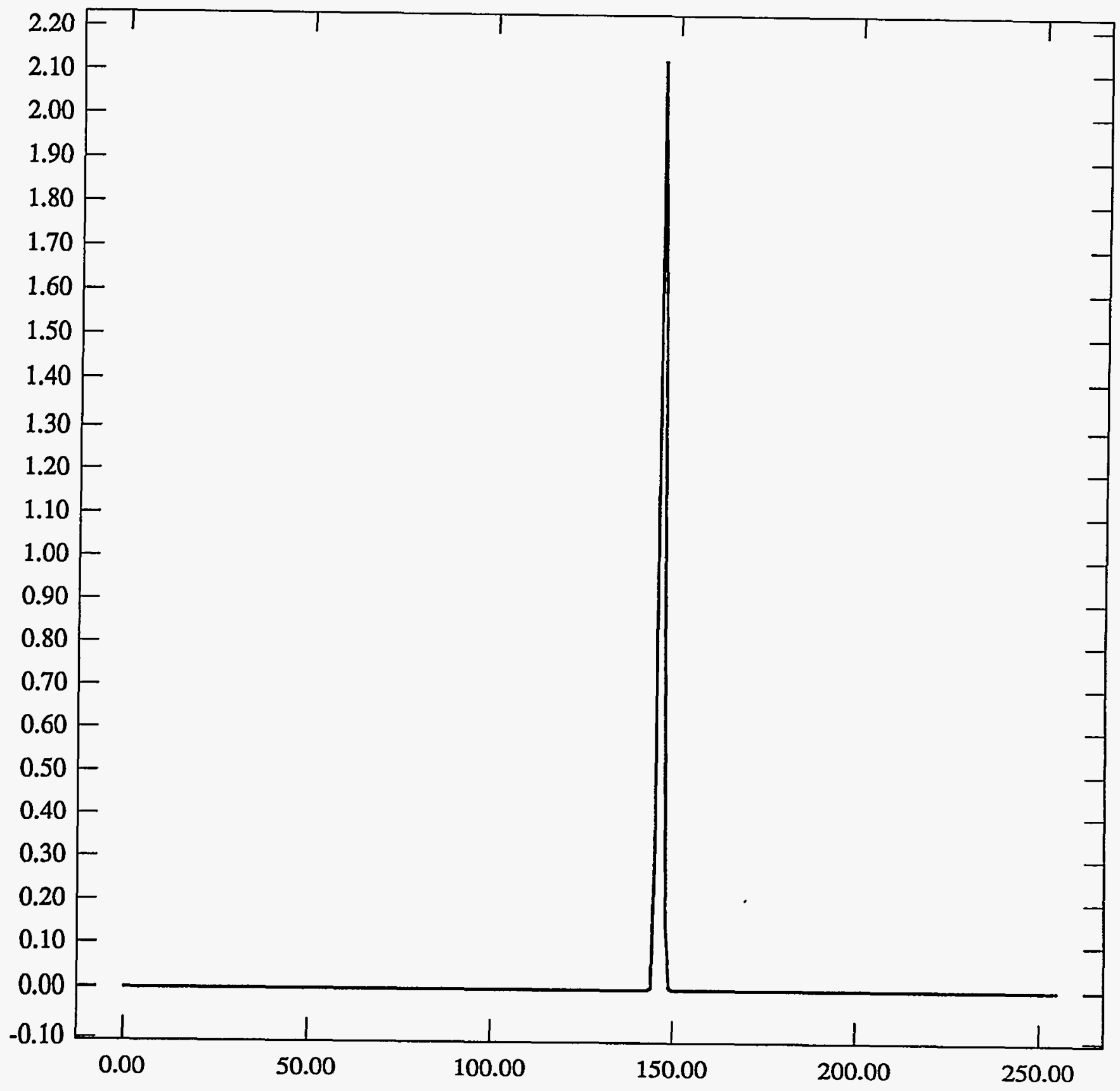


LNitxh TESF

ST Camera: ST1\#4-10htrtst: int_time= 50ms, offset= 0, gain=1 (350 e/bit) Fri Jul 2 09:50:09 1993

Pixel Values Min 41 Max 44 Mean 41.5 Sigma $0.50 \times 10^{3}$

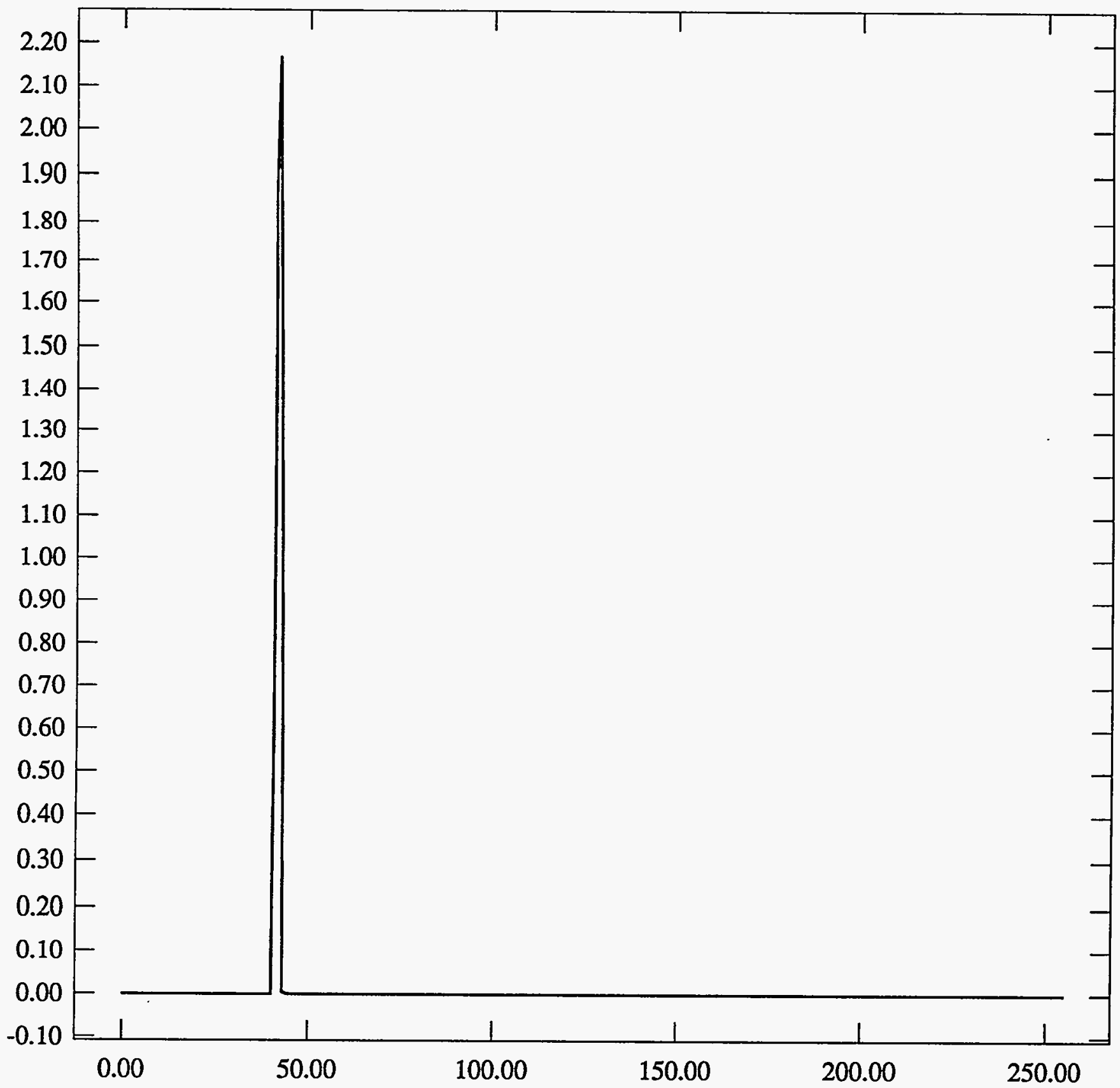


ST Camera: ST1\#4-10htrtst: int_time=100ms, offset= 0, gain=1 ( 350 e/bit) Fri Jul 2 09:50:22 1993 Pixel Values Min 43 Max 50 Mean 44.2 Sigma $0.40 \times 10^{3}$

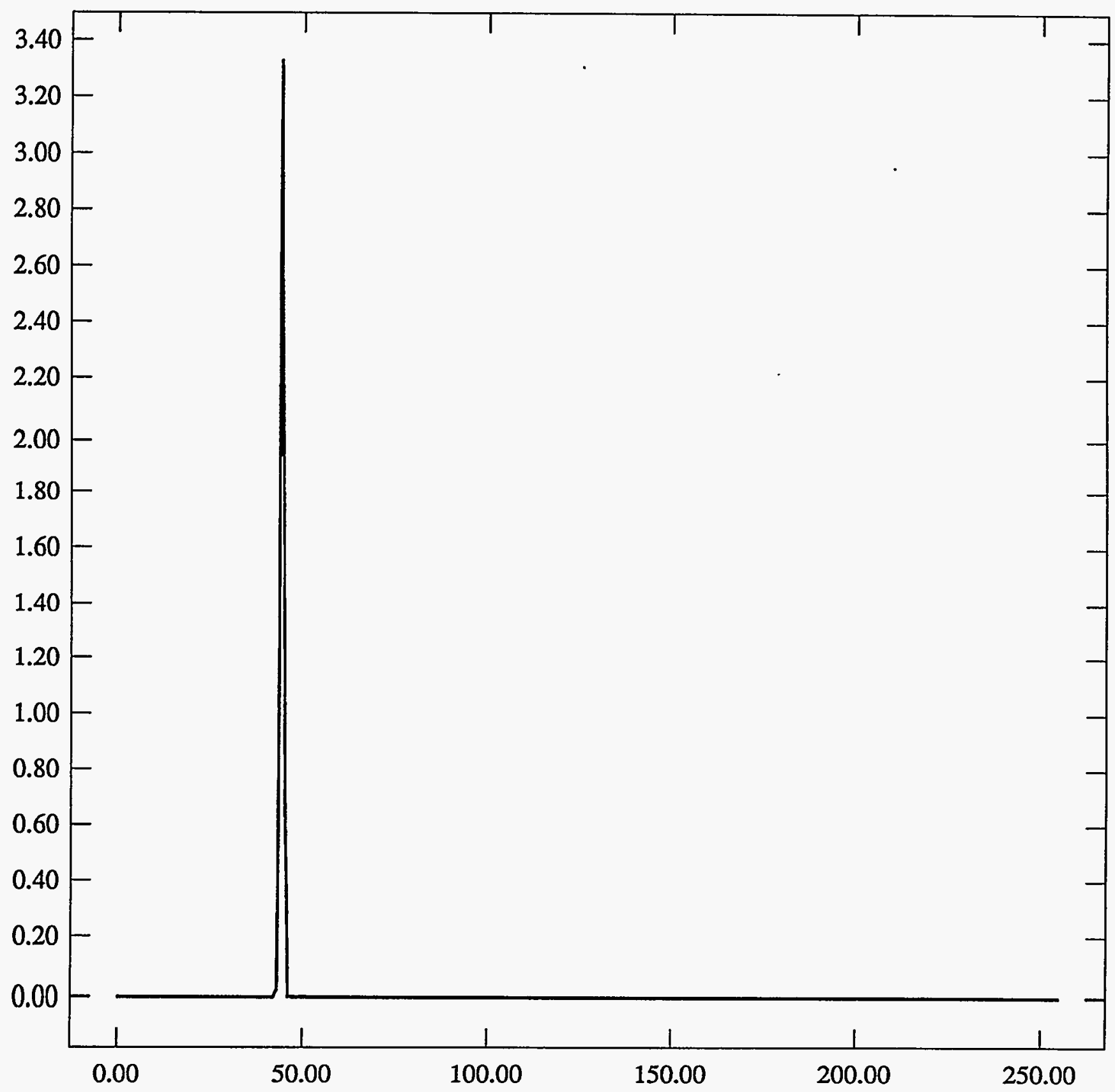


ST Camera: ST1\#4-10htrtst: int_time=200ms, offset= 0, gain=1 ( 350 e/bit) Fri Jul 2 09:50:33 1993

Pixel Values Min 49 Max 61 Mean 50.2 Sigma $0.61 \times 10^{3}$

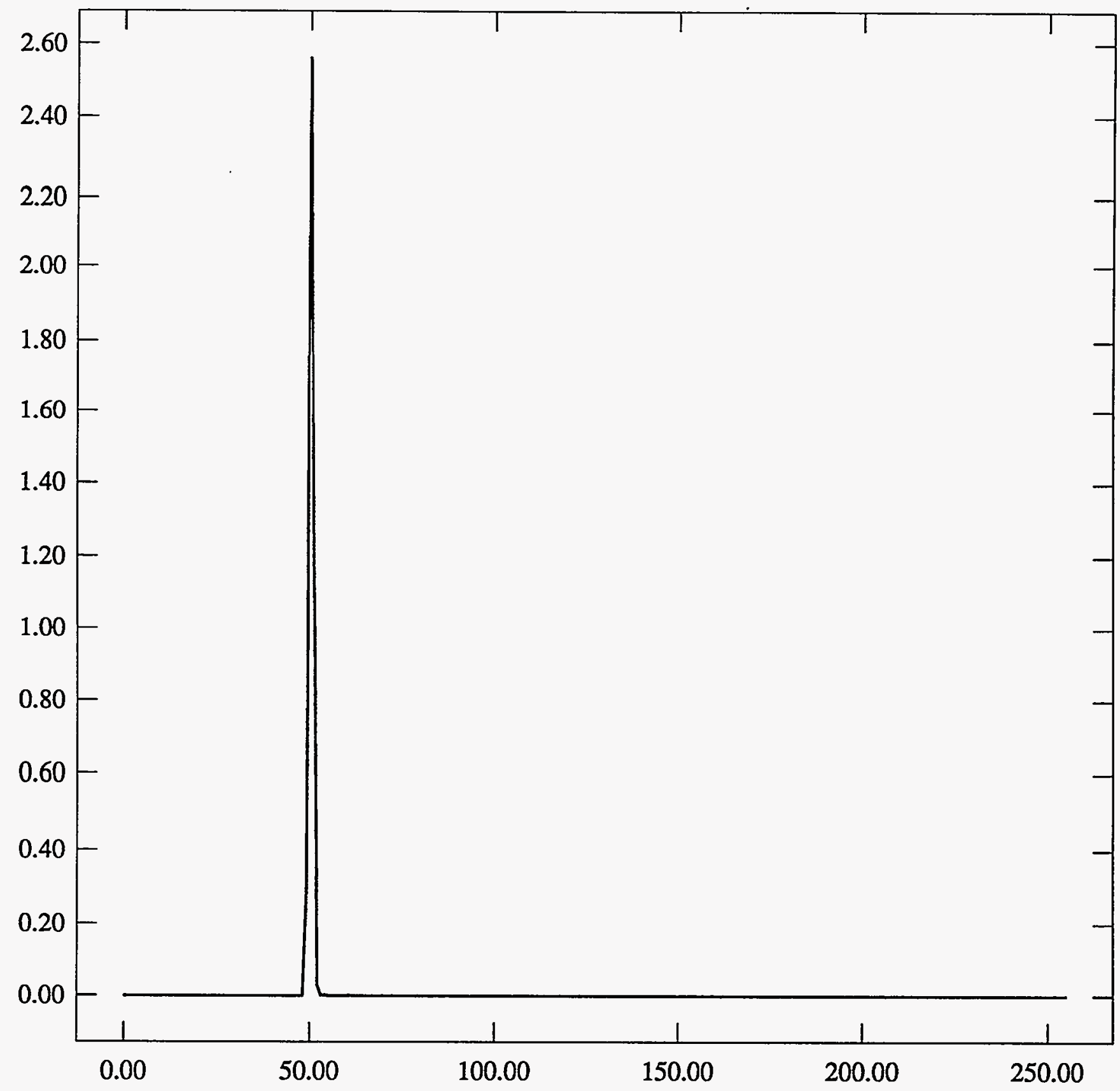


ST Camera: ST1\#4-10htrtst: int_time $=50 \mathrm{~ms}$, offset= 0, gain=2 (150 e/bit) Fri Jul 2 09:50:44 1993 Pixel Values Min 82 Max 89 Mean 84.1 Sigma $0.77 \times 10^{3}$

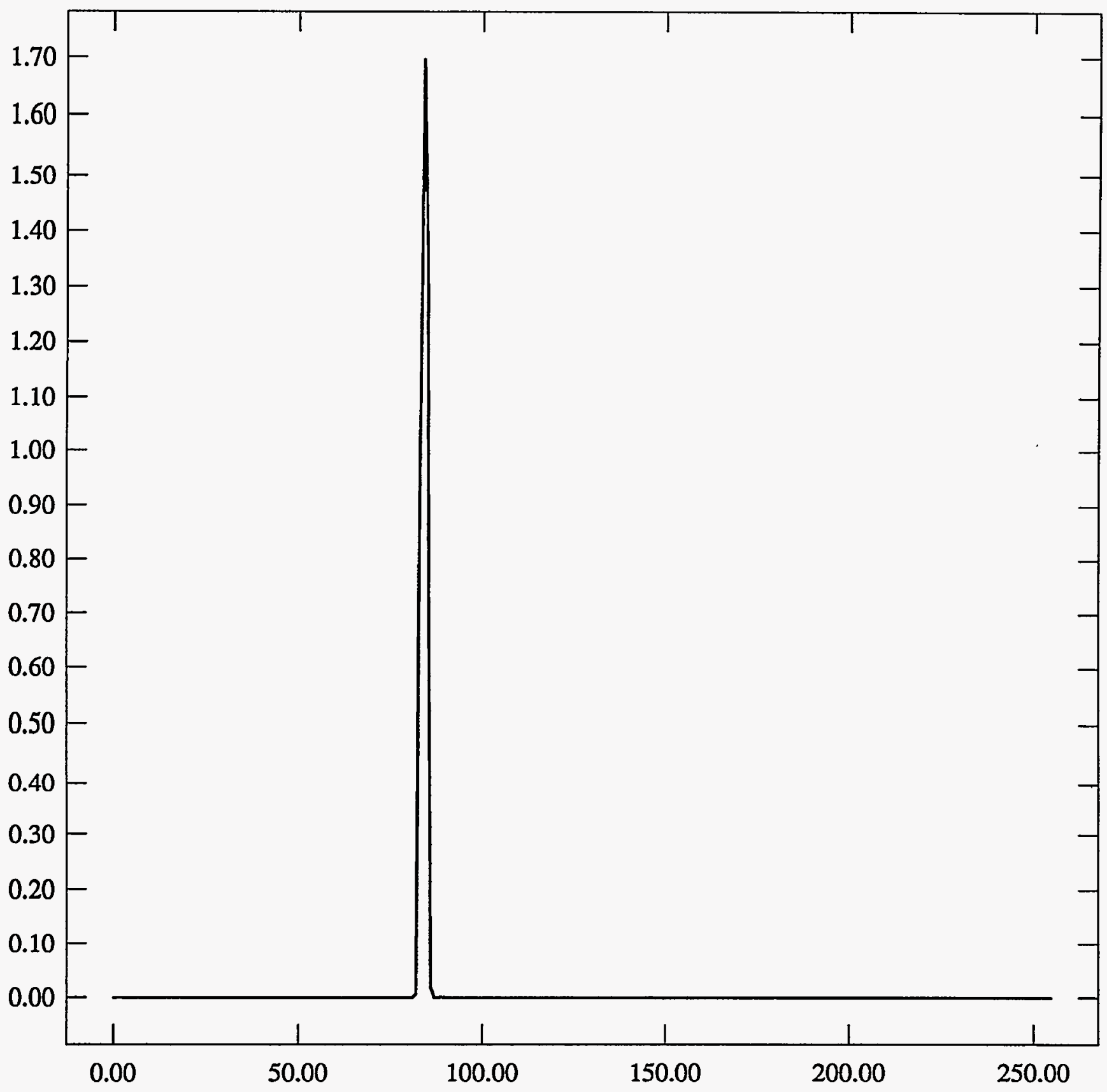


ST Camera: ST1\#4-10htrtst: int_time=100ms, offset= 0, gain=2 ( 150 e/bit) Fri Jul 2 09:50:57 1993 Pixel Values Min 88 Max 102 Mean 90.7 Sigma $0.86 \times 10^{3}$

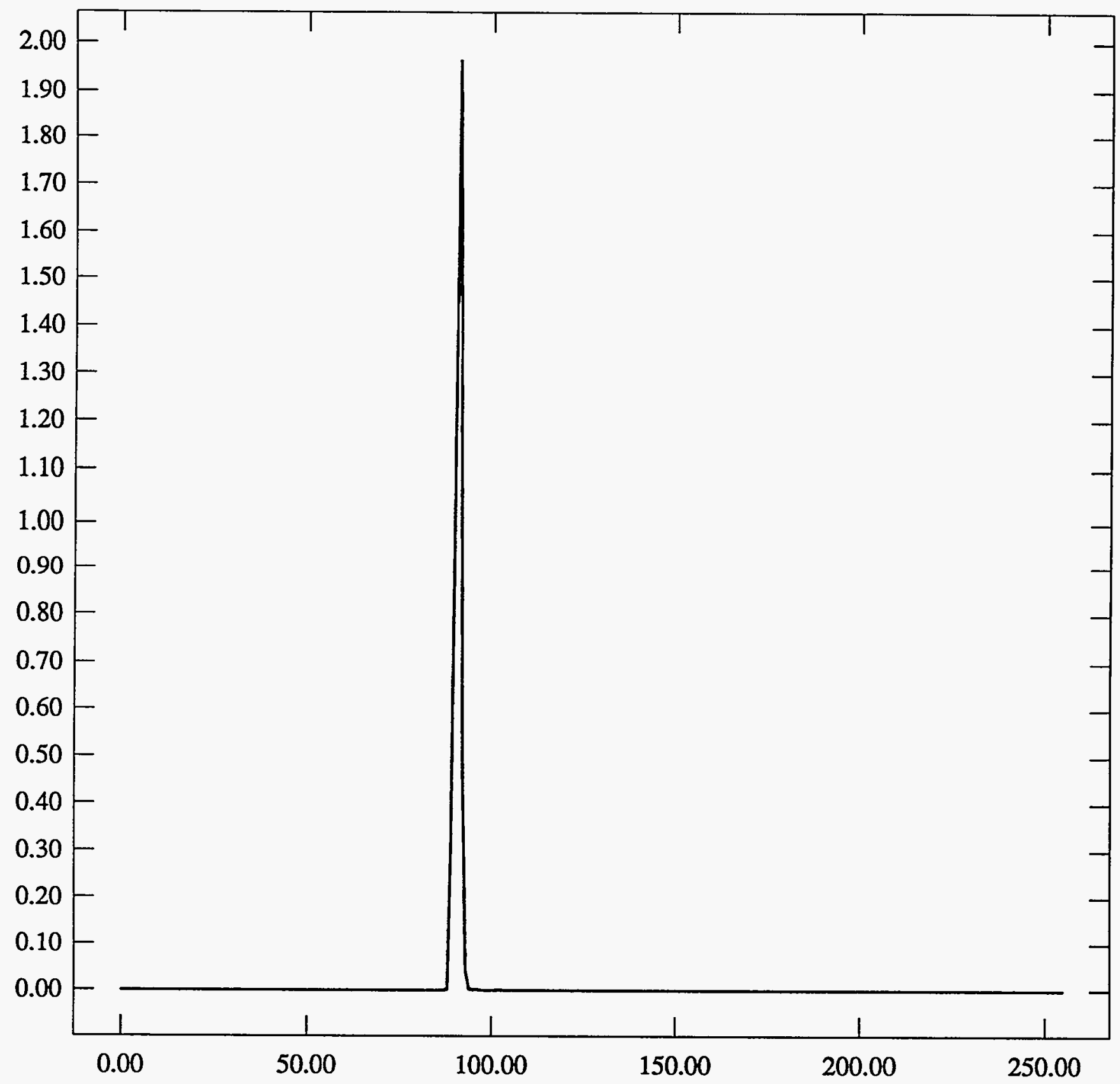


ST Camera: ST1\#4-10htrtst: int_time=200ms, offset= 0, gain=2 (150 e/bit) Fri Jul 209:51:09 1993

Pixel Values Min 101 Max 130 Mean 104.4 Sigma $1.38 \times 10^{3}$

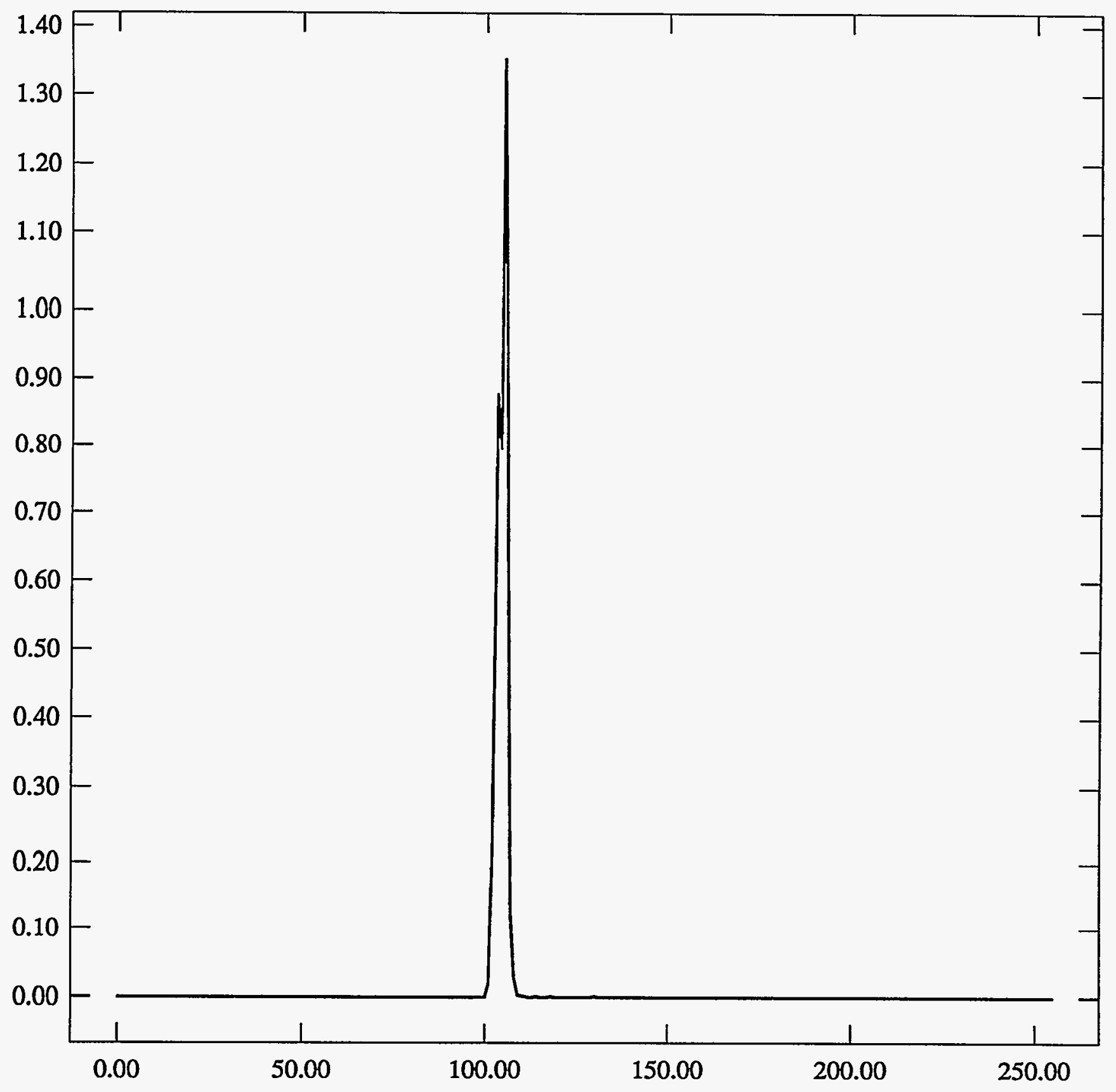


ST Camera: ST1\#4-10htrtst: int_time= 50ms, offset= 0, gain=4 ( 75 e/bit) Fri Jul 2 09:51:26 1993

Pixel Values Min 151 Max 165 Mean 155.0 Sigma $1.18 \times 10^{3}$

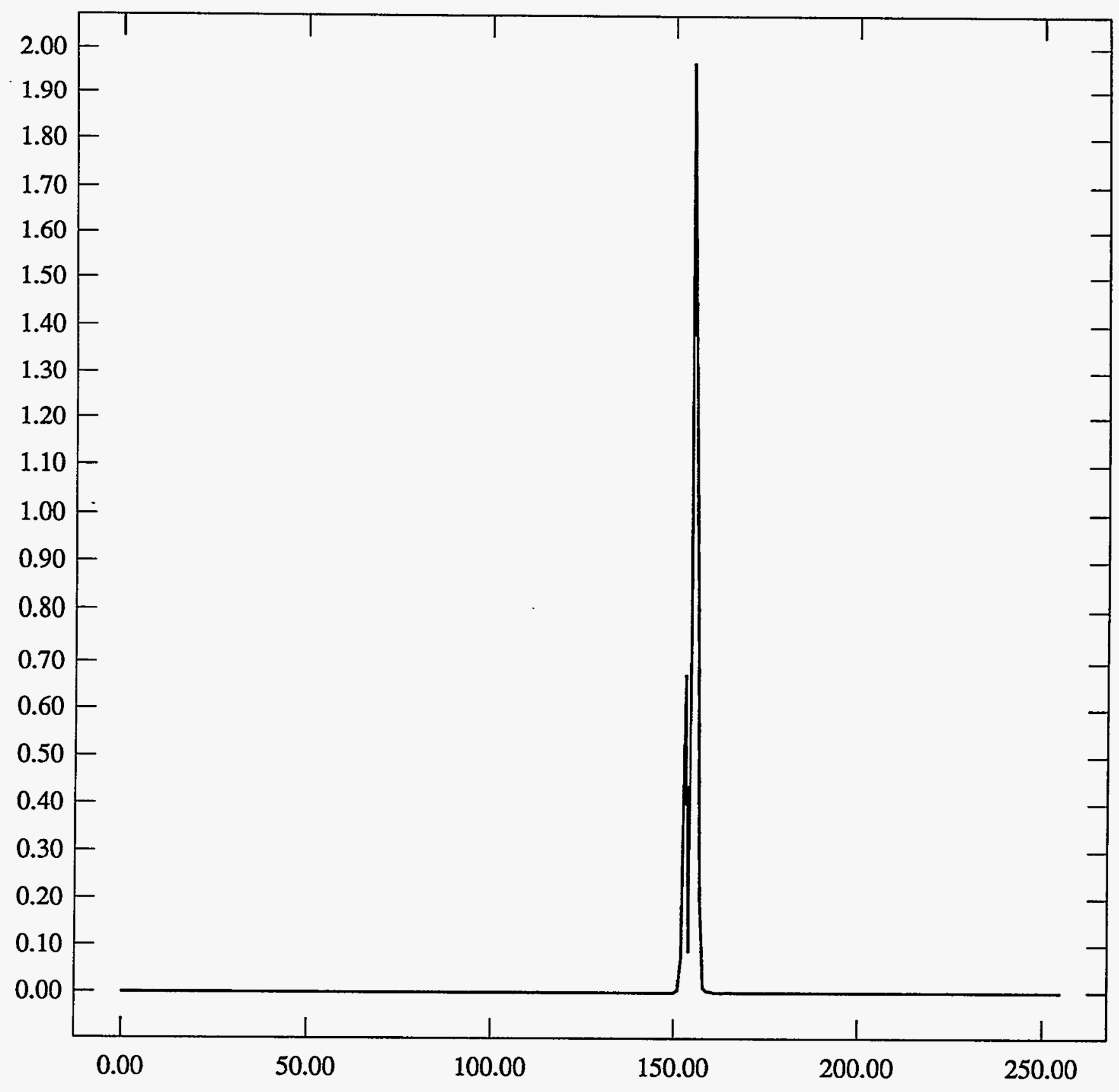


ST Camera: ST1\#4-10htrtst: int_time=100ms, offset= 0, gain=4 ( 75 e/bit) Fri Jul 2 09:51:42 1993 Pixel Values Min 163 Max 193 Mean 168.1 Sigma 1.50 x $10^{3}$

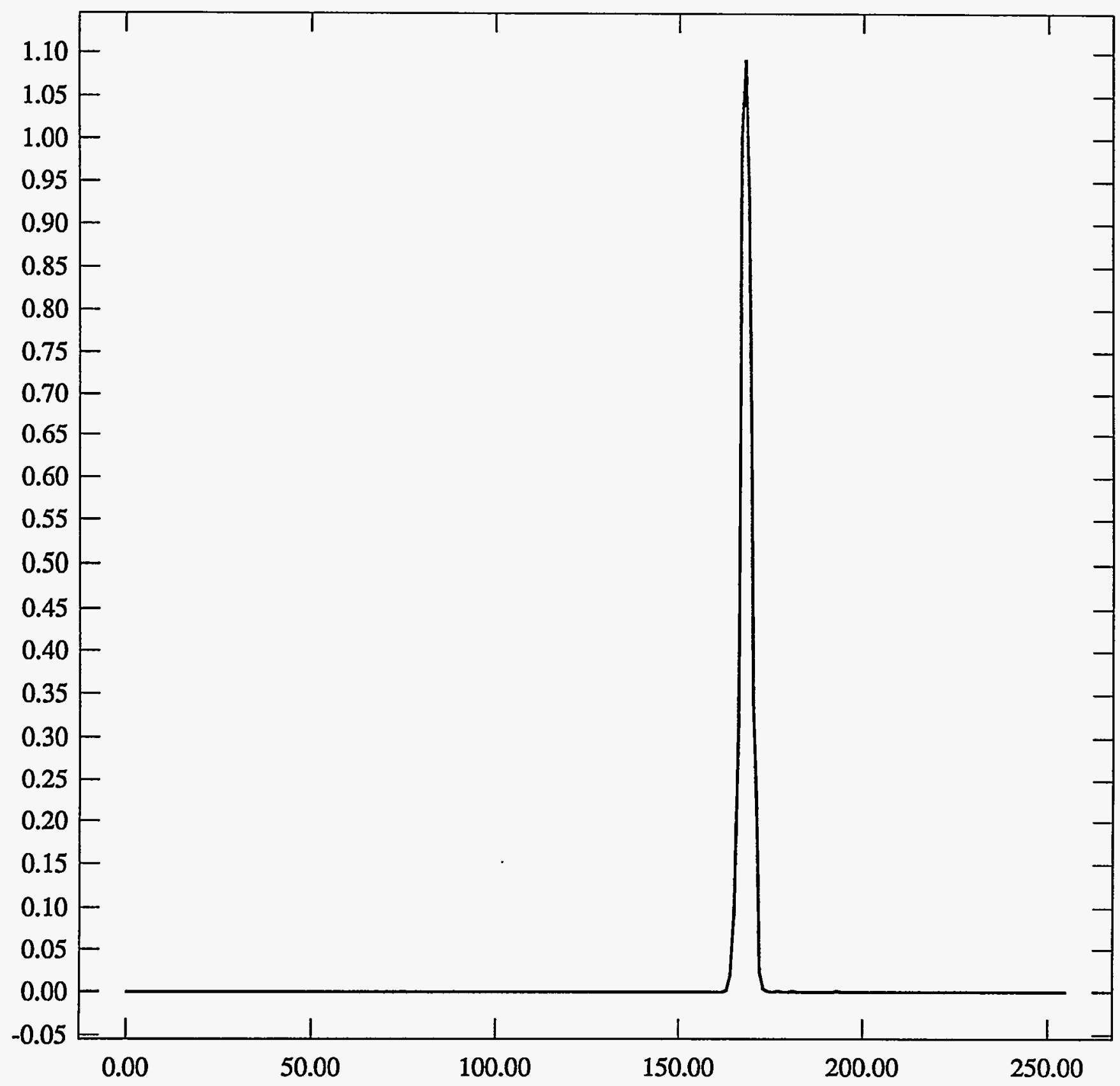


ST Camera: ST1\#4-10htrtst: int_time=200ms, offset= 0, gain=4 ( 75 e/bit) Fri Jul 2 09:51:58 1993 Pixel Values Min 187 Max 238 Mean 194.3 Sigma 2.62

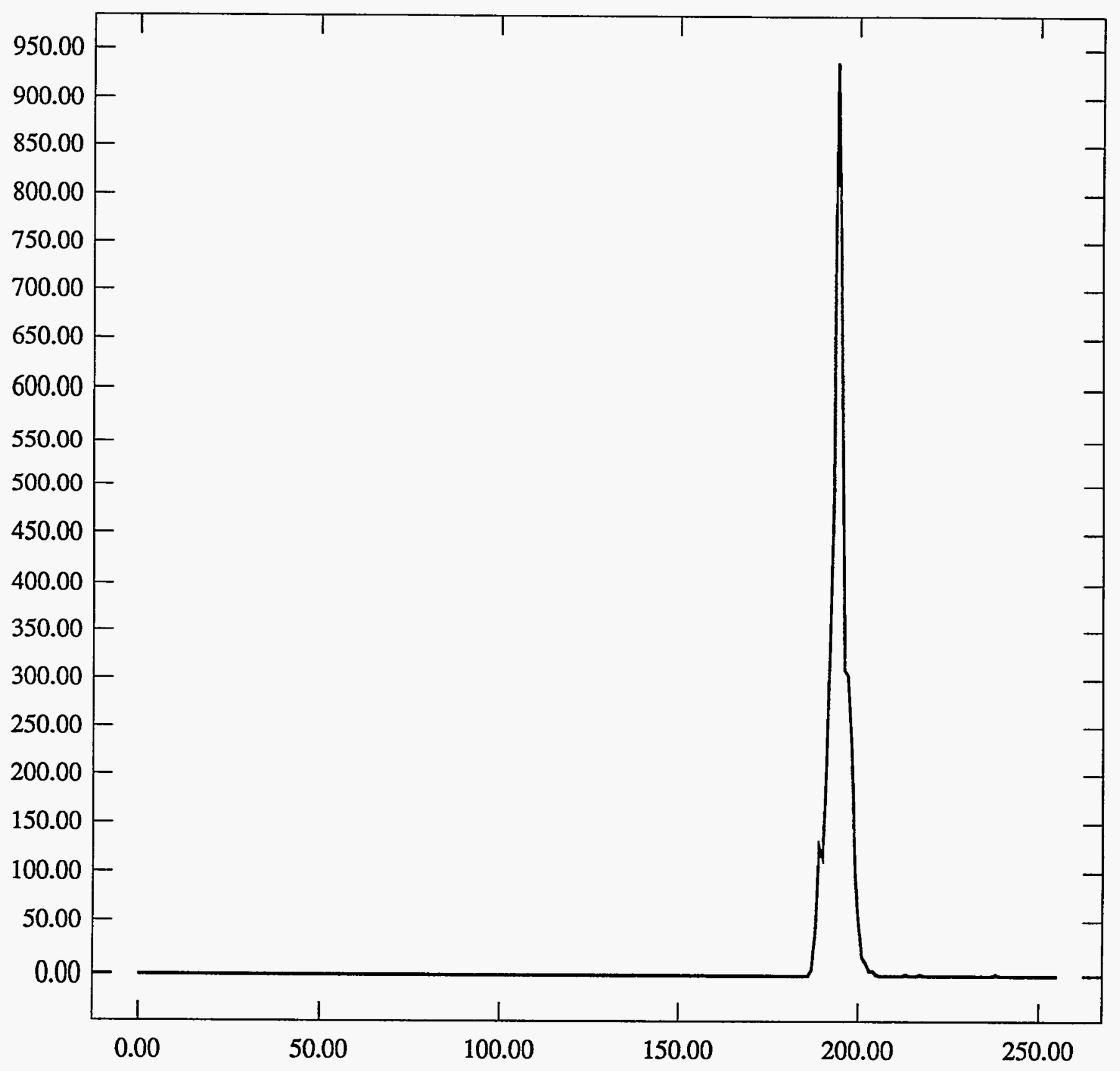




\section{Appendix I}

Miscellaneous 


\section{Appendix 1.1 \\ Clementine Sensor Test Acceptance Procedure for ST 313}




\section{Clementine}

\section{Sensor Test Acceptance Procedure}

Submit Comments to:

Robert F. Hills

Lawrence Livermore National Laboratory

510.423.7344 Office

hills1@llnl.gov EMAIL

\section{RECORD OF CHANGES}

\begin{tabular}{|l|l|l|c|}
\hline Revision Letter & Date & Title or Brief Description & Entered by \\
\hline Draft & 7 July 1993 & Working Draft & RFH \\
\hline Draft-A & 13 July 1993 & Modified to expand test procedure steps & RFH \\
\hline Draft-B & 15 July 1993 & Modified for corrections and additional steps & RFH \\
\hline Draft-C & 27 July & Modified for corrections and additional steps & RFH \\
\hline
\end{tabular}

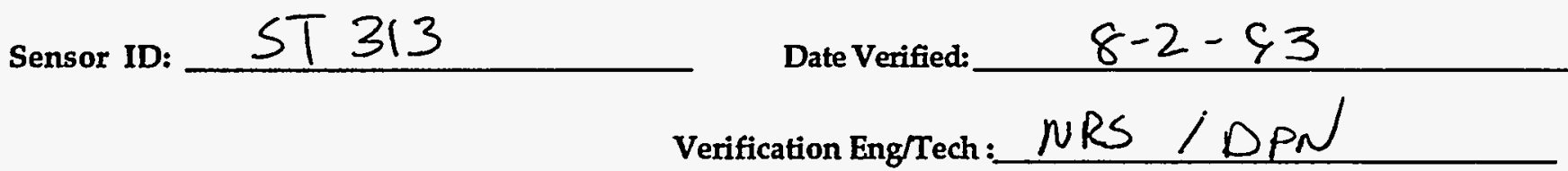


This Page intentionally left Blank 
1.1. Scope

This document is the LLNL Clementine sensor acceptance test procedure for the DSPSE spacecraft. It defines the optical, mechanical, thermal, electrical, and software tests necessary to verify the functionality of the sensors for the Clementine Sensor Integration Project at NRL

The subsystems associated with the sensor data acquisition verification process are shown in Figure 1.1.

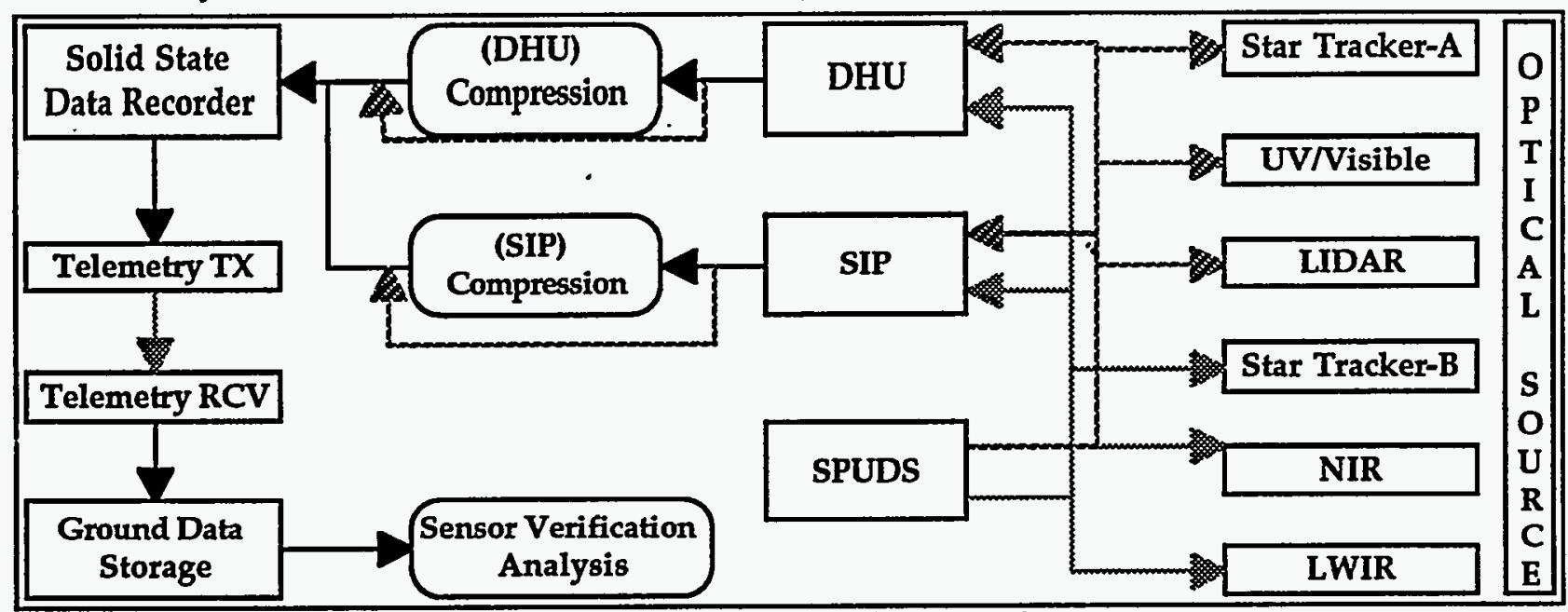

Figure 1.1 Sensor Test \& Verification Subsystems

LLNL will provide a Pre-Integration Sensor Acceptance Testing, verification, and a debug platform using interfaces which imitates the S/C interface. The LLNL Setup is shown in Figure 1.2

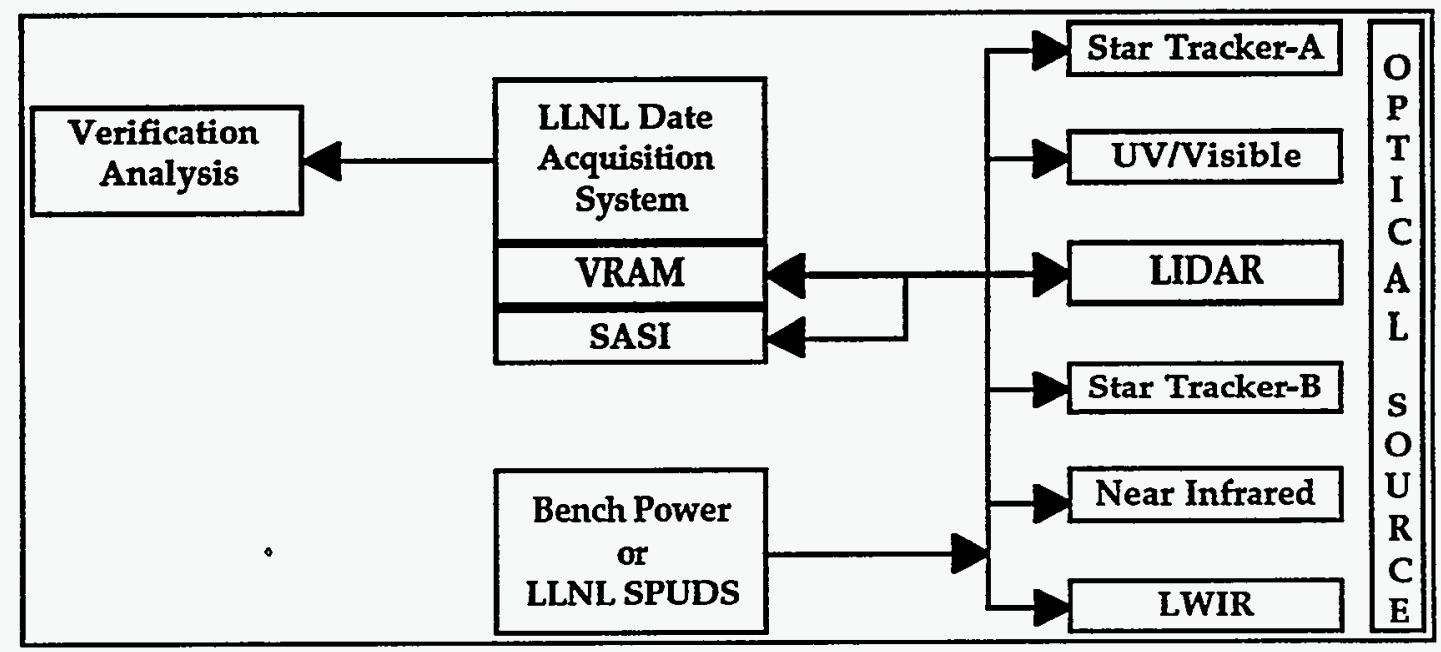

Figure 1,2 Pre-Spacecraft-Integration Sensor Verification Model 


\subsection{Verification Modes}

Two verification modes are defined for this verification plan. These are 1) Functional verification and 2) Performance Verification.

Functional verification is defined as an application of a test at nominal spacecraft conditions; i.e. voltages and ambient (room) temperatures. These environmental parameters must be maintained within the acceptable ranges for all components included in the test and are summarized below.

Performance verification is defined as an application of a test at the full range of space conditions; i.e. Max-min voltages and temperatures. These environmental parameters must be maintained within the acceptable ranges for all components included in the test and are summarized below.

Each verification test in this plan will include the operational parameters (for temperature, voltages, etc.) that are necessary for the above listed verification modes.

\subsubsection{Verification Tests}

The followings tests will be performed on each sensor:

- Sensor Physical Examination (LLNL)

- Filter Positioner (LLNL)

- Electrical Wave-form (LLNL)

- SASI Command Set (LLNL)

- Dark Field (LLNL)

- Image Field Analysis (LLNL)

- Flat Field (LLNL)

The Naval Research Laboratory will need to provide the additional tests listed below to complete the test suite for the sensors at NRL.

- Radiometric Sensitivity (NRL)

- Point Spread Function (NRL)

- SIP-DHU-Sensor Interface (NRL)

- Sensor Timeout (NRL)

- Image Compression/Decompression (NRL)

- Boresight Alignment (NRL)

- Sensor Data Telemetry (NRL)

- Sensor Software Algorithms (NRL)

Each of the procedures allows a comparison to the calibrations performed at LLNL. A comparison of the results of the sensor verification tests and the LLNL calibrations will be made. 


\subsection{Documents}

\subsubsection{LLNL Documents}

Interface Control Documents

\begin{tabular}{|ll|}
\hline C1-S4-008 & LIDAR High Resolution Camera/Range Receiver \\
C1-S4-011 & LIDAR Laser Transmitter Assembly \\
C1-S2-008 & UV/Visible Camera \\
C1-S1-010 & Star Tracker Camera \\
C1-S3-008 & Near Infrared Camera \\
C1-S3A-006 & Long wave Infrared Camera \\
\hline & Performance Specifications \\
\hline TBD & LIDAR High Resolution Camera/Range Receiver \\
TBD & LIDAR Laser Transmitter Assembly \\
TBD & UV/Visible Camera \\
TBD & Star Tracker Camera \\
TBD & Near Infrared Camera \\
TBD & Long wave Infrared Camera \\
\hline
\end{tabular}

\subsection{Environments \& Handling Procedures}

\subsubsection{Anti Static Environment}

The sensors are electrostatic sensitive devices and will be handled in a manner so as to prevent damage due to static charge. This will include the grounding of the operator (grounded wrist band), camera, working surface, and conductive floor mats to a common point. The sensors will be sealed in a anti-static bag before leaving the anti-static environment and will be packed in its aluminum case when being transported.

\subsubsection{Contamination}

All sensors must be maintained within a contamination environment specified in their ICD's. The Sensor usage and environment must be logged in order to maintain the proper level of contamination prior to flight. Analysis of exposure levels and usage will be periodically verified.

To prevent dust from accumulating on the optics, a mask and lint-free gloves shall be worn when in close proximity to the uncovered sensor. The sensor lens and baffle shall be covered at all times when the camera is not in use.

\subsubsection{Temperature}

Temperature limitations placed upon the sensors are in terms of the Base Plate temperature, CCD temperature and the lens temperature. The base plate temperature limits are specified to protect the electronic and mechanical parts from thermal damage. The CCD temperature limits are primarily concerned with achieving required $C C D$ performance. The lens temperature limits are concerned with the performance of the STC optics and the protecting them from thermal damage. The various - . temperature limits are described below:

1- Operational-In-Spec - This is the temperature range which is required in order to achieve sensor performance requirements.

Sensor Verification Test Procedure

Draft-C: August 2, 1993 
2- Operation-Out-Spec - This is the temperature range which is required in order to prevent damage to the sensor while maintaining a functional state. Damage and/or a reduction in reliability can occur to a sensor because the electronic junction temperatures are outside operating limits. This temperature limit will prevent the worst case electronic component from exceeding its maximum, derated, junction temperature. Maximum junction temperatures are derated according to thermal design and reliability requirements.

During all tests the CCD, base plate, and where appropriate, lens temperatures must be monitored on a continuous basis. If the node temperature exceeds the specifications listed in the sensor ICD, then the test must be terminated until all temperature conditions return with the specified limits.

Table x.x.x Sensor temperature range Summairy

\begin{tabular}{|c|c|c|c|c|c|c|c|c|c|c|c|c|c|c|}
\hline Requirements $\left({ }^{\circ} \mathrm{C}\right)$ & \multicolumn{2}{|c|}{ StarTracker } & \multicolumn{2}{|c|}{ UV-VIS } & \multicolumn{2}{|c|}{ NIR } & \multicolumn{2}{|c|}{ LWIR } & \multicolumn{2}{|c|}{ HiRes } & \multicolumn{2}{|c|}{ Laser } & \multicolumn{2}{|c|}{ Suite } \\
\hline & Min & Max & Min & $\operatorname{Max}$ & Min & Max & Min & $\operatorname{Max}$ & Min & Max & Min & $\operatorname{Max}$ & Min & Max \\
\hline Base Plate: & & & & & & & & & & & & & & \\
\hline Operational In-Spec & -20 & 2 & -20 & 2 & & & & & & & & & -20 & 2 \\
\hline Operational Out-Spec & -20 & 10 & -20 & 25 & & & & & & & & & -20 & 10 \\
\hline Non-Operating & -40 & 70 & -35 & 50 & & & & & & & & & -35 & 50 \\
\hline CCD: & & & & & & & & & & & & & & \\
\hline Operational In-Spec & -20 & 10 & -20 & 10 & & & & & & & & & -20 & 10 \\
\hline Operational Out-Spec & -20 & 60 & -20 & 25 & & & & & & & & & -20 & 25 \\
\hline Non-Operating & -40 & 85 & -40 & 50 & & & & & & & & & -40 & 50 \\
\hline Lens: & & & & & & & & & & & & & & \\
\hline Operational In-Spec & -20 & 40 & -20 & 40 & & & & & & & & & -20 & 40 \\
\hline Operational Out-Spec & -30 & 70 & -30 & 50 & & & & & & & & & -30 & 50 \\
\hline Non-Operating & -30 & 70 & -30 & 50 & & & & & & & & & -30 & 50 \\
\hline
\end{tabular}

\subsubsection{Humidity}

The environment in which the tests are to take place shall be maintained at a relative humidity between 40 and $70 \%$. At no time shall condensation occur. 
Operator: DPN/LR\&_ Date: $x-2-93$

2.1. Applicable Sensors:

StarTracker 313

प Laser Transmitter

$$
\text { 口UV-VSS }
$$

QNIR

2.2. Data Storage Locations:

$\begin{array}{ll}\text { Images: } & \text { NONE } \\ \text { Temp: } & \text { NONE }\end{array}$

\subsection{Purpose:}

Upon arrival of each sensor at NRL, a physical examination will be performed to check for any damage that may have occurred during shipping. This will include verification of the serial number and a visual check of the structure, optics, baffles, and all connectors.

\subsection{Test Environment \& Procedure}

(1) Verify that the sensor Certification Log has an exposure log in the front of the book, and that it has been started.

Verify that the sensor Certification Log has work sheets to log all sensor activities and has been started.

(7) Unpack the sensor using the "Sensor Activity Log Sheet LLNL-SALO024 (Enter Number here) , "Preparation \& Grounding" section. Note on the LLNL-SAL that other sections are skipped due to the nature of the verification test.

Log the execution of the "LLNL Physical Examination Test" in the sensor certification log.

Log or verify the following:

$\longrightarrow$ Verify that the sensor has the proper sensor identification and LLNL property tag.

Verify that Sensor shorting plugs are present.

a Verify the presence of connector savers on all sensor connectors.

0 Verify that the sensor has a baffle cover and that it is labeled to its sensor

№te any loose screws, broken staking, or other physical damage.

8 Note the condition of the optics and any contamination found.

Verify that the sensor has flying leads for the lens temperature, and lens heater and that ther is no apparent damage. 
- Store the sensor using the "Sensor Activity Log Sheet (LLNL-SAL), "Securing the Sensor" section.

When the test is successfully completed, Update the LLNL Sensor Acceptance Testing Summary Sheet.

\subsection{Performance Analysis \& Reporting Criterion}

No post processed data reduction is necessary for this test. The report shall contain a detailed description of the results of the examination steps outlined in the test procedure. 
Operator: $D P(1)$ Date: $8-2-93$

3.1. Applicable Sensors:

HtarTracker 313

$\square$ Laser Transmitter

QUV-VIS

口NIR a HiRes

口LWIR

\subsection{Data Storage Locations:}

Images: $\quad$ NONE

Data: $\quad$ /dspse/<Sensor $>/$ filterPos/date/<sensorname.filtertest $>$

Temp: $\quad /$ dspse/<Sensor $>/$ filterPos/date/temperature_log_data

\subsection{Purpose:}

Verify the step operation and position status of the sensor's filter wheel.

\subsection{Test Environment \& Procedure}

Unpack the sensor using the "Sensor Activity Log Sheet (LLNL-SAL)

- At Power-On, Start the Fluke Temperature Data Logger bu pushing the "Start Log" button on the Macintosh interface. Save the file as: <sensorID> - LLNL-SAL-xxxxx.temp.

Example: UV311-LLNL-SAL-0016.temp

- Log the execution of the "LLNL Filter Positioner Test" in the sensor certification log.

Step, settle and read the filter on the sensor using the filter position driver software "filterStepTest" for 1000 revolutions of the filter wheel.

When testing has been completed, turn the power to the sensor off and close the temperature data log file on the macintosh.

The software will verify that the filterwheel stops at the correct position each time by comparing the SASI command expected position (software state machine) and the position obtained by sending a SASI request for filter position command.

Note Any exceptions in the test

Store the sensor using/completing the "Sensor Activity Log Sheet (LLNL-SAL)

When the test is successfully completed, Update the LLNL Sensor Acceptance Testing Summary Sheet. 


\subsection{Performance Analysis \& Reporting Criterion}

Note any software exeception that were generated (due to mis synchronization of the software state machine and the physical hardware).

Plot temperature vs time of the sensor $C C D$, and baseplate starting at power-on, notated with room temperature. 
Operator:

Date:

4.1. Applicable Sensors

HstarTracker 313

口 Laser Transmitter

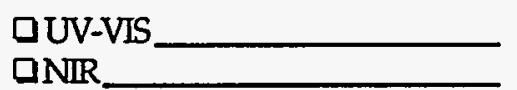

口HiRes QLWIR

4.2. Data Storage Locations

Ifrages:-

Temp :

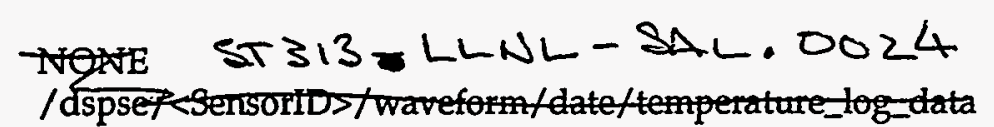

4.3. Purpose

Verify the sensor logical waveform tranisitions, timings, switching characteristics in a single [OPTIONAL: or multiple] sensor bus environment.

Verify that the sensor powers up with its bus drivers tri-stated.

\subsection{Test Environment \& Procedure}

(1) Unpack the sensor using the "Sensor Activity Log Sheet (LLNL-SAL)

(1) At Power-On, Start the Fluke Temperature Data Logger bu pushing the "Start Log" button on the Macintosh interface. Save the file as: <sensorID> -'LLNL-SAL-xxxxx.temp. Example: UV311-LLNL-SAL-0016.temp cosh

1. Log the execution of the "LLNL Electrical Waveform Test" in the sensor certification log.

9 Run this test at ambient conditions, monitor and logging temperature profiles of the CCD and baseplate temperature.

Use the Lecroy Oscilloscope and set the following Parameters.

QLecroy Function E: is ON and set to Math function: (Channel1 - Channel2) Place the raw data differential output (channel1) on the top of the screen, and the (Channel1 channel2) subtraction on the bottom of the screen.

$\$$ Calibrate the probes to a flat response on the Scope calbiration point. Then Remove any bias from the probes for the channel-1 - Channel 2) subtraction function.

Run the program "tv" on the Sun system. 
Using an integration time of $100 \mathrm{~ms}$ obtain plots of each of the following differential driver outputs at the MDM-51 Breakout Box:

\begin{tabular}{|c|c|c|c|c|c|}
\hline Signal & $\begin{array}{l}\text { MDM-51 } \\
\text { DiffSig Pin\# }\end{array}$ & $\begin{array}{l}\text { MDM-51 } \\
\text { DiffSig.N Pin\# }\end{array}$ & We & Time /Div & Volage/Div \\
\hline \$ Hsync & 12 & 11 & 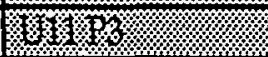 & $20 \mu \mathrm{Sec}$ & 5.0 \\
\hline Vsync & 4 & 28 & W & $10 \mathrm{mSec}$ & 5.0 \\
\hline Pixclk & 18 & 35 & J & $50 \mathrm{nSec}$ & 5.0 \\
\hline Dopixval & 10 & 27 & 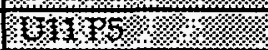 & $50 \mu \mathrm{Sec}$ & 5.0 \\
\hline बDO & 17 & 34 & 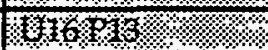 & $500 \mathrm{nSec}$ & 5.0 \\
\hline$\overline{x D 1}$ & 50 & 33 & 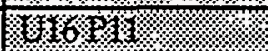 & $500 \mathrm{nSec}$ & 5.0 \\
\hline ब D2 & 16 & 15 & 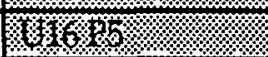 & $500 \mathrm{nSec}$ & 5.0 \\
\hline 80 & 49 & 32 & 46630 & $500 \mathrm{nSec}$ & 5.0 \\
\hline D4 & 14 & 31 & 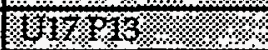 & $500 \mathrm{nSec}$ & 5.0 \\
\hline वD5 & 48 & 47 & (1) & $500 \mathrm{nSec}$ & 5.0 \\
\hline क्षA6 & 13 & 30 & 6795 & $500 \mathrm{nSec}$ & 5.0 \\
\hline 月7 & 46 & 29 & 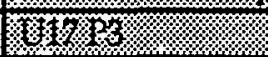 & $500 \mathrm{nSec}$ & 5.0 \\
\hline क्रCmdClk & 9 & 26 & F $2 \% 1 \%$ & $10 \mu \mathrm{Sec}$ & 5.0 \\
\hline CmdStat & 42 & 25 & 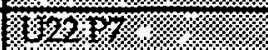 & $5 \mu \mathrm{Sec}$ & 5.0 \\
\hline CmdDat & 43 & 44 & 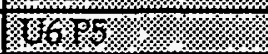 & $10 \mu \mathrm{Sec}$ & 5.0 \\
\hline
\end{tabular}

MDM-51 Pin \#20 is Ground for the Differential Signals

Vram Pins: U11-XX and U17-YY are grounds for the single Ended Signals.

\& Verify log and plot the the Pixel Clock Rate.

Pixel Clock Rate: $5 \mathrm{~m} / \mathrm{z}$

Terify, log and plot the line time for the sensor based on the High-State of Pixval.

Line Time:

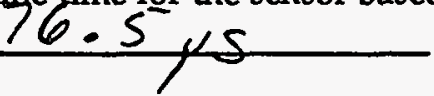

6 Verify, log and plot the interline time for the sensor based on the Low-state of Pixval.

Interline Time:

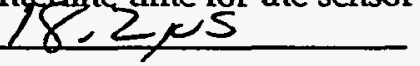

A Verify log and plot the Imge Frame Readout Time based on the High-State of Vsync.

Frame Time: $54.7 \mathrm{~ms}$

For an integration time of:

XStarTracker :100mSec

Nir: $100 \mathrm{mSec}$

$\square$ HiRes : $100 \mathrm{mSec}$

UV-VIS : $100 \mathrm{mSec}$

Generate a detailed logic timing diagram (using the HP Data Analyzer)

Beginning of the Frame Transfer

$\Delta$ End-Of-Frame Transfer

Q Sasi Command Transaction, showing CMDCLK, CMDSTAT, CMDDAT

(Q) When testing has been completed, turn the power to the sensor off and close the temperature data $\log$ file on the macintosh. 
Note Any exceptions in the test

Store the sensor using/completing the "Sensor Activity Log Sheet (LLNL-SAL)

When the test is successfully completed, Update the LLNL Sensor Acceptance Testing Summary Sheet.

\subsection{Performance Analysis \& Reporting Criterion}

Plot both Logic Timing Transitions, and Waveform Transitions for the Data acquired in the test procedure.

Verify that the both the timing and Waveform Transitions meet ICD specifications.

Plot temperature vs time of the sensor $C C D$, and baseplate starting at power-on, notated with room temperature. 
This page intentionally left blank 
Operator:

Date:

5.1. Applicable Sensors:

口StarTracker

QUV-VIS

DHiRes

$\square$ Laser Transmitter

$\square \mathrm{NIR}$

口LWIR

5.2. Data Storage Locations:

Images: $\quad$ NONE

Temp: $\quad$ /dspse/ $\quad<$ Sensor $>/$ sasiCmd/date/temperature_log_data

5.3. Purpose:

Test the sensors parameter memory against valid and invalid SASI commands. This test will use computer software to run through all the possible permutations of SASI commands, and verify that the parameter memory state is properly modified by proper SASI commands, and not modified by illegal commands.

The Test will also ensure that a sensor will not come on the bus if an illegal command is sent while the sensor's drivers are tri-stated.

5.4. Test Environment \& Procedure

a Unpack the sensor using the "Sensor Activity Log Sheet (LLNL-SAL)

Log the execution of the "LLNL Physical Examination Test" in the sensor certification log.

Use a class 1000 or better environment if possible.

- At Power-On, Start the Fluke Temperature Data Logger bu pushing the "Start Log" button on the Macintosh interface. Save the file as: <sensorID> - LLNL-SAL-xxxxx.temp.

Example: UV311-LLNL-SAL-0016.temp

When testing has been completed, turn the power to the sensor off and close the temperature data $\log$ file on the macintosh.

․ Store the sensor using/completing the "Sensor Activity Log Sheet (LLNL-SAL)

Use aclass 1000 or better environment if possible.

W When the test is successfully completed, Update the LLNL Sensor Acceptance Testing Summary Sheet.

Note Any exceptions in the test 


\subsection{Performance Analysis \& Reporting Criterion}

Sofware should report the status of both good and bad SASI commands, reporting any anomolies that were generated while testing all possible data inputs to the sensor.

Plot temperature vs time of the sensor $C C D$, and baseplate starting at power-on, notated with room temperature. 
Operator: DPN

Date: $8-2-93$

6.1. Applicable Sensors:

aStarTracker ST 313
$\square$ Laser Transmitter

QUV-VIS

a HiRes QLWIR

\subsection{Data Storage Locations:}

Images: $\quad /$ dspse/<Sensor>/darkField/date/<sensorname.imagenumber $>$

Temp: $\quad /$ dspse/<Sensor $>/$ darkField/date/temperature_log_data

6.3. Purpose:

The dark field images recorded will be used to measure the dark current and dark current uniformity at a known temperature. These values will be used to verify the dark fièld sensitivity to integration time and the fixed pattern noise as measured at LLNL. .

\subsection{Test Environment \& Procedure}

This test is performed in at ambient temperature [OPTIONAL: with a cooled base-plate], recording dark field images and the temperature environment at which they were obtained.

Unpack the sensor using the "Sensor Activity Log Sheet (LLNL-SAL)

Log the execution of the "LLNL Dark Field Uniformity Test" in the sensor certification log.

Power the sensor and allow the sensor to come to thermal equilibrium for 15 minutes.

8 At Power-On, Start the Fluke Temperature Data Logger bu pushing the "Start Log" button on the Macintosh interface. Save the file as: <sensorID> - LLNL-SÁL-xxxxx.temp.

Example: UV311-LLNL-SAL-0016.temp

Take 5 dark fields images with the appropriate source for the listed integration times:

\begin{tabular}{|c|c|c|c|c|c|c|}
\hline Sensor & $\begin{array}{l}\text { Integration } \\
\text { Times }\end{array}$ & Offset & Gain & Source & $\begin{array}{l}\text { Intensifier } \\
\text { Gain }\end{array}$ & $\begin{array}{l}\text { Filterwheel } \\
\text { Position }\end{array}$ \\
\hline StarTracker & $\begin{array}{l}Q 50 \\
d 100 \\
Q 200 \\
\square 250\end{array}$ & 0 & $75,150,350$ & Dark Cloth & $\mathrm{N} / \mathrm{A}$ & \\
\hline UV-VIS & $\begin{array}{l}\square 50 \\
\square 100 \\
\square 200 \\
\square 250\end{array}$ & 0 & $150,350,1000$ & Dark Cloth & N/A & \\
\hline HiRes & $\begin{array}{l}\square 50 \\
\square 100 \\
\square 200 \\
\square 250\end{array}$ & 0 & 150 & Dark Cloth & 0 & \\
\hline NIR & & & & $\begin{array}{l}300,350^{\circ} \\
\text { Baseplate }\end{array}$ & & \\
\hline LWIR & & & & & & \\
\hline
\end{tabular}


[OPTIONAL: For LLNL CCD sensor take images at each of a $5,10,15^{\circ} \mathrm{C}$ baseplate temperatures]

Q Make a README.IMAGES in the image directory (/dspse/sensor/darkField/date) file to describe the images taken in the sequence. Include the following line for each sensor:

Filename Integration time $=x x x$ Gain $=x x x \quad$ Offset $=x x x$

ф

Record the temperature conditions of the following: Ambient temperature, sensor baseplate temperature, CCD temperature, lens temperature, relative humdity.

$$
\text { cics } 29^{\circ} \mathrm{C} \text { hen } 26^{\circ} \mathrm{C}
$$

- When testing has been completed, turn the power to the sensor off and close the, temperature data $\log$ file on the macintosh.

Store the sensor using/completing the "Sensor Activity Log Sheet (LLNL-SAL)

Use aclass 1000 or better environment if possible.

When the test is successfully completed, Update the LLNL Sensor Acceptance Testing Summary Sheet.

Note Any exceptions in the test

\subsection{Performance Analysis \& Reporting Criterion}

The Dark Field Uniformity Report Shall contain the following:

Histogram showing the distribution of the image field pixel values, notated with temperatures.

Plot showing the integration time VS (Averaged) Dark Current for both a entire frame and defined regeion. (mean, StdDev, Var)

a [Optional] Plot showing the (averaged) dark current VS temperature

$\square$ Compare the Dark current wiht LLNL calibration Summary Report

Plot an Image Field showing the Fixed Pattern noise of the summation of each Integration times images (10-20each).

Plot temperature vs time of the sensor $\mathrm{CCD}$, and baseplate starting at power-on, notated with room temperature. 
Operator: DPN Date: $8-2-93$

7.1. Applicable Sensors:

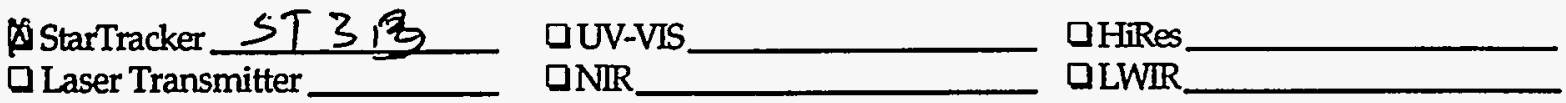

7.2. Data Storage Locations:

Images: $\quad$ /dspse/<Sensor>/imageField/date/<sensomame.imagenumber>

Temp: $\quad /$ dspse/<Sensor $>/$ imageField/date/temperature_log_data

\subsection{Purpose:}

Acquire and store a re-creatable image field for analysis.

\subsection{Test Environment \& Procedure}

Unpack the sensor using the "Sensor Activity Log Sheet (LLNL-SAL)

Log the execution of the "LLNL Image Field Analysis Test" in the sensor certification log. Use a class 1000 or better environment if possible.

Q At Power-On, Start the Fluke Temperature Data Logger bu pushing the "Start Log" button on the Macintosh interface. Save the file as: <sensorID> - LLNL-SAL- $x \times x x x . t e m p$.

Example: UV311-LLNL-SAL-0016.temp

For Each Filter Position

Using a StarField Generator, or Opto-Image

Vary Integration time and Gain to produce peak pixel of $\sim 220$ digital counts

\begin{tabular}{|c|c|c|c|c|c|c|}
\hline Sensor & $\begin{array}{l}\text { Integration } \\
\text { Times }\end{array}$ & Offset & Gain & Source & $\begin{array}{l}\text { Intensifier } \\
\text { Gain }\end{array}$ & $\begin{array}{l}\text { Filter } \\
\text { Position }\end{array}$ \\
\hline StarTracker & $\begin{array}{l}\square 100 \\
\square 200 \\
\square 300\end{array}$ & $\begin{array}{l}\mathbf{0} \\
\mathbf{0} \\
\mathbf{0}\end{array}$ & $\begin{array}{l}75 \\
150 \\
350\end{array}$ & $\begin{array}{l}\text { Cassiopeia Source } \\
\text { Dark Eloth } \\
\text { Bark Eloth }\end{array}$ & N/A & N/A \\
\hline UV-VIS & $\begin{array}{ll} & 50 \\
\square & 100 \\
\square & 200\end{array}$ & $\begin{array}{l}0 \\
0 \\
0\end{array}$ & & $\begin{array}{l}\text { Dark Cloth } \\
\text { Dark Cloth } \\
\text { Dark Cloth }\end{array}$ & & \\
\hline HiRes & $\begin{array}{l}50 \\
\square 200 \\
\square 250\end{array}$ & $\begin{array}{l}0 \\
0 \\
0\end{array}$ & & $\begin{array}{l}\text { Dark Cloth } \\
\text { Dark Cloth } \\
\text { Dark Cloth }\end{array}$ & & \\
\hline$\overline{\text { NIR }}$ & & & & $\begin{array}{l}300^{\circ} \\
350^{\circ}\end{array}$ & & \\
\hline LWIR & & & & $300^{\circ}$ & & \\
\hline
\end{tabular}

When testing has been completed, turn the power to the sensor off and close the temperature data log file on the macintosh.

Sensor Verification Test Procedure Draft-C: August 2, 1993 
Store the sensor using/completing the "Sensor Activity Log Sheet (LLNL-SAL)

When the test is successfully completed, Update the LLNL Sensor Acceptance Testing Summary Sheet.

$\square$ Note Any exceptions in the test

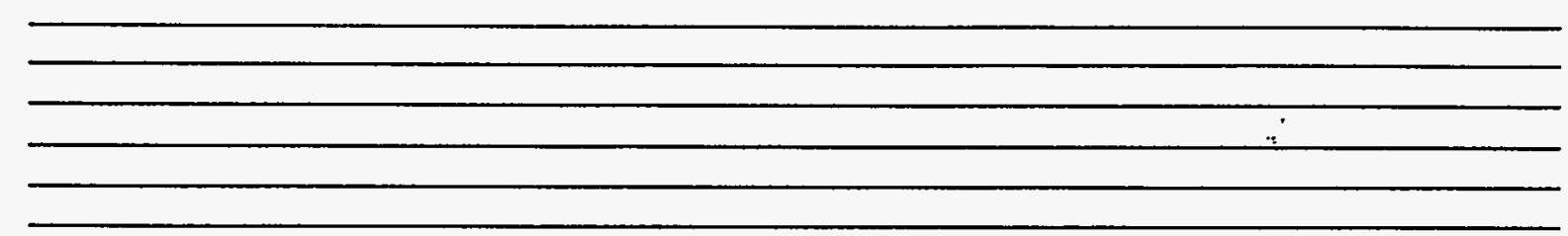

7.5. Performance Analysis \& Reporting Criterion

Generate PSF for Point Source at a Pixel near the center of the Field of View and 4 points evenly spaced off axis.

a Plot temperature vs time of the sensor $\mathrm{CCD}$, and baseplate starting at power-on, notated with room temperature. 


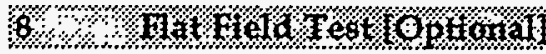

Operator:

Date:

8.1. Applicable Sensors:

\begin{tabular}{|c|c|c|c|}
\hline $\begin{array}{l}\text { StarTracker } \\
\text { NIR }\end{array}$ & $\begin{array}{l}\text { Q UV-VIS } \\
\text { Q LWIR }\end{array}$ & $\square$ HiRes & D Laser Transmitter \\
\hline
\end{tabular}

8.2. Data Storage Locations:

Images: $\quad /$ dspse/<Sensor $>/$ flatField/date/<sensorname.imagenumber $>$

Temp : $\quad /$ dspse/<Sensor $>/$ flatField/date/temperature_log_data

8.3. Purpose

A verification of the LLNL absolute radiometric calibration will be performed on the sensors with an accuracy of TBD. A Labsphere Uniform Source System will be used to provide a calibrated (NIST traceable) radiance for a wavelength range of 0.4 to $2.3 \mathrm{~mm}$. This source will be used for all visible sensors and the NIR sensor. For the LWIR and upper wavelength filters of the NIR, the extended blackbody source will be used. The source will be placed near the sensor to ensure the source fills the entire sensor field of view. A radiometric analysis will be performed as follows: For each filter setting, gain setting, and a set of appropriate integration time two images will be acquired and stored:

8.4. Test Environment \& Procedure

Unpack the sensor using the "Sensor Activity Log Sheet (LLNL-SAL)

Log the execution of the "LLNL Flat Field Test" in the sensor certification log.

Use a class 1000 or better environment if possible.

- At Power-On, Start the Fluke Temperature Data Logger bu pushing the "Start Log" button on the Macintosh interface. Save the file as: <sensorID> - LLNL-SAL-xxxxx.temp.

Example: UV311-LLNL-SAL-0016.temp

口 Do SOMETHING!!!

Store the sensor using/completing the "Sensor Activity Log Sheet (LLNL-SAL)

When testing has been completed, tum the power to the sensor off and close the temperature data log file on the macintosh.

When the test is successfully completed, Update the LLNL Sensor Acceptance Testing Summary Sheet. 
Note Any exceptions in the test

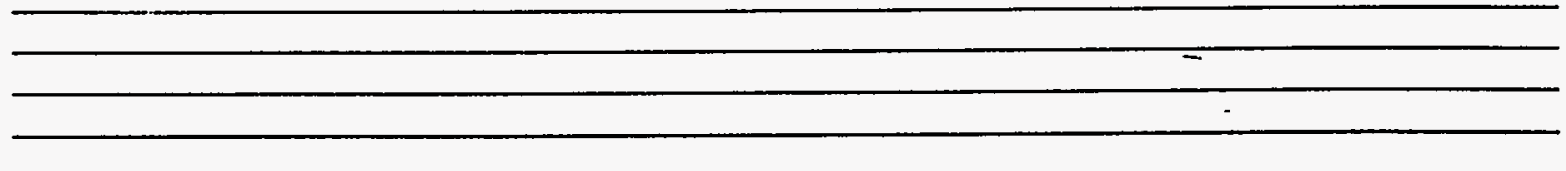

8.5. Performance Analysis \& Reporting Criterion

Plot temperature vs time of the sensor $C C D$, and baseplate starting at power-on, notated with room temperature. 


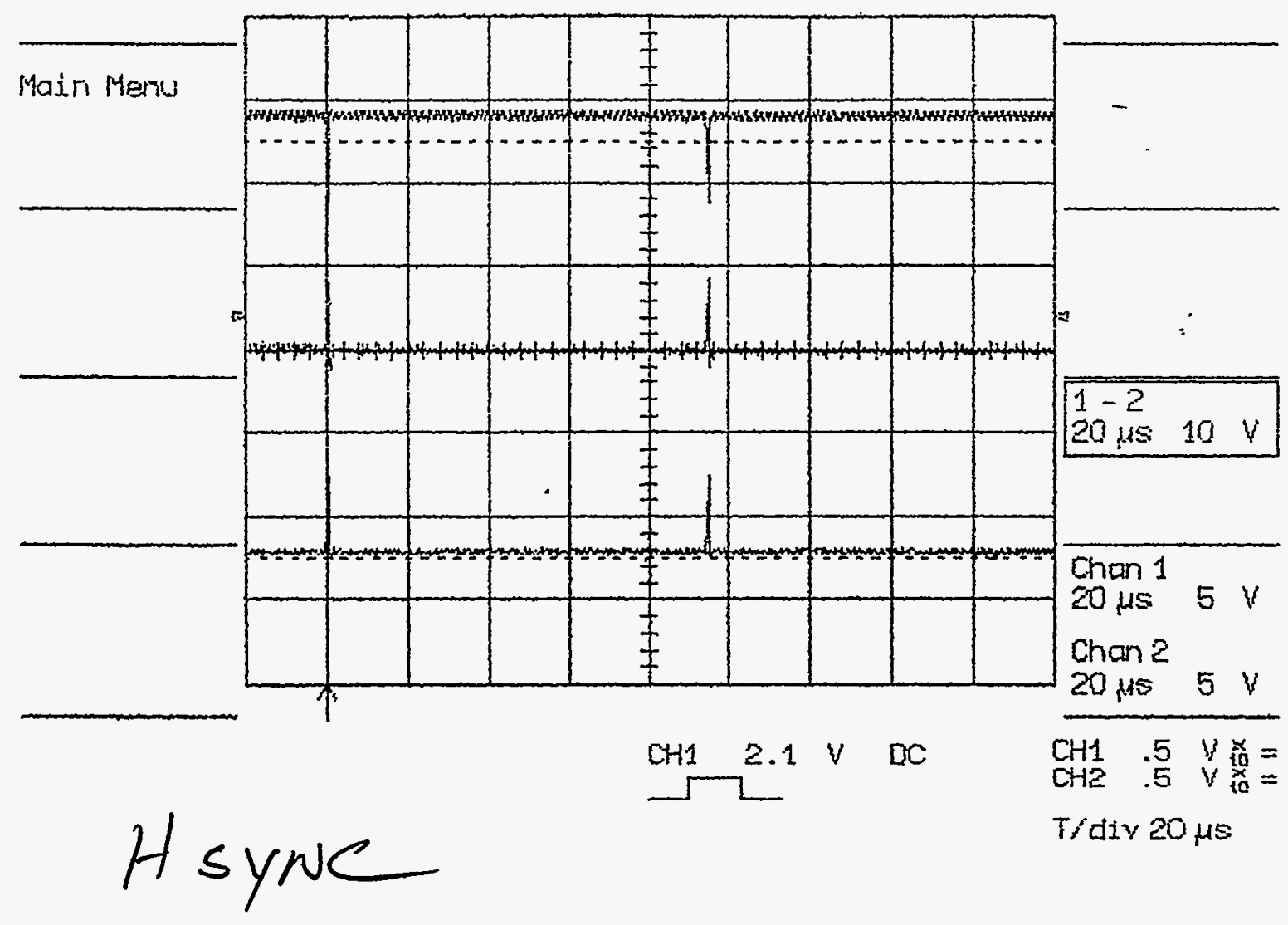


$2-\operatorname{lng} 95$

$13: 34: 44$

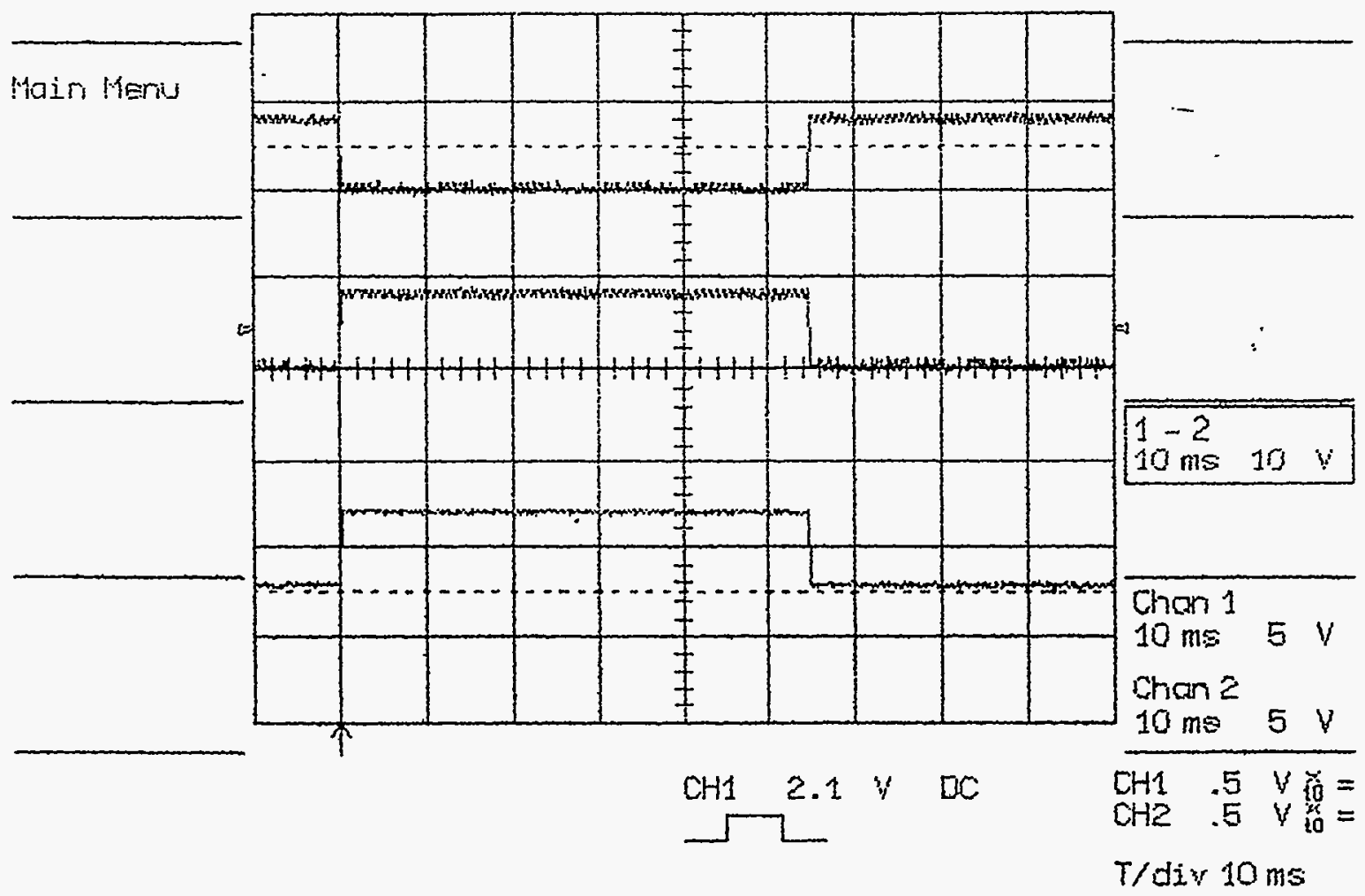

Vsyoue

$\cdots \ldots, \because, \ldots+\cdots, \cdots, \ldots, \ldots$ 
2-kug-9s

$13: 37: 43$

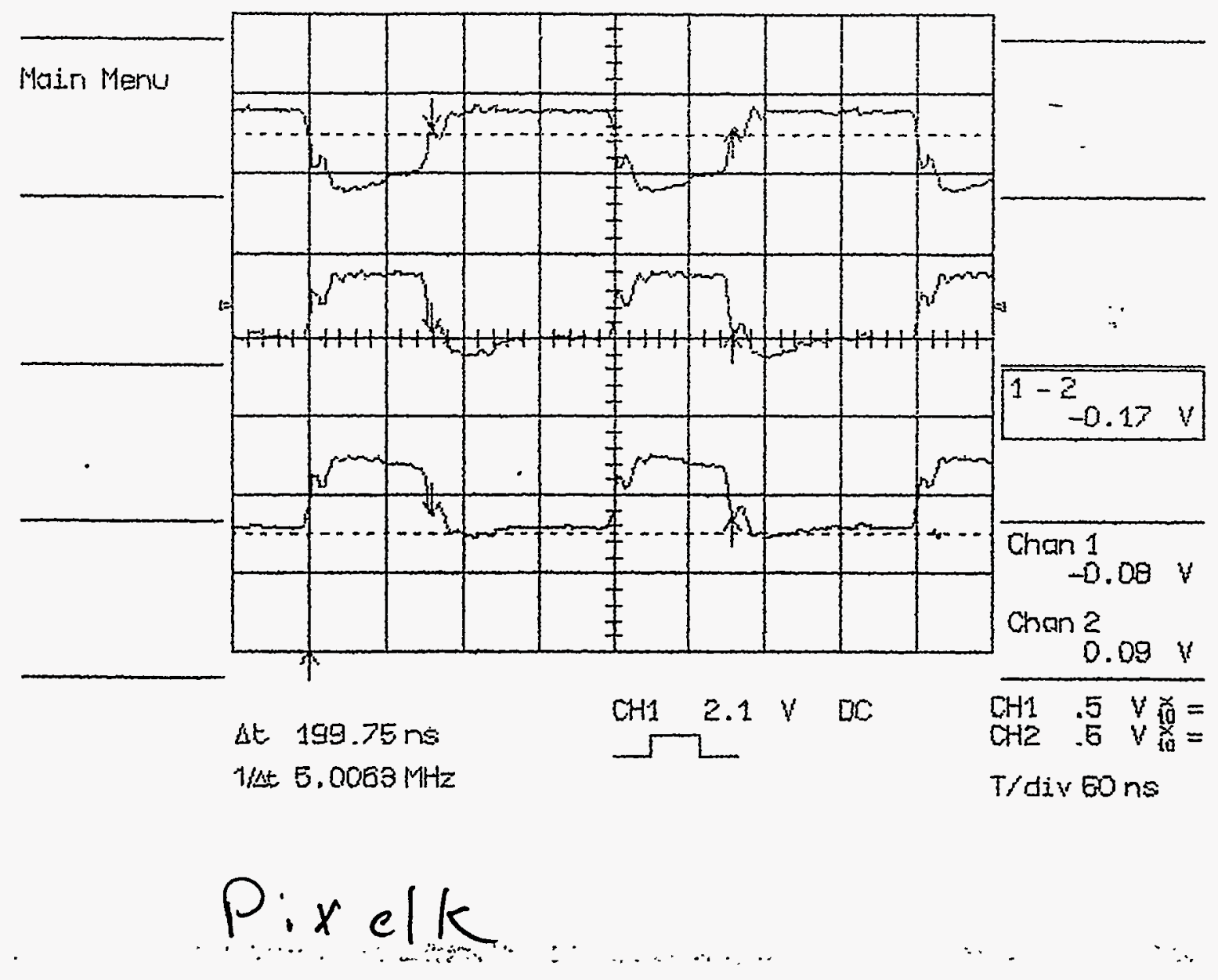


$2-4.49-93$

$13: 40: 22$

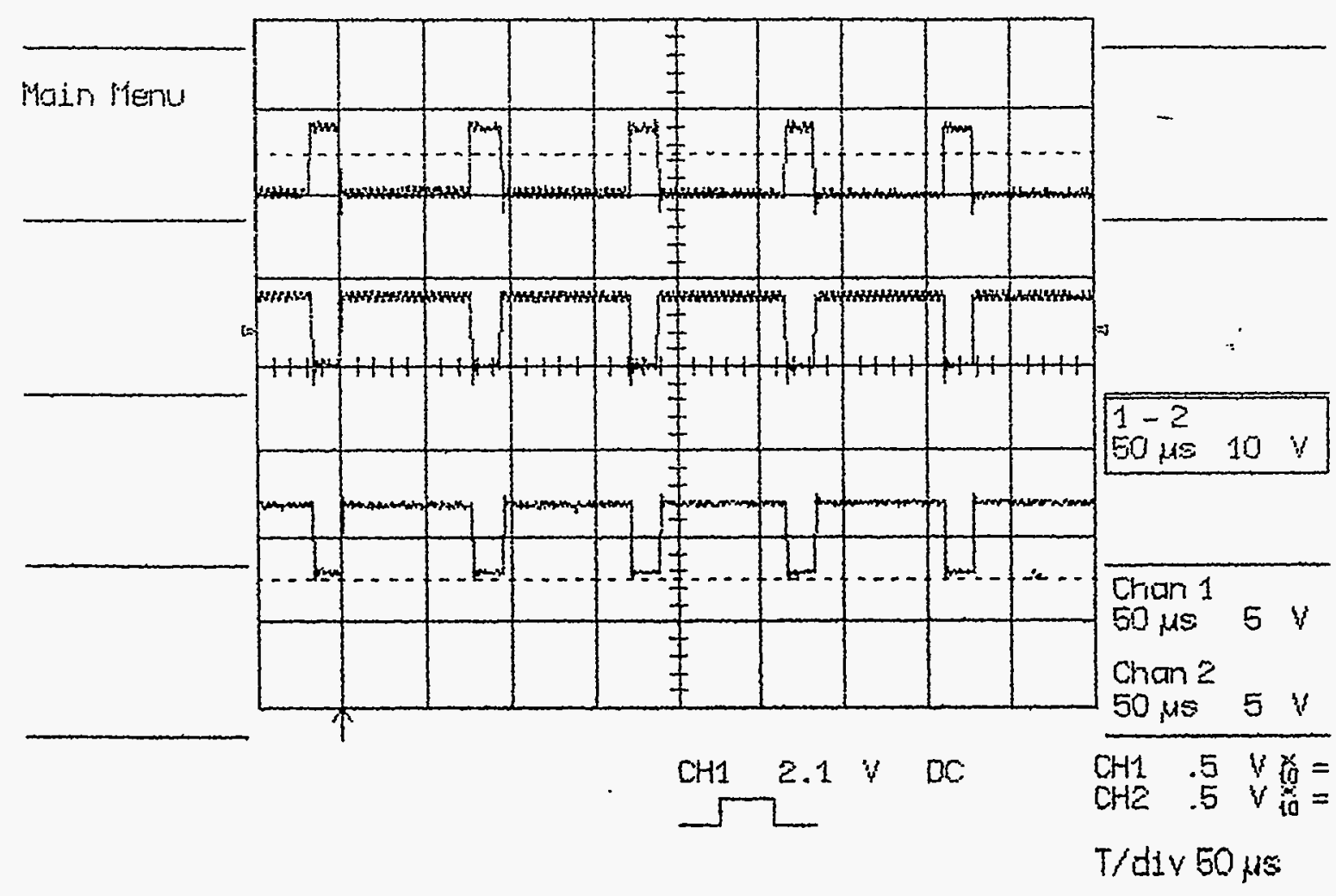

Pix Val

$\therefore \quad \therefore \cdots \cdots$ 
2-Aun-95

$13: 44: 04$

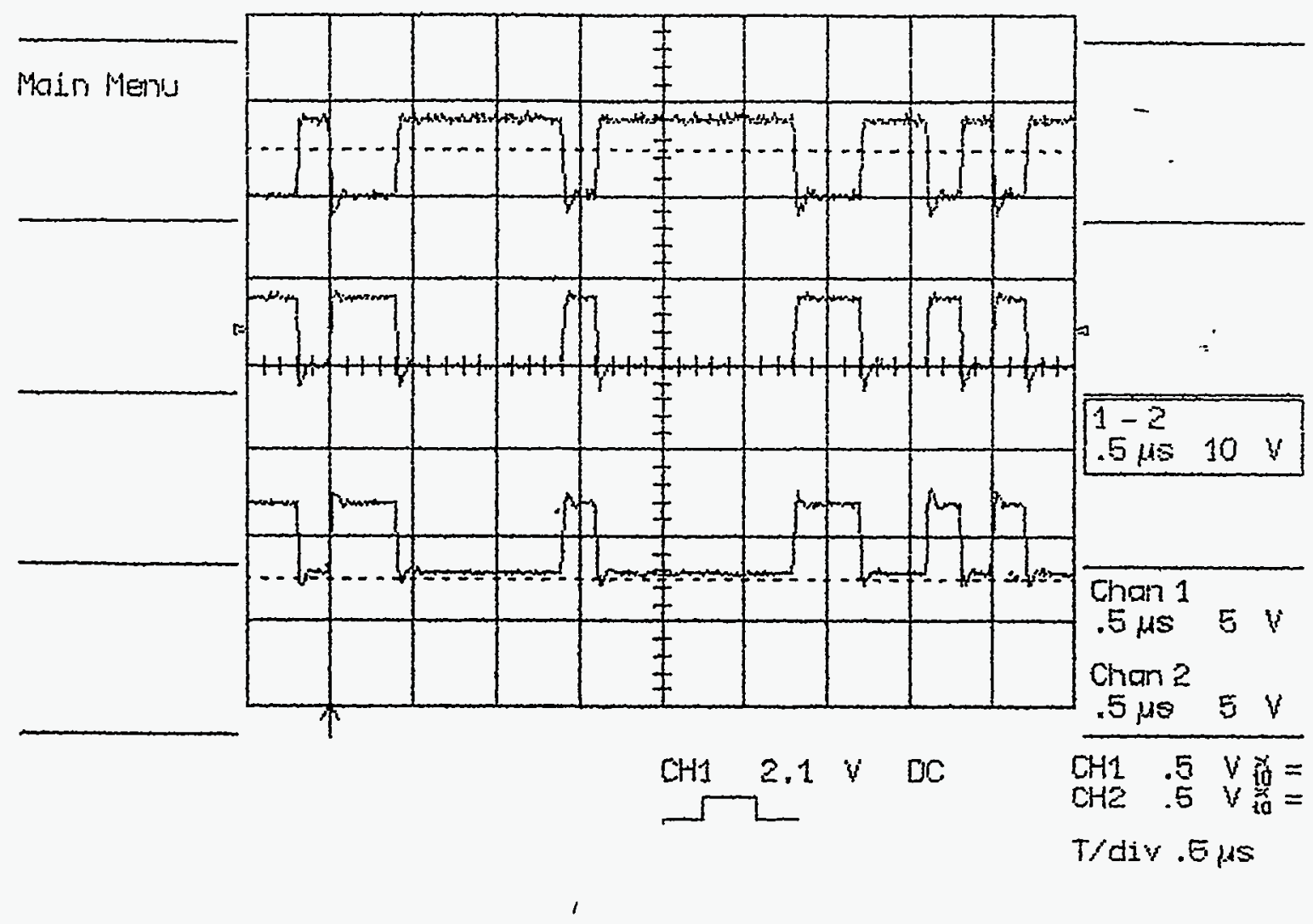

D. 
2-xug-96

13:45:23

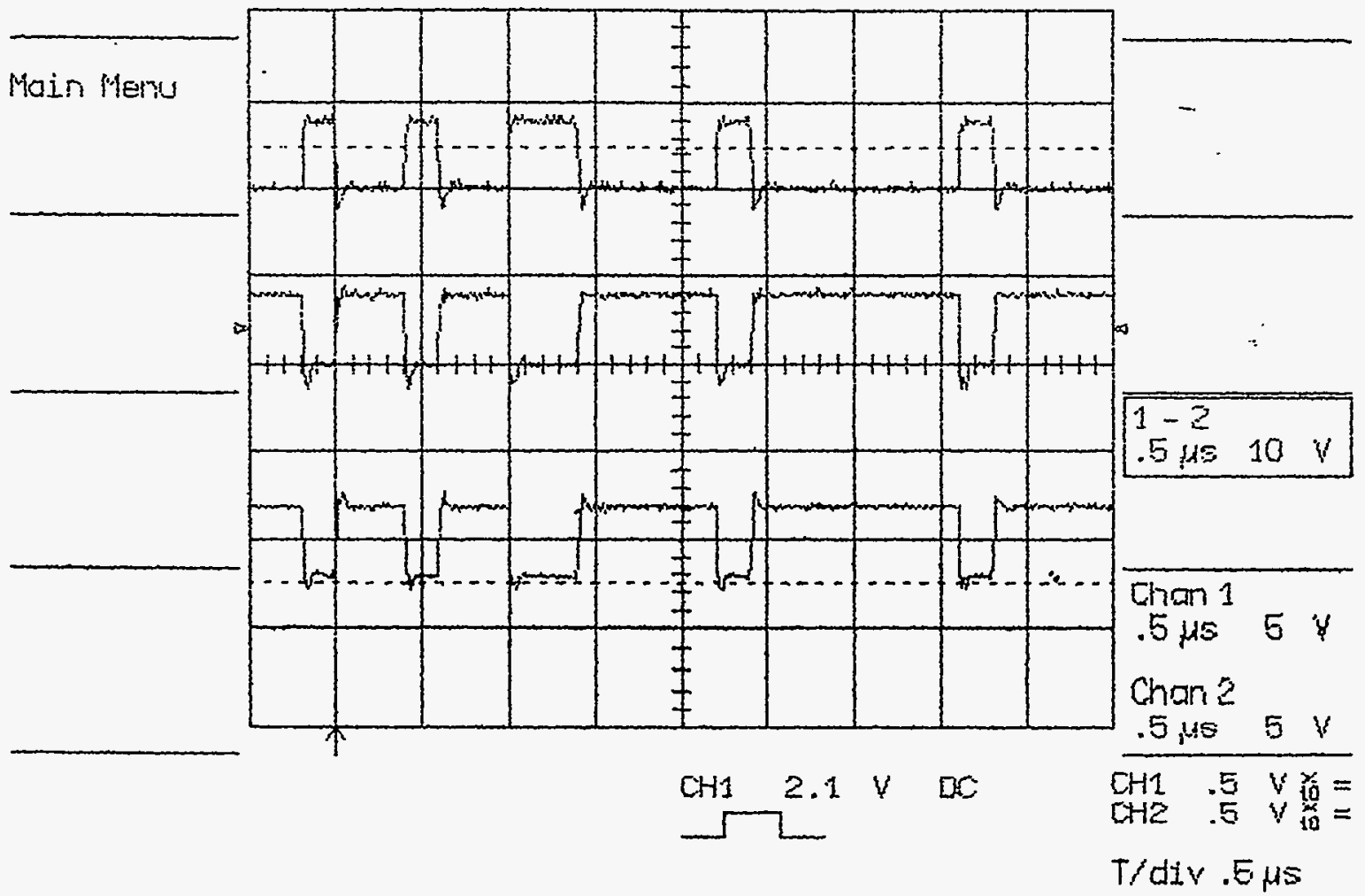

$\because \quad$ D 1 
2-A்日-9S

$13: 47: 27$

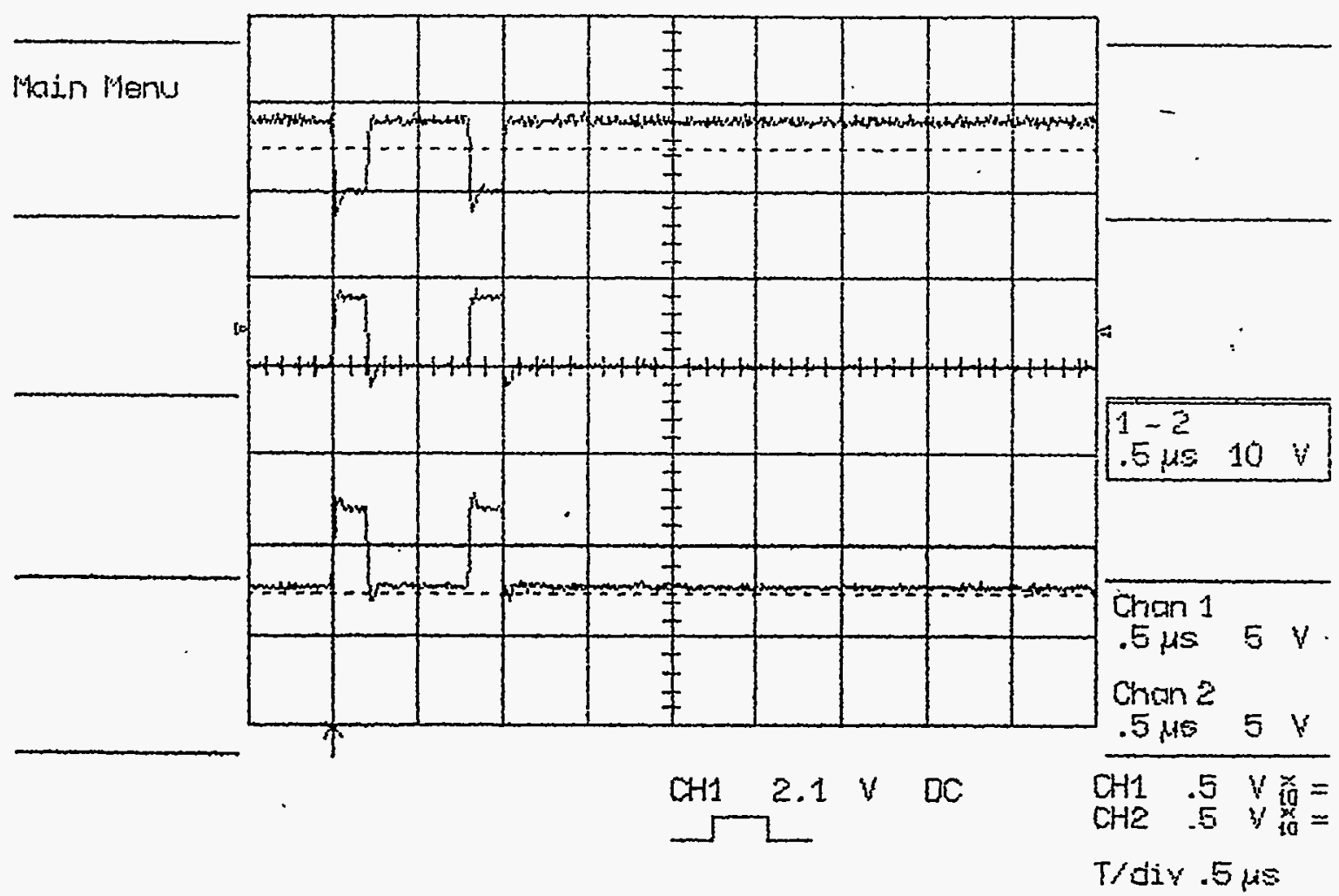

$D 2$

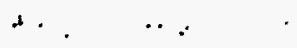


2-hug-s3

$13: 49: 23$

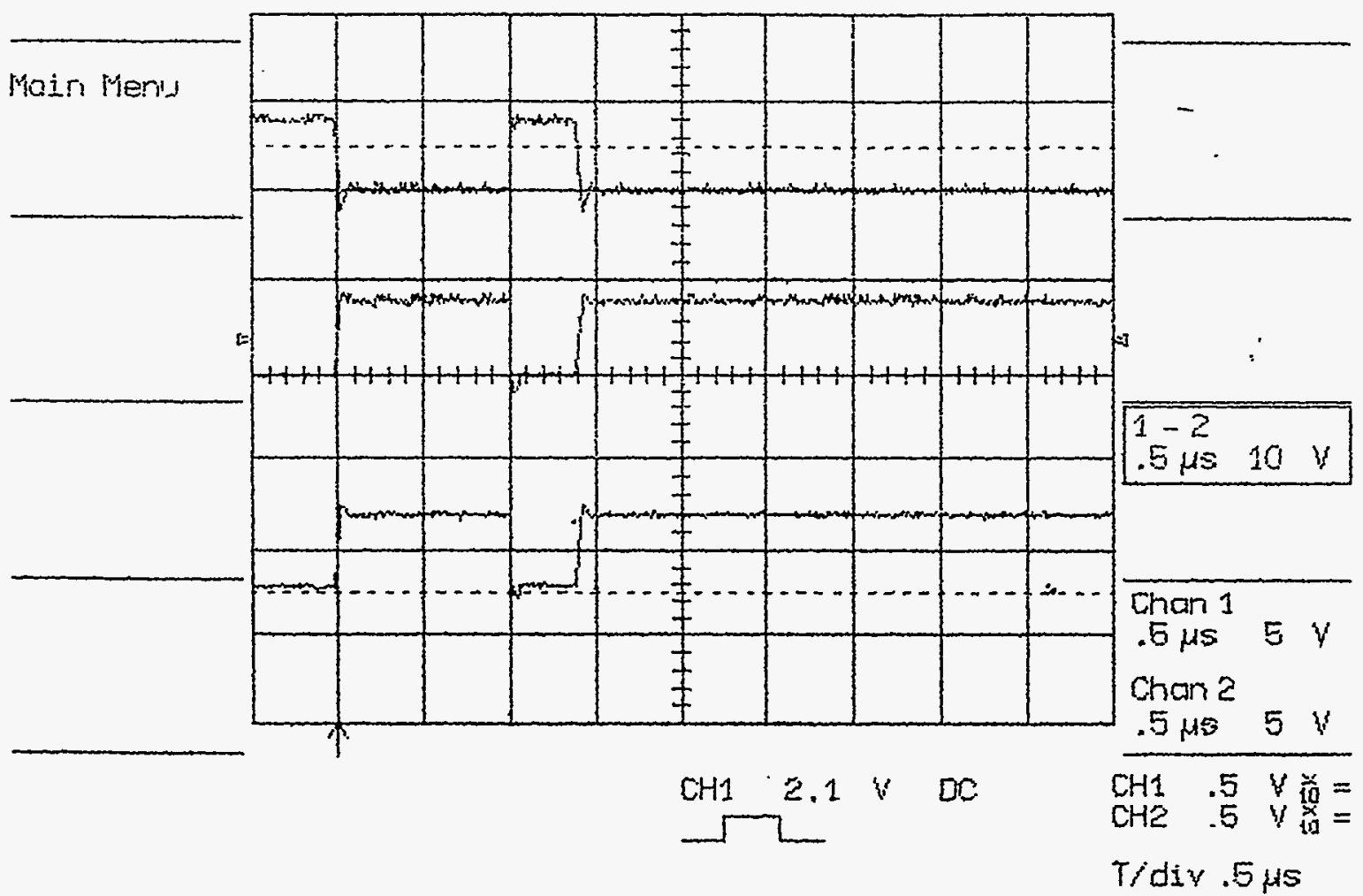

D3 
$2-A \cup 5-93$
$13: 51: 46$

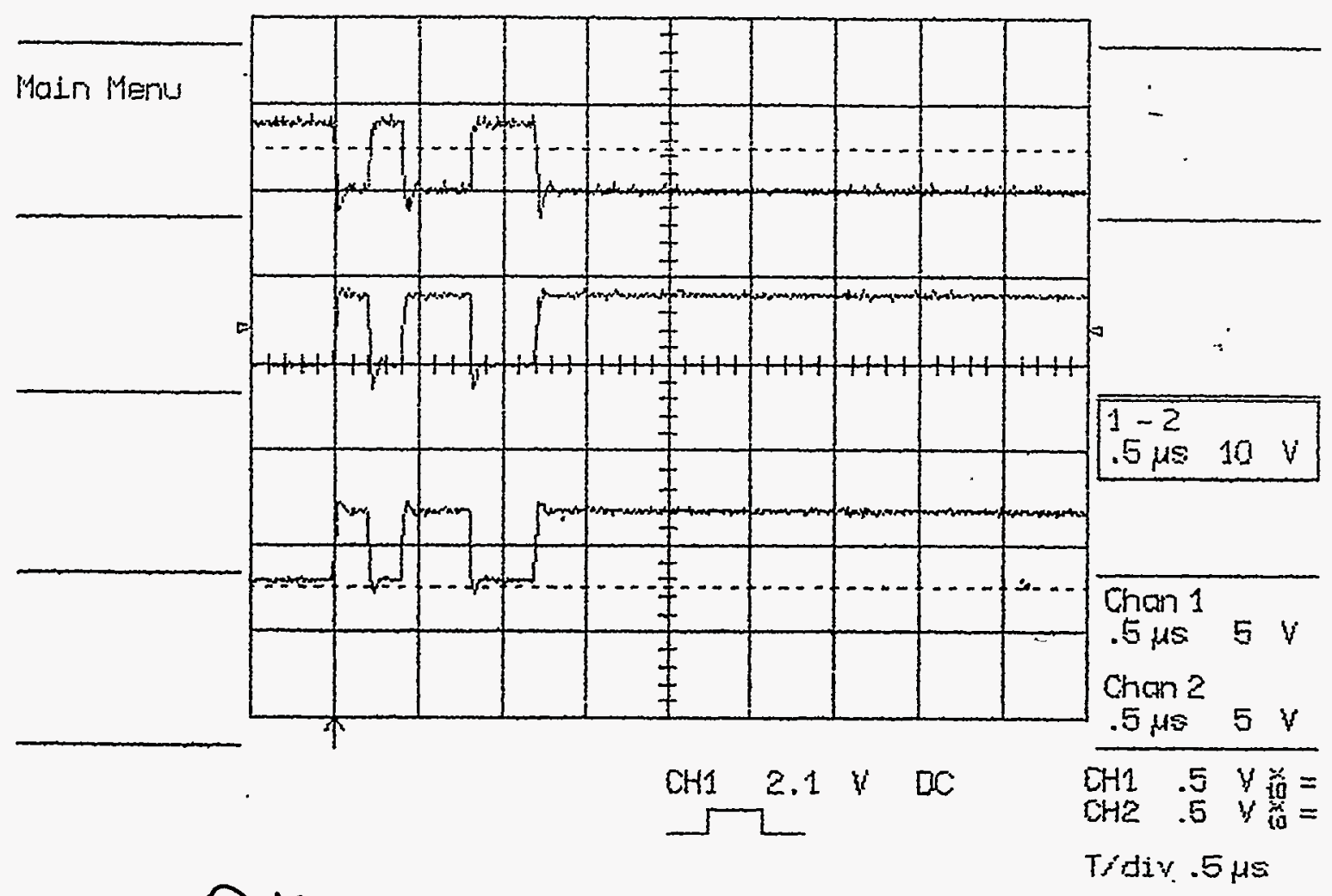

D4 

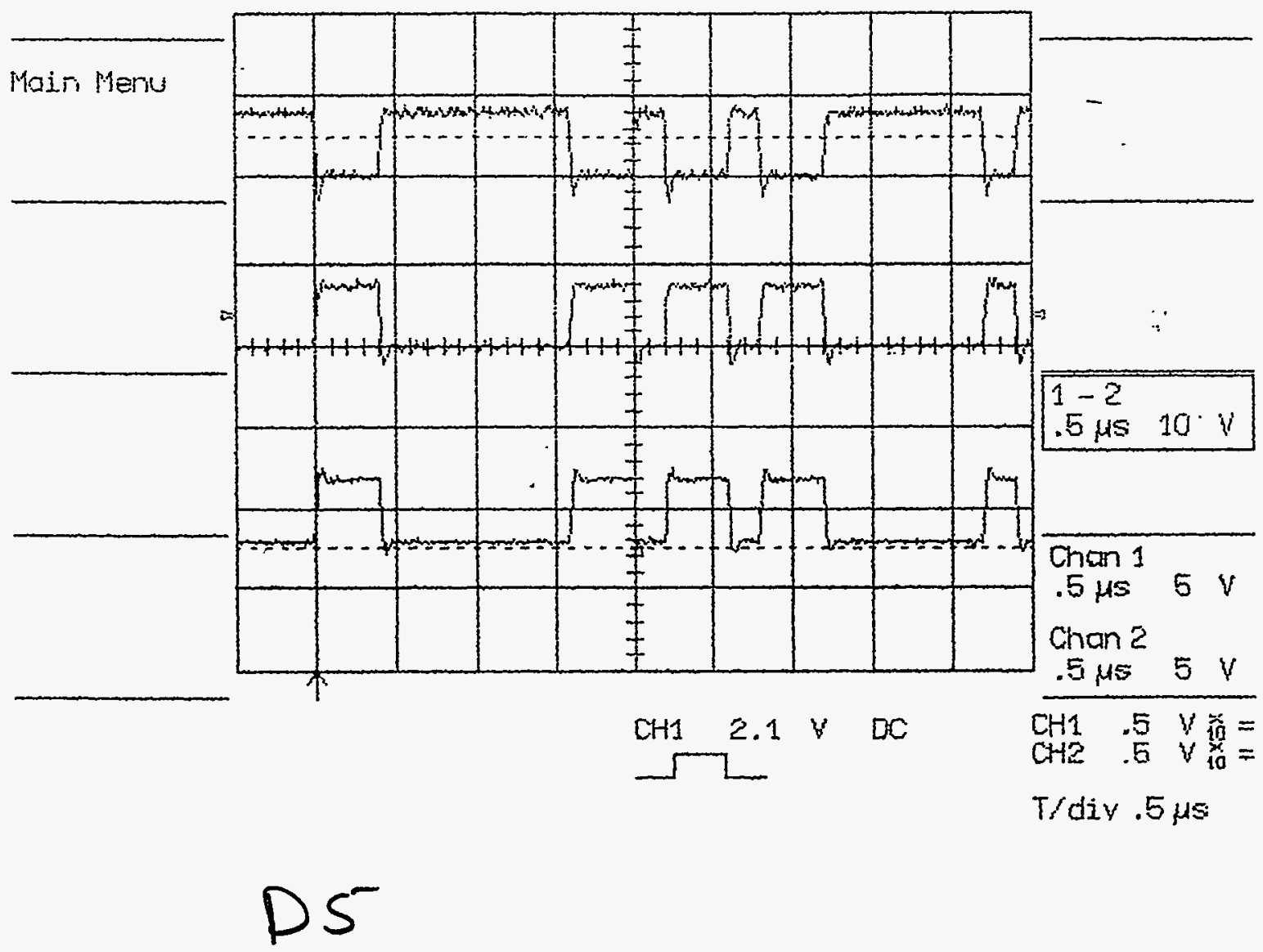
$2-A \cup g-93$
$13: 53: 46$

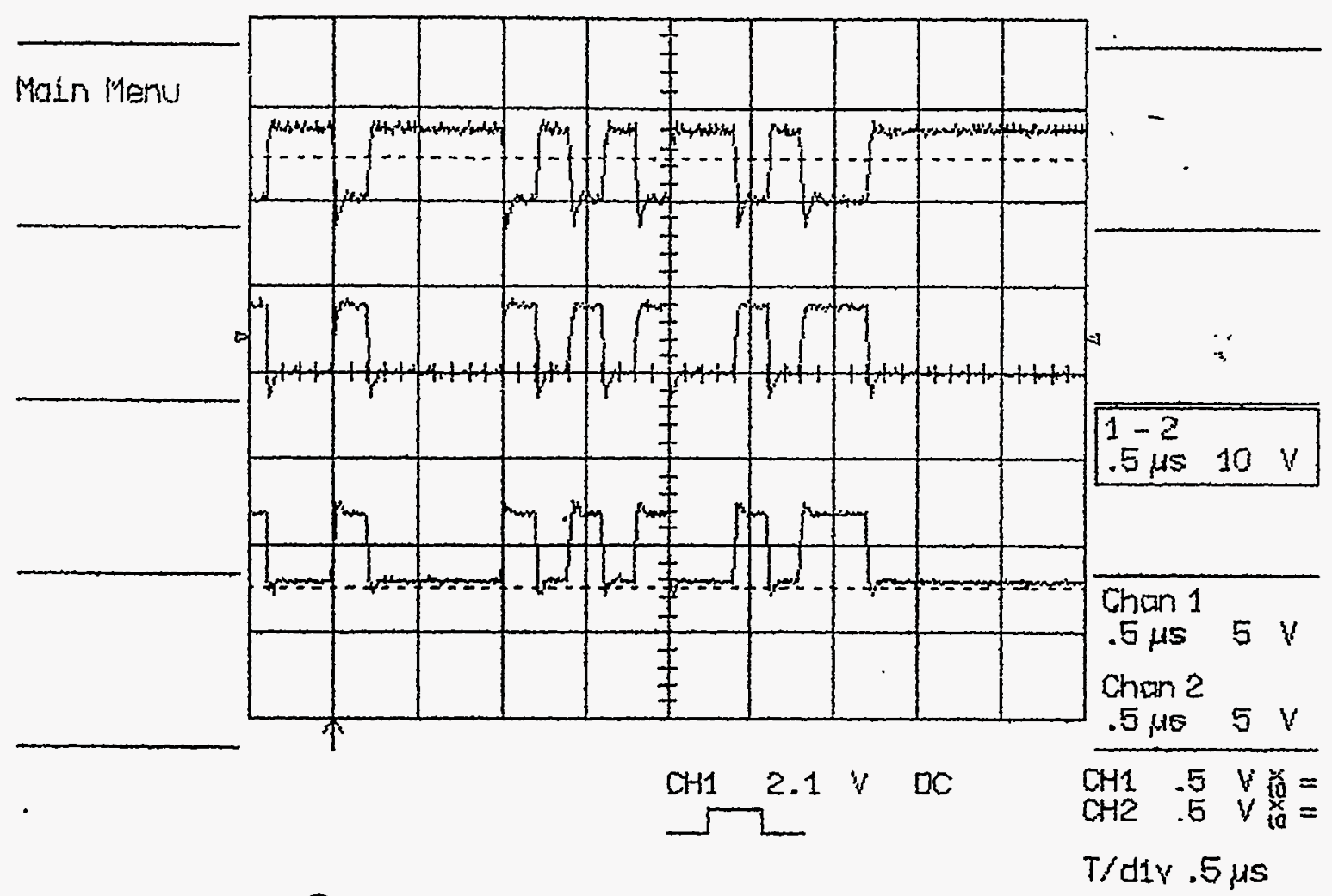

P6 
2-Aug-93

$13: 57: 20$

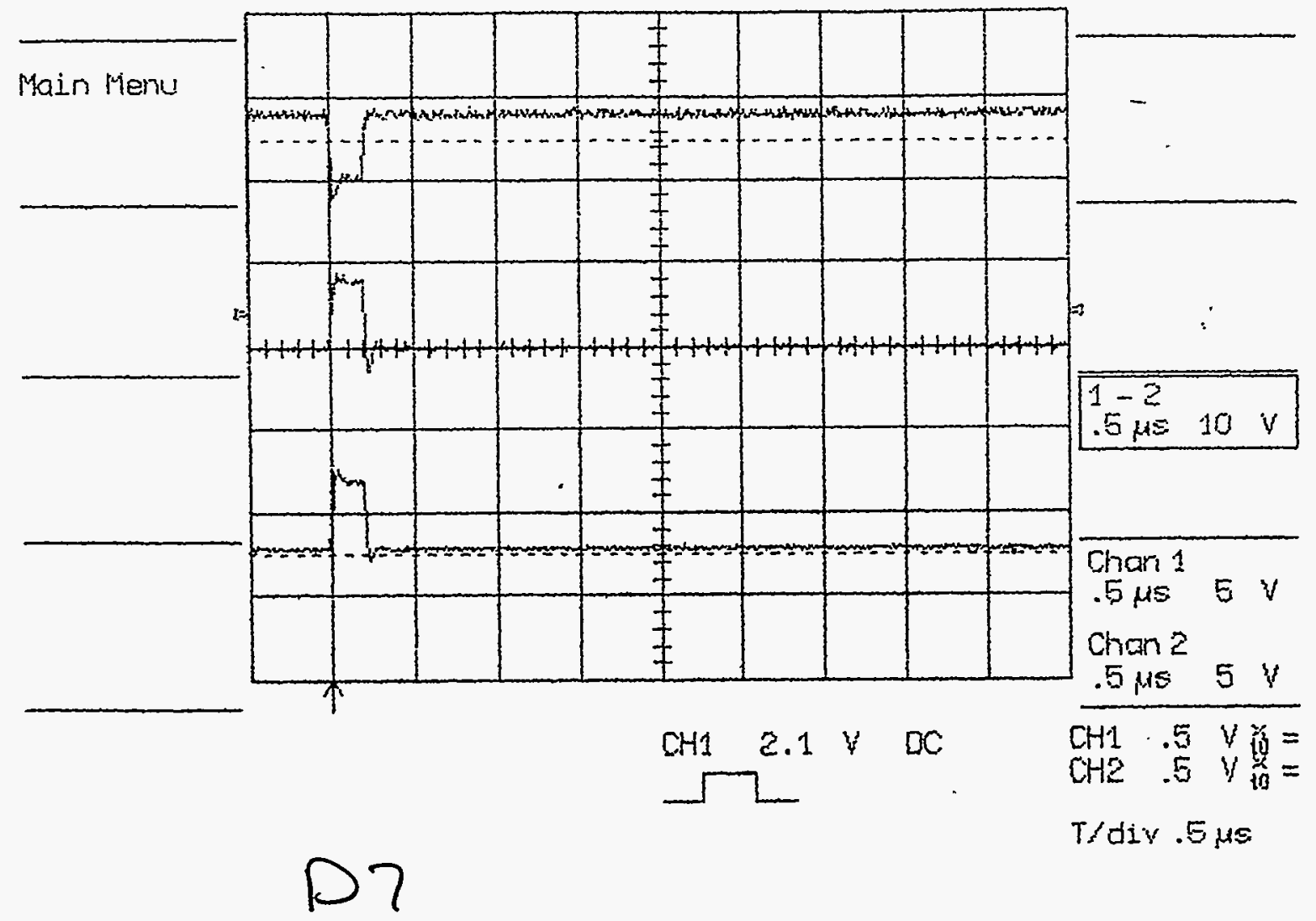


2-4ug-95

13:59:07

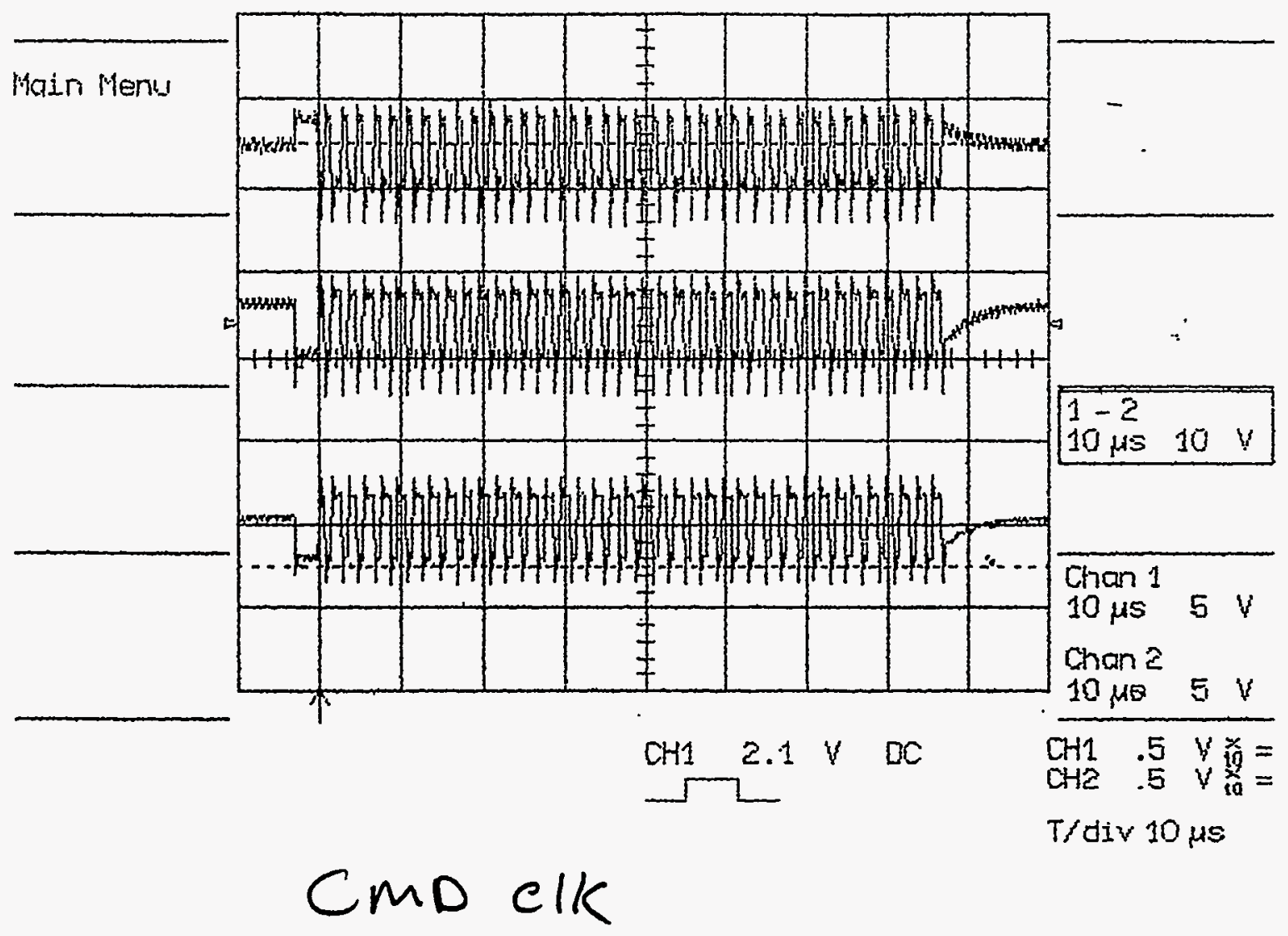


2-Aug-Sล

$14: 01: 37$

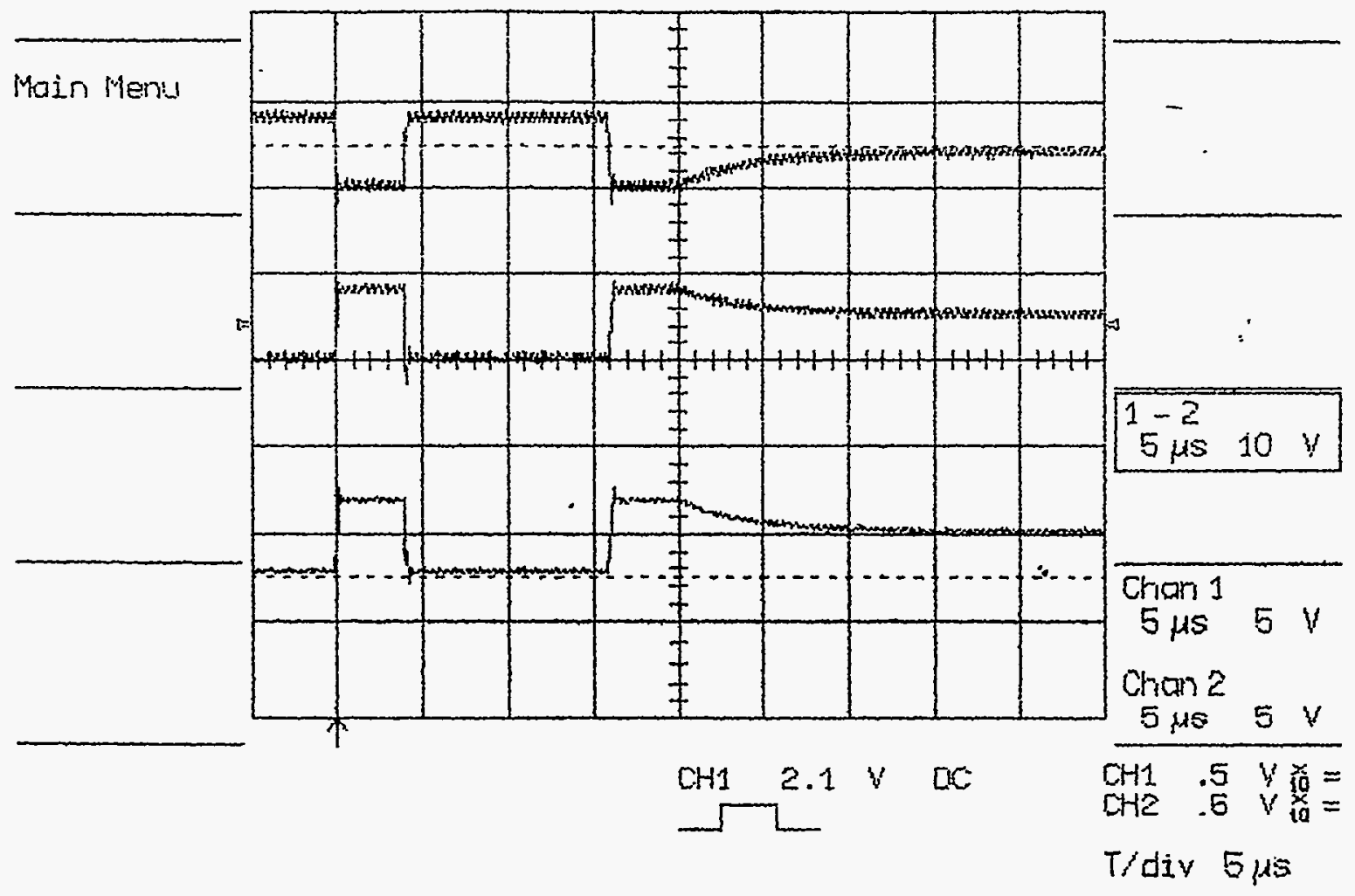

Cand StAT 
+40 amo

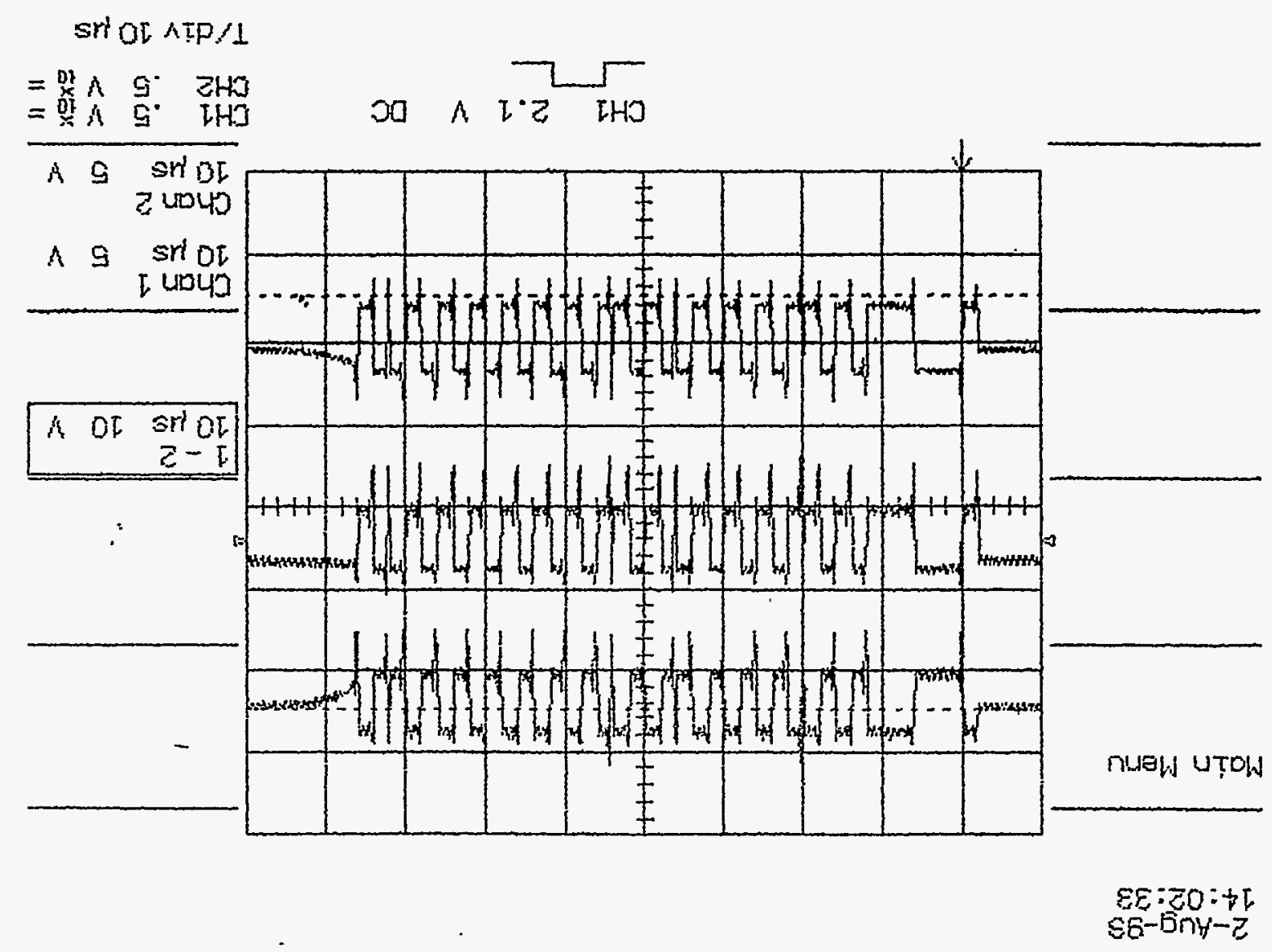


Timing Waveform Diagram_......._Cont inuaus trace in pracess_.....

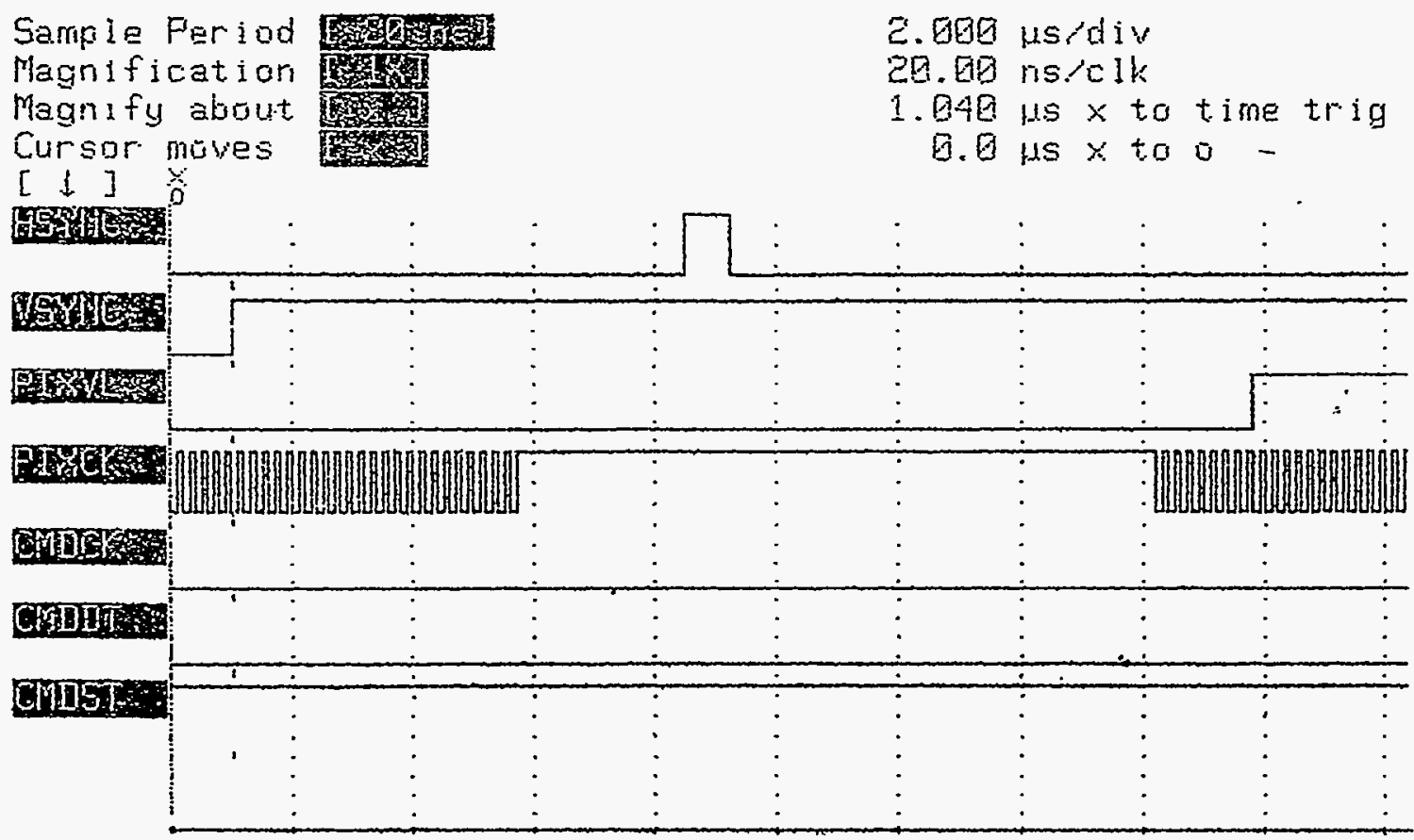

Beginuing of Frame 
Timing Waveform Iliagram Continuaus trace in process

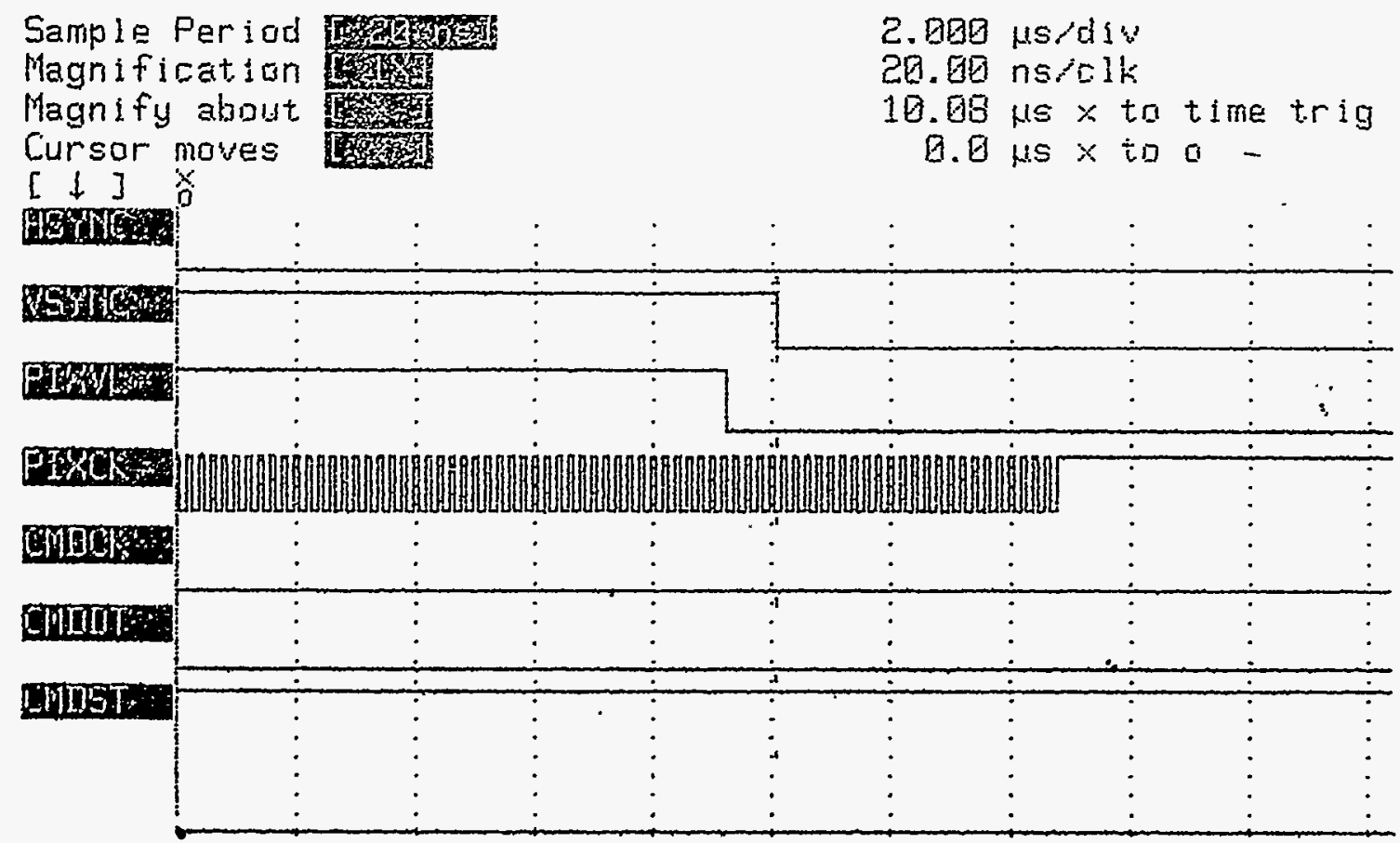

End of Frame 
$\therefore$

Timing Wakeform Diagram_______Continuous trace in process_-_._

Sample Feriod [Er] [6]

Magnification [4]

$10.00 \mu s / d i v$

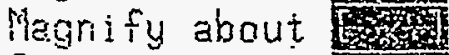

$100.0 \mathrm{~ns} / \mathrm{clk}$

Cursor moves ferpar

5.200 us $x$ to time trig

cursor moves

0.0 us $x$ to 0 -

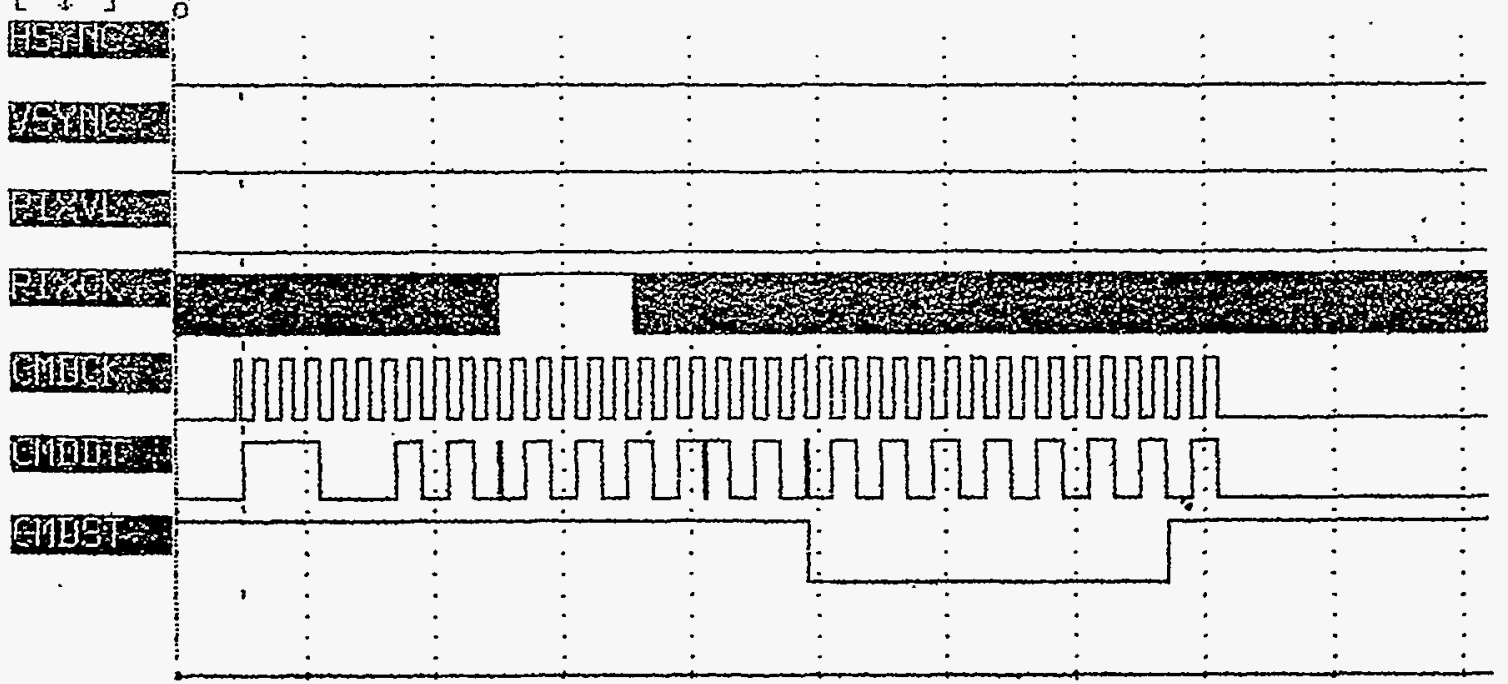

SaSi CMD 


\section{Appendix 1.2}

Clementine Sensor Test Acceptance Procedure for ST 314 


\section{Clementine}

\section{Sensor Test Acceptance Procedure}

Submit Comments to:

Robert F. Hills

Lawrence Livermore National Laboratory

510.423.7344 Office

hills1@llnl.gov EMAIL

\section{RECORD OF CHANGES}

\begin{tabular}{|l|l|l|c|}
\hline Revision Letter & Date & Title or Brief Description & Entered by \\
\hline Draft & 7 July 1993 & Working Draft & RFH \\
\hline Draft-A & 13 July 1993 & Modified to expand test procedure steps & RFH \\
\hline Draft-B & 15 July 1993 & Modified for corrections and additional steps & RFH \\
\hline Draft-C & 27 July & Modified for corrections and additional steps & RFH \\
\hline OA & 10 August 1993 & Modified to add steps for IR sensors & RFH \\
\hline
\end{tabular}

Sensor ID: $\quad 5 T 3 / 4$

Date Verified:

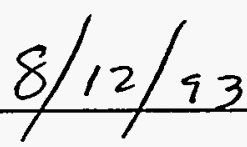

Verification Eng/Tech :

Nielsen 
This Page intentionally left Blank 


\subsection{Scope}

This document is the LLNL Clementine sensor acceptance test procedure for the DSPSE spacecraft. It defines the optical, mechanical, thermal, electrical, and software tests necessary to verify the functionality of the sensors for the Clementine Sensor Integration Project at NRL

The subsystems associated with the sensor data acquisition verification process are shown in Figure 1.1.

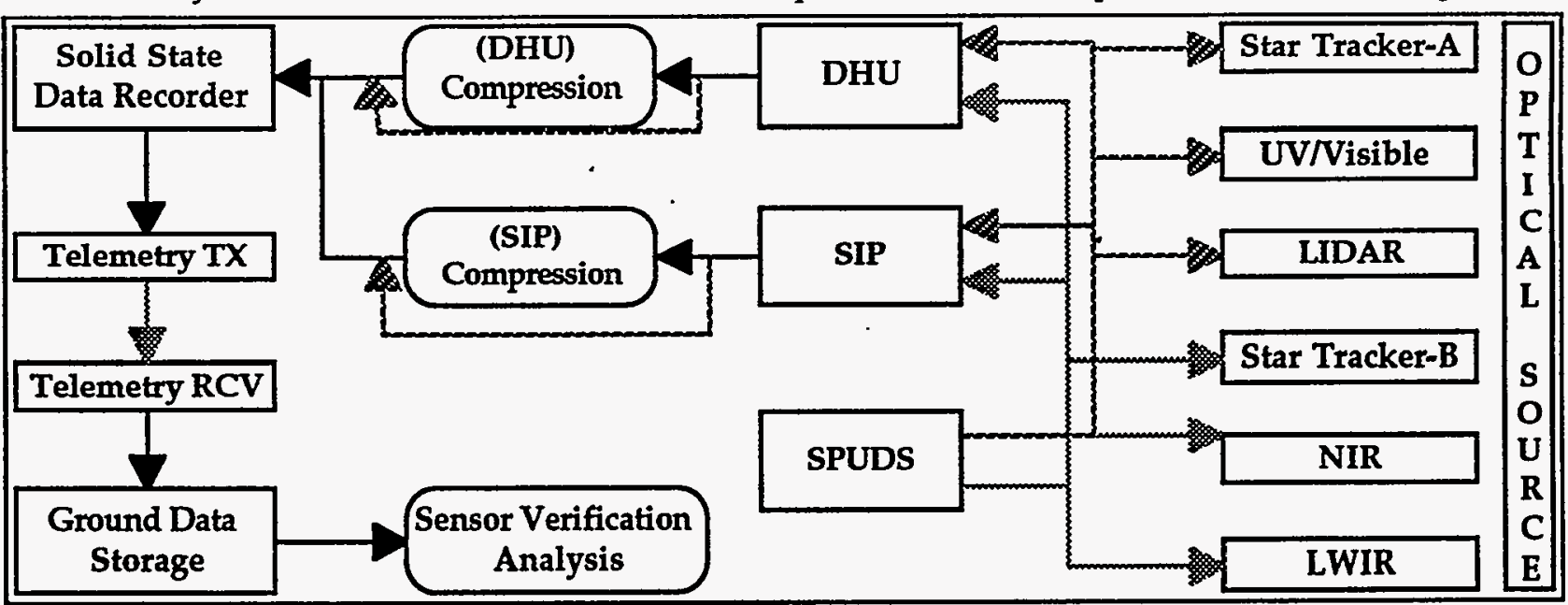

Figure 1.1 Sensor Test \& Verification Subsystems

LLNL will provide a Pre-Integration Sensor Acceptance Testing, verification, and a debug platform using interfaces which imitates the S/C interface. The LLNL Setup is shown in Figure 1.2

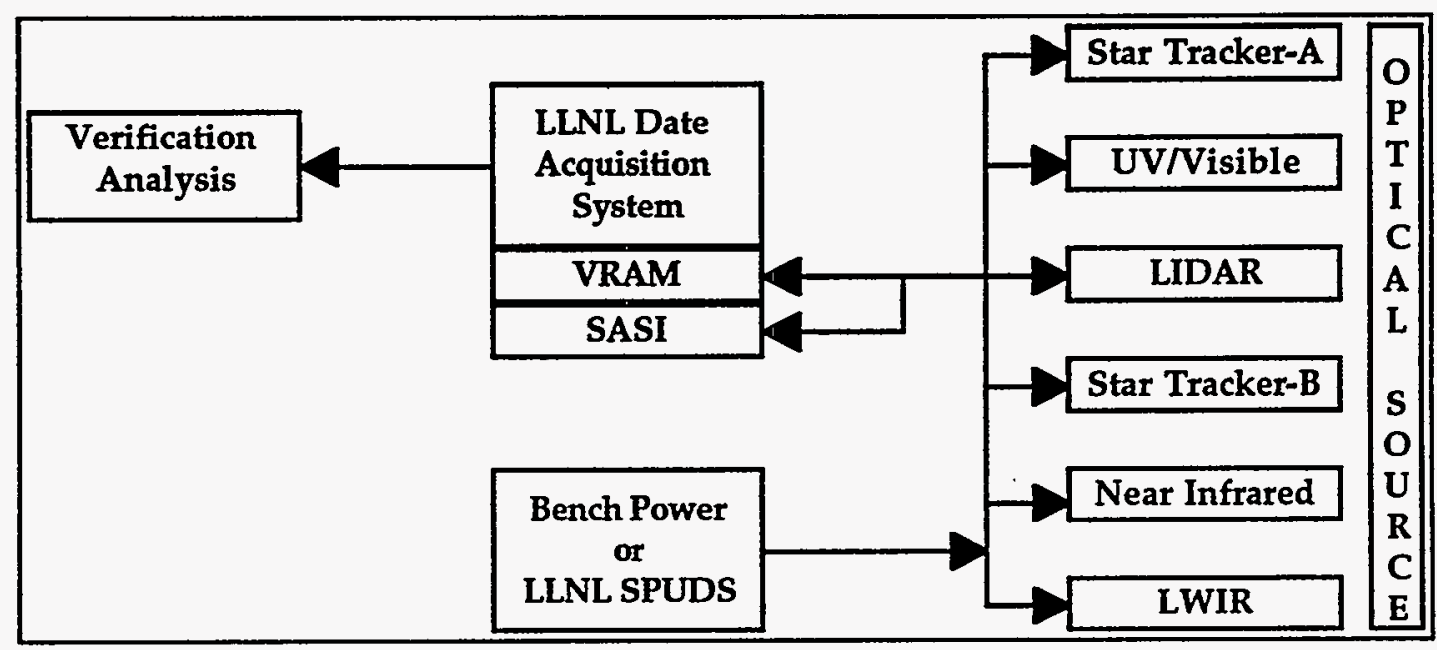

Figure 1.2 Pre-Spacecraft-Integration Sensor Verification Model 


\subsection{Verification Modes}

Two verification modes are defined for this verification plan. These are 1) Functional verification and 2) Performance Verification.

Functional verification is defined as an application of a test at nominal spacecraft conditions; i.e. voltages and ambient (room) temperatures. These environmental parameters must be maintained within the acceptable ranges for all components included in the test and are summarized below.

Performance verification is defined as an application of a test at the full range of space conditions; i.e. Max-min voltages and temperatures. These environmental parameters must be maintained within the acceptable ranges for all components included in the test and are summarized below.

Each verification test in this plan will include the operational parameters (for temperature, voltages, etc.) that are necessary for the above listed verification modes.

\subsubsection{Verification Tests}

The followings tests will be performed on each sensor:

- Sensor Physical Examination (LLNL)

- Filter Positioner (LLNL)

- Electrical Wave-form (LLNL)

- SASI Command Set (LLNL)

- Dark Field (LLNL)

- Image Field Analysis (LLNL)

- Flat Field (LLNL)

The Naval Research Laboratory will need to provide the additional tests listed below to complete the test suite for the sensors at NRL.

- Radiometric Sensitivity (NRL)

- Point Spread Function (NRL)

- SIP-DHU-Sensor Interface (NRL)

- Sensor Timeout (NRL)

- Image Compression/Decompression (NRL)

- Boresight Alignment (NRL)

- Sensor Data Telemetry (NRL)

- Sensor Software Algorithms (NRL)

Each of the procedures allows a comparison to the calibrations performed at LLNL. A comparison of the results of the sensor verification tests and the LLNL calibrations will be made. 
1.3. Documents

1.3.1. LLNL Documents

Interface Control Documents

\begin{tabular}{|ll|}
\hline C1-S4-008 & LIDAR High Resolution Camera/Range Receiver \\
C1-S4-011 & LIDAR Laser Transmitter Assembly \\
C1-S2-008 & UV/Visible Camera \\
C1-S1-010 & Star Tracker Camera \\
C1-S3-008 & Near Infrared Camera \\
C1-S3A-006 & Long wave Infrared Camera \\
\hline
\end{tabular}

Performance Specifications

\begin{tabular}{|ll|}
\hline TBD & LIDAR High Resolution Camera/Range Receiver \\
TBD & .LDAR Laser Transmitter Assembly \\
TBD & UV/Visible Camera \\
TBD & Star Tracker Camera \\
TBD & Near Infrared Camera \\
TBD & Long wave Infrared Camera \\
\hline
\end{tabular}

1.4. Environments \& Handling Procedures

\subsubsection{Anti Static Environment}

The sensors are electrostatic sensitive devices and will be handled in a manner so as to prevent damage due to static charge. This will include the grounding of the operator (grounded wrist band), camera, working surface, and conductive floor mats to a common point. The sensors will be sealed in a anti-static bag before leaving the anti-static environment and will be packed in its aluminum case when being transported.

\subsubsection{Contamination}

All sensors must be maintained within a contamination environment specified in their ICD's. The Sensor usage and environment must be logged in order to maintain the proper level of contamination prior to flight. Analysis of exposure levels and usage will be periodically verified.

To prevent dust from accumulating on the optics, a mask and lint-free gloves shall be worn when in close proximity to the uncovered sensor. The sensor lens and baffle shall be covered at all times when the camera is not in use.

\subsubsection{Temperature}

Temperature limitations placed upon the sensors are in terms of the Base Plate temperature, CCD temperature and the lens temperature. The base plate temperature limits are specified to protect the electronic and mechanical parts from thermal damage. The CCD temperature limits are primarily concerned with achieving required CCD performance. The lens temperature limits are concerned with the performance of the STC optics and the protecting them from thermal damage. The various temperature limits are described below:

1- Operational-In-Spec - This is the temperature range which is required in order to achieve sensor performance requirements. 
2- Operation-Out-Spec - This is the temperature range which is required in order to prevent damage to the sensor while maintaining a functional state. Damage and/or a reduction in reliability can occur to a sensor because the electronic junction temperatures are outside operating limits. This temperature limit will prevent the worst case electronic component from exceeding its maximum, derated, junction temperature. Maximum junction temperatures are derated according to thermal design and reliability requirements.

During all tests the $C C D$, base plate, and where appropriate, lens temperatures must be monitored on a continuous basis. If the node temperature exceeds the specifications listed in the sensor ICD, then the test must be terminated until all temperature conditions return with the specified limits.

Table x.x.x Sensor temperature range Summary

\begin{tabular}{|c|c|c|c|c|c|c|c|c|c|c|c|c|c|c|}
\hline \multirow[t]{2}{*}{ Requirements $\left({ }^{\circ} \mathrm{C}\right)$} & \multicolumn{2}{|c|}{ StarTracker } & \multicolumn{2}{|c|}{ UV-VIS } & \multicolumn{2}{|c|}{ NIR } & \multicolumn{2}{|c|}{ LWIR } & \multicolumn{2}{|c|}{ HiRes } & \multicolumn{2}{|c|}{ Laser } & \multicolumn{2}{|c|}{ Suite } \\
\hline & Min & Max & Min & Max & Min & $\operatorname{Max}$ & Min & Max & Min & Max & Min & Max & Min & Max \\
\hline Base Plate: & & & & & & & & & & & & & & \\
\hline Operational In-Spec & -20 & 2 & -20 & 2 & & & & & & & & & -20 & 2 \\
\hline Operational Out-Spec & -20 & 10 & -20 & 25 & & & & & & & & & -20 & 10 \\
\hline Non-Operating & -40 & 70 & -35 & 50 & & & & & & & & & -35 & 50 \\
\hline CCD: & & & & & & & & & & & & & & \\
\hline Operational In-Spec & -20 & 10 & -20 & 10 & & & & & & & & & -20 & 10 \\
\hline Operational Out-Spec & -20 & 60 & -20 & 25 & & & & & & & & & -20 & 25 \\
\hline Non-Operating & -40 & 85 & - & 50 & & & & & & & & & -40 & 50 \\
\hline Lens: & & & & & & & & & & & & & & \\
\hline Operational In-Spec & -20 & 40 & -20 & 40 & & & & & & & & & -20 & 40 \\
\hline Operational Out-Spec & -30 & 70 & -30 & 50 & & & & & & & & & -30 & 50 \\
\hline Non-Operating & -30 & 70 & -30 & 50 & & & & & & & & & -30 & 50 \\
\hline
\end{tabular}

\subsubsection{Humidity}

The environment in which the tests are to take place shall be maintained at a relative humidity between 40 and $70 \%$. At no time shall condensation occur. 
Operator: Nielser Date: $\frac{8 / 12 / 93}{12}$ Activity Sheet:LLNL-SAL-0029

2.1. Applicable Sensors:

口StarTracker ST 3
$\square$ Laser Transmitter
Data Storage Locations:
Images: NONE
Temp: $\quad$ NONE

\subsection{Purpose:}

Upon arrival of each sensor at NRL, a physical examination will be performed to check for any damage that may have occurred during shipping. This will include verification of the serial number and a visual check of the structure, optics, baffles, and all connectors.

\subsection{Test Environment \& Procedure}

区 Verify that the sensor Certification Log has an exposure log in the front of the book, and that it has been started.

Verify that the sensor Certification Log has work sheets to log all sensor activities and has been started.

Unpack the sensor using the Sensor Activity Log Sheet, "Preparation \& Grounding" section.

Log the execution of the "LLNL Physical Examination Test" in the sensor certification log.

Log or verify the following:

$\square$ Verify that the sensor has the proper sensor identification and LLNL property tag.

Verify that sensor shorting plugs are present.

$7^{\circ}$ Verify the presence of connector savers on all sensor connectors.

Werify that the sensor has a baffle cover and that it is labeled to its sensor

Note any loose screws, broken staking, or other physical damage.

to Note the condition of the optics and any contamination found.

fi Verify that the sensor has flying leads for the lens temperature, and lens heater and that ther is no apparent damage. 
- Store the sensor using the "Sensor Activity Log Sheet (LLNL-SAL), "Securing the Sensor" section or continue to next test. $\square$ Stored Sensor I Continued Testing.

$\square$ When the test is successfully completed, Update the LLNL Sensor Acceptance Testing Summary Sheet.

\subsection{Performance Analysis \& Reporting Criterion}

No post processed data reduction is necessary for this test. The report shall contain a detailed description of the results of the examination steps outlined in the test procedure. 
Operator:

Date:

Activity Sheet: LLNL-SAL-

3.1. Applicable Sensors:

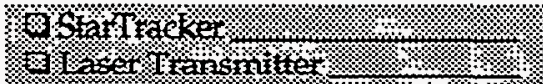

QUV-VIS

$\square$ HiRes

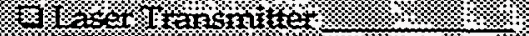

ONIR

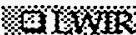

3.2. Data Storage Locations:

Images: $\quad$ NONE

Data: $\quad /$ dspse/<Sensor / filterPos/date(YYMMDD)/<filtertest>

Temp : $\quad$ MAC:<SensorID>-LLNL-SAL-XXXX.temp.FPT

3.3. Purpose:

Verify the step operation and position status of the sensor's filter wheel.

3.4. Test Environment \& Procedure

Unpack the sensor using the "Sensor Activity Log Sheet (LLNL-SAL)

$\square$ Log the execution of the "LLNL Filter Positioner Test" in the sensor certification log.

At Power-On, Start the Fluke Temperature Data Logger bu pushing the "Start Log" button on the Macintosh interface. Save the file as: <sensorID> - LLNL-SAL-xxxxx.temp. FPT Example: UV311-LLNL-SAL-0016.temp.

- Step, settle and read the filter on the sensor using the filter position driver software "filterStepTest" for 1000 steps of the filter wheel. Do both Clockwise (CW) and CounterClockWise $(\mathrm{CCW})$

filterStepTest $-\mathrm{s}<$ Sensor $>-\mathrm{f} C \mathrm{CW}-\mathrm{d} 250$-n 1000

filterStepTest $-s<$ Sensor $>$-f CCW -d 250 -n 1000

When testing has been completed, turn the power to the sensor off and close the temperature data log file on the macintosh.

The software will verify that the filterwheel stops at the correct position each time by comparing the SASI command expected position (software state machine) and the position obtained by sending a SASI request for filter position command. 
Note Any exceptions in the test

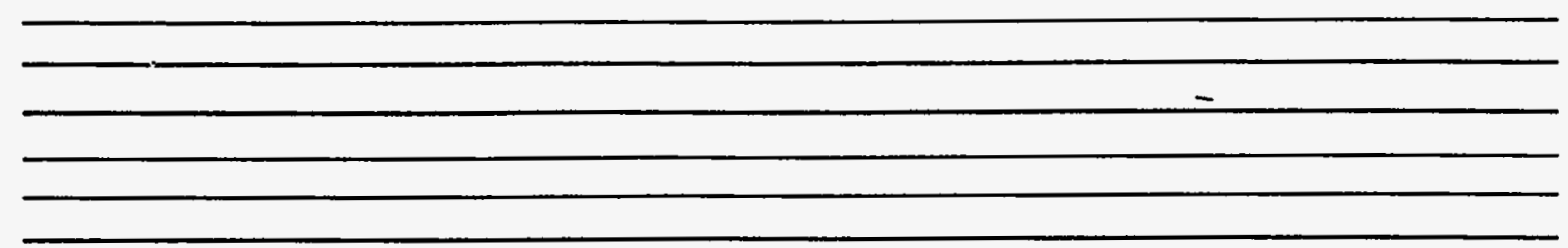

$\square$ Store the sensor using the "Sensor Activity Log Sheet (LLNL-SAL), "Securing the Sensor" section or continue to next test. $\square$ Stored Sensor $1 \square$ Continued Testing.

When the test is successfully completed, Update the LLNL Sensor Acceptance Testing Summary Sheet.

\subsection{Performance Analysis \& Reporting Criterion}

Note any software exeception that were generated (due to mis synchironization of the software state machine and the physical hardware).

Plot temperature vs time of the sensor $C C D$, and baseplate starting at power-on, notated with room temperature. 
Operator: Dr Nielsen Date: $\frac{8 / 12 / 43}{1 / 4}$ Activity Sheet: LLNL-SAL-

4.1. Applicable Sensors

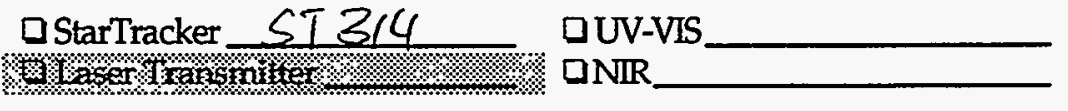

DHiRes QLWIR

4.2. Data Storage Locations

Images: $\quad$ NONE

Temp : $\quad$ MAC:<SensorID>-LLNL-SAL-XXXX.temp.EWVT

4.3. Purpose

Verify the sensor logical waveform tranisitions, timings, switching characteristics in a single [OPTIONAL: or multiple] sensor bus environment.

Verify that the sensor powers up with its bus drivers tri-stated.

4.4. Test Environment \& Procedure

Unpack the sensor using the "Sensor Activity Log Sheet (LLNL-SAL)

At Power-On, Start the Fluke Temperature Data Logger bu pushing the "Start Log" button on the Macintosh interface. Save the file as: <sensorID> - LLNL-SAL-xxxxx.temp.

Example: UV311-LLNL-SAL-0016.temp

Log the execution of the "LLNL Electrical Waveform Test" in the sensor certification log.

Run this test at ambient conditions, monitor and logging temperature profiles of the $\mathrm{CCD}$ and baseplate temperature.

Use the Lecroy Oscilloscope and set the following Parameters.

Lecroy Function E: is ON and set to Math function: (Channel1 - Channel2)

Place the raw data differential output (channel1) on the top of the screen, and the (Channel1 channel2) subtraction on the bottom of the screen.

$\$$ Calibrate the probes to a flat response on the Scope calbiration point. Then Remove any bias from the probes for the channel-1 - Channel 2) subtraction function.

Run the program "tv" on the Sun system.

Sensor Verification Test Procedure

Draft-C: August 10, 1993 
For an integration time of:

StarTracker : $100 \mathrm{mSec}$

Gir: $11 \mathrm{msec}$

$\square$ HiRes : $100 \mathrm{mSec}$

$\square$ LWIR : 5.76

QUV-VIS : $100 \mathrm{mSec}$

Obtain plots of each of the following differential driver outputs at the MDM-51 Breakout Box:

\begin{tabular}{|c|c|c|c|c|c|c|}
\hline Signal & $\begin{array}{l}\text { MDM-51 } \\
\text { DiffSig } \\
\text { Pin\# }\end{array}$ & $\begin{array}{l}\text { MDM-51 } \\
\text { DiffSig.N } \\
\text { Pin\# }\end{array}$ & (1) & $\begin{array}{l}\text { Time/Div } \\
\text { (St, UVVIS, } \\
\text { Hires) }\end{array}$ & $\begin{array}{l}\text { Time /Div } \\
\text { (NIR/LWIR) }\end{array}$ & Volage/Div \\
\hline Hsync & $\overline{12}$ & 11 & $345 \%$ & $20 \mu \mathrm{Sec}$ & $20 \mu \mathrm{Sec}$ & 5.0 \\
\hline Vsync & 45 & 28 & 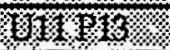 & $10 \mathrm{mSec}$ & $10 \mathrm{mSec}$ & 5.0 \\
\hline QPixclk & 18 & 35 & UYEP & $50 \mathrm{nSec}$ & $200 n s$ & 5.0 \\
\hline \& Pixval & 10 & 27 & 6119.5 & $50 \mu \mathrm{Sec}$ & $50 \mu \mathrm{Sec}$ & 5.0 \\
\hline D DO & $\overline{17}$ & 34 & 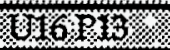 & $500 \mathrm{nSec}$ & $500 \mathrm{nSec}$ & 5.0 \\
\hline D1 & 50 & 33 & $416 \% 3 \%$ & $500 \mathrm{nSec}$ & $500 \mathrm{nSec}$ & 5.0 \\
\hline XD2 & 16 & 15 & XY695 & $500 \mathrm{nSec}$ & $500 \mathrm{nSec}$ & 5.0 \\
\hline 803 & 49 & 32 & 8 zas & $500 \mathrm{nSec}$ & $500 \mathrm{nSec}$ & 5.0 \\
\hline D4 & $\overline{14}$ & 31 & 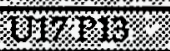 & $500 \mathrm{nSec}$ & $500 \mathrm{nSec}$ & 5.0 \\
\hline प.0D5 & 48 & 47 & 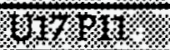 & $500 \mathrm{nSec}$ & $500 \mathrm{nSec}$ & 5.0 \\
\hline ED6 & 13 & 30 & 81785 & $500 \mathrm{nSec}$ & $500 \mathrm{nSec}$ & 5.0 \\
\hline बंD7 & 46 & 29 & $637 \%$ & $500 \mathrm{nSec}$ & $500 \mathrm{nSec}$ & 5.0 \\
\hline वCmdClk & 9 & 26 & XYYY & $10 \mu \mathrm{Sec}$ & $10 \mu \mathrm{Sec}$ & 5.0 \\
\hline CmdStat & 42 & 25 & 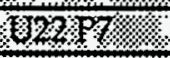 & $5 \mu \mathrm{Sec}$ & $5 \mu \mathrm{Sec}$ & 5.0 \\
\hline ECmdDat & 43 & 44 & 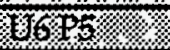 & $10 \mu \mathrm{Sec}$ & $10 \mu \mathrm{Sec}$ & 5.0 \\
\hline
\end{tabular}

MDM-51 Pin \#20 is Ground for the Differential Signals

Vram Pins: U11-XX and U17-YY are grounds for the single Ended Signals.

Verify log and plot the the Pixel Clock Rate.

Pixel Clock Rate: $5 \mathrm{mHz}$

Verify, log and plot the line time for the sensor based on the High-State of Pixval.

Line Time:

$25.10 \mathrm{~s}$

4 Verify, log and plot the interline time for the sensor based on the Low-state of Pixval.

Interline Time:

17.1025

Verify log and plot the Imge Frame Readout Time based on the High-State of Vsync.

Frame Time: $54.65 \mathrm{~ms}$

Generate a detailed logic timing diagram (using the HP Data Analyzer)

Deginning of the Frame Transfer

End-Of-Frame Transfer

4 Sasi Command Transaction, showing CMDCLK, CMDSTAT, CMDDAT

When testing has been completed, turn the power to the sensor off and close the temperature data . $\log$ file on the macintosh. 
Note Any exceptions in the test

Store the sensor using the "Sensor Activity Log Sheet (LLNL-SAL), "Securing the Sensor" section or continue to next test. $\square$ Stored Sensor $1 \square$ Continued Testing.

When the test is successfully completed, Update the LLNL Sensor Acceptance Testing Summary Sheet.

\subsection{Performance Analysis \& Reporting Criterion}

Plot both Logic Timing Transitions, and Waveform Transitions for the Data acquired in the test procedure.

Verify that the both the timing and Waveform Transitions meet ICD specifications.

Plot temperature vs time of the sensor $C C D$, and baseplate starting at power-on, notated with room temperature. 
This page intentionally left blank 
Operator:

Date:

Activity Sheet:_LLNL-SAL-

5.1. Applicable Sensors:

口StarTracker

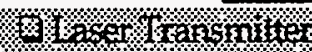

QUV-VIS

口HiRes

aNIR

DLWIR

5.2. Data Storage Locations:

Images: NONE

Temp : $\quad$ MAC:<SensorID>-LLNL-SAL-XXXX.temp.SCPT

\subsection{Purpose:}

Test the sensors parameter memory against valid and invalid SASI commands. This test will use computer software to run through all the possible permutations of SASI commands, and verify that the parameter memory state is properly modified by proper SASI commands, and not modified by illegal commands.

The Test will also ensure that a sensor will not come on the bus if an illegal command is sent while the sensor's drivers are tri-stated.

\subsection{Test Environment \& Procedure}

Unpack the sensor using the "Sensor Activity Log Sheet (LLNL-SAL)

Log the execution of the "LLNL Physical Examination Test" in the sensor certification log.

At Power-On, Start the Fluke Temperature Data Logger bu pushing the "Start Log" button on the Macintosh interface. Save the file as: <sensorID> - LLNL-SÄL-xxxxx.temp.

Example: UV311-LLNL-SAL-0016.temp

When testing has been completed, turn the power to the sensor off and close the temperature data $\log$ file on the macintosh.

Store the sensor using the "Sensor Activity Log Sheet (LLNL-SAL), "Securing the Sensor" section or continue to next test. $\square$ Stored Sensor $1 \square$ Continued Testing.

$\square$ When the test is successfully completed, Update the LLNL Sensor Acceptance Testing Summary Sheet.

Note Any exceptions in the test 
5.5. Performance Analysis \& Reporting Criterion

Sofware should report the status of both good and bad SASI commands, reporting any anomolies that were generated while testing all possible data inputs to the sensor.

Plot temperature vs time of the sensor $C C D$, and baseplate starting at power-on, notated with room temperature. 
Operator:

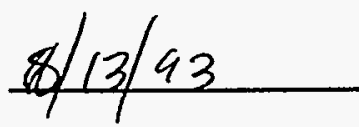
Activity Sheet: -LLNL-SAL- 20230

6.1. Applicable Sensors:

QStarTracker $\frac{S \bar{B} T^{4}}{\text { GUV-VIS }}$
QHiRes
QLWIR

\subsection{Data Storage Locations:}

Images: $\quad$ /dspse/<Sensor $>/$ darkField/date/<sensorname.imagenumber $>$

Temp : $\quad$ MAC:<SensorID>-LLNL-SAL-XXXX.temp.DFUT

\subsection{Purpose:}

The dark field images recorded will be used to measure the dark current and dark current uniformity at a known temperature. These values will be used to verify the dark field sensitivity to integration time and the fixed pattern noise as measured at LLNL.

\subsection{Test Environment \& Procedure}

This test is performed in at ambient temperature [OPTIONAL: with a cooled base-plate], recording dark field images and the temperature environment at which they were obtained.

(6) Unpack the sensor using the "Sensor Activity Log Sheet (LLNL-SAL)

Log the execution of the "LLNL Dark Field Uniformity Test" in the sensor certification log.

Power the sensor and allow the sensor to come to thermal equilibrium for 15 minutes.

At Power-On, Start the Fluke Temperature Data Logger bu pushing the "Start Log" button on the Macintosh interface. Save the file as: <sensorID> - LLNL-SAL-xxxxx.temp.

Example: UV311-LLNL-SAL-0016.temp

Acquire Images at the settings listed below:

\begin{tabular}{|c|c|c|c|c|c|c|c|}
\hline Sensor & $\begin{array}{l}\text { Integration } \\
\text { Times }\end{array}$ & Offset & $\begin{array}{l}\text { Video } \\
\text { Gain } \\
\end{array}$ & \#Images & Source & $\begin{array}{l}\text { Intensifier } \\
\text { Gain } \\
\end{array}$ & \begin{tabular}{|l|} 
Filter \\
Position \\
\end{tabular} \\
\hline StarTracker & $\begin{array}{l}Q 50 \\
Q 100 \\
\square 200 \\
\square 250\end{array}$ & $\begin{array}{l}0 \\
0 \\
0 \\
0\end{array}$ & $\begin{array}{l}75 \\
75 \\
75 \\
75\end{array}$ & $\begin{array}{l}5 \\
5 \\
5 \\
5\end{array}$ & $\begin{array}{l}\text { Cover \& DarkCloth } \\
\text { Cover \& DarkCloth } \\
\text { Cover \& DarkCloth } \\
\text { Cover \& DarkCloth }\end{array}$ & $\begin{array}{l}\text { N/A } \\
\text { N/A } \\
\text { N/A } \\
\text { N/A }\end{array}$ & $\begin{array}{l}\text { N/A } \\
N / A \\
N / A \\
N / A\end{array}$ \\
\hline UV-VIS & $\begin{array}{l}50 \\
\square 100 \\
\square 200 \\
\square 250\end{array}$ & $\begin{array}{l}0 \\
0 \\
0 \\
0\end{array}$ & $\begin{array}{l}150 \\
150 \\
150 \\
150\end{array}$ & $\begin{array}{l}5 \\
5 \\
5 \\
5\end{array}$ & $\begin{array}{l}\text { Cover \& DarkCloth } \\
\text { Cover \& DarkCloth } \\
\text { Cover \& DarkCloth } \\
\text { Cover \& DarkCloth }\end{array}$ & $\begin{array}{l}\text { N/A } \\
\text { N/A } \\
\text { N/A } \\
\text { N/A }\end{array}$ & \\
\hline HiRes & $\begin{array}{l}\square 50 \\
\square 100 \\
\square 200 \\
\square 250\end{array}$ & $\begin{array}{l}0 \\
0 \\
0 \\
0\end{array}$ & $\begin{array}{l}150 \\
150 \\
150 \\
150\end{array}$ & $\begin{array}{l}5 \\
5 \\
5 \\
5\end{array}$ & $\begin{array}{l}\text { Cover \& DarkCloth } \\
\text { Cover \& DarkCloth } \\
\text { Cover \& DarkCloth } \\
\text { Cover \& DarkCloth }\end{array}$ & $\begin{array}{l}0 \\
0 \\
0 \\
0\end{array}$ & $\begin{array}{l}3 \\
3 \\
3 \\
3\end{array}$ \\
\hline
\end{tabular}




\begin{tabular}{|l|l|l|l|l|l|l|l|}
\hline NIR & $\square 11 \mathrm{~ms}$ & N/A & N/A & 5 & $300^{\circ}$ CSoder Iron & N/A & \\
& I33 ms & N/A & N/A & 5 & $350^{\circ}$ C Soder Iron & N/A & \\
& $\square 57 \mathrm{~ms}$ & N/A & N/A & 5 & & & \\
& $\square 100 \mathrm{~ms}$ & N/A & N/A & 5 & & & \\
\hline LWIR & $\square 0.18 \mathrm{~ms}$ & N/A & N/A & 5 & Black Body $35^{\circ} \mathrm{C}$ & N/A & N/A \\
& $\square 1.44 \mathrm{~ms}$ & N/A & N/A & 5 & BlackBody $77^{\circ} \mathrm{C}$ & N/A & N/A \\
& $\square 2.88 \mathrm{~ms}$ & N/A & N/A & 5 & & & N/A \\
& $\square 5.76 \mathrm{~ms}$ & N/A & N/A & 5 & & & N/A \\
\hline
\end{tabular}

[OPTIONAL: For LLNL CCD sensor take images at each of $\mathrm{a}, 10,15^{\circ} \mathrm{C}$ baseplate temperatures]

C Make a README.IMAGES in the image directory (/dspse/sensor/darkField/däte) file to describe the images taken in the sequence. Include the following line for each sensor:

Filename Integration time $=x x x$ Gain $=x x x \quad$ Offset $=x x x$

Record the temperature conditions of the following: Ambient temperature, sensor baseplate temperature, $C C D$ temperature, lens temperature, relative humdity. $C C D 27^{\circ} \mathrm{C}$ Lans $26^{\circ} \mathrm{C}$

When testing has been completed, tum the power to the sensor off and close the temperature data log file on the macintosh.

(t) Store the sensor using the "Sensor Activity Log Sheet (LLNL-SAL), "Securing the Sensor" section or continue to next test. $\square$ Stored Sensor 1 \&Continued Testing.

When the test is successfully completed, Update the LLNL Sensor Acceptance Testing Summary Sheet.

Note Any exceptions in the test

6.5. Performance Analysis \& Reporting Criterion

The Dark Field Uniformity Report Shall contain the following:

Histogram showing the distribution of the image field pixel values, notated with temperatures.

$\square$ Plot showing the integration time VS (Averaged) Dark Current for both a entire frame and defined regeion. (mean, StdDev, Var)

$\square$ [Optional] Plot showing the (averaged) dark current VS temperature

$\square$ Compare the Dark current wiht LLNL calibration Summary Report

Plot an Image Field showing the Fixed Pattern noise of the summation of each Integration times images (10-20each).

Plot temperature vs time of the sensor $C C D$, and baseplate starting at power-on, notated with room temperature.

Sensor Verification Test Procedure

Draft-C: August 10, 1993 
Operator: Nielsen Date: $8 / 13 / 93 \quad$ Activity Sheet:-LLNL-SAL-0030

7.1. Applicable Sensors:

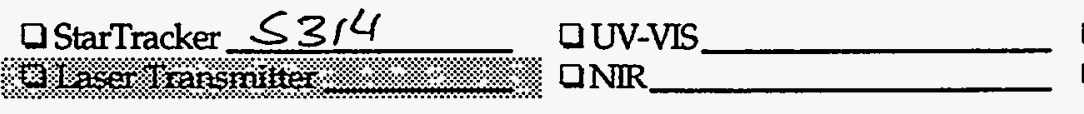

$\square$ HiRes
$\square$ LWIR_-

7.2. Data Storage Locations:

Images: $\quad$ /dspse/<Sensor>/imageField/date/<sensorname.imagenumber>

Temp : $\quad$ MAC:<SensorID>-LLNL-SAL-XXXX.temp.IFAT

7.3. Purpose:

Acquire and store a re-creatable image field for analysis.

7.4. Test Environment \& Procedure

Unpack the sensor using the "Sensor Activity Log Sheet (LLNL-SAL)

Log the execution of the "LLNL Image Field Analysis Test" in the sensor certification log.

At Power-On, Start the Fluke Temperature Data Logger bu pushing the "Start Log" button on the Macintosh interface. Save the file as: <sensorID> - LLNL-SAL-xxxxx.temp.

Example: UV311-LLNL-SAL-0016.temp

Vary Integration time and Gain to produce peak pixel of $\sim 220$ digital counts

\begin{tabular}{|c|c|c|c|c|c|c|c|}
\hline Sensor & $\begin{array}{l}\text { Integration } \\
\text { Time (ms) }\end{array}$ & Offset & $\begin{array}{l}\text { Video } \\
\text { Gain }\end{array}$ & \# Images & Source & $\begin{array}{l}\text { Intensifier } \\
\text { Gain }\end{array}$ & \begin{tabular}{|l|} 
Filter \\
Position
\end{tabular} \\
\hline StarTracker & $\begin{array}{l}\square 100 \\
200 \\
300\end{array}$ & $\begin{array}{l}0 \\
0 \\
0\end{array}$ & $\begin{array}{l}75 \\
150 \\
350\end{array}$ & $\begin{array}{l}5 \\
5 \\
5\end{array}$ & $\begin{array}{l}\text { Cassiopeia } \\
\text { Cassiopeia } \\
\text { Cassiopeia }\end{array}$ & $\mathrm{N} / \mathrm{A}$ & $N / A$ \\
\hline UV-VIS & $\begin{array}{l}\square 50 \\
\square 100 \\
\square 200\end{array}$ & $\begin{array}{l}0 \\
0 \\
0\end{array}$ & & $\begin{array}{l}5 \\
5 \\
5\end{array}$ & $\begin{array}{l}\text { Dark Cloth } \\
\text { Dark Cloth } \\
\text { Dark Cloth }\end{array}$ & & \\
\hline HiRes & $\begin{array}{l}010 \\
025 \\
\square 50 \\
010 \\
\square 25 \\
050\end{array}$ & $\begin{array}{l}0 \\
0 \\
0 \\
0 \\
0 \\
0\end{array}$ & & $\begin{array}{l}5 \\
5 \\
5 \\
5 \\
5 \\
5\end{array}$ & $\begin{array}{l}\operatorname{RefStar}^{*} \\
\text { RefStar}^{*} \\
\text { RefStar }^{*} \\
\text { RefStar }^{*} \\
\text { RefStar } \\
\text { RefStar }\end{array}$ & $\begin{array}{l}190 \\
190 \\
190 \\
190 \\
190 \\
190\end{array}$ & $\begin{array}{l}2 \\
2 \\
2 \\
4 \\
4 \\
4\end{array}$ \\
\hline NIR & & & & $\begin{array}{l}5 \\
5\end{array}$ & $\begin{array}{l}300^{\circ} \\
350^{\circ}\end{array}$ & & \\
\hline LWIR & & & & 5 & $300^{\circ}$ & & \\
\hline
\end{tabular}

* Ref star is the Cassiopeia Constellation StarSimulator Reference star with $3.9 \mathrm{~K}-\mathrm{Ohm}$ resistor in series with the power supply. 
When testing has been completed, turn the power to the sensor off and close the temperature data $\log$ file on the macintosh.

Store the sensor using the "Sensor Activity Log Sheet (LLNL-SAL), "Securing the Sensor" section or continue to next test. $\$$ Stored Sensor $1 \mathbb{Q}$ Continued Testing.

When the test is successfully completed, Update the LLNL Sensor Acceptance Testing Summary Sheet.

- Note Any exceptions in the test

$\because$

7.5. Performance Analysis \& Reporting Criterion

G Generate PSF for Point Source at a Pixel near the center of the Field of View and 4 points evenly spaced off axis.

Plot temperature vs time of the sensor CCD, and baseplate starting at power-on, notated with room temperature. 
Operator:

Date: Activity Sheet:-LLNL-SAL-

8.1. Applicable Sensors:

\begin{tabular}{|c|}
\hline 口StarTracker \\
\hline
\end{tabular}

DHiRes

8.2. Data Storage Locations:

Images: $\quad /$ dspse/<Sensor $>/$ flatField /date/<sensorname.imagenumber $>$

Temp : $\quad$ MAC:<SensorID>-LLNL-SAL-XXXX.temp.FFT

\subsection{Purpose}

A verification of the LLNL absolute radiometric calibration will be performed on the sensors with an accuracy of TBD. A Labsphere Uniform Source System will be used to provide a calibrated (NIST traceable) radiance for a wavelength range of 0.4 to $2.3 \mathrm{~mm}$. This source will be used for all visible sensors and the NIR sensor. For the LWIR and upper wavelength filters of the NIR, the extended blackbody source will be used. The source will be placed near the sensor to ensure the source fills the entire sensor field of view. A radiometric analysis will be performed as follows: For each filter setting, gain setting, and a set of appropriate integration time two images will be acquired and stored:

\subsection{Test Environment \& Procedure}

Unpack the sensor using the "Sensor Activity Log Sheet (LLNL-SAL)

Log the execution of the "LLNL Flat Field Test" in the sensor certification log.

At Power-On, Start the Fluke Temperature Data Logger bu pushing the "Start Log" button on the Macintosh interface. Save the file as: <sensorID> - LLNL-SAL-xxxxx.temp.

Example: UV311-LLNL-SAL-0016.temp

\section{Do SOMETHING!!!}

Store the sensor using the "Sensor Activity Log Sheet (LLNL-SAL), "Securing the Sensor" section or continue to next test. $\square$ Stored Sensor $1 \square$ Continued Testing.

When testing has been completed, turn the power to the sensor off and close the temperature data $\log$ file on the macintosh.

When the test is successfully completed, Update the LLNL Sensor Acceptance Testing Summary Sheet. 
Note Any exceptions in the test

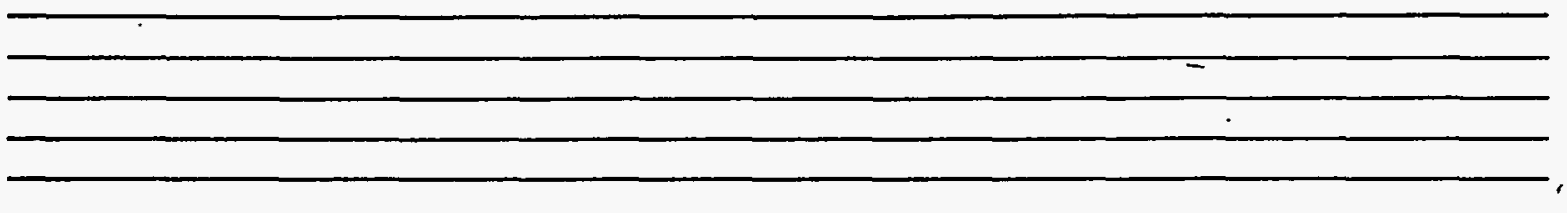

\subsection{Performance Analysis \& Reporting Criterion}

- Plot temperature vs time of the sensor CCD, and baseplate starting at power-on, notated with room temperature. 


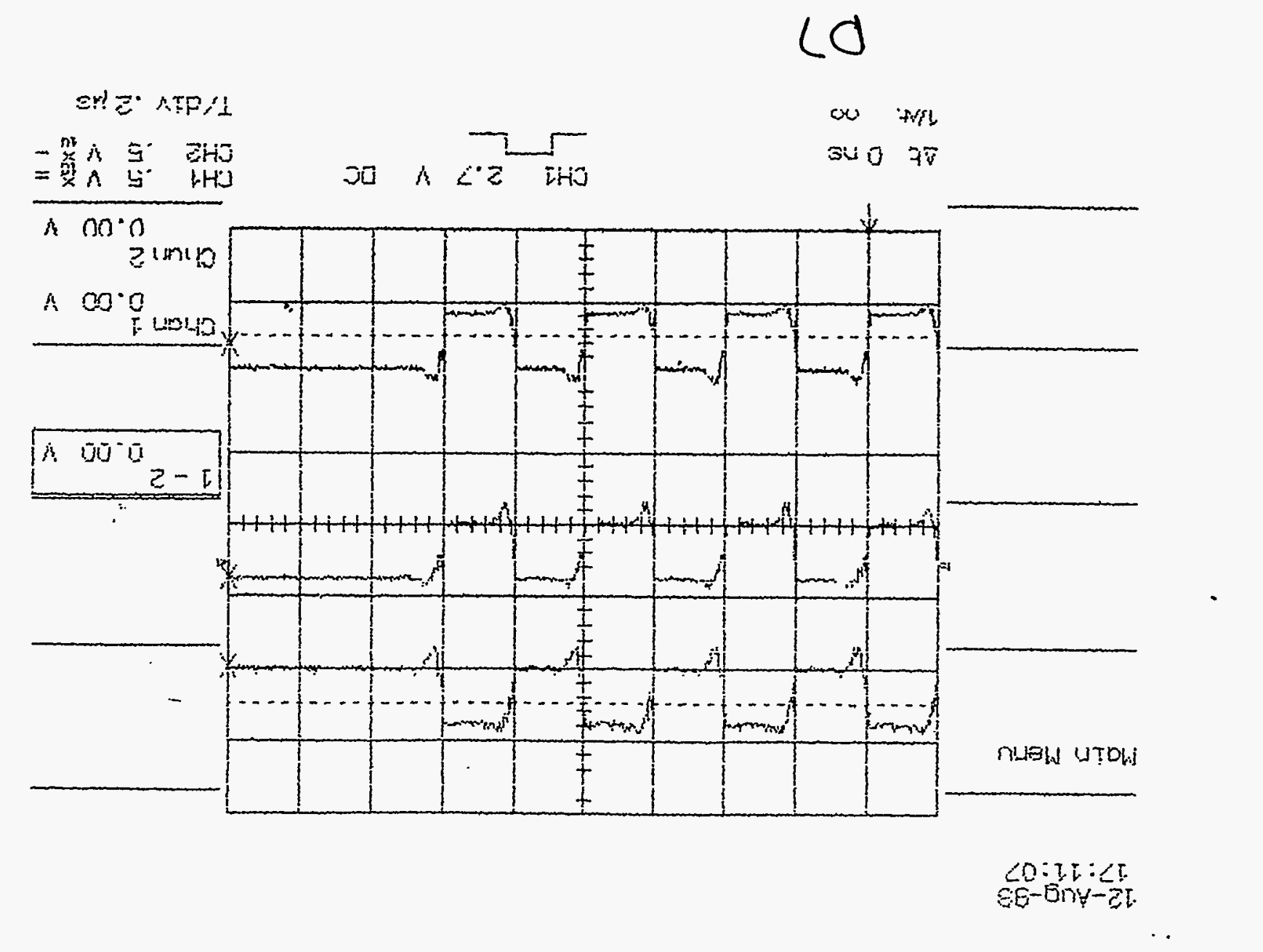




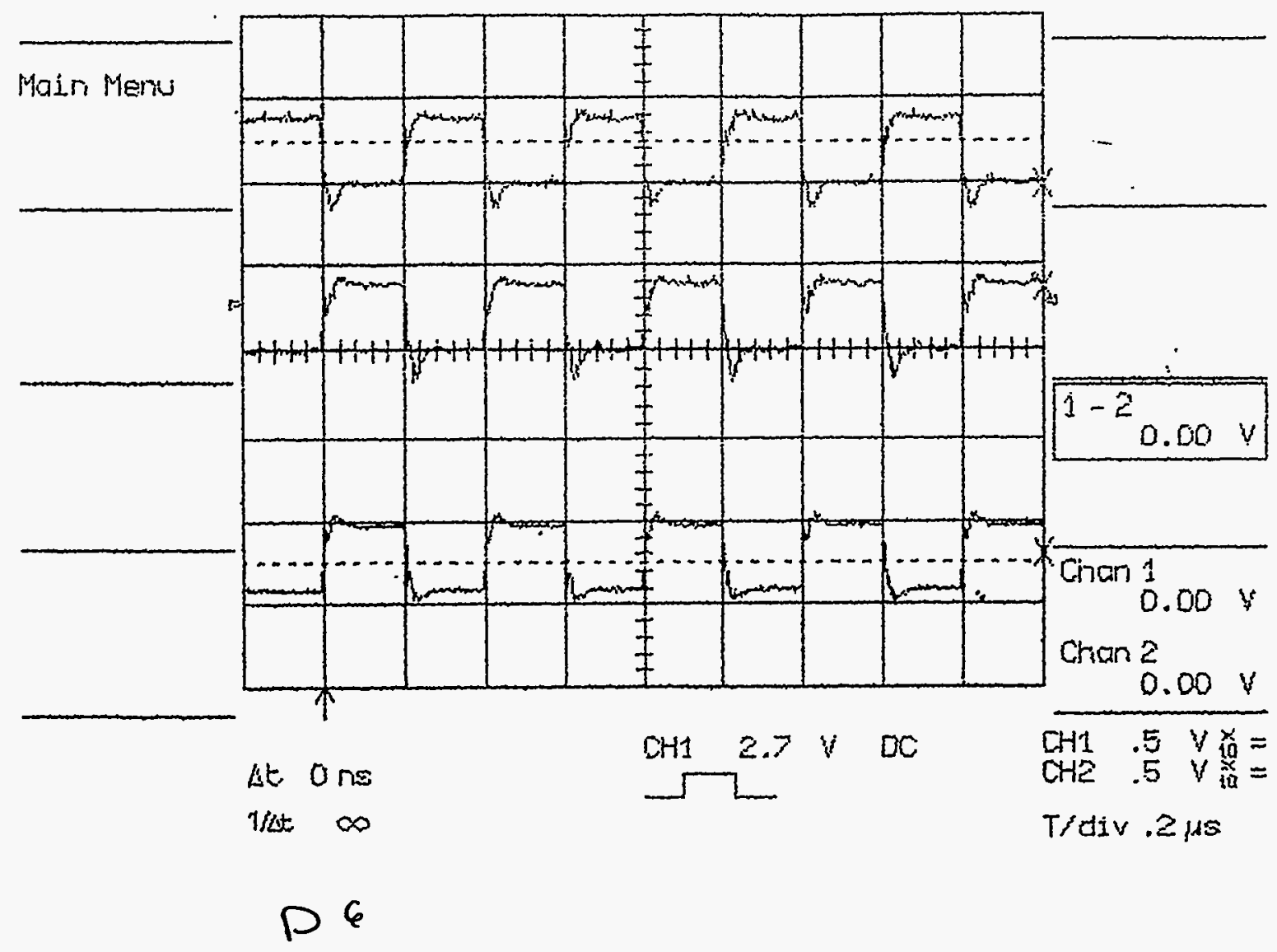




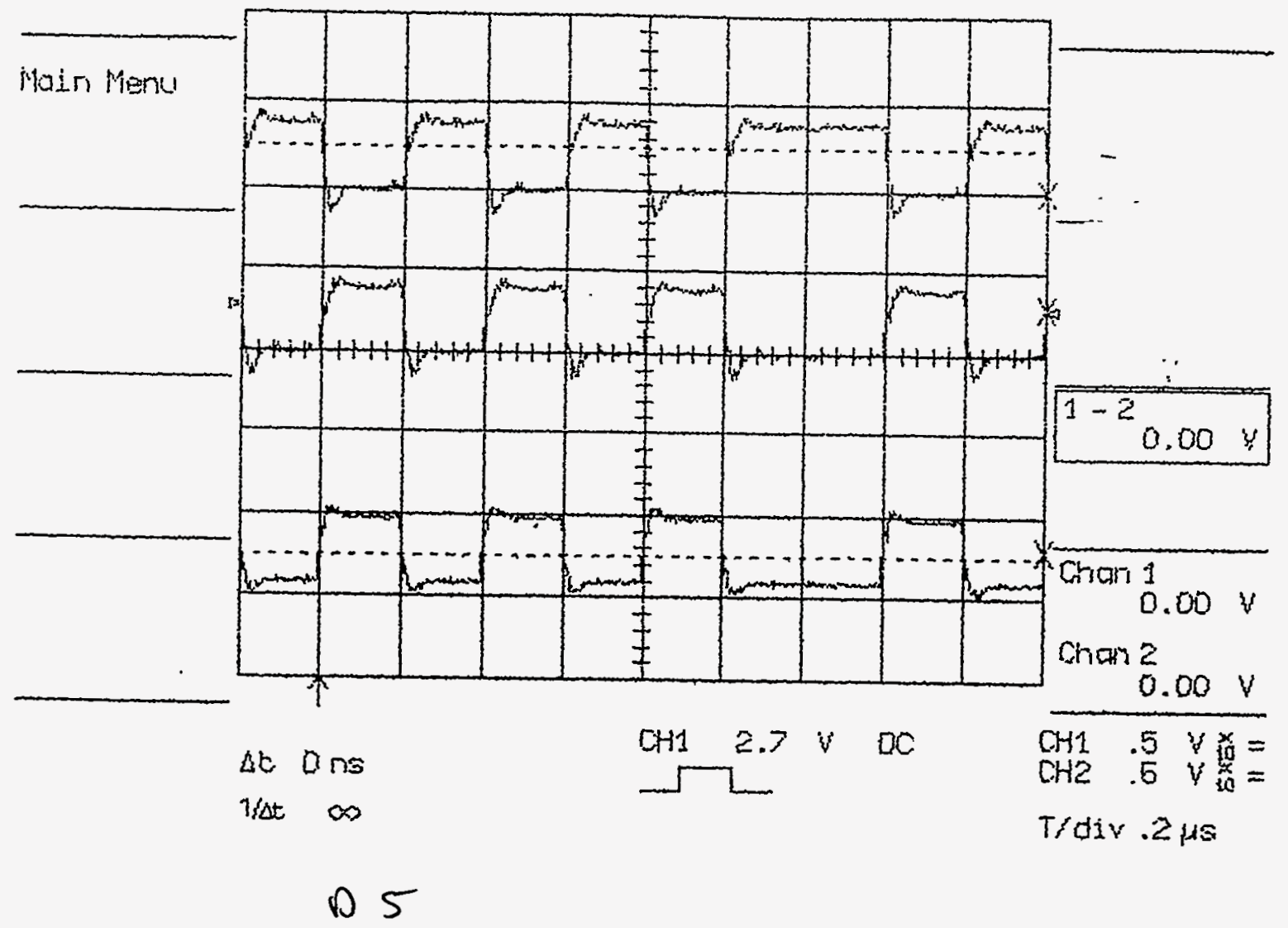




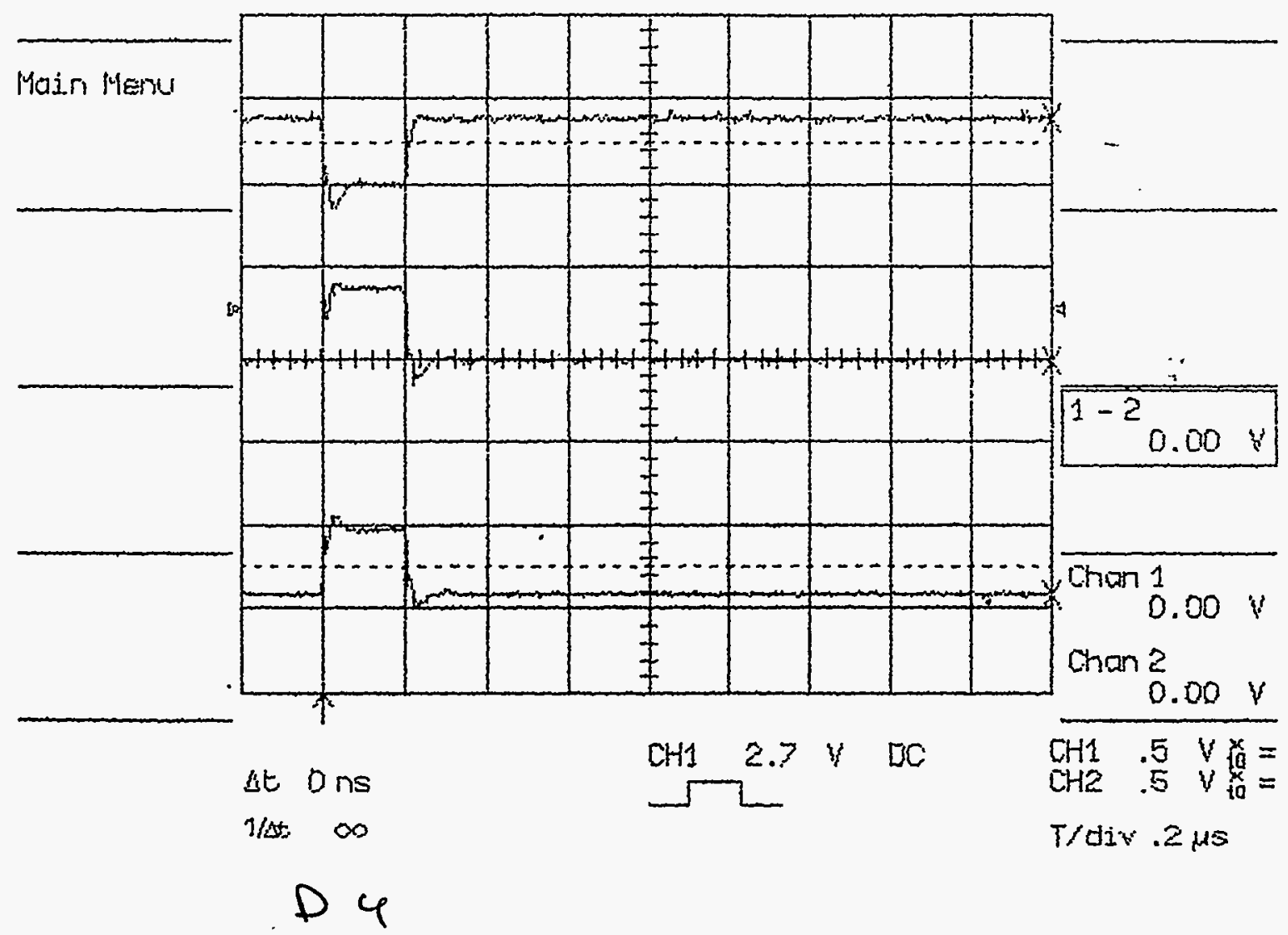


$12-+45-95$

1):06: $1 \%$

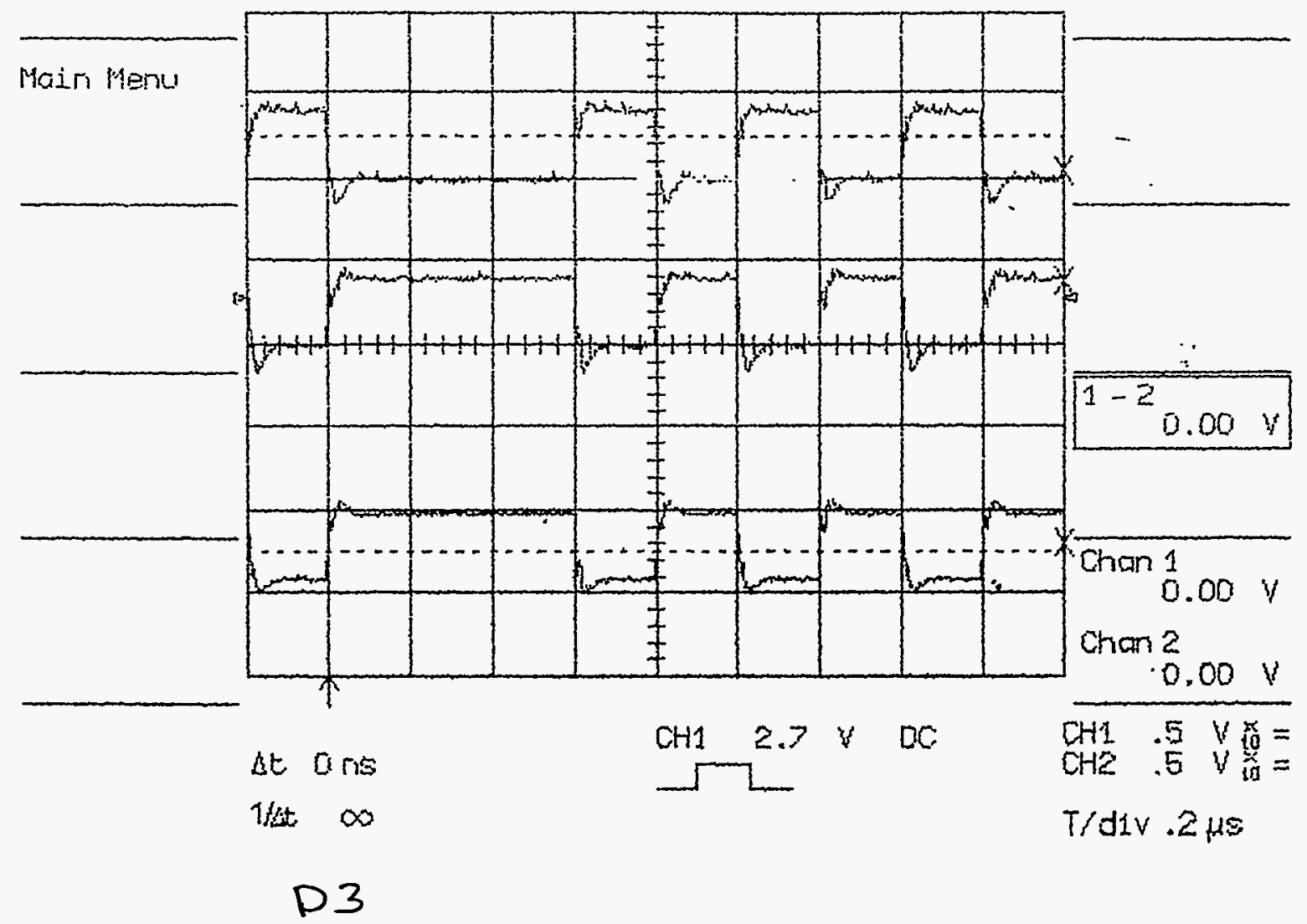




$$
\begin{aligned}
& \text { 12-Aug }-93 \\
& 17: 05: 25
\end{aligned}
$$

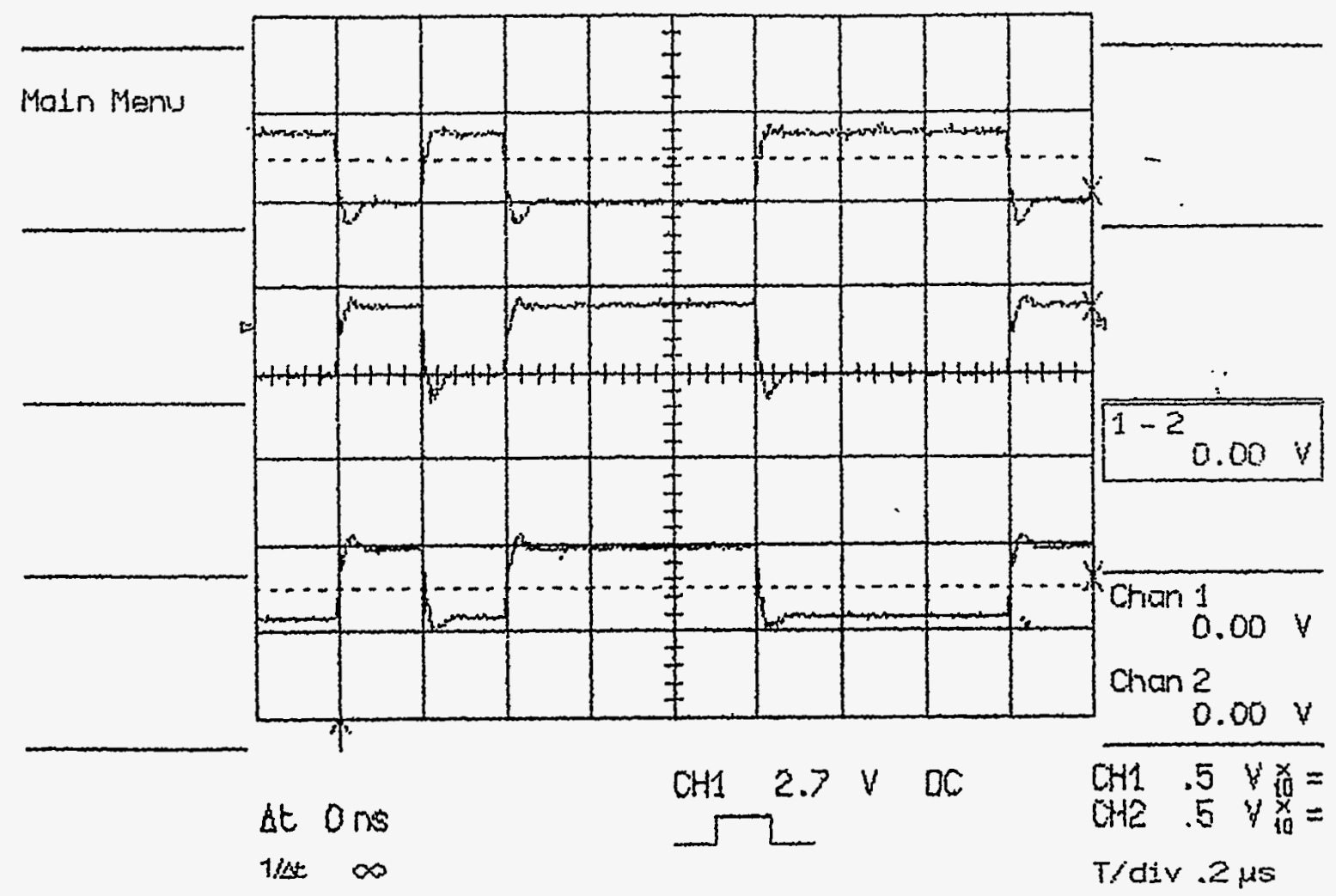

$D^{2}$ 
12-Aug-93

$17: 04: 21$

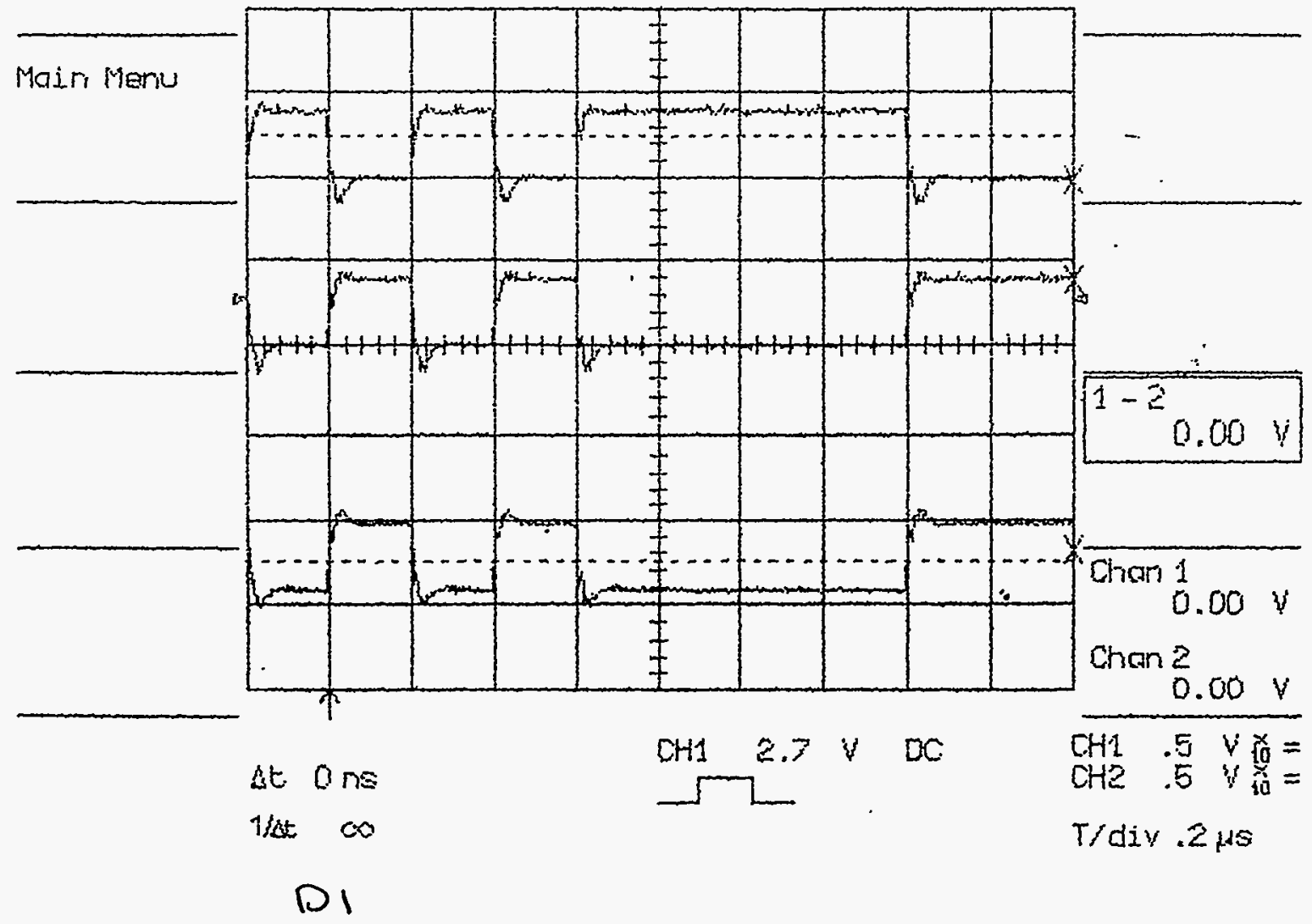




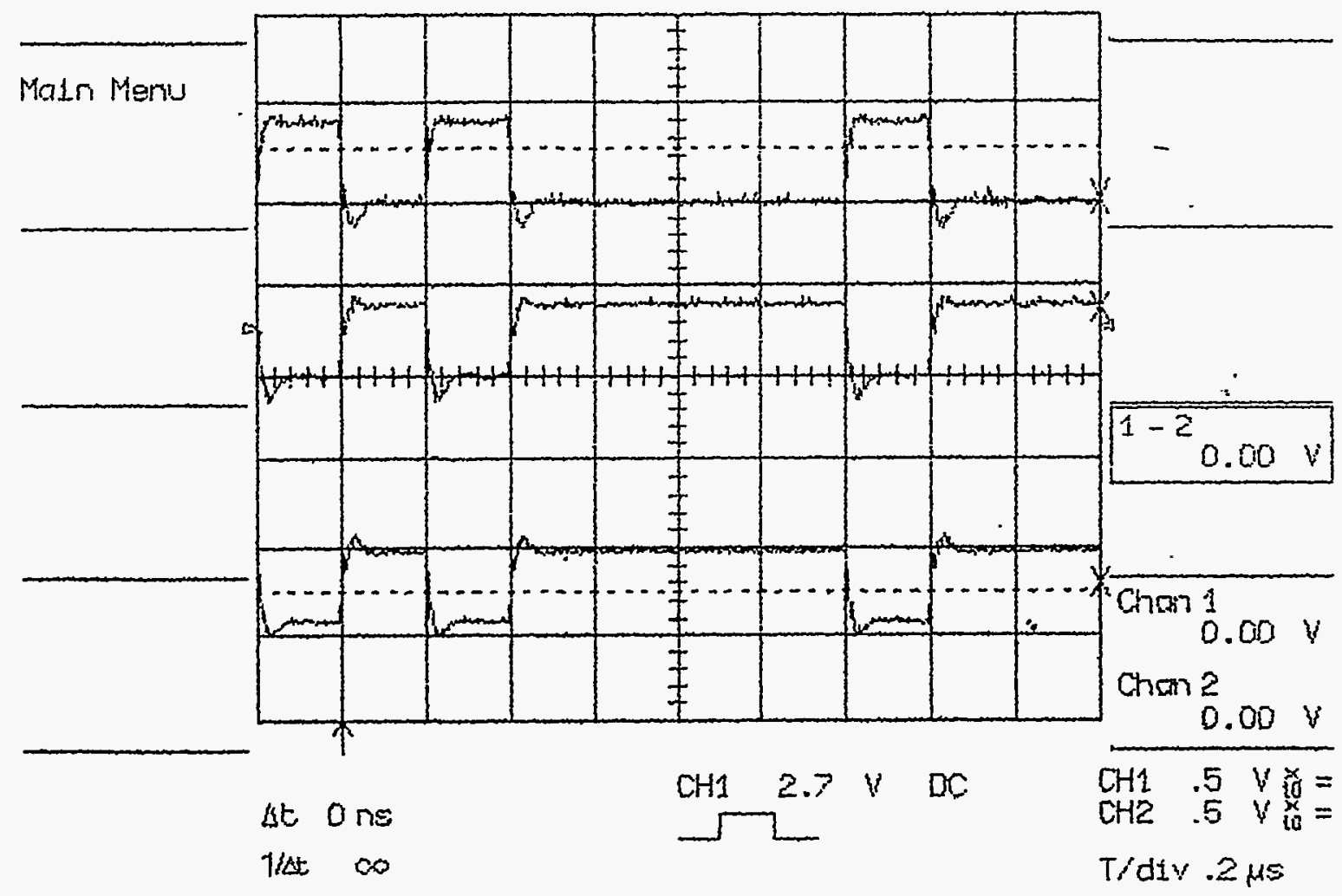

DO 


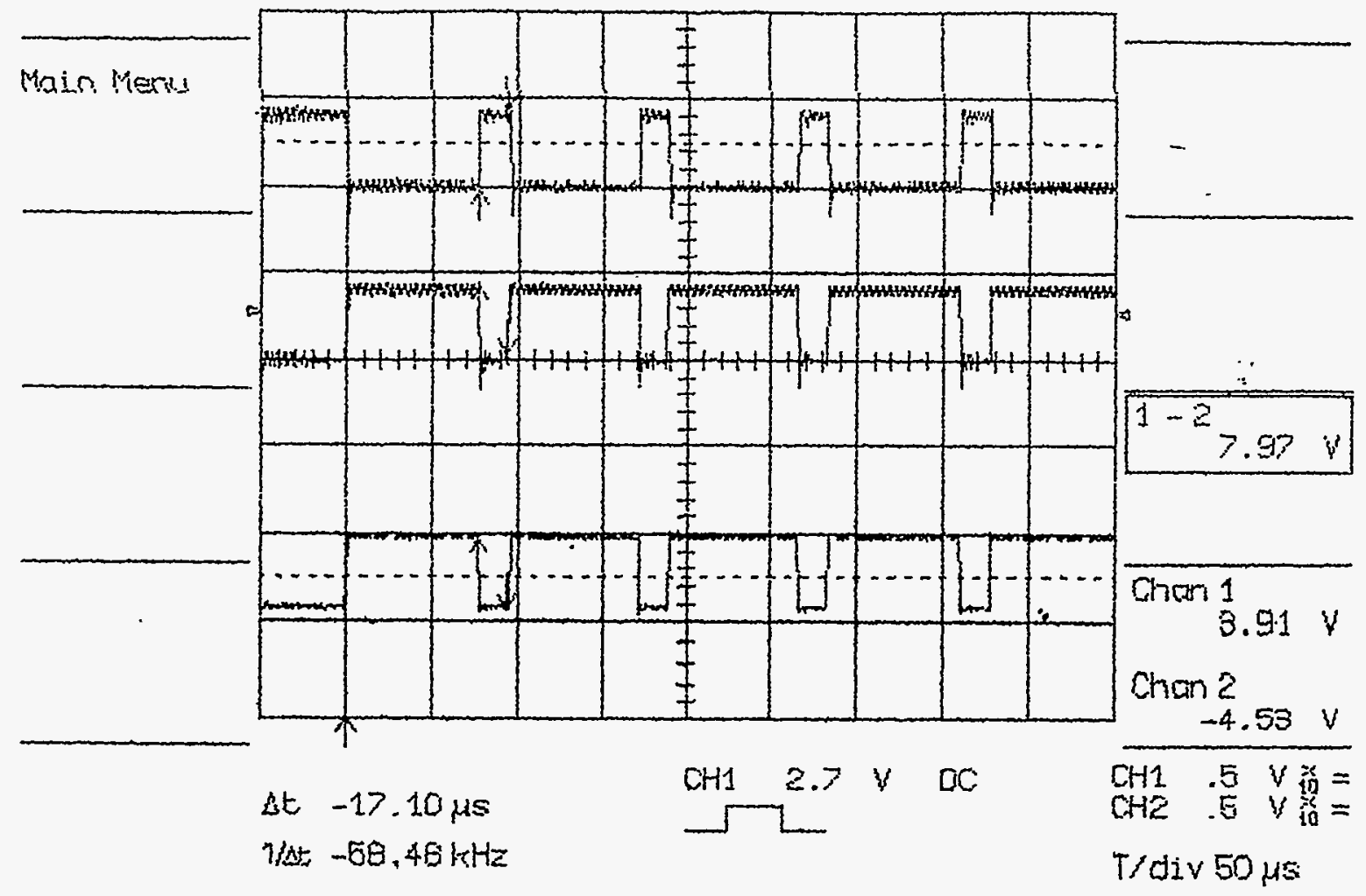

Pixual 
$12-4 \cup 9-95$
$16: 57: 53$

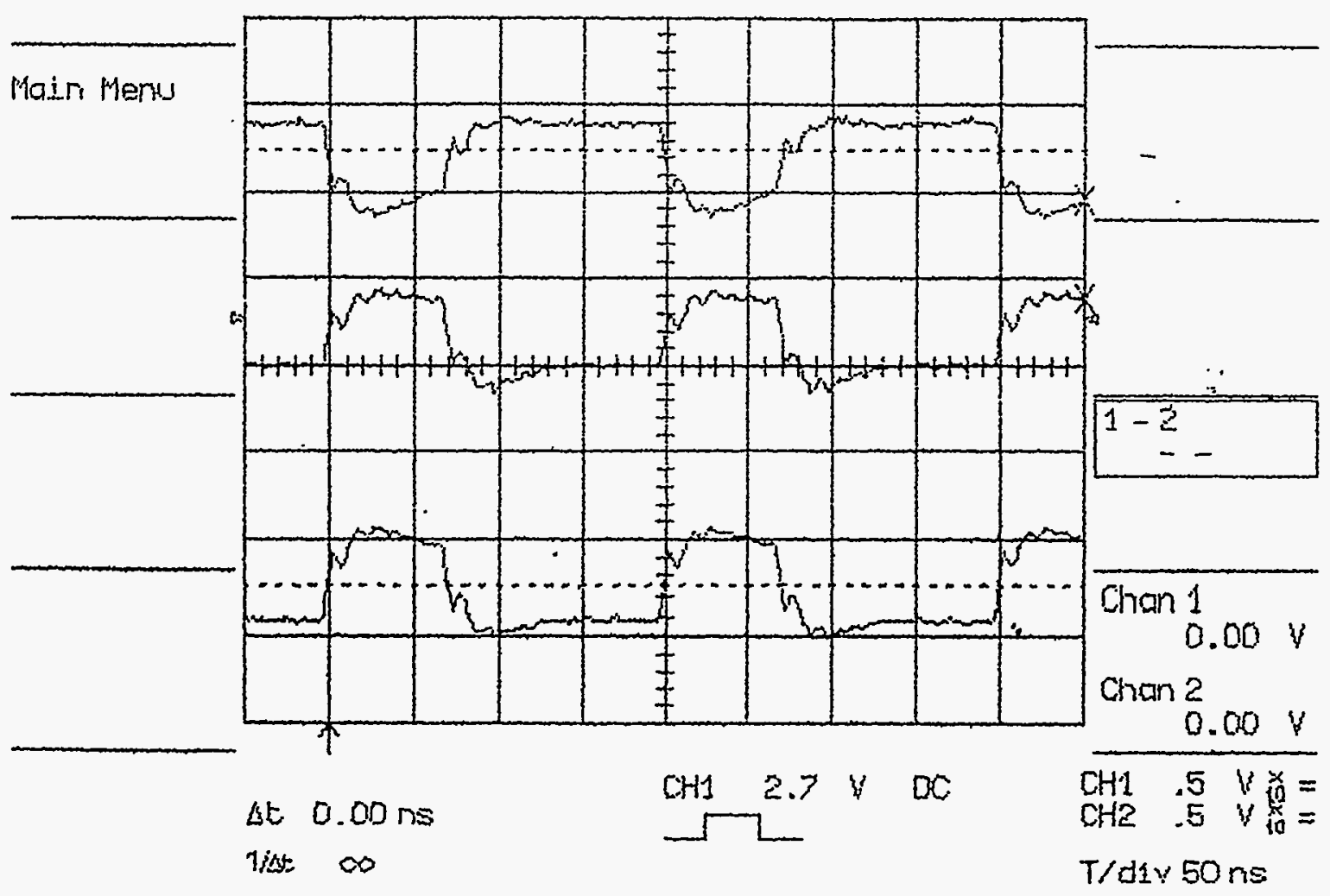

$$
\text { Pixdk }
$$


12-Aug-93

16:56:39

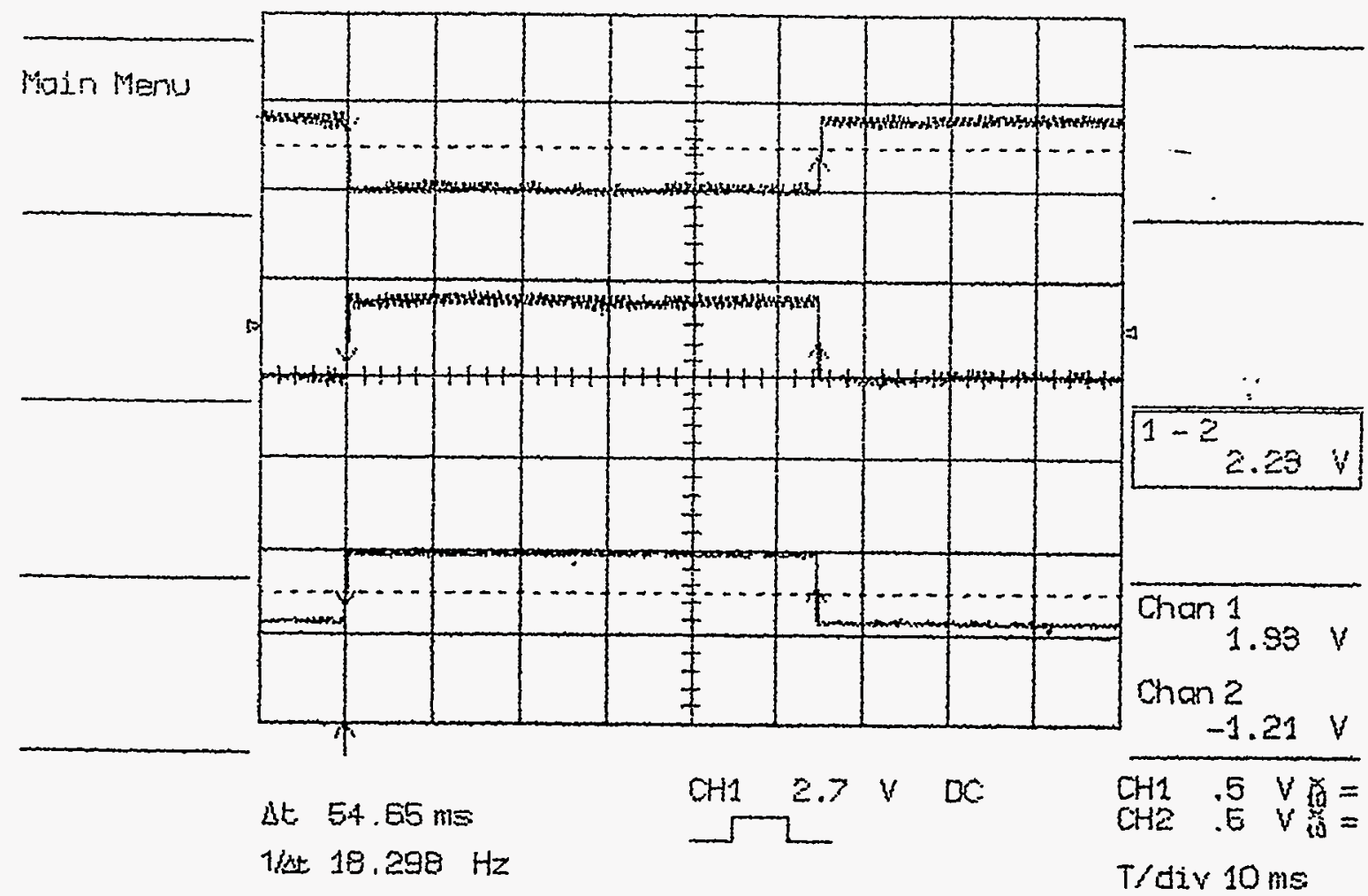

Vsyne 


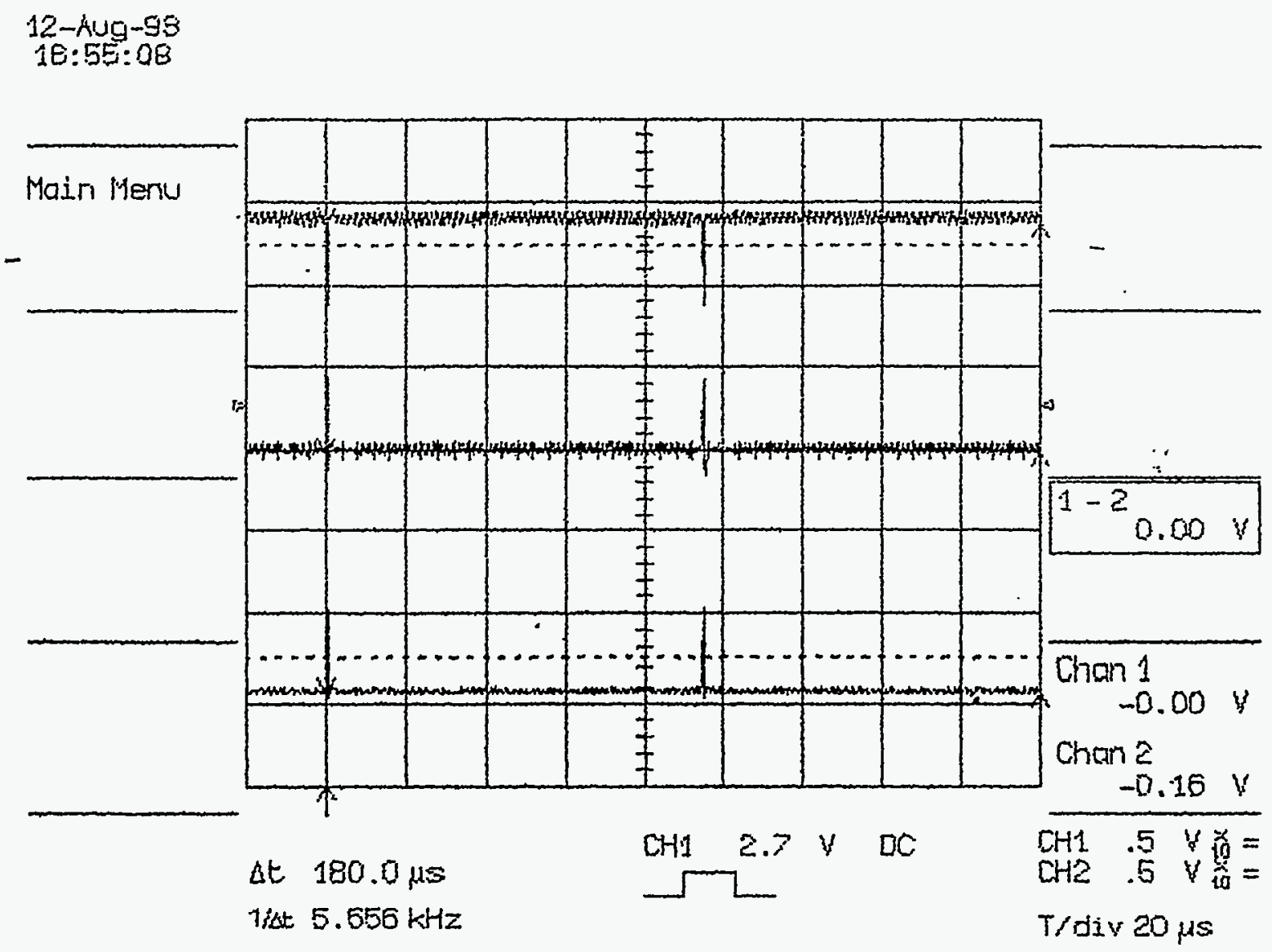

H syne 
12-4Ug-9S ND ON SLOW TRIGGEF
i7:15:17

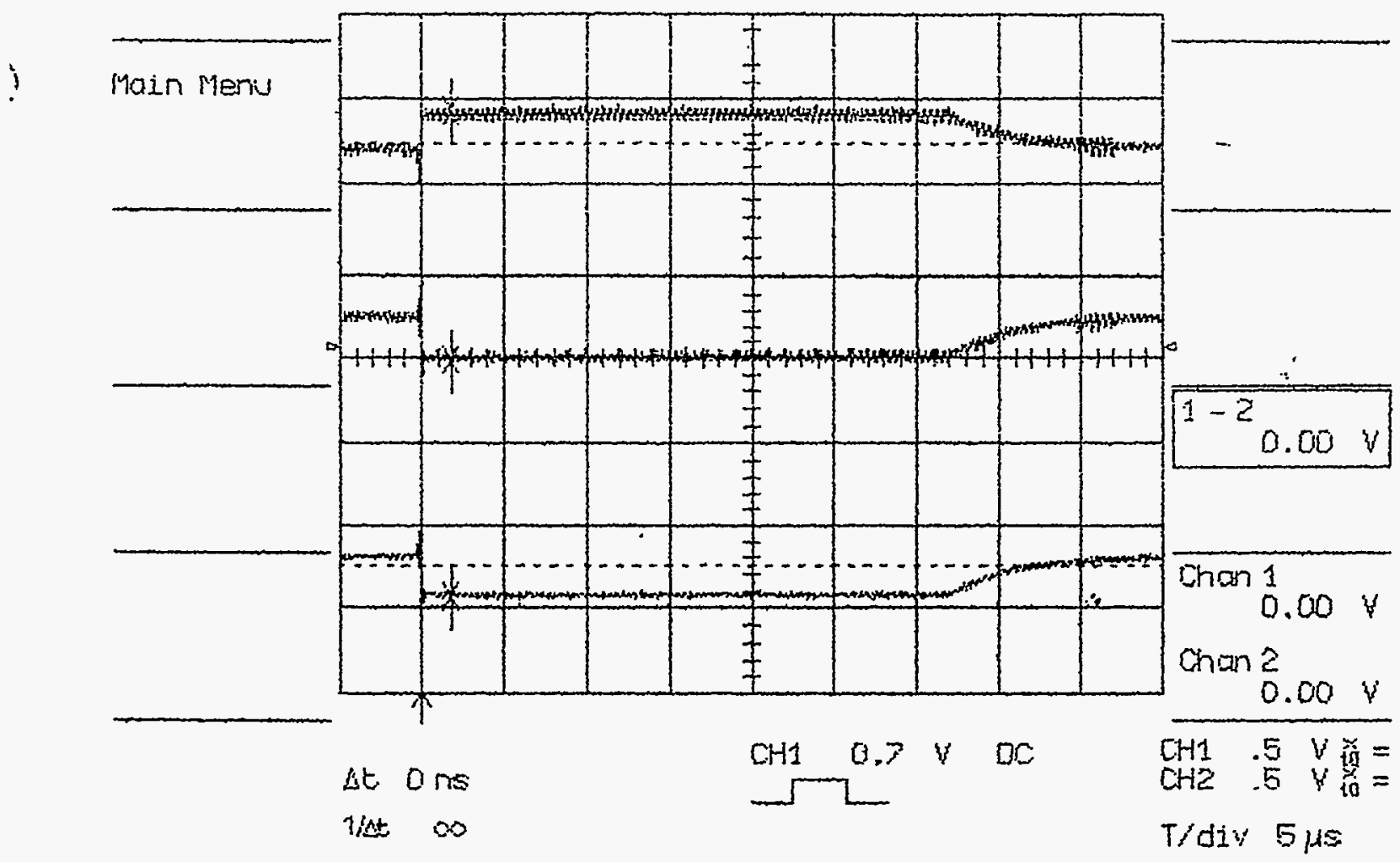

SASI Steetos 


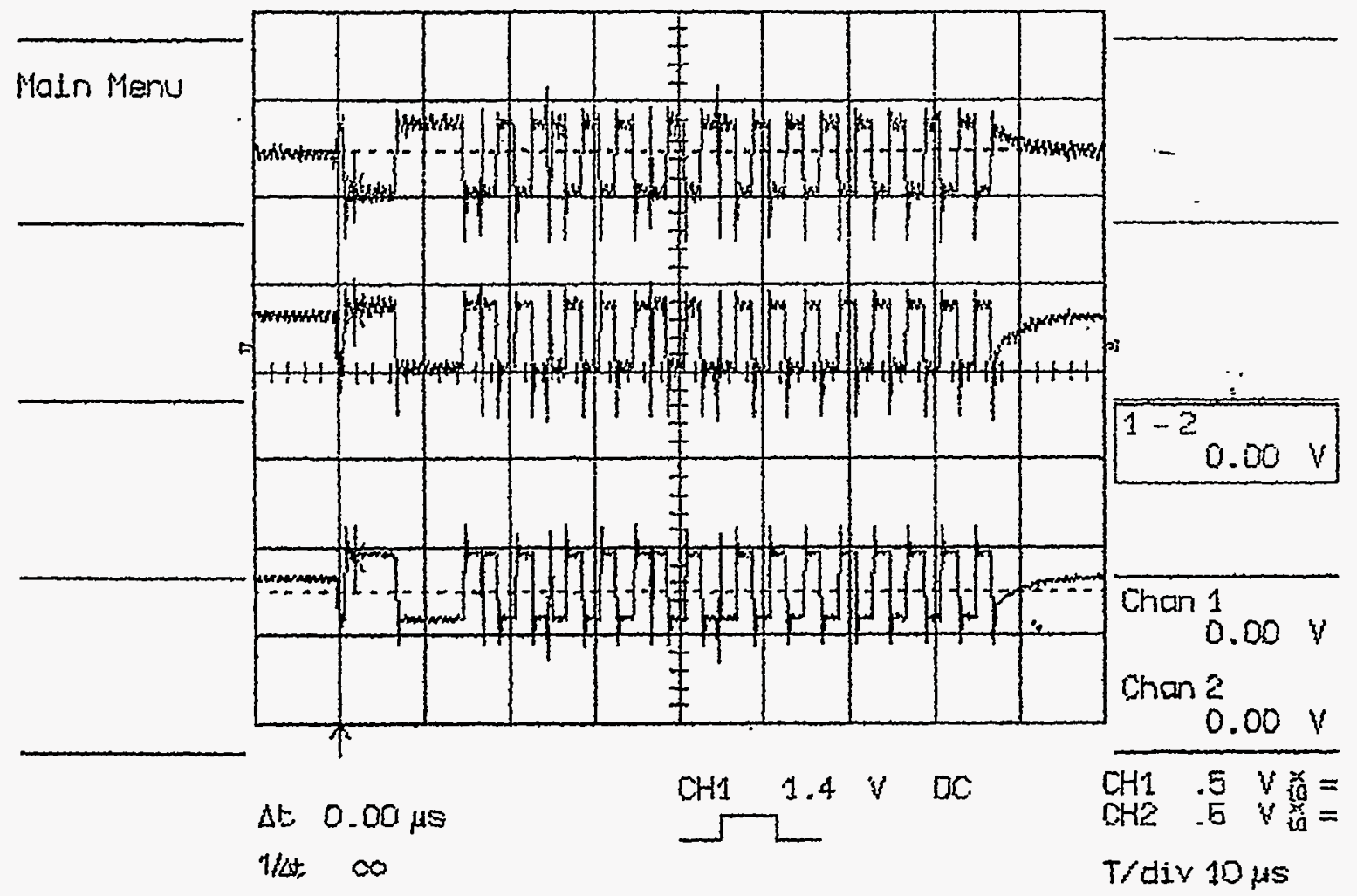

SASI Data 
$12-n_{i j 0}-93$

17:13:20

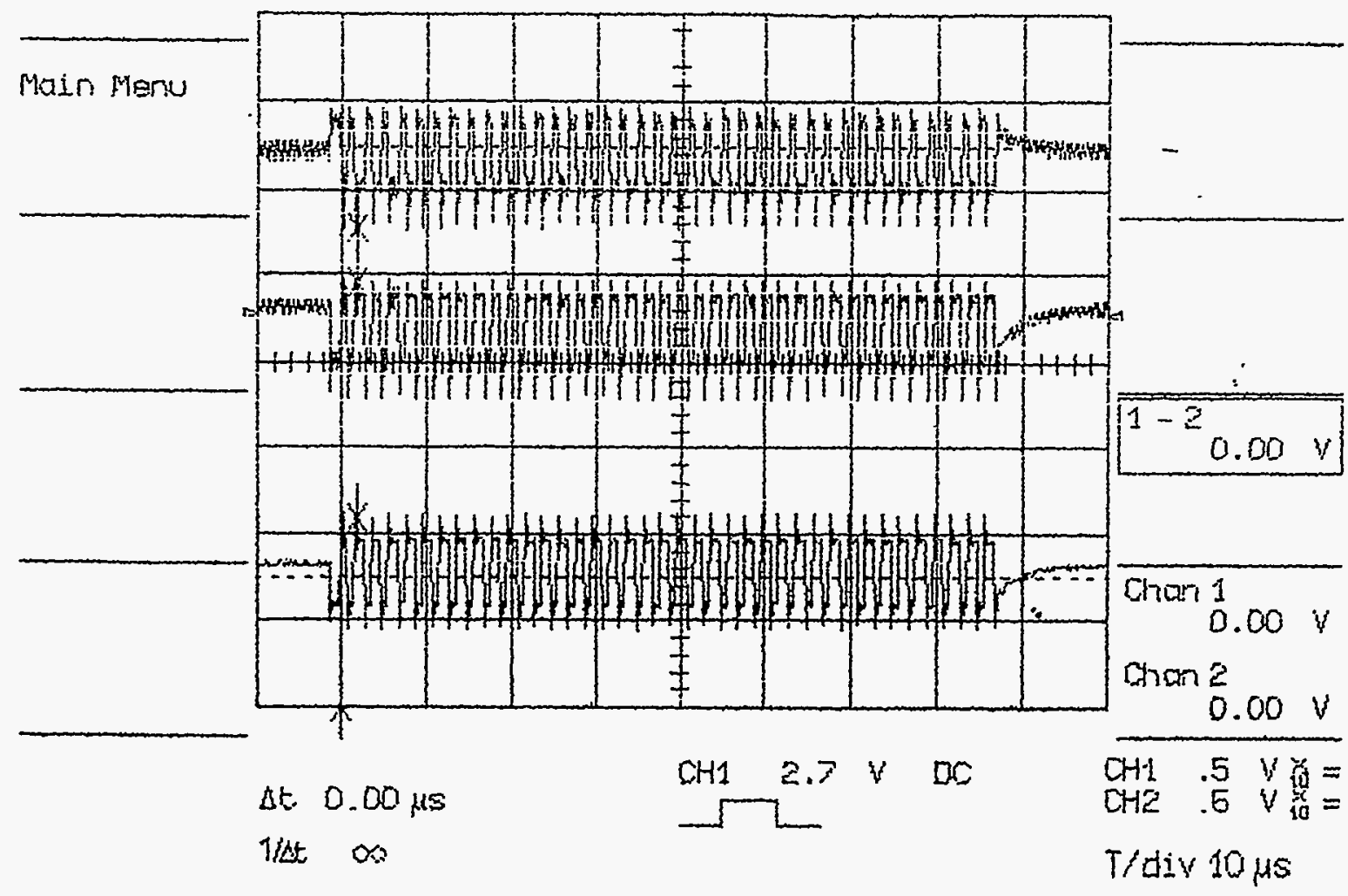

SASI CIK 
Timing Waveform Diagram._........Continubus trace in process_._._.

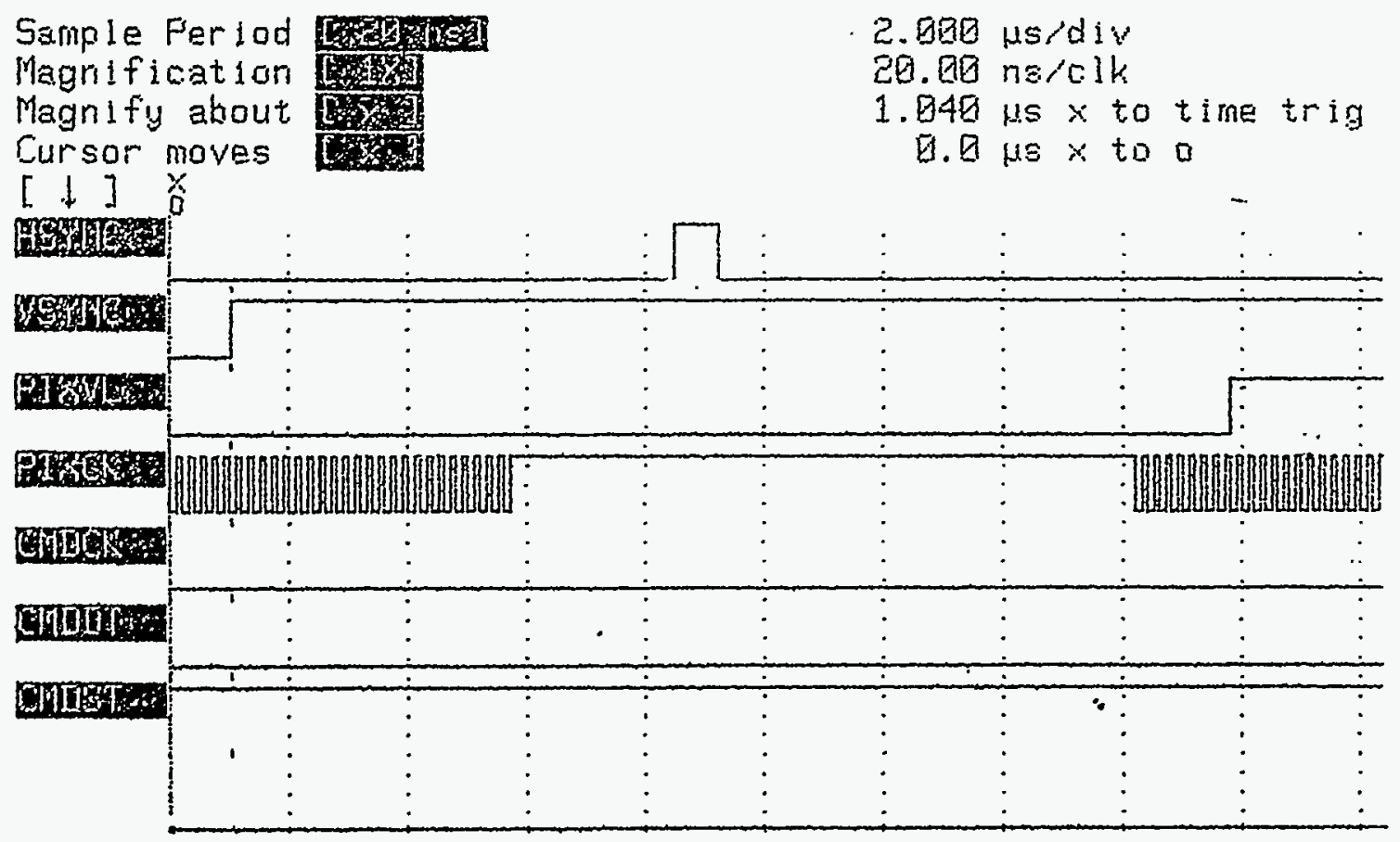

\section{Beginning}


$\therefore$ inns $\quad \cdots \cdots \cdots$

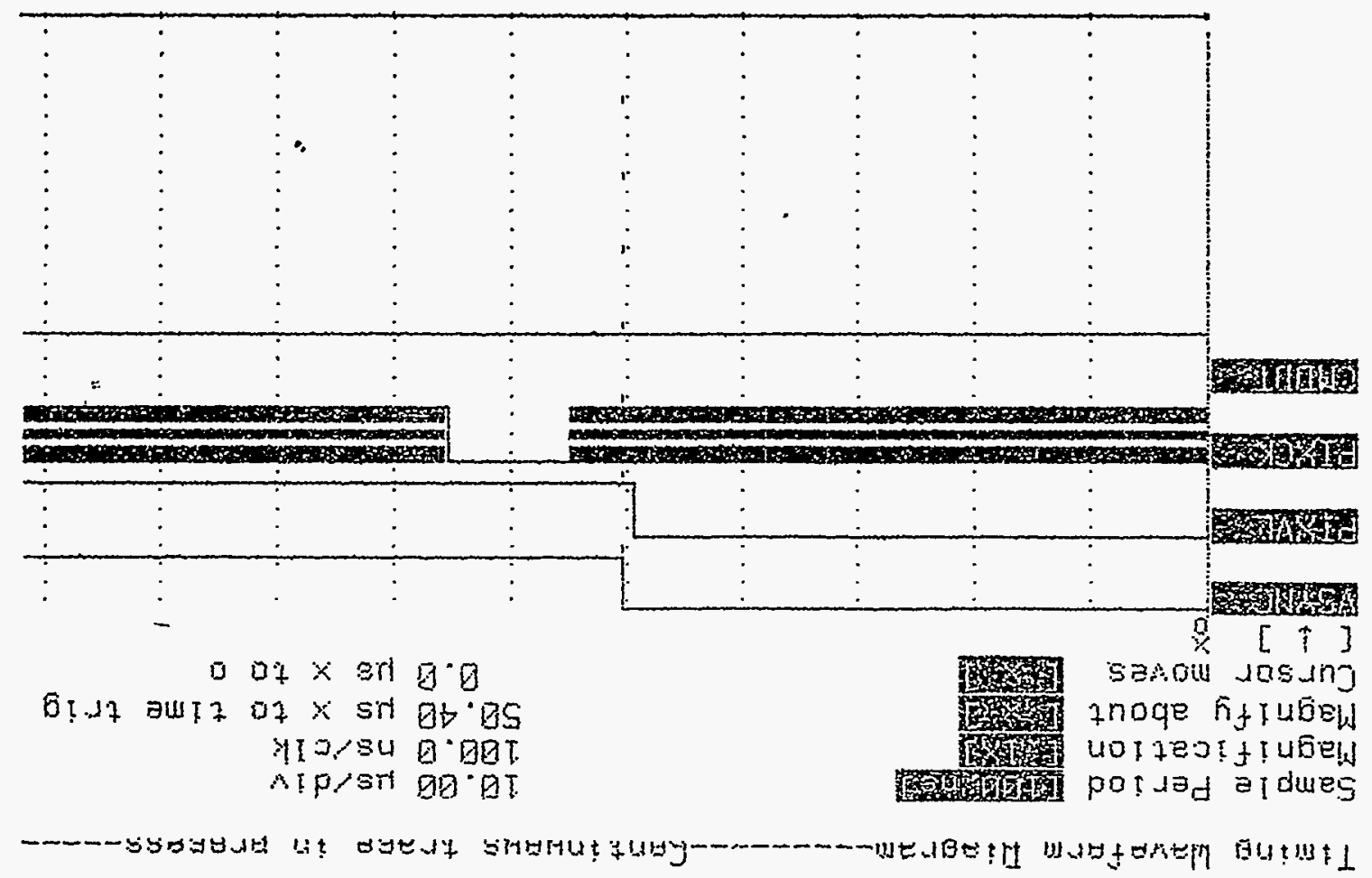


Timing Waveform Iliagram_________Continurus trace in process_._._.

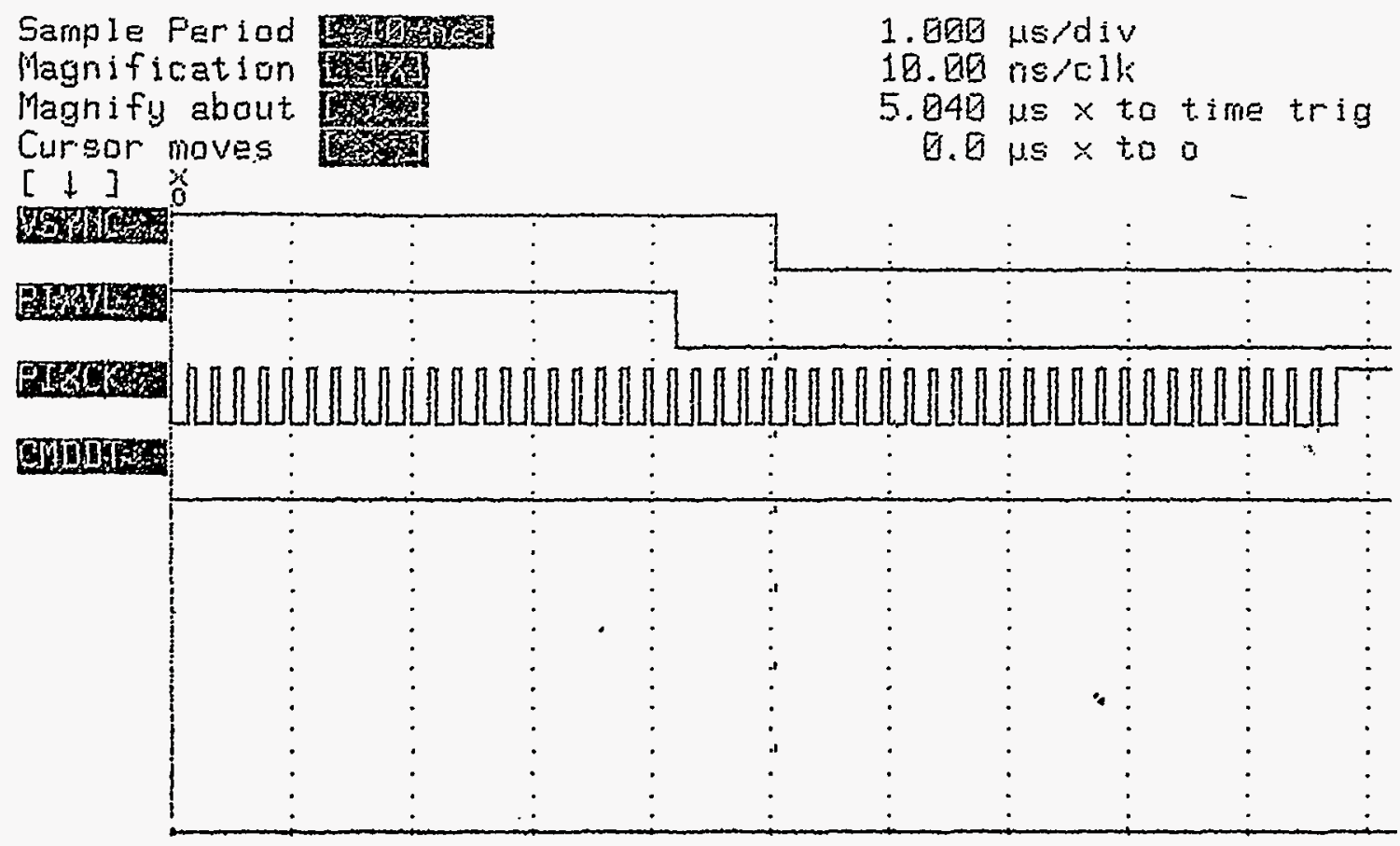

End of Frame 


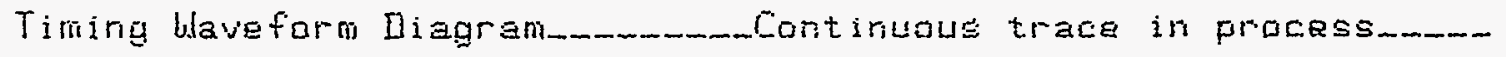

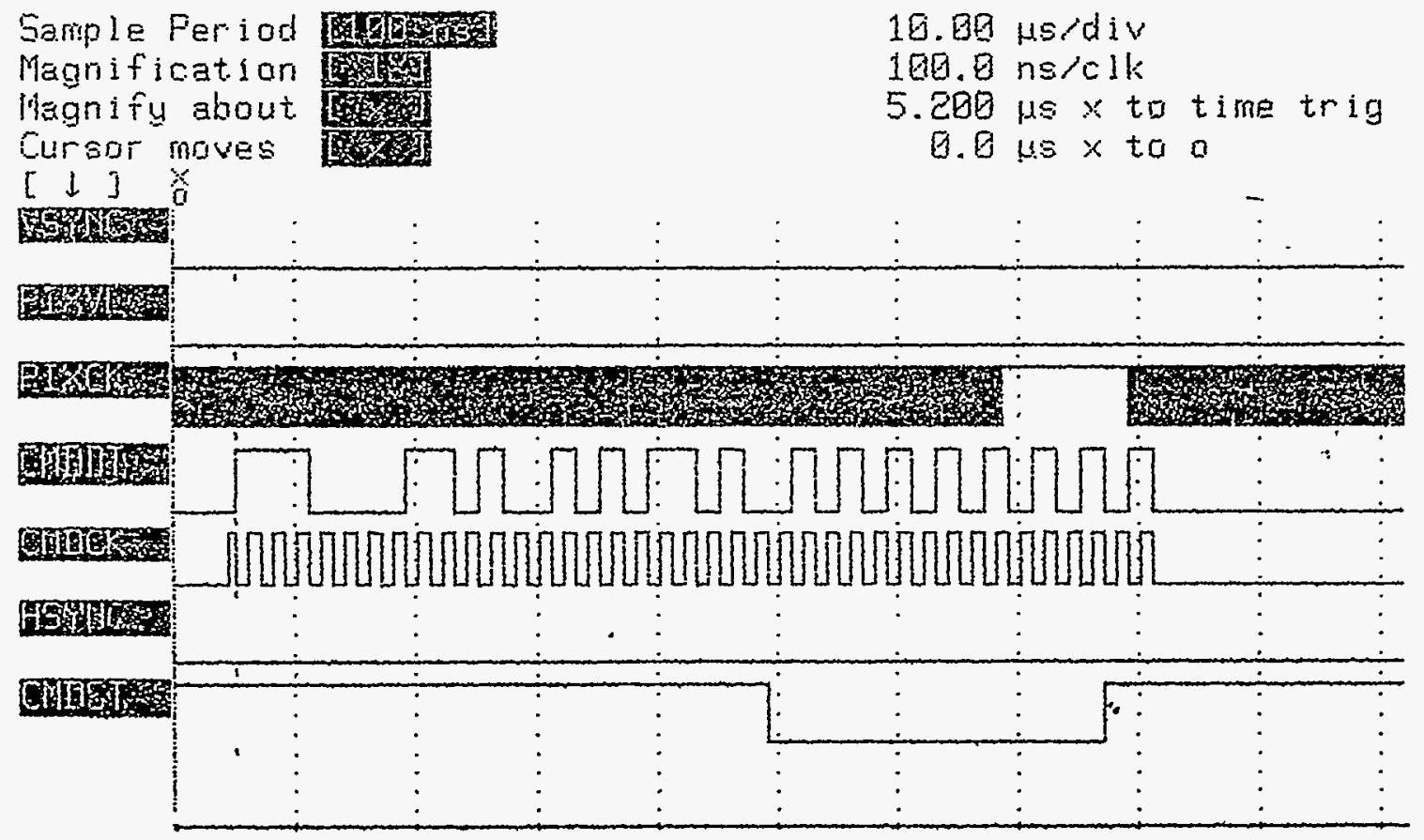

SASI 